
B10LOGY LISRมล
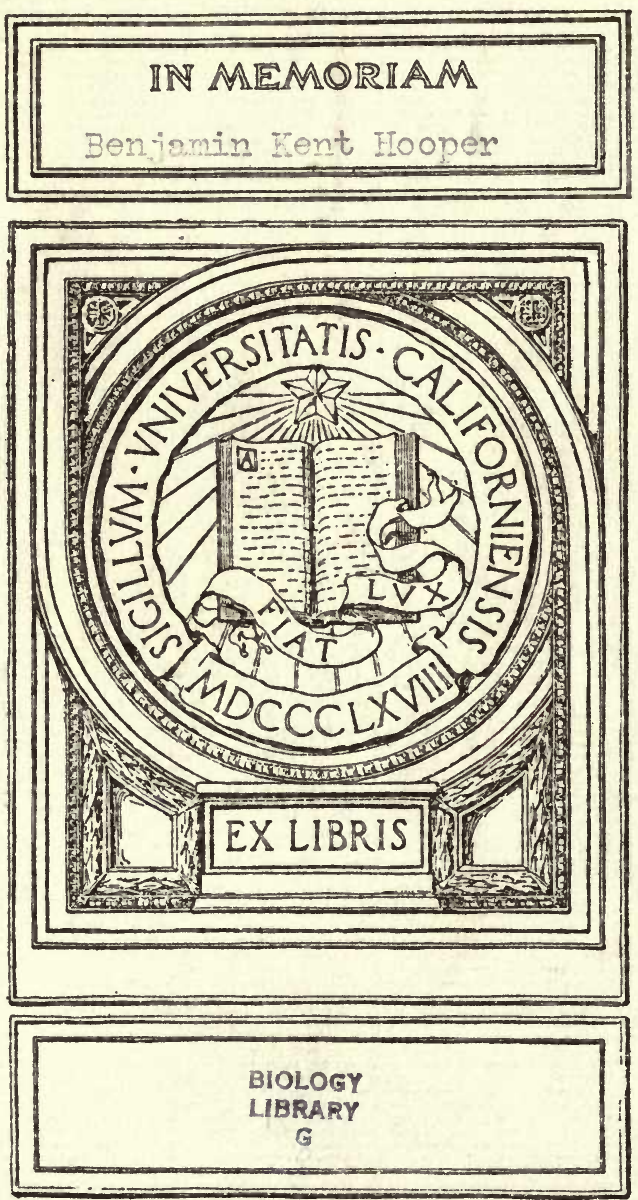


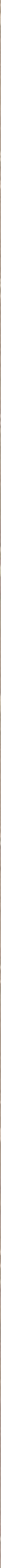






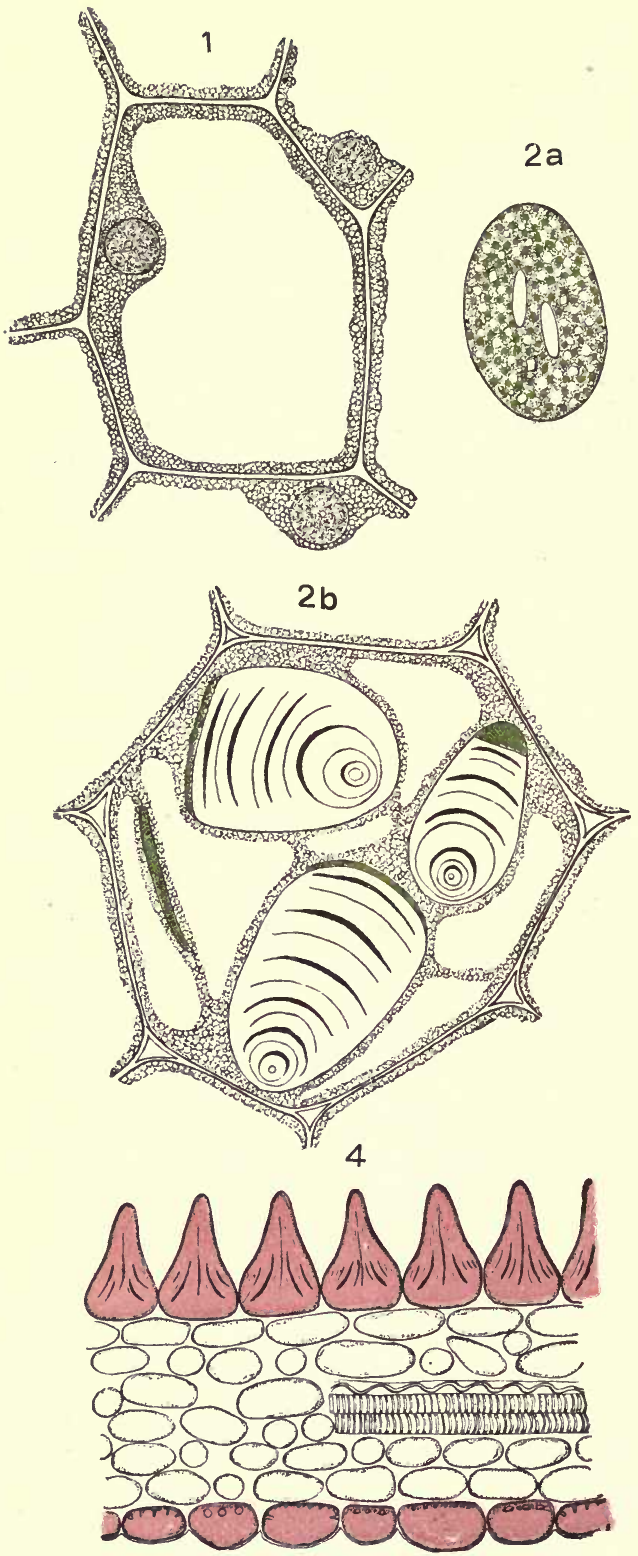

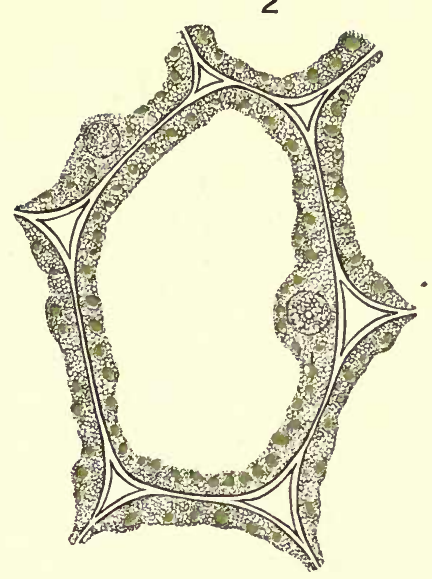

3

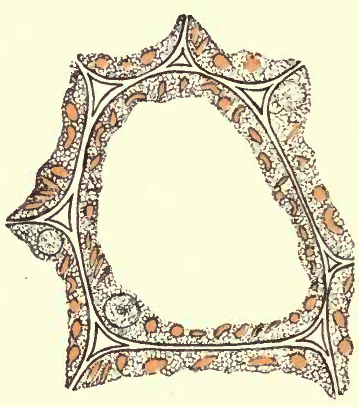

$3 a$

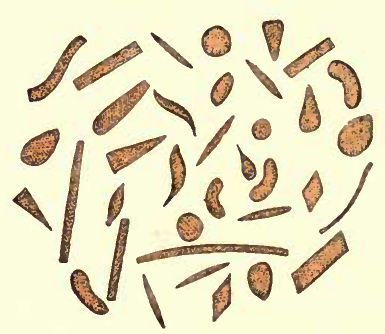

Frontispiece. I, cell of fleshy scale of bulb of onion (Allium Cepa) showing cytoplasm, nucleus and large central vacuole.

Chloroplasts: 2, a parenchyma cell of green fruit of garden pepper (Capsicum annuum) showing cytoplasm, nucleus and chloroplasts; $2 \mathrm{a}$, a chloroplast of a moss (Funaria) showing green granules, assimilation starch grains and protein granules; $2 \mathrm{~b}, \mathrm{a}$ cell near the periphery of the pseudo-bulb of the orchid (Phaius grandifolius) showing cytoplasm and three reserve starch grains formed by leucoplasts, which latter under the influence of light have developed into chloroplasts.

Chromoplasts: 3, a parenchyma cell of ripe fruit of Capsicum annuum showing cytoplasm, nucleus and yellowish-red chromoplasts; $3 a$, isolated chromoplasts of carrot (Daucus Carota).

4. transverse section of petal of wild pansy (Viola tricolor) showing colored cell-sap in epidermal cells. 


\section{APPLIED AND ECONOMIC}

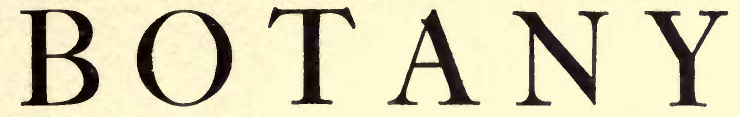

ESPECIALLY ADAPTED FOR THE USE OF STUDENTS IN TECHNICAL SCHOOLS, AGRICULTURAL, PHARMACEUTICAL AND MEDICAL COLLEGES, AND ALSO AS A BOOK OF REFERENCE FOR CHEMISTS, FOOD ANALYSTS AND STUDENTS ENGAGED IN THE MORPHOLOGICAL AND PHYSIOLOGICAL STUDY OF PLANTS

BY

HENRY KRAEMER, Ph.B. (in Chemistry), Ph.M. (in Pharmacy), Ph.D. (in Botany).

PROFESSOR OF BOTANY AND PHARMACOGNOSY, AND DIRECTOR OF THE MICROSCOPICAL, LABORATORY IN THE PHILADELPHIA COLLEGE OF PHARMACY; MEMBER OF THE EXECUTIVE COMMITTEE OF REVISION OF THE PHARMACOPGIA OF THE UNITED STATES OF AMERICA; CORRESPONDING MEMBER OF THE SOCIÉTÉ DE PHARMACIE DE PARIS, ETC.

ILLUSTRATED

With 424 plates, comprising about 2000 figures

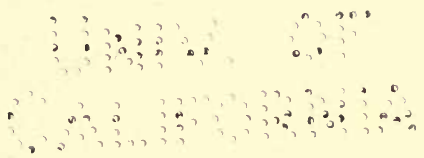

PUBLISHED BY THE AUTHOR

145 NORTH TENTH ST., PHILADELPHIA 
COPYRIGHT, 1914, BY HENRY KRAEMER

ALL RIGHTS RESERVED
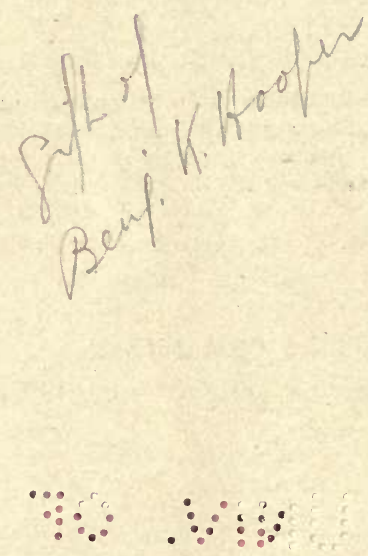

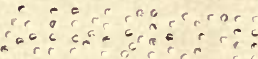




\section{PREFACE.}

THERE are quite a number of books on botany, many of which serve a very excellent purpose. For the most part, however, they are not adapted for the use of students in the applied sciences where the knowledge of botany is to be utilized later in practical work. It is now more than sixty years since Schleiden showed the value of the microscope in the examination of drugs and Schacht demonstrated its usefulness in the study of textile fibers. Since that time quite a number of works have been published dealing with the microscopy of special technical products, as drugs, foods, fibers, woods, etc., but there have been no text-books which could be employed in the courses on applied and economic botany that would satisfy either the desires of the student or fit the graduate for practical work in commercial life. It is not generally appreciated that there is a department of applied botany which is distinct from every other phase of botanical study; the point of view and the technique being peculiarly its own and the problems so intricate and important that they should ever be held before the student and command his constant attention. It is almost selfevident that courses in botany which are intended for intellectual culture or scientific discipline are not adapted for technical courses of instruction. In the latter the student has a right to ask for the application of the instruction which he is receiving and to show an interest in proportion as the instructor is able to demonstrate its value. There are some who consider that a more or less superficial knowledge of botanical principles and microscopic technique is sufficient for the student in applied or economic botany. On the contrary, we find that a rather extended knowledge of botany and a very thorough preparation in certain phases of botanical work are absolutely required in order to prepare him to meet and solve the many problems that arise in the commercial world. Many of the commercial problems that are held to be chemical and which are handed to the chemist for solution are, as a matter of fact, of a botanical character and can be solved with less expense and less time by the trained botanist. What is really needed is the trained analyst, who, while proficient with chemical methods, is also thoroughly versed in microscopic technique. We have come to a time, if real progress is to be made both in the manufacture of plant materials and in the examination of commercial substances, that it is necessary to bring both chemical and botanical training and knowledge to bear upon the problems involved.

Nearly all of the problems upon which one is liable to be consulted in active practice, whether they involve new processes of manufacture or the examination of the finished market material, show at the outset that the analyst must have a very thorough knowledge of the cell constituents and the tissues composing the raw material. It is for this reason that almost one-half of the material of this volume is devoted to the study of 
cell-contents, forms of cells, and the outer and inner morphology of higher plants. The facts and illustrations here presented cover not only the latest researches on their morphology, origin, and distribution, but also the most recent advances in regard to their chemical nature. A fair amount of this work is original, and the presentation in one volume, it is hoped, will be appreciated in addition also by students of the plant cell as well as the phyto-chemist.

In the practical examination of the crude materials of the market we find more or less contamination with fungi, lichens, anci other lower plants, and for this reason, as well as for the understanding of the morphology of the higher plants, a more or less succinct treatment of the Principal Groups of Plants is given in Chapter I. Another reason which has prompted the author to lay considerable stress on the knowledge contained in this chapter is that if the student will master the technique and will apply himself to this part of the work, he will be better prepared to take up the study of the structures of higher plants.

The chapter on Classification of Higher Plants is quite extended and illustrated with a large number of photographs, showing not only many of our interesting wild plants but the principal economic plants that are used as foods, drugs, and for other economic purposes, with considerable valuable technical information concerning them. The chapter on Nomenclature has been included in order that the derivations of botanical names might be better understood and their correct spelling facilitated. The chapter on Cultivation of Medicinal Plants, while especially prepared for those interested in the subject, will be found useful to those interested in other industries where the extermination of native plants is calling attention to practical means for their replenishment. The chapter on Microscopic Technique contains methods for the preparation of commercial materials and much information that doubtless will facilitate practical work. The index contains some 6,000 titles, making the information contained in this volume readily accessible.

The work is illustrated throughout, and the legends accompanying the illustrations will be found interesting and instructive and in most instances supplement the information given in the text. All of the illustrations which are not reproductions of photographs and drawings made by the author are duly credited. The author acknowledges the valuable services rendered by his associates in the preparation of the text, reading of proof, and preparation of the index; to Professor Wallace Truesdell for assistance in the chapter on Botanical Nomenclature and to Mr. Stewardson Brown for the use of a number of photographs. When larger monographs and authoritative works have been consulted, due credit has been given in the text, so that the present work is a foundation not only of a text-book for students of applied and economic botany but as a reference book for manufacturers and analysts.

NOVEMBER, IOI4.

H. K. 


\section{CONTENTS.}

\section{CHAPTER I.-PRINCIPAL GROUPS OF PLANTS.}

INTRODUCTORY

Thallophytes.

Schizophytes

Schizophyceæ $($ Fission Algæ) $\ldots \ldots \ldots \ldots \ldots \ldots \ldots \ldots \ldots \ldots$

Algæ

Schizomycetes (Bacteria) .................. I2

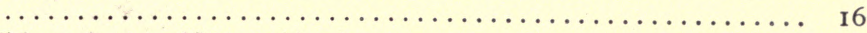

Chlorophyceæ (Green Algæ) .................. 20

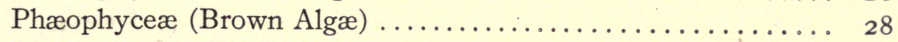

Rhodophyceæ $($ Red Algæ) . . . . . . . . . . . . . . .

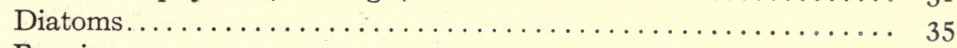

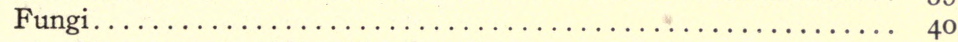

Phycomycetes (Alga-like Fungi)............... 42

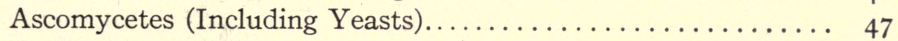

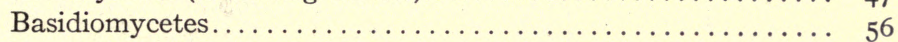

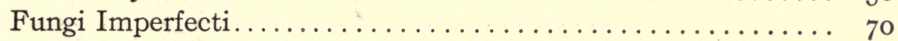

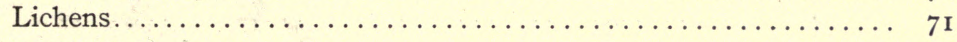

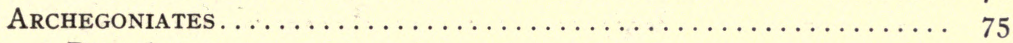

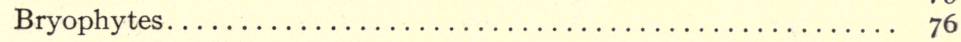

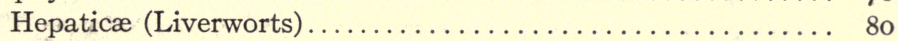

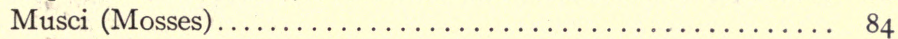

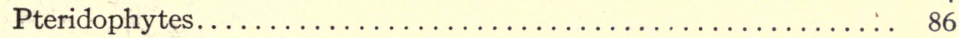

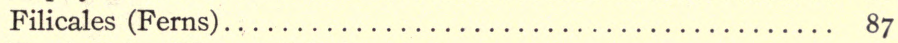

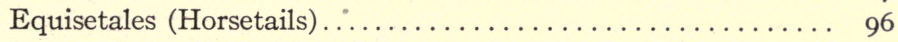

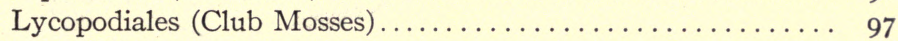

Spermophytes $($ Seed Plants) $\ldots \ldots \ldots \ldots \ldots \ldots \ldots \ldots \ldots \ldots \ldots$ ioo

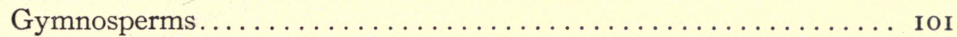

Angiosperms........................ II9

Organic Evolution $\ldots \ldots \ldots \ldots \ldots \ldots \ldots \ldots \ldots \ldots \ldots \ldots \ldots \ldots \ldots \ldots \ldots \ldots$

CHAPTER II.-CELL-CONTENTS AND FORMS OF CELLS.

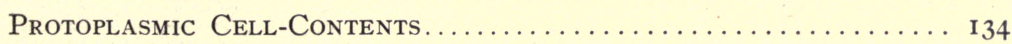

Non-Protoplasmic Cell-Contents ................... 140

Factors Influencing Growth, Including Food of Plants....... 246

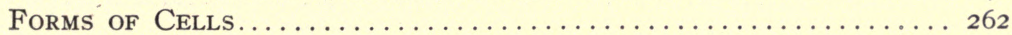

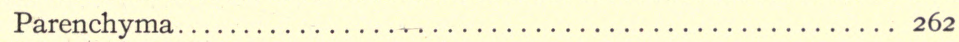

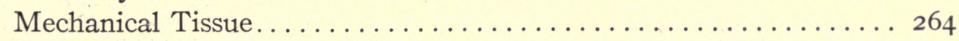

Conducting or Mestome Cells.................... 272

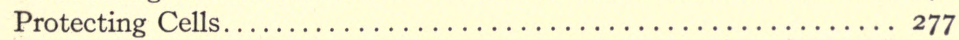


CHAPTER III.-OUTER AND INNER MORPHOLOGY OF THE HIGHER PLANTS.

InTRODUCTORY.................................. 298

I. Outer Morphology of the Root................... 299

Inner Structure of the Root........................ 309

II. Outer Morphology of the Stem .................... 320

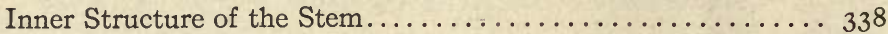

III. Outer Morphology of the Leaf .................. 348

Inner Structure of the Leaf....................... 365

IV. Outer Morphology of the Flower............... 374

Inner Structure (Histology) of the Flower............ 402

V. Outer Morphology of the Fruit................ 408

Inner Structure of the Fruit......., $\ldots, \ldots, \ldots \ldots \ldots \ldots, 42 \cdot 1$

VI. Outer Morphology of the Seed.................. 423

Inner Structure of the Seed................... 427

CHAPTER IV.-BOTANICAL NOMENCLATURE.......... 430

CHAPTER V.-CLASSIFICATION OF ANGIOSPERMS YIELDING ECONOMIC PRODUCTS.

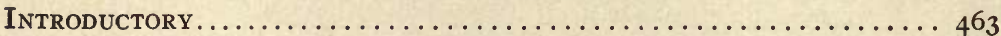

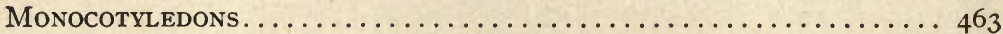

Dicotyledons............................... 50 I

Archichlamydeæ or Choripetalæ.................. 504

Metachlamydeæ or Sympetalæ..................... 643

CHAPTER VI.-CULTIVATION OF MEDICINAL PLANTS

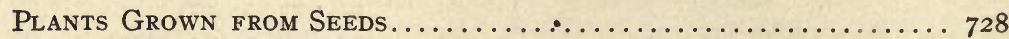

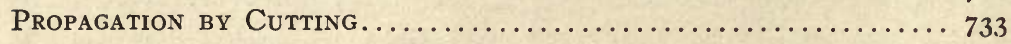

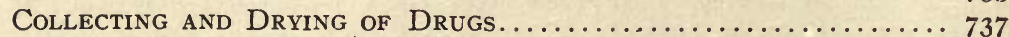

Relative Value of Drugs from Cultivated and Wild Plants... 739

Progress in the United States............................... 744

CHAPTER VII.-MICROSCOPIC TECHNIQUE AND REAGENTS.

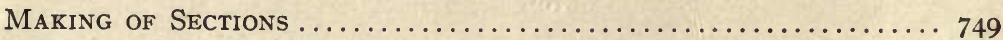

Practical Suggestions................................. 75 I

Micrometry or Microscopic MEASUREMENT................. 754

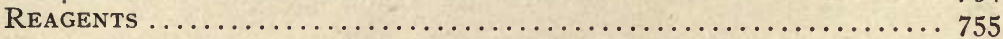

Effects of Important Micro-Chemical Reagents ............ 759

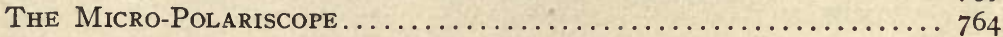

The Spectroscope in Microscopic Analytical Work........... 764

Dark Field Illumination and the Ultra-Microscope.......... 765

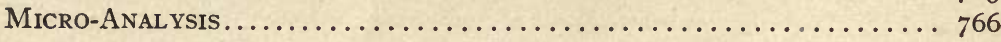




\title{
BOTANY
}

\author{
CHAPTER I \\ PRINCIPAL GROUPS OF PLANTS
}

INTRODUCTORY

THERE are four main lines of botanical work now recognized, -namely, Morphology, Histology, Physiology, and Ecology. Morphology treats of the form and structure of plants and the subject is sometimes divided into (I) external morphology or organography and (2) internal morphology or anatomy (histology). The former deals with external characters of plant parts and the latter with their minute inner structare. Physiology may be defined as the study which considers life processes and the conditions which influence these. Ecology is the study of the adaptation of plants and their parts to external conditions. It is important to bear in mind, however, that these several departments are more or less interdependent, and that one of them cannot be intelligently studied without a consideration of the problems of the others. For instance, as Goebel states, we cannot understand the relation of the external forms of organs without reference to their functions. In other words, form and function have a direct relation; one influences the other. So, too, in the study of ecology we study the influence of external conditions on plants and these, as indicated above, have a direct influence on physiological processes, and thus the study of ecology merges into the study of physiology on the one hand and into morphology on the other.

While this book will deal chiefly with the structure of plants and their parts, still it will be necessary occasionally to refer to some of the characters of plants which properly belong to other clepartments of botanical study.

Basis of Plant Structure.-In order to understand the significance and relation of the various parts of plants it is necessary 
to know something of their functions and habits of life as well as of their internal structure. It is desirable at this point to give a brief consideration to the cell, as it is the unit of plant structure.

If we make a section of a plant and examine it by means of the microscope, the cut surface presents the appearance of a network, indicating that the tissue is made up of small compartments or chambers. One of these compartments together with its contents constitutes the structure known as the CELL (see Frontispiece).

The cell-contents vary greatly in appearance and composition, but in all active or living cells there is always present the substance known as PROTOPLASM. The protoplasm is the basis of all plant structures whether they belong to the lowest or highest forms; for by its aid or from it all parts of the plant are developed. Even the cell-wall is a product of protoplasmic activity. The protoplasmic content of the cell consists of several intimately related but more or less distinct portions,-namely, a somewhat thin, semi-liquid, granular portion known as the CYToplasm; a more or less spherical body embedded in the cytoplasm called the NUCLEUS; and frequently, but not always, certain small bodies which are more or less variable in shape called PLASTIDs, these being also embedded in the cytoplasm (see Frontispiece). The cytoplasm and nucleus are sometimes considered together as a unit, which is known as the PROTOPLAST. A fuller discussion of the differentiated portions of the protoplasm will be found in Chapter II.

The lowest organisms, as the slime molds, do not have an enclosing membrane, but consist of a naked mass of protoplasm. With this exception plants have an outer wall or membrane. They may consist of a single cell, as in the Bacteria, or a chain of cells, as in the filamentous Algæ, or a mass of cells, as in the majority of plants, and are accordingly designated as unicellular or multicellular. The cell-wall is composed for the most part of cellulose, but may be modified in various ways.

Nomenclature.-The names for describing plants have been derived for the most part from studies of the higher plants, they having exclusively attracted the attention of botanists at first. But with the light which has been thrown on the relationship 
of the higher and lower groups of plants by the more recent study of the lower forms the older terminology has been somewhat modified. Thus, for example, we speak of the root and shoot, with its leaves, as the vegetative organs of the higher plants, and in describing the corresponding organs (where they exist) in the lower plants, we either apply these terms directly, or indirectly by saying that the latter are root-like, stem-like, etc. On the other hand, we now speak of the sexual organs of the higher plants as antheridia and oögonia (or archegonia) instead of classifying them roughly as stamens and pistils, the latter names being retained but with a different signification.

Plant Organs.-Depending upon the fact that the plant requires nourishment for its growth and development and that it has also to carry on the work of reproduction or propagation, -i.e., the production of new plants, - we distinguish between vegetative or nutritive organs and propagative or reproductive organs. The vegetative organs, such as the root, stem and leaves in higher plants, manufacture the food necessary for the life of the plant, while certain other more or less specialized organs or cells carry on the work of reproduction.

In the lower plants, however, the whole structure is much simpler, and in some instances a cell which performs the work of a nutritive cell at one stage may become a reproductive cell at another, or, as in the case of the unicellular Algæ, all the various functions of the plant may be carried on by a single cell.

Generally speaking, there are two principal ways in which plants are multiplied or reproduced: ( I ) By CELL DIVISION or cell fission, and (2) by the formation of special cells known as SPOREs. In cell division (Fig. 85) the nucleus and cytoplasm of a cell divide to form two new cells or protoplasts, which become distinct by the formation of a wall or cell-plate between the two halves. All growth in plants is dependent upon this method, and in growing parts the cells are said to be in a state of division. Owing to the plasticity of the plant organism, detached portions will often grow and give rise to new plants, as in the case of cuttings. Growth here as in the parent plant is accompanied by cell division. In some of the lower Algæ (Fig. Io) cell division is the only method of propagation, and as only the ordinary vegetative or 
nutritive cells of the plant are involved in the process it is sometimes spoken of as vegetative multiplication.

In both lower and higher plants, with the exceptions just noted, reproduction is also carried on by means of spores.

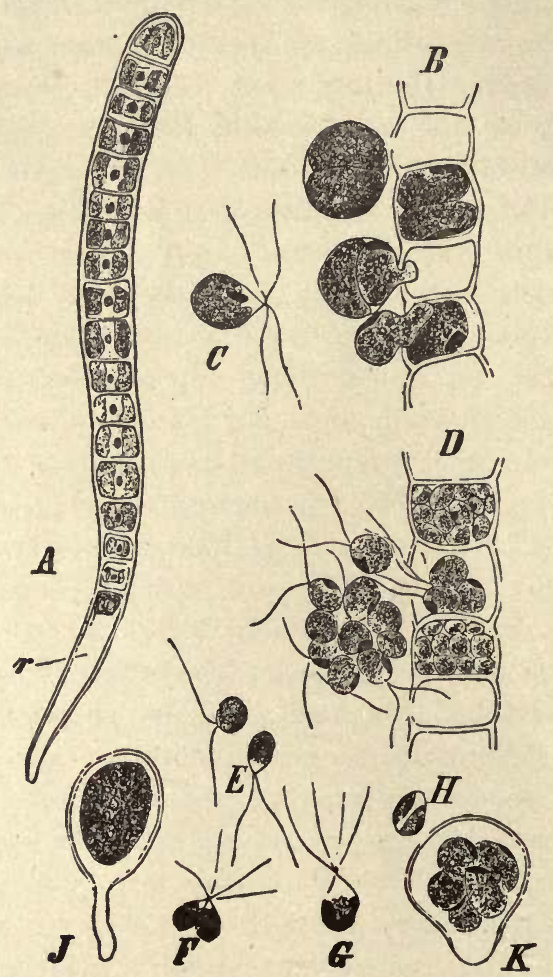

FIG. 5. Ulothrix zonata. A, young flament with rhizoid cell ( $\mathrm{r}$; $\mathrm{B}$, piece of filament showing escape of swarm spores; C, a swarm spore or zoöspore with 4 cilia; D, biciliate gametes escaping from a filament; E, F, G, showing different stages of union of two gametes; $\mathrm{H}$, young zygote or zygospore in which the cilia have been absorbed; $\mathrm{J}$, I-celled plant developed from zygote; $K$, young plant organizing zoöspores.-After Dodel-Port.

Depending upon their origin two classes of spores are distinguished, namely, $(a)$ asexual spores, and $(b)$ sexual spores. In the production of asexual spores the contents of a certain cell called a mother cell or SPORANGIUM break up into a number of new cells sometimes called daughter cells, which escape through the cell-wall. In the lower plants, particularly those growing 
in water or in moist places, these cells are provided with short thread-like appendages known as cilia, which enable them to move about in the water. They are known as zoöspones or swarm spores (Fig. 5, B, C), and each individual zoöspore is able to produce a new plant.

The number of zoöspores formed in a sporangium is usually 2 to 8 , as in Ulothrix, but the number may be larger. The method of cell formation which gives rise to zoöspores is sometimes spoken of as INTERNAL DIVISION from the fact that they arise within the old cell and retain no relation to the old wall as is the case in cell fission. The zoöspores are at first naked protoplasts, but later, on coming to rest, may form a wall. Sexual spores, on the other hand, are formed by the union of two cells known as GAMETES. When the gametes are similar the resulting spore is known as a zYGospore or zygote (Fig. $5, E, F, G$ ). When the gametes are unlike, the spore produced by their union is known as an oösPoRE. In the latter case one of the gametes is larger than the other, is less active, and is spoken of as the female gamete, oösphere, or egg (Figs. 12, 2I ). The other more active cell is known as the male gamete, antherozoid or sperm (Fig. $5 \mathrm{I}, I I I)$. The cell giving rise to the oösphere is known as the oögonium (Figs. 12, 21), while the one in which the antherozoid or sperm originates is called the antheridium (Figs. 12, $2 \mathrm{I}$, $22,5 \mathrm{I})$.

\section{PLANT GROUPS.}

Until a comparatively recent time, botanists divided the plant kingdom into two large groups, as follows:

The flowering plants, or Phanerogams, meaning " reproductive process evident," so applied because the reproduction of the plant was readily seen to develop in the flower through the agency of the pistil and stamens.

The non-flowering plants, or Cryptogams, meaning " reproductive process concealed," so applied to the lower plants like the ferns, mosses, sea-weeds, etc., because in these plants the method of reproduction was not known.

Now, however, after a considerable amount of study, it has been learned that a great many of the lower plants have repro- 
ductive organs which are analogous, even if they are not exactly similar, to those of the flowering plants. Consequently the former classification is no longer applicable, and the following arrangement is now generally adopted:

$$
\begin{aligned}
& \text { Thallophytes } \ldots \ldots\left\{\begin{array}{l}
\text { Algæ } \\
\text { Fungi }
\end{array}\right. \\
& \text { Archegoniates } . . .\left\{\begin{array}{l}
\text { Bryophytes } \\
\text { Pteridophytes. }
\end{array}\right. \\
& \text { Spermophytes } \cdots .\left\{\begin{array}{l}
\text { Gymnosperms } \\
\text { Angiosperms }
\end{array}\right.
\end{aligned}
$$

In our study of these groups we shall see that in passing from the Thallophytes through the various groups to the Angiosperms we pass from very simple forms to those which are quite complex.

\section{THALLOPHYTES.}

General Characteristics.-This group comprises those plants which are simplest in form and structure. They are supposed also to represent more or less primitive types. In these the plant body does not show a differentiation into root, stem, and leaf, as in the higher plants, and is termed a thallus, the word thallus meaning a "mass" of cells. The cells making up a thallus are all alike and are not differentiated for special functions. However, it must not be thought that every Thallophyte is characterized in this way. Many of the Thallophytes have cells or groups of cells which become specialized, i.e., set apart for a particular function, as for example the reproductive cells. We see, therefore, that the word Thallophyte is a general term and is applied to many plants which are not thallus-bearing, but which are really closely related to the simpler forms to which the word Thallophyte is strictly applicable. When made up of a mass of cells they may branch in various ways, but the essential structure remains more or less uniform throughout.

The Thallophytes vary in size and general appearance from minute, unicellular organisms to those which are filamentous and delicately branched, and even becoming leaf-like structures, attaining a length in some of the marine algæ of a thousand feet 
and even more. Some of these are more or less complicated in structure.

The Thallophytes are subdivided into two important groups, as follows :

The Algæ, plants producing chlorophyll or green cell-contents, and hence capable of manufacturing food from the inorganic substances air and water.

The Fungi, plants not producing chlorophyll, and hence not capable of forming their own food, but living upon dead or living matter.

Before considering the Algæ proper we will consider two groups which are very simple in structure and whose method of reproduction as well as life history is also very simple; namely, the Blue-green Algæ and the Bacteria. The Blue-green Algæ are ordinarily classified with the Algæ, and the Bacteria are very often grouped with the Fungi. Owing to certain resemblances between these two groups it is convenient to arrange them together under the name Schizophytes, or fission plants.

\section{SCHIZOPHYTES.}

Characteristics.-The name Schizophyta means "fission plants," and is applied to this group because the reproduction is chiefly by means of the division of the cells, which may occur either at the middle of the cell and in one direction, in which case a series of connected cells are formed, or in two or three directions, giving rise to spherical aggregates or colonies. They do not usually contain chromatophores, and the coloring substance, when present, is either uniformly distributed throughout the cell or occurs on the external surface of the protoplasmic content.

There are two chief groups: the one corresponds to Algæ, and, while they do not contain a simple green substance, they are for the most part of a blue-green color, although they may assume various shades of orange, yellow, and brown, even appearing chocolate or purplish-red at times. The second group, corresponding to the Fungi, comprises the Bacteria or Schizomycetes, which are distinguished for the most part by being nearly colorless and only occasionally of a reddish or green color. 
SCHIZOPHYCEÆ, OR FI\$SION ALGÆ.-This group of plants, also known as Cyanophyceæ or Blue-green Algæ (Fig. 6), are generally found in more or less stagnant water and are characterized by having associated with the chlorophyll a definite bluegreen principle known as phycocyanin. However, many of these Algæ contain other pigments in such quantity as to give them distinct colors much like those found in the red and brown Algæ, such as Trichodesmium, a filamentous Alga giving the Red Sea its characteristic appearance. Some of these live at the highest temperature known to support life; some developing, as Gloeocapsa, on the sides of the geysers in the Yellowstone Park. These forms have very wide habits, some living, as Stigonema, in symbiosis with fungi; some, as Nostoc, are endophytic in habit, living in the depressions of various plants, and others, as Mastigocoleus, boring into shells.

They are found mostly in fresh water, and some, as Uroglena, cause considerable trouble in public water supplies by reason of their breaking down the cell-wall and the liberation of a fetid oily substance.

While these plants do not produce true spores, yet they are able to tide themselves over adverse conditions by producing resting bodies through the formation of a thicker membrane and a more concentrated cell-content. In this condition they are able to hold over for several years and then grow when the conditions of temperature, nutrition, etc., are suitable for their germination. As a rule, they grow best in shallow, stagnant water with the relatively high temperature of the summer months. When public water supplies are polluted by these blue-green Algæ it has been found that the Algæ are completely destroyed by the addition of a very small amount of copper sulphate to the reservoir. As small a quantity as one part per million is sufficient to accomplish this result, not only killing the troublesome organisms, but preventing their development for some months to come. A few of the common forms will be considered.

Gloeocapsa is one of the simplest of the Blue-green Algæ (Fig. 6), consisting of spheroidal cells from 0.0035 to $0.005 \mathrm{~mm}$. in diameter, of a yellowish or brownish-yellow color, and usually embedded in groups of two or some multiple of four in an olive- 


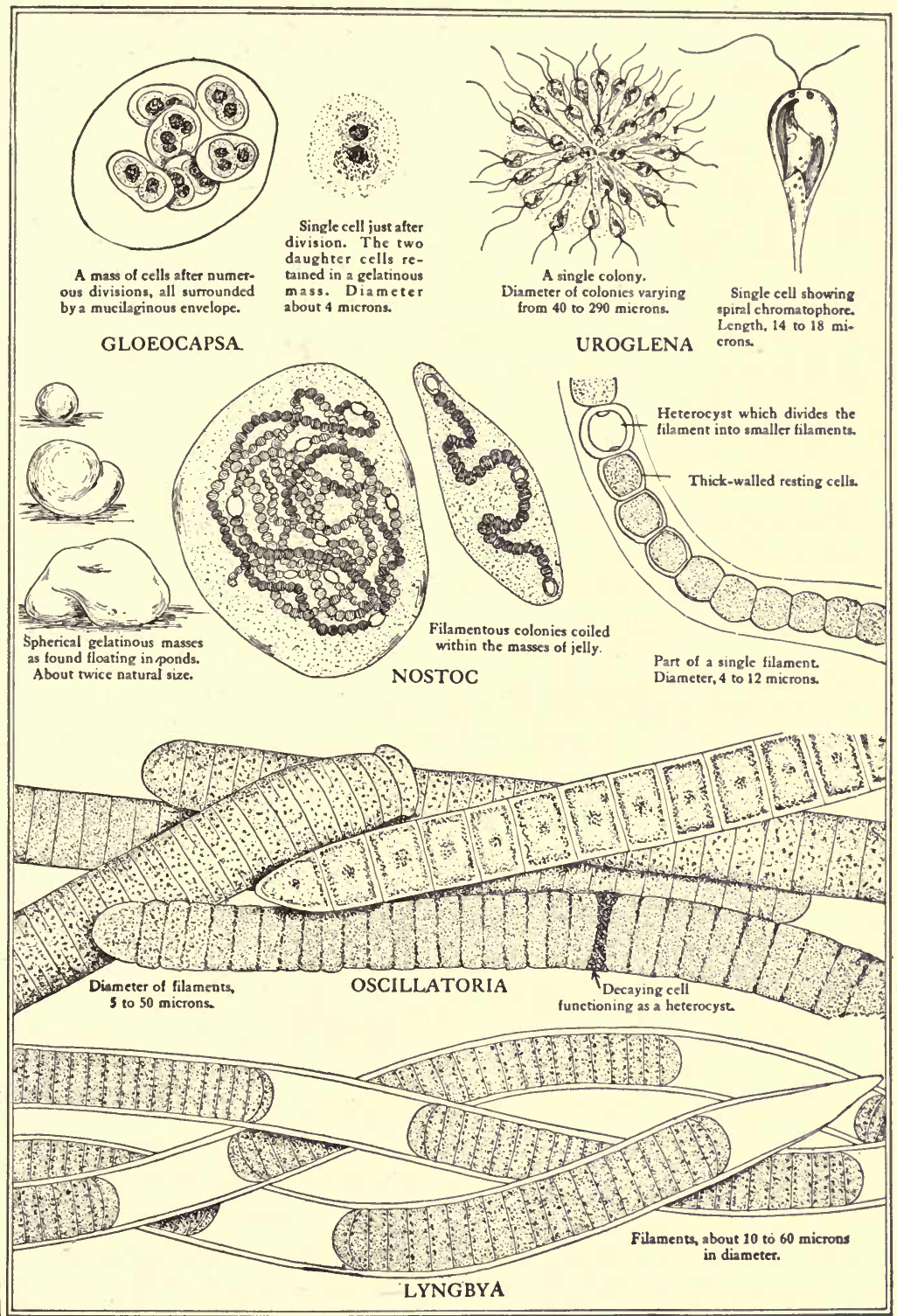

Fig. 6. Forms of Cyanophyceæ or Blue-Green Algæ.-Adapted from Engler and Prantl and somewhat modified by Lobeck. 
brown gelatinous stratum, this arrangement due to the cell dividing in all directions. They occur on moist earth, stones, wharf pilings, and even on window panes of greenhouses, thus being distributed in both fresh- and salt-water regions. They sometimes form a kind of crustaceous stratum, and sometimes soft, slimy masses sufficiently abundant that they can be stripped by the handful from dripping, partially shaded rocks. Owing to the variation in color and general habit of the plant a great many species have been described, but up to the present time about 60 have been sharply distinguished.

Oscillatoria, formerly known as Oscillaria, is the name applied to a simple filamentous blue-green alga (Fig. 6) that is characterized by movement from side to side as in a pendulum, due, as has been suggested, to the movement of spiral masses of protoplasm extending from cell to cell. These filaments consist of a series of disk-shaped cells like a pile of coins placed side by side, the end cell being rounded off and more or less convex. The contents are made up of a finely granular substance differentiated into two areas, a dark central nuclear portion, and a peripheral holding the pigment, which may vary from a bluish-green to dark olive-green or even red sufficiently intense to give the water a red color. The filaments vary from 0.001 to $0.005 \mathrm{~mm}$. in diameter, though they may attain a size of $0.050 \mathrm{~mm}$.

Oscillatoria is usually found on wet, marshy grounds, in ditches among decayed vegetable matter, on wood subject to hot waste from steam engines, around pumps and cisterns, and in greenhouses. It occurs in fresh and salt water.

Lyngbya somewhat resembles Oscillatoria, but does not show any oscillations and the filaments are each provided with a distinct sheath (Fig. 6). It forms late in the summer in large tufts. It is of a bluish-green color, forms long filaments, occurring in the late summer upon Zostera and other Algæ. The groups are large and characteristic and have been given the common name Mermaid's Hair. The cells are about $0.030 \mathrm{~mm}$. in diameter.

Uroglena is a form which is more or less oval or pear-shaped, about 0.014 to $0.018 \mathrm{~mm}$. in length, and extended into a stalk below, the upper end being provided with two unequal cilia (Fig. 6). The wall secretes a large amount of mucilage. The organisms 
arrange themselves in a radiating sphere, with the cilia at the periphery. Each cell of the colony contains a more or less spiral, yellowish chromatophore, bearing a reddish spet at one end, a nucleus at the centre, and a few vacuoles. The cells secrete a large quantity of oil, which is of an unpleasant, fish-like odor, and is due either to the decay or breaking up of the cells by mechanical means. This breaking up of the cells is the cause of the disagreeable odor occasionally found in public water supplies. Uroglena is found in New England and has been reported as far west as Indiana, and is probably rather widely distributed in the United States. It seems to thrive best in cold temperatures, usually occurring in greatest numbers when the water is frozen over. It multiplies by cell division, which takes place when the colony becomes rather large. It also produces resting spores which enable the organism to survive conditions which would otherwise exterminate it.

A closely related organism, Synura, is responsible for the ripe cucumber odor which was formerly thought to be caused by fresh-water sponges'.

Nostoc, a form occurring in filaments like a string of pearls, is made up of spherical or elliptical cells, the whole being surrounded by a thick, mucilaginous membrane (Fig. 6). Usually one finds a number of these filaments growing together in a mass which can be seen by the naked eye floating in the water. These masses vary from globular to sub-globular, are irregularly divided or occur in definitely expanded groups. These forms are marked by having two kinds of cells, the one filled with a granular protoplasmic content, the other being free from protoplasm and somewhat larger than the other cells. These latter are fewer in number and are called " heterocysts," which means simply "other cells." At these latter cells the filaments separate, and thus many new colonies are formed. Nostoc is mostly of an olive-green color, but may be dark bluish-green, dark brown, or light yellow or even colorless. It occurs mostly in fresh-water ponds, seldom in brackish water, being found on damp rocks, on mosses and more or less submerged plants, and variously in limestone springs or wet calcareous rocks or on aluminous soil. The colonies vary greatly in size and color, and while some of them may be of microscopic 
size at one period, later they may be as large as peas or cherries. Owing to their variation in appearance in different seasons various names have been given to the same form by different investigators. They are also associated with lichens. According to systematists, the forms of Nostoc are arranged according to their aquatic or terrestrial habits.

SCHIZOMYCETES, OR BACTERIA.-The Bacteria, or Fission Fungi, occupy rather an anomalous position, some writers classifying them with Fungi and some with Algæ. They are Icelled plants, microscopic in size, and of various shape. The contents consist of protoplasm and a central body in some cases, which is looked upon as a rudimentary nucleus. They are more or less colorless, but sometimes produce a distinct pigment called bacteriopurpurin which is rose-red or violet, and occasionally a chlorophyllgreen color substance. They are capable of multiplying by division in one. two, or three directions, and under favorable conditions increase very rapidly in number. The wall is more or less albuminous in character, in this respect resembling the wall of the animal cell, and is provided with one or more cilia, or flagella, the number and position of which have been used as a basis of classification. Sometimes the walls of the cells become mucilaginous, so that the bacteria hold together, forming a mass known as a zoöglœa. Bacteria may form resting spores which arise in two ways. In one case the contents round off and take on a membrane forming a so-called ENDOSPORE; in the other case the plant body is transformed directly into a spore known as an ARTHROSPORE, as in some of the Blue-green Algæ. This body is not strictly a spore, but is in the nature of a resting cell (Fig. 7). Two classes of bacteria are frequently distinguished, as follows: Aërobic, or those which require oxygen for their development and consequently grow best when they have access to air or oxygen; and anaërobic, or those whose development is accelerated under reverse conditions, as in underlying tissues or in the interior of cultures.

Occurrence.-Bacteria occur everywhere in nature, and play a most important part in decay and putrefaction, in that they change dead animal and plant tissues back again into simple inorganic substances, as carbon dioxide, hydrogen, water, ammonia, 
etc. They serve a useful purpose in many technical operations, as in the making of cheese, acetic acid, fermentation of tobacco, curing of vanilla and many vegetable drugs, and in soil nitrification, helping to change ammonia into nitrates-one of the sources of the nitrogen used by plants. Many of them are disease-producing, or pathogenic, and are the cause of a number of infectious diseases in man and the lower animals, and plants as well. They are
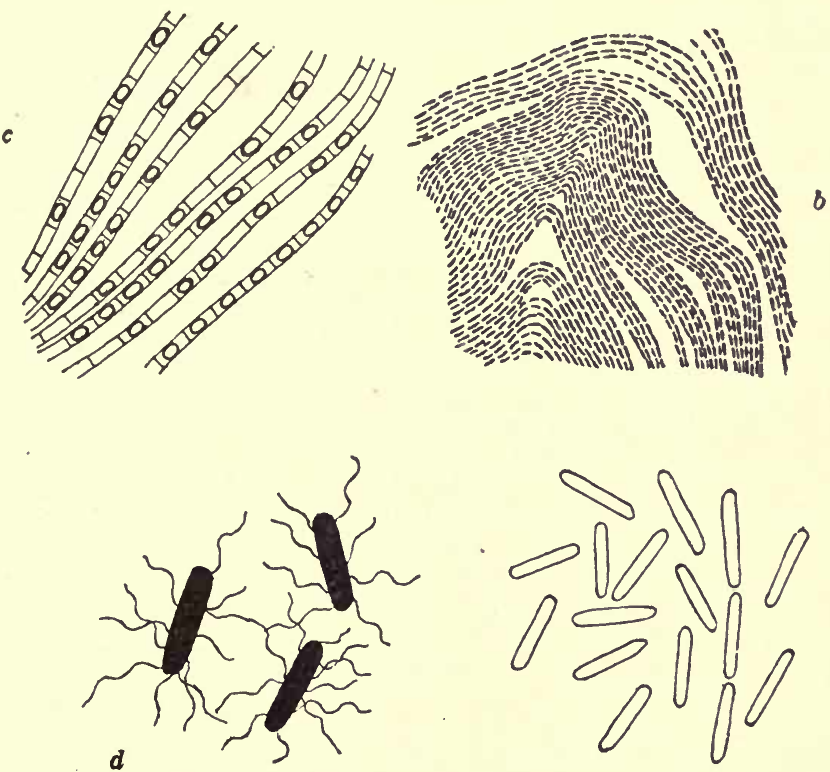

$a$

Fig. 7. Bacillus subtilis (hay bacillus). a, Small rod-like organisms such as are found in an infusion of hay, or bouillon; b, zoöglœa or mass of bacilli forming the "skin" on the surface of infusions; c, chains of organisms forming spores; d, individual bacilli showing flagella, which are only seen after staining.-After Migula.

injurious in two ways: in one case they consume the tissues of the host, as in tuberculosis, and in the other they produce powerful poisonous substances, or toxins, as in diphtheria.

Classes of Bacteria.-In order to study Bacteria they are grown upon nutrient media, such as sterile bouillon, potato, milk, etc. They are divided into a number of classes, depending for the most part on the shape of the cell: (I) The Sphærobacteria, or Cocci, are those whose cells are spherical or spheroid, and in 
which division takes place in one, two, or three directions of space. Very few of this group are provided with cilia. According to the number of cells in a colony they are distinguished as Micrococci, Diplococci, etc. (2) Bacteria proper are elongated, rod-shaped organisms in which division occurs in only one direction, namely, transversely to the long axis, and only after a preliminary elongation of the bacterium. The Bacteria are subdivided into two important groups, namely, Bacterium and Bacillus. The Bacilli are motile organisms and produce endospores (Fig. 7), whereas the Bacteria are non-motile and do not usually produce endospores. (3) Spiral bacteria constitute the third principal group and are characterized by the cells being spirally coiled. Division is in only one direction. These bacteria are usually motile, and seldom produce endospores. (4) There is another important group which includes the Sulphur Bacteria, of which the most common one is Beggiatoa. These occur in long threads, and move in an undulating manner much like Oscillaria, one of the Blue-green Algæ. They are found in sulphur waters, as in sulphur springs, and contain sulphur granules.

Bacteriological Technique.-Principally because of the minuteness in size of micro-organisms a different technique is required in their study from that required in the study of the higher plants. In the first place it is difficult to isolate them so as to be able to study individual forms. Another difficulty is to prevent contamination after they are isolated. And even though a pure culture is obtained it is difficult on purely morphological grounds to differentiate the various forms, as they are all so much alike.

I. While it is comparatively easy to prepare a sterile solution,that is, one in which all life is absent,-it is very difficult to prevent subsequent contamination under ordinary conditions. Even when a cork- or glass-stoppered bottle for keeping liquids is used it is difficult to prevent the entrance into and development of microorganisms in the liquids. The use of stoppers consisting of plugs of absorbent cotton was first suggested by Schroeder and von Dusch in 1854. They found that if flasks containing liquids, which under ordinary conditions were likely to decompose, as beef broth, etc., were stoppered with plugs of absorbent cotton 
and the liquid then boiled for some time it would keep indefinitely.

II. It remained for Koch and Pasteur to show what took place in the boiling of the liquid, who at the same time developed the principles of sterilization in bacteriological work. These authors discovered that micro-organisms have two stages of development, one of which is active and the other resting, the latter being known as the egg or spore condition. They found that the organisms in the active condition were completely destroyed on heating the solution containing them for 30 minutes at $100^{\circ} \mathrm{C}$. If this solution was allowed to stand for 24 hours or longer there would be evidences of decomposition, which was due to the fact that the spores representing the resting stage of the organisms were unaffected by the first heating and developed into the active stage. As a result of further experiments they found that if the solution were heated on the second day for 30 minutes at a temperature of $100^{\circ} \mathrm{C}$. the second growth of organisms was destroyed, but it was found that the solution might still undergo decomposition in the course of time, owing to the later development of a few remaining spores. It was, however, found that heating the liquid again on the third day was sufficient to kill all of the spores as well as the organisms in the active stage. By repeating these experiments the authors confirmed their observations and established the process known as discontinuous sterilization, which simply means that if a solution of a putrescent or fermentative substance is heated on three consecutive days for 30 minutes at a temperature of $100^{\circ} \mathrm{C}$., the flask or bottle being stoppered with absorbent cotton, it will keep indefinitely. Instead of using a plug of absorbent cotton the neck of the flask can be drawn out into a narrow tube and directed downwards (see Reagents). The time required for producing a sterile solution,- - that is, one free from micro-organisms or their spores,-can, however, be much reduced by increasing the temperature, or pressure, or both. By use of the autoclave, in which the pressure can be increased from Io to 20 pounds, sterilization can be accomplished in 30 minutes by using a temperature of $110^{\circ} \mathrm{C}$.

III. As already indicated, one of the greatest difficulties is to isolate the organisms. In a cubic centimetre of water there 
may be a million organisms representing various groups of bacteria. In trying to solve the problem of their separation it occurred to Koch that if he could secure a medium which was solid at the ordinary temperature and liquid at a slightly higher temperature, he could mix a certain quantity of liquid containing micro-organisms with the medium in a sterile condition, and then by solidifying the mixture the organisms would be fixed, and thus from each organism a colony would be developed which could be isolated and further studied. We are indebted to Koch for the use of solid culture media like nutrient gelatin and nutrient agar in the study of these organisms.

IV. The application of stains for differentiating the various organisms was introduced by Weigert in 1877 . Staining is of use in the determination of the number of flagella of certain organisms, in the study of spores, and the identification of certain pathogenic organisms, which occur in mucus and pus, as tubercle bacilli, etc. Gram's method of staining is of great use in differentiating many pathogenic as well as non-pathogenic organisms, and is of importance in classifying bacteria.

ALG瓜.

Characteristics.-Algæ are characterized by their habit of living in water or in moist places. They vary from simple, I-celled microscopic forms to those of great size like the sea-weeds. In the various types, however, the cells show little variation in shape. All the Algæ contain more or less of a green coloring matter, even though it may be concealed by other pigments of a blue (as in Schizophyta), brown, or reddish color. The possession of this green cell-content or chlorophyll enables the Algæ, in the presence of sunlight, to manufacture food substances from simple materials like carbon dioxide and water.

The occurrence of chlorophyll can be readily demonstrated by extracting it with 95 per cent. alcohol. Even in the most delicate of the red Algæ it can be shown by placing the fresh material in a strong solution of common salt and afterwards extracting the chlorophyll with alcohol, the other pigments being unaffected.

Algæ are sometimes grouped as Fresh-Water Algæ, includ- 
ing most of the Green Algæ, and the Marine Algæ or Sea-weeds, including most of the brown and red forms.

Algæ are classified in three natural groups, not only on account of color differences, but because of certain corresponding structural relationships, thus :

Chlorophyceæ (Green Algæ).

Phæophyceæ (Brown Algæ).

Rhodophyceæ (Red Algæ).

Arranging the Algæ in this way provides the simplest classification. But in addition to these groups there is another some what isolated group that will be taken up first before the Chlorophyceæ,-namely, the Conjugatæ. These are Green Algæ consisting of either single cells or a chain of cells united into threads and further characterized by dividing always in the one direction so that a filament results. They furthermore do not produce zoöspores, but produce zygospores as a result of a union of two similar or only slightly different cells. After a period of rest they break from the outer membrane and develop directly into new vegetable cells. To this class the Desmids and Spirogyra belong.

The Desmids are unicellular Algæ, varying from torpedoshaped to variously branched forms, occurring even in chains. The protoplast is usually separated at or near the middle, where the nucleus is located, dividing the cell into two symmetrical portions (Fig. 8, E). In the protoplast is a more or less complex chromatophore, through the center of which are distributed a number of globular pyrenoids. The latter are distinct structures embedded in the chromatophores of Green Algæ and consist of a central protein substance surrounded by a number of starch grains, and, therefore, give a purple reaction with iodine. Owing to the fact that the Desmids are motile they were formerly considered to be members of the animal kingdom. The movement is slow and steady and largely influenced by the light. There is also a circulatory movement frequently observed in the contents of active living material. In addition, there is almost always observable at the ends a well-defined spherical vacuole containing numerous small crystals of calcium sulphate which exhibit a dancing movement due to surface tension and is known as molec- 
ular or Brownian movement. Reproduction is either by simple division or by the union of two Desmids. In the latter case the contents of each flow together into a connecting tube formed by the union of the two Desmids, the resultant mass rounding off to form a zygospore.

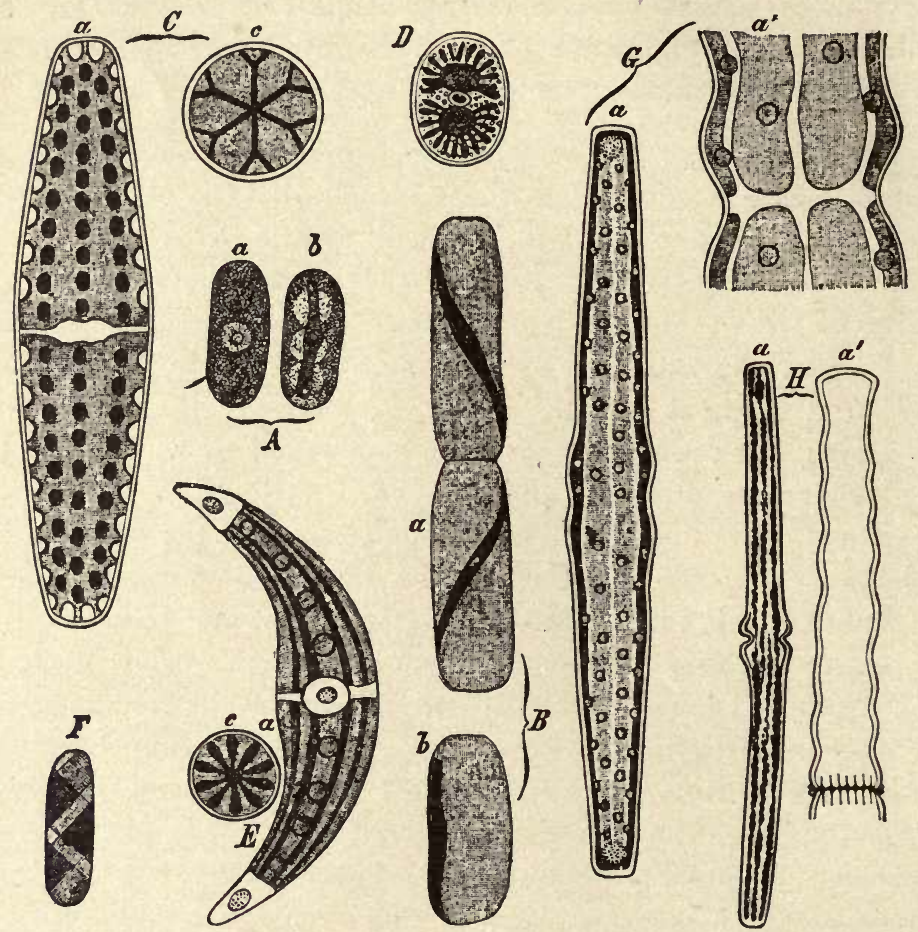

FIG. 8. Forms of Desmids in longitudinal view and transverse section. A, Mesotanium Braunii; B, Ancylonema Nordenskioldii; C, Penium digitus; D, Cylindrocystis crassa; E, Closterium moniliferum; F, Spirotænia muscicola; G, Pleurotonium trabecula; H, a Docidium baculum; Ha', D. dilatatum.-From Wille in Engler and Prantl's "Die Naturlichen Pflanzenfamilien."

Spirogyra.-Another one of the common Green Algæ is Spirogyra (Fig. 9), one of the pond-scums, which in the spring forms floating green masses on ponds and shallow water. The plant-body consists of a chain of cylindrical cells forming long threads or filaments. The transverse walls are sometimes peculiarly thickened. The chromatophores occur in one or more spiral 
bands (Fig. 9, II), which extend from one end of the cell to the other. In these bands are embedded protein bodies known as pyrenoids. The nucleus lies in the centre of the cell and is connected with the cytoplasmic layer lining the walls of the cell by delicate threads of cytoplasm.

Spirogyra may be propagated vegetatively by one or more cells of a filament breaking off and forming new individuals by
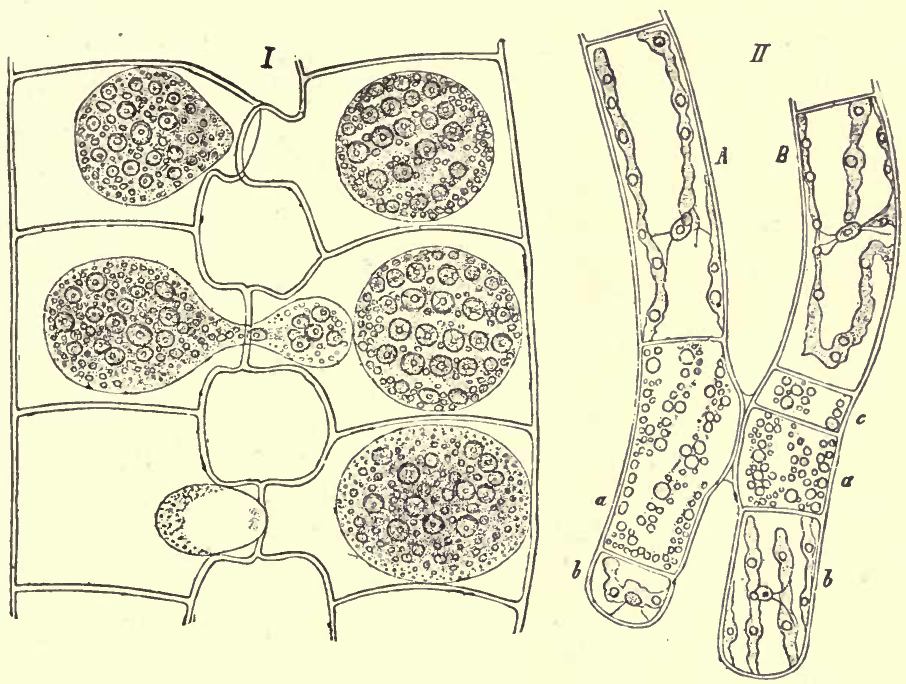

FIG. 9. II. Spirogyra stictica, showing parts of two filaments with band-like chromatophores (chloroplasts), in which are embedded spherical pyrenoids. Nuclei are shown in some of the cells with delicate threads of cytoplasm radiating from them. Two of the cells $(\mathrm{a}, \mathrm{a})$ of the adjoining filaments $(\mathrm{A}, \mathrm{B})$ are beginning conjugation. I, S. Heeriana, showing different stages of conjugation. In the upper cells, the contents have rounded off previous to the rupture of the adjoining walls of the two filaments. The two middle cells show the contents passing from one cell into the opposite cell. In the lower cell to the right the zygospore is shown.-After De Bary.

cell division. The plant is also reproduced by means of zygospores, as follows: The cells of two adjoining filaments each send out processes (Fig. 9, II, $a, a$ ), which meet; the end walls are absorbed, forming a tube through which the contents from onecell pass over into the other (Fig. 9, $I$ ) ; the contents of the two cells then fuse, after which the mass becomes surrounded by a cellulose wall. The spore thus formed may remain dormant over winter, and the following spring germinate and form a new Spyro- 
gyra filament or plant. This method of reproduction is known as CONJUGATION, and the zygospore is called a resting spore. It should be explained that certain cells, as well as spores, may lie dormant for a period, as during the winter season or at other times, when the conditions are unfavorable to growth, and then renew their activities, these being known as " resting cells."

Chlorophyceж.- The Chlorophyceæ, or Green Algæ, are distinguished by usually having a green color, due to chlorophyll, and by having no other pigment. The cells contain one or more nuclei. They are either unicellular or made up of many cells forming filaments or flat sheets. They occur either singly as simple cells or in groups representing a single individual or a colony. They are found mostly in fresh or salt water, usually being microscopic in size so as not to be noticed, but often attracting attention when they occur in sufficient quantity to form a scum on the surface. The reproduction is mostly by ciliated cells called zoöspores or swarm spores. Reproduction also takes place by the union of the zoöspores and through the fertilization of egg cells. The sexual spore resulting from this union of like cells (forming a zygospore) or of unlike cells (forming an oöspore) seldom develops immediately, but usually undergoes a resting period before growth is continued

Protococcus.-One of the commonest of the Green Algæ as well as one of the simplest is Protococcus (Pleurococcus) vulgaris (Fig. IO). It occurs as a green coating, in both winter and summer, on the moist bark of trees, moist ground, and stone walls, and is a component of some lichens. The plant is Icelled, more or less spherical, and at one stage contains a number of chlorophyll grains which finally unite to form a single plate which lies against the wall and is known as a cHromatophore. Besides it contains a considerable amount of oil. An allied species (Protococcus viridis) contains the sugar erythrite. The plant usually reproduces by simple division,- that is, one cell or plant divides to form two. The divisions may continue by the production of another cross wall, so that four cells result. Under favorable conditions, division may take place by the formation of still another wall at right angles to the other two. In this way two, four and finally eight individuals arise which adhere 
more or less to one another, thus forming colonies. The number of individuals in a colony depends upon the number of individuals in the colony when division begins and the extent to which division is carried. Thus if there were four cells in a colony to begin with and division took place in three planes, there would be thirty-two cells in the colony at the end of the period.

The development of the green coating on the barks of trees, due to the growth of Protococcus and the protonema of mosses, is usually thought to be more pronounced on the north side. This, however, is a slightly false notion. The fact which determines the position of these plants is the quantity of moisture available. The south and southwest sides of trees in the northern hemisphere are exposed to more light and heat and consequently are apt to be drier, with the result that they are rarely covered with coatings of

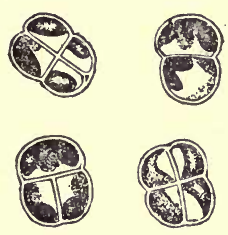

Fig. Io. Protococcus vuigaris. Different stages of division of the cell.-After Wille.

Protococcus and mosses. The under side of slanting trees is a very favorable place, as are also the lower slanting surfaces near the ground of large upright trees, because in these places the water is more likely to be conserved. A careful investigation by Kraemer showed a more abundant growth of green plants on the east and southeast exposure, although the north side of many trees showed good growth also.

Volvox occurs widely distributed throughout the United States in ponds and pools of fresh water. It is most abundant in warm weather, but also found in midwinter. It appears as a minute spherical colony about $1 / 2 \mathrm{~mm}$. in diameter, made up of numerous cells, the number ranging from several hundred to many thousand (Fig. II). The cells at the periphery are provided with cilia, so that the colony rolls slowly through the water. Each cell contains a chloroplastid in which starch granules and often a red pigment spot are present. The asexual reproduc- 
tion is through the formation of daughter colonies within the mother colony, and these after a time develop motile cells like the parent, which swim about and finally escape. A sexual method of reproduction also occurs in which there is a union of cells within the spheres, the resulting cells after germination forming swarm spores that cling together to form a new colony.

Hydrodictyon, or Water Net, is a form often very abundant in sluggish and stagnant waters. It consists of a number of cells forming a net, the meshes of which are usually hexagonal or pentagonal in shape, depending on the number of cells outlining them (Fig. II). The cells are all alike, cylindrical in form, attaining sometimes a length of I $\mathrm{cm}$., and usually contain a number of nuclei. The green chromatophore occurs in a plate at the periphery of the cell and usually contains numerous pyrenoids.

The asexual reproduction is by means of zoöspores which are formed simultaneously in large numbers, sometimes numbering many thousands in each cell. These zoöspores as formed inside of the mother cell show more or less definite movement and arrange themselves finally to form a new net. The sexual reproduction is characterized by several stages. (I) Some of the zoöspores are liberated through a pore in the cell-wall of the mother cell and after swimming around for some time pairs of them unite, forming zygospores. (2) After a resting period each zygospore develops 2 to 5 zoöspores, which escape into the water and develop into irregular, sharp-angled cells, called polyhedra, which persist through the winter. (3) When these polyhedra develop, small zoöspores are again formed, and these arrange themselves to form a net inside of the polyhedron, which then escapes and increases in size.

Vaucheria (Fig. I2) is another common green alga which may also be selected as showing the habits of this group of plants. The plant has a branching thallus and lives in shallow water or on moist earth, being attached to the substratum by means of delicate root-like processes sometimes spoken of as rhizoids (Fig. I2, w). In the thin layer of protoplasm lying near the wall are numerous nuclei and small oval chromatophores. 


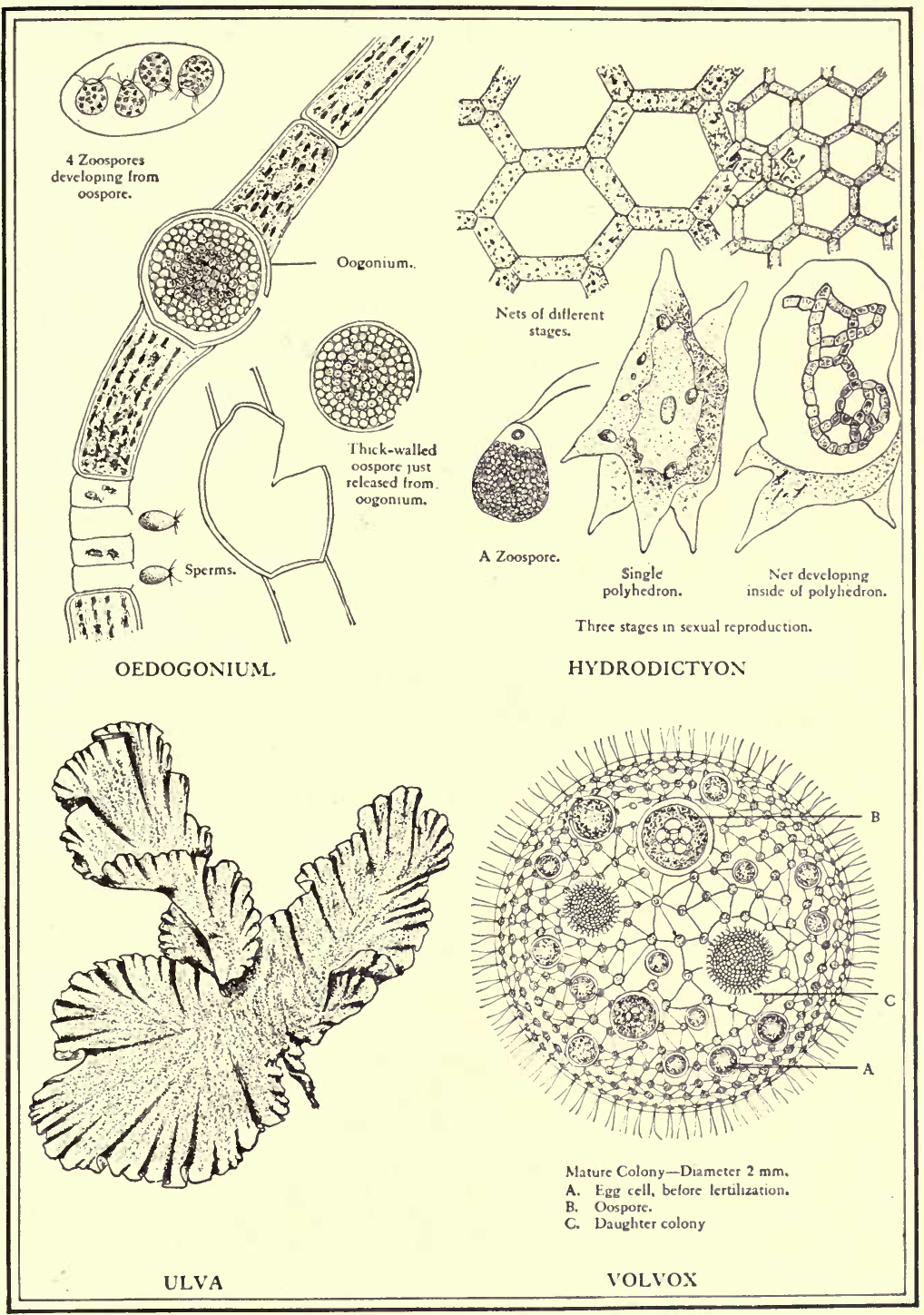

FIG. II. Forms of Chlorophyceæ or Green Algæ.-All adapted from Engler and Prantl except Ulva. Drawn by A. K. Lobeck. 
Numerous oil globules are also found in the protoplasm, and calcium oxalate crystals may occur in the cell-sap.

Vaucheria furnishes an example of a plant whose interior is not segmented by cell-walls. In other words, the cavity within the outer or enclosing membrane is continuous, and such a plant is said to be cœnocytic,-i.e., like a syphon. But it should be borne in mind that the plant contains a great many nuclei, and, as we have seen (page 2), a nucleus with its associated cytoplasm

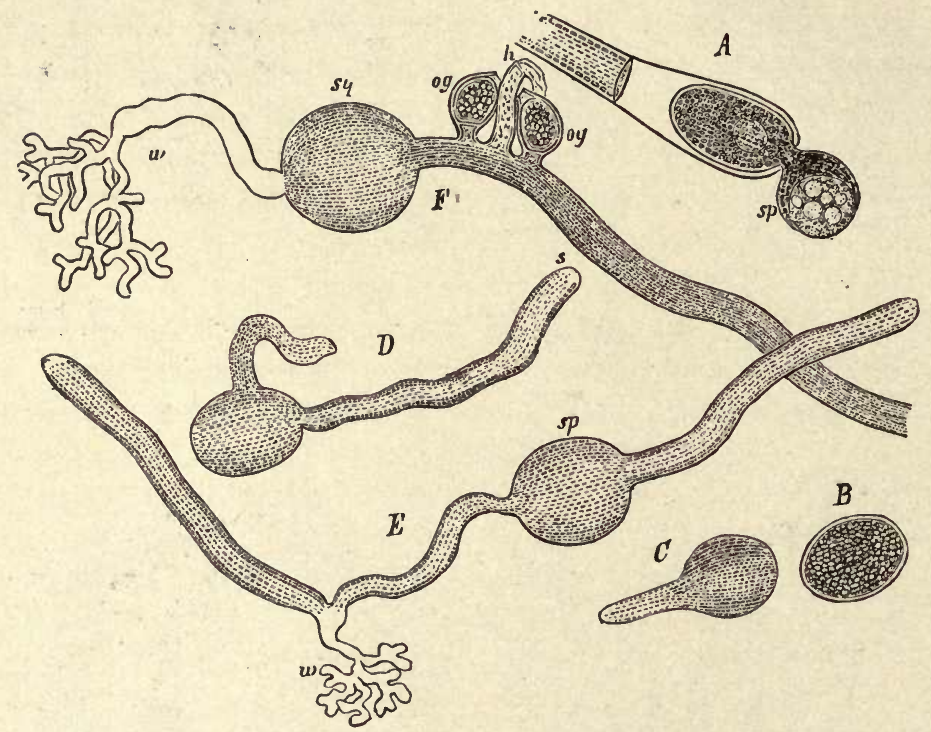

FIG. I2. Vaucheria sessilis. A, sporangium from which the multiciliate zoôspore is escaping; B, resting zoöspore; C, D, germinating zoöspores with growing point (s); E, plant showing root-like organ of attachment $(w)$, spore from which the plant is developing (sp); F, showing in addition two oögonia $(\mathrm{og})$ and an antheridium (h). - After Sachs.

constitutes a unit of work. Hence such a plant as Vaucheria is in a certain sense equivalent to a plant having as many uninucleate cells as it has nuclei. It would probably be better to call such a plant multinucleate rather than unicellular.

Reproduction by means of asexual spores is brought about as follows (Fig. 12, $A$ ) : A cross wall is formed near the end of one of the branches, the end portion constituting a sporangium. The contents, including numerous nuclei, group themselves into one large zoöspore, which escapes through an opening in the sporan- 
gial wall, and after swimming about for a time comes to rest and germinates, giving rise to a new plant (Fig. 12, $C, D$ ). This large zoöspore is multinucleate and multiciliate, there being two cilia for each nucleus, and by some botanists is considered to be an aggregation of numerous biciliate zoöspores. It is also of interest to note that the zoöspores of Vaucheria appear to arise by a grouping of the cytoplasm and the nuclei already existing in the sporangium rather than by repeated divisions of a single nucleus.

Another method of reproduction in Vaucheria (Fig. I2, F) is that by means of oöspores, or spores formed by the union of egg and sperm cells. Two special branches are formed on the thallus as short side shoots. One of these branches, known as the oögonium (Fig. 12, og), is somewhat egg-shaped and separated from the thallus by means of a cross wall. It contains a great many chromatophores and considerable oil, and has a comparatively thick wall. The apex is somewhat beaked and contains colorless protoplasm. The second branch, which is known as an antheridium (Fig. I2, $h$ ), is smaller, somewhat cylindrical and curved towards the oögonium. It is also cut off from the thailus by means of a cross wall. The antheridium contains very little chlorophyll, but a great many sperm cells. These are oval or egg-shaped and have two cilia, one at each end. The sperms escape from the apex of the antheridium and enter an opening at the apex of the oögonium, one of them uniting with the egg cell, which then develops a thick membrane, the resulting oöspore being a resting spore.

Ulva, or Sea Lettuce, is a common form found all over the world, especially in brackish waters. In its usual form it consists of flat, thin, unbranched fronds which are more or less ovate or orbicular in outline and frequently deeply incised, sometimes becoming linear or even ribbon-shaped (Fig. I I). The fronds consist of two layers of cells, which are either in close contact with each other or else at maturity separate so as to form a tubular frond. It sometimes occurs in large quantities in the shallow water along our coast, and is conspicuously disagreeable by its resemblance in shape to the swollen intestines of some animal.

Edogonium is a filamentous alga occurring usually in simple unbranched filaments and attached by a disk-like cell or hold- 
fast (Fig. II). It occurs in meadow pools or ponds, frequently in streams attached to rocks near rapids. The cells are somewhat elongated and contain a large, irregular chromatophore with pyrenoids. Most of the cells are vegetative cells, interspersed among which are the cells producing the spores. Zoöspores are produced singly in the cells and are provided with cilia at one end. After swimming about for some time they attach themselves at this ciliated end to a substratum and develop into filaments. Two other types of cells are formed and which give rise either to oögonia, the female organ containing a large egg cell, or to antheridia, the male organ containing many sperms. The union of a sperm with an egg cell produces an oöspore with a very thick wall, capable of over-wintering and developing again when conditions are favorable.

The Characes, or Stoneworts, is a highly differentiated group that is considered as a distinct class between the Chlorophyceæ and the Phæophyceæ. They stand so entirely by themselves that many authorities do not consider them as even Algæ. They consist of jointed stems, from the nodes of which whorls of from 4 to Io leaves are developed, and these bear the sexual organs (Fig. 13). In many of the members of this family the cellwall is incrusted with lime salts. Chara occurs in great masses in the bottom of ponds and shallow lakes. It occurs in sufficient quantity in many places so that the body of water has a distinct orange color, due to the immense numbers of antheridia. The plant is of such luxuriant growth that if single individuals are kept in an aquarium or large glass vessel it will greatly multiply during the winter and persist for many years. In ponds where Chara occurs large quantities of lime are deposited, so that in ancient deposits now exposed to view one often finds imbedded therein the remains of the spore-fruits.

In the long cells or internodes there is a large vacuole and a thin layer of protoplasm containing a central nucleus and a large number of oval or lens-shaped chromatophores. In some forms, especially in Nitella, the inner protoplasmic layer shows a streaming movement. This is very interesting, as a distinct streaming movement does not occur in most plants and is limited to a few water plants, the staminal hairs of Tradescantia, the leaf 
hairs of Cucurbita and Urtica and the hyphæ or Rhizopus, etc. This streaming movement in plants like Characeæ, as pointed out by Pfeffer (Physiology of Plants), has in most cases a definite purpose. It is, in any case, always possible that the streaming movement may be an accessory but unavoidable accompaniment of some other form of vital activity. In Chara and Nitella the

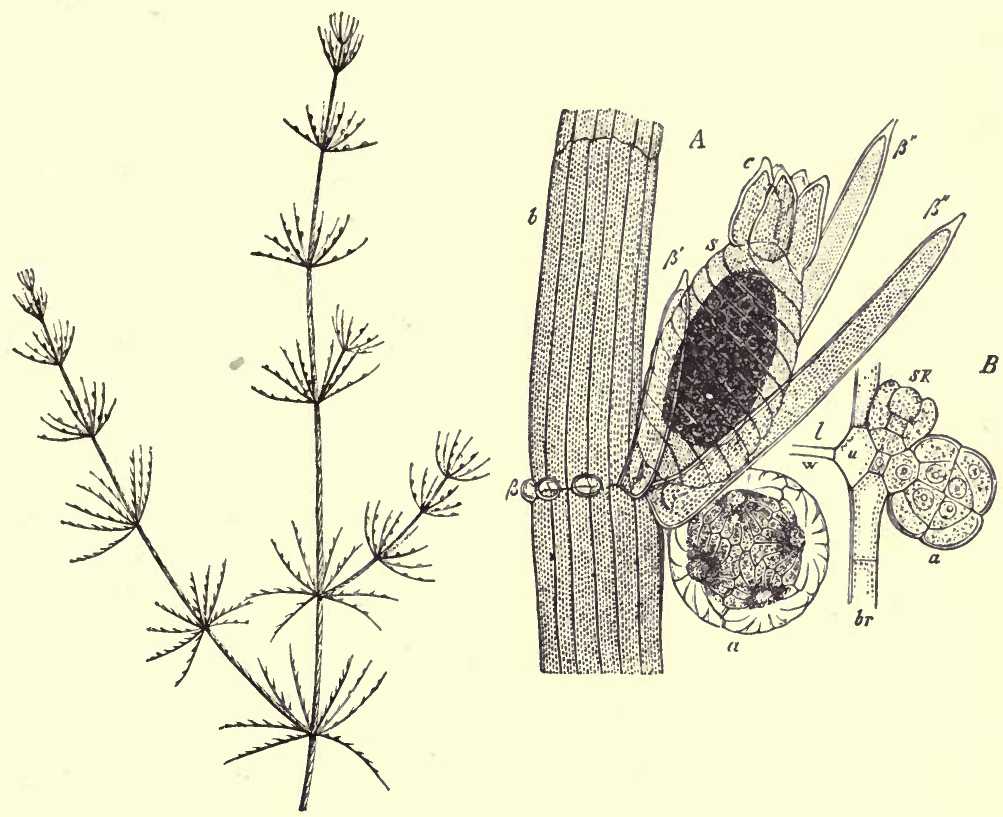

Fig. 13. Stonewort or Chara. At left showing the habit of the plant with minute reproductive organs on the leaves. At right enlarged view of reproductive organs. A, mature organs showing (a) antheridium, (S) oogonium surmounted at the top by a crown of cells (c); b, stem of plant; $\beta^{\prime}, \beta^{\prime \prime}$, whorl of leaves, some of which have been removed, as at $\beta ; \mathrm{B}$, a young antheridium (a), with young oögonium (SK), together with the adjoining cells of the stem; the whorl of leaves not represented.-A, after Wille; B, after Sachs.

streaming endoplasm (inner layer of protoplasm) does not cover more than 2 to $3 \mathrm{~mm}$. per minute. The activity of the streaming is influenced by sunlight, oxygen, acids, chloroform, etc. Two kinds of protoplasmic streaming are recognized: ( I) in which the movement is confined to the layer enclosing the central vacuole, that is known as "rotation," and (2) in which the streaming follows more or less irregular paths up and down the strands of protoplasm, crossing the latter, which is called "circulation." 
Vegetative reproduction is much like that of the higher plants, through the production of root-tubers or bulbils, stem bulbils, and through special branches arising at the nodes. The bulbils are filled with starch and are capable of over-wintering. The sexual mode of reproduction is through the activity of oögonia producing oöspores, and antheridia producing antherozoids or sperms. These are adjacent to each other at the nodes, the oögonium forming a central elliptical cell which is surrounded by a crown of cells through which fertilization takes place (Fig. I3).

Phжорнусеж.-The Phæophyceæ, or Brown Algæ, are distinguished by having brown chromatophores. They are mostly found in the colder waters of the ocean, and are either free or attached to a substratum. They vary in size from microscopic organisms to delicate filamentous or cord-like forms, and may become of enormous size. Some are called rock-weeds and give the characteristic color to the rocks between low- and high-tide marks. Others are known as "kelps," and these grow near the low-water mark. They vary in color from an olive-green to a brown. The chlorophyll may be extracted by alcohol, leaving the other pigments, phycoxanthin and phycophæin. Many of these Algæ are rich in iodine, being one of the sources of this element. They also contain large quantities of sodium, and were used at one time in the manufacture of sodium, and have been used to fertilize the soil in parts of Europe as well as in New England.

They are more complex in form than the Green Algæ, and are distinguished by having hold-fasts which, while not in the nature of true roots, yet serve to hold the plant. They may also develop stems and bear leaf-like structures of many varied forms. Others also develop swollen bladders which contain oxygen and which serve to buoy up the plant.

Fucus, or Bladder Wrack, is one of the common rock-weeds (Fig. I4, B). It grows near the surface of the water, attached to rocks, and produces a regularly dichotomously branching thallus. Some of the forms in the upper branches produce air bladders which are spherical or slightly elongated and usually in pairs. The margins of the branches are either entire or somewhat serrate. The tips of older branches become more or less swollen and are termed receptacles. They are dotted over with minute 
cavities, called conceptacles, and these contain the reproductive organs. These consist of oögonia and antheridia, which may be

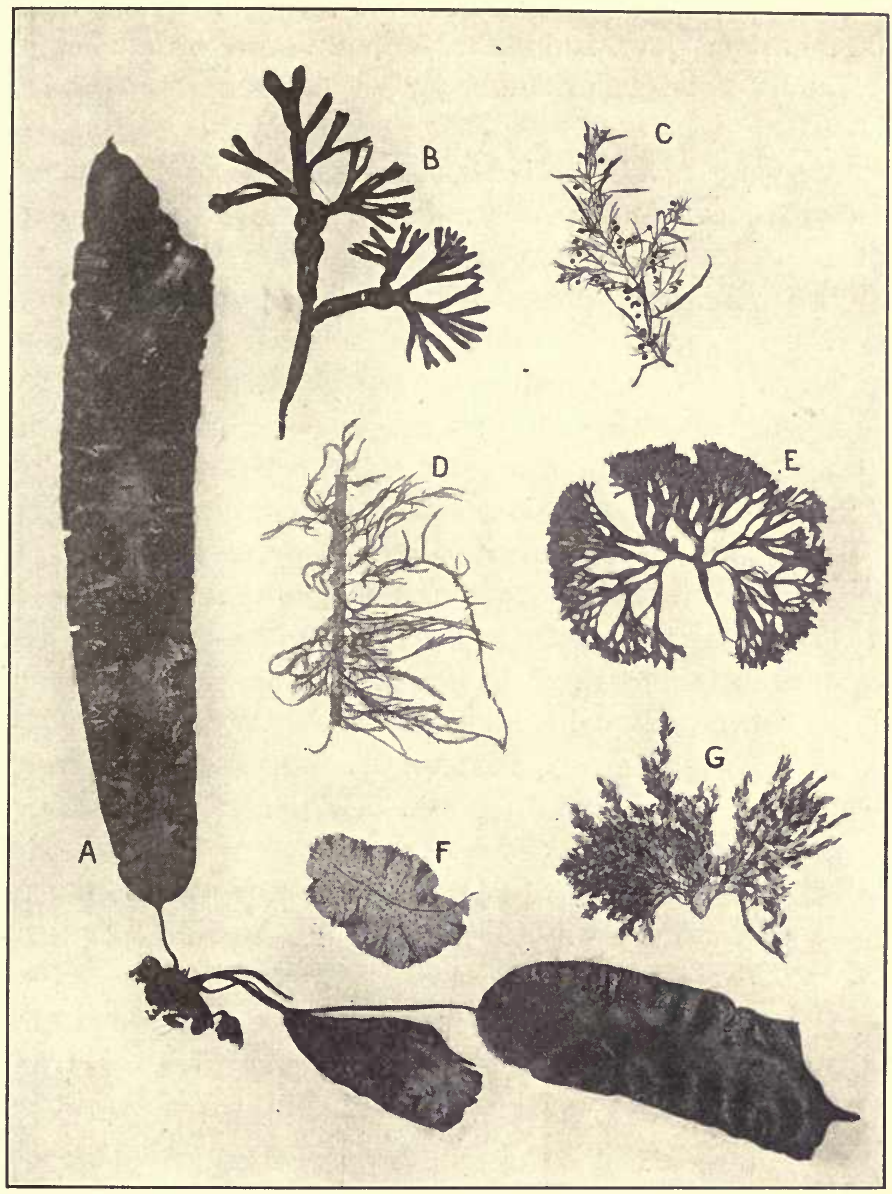

Fig. I4. Some common marine algæ. A, Laminaria, showing portions of three leaflike thalli and hold-fast; B, dichotomously branching thallus of Fucus; C, Sargassum, or "gulf weed," showing a thallus resembling a leafy branch, with swollen, berry-like air bladders, which act as floats; D, Dasya, a delicate branching filamentous sea-weed, attached to a blade of eel-grass; E, dichotomously branching thallus of Chondrus, or Irish moss; F, leaf-like thallus of Grinnellia; G, densely, but delicately branched thallus of Polysiphonia. A, B, C are Brown Algæ and D, E, F, G are Red Algæ.

present on the same or on different plants. The egg cells and the sperm cells escape into the sea-water, and after their union an 
oöspore results, which, upon finding a favorable resting place, begins shortly to develop into new Fucus plants. The plant contains both iodine and bromine, chiefly combined with salts of sodium and potassium, and was at one time used in medicine. It also contains a bitter principle and a considerable amount of mucilage.

Ascophyllum, a rock-weed closely related to Fucus, is distinguished from this genus by the fact that the branches are destitute of midribs and the spores occur in groups of four instead of eight. The frond is thick and narrow, branching somewhat dichotomously, and at intervals produces large, conspicuous floats, which are broader than the frond. The plants occur from $1 / 3$ to 2 metres in length. The fruit is found in lateral branches in winter and spring, and in June the receptacles fall off and are sometimes found in immense quantities, covering the bottom of tide pools.

LAMINARIA is one of the common kelps or devil's aprons which inhabit principally the colder seas of high latitudes. They all grow in pools at low-water mark, attached to the rocks and in deep water, and some attain a very large size. The species vary greatly in outline and habit according to the season and place of growth-whether on an exposed or sheltered coast or partly exposed at low tide. It consists of three parts (Fig. I4, $A$ ) : a long, leaf-like expansion or blade supported by a more or less cylindrical stalk or stipe, which in turn is attached to the rocks by a hold-fast made up of a cluster of fibrous outgrowths. In general the species may be classed in two groups, one in which the frond is ribbon-like or long in proportion to the breadth and not split up into segments, and the other in which the frond is proportionally broader and fan-shaped and laciniate. To this latter belongs the Laminaria digitata. There are some 25 species, distinguished by the arrangement of root-fibres comprising the hold-fast, the structure of the stipe, whether solid or hollow and whether provided with distinct cavities containing mucilage, the shape, especially of the basal portion of the lamina, and the character of the margin and the position of the fruit. The growing portion of the lamina is at the base, as in the leaves of the Spermophytes. The kelps of the Pacific Ocean are among the largest sea-weeds known, the Giant Kelp, Macrocystis, attaining a length 
of nearly a thousand feet. Other forms have large floats at the base of the lamina. Reproduction is chiefly by zoöspores formed in I-celled sporangia which occur either in dispersed patches or in continuous bands near the centre of the frond.

Sargassum, or Gulf Weed, grows attached to rocks by means of disk-like hold-fasts (Fig. I4, C). When it is torn from the rocks it is carried into the open ocean by currents such as the Gulf Stream. Sargassum is most highly organized and is represented by a very large number of species. They are found especially in the warmer waters near Australia, Japan and the adjacent coast of Asia, and also in the West Indies and at various parts of the Atlantic Coast near the Gulf Stream, some occurring as far north as Cape Cod. The plants vary from $15 \mathrm{~cm}$. to nearly 2 metres in length, and consist of a stem-like axis which bears leaf-like branches with a distinct midrib, berry-like air sacs on stalks, and reproductive branches or receptacles.

RHodophyce. - This includes all the Algæ which are of a reddish or violet color. They contain chromatophores in which the chlorophyll is masked by other pigments, mostly red, and known as phycoerythrin or rhodophyll. The red Algæ are mostly found in salt water, occasionally in fresh and running water. They are usually found growing upon other plants or variously attached to some substratum. They vary from microscopic forms or very delicate filamentous types to large plants. They are usually composed of a number of cells or filaments which are so closely arranged as to resemble the tissues of higher plants. Many of the cells are connected by strands of protoplasm, giving them a rather characteristic appearance. Others have an incrustation of lime on the wall. They are mostly found in deep waters of the Tropics. Reproduction is almost entirely by sexual or asexual spores.

Chondrus, or Carragheen or Irish Moss (Figs. I5, 16), is a common rock-weed found at low-water mark, and in this country is common from New York northward, being extensively collected at a few points about 15 to 20 miles south of Boston. The plant varies considerably in color, being more or less green when close to the surface of the water and of a deep purplish-red when growing at some depth. It varies from 4 to $15 \mathrm{~cm}$. in length, and 
is attached to rocks by means of a slender hold-fast. The thallus is dichotomously branching, somewhat flattened, but may be quite linear. The fronds show a mucilaginous modification of the cellwalls. In the upper segments occur small differentiated areas,

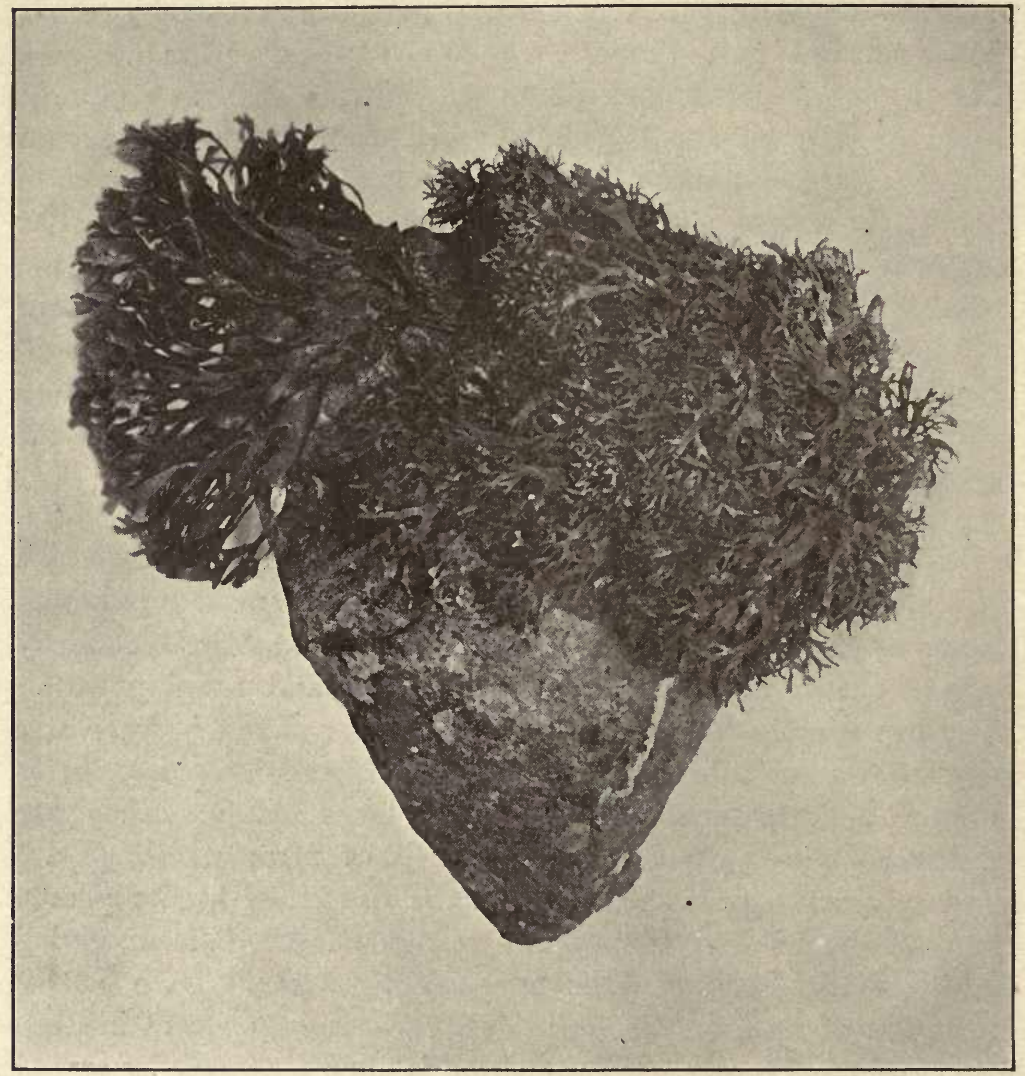

FIG. 15. Specimen of Chondrus crispus still attached to the rock where it was found growing along the Massachusetts coast.

sometimes called sori, of a more or less elliptical outline, which on sectioning are found to be in the nature of sporangia, containing numerous tetraspores (Fig. 16). The spores are discharged through narrow canals extending through the more or less compact outer layer of the frond. The article found in commerce has the color removed by being bleached through the action of the sun 
and dews. It shows, however, all the morphological structure of the growing plant.

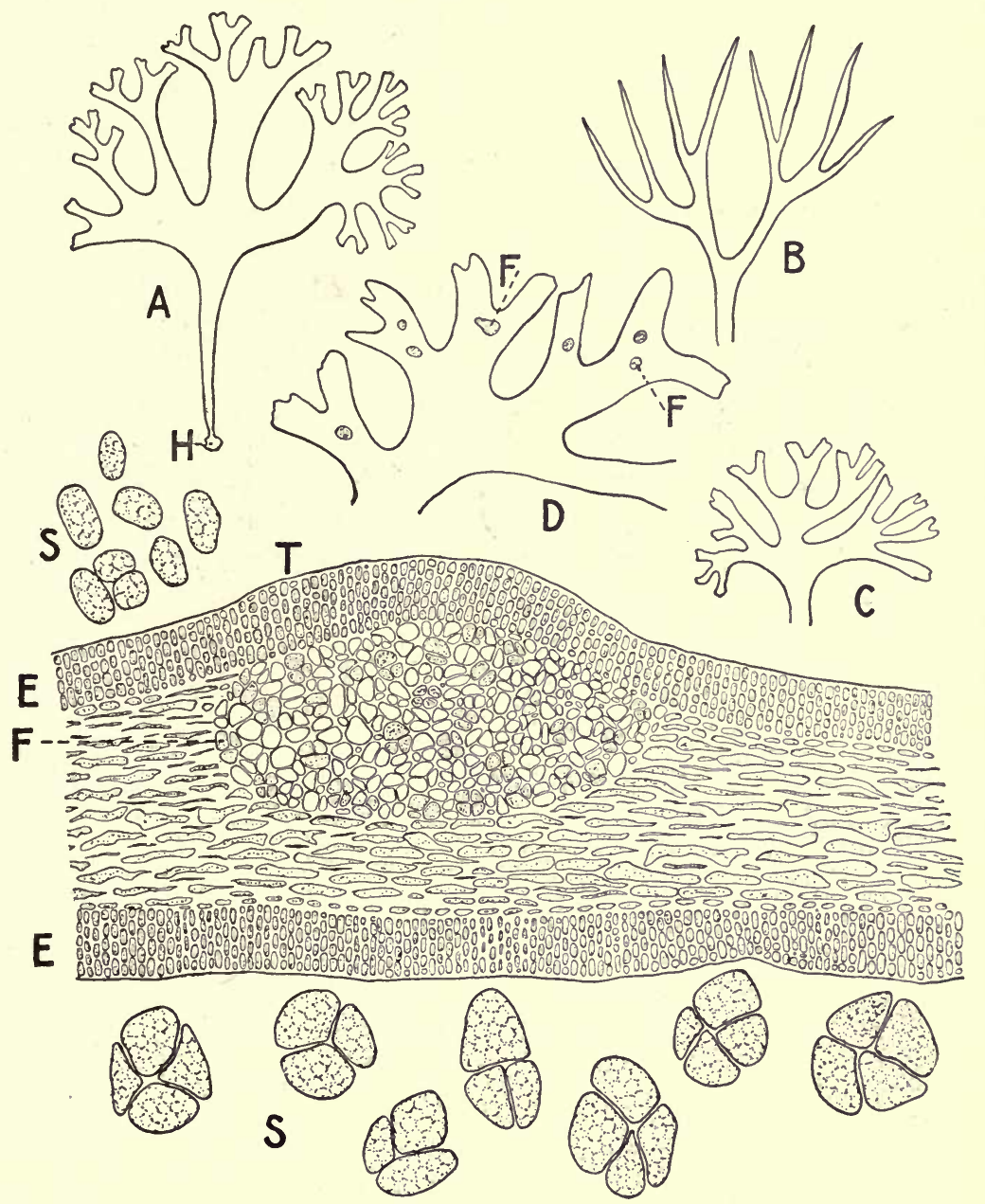

FIG. 16. Chondrus crispus: A, B, C, D, various forms of thallus; H, hold-fast; F, sporangia; $T$, transverse section of thallus showing epidermis (E), sporangium with spores $(F) ; S$, spores separated in glycerin preparation of thallus by pressure on the cover-glass. The spores occur in groups of four (tetraspores) and the tetrad group is about $30 \mu$ in diameter.

In a closely related genus, Gigartina (Fig. I7), which is found in imported Chondrus, the fruit bodies occur in numerous cylindri- 
cal outgrowths developed on the surface of the fronds. This form is found more abundantly north of Boston than south, but, as Chondrus is collected at Cohasset, Scituate, and other towns south of Boston, it is not seen in commerce in this country.

RHodymenia, or Irish Dulce, is one of the commonest red sea-weeds in the North Atlantic Ocean, usually growing with Fucus, Laminaria, and other Algæ between tide marks and extending into deep water. The fronds are purplish-red, flat, membra.

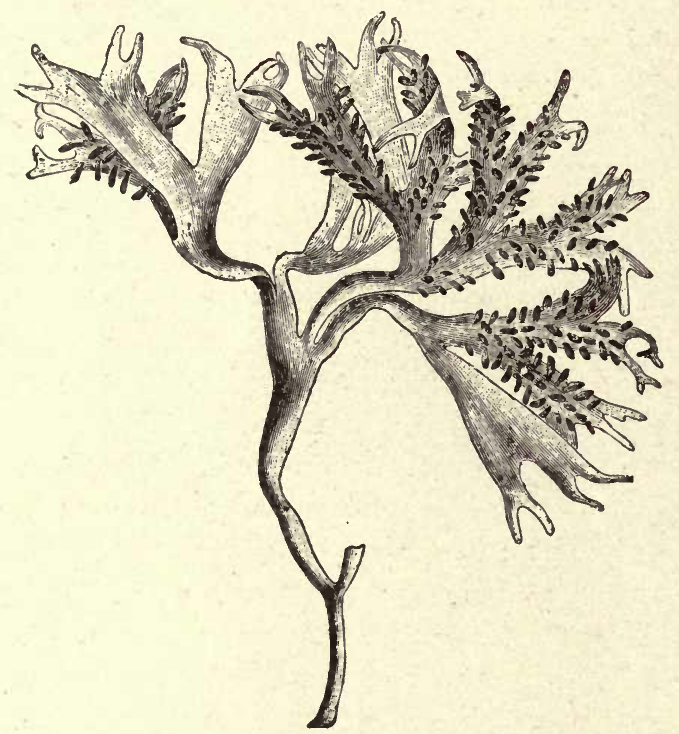

FIG. I7. Gigartina mamillosa, a red sea-weed closely related to Chondrus crispus, showing a dichotomously branching thallus and bearing at the upper part numerous cylinArical outgrowths in which the fruit bodies (sporangia) are found.-After Kutzing.

naceous, 15 to $30 \mathrm{~cm}$. in length, irregularly cleft, palmate or dichotomous, the margin often being marked with numerous small divisions. The sporangia occur in scattered patches immersed in the cortical tissues of the frond. It is a common article of commerce and is said to possess anthelmintic properties.

AGAR-AGAR is derived from several of the marine Algæ growing along the eastern coast of Asia, notably species of Gracilaria, Gelidium, and Gloiopeltis. It is a mucilaginous substance which is extracted from the sea-weeds, and is used extensively as a 
culture medium in bacteriology and in other work where a nutrient is desired. It occurs commercially in bundles 4 to 6 decimetres in length; consisting of thin, translucent, membraneous, agglutinated pieces, yellowish-white in color. It is usually brittle, but becomes tough when moistened. It is used in medicine in the powdered

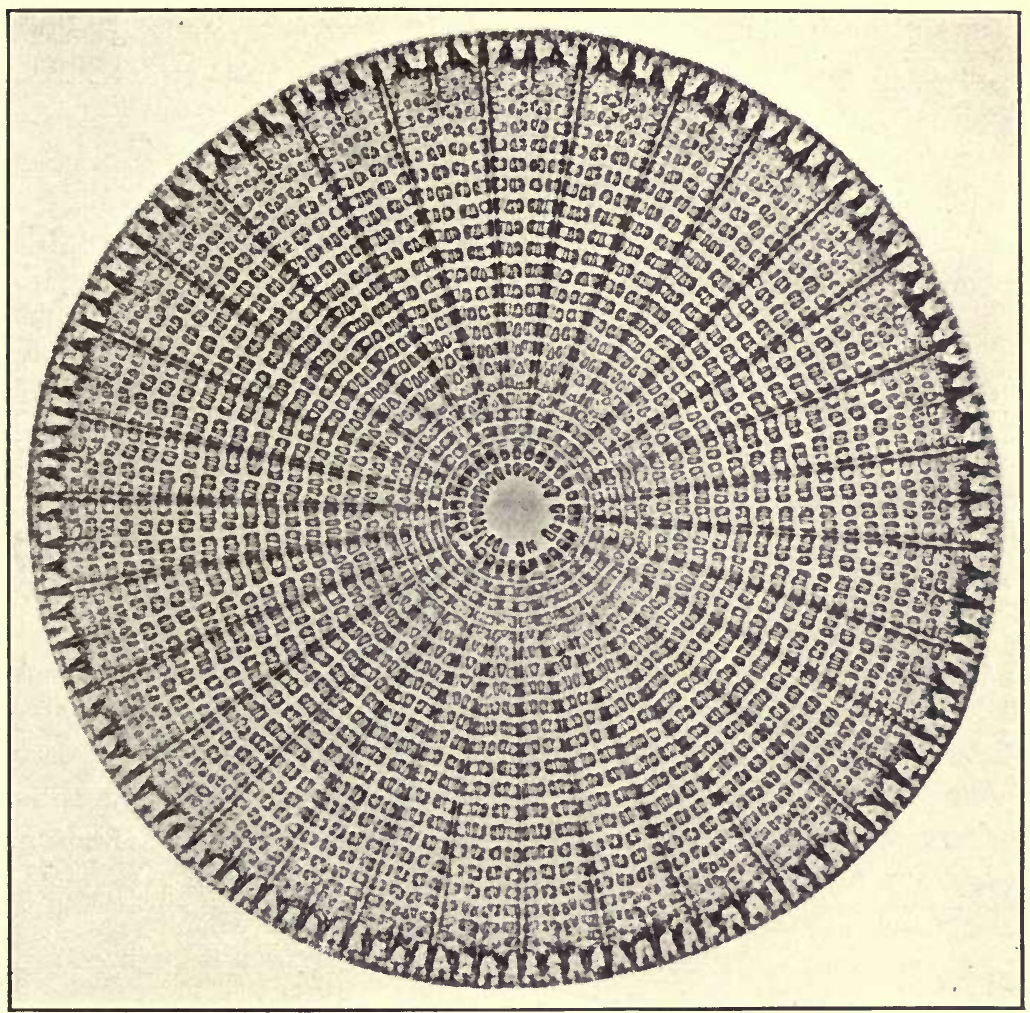

FIG. I8. Arachnoidiscus Ehrenbergii, a characteristic Diatom found in Agar-agar.-From a photomicrographic negative by J. J. Woodward, Surgeon, U. S. A.

form. Under the microscope Agar-agar frequently shows the frustules or siliceous cell walls of diatoms, which are disk-shaped (Fig. I8). It is insoluble in cold water, but dissolves slowly in hot water. Upon boiling I part in Ioo parts of water it should yield a stiff jelly upon cooling.

Diatoms constitute a large group of unicellular plants, occur- 
ring in both fresh and salt waters. They form the plankton or floating microscopic life found in oceans and lakes, which is the source of food of small animal forms inhabiting these waters. The mud at the mouths of many rivers, the sediment of ponds, ditches, and even rain troughs may contain great numbers of these minute organisms. They have been found in the polar ice, and have been detected in the dust evolved from volcanoes. One of the distinguishing characters of the group is that the cell wall is incrusted with silica. For this reason they are practically indestructible and form marls and strata in the earth. They occur either singly or grouped in bands or chains. They are very variable in shape, being boat-shaped, ellipsoidal, spherical, or peculiarly curved in some forms. They are either free or attached to a substratum, as stones, water plants, etc., those which are free having an active movement (Fig. I9).

The cell wall of Diatoms practically consists of two halves, one fitting over the other like the lid of a box. These are known as "valves" or "theca." The manner in which the two valves are joined results in the formation of a "girdle" or "pleura." The girdle is provided with a series of pores conecting with canals at either end and in the middle, through which food from without is supplied to the protoplast. The valves are very often beautifully marked by a series of parallel cross lines, dots, circles, or polygons, which are characteristic of the different groups. Some forms are used in testing the definition of objectives, as Pleurosigma angulatum, in which the lines are one-half micron (0.0005 mm.) wide (Fig. I9, $A$ ).

In the Diatoms the protoplasm lies as a thin layer close to the wall surrounding a large central vacuole. The nucleus is surrounded by a relatively dense mass of cytoplasm, and occurs in definite positions according to the species. The chromatophores frequently occur in plates which are typical for certain species. They are sometimes greenish-yellow, the color being generally masked by the presence of a brown substance known as diatomin. They frequently contain pyrenoids, which are sometimes associated with granules of starch.

Reproduction takes place by simple division or fission, the two valves separating and a new valve forming on each half to replace 
the old one. In each case the valve formed fits into the old one, and hence in the case of the smaller valve the new cell or plant becomes smaller than the parent plant, the walls not being able to expand on account of the siliceous composition. In this way the cells of one series gradually becomes smaller and smaller until a certain minimum is reached, when the plant rejuvenates itself

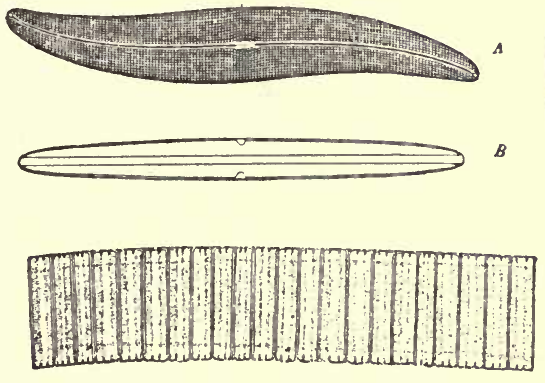

E

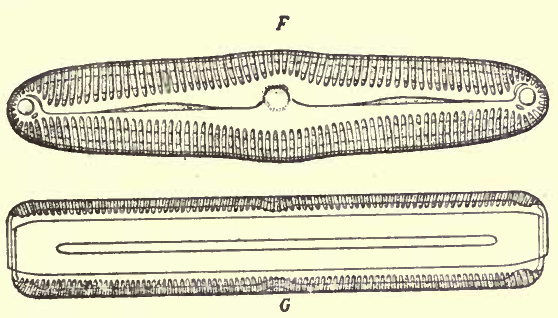

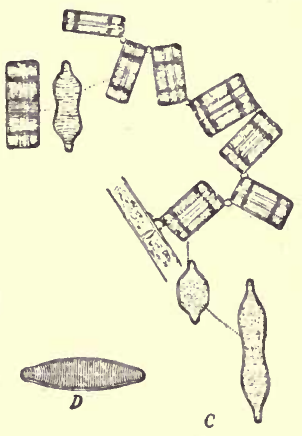

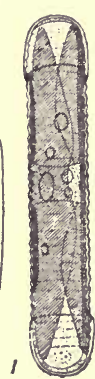

FIG. 19. Diatoms: A, Pleurosigma attenuatum as seen from above; B, Pleurosigma balticum as seen from the girdle side; C, D, E, Fragilaria virescens showing colonies attached to an alga in $\mathrm{C}$, a view of a single diatom from above at $\mathrm{D}$, and a chain of diatoms viewed from the girdle side at E; F, G, two views of Navicula viridis; H, I, the formation of auxospores in Navicula firma, H showing the exit of the protop!asts and the throwing off of the original valves.-A, B, D, after Van Heurck; C, E, after W. Smith; F-I, after Pfitzer.

by the production of spores (auxospores). These are formed in two ways: In one case the valves separate from each other, the protoplast escapes, grows larger and develops a new wall; in the other case, of which there are several types, two individuals come together, and envelop themselves in a mucilaginous covering. They then throw off their siliceous walls and the protoplasts unite to form a zygospore, which grows until it is three times the 
original size, after which it develops a new wall, the larger valve forming first (Fig. 19, $H, I$ ).

Diatomaceous Earth, also known commercially as "Infusorial Earth," or "Kieselguhr" (meaning siliceous marl), occurs in extensive deposits, some of these, as the stratum at Richmond, Va., extending to a depth of 18 feet. These deposits consist of the siliceous walls of the Diatoms, which, owing to their composition, are practically indestructible, and are accumulated in those localities which have favored the growth of the organism. The natural deposit is mined and usually calcined to destroy the organic matter, after which it is washed and dried. The article used in pharmacy is further purified by boiling with diluted hydrochloric acid, washing, and calcining. This purified product is known as Terra Silicea Purificata, and occurs in the form of an almost whitish, or light grayish, or light brown powder. It is odorless, insoluble in water and in mineral acids or dilute solutions of the alkalies. Under the microscope mounts made in water or solutions of hydrated chloral show the frustules or siliceous walls of the Diatoms. In the better grades of Diatomaceous Earth the entire skeleton with the characteristic markings is present. Material coming from various localities shows a difference in genera of Diatoms. The exact naming of the species requires the assistance of specialists. In order to avoid confusion it is necessary to bear in mind that there are two and sometimes even three views which may be obtained of the same Diatom.

Diatomaceous Earth consists of about 85 per cent. of $\mathrm{SiO}_{2}$, Io per cent. of water, and 5 per cent. of clay, iron oxide, magnesia, lime, and organic material. Owing to the fact that Diatomaceous Earth is made up of the hollow shells of Diatoms, it has the property of absorbing by capillarity gases and liquids. For this reason it is used in the preparation of dynamite; the highly explosive nitroglycerin being absorbed by the diatomaceous shells, rendering the product capable of being handled. When calcined, it will absorb its own weight of water. It is used in pharmacy for filtering and as a diluent for powdered extracts, etc. Among the technical uses may be mentioned: polishing of metals and woods, insulating steam pipes and electrical insulators, packing of caustic and inflammable liquids, and the manufacture of glass, paper, and 
soap. It is also used to some extent in dermatology. In India it has been used as a rubefacient. In Sweden, and among the Chinese and Laplanders, Diatomaceous Earth has been used as an

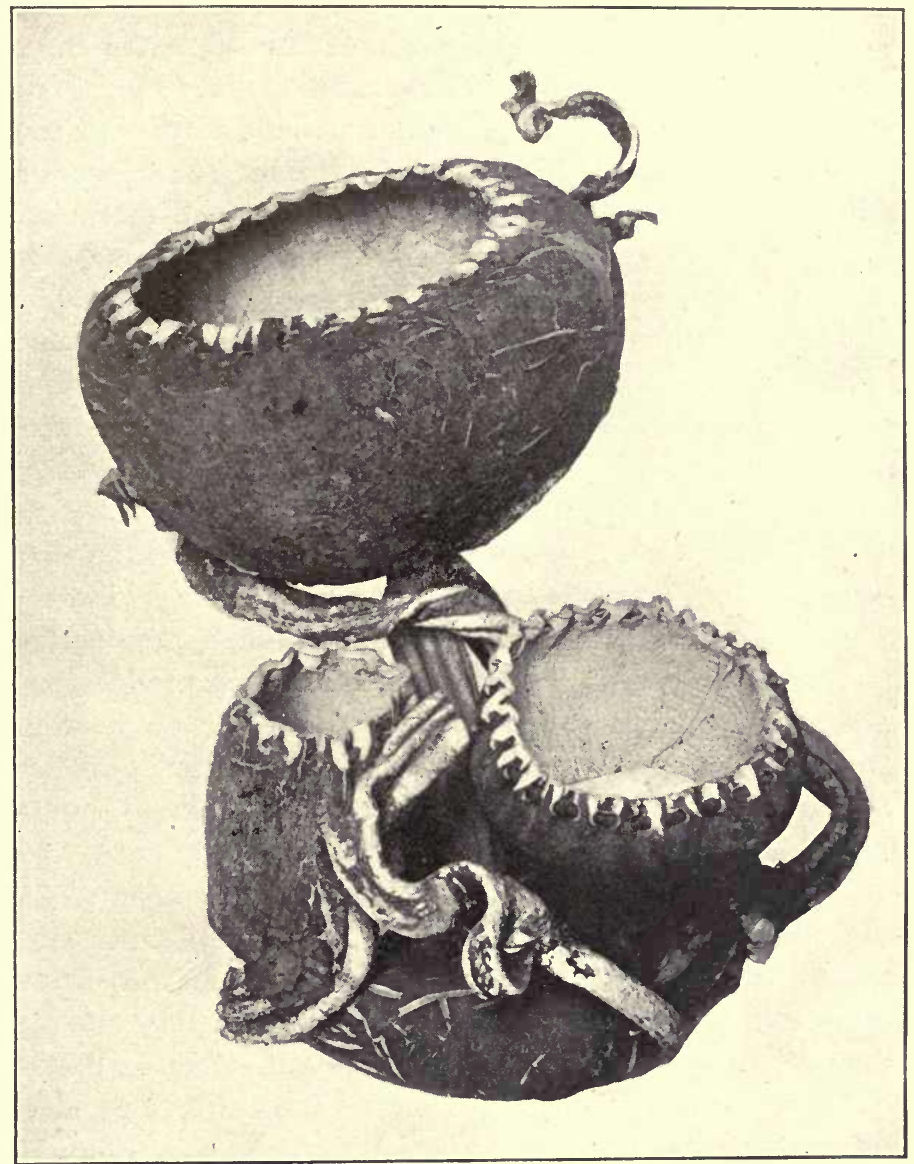

FIG. 20. The Algæ are put to various uses by the people who collect them. The illustration is taken from an ornament purchased at the Louisiana Purchase Exposition and was made by the Filipinos from various kelps having large, bladder-like floats.

edible earth under the name of "mountain meal" or "breadstone." Humboldt also calls attention to the fact (Aspects of Nature) that the practice of eating earth is diffused throughout the torrid zone, among indolent races inhabiting the finest and 
most fertile parts of the globe. It is a saying even among the most distant of the different tribes living on the Orinoco, when speaking of anything very unclean, that it is "so dirty that the Otomacs eat it."

Economic Uses of Algs.-Many of the Algæ are of use as food, of which the following may be mentioned: Vaucheria fastigiata, Griffithsia coralina, Ceramium Loureirii, Chondrus crispus, Gigartina mamillosa, Gelidium cartilagineum, Gelidium crinale (yielding agar-agar), Rhodymenia palmata (yielding dulse), and several species of Gracilaria (which also yield agar-agar).

Some of the sea-weeds are used in the production of iodine, as Durvillaa utilis, Ascophyllum nodosum, Fucus vesiculosus (bladder-wrack), Sargassum linifolium, Laminaria saccharina, Laminaria digitata, Alaria esculenta, Rhodymenia palmata, Phyllophora membranifolia, Macrocystis pyrifera, and Fastigiaria furcellata.

A number of the Algæ are also used in medicine, particularly for phthisis, as Fucus cartilagineus, Stilophora rhizodes and Dictyopteris polypodioides. Alaria esculenta and Laminaria digitata are used in the making of bougies and tents used in surgery. Owing to the toughness of some of the Algæ on drying, the material is used in the manufacture of various articles, as handles for tools from the thick stem of Lessonia fucescens, fishing lines from Chordaria Alagelliformis (Fig. 20), etc.

FUNGI.

The Fungi form a large group of plants which do not produce chloroplasts or any bodies having a similar function. They have not the power of carbon dioxide assimilation,- that is, unlike the Algæ, they are unable to manufacture food materials, such as carbohydrates (starches, sugars, etc.), from carbon dioxide and water. Hence they are dependent upon previously formed food products, and may derive their food from living plants or animals, when they are known as PARASITES, or from decaying animal or vegetable matter, when they are known as SAPROPHytes. The living plant or animal atacked by a fungus is known as the host.

Fungi are especially characterized by the habit of arising from spores and of producing thread-like cells the growing point 
of which is at the apex. These threads are known as HYрне (singular hypha). They branch and become interwoven, forming a mass or mat known as the Mycelium (Fig. 23). The mycelium constitutes the plant body proper, and absorbs the food material from the substratum, which it ramifies, often causing decay. The mycelium is frequently not visible, and the presence of the fungus is not recognized until the so-called fruit bodies are developed, as sometimes seen in the case of moldy oranges, mildewed linen, and as illustrated by the common mushroom. The mycelium has a cellulose wall which in some cases is modified to chitin, a nitrogenous substance related to animal cellulose and found in crabs and other lower animals. The protoplasm either occurs in a more or less delicate form lining the hyphæ and enclosing large vacuoles, or is comparatively dense enclosing numerous small vacuoles. Many Fungi contain color substances which are dissolved in the cell-sap and are of a quite brilliant hue. One of the most interesting classes of substances produced by Fungi is that of the ferments, including the oxidizing ferment allied to laccase. They contain also amido-substances related to lecithin; fats; carbohydrates, as trehalose and mannitol; organic acids, as oxalic, tartaric, malic, etc.; and calcium oxalate may be present in some cases.

Reproduction in the Fungi is chiefly by means of asexual spores, which arise in two ways. In the one case they are developed in a special cell or sporangium at the end of a mycelial thread and are known as ENDOspores. In the other case they arise on special hyphæ, or directly from the mycelium, and are known as EXOSPORES or conidia. There are also several modifications of these two types.of spores, which may be referred to later.

Groups of Fungi.-There are four principal groups of Fungi:

I. Phycomycetes.

2. Basidiomycetes.

3. Ascomycetes.

4. Fungi Imperfecti.

The Phycomycetes, or Algal-like Fungi, are so called because they show a certain relation to the Algæ.

The Ascomycetes are distinguished by having a sporangium of 
a definite shape and size, which is called an Ascus, and which contains a definite number of spores, which is two or some multiple thereof.

The Basidiomycetes are the most highly developed Fungi, producing large fruit bodies, such as are seen in mushrooms, toadstools, and puffballs. They are characterized by producing spores (basidiospores) on special hyphæ. The spores are usually four in number, and the spore-producing organ is known as a BASIDIUM.

The Fungi Imperfecti constitute a group of Fungi which, while having certain natural relationships with the other types already considered, yet do this so imperfectly that they are brought in a class by themselves. The complete life-cycle is not in all cases known, and future studies will probably distribute them among the other principal groups.

PHYCOMYCETES: ALGA-FUNGI.-The plant body of the Phycomycetes consists of a mycelium which is unsegmented, more or less thread-like and sometimes considerably branched. Reproduction takes place by means of several kinds of spores, and by reason of the production of two kinds of sexual spores they are subdivided into two important groups. These are (I) the Oömycetes, which produce oöspores, and (2) Zygomycetes, which produce zygospores.

Saprolegnia.-Probably one of the best representatives of the Oömycetes is the group of water molds known as Saprolegnia, which are aquatic in their habits and are both parasitic and saprophytic, occurring on living fish, insects, crayfish and decaying plants and animals as well. The plant body consists of a mycelium which may be simple or branched, sometimes forming a dense mass (Fig. 21, $A$ ). Like the alga Vaucheria, it produces both swarm spores (zoöspores) and oöspores. The swarm spores (Fig. $2 \mathrm{r}, B, C$ ) are produced in sporangia formed by the production of a partition wall at the end of a hypha. The sporangia are either cylind rical or spherical, and contain numerous zoöspores which have two cilia at one end. These spores are peculiar in that after their escape from the sporangium they swim about, then come to rest and take on a wall, after which resting period they develop two cilia on the side, again move about, and germinate when they find a suitable host. 
The oögonia and antheridia (Fig. 2I, $D-F$ ) are also formed at the ends of hyphæ. The oögonia are usually spherical and the wall contains a number of small pores. The contents, which are at first more or less uniform, later develop egg-cells, of which there may be as many as fifty in a single oögonium. The antheridium is more or less cylindrical and contains a somewhat uni-

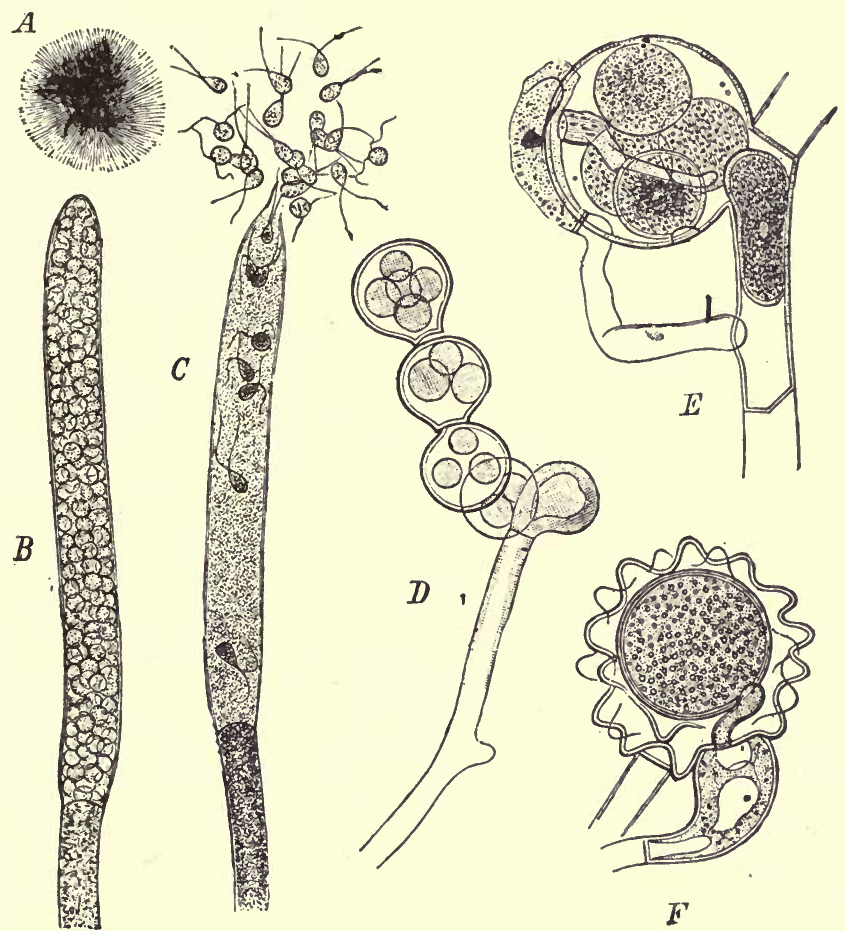

Frg. 21. Species of Saprolegnia: A, mycelium growing out from and surrounding a dead house-fly in a water culture; B, C, sporangia with biciliate swarm spores; D, a number of oogonia containing oöspheres; E, F, oögonia and antheridia, in F the tube of the antheridium having penetrated the oogonium.-A-C, after Thuret; D-F, after De Bary.

form mass of protoplasm. The antheridium bends toward the oögonium and comes in contact with it, but apparently does not in all cases penetrate it. Nevertheless the egg-cells develop walls and become resting oöspores.

In Peronospora, one of the Oömycetes, the antheridium (Fig. 22, n) develops a tube which pierces the wall of the 
oögonium (Fig. 22, 0 ); the contents unite with the egg-cell, after which a heavy membrane develops, forming an oöspore, which germinates when it finds a suitable host. The plants belonging to Peronospora as well as related genera are destruc-
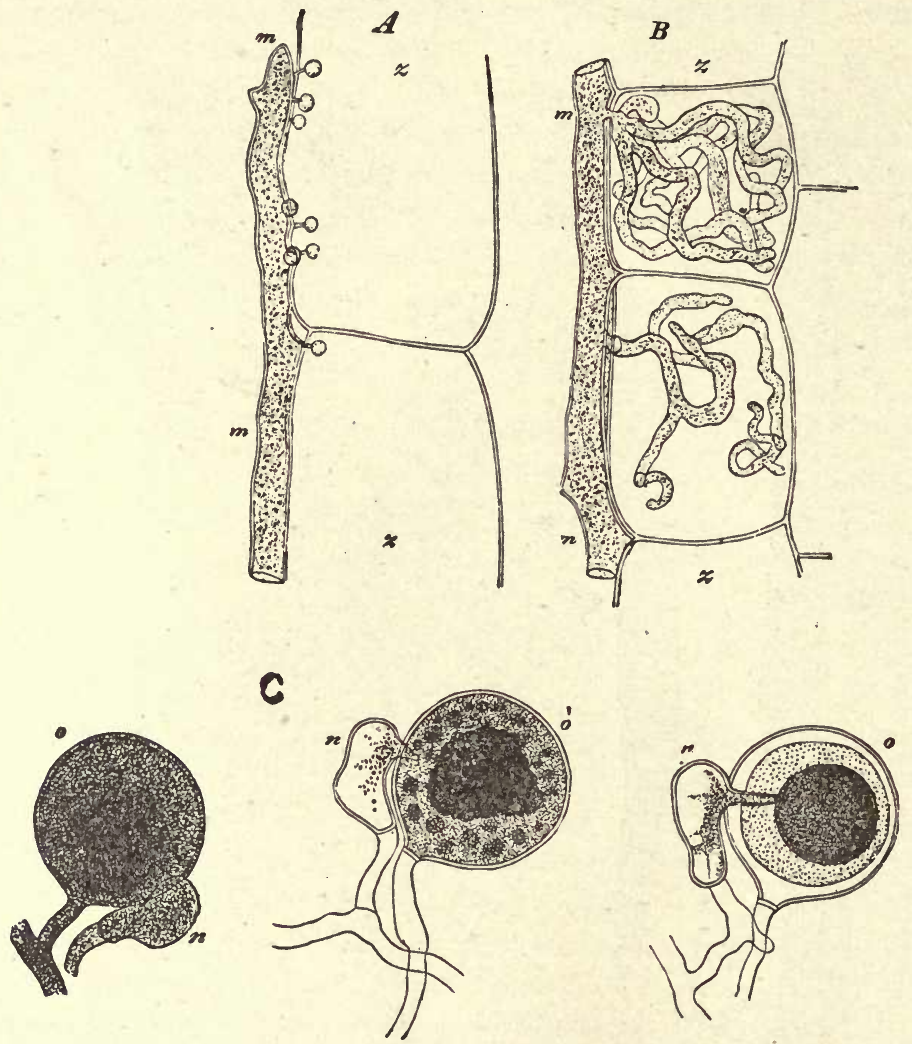

FIG. 22. A, Cystopus candidus; B, Peronospora calotheca. Mycelia $(m)$ with haustoria penetrating cells $(\mathrm{z})$ of hosts. C, Oöspore formation in Peronospora: o, oögonium; $n$, antheridium. At the left the antheridium is in contact with ooggonium; the next stage shows the antheridium penetrating oögonium and discharging its contents; at the right the resulting oöspore is shown.-After De Bary.

tive to many cultivated plants, constituting mildews or blights, as those occurring on the leaves of hyoscyamus, tobacco, anthemis, matricaria, aconite, grape vine, lima bean, potato, etc. The group has received the name "downy mildews" because of the 
fact that the conidiophores rise to the surface of the leaves where the spores are discharged, forming powdery patches.

Black Mold.-A common example of the Zygomycetes is furnished by the "black mold," Mucor Mucedo. The mycelium

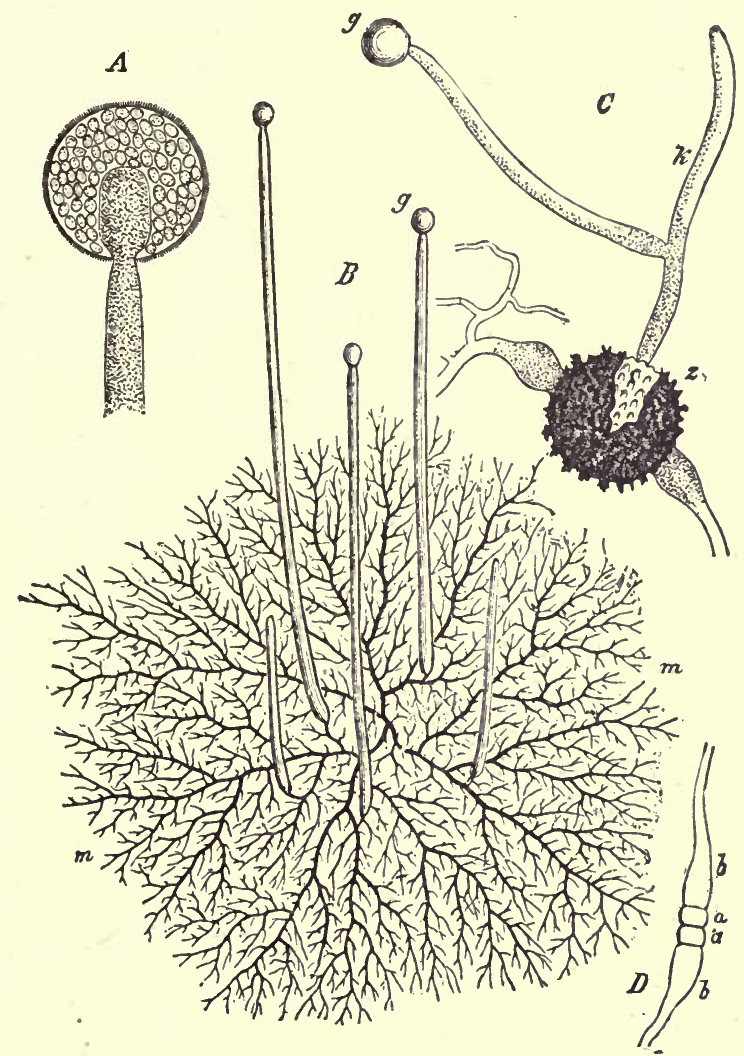

FIG. 23. B, richly branching mycelium (m) of the mold Phycomyces nitens showing upright hyphæ bearing sporangia (g). A, C, D, the common black mold Mucor Mucedo. A, sporangium with columella; C, germination of zygospore $(z)$, with formation of hypha $(\mathrm{k})$, and sporangium $(\mathrm{g}) ; \mathrm{D}$, earliest stages in the development of a zygospore, the hyphal branches (b) showing adjoining ends (a) cut off by cross walls.-After Sachs.

of this plant is cœnocytic, thread-like, very much branched, and profusely developed, much like that of Phycomyces nitens (Fig. $23, B)$. This mold is widely distributed, causing trouble in the spoiling of many sugar- and starch-containing substances in the household, including preserves, syrups, fruits, etc. In fact, a 
number of species of Mucor have the power of inducing alcoholic fermentation in glucose-containing solutions. They are also commonly found in many aqueous solutions of inorganic chemicals as well as organic substances. Asexual spores are formed at the ends of hyphæ which rise into the air. The sporangia are spherical and are cut off from the hyphæ by means of a transverse wall which projects upward into the sporangium and which is technically known as the columella (Fig. 23, A). The contents by
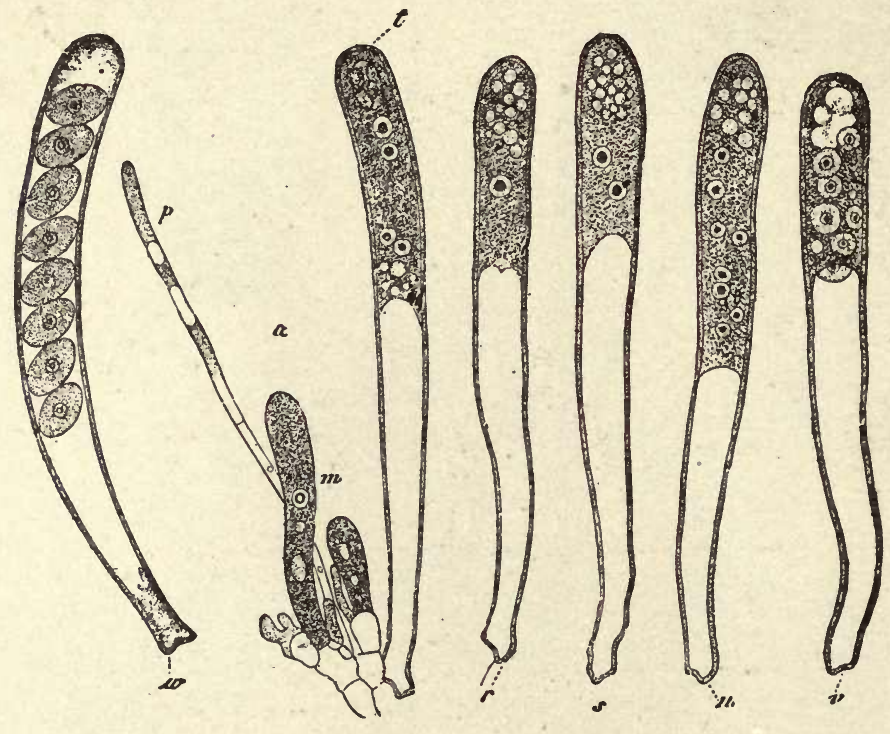

Fig. 24. Peziza confluens showing stages in the development of ascospores. In the youngest asci $(\mathrm{m}, \mathrm{r})$ there is only one nucleus; this divides into two ( $\mathrm{s}$; the division is repeated, so that there are 4 nuclei in $(t)$ and 8 in $(n)$. These surround themselves with protoplasm and a cell-wall $(v, w)$, but the protoplasm of the mother cell or ascus is not entirely used up.-After De Bary.

simultaneous division form numerous I-celled spores, which are discharged by the bursting of the sporangium wall and distributed by air-currents or the wind. As the name of the group to which this plant belongs indicates, it also produces zygospores (Fig. $23, D)$. These are formed by hyphal branches which ascend from the substratum. The ends of two branches come together, a transverse wall is formed in each branch, the walls in contact are absorbed, the contents unite, and a spore is formed with 
three membranes, two belonging to the spore proper and the third being formed by the united hyphæ. As would be expected, these spores are quite resistant, being able to withstand unfavorable conditions, and germinate (Fig. 23, C) only after a period of rest.

ASCOMYCETES.-The Ascomycetes are distinguished for the most part, like the other higher Fungi, in having a septate mycelium, i.e., one cellular in structure, and in producing asci
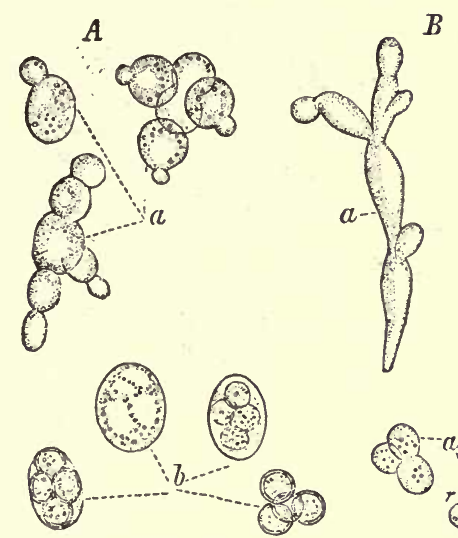

$B$

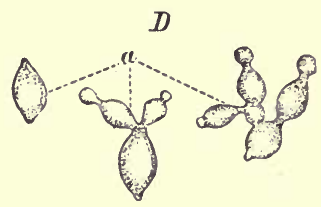

b.
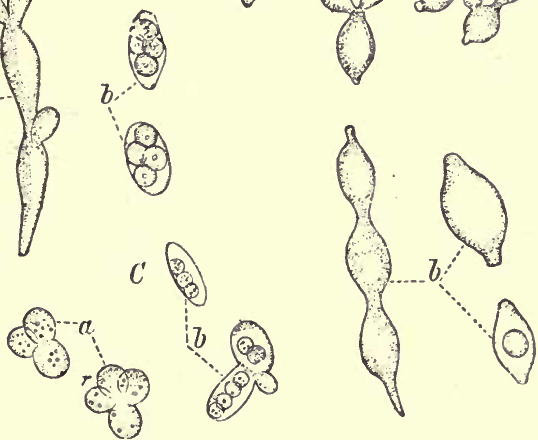

FIG. 25. Species of Saccharomyces (Yeasts). A, S. cerevisice or beer yeast; B, $S$. Pastorianus; C, S. glomeratus; D, S. Piculatus: a, vegetative cells reproducing by budding; b, formation of ascospores.-After Reesz.

(sacs), which latter are formed at the ends of the branches of the mycelia. Two main sub-groups are recognized, the one producing an indefinite number of spores in asci which are not well developed, and known as the HEMIASCI; the other producing a definite number of spores, which number is characteristic for each species, in a well-developed ascus, and known as the EuAScI. In the latter group the spores arise by successive divisions of the primary nucleus into two, as shown in Peziza confluens (Fig. 24).

Yeasts.-The simplest of the Ascomycetes is the sub-group known as the Saccharomyces, or Yeasts. The Yeasts do not produce a mycelium, but the plant body consists of a single cell, or a chain of cells, and multiplies by a peculiar process known as "yeast budding" (Fig. 25, a). From either end of the cell a wart-like process develops, which enlarges until about the size 
of the original cell, from which it is then separated by the formation of a transverse wall. The cells are spherical, ellipsoidal, or egg-shaped, and in some cases somewhat elongated and hyphalike. In the protoplasm are one or more large vacuoles. In certain of the cells, which may be considered to be asci, two to eight spherical or ellipsoidal spores are produced (Fig. 26). There are a number of different species of Yeasts, some of which

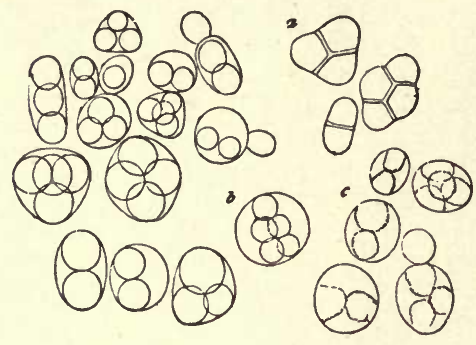

1

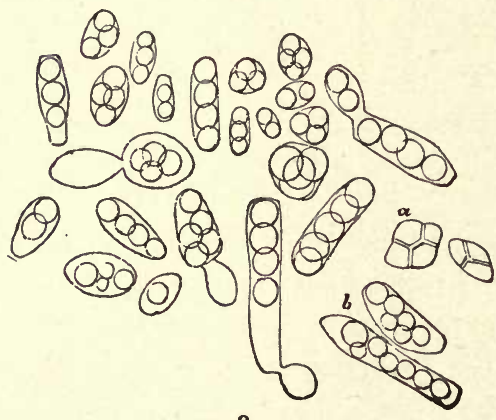

3

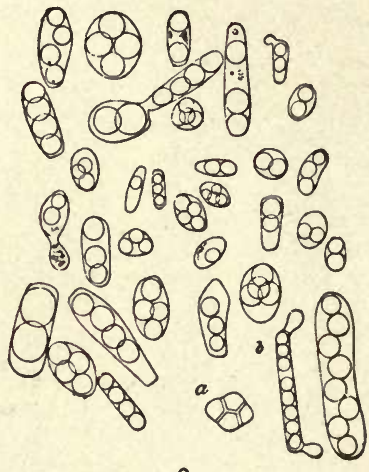

2

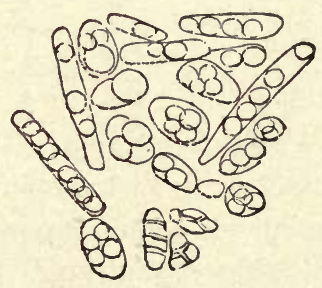

4

Fig. 25. Formation of ascospores in a number of different species of Yeasts. I, Saccharomyces cerevisia; 2, S. Pastorianus; 3 , S. intermedius; 4 , S. validus.-After Hansen.

are cultivated; and these latter are of great economic importance on account of their property of inducing alcoholic fermentation. They are also of use in the making of bread, changing the carbohydrates in part into carbon dioxide and alcohol, both of which are driven off in the baking.

The property of yeast causing the fermentation of a solution 
of sugar whereby alcohol is formed, was for a long time supposed to be due to the presence of the living yeast cell or to the action of living yeast protoplasm, and hence fermentation brought about by living organisms was distinguished from those fermentative processes where distinct principles such as diastase were involved; the former being known as "organized" ferments, while the latter were referred to as "unorganized" ferments. Büchner obtained from freshly expressed yeast a nitrogenous substance capable of changing solutions of cane sugar or glucose into alcohol and carbon dioxide. This principle he termed zymase, and it has all of the properties of an enzyme or ferment and behaves exactly as the living yeast cell in a sugar solution. In the living yeast plant zymase is continually being formed and decomposes the sugar which has diffused into the cell.

Yeasts are used in the treatment of certain skin diseases, their action being attributed to a fatty substance, ceridine. Other principles found in yeasts as well as extracts are used in the treatment of cancer.

Under the name of Xerase a mixture is marketed consisting of I 50 parts of dried beer yeast, 20 parts of dextrose, I 25 parts of white clay or aluminum silicate, and 3 parts of a mixture of nutritive salts. It is used in the treatment of putrid wounds, ulcers, etc.

The ginger beer plant, which is used in England for making a beverage known as ginger beer, consists of a yeast (Saccharomyces pyriformis) and a bacteria (Bacterium vermiforme). These two organisms live in a somewhat symbiotic relationship, the yeast changing the sugar into alcohol and the bacteria developing lactic acid (see Technical Mycology, by Lafar).

Green and Yellow Mildews.-To the Ascomycetes also belong the green and yellow Mildews, Penicillium and Aspergillus, so common in the household, the dairy, and the granary. These plants produce profusely branching mycelia which form patches upon or just under the surface of the materials upon which they grow. These areas become soft and spongy and are always white at first. After a time hyphal branches, which are more or less flask-shaped, rise above the substratum, and by a process of division at the end of the branch, or conidiophore, a spore called 
a conidiospore is formed (Fig. 27, $A$; Fig. 28, $A$ ). The process of division at the end of the conidiophore continues from below until a chain of conidiospores is formed. The conidiophore frequently branches, so that a fan-like series or group of conidia or
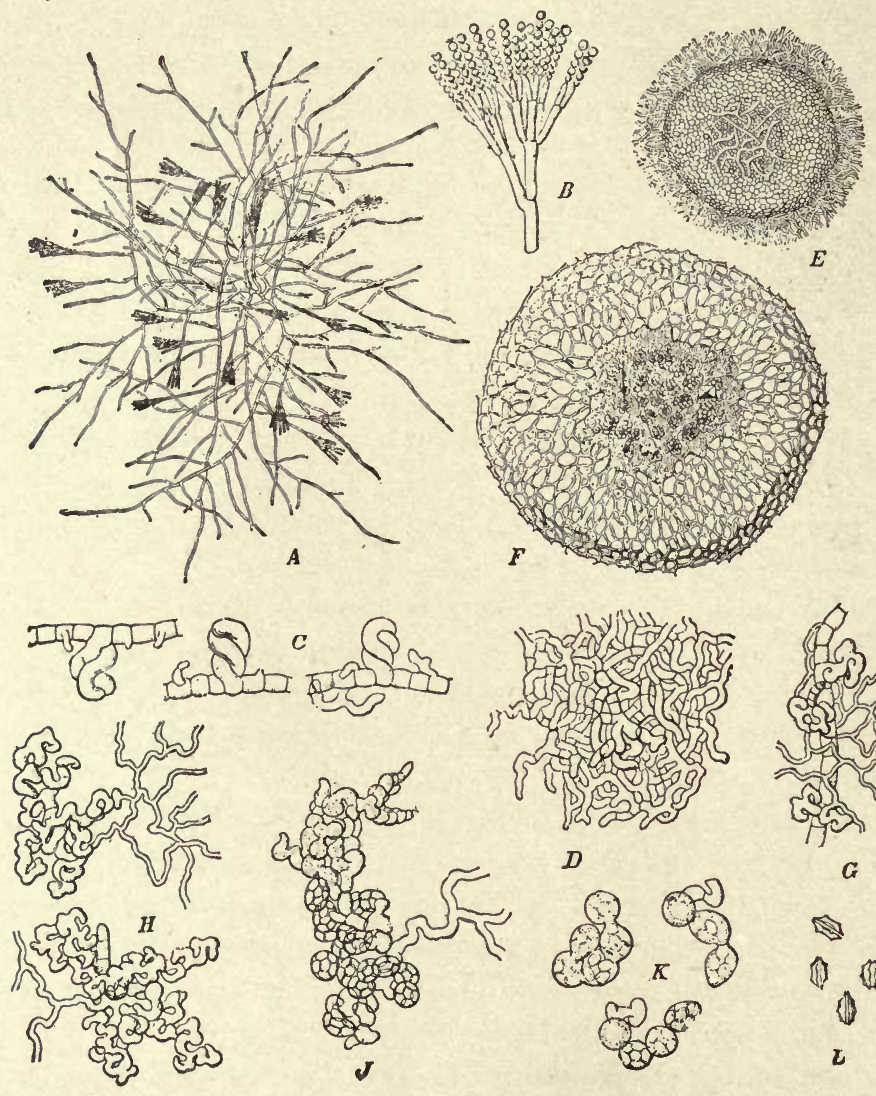

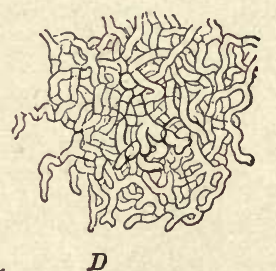

$D$

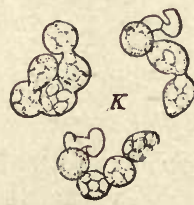

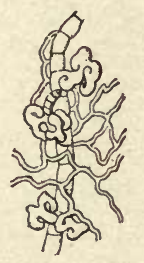

c

5

Q1

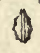

FIG. 27. Penicillium, a green mildew. A, richly branching mycelium with conidiophores; B, enlarged view of conidiophore showing chains of conidia; G, D, E, F, successive stages in the development of a perithecium; G, H, J, development of asci; K, groups of asci containing from 4 to 8 ascospores; L, ascospores seen from the side and showing characteristic markings. - After Brefeld.

conidiospores is produced (Fig. 27, B; Fig. 28, $A$ ). The conidia are usually some shade of green, but finally they may become more or less brown. They are thin-walled, quite small, and so light that they float freely in the air. If a colony is inhaled it gives 
the sensation commonly called the "smell of mold." They are capable of germinating on almost everything, as old shoes, old paper, as well as on bread and other articles of the household, and are commonly found on " moldy drugs," and may occur in pharmaceutical preparations, as syrups and infusions, and even in solutions of inorganic as well as organic chemicals.

Aspergillus (Fig. 28) is distinguished from Penicillium (Fig.

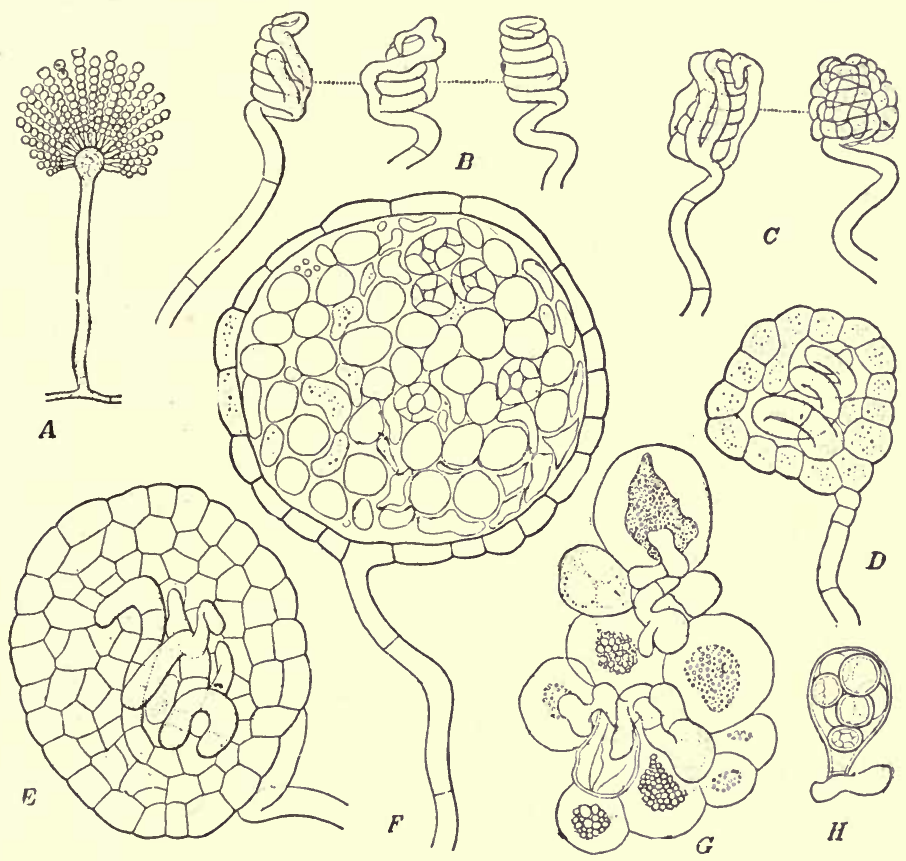

FIG. 28. Aspergillus, a yellow mildew. A, conidiophore with enlarged, more or less spherical end, from which the fan-like series of chains of conidia arise; B-E, successive stages in the development of perithecium; F, section through a nearly ripe perithecium; $\mathrm{G}$, groups of young asci; $\mathrm{H}$, a ripe ascus with 8 spores.-A, after Kny; B-H, after De Bary.

27 ) by the fact that the upper end of the hyphal branch or conidiophore is somewhat enlarged and more or less spherical.

In addition to the conidiospores these Fungi sometimes produce in the fall of the year, particularly when grown upon bread, asci fruits (Fig. 27, $C-F$; Fig. 28, $B-E$ ). In this case two fertile initial hyphæ wind themselves around each other, after which they become surrounded with sterile branches which form a kind of 
loose tissue, more or less cellular in structure, that finally develops into a yellowish leathery wall. This body, which may be regarded as a closed ascocarp, is known as a perithecium (Fig. 27, F; Fig. $28, F)$. As a result of the conjugation of the fertile cells, asci (Fig. 27, $G, H, J$; Fig. 28, $G, H$ ) develop within the perithecium, which are more or less spherical or ellipsoidal and contain from four to eight spores (ascospores) (Fig. 27, $K$; Fig. 28, $H$ ). After maturity the cellular tissue around the asci dries up and disintegrates, the walls of the asci dissolve, and the ascospores are liberated from the perithecium by slight pressure. The spores lie over winter and then germinate, producing a mycelium from which conidia first develop and afterwards the perithecia, thus repeating the life history of the plant.

Ergot.-Another Ascomycete of special interest is the fungus known as Ergot (Claviceps purpurea). The spores of this fungus germinate on the flowers of certain grasses. The mycelium penetrates the walls of the ovary, absorbing the nutriment. After a time the mycelium develops on the surface, and from this short conidiophores arise bearing small ovoid conidia (conidiospores) (Fig. 29, A). The mycelium secretes a sweet fluid, the so-called honey dew which attracts insects, and thus the conidia are carried to other plants. As the conidia are capable of immediate germination the so-called "ergot disease" rapidly spreads during the flowering season of the host plants. After the formation of 'conidia ceases, the mycelium forms a dense mass which is surrounded by a dark layer, and this, if developed upon rye, constitutes the ergot grains (Fig. 29, B) used in medicine, these grains being a number of times larger than the rye grains which they replace. The mycelial tissues connected with the host plant die, and the ergot drops to the ground. At this stage the ergot mass is more or less cellular in structure and is known as the SCLEROTIUM. It is quite resistant and usually remains dormant until the following spring when the grasses are in flower again. The sclerotium then shows signs of renewed activity by the development of small, reddish, spherical bodies with a fair-sized stalk (Fig. 29, C). Within the periphery of these spherical heads are produced flask-shaped perithecia or ascocarps (Fig. 29, D) 
containing numerous cylindrical asci (Fig. 29, E), each of which contains eight spores (Fig. 29, F) ; the latter are. I-celled, hyaline, and thread-like (Fig. 29, $H$ ). These spores are carried by
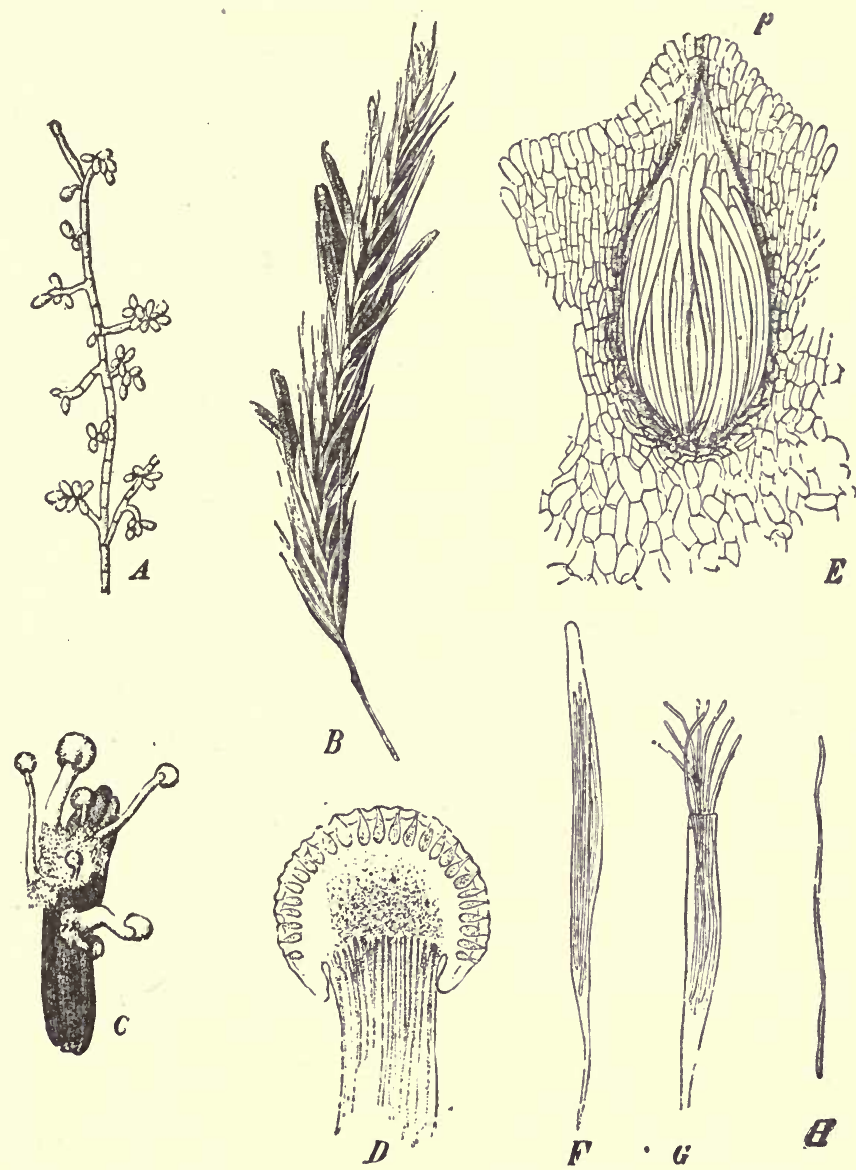

Fig. 29. Claviceps purpurea. A, mycelium developing conidia; B, an ear of rye with a number of ripe sclerotia replacing grains of rye, and known as ergot: $\mathrm{C}$, sclerotium developing spherical fruit bodies; D, fruit body in longitudinal section showing numerous flask-shaped perithecia at the periphery; E, enlarged perithecium with numerous cylindrical asci; F, closed ascus with 8 ascospores; $G$, discharge of ascospores; $H$, single threadlike ascospore.-A, after Brefeld; B, after Schenck; C-H, after Tulasne.

the wind to the flowers of certain of the grasses, as already stated, and the life history or cycle of growth begins again. 
Chestnut Bark Disease is caused by a fungus parasite known as Diaporthe parasitica Murrill, and is said to very closely resemble the parasite found in Italy, Endothia radicalis. This fungus has been the cause of very great destruction of chestnut trees in the eastern United States. When any of the spores of this fungus gain entrance into a wound on any part of the tree, thread-like mycelia are developed in the inner layers of the bark, and these spread concentrically until they girdle the trunk or

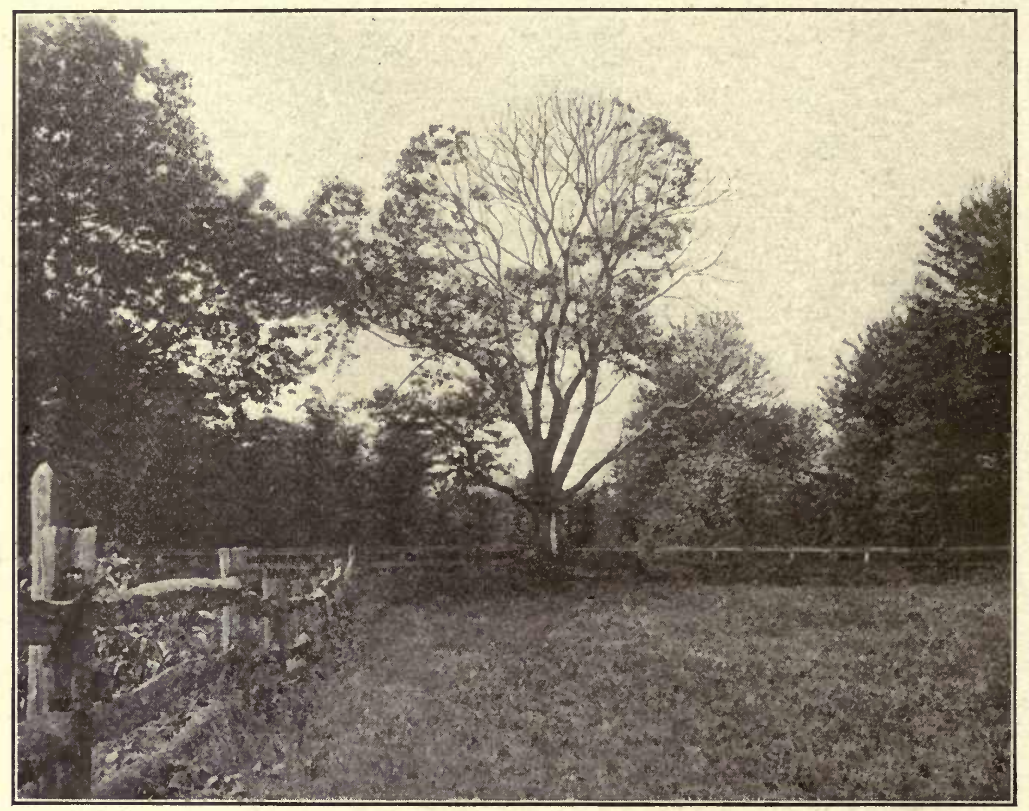

FIG. 30. Large Chestnut tree partly killed by the bark disease. Note branches in the center either killed or bearing dwarfed leaves, and the other larger branches still unaffected.-From photograph by Haven Metcalf.

limb, so that if it happens that the trunk is affected the entire tree may die within the year, while if it is the smaller branches which are attacked, only those parts beyond the point of infection are killed, while the remainder of the tree will survive for some years (Fig. 30).

When the bark is attacked by the fungus it shows minute, more or less crater-like spots of a yellowish-orange or reddish-brown 
color which are pustules of the fruiting fungus. These pustules produce mostly winter spores (ascospores), although occasionally a long strip of summer spores (conidia) are also produced (Figs. 3 I and 32 ).

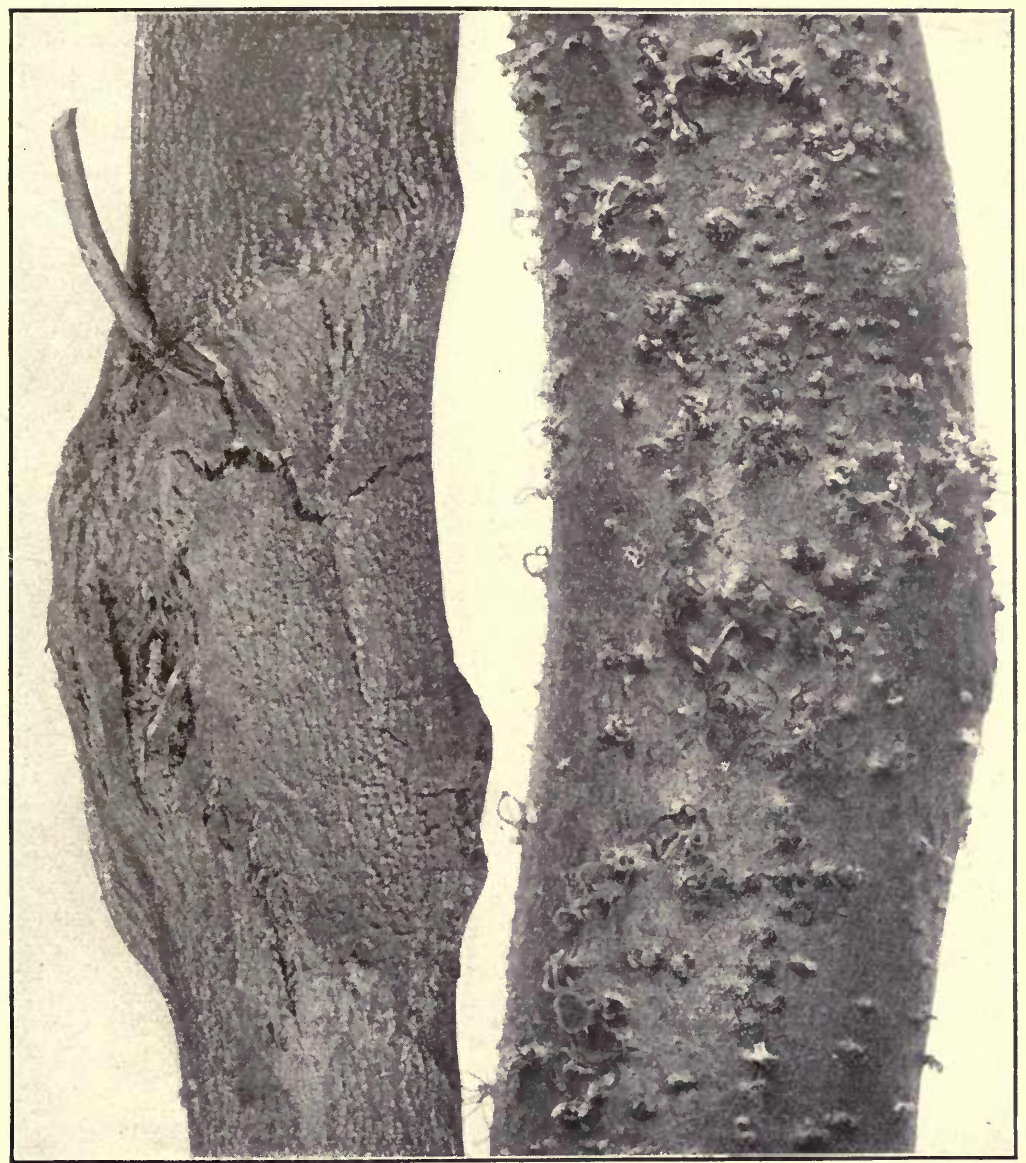

FIG. 3r. Typical appearance of branches of Chestnut tree affected with chestnut blight. At left, bark showing pustules of the parasitic fungus bearing winter spores. At right, the diseased bark showing pustules and form of discharge of summer spures in damp weather.-From photograph by Haven Metcalf.

The control of the disease over large districts consists mainly in destroying the affected trees and carefully burning the rubbish. 
Single trees are treated by removing the affected branches and painting over the cut ends with coal tar to prevent reinfection.

For further details on this fungus consult: Murrill, "A New Chestnut Disease," Torreya, Sept., I906; Farmers' Bulletin 467, U. S. Department of Agriculture; Metcalf, "Diseases of the Chestnut and Other Trees," Trans. Mass. Hort. Soc., August,

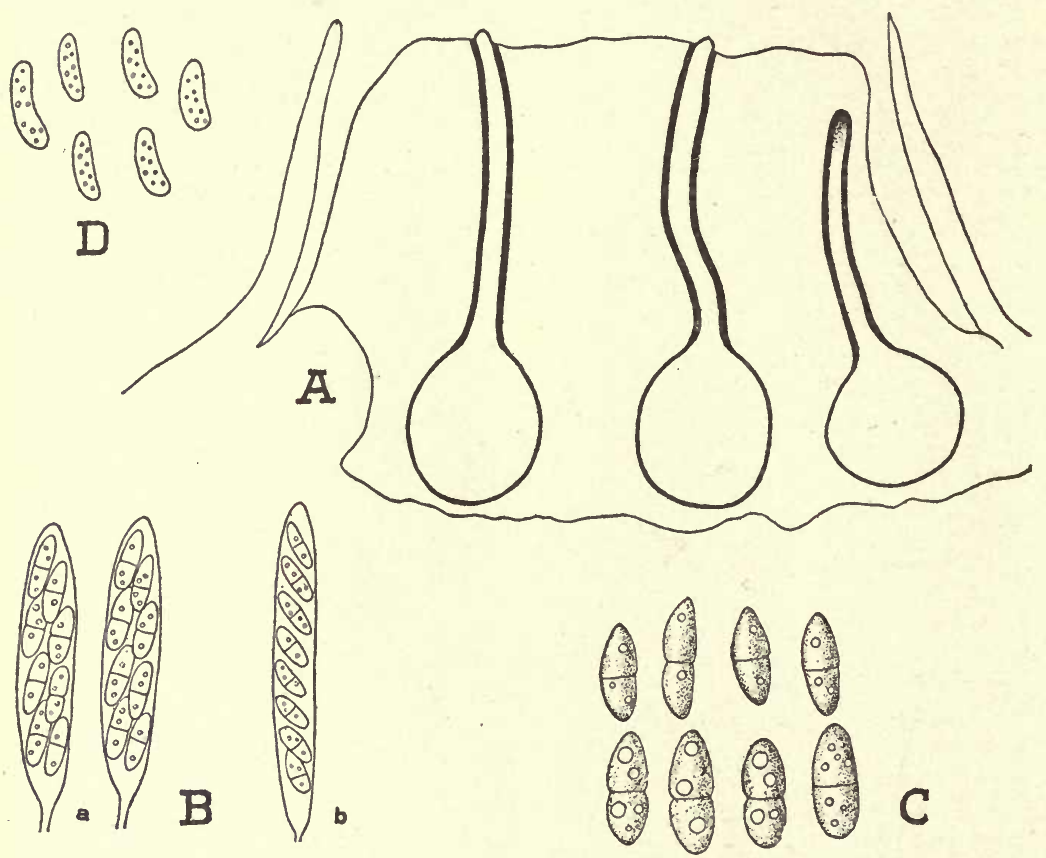

FIG. 32. Chestnut-blight disease, which occurs in small yellowish pustules the size of a pin head. A, section of pustule showing perithecia; B, asci with sporidia; a, usual form; $b$, form rarely found; C, sporidia; D, summer spores.-After Murrill.

I9I2; Farlow, "Fungus of the Chestnut-Tree Blight," Science, May io, I9i2.

BAsidiomycetes.-The Basidiomycetes are the most highly organized of the Fungi. The mycelium consists of white branching threads and is usually concealed in the substratum. In the cultivation of the edible mushrooms propagation is by means of the mycelium, which is known commercially as "spawn." It is recognized, however, that mushrooms can not be propagated in 
this way exclusively for more than two or three years. The mycelium is really the plant body, and the part which rises above the surface and is commonly regarded as the toadstool or mushroom (Figs. 33 to 37 ) is a fruit branch, or spore-producing organ. When these branches first make their appearance they are in the form of smali solid bodies known as "buttons" (Fig. 33, $I-V$ ).
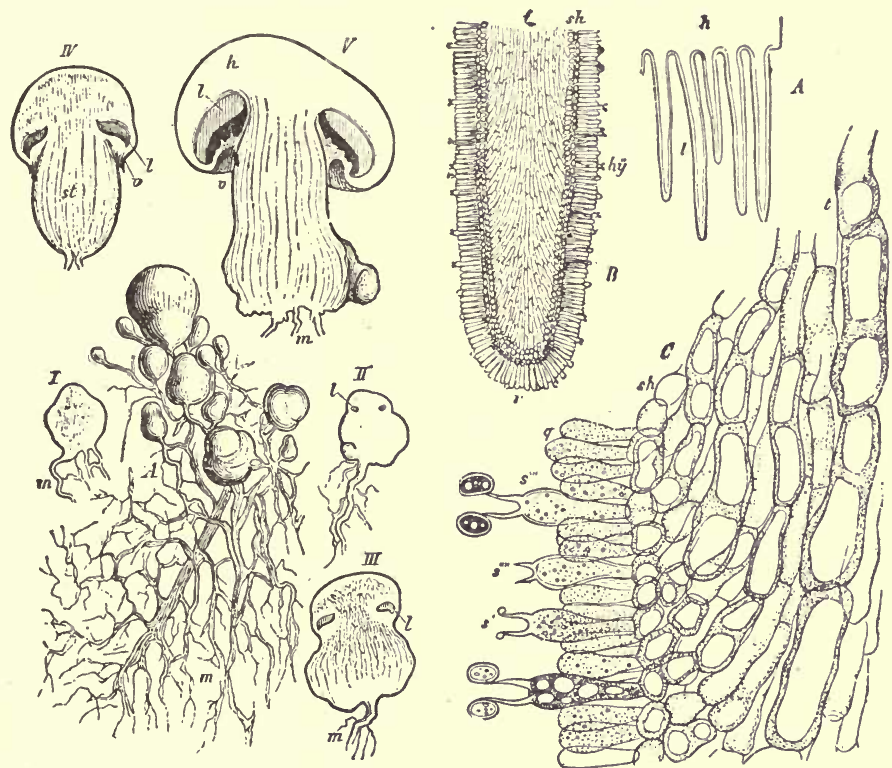

FIG. 33. Agaricus campestris, the common edible mushroom, showing at A on the left mycelium (m) and development of buttons or young mushrooms; I to V, longitudinal sections showing successive stages in development of fruit body; $\mathrm{m}$, mycelium; st, stipe; $h$, portion between veil (v) and spore-bearing portion (1).

The illustration to the right $(\mathrm{A}, \mathrm{B}, \mathrm{C})$ shows the structure of the hymenium in different degrees of magnification: A, section through portion of pileus showing five of the gills; $\mathrm{B}$, section of a gill somewhat magnified; C, section of gill still more magnified and showing sterile cells or paraphyses (q), and the fertile celis or basidia (s), from each of which arise two basidiospores.-After Sachs.

As growth proceeds these bodies differentiate into a stalk-like portion known as the stipe (Fig. 33, st), which is directly connected with the mycelium, and an umbrella-like portion borne at the summit of the stalk, called a pileus, which at first is closed down over the stalk, but later expands or opens more or less widely according to the species. On the under surface of the pileus, known as the hymenium, the spores are borne (Fig. 33, 

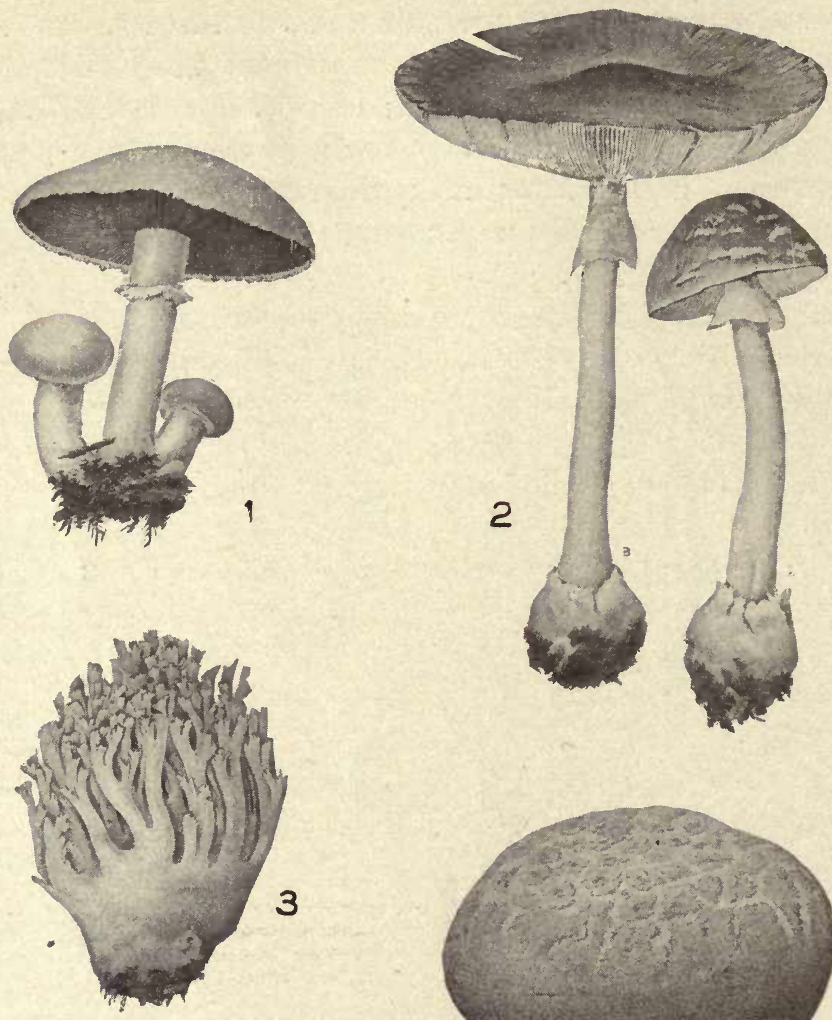

3

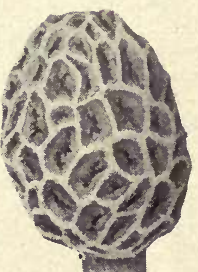

4
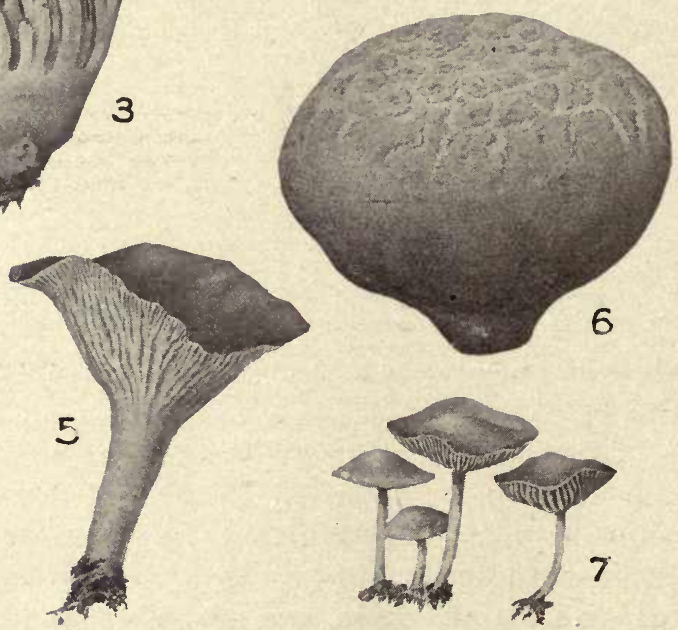

Fig. 34. Some common edible mushrooms and a common poisonous one. The following are edible: I, Common Field mushroom (Agaricus campestris); 3, Clavaria flava, young plant; 6, Puffball (Lycoperdon cyathiforme); 4, Morel (Morchella esculenta); 5 , Chanterelle (Cantharellus cibarius); 7, Fairy-ring Fungus (Marasmius oreades).

Only one poisonous species is shown, namely, 2, the deadly Agaric (A manita phalloides). -Adapted from Farlow. 
$A, B, C)$. In some cases the under surface is composed of a series of narrow, radiating, knife-like plates, or gills, as in the common edible mushroom Agaricus. On the surface of the gills the basidia or spore-bearing organs arise. The basidia are somewhat swollen terminal cells of the closely arranged hyphre composing the gills, which bear a group of spores on short stalks (Fig. 33, C). Both the basidia and spores (basidio-spores) are of a characteristic size and number for the different species.

Several types of Basidiomycetes are usually recognized, depending on the manner in which the spores are borne.

I. The Gill Fungi (Agaricaceæ), in which the spores are borne on plates or gills which radiate from the stem to the edge of the cap.

2. The Pore Fungi (Polyporaceæ), in which the spores are borne in tubes or pits opening by pores rather than on gills.

3. The Coral Fungi (Clavariaceæ), in which the Fungi are coral-like or leaf-like, the surface of the cap or its branches being smooth.

4. The Leather Fungi (Thelephoraceæ), in which the sporebearing surface is smooth or slightly wrinkled. The texture is usually leathery or papery.

5. The Jelly Fungi (Tremellaceæ), in which the fruiting surface is smooth and the cap is more or less jelly-like when wet.

6. The Puff Balls (Lycoperdaceæ), in which the cap is a closed ball which breaks open at maturity to release the enclosed spores.

7. The Carrion Fungi or Stink-horn Fungi (Phallaceæ) resemble the puffballs when young, but are ruptured longitudinally, the spores thereby being exposed on the top as a gelatinous mass.

Of these seven groups the Gill Fungi are the commonest, and one or two types will be considered, namely, the common edible mushroom and two of the poisonous group, Amanita.

Edible Fungi.-Agaricus campestris (common mushroom) (Figs. 33 and 34 ) is practically the only edible species cultivated in this country. The plant grows wild in open grassy fields during August and September. It is not found in the mountains to any extent, and is never found in the woods or on trees or fallen trunks. The color of the stipe and the upper surface of the 


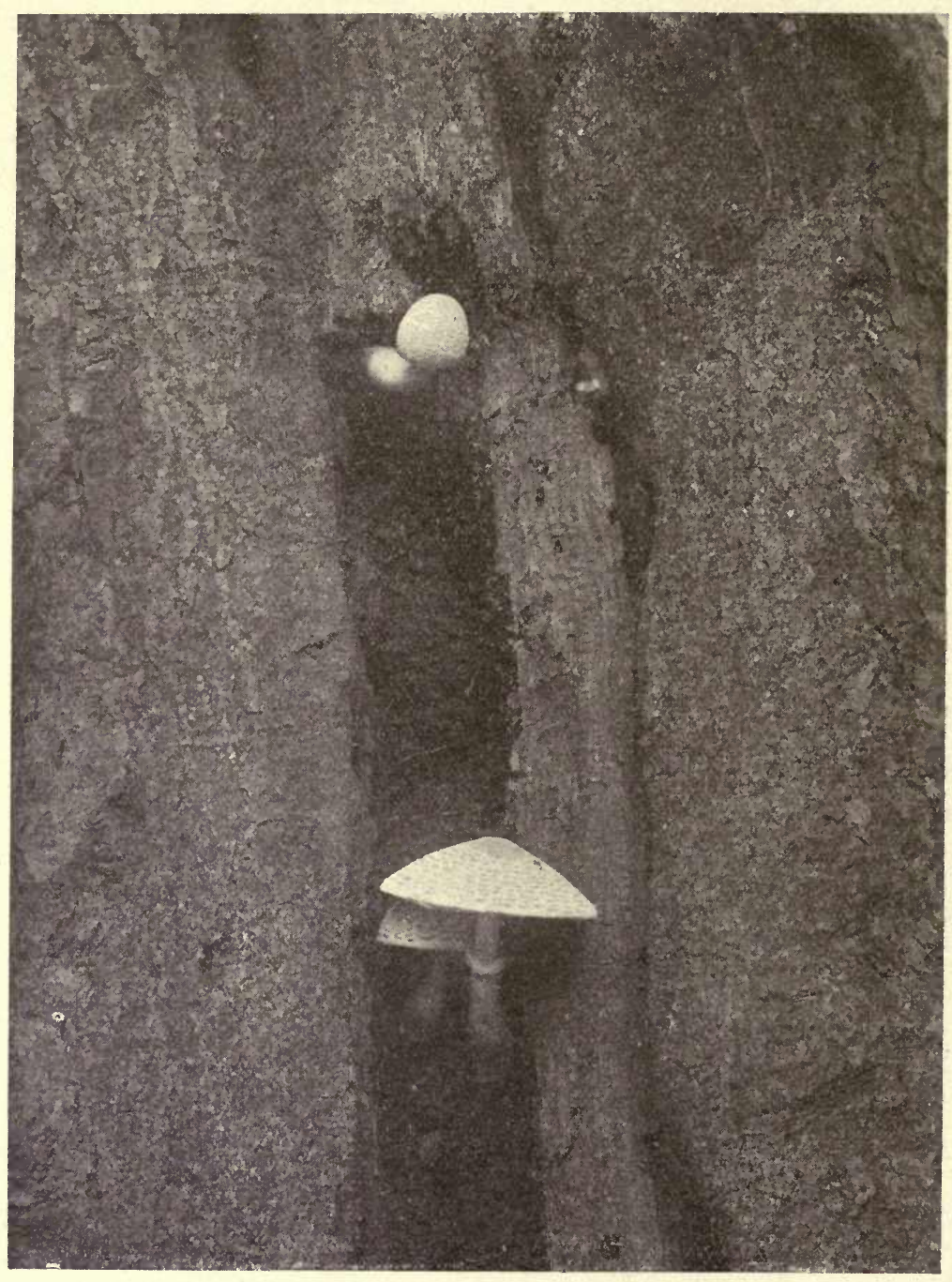

FIG. 35. A decaying tree trunk showing the cause of the death of the tree by the appearance of the several fungi (probably Amanita muscaria). It is not unusual to find trees showing signs of disease and, finally, even dying, and it is not until the death of the tree that the mature fungus makes its appearance. For some years the mycelium of the fungus has been working its way into the tissues not only of the bark but of the wood, sapping it of its vitality. When there is no longer any food supply the fungus produces its fruit; the spores, being scattered by either the wind or through the agency of birds, are carried to other trees and find entrance into wounds, where they germinate and repeat their destruction.-From a photograph by Henry Troth. 
pileus varies from whitish to a drab color, but the color of the gills is at first pinkish and then of a brownish-purple, which is an important character, the color being due to the spores. The stipe is cylindrical and solid, and a little more than half way up is furnished with a membranous band known as the ring. There are no appendages at the base of the stipe, which appears to rise

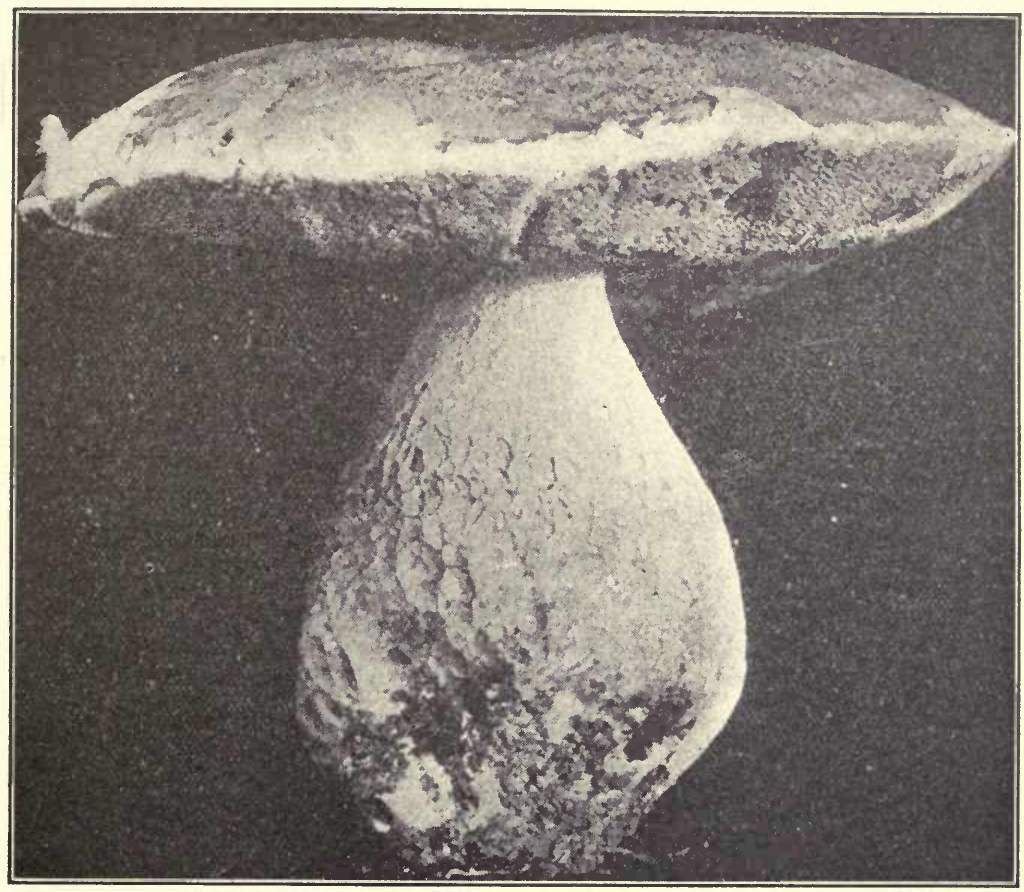

Fig. 36. Edible Boletus (Boletus edulis), an excellent edible mushroom found in woods and openings in summer and autumn. The cap is 8 to $\mathrm{I} \mathbf{\mathrm { cm }}$. wide, grayish-, yellowish-, or brownish-red, sometimes paler toward the edge, smooth, and more or less convex; flesh whitish or yellowish, or somewhat reddish just beneath the skin; stem white, stout, and often bulbous.-From monograph on Minnesota Mushrooms by Frederic E. Clements.

directly out of the ground. Before the pileus is fully expanded a veil extends from its border to the stipe, which when ruptured leaves a portion attached to the stipe, and it is this which constitutes the ring. The ring shrinks more or less in older specimens, but usually leaves a mark indicating where it has been formed.

Poisonous Fungi.-There are two of the poisonous group of Fungi which are very common and which have some resem- 
blance to the edible mushroom just described, namely, the fly agaric (Amanita muscaria) (Fig. 38) and the deadly agaric (Amanita phalloides) (Fig. 34). The fly agaric, while more abundant in some localities than the common edible mushroom, is

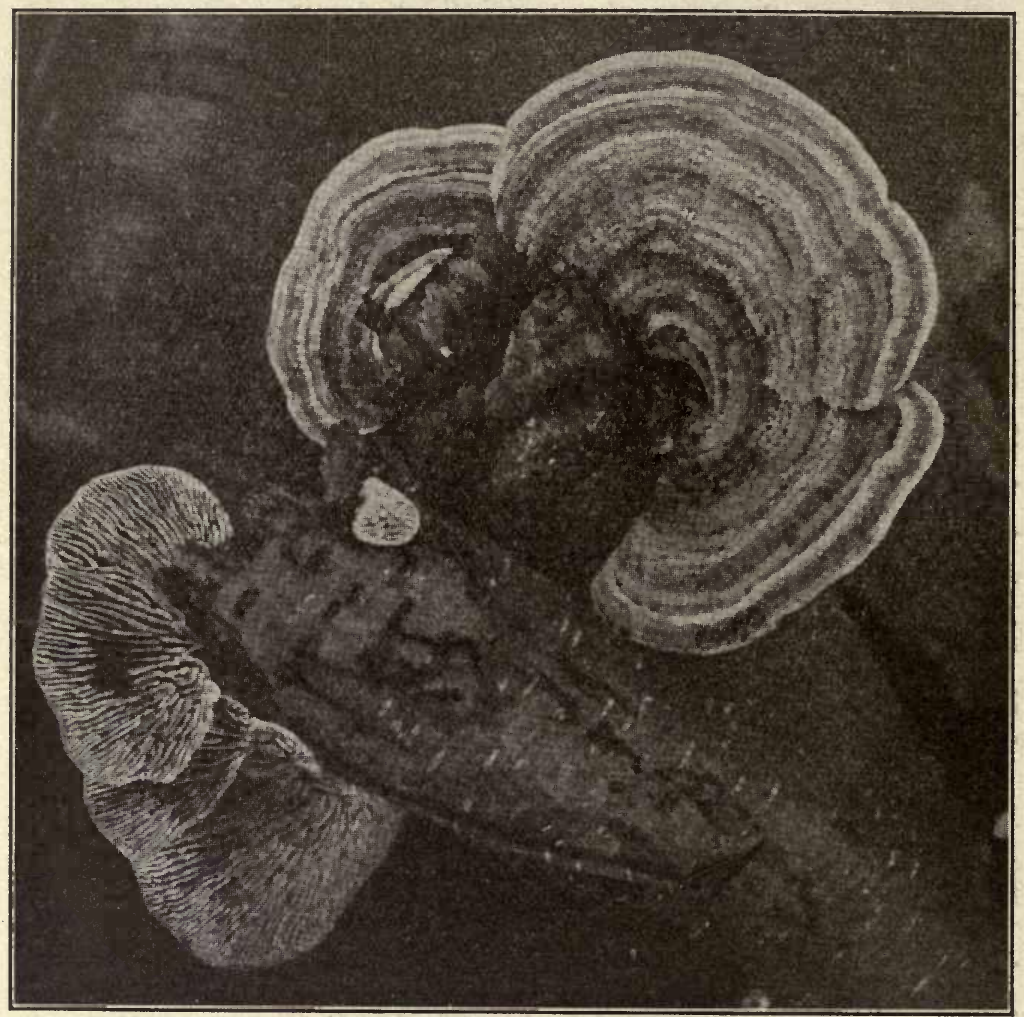

FIG. 37. Pale Lenzites (Lenzites betulina), a non-edible fungus common on trunks and stumps throughout the year. The cap is whitish, corky, more or less densely hairy, and marked by concentric grooves; the stem is lacking and the gills are whitish, more or less branched and united.-From monograph on Minnesota Plant Diseascs by E. M. Freeman.

seldom found in grassy pastures, but more generally in poor soil, especially in groves of coniferous trees. It occurs singly and not in groups. The gills are always white; the stipe is white, hollow, and provided with a ring at the top, and the base is bulbous, having fringy scales at the lower part. The pileus is yellow or orange 


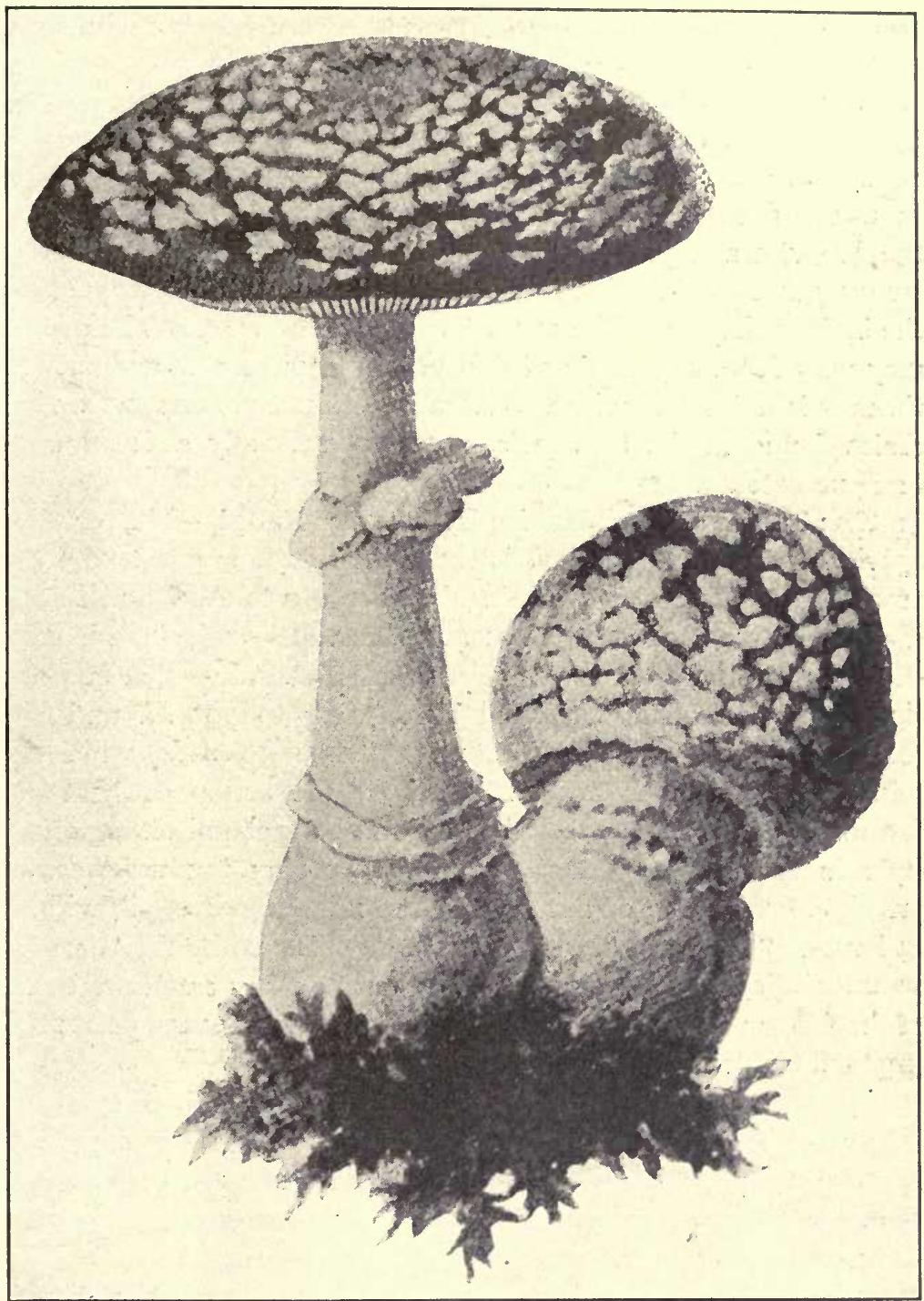

FIG. 38. Fly Agaric (Amanita muscaria), a very deadly mushroom. The cap is bright red or orange, becoming yellow or even whitish in age, roughened with many thick, white angular fragments of the volva; the stem is stout, white, scaly, bulbous, and hollow; volva forming several concentric scaly rings on the bulb; gills free or touching, white or yellowish. This is frequent in woodland, forest, or clearing from June to frost, and is deadly poisonous. -From monograph on Minnesota Mushrooms by Frederic E. Clements. 
and sometimes reddish; the surface is smooth, with prominent, angular, warty scales, which can be easily scraped off.

The deadly agaric (Fig. 34, illus. 2) somewhat resembles the fly agaric and also differs from the common mushroom in not usually growing in pastures. It occurs singly, but not in groups, in woods and borders of fields. The gills and stipe are white, the latter, when young, having a number of mycelial threads running through it. The base is quite bulbous, the upper part of the bulb having a sac-like membrane called the volva. The pileus may vary from any shade of dull yellow to olive, although sometimes it is shiny and white. While it does not possess the warty scales found in the fly agaric, it has occasionally a few membranous patches.

The Toxic Principles in Poisonous Fungi.-The deadly agaric (Amanita phalloides) is the cause of the greatest number of cases of mushroom poisoning. According to Abel and Ford, it contains two toxic principles: ( I) Amanita-hemolysin, a bloodlaking principle, which is a very sensitive glucoside,- that is, precipitated by alcohol, destroyed by heating to $70^{\circ} \mathrm{C}$. and by the action of digestive ferments; (2) Amanita-toxin, which is soluble in alcohol, is not destroyed by the action of heat or ferments. The latter principle is the important poisonous principle in mushroom poisoning and is probably the most toxic principle known, 0.4 of a milligramme killing a guinea pig within 24 hours. "The majority of individuals poisoned by the "deadly amanita' die, but recovery is not impossible when small amounts of the fungus are eaten, especially if the stomach be very promptly emptied, either naturally or artificially."

The fly agaric (Amanita muscaria) owes its toxicity to muscarine, an alcohol-soluble crystalline substance. It is supposed by Ford that the fly agaric may contain another poisonous constituent. In cases of poisoning atropine has been successfully administered hypodermically in doses of $\frac{1}{100}$ to $\frac{1}{50}$ of a grain.

It is stated that the $A$. muscaria, used by the peasants of the Caucasus in the preparation of an intoxicating beverage, is deficient in muscarine.

The question as to whether the ordinary edible mushrooms, as distinguished from the poisonous toadstools, may not in cer- 
tain localities or at certain periods of the year be the cause of fatal intoxication is answered by Ford in the negative. He states (Science, 30, p. 105, July 23, I909) that there are no authentic cases of poisoning from the black or brown spored agarics, although old and badly decomposed specimens may cause transient illness.

Economic Uses of Fungi.-A large number of the Fungi, particularly of the Basidiomycetes, are used for food. There are, however, only a few of these which enter the market. These are derived chiefly from Agaricus campestris (Figs. 33 and 34) and Agaricus arvenis, although some other species of Agaricus as well as Morchella esculenta (Fig. 34, illus. 4) furnish excellent products and are cultivated to a limited extent. The "truffles" of the market are tuber-like masses formed under ground, which consist of the ascocarps of certain Tuberacex, one of the subgroups of the Ascomycetes, and which are used as a condiment and sometimes roasted like potatoes. Tuckahoe or "Indian bread" is also produced under ground and consists apparently of the fungus Pachyma Cocos and the roots of Liquidambar, the tissues of which have been changed into a compound resembling pectic acid by the fungus. Quite a number of Fungi have been used in medicine, as Claviceps purpurea (Fig. 29), Polyporus officinalis and other species, and various species of Lycoperdon. A number of species are used in making surgeon's agaric (Fungus chirurgorum) formerly used as a hæmostatic, including Lycoperdon Bovista and Polyporus fomentarius. Many of them yield very toxic principles, as ( I) several species of Amanita which contain several toxic principles; (2) Lactarius piperatus and others which yield highly poisonous resinous principles. Other uses of Fungi have been mentioned under the several groups.

Ustilagines and Uredineas.-There are two groups of Fungi of considerable economic interest which by some writers are classed by themselves, and by others placed with the Basidiomycetes. These are the Ustilagineæ, or Smut Fungi, and the Uredineæ, or Rust Fungi.

The Smut Fungi are parasitic on higher plants. The mycelium penetrates the tissues of the host, but does not seem to cause either disease or malformation of the plant. Injury to the 
host results only after the development of resting spores. The mycelia are hyaline, more or less branched, and finally become septate. They send short branches, called haustoria, into the cells of the host, from which they obtain nourishment. Eventually the mycelium becomes much branched, compact and more or less gelatinous through a transformation of the hyphal walls, forming gall-like swellings or blisters on the host. Spores are formed within this gelatinous mass at the ends of the branches

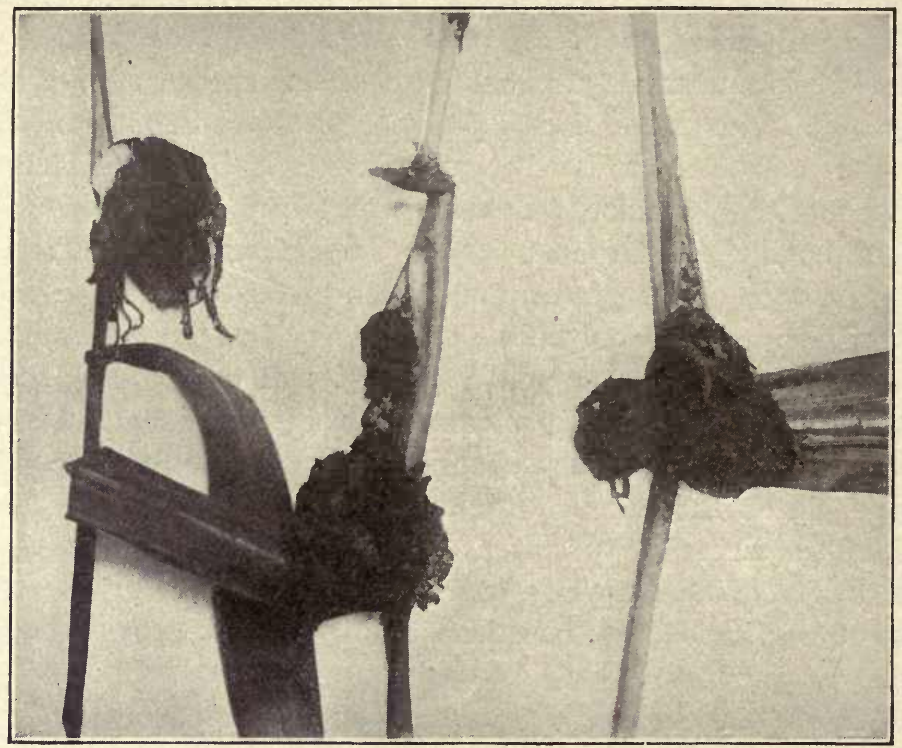

FIG. 39. Corn smut (Ustilago Maydis) showing several gall-like masses of smut full

of the mycelium. At a later stage the smut loses its gelatinous character, the mass breaks up, and the spores are freed and distributed as a dry, dusty powder. The spores (primary conidia) are somewhat spherical or ellipsoidal, and are generally separate, but are sometimes united into a mass forming the so-called "spore balls." These are resting spores and upon germination (Fig. 40) produce a promycelium or basidium which becomes septate and from each cell of which conidia called sporidia arise. The sporidia are formed in succession one after another and the process con- 
tinues for some time. On germination they bud like yeast, forming new conidia, or when nutrition is not abundant they may form a mycelium, which is usually the case when they germinate on a host plant.

Corn Smut.-One of the Smut Fungi, namely, Ustilago Maydis, which develops on Indian corn (Fig. 39), is used in medi-
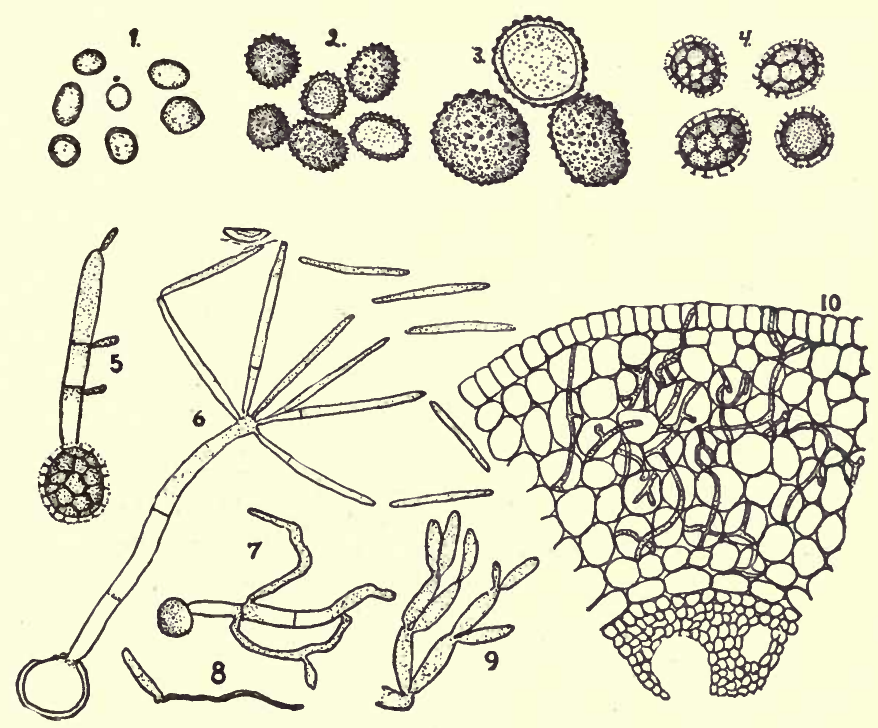

FIG. 40. Spores of various Smuts. I, Ustilago longissima growing on the reed meadowgrass (Panicularia americana); 2, Ustilago Maydis from Indian corn (Zea Mays); 3, Ustilago Oxalidis on the yellow wood-sorrel (Oxalis stricta); 4, Ustilago utriculosa on the Pennsylvania persicaria (Polygonum pennsylvanicum).

FIG. 40a. Germination of spores. 5, Ustilago utriculosa, in water, showing promycelium and sporidia; 6, Doassansia opaca from the broad-leaved arrow-head (Sagittaria latifolia) in water, showing promycelium, sporidia, and secondary sporidia which are falling off; 7 , Ustilago Avence from oat (Avena sativa) in horse dung, showing promycelium, and lateral "infection threads" or hyphæ; 8, germination of a sporidium of Ustilago Sorghi into an infection thread; 9, small portion of a group of sporidia developed from promycelium of Tolyposporium eriocauli in potato agar; 10, cross-section of epicotyl of broom-corn infected by Ustilago Sorghi showing mycelium ramifying through parenchyma cells of the cortex.-After Clinton.

cine. It forms rather large gall-like masses on all parts of the plant, including the root, stem and leaves, and both staminate and pistillate flowers. The spores (Fig. 40) are at first a dark olivegreen, but on maturity are dark brown. They are sub-spherical, have prominent spines, and vary from 8 to 15 microns in diameter. They do not germinate at once, but on keeping them for six 
months to a year they germinate readily on a culture medium of potato, and retain their power of germination for years

Rust Fungi.-The Rust Fungi are parasitic on higher plants

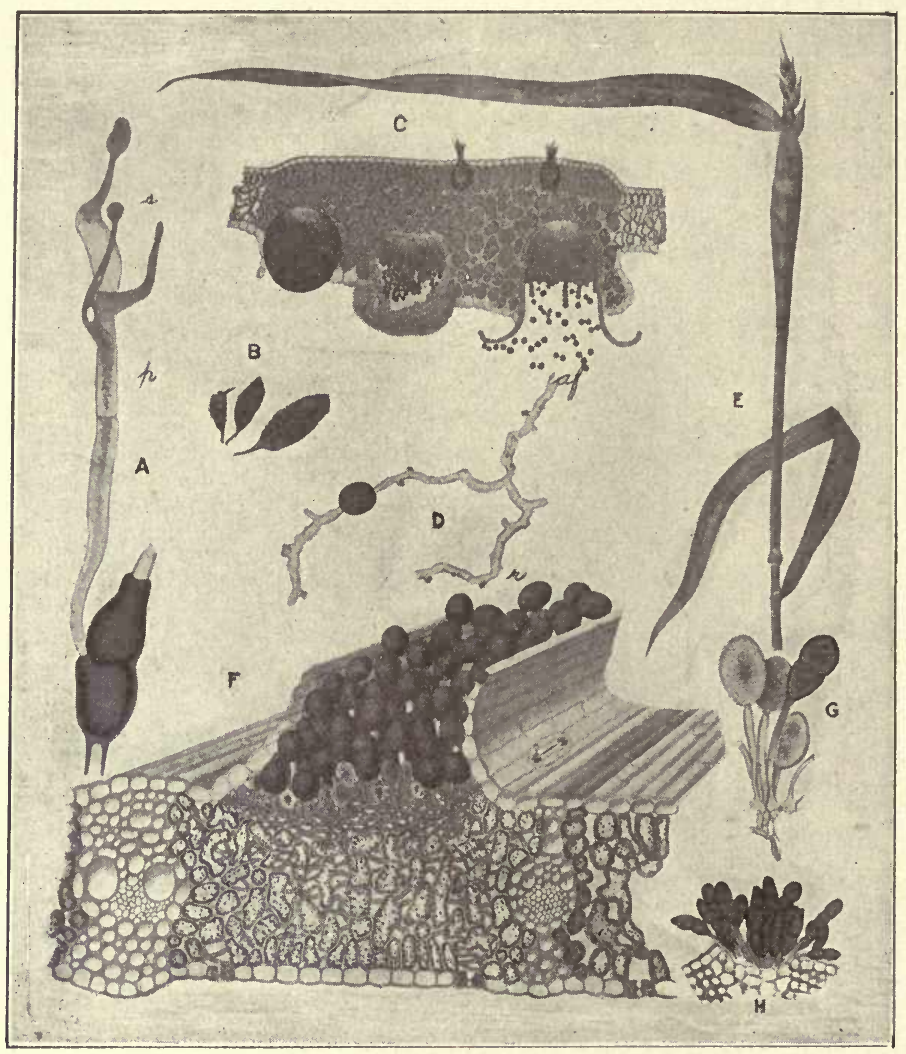

FIG. 4I. Wheat rust (Puccinia graminis). A, teleutospore or winter spore germinating and giving rise to a promycelium (p) and sporidia (s); B, a few leaves of barberry attacked by sporidia which give rise to the æcidia; $\mathrm{C}$, transverse section through barberry leaf showing three cup-like receptacles (æcidia) on the lower surface of the leaf containing perpendicular rows of conidia (æcidiospores); D, germinating æcidiospore on wheat; E, wheat plant attacked by æcidiospores as shown by the elongated blotches on the leaves; $\mathrm{F}$, cross section of leaf of wheat showing on the upper surface the rust spores which are breaking through the epidermal layer (r); G, summer spores (uredospores); $H$, teleutospores or winter spores formed on wheat leaf.-After Dodel-Port.

and produce a thread-like branching, cellular mycelium, which develops in the tissues of the host. They differ especially from the other Fungi in producing resting spores known as TELEUTOSPORES. 
These spores consist of one or more cells surrounded by a thick black wall, and they produce the "black rust" seen on foliage at the end of the season.

Wheat Rust.-The most important member of the Rust Fungi is Puccinia, of which there are a large number of species that are destructive to economic plants, as wheat, plum, cherry, red currant, etc. The one whose life history has been best studied is the wheat rust (Puccinia graminis), which requires two different plants to complete its life history, namely, wheat and barberry. The Teleutospores, or "winter spores" (Fig. 4I, $H$ ), as they are called, because of their carrying the life of the plant over the winter season, consist of two cells. These spores exist on the leaves and stems of wheat over winter, and in the spring they germinate (Fig. 4I, $A$ ). From each cell a mycelium (promycelium or basidium) consisting of two to four cells arises (Fig. $4 \mathrm{I}, A, p$ ), and from the tip of each branch of the promycelium a spore known as a sporidium develops (Fig. 4I, $A, s$ ). The Sporidia are scattered by the wind, and when they fall on the barberry leaves (Fig. 4I, B) they germinate, producing a dense mass or mycelium which penetrates into the tissues of the host.

Sooner or later, just within the under surface of the leaf, there is formed a more or less spherical, dense mass, which grows outward, breaking through the surface, forming a cup-like receptacle known as an æcidium (Fig. 4I, C). The Ecidia, or cluster cups, are orange or yellow and are filled with perpendicular rows or chains of spores which arise from the basidium-like mycelium below. The spores, which have received the name Ecidiospores, are somewhat spherical or polyhedral, and contain a reddish-yellow oil. They are scattered by the wind and, falling upon the wheat plant (Fig. 4I, E), germinate immediately, forming a dense mycelium. At first it produces what is known as a “Summer spore," or Uredospore (Fig. 4I, G), giving rise to the reddish-brown spots and stripes on the leaves and stalks of the wheat plant. The Uredospores are I-celled, and are carried by the wind to other wheat plants, thus rapidly spreading the disease.

The Uredospores arise in much the same way as the Teleutospores (Fig. 4I, $H$ ), which form brown patches later in the season, and which have been already considered. The Teleutospores 
last over winter on the old wheat plant, and in the spring begin again the life-cycle of the rust. The plant which results from the germination of a teleutospore gives rise to sporidia, which are carried to the barberry leaves where æcidiospores are produced. The latter are then carried to growing wheat, forming first uredospores and later teleutospores. It should be remembered that these are all asexual spores. In regions where there are no barberry plants to act as host the rcidiospore stage is omitted.

The Fungi Imperfecti.-The miscellaneous fungi included in this group are of importance because of the great damage which they cause to agricultural crops. The potato scab is an especially destructive pest in New England and in Canada. The scab not only develops on the growing tubers in the soil, but can be spread from a few affected potatoes to a whole bin of clean ones if they come in contact with them. Prevention of this disease usually consists in disinfecting the tubers which are used for seed so as not to carry the minute organisms into the soil.

A disease affecting the leaves of the potato and thereby destroying the crop is due to a fungus whose spores, settling on the leaves, germinate and penetrate to the interior through the stomata, finally weakening or killing the plant.

Some of the other important forms produce a pink mold on apples, scabs on peaches and other fruits, mold on onions and other garden crops. The blight of ginseng and the blight of cotton, the dry rot of various vegetables and the blotches on many of our common fruits can be traced to the development of these fungi. The study of these forms is a very difficult one, and researches are constantly being carried on at the government experiment stations, as well as by individual workers.

For a description of these forms, as well as many other harmful fungi, consult “ Fungous Diseases of Plants,” by Duggar.

Detection of Fungus in Host.-Unless special means are employed, it is ofttimes rather difficult to trace the mycelial of the fungus in among the cells of the host plant. Vaughan (Annals of the Missouri Botanical Garden, I9I4, p. 24I) has used the stain known as "Pianeze IIIb" in differentiation of the fungus from the plant substratum. The host tissue stains green and the mycelium a deep pink. This stain, devised by Dr. Pianeze for the 
study of cancer tissue, is made up as follows: Malachite green, 0.50 Gm.; acid fuchsin, o.Io Gm.; “Martius gelb,” о.oI Gm.; water distilled, 150.00 c.c.; alcohol (95 per cent.), 50.00 c.c. For use with plant tissues the procedure is as follows: Wash in water or alcohol, stain in the undiluted mixture 15 to 45 minutes, remove excess stain in water, and decolorize in 95 per cent. alcohol to which a few drops of hydrochloric acid have been added. For permanent mounts, clear with a carbol-turpentine mixture, remove clearing solution, and mount in balsam.

This stain is also valuable for staining spores which have been allowed to germinate on the surfaces of leaves. In such cases the killing and tissue-clearing mixture proposed by Duggar is recommended, viz., consisting of equal parts of glacial acetic acid and alcohol. In the study of the rusts, the best results are obtained by the use of Durand's combination of Delafield's hæmatoxylin and eosin (Phytopathology, I9I I, p. I29).

\section{LICHENS.}

General Characters.-The Lichens are a peculiar group of plants in that an individual lichen consists of both an alga called a GONIDIUM and a fungus. These are so intimately associated that they appear to be mutually beneficial, and such a relation is known as Symbiosis (Fig. 42). The Algæ which may be thus associated in the Lichens are those members of the Blue and Green Algæ which grow in damp places, as Pleurococcus, Nostoc, Lyngbya, etc. (Fig. 42). The Fungi which occur in this relation belong both to the Ascomycetes and Basidiomycetes, and it is on the characters of the fruit bodies of these particular Fungi that the main divisions of Lichens are based. The Fungi, however, are not known to exist independently of the Algæ with which they are associated; that is, the mycelia of the fungi will not live for any length of time unless they come in contact with suitable algæ. In its development the fungus forms a mycelium which encloses the alga, the growth of which latter is not hindered. The two organisms then continue to grow simultaneously, forming lichen patches. A section of a lichen shows a differentiation into several parts (Fig. 43) : a more or less compact row of cells on both surfaces forming two epidermal layers; and an inner portion 
made up of the hyphal tissue of the fungus in which the alga is embedded either in a single layer or throughout the mycelium. The mode of growth and branching is influenced largely by the fungus, although in some cases the alga may exert the most influence. In some cases the lichen consists of a thallus which is irregular in outline, growth taking place at no definite point, and in other cases branches which are more or less regular are formed, growth taking place at the apex.

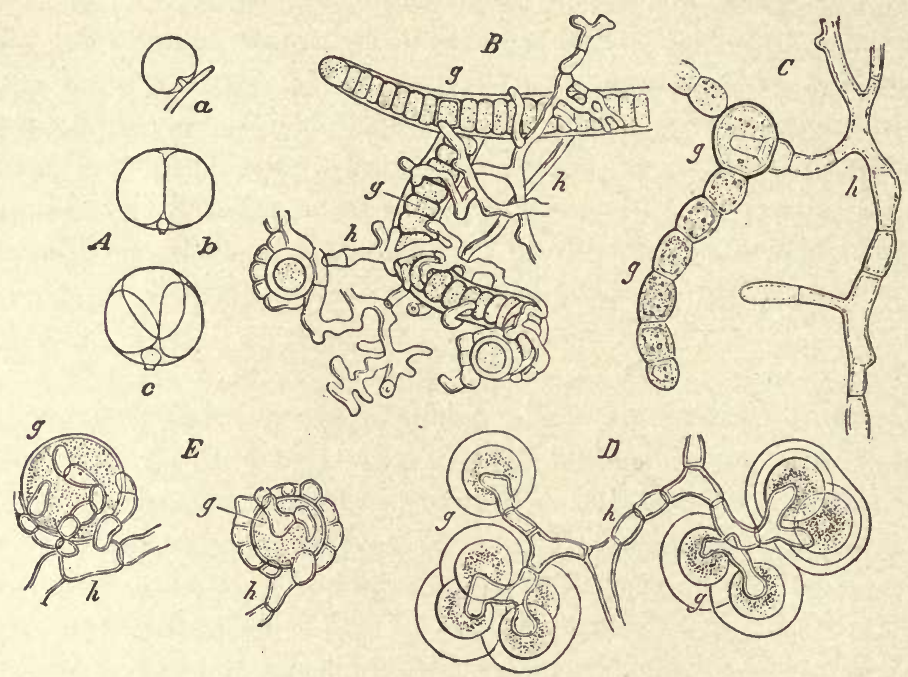

FIG. 42. Lichens showing manner of union of algæ or gonidia $(\mathrm{g})$ and hyphæ $(\mathrm{h})$ of Fung1. A, Protococcus, showing the manner in which hyphæ penetrate the cell and influence cell division; B, Scytonema, an alga surrounded by richly branching hyphæ; C, chain of Nostoc showing hypha of fungus penetrating a large cell known as a heterocyst; D, fungal hyphæ have penetrated the cells of Glcocapsa, a blue-green, unicellular alga; E, Chlorococcum, a reddish or yellowish alga found in Cladonia furcata, the cells of which are surrounded by the short hyphæ of the fungus. - A, after Hedlund; B-E, after Bornet.

The walls of the hyphæ of the fungus comprising Lichens consist at first of pure cellulose. In older material the walls undergo more or less modification, being changed in part to starch, mucilage, or fixed oil. There may be also infiltrated among the layers of the wall calcium oxalate, the latter constituent being especially characteristic of the crustaceous Lichens. The most interesting constituents of Lichens are the coloring principles, which are mostly of an acid character and are termed Lichen-acids. They 
give very striking reactions with solutions of the alkalies and solutions containing chlorine. The reaction with iodine solutions is also employed for diagnostic purposes; some of the Lichens give a blue reaction, while others behave like amylo-dextrin.

Groups of Lichens.-According to the manner of growth and the manner of attachment to the substratum, three principal groups of Lichens may be distinguished: namely, (I) Crustaceous Lichens, where the thallus adheres closely to the stones and barks of trees and practically can not be removed without injury; (2) Foliose Lichens, or those which are more or less flattened, somewhat leaf-like and attached at different points; (3) Fruticose Lichens, or those which are attached at a particular part of the thallus, and form diffusely branching clumps. To this latter group belong Cetraria islandica or Iceland moss (Fig. 43), which is used in medicine, Usnea barbata and the red-fruiting Cladonias which are so common.

Reproduction in the Lichens takes place in several ways. In all of them there is a vegetative mode by means of what are known as SOREDIA. These are small spherical bodies consisting of a group of algal cells, which are surrounded by a mass of hyphæ, and which when cut off from the main body are able to grow. Lichens also produce spores of a number of kinds. In the largest group, the one to which Cetraria islandica (Fig. 43) belongs, the spores are found in special spherical receptacles, known as PYCNIDIA, which are formed on the teeth of the margin of the thallus. The spores arise from the ends of hyphæ at the base of the pycnidia and are in the nature of conidiospores. To these spores the name PYCNOCONIDIA has been applied. Cetraria also produces, like many other Lichens, disk-like or cup-shaped bodies at various places on the surface of the thallus, which are known as APOTHECIA and which may be regarded as exposed or open ascocarps. The inner surface of the apothecia is lined with a number of asci as well as sterile cells, the former giving rise to ascospores.

Economic Uses of Lichens. - A number of the Lichens are used in medicine, as several species of Cetraria, Pertusaria communis, Physica parietina, Sticta pulmonacea, Evernia furfuracea. Some of those used in medicine are also used as foods on account 
of the gelatinous carbohydrate lichenin which they contain. Besides those given, the following may be mentioned: Cladonia rangiferina (reindeer moss), Lecanora esculenta (supposed to be the manna of the Israelites). The Lichens are, however, chiefly of interest because of the coloring principles which they contain.

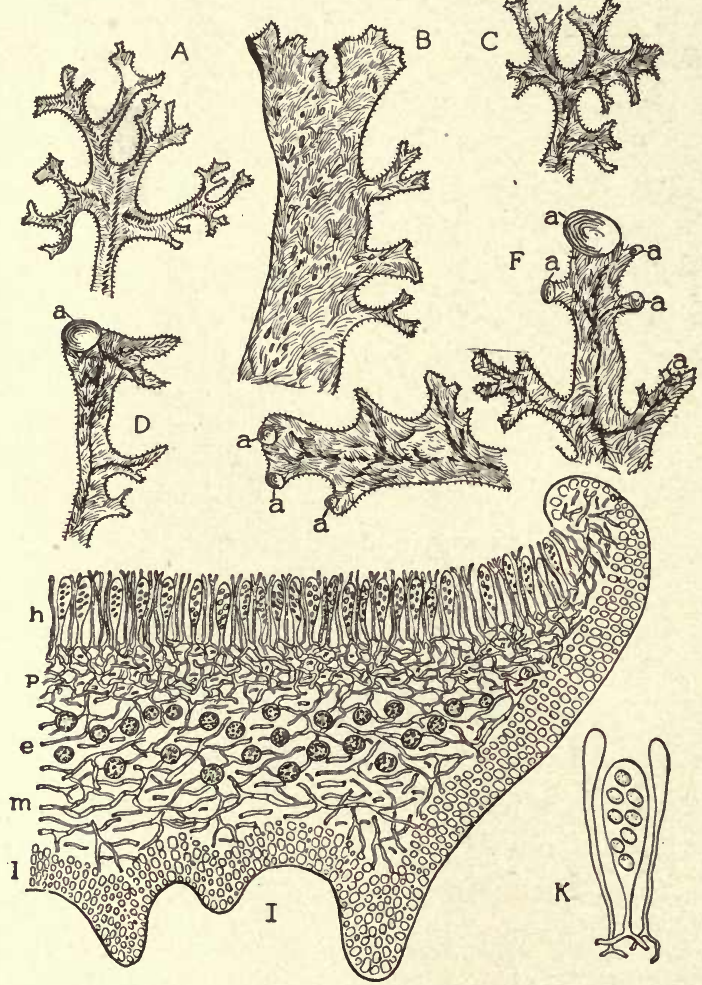

FIg. 43. Iceland Moss (Cetraria islandica). A-F, various forms of thalli showing apothecia (a); I, cross-section of an apothecium showing the hymenium (h), the hypothecium (p), the algal layer (e), the medullary layer (m), and lower or ventral surface (1); K, an ascus with eight ascospores and two paraphyses from the hymenium (h).

Roccella tinctoria, Lecanora tartarea, and other species of Lecanora, yield upon fermentation the dyes orcein and LITMUS, the latter of which finds such general use as an indicator in volumetric analysis. Cudbear, a purplish-red powder, is prepared by treating the same lichens with ammonia water; while in the prep- 
aration of orchil, a purplish-red pasty mass, sulphuric acid and salt are subsequently added. A number of species contain a yellow coloring principle, as Zeora sulphurea, Zeora sordida, Lecidea geographica and Opegrapha epigera.

\section{ARCHEGONIATES.}

The two main features which distinguish the Archegoniates from the Thallophytes are the structure of the sexual organs and the distinct manner in which the peculiar phases known as alternation of generations are shown. The antheridium or male sexual organ is a well differentiated multicellular body which is either sunk in the adjacent tissues of the plant or is provided with a stalk. Within it are organized the sperms or spermatozoids, which are ciliate and swim freely in water. Corresponding to the ooggonium of the Thallophytes is the ARCHEGonium or female sexual organ which gives name to the group. The archegonium is a flask-shaped cellular body consisting of a basal portion of venter, which contains a single egg, and a neck through which the sperms enter (Figs. 49 and 5I).

In the life history of this group of plants there are two generations or phases of development. During one stage the archegonium and antheridium are developed, and this is known as the sexual generation, and as these organs give rise to gametes or sexual cells it is also spoken of as the Gametophyte. By the union of the sex cells (sperm and egg) an oöspore is formed which germinates at once within the archegonium. That portion of the plant which develops from the oöspore gives rise to asexual spores, and hence this phase is called the asexual generation. It is also spoken of as the sporophyte from the fact that it gives rise to spores. These spores are in the nature of resting spores and do not germinate on the plant as does the oöspore. They are distributed and on germination give rise to the gametophyte stage.

In some of the Archegoniates these two phases are combined in one plant, as in the Bryophytes, whereas in other members of the group the two phases are represented by two distinct plants; that is, the gametophyte and sporophyte become independent of each other, as in the Ferns. 
The following table shows the main divisions and subdivisions of the Archegoniates:

$$
\text { Archegoniates } \begin{cases}\text { Bryophytes.... } & \left\{\begin{array}{l}
\text { Hepaticæ (Liverworts). } \\
\text { Musci (Mosses). }
\end{array}\right. \\
\text { Pteridophytes.. } & \left\{\begin{array}{l}
\text { Filicales (Ferns). } \\
\text { Equisetales (Horsetails). } \\
\text { Lycopodiales (Club Mosses). }
\end{array}\right.\end{cases}
$$

BRYOPHYTES

The structure of the sexual organs in the Liverworts (Fig. 44) and Mosses (Fig. 49) is essentially the same, but the vegetative organs are more or. less dissimilar. In the Liverworts the plant

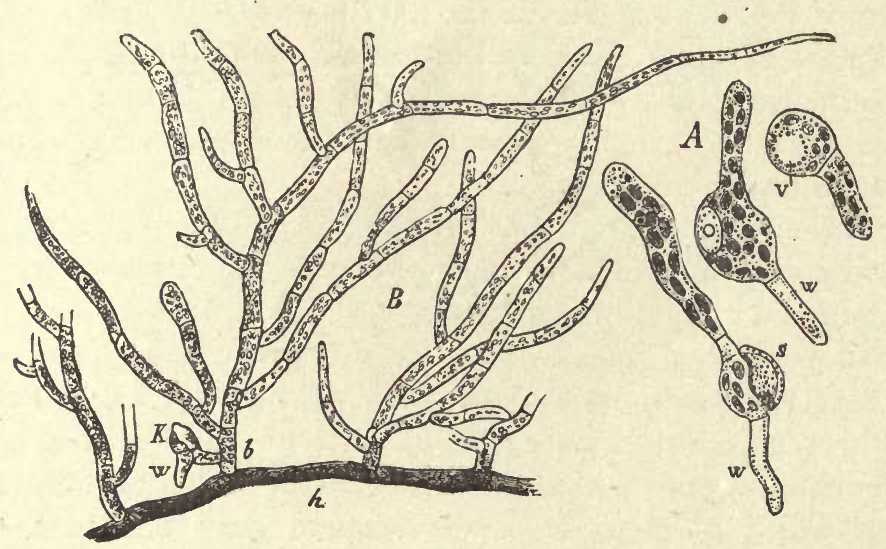

Fig. 44. A common moss (Funaria). A, germinating spores: v, vacuole; $w$, roothair; s, exospore. B, protonema about three weeks after germination: $h$, procumbent primary shoot; $\mathrm{b}$, ascending branch of limited growth; $\mathrm{K}$, bud or rudiment of a leaf-bearing axis with root-hair (w).-After Sachs.

body or thallus lies more or less close to the substratum or rises somewhat obliquely, whereas in the Mosses the part we designate as the plant is in all cases an upright leafy branch. The moss plant is said to have a radial structure from the fact that the leaves radiate from a central axis, while in the Liverworts the thallus is dorsiventral ; that is, as a result of its habits of growth, it is characterized by having a distinct upper and lower surface. 
The Life History of this group of plants may probably be best illustrated by following that of a moss plant. Beginning with the germination of an asexual spore which is microscopic in size and which germinates on damp earth, there is produced an

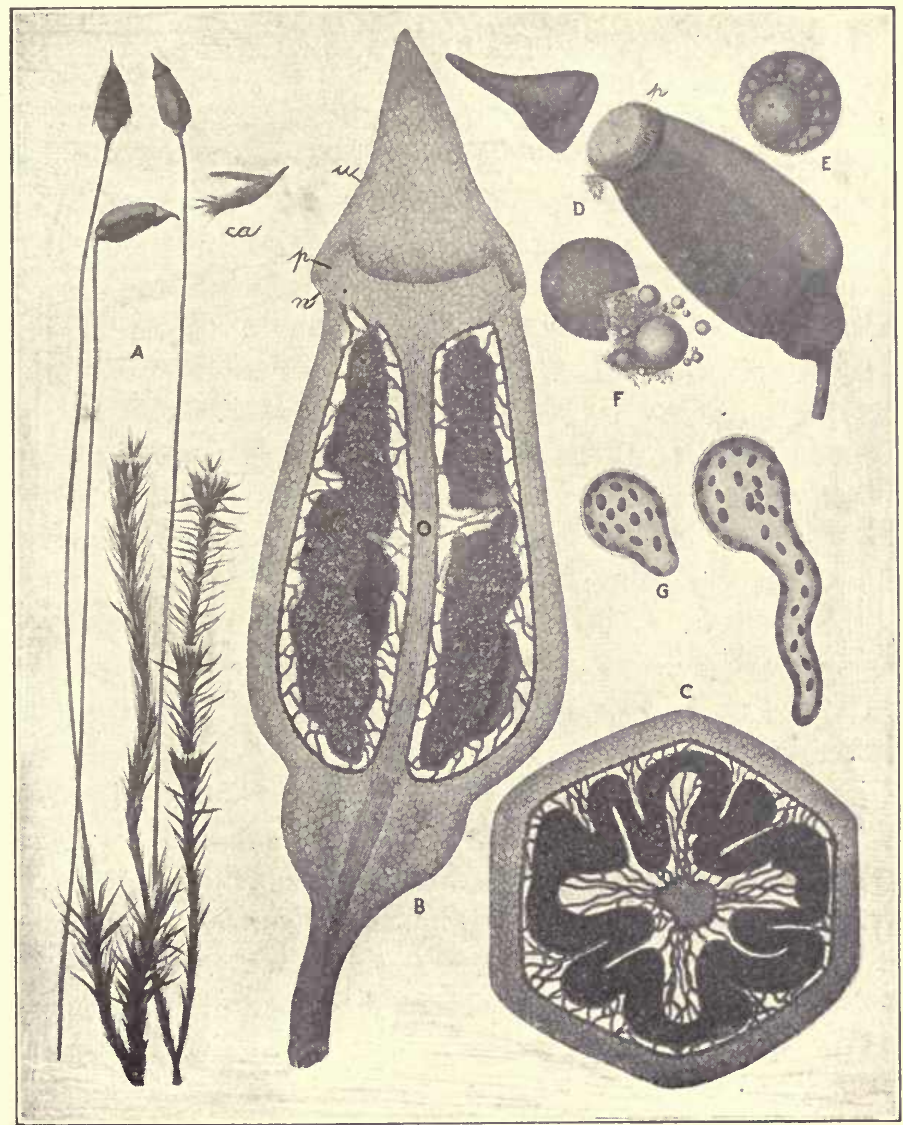

FIG. 45. A common moss (Polytrichum gracile). A, showing leafy branches (gametophores) two of which bear sporogonia, a detached sporogonium (sporophyte) with sporangium from which the calyptra (ca) has been detached. B, longitudinal section through a nearly ripe sporangium showing columella (o), the elongated area of sporogenous tissue (archesporium) on either side, annulus $(n)$, peristome $(p)$, lid or operculum (u); C, transverse section of sporangium showing columella in center and dark layer of sporogenous tissue (archesporium); D, ripe sporangium (capsule) showing the escape of spores after detachment of lid; E, ripe spore containing large oil globules; F, ruptured spore showing separated protoplasm and oil globules: G, two germinating spores $\mathrm{I} 4$ days after being sown, showing beginning of protonema in which are a number of ellipsoidal chloroplasts. - After Dodel-Port. 
alga-like body consisting of branching septate filaments, which is known as the protonema, or prothallus (Fig. 44). The Protonema lies close to the surface of the ground and is more or less inconspicuous except for the green color. From the lower portion thread-like processes, or rhizoids consisting of a row of cells, are developed, which penetrate the ground. Sooner or later lateral buds arise from some of the lower cells. Growth continues from an apical cell which divides and gives rise to cells that differentiate into stem and leaves, forming an upright branch, which constitutes the structure commonly regarded as the "moss plant" (Fig. $45, A)$. The leaf-bearing axis varies considerably in size; in some cases it is but a millimeter high, whereas in some species, as Polytrichum (Fig. 45), it may be several hundred millimeters in height. At the tip of the branch the antheridium (Fig. 49, $A$ ) and archegonium (Fig. 49, $B$ ) are formed. These organs are developed in among the leaves and certain hairy processes, known as paraphyses (Fig. 49, p). They may both occur at the end of one branch (Fig. 49, C) or they may occur on separate branches (Fig. 49, D), when the plants are said to be monøecious, whereas when these organs occur on separate plants (Fig. 49, $A, B$ ) the plants are called diœcious. In the case of diøciotis plants the plant bearing the antheridium is frequently smaller and less complex than the one producing the archegonium. As already stated, the archegonium produces the egg-cell or female gamete (egg) and the antheridium, the sperm cell or male gamete (sperm).

The sperms in the Bryophytes are more or less filiform and are provided with a pair of cilia at one end. The antheridia, 'owing to the peculiar mucilaginous character of the cells, only open when there is an abundance of moisture, when the sperms are discharged and move about in the water, some being carried to the archegonium, which likewise opens only in the presence of moisture. With the transferral of the sperms to the archegonium and the union of one of these with the egg which remains stationary, the work of the gametophyte may be said to be completed. The act of union of the egg and sperm is known as FERTILIZATION, and when this is effected the next phase of the life history begins.

The egg after fertilization divides and re-divides within the 
archegonium, which becomes somewhat extended until finally it is ruptured. The dividing cells differentiate into a stalk and a spore case or sporangium which is borne at the summit, the whole structure being known as the sporogonium (Fig. 45). The base of the stalk is embedded in the apex of the moss plant, and is known as the foot, it being in the nature of a haustorium or nourishing organ. As the sporogonium develops and rises upward it carries with it the ruptured archegonium which forms a kind of covering over the top, called the calyptra (Fig. 45, ca). At first the sporangium is more or less uniform, but eventually differentiates into two kinds of tissues, the one being sterile and the other fertile (producing spores), which latter is known as the ARCHESPORIUm (Fig. 45, $B, C$ ). The fertile tissue in both the Liverworts and Mosses is variously disposed; sometimes it forms a single area and is dome shaped, spherical, or in the form of a half sphere. In other cases it is separated into two areas by sterile tissue. The sterile tissue which extends up into the dome-shaped archesporium, or which in other cases separates the fertile tissue into two parts, is known as the columella (Fig. 45, B, C). The sporangium in the mosses is capsule-like and the spores are distributed in three ways: (I) In some cases the capsule does not open, but when it decays the spores are liberated. (2) In other cases the capsule dehisces longitudinally in dry weather, and thus the spores are freed. (3) There is a third method in which the capsule is provided with a lid or operculum which comes off and permits the spores to escape, this being the most common method for the escape of the spores (Fig. 45, D). In the latter instance the mouth of the capsule is usually marked by one or two series of cells, constituting the PERISTOME, which are teeth-like and characteristic for some of the groups of mosses. These teeth bend inward or outward, according to the degree of moisture, and assist in regulating the dispersal of the spores. In the sphagnum mosses there is no peristome, but, owing to unequal tension of the lid and capsule on drying; the lid is thrown off, and the spores are sometimes discharged with considerable force and sent to quite a distance (as much as Io centimeters), in this way insuring their dispersal. The spores (Fig. 45, E) vary in diameter from Io to 20 
microns, being sometimes larger. They occur in groups of four in a mother-cell, and the spore-group is known as a tetrad, which is characteristic for the Bryophytes and the higher groups of plants. The spores therefore vary in shape from spherical tetrahedrons to more or less spherical bodies, depending upon the degree of separation. The contents are rich in protoplasm and oil (Fig. 45, F). The wall consists of two layers, the outer of which is either yellowish or brown and is usually finely sculptured. At the time of germination the outer wall is thrown off, and the protonema develops (Fig. 45, G). The spores may germinate almost immediately, or only after a considerable period. These spores are asexual and each one is capable of giving rise to a new plant. With the formation and dispersal of the spores the work of this generation terminates, and this phase is called the sporophyte or asexual generation, from the fact that it produces spores.

Having thus followed the stages of development in the life history of a moss, we see that it is composed of the following parts: (I) The alga-like protonema; (2) the leafy branch which gives rise to an oöspore (sexual spore), and (3) the sporogonium which produces asexual spores. The leafy branch is sometimes spoken of as the gametophore (gamete-bearer), and it and the protonema together constitute the gametophyte or sexual generation, while the sporogonium represents the sporophyte or asexual generation.

The protonema sooner or later dies off in most plants, but in other cases it persists, forming a conspicuous portion of the gametophyte.

\section{HEPATIC蚱.}

General Structure.-The Hepaticæ or Liverworts (Fig. 46) are usually found in moist situations. The protonema formed on germination of a spore is filiform, and the plant body which develops from it consists of a flat, dichotomously-branching thallus, or it may in some of the higher forms differentiate into a leafy branch, as in the leafy liverworts. The thallus, owing to its position, has an upper and an under surface which are somewhat different, as in Marchantia (Fig. 46), hence it is said to be 
DORSIVENTRAL. From the lower colorless surface unicellular rhizoids arise (Fig. 47, $h$ ). The upper surface consists of several layers of cells containing chlorophyll which give the green color to the plant.

Vegetative propagation may ensue by the lower portion of a branch dying and the upper portion continuing as an independent plant. Or special shoots, known as GEMM

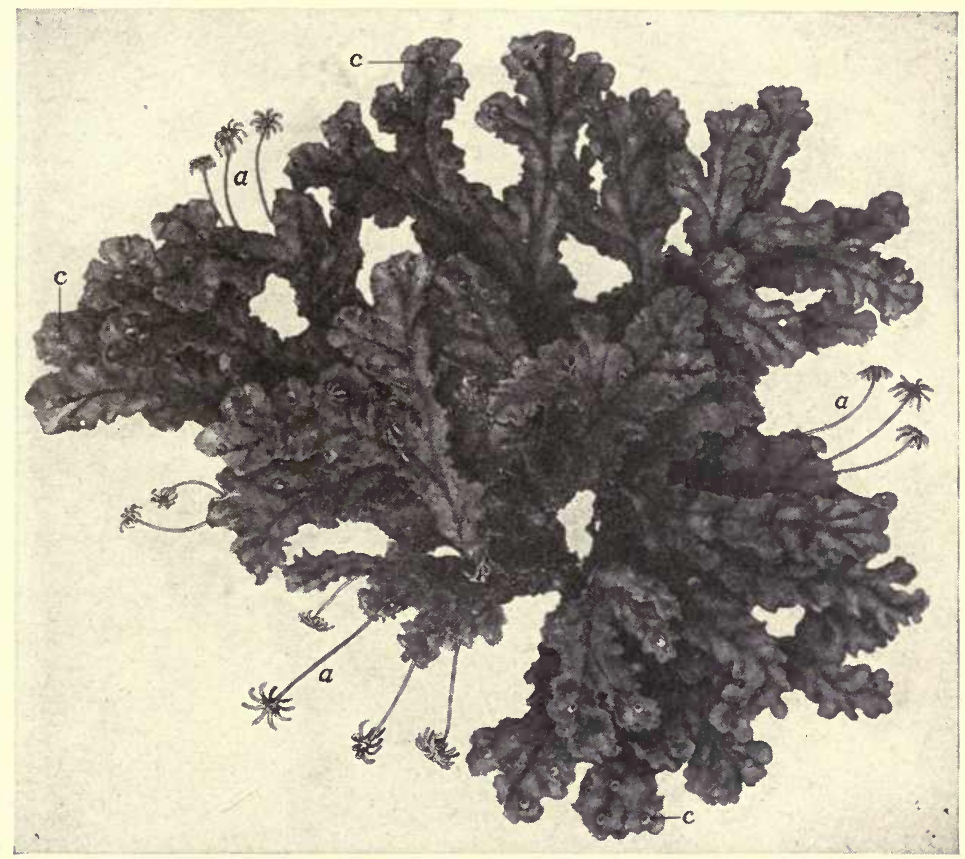

FIG. 46. Dichotomously branching thallus of the common liverwort (Marchantia polymorpha) showing near some of the margins the cup-like depressions in which gemmæ are borne (c), and several archegoniophores (a).

either on the margin of the thallus or in peculiar cupules, which, when detached by rain or other means, are capable of growing and producing a new plant.

In addition the thallus body produces both antheridia and archegonia (Fig. 46) which may arise on special stalks above the surface. After fertilization of the egg-cell, which completes the work of the sexual generation of gametophyte, the sporophyte develops, 
producing a sporogonium consisting of a short stalk which is embedded in the tissues of the gametophyte, and a capsule (sporangium). The latter at maturity dehisces or splits and sets free the spores, which are assisted in their ejection by spirally banded cells called " elaters" (Fig. 48, C-F). The spores on germination give rise to a protonema which then develops a thallus bearing the sexual organs. As in the mosses, the sporogonium represents the asexual generation known as the sporophyte.

Liverwort Groups.-There are three important groups of
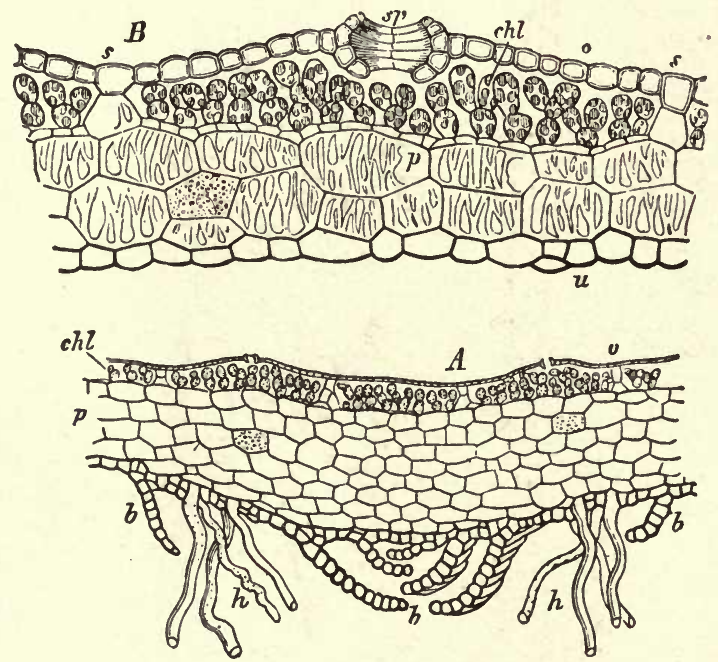

Frg. 47. Transverse section through the thallus of Marchantia polymorpha. A, middle portion with scales (b) and rhizoids (h) on the under side; $B$, margin of the thallus more highly magnified, showing colorless reticulately thickened parenchyma (p), epidermis of the upper side (o), cells containing chlorophyll (chl), air pore (sp), lower epidermis (u). -After Goebel.

Liverworts: (I) The Marchantia Group (Fig. 46), in which the thallus is differentiated into several layers and so somewhat thickened. Another character is the diversity in form of the sexual organs, which range from those which are quite simple to those which are highly differentiated. In Riccia the sexual organs are embedded on the dorsal (upper) side of the thallus, while in Marchantia they are borne upon special shoots, one, which has a disk at the apex that bears the antheridia, known as the antheridiophore, and another whose summit consists of a number of radiate 
divisions and bears the archegonia (Fig. 46) on the lower surface, known as the archegoniophore; these being borne on separate plants. In Riccia, the simplest of the Liverworts, the sporangium is enclosed by the thallus and the spores are not liberated until the decay of the plant.

(2) The Jungermania Group, known as "Leafy Liverworts" or "scale mosses," includes those forms which are more

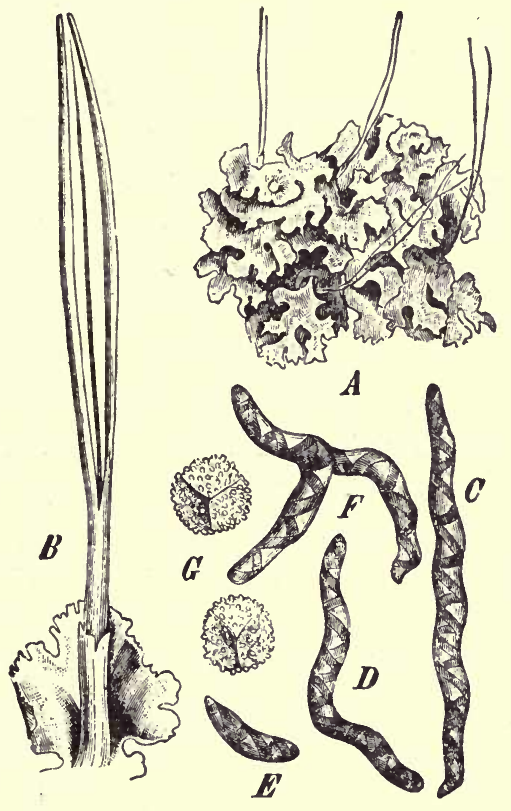

FIG. 48. Anthoceros gracilis, one of the liverworts. A, thallus with 4 sporogonia; $\mathrm{B}$, a ripe elongated sporogonium, dehiscing longitudinally and showing two valves between which is the slender columella; C, D, E, F, various forms of elaters; G, spores.-After Schiffner.

or less moss-like and develop stems and small leaves. The sporogonium has a long stalk and the capsule is 4 -valved, i.e., separates into four longitudinal sections at maturity.

(3) In the Anthoceros Group (Fig. 48) the gametophyte is thallus-like and very simple in structure, the sexual organs being embedded in the thallus. The sporogonium is characterized by a bulbous foot and an elongated, 2 -valved capsule. Like the thallus, 
it develops chlorophyll and possesses stomata resembling those found in certain groups of mosses and higher plants.

\section{MUSCI.}

In the Mosses the archegonia always form the end of the axis of a shoot, whether this be a main one or a lateral one. As has already been stated (p. 78), the sexual organs are surrounded by leaves or leaf-like structures, known as perichætia or perichætal leaves, and by hair-like structures or paraphyses, both of which are considered to act as protective organs. Sometimes the groups of sexual organs together with the protective organs are spoken of as the "moss flower." As already stated, the Mosses are both monœcious (Fig. 49, $C, D$ ) and diøcious (Fig. 49, $A$, $B$ ), hence a moss flower may contain only one of the sexual organs or it may contain both. Mosses are also characterized by an abundant vegetative propagation. New branches are developed from the old. "Almost every living cell of a moss can grow out into protonema, and many produce gemmæ of the most different kinds." Entire shoots provided with reserve material are cut off and form new plants. In this way moss carpets are frequently formed in the woods, or masses in bogs.

Moss Groups.-There are two general classes of mosses: (I) Sphagnum forms are those which produce leaves without nerves, and in which the sporogonium does not possess a long stalk or seta. What appears to be the stalk is the prolongation of the gametophyte stem which is known as the pseudodium or "f false stalk." These forms are characteristic of wet places. Some of the group, as Sphagnum proper, form "sphagnum bogs." New plants develop on top of the old, which latter gradually die and finally pass into sphagnum peat, which forms thick masses and finds use as a fuel. (2) The True Mosses are especially distinguished by the differentiated character of the sporogonium, which not only produces a stalk but also the peristome (Fig. $45, p$ ), which when present is of great importance in distinguishing the different species.

Economic Uses of Bryophytes.-The investigations on the chemistry of the Liverworts and Mosses have not been very numerous. The constituents which have been found are in the 
nature of tannin, resins, ethereal oils, glucosides, alkaloids, coloring compounds, and organic acids like citric, oxalic, tartaric, and aconitic. In the mosses starch and silicon salts are found in addition. Several species of Marchantia and Jungermannia are
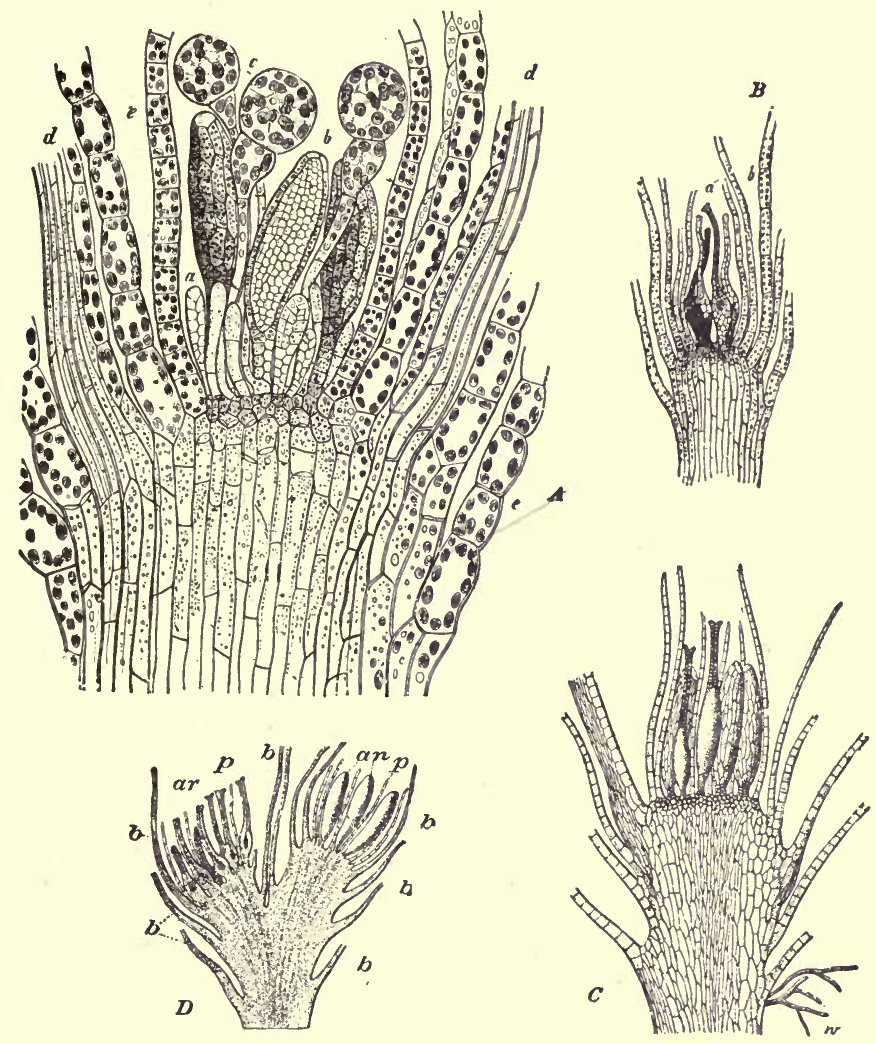

FIG. 49. Longitudinal sections through tips of leafy branches of mosses. A, showing antheridia $(\mathrm{a}, \mathrm{b})$ in different stages of development and paraphyses or cell-threads (c), the apical cell of which is spherical and contains chlorophyll, and leaves (d, e); B, showing archegonia (a) and leaves (b); $\mathrm{C}$, section of Bryum showing both archegonia, and antheridia, paraphyses, and leaves; D, section of Phascum showing archegonia (ar), antheridia (an), thread-like paraphyses (p), and leaves (b).-A, and B, after Sachs; C, after Limpricht; D, after Hofmeister.

used in medicine. Of the mosses the following have been found to have medicinal properties: Sphagnum cuspidatum, Grimmia pulvinata, Funaria hygrometrica, Fontinalis antipyretica, and several species of Polytrichum and Hypnum. 


\section{PTERIDOPHYTES.}

The Pteridophytes were formerly known as the Vascular Cryptogams. Like the Bryophytes, these plants show a distinct alternation of generations; i.e., the gametophyte or sexual generation alternates with the sporophyte or asexual generation. Their relation is, however, somewhat changed. In the Bryophytes the gametophyte is the most conspicuous and is looked upon as constituting the plant proper, whereas in the Pteridophytes the gametophyte is rather insignificant in size, while the sporophyte constitutes the generation or phase which is ordinarily regarded as the plant. In the higher members of the Pteridophytes the sporophyte is entirely detached from the gametophyte and is able to lead an independent existence. This group also shows a distinct advance in structure. There is a differentiation into root, stem, and leaves, and the development of a system of conducting tissue known as the vaSCULAR SYSTEM.

The Pteridophytes include three principal groups, namely, (I) Filicales or Ferns, (2) Equisetales or Scouring Rushes, and (3) Lycopodiales or Club Mosses, which differ considerably in general appearance and general morphological characters.

With the exception of the sperms in the Club Mosses, which are biciliate and somewhat resemble those in the Bryophytes, the sperms in the Pteridophytes are spirally coiled and multiciliate, and according to the number of cilia of the sperms some writers divide the Pteridophytes into two classes, namely, biciliate and pluriciliate (Figs. 51, C; 62, F).

Some of the Pteridophytes, as Selaginella (Fig. 60), are distinguished by the fact that they produce two kinds of asexual spores, which are known respectively as MICROSPOREs (Fig. 60, $F$ ) and MEgaspores (Fig. 6o, E). The two kinds of spores are formed in separate sporangia, which organs may occur on the same plant or on different plants. The sporangia have the corresponding names, microsporangia (Fig. 6o, $B, i$ ) and megasporangia (Fig. 6o, $B, g$ ). This differentiation in sporangia and spores also leads to a differentiation in the resulting gametophytes, the microspores giving rise to gametophytes which produce antheridia, and hence called male gametophytes; and the megaspores to 
gametophytes which give rise to archegonia, and hence called female gametophytes. When a plant produces both microspores and megaspores it is said to be neterosporous, as in Selaginella (Figs. 60, 62, and.63) ; while one that produces but one kind of sporangium and one kind of asexual spores is said to be Isosporous. In this connection attention should be called to the fact that the spores from a single sporangium of an isosporous plant may give rise to male and female gametophytes, which shows that a certain degree of differentiation in the spores has already taken place. The causes leading to the differentiation of the spores seem to be

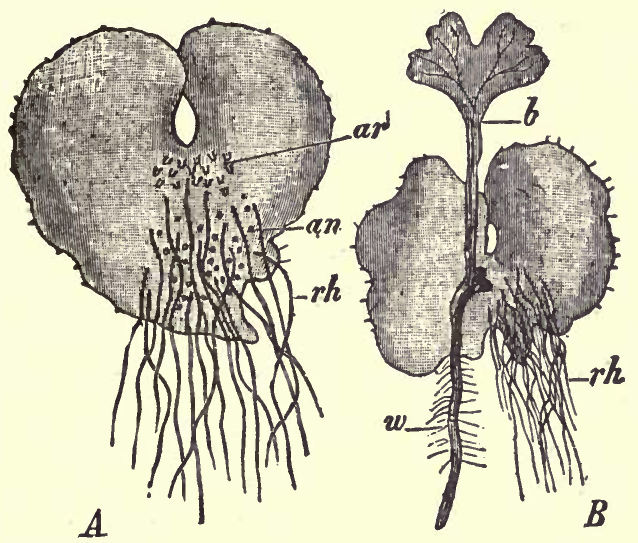

FIG. 50. Male fern [Dryopteris (Aspidium or Nephrodium) Filix-mas]. A, prothallus of gametophyte as seen from the under (ventral) side showing archegonia (ar), antheridia (an), and rhizoids ( $\mathrm{rh})$; B, prothallus showing young plant (sporophyte) which has developed from an oöspore and is still connected with the gametophyte, roots (w), and the first leaf (b).--After Schenck.

connected with nutrition, those nuclei which are in more favorable positions giving rise to larger and better nourished spores which eventually lead to the formation of the megaspores, and those which are less favorably placed leading to the microspores.

The subject of heterospory is one of great interest, and when it is pointed out that all of the higher plants are heterosporous the subject has even more interest.

FILICALES.

General Characters.-On germination the asexual spore in the Filicales or Ferns gives rise to a thallus-like body known as 
the prothallus which is frequently dorsiventral and in a number of cases somewhat heart-shaped, but varies considerably in outline, being sometimes more or less tuberous. The prothallus is frequently but a few millimeters in diameter, and the cells usually contain chloroplasts. On the under or ventral surface rhizoids are usually present (Fig. 50, $r h$ ). The sexual organs usually arise on the lower surface (Fig. 50), but they may develop on the upper or dorsal surface or even laterally. A single prothallus gives rise to both kinds of organs, unless stunted in its growth, when it produces antheridia only.
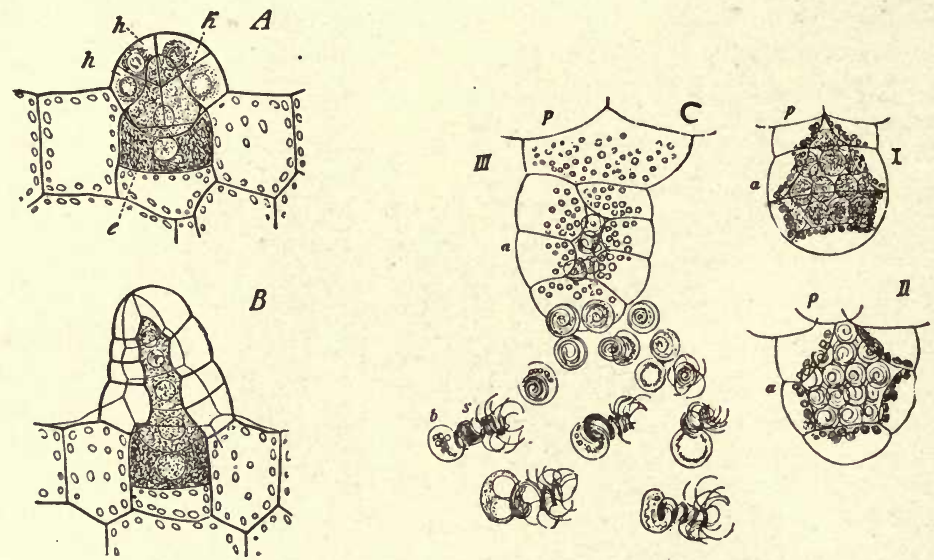

FIG. 51. A, B, development of archegonia of a fern (Pteris) showing the neck (h), the neck-canal cells (k), and oösphere (e).-After Strasburger.

$\mathrm{C}$, development of antheridium in the Venus-hair fern (Adiantum Capillus-Veneris): prothallus (p), antheridium (a), sperm (s), sperm mother cell with starch grains (b); I, immature state of antheridium, II, sperms developed, and III, discharge of sperm mother cells and escape of coiled and pluriciliate sperms.-After Sachs.

The antheridia either develop upon or are sunk in the tissues of the prothallus. The archegonia (Fig. $5 \mathrm{I}$ ) are not flask-shaped as in the Bryophytes. The venter containing the oösphere or eggcell (Fig. $5 \mathrm{I}, e$ ) is embedded in the thallus, the structure being surmounted by a few-celled neck (Fig. $5^{\mathrm{I}}, h$ ). The inner cells of the neck are known as canal cells (Fig. $5 \mathrm{I}, k$ ), and these at the time of ripening of the egg swell and exit through the opening of the archegonium, through which then the sperms enter, one of which unites with the egg, thus effecting fertilization. The fertilized egg or oöspore takes on a cellulose membrane. 
The oöspore which is held in the venter of the archegonium is not a resting spore, but germinates immediately and early differentiates into the several organs (Fig. $5^{2}$ ). These arise independently and include a stem-bud (Fig. 52, $s^{\circ}$ ); a first leaf or cotyledon (Fig. 52,b), so called because it does not arise out of the stem as the later leaves do; a first or primary root (Fig. 52, w) ; and a foot or haustorial organ (Fig. $52, f$ ) whereby it obtains nutriment from the prothallus (Fig. 52, pr). This latter organ is, however, only a temporary provision, for as soon as the root grows out and penetrates the soil, it dies off and the sporophyte thus becomes independent. The stems are frequently more or less con-

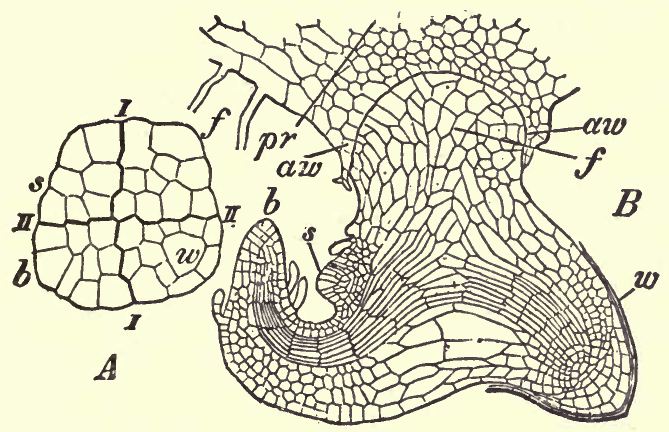

FIG. 52. The brake fern (Pteris). A, differentiation of cells in germinating oöspores; $B$, later stage showing development of embryo: $p r$, prothallus; $f$, foot embedded in the archegonium (aw); w, root; s, young stem; b, young leaf.-A, after Kienitz Gerloff; B, after Hofmeister.

densed and lie prostrate in the soil, developing roots from the under surface and leaves from the sides and upper surfaces. The leaves which constitute the conspicuous part of the ordinary ferns consist of a stalk and lamina or blade on which are borne the sporangia (Figs. 53 to 55). The sporangia usually occur on the under surface of the leaf in groups or clusters known as SORI (Fig. 53, A). The sori are of characteristic shape and in certain species are covered by a plate called the indusium (Fig. 53, $B$ ) which rises from the epidermis. In some species the entire leaf becomes a spore-bearing organ, and is then known as a sporoPHYLL (Figs. 54, 55), to distinguish it from the foliage leaves. The sporangia develop a row of cells around the margin consti- 
tuting what is known as the ANNuLus (Fig. $53, n$ ). The form of the annulus determines the manner of dehiscence of the sporangia, which occurs on drying. The spores are ejected with consider-

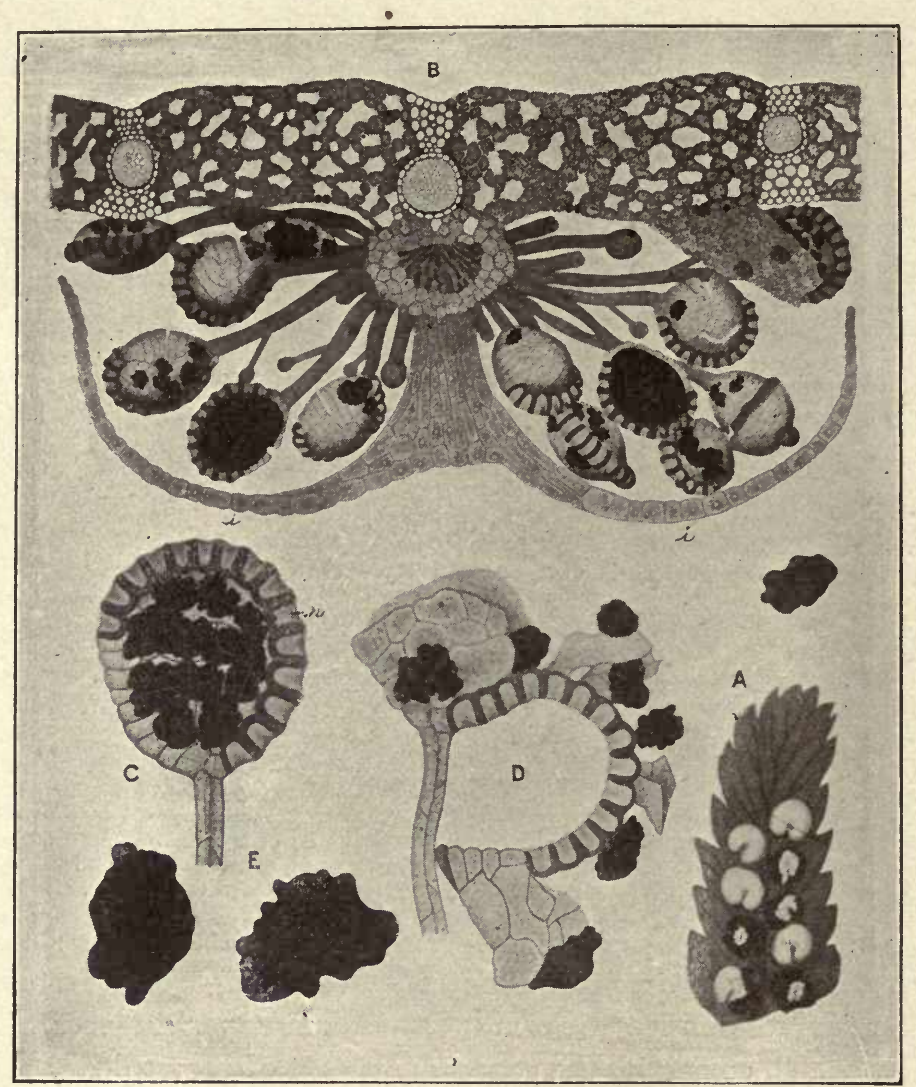

FIG. 53. Male fern [Dryopteris (Aspidium or Nephrodium) Filix-mas]. A, portion of leaflet showing a number of more or less reniform sori near the mid-vein; $B$, transverse section through a ripe sori showing clusters of stalked sporangia, which are covered by the indusium (i), an outgrowth of the leaflet; C, a closed but ripe sporangium showing the annulus or ring $(n)$, and the irregular-shaped spores within; D, showing the manner of bpening of the mature sporangium and the dispersal of the spores; $\mathrm{E}$, two spores much magnified.-After Dodel-Port.

able force (Fig. 53, D). They (Fig. 53, E; Fig. 57) are either bilateral or tetrahedral and require a short period to elapse before they germinate. They retain their vitality for a long time, except those which are green, i.e., contain chlorophyll. The spores are 
greenish or yellowish in color, variously sculptured, and vary from $0.025 \mathrm{~mm}$. to $0.158 \mathrm{~mm}$. in diameter.

Fern Groups.-There are a number of distinct groups of

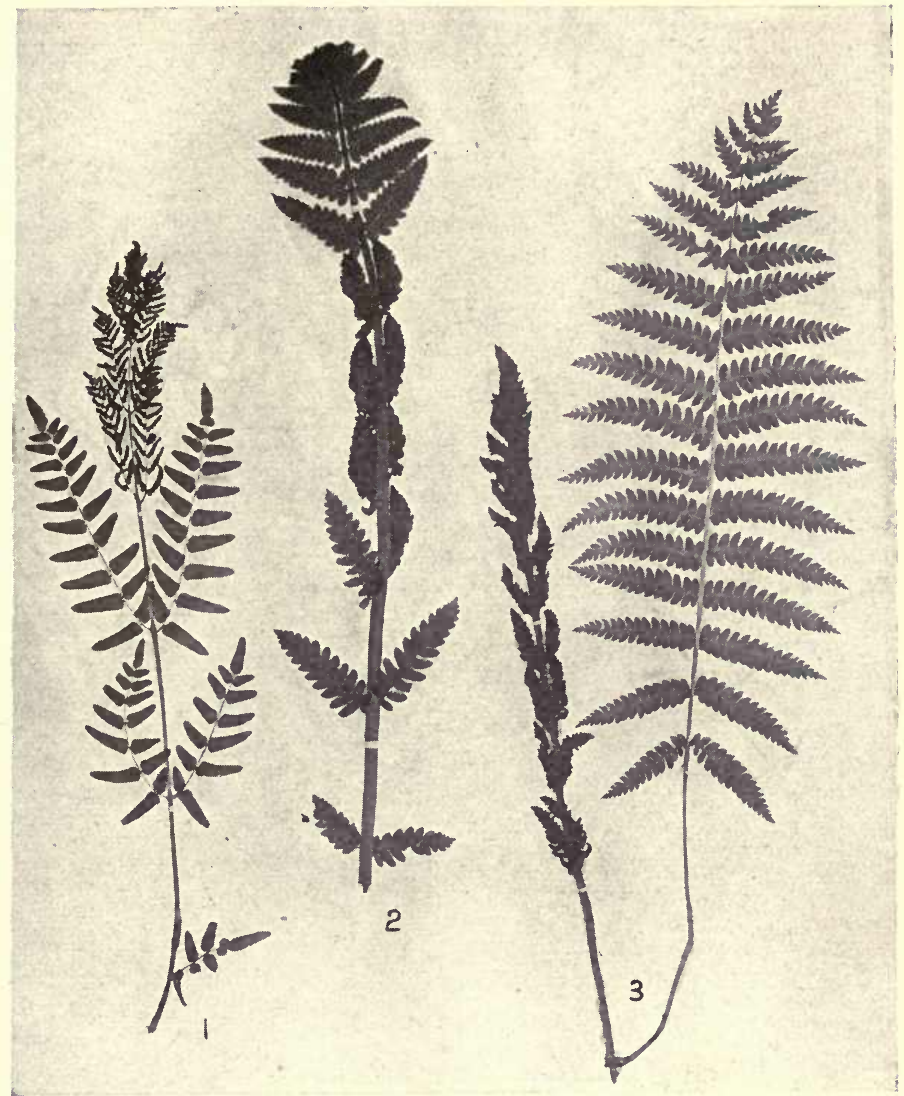

Fig. 54. Several Osmundas. I, the royal fern (O. regalis) showing fertile tip of branch and sterile bipinnate leaflets below; 2, Clayton's fern (O. Claytoniana) showing three pairs of fertile leaflets in the middle and a number of sterile leaflets above and below; 3, cinnamon fern (O. cinnamomea) showing a fertile leaf (sporophyll) to the left and a sterile leaf (foliage leaf) to the right.

ferns which vary considerably in appearance. ( I) In the Tropics as well as in greenhouses TREE FERNS, characterized by an overground stem, occur. The leaves arise at the summit of the stem or trunk and form a crown. 
(2) The TRUE FERns include by far the largest number of species which inhabit temperate regions. These vary considerably in size, ranging from quite diminutive plants 5 to $12 \mathrm{~cm}$. high, as the slender Cliff Brake (Pellea atropurpurea and the variety

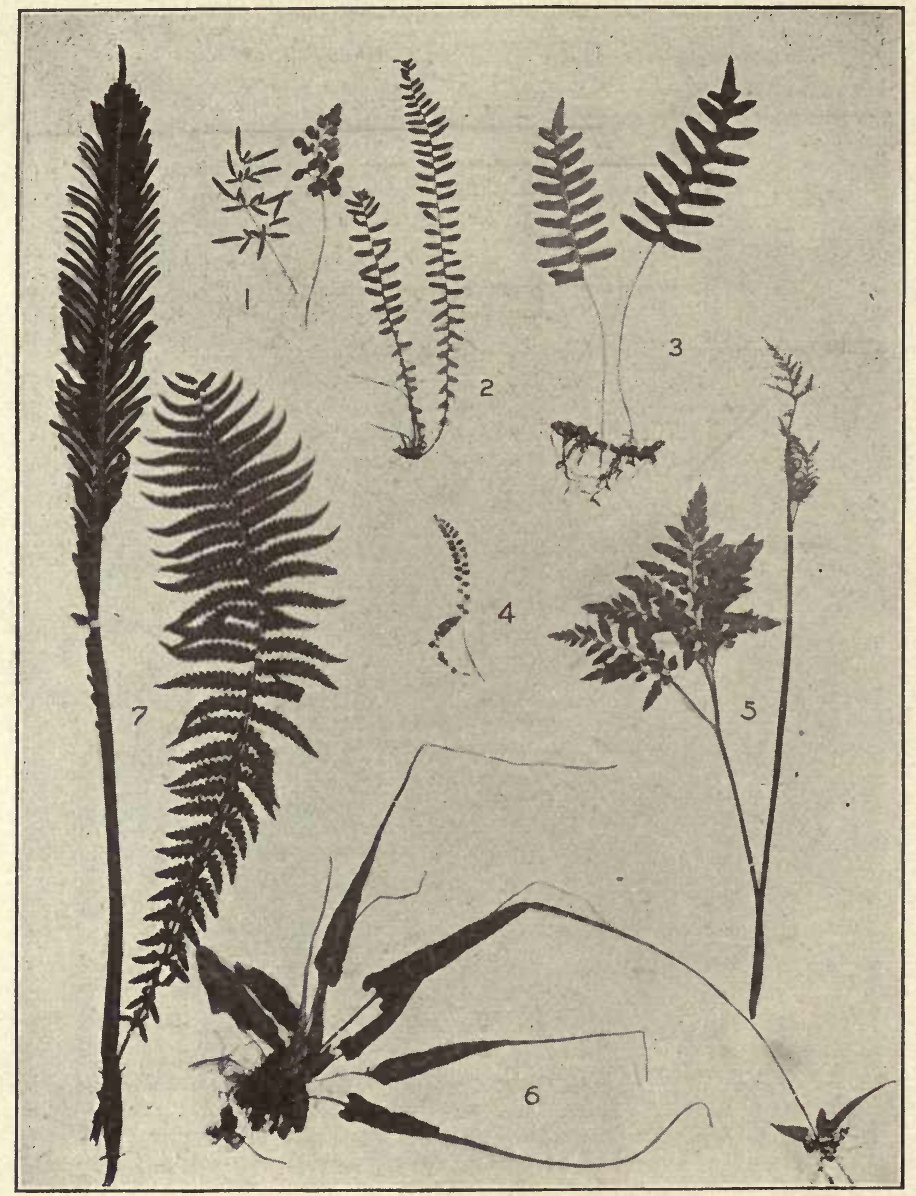

Fig. 55. Different types of Ferns and fern allies. I, fertile and sterile leaves of slender cliff brake (Pelloa Stelleri); 2, ebony spleen-wort (Asplenium platyneuron); 3, rhizome with two leaves of the common polypody (Polypodium vulgare); 4, maiden-hair spleenwort (Asplenium trichomanes); 5, ternate grape-fern (Botrychium ternatum), showing the tripinnate sterile leaf on the left and the upright sporophyll on the right; 6 , walking fern (Camptosorus rhizophyllus) showing a new plant developing from the tip of one of the leaves; 7. fertile and young sterile leaves of ostrich fern (Onoclea Struthiopteris). 
cristata) and maiden hair spleenwort (Asplenium Trichomanes), to plants several feet high, as in the several species of Osmunda (Fig. 54), ostrich fern (Fig. 55), etc. This group is chiefly
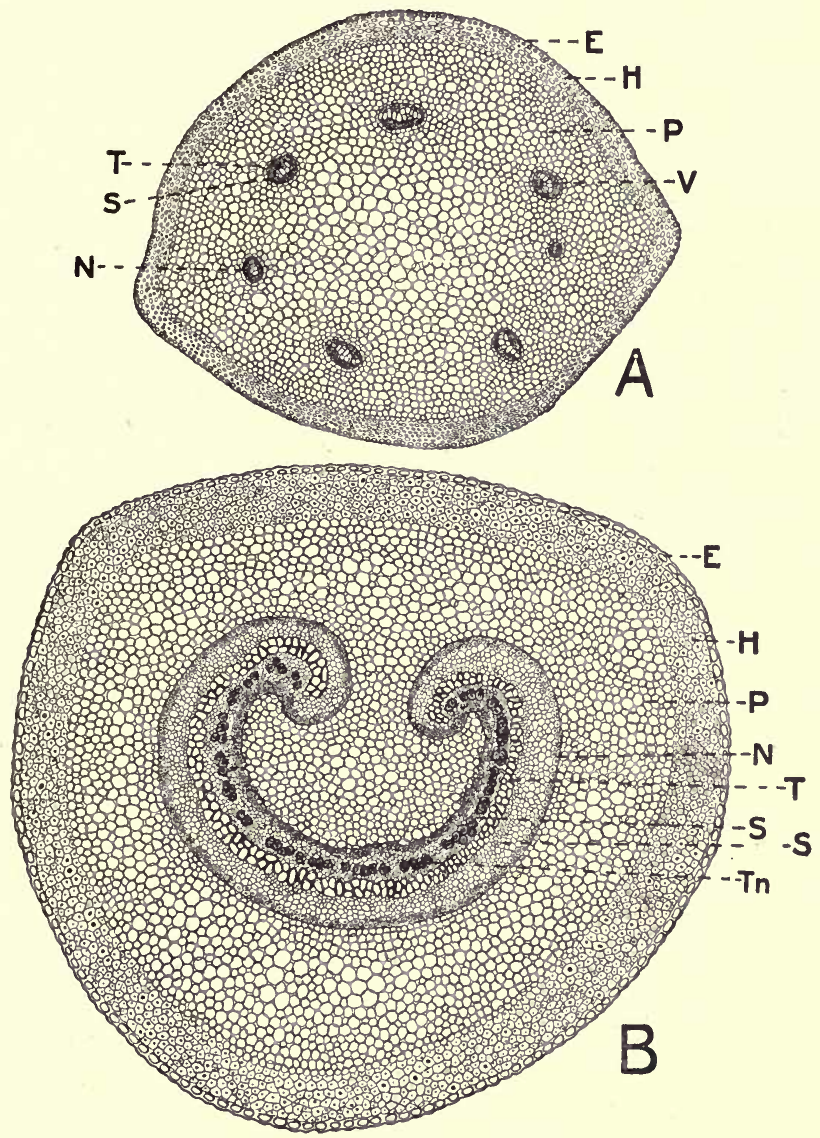

FIG. 56. A, transverse section of stipe of Dryopteris marginalis: E, epidermis; H, hypodermis of collenchymatous cells; $\mathrm{P}$, parenchyma containing starch; V, fibrovascular bundle; $\mathrm{S}$, sieve; $\mathrm{T}$, tracheæ; $\mathrm{N}$, endodermis surrounding each bundle. $\mathrm{B}$, transverse section of stipe of Osmunda Claytoniana: H, hypodermis of lignified sclerenchymatous fibres; $\mathrm{N}$, endodermis surrounding a large central fibrovascular bundle; $\mathrm{Tn}$, tannin cells.

characterized by the underground or prostrate stems, known as rhizomes, the part of the plant that is seen above ground being the leaf. 
(3) There is also a group of ferns known as Water Ferns which are aquatic in habit; that is, they live in marshy places or float on water. As representatives of this group may be mentioned Marsila, from whose slender rhizome that is buried in the
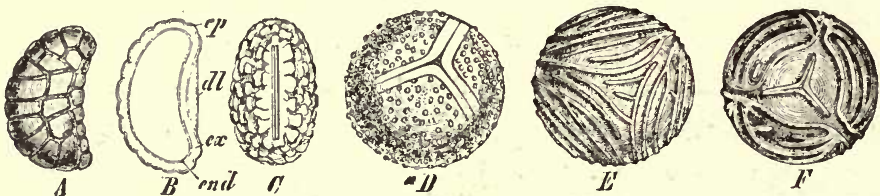

Fig. 57. Some fern spores. A, B, C, different views of the bilateral spores of the common polypody (Polypodium vulgare), showing outer wall (ep), middle wall (ex), inner wall (end) and line of dehiscence (d1); D, a tetrahedral spore of the royal fern (Osmunda regalis); E, F, spores of Ceratopteris thalictroides seen in two views.-A-D, after Sadebeck; E-F, after Kny.

muddy bottom of streams arise the clover-like leaves that float on the water (Fig. 59); and Salvinia (Fig. 58), which is a small floating plant that develops two kinds of leaves, one which float on the surface of the water and are more or less oblong, and

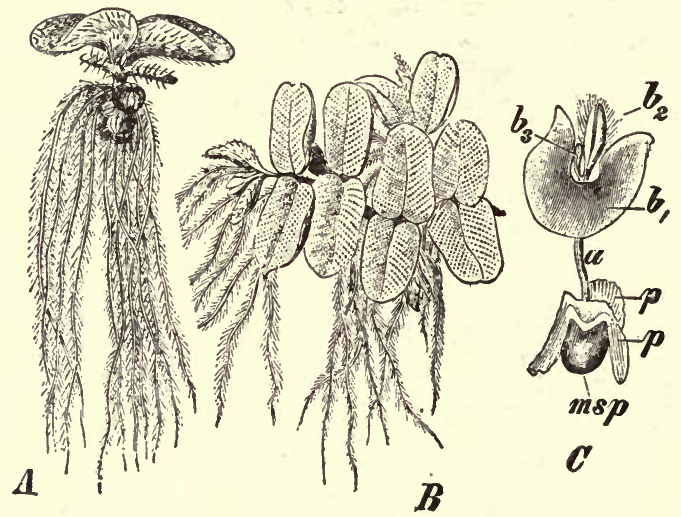

FIG. 58. A water fern (Salvinia natans). A, a plant seen from side and showing floating leaves at top attached to the horizontal stem, root-like finely divided leaves beneath, and a cluster of globose sporocarps; B, a view from above showing especially the character of the upper leaves; C, young plant developing from a megaspore (msp).-A and B, after Bischoff; C, after Pringsheim.

another which are filiform, branching, root-like, and submerged. The water ferns are further distinguished by the production of megaspores and microspores.

(4) The Adder's Tongue Family, to which Ophioglossum 
and Botrychium belong, develops a subterranean prothallus which is destitute of chlorophyll. The prothallus is in some cases tube-

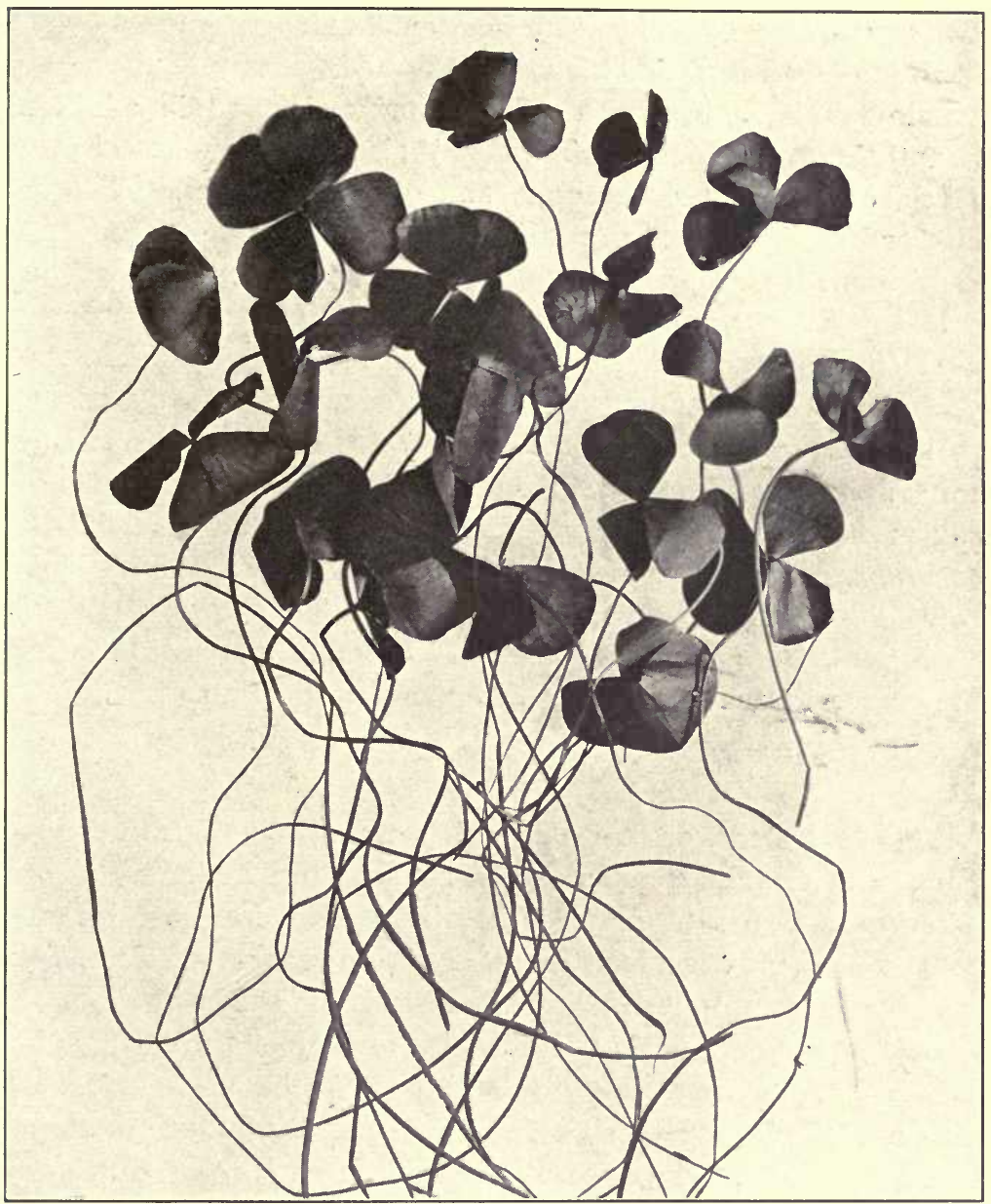

Fig. 59. Marsilea quadrifolia (from Bantam Lake, Conn.), a submersed or emersed aquatic plant belonging to the Marsileaceæ, a family of the Pteridophytes. Of the forty different species, only two or three are found in the United States. It produces long, slender rhizomes, which are buried in the muddy bottoms of shallow lakes or streams and from which arise the leaflets which float on the surface. The leaves are on long, slender petioles and 4 -foliate, the leaflets being mostly triangular-obovate. In Marsilec quadrifolia, a European form growing in Connecticut and Massachusetts and frequently cultivated, the leaves are nearly glabrous, while in $M$. vestita, a form found in shallow ditches in the Southern States, the leaflets are usually hairy. This character is quite marked in the sporocarps of the two plants.--After a photograph by Henry Troth. 
rous, and the sporophyte produces two kinds of leaves, namely, foliage leaves, and fertile leaves or those which bear the sporangia. The sporangia occur on lateral branches of the sporophyll and open at maturity by means of a horizontal slit.

Ferns Used in Medicine and as Foods.-Many of the ferns contain tannin, a brownish coloring principle, and in addition an anthelmintic principle. They may also contain ethereal oils, starch, coumarin, aconitic acid, and other principles. A large number have been used in medicine, of which the following may be mentioned: Dryopteris (Aspidium or Nephrodium) marginalis and $D$. Filix-mas, yielding the official Aspidium. A number of other species of Aspidium, as well as species of Adiantum, Asplenium and Polypodium, are also used in various parts of the world. The rhizomes of some of the ferns contain considerable starch and are used to some extent as foods, as Pteris esculenta of China; Pteridium aquiliana var. lanuginosa of the Canary Islands ; Aspidium varium and Asplenium bulbosum of Cochin China. Polypodium vulgare contains a substance related to glycyrrhizin. Adiantum pedatum and Polypodium Phymatodes are said to contain coumarin, the latter plant being used in perfumery.

\section{EQUISETALES.}

The Horsetails, or scouring rushes (Equisetums), are perennial plants containing a large amount of silica in their tissues. Like in the ferns, the more or less branching, creeping rhizome persists from year to year, sending out each year new shoots. As in some of the ferns, it develops two distinct kinds of leaf-shoots, a fertile and a sterile one, each of which is distinctly jointed. The scale-like leaves are arranged in circles about the joints or nodes, the work of photosynthesis being carried on by the green stems. The fertile branch develops at the apex a group of sporophylls known as a cone or strobilus. The archesporium, or initial sporeproducing zone, is unilocular. In Equisetum, the only representative of the group, the spores are spherical and each is furnished with two spiral bands or elaters which assist in its dispersal. Some of the Equisetums contain aconitic acid and are used in medicine. Common scouring rush (Equisetum hyemale) is used for 
polishing woods, and Equisetum arvense is used for scouring tinware.

\section{LYCOPODIALES.}

The Lycopodiales, or Club Mosses (Fig. 66), are perennial moss-like plants, with more or less erect or creeping and branching stems, on which are borne numerous small simple leaves. The sporangia arise either at the base of the upper surface of the leaves or occur in terminal cones. They have short stalks, are unilocular and 2-valved. The asexual spores are of one kind in Lycopodium and in the form of spherical tetrahedrons, resulting from the manner in which division has taken place (see Vol. II). In Selaginella (Fig. 6o) two kinds of asexual spores are produced, that is, both microspores and megaspores, which in turn give rise to male and female prothalli respectively. The microspore develops a male gametophyte (Fig. 62) which remains entirely within the spore, and consists of a few-celled prothallus and a number of mother cells which produce sperms that eventually escape by the breaking of the wall.

The megaspore frequently begins to develop the gametophyte (Fig. 63) while still within the sporangium. The prothallus consists of a number of cells and partly protrudes through the ruptured spore wall. On the upper part of the prothallus or nutritive layer a few archegonia are borne. It should be stated that sometimes the archegonia are developed very early on the prothallus tissue, but usually they are developed after the spores have escaped from the sporangium. After fertilization of the egg a multicellular embryo develops which shows the following parts (Fig. 6I ) : ( I) An elongated cell or row of cells which extends into the tissues of the prothallus for the purpose of obtaining nutriment; (2) a root; and (3) a stem bearing at its tip two leaves, or cotyledons. One of the specially notable characters of the plants of the Selaginella group is, as we have seen, the great reduction in size of the gametophyte, which in the case of the microspore does not enlarge beyond the wall of the spore, and in the case of the megaspore only partly protrudes beyond its wall.

Isoetes.-This is a genus of aquatic or marsh plants known 
as quillworts. The plants produce a number of filiform roots which penetrate the mud, and a compact tuft of rush-like leaves. The plants are heterosporous, as in Selaginella. The sporangia

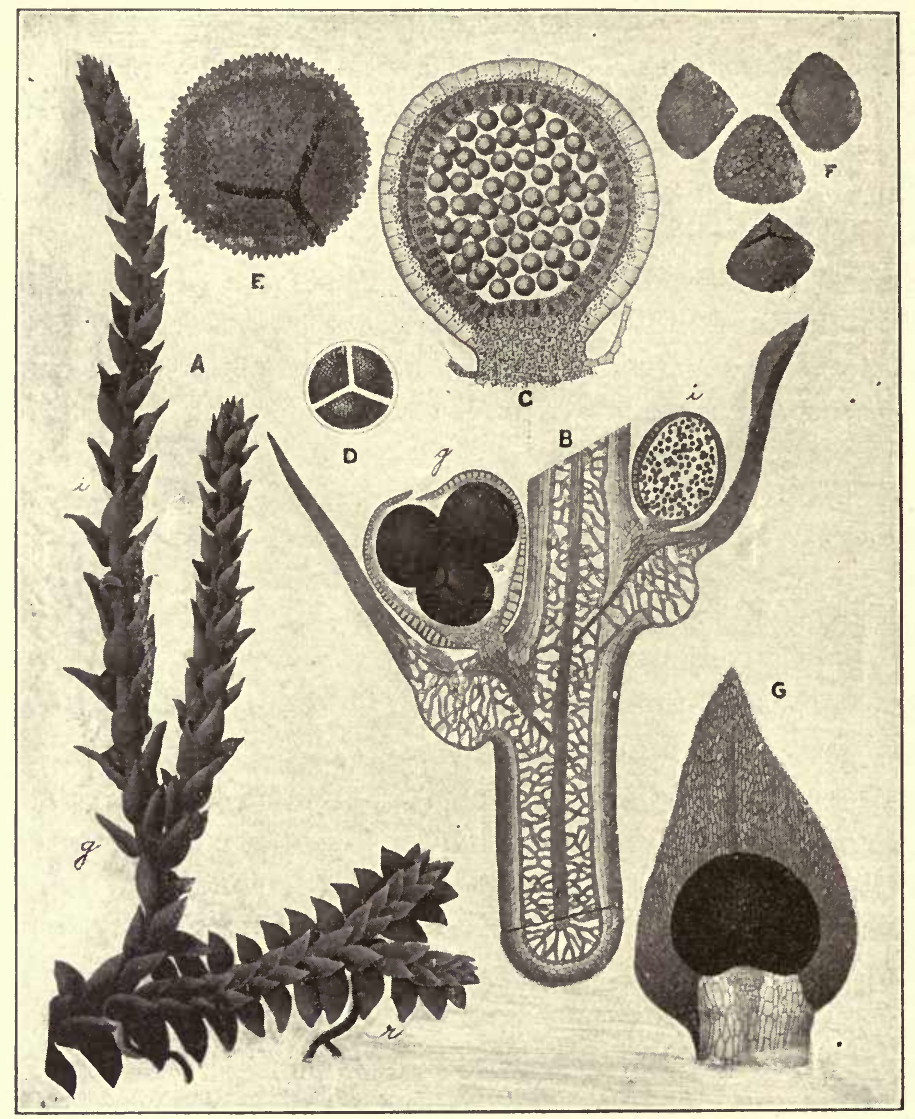

FrG. 60. Selaginella helvetica. A, sporophyte consisting of leafy branches giving rise to microsporangia (i), megasporangia $(\mathrm{g})$, and rhizoids $(\mathrm{r}) ; \mathrm{B}$, longitudinal section of portion of branch showing a megasporangium $(\mathrm{g})$ with 3 megaspores in view, a microsporangium (i) containing microspores; $\mathrm{C}$, a young microsporangium showing free mother cells before formation of tetrads; D, tetrahedral division of spore mother cell; E, ripe megaspore; F, four microspores of tetrad separated; G, microsporophyll seen from above showing ripe microsporangium.-After Dodel-Port.

are borne in the axils of the leaves, the outer leaves bearing the megasporangia and the inner leaves the microsporangia. The gametophytes consist of but a few cells. While the group is het- 
erosporous and the gametophytes resemble those in Selaginella, the sperms are multiciliate and coiled as in the Ferns.

Distribution and Uses of Lycopodiales.-A number of the Lycopodiums are common on rocks, damp woods, sandy bogs, and illustrations of several of these are shown in Fig. 66. Some tropical species are used in medicine; the spores of Lycopodium clavatum, on account of their fixed oil, are used as a dusting powder, and for burning in the production of flash lights (see Vol. II). The Selaginellas, of which there are several native species, are commonly used for decorative purposes. Some species

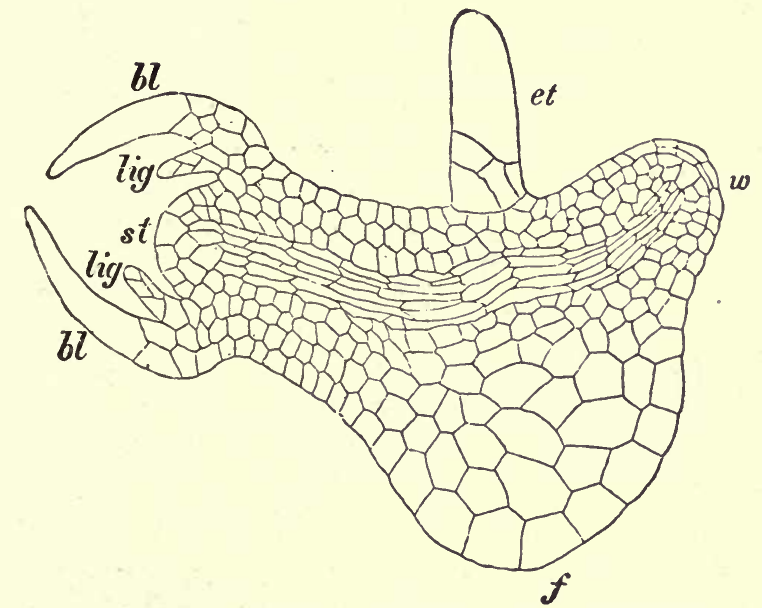

FIG. 6r. Longitudinal section of young embryo of a Selaginella before separation from the prothallus: et, suspensor; $w$, root; $f$, foot; bl, cotyledons; lig, ligules or bud scales. - After Pfeffer.

are, however, also used in medicine, and it is interesting to note that the spores of one species (Selaginella selaginoides) are used like those of Lycopodium.

While the Pteridophytes do not form a very conspicuous portion of the flora at the present time and yield but few products of use to man, it may be pointed out that in former ages they formed the dominant vegetation of the earth. Many of the ancestral forms of this group attained the size of trees and made up the forest vegetation during the Devonian and Carboniferous Ages, the latter being sometimes spoken of as the age of Pteridophytes. It is also called the Coal Age from the fact that the coal 
measures were chiefly laid down during this period. By some it is thought that the deposits of coal of this age were probably principally formed from the remains of certain marsh plants including two extinct groups of huge, tree-like club mosses (Lepidodendron and Sigillaria) and the Calamites, representatives of the scouring rushes.

\section{SPERMOPHYTES.}

The Spermophytes, or Seed Plants, constitute the third of the great divisions into which plants are divided. The plants belong-

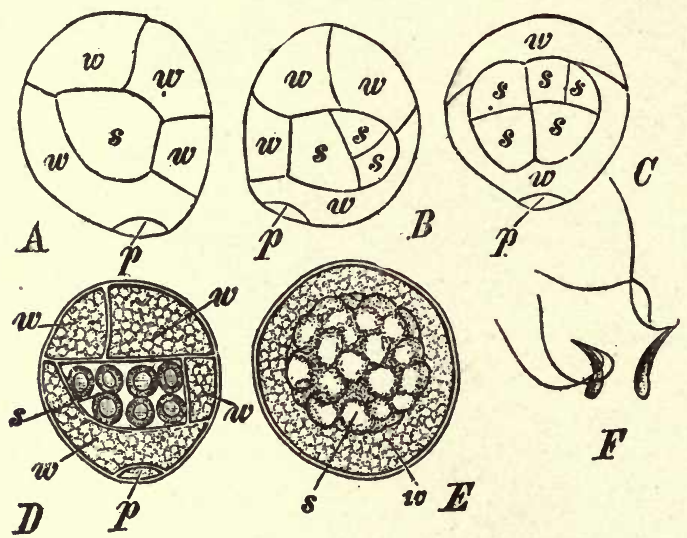

FIG. 62. Successive stages in the germination of the microspores of a Selaginella: $\mathrm{p}$ and $\mathrm{w}$, cells of the prothallus; $\mathrm{s}$, cells giving rise to sperms. A, B, D, views of spores from the side; C, view from the back; in E, the cells surrounding the sperm mother cell are disorganized; F, two biciliate sperms.-After Belajeff.

ing to this division not only form the most conspicuous feature of the flora because of their size and general distribution, but also because of the fact that they produce flowers renders a large number of them especially attractive. The plants of this group are also of great importance from an economic point of view. They furnish a large part of the food of man and other animals, as well as materials for clothing, shelter, fuel, and divers other purposes. In this group of plants there are the highest differentiation of tissues and the most complicated structure. The one character which especially distinguishes them from the lower groups of plants is that of the production of seeds. 
The plants have for the most part well-differentiated stems and leaves, and represent the sporophyte or asexual generation. The sporophyte produces sporophylls which are of two kinds, namely, megasporophylls and microsporophylls. The megasporophylls bear small ellipsoidal bodies known as ovules, which develop into seeds. The megasporangium is not separate and distinct in the spermophytes as it is in Selaginella, but is embedded within an ovule and corresponds to that part of the ovule known as the nucellus. The nucellus encloses the embryo-sac, which is regarded as a megaspore (Figs. 70, 7I, and 8I). Each megasporangium (nucellus) therefore contains but a single megaspore, whereas in Selaginella the megasporangia contain from $\mathrm{I}$ to 8 megaspores. The microsporophyll bears microsporangia (pollen sacs) which contain microspores (pollen grains). The female gametophyte in the Spermophytes is still more limited in its development than even in the highest Pteridophytes (as Selaginella and Isoetes) and remains wholly within the megaspore or embryo-sac. As a result of fertilization of the egg-cell an embryo is produced which consists of root, stem, and one or more cotyledons and which with the integuments covering it constitutes the seed.

Spermophytes embrace two well-defined groups, namely, (I) Gymnosperms, or naked-seeded plants, and (2) Angiosperms, or enclosed-seeded plants.

GYM NOSPERMS.

In the Gymnosperms the ovules, each of which contains a megasporangium (nucellus), are borne on an open sporophyll (carpel), and thus are exposed, as are also the seeds developed from them. In the Angiosperms the ovules are borne within closed sporophylls, and are thus protected or covered until the seeds, which develop from them, mature.

The Gymnosperms represent an ancient group of plants and were more numerous during the Triassic period than now. They are mostly shrubs and trees, and do not shed their leaves periodically as the Angiosperms do, and hence are known as "evergreens." As in some of the Pteridophytes (Lycopocium, Equisetum), the sporophylls occur in groups forming cones or strobiles (Fig. 72). They not only differ in external appearance from the 
Angiosperms but also in the anatomical structure of the stem, which is without large conducting vessels. In order to understand the relation of the Gymnosperms to the Pteridophytes on the one hand and to the Angiosperms on the other, it will be necessary to consider briefly the life history of a representative group, such as the Coniferæ.

General Characters.-The seed consists essentially of three parts, namely, a woody or leathery seed-coat, a nutritive layer rich in oil known as the endosperm, and a straight embryo. The latter is a more or less differentiated plantlet, consisting of a stem

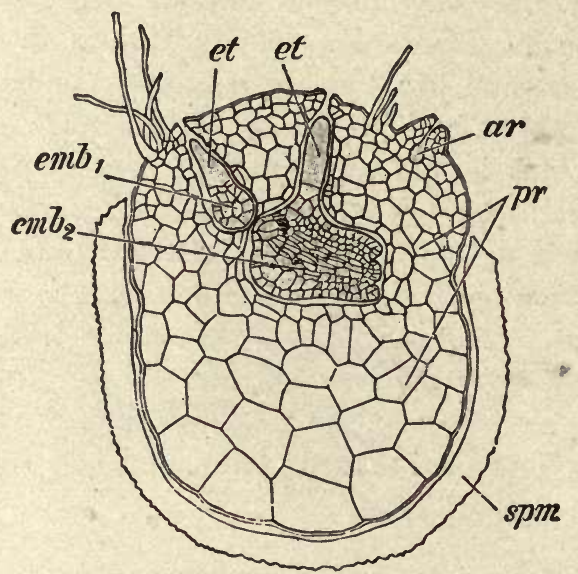

Fig. 63. The female gametophyte of a Selaginella; prothallus (pr) projecting through the ruptured wall (spm) of the megaspore; ar, sterile archegonium; emb embedded in the tissue of the prothallus; et, et, suspensors.-After Pfeffer.

with a varying number of cotyledons or first leaves ( 2 to 16 ), and a small root which is attached to a suspensor, as is the embryo in Selaginella (Fig. 63). When the embryo begins its development into the plant it uses up the nourishment with which it is surrounded in the endosperm, and as it increases in size the seedcoat is split. The root then protrudes and the cotyledons, to some of which the seed-coat is still attached, are carried upward by the stem through the surface of the soil, when the seed-coat is cast off and the plant begins an independent existence. The first root is the primary or tap root, and from this are sent out numerous branches known as secondary roots, constituting a well-developed 
root system which serves the double purpose of absorbing nutriment from the substratum or soil and holding or fixing the plant in its upright position. The embryonal stem grows vertically upwards, continuing its growth indefinitely. Lateral branches arise at more or less regular intervals which extend from near the ground to the apex, the younger branches continually succeeding

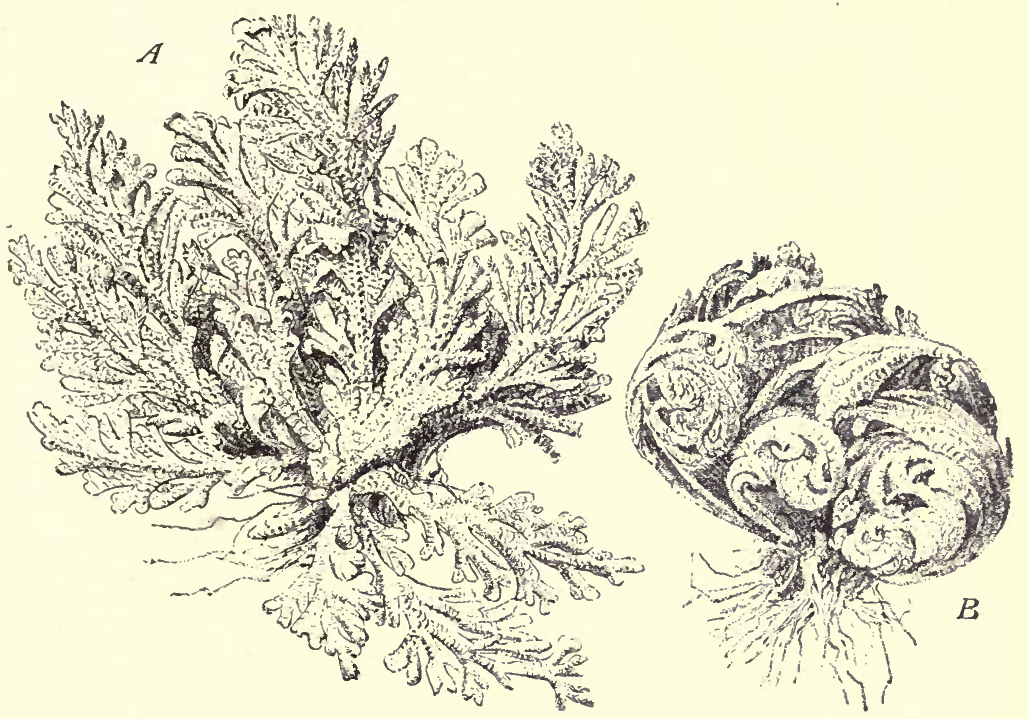

Fig. 64. Bird's Nest Moss (Selaginella lepidophylla). A, the plant growing in a moist situation or upon the addition of water; B, the habit of the plant under dry conditions, it unrolling and becoming as (A) upon the addition of water. This plant is also known as Resurrection plant and Rose of Jericho, the latter name is more correctly applied to Anastatica hierochuntica, a cruciferous plant of the East Mediterranean and Egypt, the stems on drying becoming folded together and the whole plant being scattered by the wind. The Bird's Nest Moss grows in Mexico and western Texas, and in the rolled-up condition (B) is found occasionally in commerce and is used as a table decoration. It has the advantage that even though it dries out, it may be renewed many times.-After Hieronymus in Engler and Prantl.

the older ones from the ground upward, thus giving the trees a cone-like outline. The leaves arise on the branches and are of two kinds, primary leaves which are more or less scale-like and deciduous, and secondary. leaves which are true foliage leaves, and are usually quite simple in structure. The leaves vary in form but are usually narrow and somewhat thickened, giving them a needle-like appearance. 
In addition, sporophylls (spore-bearing leaves) are formed at the ends of the young shoots or in the axils of more mature ones

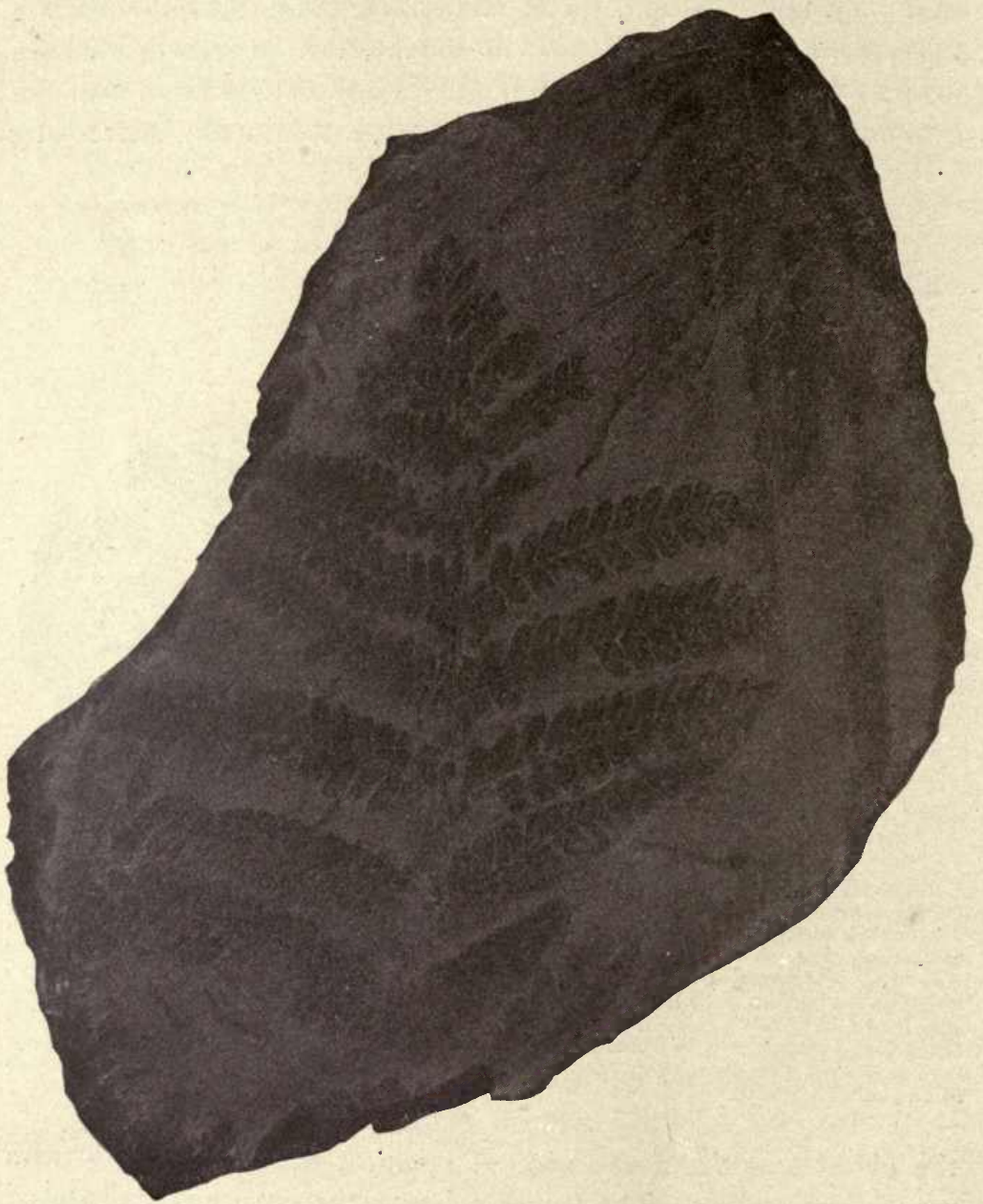

Frg. 65. A piece of slate from the coal formation in Shenandoah, Pennsylvania, showing a fossil fern which is probably a species of Neuropteris.

(Fig. 69). These are compactly arranged, forming cones or strobili which are always of two kinds and borne on different twigs of the same plant or on different plants. The staminate cones 
consisting of microsporophylls (stamens) are more or less elongated and cylindrical or ovoid (Fig. 69, A). The carpellate cones consisting of megasporophylls (carpels) have a shorter longitudinal axis, and the cones vary considerably in the different groups (Fig. 72).

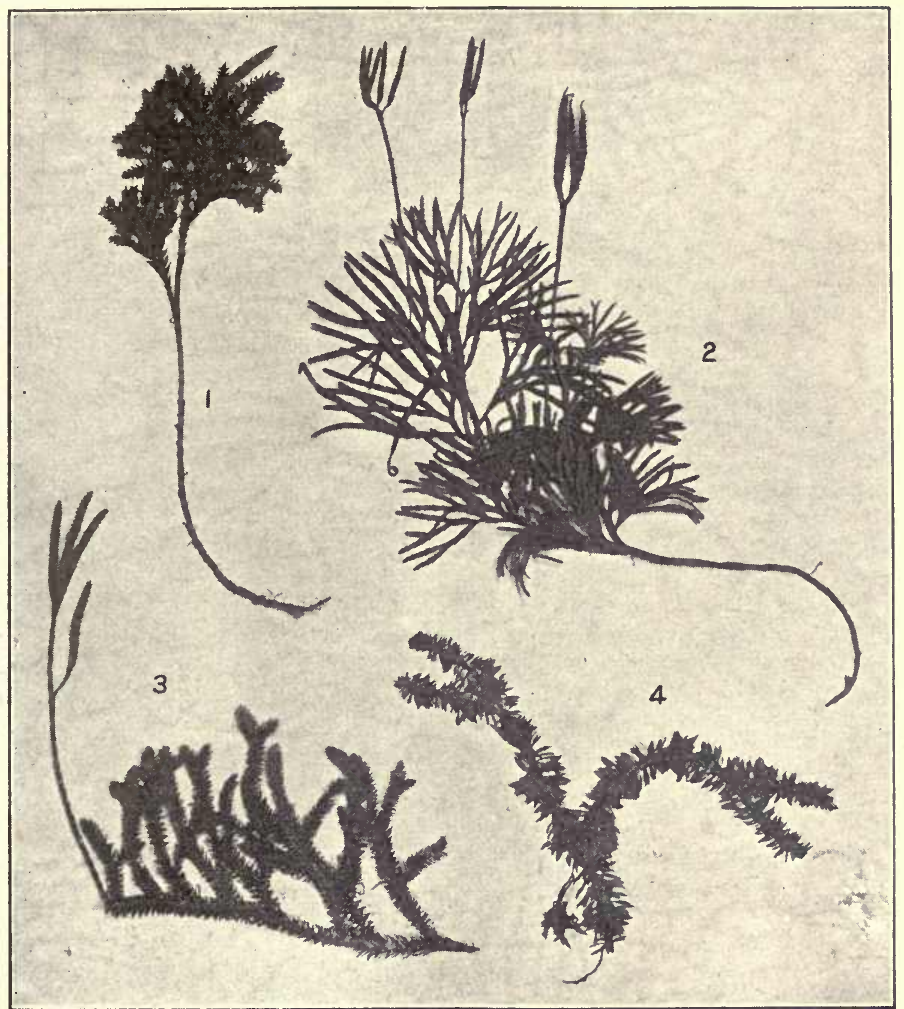

FIG. 66. Several species of Lycopodium. I, Ground pine (L. ohscurum) showing a leafy branch with one strobile at the apex; 2, a branch of trailing Christmas green (L. complanalum) bearing four or five strobiles at the apex of long dichotomously branching stalks; 3, club moss or running pine (L. clavatum) with a branch bearing four strobiles; 4, shining club moss (L. lucidulum) with small sporangia borne in the axils of the leaves.

The Microsporophylls (Fig. 69) are usually of a yellowishbrown color, and consist of a slender stalk and a lamina which bears the microsporangia (pollen sacs) on the lower or dorsal surface (Fig. $69, B, C$ ). In this they show a resemblance to 


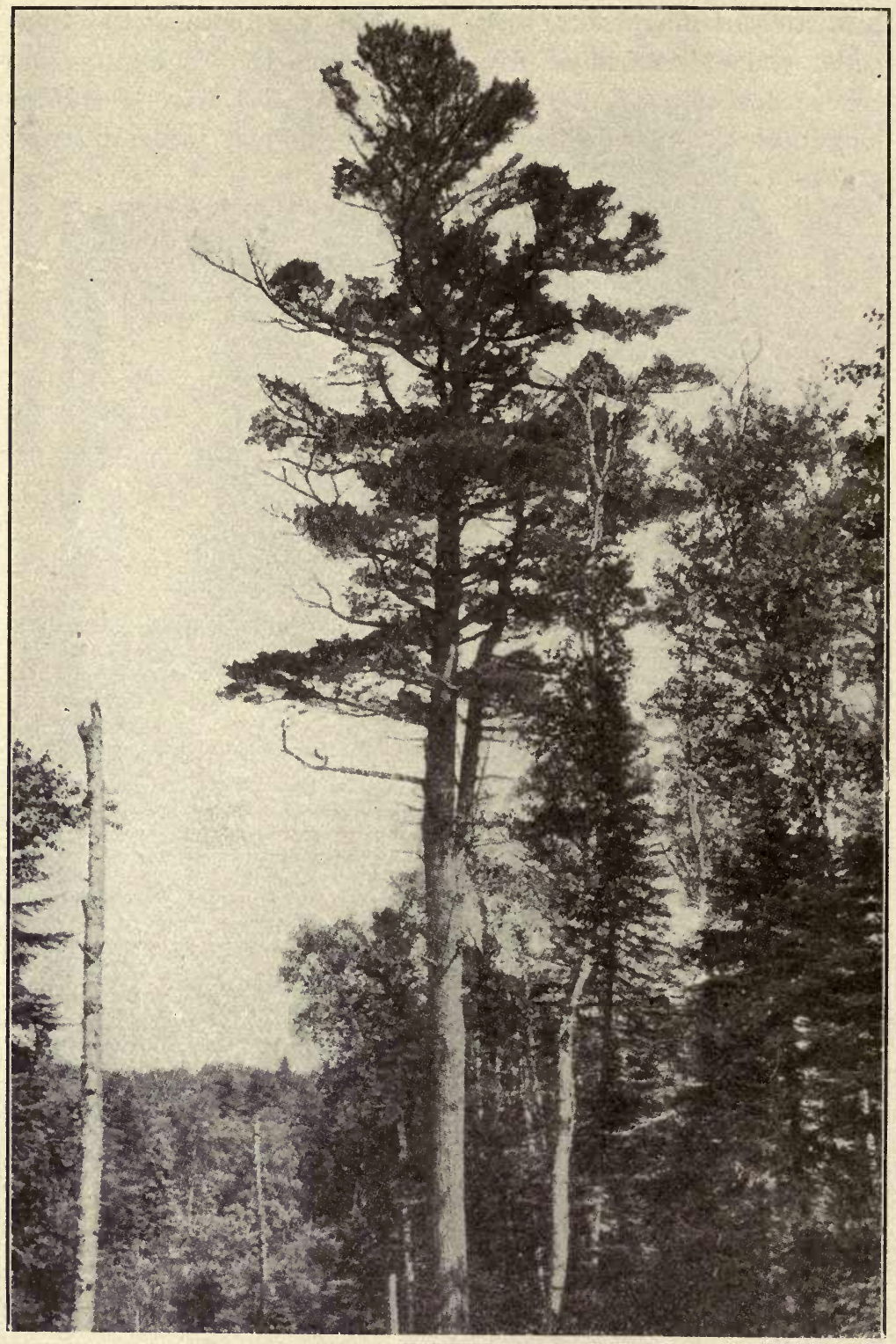

FIG. 67. White Pine, also called Weymouth Pine, (Pinus Strobus). -From a photograph Ey Mr. C. J. Hibbard in "Minnesota Trees and Shrubs." 
ferns where the sori are borne on the under surface of the leaves. The microsporangia vary in number from 2 to I5, and are protected in various ways, either being sunk in the tissues of the sporo|phyll, as in Pinus and Abies, or they are, as in Juniperus and Thuja, provided with a covering resembling the indusium of the ssori of the ferns. The walls are variously thickened and on drying,

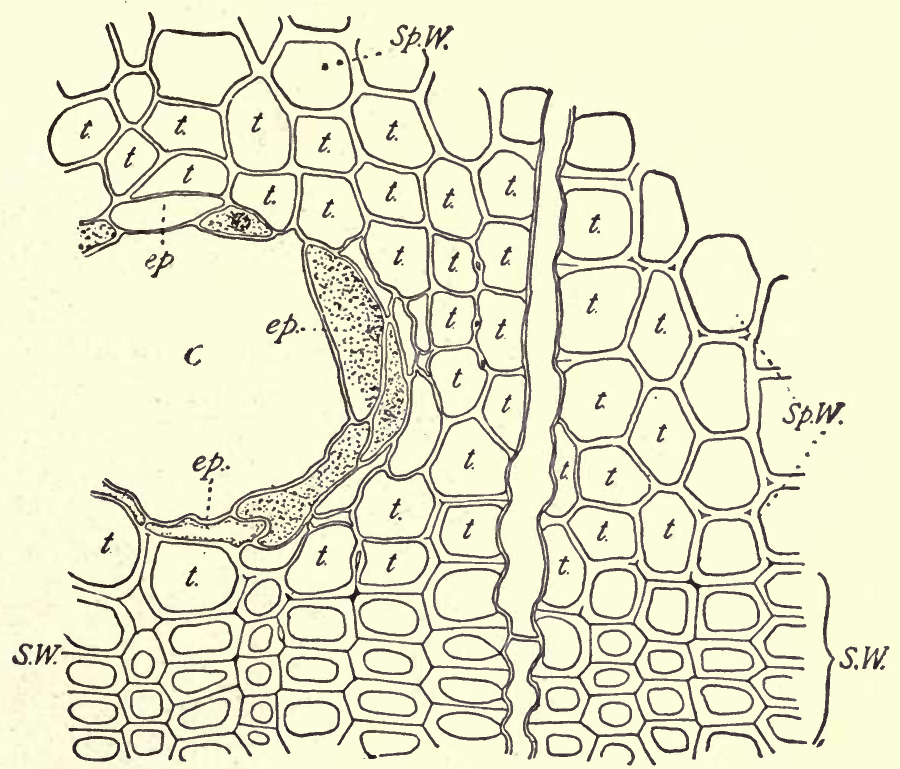

Fig. 68. Pinus reflexa. Transverse section of a portion from the inner face of the spring wood showing a schizogenous resin duct or passage with the central canal (C) and the thin-walled and resinous epithelium (ep); with parenchyma tracheids $(t)$, the spring wood (Sp. W.) and the summer wood (S. W.).--After Penhallow.

The Coniferæ represent the most ancient group in which resin passages or reservoirs are found. While these passages show certain important variations in structure and origin. and while even in certain genera of the group, as in the genus Pinus, they exhibit considerable variation in detail, yet in this genus they are all of the same structural type as in Pinus reflexa, the white pine of the high mountainous regions of New Mexico and Arizona. The epithelial tissues are thin-walled and readily broken in making sections except in the hard pines as the Loblolly pine $(P . T æ d a)$, where the cells often become strongly resinous.' (See Penhallow's "Manual of the North American Gymnosperms.")

owing to unequal tension, the sacs are ruptured longitudinally and the spores scattered. The microspores are very numerous, sometimes forming powdery deposits. They are either I-celled or 3-celled. In the latter case two lateral cells act as wings for the dispersal of the spores by the wind (Fig. 69, D). 
The Megasporophylls consist of sessile carpels (leaves) on which are borne one or two naked ovules containing the sporangia (nuclei). In certain groups, as in the pines, balsams, etc., a scale is formed at the base of the carpel which bears the ovules, and this scale is called the seminiferous scale. The ovules consist of several parts (Figs. 7O and 7I) : a stalk; an integument or wall which has an opening at the apex known as the micropyle; a nucellus (megasporangium), being that portion next within the
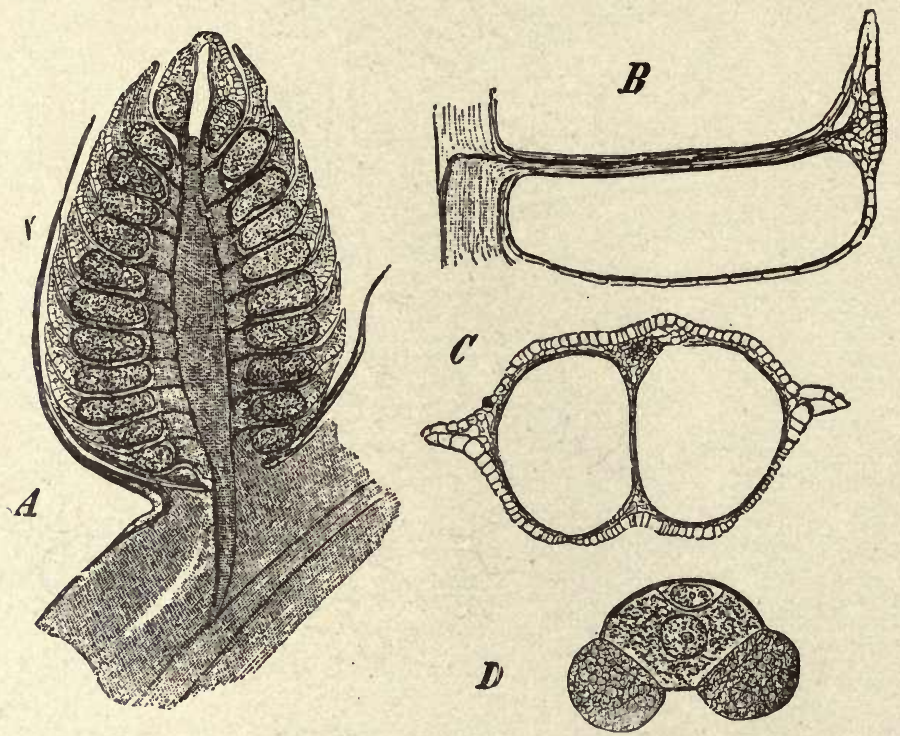

Fig. 69. A, longitudinal section of cone composed of microsporophylls, of one the pines; B, longitudinal section of microsporophyll showing microsporangium (pollen sac); $\mathrm{C}$, the same in transverse section showing both microsporangia; D, winged microspore (pollen grain), with a two-celled male gametophyte, the upper cell being the generative cell, the remaining nucleated cell giving rise to the pollen tube.-After Schimper.

integument; and embedded within the nucellus a portion known as the megaspore or embryo-sac.

Gametophytes.-The development of the gametophytes from the asexual spores, namely, the microspore or pollen grain, and the megaspore or embryo-sac, is as follows: The nucleus of the megaspore divides repeatedly (Fig. 7I), cell walls are formed, and a multicellular structure known as the ENDOSPERM is produced. This structure constitutes the prothallus of the female 
gametophyte (Fig. 70, E; Fig. 7I). In the upper portion of the prothallus (that is, at the micropylar end), three to five archegonia are formed (Fig. 70, $a$; Fig. 7I), which are separated from one another by cells of the endosperm or prothallus, which are rich in protoplasm. The structure of the archegonium is much like that

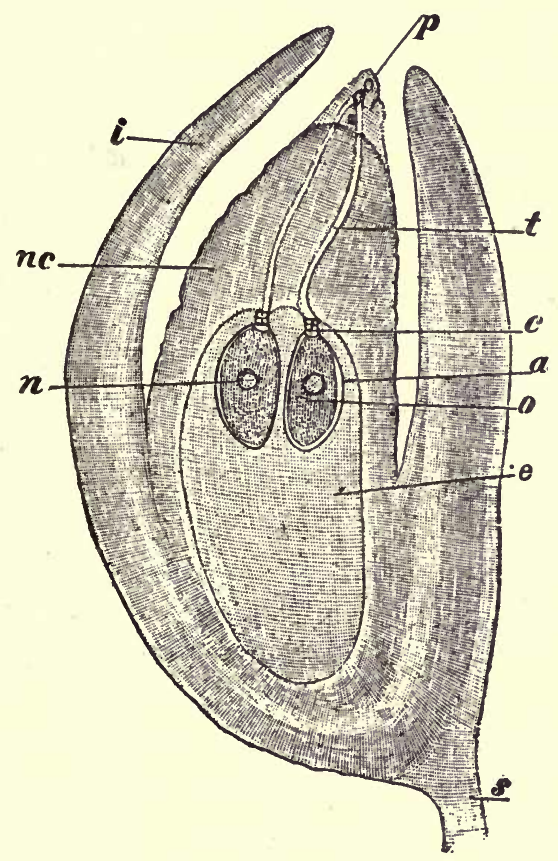

FIG. 70. Longitudinal section of an ovule of a spruce (Picea): i, integument; nc. nucellus (megasporangium); e, embryo-sac (megaspore) which has developed the female gametophyte consisting of endosperm (e), two archegonia (a), which show the neck (c), and the egg $(n) ; p$, germinating pollen grains (microspores) with pollen tubes (t) which have penetrated the nucellus (nc) and reached the neck cells of the archegonia.-After Schimper.

of the preceding group, consisting of a venter which contains the egg, and a short neck composed of 4 to 8 cells.

The male gametophyte begins to develop while the pollen is still in the sporangium. At this stage it consists of a generative cell and a wall-cell, which constitute the antheridium, the cells of the prothallus being usually suppressed (Fig. 69, D).

In addition to the extreme minuteness of the gametophytes 
we have also to note the character of the male gamete or sperm. With the exception of the Cycads and Ginkgo, motile sperms are

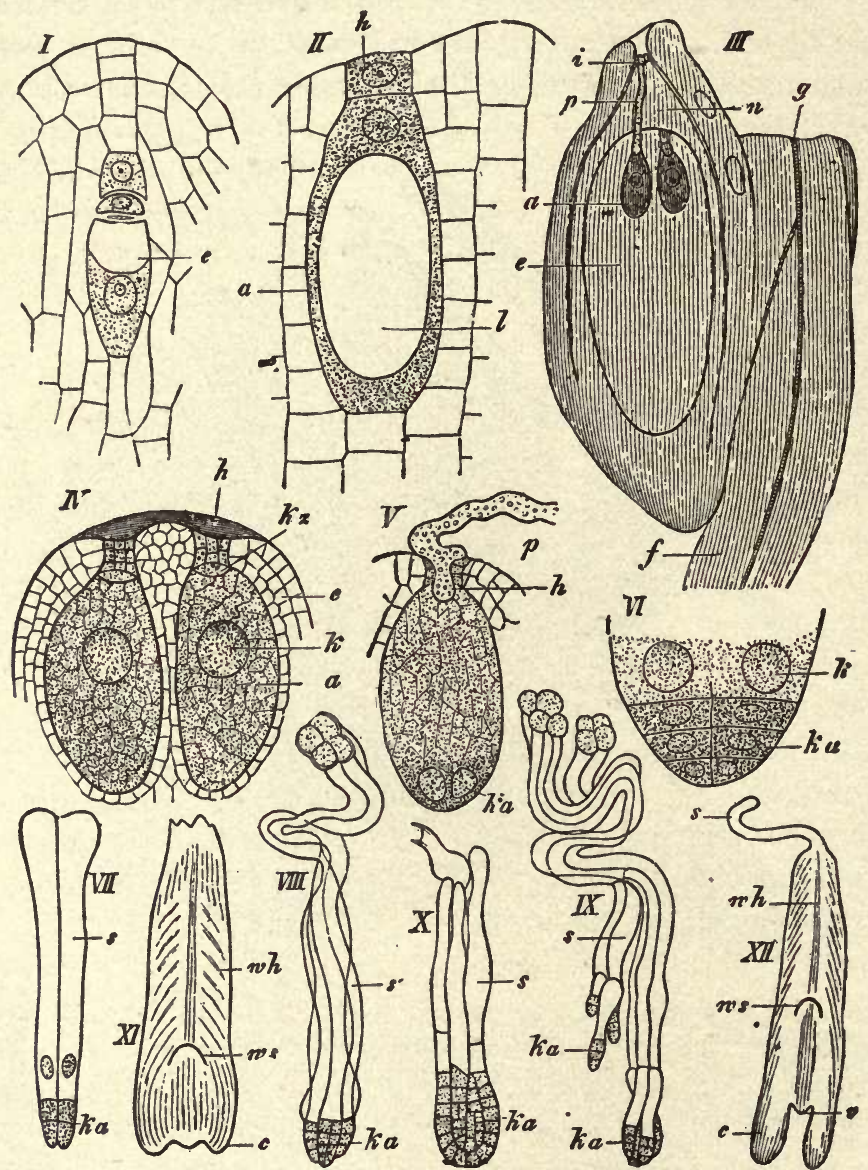

FIG, 7r. Development of gametophyte and embryo in one of the Coniferæ. e, embryo-sac (megaspore); a, archegonium; h, neck of archegonium; $i$, integument; $p$, pollen tube; $n$, nucellus; $f$, wing of seed; $g$, fibrovascular tissue; $k z$, canal cells of archegonium; ka, beginning of embryo; $k$, nuclei; ws, tip of root; wh, root-cap; $c$, cotyledons; $v$, point of growth of stem; s, suspensor.

I, early stages of embryo-sac (e); II, young archegonium (a) after development of neck cells (h), cell lumen (1); III, section of ovule with portion of attached seminiferous scale (f) showing entrance of pollen tube; IV, embryo-sac with two developed archegonia; $\mathrm{V}$, archegonium after fertilization, there being four nuclei at the lower part, only two of which are seen; VI, further development of embryo; VII, VIII, IX, X, showing development of large tortuous suspensor, to which is attached the young embryo (ka); XI, XII, mature embryo.-After Strasburger. 
not found in the Gymnosperms, but these are represented by two male nuclei which are transferred directly to the archegonium from the male gametophyte, formed through germination of the microspore (pollen grain). It may be recalled that in the Pteridophytes the motile sperms are discharged from the antheridium and carried by the agency of water to the archegonium, but in the Gymnosperms water is no longer a medium of transferral. The microspores themselves are carried to the ovules usually through the agency of wind, after which they germinate, developing a tube which carries the male nuclei directly to the archegonium without their ever having been free.

The transferral of the microspores or pollen grains to the ovule is known as pollination. After pollination the wall-cell develops a tube, the pollen tube, and the generative cell gives rise to two male nuclei, which, with the remaining protoplasmic contents of the antheridium, are carried by the pollen tube to the micropyle, which it enters, penetrating the tissue of the nucellus (Fig. 7o, $t$ ). On reaching the neck of an archegonium the pollen tube pushes its way down into the venter, where it discharges one of the sperm nuclei, which unites with the egg, forming an oöspore. Cessation in growth does not yet take place and the oöspore develops into the embryo already described. The developing embryo obtains its nourishment by means of a suspensor. (Fig. $7 \mathrm{I}, \boldsymbol{s}$ ), which also places the embryo in a favorable position.

There being several archegonia in an ovule (Figs. 7O, 7I), a corresponding number of embryos may be formed, but rarely more than one survives. While the embryo is developing, the other tissues of the megaspore are likewise undergoing changes leading to the maturity of the seed. The carpels and seminiferous scales also continue to grow, and they usually become more or less woody, forming the characteristic cones of the pines (Fig. 72 ), but may coalesce and become fleshy, producing the berry-like fruits of Juniper (Fig. 75). The seed on germination gives rise to the sporophyte (tree).

Groups of Gymnosperms.-There are several important groups of Gymnosperms: (I) The Cycads or Fern Palms, which are characteristic of tropical and sub-tropical countries. The trunk does not branch as in the ordinary evergreens, and 


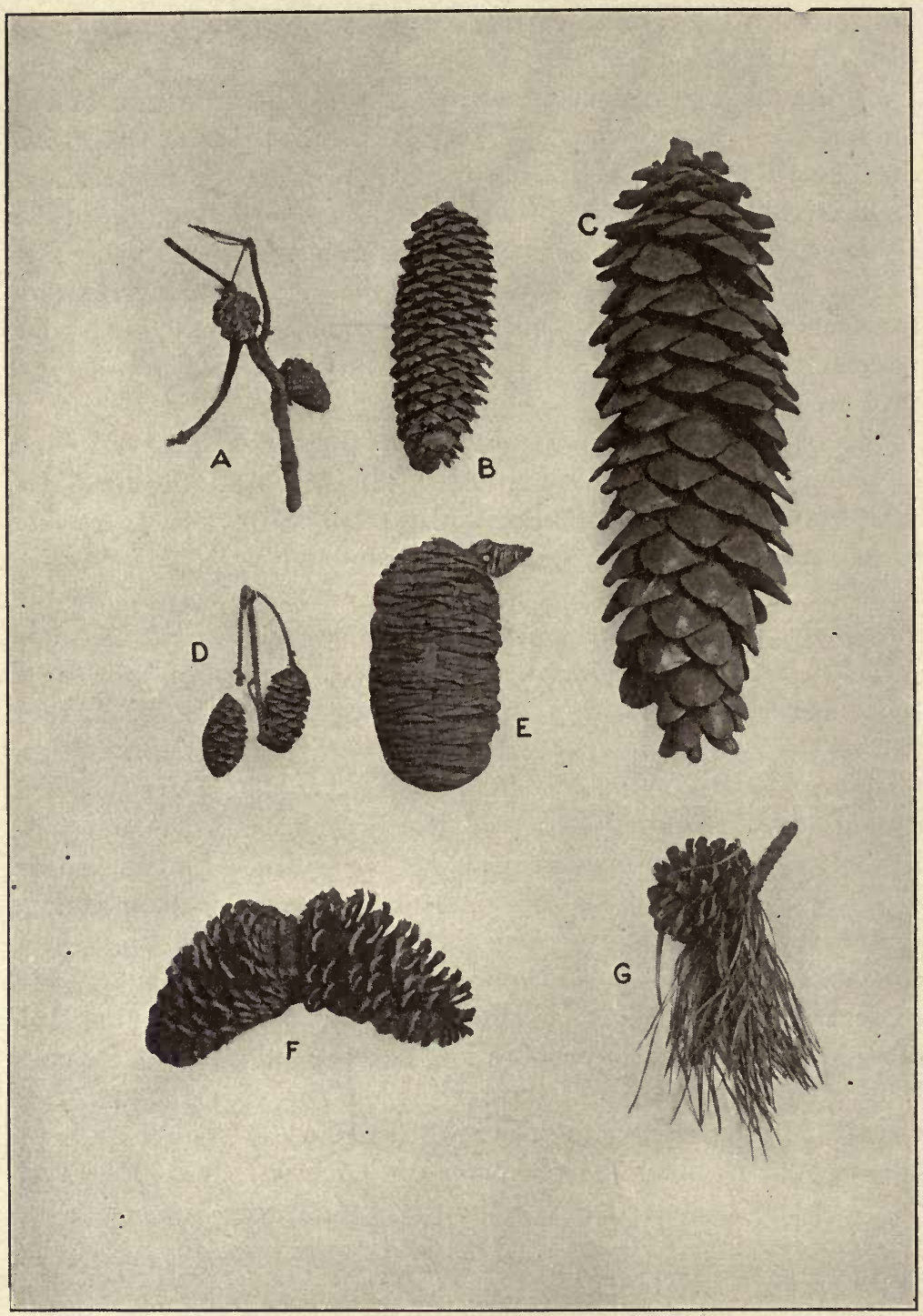

Fig. 72. Cones of some of the Coniferæ. A, branch of Spruce Pine (Pinus echinata) with two cones; B, from Pitch Pine (Picea excelsa); C, from Great Sugar Pine (Pinus Lambertiana); D, from Black Spruce (Picea mariana); E, from the California Silver Fir (Abies magnifica); F, from Loblolly or Frankincense Pine (Pinus Tada); G, branch of Pitch or Torch Pine (Pinus rigida). 
the leaves form a crown at the summit of the stem or trunk. An important character of some of the Cycads is the production of multiciliate sperms, as in the ferns, Equisetum and Isoetes. (2) The Ginkgonaceæ (to which belongs the Ginkgo or Maidenhair Tree, which is extensively cultivated in China and Japan and is found wild in China. It is very widely cultivated in this country, owing to its ornamental foliage; the staminate tree is preferable, as the seeds of the pistillate tree have a very offensive odor. The triangular shaped leaves occur in fascicles and the seeds are berry-like. (3) The Coniferæ is by far the most important group and consists of two families, the Taxaceæ and the Pinaceæ. To the Taxaceæ belongs Taxus, or yew, a low tree bearing flat, linear leaves and a seed which is exposed and surrounded by the scarlet, fleshy, aril-like disk or scale.

To the Pinaceæ belong most of our important Gymnosperms.

Pinus (Pine) is the most important genus (Figs. 67, 73, and 74). It is characterized by having needle-like leaves arranged 2 to 5 in a fascicle. The cone of the pine is usually woody, and upon becoming dry splits open so as to release the winged seeds. Perhaps the most valuable member of this genus is the white pine (Fig. 67) which is found throughout the northern half of the United States east of the Mississippi River. Its timber is light brown or reddish, soft and fine-grained, but not very strong. It is used extensively in rough building construction.

Pinus palustris, or long-leaved pine, is one of the most valuable members of this group. It is the chief source of the terebinthinous products of this country, and its wood contributes no small part to the lumber industry. The long-leaved pine is tall, straight, has a thin-scaled bark and a very hard, resinous wood. The stem separates near the summit into several diverging branches, giving the tree a flattened top. The leaves are in threes, rarely in fours, from Io to I 5 inches long, and the cones are 6 to Io inches long, the scales being armed with short recurved spines. Other pines yielding turpentine are Pinus Tada, loblolly pine; Pinus heterophylla, Cuban or swamp pine; Pinus echinnata, short-leaved yellow pine.

Tsuga canadensis (Hemlock) is a common tree of eastern Norih America (Fig. 73). It attains a large size, and the delicate 


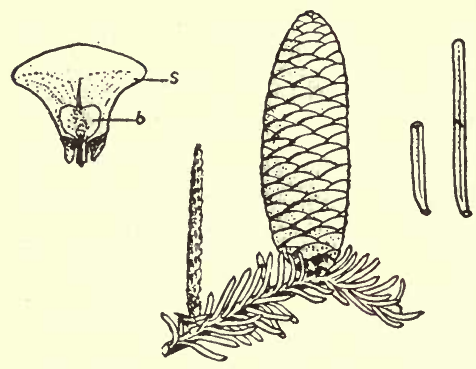

Abies

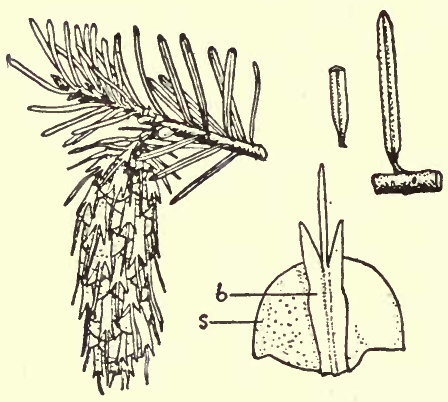

\section{Pseudotsuoga}
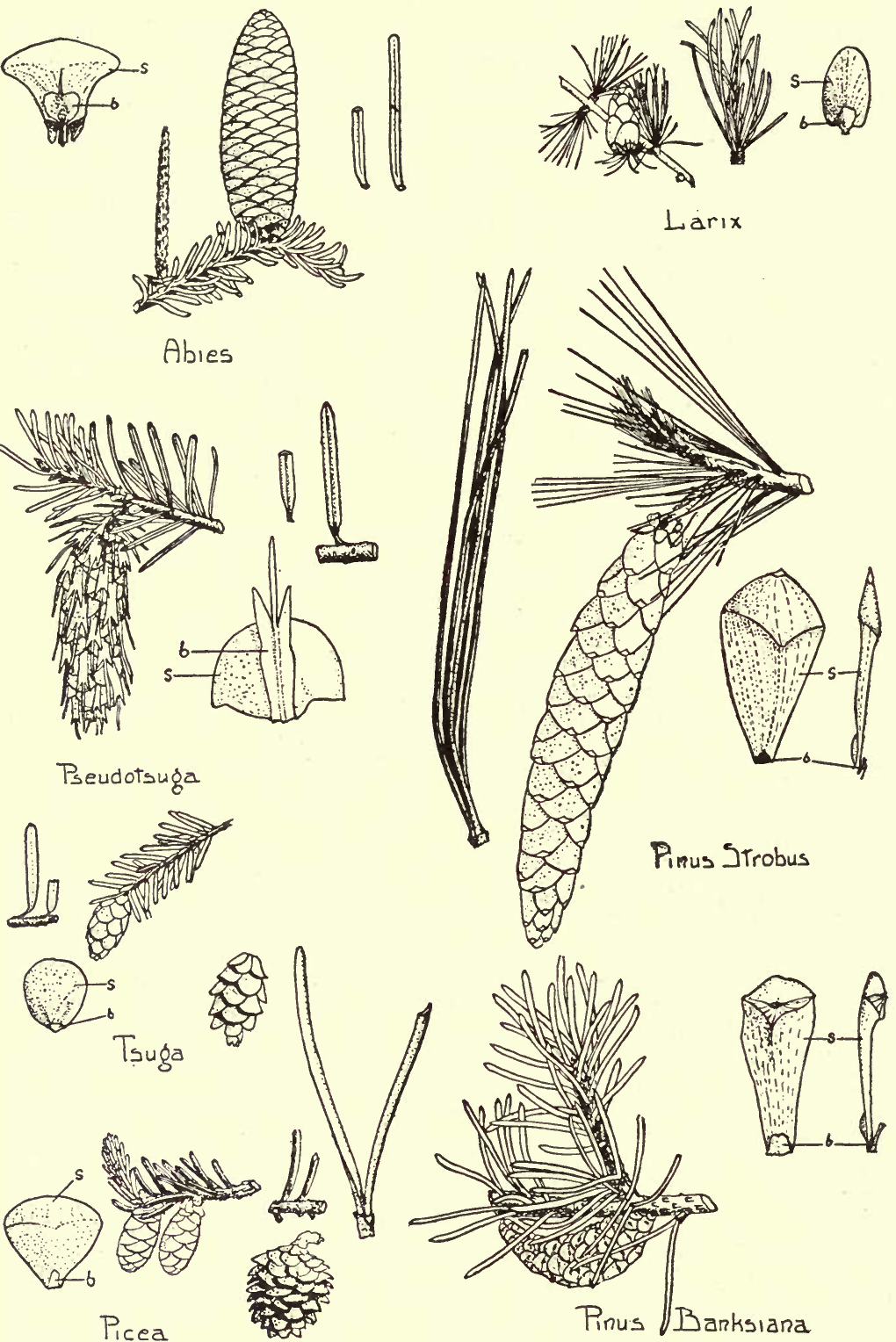

FIG. 73. Leaves and cones of Balsam Fir (Abies balsamea), Larch (Larix laricina), Douglas Fir or Douglas Spruce (Pseudotsuga taxifolia), White Pine (Pinus Strobus), Hem. lock (Tsuga canadensis), Spruce (Picea mariana), and Jack Pine (Pinus Banksiana)., From "Minnesota Trees and Shrubs." 
spray of its branches gives it a delicate beauty. Although its lumber is not very strong nor durable, it is extensively used. The bark is also used to an enormous extent in the manufacture of heavy leather. In recent years many tanneries have been built in the hemlock districts so as to be near the supply of bark. For the finer grades of leather the hemlock bark is mixed with that of
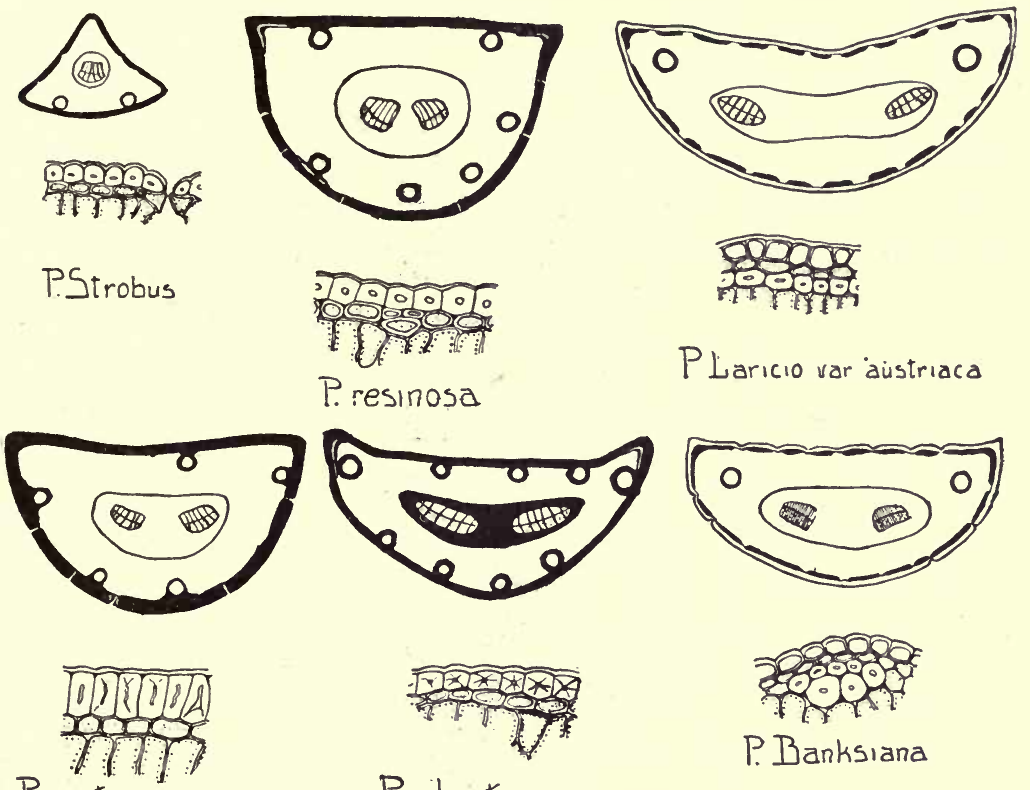

Pmontana
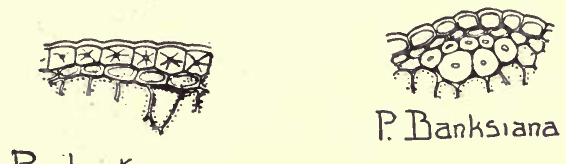

FIG. 74. Cross-sections of leaves of six different species of Pinus, showing in the diagrams the variation in the shapes of the cross-sections, with the distribution of the oil reservoirs, and beneath each an enlarged view of the epidermal layer and underlying tissues. -From "Minnesota Trees and Shrubs."

the oak, in order to avoid the reddish color produced by the former.

Another important genus is Juniperus. The red cedar (J.virginiana, also called Sabina virginiana) or savin is a tree producing valuable fine-grained soft and durable wood which is used extensively in making chests, pails, posts, etc. It is interesting to note that this tree, which is frequently planted to form windbreaks, develops the fungus Gymnosporangium in the form of cedar apples, which in the æcidial stage produce the leaf rust of apple. 
The berries of the common juniper ( $J$. communis) are sweet and fleshy and are used medicinally as a diuretic and also in the manufacture of gin.

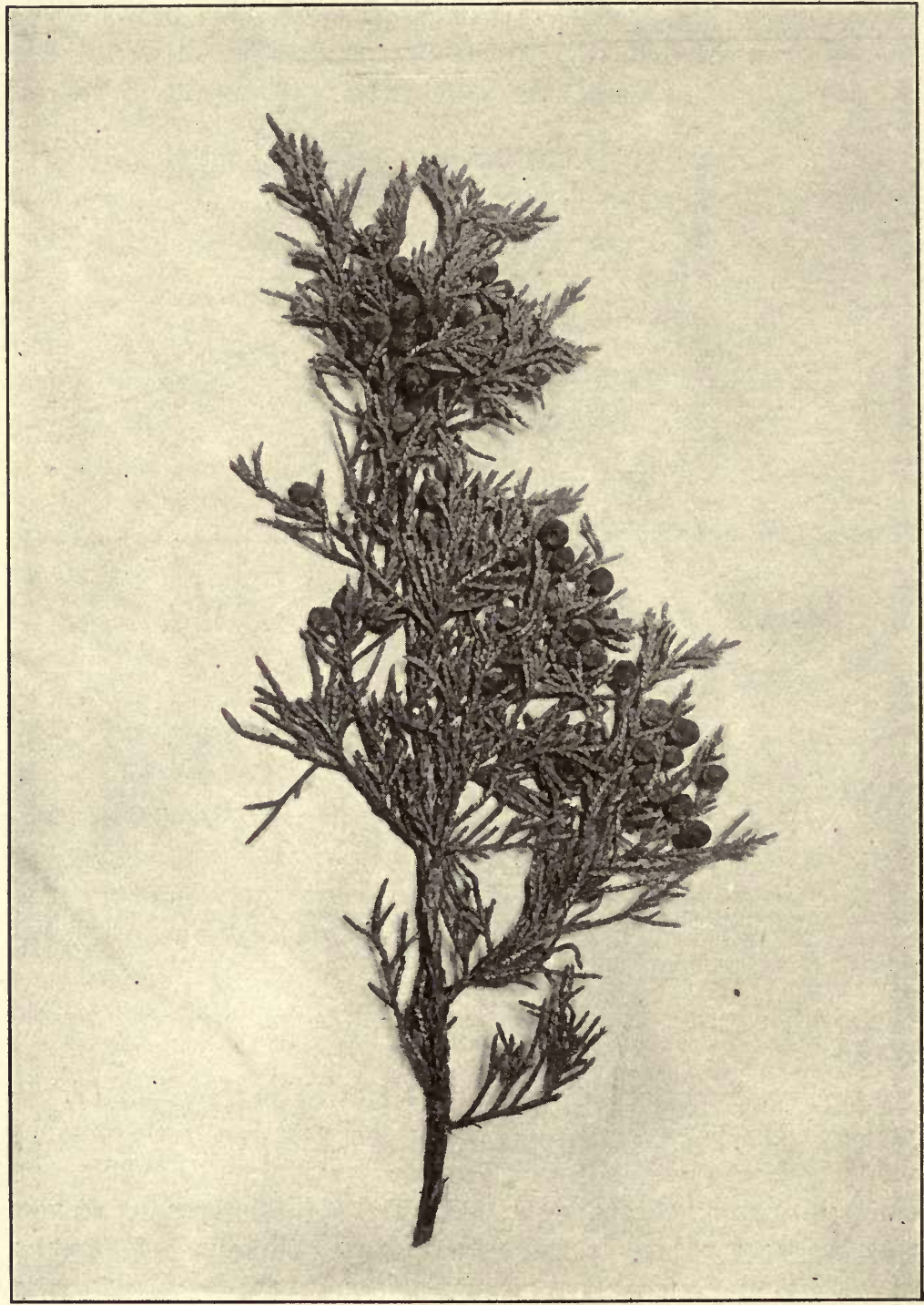

FIG. 75. A branch of Red Cedar (Juniperus virginiana) with numerous berry-like cones. 
Economic Uses of the Coniferæ.-From an economic point of view the Coniferæ are by far the most important group of plants thus far considered. In fact, they may be ranked first in the production of valuable timber. Of those yielding timber the following species may be mentioned: White pine (Pinus Strobus) ; long-leaved, yellow, or Georgia pine (Pinus palustris Mill); spruce pine (Pinus echinata); the Redwood of Upper California (Sequoia sempervirens) ; pitch pine of New Mexico (Pinus ponderosa); the Scotch fir, the common pine of Europe (Pinus sylvestris). Some of the woods are adapted for special purposes: as that of Pinus Celubra of the high mountains of Europe and Northern Siberia, which is excellent for wood-carving; red cedar (Juniperus virginiana) (Fig. 75) used in the making of cigar boxes and lead pencils; balsam fir (Abies balsamea) used in the manufacture of wood pulp.

By reason of the oleoresinous constituents the woods of some of the Coniferæ are among the most durable known. A few years ago Jeffrey examined a specimen of Sequoia Penhallowii which was obtained from auriferous gravels of the Miocene in the Sierra Nevada Mountains and found it to be in a very perfect state of preservation. Penhallow (loc. cit.) considers this to be the most ancient record of an uninfiltrated and unaltered wood. Coleman, in 1898 , found in the Pleistocene clays of the Don Valley a specimen of red cedar (Juniperus virginiana) which not only possessed all of the external characteristics of this species but when sawed emitted the aromatic odor of the bark. In the Pleistocene deposits of the western United States and Canada are found more or less unaltered specimens of various species of Juniperus, Pseudotsuga, Picea, and Larix.

Some of the pines yield edible seeds which have been used by the Indians of Western America; as the edible or " nut pine" of California and New Mexico (Pinus edulis) ; Pinus monophylla, discovered by Colonel Fremont in Northern California; Pinus Jeffreyi of Northern California ; and Pinus Pinea of Europe, the seeds of the latter being used like almonds and known as "pignone." The seeds of Pinus Lambertiana (Fig. 72, C) of California are baked before being used as a food. This latter species is also known as the sugar pine, as it yields a manna-like product. 
A manna is also yielded by Cedrus Libani and Larix decidua. The latter is known as "Briancon Manna," and contains melizitose. The bark of some species furnishes valuable tanning material, as that of the hemlock spruce (Tsuga canadensis).

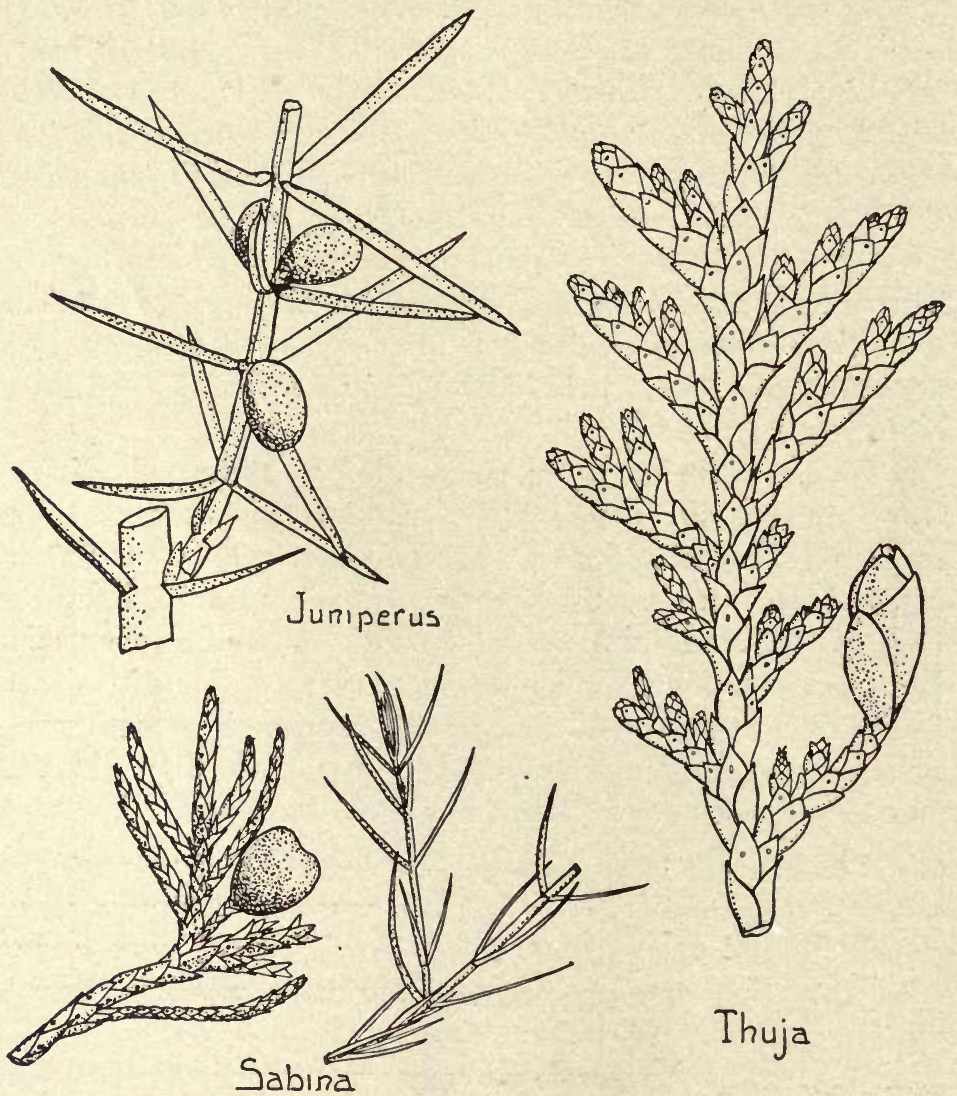

FIg. 76. Fruiting twig of common Juniper (Juniperus communis), of Red Cedar or Savin (Juniperus virginiana), and young twig of White Cedar or Arbor Vitæ (Thuja occidentalis).-From "Minnesota Trees and Shrubs."

The Coniferæ yield large quantities of volatile oils, resins, and allied products which are used both in medicine and the arts. A number of them yield turpentine (see Vol. II). Larix decidua of the Alps and Carpathian mountains yields Venice turpentine. Abies balsamea is the source of Canada turpentine or balsam of 
fir; Seudotanga mucronata or Douglass Spruce (Red fir) is probably the source of a balsam resembling Canada turpentine and which is known commercially as Oregon balsam. Picea Mariana or black spruce yields spruce gum, largely used in the manufacture of chewing gum, and is also the source of spruce beer. Picea excelsa or Norway spruce yields Burgundy pitch. Abies alba, white fir or silver fir yields the Strasburg turpentine. Canada pitch is the resinous exudation from the common hemlock (Tsuga canadensis). Sandarac is yielded by Callitris quadrivalvis found growing in Northwestern Africa. Volatile oils are yielded by a number of the Coniferæ, of which the following may be mentioned: Juniperus Sabina yielding oil of savin; Juniperus communis yielding oil of juniper, both of which are used in medi-

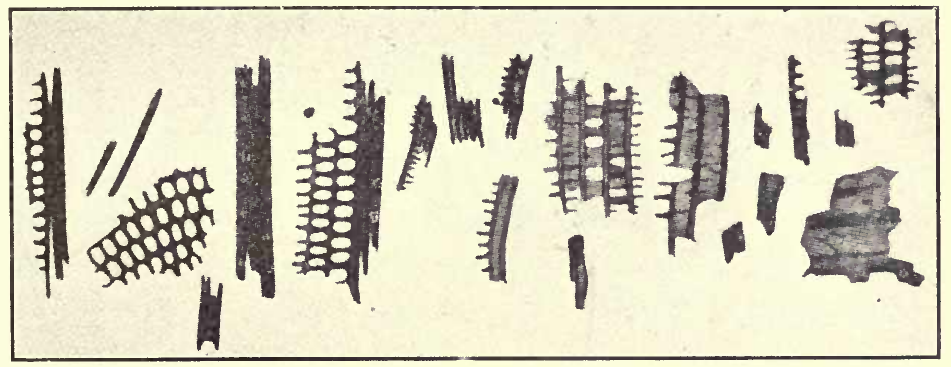

FIG. 77. Microscopical view of fragments of wood found in the coal deposits of upper Silesia, Prussia.--After Link, from article by Potonie on the origin of coal and petroleum in Ber. d. d. pharm. Ges., 1907, p. 181 .

cine. The remains of Coniferæ (Picea, etc.) are often found as fossils, as the fossil resin amber, which is used in the arts, and on distillation yields a volatile oil having medicinal properties.

Angiosperms, General Characters.-They constitute the most conspicuous portion of the flora, embrace the greatest variety of forms, and are the most highly organized members of the plant kingdom. They vary in size from diminutive plants like the windflower to the giant oak which shelters it. They may accomplish their life work in a few months, as the common stramonium, or they may persist for several hundred years, as the trees of our primitive forests. They may inhabit dry desert regions, as the Cacti and Chenopodiaceæ, or they may live wholly in water, as the water lilies. In short, they show the greatest adaptability 
to their surroundings. But no matter how diversified they may seem in form and structure, they agree in this with possibly one exception, namely, mignonette, that the seeds are produced in a closed carpel. This has been considered, as already indicated, to be the chief difference between the Gymnosperms and Angiosperms.

The two groups are further distinguished by several other important characters: (I) The carpel or carpels (megasporophyll) is developed into an organ commonly known as a pistil (Fig. 78). This organ consists of three parts, namely, ovary, style, and stigma, the ovary enclosing the ovules. (2) In the Angiosperms the megaspore (embryo-sac) develops a gametophyte which does
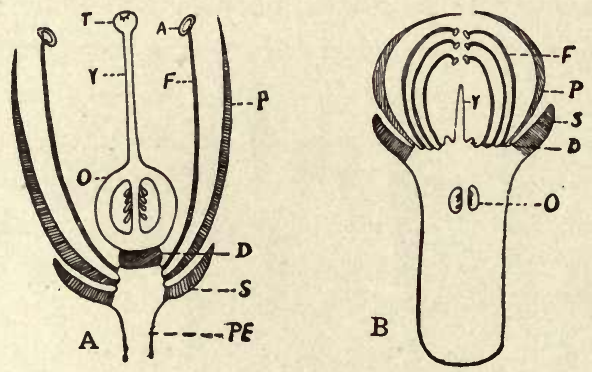

FIG. 78. A, longitudinal section through orange flower (Citrus A urantium) showing stalk (PE); sepals (s); petals (p); stamen with filament $(F)$ and anther (A); compound pistil (composed of united carpels) with stigma (T), style (Y) and superior ovary (O) with ovules; disk or nectary (D). B, longitudinal section of a bud of clove (Caryophyllus) showing inferior ovary $(\mathrm{O})$, style $(\mathrm{Y})$, stamens $(\mathrm{F})$, petals $(\mathrm{P})$, sepals $(\mathrm{S})$, nectary (D).

not give rise to archegonia, but the egg arises directly from the megaspore nucleus by a series of divisions. (3) The Microsporophyll (stamen) differs considerably in structure and appearance from that of the Gymnosperms. The stamen may be defined as a leaf which bears sporangia (spore cases). It usually consists of the following differential parts: filament and anther, the latter consisting of pollen sacs (microsporangia) in which the pollen grains (microspores) are developed (Figs. 78, 79, and 80). (4) In a large number of cases in the Angiosperms there is developed in addition to the sporophylls or sporangial leaves (stamens and pistils) another series of leaves known as floral leaves (Fig. 78). The latter usually are of two kinds, known as sepals and petals. 
The Development of the Two Generations, namely, the sporophyte and gametophyte, is much the same in the Angiosperms as in the Gymnosperms; that is, the sporophyte constitutes the plant body and what is commonly considered to be the plant. The gametophytes are still more reduced than was the case in the Gymnosperms, the male gametophyte consisting of but two cells.

Beginning with the germination of the seed, we may outline the life history of the plant as was done under Gymnosperms. The seeds in the two groups are much alike, with the exception that in the Angiosperms they usually have two integuments. Within the Angiosperms two classes of embryos are distinguished, which give rise to the most important division of this group of plants. In the one case a single cotyledon is formed at the apex of the stem, and all plants having an embryo of this kind are known as monocotyledons, that is, plants having one seed leaf. In the other case two cotyledons arise laterally on the stem and opposite each other, and those plants having an embryo of this type are grouped together as DICOTYLEDONs, or plants having two seed leaves. In the monocotyledons the cotyledon is limited to one, but in the dicotyledons the seed leaves are not limited in number and there may sometimes be three or more.

The sporophyte which develops from the germinating seed consists of the essential parts already given, i.e., root, stem, and leaves. The leaves are of four kinds: (I) Foliage leaves, (2) scale leaves or bud scales, (3) floral leaves, which in some cases are wanting, and (4) sporangial leaves or sporophylls. Inasmuch as the latter give rise to the gametophytes (male and female) the development of the sporangia in each will be considered in detail.

The Microsporangia (pollen sacs) arise by the division of certain cells under the epidermis of the anther (Fig. 79). This process of division continues until four regions of fertile tissue (sporangia) are produced (Fig. 79, D). The sporangia are directly surrounded by a continuous layer of cells which constitutes the tapetum or tapetal cells (Fig. 79, t), these being in the nature of secretion cells and containing considerable oil. The tapetum is in turn surrounded by a layer of cells which are peculiarly thickened and which on drying assist in the opening 
of the anther and the discharge of the pollen, and this layer is called the endothecium (Fig. 79, end). There is still a third or external layer of cells, which constitutes the exothecium (Fig. 79, $e x)$. These four sporangial regions may remain more or less distinct and separate at maturity, or the two on either side may
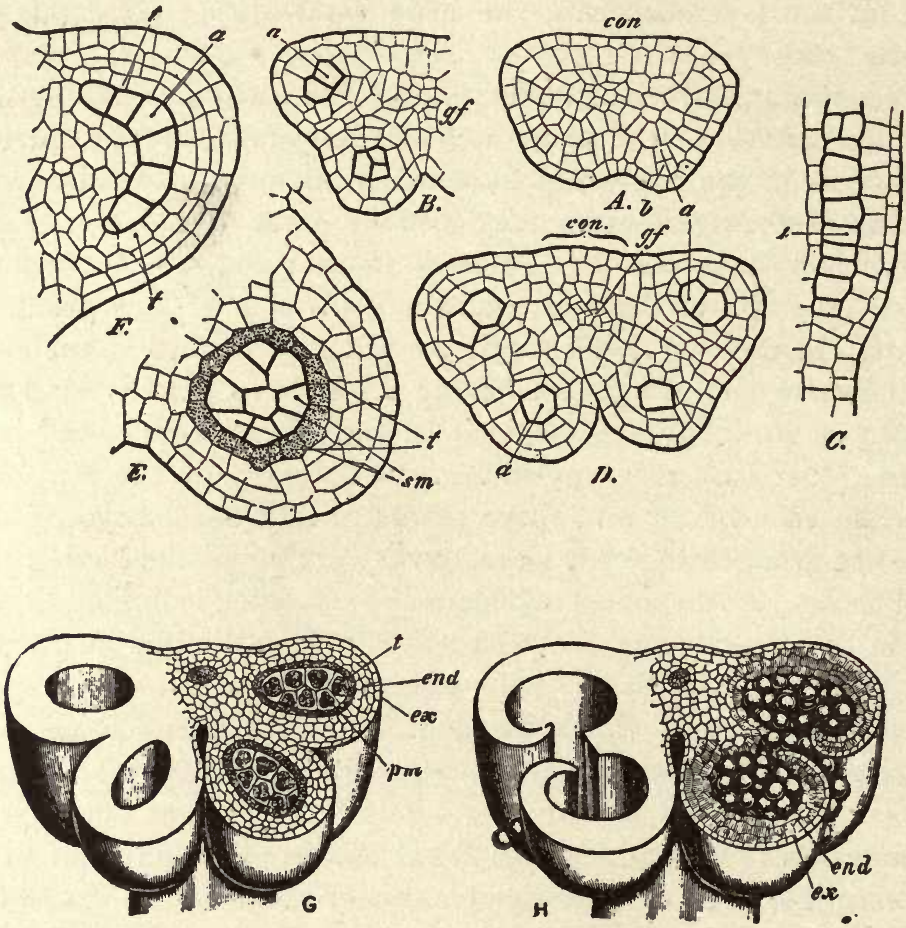

Frg. 79. Development of pollen sacs (microsporangia) in several of the Angiosperms: A, showing beginning of archesporium (a), an outer sterile layer (b), position of connective (con); B, later stage showing development of fibrovascular tissue (gf); C, longitudinal section of archesporium; D, E, F, successive later stages showing in addition pollen mother cells $(\mathrm{sm})$ and tapetum layer $(t)$. G, H, diagrammatic sections of mature pollen sacs showing pollen mother cells ( $\mathrm{pm}$ ), tapetum $(\mathrm{t})$, endothecium (end), exothecium (ex), and in $\mathrm{H}$ longitudinal dehiscence with formation of what appears to be a unilocular pollen sac on either side of the connective.-A-F, after Warming; $\mathrm{G}-\mathrm{H}$, after Baillon and Luerssen.

coalesce. This latter usually occurs at maturity, when dehiscence takes place, forming apparently a single pollen sac on either side of the connective or axis (Fig. 79, $H$ ).

The Microspores (pollen grains) are developed somewhat differently in Monocotyledons and Dicotyledons. In most mono- 
cotyledons the nucleus of each cell (pollen mother cell) making up the archesporium divides into two nuclei, each of which takes on a wall of cellulose. Each of these (daughter cells) in turn divides, giving rise to four pollen grains. In dicotyledons (Fig. 80 ) the nucleus of a mother cell divides into four nuclei before the walls are formed which separate the nuclei, thus giving rise to the tetrad group of spores to which attention has already been called (Fig. 6o, $D$ ) under Bryophytes. The wall of each spore is divided into two layers, an inner layer consisting of cellulose known as the intine, which gives rise to the pollen tube on germination of the spore; and an outer layer somewhat different in

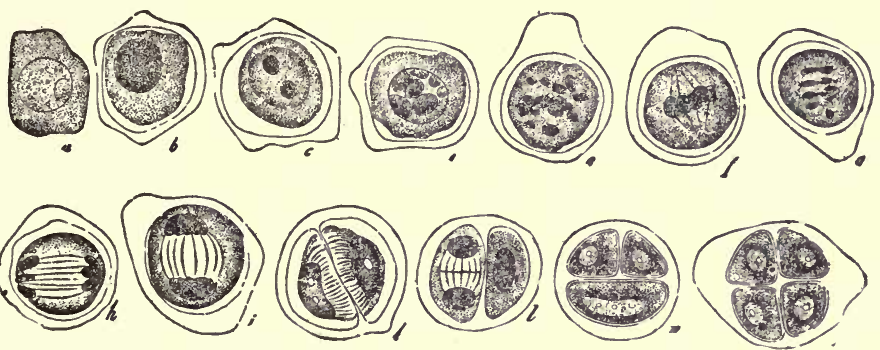

Fig. 8o. Development of pollen grains (microspores) of garlic (Allium narcissiflorum): a, pollen mother cell with nucleus; $b$, the same with homogeneous nucleus and a thicker wall; $c-e$, changes in nucleus prior to division; $f$, formation of spindle with nuclear masses in the center from which nuclear threads extend to the poles of the spindle; $g$, division of nuclear substance and receding of it from the center of the cell; $h-i$, further stages in the organization of the nuclear substance at the poles; $\mathrm{k}$, formation of a wall between two daughter cells; 1 , beginning of division of one daughter cell; $m-n$, final divisions resulting in the formation of a tetrad (group of 4 cells).-After Strasburger.

composition and variously sculptured, known as the exine. When the spores are mature the original walls of the cells of the archesporium dissolve and the ripe pollen grains are set free, forming a yellowish powdery mass filling the pollen sac. In some cases the spores of the tetrads hang together, or even the whole mass of pollen tetrads may be more or less agglutinated, as in the orchids and milkweeds, these masses being known as pollinia.

Male Gametophyte.-Before the dispersal of the pollen grains or microspores, certain changes leading to the development of the gametophyte have taken place (Fig. 8I). The spore, as we have seen, is unicellular. This divides into two cells: one, which is relatively small, known as the mother cell of the antheridium (Fig. 8r, v), and another, which, composed of the remaining 
nucleus with the surrounding cell-contents, constitutes the tube- or wall-cell of the antheridium.

Development of Ovule and Megasporangium (nucellus).The ovule at first develops as a small protuberance on the inner surface of the ovary, after which it differentiates into $(a)$ a stalk or funiculus by which it is attached to the ovary, the tissue to which it is attached being called the placenta; and $(b)$ an upper portion which becomes the ovule proper. The differentiation of the tissues is in a general way as follows: (I) The cells beneath the epidermis in the apical portion of the ovule go to make up the megasporangium (nucellus); (2) the peripheral cells from below the nucellus give rise to the integuments; and (3) while the integuments are developing the archesporium or mother cell of the

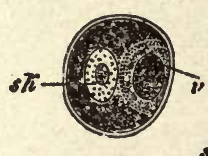

I.

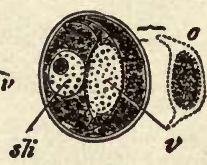

II.

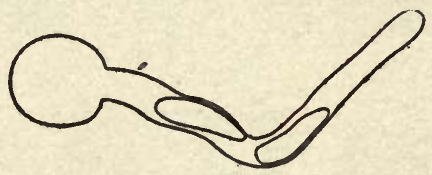

III.

Fig. 8r. Development of male gametophyte in an Angiosperm. I, pollen grain (microspore) which has divided into the mother or generative cell (v) and a larger tube-cell with nucleus (sk); II, appearance of pollen on treatment with osmic acid showing the separation of the generative celi (v) from the wall of the pollen grain; o, at the right giving a view of the generative cell with the nucleus embedded in the hyaline protoplasm; III, showing the development of the tube-cell into the pollen tube which contains the two male cells (nuclei) or gametes formed by the generative cell.-After Elfving.

embryo-sac (megaspore) is being formed within the nucellus near the apex.

Female Gametophyte.-The archesporium divides into two cells, the lower one of which repeatedly divides, finally giving rise to the embryo-sac which is sunk in the tissues of the nucellus. The nucleus of the embryo-sac divides and redivides until 8 cells are produced (Figs. 82 and 83 ), which are separated into the following groups: (I) Three of the cells form a group lying at the apex, the lower cell of the group being the egg or egg-cell, the other two cells being known as synergids or helping cells. (2) At the opposite end of the sac are three cells, known as antipodal cells, which usually develop a wall of cellulose and do not seem to have any special function. (3) Near the centre of the sac are the two remaining nuclei, which unite to form a single nucleus, from 

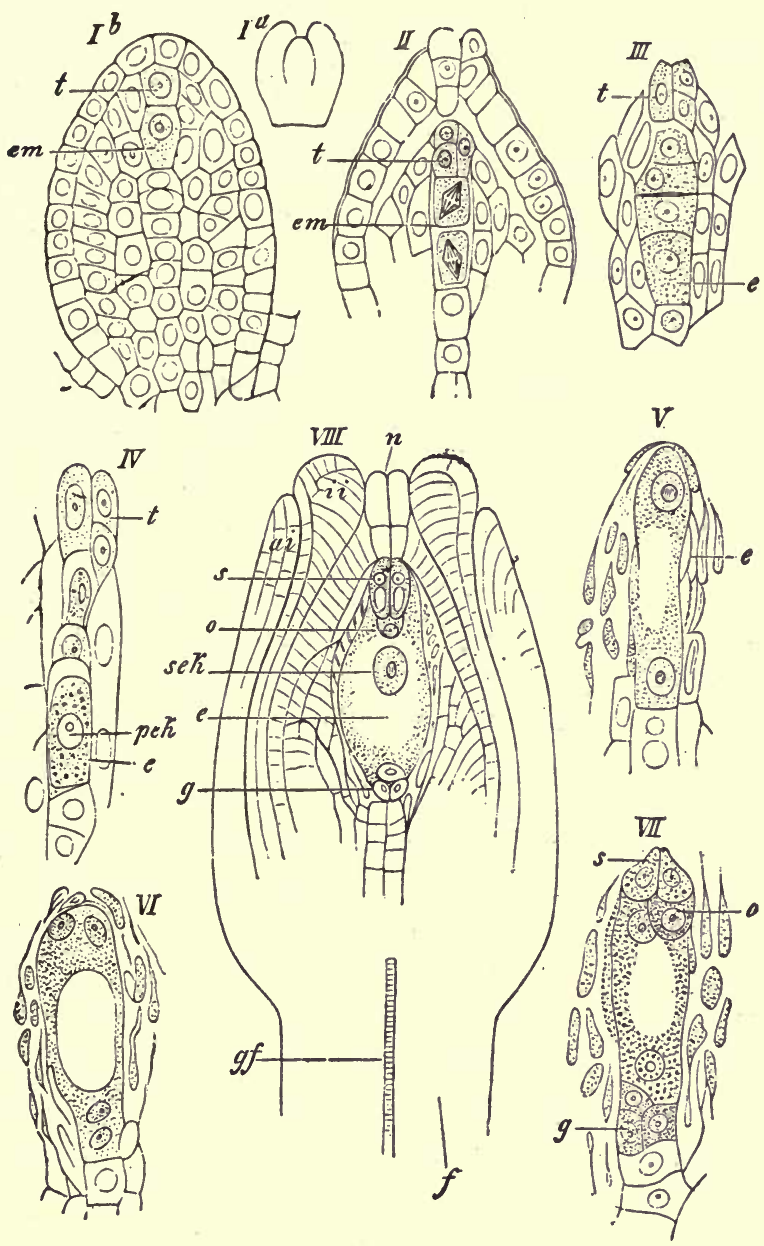

FIG. 82. Development of embryo-sac or megaspore in an Angiosperm. Ia, longitudinal section through a young ovule. Ib, longitudinal section through a rudimentary ovule before the formation of the integument, showing mother cell of the embryo-sac (megaspore) (em) and primary tapetal cell (t). II, later stage showing the two cells into which the mother cell has divided, the nuclei of which are in the act of dividing. III, mothercell of the embryo-sac divided into four cells (sporogenous mass of cells); the lowest of these cells (e) displaces the rest and becomes the embryo-sac in IV. IV, pek, is the primary nucleus of the embryo-sac. V, two daughter cells resulting from the division of the nucleus of the embryo-sac. VI, VII, show egg apparatus composed of two synergids (s) and the oossphere (o), and antipodal cells $(\mathrm{g})$. VIII, longitudinal section through a mature ovule with the inner integument (ii), the outer integument (ai), the nucellus ( $n$ ), the vascular bundle (gf) entering the funiculus (f), and secondary nucleus in the embryo-sac (sek).After Strasburger. 
which after fertilization the endosperm is derived. The embryosac, as it is organized at this stage, constitutes what is regarded as the female gametophyte (Fig. 82). The undifferentiated embryo-sac constitutes the megaspore, which latter, after germination or differentiation into egg-cell and other cells, constitutes the gametophyte. It is thus seen that in the female gametophyte of the Angiosperm archegonia are apparently not formed. The gametophyte, then, consists of the cell group containing the egg and the remaining portion of the embryo-sac, which latter may be compared to a prothallus. This comparison is not difficult to understand if we bear in mind the structure of the gametophyte in the Gymnosperms, and particularly if we recall the structure in Selaginella and other higher Pteridophytes.

Fertilization.-While in the Gymnosperms the pollen grains are usually provided with wings so as to bring about their transferral to the carpel by the agency of the wind, in the Angiosperms, on the other hand, the grains are not provided with wings, but are adapted to the transferral by insects. Pollination, however, may be also effected by the wind, as is the case with many of our forest trees. After the deposition of the pollen grain on the stigma, the tube-cell begins to form a tubular process (pollen tube) which carries the male nuclei to the egg-cell (Fig. 83, $i$ ). It pierces the tissue of the stigma (Fig. 83, $h$ ) and traverses the style (Fig. $83, g$ ) until it reaches the micropyle of the ovule, which it enters (Fig. $83, m$ ), then reaching the nucellus it penetrates this, entering the embryo-sac. The tip of the tube breaks and one of the generative nuclei which has been carried downward unites with the egg, after which a wall is formed, giving rise to an oöspore. The oöspore develops at once into the embryo or plantlet as seen in the seed, this stage being followed by a period of rest. In fact, the young plant may lie dormant in the seed for years.

Development of Seed.-The steps in the development of the mature seed occur in the following order (Fig. 84). The oöspore divides into two parts, an upper portion which gives rise to the embryo, and a lower portion which by transverse segmentation gives rise to a short suspensor (Fig. 84, v) which practically serves the same purpose as in the Gymnosperms (page III). The embryonal cell develops the embryo, which consists of : (I) a root por- 
tion which is connected with the suspensor (Fig. 84, w); (2) one or two cotyledons (Fig. 84, c) which are attached to the stem; (3) a little bud at the apex of the stem which is known as the plumule.

While the embryo is developing, the nucleus of the embryosac, either after fusing with the prothallial cell of the pollen grain, or in the absence of such union, begins active division, forming,

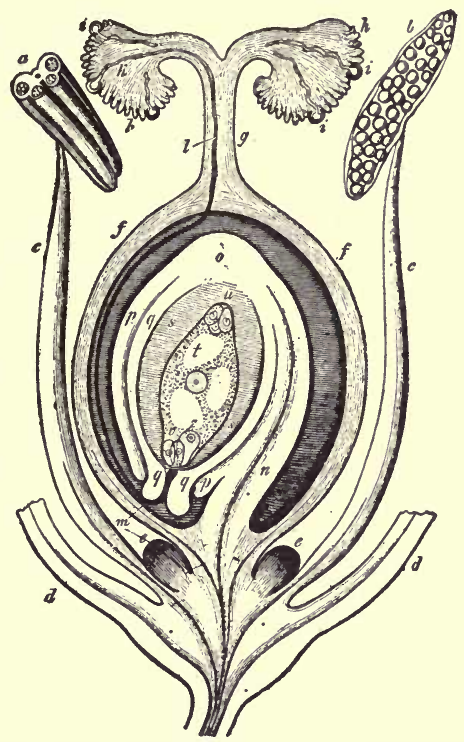

FIG. 83. Diagrammatic representation of fertilization in an Angiosperm. d, floral leaves; stamen consisting of filament (c) and anthers (a,b), one of which (b) has dehisced, exhibiting numerous pollen grains; e, nectar-secreting bodies; pistil consisting of ovary (f), style (g), and stigma (h). On the latter pollen grains (i) are germinating, the tube (1) of one of them has penetrated the tissues of the stigma and style, and entered the foramen $(m)$, or opening of the ovule. The ovule consists of several parts: raphe $(n)$, outer integument $(p)$, inner integument $(q)$, chalaza (o), nucellus (s), embryo-sac or megaspore $(t)$ with egg-cell (z), synergids (v), antipodal cells (u), and the nucleus in the center which gives rise to the endosperm.-After Sachs.

a highly nutritive tissue rich in starch, oil, or proteins, known as the endosperm (see chapter on Seed). Simultaneously with the development of the endosperm the nucellus may give rise to a nutritive layer called the perisperm, or the tissues of the nucellus may be modified and form, with the altered integuments or coats of the ovule, the seed-coat.

Inasmuch as the Angiosperms furnish by far the larger proportion of plants and plant products used in medicine, it is desir- 
able to give particular attention to the morphology of this group, as also to the distinguishing characters of a number of the important families.

Economic Importance.-As indicating the great usefulness to mankind of the products obtained from the Angiosperms it will be sufficient to merely mention that all of our garden vegetables as

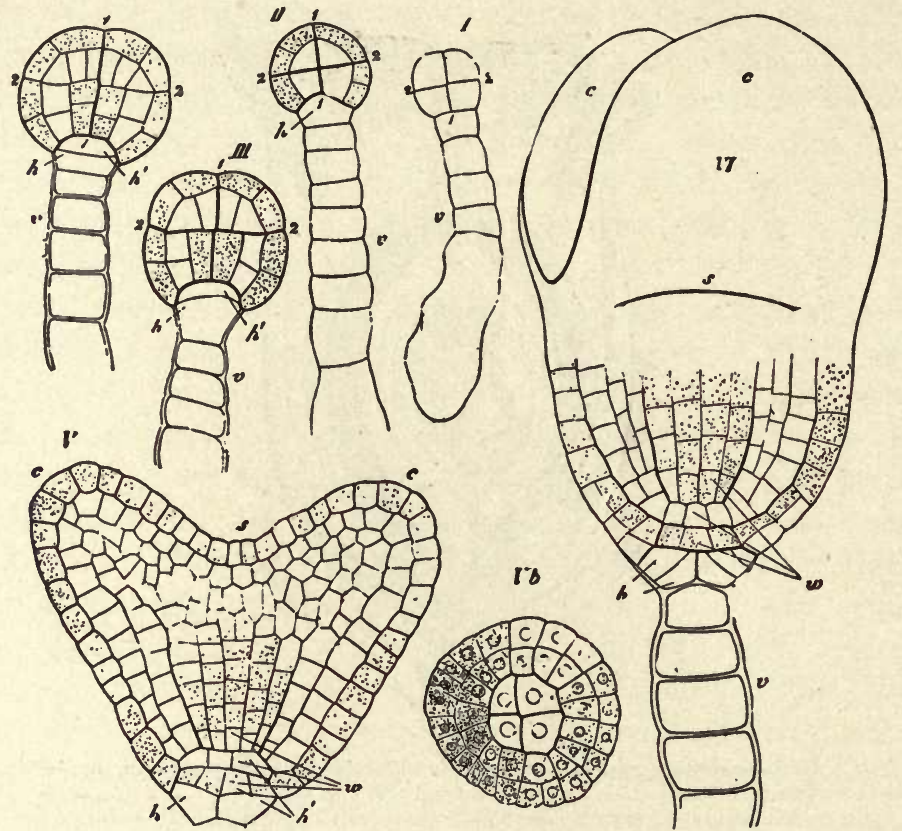

Fig. 84. Development of embryo in the shepherd's purse (Capsella Bursa-pastoris). I-VI, various stages of development: Vb, apex of the root seen from below. $I, 1,2,2$, the first divisions of the apical cell of the pro-embryo (suspensor); $h, h$, cells from which the primary root and root-cap are derived; $v$, the pro-embryo; c, cotyledons; s, apex of the axis; w, root.-After Hanstein.

well as the great crops of cereals like wheat, corn, rye, etc.; edible fruits and seeds ; textile products, such as cotton, flax, etc. ; medicinal products; timbers of various kinds, as oak, mahogany, walnut, chestnut, cherry, etc., are furnished by this great group of plants.

\section{EVOLUTION.}

Contrary to a popular opinion, the idea of evolution is almost as old as the human race. From the time when man began to think about the things around him he could not help but see that 
nothing was permanent, and he could not help but wonder how both the inorganic and the organic world came to be as he found them. The fact is, then, that for years the thinking element of the human race has had a fairly clear conception of the idea of evolution; all they lacked was the proof. Nothing is more decidedly

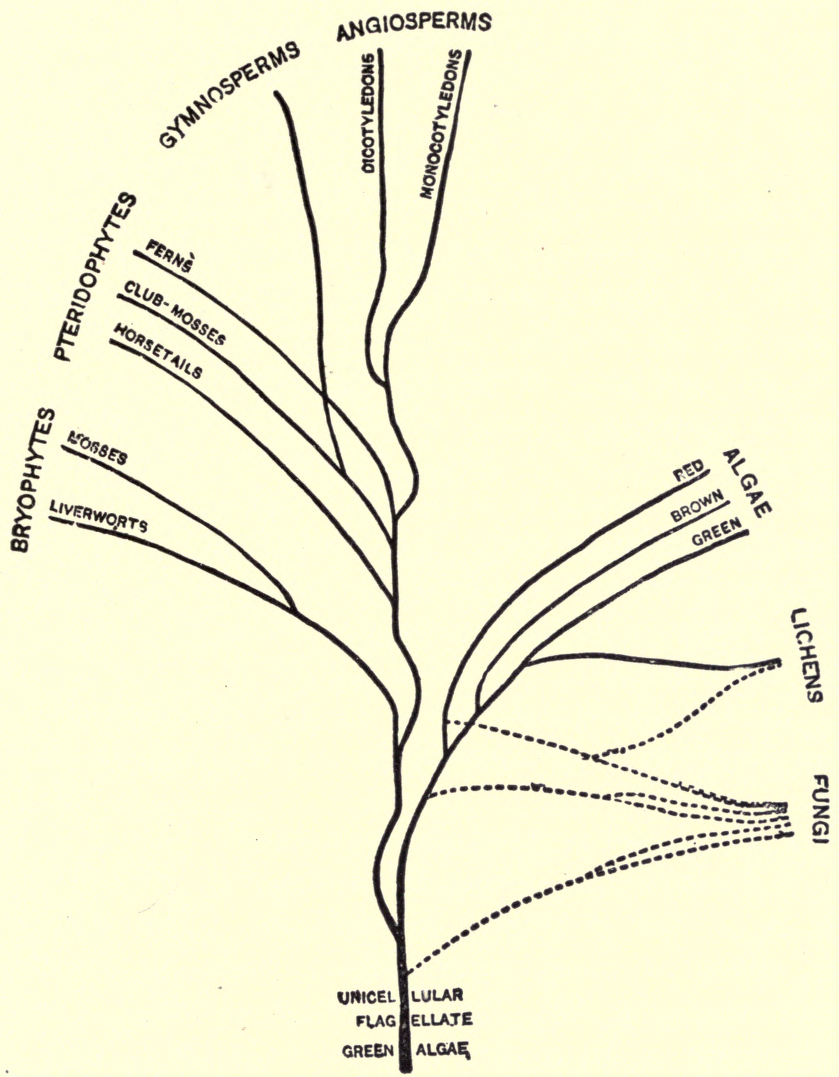

FIG. 84A. Hypothetical tree of relationship and descent of the leading groups of plants. - After Ganong.

wrong than the belief that Darwin first conceived the theory of evolution. His renown only lies in the fact that he was one of the first to suggest an explanation, and probably also because his explanation came at a most opportune time and was worked up in such a masterly way. 
The theory of evolution has as its basis the idea that the existing species of plants and animals are the descendants of earlier forms. It holds that there is an unbroken line of descent from the beginning of life on the earth, but that during the long ages the successive descendants gradually changed in appearance from their ancestors until we find the forms of the present day.

Nearly all branches of biological science give evidence in support of the theory of evolution. Embryology, for instance, has shown that in its development the individual during its life, beginning with the fertilization of the egg-cell, passes through a series of stages which are thought to represent the same series of stages through which the whole race before it passed. The development of the individual (i.e., ontogeny) represents in a very brief space of time the evolution of the race (i.e., phylogeny). In other words, "ontogeny epitomizes phylogeny."

Another branch of science which is bringing forth new evidence is the branch called paleontology. This subject has to do with the study of fossil remains and with the time they existed on the earth in the living state. It has been found that fossils from the different series of formations that make up the earth's outer crust represent a regular advancement from the very simplest types to those which are most complicated, right up to the most recent forms. In not a single instance has a highly developed form been found in a layer of rocks representing an early stage in the earth's history.

Every scientist of the present time, probably without exception, believes in the theory of evolution, but there is a great diversity of opinion as to how it should be explained. This diversity of thought, instead of disproving the idea of evolution, is making its truth more generally felt. The problem, then, which is confronting the scientist is not to prove that evolution is a truth, but to explain it; to show how new forms may arise from old ones,that is, to account for the origin of species. Among the many explanations the following have become most conspicuous:

ENVIRONMENT.-It was naturally thought at first that the natural conditions under which organic life developed must have a certain effect upon the individual, thereby bringing about a certain modification which would be transmitted in successively 
greater degree to those progeny living under the same conditions, and so gradually give rise to a different species. This, of course, assumes that any change induced by environment would be transmitted to the offspring, to be retained so long as the environment remained constant, an assumption which is probably not far from the truth. While it is admitted that changes in the environment may cause direct responses, yet it is doubtful whether they are definite or permanent enough to produce new forms. Near the end of the eighteenth century this explanation was supported by Erasmus Darwin of England, St. Hilaire of France, and Goethe of Germany.

USE AND DisUSE.-There is very little difference between this explanation and the preceding one. Lamarck proposed, in the early part of the nineteenth century, that the use or disuse of organs would so modify them that the acquired differences would be inherited by the offspring. But, here again, the proof depends upon the transmission of acquired characters, and this is now almost disproved.

Natural Selection.-In I859 Darwin published his " Origin of Species by Means of Natural Selection," and this single event revolutionized science. In this book Darwin arranged an enormous mass of facts gained through many travels, incessant observation, and prolonged experiments. He built up an argument in such a convincing way as to immediately attract the attention of the world, not only of scientists but of laymen. The theory of natural selection has for its basis the idea that great competition is continually taking place between individuals of the same species and between the individuals of various species. This struggle for existence results in the "survival of the fittest" and the destruction of the unfit. The idea that two plants or animals from the same parent might vary slightly, suggested the belief that the one which was better equipped for the struggle for existence would survive and so transmit its desirable characteristics to its offspring, and that the unfortunate one would not survive and its undesirable characteristics would thus be lost to the race.

The objections to the theory of natural selection are of various kinds, but the most serious is probably the fact that it is hard to conceive how a very slight difference in character can be of advan- 
tage in a life and death struggle. Necessarily when natural selection first begins to operate on two individuals the differences must be only slight and hardly sufficient to give one of them such a vital advantage over the other.

Mutation.-This explanation was offered in I90I by Hugo de Vries of Holland. The word mutation means a change. In this sense it means a sudden change and has to do with the fact that among the offspring of a certain individual may be found one or more individuals markedly differing from the parent, so much so as to be regarded in a few instances as a distinct species. Moreover, these mutants, as they are called, continue to breed true, thereby giving rise to what might very well be called a new species. In the study of mutation many experiments have been conducted by scientists and breeders.

MendeL's LAw.-In intimate relationship with the subject of evolution is the question of heredity. In the middle of the last century there lived an Austrian monk, Mendel by name, who experimented with the cultivation of peas and other plants in the monastery garden. In his studies he discovered a certain law underlying the transmission of characters in reproduction. This law, which for many years lay hidden from the scientific world, was recently brought to light and now forms the basis of most of the recent breeding experiments and is of profound value in the study of heredity. In the simplest case it is as follows: If two different species, $\mathrm{A}$ and $\mathrm{B}$, are crossed, the result is a hybrid (AB) which combines certain characters of both parents. When this hybrid propagates, the progeny splits up into three sets: one resembling the hybrid parent $(\mathrm{AB})$; and the other two sets resembling the parent forms ( $A$ and $B$ ) that entered into the hybrid. Mendel's law is a statement of the mathematical ratio expressed by these three groups of forms derived from a "splitting" hybrid. This means that in a series of generations initiated by a hybrid, approximately one-half of the individuals of each generation will represent the hybrid mixture, one-fourth of the individuals will represent one of the pure forms that entered into the hybrid, and the remaining fourth will represent the other pure form. Of course, the I: $2:$ I ratio holds only when the one unit-character is involved, and does not apply to the hybrids as a whole, as different characteristics are generally inherited independently of others. 
It should be understood that the use, of hybrids in such experimental work is simply a device to secure easy recognition of the contributions of each parent to the progeny. For example, if red and yellow races of corn are crossed, it is very simple to recognize the color contribution of each parent to the hybrid progeny, when it would be impossible to separate the contribution of two yellow parents. The inference is, that what is tue of hybrids is true of fcirms produced in the ordinary way so that laws of heredity obtained from a study of hybrids thay be regarded as laws of heredity in general.

In the working out of Meplel's law it has been observed that, while one-fourth of the proghny are like one parent, the remairing three-fourths will all show the characteristics of the other parent, although only one of $i$ the renaining three-fourths will breed true. That is to say that the hybrids, which make us half of the progeny, look like one of the parents, but all do not breed true to that parent.

In this case the character of the true pure-strain parent which marks the hybrids is said to be a dominant character, while the character of the other pure-strain parent is said to be a recessive character, because in the hybrids its presence can not be observed and can be discovered only by breeding the hybrids.

It is only by experiment and breeding that dominant and recessive characters can be determined. For instance, in the culture of peas the character of being tall has been found to be dominant over the character of being dwarf. This means that all the hybrids will be tall, although one-fourth of their progeny will be dwarf.

Again in the pea, the character of having a round seed is found to be dominant over that of having a wrinkled seed. In wheat the character of being beardless is dominant over that of being bearded, and again the character of being susceptible to rust is dominant over that of being immune to rust.

The infinite number of characters which complicates the study of hybrids and the fact that in breeding it is sometimes the dominant and sometimes the recessive character which is the desirable one to maintain suggest at a glance the breadth and difficulty of the problem. 


\section{CHAPTER II. \\ CELL-CC INTENTS AND FORMS OF CELLS.}

A TYPICAL livin' $\mathrm{g}$ cell may be said to consist of a walı and a protoplast (a unit or protoplasm), although it is often customar to refer to the protoplas + alone as constituting the cell. This is $y$ in stance of the protoplast is the living substance of the plo sub-

Besides the protoplasm other surbstances are also fr ant. sund in the cerl, hence in a general way the cel 4 may be said, 5 ' be composed of a wall andi contents (cell-content 3 ; cell-contents, consists of a number if substances, and, as the cellcontents are of primary importan 2 in the development of the plant, their nature and conipositir $n$ will be considered first.

Cell-contents.-With the distinction already made the cellcontents may be grouped into two classes: (I) Protoplasmic, or those in which the life-processes of the plant, or cell, are manifested; and (2) non-protoplasmic, or those which are the direct or indirect products of the protoplast. The first class includes the protoplasm with its various differentiated parts, and the second, the various carbohydrates (starches and sugars), calcium oxalate, aleurone, tannin, oil, and a number of other substances.

\section{PROTOPLASMIC CELL-CONTENTS.}

Protoplasm.-Protoplasm occurs as a more or less semifluid, slimy, granular, or foam-like substance, which lies close to the walls of the cell as a relatively thin layer and surrounding a large central cavity or vacuole filled with cell-sap, or it may be distributed in the form of threads or bands forming a kind of network enclosing smaller vacuoles. Protoplasm consists of two comparatively well differentiated portions: (I) Certain more or less distinct bodies which appear to have particular functions and to which a great deal of study has been given, as the nucleus and plastıds; and (2) a less dense portion which may be looked upon 
as the ground substance of the protoplast and which is now commonly referred to as the CYTOPLASM (see Frontispiece). These differentiated bodies and the cytoplasm are intimately associated and interdependent. The nucleus and cytoplasm are present in all living cells, and it is through their special activities that cell

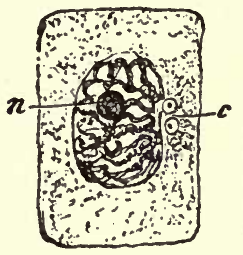

1

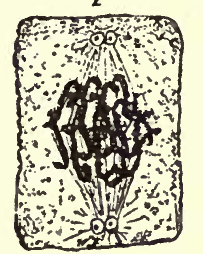

5

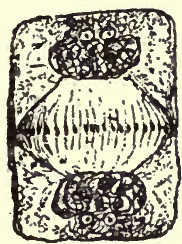

$\vartheta$

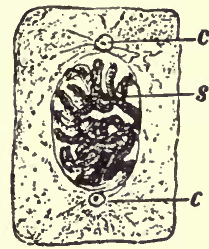

2

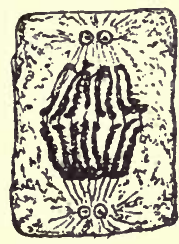

6

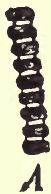

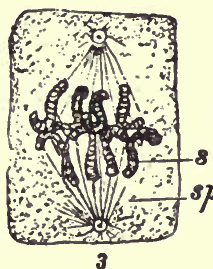

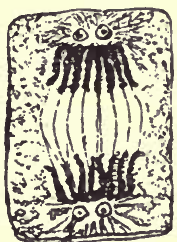

7
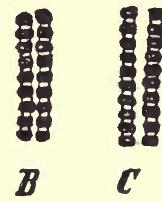

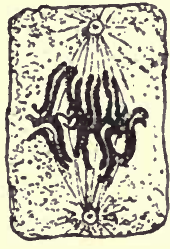

4

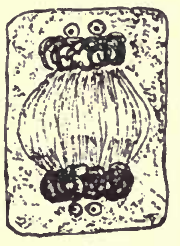

8

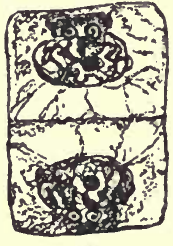

10

FIG. 85. Successive stages in nuclear and cell division. n, nucleolus; c, centrospheres s, chromosomes; sp, spindle fibers; A, B, C, division of chromosomes. I, cell with nucleus containing nucleolus $(n)$, and two centrospheres (c); 2 , showing separation of nucleus into distinct chromosomes (s) and the centrospheres at either pole of the nucleus; 3 , formation of spindle fibers ( $\mathrm{sp}) ; 4$, longitudinal division of chromosomes; 5 , division of the centrospheres; $6,7,8$, further stages in the development of the daughter nuclei; 9, formation of cell-wall which is completed in ro giving rise to two new cells.-After Strasburger.

division takes place. When, in addition, plastids are present, constructive metabolism takes place, whereby complex substances are formed from simpler ones.

Besides the nucleus and plastids other protoplasmic structures are sometimes found embedded in the cytoplasm. These are the CENTROSPHERES (Fig. 85, c), small spherical bodies that are 
associated with the nucleus and appear to be concerned in cell division. There are, in fact, quite a number of minute bodies in the cytoplasm which may be always present or only under certain conditions, and which are grouped under the general name of MICROSOMES Or MICROSOMATA.

Chemically protoplasm is an extremely complex substance, but does not appear to have a definite molecular structure of its own, being composed in large measure of proteins, a class of organic compounds which always contain nitrogen, and frequently phosphorus and sulphur. The molecule of the proteins is large and more or less unstable, and hence subject to rapid changes and a variety of combinations, and it is to these interactions that the vital activities of the plant are attributed.

Nucleus.-The nucleus consists of (I) a ground substance in which is embedded (2) a network composed of threads containing a granular material known as chromatin, and (3) generally one or more spherical bodies called NucLEoLEs, the whole being enclosed by (4) a delicate membrane (Fig. 85 ). The chromatin threads are readily stained by some of the aniline dyes, and are mainly composed of nucleins (proteins) rich in phosphorus, which by some writers are supposed to be essential constituents of the nucleus and necessary to the life of the protoplast. Chromatin is constant in the nucleus, and prior to cell division the threads become organized into bodies of a definite number and shape known as CHRomosomes (Fig. $85, s$ ).

Plastids.-The plastids or chromatophores form a group of differentiated protoplasmic bodies found in the cytoplasm (Frontispiece) and are associated with it in the building up of complex organic compounds, as starch, oil, and proteins. The term chromatophore means color-bearer, but applies also to those plastids which may be colorless at one stage and pigmented at another. Hence we may speak of colorless chromatophores. According to the position of the cells in which these bodies occur and the functions they perform, they vary in color-three distinct kinds being recognized. ( I ) In the egg-cell and in the cells of roots, rhizomes, and seeds the plastids are colorless and are called LEUCOPLASTIDS. (2) When they occur in cells which are more or less exposed to light and produce the green pigment called chloro- 
phyll, they are known as CHLOROPLASTids or chloroplasts. (3) In other cases, independently of the position of the cells as to light or darkness, the plastids develop a yellowish or orange-colored principle, which may be termed chromophyll, and are known as CHROMOPLASTIDS. Chloroplastids are found in all plants except Fungi and non-chlorophyllous flowering plants, and chromoplastids in all plants except Fungi. Plastids vary in form from more or less spherical to polygonal or irregular-shaped bodies, and they increase in number by simple fission. They suffer decomposition much more readily than the nucleus, and are found in dried material in a more or less altered condition.

Leucoplastids.-The chief function of the leucoplastids is that of building up reserve starches or those stored by the plant for food, and they may be best studied in the common potato tuber, rhizome of iris, and the overground tubers of Phaius (Fig. $2, b)$. The reserve starches are formed by the leucoplastids from sugar and other soluble carbohydrates.

The chloroplastids occur in all the green parts of plants (see Frontispiece). They vary from 3 to II $\mu$ in diameter and are more or less spherical or lenticular in shape, except in the Algæ, where they are large and in the shape of bands or disks (Figs. 8 and 9), and generally spoken of as chromatophores. Chloroplastids are found in greater abundance in the cells near the upper surface of the leaf than upon the under surface, the proportion being about five to one. These grains, upon close examination, are found to consist of (I) a colorless stroma, or liquid, in which are embedded (2) green granules; (3) colorless granules; (4) protein masses; (5) starch grains; and (6) a membrane which surrounds the whole. The green granules are looked upon as the photosynthetic bodies; the colorless grains are supposed to assist in the storing of starch or in the production of amylase, the conditions for these processes being directly opposite, i.e., when photosynthesis is active, starch is stored, and when this process is not going on, as at night, amylase is produced and the starch is dissolved. The protein grains may be in the nature of a reserve material of the plastid and probably are also formed in connection with photosynthetic products.

While the protoplasm has been termed by Huxley " The phys- 
ical basis of life," the chloroplastid has been spoken of as the mill which supplies the world with its food, for it is by the process of photosynthesis that the energy of the sun is converted into vital energy, and starch and other products formed, which become not only the source of food for the plant itself, but also the source of the food-supply of the animals which feed upon plants. In other words, horse-power is derived from the energy of the sun which is stored in the starch grains of the chloroplastids.

Chromoplastids.-In many cases, as in roots, like those of carrot, or flowers and fruits, which are yellowish or orangecolored, there is present a corresponding yellow pigment, and to this class of pigments the name chromophyll may be applied. Some of these pigments, as the carotin in carrot, have been isolated in a crystalline condition (see Frontispiece, also Fig. 86).

Chromoplastids usually contain, as first pointed out by Schimper and Meyer, protein substances in the form of crystal-like bodies; starch-grains may also be present. The chromoplastids are very variable in shape and in other ways are markedly different from the chloroplastids. They are more unstable than the chloroplastids, and are formed in underground parts of the plant, as in roots, as well as in parts exposed to the light, as in the flower. Their formation frequently follows that of the chloroplastids, as in the ripening of certain yellow fruits, such as apples, oranges, persimmons, etc.

The PLASTID PIGMENTS are distinguished from all other colorsubstances in the plant by the fact that they are insoluble in water and soluble in ether, chloroform, and similar solvents. In fact, they are but little affected by the usual chemical reagents under ordinary conditions.

Apart from the difference in color, the yellow pigment (chromophyll) is distinguished from the green (chlorophyll) by the fact that the latter is said to contain nitrogen, and also by their difference in behavior when examined spectroscopically, chlorophyll giving several distinct bands in the yellow and orange portion of the spectrum, which are wanting in the spectrum of the yellow principle.

Cytology, or the science of cell formation and cell life. During recent years considerable attention has been given by botanists 

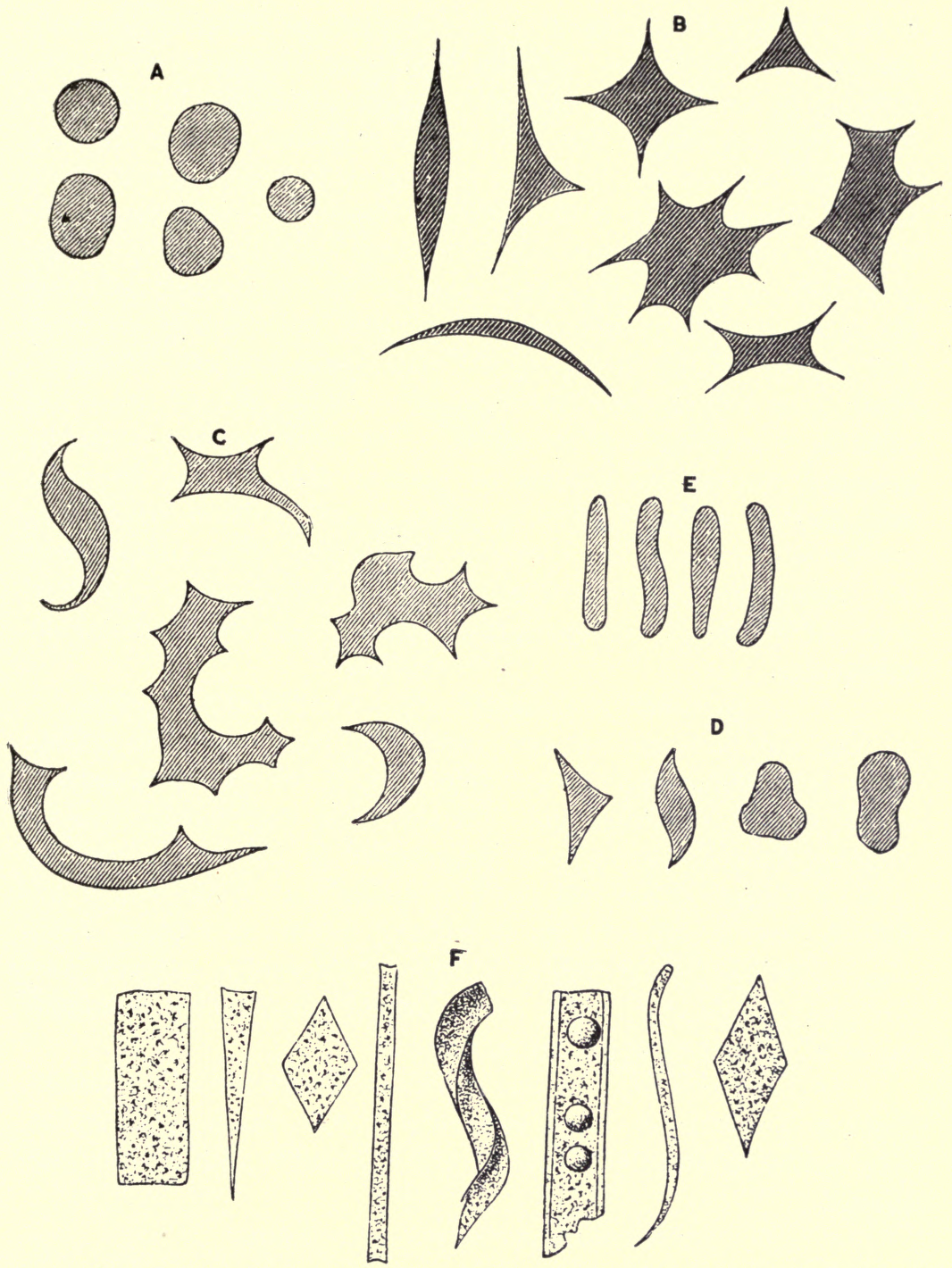

FIG. 86. Various forms of Chromoplastids: A, from the fruit of Bryonia dioica; B, the fruit of the European mountain ash (Pyrus aucuparia); C, the petals of nasturtium (Tropaolum majus); D, petals of Iris pseudacorus, E, petals of Tulipa Gesneriana; F, the root of carrot (Daucus Carota).-After Dippel in "Das Mikroskop." 
to the studies of the protoplasmic structures of the cell, especially the nucleus; the reason for this being that all of the vital phenomena of which living organisms are capable have their origin in these substances. The nucleus is regarded as a controlling center of cell activity, for upon it all growth and development of the cell depend, and it is the agent for the transmission of specific qualities from one generation to another. Furthermore, cytologists look upon the chromatin material of the nucleus as being the agent for the transmission of individual characters to offspring. The reason for this is that in the male generative cell it is practically only the nucleus which fuses with the egg-cell, no other substances entering into the union. The centrosomes are usually apparent during the process of nuclear division and by some are regarded as the controlling organ of cell division, hence they are known as the dynamic centers of the cell. The functions of the plastids and cytoplasms are largely, if not entirely, connected with the synthesis, transportation, and dissociation of metabolic substances.

\section{NON-PROTOPLASMIC CELL-CONTENTS.}

The non-protoplasmic constituents of plants may be said to differ from the protoplasmic cell-contents in two important particulars, namely, structure and function. For convenience in considering them here, they may be grouped as follows:

(I) Those of definite form including (a) those which are colloidal or crystalloidal, as starch and inulin; (b) those which are crystalline, as the sugars, alkaloids, glucosides, calcium oxalate; (c) composite bodies, as aleurone grains, which are made up of a number of different substances.

(2) Those of more or less indefinite form, including tannin, gums and mucilages, fixed and volatile oils, resins, gum-resins, oleo-resins, balsams, caoutchouc, and also silica and calcium carbonate.

I. SUBSTANCES DEFINITE IN FORM.

\section{COLLOIDAL OR CRYSTALLOIDAL.}

Starch is the first visible product of photosynthesis, although it is probable that simpler intermediate products are first formed. This substance is formed in the chloroplastid (see Frontispiece) and is known as ASSIMILAtion stäch. Starch grains are 

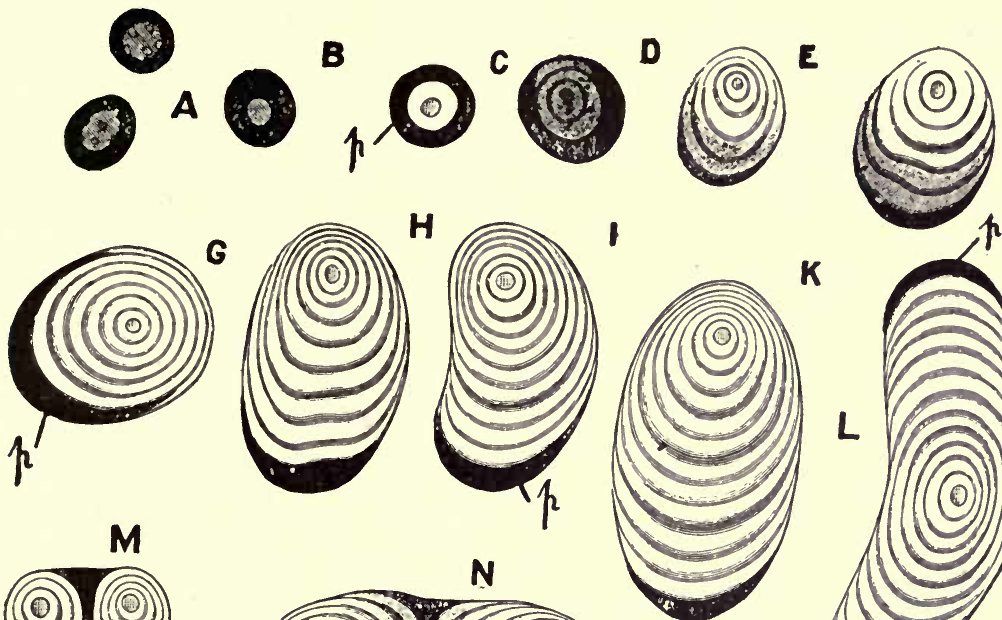

$\mathbf{F}$
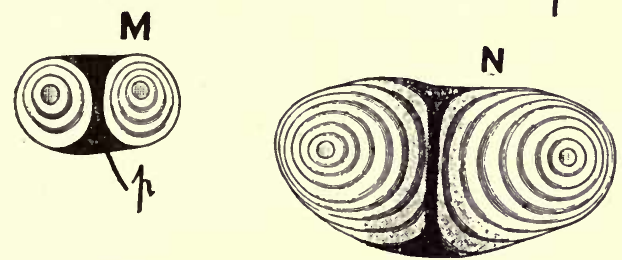

$\mathbf{K}$

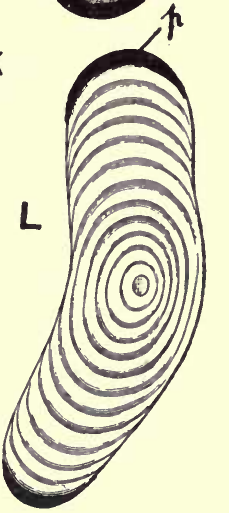

14.
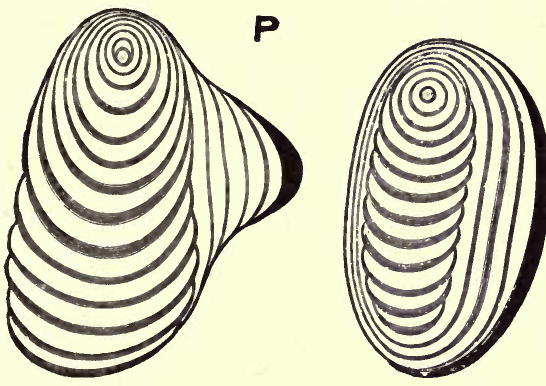

$\mathbf{0}$

$\mathbf{R}$

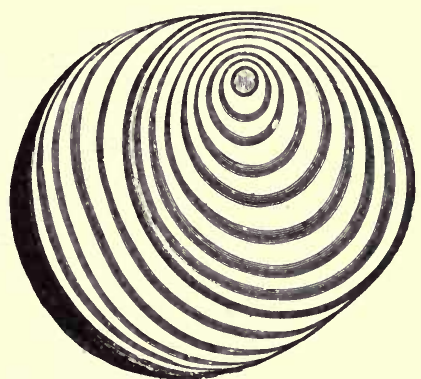

FIG. 87. Successive stages in the development of starch grains, in Pellionia Daveauana (A to N); and in the fruits of the potato plant, Solanum tuberosum ( $P$ to $R$ ). In $A$, two plastids with a number of small starch grains; B, a plastid in which a single starch grain is differentiated; $\mathrm{C}$ to $\mathrm{L}$, successive stages of the development of a single grain, the plastid body being shown on the surface (p); M, N, the development of several 2-compound starch grains; $P$ to $R$, the development of additional layers at right angles to the original grain.After Dippel in "Das Mikroskop."

usually found in the interior of the chloroplastid, but may attain such a size that they burst through the boundary wall of the plastid, which latter in the final stage of the growth of the starch grain forms a crescent-shaped disk attached to one end of the 
grain, as in Pellionia. Starch is changed into soluble carbohydrates by the aid of ferments and probably other substances, and in this form is transported to those portions of the plant requiring food. The starch in the medullary rays and in other cells of the
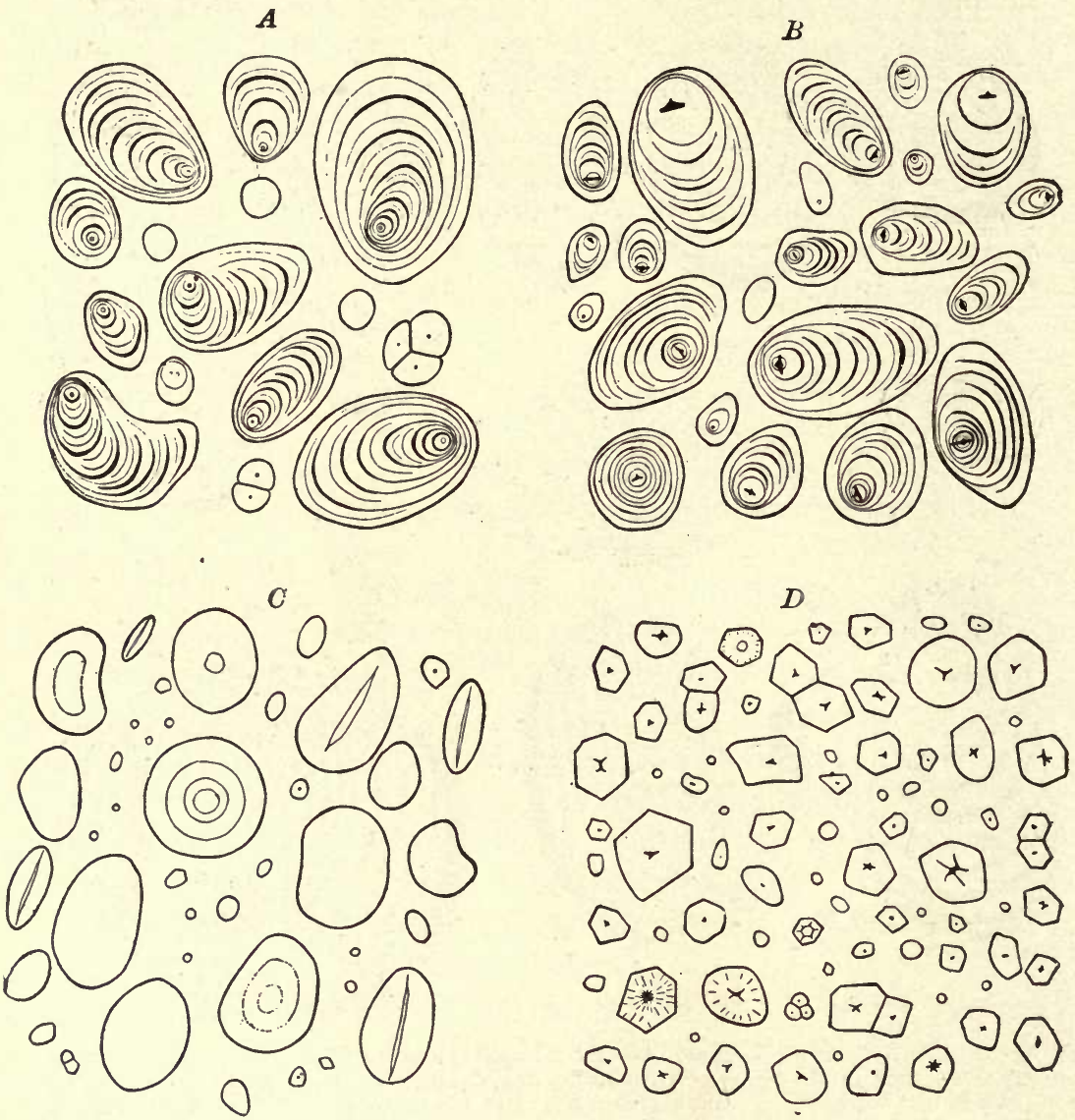

FIG. 88. A, potato starch grains showing the excentral and circular point of origin of growth, and lamellæ; B, maranta starch grains showing fissured point of origin of growth, and distinct lamellæ; C, wheat starch grains showing indistinct point of origin of growth, and lamellæ; D, corn starch grains, which are more or less polygonal in outline and have 2 3- to 5 -angled point of origin of growth.

wood and bark of plants is distinguished by being in the form of rather small and nearly spherical grains. In rhizomes, tubers, bulbs, and seeds the grains are, as a rule, quite large, and possess 
more or less distinct characteristics for the plant in which they are found. Starch of this kind is usually spoken of as RESERVE STARCH (Fig. 87).

Occurrence of Starch.-Starch is found in most of the algæ and many of the mosses, as well as in the ferns and higher plants. The amount of starch present in the tissues of plants varies. In the grains of rice as much as $84.4 \mathrm{I}$ per cent. has been found. This constituent also varies in amount according to the season of the year. Rosenberg has observed that in certain perennial plants there is an increase in the amount of starch during the winter months, whereas in other plants it decreases or may entirely disappear during this period. In the latter case, from six weeks
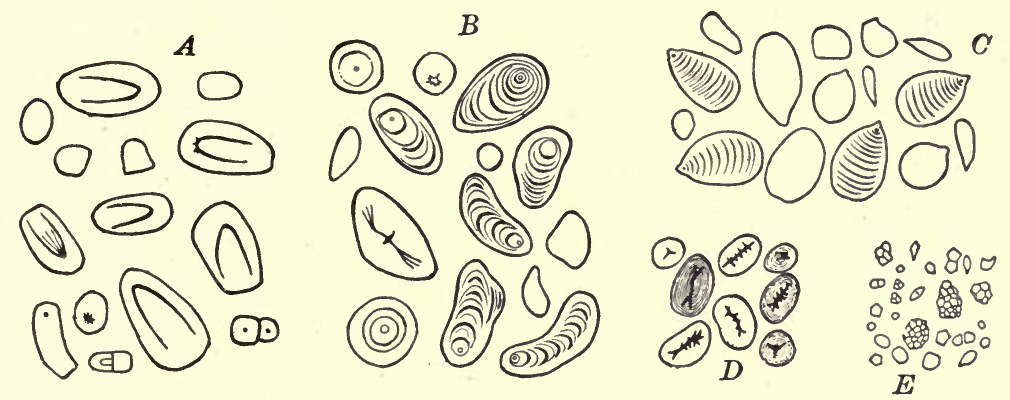

FIG. 89. A, starch grains of Iris florentina showing peculiar horseshoe-like fissure extending from point of origin of growth; B, irregular starch grains of calumba root; C, peculiar beaked starch grains of ginger rhizome; D, starch grains of bean showing irregular longitudinal fissures; $E$, compound starch grains of oat.

to two months in the spring are required for its re-formation, and about an equal period is consumed in the fall in effecting its solution.

Structure and Composition of Starch Grains.-The formula which is generally accepted for starch is $\left(\mathrm{C}_{6} \mathrm{H}_{10} \mathrm{O}_{5}\right)_{n}$, this being recognized by Pfeffer, Tollens, and Mylius. It is supposed that the molecule of starch is quite complex, it being composed of different single groups of $\mathrm{C}_{6} \mathrm{H}_{10} \mathrm{O}_{5}$ or multiples of the same. While this formula may be accepted in a general way, still it has been shown that there are at least two substances which enter into the composition of the starch grain, and more recent studies tend to show that it is in the nature of a sphero-crystalloid, resembling inulin in some respects. Starch grains have an interesting struc- 
ture. They vary in shape from ovoid or spherical to polygonal, and have a. more or less distinct marking known as the "hilum," "nucleus," or the POINT OF ORIGIN OF GROWTH. The substances of which the grains are composed are arranged in concentric layers or lamellæ which are more or less characteristic and which sometimes become more distinct on the application of certain reagents (Fig. 90). The point of origin of growth and alternate lamellæ are stained by the use of gentian violet and other aniline dyes, which may be taken to indicate that these layers contain a colloidal substance somewhat resembling a mucilage, while the
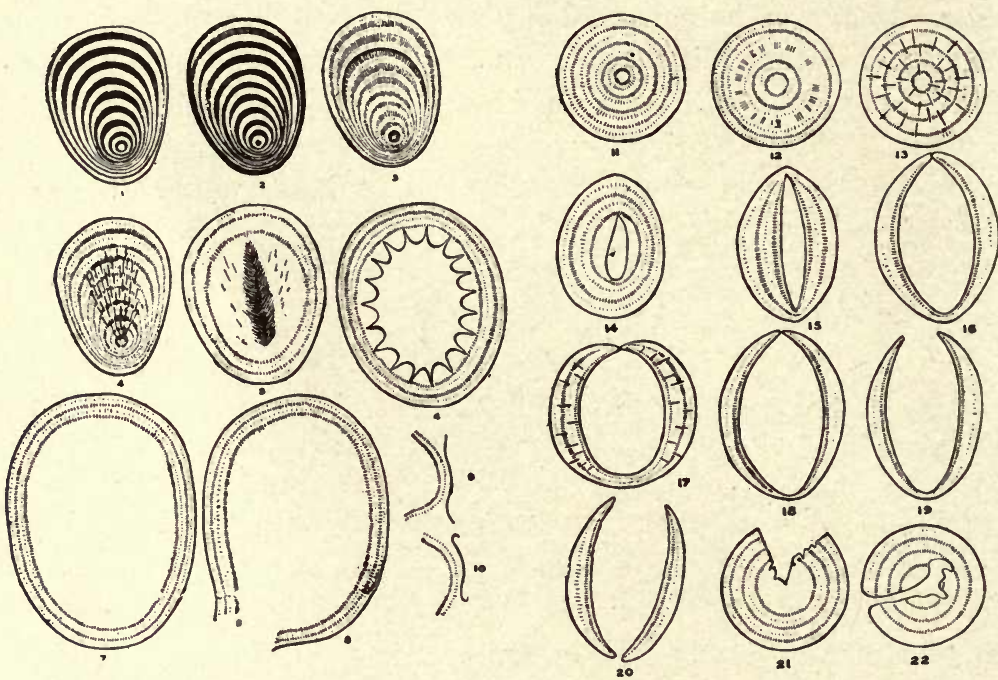

FIG. 90. Successive stages in the swelling and disintegration of starch grains in the presence of water on the application of heat $\left(60^{\circ}-70^{\circ} \mathrm{C}\right.$.), or certain chemicals. Potato starch I-IO; wheat starch I Ir-22.

alternating layers are stained with dilute iodine solutions and are probably composed of soluble starch, this latter corresponding to the $a$-amylose of Arthur Meyer or the granulose described by Nägeli. The peripheral layer of the grain appears to be a distinct membrane. It is quite elastic, more or less porous, and takes up stains readily.

While starch grains usually occur singly, they are not infrequently found in groups of two, three, or four grains, when they are spoken of as two-, three-, or four-compound. In some of the 
cereals, as rice and oat, they are Ioo-compound or more. The individuals in compound grains are in some cases easily separated from one another. This occurs frequently in microscopical preparations, and is especially noticeable in the commercial starches.

The various commercial starches belong to the class of reserve starches and may be distinguished by the following characteristics:

(I) The shape of the grain, which may be spherical, ellipsoidal, ovoid, polygonal, or of some other characteristic form (Figs. 88 and 89$)$.

(2) The size of the grain, which varies from I to $2 \mu$ to about $100 \mu$ in diameter.

(3) The position of the point of origin of growth, which may be central (Fig. 88, $C, D$ ) or excentral (Fig. 88, $A, B$ ). In some cases there are apparently two points of origin of growth in a single grain, and it is then spoken of as "half-compound," as occasionally found in potato.

(4) The shape of the point of origin of growth, which may be spherical, as in potato (Fig. 88, $A$ ); cross-shaped, as in maranta (Fig. 88, B) ; a three- or five-angled fissure or cleft, as in corn (Fig. 88, D), or indistinct or wanting, as in wheat (Fig. $88, C)$.

(5) The convergence of the lamellæ, which may be either toward the broad end of the grain, as in maranta (Fig. 88, $B$ ), or toward the narrow end, as in potato (Fig. 88, $A$ ). In most grains the lamellæ are indistinct or wanting, as in wheat and corn (Fig. 88, C, D).

(6) Behavior toward dilute iodine solutions, the color produced varying from a deep blue in most starches to a red or yellowish-red, as in the amylodextrin grains of mace.

(7) The temperature $\left(45^{\circ}-77^{\circ}\right.$ C. $)$ at which the "kleister" or paste is formed, and its consistency.

(8) The appearance as viewed by polarized light, the distinctness of the cross, as well as the degree of color produced, varying considerably as Nichol's prism is revolved (Fig. 9I).

(9) Behavior toward various reagents, as chromic acid, calcium nitrate, chlor-zinc-iodide, diastase, and various aniline stains, showing peculiarities of both structure and composition (Fig. 90).

General Properties of Starch.-If starch is triturated with 
water and the mixture filtered, the filtrate does not give a reaction with iodine solution; if, on the other hand, the starch is previously triturated with sand and then with water, the filtrate becomes blue

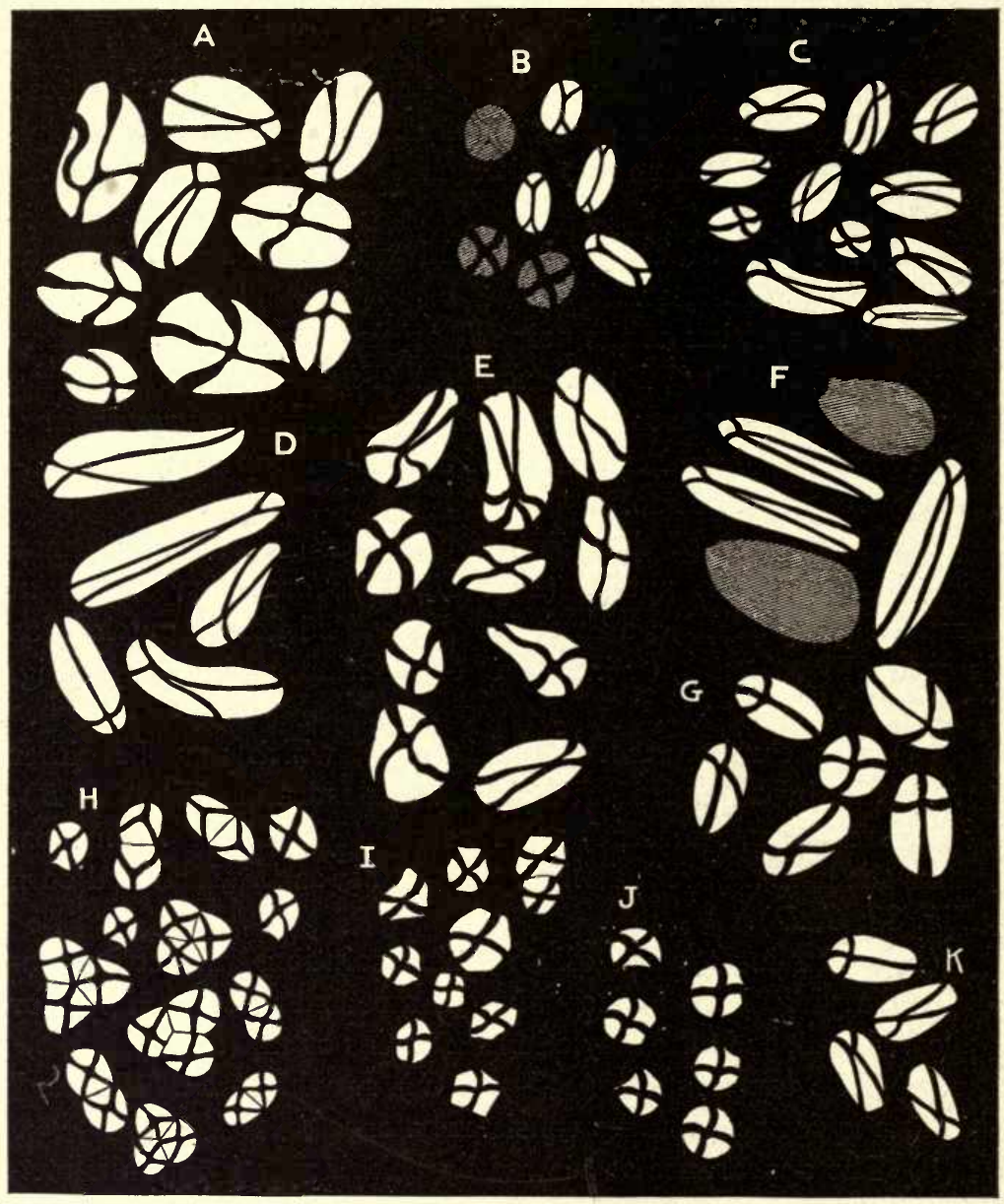

FIG. 9I. Larger grains of various starches as viewed through the micropolariscope when mounted in oil: A, potato $(70-80 \mu) ; \mathrm{B}$, wheat $(30-40 \mu) ; \mathrm{C}$, ginger $(30-50 \mu) ; \mathrm{D}$, galangal $(45-55 \mu)$; E, calumba $(40-60 \mu)$; F, zedoary $(50-75 \mu)$; G, maranta $(35-50 \mu)$; $\mathrm{H}$, colchicum $(10-20 \mu) ; \mathrm{I}$, corn $(20-25 \mu) ; \mathrm{J}$, cassava $(20-35 \mu) ; \mathrm{K}$, orris root $(30-35 \mu)$.

on the addition of iodine solution. It appears that in the latter operation the wall of the grain is broken and the soluble starch present in the grain is liberated. 
If dry starch and iodine are triturated together no color or, at the most, a faint blue color is produced; whereas, if a litt. $\mathrm{c}$ water is added and the trituration repeated, a deep blue color is immediately produced.

The blue color of starch solution and iodine disappears on the application of heat, but slowly returns on cooling the solution, but not with the same degree of intensity, part of the iodine being volatilized.

When starch is heated with glycerin it dissolves, and if alcohol is added to the solution, a granular precipitate is formed which is soluble in water, the solution giving a blue reaction with iodine.

When starch is heated with an excess of water at $100^{\circ} \mathrm{C}$. for even several weeks, dextrinization of the starch does not take place; i.e., the solution still gives a blue color with iodine. If, however, a mineral acid be added, it is quickly dextrinized, turning violet-red, reddish, and yellowish with iodine; finally, maltose and dextrose are produced, these giving no reaction with iodine, but reducing Fehling's solution. The ferments and other chemicals have a similar effect on starch.

When dry starch is heated at about $50^{\circ} \mathrm{C}$. from $\mathrm{I} 5$ to $30 \mathrm{~min}$ utes the lamellæ and crystalloidal structure become better defined and the polarizing effects produced by the grains also become more pronounced. When starch is mounted in a fixed oil, as almond, the polarizing effects are more pronounced than when it is mounted in water, but the inner structure is not usually apparent, unless the starch has been previously heated. (For literature on the starch grain see Kraemer, Bot. Gazette, Vol. XXXIV, Nov., I902; Ibid., Vol. XL, Oct., I905; also Eighth International Congress of Applied Chemistry, Vol. 17, p. 31.)

Botanical Distribution of Starch.-This constituent is commonly present as a reserve material in a large number of plants. The sources of the commercial starches are constantly being extended. The commercial starches are chiefly obtained from one or more genera of the Graminex, Marantaceæ, Euphorbiaceæ, and Solanaceæ. The following is a list of the families yielding one or more economic products which contain starch: Cycadaceæ, Gramineæ, Araceæ, Liliaceæ, Amaryllidaceæ, Iridaceæ, Musaceæ, Zingiberaceæ, Cannaceæ, Marantaceæ, 
Orchidaceæ, Piperaceæ, Fagaceæ, Aristolochiaceæ, Polygonaceæ, Phytolaccaceæ, Nymphæaceæ, Ranunculaceæ, Menispermaceæ, Myristicaceæ, Lauraceæ, Papaveraceæ, Cruciferæ, Rosaceæ, Leguminosæ, Geraniaceæ, Rutaceæ, Simarubaceæ, Euphorbiaceæ, Celastraceæ, Sapindaceæ, Rhamnaceæ, Malvaceæ, Thymelæaceæ, Punicaceæ, Myrtaceæ, Umbelliferæ, Loganiaceæ, Apocynaceæ, Convolvulaceæ, Solanaceæ, Scrophulariaceæ, Gesneraceæ, Rubiaceæ, Caprifoliaceæ, Valerianaceæ, and Cucurbitaceæ.

Percentage of Starch in Plants. - The amount of starch in economic plants, especially those used for food, is very high, being, on an average, much greater than that of any other constituent except water. The percentage of starch, calculated on dry material, in a number of foods and spices is here given: Barley, 53.45 to 72.90 ; cardamom seed, i 8.66 to 40.53 ; carrot, 0.87 to 0.92 ; chestnut, 37.31 to 47.93 ; chinquapin, 44.45 ; cinnamon, 10.44 to 65.72 ; cloves, $9.4 \mathrm{I}$ to $5^{\mathrm{I} .03}$; cocoa (cacao), 3.83 to 48.73 ; corn, 36.72 to 77.54 ; ginger, 46.16 to 62.53 ; lentils, 45.37 ; mace, 26.77 to 56.1 I ; millet, 56.70 to 74.40 ; nutmeg, I7.I9 to 40.12 ; oak acorns, 32.64 ; oats, 42.64 to 63.50 ; onion, 11.00 to 29.39 ; peas, 50.02 to 57.59 ; pepper, 28.15 to 64.92 ; pimenta, 16.56 to 59.28 ; potatoes (sweet), 8 to 78.59 ; potatoes (white), 25.00 to 75.00 ; rice, 74.80 to 84.41 ; rye, 5 I.I 5 to 74.08 ; wheat, 53.66 to 76.51 .

Manufacture of Starch.-In the preparation of commercial starches the object is to break the cells and separate the starch grains, freeing the product from the other constituents of the cell as much as possible. The preparation of potato starch is exceedingly simple, as all that is necessary is to reduce the tubers to a fine pulp, the starch grains being separated from the tissues by means of a sieve. The water containing the starch is removed to tanks, the separation of the starch being facilitated by the addition of alum or sulphuric acid which coagulates the dissolved protein substances. The starch is washed and dried over porous bricks by exposure to air. It is then thoroughly dried in a hot chamber, reduced to a powder, and sifted. One hundred pounds of potatoes yield about 15 pounds of dry starch. It is said that diseased tubers produce as good a quality of starch as the sound tubers.

In the preparation of the cereal starches the gluten interferes 
with their ready separation. The process is therefore modified by either allowing the cereals to ferment, whereby the gluten is rendered soluble and easily removed, or the flour is made into a dough which is kneaded over running water, whereby the starch grains are separated. The starch is subsequently purified by washing and settling. It is dried by gentle heat and assumes the columnar structure as seen in the more or less irregular particles in the commercial product. One hundred pounds of wheat yield from 55 to 59 pounds of starch, the fermentation process giving a larger amount.

In the preparation of corn starch, a weak solution of sodium hydrate is usually employed to facilitate the separation of the starch. Sulphurous acid is also used. One hundred pounds of corn yield 50 pounds of starch.

Rice starch is prepared by either an alkaline process or by an acid process similar to that used in the manufacture of corn starch, hydrochloric acid being employed instead of sulphurous acid. Rice yields a greater percentage of starch than any of the other raw materials, IOO pounds of the grain giving 70 per cent. of starch.

Starch is used as a food and for various other industrial purposes. The principal nutritive starches are sago, tapioca, and corn. Maranta, or arrowroot starch, is largely employed in the preparation of infant foods. Much of the dextrin of commerce is prepared by the action of dilute acids upon potato starch. Starch for laundry purposes is prepared from wheat. Rice starch is largely used as a dusting-powder. Cassava starch has considerable advantages over the other starches in the making of nitrocompounds, and is employed in the preparation of smokeless powders.

PyRENOIDS.-In the chromatophores of a number of algæ a distinct body is observed. It is more or less of a lenticular shape, stained a dark purple on the addition of iodine, and is known as a Pyrenoid. It is not definitely known whether it is a true cell organ having a function similar to the plastids in manufacturing starch or whether it is merely a mass of complex reserve substances. It can be differentiated readily into two distinct portions: an inner, somewhat highly refracting and 
consisting of protein matter, and an outer layer, consisting of a number of starch grains. The studies of Baubier tend to show that the pyrenoid is perfectly differentiated and independent of the chromatophore, and that the starch is formed from a leucoplastid which surrounds a phyto-globulin or crystalloid at the center. This would quite agree with the studies of Timberlake, who observed the complete conversion of the pyrenoid into starch. That the substances of the pyrenoid are in the nature of reserve food materials, is apparent from the fact that the pyrenoid entirely disappears in Hydrodictyon prior to spore formation, and that it is afterward formed anew in the young cells, thus behaving very much like a leucoplastid. Attention should also be directed to the fact that in some of the unicellular and filamentous algæ the pyrenoid divides during the division of the cell, thus behaving like other protoplasmic organs.

INULIN appears to be an isomer of starch and occurs in solution in the cell-sap of parenchyma cells of stems and roots, being also found in the medullary rays. It exists in greatest amounts during the early fall and spring, being changed at other times to levulose. In the Monocotyledons it is found in the Amaryllidaceæ, Liliaceæ, etc. In the Dicotyledons it is characteristic of the Compositæ, but also occurs in the following: Asclepiadaceæ, Bignoniacex, Cactaceæ, Campanulaceæ, Caprifoliaceæ, Compositæ, Cruciferæ, Droseraceæ, Euphorbiaceæ, Geraniaceæ, Labiatæ, Leguminosæ, Lythraceæ, Magnoliaceæ, Menispermaceæ, Moraceæ, Nepenthaceæ, Passifloraceæ, Ranunculaceæ, Rubiaceæ, Rutaceæ, Salicaceæ, Santalaceæ, Theaceæ, Thymelæaceæ, Urticaceæ, Valerianaceæ, Verbenaceæ, Violaceæ, etc.

According to Dragendorff, there are two forms of inulin; one of which is amorphous and easily soluble in water, and another which is crystalline and difficultly soluble in water. The latter is probably, however, a modification of the former, and it is not unlikely that the various principles known as pseudoinulin, inulenin, helianthenin, and synantherin are all modifications of inulin.

In examining fresh material (Fig. 92) the sections should be mounted in as little water as is necessary to enclose the section. If inulin is present it shows in the form of colorless, highly refracting globules. The latter are usually relatively small and tend to unite, forming one or more large globules. Upon increas- 
ing the amount of water they dissolve and are diffused among the other constituents. If fresh sections are mounted directly in alcohol, or if to the original aqueous mount strong alcohol is added, the inulin separates in the form of rod-like or needle-like crystals, which strongly polarize light. If the plant material is preserved for some days in 70 per cent. alcohol, the inulin separates in the form of sphere-crystals which adhere to the walls of the cell. This aggregate consists of concentric layers of radially arranged, needle-shaped crystals, the structure of which is more apparent upon the addition of either nitric acid or a solution of hydrated chloral. The crystal mass is insoluble in glycerin and sparingly soluble in cold water. It is soluble in warm water, warm solutions of glycerin and water, acetic acid, mineral acids, chlorzinc-iodide, and ammoniacal solution of cupric oxide. With solutions of the alkalies it dissolves with a lemon yellow color, and with acetic acid the crystals dissolve, forming a greenish colored solutior which soon fades.

Tunmann (Ber. d. d. pharm. Ges., I9Io, p. 577) has suggested the use of a solution of pyrogallol as a distinctive reagent for the microscopic study of inulin. The solution consists of $0.100 \mathrm{Gm}$. Pyrogallol, alcohol 5 c.c., and 5 c.c. of hydrochloric acid. Upon carefully heating sections treated with this reagent the cells containing inulin are colored a violet red. A similar solution made with resorcin in place of pyrogallol colors inulin a cinnabar red.

In taraxacum, inula, pyrethrum, and other drugs inulin occurs in the form of an amorphous mass having a more or less angular outline. The masses are highly refracting and probably consist of aggregates of small crystals similar in appearance to those of mannit found in commercial manna.

Hesperidin.-Although not a carbohydrate, hesperidin is of wide occurrence and separates in the form of sphero-crystals resembling inulin. It is a glucoside $\left(\mathrm{C}_{22} \mathrm{H}_{26} \mathrm{O}_{12}\right)$, and it would appear, from the studies of Tunmann (Schweiz. Woch. f. Chem.u. Pharm., I909, p. 794), that, like inulin, there are several forms of it. Hesperidin, like inulin, occurs in living cells in the form of a more or less viscous fluid. Upon the addition of water, alcohol, glycerin, or solutions of hydrated chloral it separates in 
the form of yellowish sphero-crystals. If the fresh plant material is placed in alcohol the crystals separate in the form of large needles, often forming branching tufts. When examined by means of the micropolariscope, they polarize light more or less strongly, depending upon how the crystals were prepared. Upon quickly drying the plant material in which it occurs, hesperidin separates in the form of irregular, slightly yellowish clumps, resembling those of inulin found in the composite drugs of commerce. If the material is slowly dried, the crystals are decomposed. Crystals of hesperidin have been found in Citrus fruits;
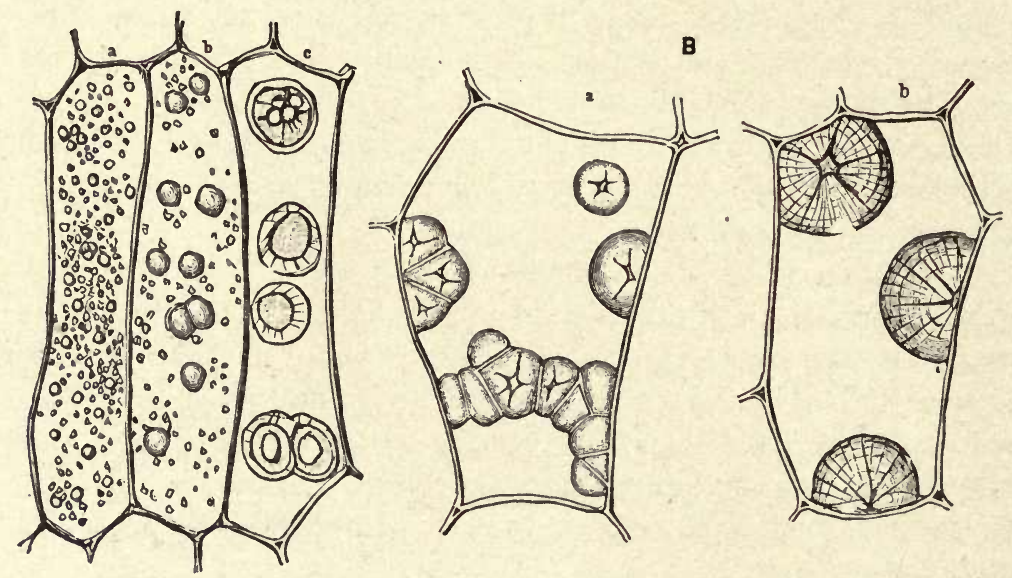

Frg. 92. Sphero-crystals of inulin. A, parenchyma cells of the root of chicory (Cichorium Intybus) treated with alcohol: a, numerous small globules shortly after the addition of alcohol; b, a somewhat later stage, showing the fusion of many of the small globules of inulin; c, crystal formation in the globules after the alcohol has acted upon the cells for 24 hours. B, sphero-crystals resembling starch grains-formed in the tubers of Dahlia variabilis in alcoholic material: in $\mathrm{b}$, the section has been treated with nitric acid, the crystal aggregate showing a trichiten structure.-After Dippel in "Das Mikroskop."

the fruit of Cocculus laurifolius; the leaves of Buchu, and Pilocarpus; species of Mentha, Hyssopus, Teucrium, Satureia, Tilia; Conium maculatum; Scrophularia nodosa, and stamen hairs of the flowers of Verbascum. The crystals are found especially in the epidermal cells of bracts. The crystals in the hairs of the flowers of Verbascum are usually referred to as a sugar, but, according to the studies of Tunmann, are in the nature of a hesperidin. 
If sections are mounted in a small quantity of water and the latter replaced with dilute glycerin, followed by concentrated glycerin, then there separates in the cells a number of yellowish globules which are highly refractive (Fig. 93); these globules tend to unite in the center and very soon crystallize. The sphero-
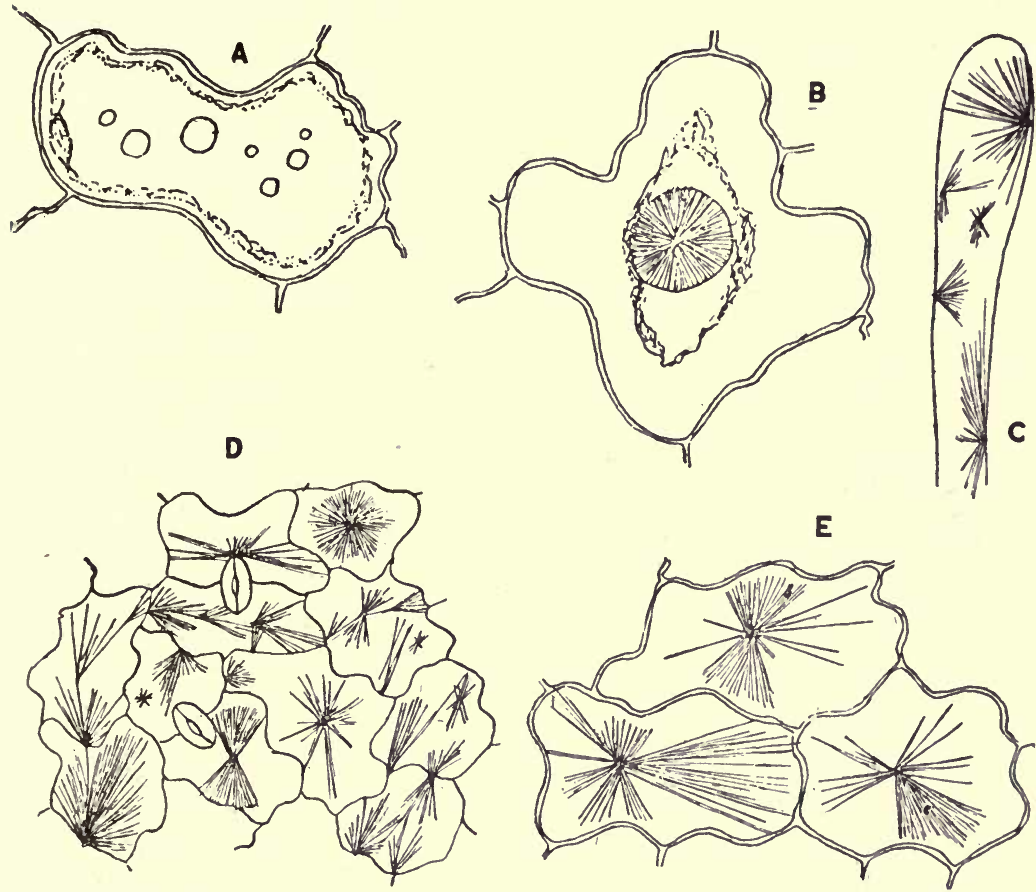

FIG. 93. Hesperidin. A, B, formation of sphero-crystals in the epidermal cells of the foliage leaves of Linden upon the addition of glycerin; in A the hesperidin occurs in highly refracting globules, which in $\mathrm{B}$ have united in a large central globule in which a crystalaggregate has formed. C, crystals in stamen hair of the flower-bud of Verbascum. D, crystals in the cells of the upper epidermis of Hyssopus officinalis. E, cells of the upper epidermis of the foliage leaves of the Linden.-After Tunmann.

crystal consists of radiating needles, the aggregate frequently being marked by concentric lamellæ, the whole being surrounded by a more or less mucilaginous wall (Fig. 93). As there are other substances in the cell the sphero-aggregate may contain some of these in the interstices. If the crystals are formed slowly and in the cold they are apt to be of a yellowish, or even dark yellow, color, whereas if heat is employed and the crystallization 
is more rapid they are nearly colorless and dissolve readily. The crystals of hesperidin are insoluble in water, alcohol, glycerin, ether, chloroform, solutions of hydrated chloral, dilute sulphuric acid and dilute or concentrated hydrochloric acid and nitric acid. They are sparingly soluble in ammonia water and hot acetic acid. Upon the addition of either dilute or concentrated solutions of potassium hydroxide or sodium hydroxide, hesperidin dissolves, forming a yellowish solution. With concentrated sulphuric acid it gives a deep yellowish solution, which upon warming becomes a reddish-brown. Sometimes hesperidin, as in the stamen hairs of Verbascum, is colored with concentrated sulphuric acid only a light yellow.

GLYCOGEN is a carbohydrate allied to amylo-dextrin and occurs commonly as a reserve food material in the fungi and some of the Cyanophycea. It usually occurs in the form of a more or less amorphous mass in the hyphre of the fungi, but occasionally is found in definite granules resembling starch. It is supposed to arise in plastid bodies resembling leucoplastids, but its general formation is controlled by the protoplasm. In yeast it is found in large quantities, sometimes nearly filling the entire cell.

\section{CRYSTALLINE SUBSTANCES.}

The sugars constitute a group of crystalline principles of wide distribution. They occur in the cell-sap, from which by evaporation or on treatment with alcohol they may be crystallized out. There are chemically two main groups: monosaccharoses (formerly termed glucoses) and disaccharoses (formerly the saccharoses). Under the former are included the simple sugars containing two or more atoms of carbon and known as biose $\left(\mathrm{C}_{2} \mathrm{H}_{4} \mathrm{O}_{2}\right)$, etc. Among the pentoses $\left(\mathrm{C}_{5} \mathrm{H}_{10} \mathrm{O}_{5}\right)$ are rhamnose, a component of certain glucosides; fucose, found in fucus and other brown algæ, and chinovite, occurring in certain Cinchona barks. The most important subdivision of the monosaccharoses comprises the hexoses $\left(\mathrm{C}_{6} \mathrm{H}_{12} \mathrm{O}_{6}\right)$, which include glucose and fructose, and are widely distributed; d-mannose, found in the manna of Fraxinus Ornus and obtained by hydrolyzing cellulose, especially the reserve cellulose in the seeds of the vegetable ivory. Of the disaccharoses $\left(\mathrm{C}_{12} \mathrm{H}_{22} \mathrm{O}_{11}\right)$ cane-sugar is the most im- 
portant. In this group are also included maltose, formed by the action of diastase on starch and by the action of ferments on glycogen; trehalose or mycose, found in the Oriental Trehala, ergot, Boletus edulis, and other fungi; melibiose, occurring in Australian manna and in the molasses of sugar manufacture; touranose, found in Venetian turpentine (obtained from Larix europaa) and in Persian manna; and agavose, occurring in the stalks of Agave americana.

Of the numerous sugars the following are likely to be met with in the microscopical study of drugs and economic products:

Dextrose (grape-sugar or dextro-glucose) is found in sweet fruits, the nectaries of the flowers, and stems and leaves of various plants. It crystallizes in needles and varies in amount from I to 2 per cent. (in peaches), to 30 per cent. in certain varieties of grapes. It also occurs in combination with other principles, forming the glucosides.

Levulose (fructose, fruit-sugar, or levo-glucose) is associated with dextrose, occurring in some instances even in larger quantities than the latter.

Sucrose (saccharose or cane-sugar) is found rather widely distributed, as in the stems of corn, sorghum and the sugar-cane; in roots, as the sugar-beet; in the sap of certain trees, as sugarmaple and some of the palms; in the nectaries and sap of certain flowers, as fuchsia, caryophyllus, and some of the Cactaceæ; in seeds, as almond and chestnut, and in various fruits, as figs, melons, apples, cherries. In some plants, as in sugar-cane, the yield is as high as 20 per cent. It crystallizes in monoclinic prisms or pyramids, and forms insoluble compounds with calcium and strontium.

Maltose is found in the germinating grains of cereals (see Malt) ; it forms colorless, needle-shaped crystals resembling those of dextrose, and forms compounds with calcium, strontium, barium and acetic acid.

Trehalose occurs in some fungi, as ergot and Amanita muscaria - the latter containing as much as Io per cent. in the dried plant.

Mannitol occurs in the form of needles or prisms and is found in the manna of Fraxinus Ornus to the extent of 90 per cent. It 
is also found in some of the Umbelliferæ, as Apium graveolens, some of the Fungi and sea-weeds, and is rather widely distributed (Fig. 94).

Dulcitol, which is closely related to mannitol, is found in Euonymus europæus and in most of the plants of the Scrophulariaceæ.

Percentage of Sugar in Plants.-No analysis is necessary to indicate that most fruits contain quite a large percentage of sugar. The following figures show the amount of sugar in some of the more common fruits, the per cent. being calculated on
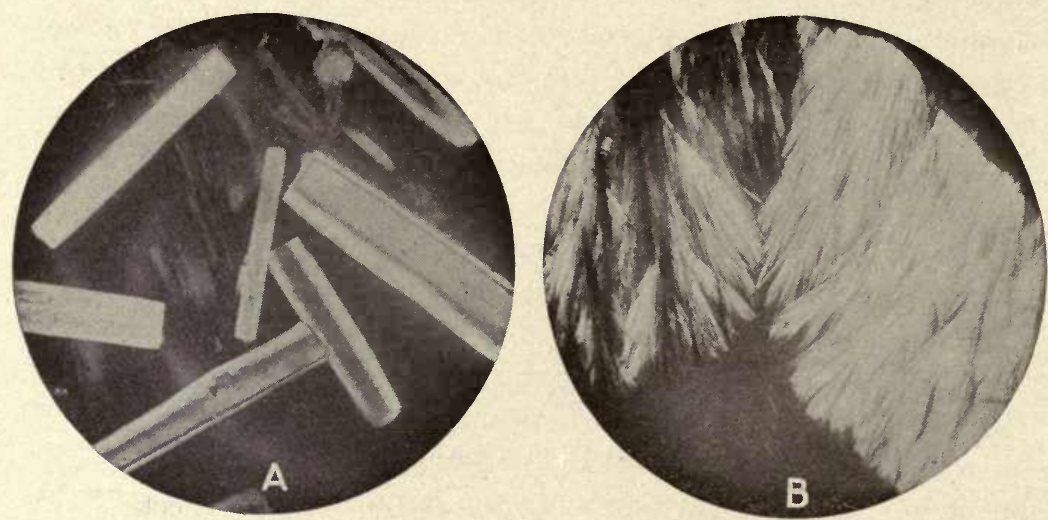

FIG. 94. Orthorhombic crystals of Mannitol (Mannit) obtained from aqueous solutions: $\mathrm{A}$, large crystals; $\mathrm{B}$, feathery aggregates of needles.

dry material: Apple, 33.16 to 87.73 ; apricot, 7.58 to 86.21 ; banana, 6.20 to 21.90 ; blackberry, 32.67 to 40.17 ; cantaloupe, 0.27 to II.98; cherry, 29.97 to 85.86 ; currant, 33.76 to 75.49 ; fig, I0.00 to 29.90 ; gooseberry, 47.33 to 79.82 ; grape, including raisin, 67.82 to 83.00 ; huckleberry, 12.60 to 46.87 ; orange, 36.48 to 66.91 ; peach, 6.69 to 74.07 ; plum, I 5.25 to 78.70 ; prune, 32.04 to 69.46 ; pumpkin, O.I 5 to II.98; and raspberry, 14.93 to 47.50 .

The following percentage of sugars is present in some of the cereals, common vegetables, etc. : Asparagus, 0.45 to 3.47 ; barley, 5.82 to 8.73 ; beet (garden), 4.20 to 31.45 ; beet (sugar), 3.55 to 89.6I ; buckwheat, I.42 to I.67; carrot, 3.62 to 15.30 ; cauliflower, I.22 to 7.40 ; chestnut, 5.22 to 8.52 ; cocoa (cacao), 2.77 ; coffee, 0.20 to 14.50 ; corn, 0.96 to 6.77 ; cucumber, 0.72 to I.5I ; 
lentils, 2.75 ; maple sap, 2 to 4 ; oats, 0.5 I to 5.27 ; onions, 0.44 to 14.02 ; rye, 0.39 to 9.46 ; sorghum juice, 8.60 to 14.70 ; sugarcane juice, I6.00 to I8. I0 ; spinach, 0.06 to 6.66 ; turnip (Swedish), 5.05 to 9.67 ; sweet potato, 0.32 to 8.42 ; tomato, 2.53 to 3.86 ; vanilla, 7.07 to 9.10 ; wheat, 0.58 to 5.12 .

HoNEY-DEW is a pathological sugar formed as a result of the stings of insects (Aphides and Coccider) on the leaves of certain trees. There are a number of trees the leaves of which, during the summer time, are covered with a thin layer of sugar solution. Among these may be mentioned the linden, tulip poplar, and chestnut. Honey-dew may also be formed, according to Bonnier, without the assistance of aphides, and may be seen oozing out of the stomata. It may be formed in such quantities that it may drip from trees, as in the so-called rain trees of the Tropics (see Pfeffer, "Physiology of Plants").

The Origin and Formation of Carbohydrates.-The first visible product of photosynthesis is starch, and this is sometimes called photosynthetic starch. Investigations during recent years seem to indicate that grape-sugar or dextrose is the basal photosynthate, and that from this starch is later formed in the plastid. This sugar is called photosynthetic grape-sugar to distinguish it from the grape-sugar found in the cell-sap of the grape, raisins, figs, etc. There is no question but that in the plastids starch is readily formed from glucose, and, vice versa, that the starch in the plastids is readily changed through the agency of the ferment, amylase, into grape-sugar.

There are four factors necessary for the formation of a photosynthetic carbohydrate ( starch or glucose) by the chloroplastids: (I) Light; and in this condition it is the energy of the red and blue rays of sunlight which are necessary to bring about the synthesis. (2) Carbon dioxide. This compound must be present in about the normal proportions that we find it in the air, namely, 3 parts in 10,000 . (3) Water is essential, and this is always present in living cells. It is by the dissociation of the $\mathrm{CO}_{2}$ and $\mathrm{H}_{2} \mathrm{O}$ and rearrangement of the atoms that carbohydrates are formed, being either starch $\left(\mathrm{C}_{6} \mathrm{H}_{10} \mathrm{O}_{5}\right)$ or glucose $\left(\mathrm{C}_{6} \mathrm{H}_{12} \mathrm{O}_{6}\right)$, with oxygen as a by-product. These interactions may be shown by the following equations: 


$$
\begin{aligned}
& 6 \mathrm{CO}_{2}+5 \mathrm{H}_{2} \mathrm{O}=\underset{6}{ }=\underset{(\text { Starch) }}{\mathrm{C}_{10} \mathrm{H}_{5} \mathrm{O}_{5}+6 \mathrm{O}_{2} .} \\
& 6 \mathrm{CO}_{2}+6 \mathrm{H}_{2} \mathrm{O}=\underset{6}{\text { (Glucose) }} \mathrm{C}_{6} \mathrm{H}_{12} \mathrm{O}_{6}+6 \mathrm{O}_{2} .
\end{aligned}
$$

(4) Certain mineral substances must be present, although, apparently, they take no part in the photosynthetic reaction. Bokorny has shown that compounds of potassium are essential to bring about the reactions above given.

Some form of iron has always been considered necessary for the development of the green pigment or chlorophyll in the chloroplastid. While this element may seem to be necessary in water culture, it is not always essential, particularly if plants are grown under control conditions in sand. The development of chlorophyll also requires the presence of oxygen. The activity of the chlorophyll apparatus is further influenced by other factors, viz., the maintenance of a proper temperature. It is self-evident that there is a minimum and maximum temperature at which photosynthesis is scarcely perceptible, and that there is an optimum temperature during which the activity of the chloroplastid is at its height. The latter varies with different plants, depending on the climate to which they are either indigenous or naturalized. In the Tropics the optimum temperature is somewhat higher, while in the Arctic regions it is much lower. In temperate climates the optimum varies between $20^{\circ} \mathrm{C}$. $\left(68^{\circ} \mathrm{F}\right.$. $)$ to $30^{\circ} \mathrm{C}$. $\left(86^{\circ} \mathrm{F}\right.$. $)$.

From the facts just given it would appear that considerable is known in regard to the conditions and the substances which are concerned in the formation of photosynthetic products. On the other hand, we know practically nothing of the successive steps in the formation of either starch or glucose in the plant. Numerous experiments have been conducted and a number of hypotheses have been advanced. According to von Baeyer, the first step in the process of photosynthesis is a reduction in the $\mathrm{CO}_{2}$, formaldehyde being formed, and this is then polymerized into a carbohydrate, which is finally changed into dextrose. This may be represented by the following equations:

$$
\begin{gathered}
\mathrm{CO}_{2}+\mathrm{H}_{2} \mathrm{O} \longrightarrow \mathrm{HCHO}+\mathrm{O}_{2} \\
\times \mathrm{HCHO}=\left({ }^{\circ} \mathrm{CH}_{2} \mathrm{O}\right) \times \\
6\left(\mathrm{CH}_{2} \mathrm{O}\right)=\mathrm{C}_{6} \mathrm{H}_{12} \mathrm{O}_{6}
\end{gathered}
$$


There are a number of other views which have been advanced. Erlenmeyer, for instance, has suggested that instead of formaldehyde being first formed, formic acid is the first product of photosynthesis, hydrogen peroxide being liberated; both of these then are decomposed, formaldehyde being formed according to the following equations:

$$
\begin{aligned}
& \mathrm{CO}_{2}+\mathrm{H}_{2} \mathrm{O}=\mathrm{HCOOH}+\mathrm{H}_{2} \mathrm{O}_{2} \\
& \mathrm{HCOOH}+\mathrm{H}_{2} \mathrm{O}_{2}=\mathrm{HCOH}+\mathrm{H}_{2} \mathrm{O}+\mathrm{O}_{2}
\end{aligned}
$$

By the further condensation of formaldehyde as in the hypothesis of von Baeyer, dextrose is formed. On the other hand, Brown and Morris consider that the first carbohydrate formed is, in reality, cane-sugar, and that from this, then, dextrose and the other carbohydrates are formed.

Some very interesting experiments were conducted by Berthelot (Compt. rend., I898, I900, etc.), who obtained both formic acid and formaldehyde while working with a mixture of carbon dioxide and hydrogen. Later he obtained a synthetic carbohydrate, which on warming had an odor of caramel. Furthermore, when using an excess of carbon monoxide with hydrogen, Berthelot obtained a substance closely related to oxy-cellulose. Lob (Ber.d.d. pharm. Ges., I907, p. I I 7 ) concludes that from formaldehyde, glycolic-aldehyde $\left(\times \mathrm{CHO} \mathrm{CH}_{2} \mathrm{OH}\right)$ is formed; this is then followed by the formation of glyceric-aldehyde $\left(\mathrm{CH}_{2} \mathrm{OH}\right.$.CH$\mathrm{OH} . \mathrm{COH}$ ), which is finally polymerized into a hexose as glucose, or even a higher carbohydrate.

The Alkaloids include a group of organic bases which possess remarkable toxicological properties. They are compounds of carbon, hydrogen, and nitrogen ; oxygen is also usually present, except in the liquid or volatile alkaloids, in which it is wanting. They are usually combined with some organic acid, as malic acid or tannic acid. In many cases the alkaloids are combined with acids that are peculiar to the genus,- - e.g., aconitic acid in Aconitum, meconic acid in Papaver, etc. They are found in a large number of plants, especially among the Dicotyledons, and are rather characteristic for certain families, as those of the genera Strychnos, Cinchona, Erythroxylon, Papaver, etc. When present, alkaloids may be found in any part of the plant, but usually they are most abundant in certain definite regions, as roots, rhizomes, fruits, 
seeds, or leaves. Furthermore, the amount is greatest at certain stages of development, as in the fully ripe seeds, more or less immature fruits, during the resting periods of roots and rhizomes, and in leaves when photosynthetic processes are most active. They occur in greatest amount in those cells which are in a potential rather than an active condition, being associated with starch, fixed oils, aleurone grains, and other reserve products in the roots, rhizomes, and seeds. They are found in fruits in greatest amount during the development of the seed, but after the maturing of the latter they slowly disappear, as in the opium poppy and conium.

The alkaloids probably arise in the protoplasm, although they may also be formed from the decomposition of protein substances. The fact that asparagine, a weak base, is usually present when the proteins are being formed from the protoplasmic substances and is also present when the proteins are being used in the growth of the plant, as during the germination of seed, would seem to indicate that both views are more or less tenable. The studies of Lotsy on Cinchona showed that alkaloids are formed in connection with photosynthetic processes and that they are subsequently stored for the use of the plant. On the other hand, it is rather interesting to note that when cinchona trees are grown in the hot-house they do not produce any quinine, and, again, it is said that the conium growing in Scotland does not contain any coniine. From these observations we must conclude that alkaloids are produced only under certain conditions, and that they are not essential metabolic substances. The fact that the presence of alkaloids may be demonstrated in the thick-walled cells of the endosperm in nux vomica has led some investigators to conclude that they may arise in the cell-wall. The occurrence of alkaloids at this point is due to their imbibition by the wall, just as other soluble cell contents are absorbed, especially upon the death of the cell.

Microchemistry of Alkaloids. - The alkaloids occur in rather large quantities in a number of plants. Seldom do we find them in the form of crystals in the plant cell. Crystals of the alkaloid Piperine are not infrequently observed in the oil secretion cells of the endosperm of Piper nigrum (Fig. 94, $A$ ). The 
alkaloids form crystallizable salts and, in many instances, definite double compounds. Nevertheless, not a great amount of progress has been made in their detection and localization, either in the living plant or in economic products. The reason for this is that other substances, as calcium oxalate, may interfere with the reactions forming crystals with the reagents, so that nothing definite can be deduced. Then again, when an alkaloid is characterized by certain color reactions, especially if a rose or violet color is formed, it may be due to the reaction of the reagent with carbohydrates or protein substance. For this reason practically
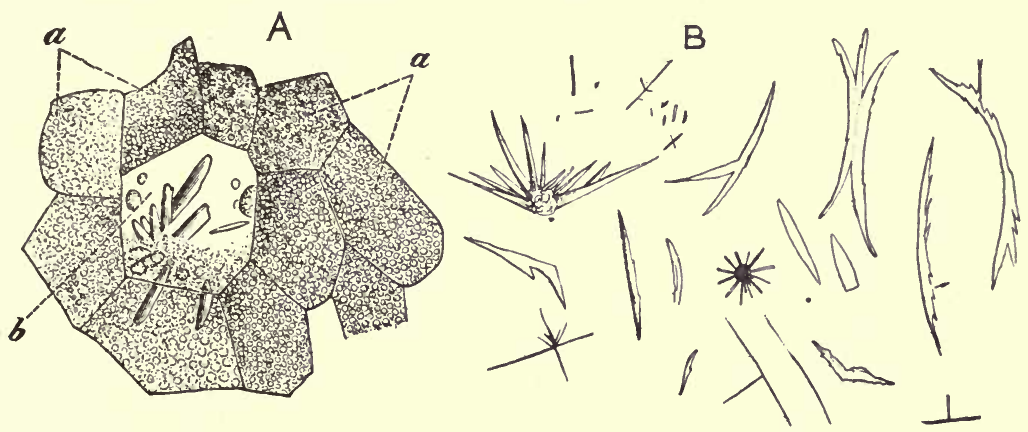

Fig. 94A. Crystals of Piperine: A, cells of endosperm showing a single oil cell (b) in which crystals of piperine have separated; (a) starch bearing parenchyma. B, piperine crystals separated from sections which have been first treated with alcohol, and to the oily globules remaining after evaporating the alcohol, a drop of distilled water has been added. In from fifteen to thirty minutes there separate needles, short rods and aggregates of piperine.-After Molisch's work on Histochemie.

there are only a few instances where satisfactory results are obtained in the study of alkaloids in plant tissues. These, for the most part, have been obtained in connection with the dried materials of commerce. As it is very important that these studies should be carried further, a few illustrations may be given.

Hydrastis contains two alkaloids in considerable quantities which form definite salts with nitric and sulphuric acids. Furthermore, this plant does not contain calcium oxalate, so that the crystals formed upon the addition of mineral acids could not be of either the nitrate or sulphate of calcium, and if in other respects they corresponded to the sulphates and nitrates of the alkaloids peculiar to hydrastis, then the crystals must be salts of the alkaloids. If sections of the fresh rhizome of hydrastis or the moist- 
ened drug are mounted directly in sulphuric acid, there separate very soon small acicular or rod-shaped crystals of berberine and hydrastine (Fig. 95). This is one of the most satisfactory of microchemical tests of the alkaloids that is known, and Leuff has shown that they can be readily determined even in the endosperm cells in the seeds of hydrastis (Pharm. Post, 19r3, p. 977).

Caffeine is an alkaloid which is rather widely distributed, and its presence can be easily determined, in dried material as coffee seeds, in several ways. (I) It may be sublimed, the long,
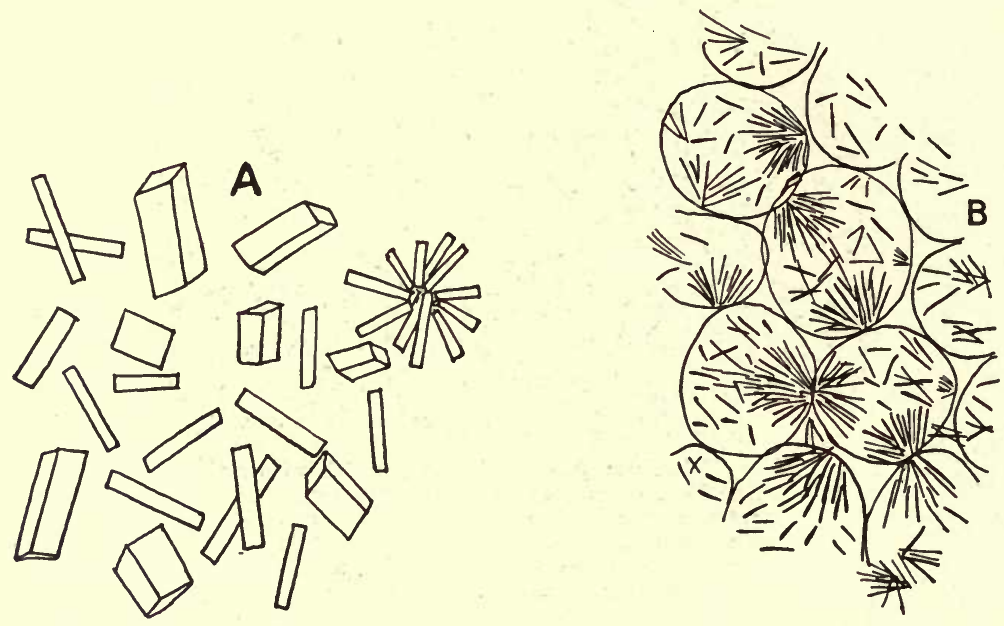

Fig. 95. Alkaloids in Hydrastis: A, prismatic crystals which separate after a time on treatment of sections of the rhizome of hydrastis or its powder with sulphuric acid; B, the separation of needle-shaped crystals of the sulphates of the alkaloids in the parenchyma cells of hydrastis upon treatment with sulphuric acid.

silky needles of caffeine being deposited upon a watch crystal or a microscopic slide. (2) Similar crystals may separate from aqueous or hydro-alcoholic mounts of the material. (3) The most satisfactory method for the detection of caffeine is to form a double salt with gold chloride, the crystals of which are very characteristic (Fig. 96). The test may be applied to coffee seeds, cola nuts, tea leaves, guarana, etc., as follows: Sections are placed in strong hydrochloric acid and slightly heated; then one or two drops of a solution of gold chloride are added and the sections pushed to one side, allowing the liquid to evaporate. Near the 
edge of the residue branching groups of needles of caffeine gold chloride separate. Cocaine is another alkaloid which forms characteristic crystals, and the double salt of the chloride with palladous chloride is very characteristic (Fig. 97). The crystals of the latter may be prepared in the same manner as caffeine, except that to the sections of coca leaves or the powdered material a smaller quantity of hydrochloric acid is added.

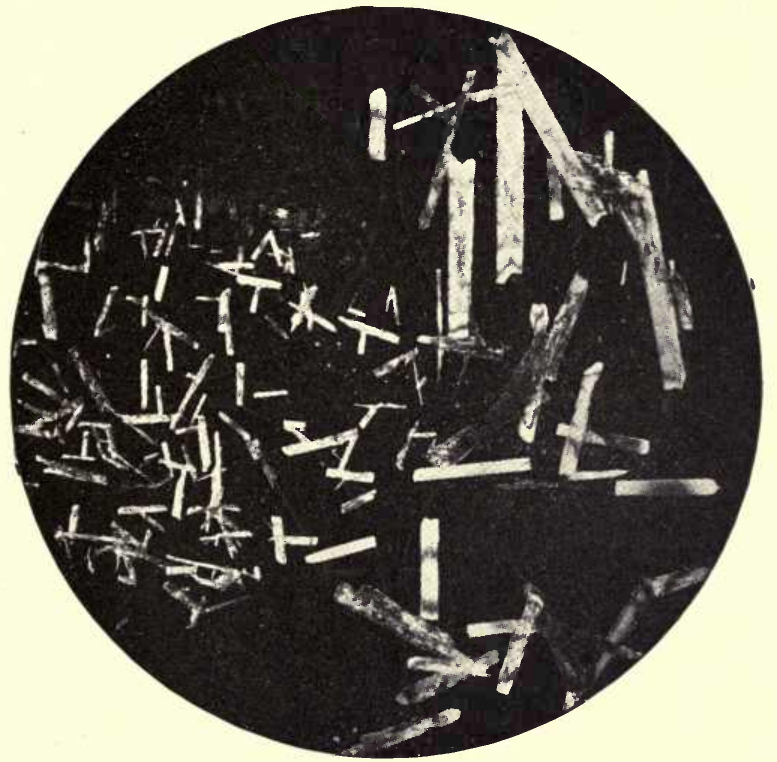

FIG. 96. Caffeine gold chloride; crystals formed on the addition of a solution of gold chloride to a dilute aqueous solution of caffeine.

Properties of Alkaloids.-In the microchemical study of the cell-contents it is important to bear in mind that the alkaloids possess certain characteristic properties and give definite reactions with the so-called "alkaloidal reagents." The alkaloids occur in combinations with acids forming salts which are mostly soluble in water or in alcohol, and consequently may be extracted by means of these solvents. From the latter well-characterized crystals may be easily formed. The free alkaloid may be separated from solutions of their salts in water by the addition of alkalies, but it is usually important that the solutions of the latter be not in excess, as otherwise the separated alkaloids may dissolve. With 
few exceptions, as Berberine and Sanguinarine, they form mostly colorless crystals. Among the alkaloidal reagents giving characteristic precipitates the following may be mentioned. Phosphomolybdic acid (Sonnenschein's Reagent) gives with nearly all of the alkaloids a yellow, insoluble amorphous precipitate. Potas-
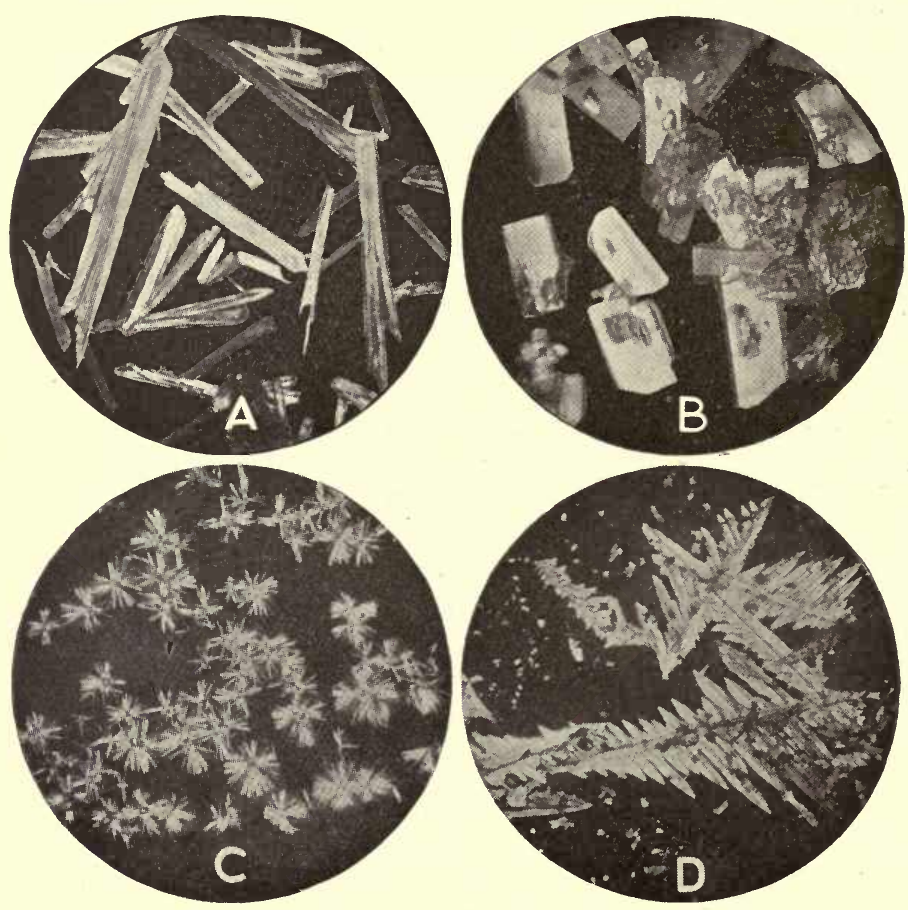

FIG. 97. Cocaine: A, monoclinic crystals of cocaine; B, orthorhombic crystals of cocaine hydrochloride; $\mathrm{C}$, monoclinic crystals of cocaine hydrochloride and palladous chloride: $\mathrm{D}$, skeleton aggregates of cocaine hydrochloride and palladous chloride.

sium mercuric iodide (Mayer's Reagent) precipitates many of the alkaloids in even dilute solutions, the precipitates being usually yellowish-white and more or less flocculent. Wagner's Reagent, or iodine dissolved in a solution of potassium iodide, is another reagent that precipitates nearly all the alkaloids. The precipitates are of a reddish or reddish-brown color, and are more readily formed in acidulated solutions. From alcoholic solutions 
crystalline double compounds may be formed. Picric acid forms characteristic crystals with a number of the alkaloids. Wormley's Reagent, or a solution of bromine in hydrochloric acid, gives definite microscopic crystals with some of the alkaloids, as atropine, hyoscyamine, and veratrine. Auric chloride and platinic chloride both form characteristic double salts with a number of the alkaloids. There are a number of other reagents which are used in the study of the localization of alkaloids in plants. Most of these depend upon certain color reactions. While it is true that the alkaloids give rather striking colors with certain reagents, yet, as a rule, they are of little value except when the alkaloids are in a pure condition. This same objection holds, but with somewhat less force, to the employment of the alkaloidal reagents just mentioned.

Families Yielding Alkaloids.-It is very difficult to determine from the literature of the analyses as to how widely distributed alkaloids are in plants. Time and again principles, which give definite reactions with certain alkaloidal reagents, are subsequently shown to be other than alkaloids. In enumerating the families in which alkaloids occur we do not mean to say that they are lacking in the families not mentioned here. Alkaloids are seldom found in the Cryptogams, being confined, with few exceptions, to the poisonous fungi, as Amanita of the Agaricacæ. Among the Monocotyledons they are found in the Palmæ and the Liliaceæ. They are more widely distributed in the Dicotyledons, occurring in the following families: Piperaceæ, Chenopodiaceæ, Ranunculaceæ, Berberidaceæ, Menispermaceæ, Lauraceæ, Papaveraceæ, Leguminosæ, Erthroxylaceæ, Rutaceæ, Aquifoliaceæ, Sapindaceæ, Sterculiaceæ, Punicaceæ, Umbelliferæ, Loganiaceæ, Apocynaceæ, Solanaceæ, Rubiaceæ, and Lobeliaceæ.

The Amount of Alkaloids in plants varies under different climatic conditions and is also very much influenced by cultivation (see chapter on "Cultivation of Medicinal Plants"). For these reasons there is a wide range in the alkaloidal content of drug products, and, as the alkaloids are among the most poisonous constituents known, the various pharmacopœias have set alkaloidal standards. At the International Conference for the Unification of Pharmacopœial Formulæ for Potent Medicaments held in Brus- 
sels in 1902 a protocol was prepared designating the strength of the various galenicals. Unfortunately, a standard for the alkaloidal content of drugs was not also established, and consequently in the several pharmacopœias there is still some variation in drug standards. For percentage of alkaloids in different drugs and their variation, consult Volume II, treating of Pharmacognosy.

Chemical Classification of Alkaloids.-The chemical study of the alkaloids shows that each plant contains not one but a number of alkaloids, cinchona bark and the opium poppy yielding not less than twenty different alkaloids. As their chemical constitution is not well known, it is customary even for the chemist to group them into certain natural classes, as the alkaloids of conium, tobacco alkaloids, the cinchona alkaloids, opium alkaloids, etc. They may also be grouped into certain fundamental groups, according to their nuclear structure derived from their probable constitution. While the natural classification may be more convenient, it will be replaced by a classification based on chemical constitution when our knowledge of this class of substances is extended. From studies thus far made the following groups of alkaloids may be recognized:

Pyridine Group.-Alkaloids derived from pyridine $\left(\mathrm{C}_{5} \mathrm{H}_{5} \mathrm{~N}\right)$ are found in Conium maculatum, Piper nigrum, and other species of Piper, Trigonella Fonum gracum, Areca Catechu, Beta vulgaris, Nicotiana Tabacum, Pilocarpus Jaborandi and other species of Pilocarpus, Lupinus, Laburnum, and other genera of the Leguminose. This group includes the liquid or volatile alkaloids.

Pyrrolidine Group.-Derivatives of Pyrrolidine $\left(\mathrm{C}_{4} \mathrm{H}_{8} \mathrm{NH}\right)$ occur in Atropa, Hyoscyamus, Datura, Scopolia and other genera of the Solanacea, Erythroxylon Coca, and Punica Granatum.

Quinoline Group.-Alkaloids with a Quinoline nucleus $\left(\mathrm{C}_{9} \mathrm{H}_{7} \mathrm{~N}\right)$ are obtained from cinchona bark and nux vomica.

Isoquinoline Group.-Isoquinoline is isomeric with quinoline; alkaloids with this nucleus are found in the opium poppy, Hydrastis canadensis, Berberis vulgaris, Menispermum canadense and quite a number of genera in the closely related families of Ranunculacea, as well as in some other plants.

Phenanthrene Group.-Morphine and codeine, closely re- 
lated alkaloids in opium, probably contain the Phenanthrene nucleus $\left(\mathrm{C}_{14} \mathrm{H}_{10}\right)$.

Purine Group.-Caffeine, the characteristic alkaloid of coffee, tea, and guarana, as well as theobromine associated with caffeine in cacao and kolanut, are derivatives of Purine $\left(\mathrm{C}_{5} \mathrm{H}_{4} \mathrm{~N}\right)$.

Amino-ACID Group.-Asparagine, or the monamide of aspartic acid, is very widely distributed throughout the plant kingdom.

Consult J. W. Bruhl, "Die Pflanzen-Alkaloide"; A. Pictet, "The Vegetable Alkaloids," translation by H. C. Biddle; O. A. Oesterle, "Grundriss der Pharmakochemie."

Asparagine $\left(\mathrm{C}_{4} \mathrm{H}_{8} \mathrm{~N}_{2}+\mathrm{H}_{2} \mathrm{O}\right)(\beta$-asparagine, the monamide of aspartic acid) is an amido compound which is most widely distributed throughout the vegetable kingdom. It is found not only in reserve organs as the tubers of the potato and dahlia, the roots of althæa, belladonna, etc., and the seeds of the chestnut tree, but it also occurs in young shoots as of asparagus and in peas, beans, and other members of the Leguminosæ. Asparagine has also been detected in some of the fungi as the Agaricineæ and certain of the Myxomycetes. Unlike certain derivatives of urea, it is a plastic product playing a very important rôle in plant metabolism. On account of its crystalline character and solubility in water, it is classed among the translocatory substances, appearing not only when proteins are being utilized by the plant, but when they are being formed. The crystals of asparagine are formed rather easily from the expressed juices of young shoots, and may be obtained even in sections upon mounting them in glycerin. The crystals vary in length from $0.3 \mathrm{~mm}$. to $15 \mathrm{~mm}$. (Fig. 98).

Asparagine occurs in two forms, one of which is lævorotatory and the other dextro-rotatory; the former is the one usually present in plants. At $17.5^{\circ} \mathrm{C}$., I part of asparagine is soluble in 47 parts of distilled water; at $98^{\circ} \mathrm{C}$., I part is soluble in $\mathrm{I} .9$ parts of distilled water.

The Glucosides or Glycosides are a class of plant substances which under the influence of ferments split up into a number of substances, one of which is always glucose (dextrose) or an analogous compound. Van Rijn has proposed the class name Glykoside for all substances of this group, restricting the name glucoside to those which yield glucose on hydrolysis. The glucosides are 
always associated in the plant cell with the special ferments which are capable of decomposing them. There are other substances which have the property of breaking up the glycosides, viz., dilute acids and alkalies. Of the mineral acids, dilute sulphuric acid and dilute hydrochloric acid are the most effective. They do not, however, always produce the same results on the same glucoside, as sometimes one acid works better than the other. Some glucosides are hydrolyzed by the use of strong

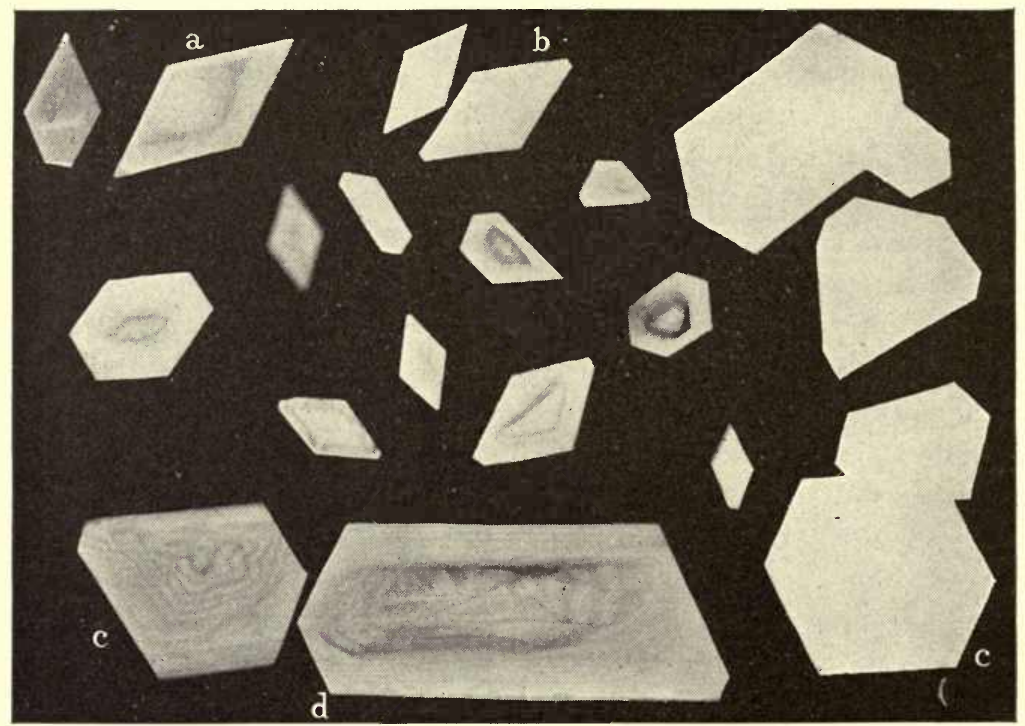

FIG. 98. Microphotograph of the rhombic prisms of Asparagine (amido-succinamic acid), which is rather widely distributed in the vegetable kingdom. From aqueous solution the smaller crystals are combinations of base and prism (a); one or both of the acute angles may be truncated on the faces of the brachydome (b); in the larger crystals (c) the brachydome is more developed and is either equidimensional or elongated on the $\alpha$-axis.

organic acids, as oxalic acid and citric acid. In view of the fact that most glucosides require the presence of water in addition to the presence of the ferment to produce an interaction, they are looked upon as ether or ester derivatives. This view is strengthened by a careful study of the glucosides which have been prepared synthetically, but it is not known in what manner the glucoside is united with the other compounds making up the natural glucosides. 
Distribution of Glucosides.-This class of substances has only been isolated in the Dicotyledons, being present in the Pinaceæ, Gramineæ, Liliaceæ, Iridaceæ, Salicaceæ, Fagaceæ, Moraceæ, Urticaceæ, Proteaceæ, Santalaceæ, Polygonaceæ, Caryophyllaceæ, Ranunculaceæ, Magnoliaceæ, Calycanthaceæ, Anonaceæ, Monimiaceæ, Cruciferæ, Saxifragaceæ, Rosaceæ, Leguminosæ, Tropæolaceæ, Linaceæ, Rutaceæ, Simarubaceæ, Polygalaceæ, Anacardiaceæ, Corynocarpaceæ, Aquifoliaceæ, Celastraceæ, Hippocastanaceæ, Sapindaceæ, Rhamnaceæ, Vitaceæ, Tiliaceæ, Malvaceæ, Theaceæ, Dipterocarpaceæ, Cistaceæ, Caricaceæ, Datiscaceæ, Thymelæaceæ, Lythraceæ, Punicaceæ, Combretaceæ, Myrtaceæ, Araliaceæ, Ericaceæ, Primulaceæ, Sapotaceæ, Oleaceæ, Loganiaceæ, Gentianaceæ, Apocynaceæ, Asclepiadaceæ, Convolvulaceæ, Hydrophyllaceæ, Boraginaceæ, Verbenaceæ, Labiatæ, Solanaceæ, Scrophulariaceæ, Bignoniaceæ, Orobanchaceæ, Globulariaceæ, Rubiaceæ, Caprifoliaceæ, Cucurbitaceæ, and Compositæ.

Chemical Classification.-The natural glucosides may be grouped either according to the nature of the sugar formed on hydrolysis or their probable organic derivatives. Most glucosides yield either dextrose or rhamnose. (I) Of the dextrose-glucosides the following may be mentioned: Esculin, amygdalin, arbutin, coniferin, fraxin, gaultherin, gossypetin, gynocardin, indican, iridin, linamarin, phloridzin, populin, prulaurasin, ruberithrinic acid, salicin, sambunigrin, saponarin, serotin, sinalbin, sinigrin, and syringin. (2) Of the rhamnose-glucosides the following may be mentioned: Baptisin, datiscin, frangulin, fustin, glycyphyllin, and quercitrin. (3) There are a few glucosides which yield peculiar sugars, as apiin, which on hydrolysis gives apiose and dextrose; barbaloin forms d-arabinose; convolvulin yields rhodeose and dextrose; digitalin forms digitalose and dextrose; digitonin forms galactose and dextrose; digitoxin yields digitoxose; gentiin yields xylose and dextrose; hesperidin forms rhamnose and dextrose, which are also formed from naringin and rutin; robinin forms galactose and rhamnose; strophanthin yields rhamnose and mannose; vicianin forms arabinose and dextrose; and xanthorhamnin yields galactose and rhamnose.

Rosenthaler (Pharm. Zentralh., 1907, p. 94) has attempted to group the glucosides, according to the constitution of the non- 
sugar substance formed on the hydrolysis of the glucoside. $\mathrm{He}$ has given the non-sugar substances the class name of "Aglykone," and groups the glucosides accordingly into the following three classes: I. Glucosides without Nitrogen Aglykones. II. Glucosides with Nitrogen Aglykones. III. Glucosides with Nitrogen and Sulphur Aglykones. Class I are further subdivided into whether they yield alipathic, aromatic, or other derivatives; each of these again is further subdivided into a number of subgroups. Among the alipathic aglykones are included the glucosides, jalapin and convolvulin. The glucosides with aromatic aglykones are subdivided as follows: $(A)$ Those yielding benzol derivatives and include arbutin, salicin, populin, gaultherin, etc. $(B)$ Derivatives containing the styrol nucleus include coniferin, daphnin, æsculin, scopolin, fraxin, naringin, and hesperidin. ( $C$ ) Derivatives containing anthracene in their constitution, as frangulin, morindin, and the glucosides of emodin, rhein, etc. $(D)$ Glucosides which are derivatives of flavon include apiin, fustin, quercitrin, rutin, xanthorrhannin. II. The glucosides with Nitrogen Aglykones include a number of cyanogenetic glucosides, of which amygdalin is the representative. III. The glucosides with Nitrogen and Sulphur Aglykones include sinigrin and sinalbin found in the genus Sinapis and other genera of the Cruciferæ. (Consult J. J. L. van Rijn, “Die Glykoside” ; O. A. Oesterle, " Grundriss der Pharmakochemie.”)

Properties of the Glucosides.-Like the alkaloids, some of the glucosides are highly toxic. Among those that possess a high degree of toxicity may be mentioned convallamarin, digitalin, scillain, strophanthin, sapotoxin, etc. They are soluble in water, alcohol, ethyl acetate, and chloroform, and insoluble in ether. The aqueous solutions are neutral or but faintly acid. Glucosides may be separated from solutions of salts of the alkaloids owing to the fact that they are soluble in chloroform and some other of the immiscible solvents, providing the solution is slightly acid. Most of the glucosides form well-developed crystals and may be studied with a petrographical microscope (Fig. 99). There is no special class of reagents, as with the alkaloids, used in their detection; on the other hand, some of them give strikingly distinct color reactions whereby they may be detected in the 


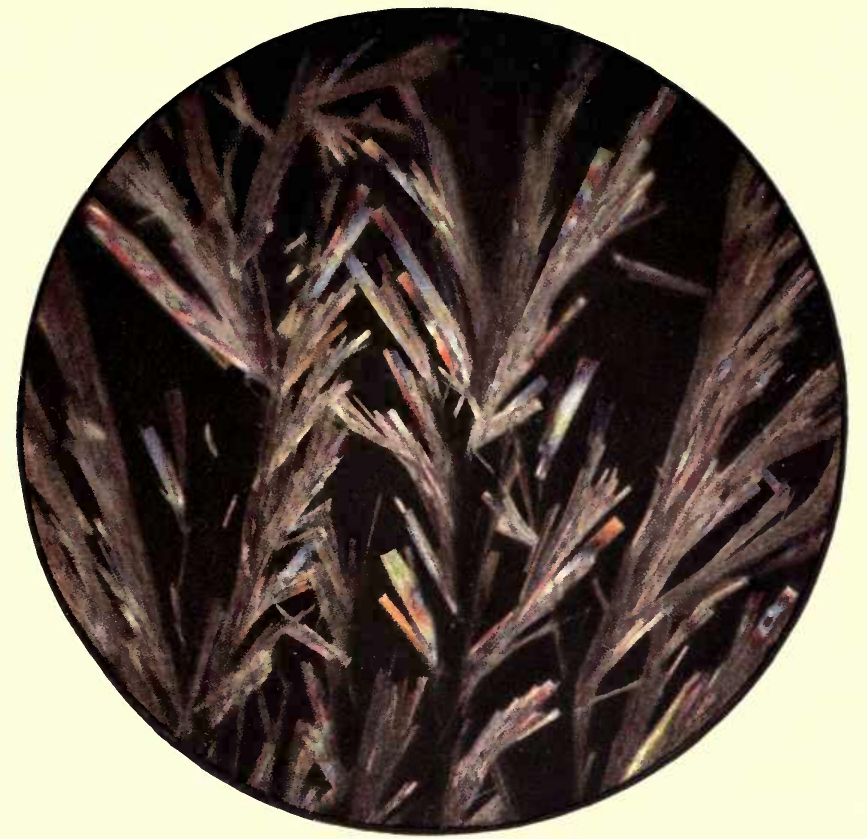

FIG. 99. Salicin. Orthorhombic crystals from alcoholic solution.

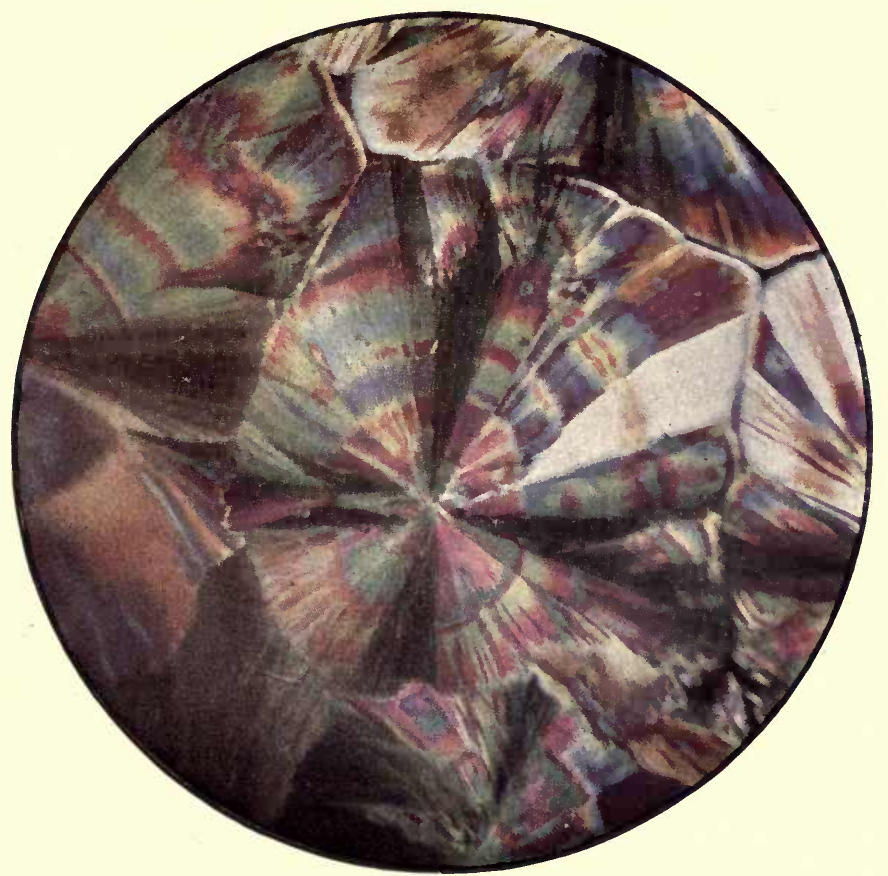

Fig. I0o. Cocaine hydrochloride. Aggregates from aqueous solution.

CRYSTALS IN POLARIZED LIGHT (Crossed nicols). 

tissues of the plant. With very few exceptions, however, the color reactions are not satisfactory.

Micro-Chemistry of Glucosides.-Although the glucosides upon extraction from the plant tissues form well-defined crystals (Fig. 99), they have not been identified as such in the plant. A few have been identified by giving distinct color reactions with certain reagents. The glucoside strophanthin can be detected in the seeds of Strophanthus hispidus. This glucoside is colored a brilliant green with sulphuric acid and is confined to the cells of the endosperm. The test is carried out as follows: Sections are mounted first in water and then transferred to a drop of sulphuric acid contained on the same slide, when the cells containing strophanthin are colored a bright green. Saponin is another glucoside which, it is stated, may be readily detected in plant cells, giving a reddish color reaction with sulphuric acid. Lafon's reagent also may be applied for the detection of saponin; this consists in the use of two solutions: $(a)$ equal volumes of alcohol and sulphuric acid; $(b)$ a very dilute solution of ferric chloride. The sections are placed in solutions $(a)$ and then a drop of solution $(b)$ is added. Cells containing saponin are colored red, changing to violet, becoming brownish-blue, or brown upon the addition of ferric chloride. Coniferin, the glucoside found in the cells of pine and other Coniferous trees, is colored red with sulphuric acid; it also gives a characteristic reaction on treatment of the section first with phenol, followed by sulphuric acid or hydrochloric acid, it becoming a deep blue almost instantly.

The SAPonins are a group of glucosides which possess the common property of forming a froth on shaking their aqueous solutions, and are present in the "soap-plants," which have been widely used as detergents. The saponins also dissolve the red blood-corpuscles, and for this reason are considered to be toxic substances. They have been found in the cell-sap of a large number of plants, occurring in parenchyma cells and medullary rays of roots and stems, the secretion cells and secretion reservoirs of leaves, and all parts of fruits and seeds. A large number of principles have been isolated from different plants, some of these being given distinct names, but the majority of them are homologous substances having the general formula $\mathrm{C}_{n} \mathrm{H}_{2 n-8} \mathrm{O}_{10}$. 
On account of some of the saponin-containing plants being added to beverages and used as emulsifying agents, the toxicity of a number of the saponins has been studied, those which are highly poisonous being known as sapotoxins. The following are some of the plants which contain sapotoxin: Quillaja Saponaria (9 per cent.), Agrostemma Githago (6.5 per cent.), Saponaria officinalis (4 to 5 per cent.), and Polygala Senega (2.5 per cent.).

Saponins have been found in more than a hundred different plants, including one or more genera of the following families: Liliaceæ, Dioscoreaceæ, Araceæ, Chenopodiaceæ, Phytolaccaceæ, Caryophyllaceæ, Berberidaceæ, Magnoliaceæ, Ranunculaceæ, Bixaceæ, Theaceæ, Rutaceæ, Zygophyllaceæ, Meliaceæ, Simarubaceæ, Sapindaceæ, Hippocastanaceæ, Melianthaceæ, Polygalaceæ, Pittosporaceæ, Rhamnaceæ, Saxifragaceæ, Passifloraceæ, Bignoniaceæ, Myrtaceæ, Rosaceæ, Leguminosæ, Primulaceæ, Sapotaceæ, Oleaceæ, Solanaceæ, Scrophulariaceæ, Rubiaceæ, and Compositæ.

Gluco-alkaloids represent a class of compounds intermediate between the alkaloids and glucosides, possessing characteristics of each. To this class belong achilleine, found in various species of Achillea, and also solanine, found in a number of species of Solanum.

Functions of Alkaloids and Glucosides.-In the growth of the plant there must not only be an adaptation to the external conditions and provision made to protect the plant against tempests, drought, excessive light, extreme temperatures, etc., but the plant must protect itself from diseases as well as from the depredations of animals. As a rule, plants, particularly of the tropics, depend on their own power to repair any injury to which they may be subjected. Nevertheless, there are many plants which produce poisonous substances, and these are usually supposed to have the function of protecting them from various diseases, as well as attack by herbivorous animals. Many of the alkaloids and glucosides are apparently aplastic substances,-i.e., are formed either occasionally or continually as unavoidable byproducts of metabolism, or are produced for special purposes. Some of these principles, as asparagine, an alkaloid, and hesperi- 
din, a glucoside, are not only products of constructive metabolism, but are entirely reassimilated.

Sublimable Principles.-Quite a number of plant principles are capable of being sublimed. Not only is this true when they are in the pure state, but also when they are associated with other compounds in the plant cell. This fact is of very great interest in the examination of commercial articles and also in the study of the localization and distribution of plant constituents. The method of procedure is very simple, and a small quantity of material only is necessary, usually from 0.020 to $0.050 \mathrm{Gm}$. being required. In the study of leaves a fragment about Io square millimeters is sufficient. The material is dried, either cut up or more or less comminuted and placed in a small watch crystal, the latter being covered either with a slide or another watch crystal for the deposition of the sublimate. The watch crystal containing the material is carefully heated either on a sand bath or on a bath containing sulphuric acid (Figs. IOI to IO4).

Rosenthaler (Ber. d. d. pharm. Ges., I9II, p. 338) has suggested in the examination of powdered drugs a specially constructed apparatus. A small quantity of the powder is introduced by means of a long funnel into a suitable tube, so that none of it comes into contact with the side walls. The powder should be covered with a layer of asbestos to prevent any of it being carried up mechanically. The tube is closed with a rubber stopper having two holes, one of which carries a cloubly bent tube leading to a small vessel acting as a receiver, the other carrying a tube connected with an air-pump. The air is exhausted and the tube containing the drug is heated in a bath of sulphuric acid or paraffin. A sublimate will form in the upper part of the tube containing the material, and distillation products will pass into the tube acting as a receiver and can be tested with various solvents and reagents. Plants containing thein, vanillin, and cumarin may be examined by direct sublimation in a watch crystal. Substances which yield tarry distillate, as cinchona, hydrastis, piper, etc., probably are better examined using the apparatus described by Rosenthaler.

Tunmann (Ber. d. d. pharm. Ges., I9I I, p. 312) examined a number of plants of the Ericaceæ and found, by the microsublima- 
tion method, that they contained arbutin. The latter is a rather widely distributed glucoside in this family and yields upon treatment with solutions of emulsin or hydrochloric acid the sublimable principle hydrochinon. The latter forms prisms and plates and may be further examined with acetone solution, dilute solutions of
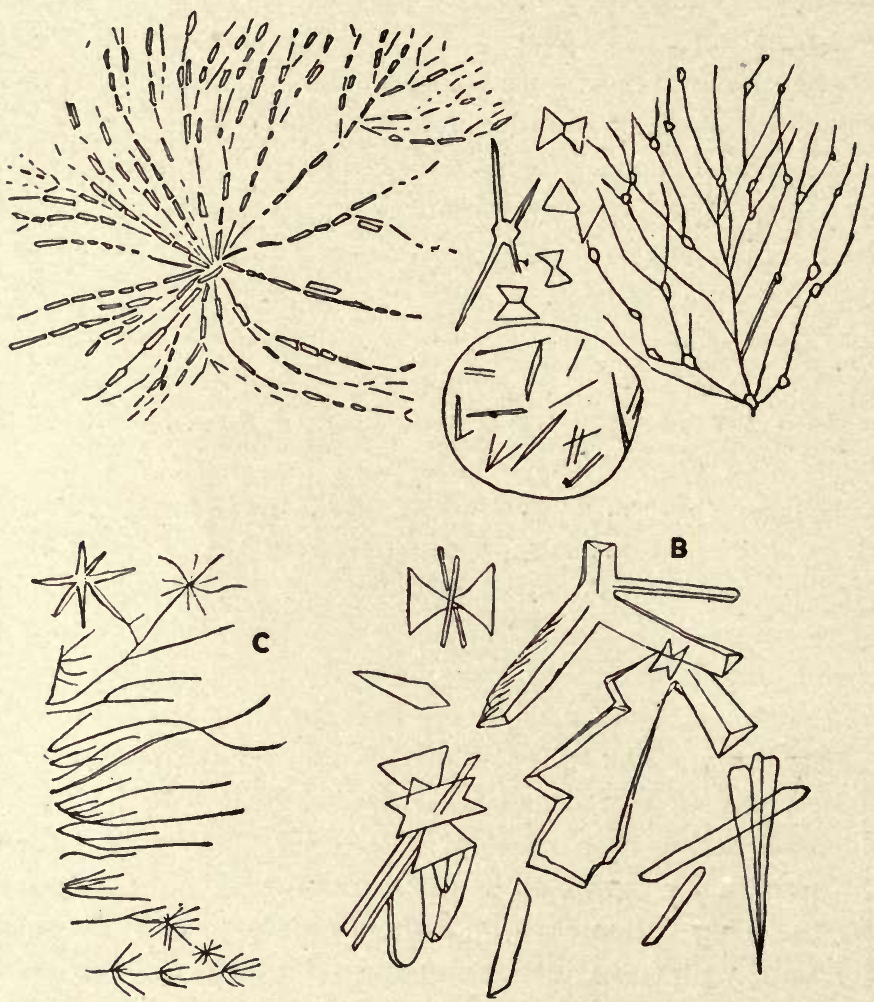

FIG. IOI. Alkaloids of hydrastis obtained by microsublimation. The method followed by Tunmann is to mix from 0.010 to $0.050 \mathrm{Gm}$. of powdered hydrastis with a drop of water upon a glass slide and heat to a temperature of $80^{\circ}$ to $95^{\circ} \mathrm{C}$. The sublimate consists of a number of radiating particles in which different types of crystals very soon separate (A). The microsublimate may be further treated with alcohol and a solution of potassium iodide, when crystals of hydrastine (B) and needle-shaped crystals of berberine (C) form.-After Tunmann in Gehe \& Co.'s Handelsbericht, ror 2.

ferric chloride and ammonia water. Arbutin occurs in the leaves of Arctostaphylos Uva-ursi, Vaccinium Myrtillus, Kalmia angustifolia, and Pyrola rotundifolia.

Rosenthaler obtained definite crystals in the microsublimation or pyro-analysis of the following drugs: cinchona, uva-ursi, fran- 
gula, rhamnus purshianus, rheum, hydrastis, opium, cubeba, piper, anisum, senna, radix scammoniæ, chrysarobium, rheum rhaponti-
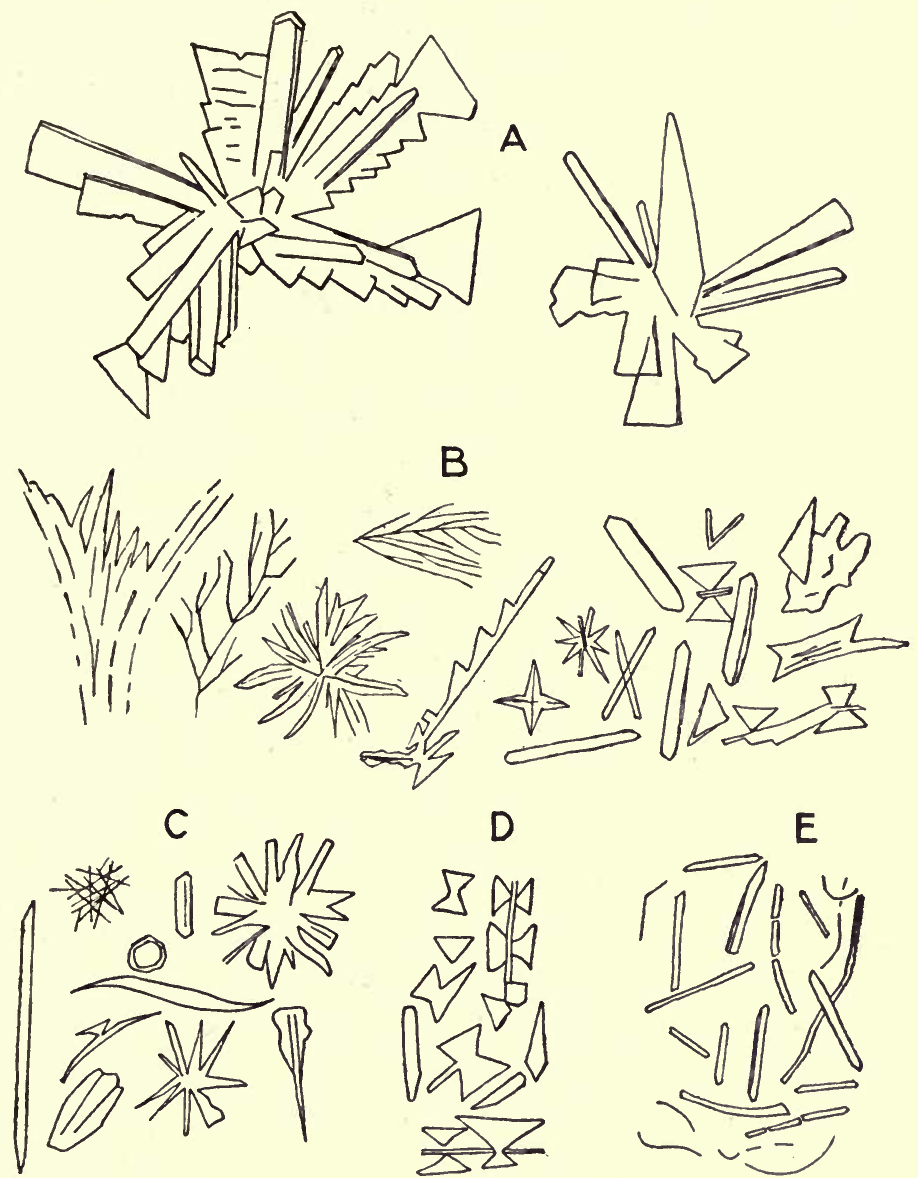

D

$E$
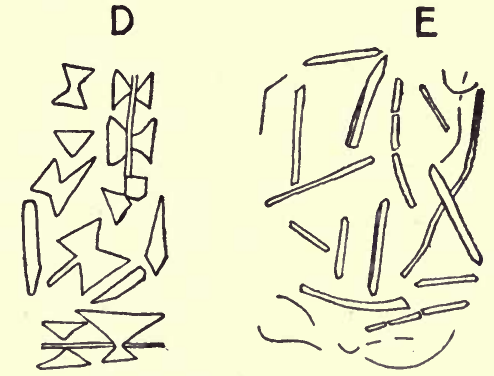

FIG. I02. Microsublimate crystals of alkaloids in hydrastis: A, White crystals of hydrastine formed upon the addition of chloroform to the sublimate. B, Type crystals obtained on the microsublimation of pure hydrastine hydrochloride. C, Type crystals obtained on the microsublimation of pure hydrastinine hydrochloride. D, Crystals of hydrastine formed upon the addition of water to the amorphous and crystalline sublimate obtained in the heating of powdered hydrastis. E, Resublimed crystals of hydrastin obtained from the chloroformic solution of the microsublimate.-After Tunmann in Gehe \& Co.'s Handelsbericht, I9I 2.

cum, jalapa, coca, stramonium, kamala, cousso, aurantii fructus cortex, guarana, cacao, kola, cantharides, podophyllum, radix canaigre, and kava-kava. (Consult Figs. Ior to I04.) 
The drugs thus far studied may to some extent be grouped according to the sublimable constituents which give characteristic reactions. I. Thein- or caffeine-containing drugs, as coffee, tea, cacao, and guarana. 2. Arbutin-containing drugs or those yielding hydrochinon, as uva-ursi and other Ericaceæ. 3. Drugs yielding oxymethylanthraquinone and giving a distinct purple color with solutions of the alkalies, as rhamnus purshianus, frangula, rheum, senna, etc.
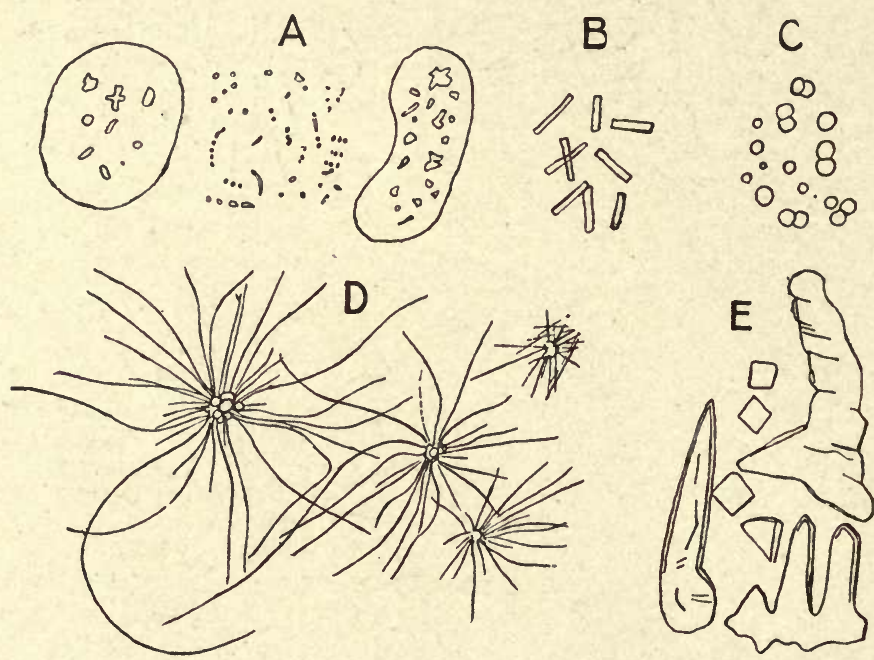

FIG. I03. Alkaloids of ipecac obtained by sublimation as follows: $0.050 \mathrm{Gm}$. of the powdered drug is mixed with 2 drops of water on a glass. slide and heated; the third distillate at a temperature of $100^{\circ}$ to $\mathrm{I} 15^{\circ} \mathrm{C}$. gives colorless or yellowish, highly refractive globules (A) in which crystals of emetin separate. B, Short, rod-shaped crystals of the double salts formed on the addition of gold chloride to the globules of the oily distillate. C, Oily globules of the distillate uniting and in which, upon the addition of potassium bismuth iodide, small spherites arise. D, Crystals of the alkaloids formed on treating small sections of ipecac or $0.00 \mathrm{I} \mathrm{Gm}$. of the powder with an aqueous solution of picric acid acidified with hydrochloric acid. E, Crystals formed at edge of cover glass.-After Tunmann in Gehe \& Co.'s Handelsbericht, I9I2.

Cell-sap Colors.-The majority of the other color-substances found in the higher plants besides the green and yellow principles previously mentioned occur in solution in the cell-sap, and may be in the nature of secondary substances derived from the plastid pigments, or they may be produced directly by the protoplasm. Upon making sections of the tissues containing cell-sap colorsubstances, not infrequently strikingly contrasting colors are observed in contiguous cells; as in the petals of the poppy and 
petals of certain lilies, where we find some cells of a deep purple color, others of a deep red, and still others of intermediate shades.

These substances are easily extracted with water or dilute alcohol and are all more or less affected by certain chemicals (many of which occur naturally in the plant), such as citric acid, oxalic acid, salts of calcium, iron, aluminum, etc.
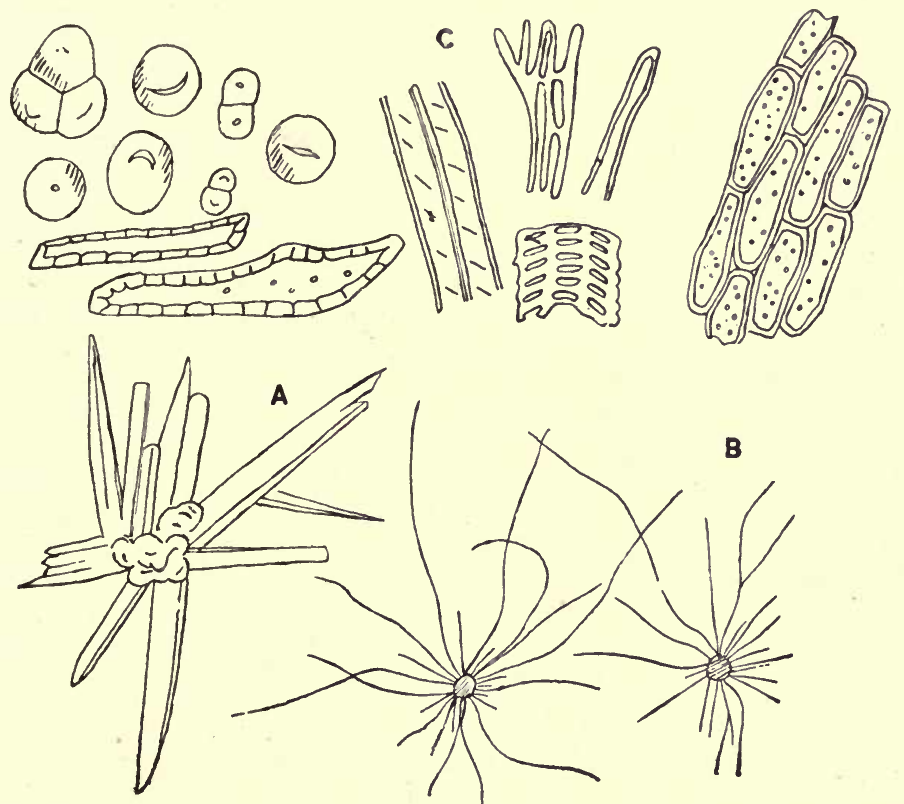

Fig. 104. Microcrystals formed in Kava-kava, the root of Piper methysticum: A. crystals of methysticin obtained on treatment of sections of the root or the powder with alcohol, the crystals being long rods, of a light yellow color, attaining a length of o.r6o mm. and becoming of a violet red on the addition of sulphuric acid. B, Crystals of methysticinic acid obtained upon heating a small quantity of the powder with one or two drops of a solution of potassium hydroxide, then adding dilute alcohol and allowing the slide to stand for 24 hours. Crystals of methysticin can also be obtained upon sublimation, providing the powder has been acted on previously with dilute sulphuric acid, emulsin, or saliva.-After Tunmann in Gehe \& Co.'s Handelsbericht, rэr2.

A number of plant pigments of this class are used as indicators in volumetric chemical analysis, their use in this connection being dependent upon their sensitiveness to acids and alkalies. The fact that they respond to iron salts,-that is, give a blue or green reaction with these salts,-would indicate that they are associated with tannin or that they are tannin-like compounds, as has been supposed by some writers, but they behave very differ- 
ently from tannin toward other reagents, such as organic acids, alkalies, lime water, and solution of alum.

An examination of the color-substances of a large number of plants shows that the flower color-substances are distributed in all parts of the plant. For example, the flower color-substance of the rose occurs in the leaves and prickles as well as in the petals.

The color-substance in the root of the radish closely corresponds to that in the flowers, while the one in the grains of black Mexican corn corresponds to that in corn silk.

The cell-sap color-substances are usually found in greatest amount at the tips of the branches, this being well marked in the foliage of the rose, and may be said to be rather characteristic of spring foliage. Not infrequently in the purple beech the young leaves will be of a distinct purplish-red color and almost entirely free from chlorophyll, suggesting a correspondence in position and color to a flower.

Color in Autumn Leaves.-The coloring matters in both spring and autumn leaves closely resemble the cell-sap colorsubstances of flowers, although it is the spring leaves which give the most satisfactory results when examined. The fact that in the autumn leaves there is little or none of the plastid pigment present would point to the conclusion that the color-substances occurring in these leaves are in the nature of by-products and of no further use to the plant. Of course, in the case of autumn leaves, we know that these products cannot be further utilized by the plant, and for this reason we are justified in regarding them as waste products.

So-called White Colors.-The so-called white colors in plants do not properly belong to either class, but may be said to be appearances due rather to the absence of color, and depending upon the reflection of light from transparent cells separated by relatively large intercellular spaces containing air. In other words, the effect produced by these cells may be likened to that produced by the globules in an emulsion. The white appearance is most pronounced in the pith cells of certain stems, where on the death of the cells the size of the intercellular spaces is increased and the colorless bodies in the cells as well as the walls reflect the light like snow crystals. 
Chemistry of Plant Color Principles.-The substances giving colors in plants may be divided into two classes: I. Substances having a specific color, as chlorophyll in leaves, chromophyll in flowers and fruits, and anthocyanin, the cell-sap color in flowers. 2. Substances which, while they themselves are colorless and known as leuco-compounds, yet form color derivatives. Some of these are more or less readily oxidized, forming characteristic color-substances, as brazilin. Again, some occur as glucosides which through the action of ferments yield color-substances, as quercitrin, which yields the yellow pigment quercetin. All of the researches which have been made seem to indicate that the color in plants is due to a basic substance or nucleus, and that the variation in color is due to the nature and arrangement of certain groups and side chains. For example, benzo-quinhydrone is green in color, while thymo-quinhydrone is of a purplish color (Pharm. Review, 1908, p. 330). Again, the hydroxybenzoquinones vary in color with the number of hydroxy groups, hydroxybenzoquinone being of a light yellow, di-hydroxybenzoquinone is of a dark yellow, tri-hydroxybenzoquinone is of a black color, and tetra-hydroxybenzoquinone is of a bluish-black color.

In the artificial dyes there are a number of so-called chromophores or chromophorous groups (radicals) characteristic of the various classes. In plant color-substances, on the other hand, we find the carbonyl group $(\mathrm{C}=\mathrm{O})$, the imido group $(\mathrm{NH})$, and $\mathrm{C}=\mathrm{C}$ group. The introduction of the chromophorous radical gives a basic compound which is more or less colored and known as a chromogen. The intensity of the color varies on the introduction of certain salt-producing groups or auxochromes. In the case of plant pigments, the most important of these is the hydroxyl group, and, as we have just seen, the intensity of color varies according to the number of these groups.

According to their constitution, plant color principles may be arranged into six different classes: I. Phenol derivatives, including orcin, the coloring principle in many lichens, that forms colorless prisms which become red; and thymo-quinone found in Monarda (Kremers, in Pharm. Rev., I908, p. 329). 2. Naphthalene derivatives, including juglon, which forms garnet-colored needles. 3. Anthracene derivatives, including alizarin, the color- 
ing principle in madder root. 4. Pyrone derivatives, of which there are several, as gentisein, maclurin, catechin, and rottlerin. being xanthone derivatives ; quercetin, rhannetin, and fisetin, which are flovone derivatives ; and hæmatoxylin and brasilin, being chromene derivatives. 5. Isoquinoline, of which berberine is an example. 6. Benz-pyrrol derivatives; in this group is indigotin or indigo blue, the coloring principle in Indigofera tinctoria.

Origin and Formation of Anthocyanin.-At the present time it is very difficult to determine the nature of the chemical processes which underlie the formation of anthocyanin, or the pigment dissolved in the cell-sap and giving the blue, purplish, and reddish color to flowers, fruits, etc. A great many observations have been made on the distribution of anthocyanin, the nature of the constituents with which it is associated in the plant cell, and their relation to various metabolic processes. In order to determine the Mendelian factors for color it is necessary that we have a definite knowledge concerning the nature and formation of this pigment. Of the numerous theories which have been proposed concerning the formation of anthocyanin, that proposed by Muriel Wheldale (Jour. Genetics, I9I I, p. I34) seems the most plausible and is as follows:

(I) The soluble pigments of flowering plants, collectively termed anthocyanin, are oxidation products of colorless chromogens of an aromatic nature, which are present in the living tissues in combination with sugar as glucosides.

(2) The process of formation of the glucoside from chromogen and sugar is of the nature of a reversible enzyme action:

Chromogen + sugar $\longleftrightarrow$ glucoside + water.

(3) The chromogen can only be oxidized to anthocyanin after liberation from the glucoside, and the process of oxidation is carried out by one or more oxidizing enzymes:

Chromogen + oxygen = anthocyanin.

(4) From (2) and (3) we may deduce that the amount of free chromogen, and hence the quantity of pigment formed at any time in a tissue, is inversely proportional to the concentration of the sugar and directly proportional to the concentration of glucoside in that tissue.

(5) The local formation of anthocyanin, which is character- 
istic of the normal plant, is due to local variation in concentration of either the free sugars or the glucosides in the tissues in which the pigment appears. The abnormal formation of pigment under altered conditions is due to differences in the concentration of these same substances due to changes in metabolism brought about by these conditions.

(6) On the above hypothesis the formation of anthocyanin is brought into line with that of other pigments produced after the death of the plant, as, for example, indigo and the post-mortem or respiration pigments, so termed by Palladin.

Function of Plant Colors.-A great many theories have been advanced as to the nature and uses of color-substances by the plant. With the exception of chlorophyll present in the chloroplastid and its relation to photosynthetic processes little is known concerning the other pigments. Without attempting to discuss the 'various theories which have been proposed concerning their uses, the following facts should be borne in mind:

I. The occurrence of chromoplastids in a reserve organ, as in the tuberous root of carrot, and the similar occurrence of chromoplastids and of reserve starch in the petals of the buttercup, lead to the inference that the petal of the buttercup, like the root of the carrot, has the function of storing nutrient material. In each case cells containing chromoplastids rich in nitrogenous substances are associated with cells containing reserve materials.

2. The distribution of the so-called flower color-substances in other parts of the plant than the flower shows them to be in the nature of metabolic substances, and that the part which they play in attracting insects to flowers is incidental rather than fundamental. (The fact that certain colored flowers as in spruce are pollinated by the wind would tend to confirm this view.)

3. Unorganized or cell-sap color-substances are distributed usually in largest amount at the termini of the branches, as in flowers and terminal leaves, or in roots, or in both tops and roots. Their occurrence in those portions of the plant which are young and growing points to the conclusion that they are not to be disregarded in the study of metabolic processes. Goebel likewise holds to this view. He says that it is "very probable that the 
feature of color which so often appears when the propagative organs are being brought forth has some connection with definite metabolic processes, although up till now we cannot recognize what these are."

Artificial Coloring of Flowers.-Ever since the time of Magnol ( 1709 ) there has been considerable interest in the subject of coloring white flowers. A number of aniline dyes can be used, but those belonging chiefly to the azo and rosaniline coloring matters, especially the acid dyes or those used for dyeing wool, give the best result. These dyes are readily soluble in water, and the solutions are made up of a strength of I part of dye to I,O0O parts of water. The effects are best seen in white flowers and are produced by allowing the flower-stalks to remain in the solutions from one to two hours, when they are placed in water. With some flowers, as the cultivated anemones, the effects are noticeable in from ten to fifteen minutes. Some flowers will take up the dyes better than others. White flowers may be changed to yellow, orange, blue, green, purplish-red or magenta, crimson, purple, salmon-pink or gray by the use of the following dyes:

I. Yellow flowers are produced by the use of the dye known commercially as "Acid Yellow A. T.," which is chemically the sodium salt of disulpho-diphenylazin-dioxytartaric acid.

2. Orange-colored flowers may be produced by the use of the dye "Orange G. G.," which is the sodium salt of benzene-azo- $\beta$ naphthol-disulphonic acid.

3. Blue flowers may be produced by the use of the dye "Cyanol F. F.," which is the sodium salt of meta-oxy-diethyldiamido-phenyl-ditolyl-carbinol-disulphonic acid.

4. Green flowers may be produced by the use of equal parts of the dyes "Acid Yellow A. T.," and "Cyanol F. F."

5. Purplish-red flowers are produced by the use of the dye "Acid Magenta," which is the sodium salt of the trisulphonic acid of rosaniline.

6. Crimson flowers may be produced by the use of equal parts of the dyes "Acid Yellow A. T." and "Acid Magenta."

7. Purple flowers may be produced by the use of equal parts of "Cyanol F. F." and "Acid Magenta." 
8. Salmon-pink flowers may be produced by the use of the dye "Brilliant Croceine M. O. O.," which is the sodium salt of benzene-azo-benzene-azo- $\beta$-naphthol-disulphonic acid.

9. Gray flowers may be produced by the use of the dye "Naphthol Black B.," which is the sodium salt of disulpho- $\beta$-naphthalene-azo- $\alpha$-naphthalene-azo- $\beta$-naphthol-disulphonic acid.

Calcium oxalate is found in many of the higher plants, and in the algæ and fungi as well; while in the mosses, ferns, grasses, and sedges it is seldom found. It occurs in plants in crystals of either the monoclinic or tetragonal system. The crystals dissolve in any of the mineral acids without effervescence, and their identity is usually confirmed by the use of dilute hydrochloric acid. The crystals of the monoclinic system are rather widely distributed, while those of the tetragonal system are less frequent in their occurrence.

The crystals belonging to the monoclinic system (Fig. I05) may be subdivided according to their prevalent forms into a number of sub-groups.

I. Solitary Crystals.-These are usually in the form of rhombohedra, sometimes in twin crystals of variable size (Fig. 108). They are very widely distributed, occurring in a number of modifications in the same plant, and are often very characteristic in the identification of economic products. The crystals of this group are sometimes mistaken for silica, owing to the fact that in some instances the lumen of the cell is completely filled by the crystal, and, the inner wall having the contour of the crystal, it is impossible to determine whether the crystal is affected by the use of hydrochloric acid. It should be stated in this connection that silica never occurs as a cell-content in sharp, angular crystals, but either in more or less ellipsoidal or irregular hollow masses, or in somewhat solid, irregularly branching forms (Fig. I09).

II. Columnar CRystales or " styloids," being elongated prisms of the monoclinic system (Fig. Io\%, $C$ ), and when typical recall the crystals of gypsum. They also occur in twin-forms, sometimes replacing raphides, and occasionally show a number of transition forms.

Solitary crystals in the form of rhombohedra or styloids occur in a number of drugs, as follows: Acer spicatum, calumba, carla- 

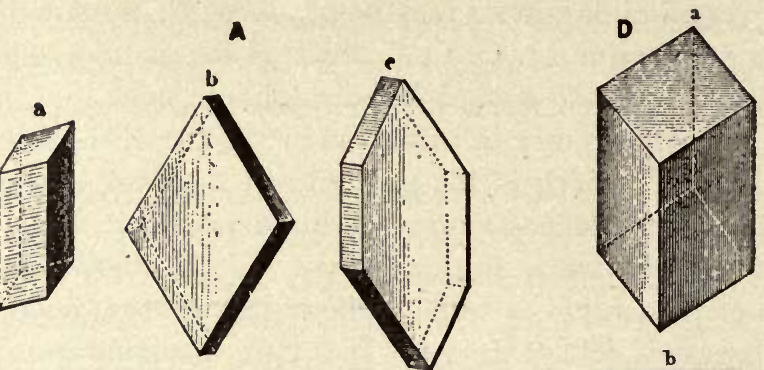

b
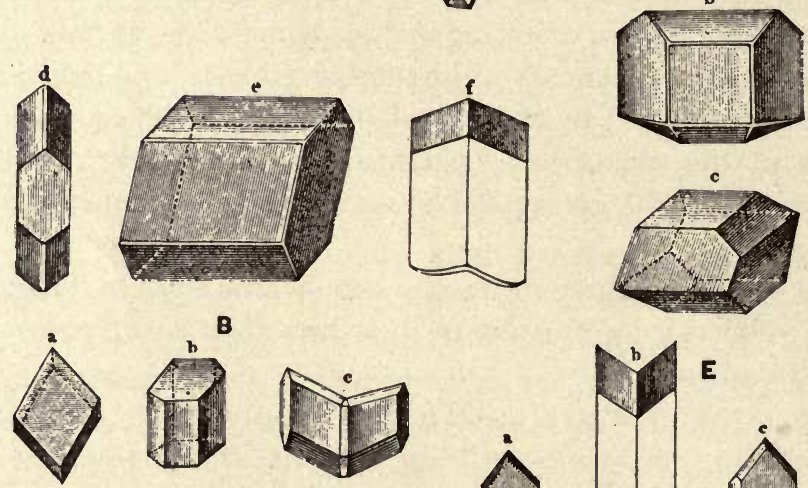

$\mathbf{B}$
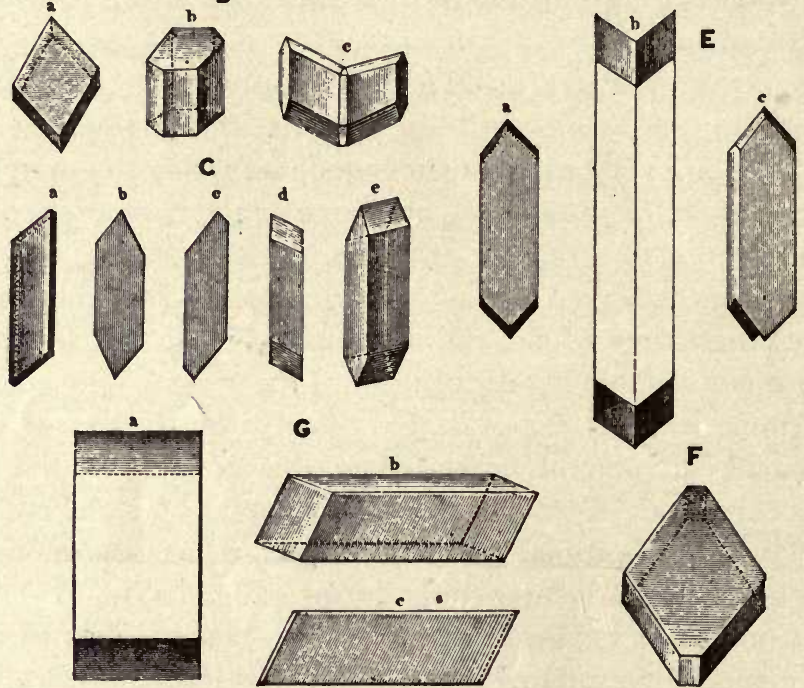

Fig. 105. Monoclinic crystals of calcimm oxalate: A, a to $f$, crystals from the parenchyma of the bark of the horse-chestnut (Esculus Hippocastanum); B, a to c, from the pith of Periploca graca; C, a to e, from the parenchyma in the region of the fibrovascular bundles in Musa sinensis; D, a to c, from the petioles of the pinnate leaves of Cycas revoluta; $\mathrm{E}$, a to c, crystals from the bark of the guaiac tree; F, a single crystal from Citrus aurantium; G, a to c, rectangular crystals trom a Brazilian bignonia. - After Dippel in "Das Mikroskop." 
momum, coca, eucalyptus, frangula, gelsemium, granatum, hamamelis, hyoscyamus, Jamaica quassia, krameria, pimenta, Prunus serotina, quercus, quillaja, rhamnus purshianus, senna, uva-ursi, vanilla, viburnum prunifolium, and xanthoxylum.

III. Rosette AGgRegates of calcium oxalate consist of numerous small prisms and pyramids, or hemihedral crystals more or less regularly arranged around a central axis, and have the appear-
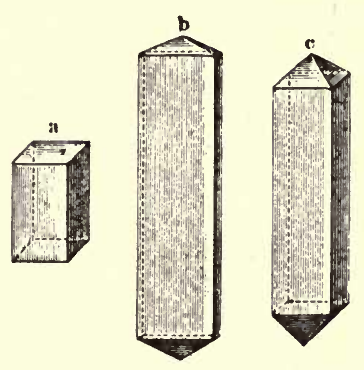

A
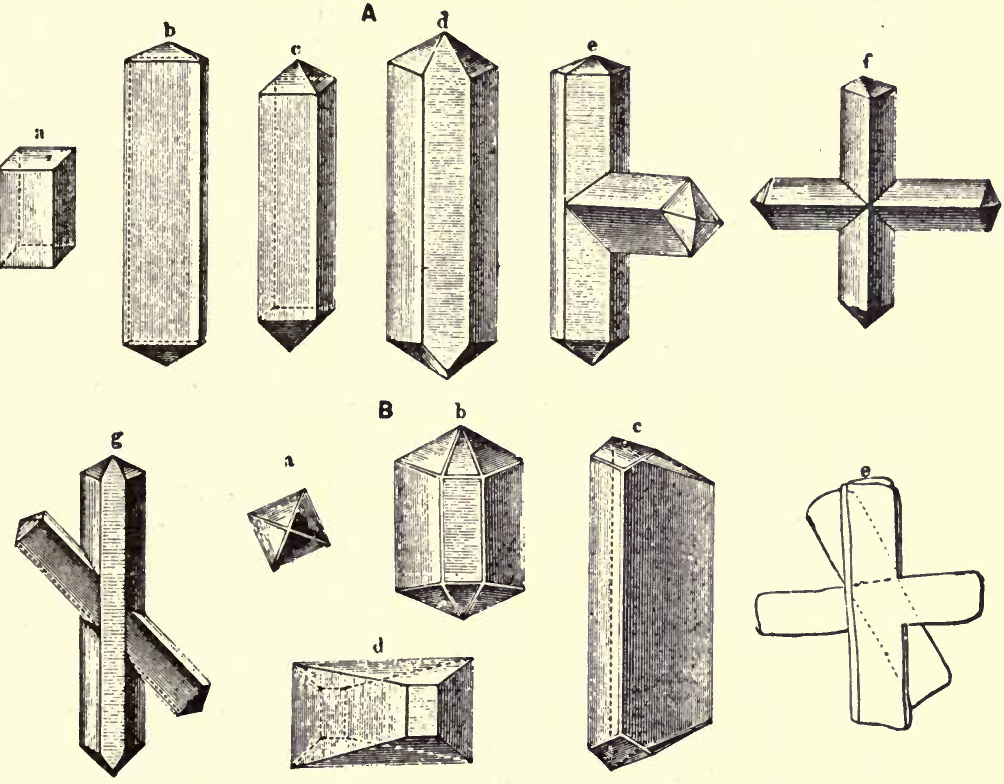

Fig. 106. Orthorhombic crystals of calcium oxalate: A, a to f, crystals from the leaves of the onion (Allium Cepa); B, a to g, crystals from the stem of Tradescantia viridis. -After Dippel in "Das Mikroskop."

ance of a rosette or star (Fig. I07, $A$ ). The development of . these aggregates may be readily observed in the stem of Datura Stramonium. Crystals of this class are more widely distributed than any of the others, and are characteristic of a number of drugs.

Clustered crystals in the form of rosette aggregates occur in numerous drugs, as follows: Althæa, anisum, buchu, calendula, cannabis indica, carum, caryophyllus, castanea, chimaphila, conium, coriandrum, cusso, eriodictyon, euonymus, fœniculum, frangula, galla, geranium, gossypii cortex, granatum, humulus, jalapa, pilo- 
carpus, pimenta, rheum, rumex, senna, stillingia, stramonii folia, viburnum opulus, and viburnum prunifolium.

IV. RAPHIDES are groups of needle-shaped crystals, especially prevalent in Monocotyledons (Fig. I07, B). They have been mis-
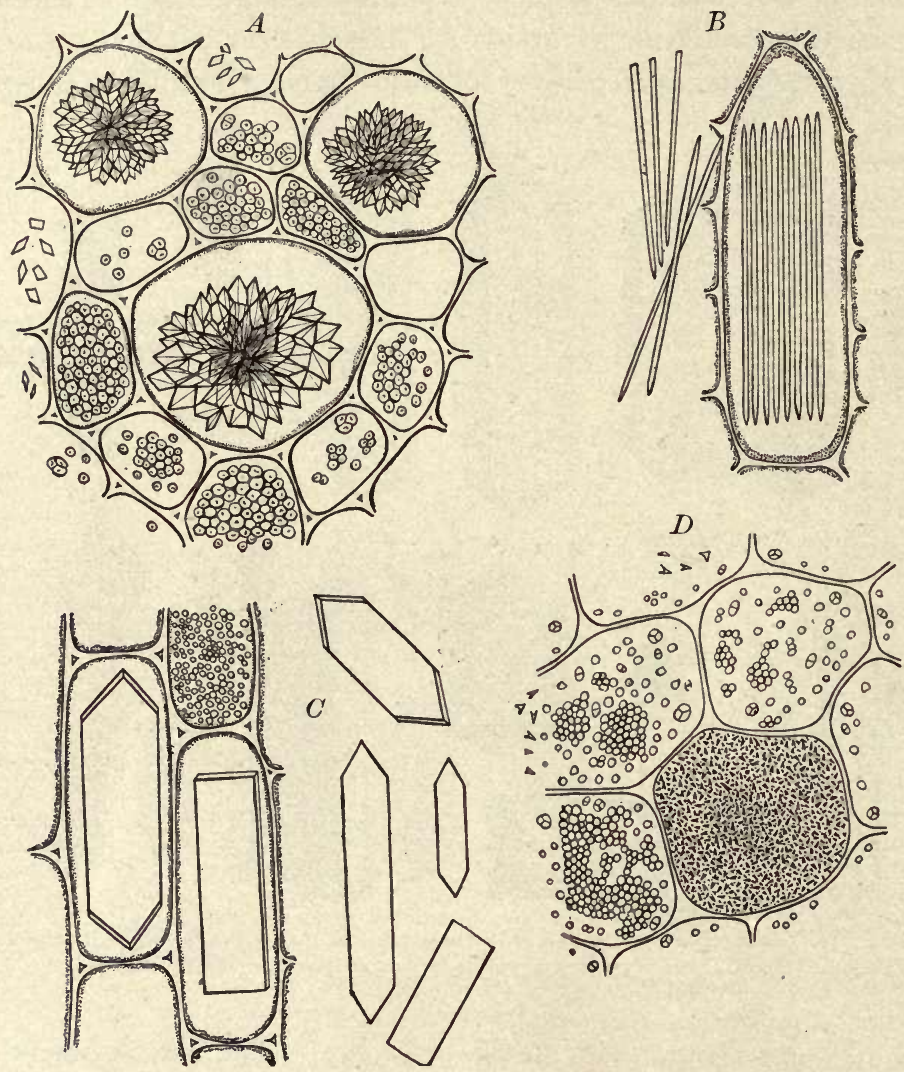

FIG. I07. Forms of calcium oxalate crystals: A, transverse section of rheum showing rosette aggregates of calcium oxalate in three of the cells and starch grains in some of the others; $\mathrm{B}$, longitudinal section of scilla showing raphides; $\mathrm{C}$, longitudinal section of quillaja showing large monoclinic prisms of calcium oxalate and also some starch grains; $\mathrm{D}$, transverse section of belladonna root showing one cell filled with sphenoidal micro-crystals, the remaining cells containing starch.

taken by several observers for calcium phosphate. Calcium phosphate, however, occurs in plants either in solution or in combination with protein substance. The cells containing raphides are long, thin-walled and contain, sooner or later, a mucilage, 
which arises from the cell-sap, is stained by corallin, and behaves with reagents much like cherry-gum. The cells are either isolated or occur in groups placed end to end, as in Veratrum viride.

Raphides are found in relatively few drugs, as follows: Cinnamomum, convallaria, cypripedium, ipecacuanha, phytolacca, sarsaparilla, scilla, vanilla, and veratrum viride.

V. Crystal Fibers.-In quite a number of drugs a single monoclinic prism or a rosette aggregate occurs in each of the parenchyma cells adjoining the sclerenchymatous fibers, and to this single longitudinal row of superimposed cells the name crystal
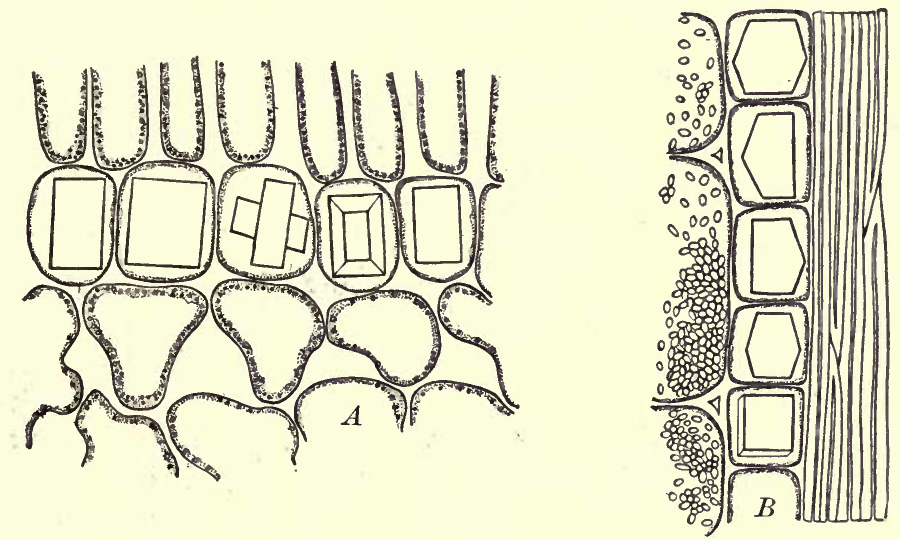

FIG. 108. A, transverse section of hyoscyamus leaf showing monoclinic prisms of calcium oxalate, also a twin-crystal; B, longitudinal section of glycyrrhiza showing a crystal fiber, i.e., a row of superimposed cells, each containing a polygonal monoclinic prism of calcium oxalate, the crystal filling the cell. Adjoining the crystal fiber is a group of bast fibers on one side and some cells containing starch on the other.

fiber has been applied (Fig. I08, B). Crystal fibers are typical of the following drugs: Aspidosperma, frangula, glycyrrhiza, hæmatoxylon, hamamelis, Prunus serotina, quercus alba, quillaja, rhamnus purshianus, and uva-ursi.

VI. Micro-Crystals are exceedingly small (about 0.2 to Io $\mu$ in diameter), apparently deltoid or arrow-shaped, and so numerous as to entirely fill the parenchyma cells in which they occur, giving the cells a grayish-black appearance which readily distinguishes them from other plant cells (Fig. IO7, D). It has been supposed that they are tetrahedrons, but they are probably sphenoids 
in the monoclinic system, inasmuch as monoclinic prisms occur in neighboring cells in the same plant or drug, as in stramonium, quassia, etc. Because they are so small and in many instances not clearly defined they have been termed by the Germans "crystal-

A

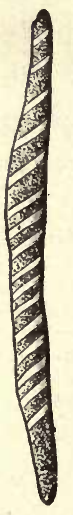

B
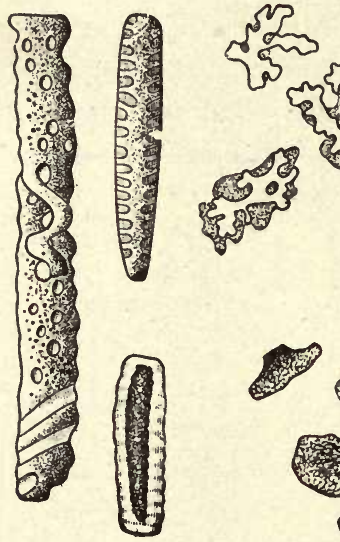

F
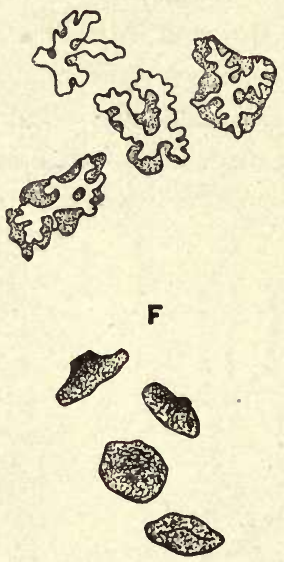

D

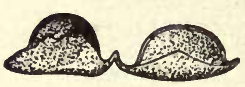

a

b

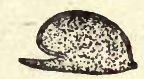

c

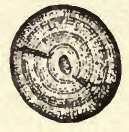

d

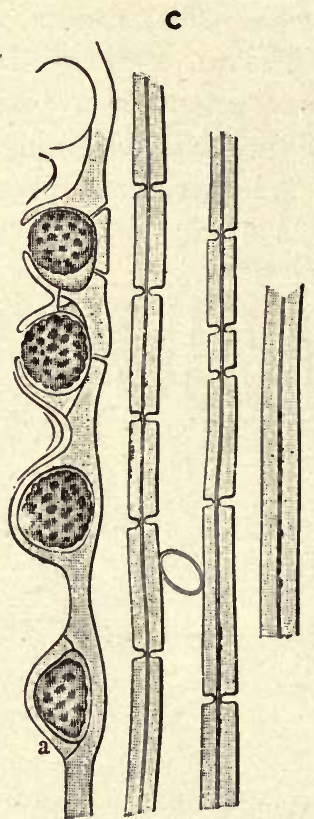

E

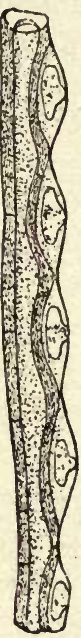

FIG. 109. Various forms of Silica found in plants. Long rods and spindle-shaped masses (A) and star-shaped fragments (B) found respectively in the thalloid structure made up of roots and shoots and in the leaves of Tristicha hypnoides, a small, moss-like plant (Podostemaceæ) growing on rocks, etc., in running water, especially in waterfalls. C, a longitudinal section of the petiole of Caryota urens, a palm of Eastern Asia, showing grape-like clusters of silica completely filling the cells. D, hat-shaped fragments of silica occurring on the edge of the leaves of Cusparia macrophylla, a rutaceous tree growing near Rio Janeiro; in a, b, c, side views of the masses, whereas in d the surface view shows a structure resembling that of sphero-crystals, $\mathrm{E}$ and $\mathrm{F}$, siliceous fragments from the leaves of an orchid, Oncidium leucochilum, growing in Guatemala; in E is shown a base fiber with siliceous masses somewhat resembling the crystal-fibers of calcium oxalate, and in $\mathrm{F}$ the isolated siliceous masses are seen.-A and $B$, after Cario; C and D, after Rosanoff; E and F, after Pfitzer.-From Dippel in "Das Mikroskop."

sand" (Kristallsand). The typical tetrahedral form was recognized by the French and termed "sable tetraedrique."

Sphenoidal micro-crystals are found in the following drugs: Belladonnæ folia, belladonnæ radix, cinchona, dulcamara, phytolacca, quassia, Solanum carolinense, and tabacum. 
VII. Membrane Crystals.-There are several forms of crystals which may be included in this group. The so-called Rosanoff crystals consist of rosette aggregates attached to inwardprotruding walls of the plant cell. These, however, do not concern us so much as the large monoclinic crystals which have a membrane surrounding them. The crystal first appears in the cell-sap, and then numerous oil globules appear in the protoplasm around it; later some of the walls of the cell thicken and grow around the crystal, which they finally completely envelop, as in Moraceæ.

Crystals of the orthorhombic system may occur either as solitary crystals or rosette aggregates, or in the form of acicular crystals and probably micro-crystals, being usually much smaller than the single crystals of the monoclinic system.

Solereder, in his work on "Systematic Anatomy of the Dicotyledons," states that the systematic value of the study of the forms of crystals varies considerably. While in some instances a certain form of crystal is characteristic of an entire order, yet in other cases it serves to distinguish only genera or species. In practical work in the identification of economic products the study of the forms of crystals is very important. A few instances may be mentioned. In Jamaica quassia calcium oxalate occurs in the form of 4- to 6-sided rhombohedral crystals, whereas in Surinam quassia the crystals are few or entirely wanting. In Levant scammony root occur numerous monoclinic prisms of calcium oxalate, whereas in the Mexican root the crystals are chiefly in the form of rosette aggregates. In the bark of Viburnum Opulus the calcium oxalate occurs almost entirely in the form of rosette aggregates, whereas in the bark of Acer spicatum solitary rhombohedral crystals are prevalent. In the identification of many drugs the presence or absence of calcium oxalate crystals and the study of the prevalent forms is very important (Fig. I Io).

Owing to the importance of the study of calcium oxalate an enumeration of the families in which calcium oxalate occurs is given.

I. Crystals of calcium oxalate, either in the form of solitary rhombohedra or clustered aggregates, are found in the following families: Aceraceæ, Ampelidaceæ (also raphides), Anacardiaceæ, Apocynaceæ, Araliaceæ, Asclepiadaceæ, Berberidaceæ, Bignonia- 
A

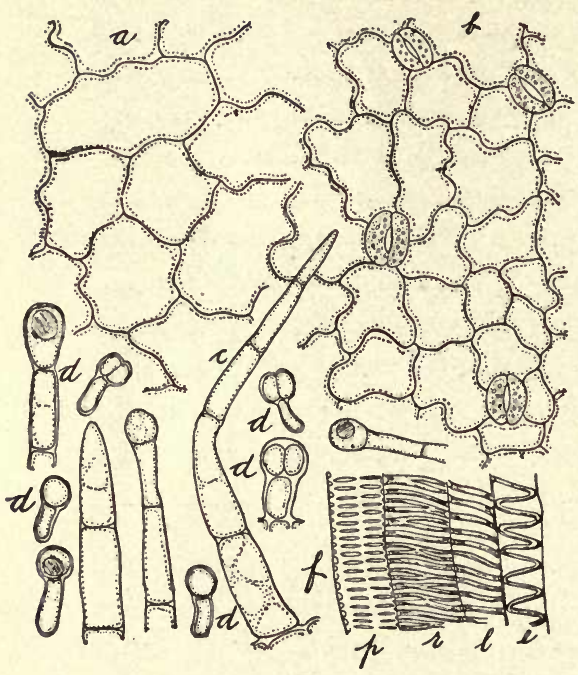

c

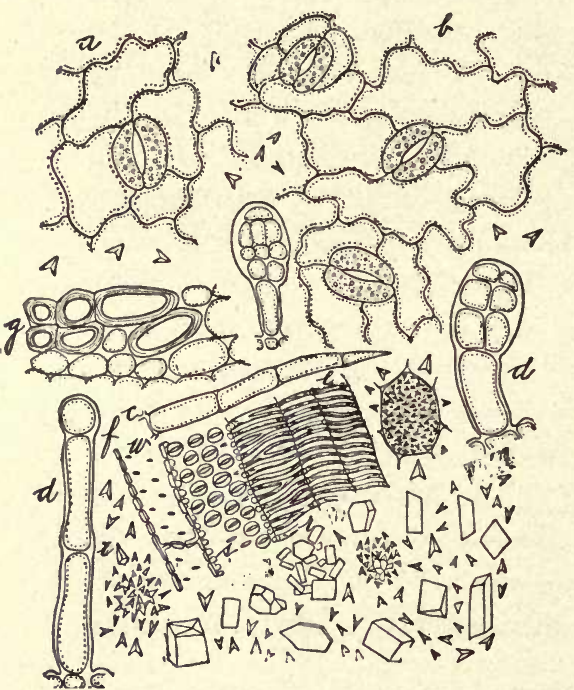

B

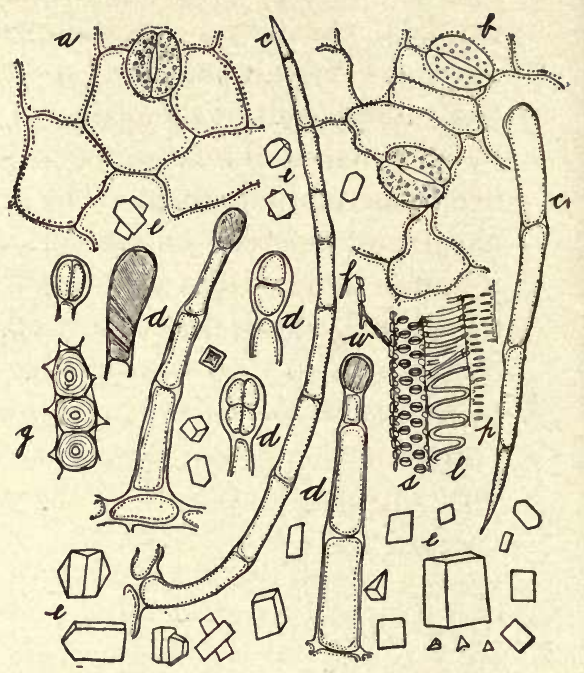

D

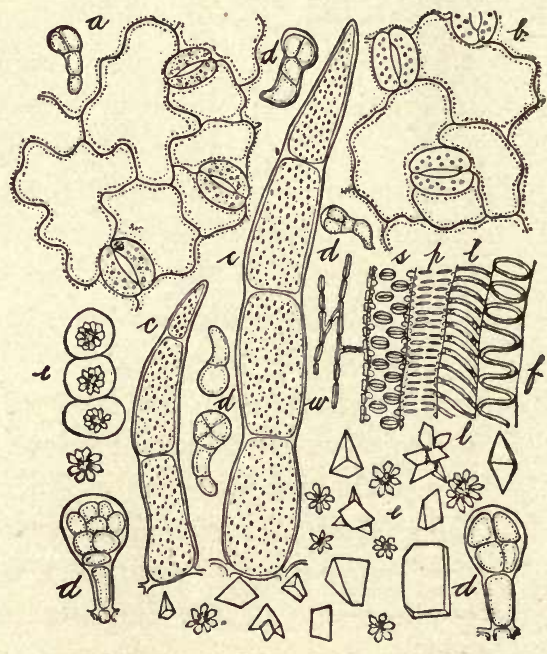

FIg. Iro. A few illustrations showing the practical value of the study of calcium oxalate: A, digitalis, without any calcium oxalate; $\mathrm{B}$, hyoscyamus in which monoclinic prisms predominate; $\mathrm{C}$, belladonna, characterized chiefly by sphenoidal micro-crystals as well as occasional prisms; D, stramonium, having rosette aggregates in addition to prisms which are found in the petioles and stems and sphenoidal micro-crystals, which are abundant in the root.-a, upper epidermis; b, lower epidermis; $c$, non-glandular hairs (which in stramonium are tuberculate); $d$, glandular hairs; $e$, calcium oxalate crystals; $f$, fragments of xylem showing tracheæ with bordered pores $(s)$, reticulate markings $(r)$, simple pores $(p)$, spiral thickening (1), and wood fibers (w); g, bast fibers, which, together with wood fibers, are wanting in digitalis. 
ceæ (also in the form of octahedra and small acicular crystals), Bixaceæ, Bruniaceæ, Burseraceæ, Вuxaceæ (also styloids and micro-crystals), Cactaceæ, Canellaceæ, Capparidaceæ, Caprifoliaceæ, Caryophyllaceæ, Casuarinaceæ, Celastraceæ, Combretaceæ, Convolvulaceæ (also small acicular crystals), Cornaceæe (also micro-crystals), Ebenaceæ, Ericaceæ, Euphorbiaceæ, Fagaceæ, Geraniaceæ (also raphides), Guttiferæ, Hamamelidaceæ, Hippocastanaceæ, Hypericaceæ, Juglandaceæ, Lecythidaceæ, Linaceæ, Loganiaceæ, Loranthaceæ, Lythraceæ; Magnoliaceæ, Malpighiaceæ, Malvaceæ, Meliaceæ, Menispermaceæ (also small acicular crystals), Moraceæ, Myricaceæ, Myrsinaceæ, Myrtaceæ, Oleaceæ, Passifloraceæ, Pittosporaceæ (also columnar crystals), Platanaceæ, Plumbaginaceæ, Podostemaceæ, Polygalaceæ, Polygonaceæ, Portulacaceæ (also micro-crystals), Rhamnaceæ, Rhizophoraceæ, Rosaceæ, Rubiaceæ (also raphides, micro-crystals, rhombohedra, and small acicular crystals), Rutaceæ (also styloids and raphides), Salicaceæ, Santalaceæ, Sapindaceæ, Sapotaceæ (also micro-crystals), Saxifragaceæ, Simarubaceæ, Solanaceæ (also micro-crystals), Staphyleaceæ, Sterculiaceæ, Theaceæ (also raphides and styloids), Thymelæaceæ (also micro-crystals), Tiliaceæ, Ulmaceæ, Umbelliferæ, Urticaceæ, Vaccinaceæ, Verbenaceæ (also small prisms and acicular crystals), Violaceæ, and Zygophyllaceæ.

Solitary rhombohedra are found in a relatively few families and are characteristic of the following: Connaracex, Crassulaceæ, Cucurbitaceæ, and Leguminosæ.

II. Crystals in the orthorhombic system occurring in the form of small octahedra or prisms, as twin-crystals, and in the form of short rods or needles are found in the following families: Aceraceæ, Apocynaceæ, Araliaceæ, Aristolochiaceæ, Begoniaceæ, Bignoniaceæ, Boraginaceæ, Cactaceæ, Cæsalpinaceæ, Calycanthaceæ, Campanulaceæ, Canellaceæ, Capparidaceæ, Chenipodiaceæ, Compositæ, Convolvulaceæ, Gentianaceæ, Gesneraceæ, Guttiferæ, Lau1-' raceæ, Loganiaceæ, Magnoliaceæ, Melastomaceæ, Menispermaceæ, Moraceæ, Myristicaceæ, Monimiaceæ, Oleaceæ, Papilionaceæ, Phytolaccaceæ, Piperaceæ, Polemoniaceæ, Ranunculaceæ, Rubiaceæ, Saxifragaceæ, Scrophulariaceæ, Simarubaceæ, Solanaceæ, Sterculiaceæ, Styracaceæ, and Zygophyllaceæ. 
III. Rosette aggregates or clustered crystals sometimes accompanying other forms are found in the following families: Acanthaceæ, Begoniaceæ, Boraginaceæ, Calyceraceæ, Campanulaceæ, Candolleaceæ, Chenopodiaceæ, Chloranthaceæ, Elatinaceæ, Empetraceæ, Gentianaceæ, Gesneraceæ, Hydrophyllaceæ, Labiatæ, Loasaceæ, Magnoliaceæ, Melastomaceæ, Melianthaceæ, Myristicaceæ, Nepenthaceæ, Nymphæaceæ, Onagraceæ, Papaveraceæ, Phytolaccaceæ, Piperaceæ, Polemoniaceæ, Ranunculaceæ, Sarraceniaceæ, and Turneraceæ.

IV. Sphærites (sphere-crystals), or rosette aggregates composed of very small needles, have been observed in certain plants of the following families: Aceraceæ, Asclepiadaceæ, Berberidaceæ, Cactaceæ, Combretaceæ, Crassulaceæ, Empetraceæ, Euphorbiaceæ, Geraniaceæ, Melastomaceæ, Papilionaceæ, Phytolaccaceæ, Rosaceæ, and Solanaceæ.

V. Raphides are sometimes associated with other forms of crystals, as micro-crystals, rosette aggregates, rhombohedra, and styloids. They are widely distributed among the Monocotyledons and occur in the following Dicotyledons: Geraniaceæ, Gesneraceæ, Melianthaceæ, Phytolaccaceæ, Rubiaceæ, Rutaceæ, Saxifragaceæ, Theaceæ, Urticaceæ, and Zygophyllaceæ.

\section{PLANT PROTEINS.}

The proteins are nitrogenous compounds, most of which contain sulphur and some of which contain phosphorus. Their constitution or the molecular structure of their molecules has not been determined, but they are very large, and are built up of aminoacids, the simplest of which is glycocoll (amino-acetic acid).

Apart from the protoplasm found in living cells, the proportion of proteins in plants is relatively small, except in seeds, where they serve as nutriment during the germinating period, being made available by the action of proteolytic enzymes. Most of the plant proteins are GLOBULINS, and collectively have been termed phytoglobulins. (I) The globulins are insoluble in pure water and in dilute acids, but are soluble in dilute solutions of sodium chloride ( $\mathrm{I}$ to 20 per cent.), ammonium chloride, sodium sulphate and dilute solution of potassium hydrate, from which solutions they may be precipitated by dilution, dialysis, or acidification with $\mathrm{CO}_{2}$ 
or dilute acids, or by "salting out" by the use of strong or saturated solutions of ammonium sulphate, magnesium sulphate, or sodium chloride. (2) The proteins which contain phosphorus are sometimes called phytovitellins, as legumin in peas, which contain O.35 per cent. of phosphorus. A third class of plant proteins, which are alcohol-soluble, are found in cereals, as the gliadin of wheat and rye and the zein of maize. The cohesive and doughing properties of wheat flour are attributed to the association of gliadin and another protein called glutenin.

Some of the plant proteins occur naturally in the crystalline form, either free in the cytoplasm, as in the potato tuber (Fig. I I I, $A$ ), or as components of aleurone grains, as in the seeds of Ricinus communis and Brazil nuts (Fig. II I, $B$ and $D$ ). Phytoglobulins in the form of crystals and spheroids have been obtained from extracts of flax-seed, hemp-seed, Brazil-nut, castor-oil seeds and others. Protein crystals are, according to Wichmann, isomorphic, and probably belong to the hexagonal system (Fig. I I2).

Aleurone grains are made up of phyto-globulins (formerly called crystalloids), globoids and a ground mass, the whole being enclosed by a membrane-like material. They may be studied by taking advantage of the difference in solubility of the substances composing them. The membrane, or lining of the protoplasm, while soluble in water, remains intact with sections examined in any of the fixed oils, as cotton-seed oil. Usually seeds which contain aleurone are rich in fixed oils, and if this oil is first removed by placing fresh sections in alcohol, or alcohol and ether, the subsequent study is facilitated. If the sections thus treated are mounted in water, the membrane gradually dissolves, leaving, the globulins, globoids, and calcium oxalate. On adding a o.I to I per cent. solution of either sodium or potassium hydrate, the globulins dissolve, the globoids and calcium oxalate crystals remaining unaffected. The globoids may be dissolved by the use of a I per cent. acetic acid solution, or concentrated solutions of ammonium sulphate or monopotassium phosphate. The calcium oxalate remaining may then be treated with hydrochloric acid in the usual way.

Classification of Proteins.-A committee on protein nomenclature of the American Society of Biological Chemists proposed 
a classification of Proteins based chiefly on their solubility under different conditions. There are some eighteen different classes recognized, and these are brought under three principal groups: (I) Simple Proteins, as albumins, globulins, glutelins, prolamins, etc. (2) Conjugated Proteins, or complex substances, as nucleo-

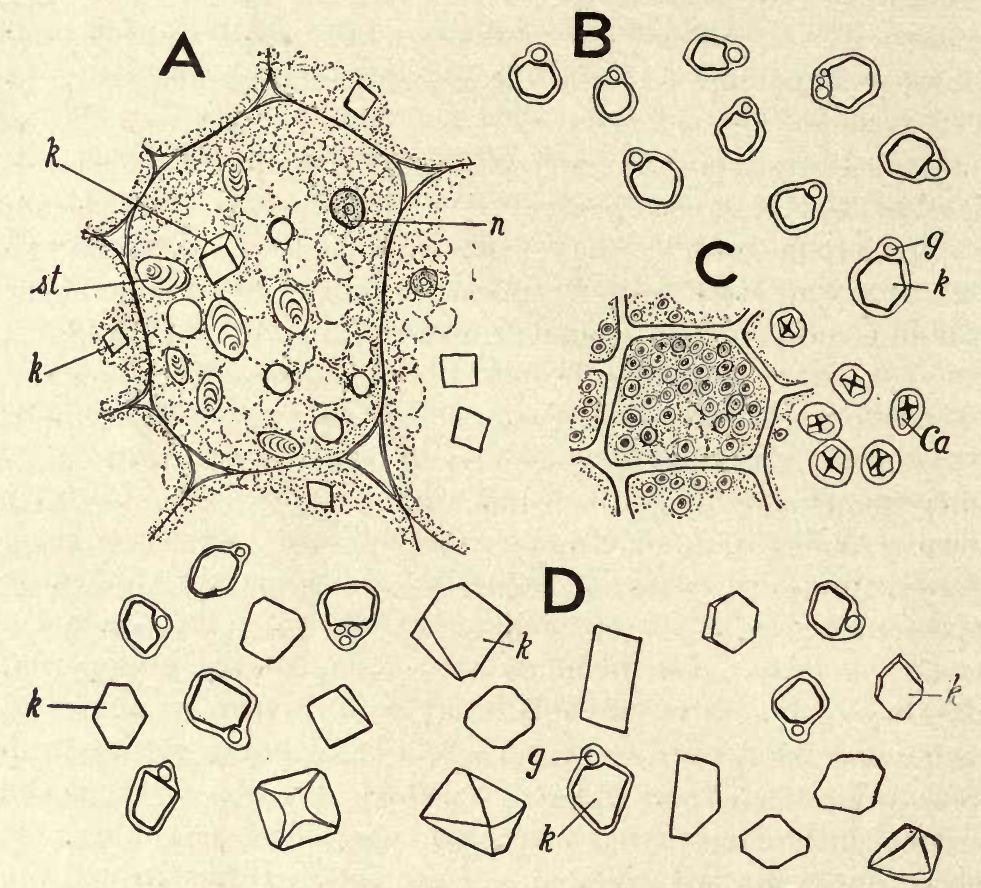

Fig. III. Phyto-globulins: A, cell of tuber of white potato (Solanum tuberosum) showing protein cyrstals (k), starch grains (st), nucleus (n); B, aleurone grains of the seed of the castor-oil plant (Ricinus communis); C. aleurone grains of fruit of fennel (Fæniculum vulgare) containing large calcium oxalate crystals $(\mathrm{Ca})$ which are strongly polarizing, as shown in the isolated grains; D, aleurone grains of Brazil-nut (Bertholletia excelsa); $\mathrm{g}$, globoids; $\mathrm{k}$, protein crystals.

proteins, which are compounds containing both nucleic acid and protein. (3) Derived Proteins, or compounds resulting from the action of enzymes or acids upon proteins.

I. Most of the investigations up until now have been conducted on the Globulins, which are distinguished by being insoluble in water but soluble in saline solutions. A number of them readily crystallize, and these can be generally obtained by diluting their 
sodium chloride solutions with water heated from $50^{\circ}$ to $60^{\circ}$ until a slight turbidity forms. Warm the diluted solution until the turbidity disappears and then allow it to cool slowly, when welldefined crystals of the protein separate (Fig. I12). Crystals of the globulin (so-called excelsin) of Brazil-nut were obtained by Osborne by simply dialyzing the faintly acid saline solution in running water. Many of the globulins have received distinctive names, as Amandin, found in the almond, peach, plum, and apricot ; Avenalin, found in oats ; Castanin, found in European chestnut; Conglutin, found in lupines; Corylin, found in hazel-nut; Edestin, found in hemp-seed; Excelsin, found in Brazil-nut; Glycinin, found in soy-bean; Juglansin, found in European walnut, American black walnut, and butter-nut; Legumin, found in peas and lentils; Maysin, found in Indian corn or maize; Phaseolin, found in kidney and lima beans; Tuberin, found in the potato; Vicilin, found in peas, horse-bean, and lentils ; and Vignin, found in cow-pea. Globulins have also been isolated from the seeds of other plants, but to these distinctive names have not yet been given. Among these may be mentioned barley, cocoanut, castorbean, cotton-seed, flaxseed, mustard-seed, peanut, radish-seed, rape-seed, rye, sesame-seed, sunflower-seed, and squash-seed.

II. Albumins are distinguished from globulins by the fact that they coagulate on the application of heat; they are also soluble in water, showing neutral or but a slightly acid reaction. Most seeds and probably most plant juices yield proteins which are as well entitled to be placed in the group of albumins as any of those of animal origin. The best characterized vegetable albumins are Legumelin, found in lentils, cow-peas, peas, and soy-beans; Leucosin, found in barley, rye, and wheat; Phaselin, found in kidney-bean; and Ricin, found in castor-bean.

III. Another well-defined class of Proteins are known as GLUTELINS, which are characterized by being insoluble in neutral aqueous solutions, saline solutions, and alcohol. The glutenin of wheat is the best representative of this group.

IV. The alcohol-soluble proteins, known as Prolamins, have been found in corn, oats, sorghum, and wheat. It has recently been proposed to bring this group of proteins in a group by themselves and call them "gliadins," but as this name has been used to 
designate a definite protein obtained from wheat, a more distinctive name has been proposed by Osborne, who calls this group "prolamins," because all its members which have thus far been hydrolyzed yield a relatively large quantity of both proline and amide nitrogen. The prolamins are characterized by their solubility in alcohol from 70 to 90 per cent. They are nearly or wholly insoluble in water, but their salts are freely soluble in solutions of acids or alkalies. (See "The Vegetable Proteins," by Thomas B. Osborne.)

GLUTEN is a mixture of proteins occurring in wheat. It consists of about 4 per cent. of gliadin (prolamin) and 4 per cent. of glutenin (glutelin). On an average 100 pounds of flour will yield 8 pounds of gluten. The " hard" wheats contain more gluten than the "soft" varieties. The gluten of wheat is said to possess a higher dietetic value than the gluten of corn or rye. Crude gluten may be prepared by making a dough with $30 \mathrm{Gm}$. of flour and about 15 c.c. of water. This is allowed to stand for an hour and the starch washed out by kneading it between the fingers under a gentle stream of tap water. The resultant product is of a grayish color, sticky, tough, and elastic, and when pure is capable of being drawn out into long bands or shreds. The strength of a flour,-i.e., its capacity for making a porous and spongy loaf,--depends mainly on the quality and quantity of gluten it contains. In the preparation of ordinary flour much of the layer containing gluten is separated with the coats of the grain in the course of bolting. Graham flour, on the other hand, being unbolted, has practically the same constituents as the wheat grain itself. The name "gluten flour" is applied to one in which the greater part of the starch is removed. Gluten flours are used by diabetic patients and have a high nutritive value when scientifically prepared.

Toxalbumins or Toxic Proteins.-Prateins which are exceedingly toxic have been isolated. from several plants. That the protein substances possess poisonous properties has sometimes been questioned, but there seems to be no doubt but that true toxalbumins occur not only in seeds, but in other parts of the plant. The following of these principles have been rather carefully studied: Ricin, found in the seeds of Ricinus communis; 


\section{CELL-CONTENTS AND FORMS OF CELLS. 197}

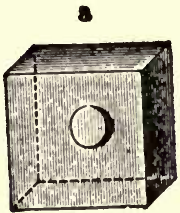

A

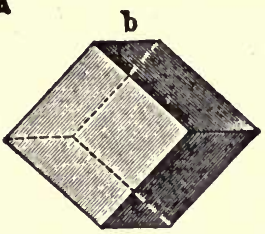

8
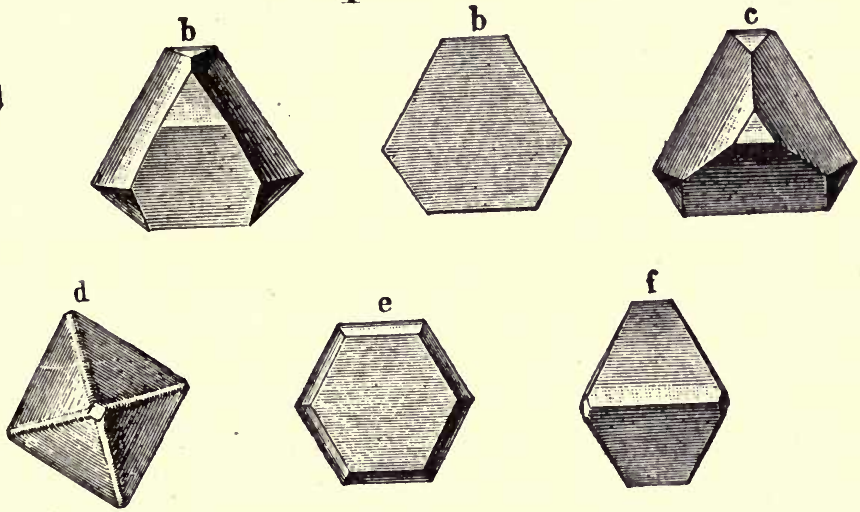

C

d

a

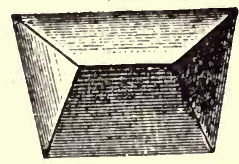

e

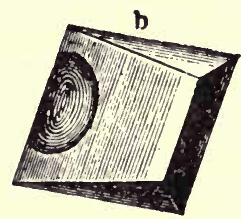

g

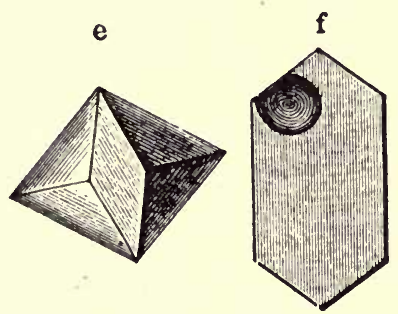

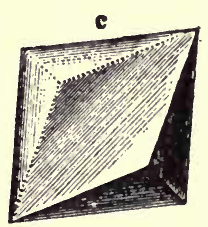
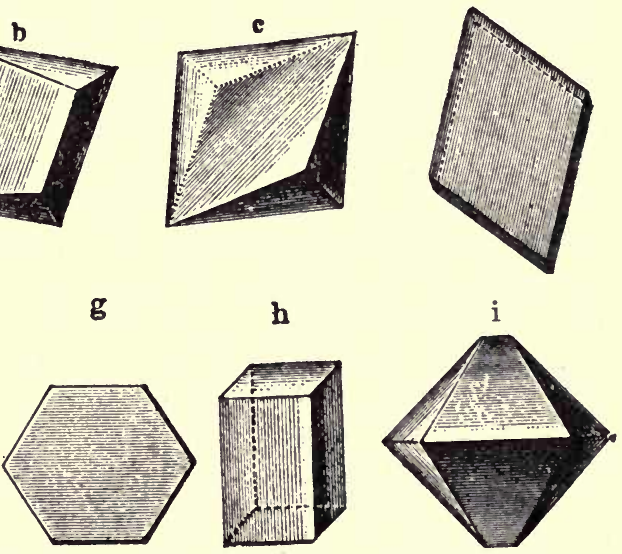

i

FIG. II 2. Phyto-globulins (crystaloids) from several sources: A, a, b, from the white potato; $\mathrm{B}$, a to $\mathrm{f}$, from the seeds of castor oil plant (Ricinus communis); in $\mathrm{b}$ and $\mathrm{b}$ are shown different views of the same crystal; $\mathrm{C}$, a to $\mathrm{f}$, from the seeds of the Brazil nut (Bertholletia excelsa).-After Dippel in "Das Mikroskop." 
Abrin, occurring in the seeds of Abrus precatorius; Curcin, in the seeds of Jatropha Curcas; Crotin, in the seeds of Croton Eluteria; and Robin, in the bark of Robinia Pseud-acacia. The pollen of rye is also said to contain a toxalbumin, which, when administered in extremely small doses, accentuates the symptoms of hay fever in patients afflicted with this disease. Under the name of "Vegetable Agglutinins" have been brought those protein substances which when added to a suspension of blood-corpuscles rapidly cause them to agglutinate. Those substances that possess the same properties but are not poisonolis are known as "Phasins." (Consult "The Vegetable Proteins," by Osborne; and "Beitrage zur Kenntnis der vegetabilischen Hämagglutinine," by R. Kobert.)

Origin and Formation of Plant Proteins.- It has been shown that carbohydrates originate in chloroplastids and are formed under the influence of sunlight from two simple substances, viz., carbon dioxide and water. Protein substances, on the other hand, are not formed in any definite organ, but arise in the protoplasmic contents of the cell. This function is not limited to the protoplasm of green plants, as fungi also possess this property. Furthermore, proteins may be formed in organs growing in the dark as well as those exposed to the light. Proteins arise through the interaction of nitrates, sulphates, and compounds of ammonia with either formaldehyde or some simple carbohydrate. It is supposed that the nitrates and sulphates are decomposed by plant acids, furnishing the necessary nitrogen and sulphur. Treub, by reason of his studies on Pangium edule, has advanced the theory that in the construction of protein compounds the nitrogen is supplied by hydrocyanic acid. Apart from the facts just mentioned, all theories with regard to the formation of proteins are mere speculations.

We are indebted to Emil Fischer and his students ("Untersuchungen über Aminosauren Polypeptide und Proteine," Berlin, I906) for much information concerning the structure of proteins. They have prepared synthetically several protein-like substances, although no natural occurring protein has as yet been obtained. From these studies it has been shown that proteins belong to a 
class of chemical substances designated as "polypeptides" which are formed by the condensation of several amino acids.

The Percentage of Protein in Plants.-The amount of protein in plants varies considerably. It is found in greatest amounts in seeds, especially in the seeds of the Leguminosæ and the grains of cereals. It is also found in surprisingly large quantities in a number of the vegetables. Were it not for the fact that the fungi contain large quantities of water, they would be considered the most nutritious of all vegetable foods, as they contain in dry substances over 50 per cent. of protein. As the fresh mushrooms, however, contain nearly 90 per cent. of water, this brings the protein content to but about 5 per cent. The percentage of protein in dried material from a number of sources may be of interest, as follows:

Grains or Cereals.-Barley, 7.64 to 17.90 ; buckwheat, 9.75 to I7.25; corn, 6.4 I to 17.02 ; oats, 8.35 to $2 \mathrm{I} .88$; rye, 8.39 to 17.38 ; rice, 6.49 to $\mathrm{I} 2.8 \mathrm{I}$; and wheat, 8.30 to 27.88 .

Leguminous Seeds.-Kidney beans, 22.53 to 36.46 ; lentils, I 4.58 to 34.34 ; lima beans, I5.94 to 25.63 ; Lupinus luteus, I 5.62 to 61.27 ; peanut, 25.39 to 33.73 ; peas, 21.59 to 32.94 ; soja beans, 24.38 to 49.10 ; string beans, 13.06 to 20.19 ; and Vicia faba, 21 .00 to 36 . Io.

Miscellaneous Seeds.-Beechnut, about 25; cacao, 7.32 to I 5.94 ; cocoanut, 7.75 to I0.90; chestnut, 5.15 to 15.75 ; hazel-nut, I6.23 to 21.22 ; flaxseed, I8.49 to 33.80 ; mustard, I5.50 to 39.66 ; coffee, I7.II to 25.09 ; rape-seed, I 5.18 to 28 .I 3 ; ricinus, I6.35 to 22.28; sunflower-seed, 5.67 to 33.89 ; sweet almond, I7.50 to 26.62 .

Common Vegetables.-Asparagus, I 5.12 to 33.52 ; sugar beets, 3.I I to 23.02 ; garden beets, 4.19 to 29.27 ; carrots, 3.79 to 16.64 ; cauliflower, $\mathrm{x} 7.23$ to 37.75 ; celery, 8.44 to 25.19 ; cucumber, $2 \mathrm{x} .38$ to 26.06 ; garlic, I.I7 to I 3.50 ; parsnips, 6.38 to I 3.50 ; potatoes, $2.2 \mathrm{I}$ to I7.59; sweet potatoes, I.70 to I9.6I ; radish, I3.00 to $22 . \mathrm{I} 3$; spinach, 27.50 to 45.33 ; and turnips, $4.0 \mathrm{I}$ to $2 \mathrm{I} . \mathrm{OO}$.

Fruits.-Apples, 0.22 to 1.32 ; apricots, O.I 3 to I.79; bananas, 3.37 to 7.75 ; cherries, 0.97 to 4.75 ; cucumber, $2 \mathrm{I} .38$ to 26.06 ; currants, O.II to I.44; figs, 0.90 to 2.58 ; gooseberries, .2I to .94 ; grapes, 0.22 to 1.20 ; lemons, 0.49 to 2.90 ; musk melon, 4.69 to 22.23 ; oranges, 4.83 to 2.24 ; peaches, 0.23 to 1.67 ; pears, 0.19 to 
0.56 ; plums, 0.27 to 0.99 ; prunes, 0.59 to 0.69 ; pumpkin, 30.31 to 36.25 ; raspberries, 0.18 to 1.47 ; strawberries, 0.35 to 1.05 .

Spices.-Anise, I6.3I to I8.I5; capsicum, II.20 to I6.8I ; cardamom, 5.50 to 14.77 ; caraway, 19.43 to 20.25 ; cloves, 4.73 to 7.06 ; cinnamon, I.or to 8.00 ; coriander, 10.94 to 12.03 ; curcuma, 9.18 to 12.56 ; dill, 6.75 to 21.56 ; fennel, 16.28 to 17.19 ; ginger, 3.27 to 10.83 ; mace, 4.55 to 7.80 ; mustard, 15.50 to 39.66 ; nutmeg, 5.16 to 7.12 ; pepper, I5.18; paprika, 10.9 to 27.16.

Miscellaneous.-Agaricus campestris, 20.63 to 62.94 ; seaweeds, 5.56 to 39.25 .

Calcium Carbonate occurs occasionally in the form of a cellcontent, being present in tracheæ or vessels and tracheids of the heart wood, as well as in the medullary rays and pith cells of certain plants. In this form it is rather characteristic of one or more genera in the following families: Aceraceæ, Anonaceæ, Cornaceæ, Cupuliferæ, Rosaceæ, Salicaceæ, Sapotaceæ, Urticaceæ, and Zygophyllaceæ. When present it almost completely fills the cells, and may be overlooked or referred to as resin unless its identity is proved by the use of certain reagents. Like the other carbonates, it dissolves with effervescence on the addition of hydrochloric acid, nitric acid, acetic acid, etc., and in this way may be detected.

Calcium carbonate is present in special structures known as Cystoliths. The latter are protuberances of the cell wall into the cell, and consist of a stalk and a body (Fig. II3). The stalk consists of a simple core of cellulose on which more or less silica is deposited. The upper or body portion consists of a more or less irregular spherical or ellipsoidal deposit of calcium carbonate. These are found in the parenchyma cells in roots and barks and the subepidermal cells of leaves. They are also found in epidermal cells, as in the short hairs of Cannabis sativa. Cystoliths occur in certain genera of the Acanthaceæ, Borraginaceæ, Cucurbitaceæ, Gesneraceæ, Oleaceæ, Ulmaceæ, Moraceæ, and Urticaceæ.

Cystoliths occur in a number of modifications, and, while they are usually simple, yet in some of the Acanthaceæ and Urticaceæ branched cystoliths occur. In some of the genera of the Cucurbitaceæ 2 - to 4 -adjoning cells may have cystoliths, and hence are known as "double cystoliths." The cystoliths found in hairs, as 
in Cannabis sativa, do not usually have a stalk, and are known as " hair cystoliths." The latter are, furthermore, variously modified, and may have incrustations of either calcium carbonate or silica or a mixture of both of these substances. In the Begoniaceæ occurs a certain form of structure resembling a cystolith, but it is uncalcified, and consists of a mucilaginous substance which is

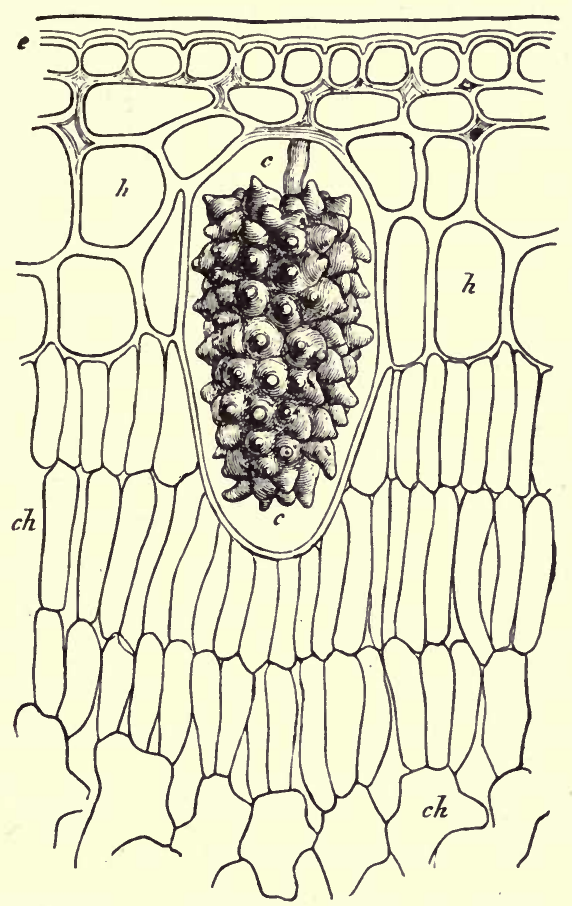

FIG. I I3. Cystolith. A cross section of a portion of the leaf of Ficus elastica showing cells of the upper epidermis (e), cells of the hypodermal layer (h), among which is a large cell containing a cystolith (c); palisade cells (ch).-After Sachs.

sometimes more or less impregnated with resin. These are known as "cystotyles." The protuberances found on the walls of certain epidermal cells and in the subsidiary cells of hairs may be either calcified or silicified, and occur in the families containing true cystoliths and also some genera of the following: Compositæ, Campanulaceæ, Oleaceæ, Leguminosæ, Hydrophyllaceæ, 
Scrophulariaceæ, Polemoniaceæ, Verbenaceæ, Euphorbiaceæ, and Urticaceæ.

Silica is seldom found as a cell-content, and when present never occurs as a crystalline deposit, being usually in the form of amorphous masses, termed "silica-bodies" (Fig. I09). The latter arise either in the cell-sap or the silica is deposited on the cell-wall, ultimately filling the lumen of the cell. In the palms the silica-bodies resemble stalkless cystoliths (Fig. I09, $C$ ). They may also occur in the form of long rods, being more or less fusiform or rectangular, or in the form of discs showing a more or less sphero-crystalline structure, or in other special forms (Fig. Io9). Silica-bodies have been found in the Palmæ, Orchidaceæ, Podostemaceæ, and Rutaceæ. Silica is insoluble in any of the ordinary solvents, being dissolved only by hydrofluoric acid. On incinerating the tissues it is not destroyed. The presence of silica may be determined readily upon heating sections with sulphuric acid or any reagent that destroys organic matter.

Silica usually occurs as an incrustation in the cell-wall, being found in epidermal cells, spinose hairs, and even the palisade and mesophyll cells of quite a number of plants. Siliceous walls are rather characteristic of the genera of the following families: Acanthaceæ, Aristolochiaceæ, Bignoniaceæ, Borraginaceæ, Burseraceæ, Calycanthaceæ, Campanulaceæ, Chloranthaceæ, Combretaceæ, Compositæ, Cucurbitaceæ, Dilleniaceæ, Euphorbiaceæ, Gesneraceæ, Goodeniaceæ, Hydrophyllaceæ, Leguminosæ, Loranthaceæ, Magnoliaceæ, Melastomaceæ, Menispermaceæ, Oleaceæ, Piperaceæ, Proteaceæ, Rosaceæ, Rubiaceæ, Santalaceæ, Saxifragaceæ, Urticaceæ, and Verbenaceæ.

TANNINS AND TANnIDES.-There is a group of water-soluble principles that occur in the cell-sap, especially of parenchyma cells, of a large number of plants. They are derivatives of phenol and phenol acids, and give either dark blue or green precipitates with solutions of ferric chloride. They were formerly designated as tannins and distinguished according to the plants from which they were obtained; thus we had chestnut tannin, oak tannin, etc. Recent studies on the constitution of these substances show that there are two principal groups of tannins, ( I) being in the nature of glucosides and (2) the other not yielding any dextrose on 
hydrolysis with acids. Both of these groups may be subdivided into two classes, namely, $(A)$ those which probably are derivatives of protocatechuic acid and $(B)$ those which are derivatives of gallic acid. A class name has been given to include these subgroups, namely, "tannides" or "tannoids." The first subgroup $(A)$ would then include the protocatechuic-tannides or -tannoids, and the second $(B)$ would comprise the gallic-tannides or -tannoids. In working out a system of classification of this kind Kunz-Krause (Swheiz. Woch. f. Chem. u. Pharm., I898, p. 424) has arranged all of the possible tannides or tannoids and has given the formulæ for a number which have not yet been found in nature.

Chemical Properties of Tannins.-The tannins are amorphous substances and do not form crystalline salts. They are soluble in water, alcohol, ethyl acetate, or a mixture of alcohol and ether. They are almost insoluble in anhydrous ether, chloroform, and the other immiscible solvents. The solutions give distinct color reactions or precipitates with ferric chloride, stannous chloride, and acetates of copper and lead. They form soluble compounds with iodine and prevent the latter from giving the characteristic blue reaction with starch. Solutions of tannin give insoluble precipitates with cinchonine and other organic bases. Tannins are, furthermore, especially in alkaline solutions, powerful reducing agents, their resulting products being of a dark red or yellowish-red color.

Upon treatment of tannins with dilute acids, or fusing with the alkali hydroxides, or heating alone, several classes of products are formed.

I. When heated in a sealed tube at $100^{\circ} \mathrm{C}$. solutions of tannin in a I per cent. solution of hydrochloric acid yield either crystallizable acids, or phlobaphenes, or insoluble red substances. $(A)$ The following glucosidal tannins yield crystallizable acids: The tannin from nut-galls, divi-divi (fruit of Casalpinia coriaria), myrobalans (fruit of Terminalia Chebula), rind of pomegranate fruit, and coffee. ( $B$ ) Phlobaphene is a reddish, or brownish-red, amorphous substance formed from the tannin of willow bark. It is insoluble in water but soluble in alcohol, dilute solutions of the alkalies and alkali carbonates, and solutions of borax. 
Quite a number of tannins yield a reddish, amorphous substance which precipitates out of the acid solution and is insoluble in water, alcohol, and solutions of the alkalies. Derivatives of this kind are obtained from the tannin of kino, krameria, etc.

2. When tannins are fused with potassium or sodium hydroxide several classes of products are formed, depending on the constitution of the tannin. ( $A$ ) Protocatechuic acid is formed not only on the fusion of certain tannins, but may be prepared from other plant substances, as vanillin, asafœtida, myrrh, etc. Usually other substances are formed in the interaction, these being either acetic acid or phloroglucinol. In this class are included the most of the tannins, which on heating with dilute acids yield either phlobaphenes or insoluble red substances. Pyrogallol, which is commercially prepared by the dry distillation of gallic acid, is also formed from the glucosidal tannins which yield crystallizable acids in acid solutions.

3. Upon carefully heating tannins to a temperature of $190^{\circ}$ to $200^{\circ} \mathrm{C}$. they are decomposed and yield two distinct classes of derivatives, being either $(A)$ pyrocatechol (a diatomic phenol) or $(B)$ pyrogallol (a triatomic phenol). Both of these substances are crystalline and may be sublimed unchanged. They are, furthermore, both soluble in water, alcohol, and ether, and are distinguished by giving very characteristic reactions with certain reagents. Solutions of pyrocatechol are colored dark green with ferric-alum and greenish with copper sulphate + ammonium hydrate, or concentrated sulphuric acid. Pyrogallol is colored bluish-black with ferric-alum, becoming green and finally brown; brownish with copper sulphate + aminonium hydrate, or sulphuric acid, and becoming violet with lime water, rapidly changing to brown. Pyrocatechol is formed from those tannins which produce protocatechuic acids on fusion with potassium hydroxide and phlobaphenes or insoluble red substances on treatment with acids. Pyrogallol is formed on heating those tannins which also yield pyrogallol on fusion with potassium hydroxide and yield either gallic acid or ellagic acid on hydrolysis with acids.

Microchemistry of Tannins.-Tannin ocurs as a constituent of the cell-sap, and the cells containing it may be determined by use of dilute solutions of methylene blue, as proposed by Pfeffer, 
which colors the cell-sap blue, afterward precipitating the tannin. This reagent has the advantage that when used in very dilute solution (I part methylene blue to 500,000 of water) it does not injure the protoplasm of the living cells, so that the cut end of a twig may be placed in the solution for I to 24 hours and sections examined from time to time. Another reagent that is very satisfactory in the examination of living material is a solution of ammonium carbonate, which causes a precipitation of the tannin in the cells in the form of very small globules or rods. This solution may be used either directly upon sections or by placing freshly cut stems in dilute solutions (I part ammonium carbonate and 200 parts water). Ammonium carbonate does not precipitate gallic acid and therefore may be advantageously used in the study of the development of tannin and related substances, as in galls. The following reagents also give distinct reactions for tannin. Copper acetate in concentrated aqueous solutions is one of the very best reagents for the localization of tannin cells. It is employed by allowing the leaves or twigs to remain in the solution for some days, when the tannin forms a reddish-brown precipitate in the cells. Ferric chloride and ferric acetate also precipitate tannin. Moeller has suggested the use of a solution of iron chloride in anhydrous ether, the cut pieces of the stems and leaves being placed directly in this reagent. Potassium bichromate and chromic acid in dilute solutions give yellowish-brown or blackishbrown precipitate with tannin.

Distribution of TANnin.-There are very few plants in which tannin does not occur in some of the parts or at least in certain cells during some period in their development. This is frequently noted in making sections of plant material with a razor; the liberated cell-sap is colored a dark blue. It is found in the form of highly refracting globules in the Zygnemaceæ and other Algæ. It occurs in relatively large amounts in some of the ferns, and, with the exception of the Monocotyledons, is widely distributed in the Spermophytes. As tannin is widely used in the making of leather and as a mordant in dyeing, etc., it is extracted from various plants and is an article of commerce. The following are some of the important tannin-yielding plants: The bark of hemlock (Tsuga canadensis, Fam. Pinaceæ) yields nearly 14 per cent. of 
tannin; the bark of several species of Pinus (Fam. Pinaceæ) growing in southern Europe yields 7 to Io per cent. of tannin; the barks of the white spruce (Picea canadensis) of Canada, of the larch (Larix laricina) of northern and northwestern part of United States and Canada, and of the fir (Abies balsamea) yield similar amounts of tannin as the barks of hemlock and pine. The wood of chestnut (Castanea dentata, Fam. Fagaceæ) yields 8 to Io per cent. of tannin; the bark of several species of Salix (Fam. Salicaceæ) growing in northern Europe yields 3 to I2 per cent. of tannin; the bark of chestnut oak, white oak, red oak, etc. (Fagaceæ), yields 12 to 15 per cent. of tannin; the scaly involucres or acorn-cups (under the name of "Valonia") of several species of Quercus growing in southern Europe and Levant yield 25 to 35 per cent. of tannin; the fruit of Terminalia Chebula (under the name of "Myrobalans") yields 35 to 40 per cent. of tannin; the stems and leaves of several species of Rhus (Anacardiaceæ) yield 16 to 24 per cent. of tannin; the fruit of Casalpinia coriaria (Fam. Leguminosæ) (under the name of "divi-divi") yields 30 to 50 per cent. of tannin; the wood and the bark of several species of Schinopsis (Fam. Apocynaceæ) growing in South America yield from I 5 to 23 per cent. of tanniil, which is usually found in commerce in the form of an extract known as "Quebracho Extract"; the bark of the common horsechestnut (\#sculus Hippocastanum, Fam. Sapindaceæ) yields considerable tannin, and is employed in Italy; the bark of Myrica Nagi (Fam. Myricacex) contains I I to I4 per cent. of tannin; the bark of Malpighia glabra (Malpighiacex) (under the name of "Nance bark") is used in Mexico and yields about 26 per cent. of tannin; the bark of Stryphnodendron polyphyllum (Fam. Leguminosæ) yields about 30 per cent. tannin. The tannin of a number of other plants has been investigated, some of these being used in medicine, as granatum, catechu, kino, krameria, tormentilla, gambir, etc. (see Vol. II).

GALLS.-There are a number of excrescences, found upon the leaves and twigs of a number of plants, termed galls. These result from injuries caused chiefly by insects, and are therefore in the nature of pathological products. Galls which are formed on trees which in themselves contain considerable tannin usually 
yield very large amounts of tannin. Nut-galls formed on certain species of oak yield 65 per cent. of tannin. The Japanese galls and Chinese galls formed on the leaf stalks and young branches of some species of Rhus contain about 70 per cent. of tannin. The galls found occasionally on sumach (Rhus glabra), a shrub abundant in North America, yield over 6o per cent. of tannic acid. The tannins obtained from excrescences of this character were at one time called " pathological tannins," to distinguish them from the tannins formed naturally in the living plant, and which were called "physiological tannins." In the light of the studies on the several tannins this terminology is no longer accepted.

Inclusion Cells and Tannin Idioblasts.-In a number of plants occur special cells which vary considerably in form and contents, but are distinguished by giving reactions for tannin. Inclusion cells were first described by Flückiger in the fruit of Ceratonia Siliqua. These occur in the form of long tubes, which are easily separated from the pulp, and the yellowish contents are colored blue with solutions of ferrous sulphate or ferric chloride. Recently Hanausek has contributed several papers on the distribution of inclusion cells in a number of different plants. In the leaves of Pistacia Lentiscus he found (Ber.d.d. Bot. Ges., I9I4, p. II7) that the upper row of palisade cells and the loose mesophyll cells (Fig. I I4, $A$ ) contain numerous somewhat elongated, transversely striated bodies, which completely fill the cells. These are colored dark green or blackish with ferric chloride and a pale violet with a solution of potassium hydrate. The contents dissolve on heating, changing to a brownish color. They are also partly soluble in concentrated sulphuric acid, and with solutions of vanillin + hydrochloric acid the contents are colored red. They are not completely soluble in hot solutions of potassium hydroxide, there always remaining a small, colorless portion. The inclusions in the date (Fig. I I $4, B$ ) and tamarind resemble those found in the fruit of St. John's Bread (Ceratonia) and leaves of Pistacia. Inclusions have been found in the seed coat of Pimenta and one or more fruits in the following families: Anonaceæ, Anacardiaceæ, Ebenaceæ, Elæagnaceæ, Leguminosæ, Palmæ, Rhamnaceæ, and Rosaceæ. 
TANNIN IDIOBLASTS were first observed by Zopf in a number of genera of the Fumariaceæ (Fig. I i 5). These are somewhat analogous to and resemble the latex or pigment cells in the Papaveraceæ. They develop in the meristematic cells of certain tissue systems and remain constant throughout the life of the plant. The

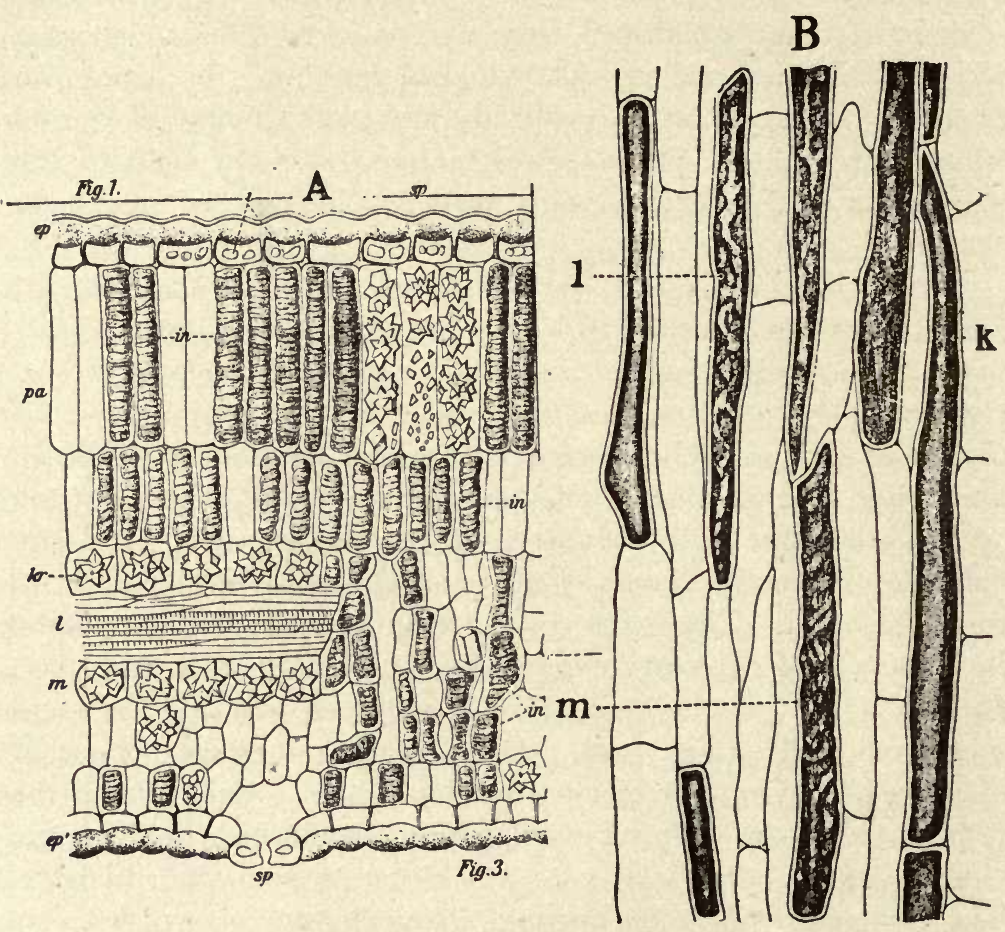

FIG. Ir4. Inclusion Cells: A, section of leaf or Pistacia Lentiscus showing numerous inclusion cells (in) in the upper palisade layer and cells of mesophyll; calcium oxalate $(\mathrm{kr})$; palisade layers (pa); loose mesophyll (m); fibrovascular bundle (I); upper epidermis (ep); granules of fatty substance (i); lower epidermis (ep); stoma (sp). B, Inclusion cells or tubes $(\mathrm{k}, \mathrm{l}, \mathrm{m})$ in the fruit of the date palm; $\mathbf{k}$, showing a homogeneous amorphous content; 1 and $\mathrm{m}$, separation of irregular inclusion masses in form of projections from the wall.-After Hanausek.

cells vary in shape, composition of wall, and color of contents. They may be either short, isolated cells or occur in chains; or they may become elongated, resembling fibers. The walls may be composed of cellulose or contain a certain amount of lignin or suberin. Some of the cells may contain a nucleus. The cell-sap 

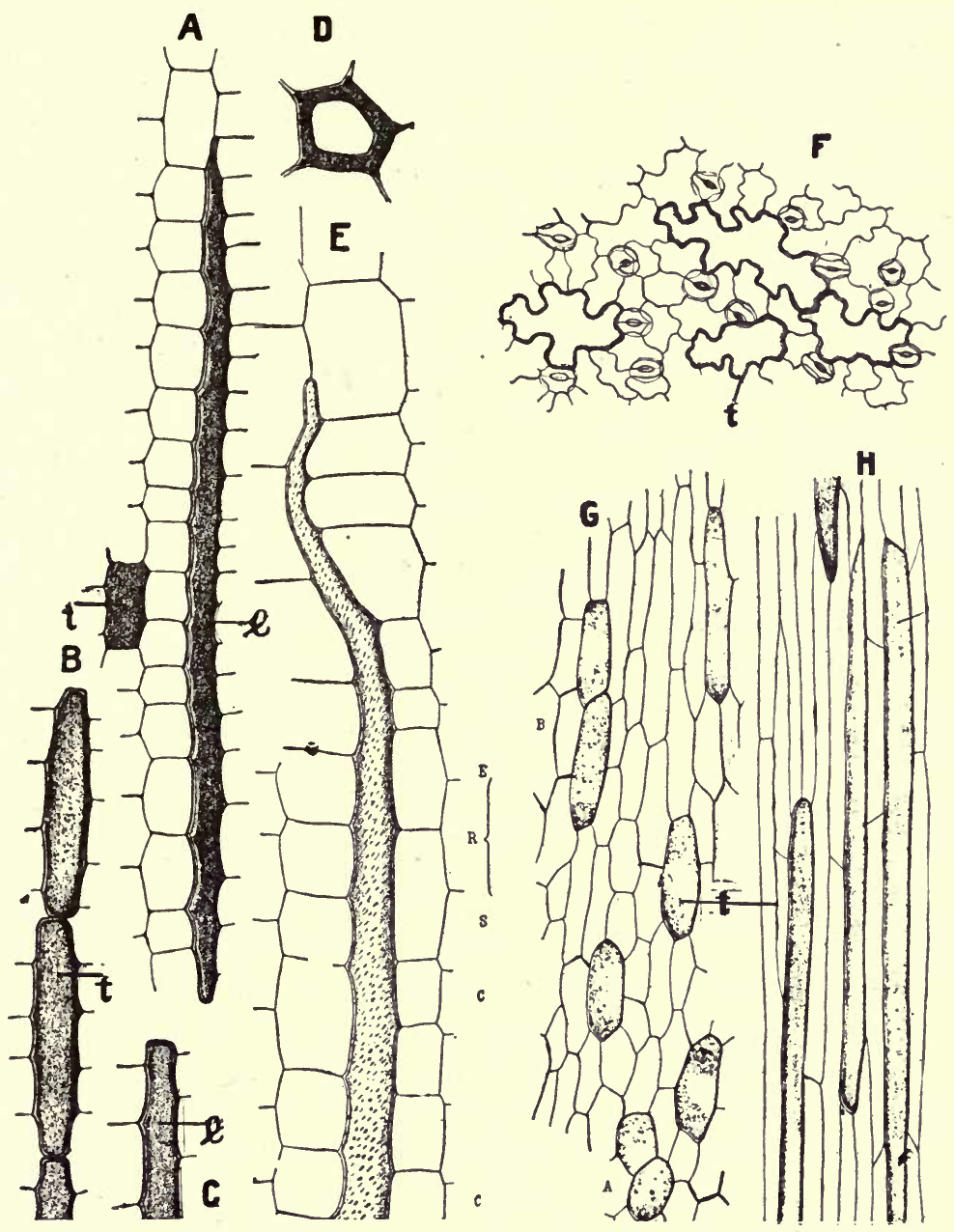

FIG. Ir5. Idioblasts containing tannin and anthocyanin: A-D, idioblasts in primary cortex of root of Corydalis ochroleuca, showing a short, thin-walled cell with reddish sap $(A, t)$, and a long fiber with yellowish content $(A, e)$; three short, thick-walled idioblasts (B) with a reddish cell-sap; a short fiber with yellowish contents (C) and transverse sections, through an idioblast (D), showing the thick, porous walls. E, a portion of an idioblast, with thick, porous walls, from the pith of Fumaria muralis. F to $\mathrm{H}$, idioblasts in Parnassia palustris; F, portion of epidermis of leaf showing 5 idioblasts $(t)$ with colorless but highly refracting tannin content; G, portion of epidermal layer of corolla tube with reddish anthocyanin idioblasts $(t) ; H$, portion of epidermal layer at the base of corolla tube with very long idioblasts $(t)$ containing a red-colored cell-sap.-After W. Zopf, "Utber die Gerbstoff- und Anthocyan-Behālter der Fumariaceen und einiger anderen Pflanzen," in Bibliotheca Botanica. 
may be either colorless or of an intensely yellow or bright red color, giving a distinct reaction for tannin. The cell-sap is soluble in water and in alcohol and gives an acid reaction. In the yellow idioblasts upon treatment with nitric acid it is colored orange-red, changing to reddish-brown; with concentrated sulphuric acid it becomes orange-red and finally of a rose-red or crimson color; with solutions of the alkalies it becomes greenish, and it is precipitated with solutions of potassium bichromate, ferric acetate, or ferrous sulphate, the precipitates resembling those found with tannin. Zopf found that the tannin idioblasts may possess either a colorless content or, in addition, have a yellow coloring principle (yellow anthocyanin) or a red pigment (red anthocyanin). He considers that the yellow pigment is derived from a colorless chromogen and that the red pigment may be formed from either a colorless chromogen or from yellow anthocyanin. Furthermore, he concludes that there is a relationship in the Fumariaceæ between the anthocyanin and tannin, as the two constituents are always found in the same cell. It is rather interesting to note that chloroplasts may be found in the idioblasts, and that sugar is also a constituent in the idioblasts, occurring in the young roots and stems of Diclytra spectabilis.

Tannin idioblasts are found in the palisade tissues of leaves or in the parenchyma cells of roots and stems of some of the genera in the Geraniaceæ, Celastraceæ, Rhamnaceæ, Leguminosæ, Solanaceæ, Rubiaceæ, Scrophulariaceæ, Polygonaceæ, Aristolochiaceæ, Piperaceæ, Euphorbiaceæ and Moraceæ.

The Fixed Oils, Fats, and Waxes include a group of substances which are widely distributed in plants, occurring especially abundant in seeds, fruits, and barks. They are distinguished by the fact that in their chemical constitution they possess radicals of the fatty acids. In the diatoms, Vaucheria, and some of the other lower plants fixed oils arise in the chromatophores in place of starch, thus being the first visible product of photosynthesis. Fixed oils usually occur in reserve cells as in seeds and the parenchyma and medullary ray cells of roots and rhizomes. They are either found in the vacuoles of the protoplasm or are formed in the cell-wall, and usually are liberated in the form of globules upon healing the sections or treating them with solutions of 
hydrated chloral or sulphuric acid. The fixed oils remain liquid at ordinary temperatures, whereas the fats tend to solidify, and are occasionally found in the form of crystals in plant cells (Fig. II6). 'Both of these classes are fatty acid-esters of glycerin, whereas the waxes are combinations of fatty acids and

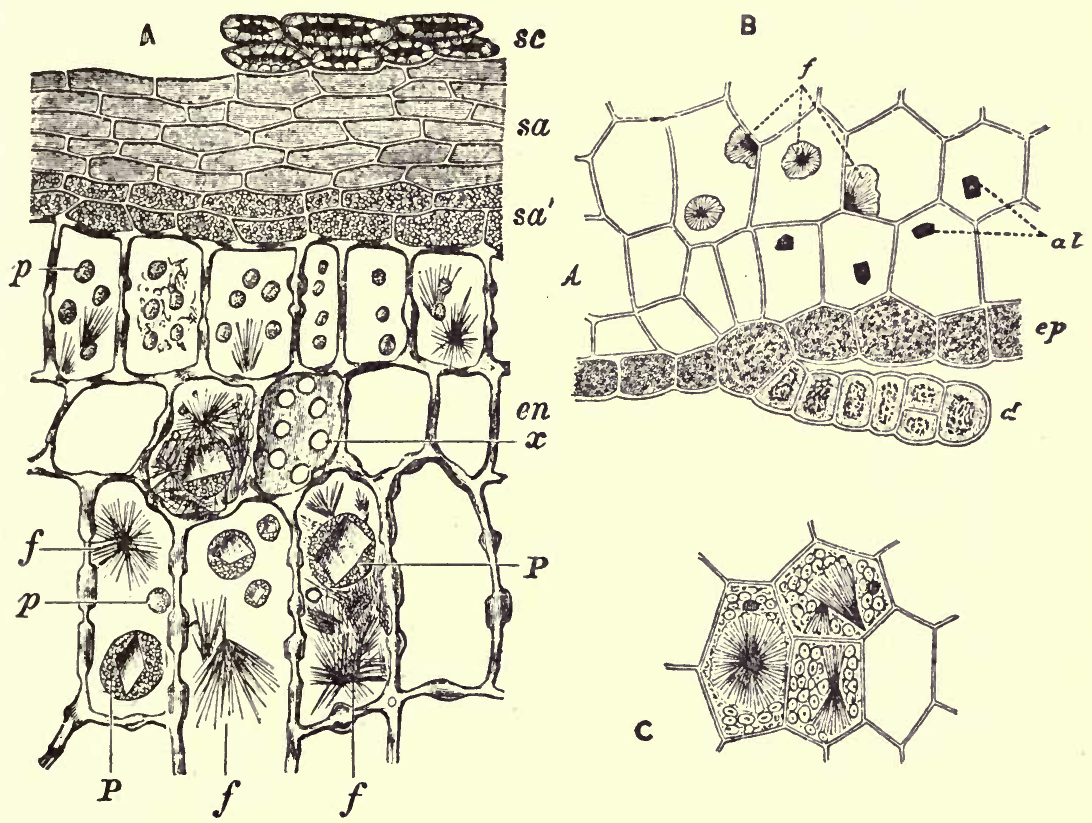

FIG. II6. Crystals of fixed oils: A, section of seed of the oil palm (Elais guineensis) treated with an alcoholic solution of iodine and very dilute sulphuric acid, showing stone cells (sc); cells with homogeneous brown content (sa); cells with yellowish granular content $\left(\mathrm{sa}^{\prime}\right)$; and cells of endosperm (en) having porous walls (x), and containing phytoglobulins (crystalloids) $(\mathrm{P}, \mathrm{p})$, associated with needle aggregates of the fatty acids. $\mathrm{B}$, cross section of a cotyledon of cacao, heated in a solution of potassium hydroxide, showing the epidermal layer (ep) with hair (d), phytoglobulin (crystalloids) (al) and aggregates of fatty acids (f). $\mathrm{C}$, a few cells of the cotyledons of ripe cacao seeds mounted in glycerin, showing separation of sphero-crystals of fatty acids in the oil and starch-bearing cells of endosperm.-After Hanausek.

some alcohol other than glycerol (glycerin). According to this distinction some waxes as myrtle wax, obtained from the berries of Myrica cerifera, are classed among the fats, it being a mixed glyceride of palmitic and lauric acids.

The fatty acids which enter into the constitution of the fixed oils and fats belong to more than one series of hydrocarbons. 
The following acids are present in the vegetable oils and fat. Normal caproic acid $\left(\mathrm{C}_{6} \mathrm{H}_{12} \mathrm{O}_{2}\right)$, Caprylic acid $\left(\mathrm{C}_{8} \mathrm{H}_{16} \mathrm{O}_{2}\right)$, and Capric acid $\left(\mathrm{C}_{10} \mathrm{H}_{20} \mathrm{O}_{2}\right)$ are found in cocoa-nut oil, expressed from the seeds of the cocoa-nut (Cocos nucifera), and in palmnut oil, obtained from the oily sarcocarp of the drupes of the palm, Elais guineensis.

LAURIC ACID $\left(\mathrm{C}_{12} \mathrm{H}_{24} \mathrm{O}_{2}\right)$ occurs in laurel-nut, obtained from the seeds of Calophyllum Inophyllum (Fam. Guttiferæ), a plant growing in the East Indies and Cochin China. It is also found in cocoa-nut oil and certain other vegetable oils.

Myristic ACID $\left(\mathrm{C}_{14} \mathrm{H}_{28} \mathrm{O}_{2}\right)$ is found in certain vegetable fats, especially in nutmeg and mace. This oil forms crystalline salts with both potassium and barium.

PALMitic ACID $\left(\mathrm{C}_{16} \mathrm{H}_{32} \mathrm{O}_{2}\right)$ occurs combined with glycerol in a large number of vegetable oils, especially in palm-nut oil, and Japan wax. The latter is obtained from fruits of Rhus vernicifera and $R$. chinensis. It is also found in myrtle wax, which occurs as an incrustation on the fruits of the wax myrtle (Myrica cerifera) and bayberry ( $M$. carolinensis). This acid is not very readily soluble in petroleum ether. A crystalline silver salt is obtained by adding an alcoholic solution of silver nitrate to an alcoholic solution of ammonium palmitate.

STEARIC ACID $\left(\mathrm{C}_{18} \mathrm{H}_{36} \mathrm{O}_{2}\right)$ occurs as a glyceride in cacao butter obtained from chocolate seeds, and in "Shea butter" obtained from the seeds of Butyrospermum Parkii, a tree growing in Upper Guinea and in the region of the Nile.

ARACHIDIC ACID $\left(\mathrm{C}_{20} \mathrm{H}_{40} \mathrm{O}_{2}\right)$ occurs combined with glycerol in peanut oil and other vegetable fats. The acid is soluble in boiling alcohol, ether chloroform, benzene, and petroleum ether. It forms crystalline salts of copper and silver.

BeHENIC ACID $\left(\mathrm{C}_{22} \mathrm{H}_{44} \mathrm{O}_{2}\right)$ occurs as a glyceride in "oil of Ben" expressed from the seeds of Moringa pterygosperma, a plant of the East and West Indies. This oil is used for the preparation of cosmetics, by perfumers for extracting odorous substances, and as a lubricating oil for clocks.

LIGNOCERIC ACID $\left(\mathrm{C}_{24} \mathrm{H}_{48} \mathrm{O}_{2}\right)$ occurs as a glyceride in peanut oil, and is distinguished from arachidic acid in being slightly soluble in cold alcohol. 
Tiglic AcID $\left(\mathrm{C}_{5} \mathrm{H}_{8} \mathrm{O}_{4}\right)$ occurs as a glyceride in croton oil, and is soluble in water.

HYPOG EIC ACID $\left(\mathrm{C}_{16} \mathrm{H}_{30} \mathrm{O}_{2}\right)$ occurs combined with glycerol in peanut oil and in corn oil. It is soluble in cold alcohol and crystallizes in needles.

LyCOPODIC ACID occurs, as a glyceride, in lycopodium spores, and is related to hypogæic acid.

OlEIC ACID $\left(\mathrm{C}_{18} \mathrm{H}_{34} \mathrm{O}_{2}\right)$ occurs as a glyceride in many vegetable oils. The glyceride of oleic acid occurs, as a rule, in larger quantities in most fixed oils than any other glyceride, being present in olive oil to the extent of 90 per cent. It is also found in a large number of seeds, principally in cotton seed, hazel-nut, peanut, sesame, walnut, corn, tea seed, almond, and the kernels of apricot, peach, and plum. These oils are generally grouped together and known as the "olive oil group." The sodium and barium salts of oleic acid are crystalline.

Rapic Acid $\left(\mathrm{C}_{18} \mathrm{H}_{34} \mathrm{O}_{2}\right)$ and ERUCIC ACID $\left(\mathrm{C}_{22} \mathrm{H}_{42} \mathrm{O}_{2}\right)$ occur combined with glycerol in the oil obtained from rape or colza seed and in other Cruciferous seeds.

LiNOLEIC ACID $\left(\mathrm{C}_{18} \mathrm{H}_{32} \mathrm{O}_{2}\right)$ is the principal acid of the glycerides forming the "linseed oil group" or " drying oils." The acid which is best known is that obtained from flaxseed or linseed, the oil of which contains from 80 to 85 per cent. of linoleic acid or its isomers. Linoleic acid is also present in the fixed oil occurring in the seeds of the following plants: Hemp, walnut, pine (Pinus sylvestris), fir (Abies balsamea), poppy, safflower, sunflower, and seeds of a number of species of Aleurites. The seeds of Aleurites moluccana yield the "candle nut oil" of the South Sea Islands, and the seeds of $A$. cordata yield the "tung oil" (Chinese wood oil or Japanese wood oil) of China and Japan.

RICINOLEIC ACID $\left(\mathrm{C}_{18} \mathrm{H}_{34} \mathrm{O}_{3}\right)$ occurs as a glyceride in castor oil, and is the principal constituent of this oil. It is also present in the seeds of other Euphorbiaceous plants, being found in croton, curcas, etc., and is also found in grape seed. Ricinoleic acid is soluble in alcohol and ether and is insoluble in petroleum ether. It forms crystalline salts with barium, calcium, and lead.

JAPANIC ACID $\left(\mathrm{C}_{22} \mathrm{H}_{42} \mathrm{O}_{4}\right)$ is the only dibasic acid occurring 
in natural fats, and is found in Japan wax. The crystals, formed from the solutions in alcohol or chloroform, are heavier than water.

Chaulmoogric acid $\left(\mathrm{C}_{18} \mathrm{H}_{32} \mathrm{O}_{2}\right)$ occurs as a glyceride in chaulmoogra oil, being obtained from the seeds of Taraktogenos Kurzii and other plants of the Bixaceæ. It has the composition of linoleic acid, but a study of its constitution shows that it is in the nature of a cyclic compound.

The following alcohols occur as esters in vegetable waxes: Ceryl alcohol $\left(\mathrm{C}_{26} \mathrm{H}_{54} \mathrm{O}\right)$, combined with palmitic acid, is the principal constituent in opium wax. Ceryl alcohol is also present in carnauba wax, which is obtained from the leaves of the Carnauba-palm (Copernicia cerifera). Carnauba wax also contains myricyl or melissyl alcohol $\left(\mathrm{C}_{30} \mathrm{H}_{62} \mathrm{O}\right)$, the latter being either free or combined as an ester of cerotic acid.

Phytosterol, a compound isomeric with cholesterol $\left(\mathrm{C}_{27} \mathrm{H}_{48} \mathrm{O}\right)$, is found in the oils derived from a number of seeds. It is unsaponifiable, and is found in the extracted oils to the extent of about I per cent. Phytosterol crystallizes in the monoclinic system (Fig. I I7), whereas cholesterol, which occurs in most animal oils and fats, forms triclinic plates resembling rhombic prisms (Bömer, Zeits. f. Unter. d. Nahr.- u. Genussmittel, 1898, p. 42).

Lecithin belongs to a group of fatty substances containing nitrogen and phosphorus, and in which the latter is present as glycerophosphoric acid. They are sometimes grouped together in a special class, known as " phosphatides," and are characterized by containing one or more molecules of phosphoric acid, an alcohol (as glycerin), one or more fatty acid radicals (as stearic or oleic acid), and one or more nitrogenous bodies (such as choline and allied substances). Lecithin occurs in seeds, buds, and young shoots. In barley, wheat, and rye it occurs to the extent of 0.6 per cent. ; in peas, I.2 per cent. ; lupine seeds, 2 per cent. ; mushrooms, 0.9 per cent. ; dry yeast, 2 per cent. (For amount in other plants see Amer. Jour. Pharm., I9I4, p. I69.) According to Stoklasa, the phosphoric acid of plants occurs in the form of organic compounds, of which lecithin is an important example. It is formed in those organs and under those conditions where photosynthesis is possible. It is even thought that lecithin may be a product 
of assimilation in the chloroplastid. The fact that fungi contain it shows that lecithin may be formed from protoplasm itself. It is one of the most interesting compounds which has been isolated from plants, and no doubt plays an important rôle in the life of the cell.

Lecithin is a yellow, viscous, waxy substance soluble in oils
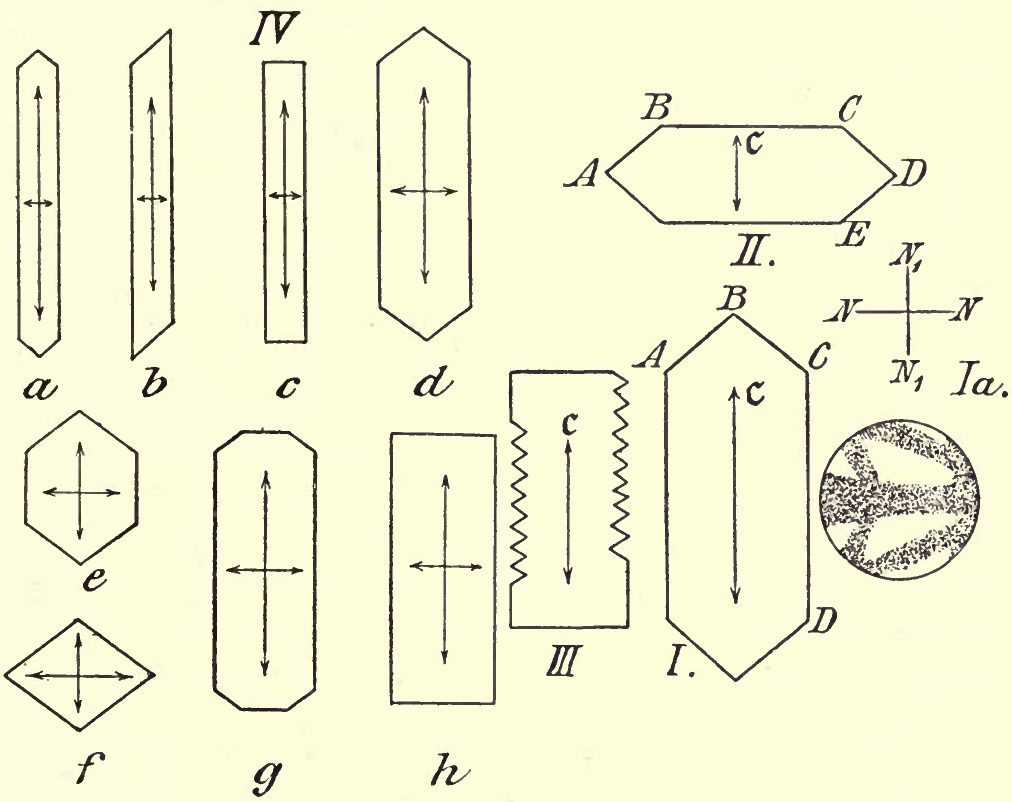

FIG. II7. Phytosterol allowed to crystallize very slowly from strong alcoholic solutions, the crystals being recrystallized until the melting-point is constant. I, crystal forms with parallel extinction C D. II, crystals with parallel extinction B C. III, crystals with parallel extinction along the long axis. IV, common crystal forms of phytosterol. Phytosterol is a constituent of most vegetable oils and is most abundant in peas, lentils, and other Leguminous seeds. The presence of vegetable oils is detected in animal oils by a study of the forms of crystals, those of phytosterol crystallizing in the monoclinic system, whereas cholesterol forms crystals which belong to the triclinic system.-After A. Bömer, in Zeils. f. Unter. d. Nahr.- u. Genussmillel, 1898, p. 45 .

and warm alcohol. In solutions of ether or chloroform it is precipitated upon the addition of acetone. In contact with water, it sefrarates in the form of spiral threads or loops, giving rise to the "myelin forms" of Kirchow and Beneke. When examined under the microscope a smear of lecithin, to which a drop of water or a sugar solution has been added, sends out a number of 
rounded projections which gradually elongate and become more and more abundant and intricate. If this process be allowed to take place in a test-tube or other vessel that can be shaken, the water becomes turbid through the dispersion of the delicate microscopic myelin protrusions, and in course of time a uniform emulsion of the lecithin in water is obtained, which consists of fine swollen particles. This is a colloidal solution that can be filtered without change. It is not coagulated by heat, nor precipitated by salts of monobasic or tribasic metals.

Wax.-The epidermal layer of the plant shows a number of modifications. It usually consists of an inner layer of cellulose and an outer covering of cutin. While some of the lamellæ beneath the cutin may be modified to mucilage or oil, the surface of the cutin layer may have deposited upon it a coating of 'wax. Frequently the wax is in such small quantities that it is not observed until the sections are heated to a temperature of $90^{\circ}$ to $100^{\circ} \mathrm{C}$., when the wax separates in the form of oily globules. According to De Bary, there are four principal forms of waxcoatings.

I. It occurs in the form of minute rods or needles, such as are found constituting the bloom of fruits as the grape and plum, and the stems and leaves of Eucalyptus Globulus, Ricinus communis, etc. 2. The most common form is a simple, granular coating consisting of isolated grains which may lie together as a single layer. These are found in the fruits of some of the Cruciferæ, Iris pallida, etc. 3. The coating may consist of minute rods which may be more or less bent or curled, standing perpendicularly on the cuticle, as in the sugar cane, canna, banana plant, etc. 4. The wax incrustation may occur in the form of membrane-like layers, varying from thin scales, as in Taxus baccata, Portulaca oleracea, and various cacti, to thick layers showing a striation and stratification similar to that found in thick-walled cells, as in the fruit of Myrica, leaves of the wax palm (Ceroxylon andicolum). According to Wiesner, the deposit of wax is often crystalline, appearing in four-sided prisms. (Consult A. deBary, "Comparative Anatomy of the Organs of Vegetation.")

Physiology of Fats.-It is stated that in the photosynthetic 
processes of some of the lower plants, as Vaucheria, Diatoms, etc., fixed oils rather than starch are formed in the chromatophores. It is well known that in the cells of the bark of a number of plants fixed oils are stored in place of carbohydrates. These facts show that there is a very intimate relationship between the fixed oils and other metabolic substances. Fixed oils constitute the reserve materials in seeds, spores, pollen grains, and are even present in the tubers of certain plants as Cyperus esculentus. The storing of fixed oils instead of starch may be of some advantage to plants, in that there is a greater supply of energy contained in them than is present in the same quantity of any of the carbohydrates. Again, as the specific gravity of the fixed oils is less than that of the carbohydrates, this is an advantage in those spores or seeds which are disseminated by the wind and require to be as light as possible.

The fixed oils are more or less intimately associated with the protoplasm occurring in vacuoles of the same in fruits and seeds. The waxes which are secreted in the epidermal cells of leaves and green stems, and also found as a covering of many fruits, serve to protect the underlying cells from loss or excess of moisture, from the attack of disease-producing micro-organisms, and also prevent the interactions caused by some of their enzymes. The resistance of certain micro-organisms, as the tubercle-bacilli, is supposed to be due to some extent to the fatty substances in which their bodies are enclosed or with which they are impregnated. "It is held by some that the fats, or, more correctly, the lecithin and phospholipines, are essential to the cohesion and physical constitution of the protoplasm, so that any interference with the physical state of these substances arrests the vital functions. The cement which binds the organized matter together is loosened by the solution in it of foreign substances, and it is the loosening of the protoplasmic cement that makes it possible for the normal processes of life to be carried on.

"Attempts to form a concrete conception of the physical relationship in the structural organization of cells between fats on the one hand and the other constituents of living matter on the other have not been successful. Some have spoken of 'lipoid membranes' as if the living cell itself were enclosed in a fatty envelope and accessible only to such substances as can permeate this envelope 
through chemical affinities with the fatty material of which it is composed. Others are inclined to think of protoplasm as an emulsion of proteins and 'lipoids.' Loeb and v. Knaff Lenz find that sea-urchin eggs are liable to undergo cytolysis under the action of any process, chemical or physical, that causes the cell fats to become more fluid." (Consult J. B. Leathes, "The Fats.”)

Mucilages and Gums.-By the terms mucilages and gums are meant those substances which are soluble in water, or swell very perceptibly in it, and which, upon the addition of alcohol, are precipitated in the form of a more or less amorphous or granular mass. Mucilage originates in the plant as a cell-content, or as a modification of the wall. In the former case it arises as a product of the protoplasm, or it may be a disorganization product of some of the carbohydrates. When it arises through modification of the wall it is spoken of as " membrane mucilage," and owes its origin to several causes: either to a secondary thickening of or an addition to the cell wall, or a metamorphosis of it, at least in part. In the latter case it may arise either as a disorganization product of the primary wall, or of the subsequent lamellæ making up the walls of the cells of the medullary rays, parenchyma, and other tissues, as in Astragalus gummifer (Fig. I 18 ), or it may arise as an intercellular substance.

The following is a classification of some plants, based upon the origin of the mucilage:

I. Mucilage in the form of a cell-content is of infrequent occurrence in plants. It is usually present in the cells containing raphides, especially in the Monocotyledons. Its orgin and development may be easily followed in the tubers of a number of Orchids, especially those yielding salep. The mucilage arises very early in the development of the cells surrounding the crystalgroups, and continues to be formed as the crystals grow in size, the protoplasm and nucleus being reduced to a very thin. layer which lie next to the cell-wall. The mucilage of salep is colored yellowish with iodine and sulphuric acid, or a yellowish-red or rose-red with aqueous eosin solution, and a carmine-red with an aqueous solution of Congo red. The cells containing mucilage are easily differentiated from the surrounding cells by the use of 
alcoholic solutions of Congo red, methylene blue, etc., which distinctly color the mucilage in them. Cell-content mucilages are also found in the fleshy scales of the onion, the rhizome of Agropyron repens, the fleshy leaves of Aloe and other succulent plants. It

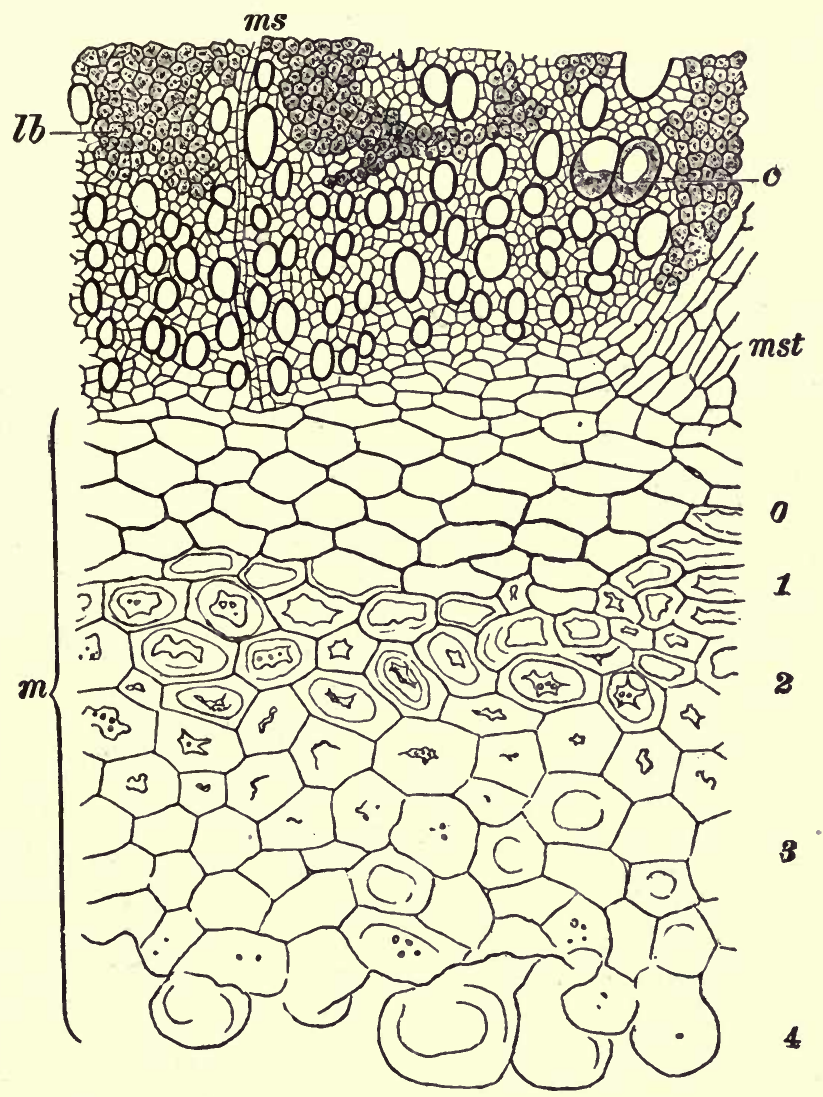

FIG. I I8. Cross section through pith (m) and the inner portion of the wood (lb) of Astragalus gummifer, showing successive stages in the modification of the walls in the formation of gum tragacanth $(0,1,2,3,4)$. Some of the tracheæ (c) contain globular masses of gum.-After Tschirch.

probably also occurs in this form in the Cyanophyceæ and in some of the red algæ, as Laminaria, although in the latter it is formed chiefly as a modification of a cell-wall and the intercellular substance. In Dicotyledons the mucilage which is present is 
usually formed as a modification of the cell-wall, and, according to Solereder, it seems to occur in the contents of the cell in only the following families: Enotheraceæ. Rubiaceæ, and Vitaceæ, in
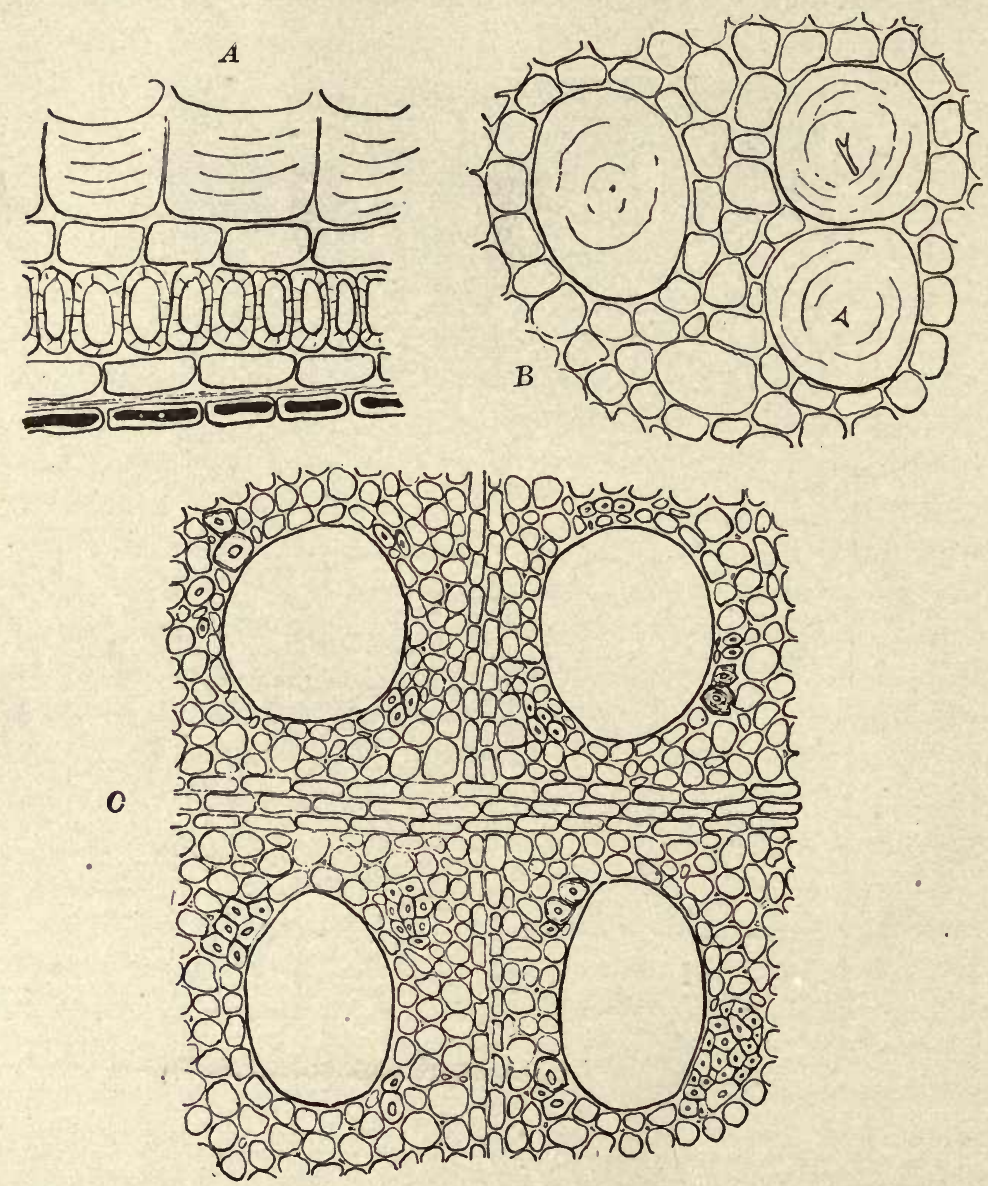

Fig. Irg. Cell-wall mucilage. A, transverse section of seed-coat of flaxseed treated with water, showing the swelling of the mucilaginous layer situated beneath the cutin; B. section of Althæa root showing three large mucilage-cells; C, transverse section of elm bark showing four large mucilage-cells.

all of which the mucilage receptacles can be interpreted as being incompletely differentiated raphide-sacs,-i.e., without raphides.

II. Cell-membrane mucilage,-i.e., mucilage formed as a 
result of a metamorphosis of the cell-wall,- -is of frequent occurrence, being found in all parts of the plant, including the endosperm cells of seeds, parenchyma cells and medullary ray cells of roots and stems, and epidermal cells of leaves, stems, fruits, and seeds. Cell-membrane mucilage is also found in some of the mucilaginous marine algæ, as chondrus laminaria, etc., although in the latter case the mucilage is often spoken of as being derived from the intercellular substance, being a modification of the
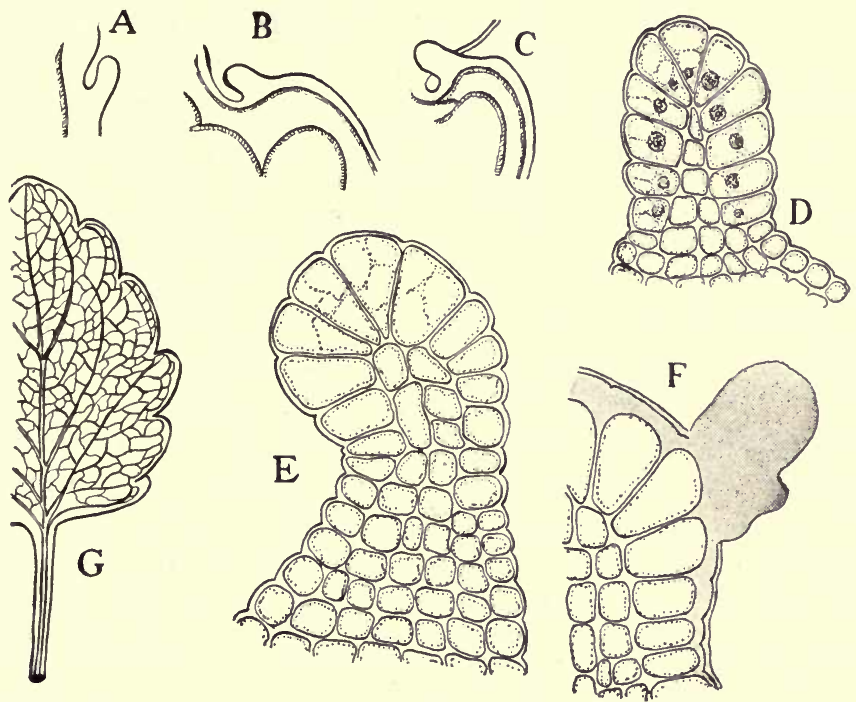

FIG. 120. A, B, C, successive stages in the development of the mucilage hairs or glands on the lobes of the leaves of Viola tricolor; D, young secretion hair showing some of the cells with large nuclei and several vacuoles; E, mature hair; F, gland showing mucilaginous layer beneath the cutin and the protrusion of a portion of the mucilage through the broken wall; $G$, portion of leaf on the upper part of the lobes of which occur the mucilage glands.

primary wall. It may also occur as a result of a decomposition of the secondary lamellæ.

Four different forms of mucilage are recognized. I. Mucilage cells, or distinct cells resembling more or less the surrounding cells, except that they contain mucilage, occur in the tissues of leaves, petals, fruits, seeds, and the parenchyma cells of pith and primary cortex of a number of plants. In this group may also be included the gelatinized cells of the integumental tissues 
(epidermis and hypodermis), as these in many cases may be mistaken, as in the Violaceæ, for distinct cells, although only the inner walls of the epidermal cells are gelatinized. 2. Mucilage cavities arise from the simultaneous gelatinization in the walls of a group of cells. These are found in the cells of the pith, cortex, and petioles in a number of plants of the Malvaceæ, Sterculiaceæ, Simarubaceæ, etc. 3. Mucilage canals are large cavities formed either $(A)$ as a result of the enlargement of the intercellular spaces between the cells, the primary lamellæ being modified to mucilage; or $(B)$ are formed by the disintegration or breaking down of a number of cells, the walls of which become gelatinized. In the former case they are spoken of as "schizogenous canals," and in the latter as "lysigenous canals." The latter are the more common form and occur in the pith and primary cortex of a number of plants belonging to the Guttiferæ, Malvaceæ, Sterculiaceæ, Oleaceæ, Rhamnaceæ, Vitaceæ, Leguminosæ, Rosaceæ, Cactaceæ, Piperaceæ, Moraceæ, and Urticaceæ. 4. Glandular hairs (Druzenzotten). In this form (Fig. II8) they are found in the lobes of the leaves and calyces of Viola tricolor, Coffea arabica, and of Prunus avium.

Chemical Classification of Mucilage.-Mucilages may be distinguished, according to their behavior with special reagents, as cellulose-mucilages or pectose-mucilages. The former are colored blue by chlor-zinc-iodide, and are soluble in ammoniacal solution of cupric oxide. To this class belong the mucilages of the tuber of salep and the seeds of cydonium. The pectosemucilages are distinguished by the fact that they are dissolved on being heated with solutions containing from 35 to 65 per cent. cane sugar. They are also stained intensely with solutions of saffranin, methylene blue, or ruthenium red.

Mucilage is formed in large quantities in certain trees, and the exudation which is collected forms the so-called gums of commerce. As these are largely used for a variety of technical purposes, their chemical properties have been studied, so that four distinct classes of gums are recognized.

I. Gums containing arabin or arabic acid. In this group are included gum arabic, obtained from Acacia Senegal and other species of Acacia ; Feronia gum, obtained from Feronia elephan- 
tum (Fam. Rutaceæ), and Anacardium gum, obtained from Anacardium occidentale.

2. Gums consisting of mixtures of arabin and cerasin (cerasic acid). To this group belong the exudations formed on a number of trees of the Rosacex, as cherry, almond, apricot, and plum.

3. Gums containing bassorin. Tragacanth is the typical gum

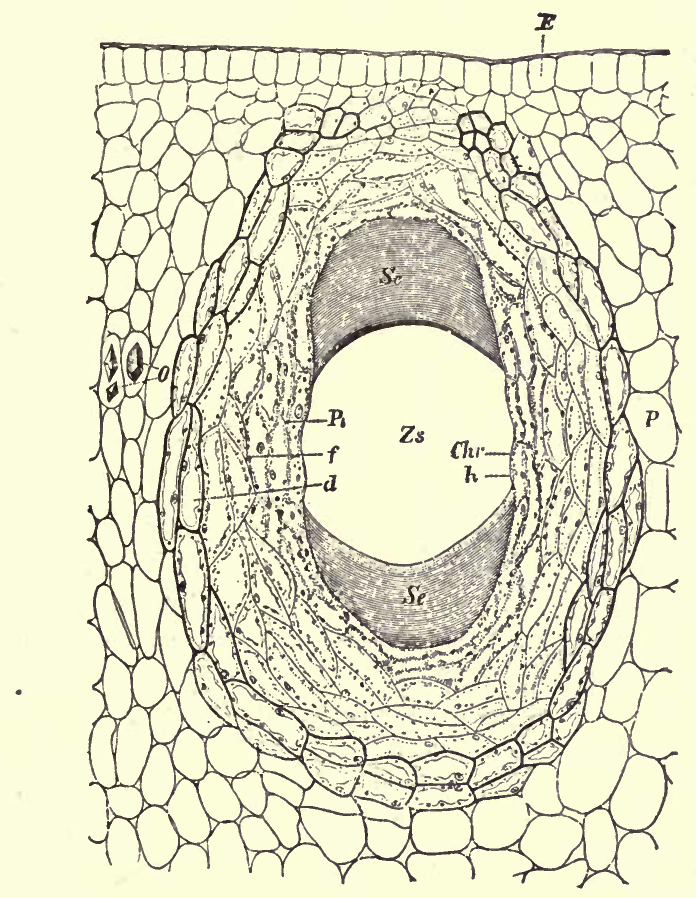

FIG. I2I. Citrus vulgaris. Longitudinal section of a young fresh fruit showing a lysig. enous oil canal or duct. Se, oil; Zs, cell sap; P1, cells in which the walls have been dissolved; $f$, thin-walled cells; $D$, thick-walled cells; $K$, nucleus; Chr, chromoplasts; o, crystals of calcium oxalate; e, epidermis.-After Meyer.

of this class. Included in this group are a few other gums which find some commercial use, as cocoa-palm gum, obtained from the bark of the cocoa-nut palm; chagual gum, obtained from Puya coarctata (Fam. Bromeliacex), and Moringa gum, obtained from Moringa pterygosperma (Fam. Moringaceæ).

4. Gums containing mixtures of cerasin and bassorin. The East Indian gum, obtained from Cochlospermum Gossypium 

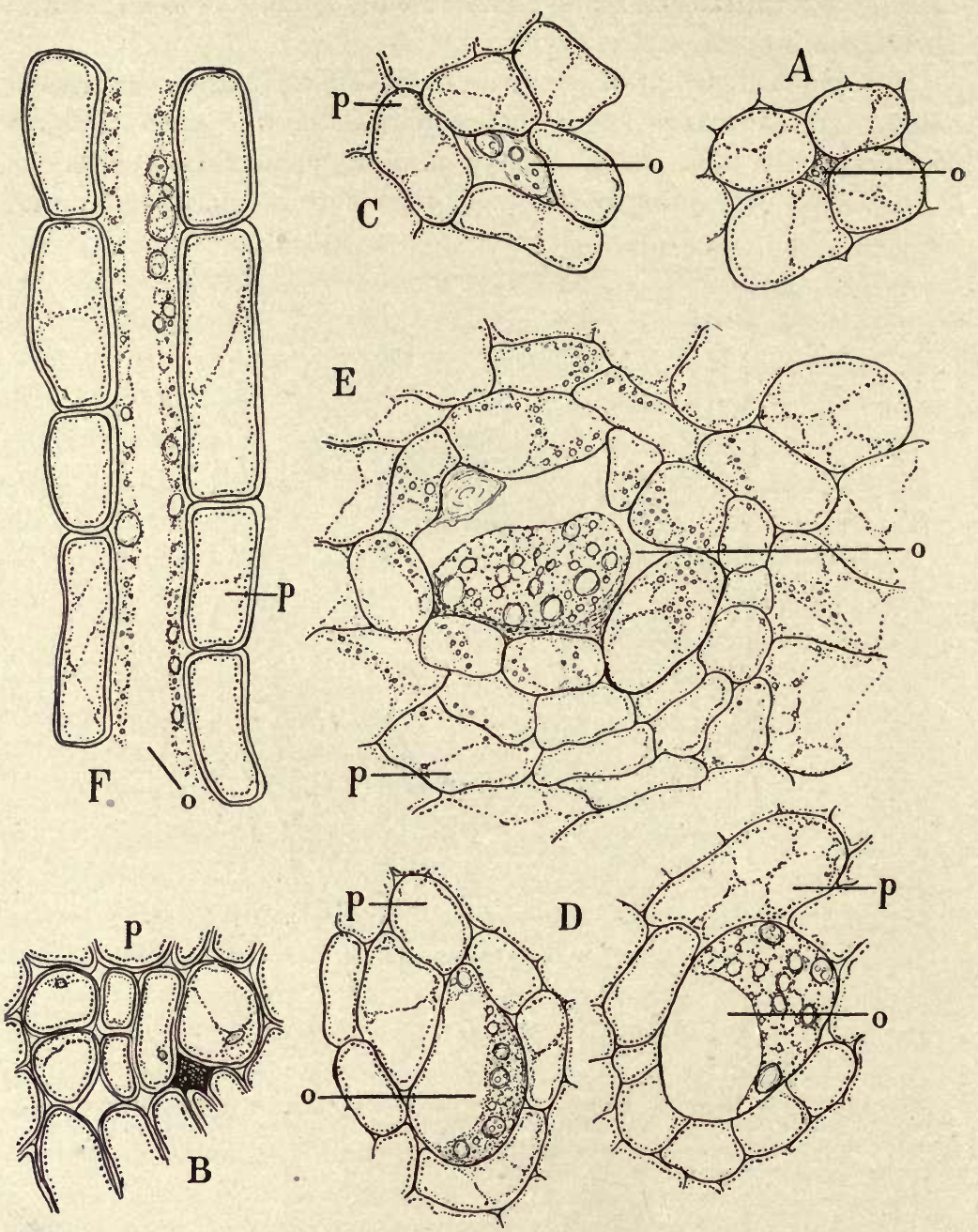

Fig. 122. Development of schizogenous oleo-resin canals in Brauneria pallida. A, intercellular space (o) between four parenchyma cells, being the seat of the early formation of the canal and indicated by a yellowish oily content. B, intercellular oleo-resin canal with five surrounding parenchymatous cells $(p)$. C, later stage of canal showing separation of small oily globules in the intercellular substance. D and E, the intercellular substance showing an almost protoplasmic-like structure, some of the lining cells being developed as papillæ and suggesting that they might be in the nature of secretion cells, although it is now considered that the oils and resins of this character are formed from a resinogenous layer in the wall. F, longitudinal section showing the elongated secretory canal between the rows of cortical parenchyma. 
(Fam. Cochlospermaceæ), has been used as a substitute and adulterant of tragacanth.

Volatile Oils and Resins.-These and related products, known as gum-resins and balsams, ${ }^{*}$ are found in a very large number of plants. Like the mucilages, they originate either as a metamorphosis of the cell-wall or as a direct product of the protoplasm. The former is of more frequent occurrence, and the

A

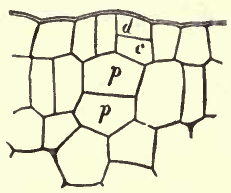

C

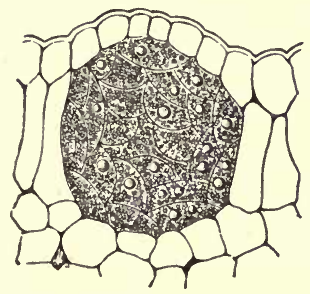

B

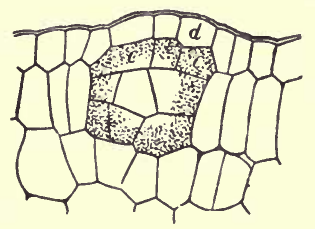

D

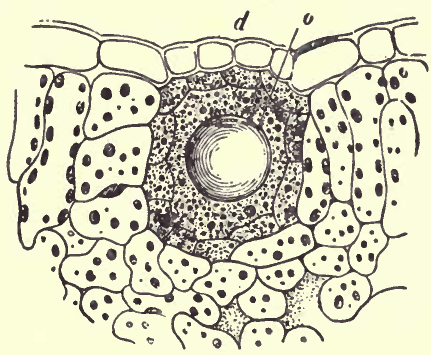

Fig. I23. Development of a lysigenous secretory canal in the leaves of Dictamnus albus (Fam. Rutaceæ). The development begins partly in the cells of the epidermal layer and partly in the underlying parenchyma (A). The outer cells divide, forming the secretion cells (c), while the inner give rise to the reservoir (B). The innermost cells then multiply by repeated division in all directions, giving rise to a large number of cells containing globules of oil (C). Later the thin walls are absorbed and the oily globules fuse together, forming a single large globule (D).--After Rauter.

* The volatile oils are not infrequently associated with other substances of the plant cell in varying proportions, as resin, gums, cinnamic and benzoic acids. Those products which consist chiefly of oil and resin are known as olEo-RESINS, and include turpentine and copaiba; those consisting chiefly of gum and resin and containing but little volatile oil are known as GUM-RESINS, and include ammoniac, asafœtida, galbanum, and myrrh; oleo-resins associated with aromatic acids are known as BALSAMS, as balsam of Tolu, balsam of Peru, storax, and benzoin, which latter is usually termed a balsamic resin. 
layer of the wall in which the decomposition takes place has been termed by $T$ schirch a resinogenous layer.

The cells or receptacles which contain oils, resins, gum-resins, and balsams are usually referred to as "secretory cells" or "secretory receptacles." The latter term is used by Solereder to include all cells, cell fusions, cavities or canals which are filled with secretions. Usually no attempt has been made to determine whether the secretion is a volatile oil or a resin, or a gum-resin or a balsam, as the appearance of the secretion is always either in the form of globules or more or less rounded masses. Secretory receptacles may arise in three different ways. (I) As a modification of the intercellular substance and an enlargement of the intercellular areas, giving rise to schizogenous receptacles (Fig. 122). (2) As a result of a disintegration of a group of cells and a decomposition of the wall substance, forming lysigenous receptacles (Fig., 123). (3) They may have at the outset a schizogenous origin, but later the surrounding cells in addition break down, so that the receptacle is more properly designated as being schizo-lysigenous. In certain plants, as in the bark of Sassafras and Cinnamon, there is a more or less even distribution of cells in the cortex, containing volatile oil, on the one hand, and mucilage, on the other. Indeed, it is supposed that the cells giving rise to mucilage may under different conditions develop volatile oil. In a general way it may be said that the secretory receptacles resemble those containing mucilage, both as to the manner in which they originate in a plant and the physical characters of the secretion. Indeed, they may be closely related to the mucilages in that they may contain a large proportion of gum, or the proportion of oleo-resin and gum may be reversed.

In the examination of technical products, and especially in taxonomic work, it is very important to note not only the chemical character of the secretions but also the fact whether the cells are isolated or whether they form canals, or whether the secretory receptacle is only a cavity. The following facts may be given in reference to the four principal types of secretory receptacles:

I. Secretory cells are distinct cells which may be quite distinct from, or may show more or less resemblance to, their neighboring cells, except that they contain oil or resin. They 
vary in length and outline, being either spherical, ellipsoidal, sacshaped (Fam. Bixaceæ), or branched (Fam. Meliaceæ). The contents may be in the form of distinct globules adhering to the wall (or in dried material may be in the form of amorphous masses), varying in color from colorless to yellowish or even dark brown. In the secretory cells of certain plants of the Lauracea, Magnoliaceæ, Canellaceæ, Aristolochiaceæ, and Piperaceæ the secretory contents are enveloped by a thin-walled sheath, connected with the cell-wall by means of a stalk. The internal glandular hairs occurring in the rhizome of Dryopteris and in Pogostemon Patchouli may be included among secretory cells, although they project into the intercellular area rather than into the cells. The cell-wall of the secretory cells not infrequently gives a distinct reaction for suberin.

Elongated secretory cells or sacs, resembling tannin-idioblasts, and with diverse contents varying from resin to latex-like substances or tannin-like masses, are distributed in the cells of the pith, bast, and pericycle of the stem and occasionally in the larger veins of the leaves of some of the genera of the following families: Anacardiaceæ, Berberidaceæ, Caprifoliaceæ, Compositæ, Crassulaceæ, Euphorbiaceæ, Lecythidaceæ, Leguminosæ (very widely distributed and with diverse contents), Menispermaceæ, Monimiaceæ, Myristicaceæ, Passifloriaceæ, Polygonaceæ, Rosaceæ, and Rubiaceæ.

Solereder also states that similar elongated sacs with brownish contents are observed in the epidermal cells and occasionally in the upper layers of mesophyll of one or more of the genera in the following families: Crassulaceæ, Euphorbiaceæ, Geraniaceæ, Moraceæ, Saxifragaceæ, and Violaceæ.

2. Secretory cavities are either spherical or ellipsoidal in shape and the contents vary from oily or resinous to gum-like or tanninlike masses. The mode of development of the cavities, as to whether schizogenous, etc., is usually not considered, as this fact is not easily determined in the mature tissues. When occurring in leaves the cavities give rise to transparent dots or glandular punctate areas. They are also found in the pith and primary cortex of quite a number of plants.

There are a number of special forms of secretory cavities, the 
latter in some cases being lined by a papillose epithelium or a form of bracket-cells, etc. They are found in the following families: Araliaceæ, Bixaceæ, Cæsalpinaceæ, Compositæ, Connaraceæ (with sphæro-crystalline contents), Euphorbiaceæ (with bracketepithelium), Geraniaceæ (with sphæro-crystalline contents), Guttiferæ, Leguminosæ (intramural glands with a papillose epithelium or bracket-epithelium), Lythraceæ, Malpighiaceæ, Malvaceæ, Meliaceæ, Menispermaceæ, Myrtaceæ, Oleaceæ, Passifloriaceæ, Piperaceæ, Podostemaceæ, Polygalaceæ, Polygonaceæ ( secretory cavities sometimes formed from four epidermal cells), Primulaceæ (occasionally with red crystalline contents), Proteaceæ (intramural glands), Rhamnaceæ (with a papillose epithelium), Rosaceæ, Rubiaceæ, Rutaceæ, Simarubaceæ, Styracaceæ, and Theaceæ.

3. Secretory canals differ from secretory cavities in that they are more or less elongated receptacles and often referred to as oil-ducts or oil-tubes. Like the secretory canals, they originate variously and have diverse contents. They may occur in a number of different portions of a plant, but their distribution is quite characteristic of certain genera or even of families. Secretory canals have been observed in the following families: Anacardiaceæ, Araliaceæ, Burseraceæ, Cactaceæ, Cæsalpinaceæ, Celastraceæ, Compositæ, Gesneraceæ, Guttiferæ, Hamamelidaceæ, Leguminosæ, Pittosporaceæ, Podostemaceæ, Rhamnaceæ, Rutaceæ, Simarubaceæ, Theaceæ, and Umbelliferæ. (Consult Solereder's "Systematic Anatomy of the Dicotyledons.")

4. Glandular hairs. Volatile oils and resins arise in the glandular hairs formed on the surface of stems, leaves, and various parts of the flower in the Labiatæ, Compositæ, and other families. In these hairs a volatile oil separates in the form of large, oily globules which lie between the cuticle and the outer wall of the underlying cells (Fig. I24). The origin of this secretion has been variously ascribed to the protoplasmic content of the cell or to a modification of the cell-wall. In the former case it is said to arise as a metabolic substance in the protoplasm, and is later diffused into the glandular area between the outer cellulose wall and cuticle. While this manner of formation of the oily secretion would seem reasonable, yet the studies by Tschirch 
and Tunmann would seem to show that the secretion in the glandular hair arises in a subcutaneous layer of the wall, which has been termed a " resinogenous layer." Even De Bary, with characteristic caution, has stated that the secretion found in the walls of glandular hairs originates in the wall even though the materials for its formation must arise in the protoplasm of the cells.

In the study of glandular hairs the method of Tunmann may be followed (Ber.d.d. pharm. Gesellsch., 1908, p. 513). Fresh, or even dried, material may be used. Surface sections are made
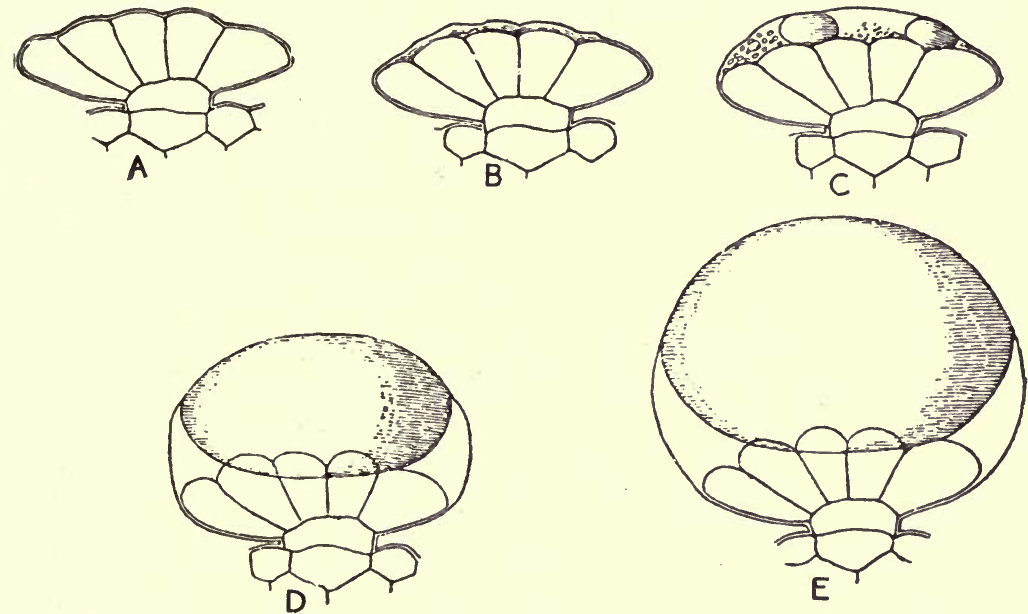

Fig. I24. A glandular hair from the young leaves of Lavandula vera seen in different stages in the course of three days, showing that the underlying cells remain of the same size and structure, but that there is a gradual increase in the glandular area or resinogenous layer.-After Tunmann.

and examined in aqueous solutions containing $10,20,30$, or 40 per cent. of hydrated chloral. The ro per cent. solution is used first, then the 20 per cent., etc. The proper solution renders the hair transparent, dissolves the resin, and, if the cover-glass is moved sidewise, the cuticle bursts, showing the resinogenous layer. Tunmann distinguishes three different types of glandular hairs, depending upon the character of this resinogenous layer. (I) In which by this treatment there separate small rod-like crystals resembling bacteria, as in Fig. I25, $A, B, C$. (2) A second type is given in which vacuoles occur consisting of 


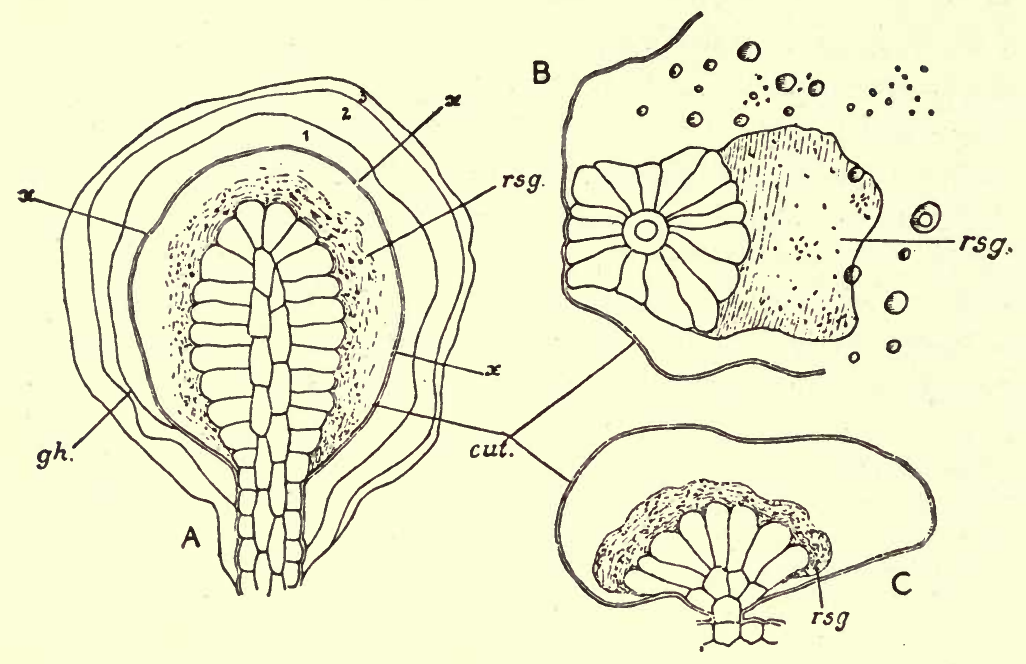

B
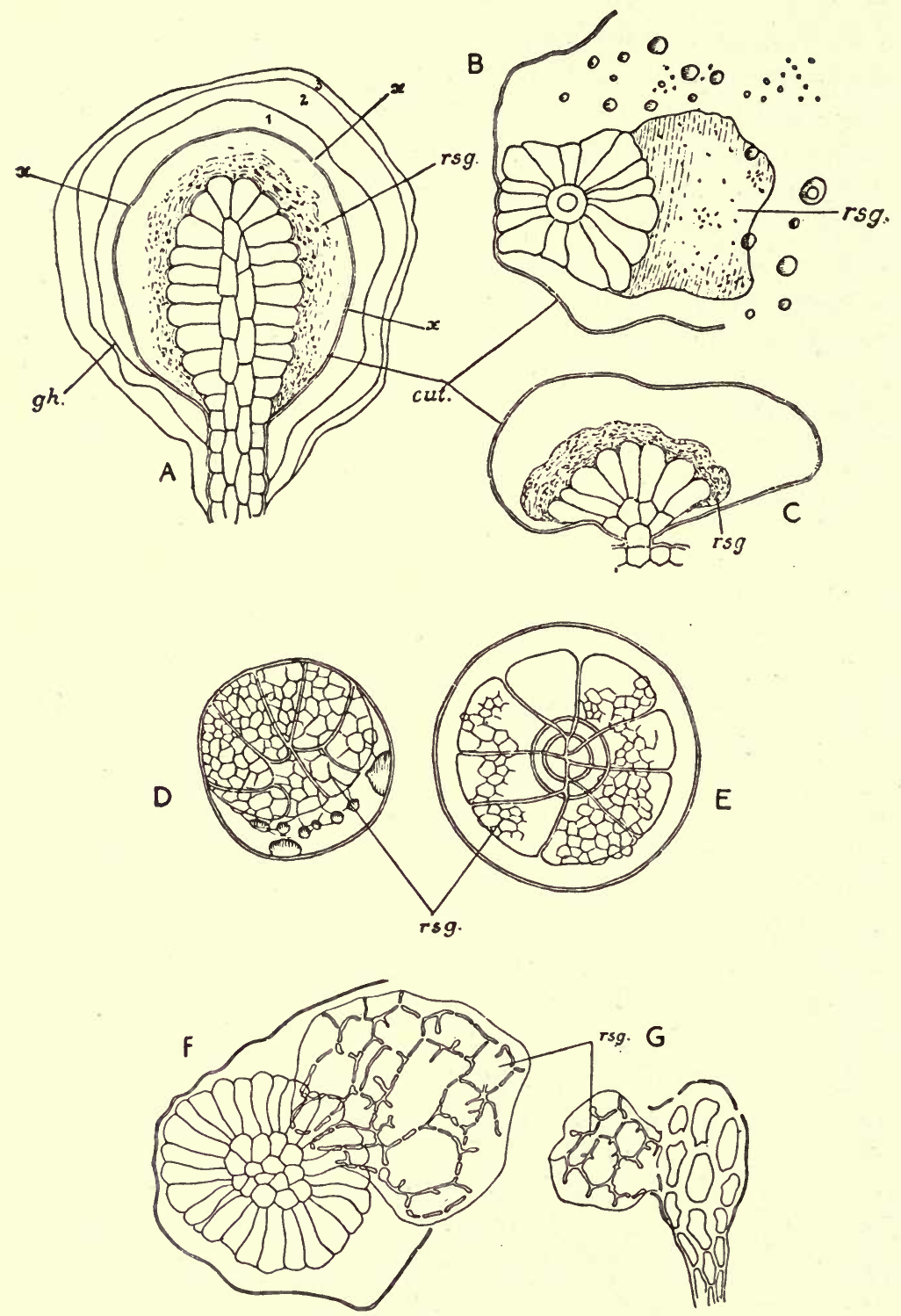

Fig. 125. Several torms of glandular hairs: I. In which the resinogenous layer (rsg) separates in the form of small rods, as the leaves of violets (A), Fraxinus (B), and Alnus (C). 2. The resinogenous layer separating in the form of vacuoles in the hairs of Salvia (D) and Hyssopus (E), observed in the dried material treated with dilute sclutions of hydrated chloral. 3. A lattice-like or cellular resinogenous layer occurring ir. the hairs of Rhododendron (F) and Azalea (G).-After Tunmann. 
a fine net-work, as in Fig. I25, D, E. (3) A third type in which the secretion is in the form of neither rods nor vacuoles but a somewhat cellular structure, termed by Tunmann a lattice-work. In the walls of the glandular hairs other substances are sometimes present, as resins, gums, etc. Hanstein originally proposed the use of a mixture of aniline dyes to distinguish resin, gum, and protoplasm (Bot. Zeit., I868, p. 754), but later studies have shown that these dyes are limited in differential diagnosis of many of these substances. The cells of the glandular hairs may contain, in addition to protoplasm, protein bodies, chlorophyll grains, starch, fixed oil, tannin, calcium oxalate, reducing sugars, and other special substances, which are colored yellowishred with solutions of the alkalies or sulphuric acid.

Microchemistry of the Volatile Oils and Resins.-They are readily soluble in alcohol, ether, chloroform, benzene, acetic ether, carbon disulphide, petroleum ether, etc. They are also quite soluble in glacial acetic acid and in aqueous solutions of hydrated chloral. Some of them are soluble in dilute alcohol. They may be liberated on the heating of sections for about ten minutes in a drying oven to a temperature between $100^{\circ}$ and $13 \mathrm{O}^{\circ} \mathrm{C}$. Like the fixed oils, they are colored brownish or brownish-black with osmic acid and are intensely colored with alkannin and cyanin. The volatile oils are also colored a carmine red with very dilute solutions of fuchsin. Cells containing resins and terpenes are colored green by the use of aqueous solutions of copper acetate, the freshly cut twigs or leaves being allowed to remain in the solution for a few days.

VOLATILE OILS.--The odors which are characteristic of very many plants are due chiefly to a group of principles known as volatile oils. They are, for the most part, mixtures of terpenes and camphors, and are obtained from the plant by distillation with steam, the oil rising to the surface of the distillate, being only slightly soluble in water. Volatile oils are readily soluble in alcohol, ether, chloroform, and in the fixed oils. Some of them show a tendency to absorb oxygen, and are converted into resinous substances. They are widely distributed and are characteristic of certain families, viz.: Pinaceæ, Cruciferæ, Labiatæ, Lauraceæ, Myrtaceæ, Rutaceæ, and Umbelliferæ. 
With the exception of the seeds, in which they are seldom found, volatile oils occur in nearly all parts of the plant. They are formed either as a direct result of the activities of the protoplasm or by reason of changes in some of the constituents of the cell-wall. In a few instances the volatile oil is formed from a mother substance, being in the nature of a glucoside, and in this form occurs in the seeds of the almond and mustard.

Botanical Classification.-The composition of volatile oils is in many cases very complex; seldom do they consist of only one substance, as in turpentine oil. Usually they consist of a number of chemical compounds, the most complex being American peppermint oil, from which no less than seventeen different, well-characterized chemical compounds have been isolated. As the volatile oils are of considerable economic value, they have been rather very extensively studied. It remains for botanists to apply this knowledge to the study of the living plant. The physiologist will find the study of the origin, transportation, and localization of volatile oils in different parts of the same plant of very great interest. Such studies will throw considerable light upon the entire question of origin and transformation of the different plant constituents. In many cases, even the constitution of the constituents in volatile oils has been ascertained, so that on a sound scientific basis, hypotheses may be developed concerning the complex changes which are possible in the substances derived from the protoplasm. Again, the distillation products obtained in the study of volatile oil show that the living plant may contain such simple compounds as formic alcohol, formaldehyde, formic acid, hydrocyanic acid, etc.

Volatile oils which have been carefully studied are obtained from plants of the following families: Polypodiaceæ, Pinaceæ, Pandanaceæ, Gramineæ, Palmæ, Araceæ, Liliaceæ, Iridaceæ, Zingiberaceæ, Piperaceæ, Salicaceæ, Myricaceæ, Juglandaceæ, Betulaceæ, Moraceæ, Aristolochiaceæ, Chenopodiaceæ, Ranunculaceæ, Magnoliaceæ, Anonaceæ, Myristicaceæ, Monimiaceæ, Lauraceæ, Cruciferæ, Resedaceæ, Hamamelidaceæ, Rosaceæ, Leguminosæ, Geraniaceæ, Tropæolaceæ, Erythroxylaceæ, Zygophyllaceæ, Rutaceæ, Burseraceæ, Meliaceæ, Polygalaceæ, Euphorbiaceæ, Anacardiaceæ, Vitaceæ, Tiliaceæ, Malvaceæ, Theaceæ, Diptero- 
carpaceæ, Cistaceæ, Turneraceæ, Lythraceæ, Myrtaceæ, Araliaceæ, Umbelliferæ, Ericaceæ, Primulaceæ, Convolvulaceæ, Verbenaceæ, Labiatæ, Solanaceæ, Caprifoliaceæ, Valerianaceæ, and Compositæ.

Composition of Volatile Oils.-The volatile oils are usually of a very complex composition; it will be found, however, that they owe their principal characteristics to one or more definite compounds. The following classes of compounds have been derived from the volatile oils.

Terpenes, hydrocarbons of the formula $\mathrm{C}_{10} \mathrm{H}_{16}$, are found in the volatile oils of the Pinaceæ, Rutaceæ, etc. The terpene pinene makes up practically the entire bulk of turpentine oil. The terpene limonene is found in the oil of lemon to the extent of 90 per cent. It is not, however, the characteristic constituent in this oil, the odor of lemon being due to an aldehyde, citral.

Sesquiterpenes, hydrocarbons of the formula $\mathrm{C}_{15} \mathrm{H}_{24}$, have been isolated from a number of oils, the best known representative of this class being cadinene, occurring in the oils of cubeb, patchouli, savin, etc.

AlconoLs belonging to the aliphatic and aromatic series occur in a number of oils combined as esters with the fatty acids. Both methyl alcohol and ethyl alcohol are found in the aqueous distillates in the preparation of certain oils. This occurrence is usually explained as being due to the decomposition of other substances. Methyl alcohol is thought to be derived from the decomposition of cellulose, while ethyl alcohol is considered to be a product of the fermentation of carbohydrates. That ethyl alcohol may be derived in this manner is probable from the observations of Maze, who obtained alcohol from germinating seeds. Esters of methyl alcohol, especially methyl salicylate, are widely distributed. Among other alcohols, the following may be mentioned: Linalool constitutes the bulk of lignaloe oil; geraniol, a diolefinic alcohol makes up the bulk of rose oil; benzyl alcohol, as an ester, occurs in the oils of jasmine, tuberose, ylang-ylang, etc. ; cinnamic alcohol, as an ester, occurs in cassia oil, storax, and Peru balsam; menthol (peppermint camphor), a secondary alcohol, is found in peppermint oil; borneol (camphyl alcohol) occurs 
in the oils of valerian and serpentaria, the acetate of this alcohol being found in many oils of the Pinaceæ.

AldEHydes.-The simplest of the aliphatic aldehydes, formaldehyde, has been found in apopin oil, the latter being derived from an unknown plant growing in Japan. Acetaldehyde is commonly present in the distillates of seeds. Citral is found in lemon oil, giving it its characteristic odor. It is also found in the oils distilled from the leaves and twigs of the lemon tree, sweet orange tree, sassafras, etc. Benzaldehyde is formed upon the hydrolysis of amygdalin.

KETONES.-Of the aliphatic ketones, acetone has been observed, together with hydrocyanic acid, in the distillation of a number of leaf oils. Carvone occurs in the oil of caraway. Pulegone occurs in large amounts in European pennyroyal oil and the oils of other members of the Labiatx. Japanese or laurel camphor is obtained by the distillation of the wood of Cinnamomum Camphora. Irone, a cyclic ketone, occurs in orris root.

Phenols and Phenol Ethers are found in a number of volatile oils. Thymol constitutes the larger part of the oil of ajowan (Ptychotis coptica). Carvacol is a constituent in many Labiate oils. Anethol is the principal constituent of the oils of Pimpinella anisatum and Illicium verum and is an important constituent in the oil of fennel. Eugenol occurs in the oils of the Myrtacea and Lauracea. Apiol is a constituent of the fruit of parsley, and safrol is the principal constituent of sassafras oil.

AcIDs.-Quite a number of acids are obtained as a by-product in the aqueous distillation of volatile oils. Among these may be mentioned formic acid, acetic acid, isovaleric acid, benzoic acid, cinnamic acid, salicylic acid, etc.

Esters give the fragrance to most volatile oils. Some oils consist almost entirely of esters, as wintergreen oil and birch oil, which contain methyl salicylate. The latter is probably one of the most widely distributed of the esters. Linalyl acetate is the characteristic constituent of bergamot and lavender oils. Geranyl acetate is found in the oils of lemon grass, neroli, 
coriander, etc. Esters of benzoic and cinnamic acids are found in storax, Tolu balsam, and Peru balsam. Bornyl isovalerate occurs in valerian oil.

LACTONES. - The odoriferous principle known as coumarin is widely distributed in the plant kingdom. It occurs in some of the ferns, grasses, tonka bean, "Waldmeister" (Asperula odorata), etc. It apparently is formed as the result of the action of a ferment, as it is detected only after the drying of the plant. Alantolactone is the principal constituent of the oil of Inula Helenium.

Nitrogen and sulphur compounds occur frequently in the aqueous distillates of plants yielding volatile oils. Hydrocyanic acid is readily detected by means of Prussian blue, and occurs in the distillates not only of cyanogenetic plants but in a large number of others as well. The mustard oils are esters of isothiocyanic acid and are characterized by their penetrating odors. Allyl mustard oil is obtained from the seeds of Sinapis nigra and a few other plants of the Cruciferæ. (Consult "The Volatile Oils," Gildemeister and Hoffman, translation by Edward Kremers ; also "Semiannual Reports,” by Schimmel \& Co.)

Formation of Volatile Oils.-The chemical study of odorous principles shows that they vary considerably in their composition. Not much is known regarding the formation of volatile oils. Charabot and Herbert have suggested that the esters may originate in the cells containing chloroplastids. They suggest that under the influence of an enzyme of reversible activity the esters are formed from the acids and alcohols present in the plant cell, and that they continue to form until the flowering period. They are then diffused to other parts of the plant, notably the inflorescence. While some of the oils are indirect products connected with photosynthesis, others arise through the decomposition of a mother substance, as the glucosides, and still others originate as a metamorphosis of the cell-wall.

Physiological Rôle of Oils.-It is usually considered that volatile oils occurring in receptacles near the surface of the plant, as in fruits like the orange, serve to prevent the entrance of animal and vegetable parasites, and thus prevent disease. Again, the oils which are found in glandular hairs covering the leaves 
and stems of many plants are supposed to be useful in preventing depredations by animals. The odorous principles which occur in many flowers are supposed to exert a directive influence upon insects and thus assist in the work of cross-pollination. While biologists usually consider the volatile oils as serving ecological uses yet those investigators, who study the perfume-yielding constituents very closely, are inclined to consider them as being in the nature of food materials that are used after the fertilization of the flower and during the development of fruit and seeds.

Resins, Gum-Resins and Balsams.-A large number of this class of plant products are found in commerce and used in medicine and in the arts. A few of these occur as normal products
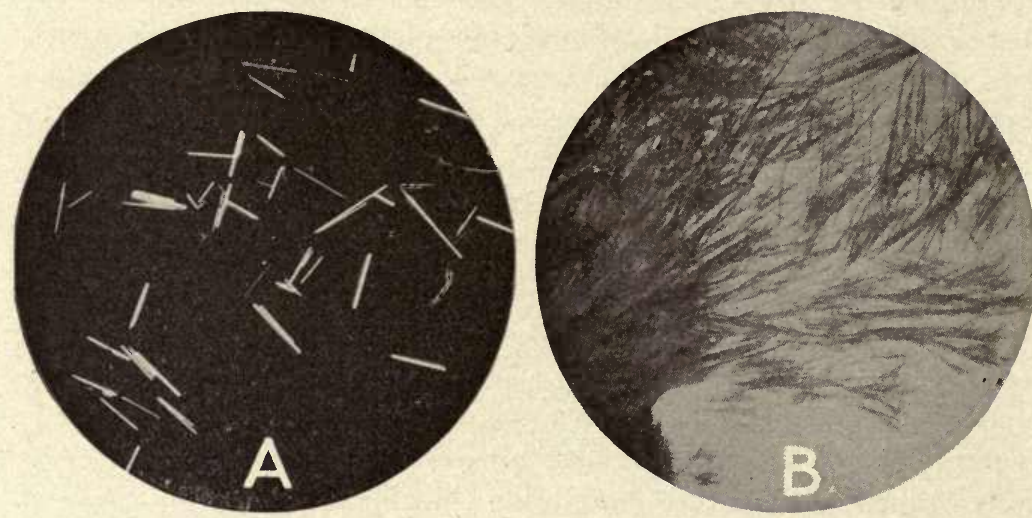

FIG. 126. Menthol: A, individual crystals obtained by sublimation; B, the commonly occurring aggregates of very fine needles.

in living plants, as the gum-resins of the Umbelliferæ, the gumresin euphorbium, and the resins of mastiche and sandarac. Most of the others arise as a result of wounds in plants and are in the nature of pathological products, as benzoin, styrax, Tolu balsam, Peru balsam, etc. Until recently not much was known except in a general way regarding the composition of resins. Largely through the researches of Tschirch and his students the nature and the constitution of the important constituents in a number of the resins have been worked out. As a result of these studies seven principal groups of resins are recognized.

I. Tannol Resins.-These are esters of aromatic phenols and 
behave toward iron salts and some other reagents like tannin. They are found in relatively large amounts in a number of the resins and balsams, and occur in rather widely separated families, as follows: Peru balsam and Tolu balsam obtained from certain members of the Leguminosæ, styrax from the Hamamelidaceæ, benzoin from the Styracaceæ, aloe from the Liliaceæ, dragon's blood from the Palmæ, and the resins from the Umbelliferæ, including ammoniac, galbanum, asafœtida, etc.

2. Resene Resins.-These are mostly colorless, indifferent substances occurring in resins and are not only insoluble in potassium hydroxide but exceedingly resistant to it, and are not capable of acetylization. To this group belong the resinous exudations of the Burseraceæ, including myrrh, olibanum, and elemi; also of the Anacardiacer, including mastic; and of the Dipterocarpaceæ, including gurjun balsam and dammar.

3. Resinolic Acid Resins.-These are oxy-acids containing either or both hydroxyl and carboxyl groups. They form colorless crystals and are either free or combined with alcohol in the form of esters. They have an acid reaction and are soluble in solutions of sodium hydroxide, and with difficulty form compounds with acetyl chloride. Acids belonging to this group have been obtained from a number of the resinous exudations of the Coniferæ, including sandarac, Canada turpentine, and Strassburg turpentine. It is also obtained from a number of resins which are in the nature of pathological products, as larch turpentine, Jura turpentine, and French turpentine. The abietic acid in colophony and the succinoabietic acid found in the fossil resin known as amber, also belong to this class of acids. Furthermore, resinolic acids are found in the fungus Polyporus officinalis, and in some of the exudations of the Leguminosæ, including the oleoresin known as copaiba and the recent-fossil resin, Zanzibarcopal.

4. Resinol Resins.-Resinols are aromatic alcohols which usually form colorless crystals and occur either free or in the form of esters. The principal constituents of guaiac resin belong to this class, namely, guaiaconresinol (guaiaconic acid), guaiacresinol (guaiacic acid), and guaiacinresinol (guaiacinic acid). Resinols are also found in small quantities in other resins. 
5. Fatty-resins. - The resins of this class differ from the others heretofore considered in that they are derivatives of some of the fatty acids. To this group belongs the resinous exudation known as "stick-lac," occurring on a number of trees growing in the East Indies, being caused by the punctures of a hemipterous insect, Coccus lacca.

6. Pigment Resins.-In this group are included those exudations in which the resins are combined with a chromogenic derivative. These have been studied but very little, and the best representative of this class is gamboge, which is used in medicine as well as for coloring in art.

7. Glucosidal Resins.-This group includes, as the name would imply, those resins which are in the nature of glucosides and yield on hydrolysis glucose as well as some other derivative. The resins found in jalap, scammony, and other plants of the Convolvulaceæ belong to this group. (Consult A. Tschirch, "Die Harze und die Harzbehalter.")

Origin of Resins.- It was at one time considered that the resins were derivatives of tannin. Now that Tschirch has shown that there are a class of resinous substances that give reactions for tannin, it might seem that this theory would receive additional support. However, as he himself explains, the resinotannols contain a great deal more carbon than the tannins. Furthermore, Tschirch has shown that a number of the constituents of the resins give color reactions with Liebermann's reagent for phytosterol. On the other hand, a number of these same constituents do not give the characteristic color reaction for phytosterol with Salkowsky-hesse's reagent. With regard to the resins of the resinolic acid series, Tschirch concludes that they are probably not derived from volatile oils, but that they are derivatives of a common mother substance. In a later publication Tschirch ("Chemie und Biologie der Pflanzlichen Sekrete") states that in all probability all the secretory products, formed as a metamorphosis or decomposition of the resinogenous lamellæ, are the direct products of ferments accompanying these layers.

LAtex OR MilK-JUICE is the product formed in special secretory organs in the plant, and exudes readily on even very slight injury of the plant. Under the microscope it is seen to be in 
the nature of an emulsion, consisting of small globules, varying from 0.0005 to $0.005 \mathrm{~mm}$. in diameter. It is of variable composition and may contain certain hydrocarbons, as in pure caoutchouc and pure gutta percha, oils, resins, mucilage, starch, calcium oxalate, and alkaloids.

Latex is found in three distinct types of tissues, differing

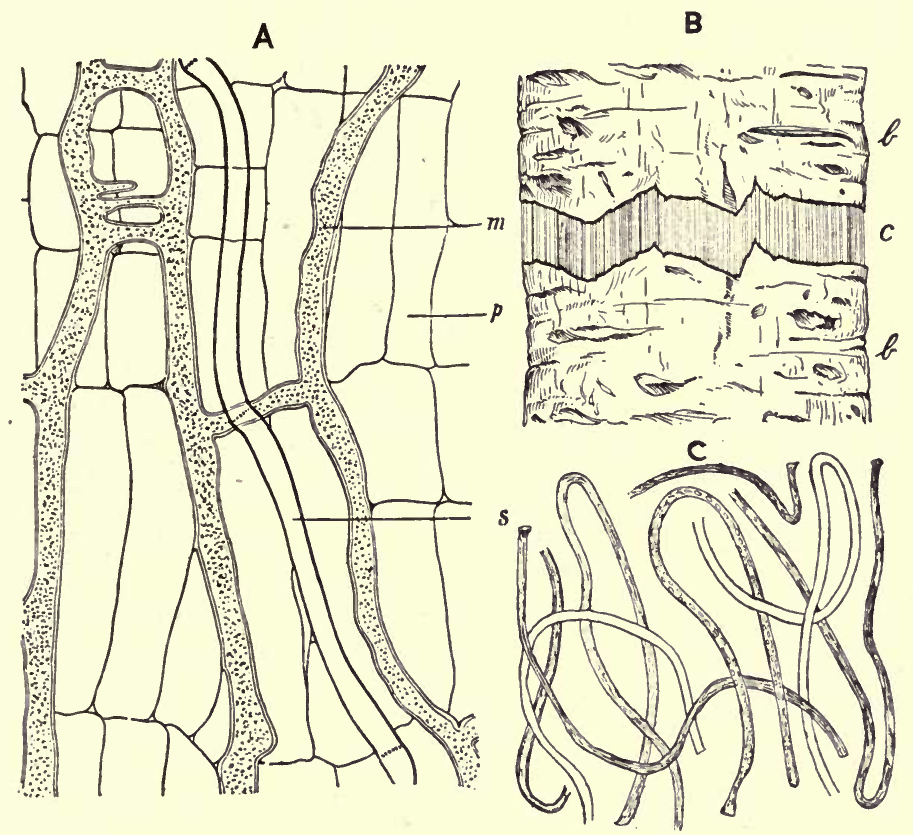

FIG. 127. Study of Latex: A, tangential-longitudinal section through root of Taraxacum, showing laticiferous vessel $(m)$, sieve tube $(s)$, parenchyma $(p)$. $B$, the bark of Euonymus, fractured and showing the thread-like latex (c) between the pieces (b). C, the fragments of thread-like latex of Euonymus viewed under the microscope, and distinguished from fibers by their dissolving in chloroform.-A, after Meyer; C, from drawing by Hogstad.

from each other in origin and manner of development. I. Laticiferous cells are long, tubular cells which arise in the initial cells of the embryo and continue to elongate, keeping pace with the growth of the plant, branching and traversing all of its organs. They may extend through the cells of the pith, bast, and primary cortex, run along the veins of the leaf, being found occasionally in the mesophyll, and extend into the fruit. Cells of this kind 
are present in the Apocynaceæ, Asclepiadaceæ, Euphorbiaceæ, Moraceæ, and Urticaceæ. 2. Laticiferous vessels are long tubes resembling the latex cells, but are formed by the absorption of the transverse walls in the superimposed cells. They develop very early, the cell-fusions taking place, in some instances, in the primary meristems. They may be either simple or branching, the branches connecting with other tubes and forming a net-work. These anastomosing tubes can be separated readily from the sur-

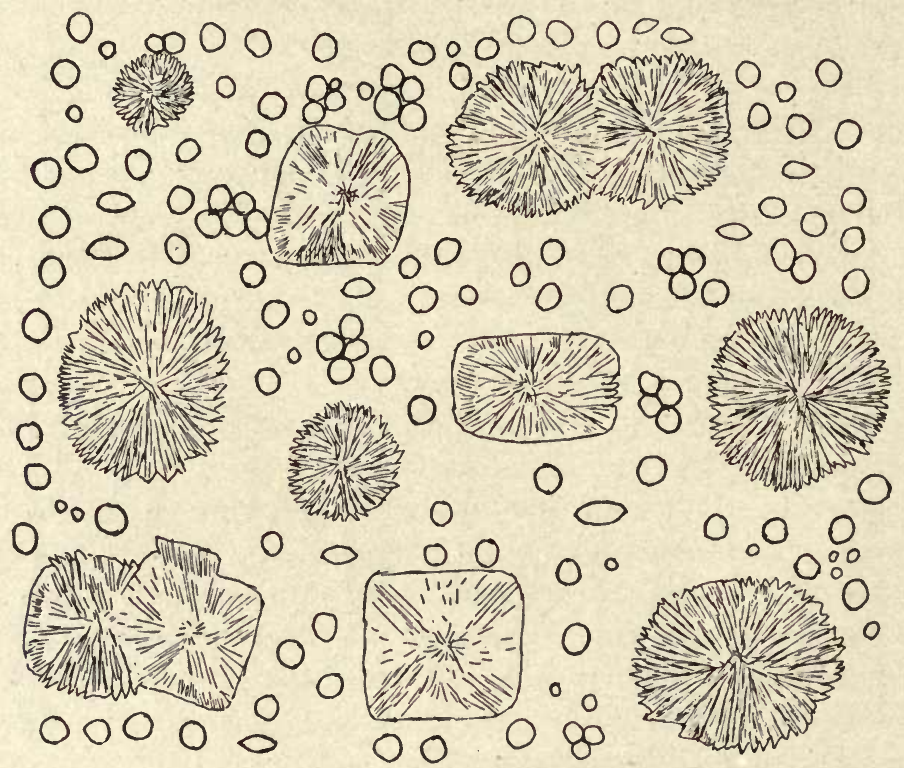

Frg. 128. Microscopical appearance of latex in Ficus elastica, showing small globules and sphero-crystals which separate soon after the removal of the fresh latex.-From a drawing by Hogstad.

rounding tissues by boiling the material with dilute solutions of potassium hydroxide. The laticiferous vessels usually occur associated with the leptome, although they may be found in other tissues of the axis and leaf. Milk vessels are found in the following families: Araceæ, Campanulaceæ, Compositæ, Convolvulaceæ, Euphorbiaceæ, Geraniaceæ, Musaceæ, Oleaceæ, and Papaveraceæ. 3. Secretory cells resembling laticiferous cells, in that they have a latex-like content, although probably of secondary origin, have been found in the Celastraceæ, Oleaceæ, 
Tiliaceæ, and Urticacex. The secretion in these cells is sometimes visible even with the naked eye, and it is possible, on breaking the bark, to obtain the latex in the form of delicate, elastic threads. These caoutchouc threads may be readily seen on breaking the bark of euonymus, and may be distinguished from bastfibers by their readily dissolving in chloroform (Fig. I27).

The milk-juice varies in color in different plants, being colorless, as in oleander ; whitish, as in the Apocynacer and Asclepiadaceæ; or yellowish, as in chelidonium, or orange-red, as in sanguinaria. The latex of a number of plants is collected to form a number of commercial products. Opium is the dried milk-juice obtained from the capsules of Papaver somniferum. Lactucarium is the dried milk-juice of Lactuca virosa and other species of Lactuca. Elastica or India rubber is the prepared milk-juice ob-1 tained from a number of plants, the most important being the Brazilian or Para rubber tree (Hevea brasiliensis), the Central American rubber tree (Castilloa elastica), the East Indian rubber tree (Ficus elastica), and the rubber vines of Africa (Landolphia species). Gutta percha is the concrete juice of Palaquium Gutta (Fam. Sapotaceæ).

Enzymes or Ferments.-In connection with the growth of the plant, there occurs a constant change in the substances which comprise it. These changes are brought about largely through the influence of a class of substances known as enzymes. Attention has been directed to the decomposition of starch with the formation of sugar. This change is brought about by the secretion in the protoplasm of an enzyme called amylase (diastase). It is produced in the living cell, can be extracted from the plant, and will produce the same effect upon starch grains which have been separated from the cells.

One of the interesting properties of the ferments is that in comparison with the amount of ferment employed the product formed through its influence is very large. Thus it is stated that amylase is able to hydrolyze I0,000 times its own bulk of starch. Results of this kind are considered to be due to catalytic action of the ferments, i.e., their power of inducing chemical reactions by their mere presence without themselves entering into the products formed. The ferments require specific temperatures for 
their action, as, for example, emulsin or sinaptase, which decomposes a number of the glucosides at a temperature of $35^{\circ}$ to $40^{\circ}$ C., while amylase, the ferment of germinating seeds, requires a somewhat higher temperature, namely, $50^{\circ}$ to $70^{\circ} \mathrm{C}$.

Another property of these ferments, which is generally regarded as characteristic of them, is that of becoming inactive when solutions are heated to a temperature of $100^{\circ} \mathrm{C}$. Nothing is known with regard to the composition and constitution of the ferments, and they are usually classified according to the class of substances which they decompose. Thus, amylases act upon starch grains with the formation of sugar; proteinases break down the true proteins, etc.

The following is an enumeration ot the principal plant enzymes, together with their occurrence and some of their properties:

AMYLASE.-The ferment acting upon starch in germinating barley, with the formation of glucose and maltose, was separated by Payen and Persoz in 1833 , and called " diastase." This ferment occurs, probably, in all parts of all green plants, and is especially abundant in all cells where starch is formed or stored. It is found in large amounts in various cereal grains, and also occurs in the fungi, yeasts, and bacteria. Recent investigation seems to show that in the cells with reserve starches there are two different kinds of diastatic enzymes, the one acting on the soluble starch, called amylase, and the other acting on the insoluble starch or amylopectin, and called amylopectinase.

INULINASE is the ferment found in the cells of plants containing inulin. It decomposes the latter, changing it into fruit sugar or fructose. Inulinase has no effect upon starch. It has been found in the Compositæ and also in Aspergillus, Penicillium, and a number of genera of the Eumycetes.

Maltase ( $a$-glucosidase) is always associated with the diastases, and from which it has not been separated. It is widely found in the vegetable kingdom, and is especially abundant in malt and some of the yeasts.

InVERTASE ( $a$-fructosidase), sometimes also spoken of as invertin or sucrose, has the property of converting cane sugar into invert sugar (a mixture of glucose and fructose). It is found in 
wheat and barley, dates, bananas, mulberries, and especially in the green leaves and young shoots of higher plants. In yeast it is accompanied in many cases by maltase.

Emulsins are a class of glucoside-resolving enzymes found in the seeds of the almond, the bark of Prunus serotina, the leaves of Prumus Laurocerasus, and in a large number of plants of the Rosaceæ. It is also found in the tuberous roots of Manihot utilissima, Monotropa, species of Polygala, Hedera Helix. Enzymes resembling emulsins, and capable of attacking glucosides, have been detected also in Aspergillus, several species of Polyporus, found growing in wood, lichens, mosses, and bacteria. A distinction is sometimes made between almond-emulsin, Aspergillus-emulsin, etc.

Myrosin, an enzyme which hydrolyzes the sulphur-glucosides, occurs in the Cruciferæ and in certain species of Manihot. It is localized in the seeds of cells which are rich in proteins. Its presence may also be demonstrated in the mesophyll of young leaves, in the pericycle of stems, and in the cork-cells of roots.

Gaultherase (Betulase), an enzyme which hydrolyzes the glucoside of methyl salicylate called "Gaultherin." This is present in Gaultheria and many other of the Ericaceæ. It is probably very widely distributed in the vegetable kingdom. (See Amer. Jour. Pharm., 1898, p. 4I2.)

Pectase and Pectinase.-The name Pectase is applied to an enzyme that is always present in ripening fruit, and is capable of converting pectose, a product insoluble in water, into a soluble substance called pectin. The latter can be further decomposed into a number of closely related substances, known as pectinic acids, and which are usually combined with calcium. The term Pectinase is applied to the enzymes which in the presence of lime coagulates the juices containing the dissolved pectinous substances forming the so-called fruit jellies. This reaction is conditioned on the presence of lime and a certain equilibrium being established between the enzyme and the concentrations of the acid and calcium salts. Pectose originates by reason of certain changes in the lamellæ of cell-walls. While it occurs in appreciable quantities in those fruits that have the properties of producing jelly, it is probably very widely distributed. 
Cytases (cellulases) is the name applied to those enzymes which are capable of dissolving cellulose. An enzyme of this character is located in the aleurone layer and in the epithelium of the scutellum in the germinating grain of barley. It is also found in the endosperm of the date palm, the cytase being formed in the embryo and the dissolved products being used up as food. Enzymes of this character are also found in wood-destroying fungi and bacteria.

Proteinases (carbamases) is the name applied to those enzymes which break down the true proteins or carbamide derivatives. They are always accompanied in the plant cells by other ferments, and occur especially in seeds, being more abundant in those containing oil than starch, as hemp, mustard, castor oil, and flaxseed. They are also found in certain fleshy fruits, as figs and pineapple; succulent leaves, as Agave, and in insectivorous plants. In the fruit and other parts of the papaw tree (Carica Papaya) occurs a proteolytic enzyme, called Papain, which readily digests fibrin, thus behaving like trypsin, a ferment in the pancreatic juice. A similar ferment, called Bromelin, has been extracted from the fleshy pulp of the pineapple. Ferments like Papain and Bromelin are naturally of very great interest, as they behave like the animal ferments, pepsin and trypsin. The Papain of commerce seems to be of varying composition, and unless obtained from authentic sources is not reliable.

Chymases or ENZyMes which effect the clotting of milk. The coagulating action of the fig (Ficus Carica) was known to the ancients. This action has been shown by Chodat and Rouge to be due to a vegetable chymase and called by them " sykochymase." A large number of plants possess the property of rendering milk ropy. Of these the following may be mentioned: Ranunculus bulbosus, Capsella Bursa-pastoris, Plantago lanceolata, Medicago lupulina, Pinguicula vulgaris, Artichokes, etc. An enzyme of this character has also been found in germinating seeds of Ricinus communis, Pisum, Datura, etc., and some of the fungi.

ZyMASE, an enzyme causing the decomposition of glucose with the formation of alcohol and carbon dioxide. This decomposition, known as alcoholic fermentation, is considerably less simple than was formerly supposed, a number of enzymes and subsidiary sub- 
stances taking part in the reaction. Zymases are widely distributed throughout the entire plant kingdom, and occur in greatest amounts in yeasts and other organisms which induce alcoholic fermentation. The enzyme, which causes the transformation of glucose into lactic acid and is secreted by lactic acid bacteria, has been given the name of "lactic acid bacteria-zymase."

Oxydases is the name applied to those enzymes in which the decomposition or reaction involves an oxidation. Several kinds of oxydases are recognized, depending upon the nature of the original substance that is broken down. (I) Alcoholase, the enzyme of acetic bacteria which oxidize ethyl alcohol to acetic acid. (2) Phenolases include the laccases, the oxidizing enzymes found in the lac-tree (Rhus succedanea), and in some other plants. The black lacquer covering the beautiful Japanese vases and boxes, and which is the most indestructible varnish known to man, is formed by an oxidizing enzyme acting on the phenolic resins of the lac-tree.

Catalases in their chemical action resemble some of the colloidal metals, in that they are able to decompose hydrogen peroxide with the liberation of oxygen. Enzymes of this character have been found in virtually all plant juices. Catalases are of two kinds, one soluble in water, occurring in the seeds of apple and peach, and an insoluble form found in the leaves of clover, rose, and spruce. Highly active catalases are also obtained from fungi, yeasts, and bacteria.

While some of the vegetable ferments have been isolated and are prepared on a commercial scale, as diastase and the peptic enzyme papain found in the latex of Carica Papaya, in other cases the ferment-producing organisms themselves are used in a number of industries involving fermentation processes, as the yeast-plants and certain of the molds and bacteria.

The microchemical study of the ferments is attended with certain difficulty on account of the lack of specific reagents for their detection. The most that can be done is to study the products formed by their action upon certain other constituents of the cell. (Consult "General Chemistry of the Enzymes," by Hans Euler, translation by Thomas H. Pope.) 
EXAMINATION OF CELL-CONTENTS

\begin{tabular}{|c|c|c|c|}
\hline \multirow{2}{*}{ PROTOPLASMIC } & \multicolumn{3}{|c|}{ NON-PROTOPLASMIC } \\
\hline & Crystaliine & Crystalloidal & Amorphous \\
\hline $\begin{array}{l}\text { 1. Cytoplasm } \\
\text { 2. Nucleus } \\
\text { 3. Plastids }\end{array}$ & $\begin{array}{l}\text { 4. Calcium oxalate } \\
\text { 5. Sugars } \\
\text { 6. Alkaloids } \\
\text { 7. Glucosides } \\
\text { 8. Phyto-globulins }\end{array}$ & $\begin{array}{l}\text { 9. Starch } \\
\text { I0. Inulin }\end{array}$ & $\begin{array}{l}\text { I1. Mucilage } \\
\text { I2. Tannin } \\
\text { I3. Resin } \\
\text { 14. Oil } \\
\text { 15. Latex } \\
\text { 16. Calcium carbonate }\end{array}$ \\
\hline
\end{tabular}

I, 2, and 3 have characteristic appearance (see Frontispiece). 4. Crystals of characteristic forms, soluble in hydrochloric acid and insoluble in acetic acid. 5. Crystalline in fresh material treated with alcohol. The glucoses give a reddish precipitate with Fehling's solution. 6. Piperine separates in definite crystals in the plant cell; the alkaloids of hydrastis form crystallizable salts with sulphuric or nitric acids; the alkaloids in hydrastis, ipecac, coffee, tea, and guarana yield crystalline sublimates. 7. Concentrated sulphuric acid gives with strophanthin a bright green color. 8. Phyto-globulins form definite crystals (see paragraph on aleurone grains). 9. Blue with dilute iodine solution, except the amylo-dextrin starches, as mace, which are colored red. Io. Sphero-crystals in fresh material treated with alcohol. I I. Colored blue with alcoholic solutions of methylene blue. I2. Reddishbrown with copper acetate solutions. I3. Terpene resins are colored green with copper acetate solutions. 14. Separation in the form of large globules on the application of sulphuric acid or solution of hydrated chloral. The volatile oils are more soluble in alcohol than fixed oils, the latter being completely removed from the cells by the use of ether or other similar solvent. I5. Latex occurs as an emulsion consisting of numerous globules. I6. Calcium carbonate dissolves with an effervescence on the addition of hydrochloric acid or acetic acid.

Factors Influencing Growth.-Plants have certain inherent or inherited tendencies or characters which make up the inner constitution, and this cannot be modified by external agencies except within more or less narrow limits. Depending upon this character we find plants as different in kind as the apple tree and pine growing under precisely the same conditions. In other 
words, the character of the structure is determined in the main by the nature of the organism. It is true that an apple tree may grow better in one locality than another, but it is still an apple tree whether it be dwarfed or attain to the full measure of its growth. These slight changes in the character are known as accidental variations. Frequently they are the result of temporary conditions and are not repeated in the succeeding generation. On the other hand, if the special conditions remain these individual variations may be repeated in generation after generation and finally become permanent characters.

The gradual change in the structure and nature of organisms which takes place through long periods of time is spoken of as EVOLUTION. In some cases specific changes in the characters of plants arise rather suddenly without any known cause, and such changes are spoken of as saltations or MUTATIONS.

The factors essential for growth in all cases are food, water, and a certain temperature. Among the food elements we may mention as of chief importance, carbon, hydrogen, oxygen, and nitrogen. Some of the other elements are also essential to most plants, although they occur in relatively small proportion in the plant, as potassium, magnesium, phosphorus, sulphur, iron, and calcium. The latter element does not seem to be necessary to the normal development of some of the Fungi and certain Algæ.

Water permeates all parts of the plant, and when the cells are in the normal turgescent state it contains more than half its weight of water. When the supply of water falls below the normal the plants begin to droop and finally die. The need of plants varies greatly in this particular; some are aquatic in their habits and live wholly in the water; others can live only on the land; and still others are adapted to desert regions.

The degree of temperature necessary for growth varies within certain limits for each kind of plant, but, as is stated by Pfeffer, the greatest extremes are shown by Fungi, Bacteria, and the lower Algæ. Generally speaking, the most favorable temperature for growth is between $24^{\circ}$ and $34^{\circ} \mathrm{C}$.

Besides the factors enumerated there are other factors which influence growth. They include light, gravity, mechanical agencies, etc., and are sometimes spoken of as external stimuli. 
It is difficult to separate those factors which act solely as external stimuli from those which are essential to the normal growth of the plant and which may be considered as physiological factors. For example, light under certain conditions may be regarded as in the nature of an external stimulus and not essential to the growth of the plant, while in other cases it has a direct influence on normal growth and is essential to the life of the plant, as in all plants or parts of plants where photosynthesis takes place.

In addition to the essential food elements, there are many substances which affect the growth of plants which may be grouped as chemical stimuli, such as $(a)$ the substances secreted by gall-forming insects, $(b)$ in a certain measure some of the substances produced by Fungi, $(c)$ and numerous substances not found as normal constituents of the plant. Depending upon the amount of the substance present and the conditions under which it is supplied, the substance may act as a poison and injure the plant, or it may accelerate growth, or cause abnormal development.

This subject has an important bearing on the physiological testing of drugs. Kobert states that in determining the qualities of a new chemical, preliminary experiments should be conducted on lower plants and animals before trying it on man. Of the plants which have been used in the testing of poisons the following may be mentioned: Oscillaria, Spirulina, Nostoc, Zygnema, Spirogyra, Saccharomyces, Mucor, Elodea, Lemna, Pistia, Potamogeton, Myriophyllum, Ceratophyllum, Tradescantia, seedlings of grasses, lupine, bean, pea, corn, etc. Kraemer has employed seedlings of Lupinus albus and Pisum sativum in testing solutions containing ethyl alcohol, strychnine nitrate, brucine sulphate, and tincture of nux vomica (Amer. Jour. Pharm., I900, p. 472).

Food of Plants.-It has already been pointed out that certain of the chemical elements are necessary for the growth of plants, and that these are derived partly from the surrounding atmosphere and partly from the soil. Those elements derived from the air are either themselves gases or exist in combination in the form of gas, and include oxygen, nitrogen in exceptional cases, 
and carbon dioxide, the source of the carbon entering into the carbon compounds formed by plants.

The elements obtained by plants from the soil exist in combination with other elements and must be in the form of solution to be absorbed. The soil consists largely of mineral substances, together with certain organic products (humus). The water held in the soil not only acts as a medium for carrying the soluble constituents in the soil to the plant, but is itself an important food product, being the source of the hydrogen used by plants, as also of assimilable oxygen. Among the mineral constituents of the soil that are useful to plants are ammonium salts and nitrates, sulphates, phosphates, chlorides, silicates, and carbonates. When plants are collected and subjected to a temperature of about $110^{\circ}$ C. the water is driven off, and then if heat sufficient to incinerate the material is applied the organic matter is driven off in the form of gases, leaving the mineral constituents in the form of ash, as calcium, magnesium, iron, potassium, sodium, and a few other elements.

Formation of Leafmold.-When the leaves of a tree fall to the ground they begin to decay and ultimately they are disintegrated, and their substances become incorporated with the other elements of the soil. The same thing happens with the leaves, stems, and roots of herbaceous plants. Such organic matter is one of the chief sources of food for plants, and its presence in the soil is therefore of fundamental importance in the maintenance of the vegetable mantle of the earth. Coville (Jour. Wash. Acad. Sci., I9I3, p. 79) determined the rate in decomposition of leaves and used silver maple, sugar maple, red oak, and Virginia pine. These were exposed to the weather in barrels and in concrete pits. In one experiment a mass of trodden silver maple leaves two feet in depth, with an initial acidity of 0.92 normal, was reduced in a single year to a three-inch layer of black mold containing only a few fragments of leaf skeletons and giving an alkaline reaction. Sugar maple leaves have shown a slower rate of decomposition than those of silver maple, while red oak leaves still showed an acidity of o.oro normal after three years' exposure, and leaves of Virginia pine an acidity of 0.055 normal under the same conditions. During the decomposition of 
leaves the acid substances are decomposed and to some extent dissipated in the form of gases.

The chief agents in the decay of leaves are fungi and bacteria. A number of forms of animal life also contribute greatly to the decay also, as earthworms, larvæ, flies and beetles and myriapods or thousand-legged worms. Coville distinguishes two kinds of leafmold: (a) In which the leaves show a condition of imperfect decomposition, due to the development and maintenance of an acid condition, which is inimical to the growth of microörganisms of decay. Because of the resemblance of this mat or turf to bog peat in appearance, structure, and chemical composition, and because it supports a type of vegetation similar to that of bog peat, it has been named UPLAND PEAT. This is characteristic of the sandy pine and oak woods, where grow huckleberries, laurel, princess bine, pink lady's slipper, trailing arbutus, etc. (b) The other is characteristic of the black mellow mold made up of completely rotted leaves, the acidity being neutralized in part by the calcium present in the leaves and partly by the underlying soil, which is usually of a calcareous nature. This is characteristic of forests of tulip poplar, ash, and oaks, in which grow sanguinaria, caulophyllum, hydrastis, trillium, etc.

Organic Constituents in Soll.-During the past few years Schreiner and his associates in the Bureau of Soils, U. S. Department of Agriculture, have isolated and identified a number of soil constituents. They have found that certain of these constituents, as dihydroxystearic acid, are rather characteristic of poor soils, and that the effect of fertilizers on such soils was to increase their fertility by neutralizing their toxic constituents rather than by the addition of any food constituents to the soil. The compounds isolated by them have varied considerably, and may be grouped into the following classes: I, Paraffin hydrocarbons, represented by hentriacontane; 2 , hydroxy-fatty acids, represented by $a$-monohydroxystearic acid and dihydroxystearic acid; 3, organic acids of unknown constitution, represented by agroceric acid, paraffinic acid, lignoceric acid, and a number of resin acids ; 4, esters and alcohols, represented by agrosterol, phytosterol, glycerides of fatty acids, and resin esters; 5 , carbohydrates, represented by pentosans and pentose sugars; 6 , hexone 
bases, represented by histidine and arginine; 7 , pyrimidine derivatives, represented by cytosine; 8 , purine bases, represented by xanthine and hypoxanthine; 9, pyridine derivatives, represented by picoline carboxylic acid.

Root Absorption.--Notwithstanding the various agents which are at work tending to break down and dissolve the substances contained in the soil, as soil bacteria, the liquids given to the soil by the roots of the plants themselves, the presence of the so-called humic acids, and the action of water and air, it has been shown that the soil water is an exceedingly weak solution. This is largely due to the peculiar absorptive and fixing power of the soil itself.

The dilution of the aqueous solution of the soil constituents is a matter of very great significance, for upon this depends its absorption by the root hairs. While other parts of roots have certain absorptive powers, the root hairs have been defined as the organs of absorption of the plant. They are very delicate in structure and contain protoplasm. Their absorbent function depends upon the principle that when a membrane (animal or vegetable) is interposed between two liquids of unequal density, the less dense liquid will pass through the membrane and mix with the denser liquid. This process is known as osmosis, and when a liquid passes outward through a membrane or cell-wall it is called exosmosis, and when inward it is called endosmosis. The soil is made up of minute earth particles, each of which is surrounded by a thin film or envelope of water, and it is this portion of the soil liquid that is absorbed by the root hairs. The root hairs come into close contact with these soil particles; in fact, appear to grow fast to them, and the cell-liquid in the root hairs being denser than that surrounding the soil particles, the latter passes through the wall into the root hairs.

If, on the other hand, the water supplied to the roots of plants should contain an excess of soluble material, the plant will be injured. In this case exosmosis ensues and the plant loses some of its own liquids or cell-sap and will show signs of wilting. It is well known that if cultivated plants are supplied with strong solutions of fertilizer the plants will be injured rather than benefited. 
Root Pressure.-The distribution of the water absorbed by the roots to other parts of the plant is influenced by a number of factors, which are commonly spoken of together as root pressure. Among these are osmosis within the plant, due to unequal density of the liquids in different cells; the changes in the equilibrium of the cell-liquids, due to chemical changes; and the transpiration of water from the leaves, thus establishing a flow of liquids from the roots upward, which is usually spoken of as the ASCENT of SAP. The cell-sap passes upward through the xylem for the most part, carrying constituents obtained from the soil to the growing parts, where they are combined with the products of photosynthesis, and through a series of reactions protoplasm is finally built up.

OxidATION.-The free oxygen taken in by plants through the stomata and lenticels serves the same purpose in plants as that inhaled by animals, namely, the oxidation of certain compounds, whereby part of the energy necessary for vital activity is liberated. Oxygen is required by all parts of the plant. When the roots of plants, such as those of Zea Mays, are surrounded by water so as to exclude the air the plants will become yellow. Germinating seeds consume a large amount of oxygen, but not all the energy formed is used by the plantlet, much of it escaping as heat, as in the germination of barley in the preparation of malt. Those plants dependent upon the presence of free atmospheric oxygen are called AËroBEs, while those which are not thus deoendent, as certain fungi and bacteria, are called ANAËROBES.

Mетавоlism.-Processes of construction and destruction are going on simultaneously in the plant, and these are all grouped under the general name of metabolism. The processes whereby complex substances are built up from simpler ones, as in photosynthesis, are together spoken of as CONSTRUCTIVE METABOLISM (anabolism), while those which involve the breaking down of complex compounds into simpler ones, either through oxidation or other chemical action, as when sugar is changed into carbon dioxide and water, are grouped under the head of DESTRUCTIVE METABOLISM (catabolism).

Inasmuch as the carbon dioxide of the atmosphere and the water taken up by the roots together with the mineral salts which 
it holds in solution are the only sources of the food supply of green plants, it follows that the highly complex proteins trace their origin to these comparatively simple substances. By some it is supposed that the final stages in the building up or synthesis of the proteins take place in the leaves, but it is probable that they take place in all the growing parts of the plant. It has already been stated in the paragraph on proteins that seeds contain reserve materials which are broken up into simpler compounds through the action of certain enzymes, and thus made available for the seedling. It is claimed that these compounds are principally amino acids, and that of these aspartic and glutaminic acids occur in largest amount and that these two acids are found in different relative amounts in different plants. It is furthermore claimed by some authors that by certain syntheses these compounds are respectively converted into asparagin and glutamin, both of which occur as reserve materials in seeds and in other parts of plants as well. Yet other syntheses take place whereby asparagin and similar bodies are converted into albumin and other proteins. In the Coniferæ the part played by asparagin and glutamin in protein syntheses is taken by arginin, which substance is found in considerable amount in the seeds of the plants of this group.

Growing Points and Meristems.-Plants are distinguished, for the most part, by having distinct growing points, known as vegetative points. These occur at the apex of shoots and roots and at definite lateral points, being in the stem near the surface and in roots beneath the endodermis. The walls of the cells in these regions are very thin and consist almost entirely of cellulose. The cells are compactly arranged and are more or less polygonal or somewhat elongated. They are rich in protoplasm, capable of rapid division, and constitute the tissue known as PRIMARY MERISTEM. In the root three kinds of primary meristem (Fig. I32) are distinguished: ( $\mathrm{I}$ ) The Plerome ( $\mathrm{m}, \mathrm{f}, \mathrm{g}$ ), an axial meristem, which gives rise to the central cylinder or stele; (2) the PERIBLEM $(x, r)$, or meristematic tissue, which gives rise to the primary cortex; and (3) the DERMATOGEN (e), from which the epidermis is developed. In addition to these three meristematic zones there is at the apex, lying next to the dermatogen, a meri- 
stematic group of cells which give rise to the root-cap, known as the CALYTROGEN (s).

At the growing point of the stem three meristematic zones are also distinguished, namely, plerome, periblem, and dermatogen. They are not, however, so well marked as in the case of roots.

The tissues which are developed from the primary meristems constitute the PRIMARY STRUCTURE. With the growth in thickness of the stems and roots of Dicotyledons other meristematic cells, known as SECONDARY MERISTEMS, arise. These are of two kinds: (I) One which gives rise to the xylem and phloem, known as the CAMBIUM, and (2) another which gives rise to the cork, known as PHELLOGEN. The tissues formed from the secondary meristems constitute the SECONDARY STRUCTURE of older dicotyledonous stems and roots.

While the point of vegetation in the higher plants (spermophytes) embraces a number of cells, in the lower plants the tissues can be traced back to a single APICAL CELL.

Cell-Wall.-Origin and Composition.-It is formed by the protoplasm, and varies in composition at different stages of the growth of the cell, and according to the various functions it has to perform.

In order to thoroughly understand the nature and composition of the cell-wall, it is necessary to study the origin and formation of new cells. Growth of the plant is attended not only by an increase in the size of the cells, but by their division (Fig. 85) new cells are also formed. Cells that have the property to divide and form new cells are known as meristematic cells and constitute the MERISTEM. The new and dividing walls resulting from the division of the cells consist of a number of substances. When a cell divides, the two daughter protoplasts which result from the division of the nucleus and cytoplasm are separated by the formation of a new wall between them (Fig. 85). The first layer formed is apparently different from the subsequent layers and is known as the middle plate or MIDDLE LAMELLA. This layer is soluble in, or readily attacked by, solutions of the alkalies or solutions containing free chlorine. It is insoluble in sulphuric acid, and readily stained by the aniline dyes. . While usually more or less permanent, this middle plate may be finally absorbed, as in 
the glandular hairs of kamala, or it may be changed into mucilage, as in chondrus, or transformed into pectin compounds, as in fleshy roots and fruits.

To this middle plate is added on either side by the newly formed protoplasts a layer of substance closely resembling cellulose, this constituting the PRIMARY MEMBRANE or primary lamella.

As the cells become older the wall increases in thickness through the addition of other layers, much in the same manner as the starch grain increases in size. These subsequent layers are known as SECONDARY LAMELL.E. In a few cells the secondary lamellæ may consist of pure cellulose. As a rule, however, the wall is rather complex and consists of alternate layers of cellulose with other substances. Some of these, as mucilage, may be a simple modification of cellulose, others may consist of cellulose in combination with other substances, as in the ligno-cellulose walls of stone cells, or the walls may consist of cellulose and suberin as in cork cells, or of cutin-cellulose as in epidermal cells. Again, there may be, through the action of special enzymes, a decomposition of the cellulose, resulting in the formation of oils, resin, and wax. Furthermore, it would not seem improbable that some of the secondary substances in the wall are direct products of the protoplasm and secreted in the cell-wall, as silica and calcium oxalate in epidermal cells. The substance called pectin originates as a modification of the intercellular substance, and is peculiar to some fruits.

As showing, to some extent, the complexity of the lamellæ in the cell-wall, the following modifications of the wall in secretion cells may be given: I. The entire outer cell-wall may consist of a thin layer of suberized lamellæ, beneath which is a secondary mucilaginous layer that develps the secretion, e.g., Hedychium Gardnerianum. 2. The outer lamellæ of the cell-wall may consist of suberin; beneath this is a cellulose lamellæ, which only after treatment with a solution of potassium hydroxide is colored blue with chlor-zinc iodide; this is followed by a mucilaginous layer, e.g., Laurus nobilis, Curcuma Zedoaria, Cinnamomum Cassia, Zingiber officinale, Acorus Calamus. 3. The outer layer may consist of cork, beneath which is a cellulose layer that is colored blue upon treatment with chlor-zinc iodide without the previous 
use of potassium hydroxide; to this is then added a mucilaginous layer, as in the secretion cells of Valeriana officinalis and Magnolia grandiflora. 4. The outer layer may be suberized, but the cellulose layer beneath this is not colored blue until the walls have been first treated with Schultze's solution; this then is followed by a mucilaginous layer, e.g., Piper nigrum, Piper Cubeba, and Sassafras officinale. 5. The outer and inner layers may be suberized, and between these are fine lamellæ of cellulose, e.g., Croton Eluteria. 6. The outer layer may be suberized, beneath which is a layer of lignocellulose, followed by a mucilaginous layer, e.g., Calycanthus floridus. 7. The outer layer may be colored yellow with chlor-zinc iodide and dissolves in sulphuric acid, while the inner layer is suberized, e.g., fruit of Conium maculatum.

Cellulose in its various modifications constitutes the greater proportion of the cell-wall. The cellulose making up the cotton fiber may be said to be the typical cellulose, and is known as " cotton cellulose." It is soluble in copper ammonium sulphate solution; is colored blue with chlor-zinc-iodide solution or iodine and sulphuric acid, and is stained by acid phenolic dyes, as alizarin, if previously treated with basic mordants, as basic salts of aluminum, etc.

The following solutions are used in the testing of mixed fabrics containing cotton: I. A solution of I part of zinc chloride in 2 parts of hydrochloric acid will dissolve cellulose in about one-half minute. 2. Upon heating a piece of fabric in a saturated solution of aluminum chloride, the cotton becomes friable, the wool remaining unaffected.

According to their origin in the plant, or their behavior toward reagents, the cellulose walls may be divided into the following groups: (I) Lignocellulose walls; (2) protective cellulose walls; (3) reserve cellulose walls; (4) mucilage cellulose walls, and (5) mineral cellulose walls.

Lignocellulose walls are composed of true cellulose and a non-cellulose (the so-called lignin or lignone), these constituting the woody (so-called lignified) portion of plants and, in some instances, also the bast portion of the bark. The lignocelluloses are colored yellow with chlor-zinc iodide, or iodine and sulphuric acid. On account of their containing in some instances furfurol, 
coniferin, vanillin, cinnamic aldehyde, benzaldehyde or other aldehydic substances, they give definite color-reactions with certain reagents. They are also stained by the aniline dyes, as fuchsin, safranin, gentian violet, aniline blue, methylene blue, etc.

Aniline hydrochloride with hydrochloric acid and aniline sulphate with sulphuric acid produce a golden-yellow color in cellwalls containing lignocelluloses.

A 2 per cent. phloroglucin solution, used in conjunction with hydrochloric acid, gives a reddish-violet color with the lignocelluloses, although there are some celluloses of this class which do not respond to this test, as flax (the bast fibers of Linum). In other plants phloroglucin may occur as a constituent of the cells.

Hartwich and Winckel (Arch. d. Pharm., I904, p. 462) have shown that the red coloration formed upon the addition of vanillin and hydrochloric acid to phloroglucin is also produced by a number of other substances, viz., thymol, guaiacol, resorcin, cresorcin, orcin, pyrogallol, pyrogallol dimethyl-ether, phloroglucin, oxyhydroquinone, eugenol, and safrol, but not with phenol, pyrocatechin, hydroquinone, or pyrogallol trimethyl-ether. The reaction cannot, therefore, be longer designated as a phloroglucin reaction, but, in a limited sense, as a phenol reaction. The same color reaction is produced by a number of other substances which contain a phloroglucin molecule, e.g., phloridzin, maclurin, luteolin, morin, catechin, filizin, gentisin, and all the phloroglycotannoides, as in oak bark and cinchona bark.

Protective cellulose walls are composed of mixtures of lignocellulose and oils and waxes, and frequently contain in addition tannin, vanillin, and other compounds. In the cuticle or epidermis of leaves and green stems the cellulose is associated with a fatty compound known as cutin (or cutose), while in the cork of stems and roots it is combined with suberin (or suberose). This class of celluloses is distinguished from cotton cellulose and lignocellulose by being insoluble in sulphuric acid.

Reserve cellulose walls are those found in various seeds, as in coffee, date, nux vomica, etc. They behave toward reagents much like the true celluloses (Fig. I35).

Mucilage cellulose walls consist of cellulose and mucilage, and are found in all parts of the plant, and in the case of seeds 
are associated with the protective celluloses. They dissolve or swell in water, are colored blue (as in flaxseed) or yellowish with iodine, and are stained with alcoholic or glycerin solutions of methylene blue.

Mineral cellulose walls are composed of cellulose and various inorganic substances, as silica, calcium oxalate, or calcium carbonate. These are more commonly found in the cell-wall of the lower plants, as Algæ, Fungi, and Equisetaceæ. Calcium carbonate and silica also occur in the cystoliths of the various genera of the Moraceæ and Acanthaceæ (Fig. II3).

From what has just been said of the chemical composition and structure of the cell-wall, it is seen that it consists of lamellæ or
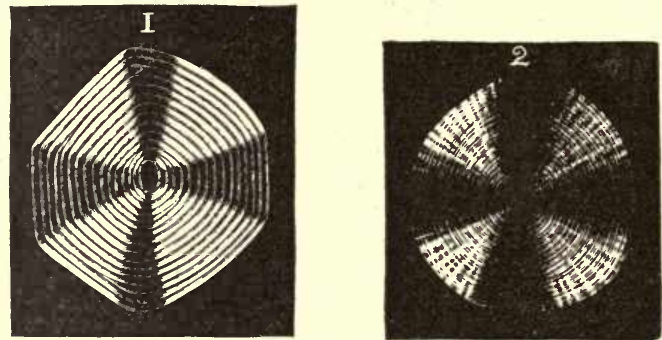

FIG. I29. I, cross-section of a bast fiber of Begonia as seen by means of the micropolariscope, and showing stratification of the wall. 2, polariscopic view of a sphero-crystal of inulin in Helianthus tuberosus.-After Dippel.

layers of different substances, and in no case does it consist of but a single substance; but for convenience we speak of a wall as consisting of cellulose, lignin, or suberin, meaning thereby that the wall gives characteristic reactions for these substances.

Phytomelane, an intercellular, carbon-like substance. It is a black, structureless substance, found only in the Compositæ, being distributed around the sclerenchymatous fibers and stone cells in a number of fruits. It has also been found in the lignified cells of roots and stems (Fig. I3I), and occasionally is found in the parenchyma cells of Inula. In the latter it occurs more or less crystalline, sometimes in the form of short needles or rods (Fig. I32). According to Hanausek ("Untersuchungen über die Kohleähnliche Masse der Kompositen”), phytomelane occurs in a large number of genera in the Compositæ. It arises in the middle lamellæ and has a high content in carbon, ranging from 69.76 per 
cent. in Helianthus anmuus to 76.47 per cent. in Dahlia variabilis. It is unaffected by most reagents except hydriodic acid. It may readily be separated in unaltered masses upon treatment of the tissues with Wiesner's chromic acid mixture or with Schultze's macerating solution. Hanausek considers the phytomelane layer to be in the nature of a mechanical protection to those fruits and seeds in which the epidermal and hypodermal layers scale off with the ripening of the fruit. (Consult Kraemer and Sollenberger, Amer.

I

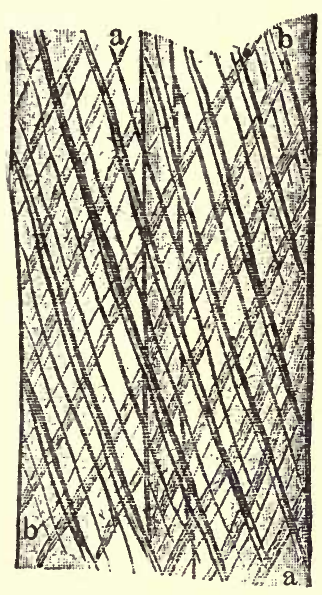

II

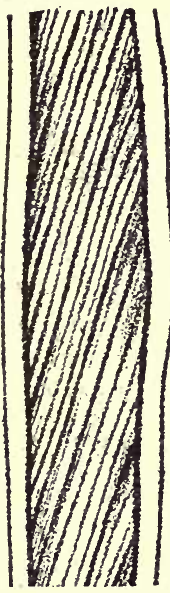

III

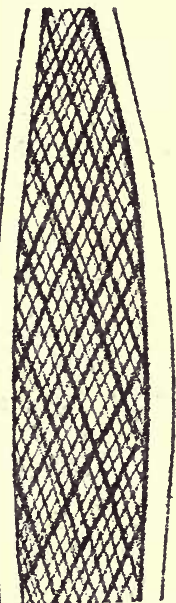

IV

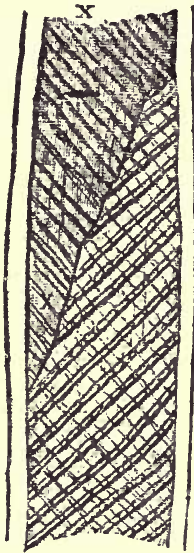

FIG. I30. Striation in cell-wall: I, a portion of bast fiber in Oleander, showing left spiral bands as seen from the outer surface (a) and the same as seen from the inner surface (b); II, portion of the bast cell of Asclepias syriaca as seen on the under surface; III, a view of the bast fiber of Asclepias syriaca as seen when looking through the middle of the cell; IV, portion of tracheid of Pinus sylvestris, showing two views of the striations of the wall.-After Dippel in "Das Mikroskop."

Jour. Pharm., I9II, p. 3I5; Senft, Pharm. Post, I9I4, No. 30; Hanausek, Ber.d.d. bot. Ges., I9I I, p. 558.)

LAMELLÆ.-In some cells, as in lignified cells, the lamellæ are quite apparent. In other cases the use of reagents, as chromic acid or chlor-zinc iodide, is necessary to bring out this structure. The layering which is observed in transverse sections of the cellwall is spoken of as stratification of the wall (Fig. I29), whereas the layering observed in longitudinal or tangential sections is referred to as striation of the wall (Fig. I3O). 
Thickening or Marking of Walls.-In the formation of the wall each cell appears to work in unison with its neighbors for the building up of the plant. The thickening of the walls of the cell is primarily for the purpose of strengthening the walls, but if the walls were uniformly thickened, osmosis, or the transferral of cell-sap from one cell to another, would be hindered.

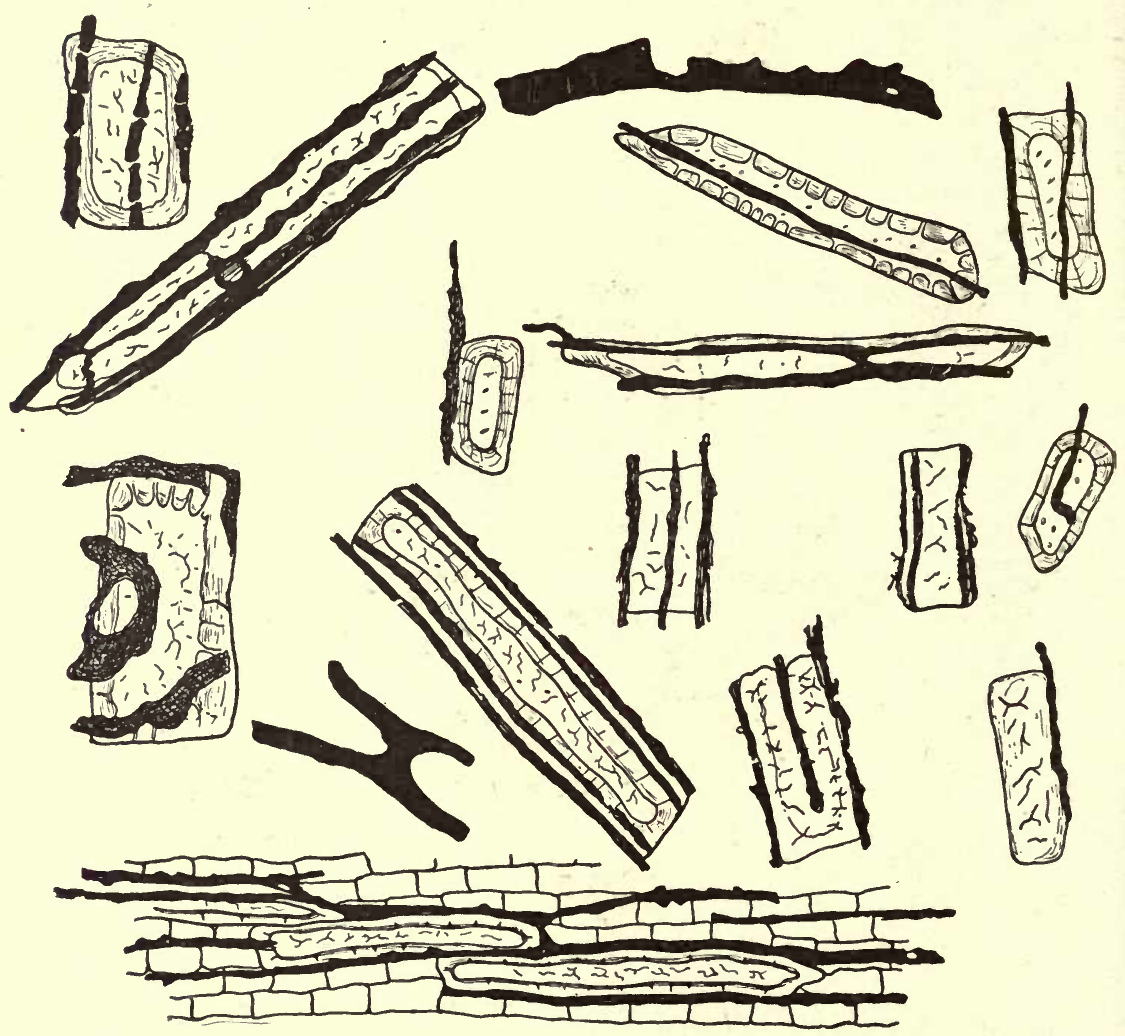

FIG. I3I . Phytomelane, an intercellular carbon-like substance occurring on the outer layers of the stone cells in Brauneria pallida (Echinacea angustifolia).

Thus we find that the contiguous walls of the cells are thickened at definite places opposite each other, leaving pores or canals which permit rapid osmosis. The pores thus formed are known as simple pores, and when seen in surface view are somewhat elliptical or circular in outline, and may be mistaken for some of 
the cell-contents. These thickenings assume a number of forms, which are quite characteristic for the plants in which they are found. They may have the form of transverse or oblique rings,
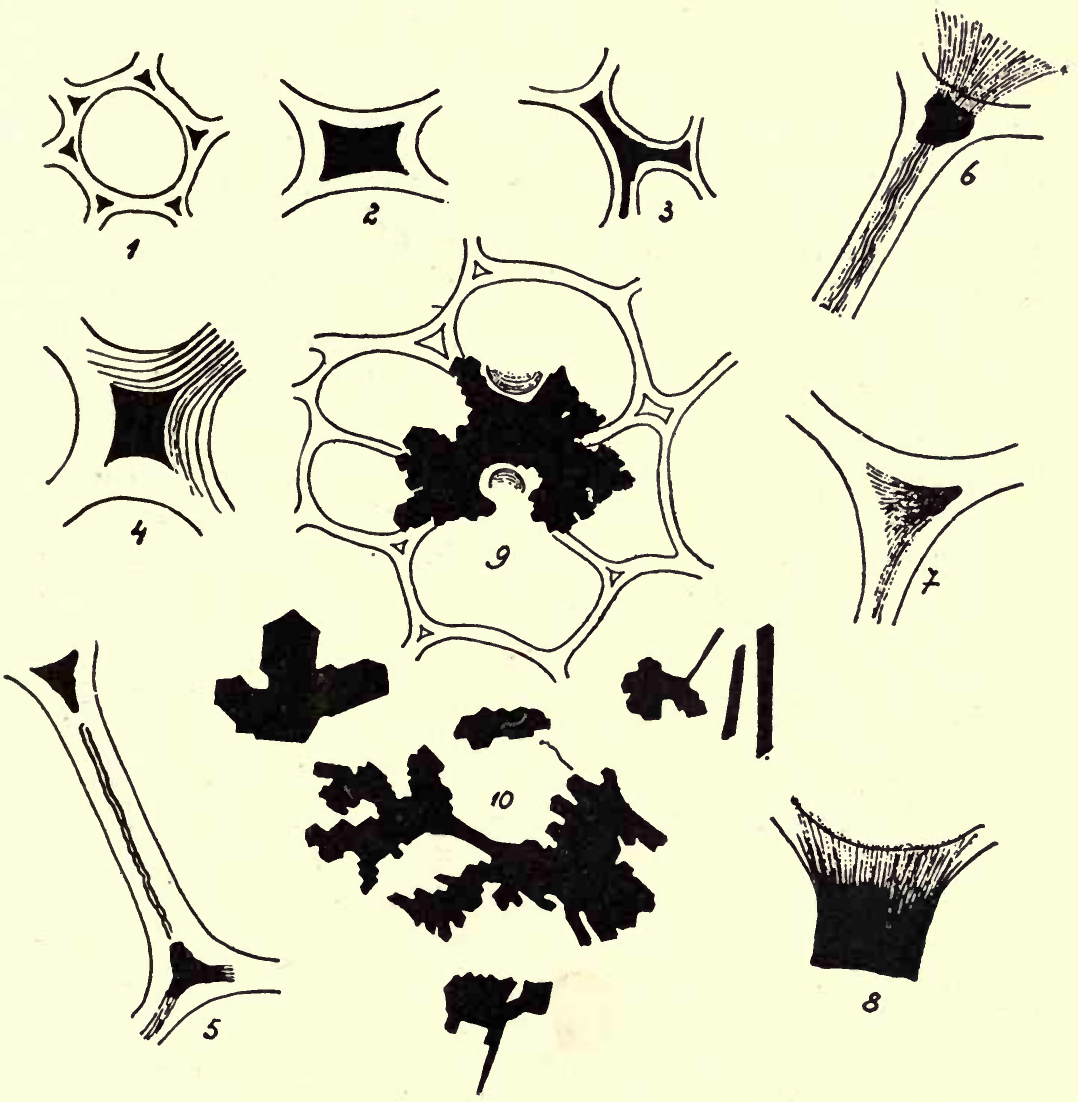

8

Fig. I32. Phytomelane in root of Inula Helenium. I-3 showing intercellular spaces with carbon-like substance; $4-8$, striated structure of intercellular phytomelane in sections which have been allowed to remain in solutions of hydrated chloral or potassium hydrate for some days; 9, a large crystal-like aggregate in a schizogenous-like reservoir formed in contiguous intercellular spaces of 5 parenchyma cells; Io, separated crystal-aggregates and rod-shaped masses of Phytomelane.-After Senft.

longitudinal spirals, or may be ladder-like or reticulate in appearance (Figs. I4I-I44). In other instances the thickening of the wall is quite complex, as in the wood of the pines and other Coniferæ (Fig. 68). The thickening, or sculpturing, as it is sometimes 
called, may not only occur on the inner surface of the wall, when it is spoken of as CENTRIPETAL, but may also take place on the outer surface, when it is known as CENTRIFUGAL, as in the spores of lycopodium and the pollen grains of the Compositæ.

\section{FORMS OF CELLS.}

Upon examining sections of various portions of the plant, it is observed that not only do the cell-contents and cell-wall vary in composition, but that the cells are of different forms, depending more or less upon their functions. Groups of cells which are similar in form and function constitute the various tissues of the plant; and include: (I) parenchyma cells, (2) mechanical cells, (3) conducting cells, and (4) protective cells.

Parenchyma.- Under the head of parenchyma are included those cells which are nearly isodiametric and thin-walled, the walls consisting of cellulose lamellæ (Fig. 134). They may contain both protoplasmic and non-protoplasmic cell-contents. According to the function and nature of contents, five kinds of parenchyma cells are recognized: (a) CHLOROPHYLL-PARENCHYMA or assimilation parenchyma contains numerous chloroplastids and occurs in leaves and all green parts of the plant. (b) RESERve PARENCHYMA occurs in seeds, roots, rhizomes, leaves, and contains starch, aleurone grains, fixed oils, and other reserve materials. In some instances the parenchyma, as in the endosperm of date, ivory nut, etc., may be very thick-walled (Fig. I35). The parenchyma in stems and leaves of various of the orchids, as well as that of plants of arid regions, which store water, may be included in this group. (c) Conducting PARENCHYMA is found either associated with the sieve or with the tracheæ, the cells of the phloem conveying the plastic substances, while those of the xylem convey water and salts. The cells of the pith and cortex are, as a rule, not utilized for the rapid translocation of food materials to far distant parts, although every living cell and every tissue has a certain power of translocation, and no doubt different parenchymatous tissues exhibit varying degrees of functional activity and differentiation. Thus large quantities of reserve materials are rapidly transferred to the developing embryo through the cells of the endosperm, and in young seedlings further trans- 
ference probably takes place mainly through the cortical and medullary parenchyma. (d) Spongy parenchyma, or loose, spongy tissue with large intercellular spaces. The cells of this

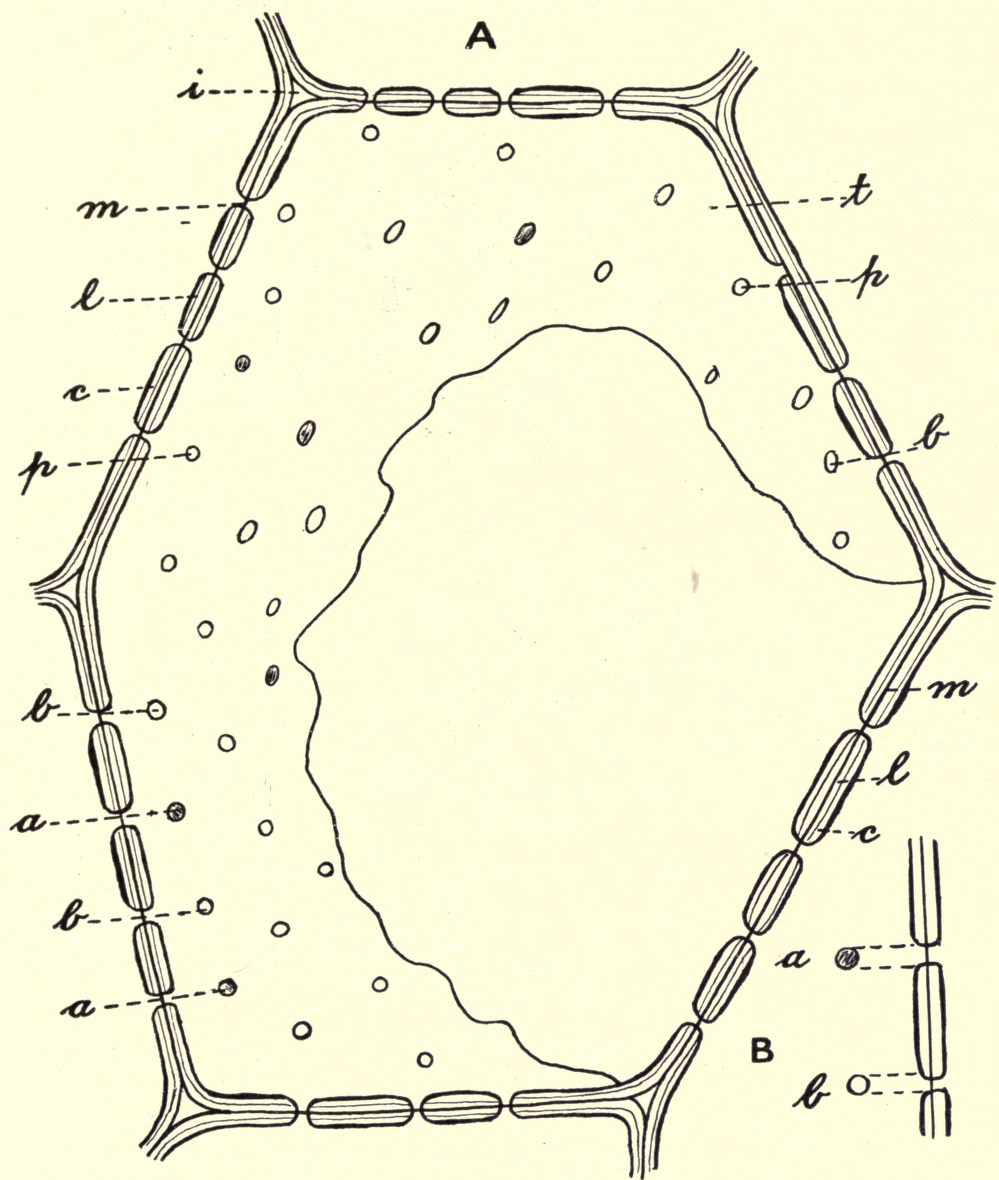

FIG. I33. A cell from sassafras pith showing intercellular space (i); middle lamella (m); layer of lignin (1); and layer of cellulose (c), which is subsequently modified to mucilage; simple pores (p) which are seen in the lower wall, the section being slightly oblique. $\mathrm{B}$, portion of wall showing the appearance of the pores when the view is transverse to the wall and the focus is at the upper part of the pore (a) or at the lower part (b).

type vary from slightly branched cells, as in the mesophyll of leaves, to those which are strongly branched and stellate, as in Juncus, Pondederia, and the stems of various marsh plants. In 
Calamus the cells are so arranged that very large intercellular spaces are formed (Fig. I34). (e) A number of modifications of typical parenchyma also occur, some of the cells being either quite thick-walled or considerably elongated. The walls of pith-
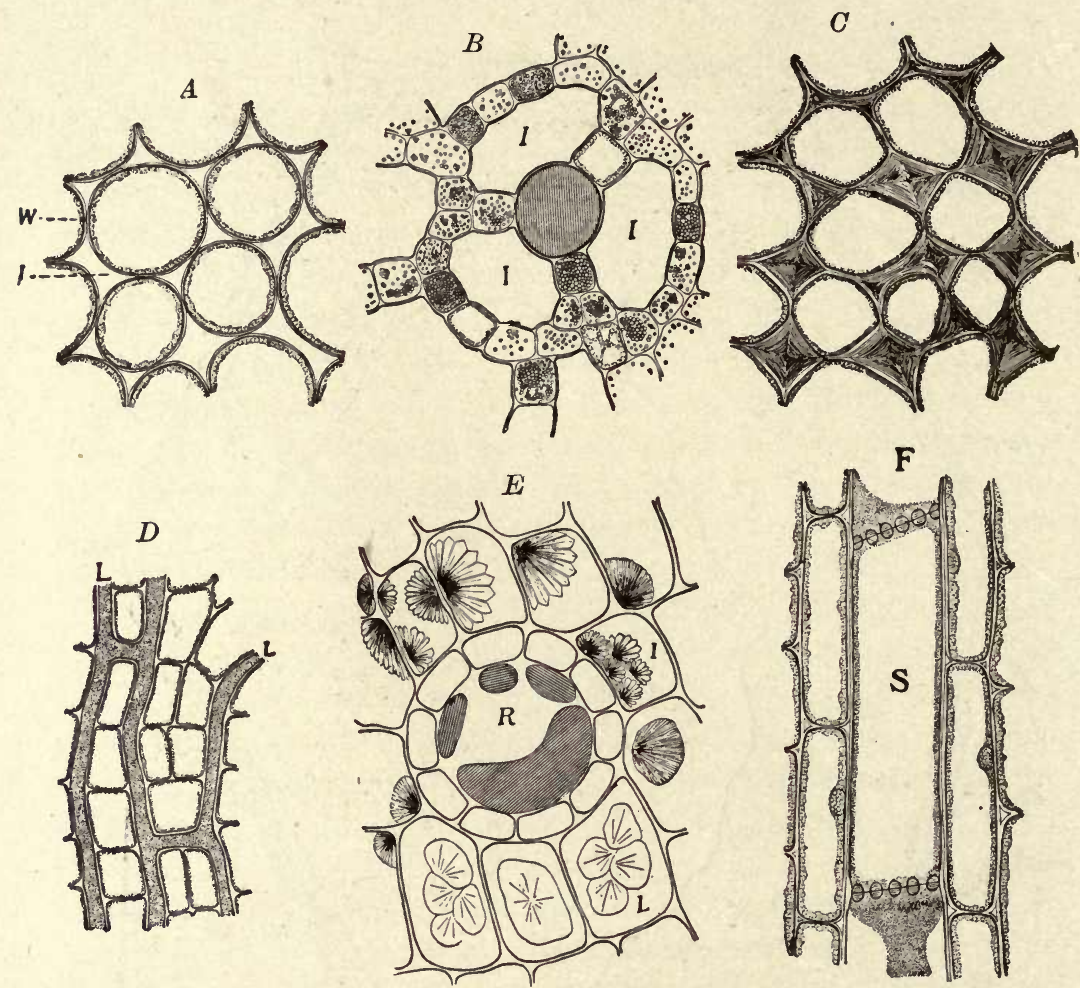

FIG. I34. Forms of cells. A.-Transverse section of the pith of Tradescantia virginica: I, intercellular space; W, cell wall. B.- Transverse section of calamus rhizome showing a large oil-secretion cell, smaller cells containing starch, and large intercellular spaces (I). C.- Transverse section of the stem of Phytolacca decandra showing collenchymatous cells beneath the epidermis. D.-Longitudinal section of taraxacum root showing branched laticiferous tissue (L). E.-Transverse section of pyrethrum root: $R$, oil-secretion reservoir with oil globules; I, cells with sphere-crystals of inulin, such as separate in alcoholic material; L, cells containing irregular masses of inulin, as found in dried material. F.-Longitudinal section of stem of Cucurbita Pepo: S, sieve-cell with protoplasm-like contents. and transverse walls (sieve plates) showing simple pores.

parenchyma may consist of lamellæ of lignocellulose and mucilage, as in Sassafras pith (Fig. I33).

Mechanical tissue includes all those cells which serve to keep the various parts of the plant in their proper positions, one 
with reference to the other, and which enable it to withstand undue strain and pressure. There are two principal forms, namely, $(a)$ collenchyma and $(b)$ sclerenchyma.

The collenchyma cell is elongated, prismatic, with soft
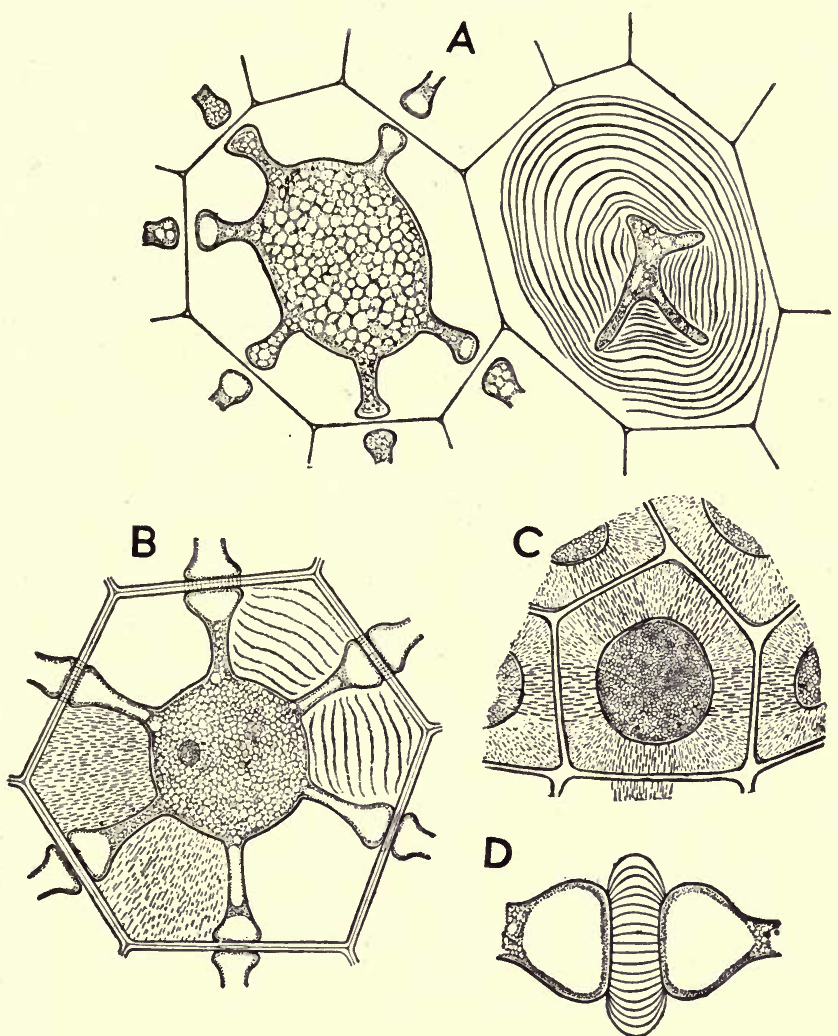

FIG. I35. A, cells of endosperm of the seed of the date palm (Phonix dactylifera), the one normal and the other showing the stratification of the wall after treatment with chlor-zinc-iodide.

$\mathrm{B}$, cell of endosperm of Phytelephas macrocarpa (vegetable ivory) showing lamellation and spherite structure in the wall after treatment with chlor-zinc-iodide, clove oil, chromic acid or certain other reagents.

C, cell of endosperm of Strychnos Nux-vomica after treatment with iodine and potassium iodide solution.

$\mathrm{D}$, opposite pores in the walls in contiguous cells of vegetable ivory showing striæ between them after treatment with iodinc solution.

walls consisting mainly of cellulose and never lignified ; the contents being rich in water. In transverse section it is readily distinguished by the local thickening of the walls, i.e., at the angles of 
the cells (Fig. I34, c). Pores are rare, but when present they are annular or slit-like. Collenchyma occurs near the surface of plant organs, as herbaceous stems. when they form ribs, as
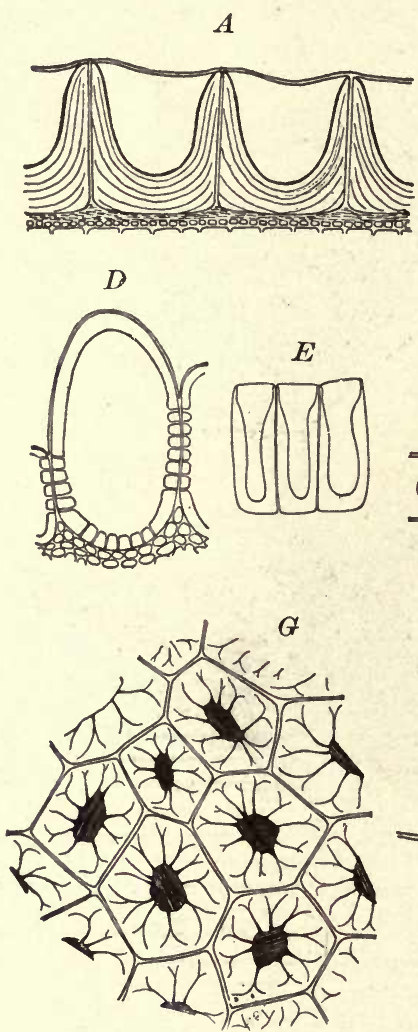
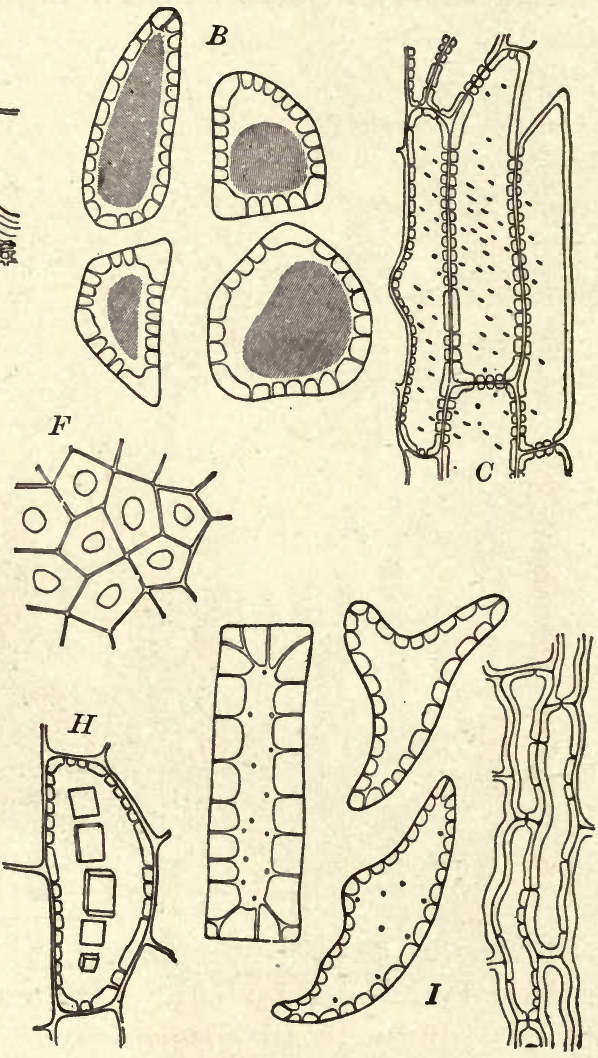

FIG. 136. Various forms of stone cells: A, epidermis of hyoscyamus seeds; B, pericarp of pimenta, containing brownish tannin masses; C, seed-coat of coffee; D, seed-coat of almond; E, transverse section of seed-coat of white mustard showing beaker cells; F, surface view of beaker cells of seed-coat of white mustard; G, transverse section through stone cells of endocarp of olive, the lumen containing air; $\mathrm{H}$, a stone cell from the periderm of calumba, containing numerous monoclinic prisms of calcium oxalate; I, various forms of stone cells isolated from pericarp of star anise.

in the Umbelliferæ. It is also found in leaves and in fruits, as in the Umbelliferæ.

Sclerenchyma cells include all of those cells which have more or less uniformly thickened walls composed of lignocellulose, 
permeated by simple or branching pores. They have a thin layer of protoplasm enclosing large vacuoles, and may contain tannin or tannin-like masses, and occasionally calcium oxalate crystals or starch, and in dead cells the lumen or cell cavity contains air. Two kinds of sclerenchyma are recognized: $\mathrm{I}$, in which the cells are more or less isodiametric (Figs. 136-138), known as stone cells (short sclerenchyma); and 2, in which the cells are elongated (Figs. I39-14I), being from 0.5 to $2 \mathrm{~mm}$. in length and known as sclerenchymatous fibers (or long sclerenchyma). Of these latter, two kinds are distinguished, chiefly according to their position in the plant, namely, bast fibers, or stereome, and wood fibers, or libriform. Seldom are the wood and
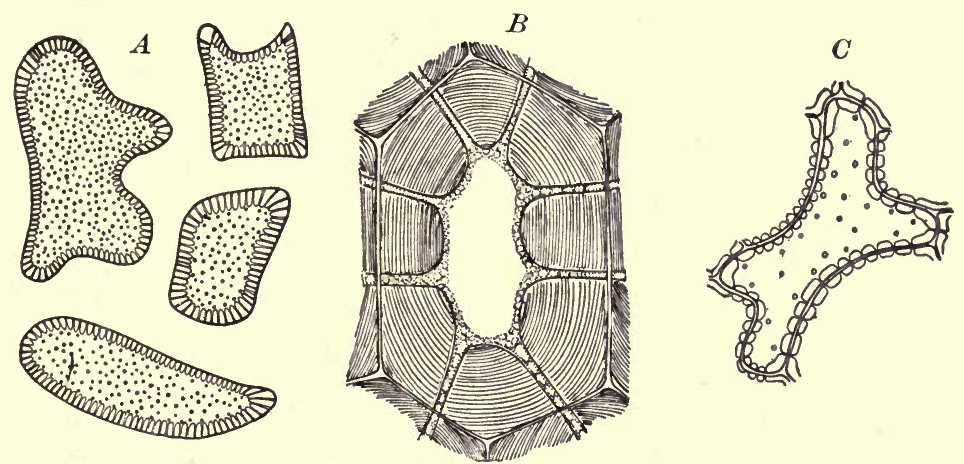

FrG. 137. Several forms of stone cells: A, white oak bark; B, white cinnamon or canella bark (Canella alba); $\mathrm{C}$, seed-coat of capsicum.

bast fibers in the same plant uniform in structure and composition, as in glycyrrhiza and althæa. On the other hand, they are with difficulty distinguished in monocotyledonous roots, and the term sclerenchymatous fiber is here best employed to include both kinds of cells. In the study of powdered drugs the term sclerenchymatous fiber may be employed with advantage when speaking of wood and bast fibers, as in this condition they are not readily distinguishable. It is usual in plant anatomy to include as stereome all lignified fibers not directly associated with the vessels of the mestome strands (or vascular bundles).

STONE CELLS or SCLEROTIC CELLS are parenchymatous cells with very thick, lignified walls, composed of numerous lamellæ, 
which are permeated with simple and not infrequently branching pores. They vary in form, being usually polygonal, or more or less irregular in outline, sometimes branching. The lamellation of the walls is brought out by the use of swelling reagents, as solutions of the alkalies, hydrated chloral, chromic acid, etc. In typical stone cells the walls always give the characteristic reaction for lignocellulose with acid solutions of either phloroglucin or aniline sulphate. The lumina of the cells frequently contains a reddish, amorphous substance, seldom are crystals of calcium oxalate present (Fig. $136, H$ ), and not infrequently they are filled with air (Fig. $136, G$ ). In the identification of com-

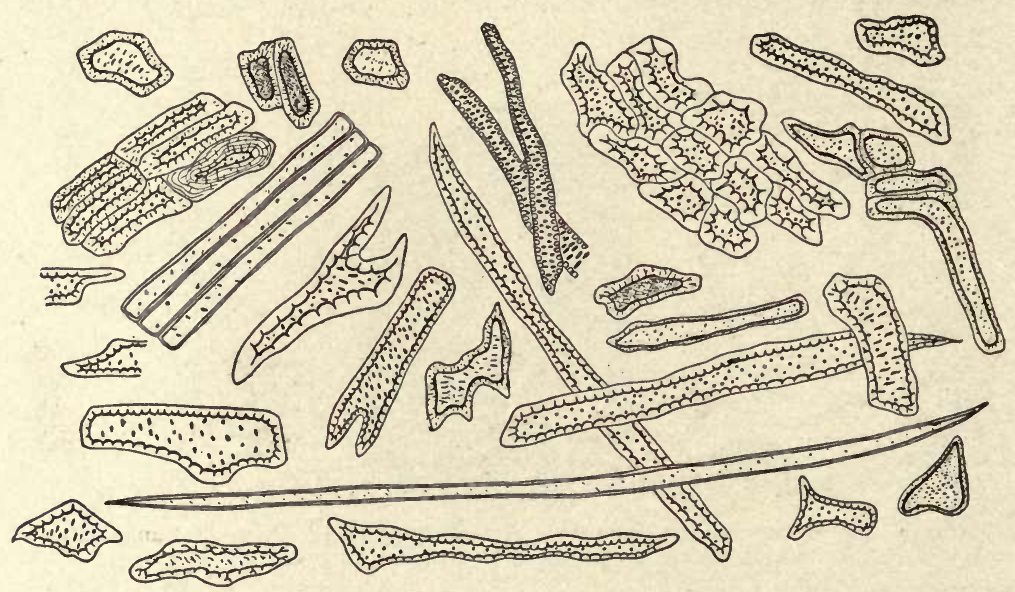

FIG. 138. Various forms of stone cells in star anise, the fruit of Illıcium anisatum.

mercial products the study of the contents of the stone cells is frequently as important as that of the forms of cells.

BAST FIBERS Or STEREOMATIC CELLS are sclerenchymatous fibers, occurring in the bark and usually associated with sieve cells. They represent the skeleton of plants and are the most important mechanical tissues of the bark, being much firmer than the collenchyma. They are very long, spindle-shaped, with more or less thick walls, and provided with slit-like, oblique pores. The walls may consist of cellulose, as in the fibers of flax, but they are usually more or less lignified; the lumina is narrow and usually contains air. In transverse sections the fibers are more or less 
Bast fibers may be isolated by the use of Schulze's macerating fluid (which is prepared by dissolving a few crystals of potassium chlorate in nitric acid) and moderately heating the solution containing the material either on a slide or in a test-tube.

The mechanical tissue consisting of cells resembling bast fibers and occurring in leaves and fruits is usually referred to as stereome.

WOOD FIBERS Or LIBRIFORM CELLS are sclerenchymatous fibers

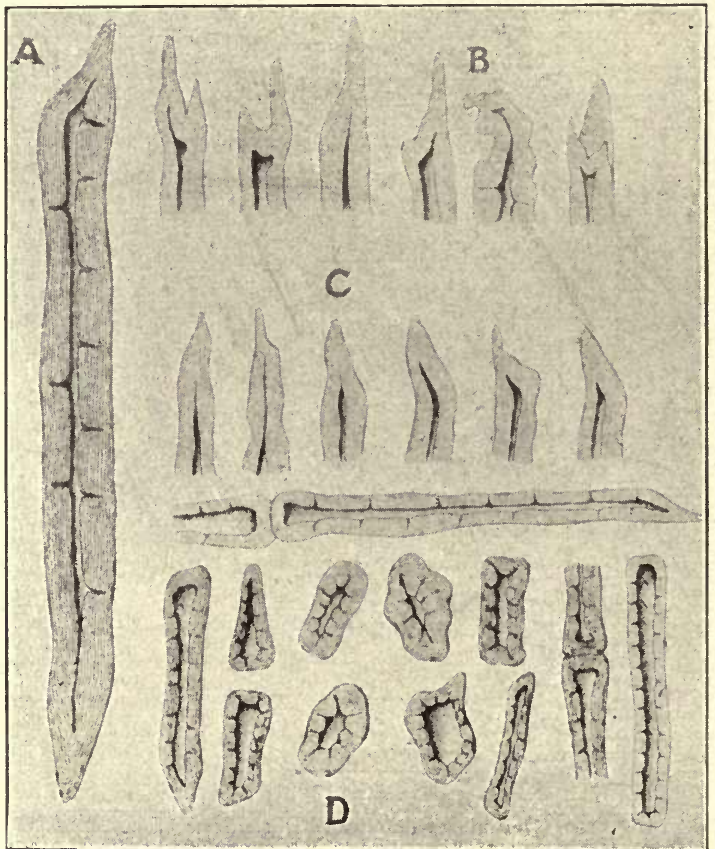

FIG. I40. A, C, bast fibers of the bark of Cinchona succirubra; B, bast fibers of the bark of Cinchona Ledgeriana; D, stone cells of Cuprea bark (Remijia peóuncuiata).-After Gesterle and Tschirch.

occurring in the wood and are usually associated with the tracheæ. They are scarcely to be distinguished from the bast fibers except by their position, and are the strengthening cells of the xylem. While the bast fiber is frequently not lignified, the walls of the wood fibers usually consist of lignocellulose, and usually give quite pronounced color reactions with acid solutions of either phloroglucin or aniline sulphate. Wood fibers are usually more 
abundant than bast fibers in the same plant, and, while the bast fibers may be wanting, the wood fibers, with few exceptions, are always present. Wood fibers seldom attain the length of bast

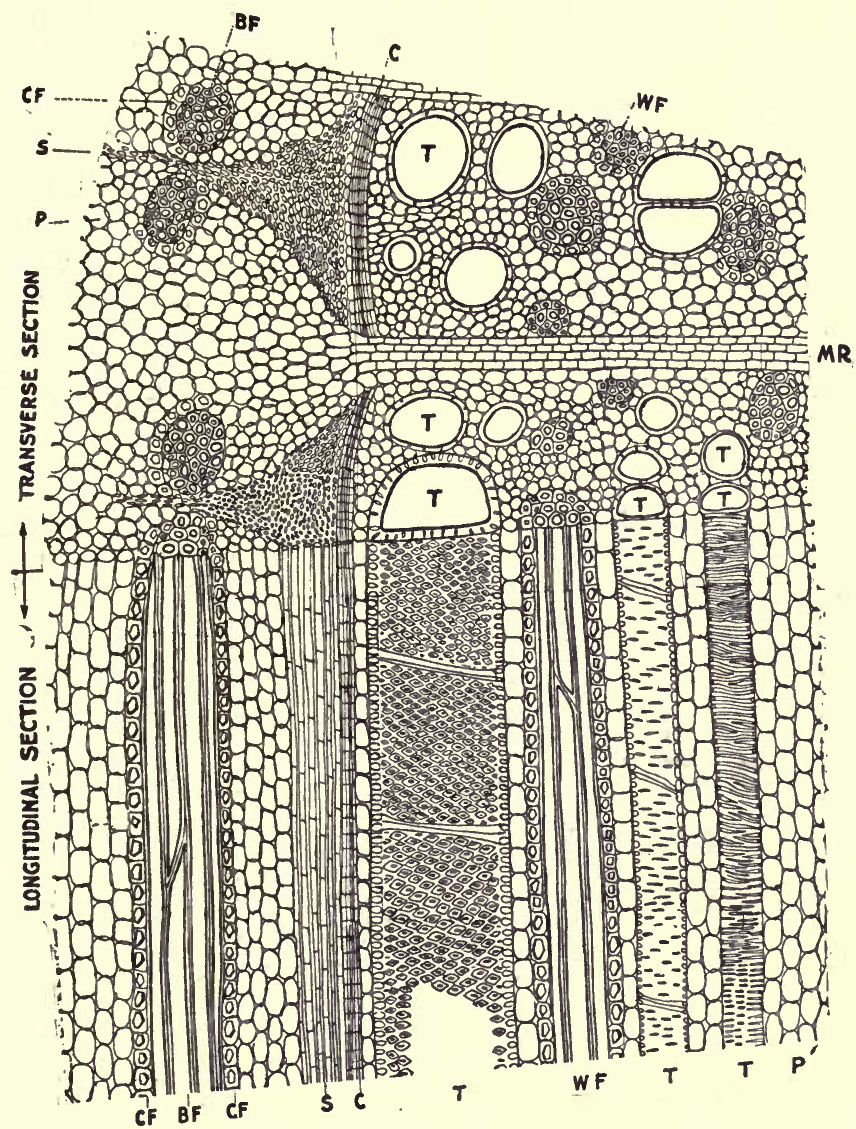

FIG. I4I. Longitudinal-transverse section of licorice rhizome including the cambium: $\mathrm{P}$, parenchyma; $T$, tracheæ or ducts; WF, wood fibers; $C$, cambium; $S$, sieve; CF, crystal fibers; $B F$, bast fibers; MR, medullary ray.

fibers. They are not infrequently branched at the ends, and, besides a thin protoplasmic layer, they usually have no other contents than water or air. They frequently have yellowish walls, characteristic of stone cells, and also exhibit a similar lamellation and refraction of the wall. 
Conducting cells or mestome include those cells which are chiefly concerned in the transferral of either crude or assimilable
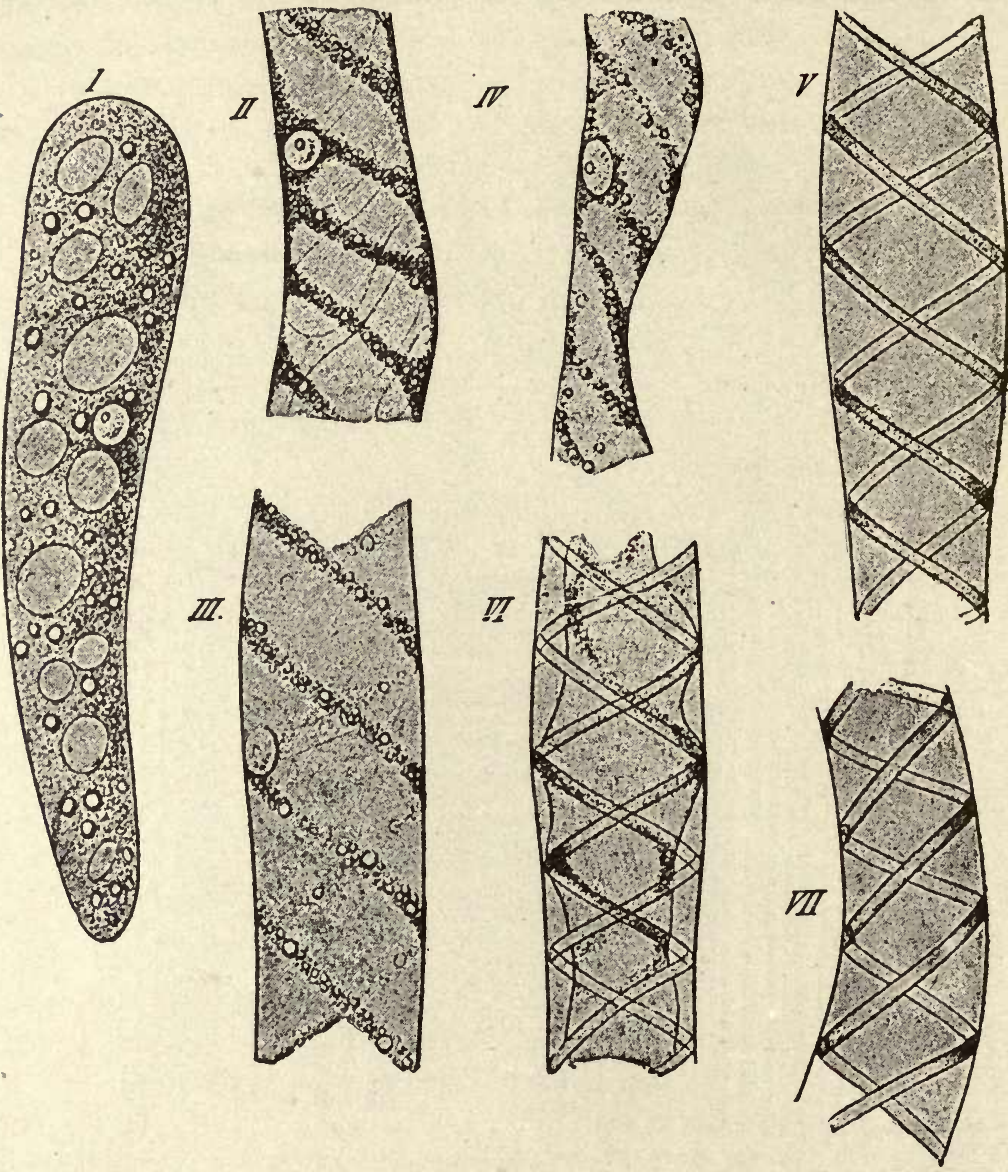

FIG. 142. Development of spiral bands in the mechanical cells of young fruits of Fegatella conica (Hepaticæ): I, young cell with vacuoles and small starch grains; II, portion of an older cell showing formation of large vacuoles in the protoplasm, the strands of which are arranged in a left-hand spiral; III, showing spiral arrangement of protoplasm; IV, portion of cell as in III treated with a sugar solution and showing plasmolysis of protoplast; V, showing formation of band; VI, a cell as in V treated with sugar solution, showing the protoplasm arranged along the thickened portions of the wall where the bands are forming; VII, the mature cell showing lignified spiral bands.-After Dippel in "Das Mikroskop."

food materials. The more or less crude inorganic materials are carried from the root through the woody portion of the stem to 
the leaves, and from the leaves the products of photosynthesis, as well as other plastic substances, are distributed through some of the tissues of the bark to other parts of the plant. The tissues or elements of the wood which conduct food materials are of several forms and include tracheæ or vessels (also called "ducts"), tracheids, and conducting parenchyma; and the elements of the bark which transport the assimilable materials comprise the leptome and conducting parenchyma (Fig. I4I). Water-conducting elements (TRACHEAL ELEMENTS) comprise the vessels (tracheæ) and the tracheids, which resemble each other, except that the latter are single cells of prosenchymatic shape, while the former are very long tubes, varying from cylindrical to prismatic in shape, and consist of long rows of cells which are superimposed lengthwise, the transverse walls being usually obliterated.
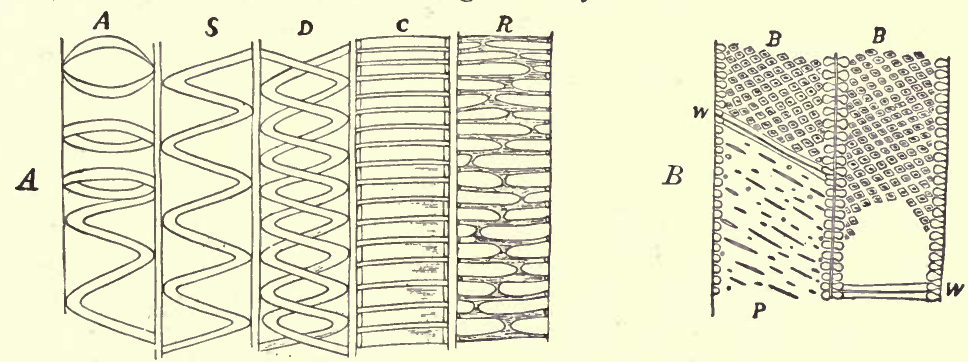

FIG. I43. Forms of tracheæ or vessels. A.-Longitudinal section of stem of Cucurbita Pepo showing various forms of tracheæ: A, annular; S, spiral; D, double spiral; C, close annular; R, reticulate. B.-Tracheæ in glycyrrhiza rhizome: W, wall; B, bordered pores; $\mathrm{P}$, oblique simple pores.

The tracheæ or vessels are formed by the disintegration and removal of the transverse walls between certain superimposed cells, forming an elongated cell or tube, which occasionally retains some of the transverse walls (Figs. I42-I44). The longitudinal walls are relatively thin and consist of lignocellulose, giving pronounced reactions with phloroglucin or aniline sulphate.

Four types of vessels or tracheæ are known: annular, spiral, reticulate, and porous. Those having the thickenings in the form of horizontal or oblique rings are known as ANNULAR TRACHEA; those having the thickenings in the form of spirals, which usually run from right to left, are known as SPIRAL TRACHEx; those having the thickenings in the form of a reticulation are known as 
RETICULATED TRACHE\&, and those with spherical or oblique slit pores are known as POROUS TRACHEe or vessels (Figs. I42-I44).

In those vessels in which but few of the transverse walls are obliterated, the walls are marked by both simple and bordered
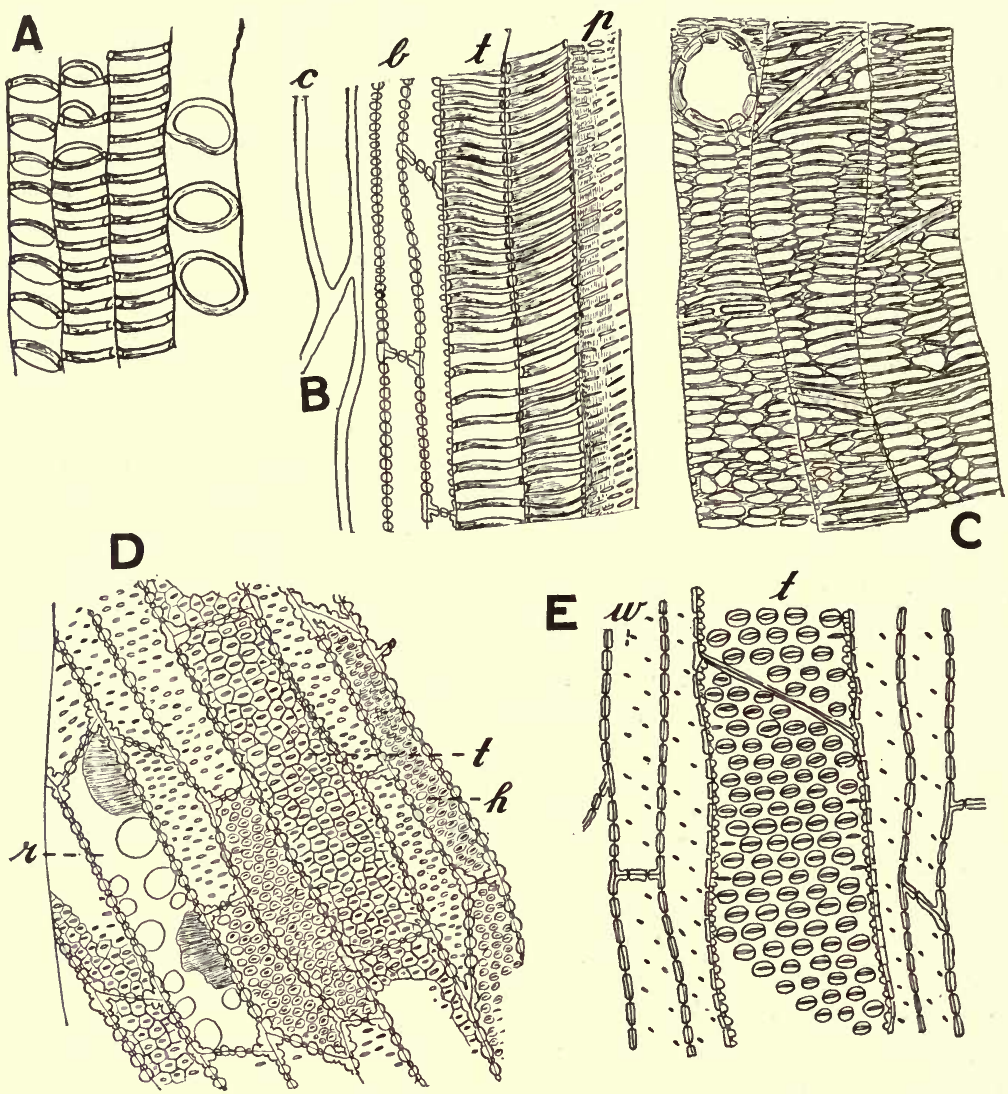

FIG. I44. Types of tracheæ or vessels. A, vessels with annular and spiral thickenings in Phlox carolina; B, longitudinal section through fibrovascular bundle in aconite, showing porous ( $p$ ) and spiral tracheæ ( $t$ ), bast fibers (b), and some of the collenchyma cells (c); $\mathrm{C}$, longitudinal section showing reticulate tracheæ in scopolia; D, longitudinal section of the woody part of the rhizome of Spigelia, showing tracheæ $(t)$, tracheids $(h)$, tracheæ $(r)$ with yellowish-brown, gum-like masses; E, portion of xylem of stem showing in Hyoscyamus tracheæ $(t)$ with bordered pores and wood fibers (w), with simple oblique pores.

pores, which latter are described under tracheids. Vessels contain water, water-vapor, and air; in some cases they contain sugar, tannin, mucilage, or resin. 
The tracheids are intermediate in character between tracheæ and libriform, resembling the former in possessing bordered pores (Fig. I45) and scalariform thickenings; and the latter in being true cells, which are usually elongated and quite thick-walled, the walls giving distinct reactions for lignocellulose with phloroglucin or aniline sulphate.

One of the chief characteristics of tracheids is the BORDERED PORES (Fig. I45). These differ from simple pores in that the wall surrounding the pore forms a dome-shaped or blister-like
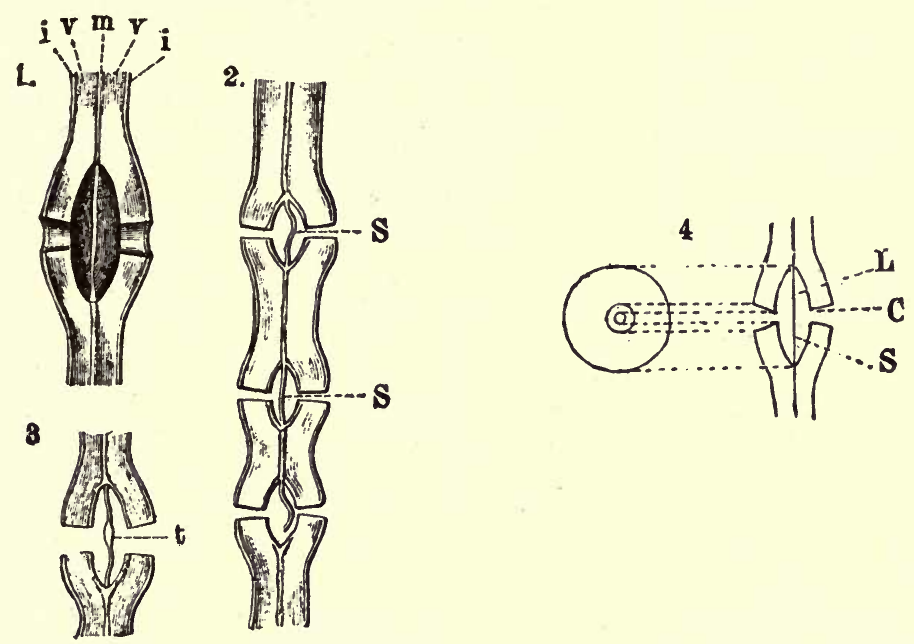

FIG. I45. Bordered pores of the tracheids of the wood of Abies alba as viewed in longitudinal section: $\mathrm{m}$, middle lamella; $\mathrm{v}, \mathrm{i}$, middle and inner layers of walls of contiguous cells; C, pore-canal through which sap passes from one cell to another; L, domeshaped cavity of pore; S, separating wall or closing membrane which is usually thickened in the middle as shown at $t$. In older cells the separating membrane is broken as shown in the lower pore in figure 2. At the right in figure 4 is shown a surface view of a bordered pore, the dotted lines indicating the relation of the circles to the structure of the pore.After Vog1.

protrusion into the cell. On surface view the pores are either circular or elliptical in outline, the dome being circular or, if the pores are numerous and arranged close together, more or less polygonal (Figs. I43, I44).

The number and distribution of bordered pores in the Coniferæ are quite characteristic for some of the genera, and may be studied in any of the pines, the pores being most numerous in the radial walls (Fig. 69). 
The leptome or sieve is distinguished from the other conducting elements in that the walls are thin and are composed of cellulose (Fig. I46). It consists of superimposed elongated cells, the transverse walls of which possess numerous pores which are supposed to be in the nature of openings, permitting of the
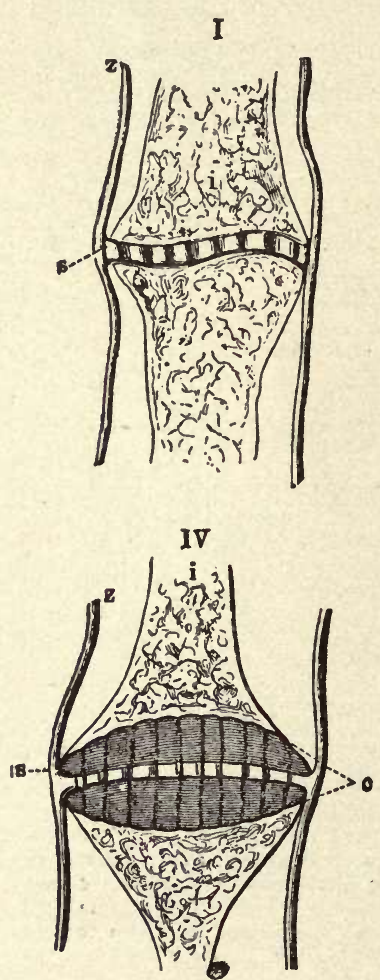
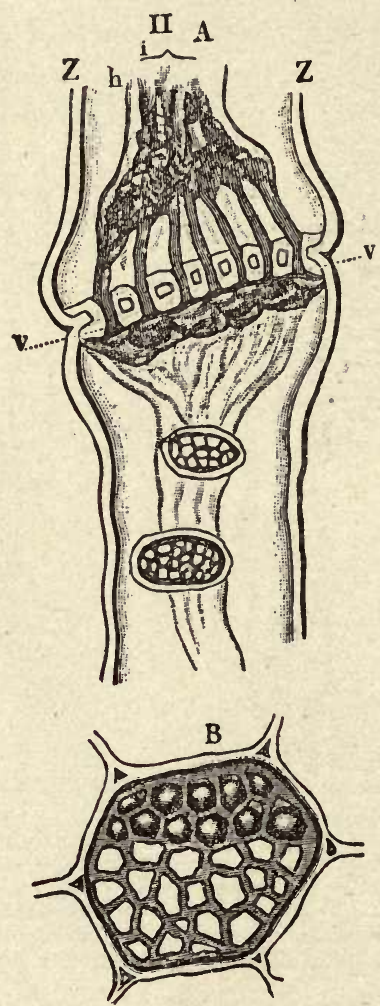

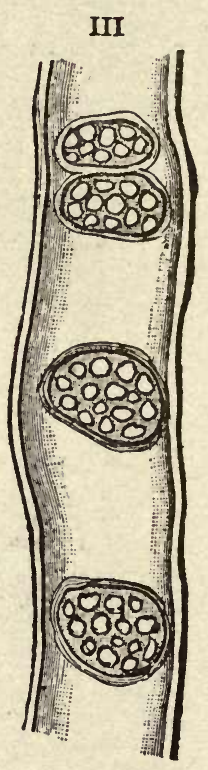

Fig. 146. Different forms of sieve pores: I, portion of sieve tube of Bryonia alba, II of Cucurbita Pepo, A longitudinal section and B in transverse section; III, portion of a sieve cell of Larix europaa showing round sieve pores; IV, an old sieve plate in Bryonia alba treated with chlor-zinc-iodide, showing the striated callous plates (c), (z) cell-wall, (s) sieve plate, (i) contents of sieve tube, (h) cell membrane, (c) callous plates. -After Dippel in "Das Mikroskop."

direct passage of the contents from one cell to the other. This transverse wall, which may be either horizontal or oblique, is known as the SIEVE PLATE, and the thin places as pores of the sieve. The sieve plates are sometimes also formed on the longi- 
tudinal walls. When the activities of plants are suspended during the winter, there is formed on either side of the sieve plates a layer of a colorless, mucilaginous substance, known as callus, which has somewhat the appearance of collenchyma, but is colored brownish by chlor-zinc iodide.

The sieve cells contain an albuminous substance somewhat resembling protoplasm; in some instances starch grains have also been found.

When the activities of the sieve tubes have ceased, they become altered in shape, and are then known as altered sieve. In the drying of plants a similar alteration is produced, and the sieve of vegetable drugs is referred to as "obliterated" sieve.

Protecting cells include those cells which are located on the outer parts of the plant. The function of these cells is to lessen the rate of transpiration, or the giving off of water; to furnish protection against changes of temperature, and to protect the inner tissues against the attack of fungi and insects; they also have a mechanical function (Figs. I47, I 57).

Depending principally upon their composition, these cells may be divided into two classes, namely, epidermal cells and cork cells.

The epidermal cells constitute the outermost layer of the plant. They contain cytoplasm, but the plastids in some instances are wanting; in petals, etc., they also contain dissolved coloring principles; and on account of the relatively large amount of water which they contain they are classed among the important water-reservoirs of the plant.

The outer walls are principally characterized by one or more lamellæ of cutin, these uniting to form a continuous wall. The cutin is often associated with wax, this constituting the bloom of fruits; less frequently such inorganic substances as calcium carbonate, calcium oxalate, and silica are present, and not infrequently mucilage is present, as in the walls of certain seeds (Fig. I I9, $A$ ).

On surface view the form of these cells varies from nearly isodiametric to oblong; they may also be polygonal or branched. In transverse section their radial diameter is much the shorter. In some instances the inner and side walls are considerably thickened, as in the seeds of a number of the Solanacex (Fig. I $36, A$ ). 
The epidermis usually consists of a single layer of cells, but may have additional layers underneath forming the HYPODERMIS, as in the upper surface of the leaves of species of Ficus (Fig. I13);
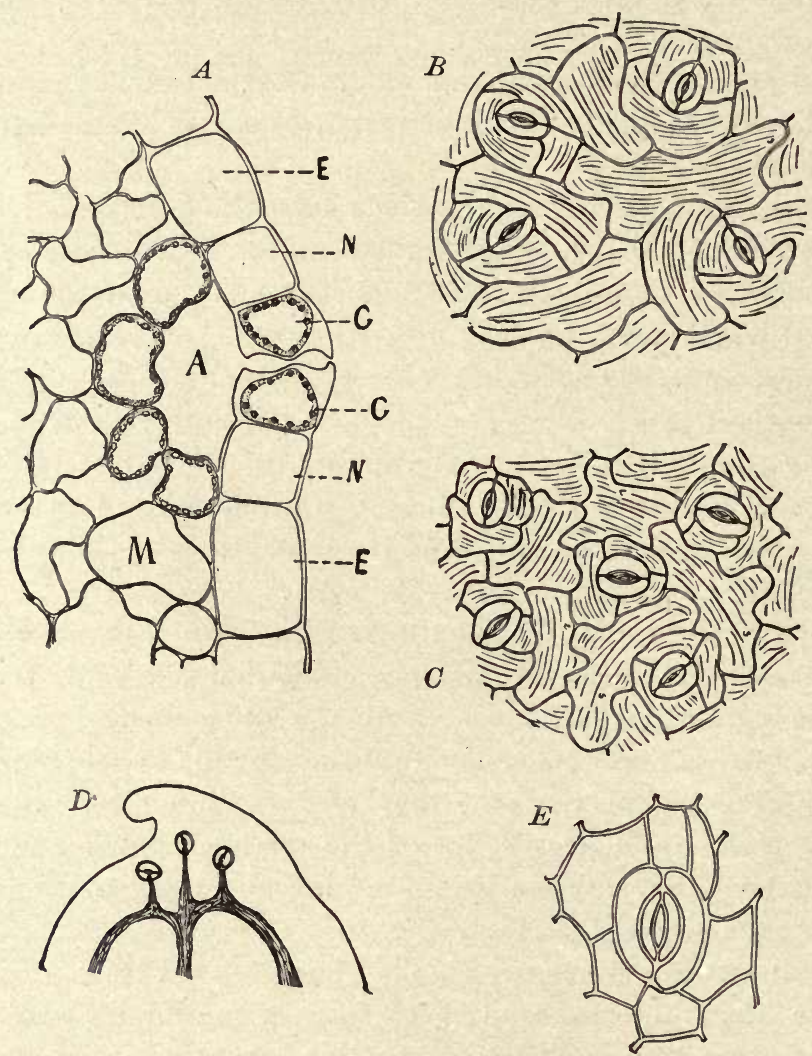

Fig. I47. Stomata and water-pores. A.-Transverse section through lower surface of leaf of stramonium: stoma, with guard cells $(\mathrm{G})$, containing cytoplasm, nucleus and chloroplastids; N, surrounding cells; A, intercellular cavity usually filled with cell-sap or watery vapor; E, epidermal cells; M, mesophyll. B.-Surface section of upper surface of leaf of Viola tricolor showing four stomata. C.- Surface section of under surface of leaf of Viola tricolor showing five stomata. D.-A section through the margin of the leaf of Viola tricolor showing a tooth with three water-pores. E.-A water-pore of Viola tricolor in surface section.

in some instances the hypodermis undergoes a mucilage modification, as in the leaves of buchu.

Stomata.-Distributed among the epidermal cells are pairs of crescent-shaped cells known as a sToma, and having an open- 
ing or pore between them, which leads to a cavity beneath it. The two cells of the stoma are known as GUARD CELLs (Fig. I47, G). The adjoining walls of the guard cells are alike in transverse section, but the cells vary in shape in different plants. The guard cells are more or less elastic, and when the cells are turgescent, as when there is an abundance of water and root pressure is strongest, the contiguous walls of the cells recede from each other, forming an opening between them, thus permitting the exit of the excess of water taken up by the plant and the exhalation of the oxygen given off during assimilation, as well as the intake of the carbon dioxide used in photosynthesis. On the other hand, when the amount of water in the plant is reduced below the normal and the plant shows signs of wilting the guard cells flatten and the opening or pore is closed (Fig. 2I4). The cells beneath the stoma are loosely arranged, so that the air containing carbon dioxide may be readily diffused to the cells containing the chloroplastids.

The guard cells may be slightly raised above or sunk below the surrounding epidermal cells, the number of the latter being characteristic for certain plants. (Compare Figs. I47, 21 I-218.)

Stomata occur in the largest numbers on the blades of foliage leaves, being more numerous on the under surface, except in aquatic plants, where they occur only upon the upper surface.

Water Pores.-Near the margin of the leaf and directly over the ends of conducting cells, not infrequently occur stomata, in which the function of opening and closing is wanting, and which contain in the cavity below the opening water and not air, thus differing from true stomata (Fig. I47, $D, E$ ). These are known as WATER PORES, and they give off water in the liquid form, the drops being visible on the edges of the leaves of nasturtiums, fuchsias, roses, etc., at certain times.

Plant Hairs.-The epidermal cells are sometimes specially modified centrifugally, giving rise to papillæ, to which the velvety appearance of the petals of flowers is due; in other cases this modification is in the form of hairs or trichomes (Figs. I 48'-I 55). These may be unicellular or multicellular, and in addition the latter may be glandular or non-glandular. Glandular hairs possess a head-like apex, consisting of one or more cells, and they secrete oil, mucilage, and other substances (Figs. I24, I25, I49, I 50). 
In the examination of technical products, as also in taxonomic work, the study of plant hairs is very important. They show a great diversity in form in not only genera and families but even in related species. They vary considerably in their distribution

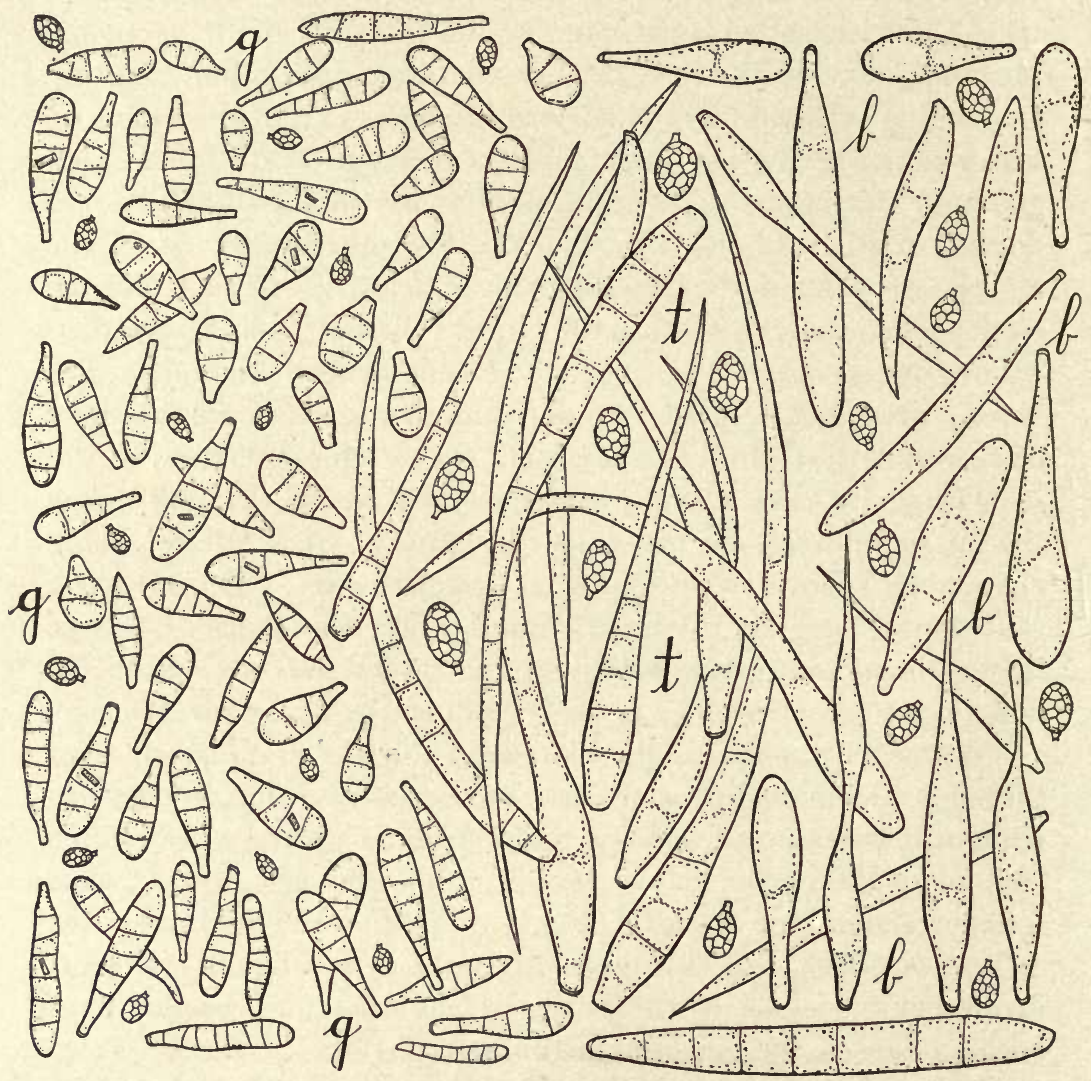

Fig. 148. Mostly non-glandular hairs and a few of the small glandular hairs covering the surface of the fruits of several species of Rhus: $g$, hairs on Rhus glabra, being more or less broadly top-shaped or carrot-shape to spatulate and occasionally narrow elliptical and from 0.100 to $0.400 \mathrm{~mm}$. in length; b, hairs on Rhus typhina, being long and needle-like, varying from 0.750 to $1.500 \mathrm{~mm}$. in length; c, hairs of Rhus glabra borealis, being intermediate between those of Rhus glabra and Rhus typhina, varying from elongate spatulate and narrow cylindrical to needle-shaped, and from 0.100 to $1.000 \mathrm{~mm}$. in length.

not only in related species, but sometimes in varieties of the same species they show marked variation in size and form. In some natural hybrids intermediate forms of hairs of the parent species 
are found. This was pointed out by Kraemer in some studies on Rhus glabra and Rhus typhina (Amer. Jour. Pharm., I913, p. 404), in which a herbarium specimen in the New York Botanical Garden and labelled by Britton as Rhus glabra borealis shows hairs which in form and size are intermediate between those of $R$. glabra and R. typhina (Fig. I48).

Plant hairs may be divided into two principal groups: I. GLANDULAR HaIRS, or those in which the summit consists of one or more cells which secrete beneath the cuticle either mucilage, oils, or oleo-resins, and the summit of the hair possesses a more or less globular form. II. Non-GLANDUlar HaIRs, or those in which the summit of the hair consists of one or more rounded or pointed cells in which no secretion is formed beneath the cuticle.

Glandular Hairs may be divided into five different groups:

I. Unicellular glandular hairs consist of a single tubular cell, the upper portion being more or less swollen and rounded (Fig. I49, $A, B$ ). Hairs of this type occur in the Euphorbiacex, in which they more or less resemble Papillæ. In the Compositæ they contain a latex and appear to be connected with the laticiferous vessels. They also occur in the Anacardiaceæ, Cornaceæ, Geraniaceæ, Leguminosæ, Malvaceæ, Menispermaceæ, Onagraceæ, Piperaceæ, Ranunculaceæ, Tiliaceæ and Zygophyllaceæ.

2. Multicellular glandular hairs consist of a number of forms; either they are differentiated into a stalk and a head, or the stalk may be wanting when the hair has a spatulate or clavate form. These are often very characteristic for certain families, as the glandular hairs in the Labiatæ (Fig. I24), which possess a short stalk and a head portion with eight cells, the cuticle being raised like a bladder owing to the great accumulation of secretion. There are a great many types of multicellular glandular hairs (Fig. I49). They may be uniseriate, i.e., consisting of a series of cells with either a unicellular head (Fig. I49, $C, E, K, M$ ), as in the Menispermaceæ, Araliaceæ, Malvaceæ, Caryophyllaceæ, Geraniaceæ, etc., or they may be bicellular (Fig. I 49, $D, F, H, J, L, O$ ), as in the Cruciferæ. The heads may consist of two to four cells (Fig. I49, $G, V, Y$ ), as in the Burseraceæ, or eight cells, as in the Labiatæ (Fig. I49, $W^{\top}$ ). Multicellular glandular hairs have been found in the following families: Aceraceæ, Anacardiaceæ, Araliaceæ, Be- 

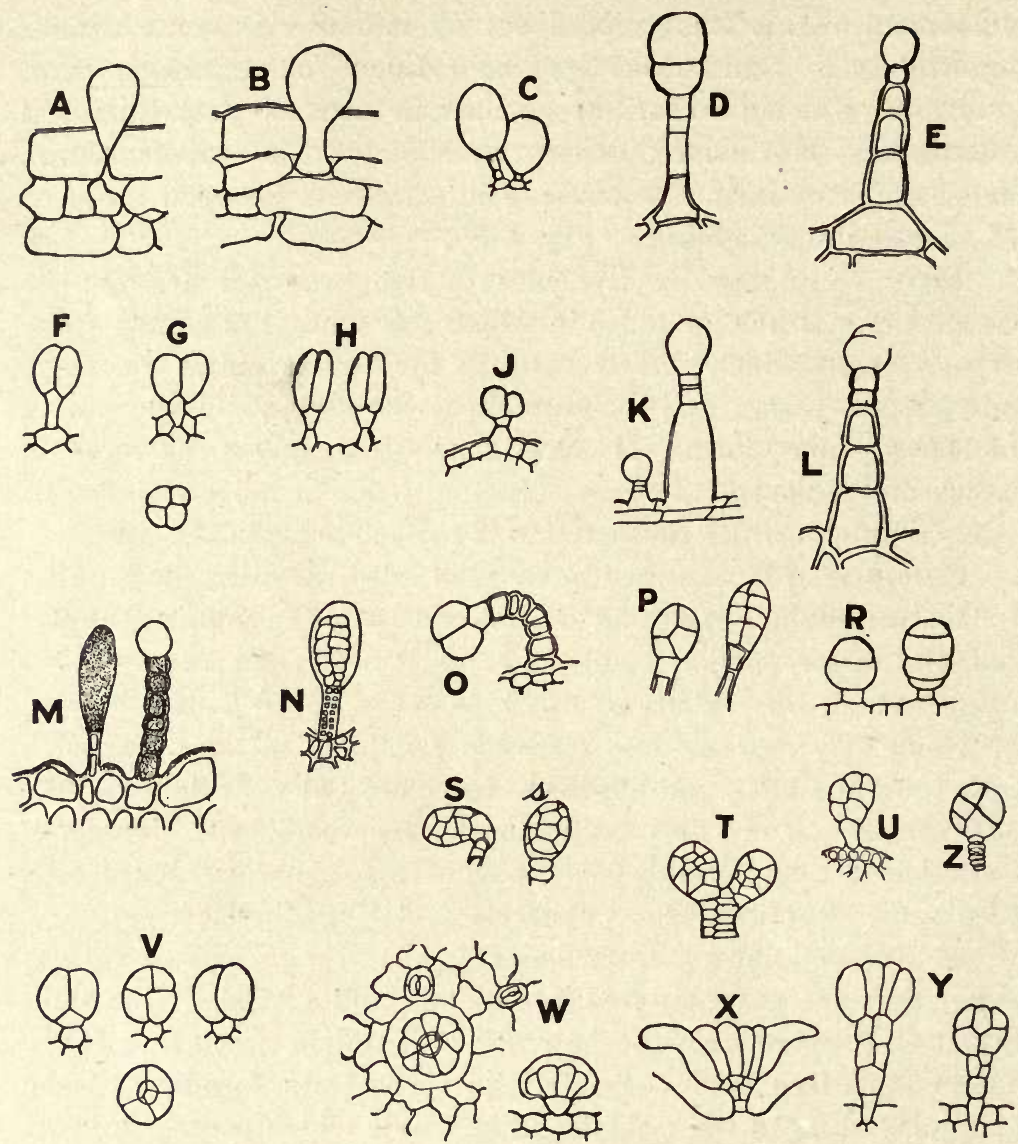

FIG. I49. Various types of glandular hairs. Unicellular hairs on Julocroton fuscescens (A), Croton monanthogynus (B). Uniseriate uni-glandular hairs on Zollikoferia nudicaulis (C), Silene villosa (E), Geranium favosum (K), Boerhaavia repens (M). Glandular hairs with two-celled heads on Hesperis glutinosa (D), Pityrodia salvifolia (F), Cyclamen. persicum (H), Lysimachia Nummularia (J), Chenopodium Botrys (L), Diospyros Kaki (O). Glandular hairs with four-celled heads on Humulus Lupulus (G), Boswellia papyrifera (V), Humulus Lupulus (Y). Glandular hairs with five-celled heads on Combretum aculeatum (Z), Humulus Lupulus (Y). Glandular hairs with six-celled heads on Rhododendron Dalhousia (X), hair characteristic on the Phaseolece (U). Glandular hairs with eight-celled heads on Lavandula vera (W). Glandular hairs with multicellular heads on Pieris foribunda (N), Begonia caroliniafolia (S), Begonia pretoniensis (s). Glandular hairs with four and eight cells respectively on Picramnia coccinea (P). Glandular hairs with two and four cells respectively on Cistus ladaniferus (R). Double glandular hair on Rhododendron lanatum (T) -Adapted from Solereder and redrawn by Hogstad. 
goniaceæ, Berberidaceæ, Bixaceæ, Borraginaceæ, Burseraceæ. Capparidaceæ, Caprifoliaceæ, Caryopyhllaceæ, Chenopodiaceæ, Combretaceæ, Compositæ, Convolvulaceæ, Cornaceæ, Crassulaceæ, Cruciferæ, Cucurbitaceæ, Dipsaceæ, Ericaceæ, Euphorbiaceæ, Fagaceæ, Geraniaceæ, Hippocastanaceæ, Hydrophyllaceæ, Labiatæ, Leguminosæ, Malvaceæ, Melastomataceæ, Meliaceæ, Menispermaceæ, Moraceæ, Myrsinaceæ, Nolanaceæ, Nyctaginaceæ, Nymphæaceæ, Piperaceæ, Platanaceæ, Plantaginaceæ, Polemoniaceæ, Polygonaceæ, Portulacaceæ, Primulaceæ, Rosaceæ, Rutaceæ, Sapindaceæ, Saxifragaceæ, Scrophulariaceæ, Simarubaceæ, Solanaceæ, Sterculiaceæ, Theaceæ, Tiliaceæ, Umbelliferæ, U1maceæ, and Valerianaceæ.

3. Glandular leaf-teeth, as the name would signify, include the glandular hairs formed on the lobes of leaves. They vary in structure and may secrete mucilage, as in the Violacex (Fig. I20) and in some of the Compositæ, or they may secrete, in addition, resin, as in the Rosaceæ, or calcium oxalate, as in the Saxifragaceæ.

4. Special forms of multicellular glands are found in the Aceraceæ, in which a pair of glands are fused together. In some of the Compositæ and Moraceæ a group of glandular hairs are united. Other special types also occur in the Droseraceæ, Anacardiaceæ, Leguminosæ, etc.

5. Hair-like external glands having a complicated structure have been observed in a number of families. They are limited to certain portions of the plant, being found in the Apocynaceæ at the base of the leaves and in the Rubiaceæ only on the stipules. They are usually very large, secreting considerable mucilage and resin. The glandular, shaggy hairs occurring on the stipules in the Rubiaceæ are of this type, the secretion being often so abundant that the young leaves emerging from the stipular sheath are coated with this resin, which is even retained by the mature leaves.

II. Non-glandular Hairs are of three general types: I. Simple hairs (Figs. I48, I5I), which may be unicellular or uniseriate,-i.e., consisting of a series of superimposed cells. 2. Peltate or stellate groups (Fig. I 53, D, E, $H, K$ ), consisting of two or more hairs united at the base and spreading like a star. 

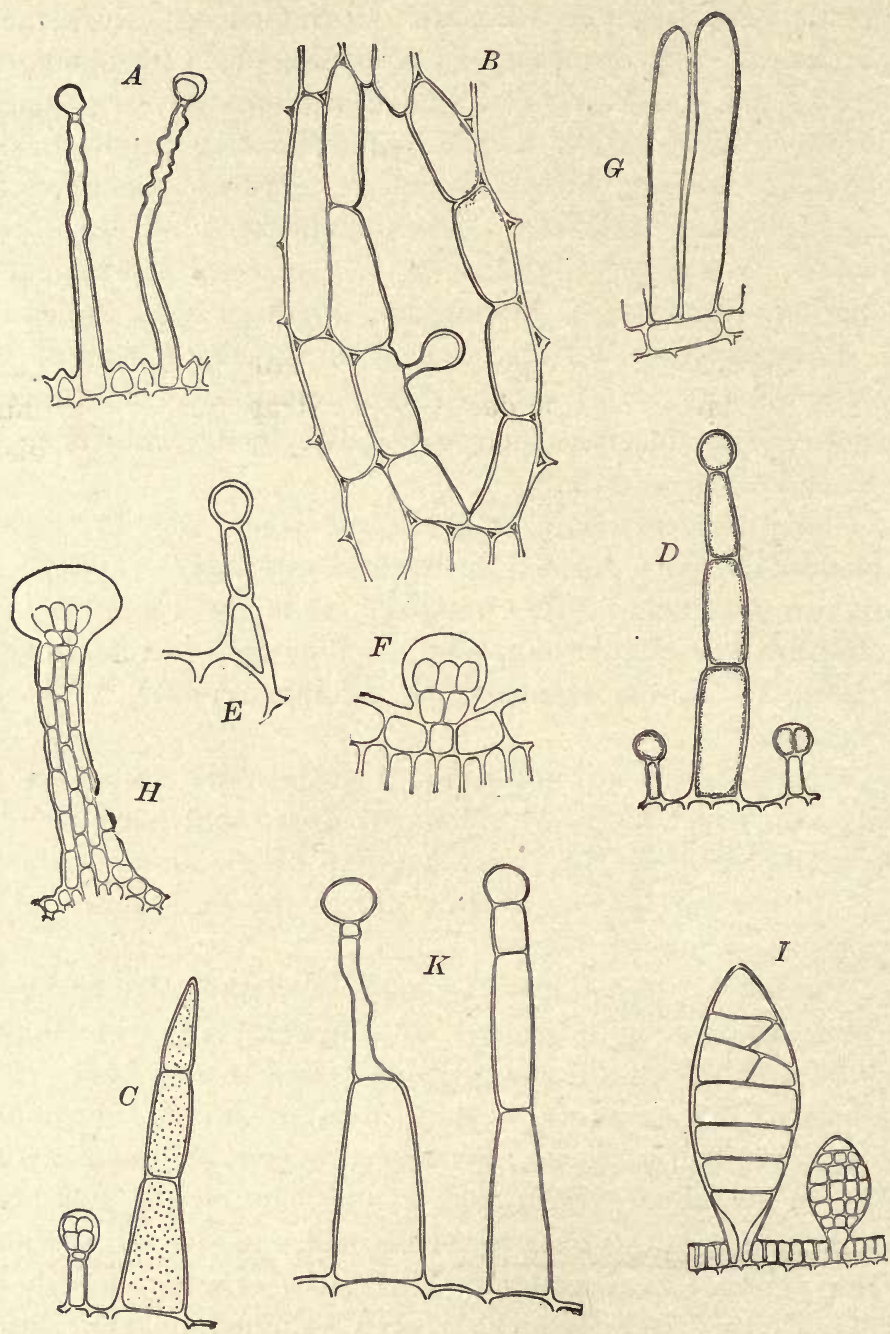

FIG. I50. Forms of glandular hairs: A, corkscrew-like hairs from the inner surface of the spurred corolla of lavender; B, longitudinal section of rhizome of Dryopteris marginalis showing large intercellular space and an internal oil-secretion hair; $\mathrm{C}$, hairs from stramonium leaf; D, hairs from Digitalis; E, hair from sage; F, hair from eriodictyon; $G$. hairs from inner walls of pericarp of vanilla; H, hair from cannabis indica; $I$, hairs from surface of fruit of Rhus glabra; K, hairs from belladonna leaf. 
These may consist of one or more series of cells, separated by a columnar cell. 3. Shaggy hairs (Fig. I53, G), in which the epidermal layer of the column of cells is modified to papillæ
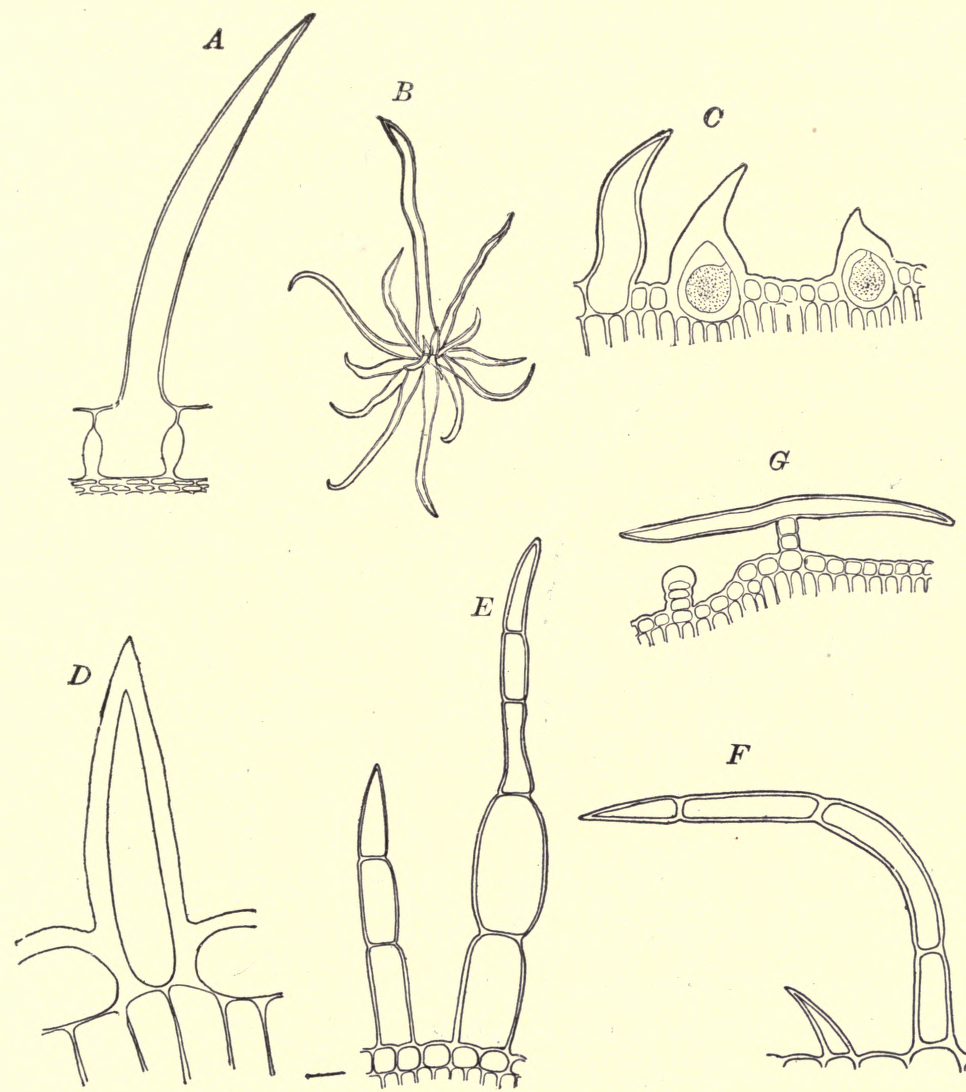

FIG. I5I. Forms of non-glandular hairs: A, hair from the epidermis of strophanthus; $\mathrm{B}$, a hair trom the capsule of Mallotus philippinensis (found in the drug known as kamala); $\mathrm{C}$, hairs from the leaves and bracts of cannabis indica, two of them containing cystoliths of calcium carbonate; D, a hair from the under surface of the leaf of senna; $E$, hairs from leaf of digitalis; F, two forms of hairs from sage leaf; G, two forms of hairs from the leaves of wormwood (Artemisia Absinthium): a T-shaped non-glandular hair and a short glandular hair.

which are directed upwards, giving the surface of the plant the appearance of being covered with rough hairs or wool.

Non-glandular hairs occur on a large number of plants. They 
vary in form and are very characteristic in a great many plants. The terms used to describe the various types of hairs are in a few instances rather simple, but there are so many modifications that nothing short of an illustration will suffice to define them. The simple hairs may be divided into a number of sub-divisions: (a) Papillose hairs, being short outgrowths of the epidermal cells, somewhat resembling the papillæ found on the ventral surfaces of petals. This form is found in a relatively few families. (b) Unicellular hairs, being outgrowths considerably longer than papillæ and occur in a large number of plants. This is also true of a third type $(c)$, known as uniseriate hairs and in which there

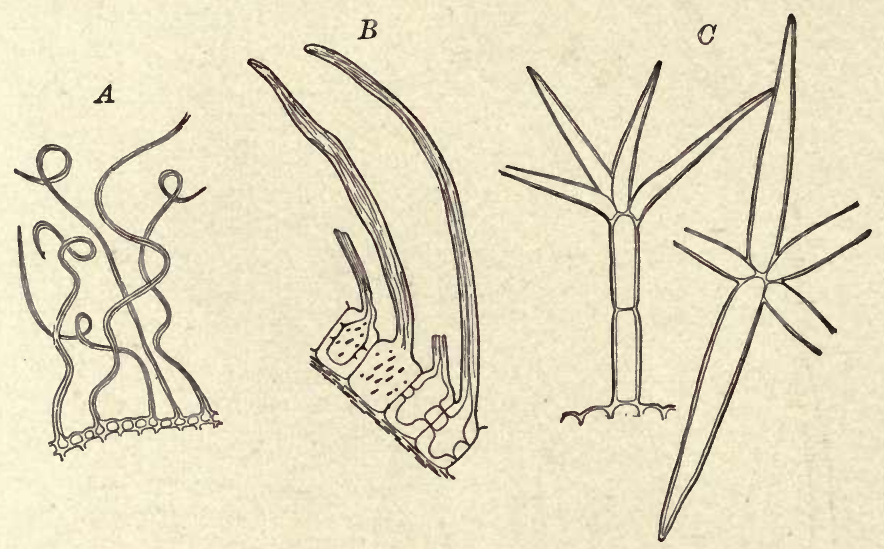

FIG. 152. Forms of non-glandular hairs: A, twisted hairs from under surface of leaf of eriodictyon; B, lignified hairs from the epidermis of nux vomica; C, branching hairs from the leaf of mullein (Verbuscum thapsus).

are two or more cells connected as in a chain. Among special terms frequently used the following may be mentioned: $(d)$ Hooked hairs (Fig. I 54, $A, B$ ), in which the summit is bent in the form of a hook. (e) Two-armed hairs (Fig. $\mathrm{r}_{53}, D$ ), in which the summit consists of two cells which diverge from each other and spread out horizontally or parallel to the surface of the leaf. ( $f$ ) Stellate hairs (Fig. I $5 \mathrm{r}, B$ ) consist of a group of cells arranged around a simple point, as in the Cruciferæ and Saxifra-

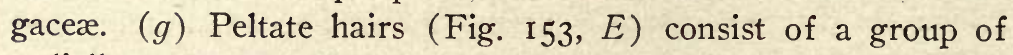
radially arranged cells, of which all or only some reach the centre of the shield, as in the Solanaceæ, Malvaceæ, Loganiaceæ, and 
Rosaceæ. ( $h$ ) Candelabra or abietiform hairs (Fig. I53, L) are those which have a uniseriate main axis, interrupted at intervals by whorls of ray cells. These show considerable variation and are very characteristic in the Solanaceæ, Acanthaceæ, Leguminosæ, Labiatæ, and Euphorbiaceæ. (i) Stinging hairs (Fig. 153, J), or those containing an irritating substance, as in the stinging nettle and other plants of the Urticaceæ. The hairs are rather long, the
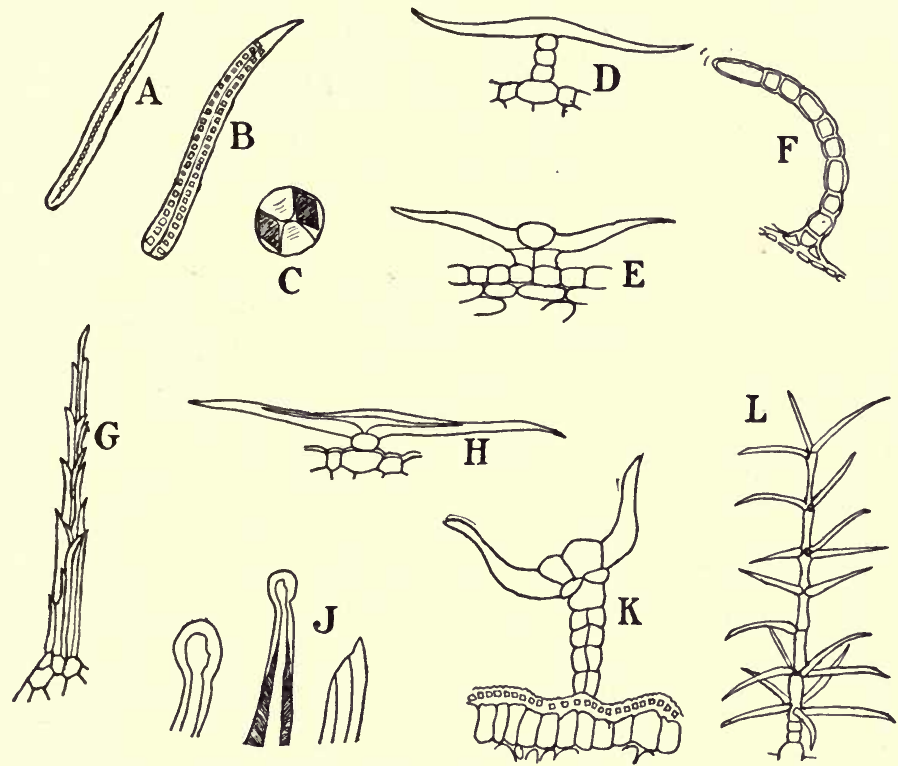

FIG. I53. Several types of non-glandular hairs. Crystal hairs on Malanea macrophylla: A, showing hair with a single row of crystals; B, cell with 2 rows of crystals; C, transverse section of B, showing crystals. Two-armed hairs on Artemisia Absinthium (D) and Dichondra repens (II); F, uniseriate non-glandular hair on Pongamia glabra; E, longitudinal view showing two of the cells of a peltate hair on Solanum argenteum; G, shaggy hair on Calandrinia umbellata; J, upper portion of stinging hairs of Urtica dioica; K, cupshaped peltate hair on Rhododendron Anthopogon; L, candelabra hair on Verbascum Thap. sus.-Adapted from Solereder and redrawn by Hogstad.

summit bearing a spherical or ovoid head, which is obliquely inserted and rather easily detached, thus leading to the emission of the contents. The stinging sensation was formerly stated to be due to formic acid, but it is now supposed to be in the nature of a substance related to the ferments. ( $j$ ) Crystal-containing hairs. Calcium oxalate (Fig. I 53, $A, B, C$ ), either in the form of rosette aggregates or prisms or needles, is sometimes present in the 

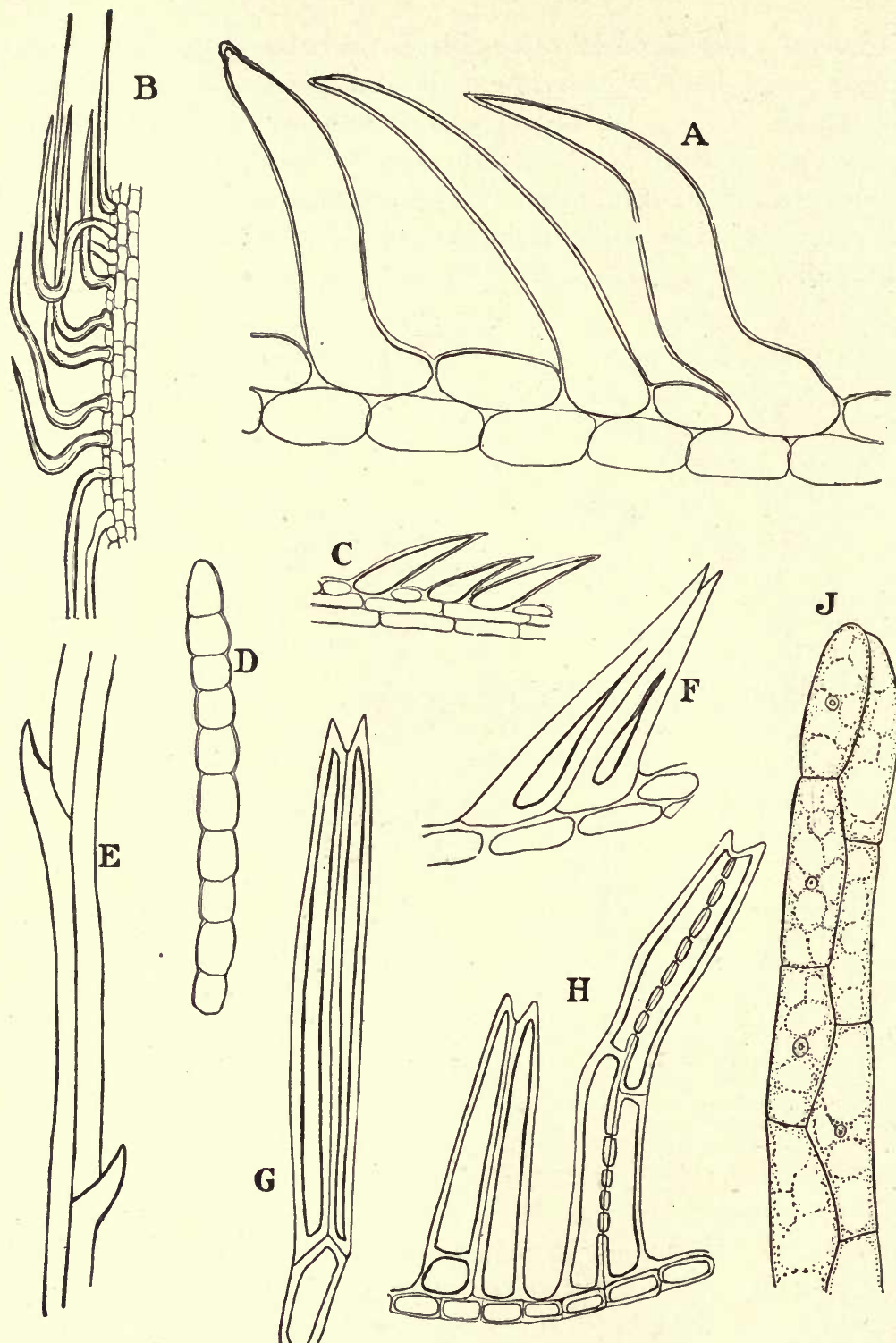

FIG. I54. Hairs in the Compositæ: A, slightly curved or hooked hairs on the corolla of Dandelion; B, hooked hairs on the filaments of Inula; C, hairs on pappus of Tragopogon pratensis; D, hair from akene of Tragopogon pratensis; $\mathrm{E}$, portion of barbed hair upon pappus of Inula; F and G, double hairs from achene of Tagetes tenuifolia; H, double hairs from achene of Inula; J, double hair from corolla of Calendula. 
CELL-CONTENTS AND FORMS OF CELLS. 289

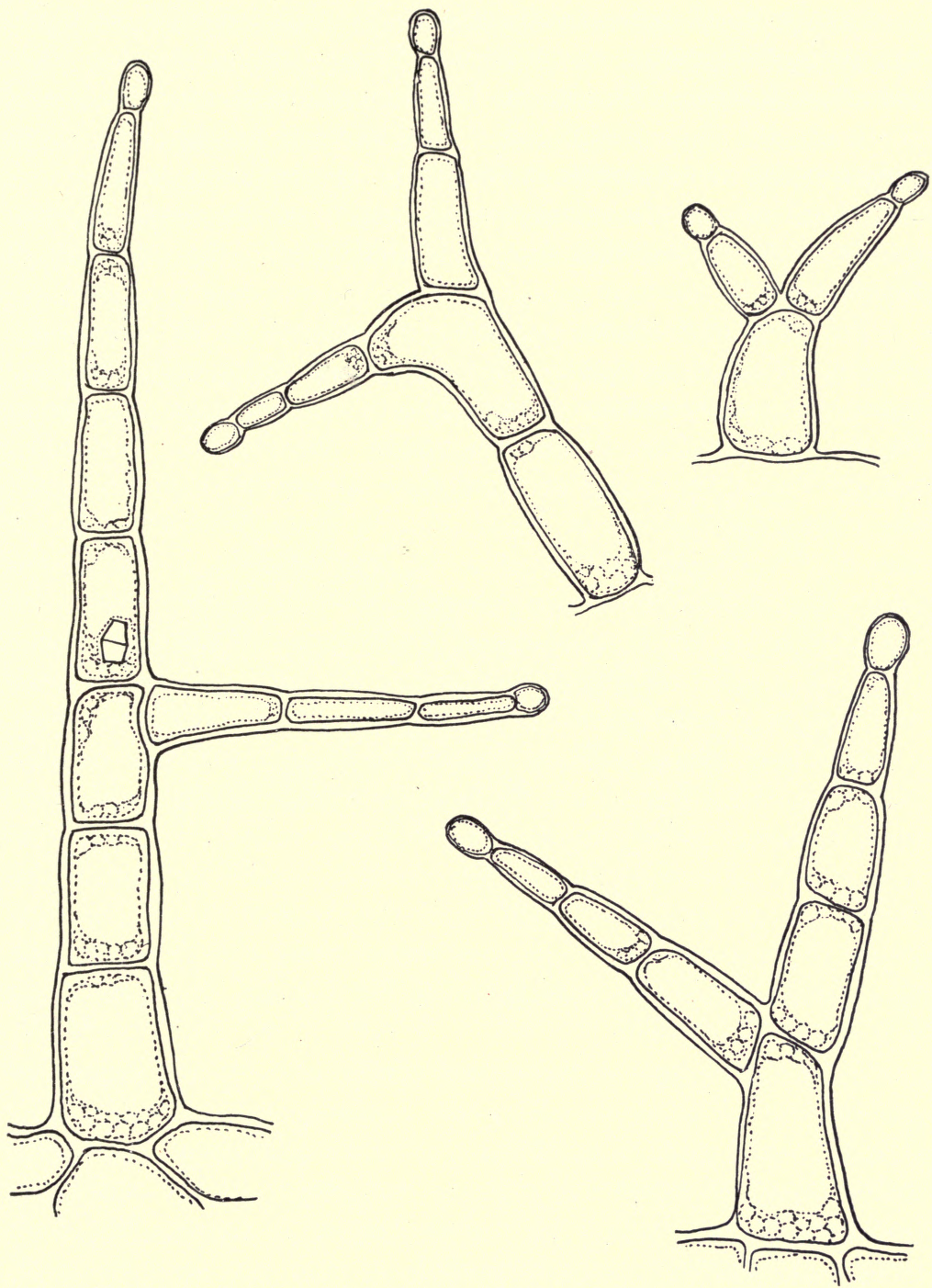

FIG. I55,- Characteristic branching hairs found on the stem, leaves, and calyx of Hyoscyamus muticus.

stinging hairs of some of the Euphorbiaceæ, as well as in some of the genera of the Cornaceæ, Geraniaceæ, Rosaceæ, and Saxifragaceæ. 
Lignified Hairs. - In some seeds, as in nux vomica, the hairs are strongly lignified, as are also the bases of the hairs of Strophantus hispidus. This is due to a lignocellulose modification of the wall, and, since broken hairs look more or less like fibers, one might easily be led astray in the study of powdered drugs. It is not usual to make a microchemical study of the walls of nonglandular hairs, but this subject is well worthy the attention of investigators.

False Plant Hairs.-While it is impossible for the careful student of plant morphology to mistake anything else for plant hairs, it is, nevertheless, worth while to call attention to some of the mistakes that are liable to be made. In works on systematic botany sometimes occur contradictory statements concerning the abundance or scarcity of hairs, especially as they relate to the flower. In a superficial examination, for instance, in the violets, large masses of germinating pollen grains with their tubes matted together are not at all uncommon in the throat of the corolla, and these have been mistaken for hairs. Furthermore, the mycelia of fungi may be mistaken for hairs, especially in young seedlings, as of hyoscyamus, belladonna, etc., where thread-like delicate branching hairs may occur. In the examination of economic products, especially powdered drugs and spices, mistakes of this kind may occur, unless the student has devoted some attention to this study. In all studies of plant hairs the student should carefully locate the summits and bases, and unless these can be recognized, or if broken made to correspond to each other, one cannot say that hairs are present.

CoRk CELLS replace the epidermal cells of roots and stems that persist year after year. They are formed, as has already been stated, from a distinct meristem, called the phellogen. Cork cells differ from the epidermal cells in that the walls are uniformly thickened and on surface view are polygonal in shape. The walls consist of suberin, a substance allied to cutin; in some instances they also contan lignocellulose, forming cork stone-cells, as in asclepias and calumba. The young cells may contain a thin layer of cytoplasm and a nucleus; they usually also contain brownish masses of tannin or tannin-like compounds, and occasionally crystals of cerin or calcium oxalate. 
Cork not only occurs as a secondary protective layer, but may also arise in other parts of the plant as a result of injury, as in leaves, fruits, stems, and tubers. It also arises as a result of the disarticulation of the leaf in autumn.

Periderm.-The epidermis is not adapted for the protection of the perennial plant organs on account of its thin, frequently delicate structure and its inability to continue with the increase in thickness of stems and roots. Hence it becomes replaced by the periderm, which consists of a lasting tissue, the CORK, and of a meristematic tissue, the PHELlogen, which reproduces the cork when it becomes torn or destroyed, by the continued growth in

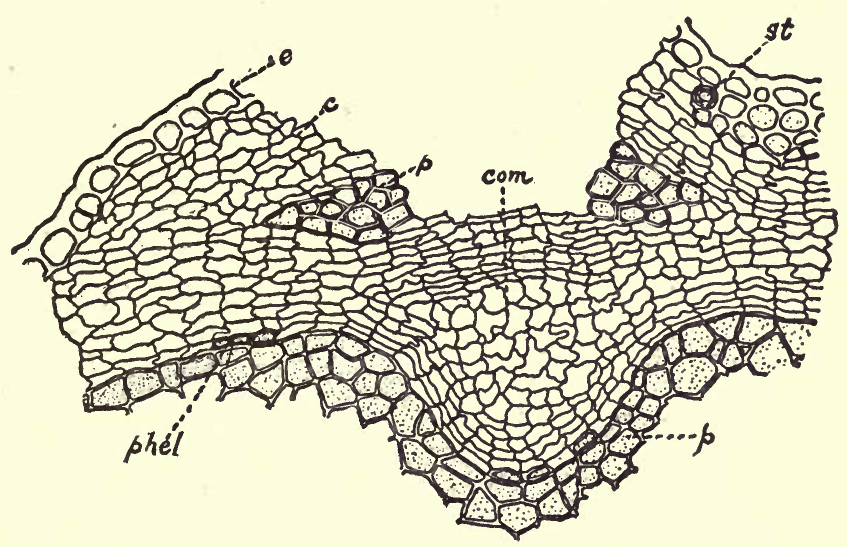

FIG. I56. Section through a secondary lenticel in the bark of Sassafras; e, epidermis: st, stone cells; phel, phelloderm derived from secondary phellogen and having thick ligni. fied wall; p, parenchyma; c, cork; com, complementary cells.-After Weiss.

thickness of stems or roots. Cork is not only of sub-epidermal origin, but may occur deeper in the cortex (Fig. I58), or even inside the endodermis. In the latter case, as in roots, it owes its existence to the activity of the pericambium. Superficial, i.e., hypodermal cork, is extremely rare in roots. Not infrequently a layer of cells is formed inside of the phellogen, being termed the phelloderm. They usually contain plastids; the walls are moderately thick and free from intercellular spaces (Fig. I56).

Lenticels may be described as biconvex fissures in the periderm which permit of the easy access of air to the intercellular spaces of the rather loosely arranged cells lying beneath them (Fig. 
I56). They usually arise as the product of a meristem situated beneath the stomata of the epidermis, the stomata being replaced by them when cork is developed. Several types of lenticels are

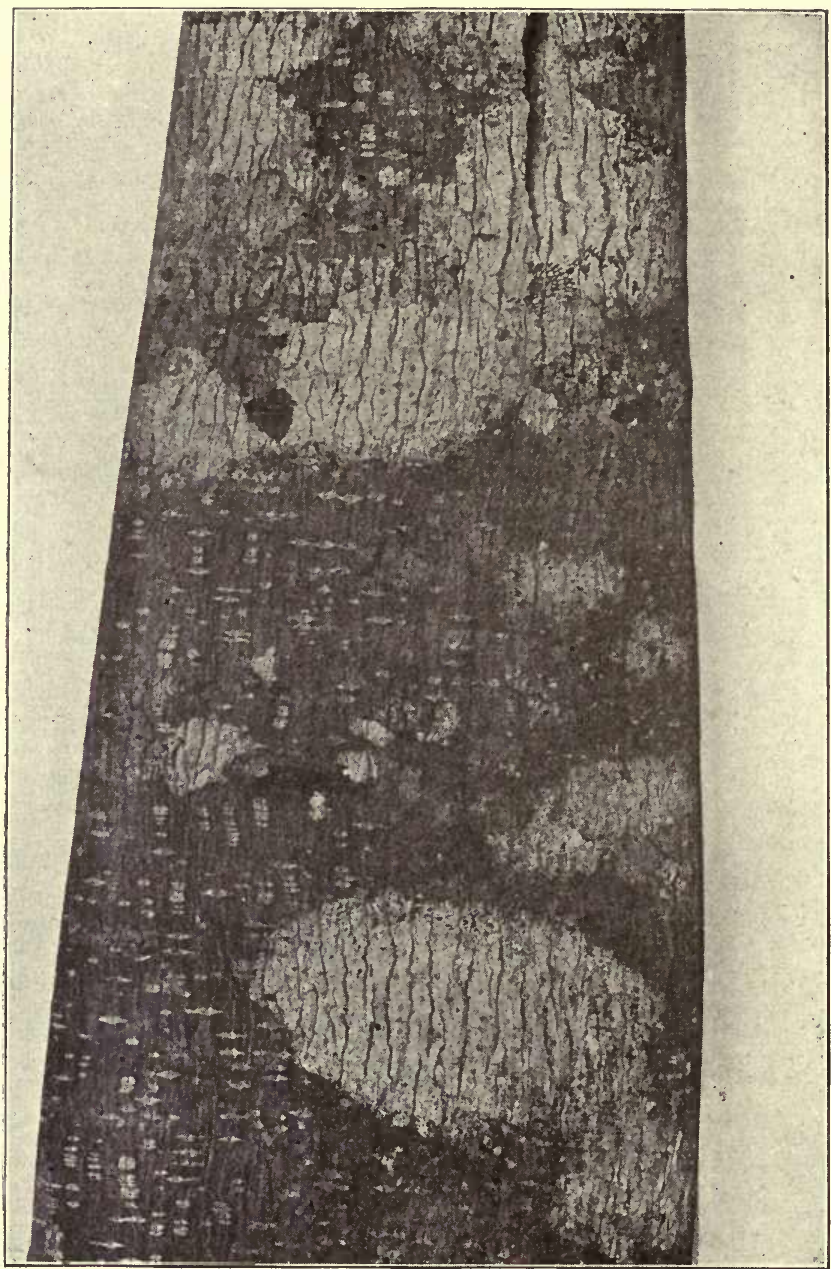

Fig. I57. Bark of Rhamnus Purshiana showing large whitish patches of lichens, and numerous lens-shaped lenticels.

distinguished. They are quite characteristic and prominent in a number of barks, as those of species of Betula, Prunus, Rhamnus (Fig. I57), etc. 

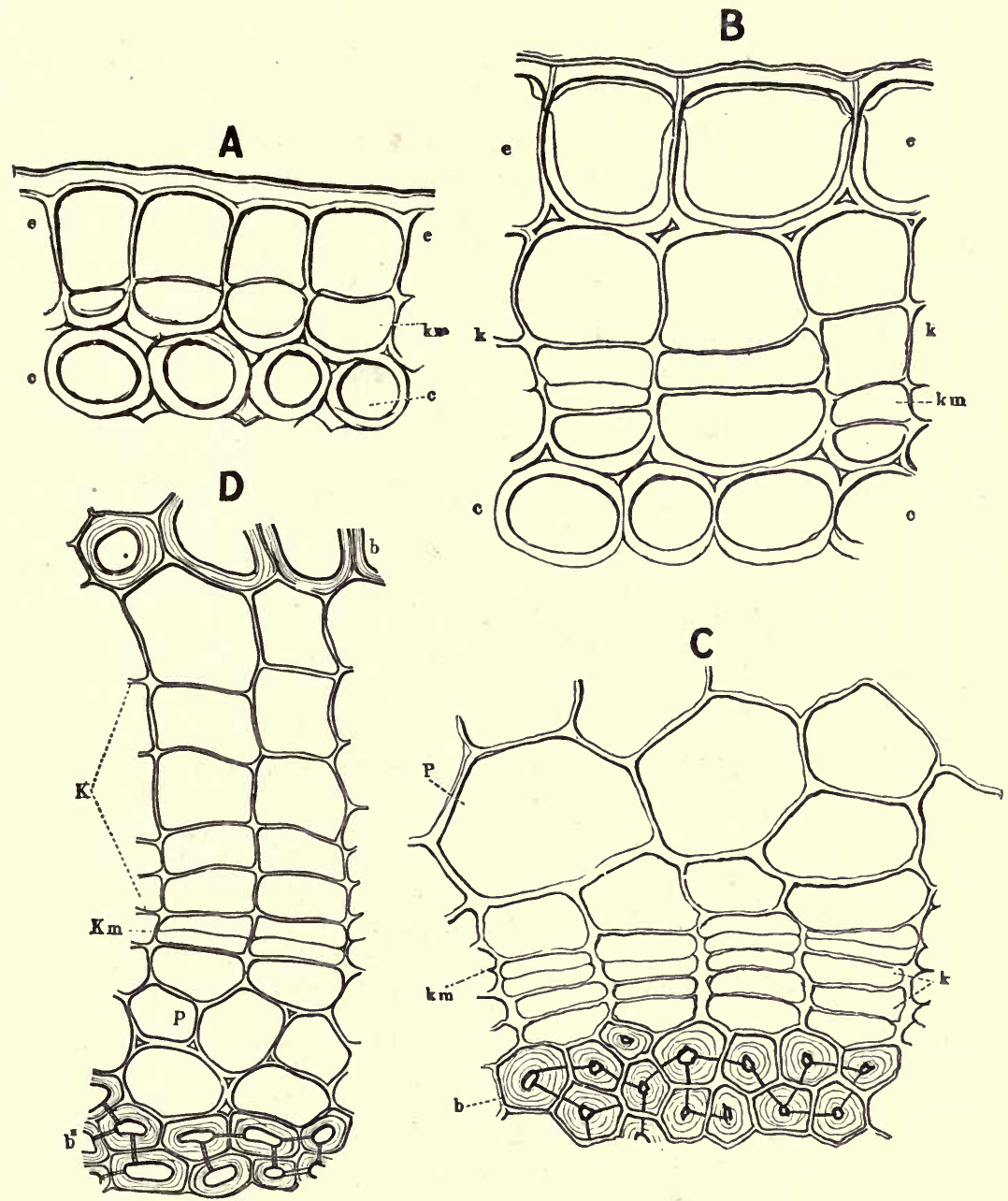

FIG. I58. Development of Cork: A, in epidermal cells of stem of Oleander; B, development of cork in upper row of collenchymatous cells in the stem of Sambucus nigra; C, development of cork meristem in cells of cortex immediately above the primary bast fibers in Rubus fruticosus; D, development of primary cork in cells above the secondary bast fibers of Clematis Vitalba; e, epidermal cells; k, cork; km, cork-meristem; c, collenchyma; b, parenchyma; $b, b$, primary bast fibers; $b$ ', secondary bast fibers; $K$, young cork cells.-After Dippel in "Das Mikroskop."

Bork.-The cork cambium or phellogen develops before maturity in the green stems of woody plants belonging to the dicotyledons. It may develop in the primary or secondary tissues 
(Fig. 158). When the phellogen develops in the deep-seated tissues, the cells outside of the corky layer sooner or later die and slough off. This is due to the fact that the cork cells are suberized and do not permit the passage of the cell-sap containing food substances. In large shrubs and trees with thick stems and trunks
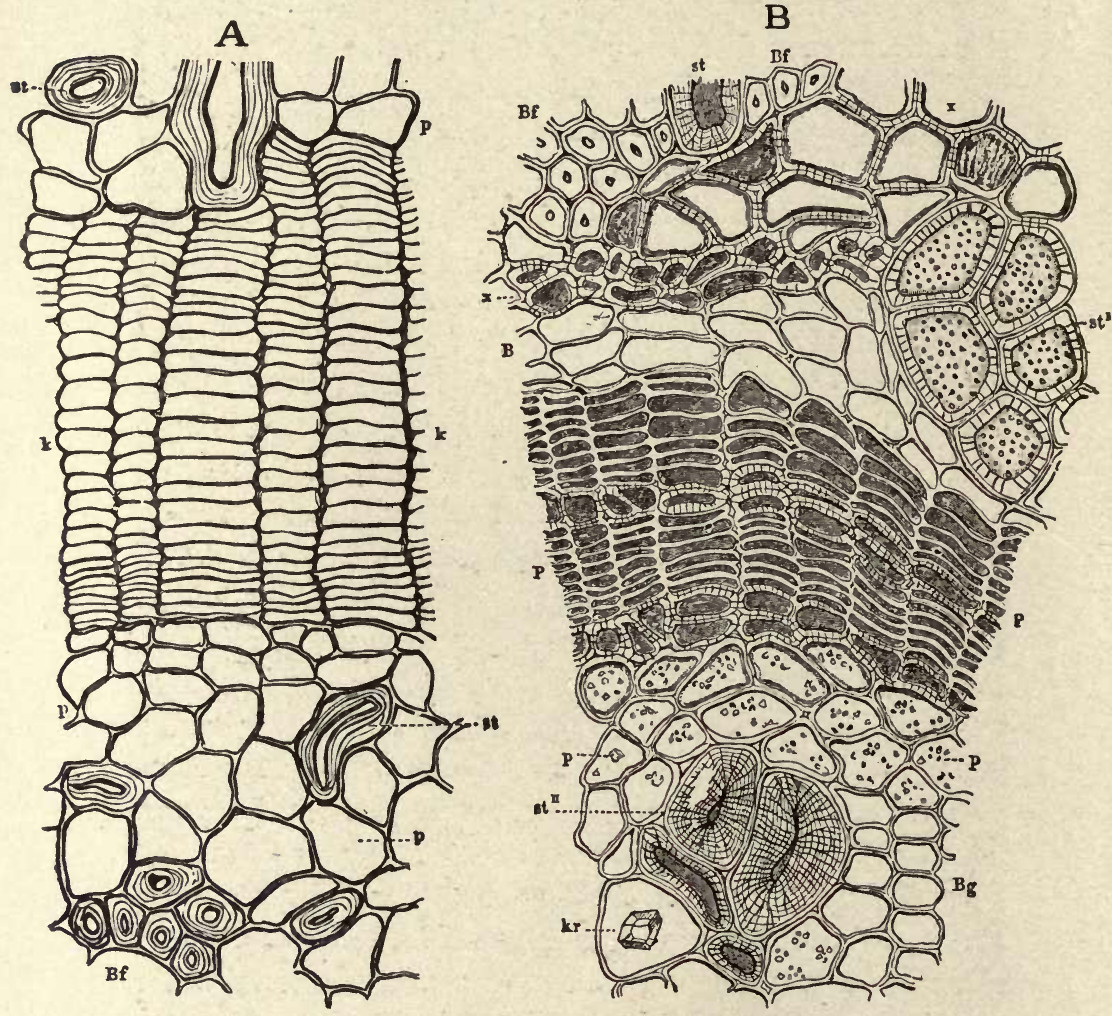

FIG. I59. Development of Bork: A, in bark of cherry (Prunus Cerasus), showing a layer of periderm (k) with thin-walled cork cells; bast fibers (Bf); parenchyma ( $p$ ); stone cells (st) occasionally branching and lengthened into fibers. B, inner layer of periderm of Quercus Robur, showing compactly arranged, thick-walled cork cells (P) filled with a reddish phlobaphene or altered tannin; starch-bearing parenchyma ( $p)$; stone cells (st); sieve tubes $(\mathrm{Bg})$; bast fibers $(\mathrm{Bf})$; prism of calcium oxalate $(\mathrm{kr})$; several rows of thickwalled, porous cells (x).--After Dippel in "Das Mikroskop."

a number of successive layers of cork or periderm are formed. These layers with the dead cortical tissues between them persist to some extent and constitute what is known as bork, i.e., bork consists of a number of alternate layers of periderm and cortical 
tissues. The cork cells in different trees are variously developed and accordingly two types of bork formation may be distinguished. In sycamore, cherry and plum trees the cork cells are only slightly thickened (Fig. I59) and the periderm in the form of layers

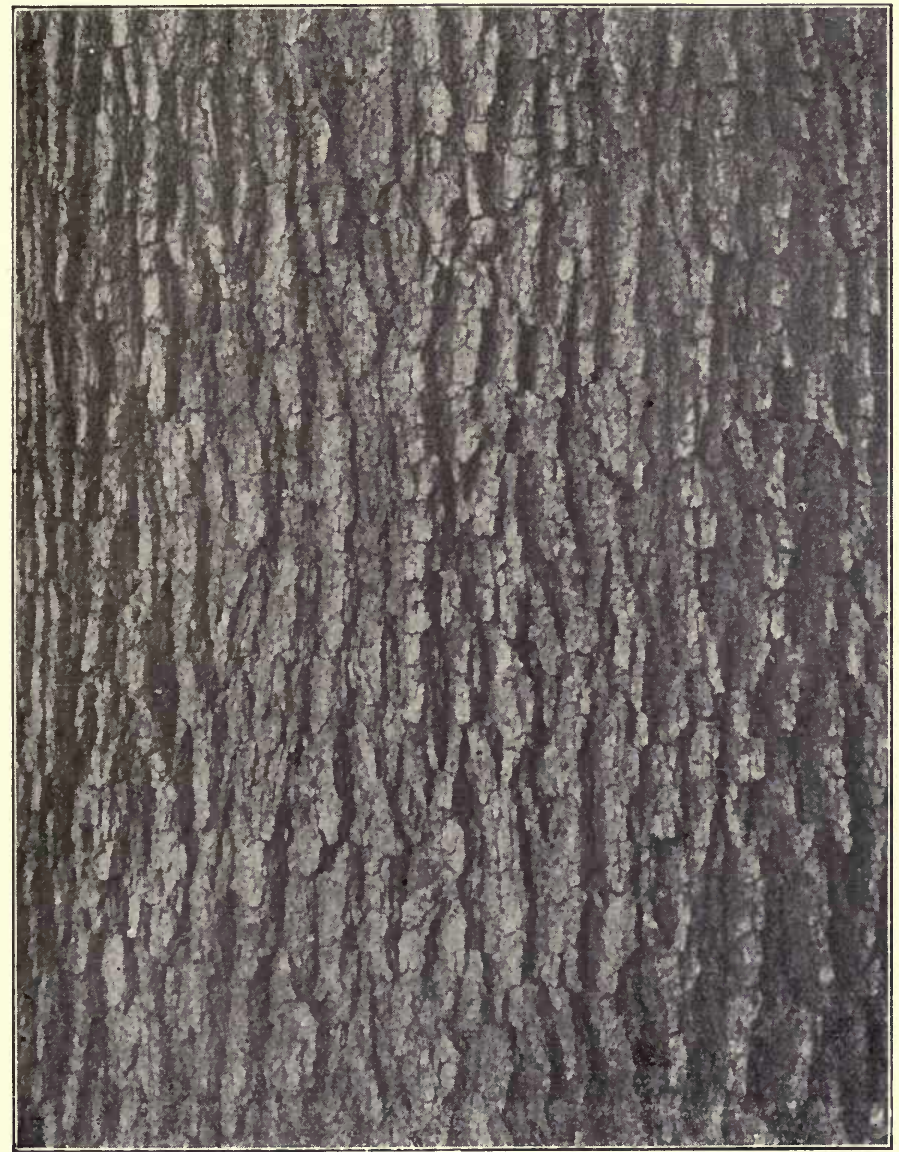

FIG. I60. White oak bark with the fissured corky layers (bork).

separates from the tree annually. In the oaks, chestnuts and tulip poplar the cork cells (Fig. I59) are thick walled and compactly arranged so that, under the stress of growth and thickness of the bark, the layers of periderm are split longitudinally, giving 
rise to the deep furrows (Fig. I60) which are so characteristic of the outer surface of our large trees.

Laticiferous or milk tissue occurs in all those plants which emit a milk-juice on being cut or otherwise wounded. The juice may be colorless, as in the oleander; whitish, as in the Asclepiadaceæ, Apocynaceæ, etc.; or yellowish, as in the Papaveraceæ. It contains caoutchouc, oils, resins, mucilage, starch, calcium oxalate and alkaloids as well. The walls are relatively thin and consist chiefly of cellulose. The tissue consists either of single cells of definite length, as in the Papaveraceæ, or the cells may be of indefinite length, as in the Asclepiadaceæ, or it may consist of a more or less branching network (Fig. 127) formed by the anastomosing of a number of cells, as in Taraxacum (consult paragraph on Latex, pp. 238-24I).

As has already been stated, the latex of plants contains a number of plastic or trophic substances,-i.e., those which, either at once or after being stored for a time as reserve food, are drawn into metabolism and serve as nutrient material. They also contain a number of aplastic or non-trophic substances, as caoutchouc, resin, alkaloids, volatile oils and tannin, which are in the nature of metabolic by-products and are incapable of further metabolism. While it is highly probable that the laticiferous tissue, on account of its being always associated with the phloem, functions to some extent for the transportation of plastic substances, yet it serves another purpose, viz., to protect the underlying cells after injury of the plant by insects or herbivorous animals. This protection results from the rapid coagulation of the exuding latex upon exposure to the air and forming a varnish-like surface. In some cases the latex contains a poisonous principle which exercises a protective function. In Rhus Toxicodendron the principle causing the eczema, namely toxicodendrol, is supposed to be formed in laticiferous tissues being transferred to the hairs, which upon being broken liberate the poison. 
CELL-CONTENTS AND FORMS OF CELLS. 297

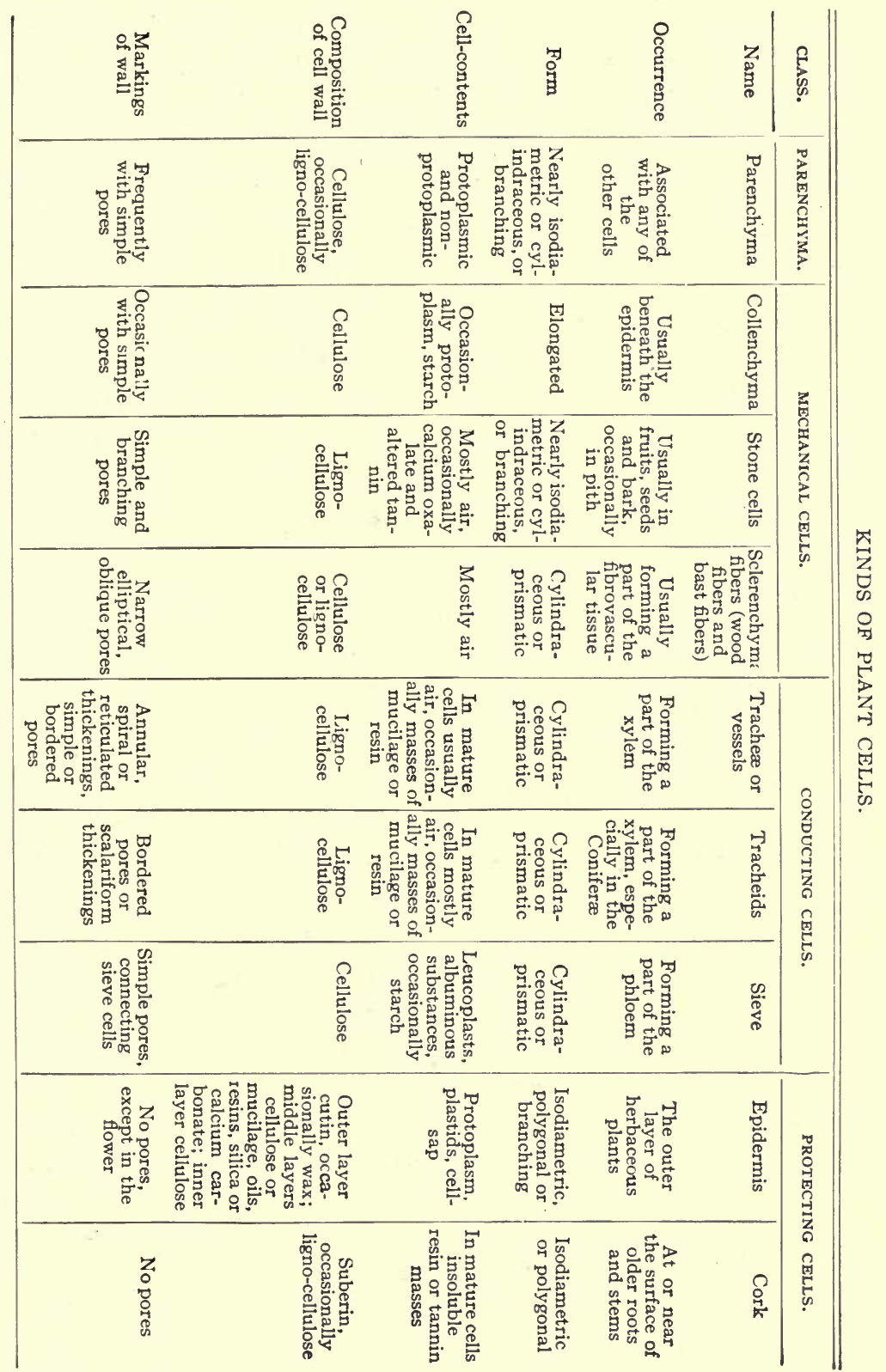




\section{THE OUTER AND INNER MORPHOLOGY OF HIGHER PLANTS.}

INTRODUCTORY.

IT may be well to repeat at this point that on germination of the megaspore the female gametophyte bearing the egg-cell is formed, and that on germination of a microspore the male gametophyte bearing male nuclei is organized. The union of egg-cell and a male nucleus gives rise to the sporophyte embryo contained in the seed, which develops into the plant we see, namely, the sporophyte. The female gametophyte always remains concealed within the embryo-sac, and the male gametophyte may be said to embody the protoplasmic contents of the pollen tube.

A complete flower is made up of floral leaves and sporophylls, the latter being essential for the reason that they give rise to the spores. While the flower belongs to the sporophyte generation, the propagative organs may be said to be derived from both the sporophyte and gametophyte, and hence may be distinguished as asexual and sexual. The following outline illustrates their derivation:

Propagative Organs
Sexual, derived from gametophytes (sexual generation)

Egg-apparatus, containing egg-cell or female gamete

Male Generative-cell, giving rise to male nuclei or male gametes

Microsporangium (pollen sacs) giving rise to microspores ( $\mathrm{p}$ oll e $\mathrm{n}$ grains)

Asexual, derived from sporophyte (asexual generation)

Megasporangium (nucellus) giving rise to megaspore (embryo-sac) 
The vegetative organs comprise the root and shoot, the latter being usually differentiated into shoot axis or stem, and leaves. The usual type of shoot is one which bears leaves and is exposed to the light. The work of carbon dioxide assimilation (photosynthesis) being carried on for the most part by the leaves, the axis is sometimes spoken of as the "assimilation shoot."
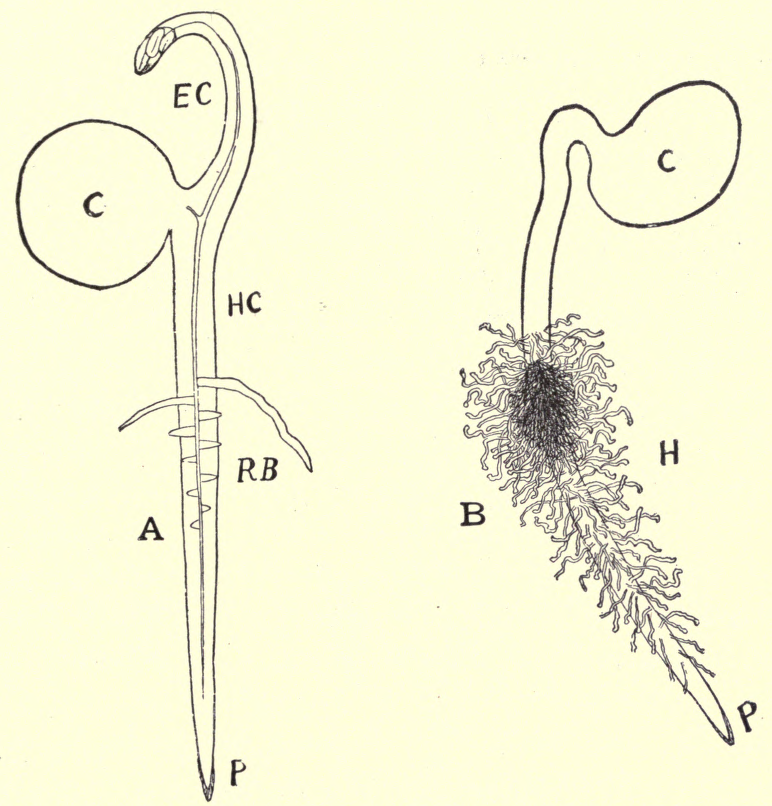

FIG. I6r. A, advanced stage of germination of the common garden pea (Pisum sativum) showing growing point of root protected by root-cap (p); root branches or secondary roots (rb); hypocotyl (hc); epicotyl or stem above the cotyledons (ec); cotylecions (one in view) (c). B, plantlet of white or yellow mustard (Sinafis alba) showing copious development of root-hairs $(\mathrm{h})$.

\section{OUTER MORPHOLOGY OF THE ROOT.}

THE Root, or descending axis of the plant, normally penetrates the soil, absorbing inorganic substances in solution and acting as an anchor and support for the shoot. True roots are found only among plants having a vascular system, as the Spermophytes and the higher Pteridophytes, although, on the other hand, some of the higher plants do not possess them, as certain of the saprophytic orchids and some of the aquatic plants as Utricularia, 
Lemna, etc. If we take a germinating plant and mark the root into ten equal divisions, beginning at the apex, and place the plant in a moist chamber, it will be found in the course of one or two days that the marks between I and 5 have become much

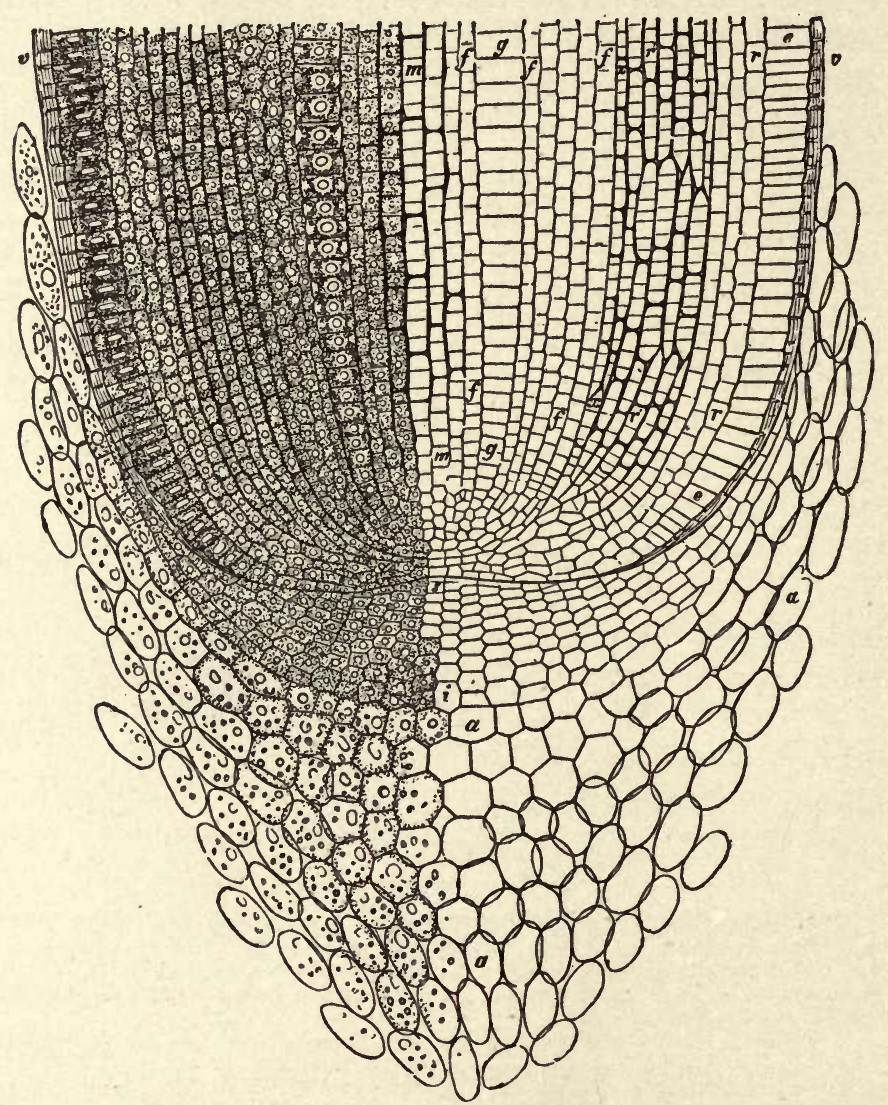

FIG. I62. Longitudinal section through the tip of the root of Indian corn (Zea Mays) showing root-cap: a, outer layer; $i$, inner layer.-After Sachs.

farther apart, and that the growth in this region is about three times that between 5 and ro. This experiment indicates that the growth of the root takes place at or near the apex, this region being known as the point of growth, or point of vegetation (Fig. I62). 
Upon examining the tip of a very young root by means of the microscope, it will be seen that the growing point is protected by a cup-shaped body of a more or less solid structure and frequently mucilaginous; this is known as a ROOT-CAP. Its function is to protect the growing point, and it exists in all roots of terrestrial, epiphytic, and aquatic plants except the parasites.

Just above the root-cap there is developed a narrow zone of delicate hairs, which arise from the surface cells and are usually thin-walled and unicellular. These are known as ROOT-HAIRS (Fig. I6I, B) and their function is twofold: (I) They secrete an acid which renders the inorganic substances of the earth soluble, and (2) they absorb these and other substances for the nourishment of the plant. It should be stated that there are a number of plants which for various reasons do not possess root-hairs, such as water-plants, marsh-plants, certain Coniferæ, Ericaceæ, etc.

When the primary root persists (as in Gymnosperms and Dicotyledons.) it increases considerably in length and becomes ramified; if, at the same time, it increases in thickness, and much more so than its branches, then it is called a TAP-ROOT (as in Dancus Beta, etc.).

In the vascular cryptogams (Pteridophytes) and the monocotyledons the primary root is generally thin and weak, frequently but little ramified, and disappears at an early stage, being replaced by SECONDARY ROOTS, as in Zea. Secondary roots may arise not only upon the stem but even upon leaves, as in Begonia and Bryophyllum. The term LATERAL ROOTS is restricted to those that develop from the root alone.

The development of roots upon shoots or of so-called " $\mathrm{AD}$ ventitious Roots" occurs in nearly all of the woody plants of the Spermophyta. Many annual herbaceous plants do not possess this capacity at all. The adventitious roots arise from "rootprimordia" which are formed under the cortex of the shoots. While ordinarily they do not develop upon the shoots, yet if cuttings are made, as of Coleus, Geranium, Rosa, etc., we find " either singly or on both sides of the axillary buds" the development of adventitious roots from the latent root-primordia.

Influence of Gravity.-The root is popularly supposed to grow downward, in order to avoid the light. On the other hand, 
the theory has been established (as a result of Knight's experiments) that the root grows downward by reason of the influence of gravity. In addition it may be said that the principal functions of the root, namely, those of absorbing inorganic food materials and of fixing the plant to the soil, determine in a measure the direction of its growth. The tendency of the root to grow downward is a characteristic which distinguishes it from other parts of the plant, and it is said to be positively Geotropic (Fig. I63, A).

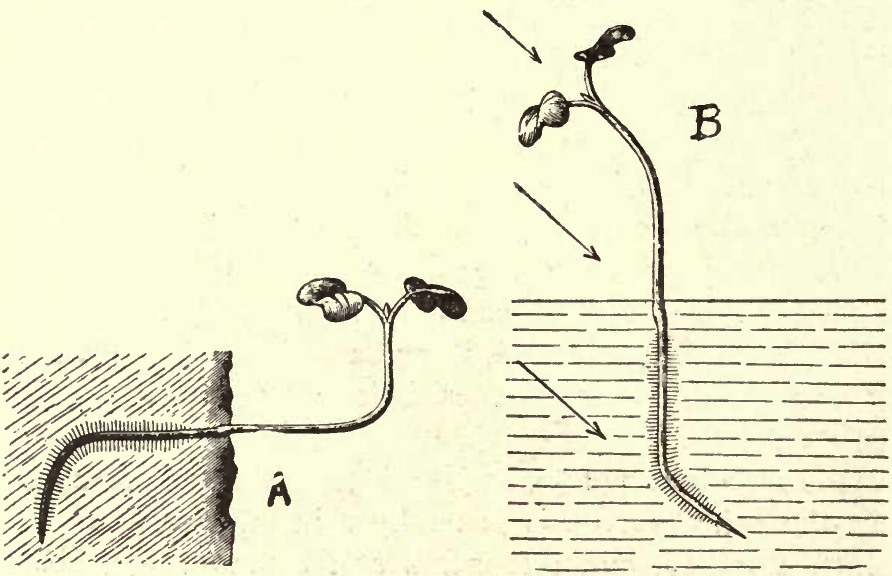

FIG. 163. A, seedling of Brassica nigra in which root and stem have curved into a vertical position after being laid horizontally. B, seedling of Sinapis alba, the hypocotyl showing a positive, the root in water a negative heliotropic curvature. The arrows show the direction of the incident rays of light.-After Pfeffer.

The influence which gravity has on plants may be best understood by bearing in mind that gravity is a constant force which acts perpendicularly to the surface of the earth, and that all parts of the plant are subject to its influence. The organs of plants respond in different ways to the action of gravity, but a clear distinction should be made between mere mass attraction, or that manifestation of the force of gravity whereby the heavily laden branch of a fruit tree bends downward, and the stimulus which causes the primary root of a plant to grow downward and the shoot to grow upward. While all parts of the plant are subject to the influence of gravity, not all the organs of plants respond in an equal degree. This is well illustrated by roots themselves. 
It is well known that, whatever the position of the seed at the time of germination, the young radicle begins to grow perpendicularly downward (Fig. I63, $A$ ). The branches, however, which arise on the primary root are less positively geotropic and, instead of growing downward parallel with the primary or tap root, diverge at an angle from it (Fig. I6I). The secondary branches are still less affected by gravity and diverge still more from the perpendicular, or grow out horizontally, while still others do not

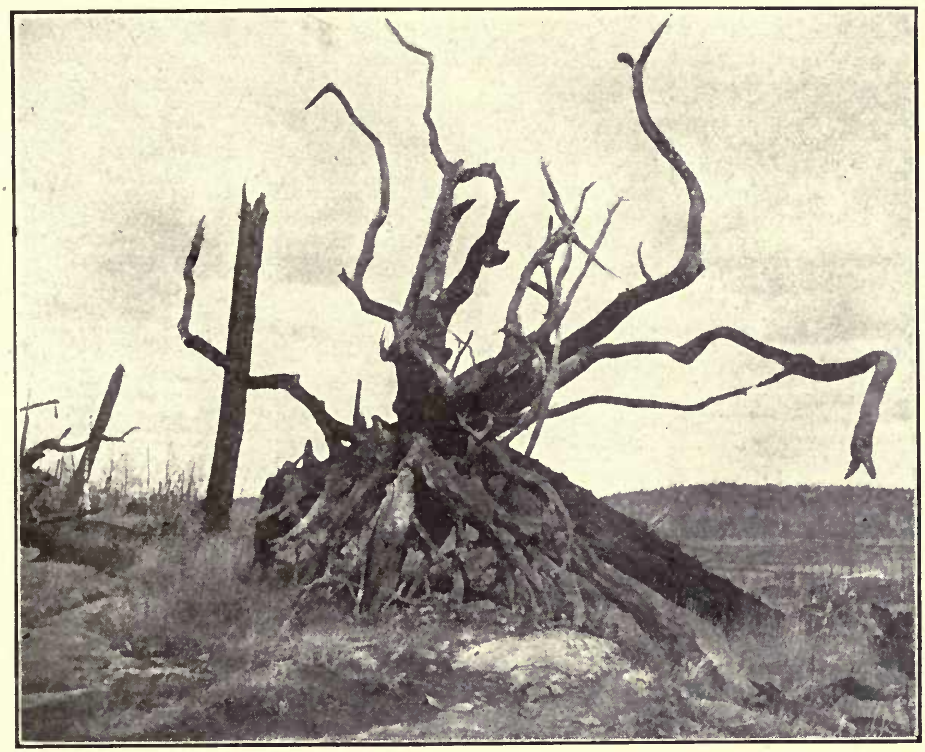

FIG. I64. Over-turned tree trunk showing spreading root-system, the main or tap root having died away

appear to be in the least affected by gravity and grow freely in any direction. In the case of large trees we frequently find that the lateral roots spread out in a more or less horizontal plane near the surface of the earth, and if the main root has died the influence of gravity is not very evident (Fig. I64). But here it must be remembered that gravity was instrumental in determining the direction of growth at an earlier stage. This spreading of the roots near the surface of the earth is of decided advantage to plants, for it enables them to avail themselves of the better soil of the surface 
layers. As indicated, gravity also determines the upward perpendicular direction of the shoot, which is therefore said to be NEGATIVELY GEOTROPIC, but, as in the case of the root, the branches are less influenced by it and hence diverge at various angles from the main axis.

Some of the other effects of gravity may be noted. If the end of a shoot be cut off, the branches next to the top will grow per-

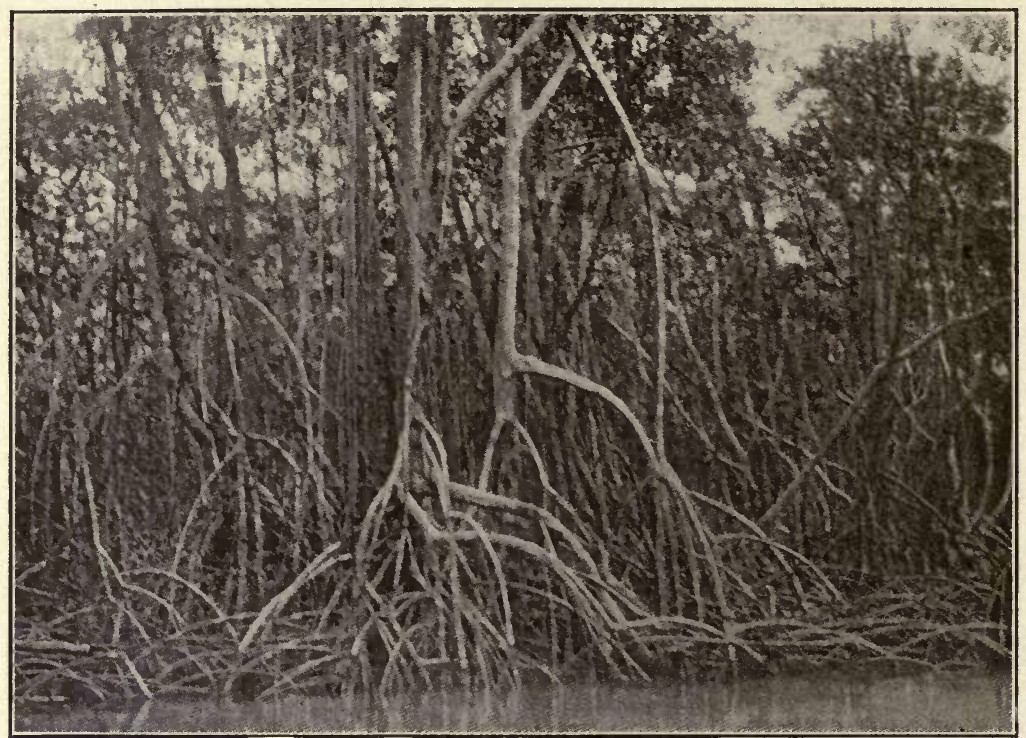

Fig. I65. Mangrove forest (Rhizophora Mangle), showing the habit of growth, especially the numerous aërial roots which form an almost impenetrable thicket. The mangrove is common along the southern shores of Florida, in the Bahama Islands, and in the West Indies. Many shellfish, lobsters, and other forms of sea life are often found clinging or attached far up on the roots where they become lodged during high tides.-Photograph from article by Henry Trimble on Mangrove Tannin in Contributions from the Botanical Laboratory of the University of Pennsylvania, I892, p. 50.

pendicularly upward and thus assume the work of the main axis. Likewise in the case of roots, if the apex of the main or tap root be cut off, the branches near the end will assume a perpendicular direction. It will frequently be noticed in the case of trees which have been uprooted or where branches have been bent over horizontally that the new branches which arise grow perpendicularly upward. Creeping shoots furnish another good example showing 


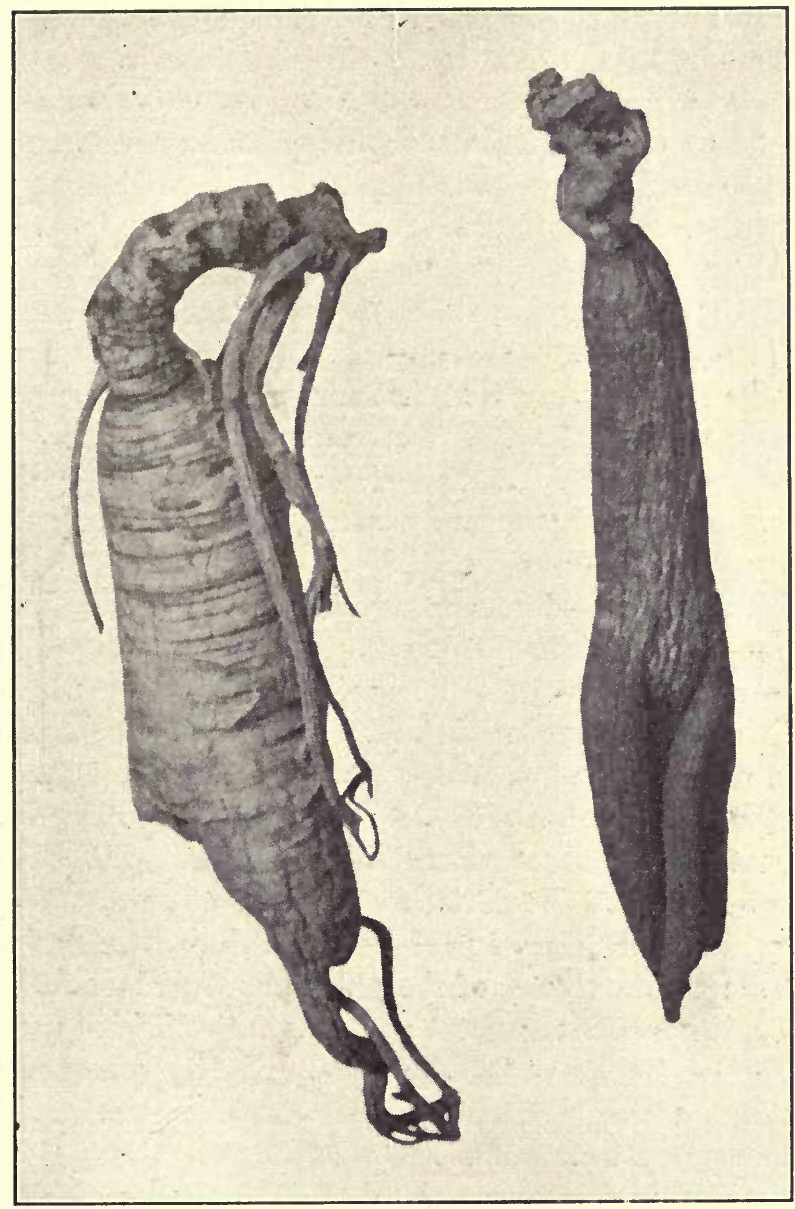

FIG. I66. Tuberous root of Ginseng (Panax quinquefolium). The root on the left is a fresh specimen and was grown in the United States. The one to the right was purchased at a Chinese bazaar. It is translucent, of a yellowish-brown color, and has the characteristic shape and markings considered desirable by the Chinese. The markings on the upper segment of the specimen are stem scars which are usually found on old roots. The translucent appearance is no doubt due to the manner of treatment. While the method is not generally known, similar specimens may be prepared by treating the recently gathered roots with freshly slaked lime.

the influence of gravity, the branches growing upward and the roots downward.

The root exerts a certain amount of upward pressure on the liquids in the stem. This fact can be demonstrated by cutting off 
the stem just above the surface of the earth and attaching thereto a glass tube by means of a tightly-fitting rubber tube. It is desirable to perform this part of the operation under water and to have the glass tube partly filled with water at the beginning of the experiment. This is done to prevent the clogging up of the vessels with air, which prevents the ready passage of fluids through them. If the root is now kept moist, the osmotic pressure 'of its cells forces water up into the glass tube, sometimes to a height of several feet. Experiments on the begonia and on many other plants succeed very well, but for some reason the geranium is impracticable to work with. The manometer devised by Ganong, while not showing the quantity of water forced up by the root, shows the amount of pressure exerted, which is really the most important fact to be ascertained.

Modified Roots.-Roots which arise from the nodes of the stem or other parts of the plant are known as secondary or adventitious roots. These include the aërial roots of the banyan tree and the Mangrove (Fig. I65), which are for the purpose of support; the roots of the ivy, which are both for support and climbing, and the roots of Indian corn and many palms which serve both for support and the absorption of nourishment. Under this nead may also be included the aerrial roots of orchids and the root-like structures, or haustoria, of parasites, as of mistletoe and dodder, which penetrate the tissues of their host plants and whose vascular strands come into most intimate relations with those of hosts.

Of special interest also are the breathing roots of certain marsh-plants which serve to convey oxygen to the submerged parts; and the assimilation roots of certain water-plants and epiphytes, which are unique in that they produce chlorophyll. In certain plants the roots give rise to adventitious shoots, as in Prunus, Rubus, Ailanthus, etc., and in this way these plants sometimes form small groves.

Root Tubercles.-The roots of the plants belonging to the Leguminosæ are characterized by the production of tubercles, nodules or swellings (Fig. I67) which have been shown to have a direct relation to the assimilation of nitrogen by the plants of this family. Like carbon, nitrogen is one of the elements essential to plant-life, being one of the constituents of protoplasm and 
present in various nitrogenous (protein) compounds which occur as normal constituents of the plant. The nitrogen required by plants is derived either from nitrogen salts contained in the soil, as nitrates and ammonium salts, or from the free nitrogen of the atmosphere. While most of the higher plants are able to assimilate nitrogen compounds existing in the soil, only the Leguminosæ and Aristolochiaceæ, with possibly a few exceptions, are able to assimilate atmospheric nitrogen, and in this respect the

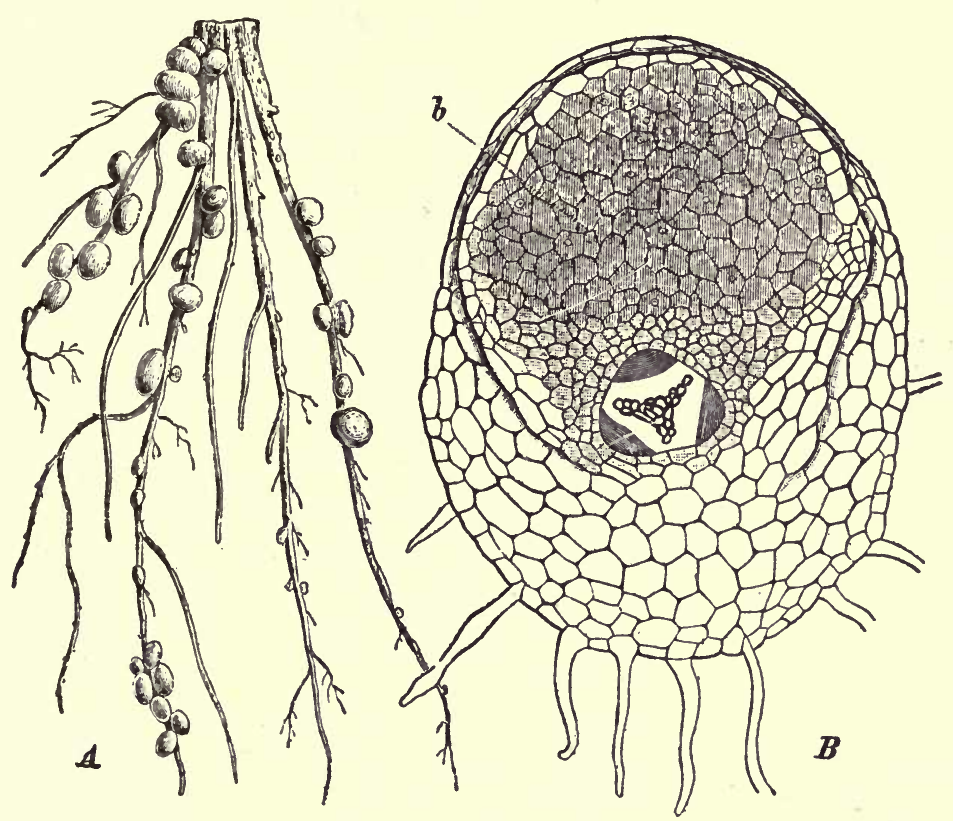

Fig. 167. Root tubercles on Lupinus, one of the Leguminose: A, roots with tubercles; B, transverse section of root showing the cells (b) which contain the nitrogen bacteria.A. after Taubert: B, after Frank.

majöi-y of the Leguminosæ stand as a class by themselves. Apparently in direct relation to this character stands the fact that the seeds of these plants contain a high percentage of nitrogen. This special ability of the Leguminosæ to fix atmospheric nitrogen in the plants depends upon the presence of the nodules, which are due to the infection of the roots by a soil-bacterium (Pseudomonas radicicola), although the precise mode of fixing the nitrogen is 
not known. The bacteria seem to be localized in the nodules and are not found in any other part of the plant.

It has been shown that when the roots of leguminous plants are free from nodules they do not have the power of assimilating free nitrogen. On the other hand, when the nodules produced by the bacteria are developed, the plants will grow in soil practically free from nitrogen salts. Because of this power the plants of this family are useful in restoring worn-out land, i.e., land in which

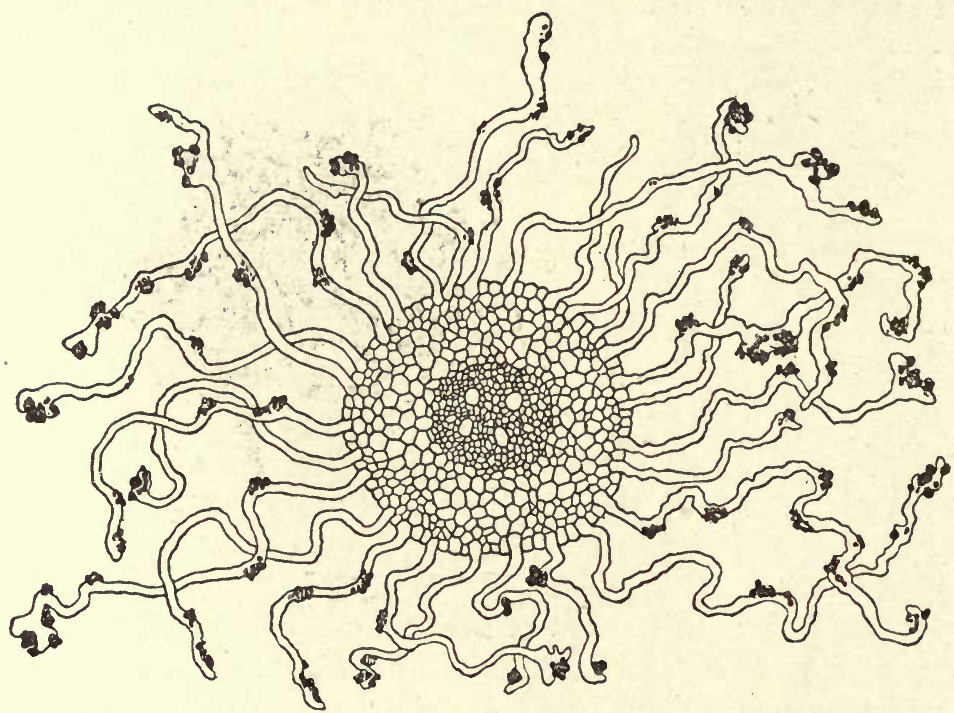

FIG. I68. Transverse section of a root bearing root hairs; the latter are thin walled, irregularly bent, and attached at various places to small particles of soil. The hairs secrete an acid, rendering the inorganic substances soluble, which are then diffused through the walls of the hairs, transmitted to the cortical parenchyma and distributed through the conducting cells of the xylem to the shoot.-After Frank.

the supply of nitrogen is exhausted, and they thus play an important rôle in agricultural pursuits.

The enriching of the soil is accomplished by ploughing under the leguminous crops, as of clover or alfalfa, or allowing the nodule-producing roots to decay, when the nitrogen compounds are distributed in the soil.

(Consult Bulletins on " Soil Inoculation for Legumes," issued by the Bureau of Plant Industry, U. S. Department of Agriculture.) 
THE INNER STRUCTURE OF THE ROOT.

Primary Structure.-If we make a transverse section of the young portion of a root (Vascular Cryptogam, Gymnosperm, or Phenogam), we notice the following tissues (Figs. I69-I74). The outermost tissue is EPIDERMIS (E), it being generally thinwalled and destitute of cuticle; it is, as a rule, hairy, and these hairs, which are relatively long, but always unicellular, are known as ROOT-HAIRS (Figs. I6I, I68); they ramify but very seldom. Inside the epidermis there is frequently present a HYPODERMIS

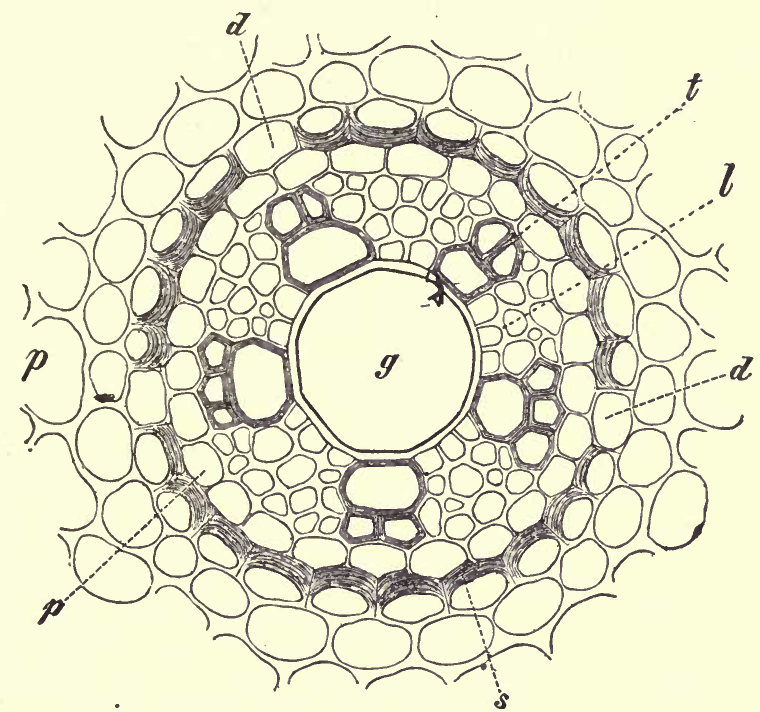

Frg. 169. Radial vascular bundle in root of Allium ascalonicum, showing a large central trachea from which radiate five small groups of tracheæ and between which are the groups of leptome or sieve; p, layer of pericambium or pericycle; d, transition cells or passage cells in the endodermal layer, and which permit the easy transfer of substances between the cortical parenchyma and the tracheæ of the stele.-After Haberlandt.

(sometimes referred to as an ExODERMIS) composed of a single layer of cells or, at the most, of but several layers, the cells of which differ in shape and size from those of the epidermis and the adjoining cortical parenchyma. The hypodermis takes the place of the epidermis when the latter is worn off, except in the few cases where hypodermal cork becomes developed, as in Cephalanthus, Solidago, and in the Bignoniaceæ.

The root bark is composed of parenchymatous cells, being 
commonly referred to as the CORTEx, and is either homogeneous or divided into two zones, the outer or peripheral being composed of thick-walled cells which naturally belong to the hypodermis and an inner or internal strata made up of thin-walled cells. The cells of the cortical parenchyma may contain starch, calcium oxalate, calcium carbonate, and there may be associated with them

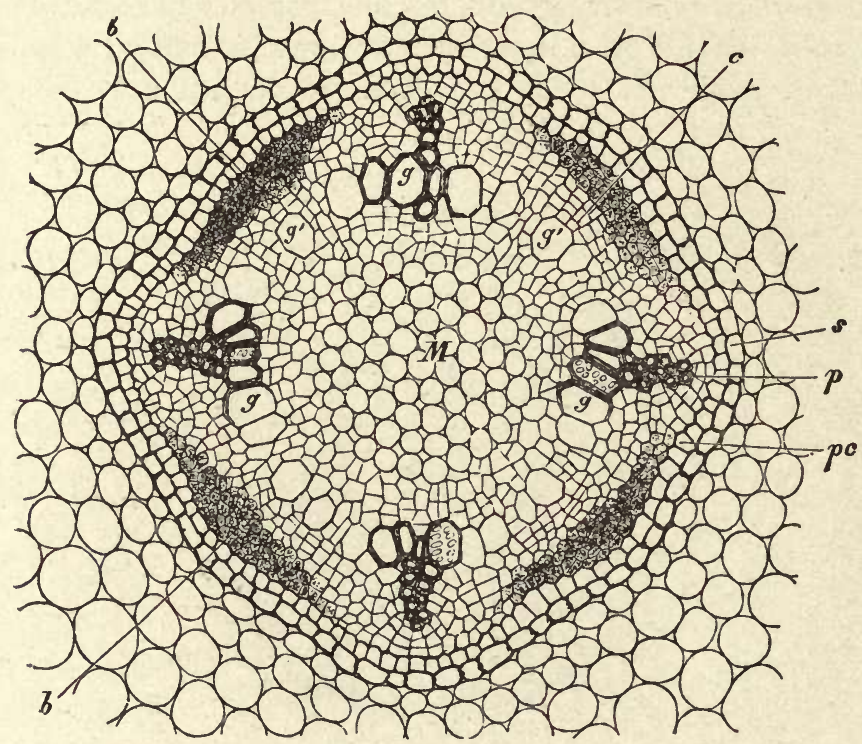

Fig. I70. Cross-section of the primary root of a germinating plant of Phaseolus multiflorus, showing development of secondary structures: p, group of primary vessels; $g$, larger tracheæ of secondary development formed between the four primary strands of xylem; b, the four groups of phloem alternating with the four initial groups of xylem and beneath which secondary tracheæ are forming $\left(\mathrm{g}^{\prime}\right)$; pc, pericambium (pericycle), a layer of cells beneath the endodermis (s). A few layers of cortical parenchyma are shown outside of the endodermis. In the middle is a well-developed pith (M) which sometimes is developed in roots.-After Sachs.

secretory cells or receptacles. Immediately beneath the innermost layer of cortical parenchyma is a distinct layer of cells usually considered part of the cortex and known as the ENDODERMIS. It consists always of a single layer of cells, without any intercellular spaces, and the radial walls show in transverse section Casparyan spots, ${ }^{1}$ depending upon a local folding of the cell-wall, which is here suberized. In the course of time the cell-walls of the en-

1 “Physiologische Pflanzenanatomie,” by Dr. G. Haberlandt, p. 245. 
dodermis frequently become thickened, either all around, or only on the inner or radial walls, so that we might speak of an Oendodermis as in Honduras sarsaparilla or an U-endodermis as in Mexican sarsaparilla, according to the manner of thickening.

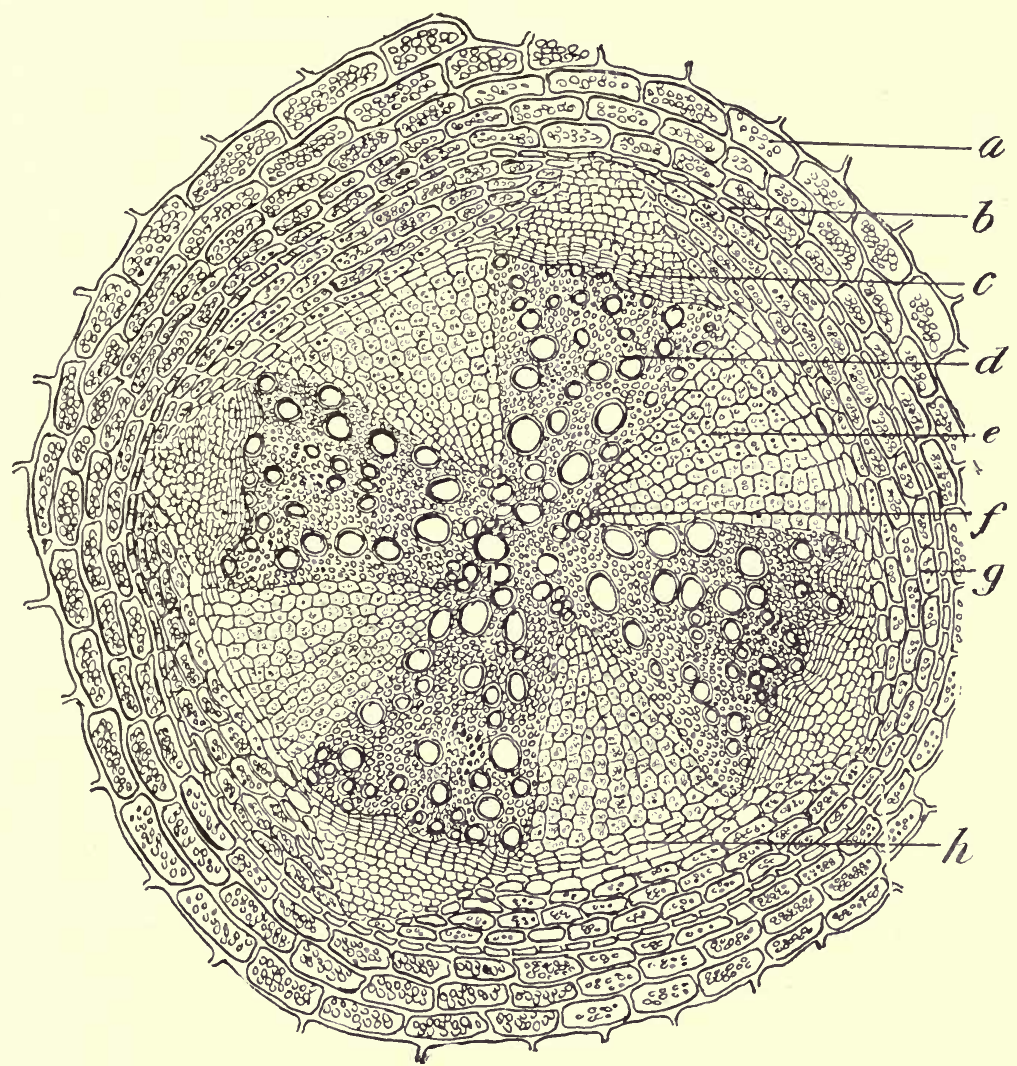

FIg. I7r. Cimicifuga. Transverse section of the central part of a mature root in which the secondary changes are completed: a, parenchyma of primary cortex; $b$, endodermis; c, cambium zone; d, tracheæ in secondary xylem; e, broad, wedge-shaped medullary ray; $f$, outer portion of one of the primary xylem bundles; $g$, pericycle-parenchyma beneath the endodermis; $h$, inter-fascicular cambium.-After Bastin.

This is especially the case in the monocotyledons where the walls of the endodermal cells become completely suberized and impermeable to water. In some roots the cells of the endodermis may be uniformly thick-walled throughout, while in others some 
of the cells may remain thin-walled, and these cells, the so-called "transition cells" or "passage cells," form channels of communication between the cortical parenchyma and the vessels of the stele (Fig. I69); they are therefore located just outside the peripheral vessels of each ray of the xylem (or hadrome).

Inside the endodermis is the STELE, formerly called the centralcylinder. In this the peripheral stratum, sometimes composed of two or three layers of cells, represents the PERICAMBIUM (or PERICYCLE). The cells are generally thin-walled, and in Dicotyledons and Gymnosperms are able by cell-division to form cork and

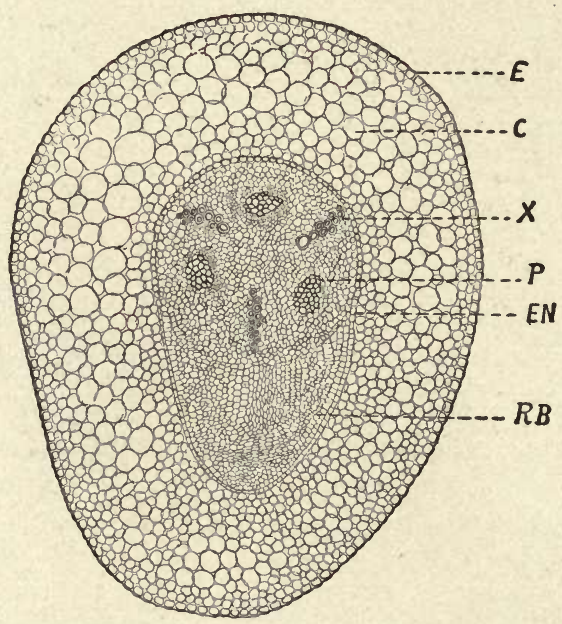

Fig. x72. A transverse section through the root of a germinating pea-plant (Pisum) about $40 \mathrm{~mm}$. from the tip, showing the origin of a root-branch (RB); E, epidermis; C, primary cortex; X, hadrome (vessels); P, leptome (sieve); EN, endodermis.

secondary cortex, but in all vascular plants it is capable of giving rise to "lateral branches" or "lateral roots" (Figs. I6r, I72), hence it is frequently referred to as the "RHIZOGENOUS LAYER."

Inside the pericambium (by some authors compared with the pericycle of the stem) we find strands of phloem (or leptome) (P) alternating radially with a corresponding number of strands of xylem (or hadrome) (X). The number of these strands vary in the different groups of plants (Figs. 169-174), being highest in the monocotyledons where a pith is developed, as in sarsaparilla, several grasses, palms, etc. This peculiar arrangement of the 
phloem and xylem, as separate strands alternating with each other and not being located, as in stems, in the same radii, has given rise to several adverse views. Some authors have considered the root-stele as one single mestome-strand (or fibrovascular strand), while others, especially of recent date, consider it to be composed of several MESTOME STRANDS.

The xylem or hadrome contains tracheæ or vessels, the peripheral being spiral and narrower than the inner, which are scalariform or reticulate. The tissue in the center of the stele in monocotyledons is not uncommonly made up of parenchyma cells, and

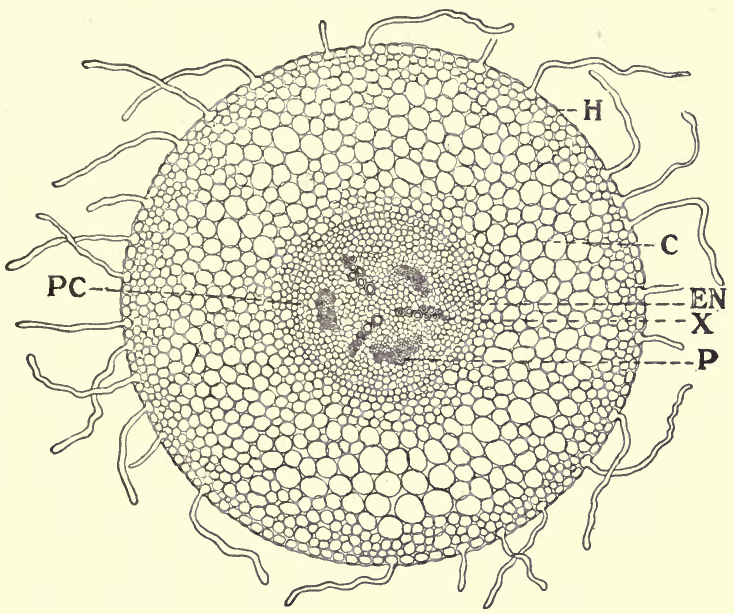

FIG. 173. Primary structure in the root. Transverse section of root of pea (Pisum) about $40 \mathrm{~mm}$. from the root-cap: $\mathrm{H}$, epidermal cells, some of which are developed into root-hairs; C, primary cortex; EN, endodermis; PC, pericambium; X, hadrome, composed of tracheæ; P, leptome, composed of sieve cells, the hadrome (vessels) and leptome (sieve) forming a triarch radial fibrovascular bundle.

corresponds exactly with the pith of the stem. In roots it is often called CONJUNCTIVE Tissue, and the cells may contain starch and crystals of calcium oxalate.

Secondary Structure.-In roots that are able to increase in thickness (as in Gymnosperms and Dicotyledons), the increase depends upon the activity in the pericambium, some of the cells becoming meristematic. These meristematic cells are known as phellogen, developing cork outwardly and secondary cortex inwardly. The meristem of the stele or cambium also becomes very active and develops on the inner face of the phloem and extends 
from there to the outside of the peripheral vessels of the xylem (Fig. I74); thus a continuous cambial zone gradually arises. From this zone secondary tracheæ or vessels become developed on the inner face of the primary phloem, while secondary phloem becomes differentiated outside the primary rays of xylem; or only parenchyma develops outside the primary xylem, resulting in

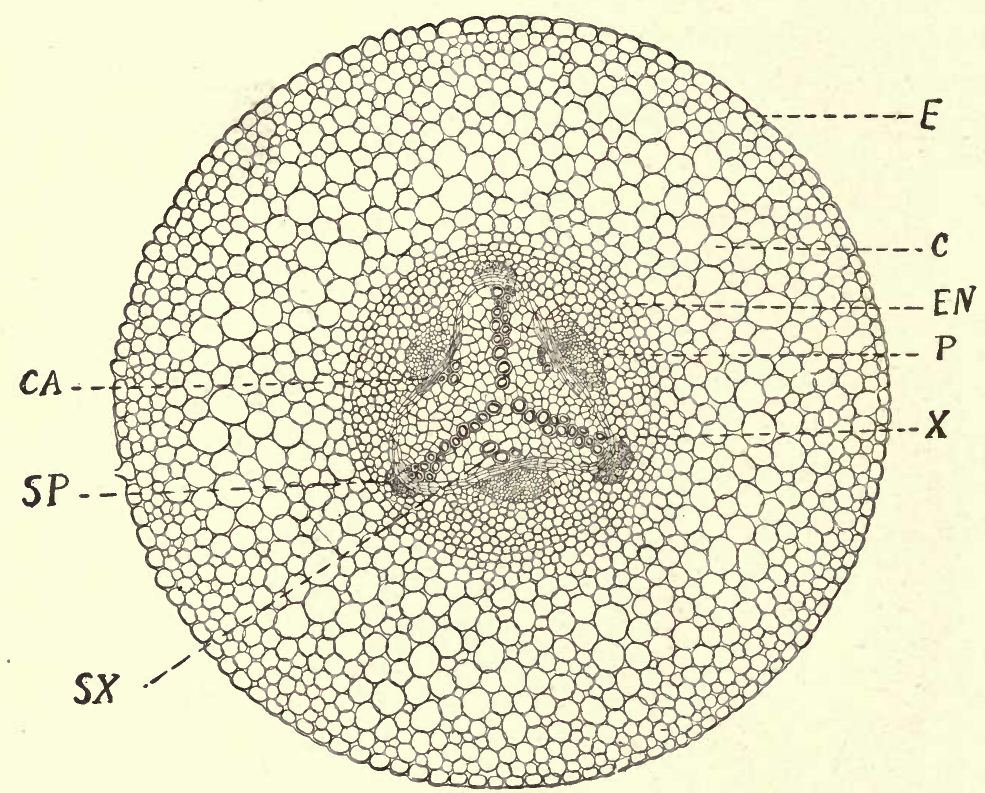

FIG. I74. Section in the older part, higher up on the root of pea (Pisum), showing in addition to what has been observed in Fig. 173, the beginning of the change from primary to secondary structure: CA, the development of a cambium; SX, secondary hadrome (or vessels), and SP, secondary leptome (or sieve).

the formation of secondary PARENCHYMA-RAYS (or medullary rays). In other words, the original radial structure of the stele changes to the collateral type (Fig. I75). Owing to this increase within the stele, the peripheral tissues from the endodermis to the epidermis naturally become broken and are subsequently thrown off, but are replaced by the pericambial cork and secondary cortex derived from the pericambium. The older roots, then, of Gymnosperms and Dicotyledons thus resemble the structure of stems, except that no pith exists in these roots, at least not usually. 
Some differences are, however, quite noticeable in some instances, as in the thick roots of Beta, Radish, etc., where the wood paren-

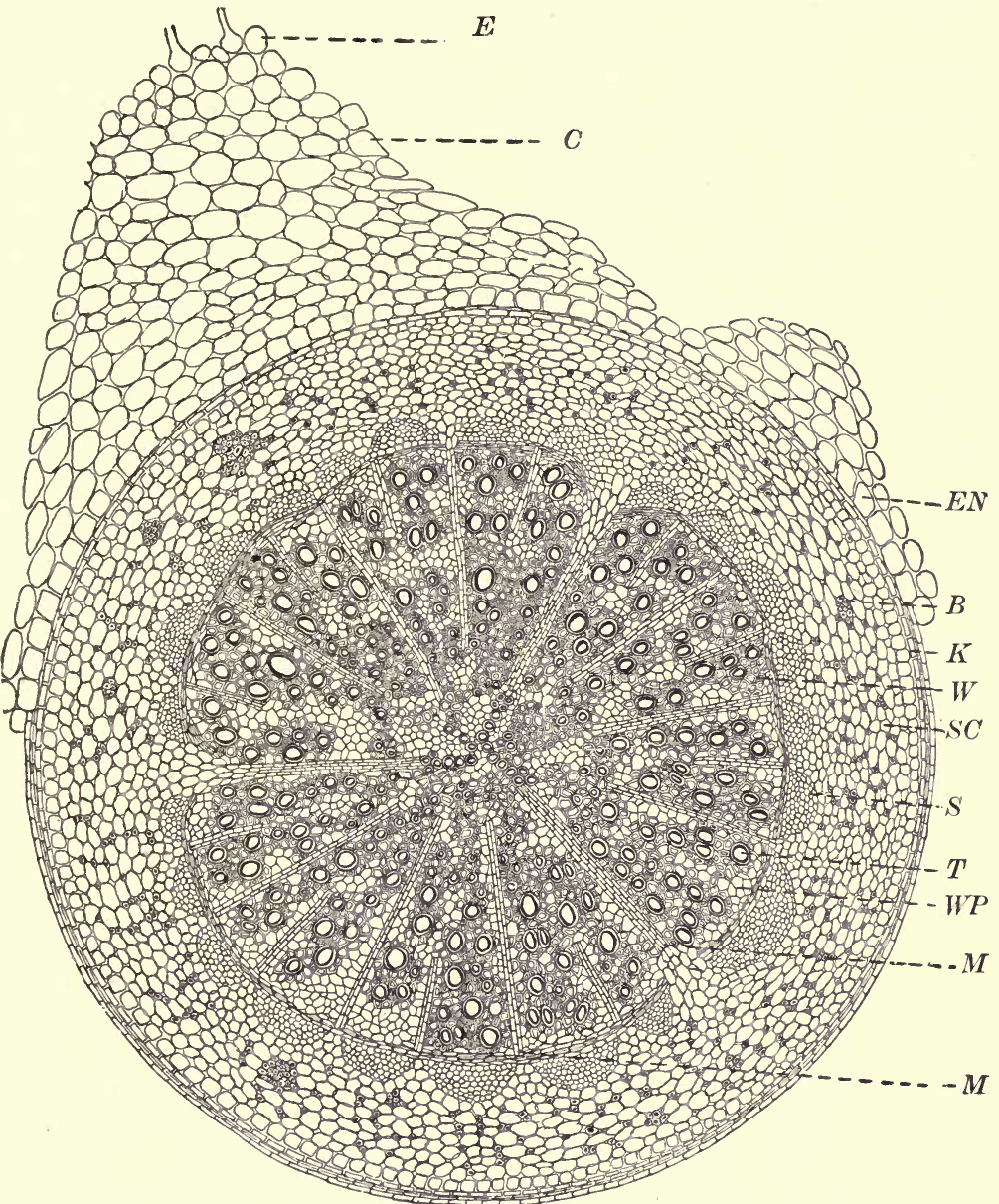

Fig. I75. Fully developed secondary structure in root. Transverse section of root of pea (Pisum) at the end of the summer's growth: E, some epidermal cells with fragments of root-hairs; C, primary cortex; EN, endodermis; K, pericambial cork; B, bast fibers; SC, secondary cortex; S, sieve; T, tracheæ; W, wood fibers; WP, wood parenchyma; $\mathrm{M}$, medullary rays; the tracheæ (or vessels) and leptome (or sieve) forming open collateral fibrovasćular bundles, these being found in dicotyledons with but few exceptions.

chyma is usually abundant, thin-walled, and not lignified, the annual rings also being mostly indistinct.

The characteristic distinguishing the primary and secondary 


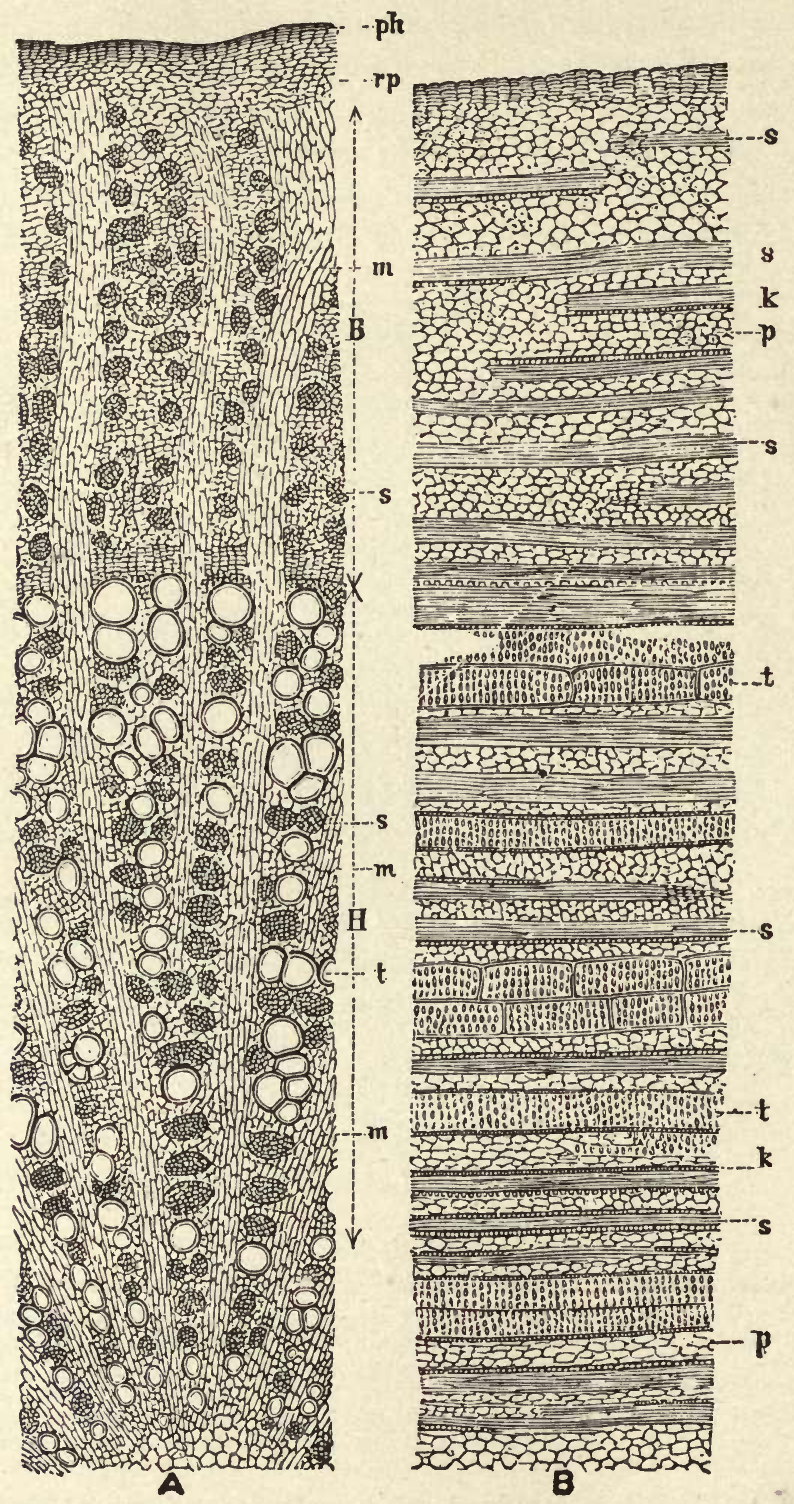

FIG. I76. Glycyrrhiza: A, transverse section; B, longitudinai section. B, bark; $\mathrm{H}$, wood; X, cambium zone; $\mathrm{ph}$, cork cells; rp, cortex; $\mathrm{p}$, parenchyma; $\mathrm{k}$, crystal fibers; $\mathrm{s}$, sclerenchyma fibers, including wood fibers occurring in the wood and bast fibers present in the bark; $t$, tracheæ; $m$, medullary rays.-After Meyer. 
structures of dicotyledonous roots may be summarized as follows:

Primary structure: Epidermis and root-hairs. Hypodermis. Primary cortex consisting of parenchyma. Endodermis, pericambium, xylem arranged in radial rays which alternate with phloem or sieve strands, constituting a radial fibrovascular bundle (Figs. I69-174).

Secondary Structure: Cork cells, phellogen, secondary cortex consisting of parenchyma. Phloem, cambium, and xylem arranged in radial groups, forming open collateral fibrovascular bundles. Medullary rays separating the fibrovascular bundles (Figs. 175-177).

Sometimes, as in glycyrrhiza and valerian, a number of parenchyma cells are found in the center of the root, these constituting the PITH (Fig. I76) or medulla; but they are usually wanting in dicotyledonous roots.

Wood and bark are terms used to distinguish those portions of the root or stem separated by the cambium; all that portion inside of the cambium, including xylem, medullary rays, and pith, being known as the WOOD. The BARK includes the hadrome, the medullary rays outside of the cambium, and the tissues formed by the phellogen, viz., secondary cortical tissue and cork.

The following diagram of the secondary structure of a dicotyledonous root may be of assistance in understanding the origin and relation of the tissues comprising it: Wood made up of ...... $\begin{aligned} & \text { Pith, which may be wanting. } \\ & \text { Xylem... } \begin{array}{l}\text { Composed of vessels, wood parenchy- } \\ \text { ma and wood fibers; or tracheids may } \\ \text { replace these cells, or be associated } \\ \text { with them. These are arranged in } \\ \text { groups forming radial rows which } \\ \text { are separated by medullary rays. }\end{array}\end{aligned}$

Cambium produces

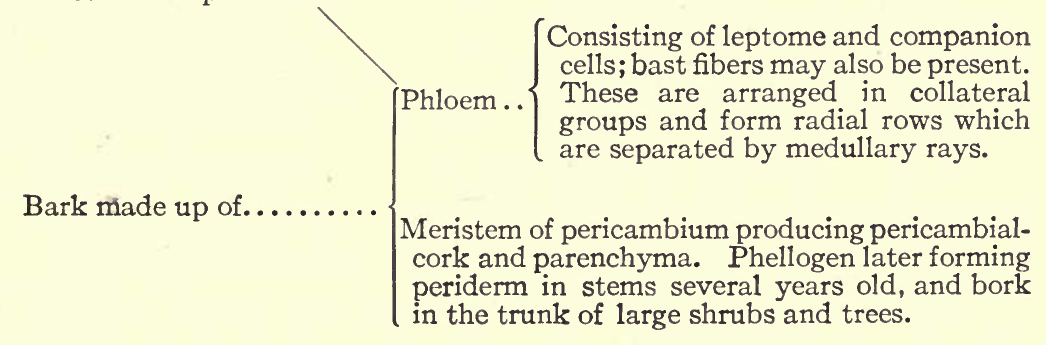




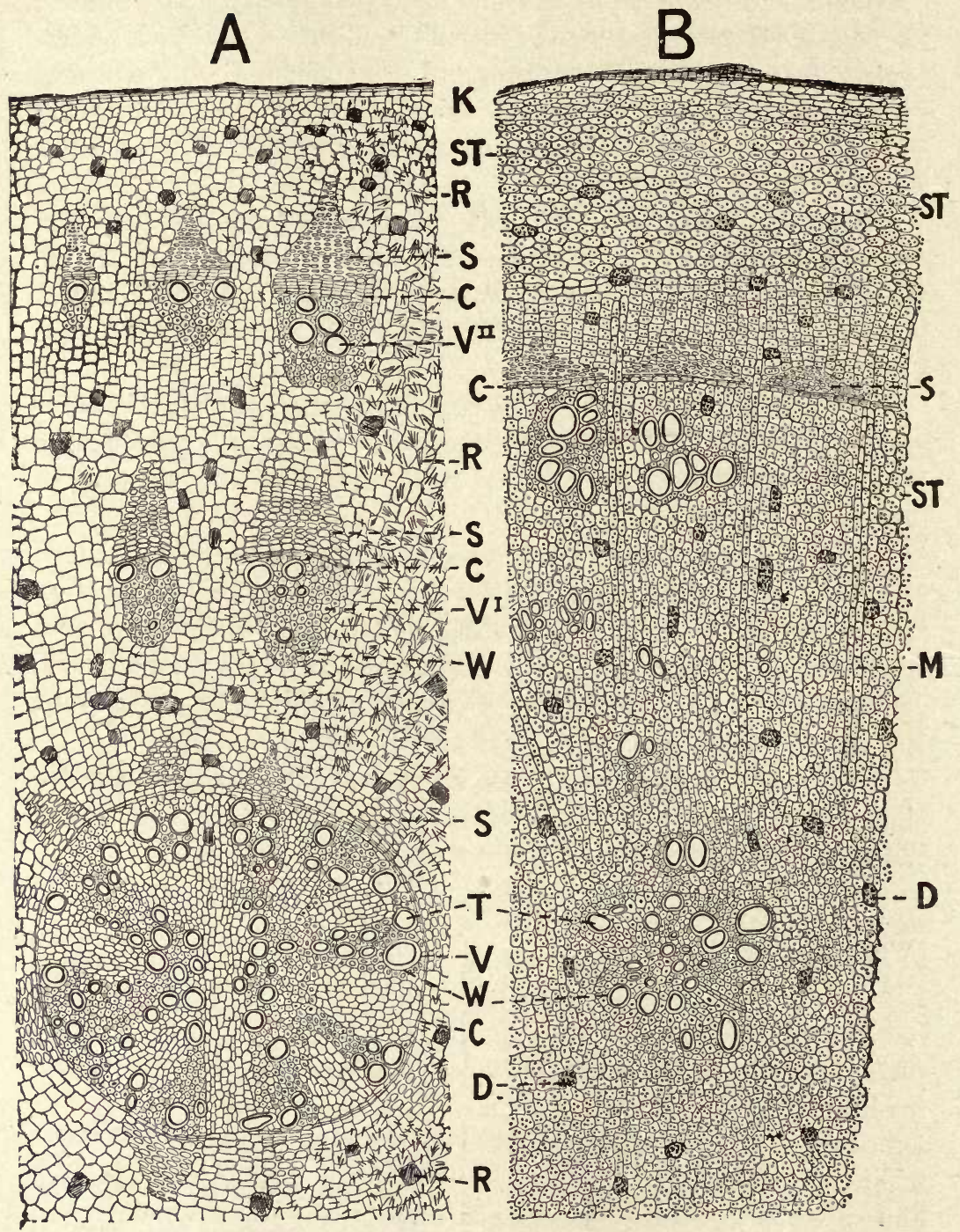

FIg. I77. A, transverse section of Phytolacca root, showing the fibrovascular bundles $\left(\mathrm{V}, \mathrm{V}^{\prime}, \mathrm{V}^{\prime \prime},\right)$ which are produced by distinct cambiums $(\mathrm{C})$. The parenchyma contains little starch, and some of the cells $(R)$ show short raphides of calcium oxalate, many of the crystals being distributed in the section.

B. Transverse section of Belladonna root which is two or three years old. There is but one cambium zone (C). Most of the parenchyma contains starch (St), the remaining cells containing cryptocrystalline crystals of calcium oxalate.

$\mathrm{K}$. cork; $\mathrm{S}$, sieve; W. wood fibers and $\mathrm{T}$, tracheæ, both of which are strongly lignified in Belladonna root: M. medullary rays. 
The root branches arise as the result of the development of primary meristems in the pericambium (Figs. I6I, I72). The tissues forming the branches are directly connected with the fibrovascular tissues of the root and protrude through the overlying tissues without having any connection with them. The structure of the branches thus formed corresponds to the primary structure of the roots, and in the case of dicotyledonous roots may also subsequently develop a secondary structure. Goebel states that in plants which grow in moist soil, or whose roots function only for a short time, the branches may be altogether suppressed, as in Colchicum, Arisæma, etc.

Contraction of roots is observed in both monocotyledons and dicotyledons, it being most apparent in the former, as in the roots of Veratrum viride (Fig. I78). The uneven or corkscrewlike appearance is due to a contraction, which arises as follows: Some of the longitudinally elongated cells beneath the epidermis, as well as cells extending to and including the endodermis, absorb large quantities of water, which causes them to assume a spherical form (as the cells of a potato are altered on boiling), the result being a longitudinal contraction of the root at this point. In this way the plant is fastened more securely to the earth, and at the end of the season's growth the apical buds of plants, with upright rhizomes, as of Veratrum viride, Dracontium, etc., are drawn into the earth and thus protected during the winter season.

Abnormal Structure of Roots.-It is often difficult to recognize the type-structure of dicotyledonous roots in drugs, owing to the anomalous and abnormal secondary structure. Sclerenchymatous fibers, while present in glycyrrhiza (Fig. I76) and althæa, are not infrequently wanting. Wood fibers may be sparingly developed, as in young belladonna roots (Fig. I77), or even wanting, as in gentian. In other cases the medullary rays are abnormal, being replaced in calumba by wood parenchyma, and in ipecac and taraxacum by sclerenchymatous cells. In asclepias and calumba a layer of stone cells occurs near the periphery; in gelsemium sieve cells develop in the xylem; in senega the xylem is not uniformly developed, and in still other cases, as in jalap, pareira, and phytolacca (Fig. I77, $A$ ), successive cambiums develop, producing concentric series of open collateral fibrovascular bundles. 


\section{THE OUTER MORPHOLOGY OF THE STEM.}

The stem, or ascending axis of the plant, usually grows in a direction opposite to that of the root, seeking the light and air. The tendency of the stem to grow upward is characteristic of the majority of plants, and is spoken of as NEGATIVE GEOTROPISM. The growing point of the stem is at the apex, and it is protected by a layer of bud scales. (Fig. I79, $B$ ).

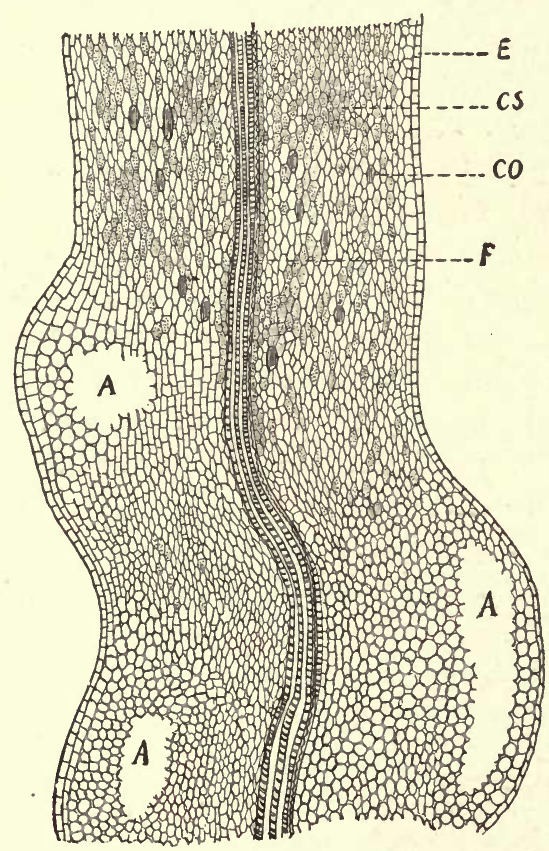

FIG. I78. Longitudinal section through a root of Veratrum viride showing the nature of the contraction of the root: E, epidermis; CS, cells of cortex containing starch; CO, cells of cortex containing raphides; F, fibrovascular bundle; A, rifts or cavities formed as a result of the radial swelling of the cells of the cortex.

Stems are further characterized by bearing leaves, or modifications of them. The leaves occur at regular intervals in the same species, and that portion of the stem from which they arise is spoken of as a NODE, while the intervening portion is called an internode.

Stem branches usually arise in the axils of the leaves, first 
appearing as little protuberances, sometimes spoken of as primordia, on the stem. Their origin differs from that of the root branches, in that they arise from meristematic or embryonic tissue developed just beneath the epidermis. The branches, like the main axis, manifest negative geotropism, although to a lesser degree. They likewise possess a growing point at the apex, covered with embryonic leaves (Fig. I79). Not infrequently more than one branch arises in the leaf axil.

Buds may be defined as undeveloped shoots in which the foliage is yet rudimentary. The buds at the ends of stems or
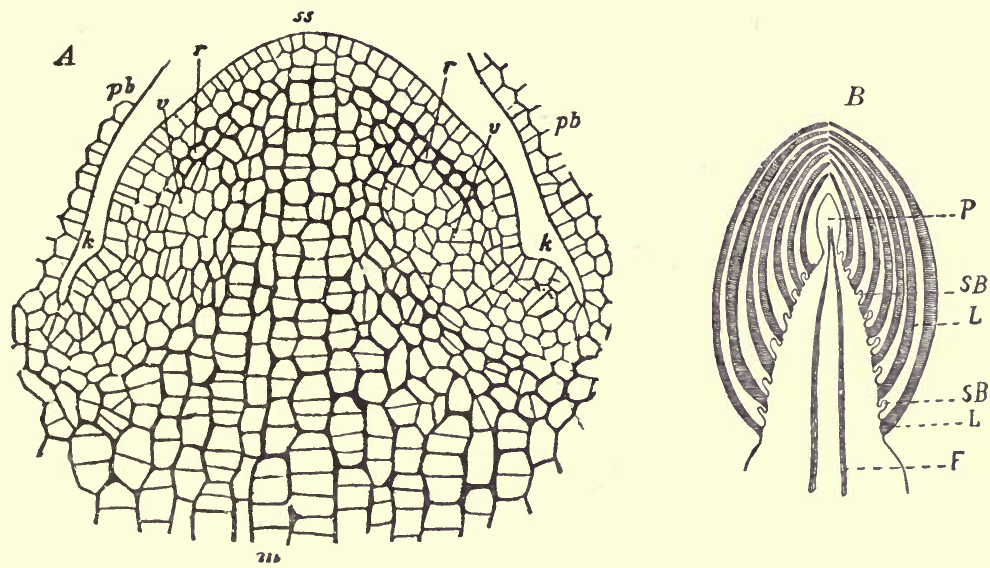

FIG. I79. A, longitudinal section through the apical region of the stem of the embryo of a bean (Phaseolus multiflorus); ss, apex; pb, parts of the two first leaves, and their axillary buds $(\mathrm{k}, \mathrm{k}$,$) ; \mathrm{r}$, periblem or primary cortex. B, diagram of longitudinal section through winter bud of Quercus coccinea: $\mathrm{P}$, growing point; $\mathrm{L}$, young leaves; SB, stem branches; F, fibrovascular bundle.-A, after Sachs.

branches are known as APICAL, or TERMINAL BUDS, and those situated in the axils of the leaves, as AXILLARY BUDS. In some cases they are protected by scales, as in hickory, when they are known as scaly buds; while buds which are not thus protected are called naked buds. They are further distinguished as leaf, flower, and mixed buds, as they develop into leaves or flowers, or both.

We have to distinguish between overground shoots and underground shoots. The former are sometimes designated as epigeous (upon the earth) and the latter as hypogeous (under the earth). 
Epigeous Shoots.-As would be supposed, these two kinds of shoots vary to a certain extent. In epigeous shoots a number of features may be noted. If the internodes are long the leaves do not usually interfere with one another so far as exposure to light is concerned, but if the internodes are short, the leaves are all brought close together on the axis, and hence, were it not for
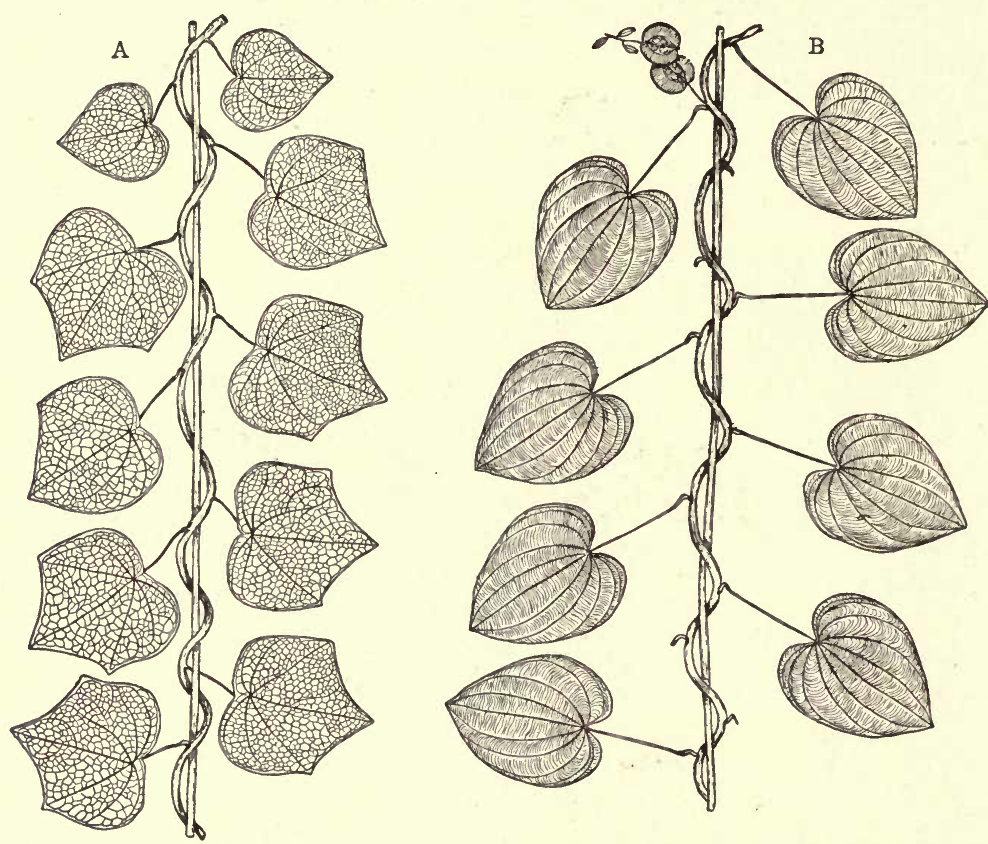

Fig. I80. A, woody vine of Canada moonseed (Menispermum canadense), which ascends by twining to the right.

$\mathrm{B}$, stem of wild yamroot (Dioscorea villosa), which ascends by twining to the left. and several of the characteristic 3 -winged capsules at the top.

The twining movements of stem climbers are due to the stimulus of gravity rather than to contact stimulus, and in the majority of twining plants the revolving movements, as seen from the side, are from the left to the right, i.e., in a direction opposite to that of the hands of a watch if represented diagrammatically.

various modifications, their relation to light would be very unequal. Sometimes the shoot-axis may share with the leaves the work of assimilation, as in the case of certain green stems. Then again there are cases in which the leaves are reduced, and the work of assimilation is carried on exclusively by the shoot-axis, as in most Cactaceæ, certain marsh-plants, and others. On the 
other hand, the shoot-axis may be modified so as to increase the assimilating surface, as by a flattening of the axis, as in some of the Cacti, the leaves being suppressed or considerably reduced.

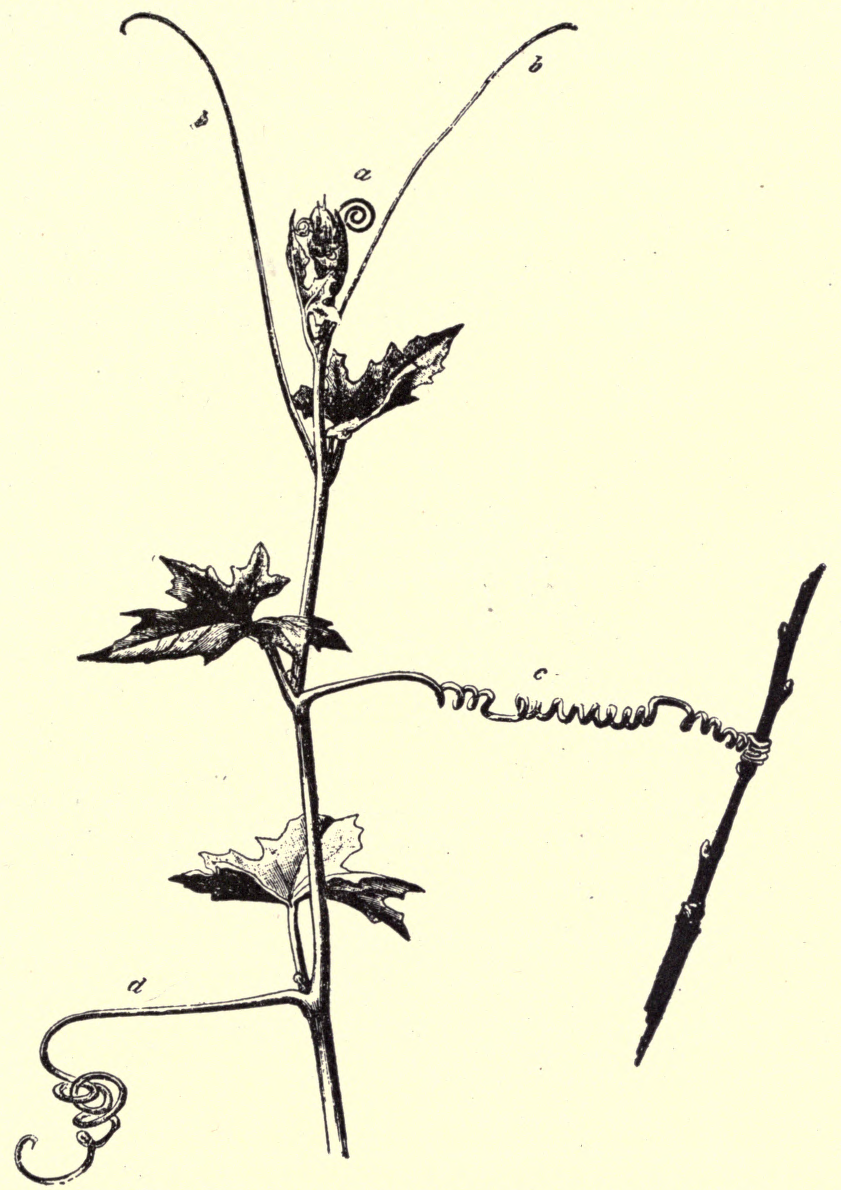

FIG. r8I. Bryonia dioica. a, young, spirally coiled tendril; b, expanded and irritable tendril; c, tendril which has grasped a support; d. tendril which has not grasped a support, and has undergone the old-age coiling.-After Pfeffer.

Branches are not infrequently modified to hard, pointed, and spiny structures, as in the Japanese quince, when they are spoken of as thorns. Leaves and even flowers may arise upon thorns, which shows that they are modified branches. 
A number of plants ascend into the air on other plants, or other objects which serve as supports, either by attaching themselves to them or by twining around them, when they are distinguished as twiners and climbers. Twiners ascend by a special circumnutating movement of the stem, as in the morning glory, Menispermum (Fig. I80), etc. Climbers, however, ascend by means of special structures, as the aërial roots of the ivy (root climbers) ; or they may climb by means of leaves, as in Clematis (leaf climbers); still others climb by means of tendrils, as in the grape and Bryonia (tendril climbers) (Fig. I8I); and again plants may climb by means of hooked hairs or spines, as in Rubus,

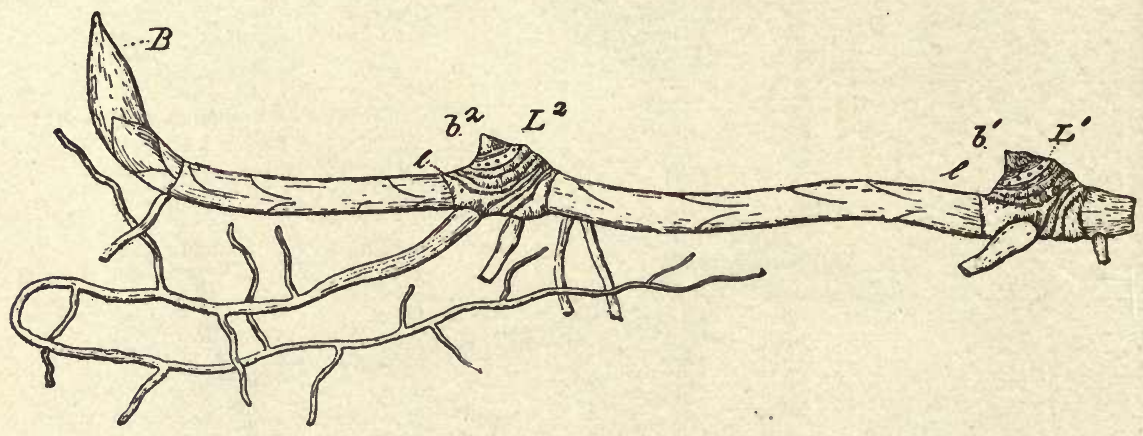

FIG. I82. Rhizome of Podophyllum representing three years' growth: $b^{1}$, the terminal bud of last year; $b^{2}$, the corresponding one of the present year; $B$, the terminal one of the entire rhizome will develop in the spring of next year. $L^{1}$ and $L^{2}$ indicate the scars of aerial leaves of the two preceding years' growth; $b^{1}$ and $b^{2}$, latent buds.-After Holm.

Rosa, etc. The tendrils, which are thread-like modifications of the stem, are in some cases provided with disk-like atachments for holding the plant in position, as in the Virginia creeper. Twiners and climbers are sometimes spoken of as LIANEs (lianas), particularly those of tropical regions, where they form a prominent feature of the forest vegetation. The lianes usually have ropelike, woody stems, the formation of leaves being either suppressed or retarded, and they often run for long distances over the ground and climb to the tops of the tallest trees. They are also frequently characterized by an anomalous stem-structure, the tracheæ being very large.

Stems vary, furthermore, in size and form. While most stems are more or less cylindrical or terete, other forms also occur, as 
the flattened stems in the Cactaceæ; triangular in the Cyperaceæ, and quadrangular in the Labiatæ and Scrophulariaceæ.

Hypogeous Shoots.-While most stems attain a more or less erect position, as in trees and shrubs, there are others which bend over to one side, or lie prostrate on the ground, and in some cases

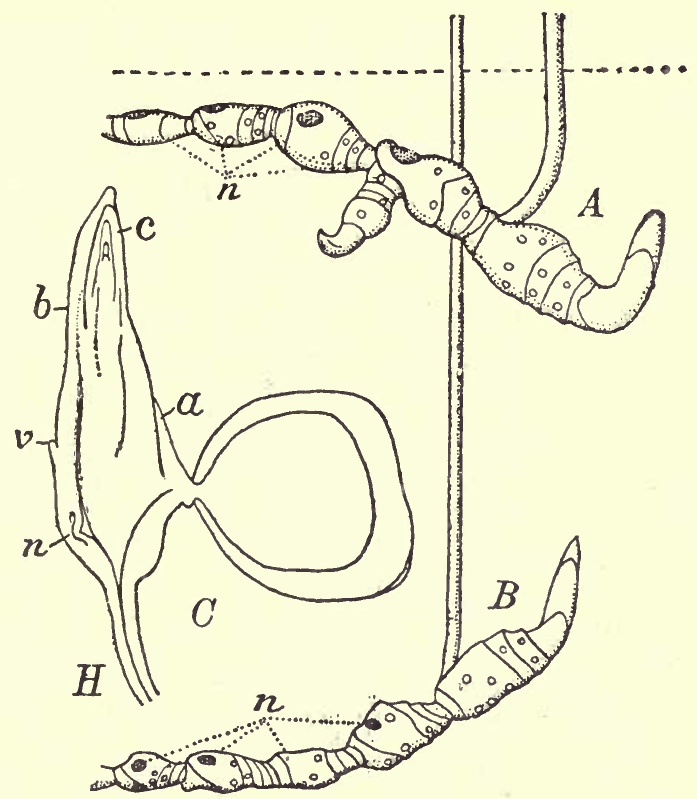

FIG. I83. Polygonatum multiflorum, a plant growing in the Northern Hemispheres and Japan and producing a rhizome resembling our Solomon's Seal (Polygonatum biflorum). A, rhizome placed artificially higher in the soil than the normal depth; its continuation shont has grown downwards. B, rhizome placed deeper than the normal depth; its continuation shoot has grown upwards. The dotted lines at $\mathrm{n}$ indicate the amount of annual growth in the rhizomes A and B. C, a seedling rhizome. At the right is the seed, which encloses the haustorial end of the cotyledon; $\mathrm{H}$, primary root; $\mathrm{n}$, lateral roots arising within the axis of the shoot; $a$, posterior side of cotylar sheath; $v$, anterior side of the same; $b, c$, katophyls (or leaves on hypogeous shoots) on the axis of the seedling.-A and B, after Rimbach: C, after Irmisch. (From Goebel's "Organography of Plants.")

produce roots from the nodes, as in Mentha spicata (Fig. I84). These latter are known as stolons or runners.

Furthermore, the stems of a number of plants grow underground, and these are known as RHIZOMES or ROOT-STOCKS (Figs. I82-190); from the upper portion of the nodes overground branches arise which bear leaves (so that the work of assimilation 
may be carried on) as well as flowers, and from the lower surface, roots (Fig. I82).

While most rhizomes are perceptibly thickened, and more or less fleshy when fresh, as Sanguinaria, in other instances they are of the ordinary thickness of the overground stem.

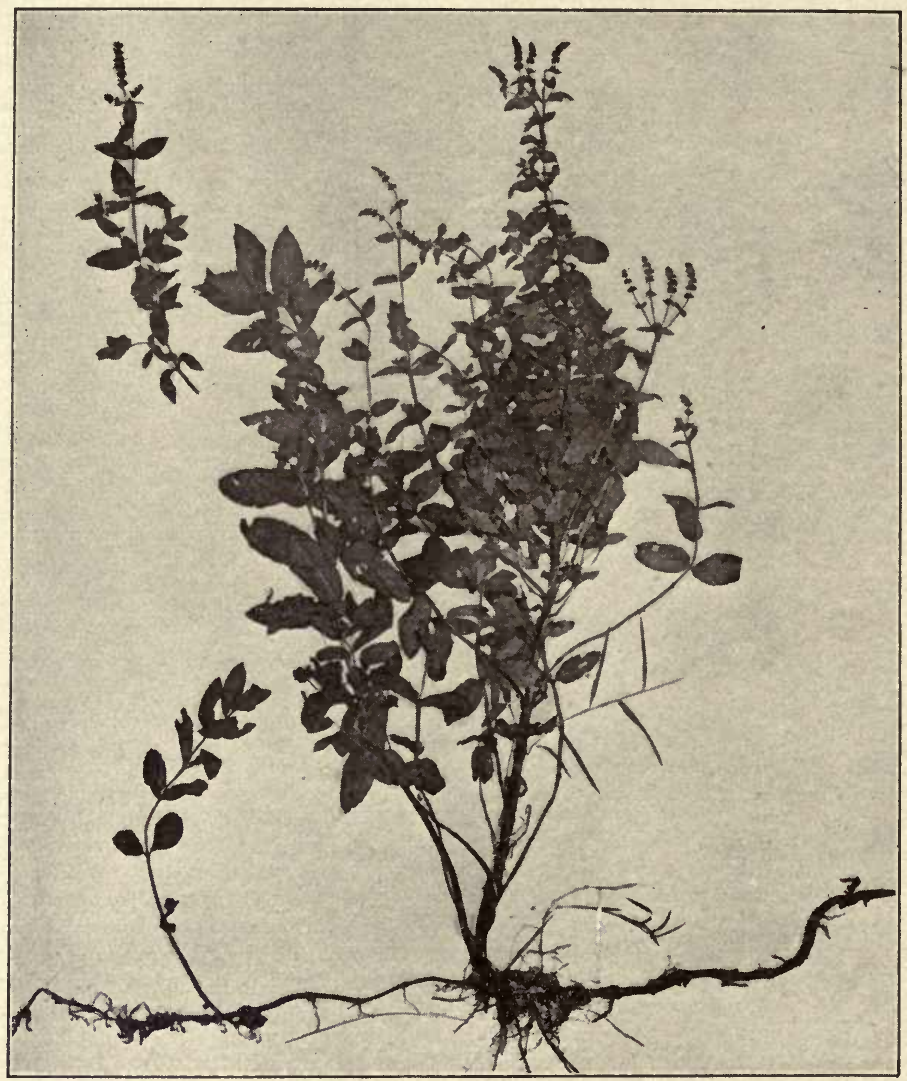

FIG. 184. Plant of spearmint (Mentha spicata) showing procumbent stems or leafy runners from which roots are developed at the nodes, and one erect branch at the left from which a new plant will be developed.

There are some rhizomes that are excessively thickened, as in the common white potato (Fig. I85), and these are called TUBERs. The so-called "eyes" are small buds covered with small, scale-like leaves which develop into shoots. Tubers should 
not be confounded with tuberous roots, as those of the sweet potato and jalap, for these latter have the morphological characters of roots (compare Figs. I85 and I86).

Instead of the node, or internode, or both, becoming excessively thickened, they may be reduced in size and crowded upon

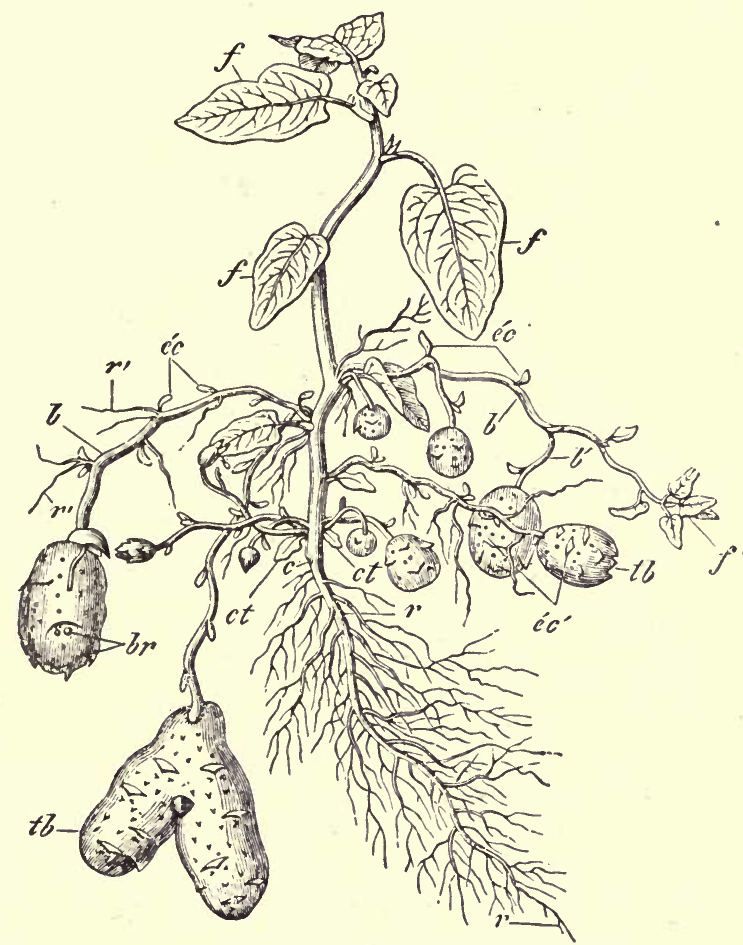

Fig. 185. A potato plant grown from seed and showing the branches upon which the potato tubers are formed. r, primary root; ct, cotyledons; c, hypocotyl; $f$, foliage leaves; $\mathrm{f}^{\prime}$, a primary branch the summit of which has developed foliage leaves; $\mathrm{e}^{\prime} \mathrm{c}$, scales on upper portion of primary branch; $\mathrm{e}^{\prime} \mathrm{c}^{\prime}$, scales representing the eyes of the potato tubers formed from the swollen branches; br, buds formed in the axils of the scales on the tubers; $r^{\prime}$, secondary roots formed on the stem branches. - After Duchartre.

each other, the leaves at the same time becoming thickened and filled with nutriment. Such a modified stem and leaves, as in the onion and tulip, is called a BULB (Fig. I88). Bulbs are sometimes produced in the axils of the leaves of overground stems, as in some lilies, and are then called bulbils or bulblets. They are also found in Allium forming what are commonly known as "onion sets." 


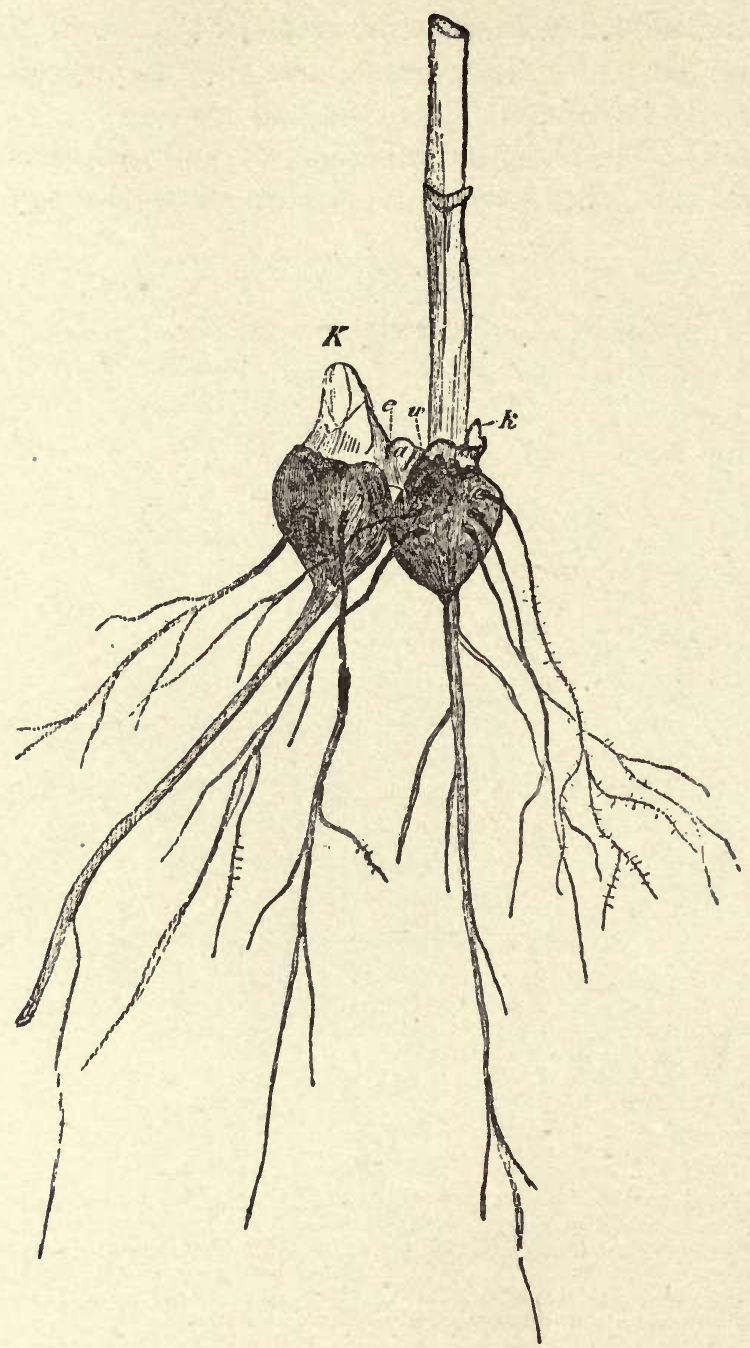

Fig. r86. Several tubers formed by a 2-year non-flowering plant of Aconitum Napellus, gathered in September. The parent tuber on the right shows a portion of the overground stem and a small bud (k); to the left has been developed an offspring tuber connected by the branch (a); K, nearly full grown bud which will produce the foliage stem of the growing plant the succeeding year. The long, filiform and branching roots are in the nature of true root branches.-After Meyer.

Bulbs and tubers serve not only as storage-organs and carry the life of the plant over from one season to another, but may form, as in 
bulblets, an important means of distributing the plants. The thickened fleshy stems of Cactaceæ are also regarded as storageorgans.

A CORM is intermediate between a true tuber and a bulb; it is more in the nature of a thickened internode, being surrounded in some cases by thin, membranous scales, as in Crocus and Colchicum.

The function of the vegetative shoot is to absorb nutrition from the earth as well as from the air. The shoot may be Ä̈RIAL or subterranean. Some plants possess only aërial shoots or Light-SHоотS, as, for instance, trees, shrubs, and herbs that flower

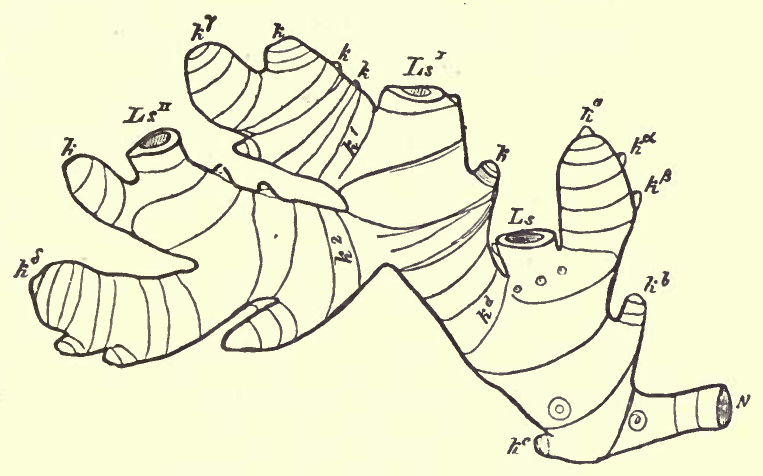

FIG. I87. Rhizome of African ginger showing scars of overground branch (Ls) and buds $(k)$. The more or less parallel lines represent leaf-scars and scars of bud-scales, and the small circles, root-scars.-After Meyer.

but once. Other plants possess both aërial and subterranean shoots, and of these the subterranean shoot may exhibit some of the peculiarities of roots, in that they do not develop chlorophyll and produce secondary roots for the purpose of obtaining nutritive substances from the soil. The subterranean shoots are generally destitute of true leaves and are furnished only with membranous or sometimes thick, fleshy leaves which are bladeless, pale, scale-like, or tubular.

Depending upon the duration of the shoot (or, better, the stem), plants are divided into HERbS, shrubs, and trEes. In herbs the aërial shoots are herbaceous, while in shrubs and trees they become woody and persist throughout many years. 
Many of the herbs have subterranean shoots, but these are generally absent from woody plants, excepting in Sambucus, Ailanthus, Calycanthus, etc. The herbs may be further subdivided as annual, biennial, and perennial.

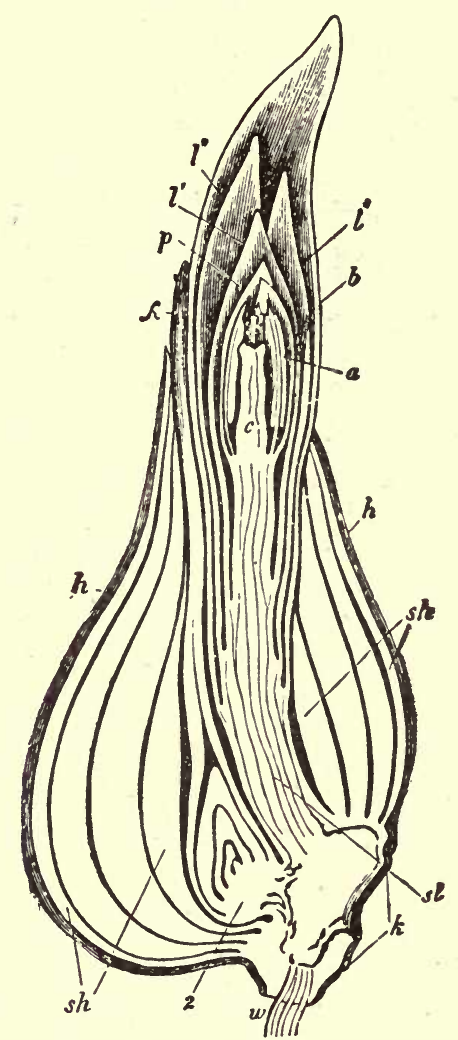

FIG. I88. Longitudinal section through a germinating bulb of Tulipa pracox: $\mathrm{h}$, the brown enveloping membrane; $k$, the flattened stem which forms the base of the bulb and bears the bulb-scales (sh); sl, the elongated part of the stem which bears the foliageleaves $\left(1^{\prime} 1^{\prime}\right)$, and terminates in the flower; $c$, the ovary; $p$, perianth; $a$, anthers; 2 , a lateral bulb in the axil of the youngest bud-scale, which develops into the bud of next year's bulb; $\mathrm{w}$, the roots which arise from the fibrovascular bundles at the base of the bulb.-After Sachs.

In ANNUAL herbs the individual possesses only aërial shoots and the plant sets fruit the same year that the individual has developed from the seed. In BIEN NIAL herbs the plant does not produce flowers until the second season. The PERENnIAL herbs, 
on the other hand, develop flowers continuously for many (or at least several) years and also produce subterranean shoots, such as creeping rhizomes, tubers, bulbs, etc.

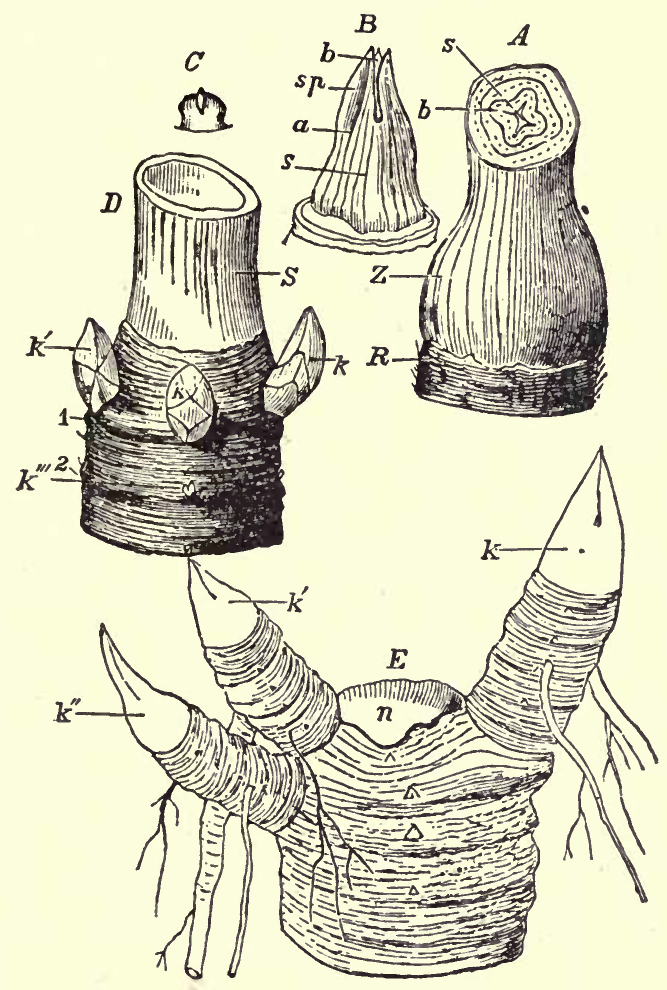

FIG. 189. Upper portion of rhizome of Gentiana lutea showing the structure of terminal buds: A, terminal bud cut open to show the foliage leaves (b), which lie close to one another, leaving only a narrow canal (s) in the middle. B, four-angled bud removed from A, showing the foliage leaves having a strongly developed basal region (s) and relatively small lamina (sp). $C$, a small bud removed from the axis of the young leaves (B). . D, upper portion of rhizome of a flowering plant showing the stem base (S) and several buds (k). E, upper portion of rhizome of a plant 6 years old showing scar $(n)$ of the flowering branch and the strongly developed side branches with terminal buds $(\mathrm{k})$. The annulations are scars formed from the bud scales which have dropped off.-After Meyer.

The roots of annuals, biennials, and perennials differ in a number of particulars. In the annuals, belonging to the monocotyledons, the roots are fibrous, possessing numerous lateral branches, whereas in the annuals belonging to the dicotyledons only the 
primary roots develop. The biennials are nearly all dicotyledons and have a persistent primary root which, while usually slender, may become fleshy, as in Beta. In the perennials, on the other hand, we find a number of different types of roots, varying from the slender aërial roots of epiphytes to the smaller tuberous, fleshy roots of many terrestrial plants, and the peculiar roots of parasites.

Alterations in the Form of Plants.-The shoot, in its

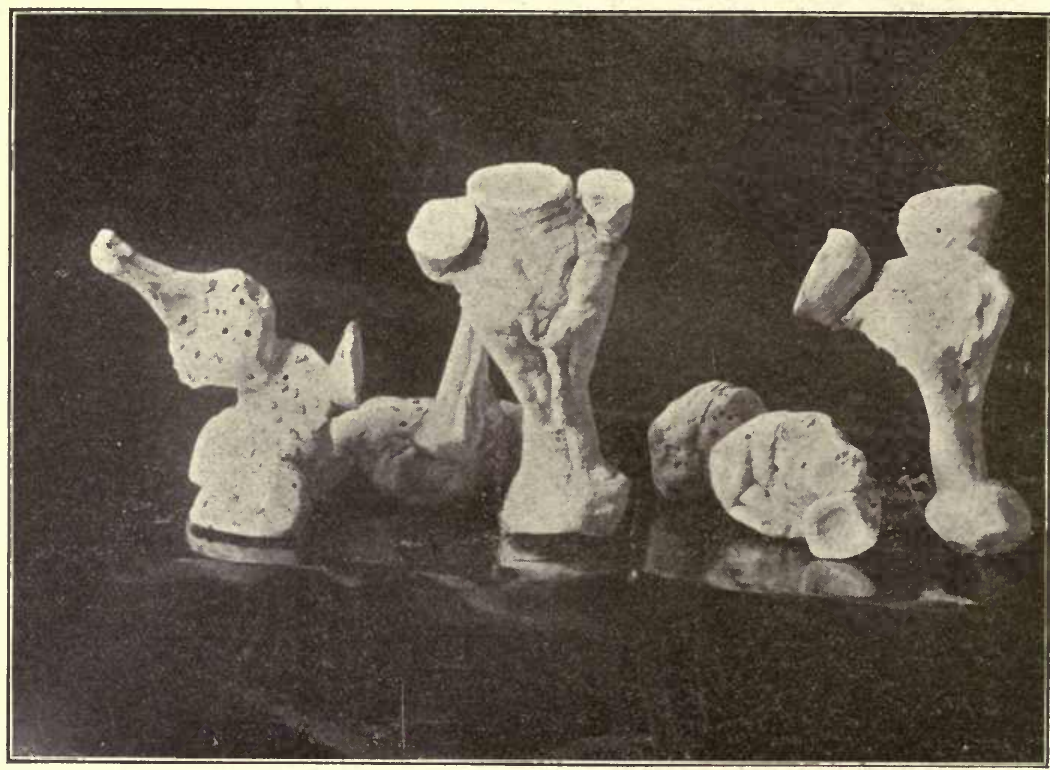

FIG. I90. Specimens of "orris root" of commerce consisting of peeled pieces of the rhizomes of Iris florentina. The rhizomes are mostly dichotomous, the branches becoming obconical and of characteristic shape. The large circular areas terminating the rhizomes are scars of stem bases, while the small black dots on the surface are scars from attachment of roots.

course of development, is subject to a great many hostile external conditions, and there results more or less mutilation and alteration in the form of the plant. One of the most destructive influences to plants is that of strong winds when they attain the the velocity of gales. They stunt the growth of woody plants and cause the branches to assume a horizontal position (Fig. I9I). This unusual growth is further accentuated if at times during the winter they are covered with snow and sleet. If they grow in close 


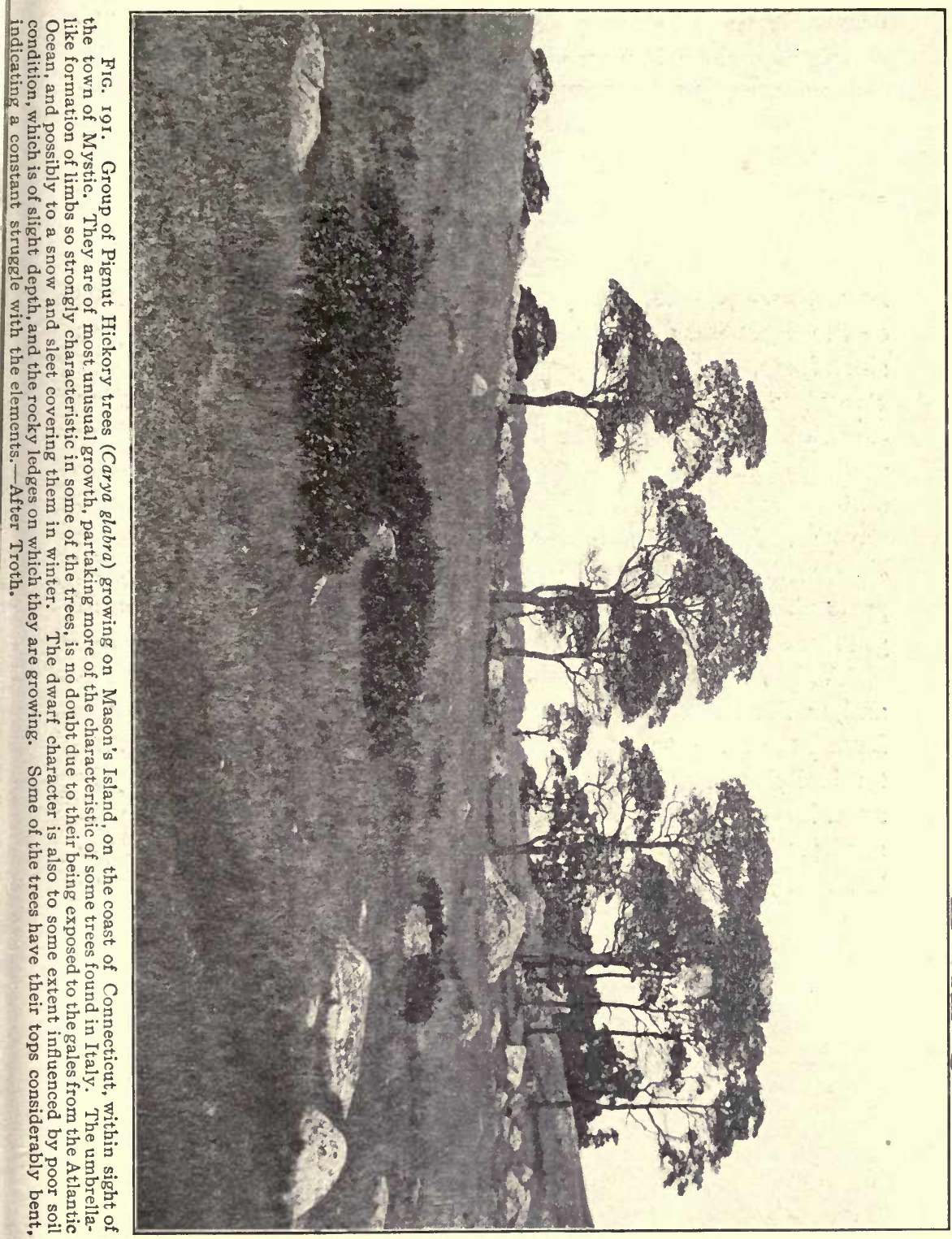


proximity their limbs will lash each other, causing a flattening of the top which is very characteristic in the groves of trees on the sea coast. In this way it is possible for the whip-like branches of the birch to mutilate even the tops of the fir tree, changing their spire-like summits to deliquescent crowns. Injuries causing an alteration in the form of plants are also caused by ruminating animals and leaf-devouring insects.

GALLS.- These are abnormal developments on the young twigs, leaves, and flowers, being caused by the punctures and presence of the deposited ova of quite a variety of insects. Galls vary in size, form, and general appearance. They are only capable of being produced either in meristematic cells or in tissues that are capable of exercising this function. They are never formed on mature stems, leaves, or flowers. The older parts may be eaten and destroyed by insects, but they are not capable of being metamorphosed. In these growing tissues the mother insect lays her eggs, which upon further growth, either through the secretion of particular substances or otherwise, determine the direction of growth of the cells and the final product which shall be formed.

As has already been stated, galls show considerable variation. and, as there are many hundreds of distinct galls, various attempts have been made to classify them. Küster has proposed an anatomical classification as follows: I. Galls in which there may be an enlargement of cells, but no cell multiplication; 2 . Soft galls, composed of numerous cells, the resulting product being more or less fleshy; 3. Hard galls, in which there is an active cell division, and sclerotic modification of the external layer so as to prevent the drying up of the gall in summer and to guard against attack by birds and other animals. Modry (Beiträge zur Gallenbiologie), on the basis of Küster's classification, has given a very comprehensive review of the various structural (both external and internal) characters of the various groups of zoo-cecidia.

In a classification of galls Thomas has suggested as a class name for these structures the word CECIDIEN (meaning nut-gall). The cecidien or galls are divided into two main groups, as follows: I. Phyto-Cecidien or fungus galls, including the parasitic fungi which cause a metamorphosis in the shoots of larger shrubs and trees forming the structures commonly known as "Witches' 
brooms." Galls exhibiting strange forms are also produced by the Gymnosporangia on the stems of the common juniper, the leaves of the mountain ash, etc. In this group would also be included the CROWN-GALLS occurring on a large number of plants, as grapes, peach, juniper, and field crops. At one time it was thought that these galls were due to frosts or mechanical injuries. The extended researches of Smith (Bulletin No. 213, Bureau of Plant Industry, U. S. Department of Agriculture) have shown that crown-galls are in the nature of bacterial diseases. $\mathrm{He}$ showed that crown-galls not only resembled malignant animal tumors, especially sarcoma, but demonstrated that this resemblance was more than superficial. II. Zoo-CECIDIEN, or those galls which are formed within the body of the plant and due to attacks by insects. This group includes by far the larger number of galls, and is further subdivided according to the various animal-groups causing them.

Galls differ in structure, but the general nature of the anatomy may be seen in a study of the common "ink ball" or "ink gall," formed on Quercus coccinea by Cynips aciculata. These galls are produced during the summer months on the young branches and sometimes on the acorns. When mature they fall from the trees and are nearly globular in shape, varying from 20 to $30 \mathrm{~mm}$. in diameter. They are solid throughout and of the consistency of the pulp of a green apple. Externally they are smooth, and are colored a mottled green, yellow, or brownishred. At this stage they are made up of three distinct zones: ( I) A central area, made up of nearly isodiametric starch-bearing, parenchymatous cells. (2) The middle zone is composed of radially elongated parenchymatous cells, possessing thick, porous cellulose walls containing a lining of protoplasm and a few starch grains. With the development of the egg of the insect there also appear in the cells of this middle zone numerous starch grains closely resembling those found in the central zone. An external layer made up of irregular parenchymatous cells, somewhat collenchymatic in character, with a lining of protoplasm as in the cells of the middle zone.

In some studies on the origin of tannin in galls Kraemer (Bot. Gaz., I900, p. 275) showed that in the "ink gall" there are three 
stages in their development, corresponding to the life periods of the insects and changes in the constituents of the cells: (I) When the galls are first formed and the larva is beginning to develop, the cells of the outer zone, as well as those of the central

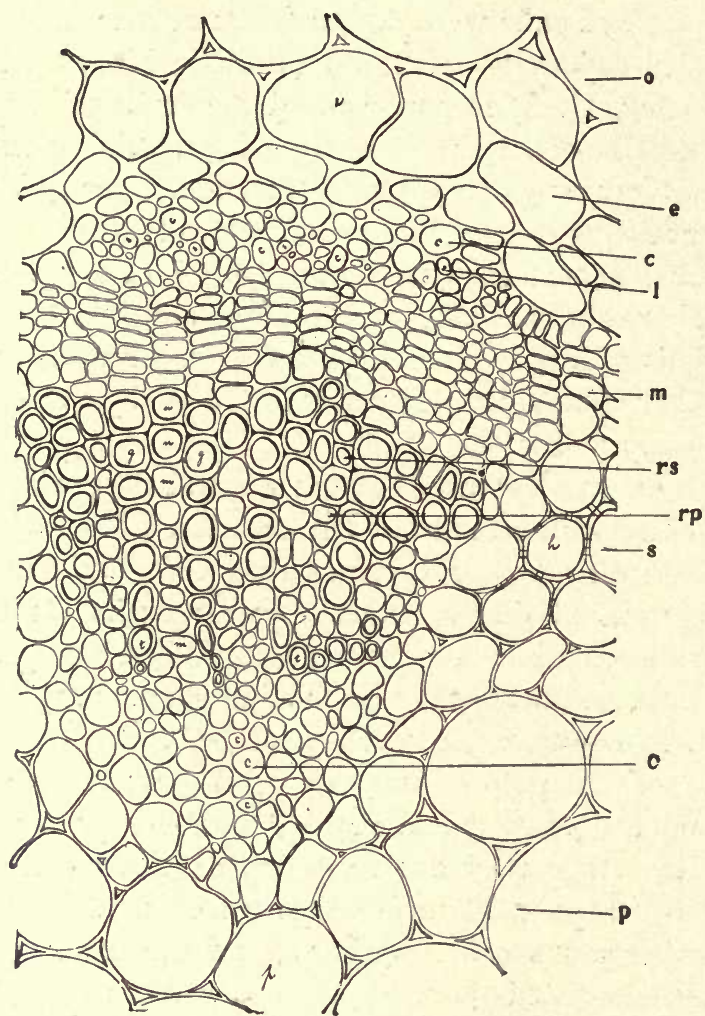

FIG. I92. Transverse section of one of the collateral mestome strands of the stem of Viola tricolor arvenis: o, portion cf cells of pericycle; e, endodermis; 1, leptome or sieve celis, in among which are some collenchymatous cells (c); $m$, cambium; $t$, spiral tracheæ or vessels; $g$, strongly lignified tracheæ; rp, medullary ray cells, the walls of which are com. posed of cellulose; rs, medullary ray cells the walls of which are strongly lignified; $s$. strongly lignified cells separating the mestome strands; $c$, collenchyma; $p$, pith.

zone, contain numerous small starch grains. (2) When the insect reaches the chrysalis stage the starch in the cells near the middle of the galls is replaced in part by gallic acid, while the cells at the center and near the periphery contain masses of tannic 

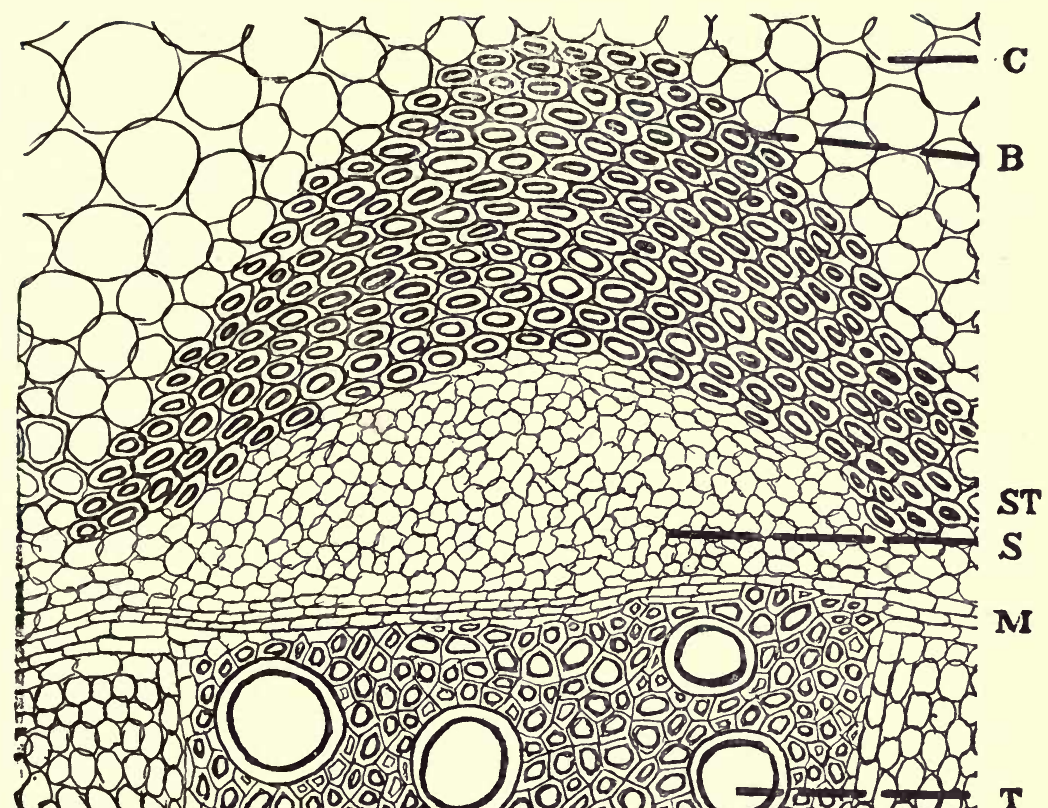
Ha

H.

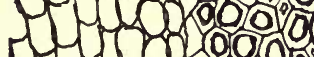

HH-

H.H. $4 H 4$.

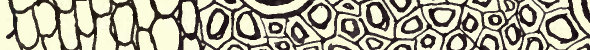

H.H H

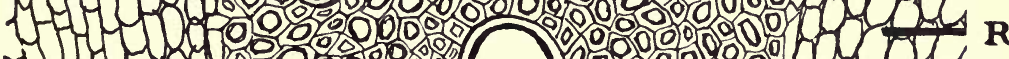
IH H H H H H MH H 4.424 M. 1.40 . Mrb

Fig. I93. Collateral fibrovascular bundle in Menispermum: C, cortex; B, bast fibers; St, stone cells connecting groups of bast fibers; S, sieve; M, cambium; T, tracheæ; $W$, wood fibers; $R$, medullary rays; $P$, pith. 
acid. (3) When the winged insect is developed nearly all of the cells contain amorphous masses of tannic acid with some adhering crystals of gallic acid. After the insect has emerged from the gall the constituents again undergo change, depending largely on the presence of moisture, when the tannic acid is changed into more or less insoluble products and the galls become more porous.

THE INNER STRUCTURE OF THE STEM.

If we make a transverse section of a young herbaceous stem, we observe a differentiation of the tissues, which in several respects agrees with that of the root previously described. In the primary structure of the stem the following tissues are to be noticed: The outermost layer is the epidermis with a more or less distinct cuticle; the second is the cortical parenchyma, frequently having strands of collenchyma near the epidermis. The cortex often contains secretory cells or receptacles, and not infrequently the innermost layer is differentiated as an endodermis. The latter surrounds the so-called pericycle, a sheath consisting of more or less distinct stereomatic strands, either forming a closed sheath or merely representing isolated arches outside the leptome of the stele. Inside the pericycle we observe the mestome strands constituting mostly one circular band (in cross section) in the Dicotyledons and Gymnosperms, or several more or less concentric bands in the Monocotyledons. The mestome strands or fibrovascular bundles may be collateral (Figs. I92-194), bicollateral or concentric, the last of which being found only in the Monocotyledons (Fig. 195) and Ferns (Fig. 56).

In the DICOTYLEDONS the collateral fibrovascular bundles occur most frequently and consist of three distinct portions, viz., phloem, xylem, and cambium. The phloem consists of sieve tubes, companion cells (or accompanying cells), and cambiform. The last two are thin-walled parenchymatous cells, those of the cambiform being considerably elongated. In addition there may be included in the phloem the stereomatic tissues or bast fibers, which are not infrequently well developed. The xylem includes tracheæ or vessels, tracheids, wood parenchyma, and libriform or wood fibers.

To the student some confusion may arise as to the apparent indiscriminate use of the terms, leptome and hadrome, the former 


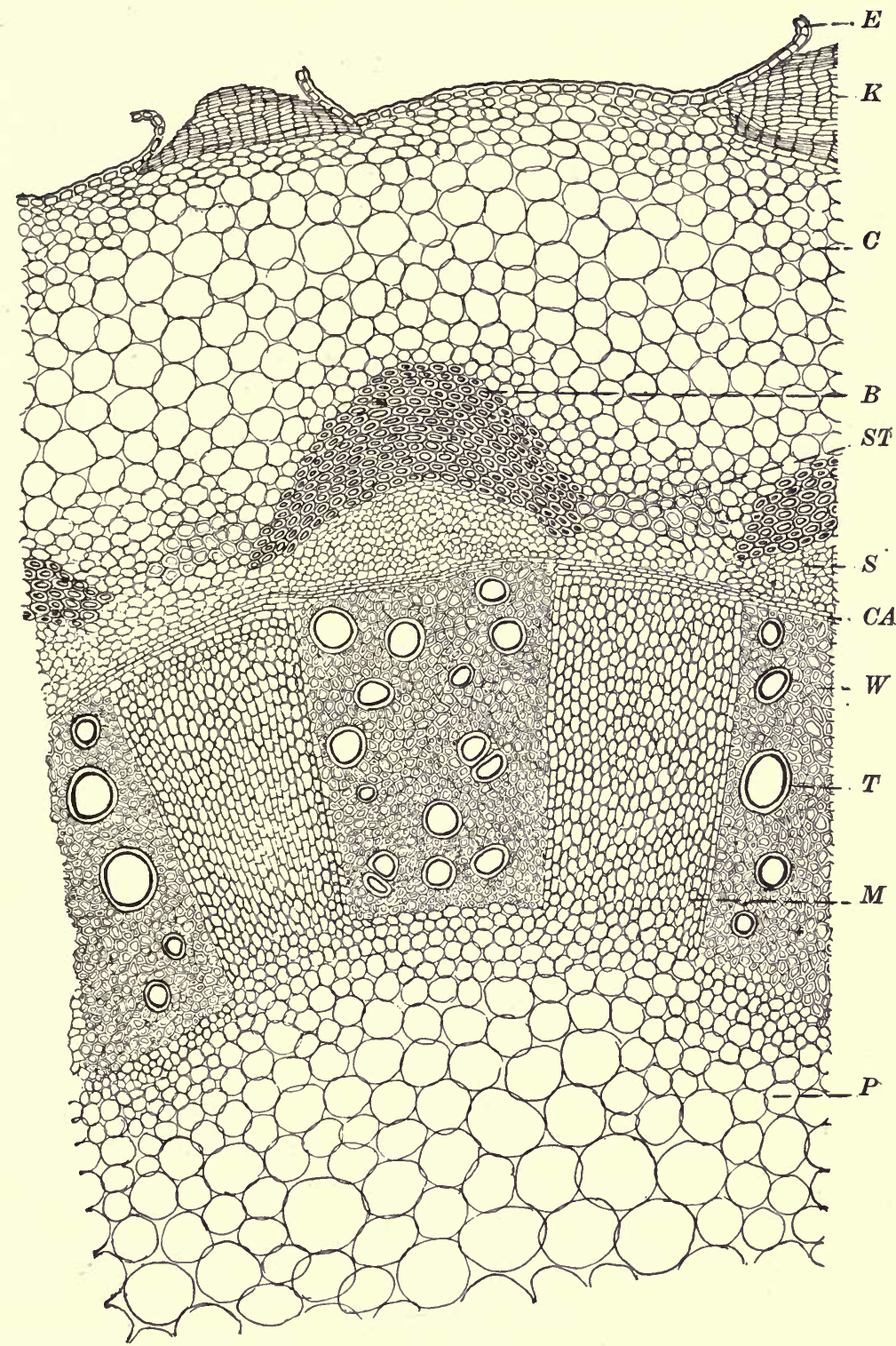

FIG. I94. Dicotyledonous stem structure. Transverse section through menispermum rhizome: E, epidermis; $\mathrm{K}$, sub-epidermal cork; $\mathrm{C}$, cortex; B, bast fibers; S, sieve; ST, stone cells; CA, cambium; T, vessels; W, wood fibers; $M$, medullary ray cells; $\mathrm{P}$, pith. 


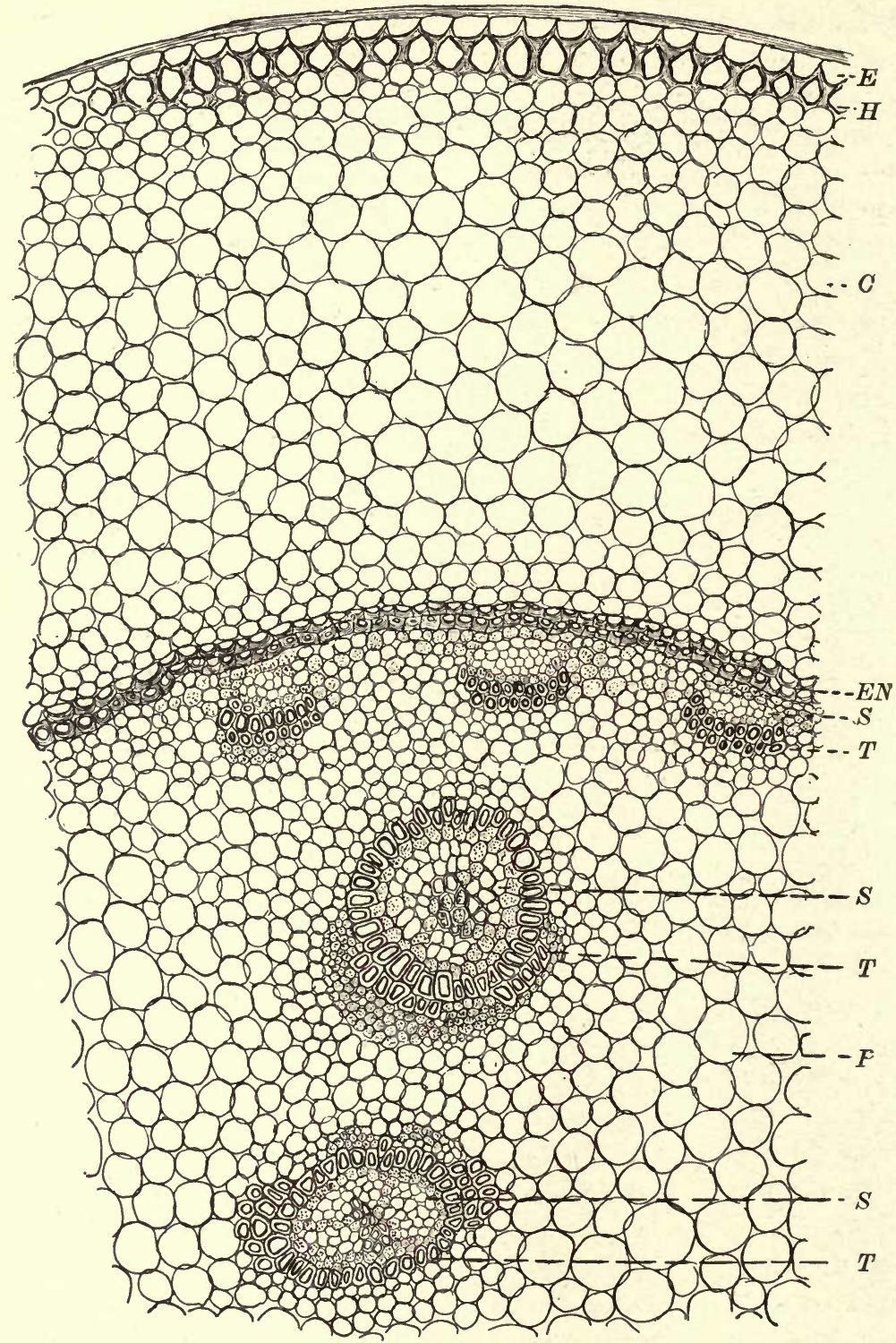

FIG. 195. Monocotyledonous stem structure. Transverse section of convallaria rhizome: $\mathrm{E}$, epidermis; H, hypodermis composed of collenchyma; C, cortex; EN, endodermis; $S$, perihadromatic sieve; $T$, tracheæ or vessels; $P$, parenchyma. The bundles are of the collateral and concentric types. 
being used as being apparently synonymous with phloem and the latter being equivalent to xylem. As a matter of fact, these terms are not equivalent, the phloem proper including bast fibers in addition to leptome; and the xylem being composed of wood fibers in addition to hadrome; nor is the fibrovascular bundle synonymous with mestome strand, as the former includes not only the conducting tissues but the mechanical tissues as comprised in the xylem and phloem; while the mestome strand includes only the conducting cells comprised in the leptome and in the hadrome, there being no sclerenchymatous fibers present. The following table will doubtless make clear to the student the relationship of these tissues to each other:

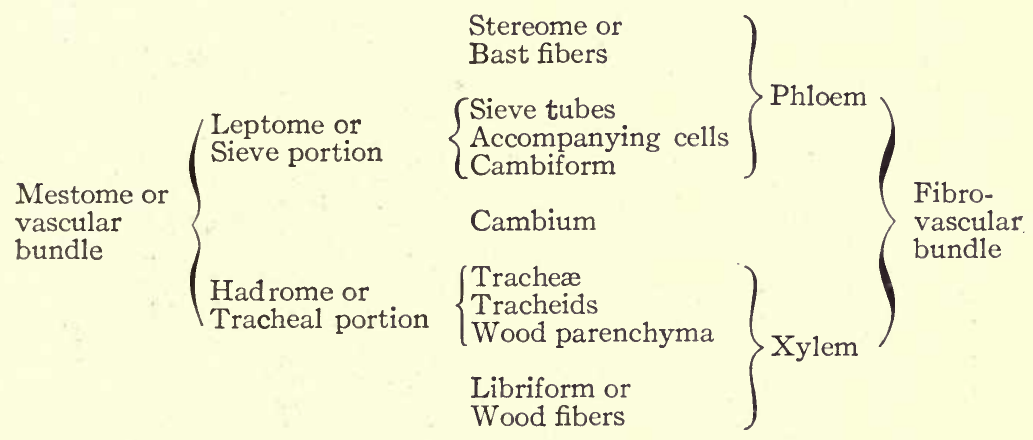

When the collateral mestome strand increases in thickness, the increase is due to the activity of the cambium, here called the INTRAFASCICULAR CAMBIUM, which then develops phloem or leptome outwardly and xylem or hadrome inwardly. Between the primary mestome strands there is frequently a procambium, which connects these strands with each other, and which generally gives rise to secondary mestome strands, or the connection may be effected by means of the intrafascicular cambium, which often extends itself from one strand to another and develops leptome and hadrome, as in the primary strands; such cambium is distinguished as INTERFASCICULAR CAMBIUM and is commonly referred to as the CAMBIUM RING.

The BICOLLATERAL mestome strands or fibrovascular bundles, characteristic of some Dicotyledons (Labiatæ, Solanaceæ, Cucurbitaceæ, etc.), differ from the collateral type by having a leptome 
strand developed on the inner face of the hadrome; thus each mestome strand carries two strands of leptome (Fig. 197, C). In the CONCENTRIC mestome strands the leptome may encircle the hadrome, as in the Ferns (Fig. 56), or the hadrome may partly

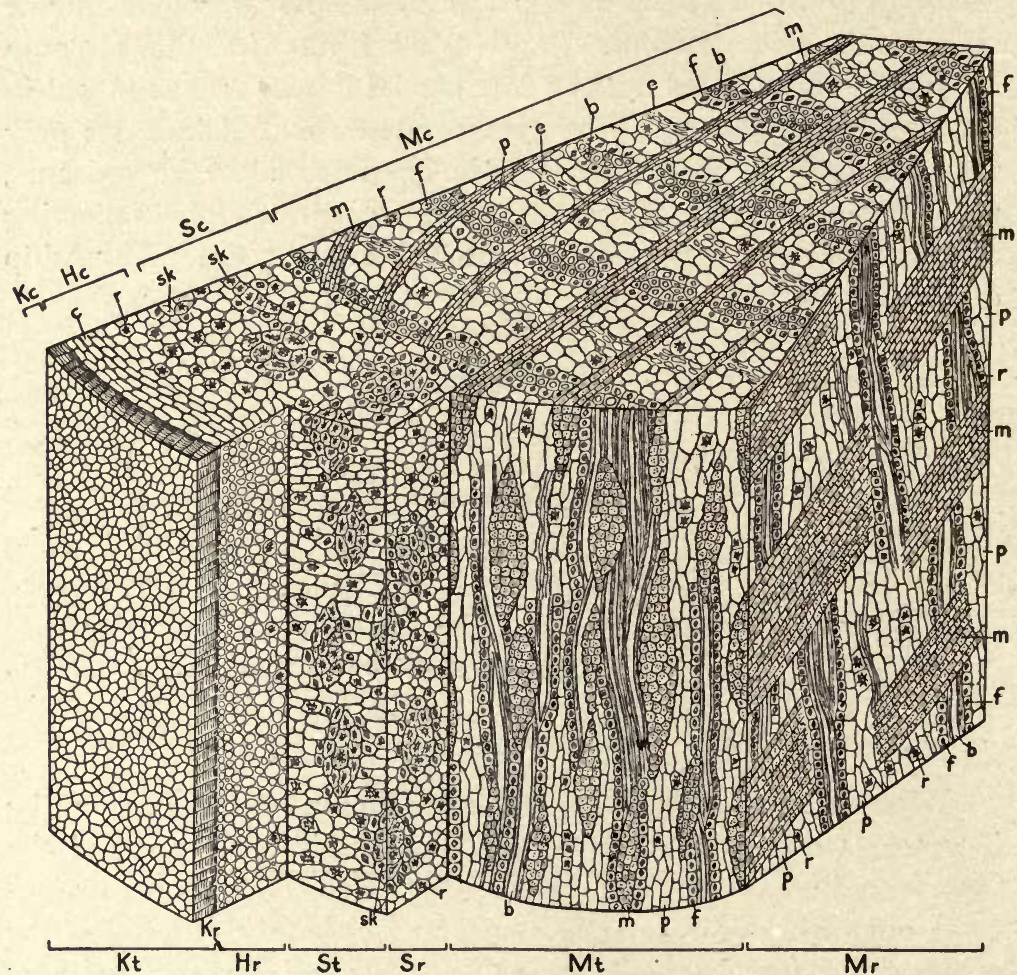

Fig. I96. The outer bark and part of the inner bark of Rhamnus Purshianus in transverse, radial-longitudinal, and tangential-longitudinal sections. Mc, transverse section of inner bark; $\mathrm{Mt}$, tangential-longitudinal section of inner bark; $\mathrm{Mr}$, radial-longitudinal section of inner bark; Sc, transverse section of stone cell area; St, tangential-longitudinal section of stone cell area; $\mathrm{Sr}$, radial-longitudinal section of stone cell area; Hc, transverse section of outer layers of cortex; $\mathrm{Hr}$, radial-longitudinal section of outer layers of cortex. $\mathrm{Kc}$, $\mathrm{Kt}$, $\mathrm{Kr}$, transverse, tangential-longitudinal, and radial-longitudinal sections of cork; $\mathrm{b}$, bast fibers; f, crystal fibers; p, parenchyma; e, sieve; sk, stone cells; $m$, medullary ray cells; c. collenchyma.

(as in the rhizomes of many Monocotyledons) surround the leptome (Fig. 195). While thus the collateral type of strand or bundle occurs in both Monocotyledons (Fig. I95) and Dicotyledons (Figs. 192, 193), etc., the presence of a cambium is found only in the Dicotyledons and occurs extremely seldom in the Mono- 
cotyledons. The central portion of the stele is frequently differentiated into a PITH of parenchymatic structure, the cells of which often contain large quantities of starch. In addition in the pith, we often find the same types of secretory cells or receptacles as occur in the cortex (as in Apocynum). The pith may constitute a homogeneous tissue or be broken, as in Phytolacca, Carya, Halesia, etc., where a longitudinal section shows the pith divided into a row of broad cavities formed by a separation of the cells as a result of the rapid longitudinal growth of the stem.

Finally it may be mentioned that cork is of frequent occurrence, especially upon stems that persist more than one year. The cork may arise in the epidermis itself, or it may develop in the hypodermal strata of the cortex, or in still other cases we find its development much deeper, even within the pericycle.

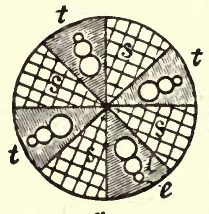

a
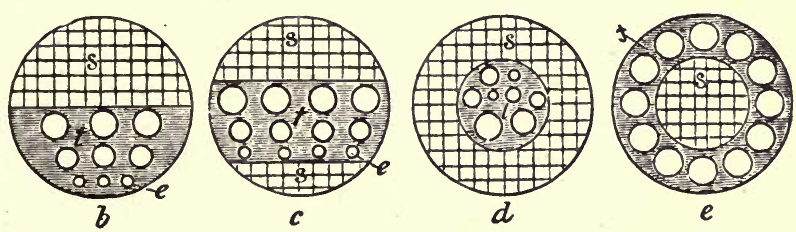

Fig. 197. Schematic representation of different types of mestome strands or fibrovascular bundles: $s$, sieve; $t$, tracheæ or vessels; e, position of the earliest tracheæ formed; a, radial bundle or mestome strand; b, collateral bundle; c, bicollateral bundle; $d$ and e, concentric bundles.-After Meyer.

In regard to the increase in thickness, the stem develops much like the root, as in the throwing off the peripheral tissues extending from the epidermis to the endodermis, or of the epidermis and adjoining cortex, the displaced tissues are replaced by strata of cork and secondary cortex. The mestome strands in the stem, however, grow in a more regular manner than is the case with those of the root, as is seen in the very distinct and frequently very regular layering of the tissues of woody stems, forming the so-called “Annual Rings," where each ring represents the growth that occurs during a single year. The development of these annual rings depends especially upon the fact that the growth of the perennial stem does not take place continuously, but is interrupted during certain periods of the season, for instance during the winter or during the dry seasons of tropical climates. And since the tissues which are formed at the beginning of each 
season's growth are distinct from those already formed during the previous season in both color and structure of the wood (especially in the thickness of cell-walls and the width of the tracheæ or vessels), we perceive in this manner distinct zones of wood, or the "annual rings" as they are called, the larger vessels with thin walls being produced in the spring and early summer.

Various abnormal stem-structures, are known which are due

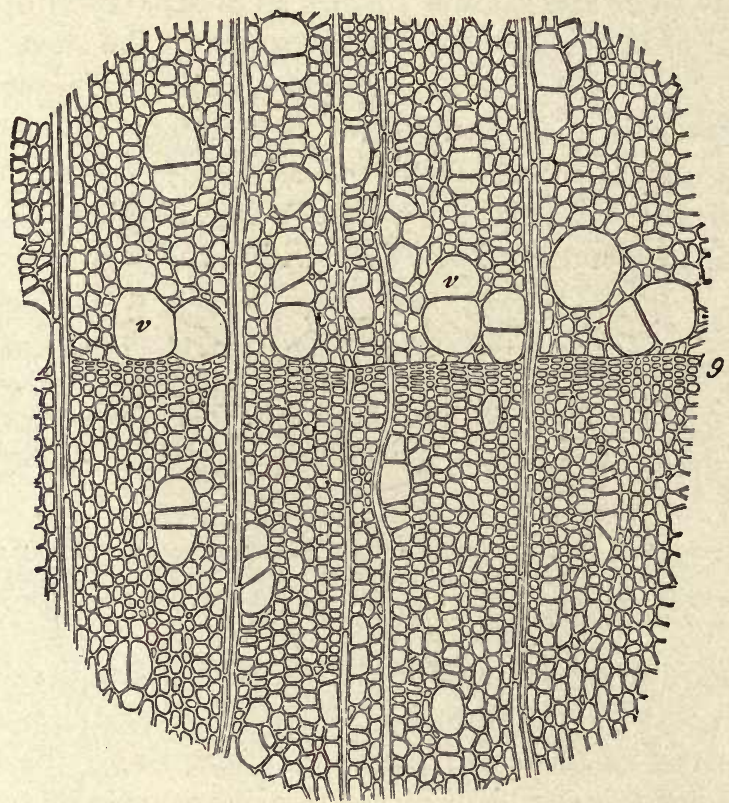

FIG. 198. Transverse section of wood of Rhamnus Frangula showing that the annular rings seen in woody portion of plants is due to a difference in the nature and structure of the cells formed in the spring and in the fall. In the spring numerous large tracheæ or vessels (v) are formed, whereas in the fall very few vessels and mostly wood fibers are developed, the cells of these being smaller as they approach the end of the year's growth.-After Rossmann.

to certain peculiarities in the growth in thickness of stems. These are especially noticeable in lianes. In some of the Monocotyledons, as in Dracæna, Yucca, Agave and Aloe, we find a secondary increase in growth of the stems.

In summarizing the root and stem structures of Monocotyledons and Dicotyledons the following general facts should be borne in mind. Monocotyledonous stems resemble Monocotyledonous roots except that the fibrovascular bundle or mestome 
strand of the former is concentric, whereas in the latter it is radial. The primary structure of Dicotyledonous roots is much the same as in Monocotyledonous roots. The primary structures of Dicotyledonous stems resemble the primary structure in Dicotyledonous roots except that the fibrovascular bundles of the former are of the collateral type. The secondary structures of both roots and stems of Dicotyledons are practically alike. The characteristics

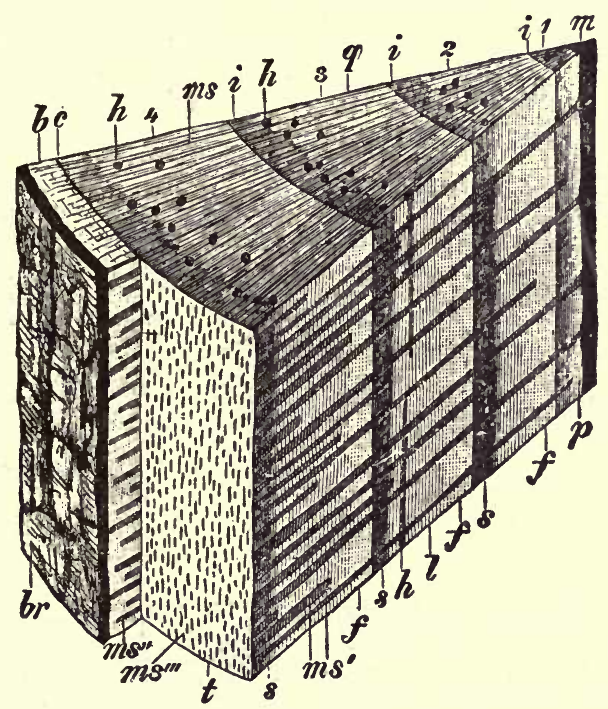

FIG. I99. Section of a four-year-old stem of a pine cut in winter; $q$, view in trans. verse section; 1 , radial-longitudinal section; $t$, tangential-longitudinal section; $f$, spring wood; $\mathrm{s}$, fall wood; $\mathrm{m}$, pith; $\mathrm{I}, 2,3,4$, successive years' rings of growth in which is shown the dividing line; $\mathrm{ms}$, medullary rays in transverse section; $\mathrm{ms}^{1}, \mathrm{~ms}^{11}$, medullary rays in radial-longitudinal section; $\mathrm{ms}^{111}$, medullary rays in tangential-longitudinal section: c, cambium; b, bast; h, resin-canals; br, bork.-After Strasburger.

distinguishing the primary and secondary structures of Dicotyledonous stems may be summarized as follows:

Primary Structures.-Epidermis, hypodermis, primary cortex, endodermis, pericambium or pericycle, stele consisting of collateral fibrovascular bundles and pith.

Secondary Structures.-Periderm derived from phellogen; secondary cortex, consisting of parenchyma and occasionally stone cells or secretory cells or vessels; phloem consisting of sieve, accompanying cells and sometimes bast fibers; cambium in 

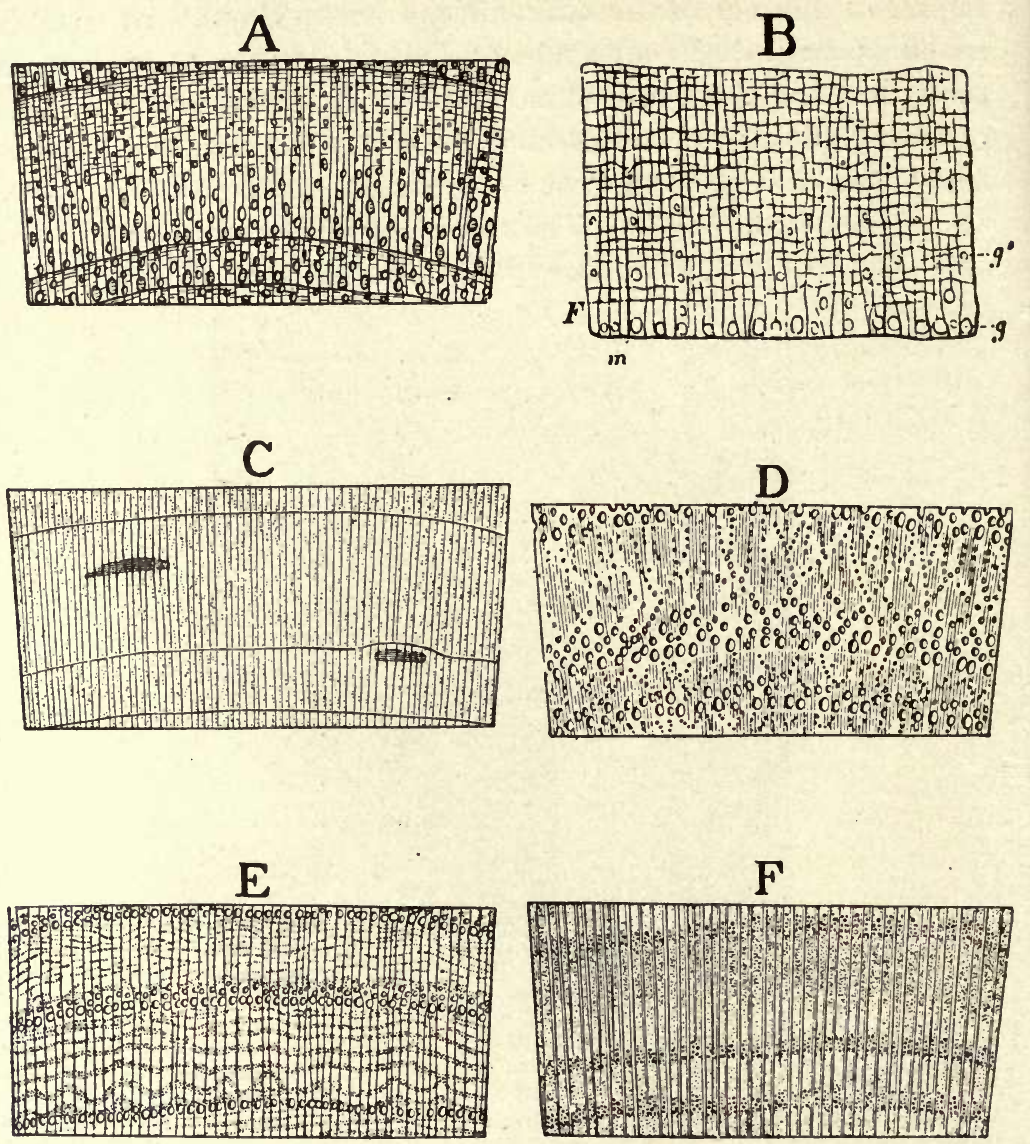

FIG. 200. Coarse structure of a number of woods as seen with a Coddington lens: A, English walnut (Juglans regia) showing the tracheæ everily distributed in the form of pores, which can be seen in the wood with the naked eye; the medullary rays are rather faint and arranged in closely radiating, parallel rows; in the fall wood are numerous fine transverse lines parallel with the annular markings. B, shell-bark hickory (Carya ovata) showing a row of large tracheæ $(\mathrm{g})$ in the summer wood and somewhat smaller tracheæ $\left(\mathrm{g}^{\prime}\right)$ scattered throughout the subsequent growth; medullary rays numerous, as are also the somewhat undulating transverse lines (F). C, white or canoe birch (Betula pendula) showing distinct annular rings and numerous medullary rays between which are scattered the small tracheæ indicated by black dots. D, chestnut (Castanea dentata) showing large tracheæ arranged in circular groups, those of the successive layers being smaller and arranged somewhat obliquely, forming triangular groups; medullary rays very faint; E, Elm (Ulmus campestris) showing tracheæ arranged in circles in the summer wood and in the later growth a number of broad more or less undulating plates ccmposed of very small tracheæ; medullary rays quite distinct; F, Cherry (Prunus domestica), tracheæ quite distinct in the summer wood, forming several circular rows; medullary rays broad and distinct.-B, after Wiesner; the remainder after $\mathrm{R}$. Hartig. 
the form of a ring known as interfascicular cambium; xylem com posed of tracheæ, wood parenchyma, usually wood fibers and sometimes tracheids; medullary rays separating the collateral bundles; pith composed of parenchyma and sometimes having stone cells and secretory cells similar to those found in the cortex. In stems having bicollateral bundles, strands of phloem also occur on the inner surface of the xylem rays.

Importance of the Study of the Structure of Wood.The structure of stems in woody plants is very characteristic, not only in different families but in genera and at times in species. In the Pinacex, for instance, the wood is entirely made up of tracheids, the tracheæ being wanting. In most of the Dicotyledons tracheæ are present, being absent only in certain water plants as Nymphæaceæ and in Drimys, a genus of the Magnoliaceæ. In the Cactaceæ the secondary wood is provided with annular and spiral tracheids. In practical work, whether it be in the study of plants for taxonomic purposes or for their industrial uses, the following are some of the observations that should be made: I. Structure of the walls and nature of the perforations or markings in the tracheæ or vessels. 2. The presence or absence and relative distribution of libriform or wood fibers (often referred to as wood prosenchyma). 3. The structure of the medullary rays not only as regards thickening of the walls and contents of the cells, but the number of the cells both as to width and height entering into the individual groups of rays. 4. Wood parenchyma is variously distributed, the cells aggregated about the vessels being distinguished from those that form tangential bands separating the circles of vessels. The distribution of the crystals is also of importance, as they may occur in isolated cells or in superimposed cells adjoining the wood fibers and form the socalled crystal fibers.

In the study of different commercial woods it is customary in practice to study the coarser features such as can be recognized by the help of an ordinary hand lens. In this superficial study many distinctive characteristics can be readily determined, as the nature of the annual rings, the size of the lumina of the vessels, as well as their abundance and arrangement, etc. (Fig. 200). 


\section{THE OUTER MORPHOLOGY OF THE LEAF.}

Leaves are lateral formations upon the stem and their growth is definite. They never occur on other portions of the plant than stems, from the surface of which they are developed. Leaves appear in acropetal succession, so that the youngest leaves occur nearest the apex of the stem. Terminal leaves are extremely rare, but arise in some instances from the flowers of certain Euphorbiaceæ.
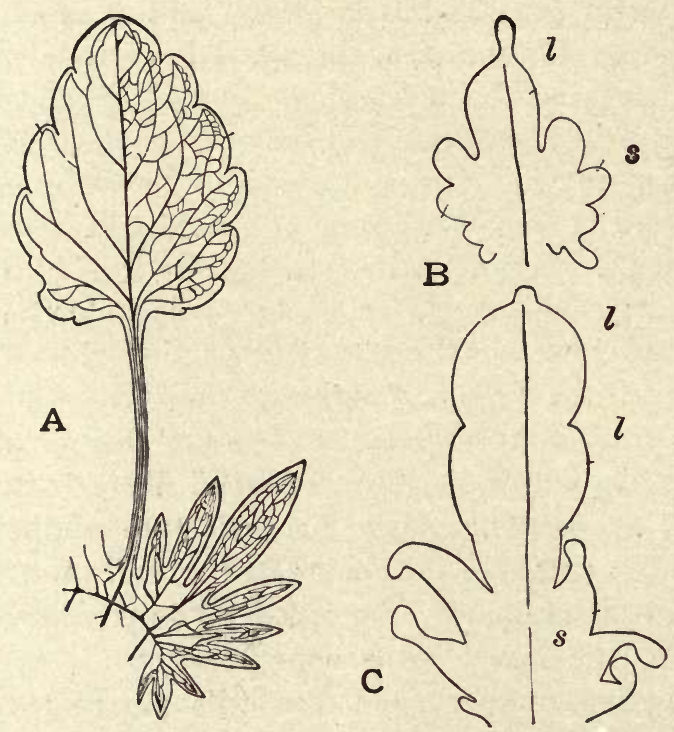

FIG. 20I. A, leaf of violet (Viola tricolor) showing broad lamina, long petiole, and one of the palmately-lobed stipules at the base of the petiole. B, C, stages in the development of the leaf. The lobes of the stipules (s) develop before the lamina (1).

A Simple Leaf consists of a LAmina or blade, which is usually membranous and of a green color, and a PETIOLE or stalk, which, however, may be wanting when the leaf is said to be sessile. Leaves may also possess a pair of leaf-like structures at the base, known as STIPULES (Figs. 20I, 204). The principal function of the latter appears to be that of protecting the buds, as in the tulip poplar (Liriodendron) (Fig. 204), although they may become leaf-like and assist in the functions of the lamina, as in Viola tricolor (Fig. 20I). 
Light Relation of Leaves.-While the lamina of the leaf appears to assume a more or less horizontal position, it usually inclines at such an angle as to receive the greatest amount of diffused daylight. Wiesner has shown, for instance, that when plants are so situated that they receive direct sunlight only for a time in the morning, and diffused daylight during the rest of the day, the position of the upper surface is at right angles to the incident rays of daylight, and not to that of the rays of the morning sun. This phenomenon may be studied in the house geranium and other window plants. In endeavoring to explain this behavior of the leaves, Frank assumes it to be due to a kind of heliotropic irritability peculiar to dorsiventral organs, and terms it TRANSVERSE HELIOTROPISM.

The stem, as well as the petiole or stalk of the leaf, is also influenced by the light, and is said to manifest positive heliotropism. Those parts of plants that turn away from the light, as the aërial roots of the ivy, are said to possess negative heliotropism.

Depending upon their relation to external agents, several forms of leaves are distinguished. In those which assume a more or less horizontal position the two surfaces of the lamina are quite different, and the leaves are said to be DORSIVENTRAL, or bifacial. Usually there is a more compact arrangement or stronger development of chlorophyll tissue on the upper or ventral surface, while on the lower or dorsal surface the veins stand out more prominently, and there is a greater number of stomata.

In contrast with this type of leaf may be mentioned those which grow edgewise and in which both surfaces of the leaf are more or less alike, as in the Eucalypts and Acacias of Australia. In Iris and Calamus, the leaf-like organ is actually not the blade, but merely a part of the dorsal face, which, in the bud, has already pushed out so as to exceed the apex. Such leaves are called SWORD-SHAPED and are frequently referred to as EQUITANT. The leaves of certain species of Juncus, Carex and some of the grasses are commonly spoken of as CyLINDric. Such leaves are, however, only apparently cylindrical, since the ventral surface is often distinct, though much narrower than the dorsal. They are also frequently hollow. 
Functions of the Leaf.-When we speak of the leaves of the plant we usually have in mind the foliage leaves or green chlorophyll leaves.

Under the influence of sunlight the chloroplasts are able to rearrange the elements in carbon dioxide and water, which are looked upon as inorganic substances, into starch or related compounds which are of an organic nature. This process is known as carbon dioxide assimilation, or PHOTOSYNTHESIS, which latter term means the building up of a compound under the influence of light. In this process, which is sometimes expressed by the following formula, oxygen is given off :

$$
\underset{\text { Carbon dioxide Water }}{6 \mathrm{CO}_{2}+5 \mathrm{H}_{2} \mathrm{O}}=\underset{\mathrm{C}_{6} \mathrm{H}_{10} \mathrm{O}_{5}}{\quad \text { Starch }}+\underset{\text { Oxygen }}{6 \mathrm{O}_{2}}
$$

The importance of this function can be best appreciated by bearing in mind that all of the organic products built up by the plant are derived almost entirely from the carbon dioxide of the air which is taken in through the leaves. (Consult also pages I $57-$ I 59.)

Transpiration and respiration are also functions of the leaf. TRANSPIRATION is the giving off of water (through water-pores), or watery vapor (through the stomata), which has been absorbed by the root-hairs and transported through the tissues of the root, stem and leaf ; the process of breathing, or RESPIRATION, consists in the taking in of oxygen and giving off of carbon dioxide, the exchange being just the reverse of what it is in photosynthesis. These several functions are, however, not confined to the leaf alone, but are carried on by all the green parts of the plant.

Physiological Experiments.-The leaf is undoubtedly the most active part of the plant from the physiological point of view. Some of its activities can be demonstrated by comparatively simple means.

For instance, it can readily be shown, that leaves or rather chloroplastids form starch when exposed to sunlight but that no starch is formed when the light is not admitted, by a simple contrivance called a leaf shield. This is a device by which a thin piece of glass can be clamped against the leaf. Over a portion of this glass a piece of tinfoil may be pasted, thereby shutting off the light from the underlying area. The procedure consists as 
follows: On the day previous to the demonstration of the experiment the leaf shield is clamped on the leaf. On the following day the leaf is allowed to stand well exposed to the sunlight for several hours. The leaf is then removed from the plant, separated from the leaf shield, and after the chlorophyll is extracted by boiling in alcohol it is placed in weak iodine solution, whereby the entire part of the leaf exposed to the light is darkened in color, while the area protected by the tinfoil remains unchanged.

The phenomenon of photosynthesis whereby the leaf uses carbon dioxide and gives off oxygen can be demonstrated by means of a photosynthometer. Ganong gives a detailed description of its construction and use. The underlying principle is that a known volume of leaf material is supplied with a known volume of carbon dioxide. After submitting the leaf to the sunlight a test is made of the proportion of carbon dioxide and oxygen in the graduated tube, from which the activity of the leaf may be accurately deduced.

The process of transpiration in leaves can also be readily shown. The mere fact of transpiration can be shown by inserting the leaves of a plant into a bell-jar which has at its base a sheet of rubber or other suitable material stretched over the opening with just sufficient aperture to admit the stem. The root being outside of the bell-jar can be kept moist and as transpiration takes place the moisture condenses on the inside of the glass.

By means of an arm balance and devices for measuring the water supplied the plant, together with some covering to prevent evaporation from the surface of the soil, rather accurate determinations can be made of the quantities of water given off by the plant and calculations made for each square unit of leaf surface.

The potometer is another ingenious simple contrivance which measures most accurately the amount of water transpired. It consists of a horizontally placed graduated tube which ends in a short vertical portion into which a stem bearing leaves can be tightly inserted after the instrument is filled with water. By means of a reservoir at the side and a stop-cock more water can be admitted as needed. Accurate readings over short periods of time are facilitated by admitting a small bubble of air as an index and observing the time of its passage along the graduated tube.

(Consult Ganong: Plant Physiology.) 
Leaf Venation.-The foliaga leaves of higher plants are traversed by vascular bundies, which enter the blade through the petiole and diverge at the base, or, as in the case of Dicotyledons, branch in various ways; and it will be seen that the form of the leaves corresponds to the distribution of the bundles. These bundles are known as veins or nerves, and they have two functions, namely, (I) that of a mechanical support, and (2) that of carrying nutritive materials to and from the leaves.

The mode of venation in Monocotyledons and Dicotyledons differs somewhat, but it will be found that in a number of instances
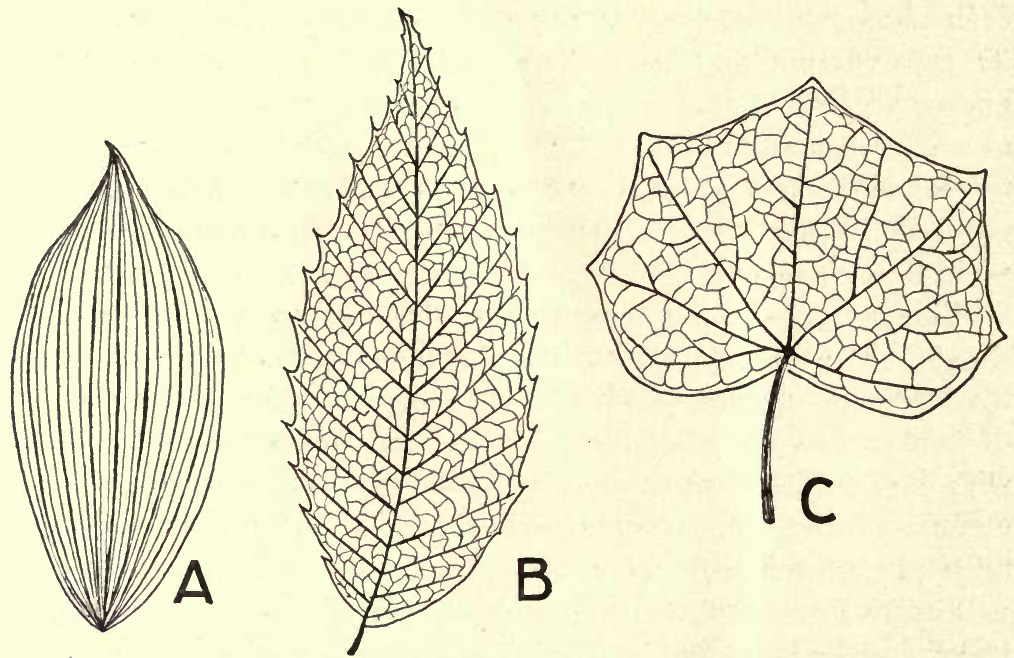

FIG. 202. Leaf venation: A, parallel-veined leaf of Solomon's seal (Smilacina racemosa); B, pinnately-reticulate leaf of chestnut; C, palmately-veined leaf of Menispermum canadense.

the venation of leaves of plants belonging to one of these great groups will resemble that of the leaves of certain plants in the other group. However, there are certain general types belonging to each group (Fig. 202).

Venation in Monocotyledons.-An examination of the leaf of lily-of-the-valley shows that the primary veins run more or less parallel to the apex with short though distinct anastomoses. Such a leaf is said to be PARALLEL-VEINED or NERVED. It will moreover be noticed that the distribution of the veins in this manner produces a lamina with an even, or entire margin, and 
such a system of venation is known as a closed system of venation (Fig. 202, $A$ ). The leaves of Veratrum and Zea Mays furnish other examples of parallel-nerved leaves.

In palms the venation is somewhat different. The veins, instead of converging toward the apex as they do in the more or less lanceolate leaf of lily-of-the-valley, radiate from the base to the margin of the more or less round leaf, and a leaf of this type is said to be PALMI-NERVED.

There is still a third type of venation in Monocotyledons. In this instance one principal vein runs from the base to the apex of the leaf, and from this branches run parallel to the margin. The banana furnishes an example of this type, and is said to be PINNI-NERVED.

Venation in Dicotyledons.-Here the veins are characterized by their habit of repeatedly branching and anastomosing, whatever the general type of venation may be, and thus form a net-work or reticulum, hence the leaves are said to be RETICULATE or NetTED-VEined. The principal types are as follows: A chestnut or chinquapin leaf (Fig. 202) furnishes a good illustration of a pinnately-reticulate leaf. The principal vein which runs from the base to the apex is called the MIDRIB, while the secondary veins which arise from it and run more or less parallel to the margin are sometimes spoken of as ribs and may be likened to the plumes on the shaft of a feather.

In other cases several large veins arise at the base and diverge toward the margin, giving rise to PALMATELY-VEINED leaves, as in the leaf of maple. There are still other types, as in cinnamon, which is said to be rib-netted, etc.

Surface of Leaves.-In addition to the markings of leaves due to veining there are certain other characters which serve to distinguish them. Hairs are of frequent occurrence on leaves, being generally most abundant on the dorsal surface, especially the veins, and various terms having reference to the kinds of hairs have been applied to leaves.

Plant Hairs.-When the surface of the plant (either of stems or leaves) is covered with short, fine hairs, which are not very dense and not matted, the surface is described as PUBESCENT; when the hairs are relatively long but scattered the surface is said 
to be vil.Lous; or when the hairs cover each other in one direction it is described as SERICEOUs or silky. When the hairs are stiff though slender we speak of a HIRSUTE covering; when the hairs are vernate, thickish and stiff, as in Borago, the surface is spoken of as being HISPID. If the hairs are bristle-like the surface is described as STRIGOSE; or if they are terminated by a globular, glandular head (Figs. IOO, I24), as GLANDUlar. Again, when the hairs are matted the surface is described as LANATE; when they are long it is said to be woolly; or when they are short and soft as in Mullein it is said to be TOMENTose.

When the hairs are hard and prickle-like the surface is described as HISPID or STRIGOSE; when they are modified to spines it is said to be SPINOSE; and when they are hooked it is described as ECHINATE.

In still other cases the epidermal cells, particularly of leaves, are uneven, forming depressions and protuberances which if slight give the surface the appearance described as RUGOSE; or if wart-like, give the appearance known as verrucose. Furthermore, the veins of leaves may be quite prominent, particularly in the lower surface, and if they are much reticulated in addition, the surface is described as RETICULATE.

Texture of Leaves.-Leaves also vary in texture. A thin pliable leaf is called membranous; one which is thick and leathery, coriaceous; and one which is thick and fleshy, succulent, as that of the century plant and Aloe (Fig. 130).

Forms of Leaves.-The leaves of plants exhibit an almost innumerable variety of forms; even on the same plant there are not infrequently several forms, as in Viola tricolor and sassafras (Fig. 203) ; even the two margins of the same leaf may vary, as in Hamamelis and Begonia, when it is known as an inequilateral or asymmetric leaf. It frequently happens that the lower leaves on a shoot are lobed while the upper ones are entire, or some of the leaves may be sessile and other petiolate. Many of the terms used in ordinary language in describing the forms of objects are applied here also, as linear, lanceolate, oblong, elliptical, spatulate, wedge-shaped, etc.

Apex of Leaf.-A number of descriptive terms are employed in describing the apex of the lamina, as ACUTE, when the form is 
that of an acute angle; oвtuse, when the angle is blunt; ICUMINATE, when the angle is prolonged; TRUNCATE, when the end of

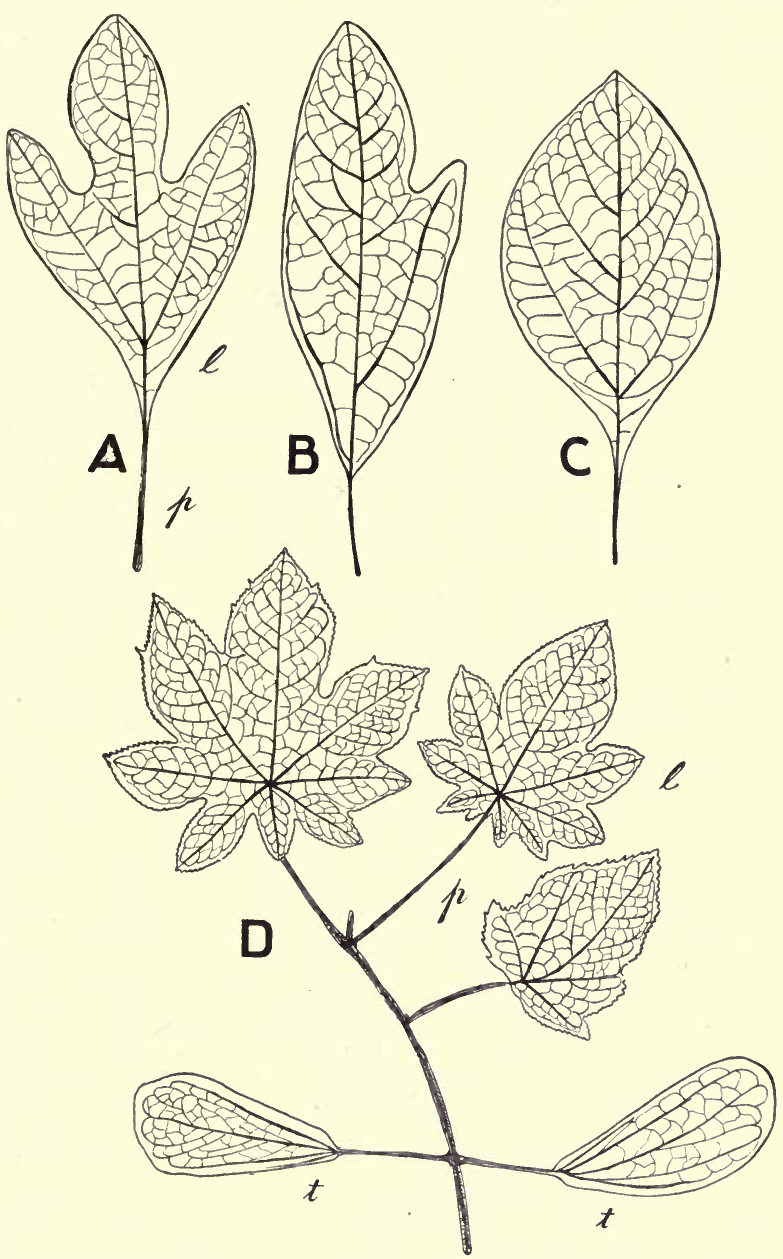

Fig. 203. Variation in the form of leaves on the same plant: A, B, C, Leaves of sassafras; D, young castor oil plant showing cotyledons ( $t$ ) and variously lobed older leaves. 1, lamina; $\mathrm{p}$, petiole.

the leaf appears to be cut off; RETUSE, when it is slightly notched at the apex; OBCORDATE, when the notch is pronounced; EMARGINATE, when the degree of notching is between retuse and 
obcordate. Sometimes the apex appears like the continuation of the midrib, when it is termed CUSPIDATE or mucronate.

BASE OF LEAF.-Some of the terms used in describing the general outline, as well as the apex of the leaf, are also applied to the base, as obtuse, truncate, cordate, reniform, etc. Other terms, however, especially apply to the base, as CUNEATE or wedgeshaped; CONNATE-PERFOLIATE, when opposite leaves are connected at the base and surround the stem; PERFOLIATE, when the leaf simply clasps the stem. In Monocotyledons the base of the leaf is frequently developed as a closed or open sheath, sometimes provided with a membranous protuberance between the sheath and the blade, as in the LIGULE of grasses and sedges.

MARGin of LEAF.-The leaves of many woody dicotyledonous plants of temperate regions possess an even margin. The others, according to the degree and character of the incisions or indentations, are described as SERRATE, when the apex of the divisions or teeth is sharp and directed forward like the teeth of a saw; DENTATE, when the divisions project outward; CRENATE, when the teeth are more or less rounded; REPAND, when the margin is somewhat wavy; SINUATE, when the wavy character is pronounced; LOBED, when the incisions extend not more than halfway into the lamina, and the sinus (or hollow) and the lobes are more or less rounded; CLEFT, when the incisions are still deeper and the sinuses and lobes are somewhat acute; and DIVIDED (Fig. 205), when the incisions extend almost to the midrib.

Compound Leaves.-The divisions of a parted leaf may assume the form of a simple leaf, when the divisions are known as LEAFLETS and the whole as a compound leaf. The distinction between a simple leaf and a leaflet is, that the former has a bud in the axil. The difference between the divisions of a simple leaf and those of a compound leaf is this,-in the former they never become detached from the petiole or midrib, whereas in the compound leaf they are articulated and drop off individually. Compound leaves may be divided into PIN NATELY-compound (Fig. 204) or PAlmately-compound (Fig. 2 Io, $E$ ), this distinction depending upon whether the leaflets are arranged pinnately or palmately. A number of forms of pinnately-compound leaves are recognized. When the leaflets are all lateral (Fig. 207) the leaf is said to be 
PARI-PINNATE; when there is an odd or terminal leaflet as in the locust (Fig. 204) the leaf is IMPARI-PINNATE; when the midrib

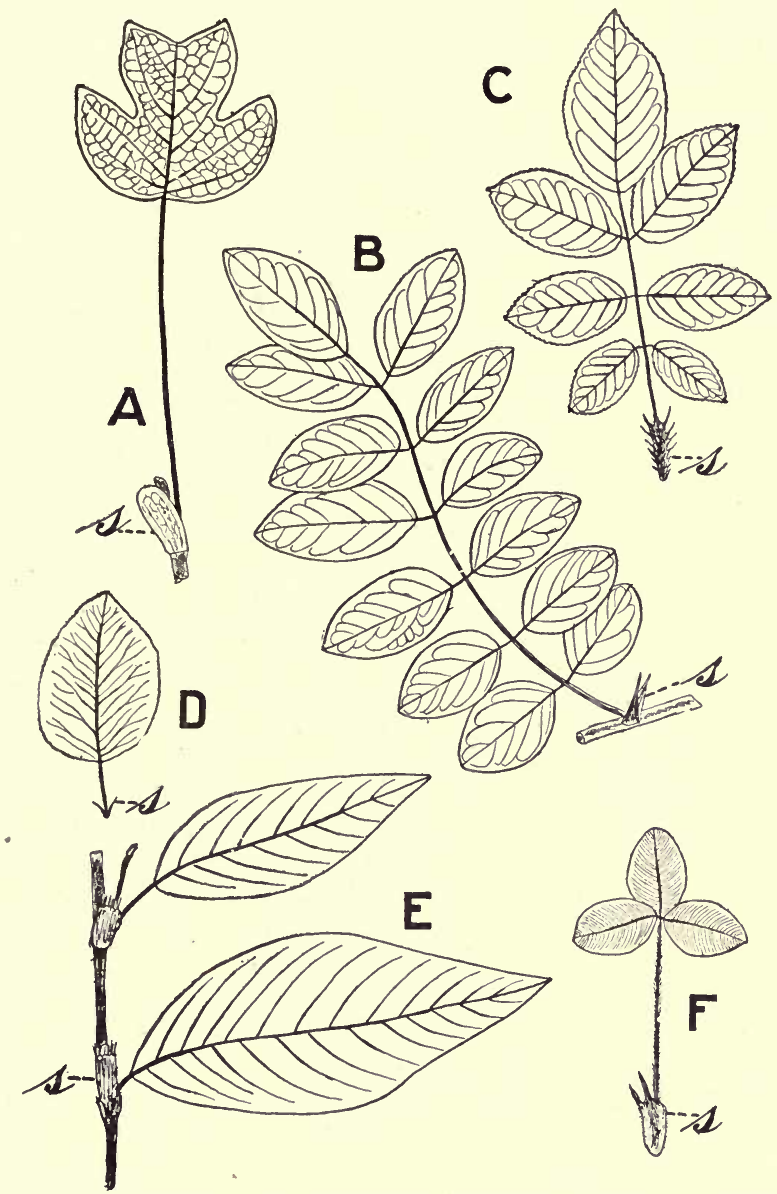

FIG. 204. Leaves having different forms of stipules (s): A, bud-scale stipules of Liriodendron Tulipifera; B, thorny stipules and odd-pinnate compound leaf of the locust tree (Robinia Pseud-acacia); C, adnate stipules of rose; D, filiform stipules of the pear; E, fringed clasping stipules (ocrea) characteristic of all of the Polygonums; F, adnate stipules of clover.

is prolonged into a tendril as in the garden-pea (Pisum) the leaf is said to be CIRrHIFEROUS-PINNATE.

Movements of Leaves.-The leaves as well as other organs of plants exhibit a variety of movements or curvatures in response 
to stimuli of different kinds, and are said to possess the property of irritability. Movements of organs are of two general classes : (I) Those due to stimuli which originate in the plant and (2) those due to the influence of external factors. To the former class

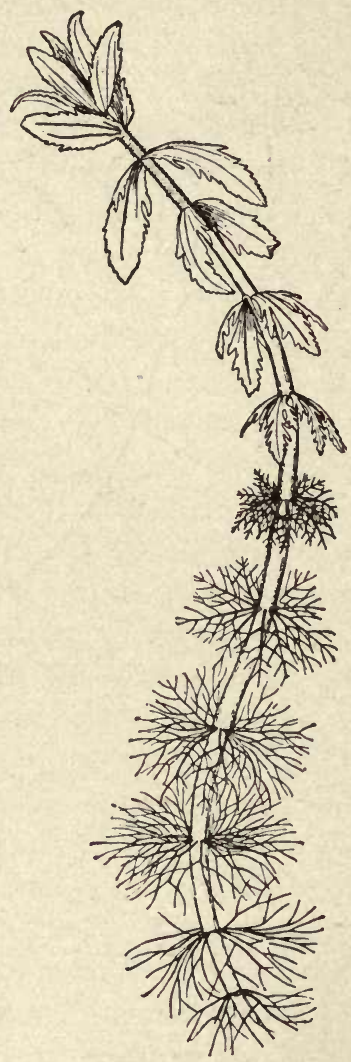

FrG. 205. Limnophila heterophylla, a marsh-plant belonging to the Scrophulariacere and growing in tropical Asia. The submerged or water leaves, below, are much diviled and arranged in apparent whorls; while the leaves at the end of the shoot above water are entire and arranged in decussate dimerous whorls. In between occur transition forms, which are divided and variously lobed and arranged in decussate whorls.-After Goebel.

belong all those movements which occur during the course of development from the young to the mature stage. These are known as growth movements or NUTATION. They are especially noticeable in tips of growing branches, which instead of growing 


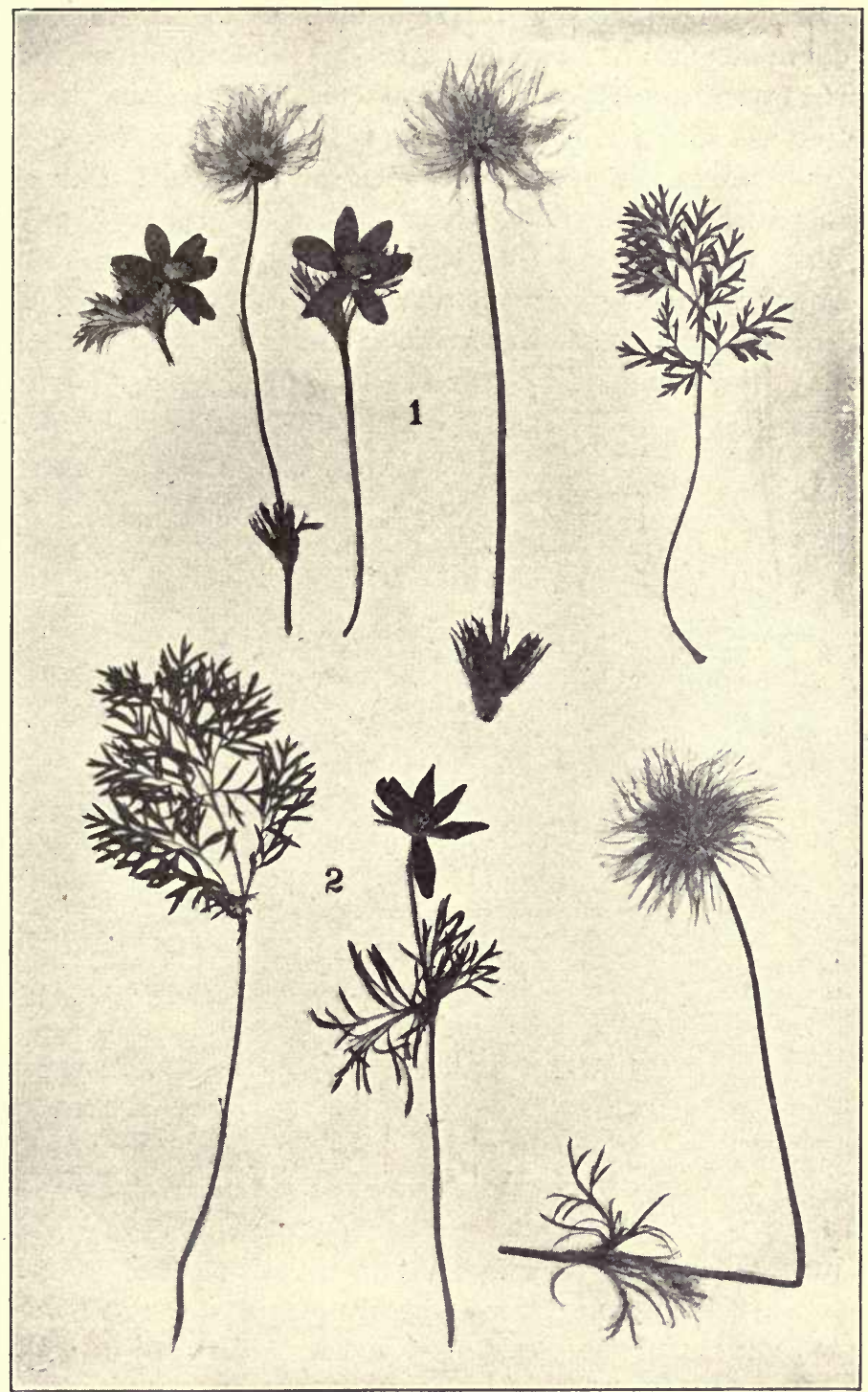

FIG. 206. I, Leaf, fruits and flowers of Anemone Pulsatilla. 2, Leaf, flower and fruit of Anemone pratensis. The leaves are pinnately divided, the divisions being further incised or dissected. 
in a straight line, move either from one side to the other, or coil or curve about an imaginary axis. This spiral movement is known as circumnutation and is characteristic of twining stems and tendrils, as the hop vine and tendrils of Bryonia (Fig. I8I). Nutation curvatures are due to unequal growth on two sides of the organ and cease when there is a cessation in growth or when the plant has reached maturity.

The movements of organs due to external stimuli are usually in a direction which shows a relation to the direction of the stimulus, as those produced by gravity and light (Fig. 207), and these

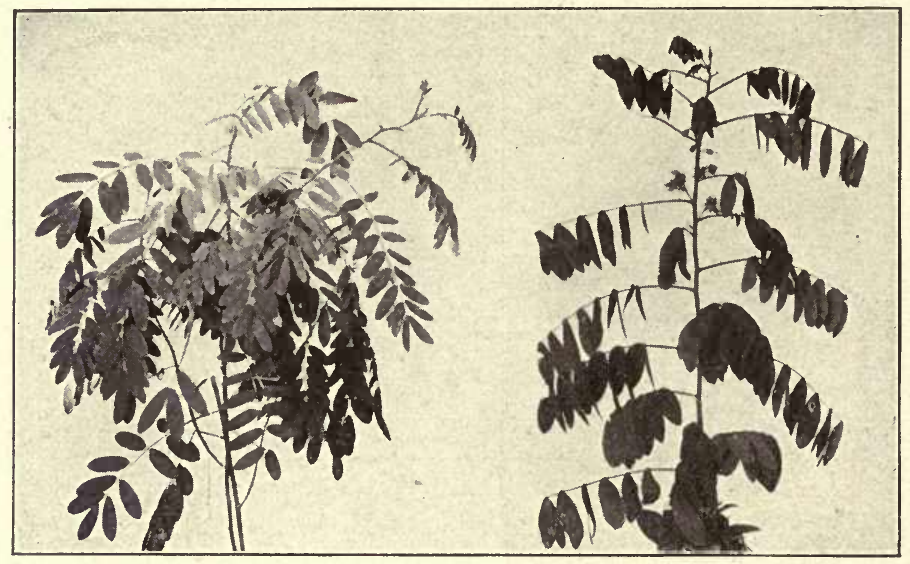

FIG. 207. American senna (Cassia marilandica). The figure at the left shows the pinnately-compound leaves in the day position when under the influence of light, and the one to the right the drooping position of the leaflets at night.

movements are of use in bringing the organs into more favorable positions for growth. Stimuli of this kind are spoken of as orienting or TROPIC. The compound leaves of a number of plants exhibit in addition certain variable and periodic movements, which have their origin in a special mechanism known as the PULVINIS. The pulvinis appears as a swelling on the petiole and consists of parenchymatous tissue which is highly turgid, i.e., full of water. Any stimulus, such as mechanical shock, which causes a difference in the degree of turgidity on two sides, will result in a movement of the leaves in such plants as Mimosa, Oxalis and locust. The leaves of Mimosa pudica, a common cultivated sensitive plant, show a very rapid response to such stimuli, the leaflets folding 
together and the petiole and petiolules drooping. In other cases there is a change in the position of the leaves following the alternations of day and night. During the day the leaflets are spread out freely, but at night or in darkness they droop and fold together. These are spoken of as nyctinastic (nyctitropic) or "sleep movements," and are exhibited by a number of leguminous plants, as clover, bean, Cassia (Fig. 207), and by wood-sorrel (Oxalis Acetosella) and various cultivated species of Oxalis. The leaves of Oxalis as well as of some other plants fold together
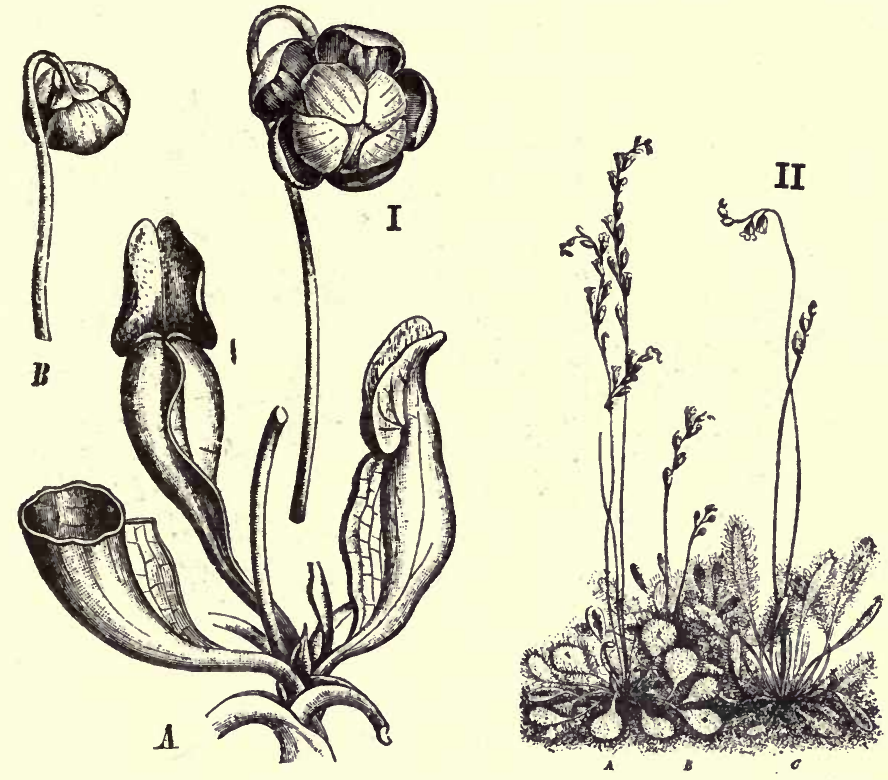

FIG. 208. So-called carnivorous plants. I, the pitcher plant (Sarracenia purpurea) showing the modified pitcher-like leaves (A) with inflated portion which narrows into the petiole, and a terminal, more or less spreading winged portion; and a flower and flower-bud (B). II, three species of sundew: A, Drosera rotundifolia; B, D. intermedia; C, D. longifolia.-I, after Gray; II, after Drude.

under the influence of intense light as well as at night or when the amount of light is reduced. Of special interest also are the lateral leaflets of Desmodium gyrans (telegraph plant) which describe curvatures at more or less regular intervals day and night when the temperature is favorable. The leaves of the sundew (Drosera) are remarkable for their sensitiveness to touch. The upper surface and margin are provided with peculiar hairs or 
tentacles (Fig. 208, II) which when touched, as by an insect, gradually curve inward. Not only this; the stimulus may be transmitted to other tentacles and sometimes even the blade itself may

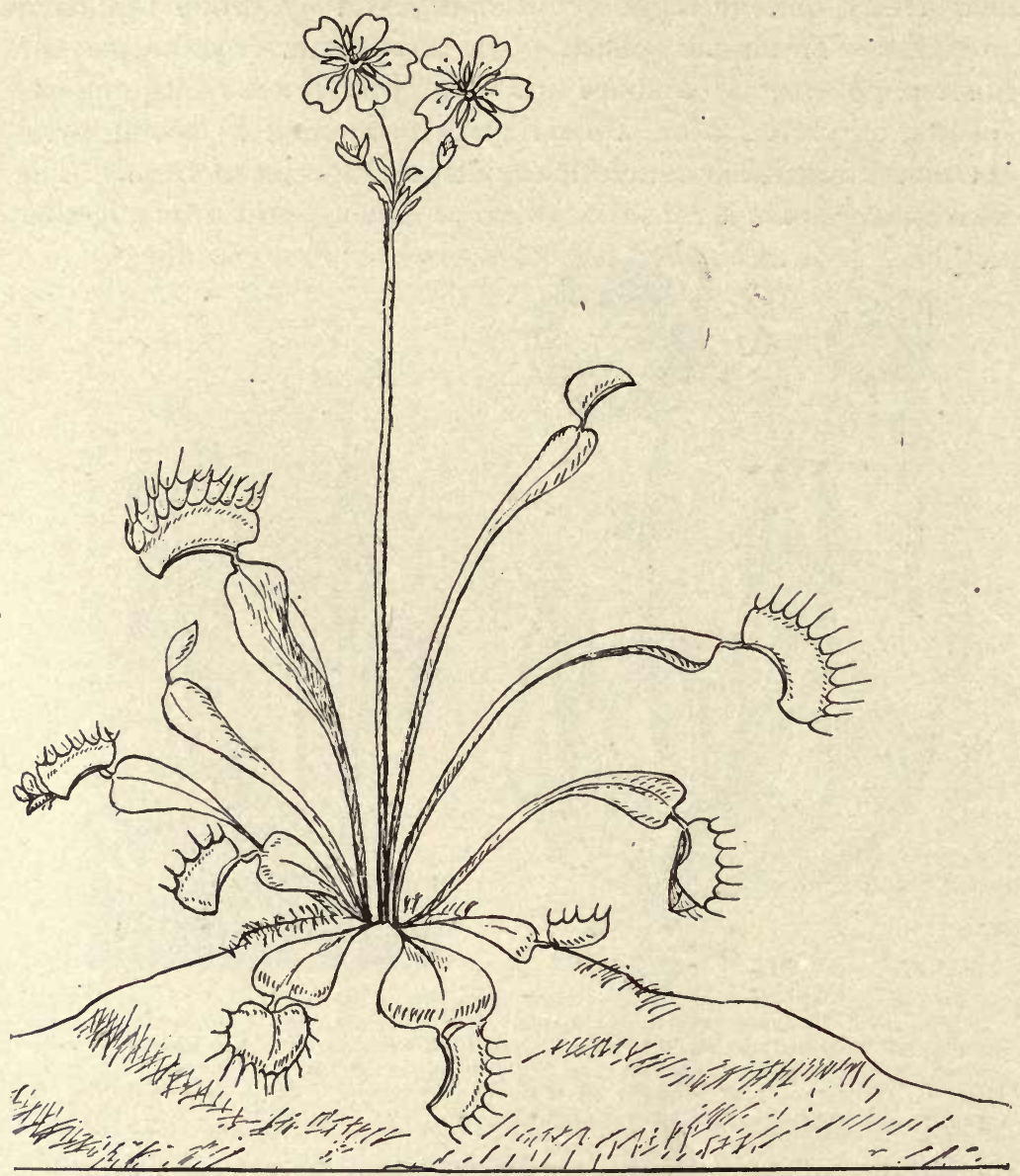

FIG. 209. Flowering plant of Venus's Flytrap (Dionaa muscipula) of North Carolina, showing the sensitive armed leaves both open and closed, in one of which an insect has been imprisoned.-Drawn from nature by Florence Newton.

roll inward to some extent, thus entrapping small insects which serve as food to the plant. The leaves of a related plant Dioncea are even more sensitive and when special hairs on the blade are touched that part of the lamina bearing these hairs closes with a 
quick, trap-like movement, imprisoning its insect prey (Fig. 209).

Phyllotaxy, or phyllotaxis, is the study of the distribution of leaves upon the stem, and of the laws which govern it. If we examine germinating plants of the beech, the elm, or the oak, we observe that, while the seed-leaves are opposite to each other, the subsequent leaves are arranged according to a different order in these several plants, but in a definite manner in each. In the elm, the distribution of the leaves is such that the third leaf is directly above the first; in the beech, the fourth leaf is above the first, and in the oak, the sixth leaf is above the first. If these leaves are connected in the order of their development, it will be seen that they describe a spiral in their arrangement, and it will also be found that one or more circuits of the stem are made between the superimposing leaves. Furthermore, it will be found that this arrangement constitutes a mathematical series which may be expressed in degrees, or the parts of a circle that the leaves are from each other, this measure being known as DIVERGENCE; or by the number of perpendicular rows of leaves on the stem, which are known as ORTHOSTICHIES.

The following may serve to illustrate the terms used:

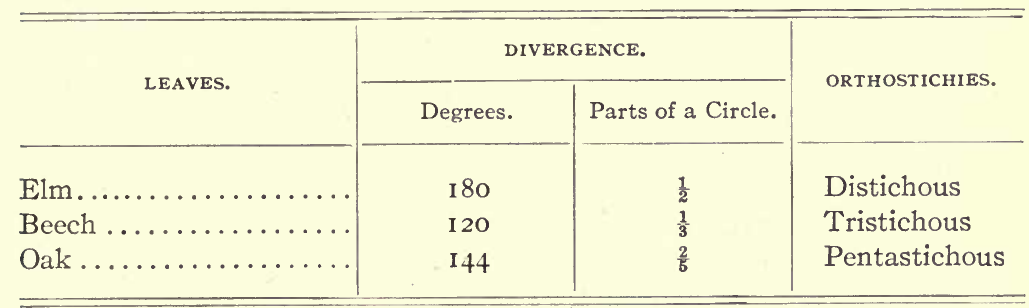

If we examine the fractions used, we will find that the numerator indicates the number of turns around the stem before encountering a superimposed leaf, and that the denominator indicates the number of leaves found; the latter also expresses the number of orthostichies. On adding the numerators and denominators of any two successive fractions, a fraction is obtained which expresses the next highest arrangement, as

$$
1 / 2+1 / 3=2 / 5 ; 1 / 3+2 / 5=3 / 8
$$

In quite a number of plants two leaves arise at the nodes, as in the Labiatæ. These are invariably situated opposite each other 
on the stem, and the successive pairs alternate with one another, forming the decussate arrangement of leaves (Figs. I80, I8' I, I84).

Modified Leaves.-Leaves are variously modified and serve for other purposes than those already described. They may be fleshy in character and serve as storehouses for nutritive material, as the seed-leaves of the oak, or they may serve for the storage of water, as in Agave, Aloe and succulents. In some instances, particularly when situated near the flowers, they lose their green color, as in the dogwood, skunk cabbage and others. In other cases they are modified so that they serve as a trap for insects, as in Dionca, Sarracenia and Drosera (Figs. 208, 209). The petiole may become enlarged and perform the functions of the leaf, as in the Acacias of Australia; or it may become bladder-like and serve as a means for floating the plant, as in the water hyacinth. The stipules may likewise be modified, becoming leaf-like, as in the pansy (Fig. 2OI) ; or metamorphosed into thorns, as in the locust; or clasping, as in Polygonum. In some cases the leaves are very much reduced, their functions being performed by the stem, as in Cactaceæ, or even by the roots, as in some orchids which have assimilating roots.

Prefoliation or vernation is the disposition of leaves in the bud. The terms used to describe the folding of the leaves in the bud are derived from an examination of transverse sections of the bud. The following are some of the terms which are employed: conduplicate, when the lamina of the leaf is folded lengthwise along the midrib so that the two halves of the upper surface lie together; as in the Magnoliace ; PLICATE or plaited, when the lamina is folded along the veins, like a closed fan, as in the maples; convolute, when rolled lengthwise and forming a coil in cross section, as in the Rosace ; INVoLUte, when both margins are inrolled lengthwise on the upper surface, as in the violets ; REVOLUTE, when both margins are inrolled lengthwise on the lower surface, as in Azalea.

In addition, there are several terms used which are derived from the appearance of the bud, as RECLINATE or inflexed, when the upper part is -bent on the lower, as in Liriodendron; and CIRCINATE, when the upper part is coiled on the lower so that the tip of the leaf is in the center of the coil, as in the ferns. 


\section{THE INNER STRUCTURE OF THE LEAF.}

In all green leaves the typical structure is as follows: A cuticle covers the outer cell-wall of the epidermis, while the epidermis itself shows much of the same modifications as exist in the stem; frequently the lumen of the cells of the epidermis is wider on the

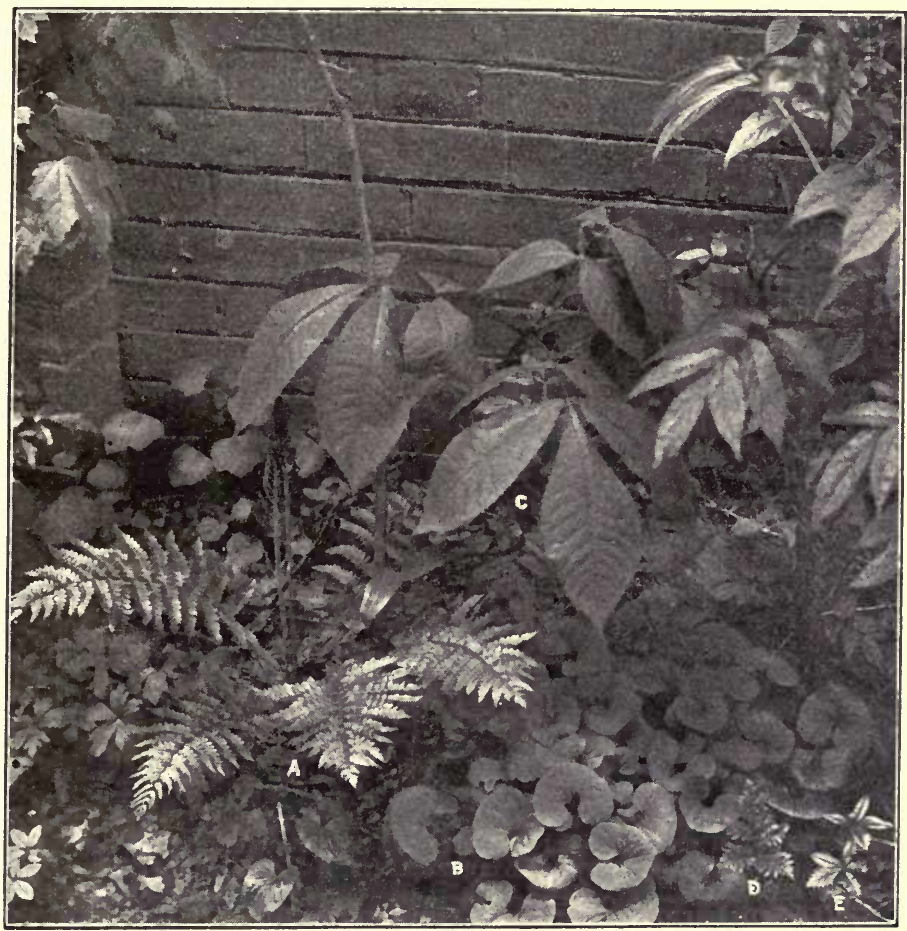

FIG. 210. Group of transplanted wild plants showing variation in form of leaves. A, Cinnamon fern (Osmunda cinnamomea) showing sporophylls (fertile leaves) and a cluster of pinnatifid sterile leaves, the pinnæ being linear-lanceolate and deeply pinnatifid; $B$, wild ginger (Asarum canadense) showing basal, reniform, long-petiolate leaves with cordate base and slightly pointed apex; $\mathrm{C}$, young hickory (Hicoria ovata) showing the odd-pinnate (imparipinnate), 5- to 7-foliate leaves; D, ternate, decompound leaf of Virginia grape fern (Botrychium virginianum); E, digitately compound leaves of cinquefoil (Potentilla).

ventral face than on the dorsal. Hairs abound on the leaves in many plants, and stomata are especially frequent on the dorsal surface. The upper epidermis may further be characterized by the presence of water-pores, the origin and function of which have already been described (Fig. 147). 
The green chlorophyll-bearing tissue is called CHLORENCHYMA (frequently spoken of as mesophyll), and is frequently differentiated into a ventral PALISADE TISSUE, composed of long cells which are placed vertically to those of the epidermis; and a DORSAL PNEUMATIC TISSUE, made up of irregularly branched or lobed cells with very large intercellular spaces. Secretory cells or receptacles occur in the chlorenchyma of many plants and correspond with those found in the cortex of the stem. When the palisade tissue occurs on both faces of the leaf blade with the pneu-

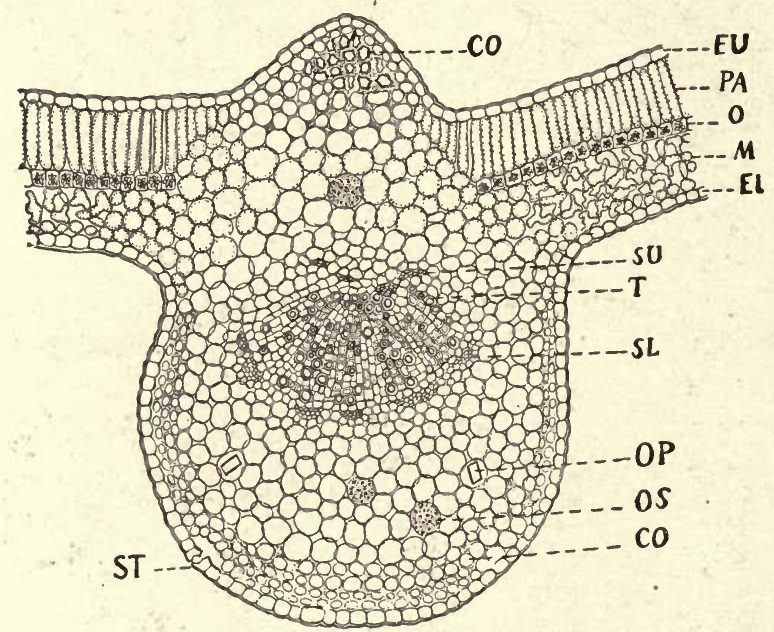

FIG. 2II. Transverse section of midrib of leaf of stramonium: EU, upper epidermis; $\mathrm{CO}$, collenchyma; PA, palisade cells; $\mathrm{O}$, layer of cells containing rosette aggregates of calcium oxalate; M, loose mesophyll; EL, lower epidermis; OP, prisms of calcium oxalate; OS, sphenoidal micro-crystals of calcium oxalate; ST, stoma; T, tracheæ; SU, leptome or sieve on upper side of tracheæ or vessels; SL, sieve on lower side of tracheæ, this arrangement of leptome or sieve and tracheæ forming bicollateral fibrovascular bundles.

matic tissue in the center, the leaf is called " unifacial" or " isolateral" (Figs. 2II, 2I5) ; otherwise the leaf is said to be "bifacial " or " dorsiventral," i.e., with two distinct surfaces.

Mechanical tissues, as collenchyma and stereome, are frequent and these accompany the veins as hypodermal strands, being best developed usually on the dorsal face of the latter, as underneath the leptome. The mestome-strands of the leaf blade generally lie in a single plane. They are collateral and have the leptome situated towards the dorsal face. They are nearly always sur- 
rounded by thin-walled PARENCHYMA-SHEATHS, or as in several grasses and sedges by thick-walled mestome-sheaths. In some plants of various families, the midrib is not only stronger devel-
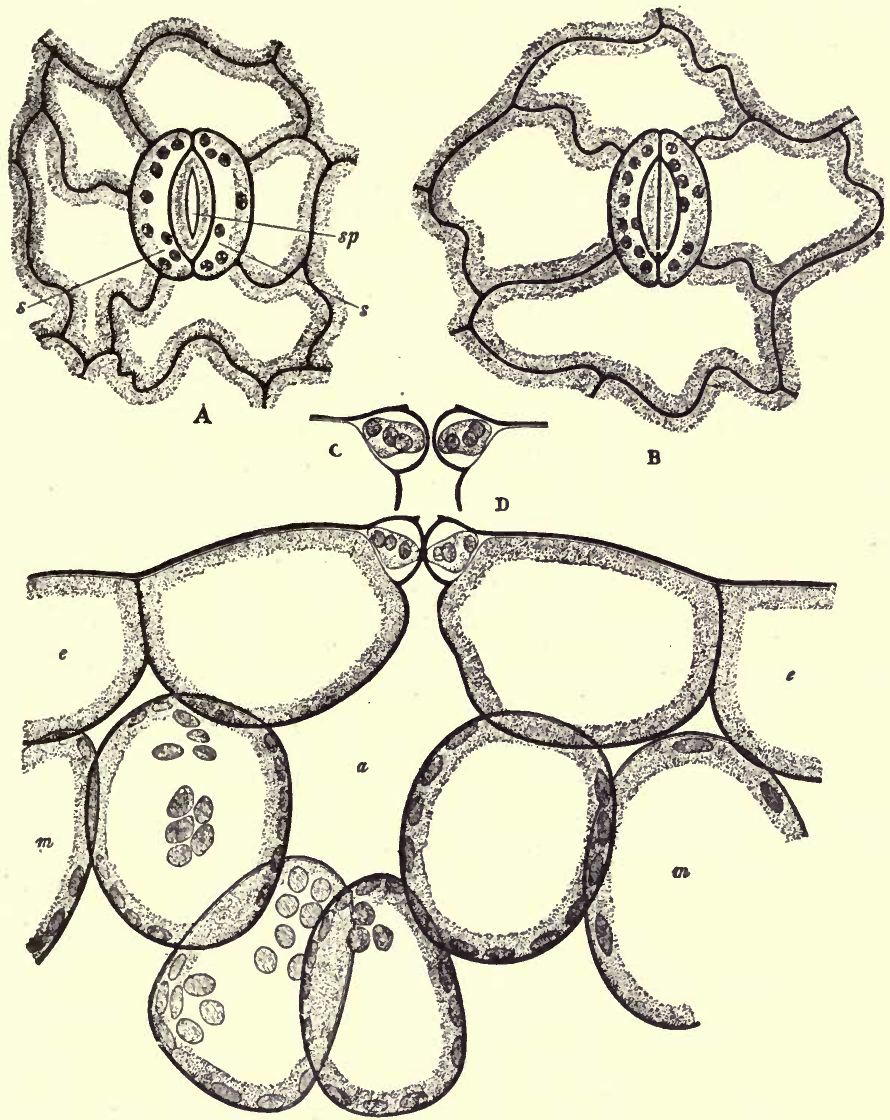

FIG. 212. Study of the stomata on leaves of Beta vulgaris: A and B, surface sections of the leaf, and $C$ and D, transverse sections of the stomata. In A and C, the stomata are shown with the guard cells (s) distended and the pore (sp) open to allow the passage of vapors and gases. $\mathrm{B}$ and $\mathrm{D}$, showing the pore or opening closed due to the plasmolysis of the contents of the guard cells, the internal pressure or tension having been relieved. e, epidermal cells; a, large cavity or intercellular space beneath stomata; and $\mathrm{m}$, loose mesophyll cells with chloroplasts.-After Frank.

oped than the lateral veins, but it may be composed of several, instead of only one, mestome-strand, sometimes representing a true stele. 
The petiole generally shows the structure of the midrib as far as concerns the mestome-strands, but possesses furthermore a more or less strongly developed parenchyma, the cells of which

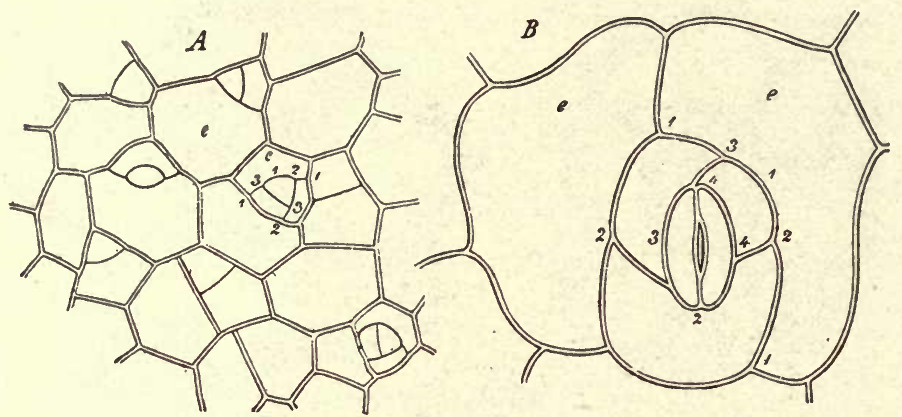

FIG. 213. Development of stomata on leaves of Sedum purpurascens: in A very early stages of growth, and B nearly completed stoma. In B are shown a stoma with two guard cells, three neighboring cells and two of the epidermal cells (e); the numbers in B correspond to those in $\mathrm{A}$ and show the origin of the several cells from the division of a single epidermal cell.-After Sachs.

are colorless, thin-walled and which may often be traced to the leaf-blade itself, where it surrounds the stronger veins, causing

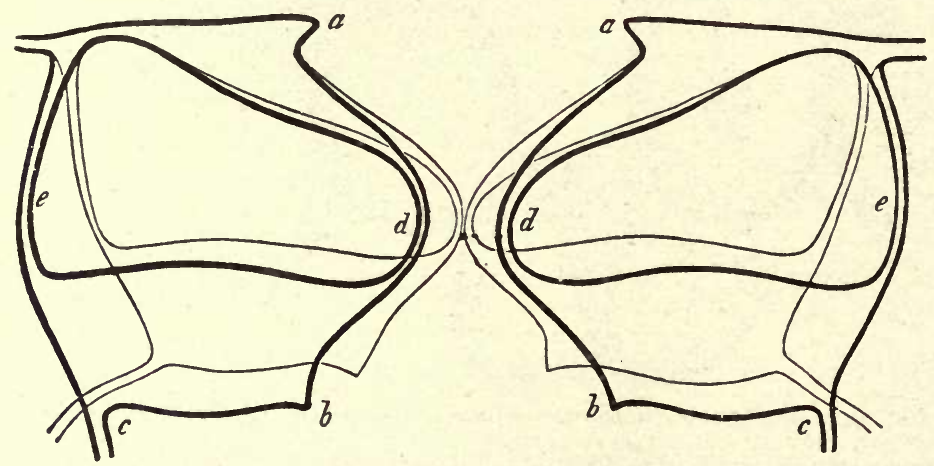

FIG. 2I4. Transverse section through a stomata showing how by a slight difference in the tension the pore is either opened or closed; the dark lines show contour of cells when open, the light lines show when they are closed.-After Schwendener (See Haberlandt, Physiologische Pflanzenanatomie).

them to project as ribs and to be much thicker in cross-section than the adjoining chlorenchyma.

From a histological point of view the leaf structure of 
Dicotyledons resembles very closely that of the Monocotyledons, except that in the latter the palisade-cells often radiate towards the center of the mestome-strands. There are, however, many instances of a similar development in the leaves of Dicotyledons.

Abnormal structures are common in leaves, especially in such

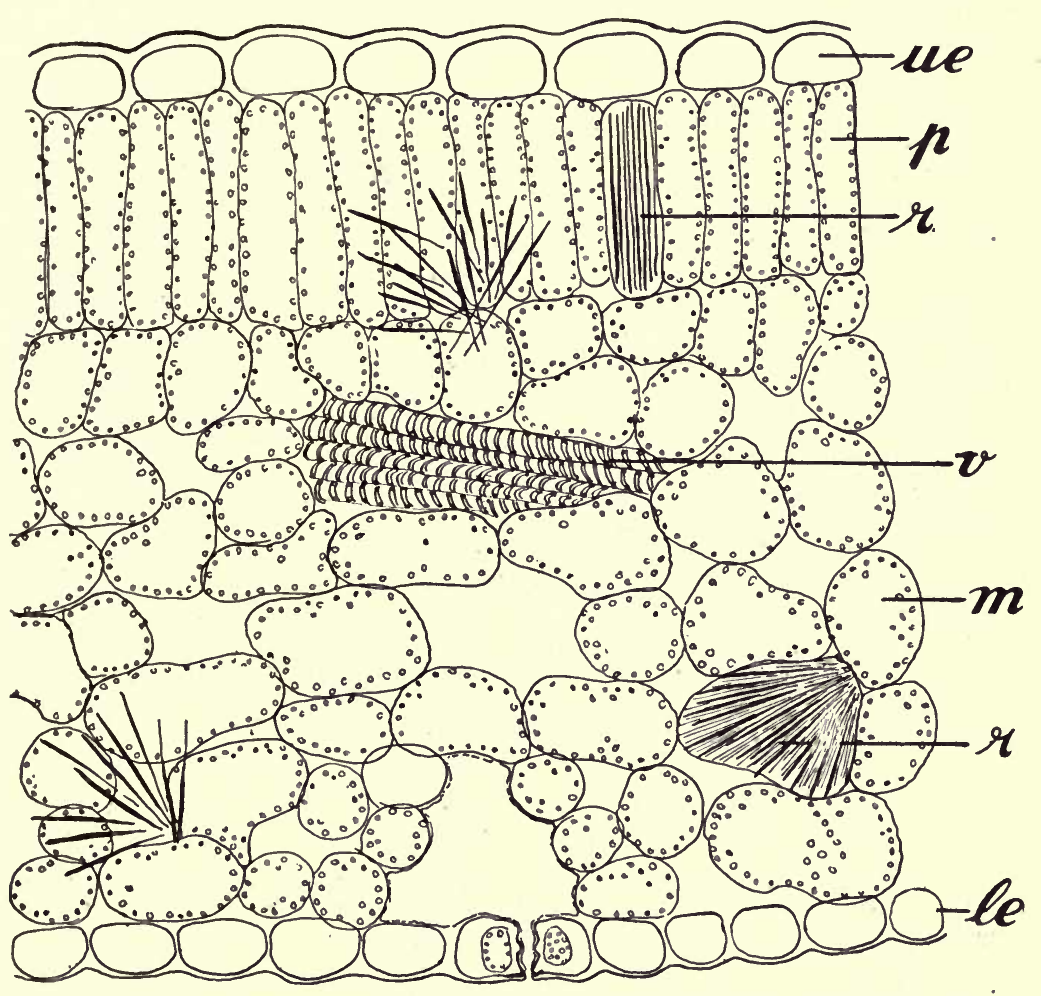

FIG. 215. Transverse section of leaf of Phytolacca decandra showing upper epidermis (ue), palisade cells (p), raphides ( $r$ ), spiral tracheæ (v), loose mesophyll (m) with large intercellular spaces, and lower epidermis (le) with a stoma.

as are not held in a horizontal position, but vertical, as those of Eucalyptus, the Irideæ, etc.

The Epidermis forms the surface of the leaf and may consist of one or more layers of cells. The outer walls are cutinized, and when nearly smooth the leaf is said to be GLABrous. They may be covered or whitened with a bloom, as in magnolia, when 
the leaves are spoken of as GLAUCous. In other cases the outer walls of the epidermal cells are modified to hairs (Figs. Ioo, I24, I25, I48-155).

Anatomical Differences in Leaves.-The walls of the epidermal cells, although usually isodiametric, are often very zig-zag in outline. In size, the upper epidermal cells are usually larger in a given species than those of the lower surface, and sometimes are rather linear, resembling a palisade layer. The
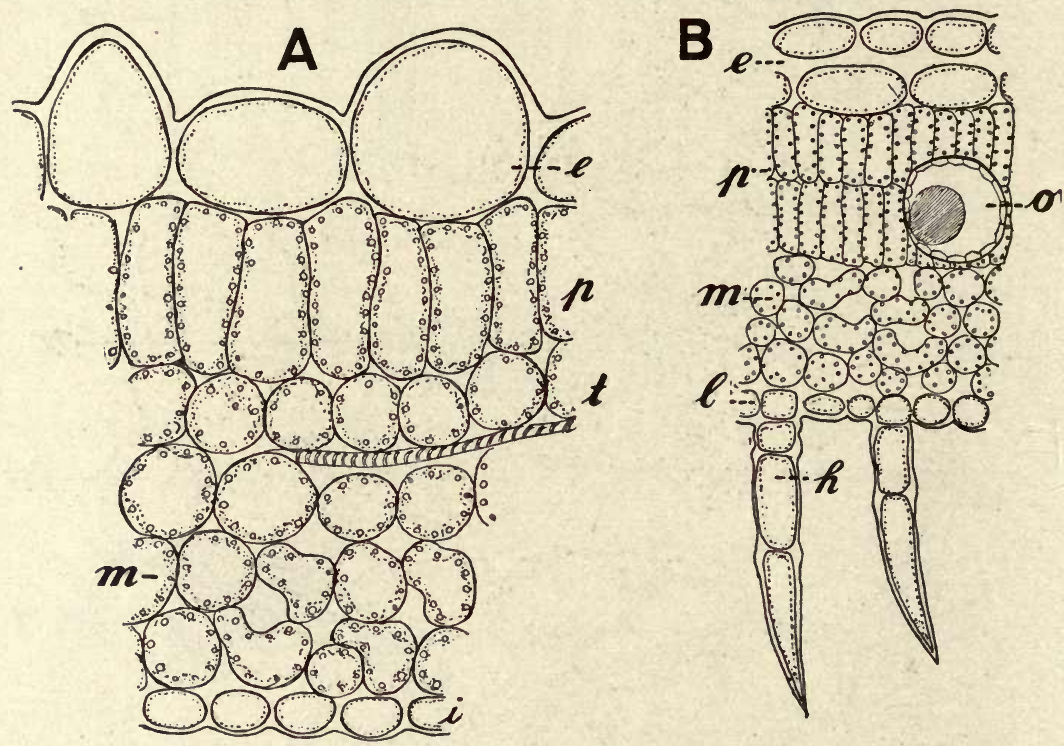

FIG. 216. A, transverse section of leaf of Lobelia inflata showing the large irregular epidermal cells $(e)$, palisade cells $(p)$, trachea $(t)$, loose parenchyma $(m)$, and lower epidermis (i). B, transverse section of leaf of Matico showing oil-secretion reservoir (o), upper epidermis (e), lower epidermis (1), with non-glandular hairs (h), palisade layers (p), loose mesophyll $(\mathrm{m})$.

cuticle may be thin or leathery and tough, and sometimes is provided with minute ridges or crests, especially on the under surface, thereby giving a dull appearance to the leaf. Many leaves, too, excrete wax on the surface and consequently have a glaucous or hoary appearance, notably some of the poppies, the common jewel-weed and many others. Other modifications may have to do with the gelatinization of the epidermis of the leaf, assisting in the storage of water, as in the leaves of the violets. The differentiation in forms of calcium oxalate crystals is also im- 
portant in distinguishing plants that resemble each other. The size and number of stomata as well as their distribution and arrangement with respect to each other varies in different plants. For example, in certain saprophytic or submerged plants the number of stomata is greatly or even completely reduced, and when present are quite functionless. Sometimes the stomata are depressed

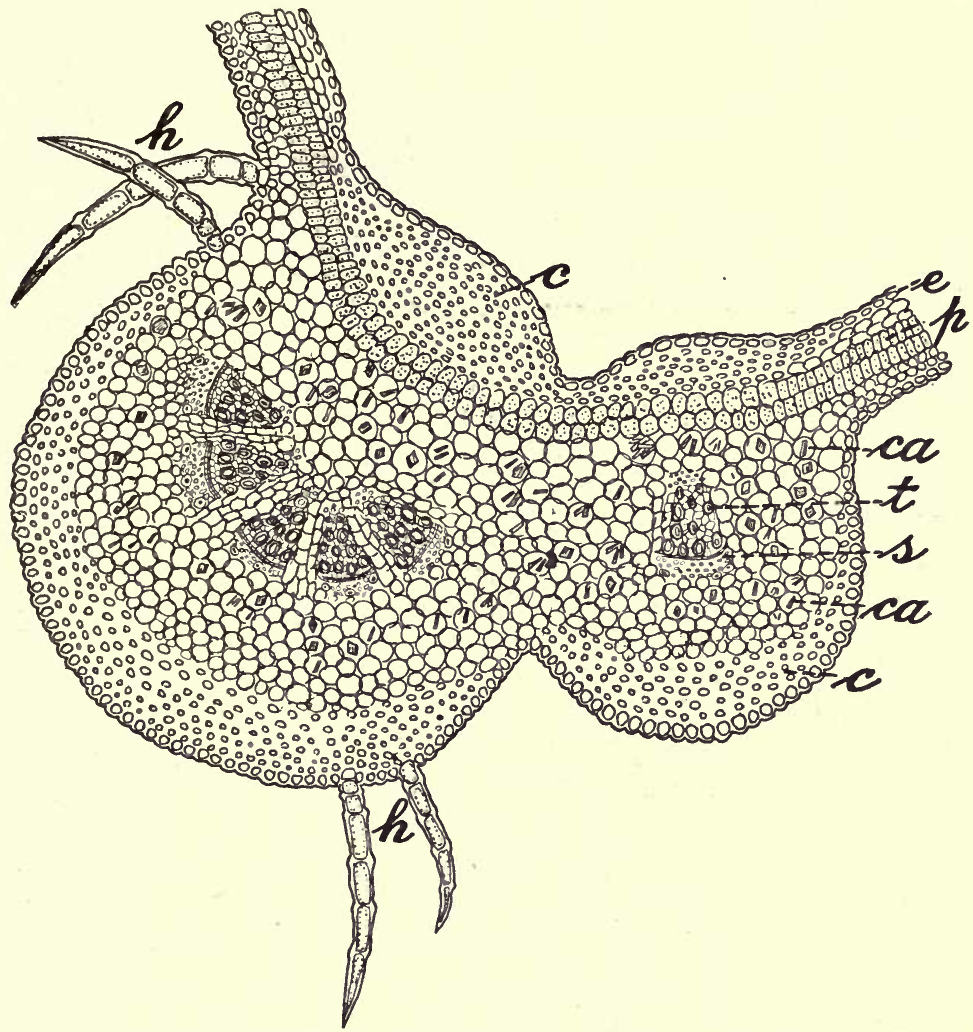

FIG. 217. Transverse section of leaf of Matico near two veins; showing the upper epidermis of several layers (e), two layers of palisade cells $(p)$, tracheæ $(t)$, sieve (s), collenchyma (c), loose parenchyma containing crystals of calcium oxalate (ca), and non-glandular hairs (h).

below the surface of the leaf, this being true in plants occurring in dry or cold districts, and is distinctly characteristic of many Coniferæ.

There is a marked difference in the arrangement of the palisade tissues, the following types being distinguished: I. In bifacial 

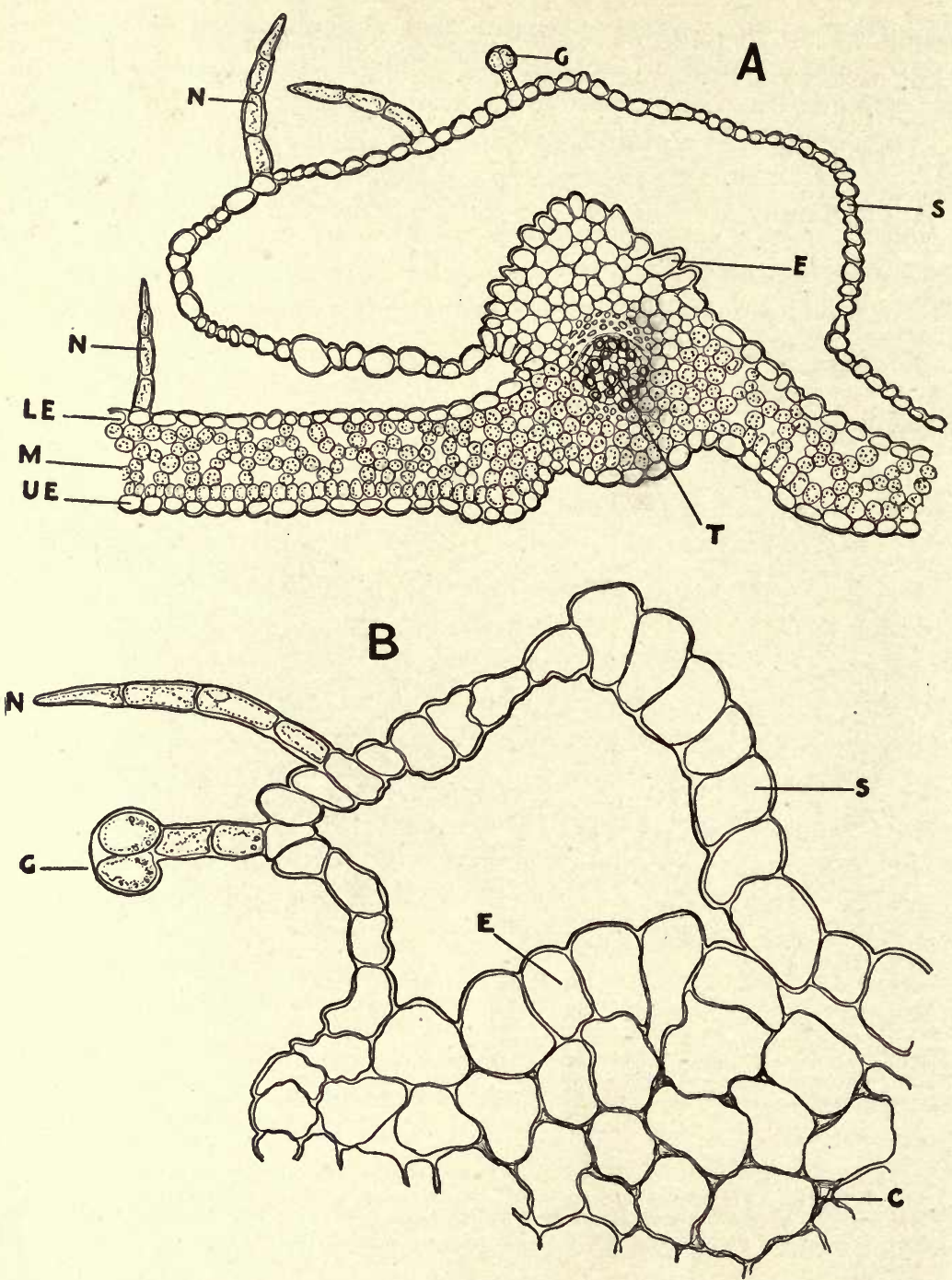

FIG. 2I8. Digitalis leaves: A, transverse section near one of the veins showing the separated or extra-epidermal layer occurring on the lower surface (S) with two non-glandular hairs (N) and glandular hair (G), epidermal layer (E), lower epidermis (LE), chlorophyll layer (M), upper epidermis (UE), and tracheæ (T). B, transverse section of portion. of leaf showing the separated or additional epidermal layer; c, collenchyma.

or dorsiventral leaves the palisade cells are distributed only below the upper epidermal layer (Figs. 2II, 215). 2. In unifacial or. 
isolateral leaves the palisade cells occur beneath the epidermal layers of both leaf surfaces, as in senna. 3. In some leaves, as in Eucalyptus, the entire parenchyma is made up of palisade cells. 4. In a few leaves there is no differentiation of a palisade layer, and these are sometimes referred to as centric leaves. The palisade cells may contain not only chloroplastids but crystals of calcium oxalate (Fig. 2I5), tannin-inclusions (Fig. I I4), etc. Distributed among the palisade cells may be the oil-secretion reservoirs (Fig. 2I6, B). Furthermore, the palisade cells may be of equal length or the stratification may be quite uneven and irregular. In shape they may vary from long, narrow cells to short, broad cells. In some special instances they are narrowed at the lower end in the form of a blunt cone forming the so-called "funnel cells," which are especially characteristic of plants inhabiting moist localities. There is still another common form known as arm-palisade parenchyma, in which the cells are branching and connected with each other by means of the branches. Tissues of this type occur in the Equisetaceæ, Filices, Coniferæ, Gramineæ, and in a number of Dicotyledons, such as Aconitum, Adonis, Anemone, Caltha, Clematis, Delphinium, Nigella, Pæonia, and Trollius in the Ranunculacex; Sambucus and Viburnum in the Caprifoliaceæ; Lysimachia and Trientalis in the Primulaceæ.

The spongy tissue or dorsal pneumatic tissue shows considerable variation in the arrangement and shape of the cells. In some leaves the cells are arranged in strata or layers, while in others they are more or less irregular. The cells may be spherical or provided with a number of arms, the latter developing parallel to the surface of the leaf or radiating in any direction, thus causing a variation in the nature and size of the intercellular spaces. In some instances there are included in the mesophyll certain mechanical cells, of which the simplest are like ordinary stone cells. They may be more or less elongated or branched or even quite fibrous, and are known as SPICULAR CELLS. The latter are sometimes quite prominent when they traverse the leaf in a vertical direction, giving rise to translucent spots. Spicular cells have been found in the mesophyll of quite a number of families. They are quite characteristic, although absolutely not constant, in the genuine tea leaf (Thea sinensis). 


\section{OUTER MORPHOLOGY OF THE FLOWER.}

It is well known if the stem of a plant, as the carnation, rose, geranium, etc., be cut into pieces so that each portion has at least one node and placed under suitable conditions for growth, roots will arise from the nodes that are in the ground and a new plant will be developed. The same result can be achieved if plants like Ficus, growing in a greenhouse, have placed around the nodes near the tip of the branches a clump of sphagnum, and if the latter be kept moist roots will arise from the joints. This method of increasing the number of individual plants, while it is limited to certain perennials and cannot be followed with annuals or biennials, is frequently resorted to by horticulturists, and is known as vegetative propagation. The production of independent plants in this manner is dependent upon the property of the meristematic cells in the pericycle of the stem to produce the meristems that give rise to the tissues of the root. As this process of propagation for plants growing in temperate regions and in cold climates would be more or less uncertain for the perpetuation of the species, it is fortunate that in Nature safer methods of reproduction are followed, depending upon the development of flowers and the production of seed. In the latter there is a young plant with all of the elements of root and shoot contained therein and so protected by a seed-coat that it may withstand extremes of climatic conditions, as well as the various hostile forces to which it might be subjected.

THE FLOWER is a shoot which has undergone a metamorphosis so as to serve as a means of propagating the individual. It is an unbranched and definite shoot, or an apex of a shoot. It might be termed a "dwarf-branch" that dies and drops off the plant after the maturation of the fruit. The most complete flower has four kinds of leaves: sepals, petals, stamens, and carpels.

The sepals, usually green and leaf-like, make up the outer spiral known as the calyx. The petals being frequently highly colored form an inner spiral known as the corolla. The stamens are the polliniferous organs of the flower, and the carpels bear the ovules which later develop into seeds.

While the flower is a very complicated structure in many 
cases, the definition given it by some writers is very simple. It is defined as a branch which bears sporophylls. As we have seen, a sporophyll is a leaf which bears sporangia. According to the definition given, the strobiles or cones of the Gymnosperms and certain Pteridophytes, as the horsetails and club mosses, are entitled to rank as flowers. In Angiosperms other leaves may be present, and these are known as the FLORAL LEAvEs. The flower, then, in Angiosperms is made up of sporophylls which are essential, and floral leaves which may or may not be present. But in speaking of the sporophylls of the flower in Angiosperms it is customary to use terms which were applied to them before their relation to the similar organs in the Gymnosperms and Pteridophytes was understood. Thus the microsporophylls, as already pointed out, are known as STAMENS, and the megasporophylls as CARPELS.

For a great many years botanists taught that the stamens and carpels are transformed foliage leaves,-in other words, that they are derived from foliage leaves,-but in more recent years the view has been established that they arise as independent members, - are, in fact, as independent as the foliage leaves themselves. Various transformations or modifications may and do occur, but these are not confined to the foliage leaves alone, for under certain conditions the sporophylls may assume the character of floral leaves.

It is true that in the case of some ferns the sporophylls bear a strong resemblance to foliage leaves, as in Dryopteris Filix-mas (Fig. 53), but this does not necessarily prove that the sporophylls of Angiosperms are transformed leaves, but only that the further back we go, the less the degree of differentiation of parts until we reach the unicellular algæ.

The flowers of the Angiosperms differ from those of the Gymnosperms in that the ovules (megasporangia) are enclosed, before pollination, in an ovary which has developed a special organ-the stigma-for the reception of the pollen grains (microspores), and the floral envelopes are much more conspicuous.

The several parts of the flower are arranged more or less compactly at the terminus of an axis known as the flower branch, the special portion bearing these parts being known as the ToRUs 
(sometimes spoken of as the receptacle), and that portion below the flower proper as the flower stalk (Fig. 78, PE). The carpel or carpels occupy the terminal portion of the branch, while the stamens and floral leaves occur in circles or whorls below.

Pistil.-There may be only one carpel present in a flower, or there may be more. In the latter case the carpels may remain distinct or they may be united, but, whatever the number or the degree of union, it is the carpel or carpels which constitute the closed structure known as the pistil. The pistil is usually differentiated into three quite distinct regions: (I) A lower bulbous portion which contains the ovules, known as the OvARY; (2) a neck-like portion known as the STYLE; and (3) at the top of the style a specialized portion which receives the pollen, known as the stigma (Figs. 78 and 219). When the pistil is made up of a single carpel it is said to be SIMPLE, and when composed of more than one carpel it is called compound.

The carpels in the compound pistil appear to be united in different ways. Sometimes they appear to have coalesced or grown together at the margins, thus forming an ovary with but one chamber or compartment (Fig. 223, B). In the other cases the carpels appear as though they were incurved or folded together at the margins along the line of union, thus forming septa or walls which divide the inner cavity into several compartments or locules (Fig. 223, A, C).

When the carpels are not united but remain separate, there are as many pistils as carpels, as in the flowers of buttercup (Fig. $223, D)$. Thus a unilocular ovary may belong to a simple or compound pistil.

Gynecium.-The aggregate of pistils in a flower constitutes the gynæcium. If the gynæcium is made up of a number of simple pistils, as in the flower of buttercup (Fig. 223, D), it is said to be APOCARPOUS. But if the carpels are united into one structure, then the gynæcium is said to be SYNCARPOUS, as in the orange flower, which is in reality equivalent to a compound pistil. Inasmuch as the styles and stigmas are frequently not united, the expression compound ovary is usually employed. According as the gynæcium consists of one, two, three, or many carpels, it is said to be monocarpellary, dicarpellary, tricarpellary, or polycarpellary. 
The pistil of the flower of the pea is simple and has an elongated ovary, and upon dissecting the ovary and also making a transverse section of it, it is observed that the ovules are borne upon the part which projects from the concrescent margins into the cavity, this part being known as the PLACENTA, and the united
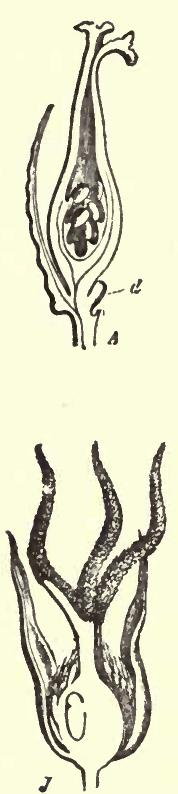
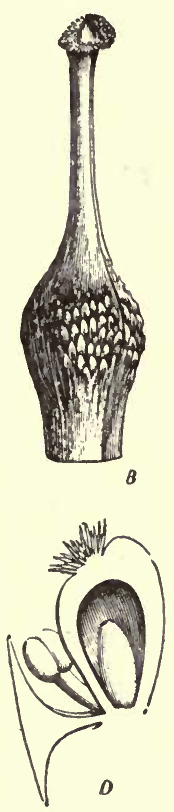
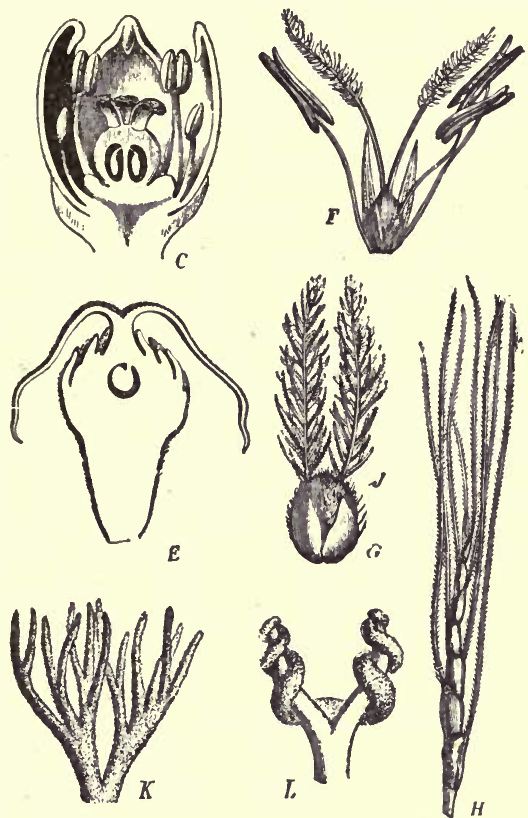

FIG. 219. Pistils and different kinds of stigmas. A, simple (monocarpellary) pistil of willow with lobed stigma; B, compound pistil of Fourcroya with head-like stigma; C, longitudinal section through flower of Spondias with five separate styles and stigmas, only three of which are shown; D, flower of Peperomia showing bristly stigma; E, recurved, thread-like stigmas of the Upas-tree (Antiaris); F, flower of a Canary grass showing the two simple plumose stigmas; $G$, pistillate flower of couch grass showing the two compound plumose stigmas; $\mathrm{H}$, thread-like stigmas of pistillate inflorescence of Euchlana one of the grasses; J, tri-parted stigmas of the pistillate flower of the castor-oil plant; K, L, two forms of stigmas of Begonia.-After Engler.

margins of the carpel forming the "inner" or VENTRAL SUTURE. In the syncarpous gynæcium the ventral suture of the carpels is directed toward the axis of the flower; in some cases that portion of the carpal corresponding to the midrib is very prominent, as in the Papilionatæ, and has received the name of "outer" or DORSAL SUTURE.

There are as many locules in the ovary as there are carpels, 
and the walls or partitions between the locules of a syncarpous gynæcium are known as DISSEPIMENTS; when three or more carpels are united the number of dissepiments corresponds to the number of carpels. It sometimes happens that a partition or wall is intruded from the mid-vein of the carpel, dividing a unilocular ovary into one that is bilocular, as in species of Astragalus, and such a partition is termed a FALSE DISSEPIMENT.

When no other than the true dissepiments exist in the syncarpous gynæcium the placentas are borne along the axis of the flower and are termed axial placentas. In the Caryophyllaceæ the ovules are borne upon a central axis, and the dissepiments having been absorbed by the gynæcium is said to possess a free central placenta. In other cases the placentas grow backward from the central axis toward the mid-vein of the carpel, carrying the ovules with them, when they are spoken of as parietal placentas, as in colocynth fruit and watermelon.

The Style not only varies in shape and size but in the manner of attachment to the ovary (Fig. 219); it may be very short, as in the clove; long and filiform, as in Enothera; club-shaped (clavate), as in the orange; or broad and petalloid, as in Iris. It is usually situated at the summit of the ovary, when it is said to be apical or terminal; it may, however, be laterally attached, as in the strawberry, or, as in a few instances, attached to the base of the ovary. It is usually smooth, but may be hairy, as in the Compositæ. The styles, like the carpels, may be separate or united, and in the latter case may have a central canal connecting the stigma with the ovary, as in the violets. While usually deciduous, the style may be more or less persistent-forming a part of the fruit - or even become much elongated, as in the dandelion.

The Strgma is an essential part of the pistil in that it is the germinating surface for the pollen grains, it being viscid and especially adapted for this purpose (Fig. 219). The stigmas may be separate, as in the Compositæ, or they may be united into a more or less club-shaped or globular head, consisting of as many lobes as there are stigmas, as in the poppy. The stigma, while usually solid, may have an opening, as in the violets, which sometimes has a lid-like appendage, as in Viola tricolor.

The Ovules (Fig. 219), as we have already seen, are small 
bodies which are borne on the placentas, and which, after fertilization, develop into seeds. The number of ovules varies considerably - there may be but one, as in the almond, or there may be a large number, as in the watermelon.

There are several principal forms of ovules (Fig. 220) recognized, of which the following may be mentioned: (I) ATropous, in which the ovule is straight and erect on its stalk, as in the Urticaceæ; (2) ANATROPOUs, in which the ovule is bent over on to the stalk so as to be in an inverted position, the line of attachment of the ovule and stalk being known as the raphe (Fig. 230, $n) ;(3)$ CAMPYLOTROPOUS, in which the ovule is bent upon itself, as in Stramonium, this form being less frequent than the other two. Most of the ovules of flowering plants are anatropous.
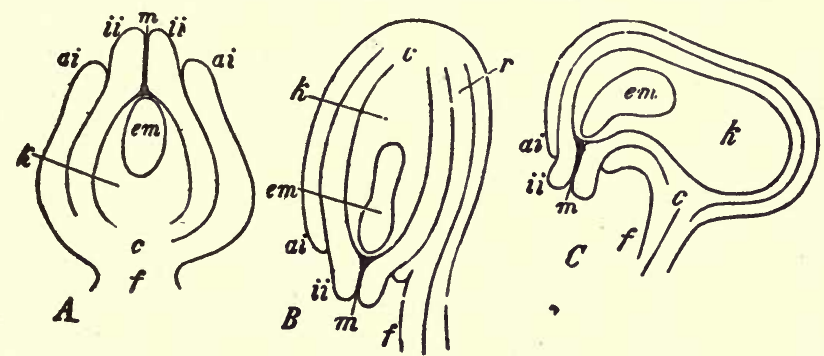

FIG. 220. Three positions of ovules. A, atropous; B, anatropous; C, campylotropous. (f) funiculus or stalk; (c) chalaza, or point of union of nucellus and integuments; (k) nucellus or megasporangium; (em) embryo-sac or megaspore; (ai) outer integument; (ii) inner integument; $(\mathrm{m})$ foramen or orifice for entrance of pollen tube, known as the micropyle in the seed; ( $r$ ) raphe.-After Prant1.

Stamen.-As already indicated, the stamen consists of a stalk-like portion called the FILAMENT, and a specialized portion which bears the sporangia, called the Anther (Fig. 78). The filament may be long or short or wanting. It is commonly threadlike, but varies considerably, and is sometimes leaf-like.

The Anthrer is the essential part of the stamen (Fig. 22I) and consists of two lobes, each of which is composed of two divisions or pollen sacs (Fig. 79). These sacs contain the pollen, which is commonly discharged either through a longitudinal suture or line of dehiscence, or through an opening at the tip. The anthers may be variously attached to the filament (Fig. 22I). When they face the axis of the flower they are said to be INTRORSE, as in the Violaceæ, and when they face the perianth they are said. 

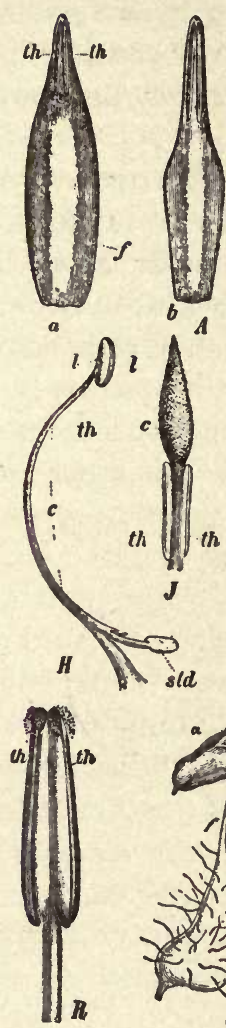
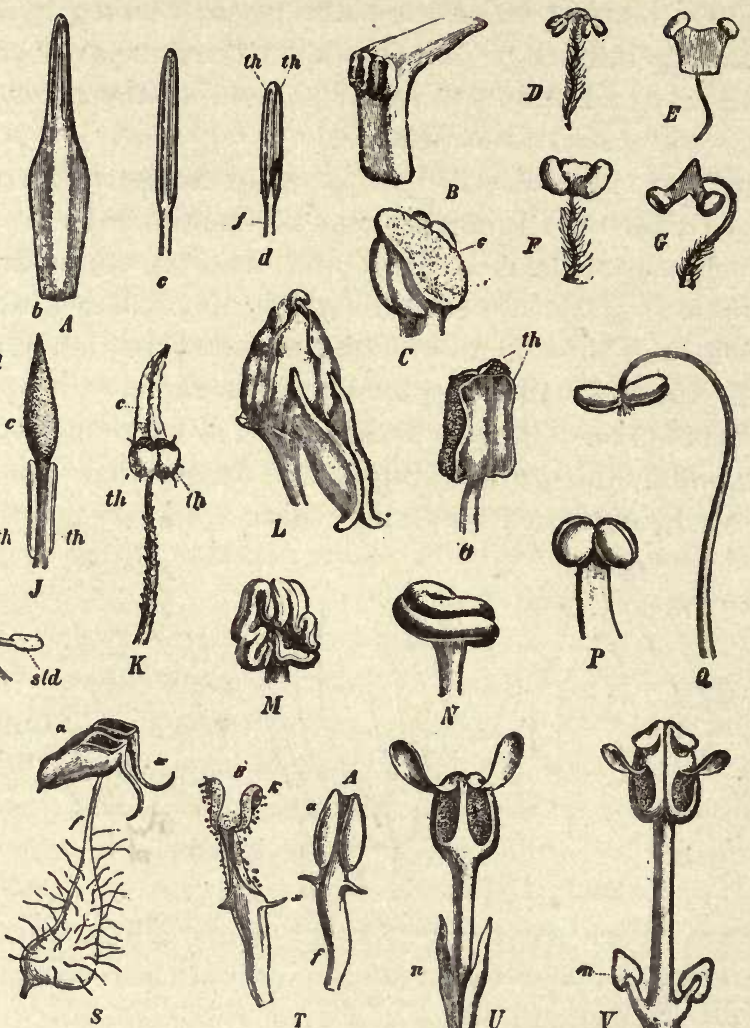

$t h$
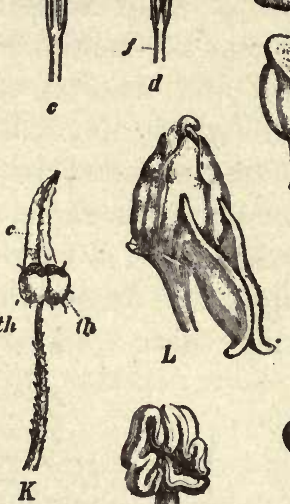

B
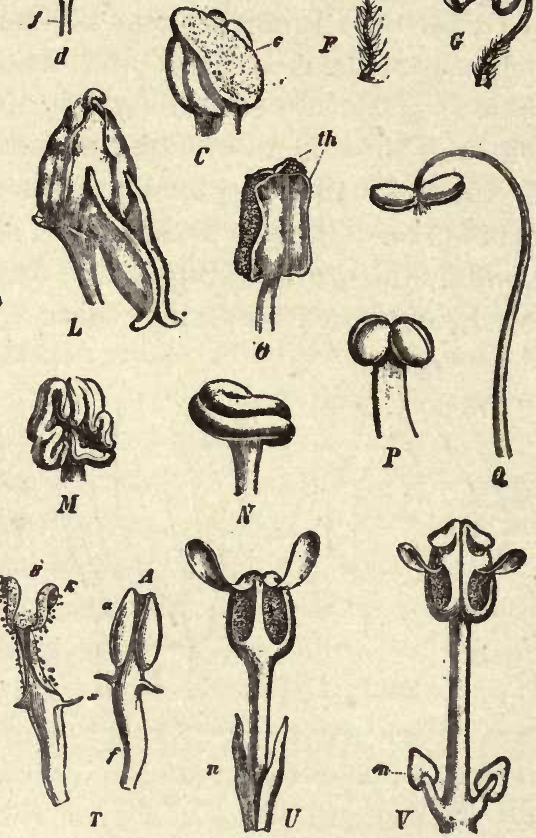

FIG. 221. Different types of stamens. Abbreviations: filament (f), pollen sacs or theca (sporangia) (th), connective (c). A, stamens of a water lily (Nymphcea) showing variation in the stamens (a-d); B, theca near middle of the stamen of Popowia; C, anther of another species of Popowia with fleshy connective and pollen sacs on either side; D, stamen of Tradescantia with transverse connective; E, F, G, stamens of several Commelinacece with broad connectives; $\mathrm{H}$, stamen of Salvia with peculiar swinging connective and an aborted pollen sac or staminodium (std) at the lower end and the fertile pollen sac above; $\mathrm{J}$, peculiar elongated connective of Unona; K, elongated connective of Humiri; L, androcium of violet showing two spurred sessile stamens; M, stamen of Columelia with sinuous confluent anthers, brozd connective and short filament; $\mathrm{N}$, confluent transverse pollen sacs of Arisarum; O, united pollen sacs of Columbine showing small connective; $\mathrm{P}$, spherical pollen sacs of Calla, with slightly developed connective; $Q$, versatile anther and long, slender filament of dead nettle (Lamium album); R, dehiscence of anther of Solanum by means of terminal pores; S, spurred anther of Arbutus with terminal pores; various kinds of valvular dehiscence, as in Berberis (T), Atherosperma (U) and Persea (V).-A, after Caspary; B, H-R, U, V, after Baillon; S, T, after Sachs; D-G, after Schönland.

to be EXTRORSE, as in the Magnoliaceæ; when they lie horizontally on the tip of the filament, so that they swing as on a pivot, as in the tiger lily, they are said to be VERSATILE; when they adhere 
longitudinally to the sides of the filament and the dehiscence is marginal, they are said to be INNATE; when they adhere longitudinally to the filament and the latter extends slightly beyond them, they are said to be ADNATE, in which case they may be extrorse or introrse. In some of the Labiatæ the lobes of the anther are united at the apex of the filament, but diverge from the point of attachment and are said to be connate, coherent, or CONFLUENT.

The Connective is that portion of the filament to which the lobes of the anther are attached or which connects them (Fig. $22 \mathrm{I})$; usually it is not very prominent ; but in some of the Labiatæ, as in Salvia, it is rather broad; in some of the Malvaceæ it is entirely wanting, the two lobes being confluent; in other cases it may be extended beyond the lobes of the anther, as in species of Asarum.

Appendages of Anther.-In certain instances the anthers are appendaged (Fig. 22I): In the violets there is a triangular growth at the apex; in the oleander the apex is plumose; in deer berry (Vaccinium stamineum) there are two awn-like appendages upon the back of the anther; in the violets the two stamens that project into the spurred petal are also spurred and secrete a nectar; in the Asclepiadaceæ the anthers possess wing-like appendages, each sac or division of which contains a pear-shaped coherent mass of pollen grains (pollinium).

When a flower has but one stamen it is termed Monandrous; and when there are two, three, or many stamens, it is said to be diandrous, triandrous, or polyandrous (Fig. 223). The aggregate of stamens in the flower is called the ANDRGECIUM. In the Labiatæ there are four stamens arranged in a longer and shorter pair, and the stamens are said to be Didynamous; in the Cruciferæ the flowers possess six stamens, four of which are longer than the other two, and the stamens are described as TETRADYNAMOUs; in some plants, as in the Lobeliaceæ, Papilionatæ, etc., the filaments cohere, forming groups (Fig. 222) which are termed monadelphous, diadelphous, etc.; in the flowers of the potato the anthers lie close together but are not united, forming apparently a continuous ring or band around the pistil, when they are said to be connivent; in the tubular flowers of the Compositæ the 
anthers are united, forming a closed ring, and the stamens are spoken of as SYNGENESious (Fig. 222, $A$ ); in many of the Cucurbitacee the filaments and anthers both are confluent; in the flowers of the Orchidacex the stamens are borne upon the pistil and are said to be GYNANDROUS.

Floral Envelopes.-As their name indicates, the floral envelopes occupy the outermost or lowest position in the arrangement of the parts of the flower. In the bud condition they protect the essential elements, and in the expanded flower are considered to play an important rôle in securing pollination through the visitation of insects. The floral envelopes are made up generally of two kinds of leaves, pctals and sepals (Figs. 224 to 227).

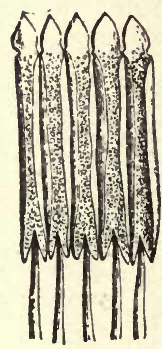

A

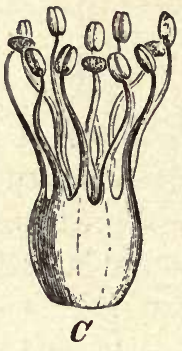

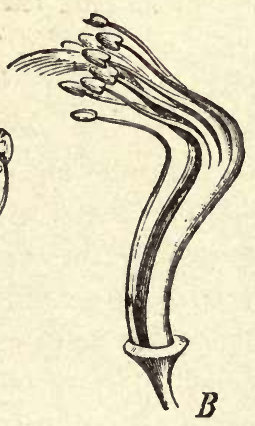

$B$

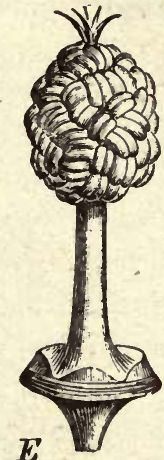

$D$

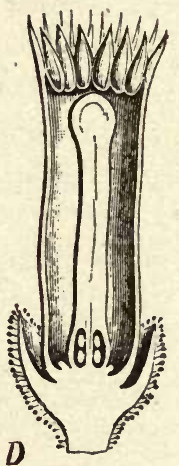

FIG. 222. Union of stamens. A, united anthers of flower of Compositæ; B, diadelphous stamens of Pisum with I free stamen and 9 united; several types of monadelphous stamens, as in Erythroxylon (C), Melia Azedarach (D), and common mallow (E).-After Baillon.

The PETALs form a spiral which surrounds the androcium. They are, as a rule, quite bright and attractive, being frequently highly colored, as in the rose, Fuchsia, violet, etc., and are known collectively as the corolla.

The SEPALS form the next and lowermost spiral. They are usually green and leaf-like, as in the rose and carnation, and together constitute the CALYX. Sometimes the corolla and calyx are spoken of together as the PERIANTH, although, strictly speaking, the term has a more special application, and is used mostly in speaking of the sepals and petals of monocotyledonous flowers, 
these parts being much alike and not distinguishable, save in position, as in certain lilies.

A

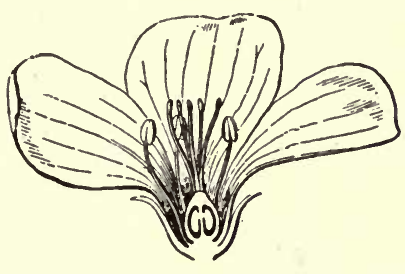

C
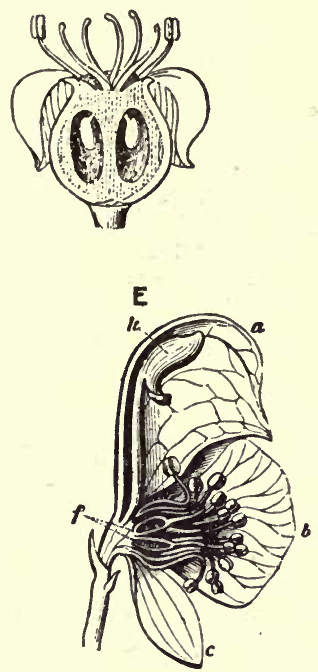

B

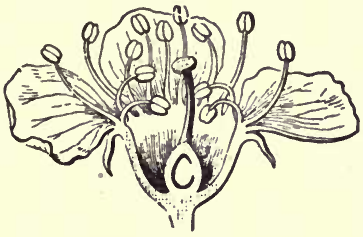

D

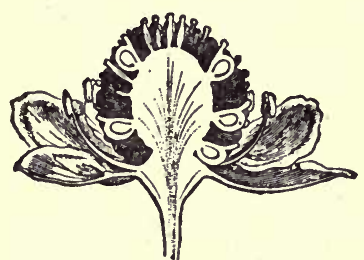

$\boldsymbol{F}$

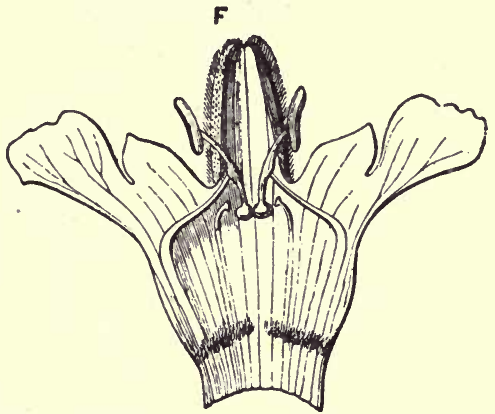

FIG. 223. Types of flowers: A, hypogynous flower of flax; B, perigynous flower of cherry, showing perianth tube with sepals, petals and stamens on its border; C, epigynous flower of American sarsaparilla; D, flower of buttercup showing apocarpous gynæcium and large conical torus; E, irregular (bilateral or zygomorphic) flower of aconite showing half of helmet-like sepal (a), other sepals (b, c), long-clawed nectary $(k)$ developed from one of the posterior petals, separate pistils (f); F, corolla of Salvia spread open and showing the two rudimentary stamens and two fertile stamens. The connectives in the latter are long and filamentous and each bears at the upper part a normal pollen sac and at the lower end a non-fertile enlarged portion which the insect pushes against in entering the flower and thus causes the pollen to be deposited on its back.-A-C, after Gray; D-F, after Warming.

When the divisions of the calyx and corolla remain separate and distinct the latter are spoken of as CHORISEPALOUs and CHORIPETALOUS, respectively; but when the divisions are united or 


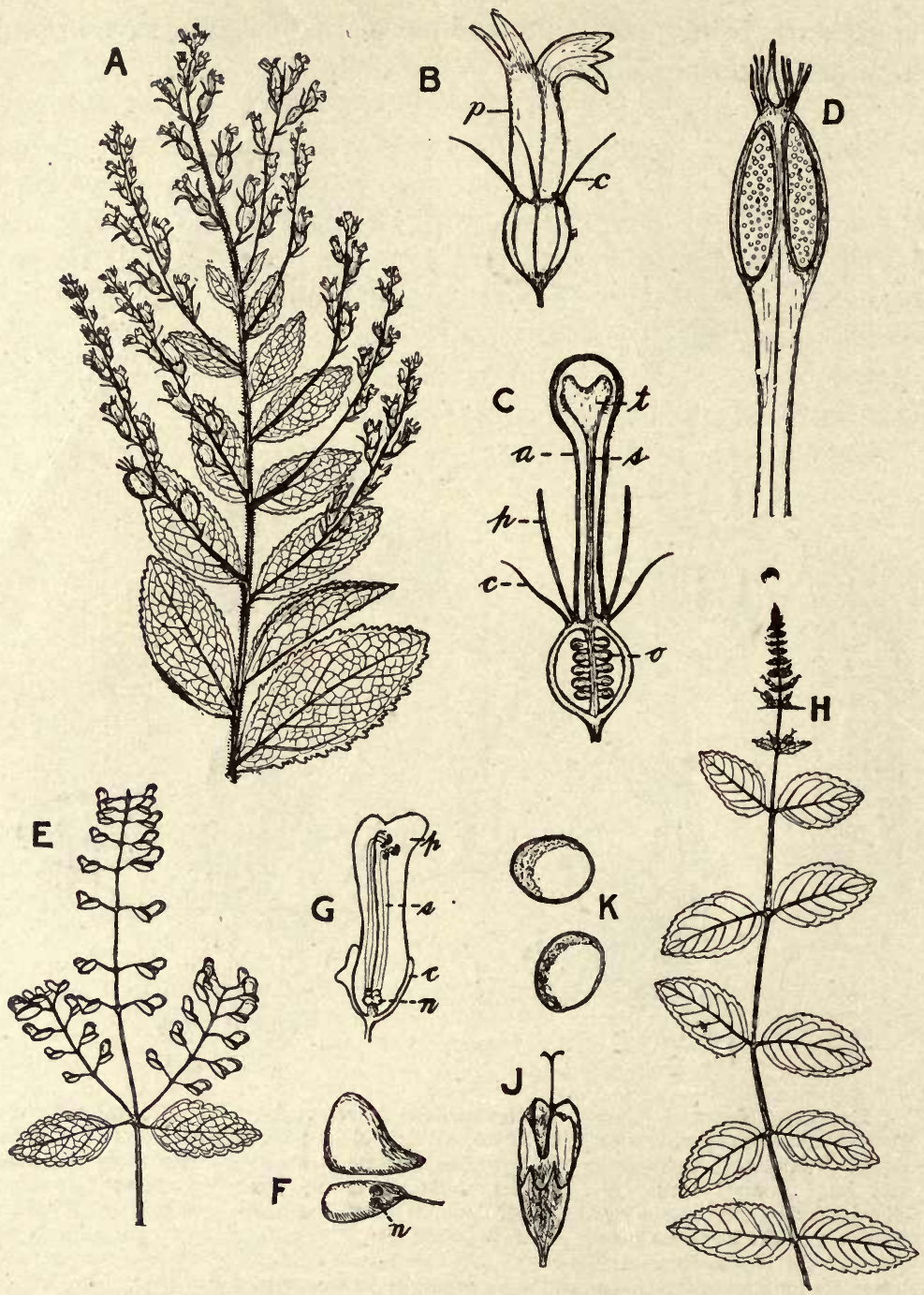

FIG. 224. Lobelia inflata: A, upper portion of shoot showing the dentate-denticulate leaves, the bracted racemes with flowers and inflated capsules, the latter developing soon after fertilization; B, flower showing linear calyx teeth and 2-lipped corolla, the upper lip with 2 rather erect lobes and the lower lip spreading and 3 -cleft; $C$, longitudinal section of flower showing the ovary with ovules $(0)$, style $(s)$, hairy bifid stigma $(t)$, united stamens (a), corolla (p) and calyx (c); D, longitudinal section of stamen showing the hairy summit.

Scutellaria pilosa: E, branch showing crenate leaves and helmet-shaped capsular fruits; F, capsule after dehiscence showing nutlets (n). G, section of flower of Scutellaria lateriflora showing calyx (c) with crest on one side, 2-lipped corolla (p), the didynamous stamens (s), and 4-locular ovary (n).

Spearmint (Mentha spicata): H, showing flowers in slender interrupted spikes; $\mathrm{J}$, flower with bell-shaped calyx, tubular corolla and 2 -lobed stigma; $K$, ellipsoidal pollen grains. 
coalesced the calyx and corolla are called GAmosepalous (synsepalous) and GAMOPETALOUs (sympetalous), respectively.

When the divisions of the calyx or corolla are entirely united these elements are said to be ENTIRE, and when the divisions are

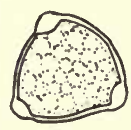

H
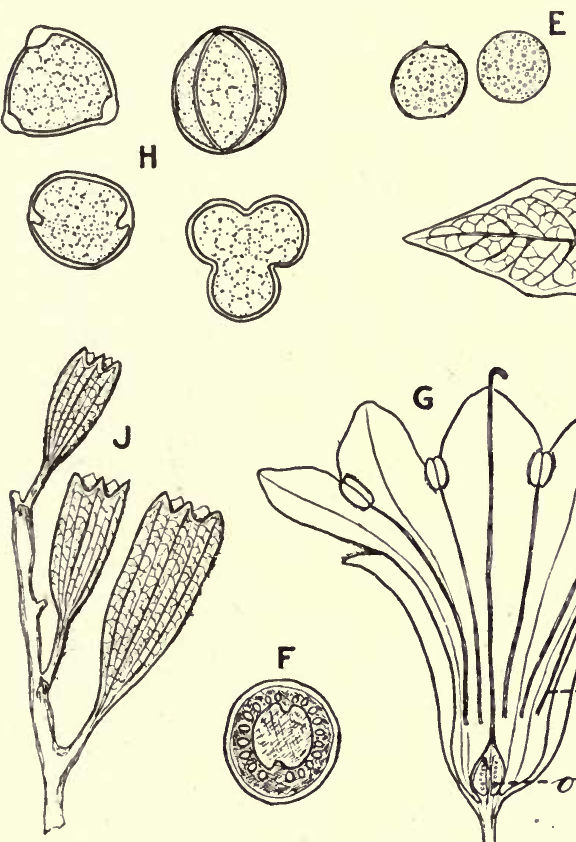

$E$
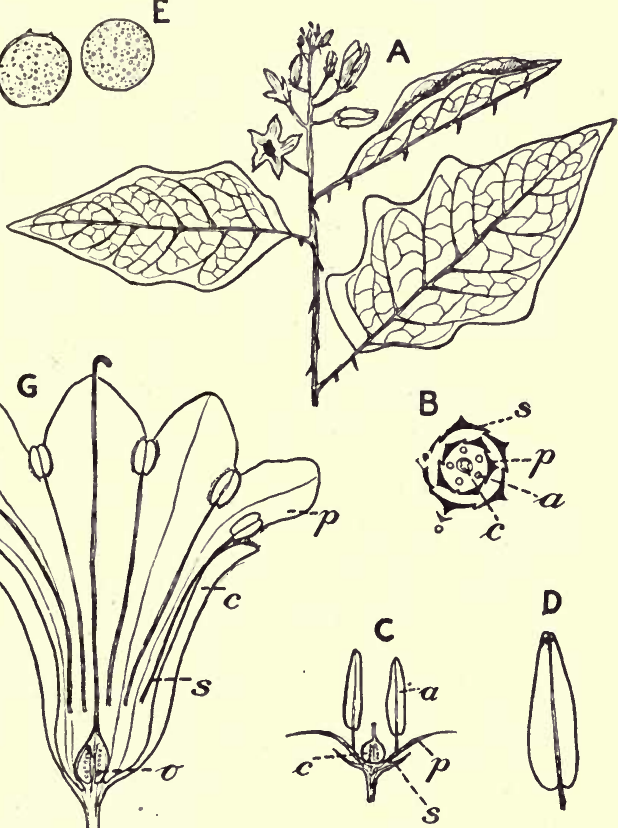

Fig. 225. Flowers of Solanaceæ. Solanum carolinense: A, portion of shoot showing a short raceme of flowers and the spinose leaves and stems; B, diagram of cross section of flower showing sepals (s), petals (p), stamens (a) and ovary (c); C, longitudinal section of flower, the letters the same as in $\mathrm{B} ; \mathrm{D}$, stamen showing terminal pores; $\mathrm{E}$, two spheroidal pollen grains; F, cross section of 2-locular berry.

Hyoscyamus muticus: G, section of flower showing calyx (c), lobed corolla (p), stamens inserted on corolla tube (s) and ovary (o) bearing at the summit a long style; $\mathrm{H}$, pollen grains in different views; J, portion of stalk with fruits showing cylindrical calyx, the fruit reaily being enclosed within the calyx and in the nature of a pyxis.

partly united they are spoken of as "toothed," "lobed," or " parted," according to the degree of union.

In the flowers of the Cruciferæ and Caryophyllaceæ there is a conspicuous stalk to each of the separate petals, which is known as the UNGUIS or CLAW; while the upper outspreading portion is known as the LAmiNa or blade. In the gamosepalous calyx and 
the gamopetalous corolla the lower united portion is known as the TUBE, and the upper outspreading portion as the LIMB or " border."

The form of the calyx and corolla is quite characteristic for a number of important families. In the Compositx there are two characteristic forms of corolla, namely, the tubular in the disk
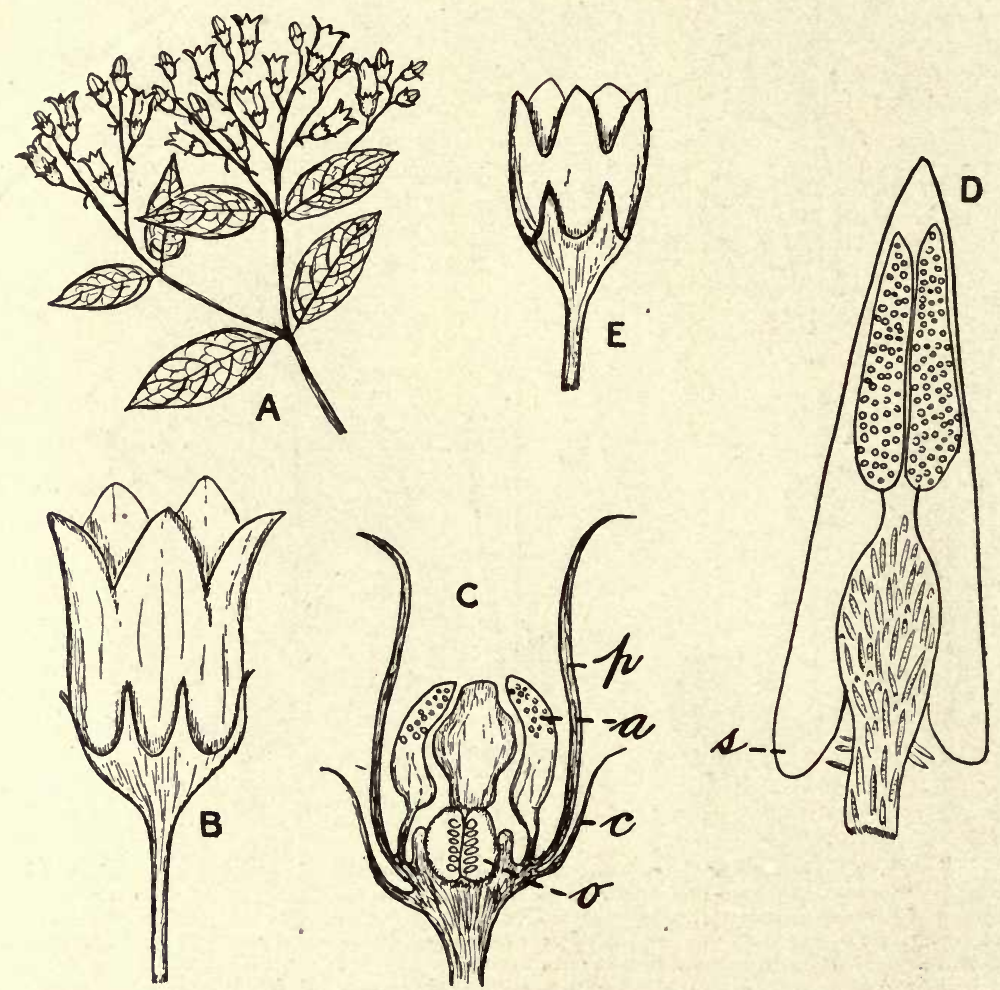

FIG. 226. A pocynum androsamifolium: A, portion of a flowering branch; B, a flower showing the short calyx tube and the corolla with more or less spreading lobes; $\mathrm{C}$; longitudinal section of flower: c, calyx teeth; $p$, corolla lobes; a, anthers; and p, ovary; D. single stamen with long spurs (s). E, a flower of A. cannabinum showing the corolla with ascending lobes.

flowers and the ligulate in the ray flowers; in the Papilionatæ the corolla, from its fancied resemblance to a butterfly, is described as Papilionaceous (Fig. 22I, $B$ ); in the Labiatæ the petals are united into two lip-like divisions, and the corolla is said to be Bilabiate (Fig. 223, $F$ ). There are two kinds of bilabiate 

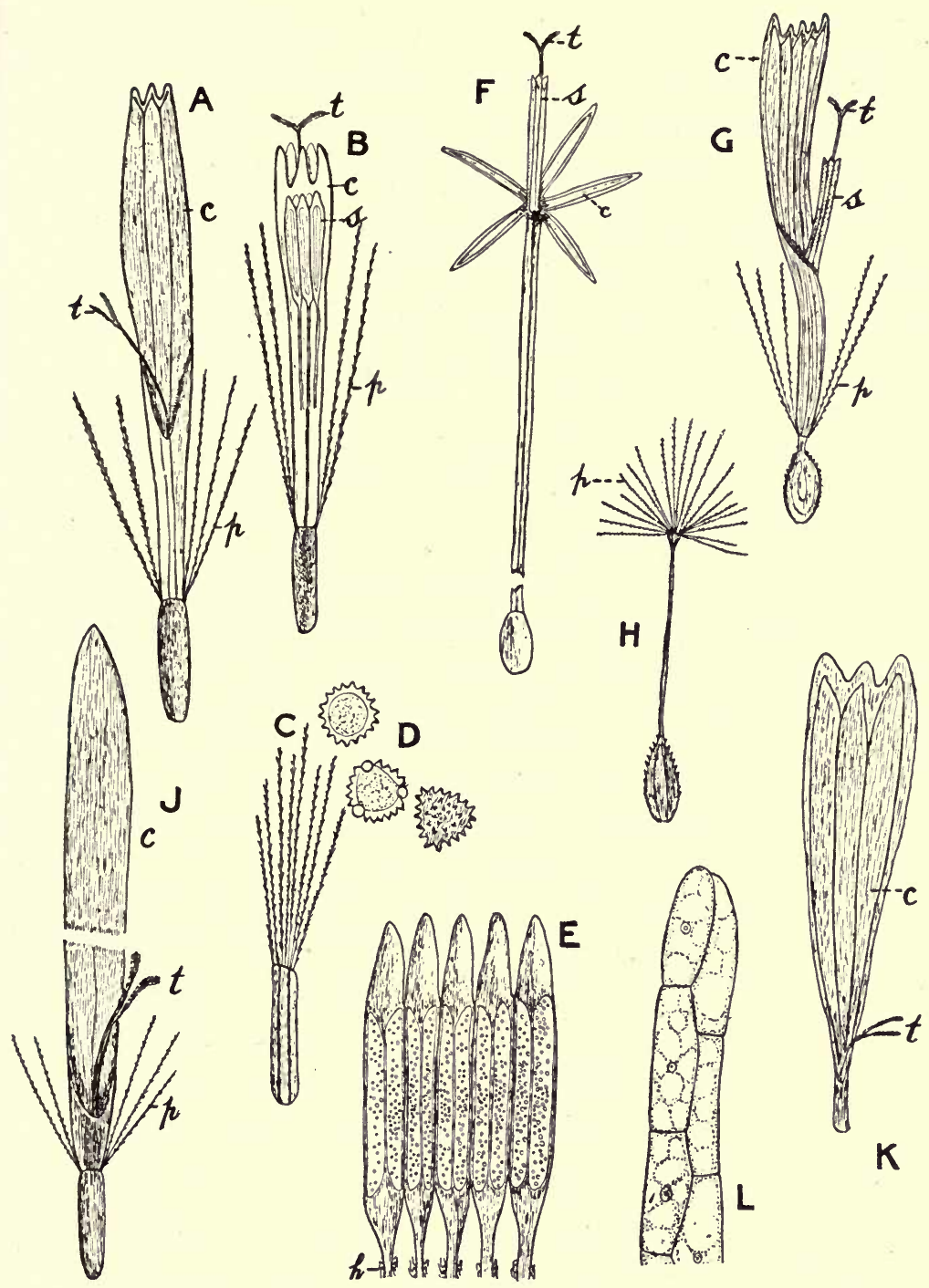

Fig. 227. Flowers of the Compositæ. Inula Helenium: A, ligulate floret: B, tubular floret; C, achene with pappus; D, pollen grains; E, united anthers showing hooked hairs (h) at the base.

F, tubular floret of Safflower (Carthamus tinctorius).

Dandelion (Taraxacum officinale): G, ligulate floret; $H$, one of the achenes showing spreading pappus on a long stalk which develops after fertilization.

J. ligulate floret of Coltsfoot (Tussilago Farfara).

Marigold (Calendula officinalis): K, ligulate floret; L, one of the double hairs from corolla. c, corolla; s, stamens; t, stigmas; p, pappus; $h$, hairs. 
corollas-one, as in lavender, where the mouth of the tube is open, known as RINGENT; and another, where the mouth is closed, as in Linaria, called PERSONATE.

There are a number of other special forms of calyx and corolla, particularly the latter, and of these may be mentioned the following: A corolla, like that of the harebell, which is more or less bellshaped, is termed CAMPANULATE; a more or less campanulate corolla contracted near the opening, as in Gaultheria, is spoken of as URCEOLATE or urn-shaped; in the morning glory and other Convolvulaceæ the corolla is said to be INFUNDIBULIFORM or funnel-shaped; a corolla in which the limb spreads abruptly from the tube, as in Phlox and coffee, is termed HYPOCRATERIFORM or salver-shaped; a corolla with a short tube and outspreading limb, as in potato, is said to be ROTATE or wheel-shaped; a rotate corolla with the margin more or less upturned is called CRATERIFORM or saucer-shaped; in aconite the upper petal is hood- or helmet-shaped, and the corolla is spoken of as GALEATE; in the violets one of the petals has a spurred appendage and the corolla is described as SACCATE or calcarate, while the modified petal in the orchids is known as the LABELLUM.

Duration of Calyx and Corolla.-There is considerable difference in the length of time that the calyx and corolla persist, not only with reference to each other but in different plants. The parts are said to be caDucous when they drop from the flower as soon as it opens, as the calyx of the poppy; when they remain for a day or so, they are said to be EPHEMERAL or fugacious, as in the petals of the poppy; in the rose and apple the petals fall away soon after the pollen reaches the stigma and they are said to be DECIDuous; in some flowers the petals wither but persist until the maturing of the fruit, as in the Droseraceæ, and are known as MARCESCENT; the calyx may remain unaffected until the maturing of the fruit, as in the Labiatæ, when it is said to be PERSISTENT.

Bracts.-In addition to the floral envelopes, other more or less modified leaves are borne on the flower branch below the flower, frequently at the base of the flower stalk, and these have received the name BRACTS. The bracts closely resemble the foliage leaves, but usually are smaller and frequently are mere scales, without chlorophyll. In some cases, however, they are large and 
showy, looking like petals (petaloid), as in the water arum (Fig. 263), the common dogwood; Bougainvillea and Poinsettia seen in greenhouses.

The Torus constitutes the terminal portion of the flower axis or stalk, and is usually more or less conical and somewhat enlarged. When the torus is of this shape the parts of the flower are inserted upon it in serial succession, all of the other parts arising below the pistil. It may, however, be modified into a hollow or cup-like structure which grows up around the ovary, carrying the other parts of the flower (sepals, petals, and stamens) with it, thus changing the relative position of the parts, although it should be understood that the ovary occupies practically the same position in the two cases.

When the torus is of the first type and the other parts of the flower are inserted below the ovary, the flower is said to be HYPOGyNous, as in the orange flower (Fig. 78, $A$ ) and the ovary superior; but when the toris forms a cup-shaped receptacle and the other parts of the flower arise on its margin above the ovary, the flower is called epigynous, as in the clove (Fig. 78, $B ; 223 C$ ) and the ovary inferior. In other cases a ring of leaf-like tissue arises from the torus, forming a cup-like receptacle or tube which is known as the perianth tube, the sepals, petals, and stamens being inserted on its margin. The perianth tube may be free from the ovary, when the flower is said to be PERIGYNous and the ovary half inferior or half superior, as in cherry (Fig. 223, $B$ ); or in the case of an epigynous flower it may form a prolongation of the cup-shaped torus.

Prefloration or estivation is the arrangement of the parts of the flower-more especially the calyx and corolla-in the bud. Some of the terms used in this connection are also employed in the study of vernation. The following are some of the terms which are employed: VALvate, when the sepals or petals meet each other at the edges, as in Malvaceæ; IMBRICATED, when the sepals or petals overlap each other, as in the Magnoliaceæ; PLiCATE or PLAITED, when the divisions are united and folded together, as in the petals of Convolvulus and Datura.

The sepals and petals do not necessarily possess the same arrangement, as in the Onagraceæ, where the sepals are valvate 
and the petals are convolute. Furthermore, in addition to the principal types of estivation and vernation already given, there are a number of special modifications of these, depending upon the number and arrangement as well as direction of the overlapping parts of the flower- or leaf-bud.

Coalescence and Adhesion.-Not only may the divisions of the same circle or whorl of the flower be united, but even those of different circles, and a number of terms are used to describe these modifications.

When the divisions of the same circle are united there is said to be a COHESION or COALESCENCE of the parts. When the divisions of different circles are united, as of stamens with corolla, the union is spoken of as ADHESION or adnation, as in Convolvulus.

Chorisis and Multiplication of Parts.-In contrast with the reduction in number of parts of the flower due to union, there may be an increase in the number of parts due to simple division or splitting of the parts, and this is known as chorisis or deduplication. An illustration of this is furnished by the stamens of the orange flower, where from a single initial stamen or primordium a group of from 3 to I I stamens may be produced. In other cases there may be a multiplication in the number of parts from the beginning, each part arising independently on the torus, as in the stamens of rose. This, of course, would not be termed chorisis, as no splitting or branching takes place.

Double Flowers.-In double flowers there is an increase in the number of petals, which is considered to be due to the methods of cultivation and the stimulus of an increased foodsupply. This results in several ways: (I) By transformation of the sporophylls, more particularly the stamens, into petals; (2) by division or chorisis of the stamens or carpels with subsequent transformation into petals; (3) by division or branching of the petals; and (4) by the production of new series of petals. The extra petals in double carnations and double roses trace their origin to the stamens, while in Fuchsia they are the result of chorisis of the petals.

In the snow-ball (Viburnum Opulus) and hydrangea the essential elements have undergone a complete transformation, and the flowers, while large and showy, are sterile. In the white water lily 
(Nymphaa) there is a series of parts ranging from stamens with narrow filaments and stamens with broad petaloid filaments to petals tipped with a small anther and regular petals (Fig. 22I, A). In this case the stamens are considered to result from the transformation of the petals. In the case of green roses and green strawberry flowers the petals become green and leaf-like, and the change is spoken of as CHLOROSIS or CHLORANTHY. In some flowers even the ovules are replaced by leaf-like processes or appendages, as in Drosera and clover.

Arrested Development.-The arrest or suppression of parts of the plant, particularly of the flower, is of very common occurrence. Just as there are millions of seeds that never find suitable conditions for germination, so in the flowers of a large number of plants a very large proportion of the ovules never develop into seeds, the plants in many instances not furnishing sufficient nutriment for all of the ovules to mature. Under Leaves it was stated that in the axil of each leaf there is a bud. This is not always apparent, but if the plant be subjected to some special stimulus, some of the latent buds will become evident. For example, the rubber plant (Ficus), so commonly cultivated as an ornamental plant, shows a tendency to develop a straight, unbranched shoot, but if the tip of the shoot be cut off, the buds in the axils of the upper leaves will develop into branches, while some of those lower down will form small protuberances, but develop no further. In other cases there is a loss of parts which seems to be due to loss of function. When there is a partial loss of the element, as of the anthers in the flower of catalpa, it is said to be imperfectly developed or ABORTIVE. When the entire element remains undeveloped, as in some of the stamens of the Labiatæ, it is said to be Suppressed (Fig. 223, F). In flax the stamens of the outer whorl are reduced to thread-like processes. Such sterile or aborted stamens are called STAMinodEs (staminodia). In other plants the parts are not apparently arrested, but have not yet been differentiated, as is the case in the Lily family, where the perianth is composed of segments which are more or less alike (Fig. 269). In other cases, however, there seems to be a suppression or arrest of the floral envelopes.

Cleistogamous Flowers.-In addition to the regular flowers 
some plants produce cleistogamous or closed flowers. In these flowers the corolla is usually suppressed. The flowers develop stamens and pistils but remain closed, and thus there is no chance for cross-pollination. The cleistogamous flowers appear later than the regular flowers and are more or less inconspicuous, developing under the leaves and sometimes underground. Of the plants producing cleistogamous flowers, the following may be mentioned: various species of Viola, Polygala, etc.

Classes of Flowers.-As we have seen, the megasporophylls and microsporophylls in the Gymnosperms are borne on separate branches, thus giving rise to two kinds of flowers or cones. While the separation of the stamens and pistils is exemplified in a number of plants in the Angiosperms, still it is not the rule, and these two elements are usually borne close together on the same axis,-i.e., they both enter into a single flower structure. Such a flower is said to be HERMAPHRODITE or bisexual, and most of the conspicuous flowers are of this kind, as roses, buttercups, lilies, etc. Inasmuch as the stamens and pistils constitute the essential elements of the flower, hermaphrodite flowers are also spoken of as PERFECT, providing the stamens and pistils are capable of exercising their generative functions. When the stamens and pistils occur in separate flowers the flowers are said to be UNISEXUAL or IMPERFECT, as in willow, oak, hickory, etc. A flower having only a pistil or pistils is called Pistillate (Fig. 219, $A$ ), while one having only a stamen or stamens is STAMINATE, as in oaks. The staminate and pistillate flowers may be borne on the same plant, when it is said to be moncecious, as in castor bean, chestnut, hickory, alder; or they may be borne on separate plants, when the plant is called DIccious, as in willows and poplars. Plants bearing hermaphrodite and unisexual flowers on the same individual plant or on different individuals are called PoLYGA Mous, as in Ailanthus.

A COMPLETE flower is one which possesses both kinds of essential elements and both kinds of floral envelopes, and is SYMMETRICAL when a plane can be laid in all directions, the parts being alike, and when the number of parts in each circle is the same or when the number in one circle is a multiple of that in the others; as a rule, the number of stamens is some multiple of one of the 
other parts, as in geranium (Fig. 223), where we find five sepals, five petals, ten stamens, and five pistils.

Flowers are also spoken of as REGULAR or IRREGULAR, according to whether all the parts of a circle are uniform in shape or not; the flowers of geranium are regular, while those of violets are irregular. Regular flowers are also spoken of as ACTinoMORPHIC or RADIAL, and irregular flowers as ZYGOMORPHIC. The latter are also spoken of as DORSIVENTRAL. Dorsiventral flowers either arise as such, as in some of the Leguminosæ (Fig. 23I), or they may arise as radial flowers and become dorsiventral during the course of development, as in willow herb (Fig. 224).

In some flowers the floral envelopes are wanting, and the flowers are said to be NAKED, as in the willows and grasses.

Anthotaxy.-The study of the arrangement of flowers on the stem is known as anthotaxy. The flowering axis may bear only a single terminal flower, as in Tulipa; or the flowers may occur singly in the axils of the leaves, as in Viola canadensis. When, on the other hand, the flowers are borne upon a branch shoot, the internodes of which are more or less condensed, and the leaves smaller and of a more simple structure than the foliaceous leaves, the whole shoot is known as an INFLORESCENCE, and the leaves are called BRACTS. The flower thus represents a single unbranched shoot, while the inflorescence represents a branched or ramified shoot.

The so-called bracts, besides being generally smaller than the leaves proper, are mostly sessile; they may, however, be green, or membranaceous, or they may exhibit a bright coloration, as in Monarda.

The stalk of the individual flower is called a PEDICEL, and may be naked, or bear one or two small bracts, which are called FORE-LEAVES or PROPHYLLA. In the monocotyledons there is usually only one fore-leaf, which turns its back to the mother-axis and is frequently two-nerved and two-keeled. In the dicotyledons there are generally two fore-leaves, which are placed to the right and left of the flower, as in the violets.

The position of the floral leaves (the sepals, the petals and those of the perianth) depends upon the arrangement of the fore-leaves, so that in most of the monocotyledons, where there 
is one mediane prophyllon, the first leaf of the perianth is placed on the front, while the two succeeding leaves of the perianth occupy a position of $120^{\circ}$ from this (Fig. 254). When, on the other hand, as in the dicotyledons with pentamerous flowers, two fore-leaves are developed, the first floral leaf (sepal) is situated obliquely above the last fore-leaf, usually on the frontal part of the flower; the second sepal is directly behind the first or diagonally opposite to it, the remaining three leaves (sepals) occurring in a spiral of two-fifths (Fig. 280). Several deviations from this type occur, as in Lobelia (Fig. 224), Polygala, etc.

Two types of inflorescence are distinguished: (I) The INDEFINITE, in which the flowers open or develop in acropetalous or centripetal succession, and (2) the DEFINITE, in which the flowers open in basipetalous or centrifugal succession. The indefinite type of inflorescence is seldom terminated by an expanded flower, and two classes of this type are distinguished: (a) Those in which the flowers are pedicelled, as in the raceme (Fig. 267) and umbel (Fig. 344), and (b) in which the flowers are sessile, as in the spike (Fig. 230) and head (Fig. 228).

The RACEME is a long inflorescence with pedicelled flowers, which are frequently subtended by bracts (Figs. 224, 225, and 293). The CORYMB is a modified raceme in which the pedicels of the basal flowers are much longer than those of the apical, and thus the inflorescence looks like an umbel. In the milkweed the flowers have pedicels of the same length which arise from the apex of the shoot or peduncle, and this form of inflorescence is known as an UMBEL. In the Umbelliferæ a flower cluster or umbellet takes the place of the individual flowers of the umbel, and is known as a compound umbel (Figs. 346-348).

The SPIKE is also generally a long inflorescence, the flowers being sessile (Fig. 230, illus. 3), the secondary spikes in grasses being known as sPIKELETs. The SPADIX is a form of spike, which is readily distinguished by the fleshy stem, in which the flowers are frequently deeply imbedded, and which is frequently surrounded by a large bract, the so-called spathe, as in Arisæma. The CATKIN is a kind of spike with small, often imperfect flowers, which falls off as a whole, as in the staminate catkins of the oak. The catkins are mostly decompound, and in some species 
of Populus the single flowers are pedicelled, and hence are actually racemose rather than spicate inflorescences.

In the head and the umbel the main inflorescential axis is exceedingly short and the innermost flowers are often destitute of bracts, in contrast with the external, which are frequently provided with bracts that are of quite considerable size. Sterile bracts also occur in these two types, and are called involucral leaves, as in Cornus florida, where they are white or pink. There is also a difference in sex of the outer and inner flowers. While the head occurs as typical inflorescence in the Compositæ, it also exists in some of the Umbelliferæ.

The flowers of the Composita are borne on a common torus, known as the disk, which is subtended by one or more circles of bracts, these constituting an InvolverE. The flowers are of two kinds, and they receive different names because of their form and position. Those situated near the margin of the disk are known as RAY-FLOWERS, and because they possess more or less strapshaped corollas are also known as Ligulate flowers. Those occupying the central portion of the disk are known as DISKFLOWERS, or as TUBULAR FLOWERS because of the tubular shape of the corolla. Most of the Compositæ possess both ligulate and tubular flowers, as Arnica, Matricaria (Fig. 228), the common daisy, etc. But some of the members of the family have only ligulate flowers, as chicory and dandelion, and a relatively few have only tubular flowers.

Two types of definite inflorescence are distinguished: the DIBRACHIOUs (bifurcate) CYME in which the inflorescence represents a series of very regularly arranged lateral axes, one on each side of the terminal or median flower, as in the Caryophyllaceæ; and (2) the Monoвrachious (simple) CYME, of which there are several modifications, but common to all of them is the development of only one lateral branch to each terminal flower. In the SCORPIOID cyme the lateral axes are arranged alternately to the right and left, while in the HELICOID cyme the lateral axes are all on the same side of the main axis, as in Hypericum. The so-called flower cluster is a cymose inflorescence of either the definite or indefinite type in which the flowers are almost sessile or very short pedicelled, as in Chenopodium, Juncus, etc. Some- 
times the inflorescence may be decompound or complex, as in several Composite, where the heads may be arranged in cymes or racemes; or, as in the Graminex, where the spikelets, which
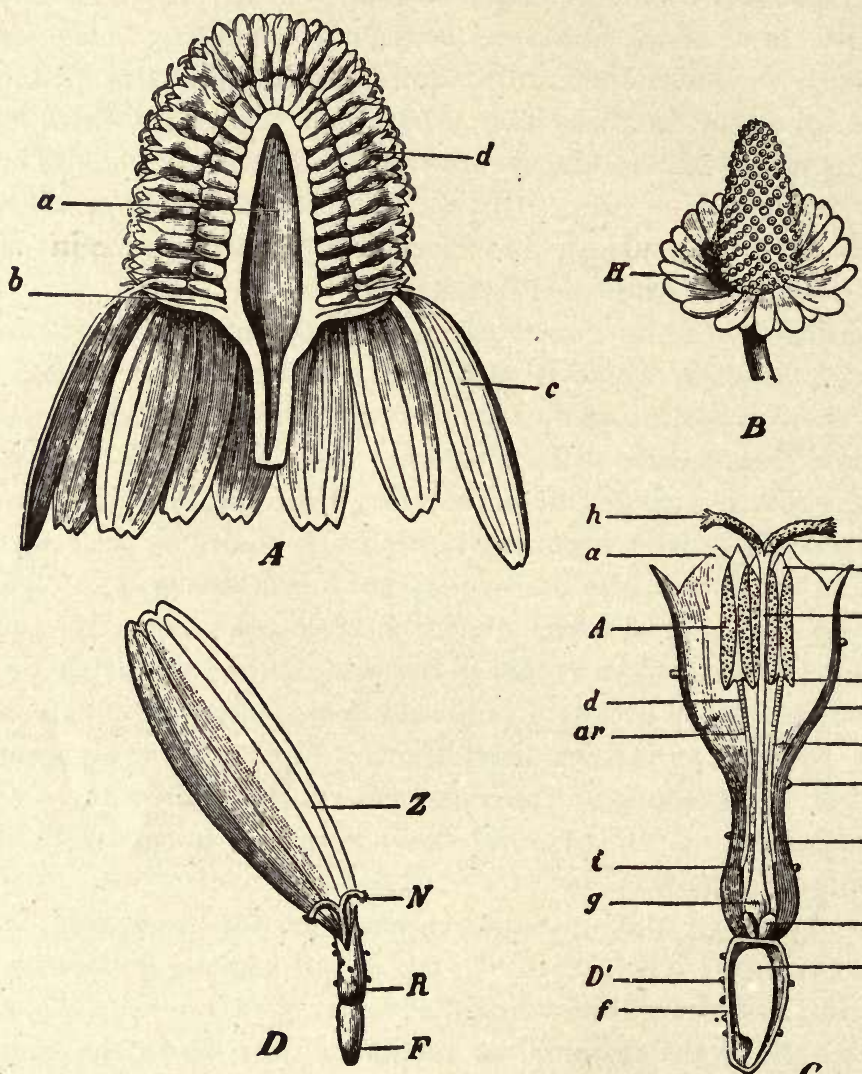

$\boldsymbol{B}$

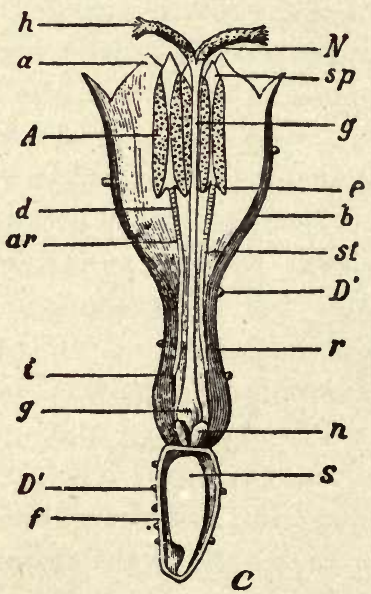

FIG. 228. Matricaria: A, longitudinal section of head showing torus (a), involucre (b), ray florets (c) and disk florets (d). B, head with the florets removed, showing the long conical torus and the involucre $(\mathrm{H})$. C, tubular floret showing the ovary $(\mathrm{f})$ with glandular hairs $\left(\mathrm{D}^{1}\right)$ and the embryo $(\mathrm{S})$, which develops after fertilization; style $(\mathrm{g})$ and bifid stigma (N), the surface of which is covered with hairs; $n$, nectaries; b, corolla tube with narrow lobes (a); stamens showing filaments (st), united anthers (A) and apex of connective (sp). $D$, ligulate floret showing ovary $(F)$, and bifid stigma $(N)$; tube of corolla $(R)$ and the upper ligulate portion (Z).-After Meyer.

are spikes, may be arranged in panicles, i.e., branched racemes; or finally, as in Cryptotænia (Umbelliferæ), where the umbels are arranged in cymes. 
Pollination and Fertilization.-Fertilization represents the final stage in the work of the flower as a whole, and has already been defined as the union of the egg-cell and a male nucleus. Pollination may be considered to include the transferral of the pollen grains from the anther to stigma and their subsequent germination thereon, this latter process resulting in the production of the male nuclei. Pollination thus represents but one series of changes or processes which precede fertilization, for, while the pollen grain is going through the various stages in development which lead to the formation of the male nuclei, a series of complex changes are going on in the embryo-sac leading to the development of the egg-cell.

Our special interest in pollination arises from the fact that the pollen grains are not retained in the pollen sacs and are dependent upon various agencies for transferral to the stigma. This is a matter of great biological significance, for it is claimed that many of the special characters of flowers have a direct relation to pollination.

The various ways in which the anthers open for the discharge of the pollen when it is ripe have already been considered (Fig. $22 \mathrm{I}$ ), but it may be added that the manner in which this is done usually appears to have a relation to the manner in which the pollen is to be carried to the stigma. In order that pollination may be effected, the stigma must be ripe or mature, when it is said to be receptive. It then usually secretes a sticky, sugary liquid which causes the pollen grains to adhere to the stigmatic surface (Fig. 83), and which at the same time serves as a nutrient to them. Usually the pollen grains begin to germinate in a short time after reaching the stigma, which is made evident by the protrusion of the pollen tubes. The stigma seems also to have the power of selection, for in many cases the pollen does not germinate as readily on the stigma of the same flower as on that of another flower, provided it be of the same or a nearly related species.

When a flower possesses both stamens and pistils, - that is, is bisexual or hermaphrodite,- - and its pollen germinates upon its own stigma, the process is known as close or SELF-POLLINATION, and if fertilization follows, this is known as SELF-FERTILIZATION. 
While most hermaphrodite flowers are self-pollinated, there are some that are not, and this is brought about in several ways: (I) As already pointed out, the pollen may germinate better on the stigma of another flower than on the stigma of the same flower. (2) The anthers and pistils of the same flower may mature at different times, and this is one of the commonest ways of preventing self-pollination. Usually in such cases the stamens mature first. The common plantain (Plantago) furnishes an example of the maturing of the stigma before the anther. The flowers of this plant are arranged in spikes (Fig. 230, illus. 3 and 4) which belong to the indefinite class, and hence the lower flowers on the spike expand first. As stated, the pistil of each, flower matures first, and after it withers the stamens protrude and discharge their pollen. It is evident that the flowers can not be , self-pollinated, nor is it likely that one flower will be pollinated by another of the same spike. (3) The stamens and pistils of the same flower may vary in length, as in Polygonum (Fig. 230, illus. I and 2) and Lythrum (Fig. 230, illus. 5), or stand in such other relation to each other that self-pollination will not be effected, as in some of the irregular or zygomorphic flowers, like those of Orchids. In these several cases the pollen grains either fall upon or are carried by various agents to the stigmas of other flowers, and this is known as cross-pollination, and the fertilization which follows as CROSS-FERTILIzATION.

Cross-fertilization is an advantage to the species, for usually the seeds which result from this process give rise to plants which are more vigorous and otherwise superior to those which result from self-fertilization. In some cases, in order to insure the production of fruit, hand-pollination is practised, as by the growers of vanilla and some other tropical plants of economic importance.

In the case of unisexual flowers, or those in which the stamens and pistils are in separate flowers, there is, of course, no chance for self-pollination. Here, as in the case of cross-pollinated hermaphrodite flowers, pollination may be more or less close or it may be remote, as between flowers of the same cluster or inflorescence, between flowers of different clusters or inflorescences on the same plant, or between flowers on different plants.

In buckwheat (Fig. 230, illus. I and 2) and partridge berry 
(Mitchella repens) two kinds of flowers are produced, viz.: (a) one with short styles and long filaments, and another $(b)$ wiih long styles and short filaments, and thus the flowers appear to be especially adapted for insect cross-pollination and are called DIMORPHIC. In still other cases one species gives rise to three kinds of flowers, depending upon the difference in the relative lengths of the styles and filaments, as in the purple loosestrife (Lythrum calcaratum), and such flowers are called TRIMORPHIC.

The external agents which are instrumental in carrying pollen from one flower to another and thereby promoting cross-pollina-

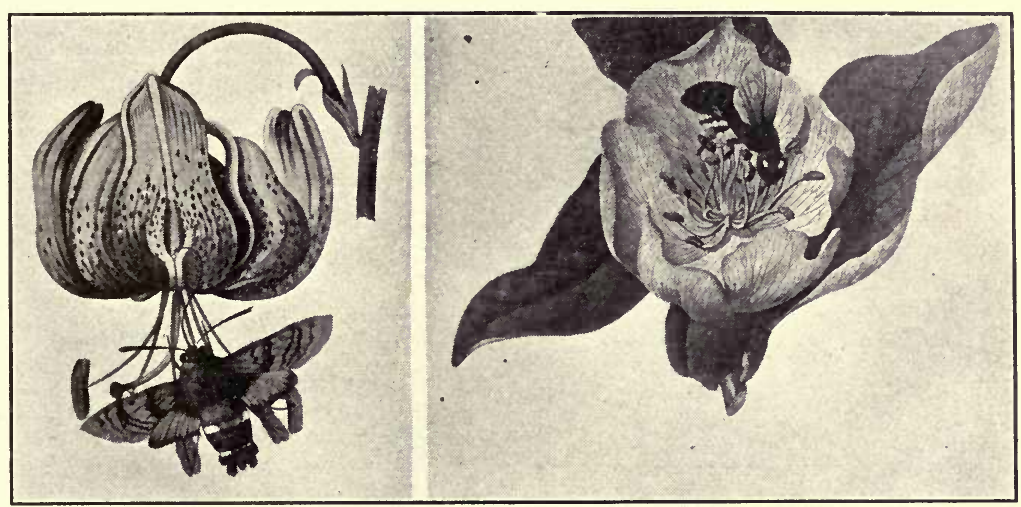

FIG. 229. Visitation of flowers by insects showing how they gather the pollen and assist in cross-pollination, the one on the left being Lilium Martagon visited by a hawk moth, showing that while the proboscis is removing honey from the nectary the under side of the body is becoming covered with pollen; at the right $C y d o n i a$ vulgaris, the common quince, visited by a bee, whose legs are becoming covered with pollen.-After Dodel-Port.

tion are the wind, water currents, insects, small animals and birds, such as humming-birds, which are, even in temperate regions, to be observed visiting the garden nasturtium.

In many of the early-flowering trees, as well as pines, Indian corn, etc., the flowers are devoid of showy, attractive features, but produce large quantities of pollen which is more or less dry and powdery and carried by the wind to other flowers. Flowers which are wind-pollinated are classed as ANEMOPHILOUS, and it is estimated that about one-tenth of all the flower-producing plants belong to this class.

Plants which are pollinated by the aid of water currents are 

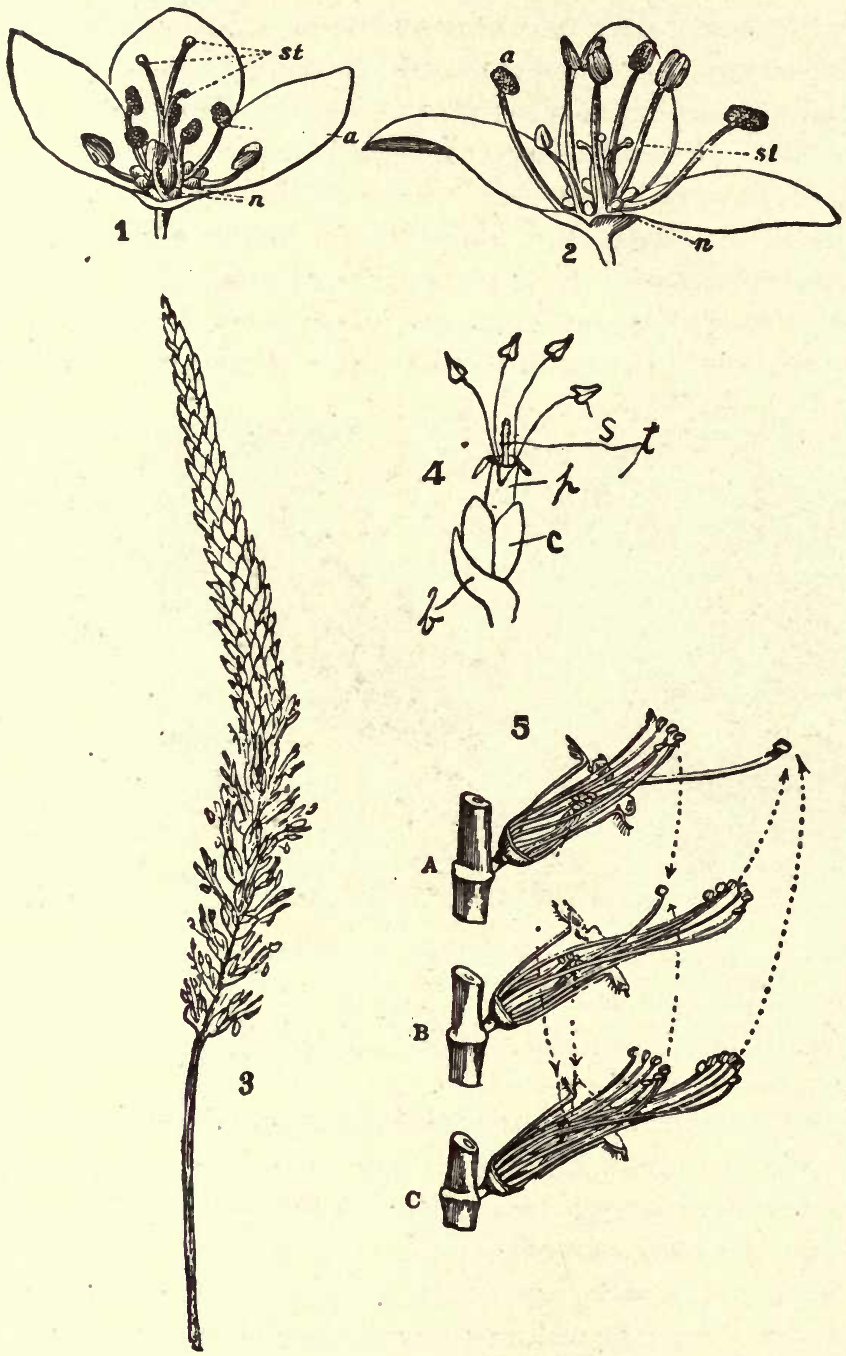

FIG. 230. Manner of cross-pollination in some hermaphrodite flowers. I, 2. Flowers of buckwheat, showing long style and short filaments in 1 , and short styles and long filaments in 2 : a, anthers; st, stigmas; $n$, nectaries. 3 , Spike of plantain showing maturing of stamens below and pistils above. 4, Dissected fiower of plantain: $b$, bract; c, calyx; p, corolla tube; s, stamens; t, protruding withered style. 5, Flowers of Purple willow-herb (Lythrum Salicaria), one side of the perianth removed from each. A is longstyled, B, medium-styled, and C, short-styled. The direction of the arrows and dotted lines indicates the best methods of crossing.- $1,2,5$, adapted from Warming. 


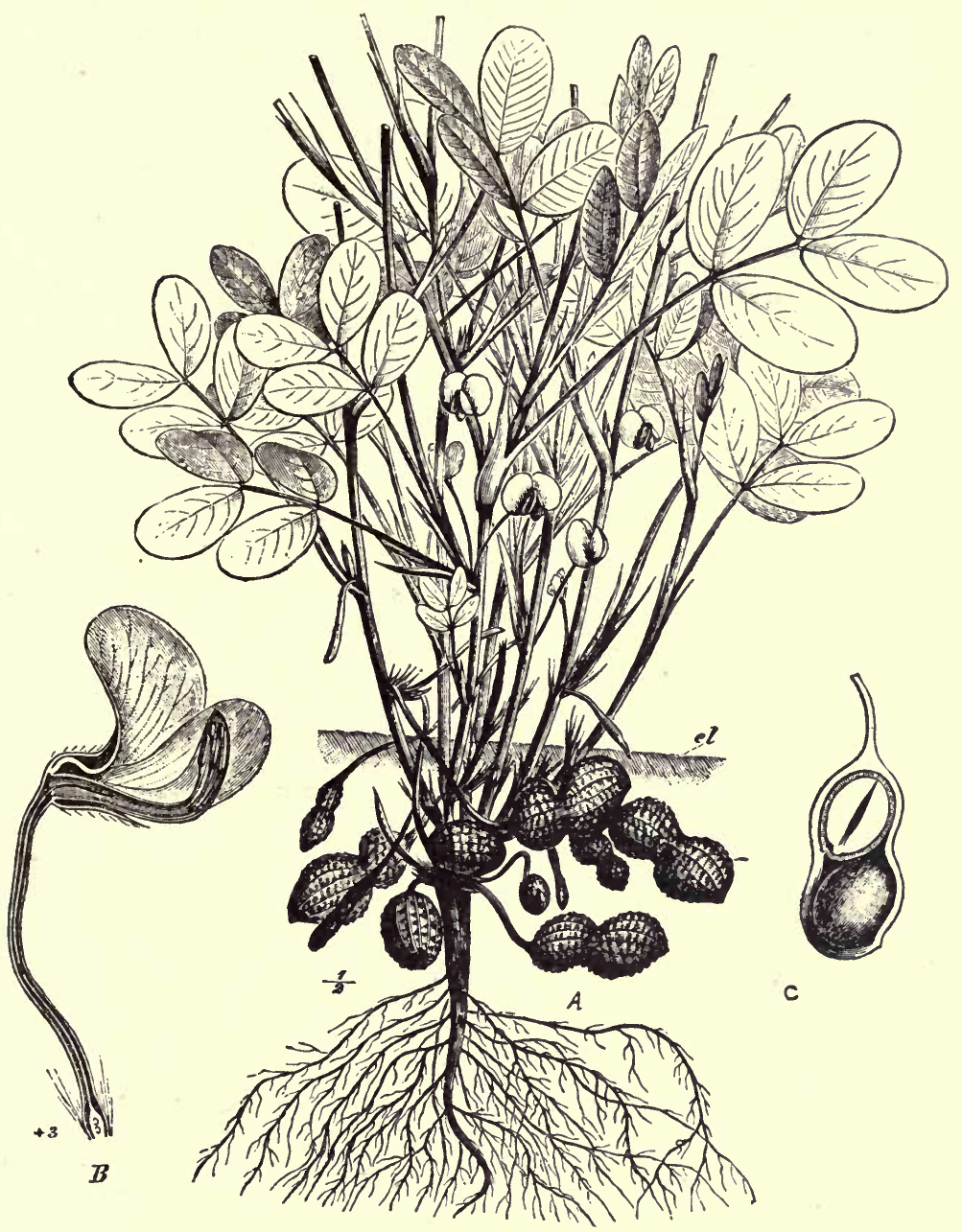

FIG. 23I. A, flowering and fruiting plant of peanut (A rachis hypogca). After fertiliza. tion the carpophore (or stalk between calyx and ovary) grows in length, sometimes 4 to 8 cm., and curves downward penetrating the soil (el), after which the fruit develops. B. longitudinal section through the papilionaceous (bilateral) fower; C. longitudinal section through the pod (peanut).-After Taubert.

known as IIYDROphilous, and under this head are included those plants which live under the water and those that produce flowers at or near the surface of the water.

Those plants which depend upon the visitation of insects for 
the transferral of the pollen in cross-pollination are called ENTOmophilous (Fig. 229). They frequently possess bright, highly colored flowers, and it is considered that these serve as an attraction to the insects which visit them. The insects are, however, probably more attracted by the odor and food products which they obtain, such as the nectar. The nectar is secreted by glands known as nectaries, which are variously located; frequently they are on the torus, either between the ovary and stamens (Fig. 78) or between the stamens and petals. Sometimes the stamen is modified to a nectar-secreting spur, as in the violets. In aconite the nectary is developed from one of the posterior petals (Fig. 223, E). In seeking the nectar the pollen of the ripe anther may fall upon or adhere to the insects and thus be carried from one flower to another (Fig. 230).

Honey is a product formed through transformation of the plant nectar by honey bees. The nectar is supposed to be acted upon by certain salivary secretions of the bee and changed into a fruit-sugar, the so-called honey, consisting of a mixture of dextrose and levulose. The nectar of buckwheat and clover (particularly white clover) is the principal source of the commercial article. The nectar of some plants is poisonous and may furnish a poisonous honey (see discussion under Ericaceæ).

\section{THE INNER STRUCTURE OF THE FLOWER.}

The inner structure of the flower bears a close resemblance to that of the stem and leaf. The BRACTS in almost all particulars are like the foliage leaf of the same plant, and the FLOWER STALK closely resembles the foliage stem. The CALYX, while resembling the foliage leaf, usually contains calcium oxalate in greater amount, and the chlorenchyma consists wholly of rather loose chlorophyll parenchyma; the outer or under epidermis contains the stomata, and if hairs are present, they also arise from this surface; the fibrovascular bundles are generally simple in structure, although in some cases, as in lavender, sclerenchymatous fibers are strongly developed.

In the COROLLA the epidermal cells are generally more or less centrifugally developed, forming prominent papillæ (Fig. 232, $A, B)$, which give the petals a velvety or satiny appearance, as in 
the rose; glandular and non-glandular hairs are also developed which are peculiar to the corollas of irregular flowers, as in Lavandula vera and Viola tricolor (Figs. I24, I49-155, 232); stomata are comparatively few in number. The epidermal cells
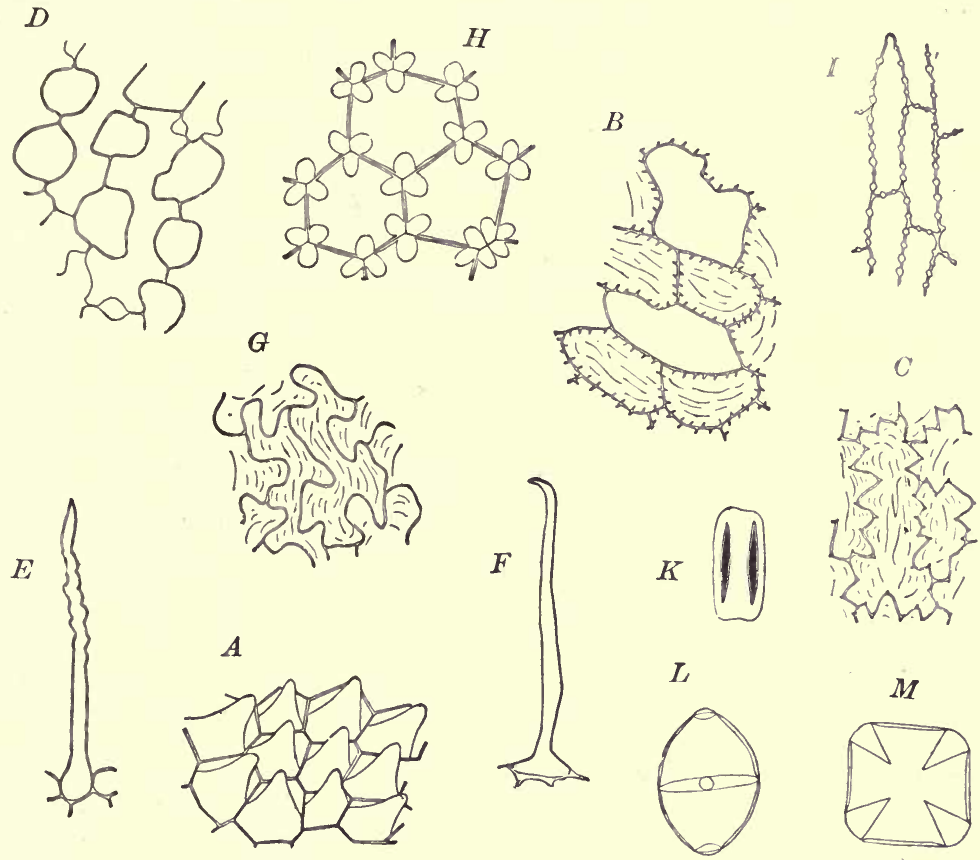

F1G. 232. Inner morphology of the flower as illustrated in Viola tricolor. A, epidermal cells from the outer surface of the spurred petal showing papillæ; B, epidermal cells from the under surface of the petals, some of the cells showing centripetal thickenings, the two without thickenings indicating the epidermal mucilage-cells; C, epidermal cells from the under surface of the petals showing a zigzag outline and short centripetal thickenings; D, surface view of the mesophyll of the petals; E, corkscrew-like hair from the inner surface of the spurred corolla near the throat; F, a hair from the edge of an anther; G, epidermal cells of the anthers; H, surface view of the mesophyll cells from the spurred stamen showing collenchymatous thickening; $I$, surface view of cells of endothecium; $K$, pollen grain viewed from the side; $L$, pollen grain examined in water; $M$, pollen grain observed in chloral solution.

are but slightly cutinized, and in surface view are strongly undulate and appear striate owing to the papillose development (Figs. 232 and 235). The chlorenchyma is made up of rather loase, branching parenchyma cells (Fig. 232, D), with large, intercellular spaces. The cells are free from chloroplastids, may contain 
chromoplastids, or, like the epidermal cells, a colored sap; in some instances, as in the buttercups, starch grains are also found in the mesophyll. Calcium oxalate crystals are usually present, and milk vessels are sometimes found, as in the Papaveracex.

The FILAMENT and connective possess a central fibrovascular bundle, around which are arranged comparatively small parenchyma cells and among which secretion cells are sometimes scattered, as in Tilia. The pollen sacs consist of but two layers of cells-an outer layer called the "exothecium," which resembles the epidermis of the corolla, and an inner layer called the "endothecium," the cells of which are contractile and peculiarly thickened, this feature being rather characteristic for certain species (Fig. 232, $I$ ). Lining the pollen sacs during their development,
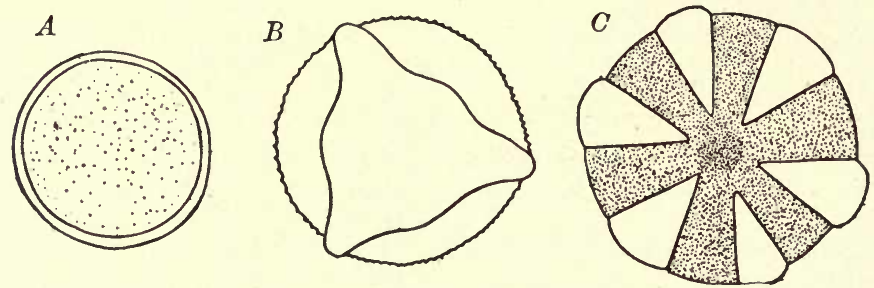

FIG. 233. Several forms of pollen grains: A, crocus; B, arnica, with three thin places in the wall through one of which the pollen tube may protrude; $C$, lavender showing six thin places in the wall.

there is a layer of cells, called the "tapetal cells"; but these are usually sooner or later absorbed.

The POLLEN GRAINS vary greatly in number, as well as in size and shape. They are usually more or less ellipsoidal, but may be spherical, as in Crocus (Fig. 233, $A$ ) ; more or less threesided, as in the Compositæ and in cloves; four- or five-sided, as in Viola tricolor (Fig. 232, K, L, M), and in some cases, as in the Pinaceæ, they may be winged. In addition to protoplasm and one or more nuclei, pollen grains contain considerable oil and starch. The outer or enclosing membrane (Fig. 233) consists of two parts: an inner one, known as the "intine," and consisting of cellulose, and an outer, known as the "exine," apparently consisting chiefly of cutin; in some cases the exine also contains an oil which is colorless, as in Salvia, or yellowish, as in lavender, and in some instances it may contain a viscid substance, causing 
the pollen grains to adhere, as in Enothera. The grains may be smooth or variously sculptured; in most instances the exine is unevenly developed, leaving thin places through which the pollen tubes protrude in germination; these give the appearance of

A

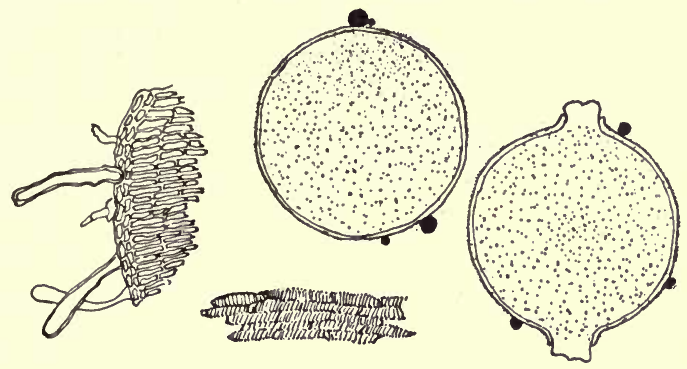

B.
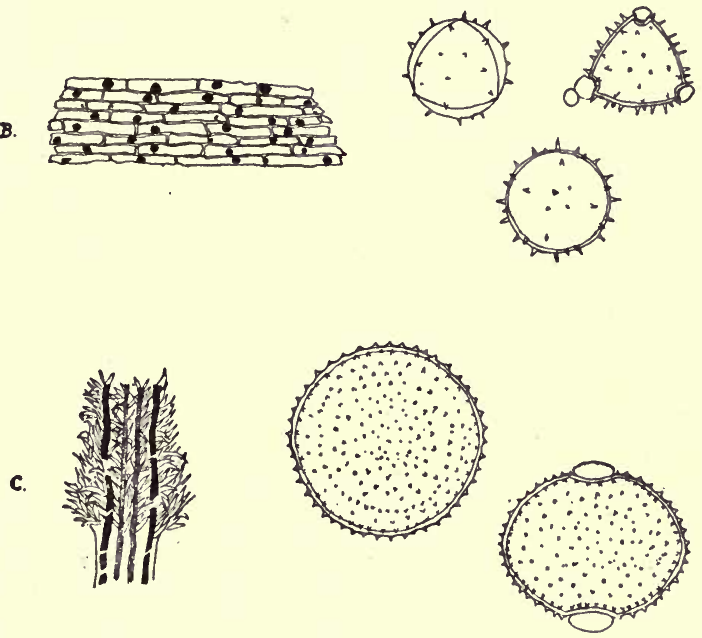

Fig. 234. A, Crocus (Spanish saffron) showing two spherical pollen grains, a fragment of stigma with papillæ, and fragment of an anther; B, Calendula showing 3 spinose pollen grains and fragment of corolla, the cells of which contain oil-like globules; C, Carthamus (so-called American saffron) showing 2 slightly spinose pollen grains and a fragment of the corolla with brown laticiferous vessels and numerous unicellular hairs.-After Weakley.

grooves when the grains are dry, and the number of grooves is characteristic for different species; in most of the Compositæ they are three in number; in the Labiatæ there are six, while in Crocus they are wanting (Fig. 234).

The epidermal cells of the stigma are quite characteristic. 
The cells of the epidermis, or so-called " stigma-epithel," may be palisade-like, forming a more or less wart-like mass, as in the viscous stigmas of the Umbelliferæ, or the outer walls may be modified to rather broad papillæ, as in matricaria and arnica, or they may be developed into hair-like processes, as in crocus. The pollen tubes either enter. the style through an open canal, as in the violets, or they penetrate into the conducting tissues of the style, either through the papillæ, as in malva, or through the middle lamella of two neighboring papillæ, as in Atropa Belladonna.

The important tissue of the style is the conducting tissue; in styles which are hollow it forms the lining of the canal, the cells resembling those of the stigma-epithel; in styles that are solid the conducting tissue occupies the central axis and consists of somewhat elongated cells, the walls of which are generally thick, frequently strongly refractive and possess the property of swelling, being furthermore separated by large intercellular spaces. Surrounding the conducting tissue are thin-walled parenchyma cells, in which the fibrovascular bundles are distributed, the number of groups of the latter corresponding to the number of carpels that compose the gynæcium. There may also occur secretion cells, containing mucilage, as in malva, or oil and resin, as in matricaria. Occasionally, the parenchyma is replaced either in part or entirely by mechanical cells, and the epidermal cells may be modified to hairs.

The tissues of the ovARY are, as a rule, in a very rudimentary condition; in fact, so rudimentary that it is difficult to distinguish the ovaries of two flowers that develop into quite different fruits. In some instances it is said that, notwithstanding the subsequent changes, each cell of the fruit is already indicated in the ovary. The ovary possesses an outer and an inner epidermis; the outer is provided with stomata and may also possess hairs; the inner may also have stomata and after fertilization may develop secretion hairs, as in the orange. Between the epidermal layers occur thin-walled parenchyma cells which contain leucoplastids and chloroplastids, and in which the fibrovascular bundles are distributed, these being usually simple, or complex, as in the pea. The number of fibrovascular bundles is more or less dependent 

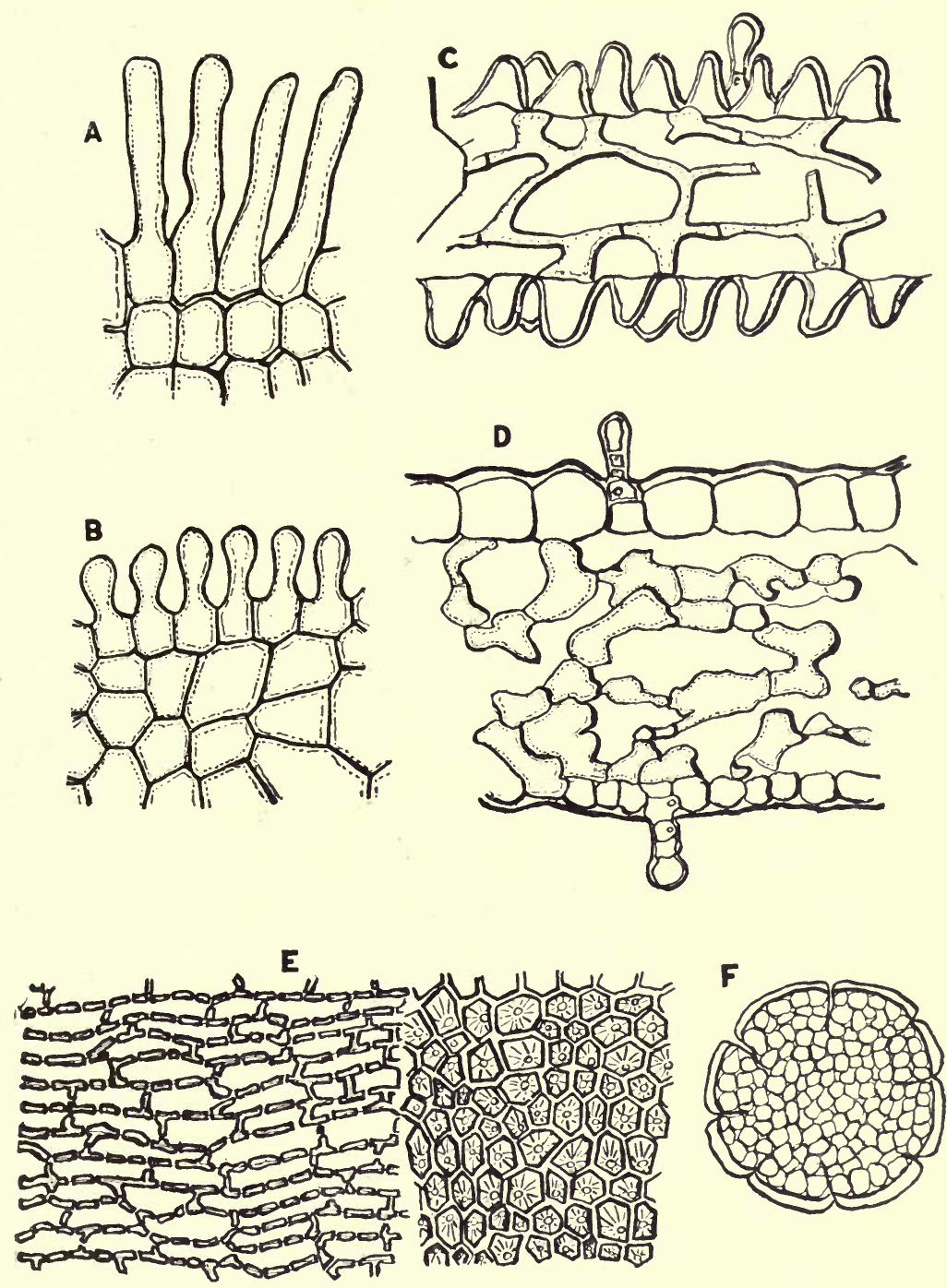

FIG. 235. Inner morphology of flower of Primula officinalis: A, papillæ on stigma of flower with long styles; B, papillæ from stigma of flower with short styles; C, section through petals showing papillose epidermal layers and branching cells of mesophyll; $D$, section through corolla tube showing glandular hairs on epidermis; E, surface view of epidermal cells of petals, those of the corolla tube being elongated and shown on the left, while those of the outspreading petals are polygonal and striated from the folds in the papillæ; F, a pollen grain.-Redrawn by Haase from drawirg of Hans Kramer in Ber. d. d. pharm. Ges., 1907, p. 352 . 
upon the number of carpels that make up the gynæcium; as a rule, there is a strong fibrovascular bundle which corresponds to the mid-vein of each carpel.

The PLACENTA is a development from the inner epidermis. It is traversed by a fibrovascular bundle from which branches are given off to the individual ovules; it may have a conducting tissue similar to that found in the style, and in some cases the epidermis of the stalk of the ovule may be developed to a stigma-epithel.

The ovULE not only possesses a distinct form as already given, but the internal structure, by reason of the changes associated with fertilization, is more or less characteristic for certain species and genera. It has an epidermal layer, the outer walls of which are more or less cutinized, and it consists for the most part of parenchyma cells rich in protoplasm and food-materials; in addition the embryo-sac contains a number of nuclei. The stalk and raphe are connected with the placenta by means of a fibrovascular bundle.

The NECTAR may be secreted by certain of the epidermal cells of various parts of the flower; these may resemble the ordinary epidermal cells or they may be modified to papillæ, as in the spurred stamens of the violets, or to hair-like processes, as in malva. The cells which secrete nectar constitute the "nectarapparatus," and the walls are usually thin and more or less cutinized. The nectar-apparatus is found more generally upon some part of the stamen, but the sepals and petals are not infrequently saccate or spurred, which adapts them for holding the nectar.

\section{OUTER MORPHOLOGY OF THE FRUIT.}

After the fertilization of the ovule or ovules, the parts of the flower that play no further part either in protecting the seed or aiding in its dispersal soon wither and are cast off; in most flowers the petals lose their color and, together with the stamens, style, and stigma, wither and fall away shortly after fertilization. The stigma may, however, persist, as in the poppy; the style may likewise remain, as in Ranunculus, or even continue to grow or lengthen, as in Taraxacum; in other cases the calyx persists, as in orange and belladonna; in still other cases the torus may become fleshy and form a part of the fruit, as in pimenta and apple. The fruit may consist, therefore, not only of the ripened pistil, 

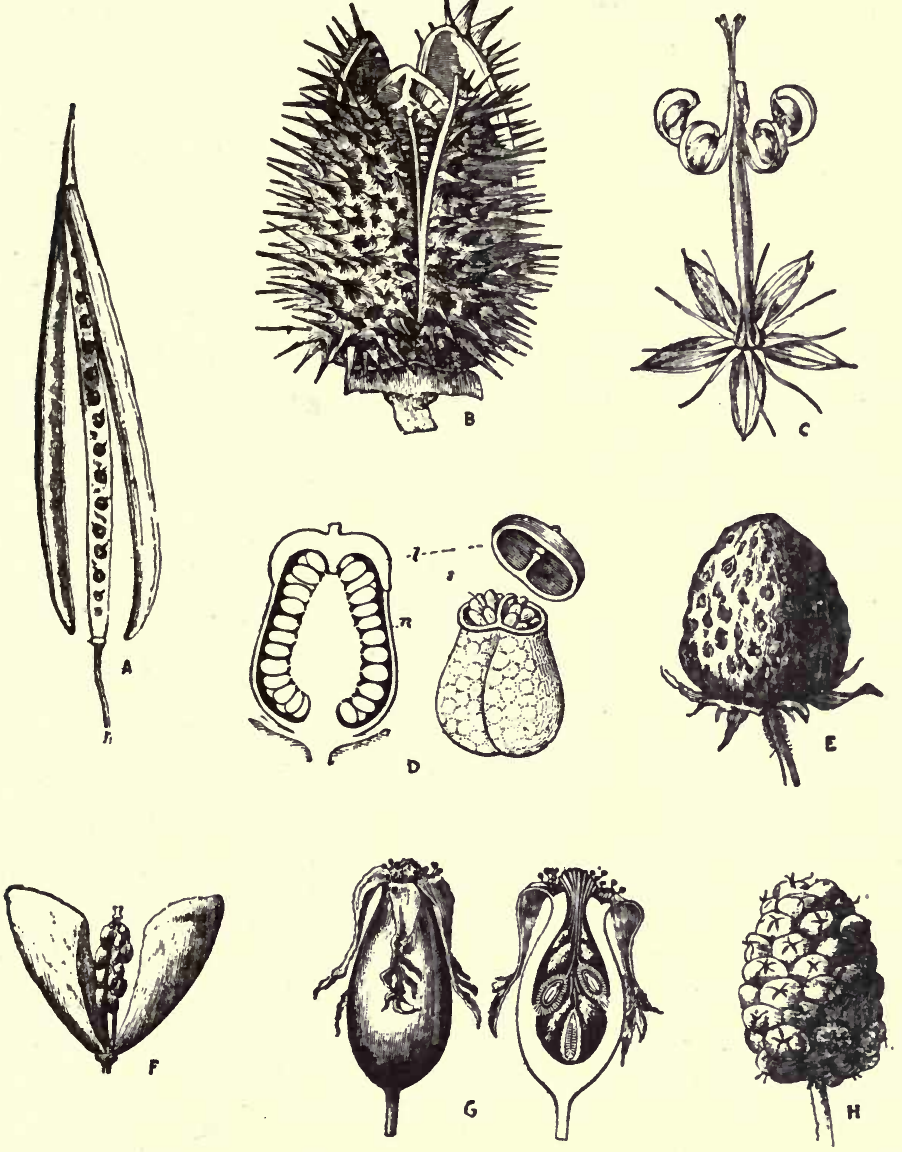

FIG. 236. Different types of fruits. A, silique of mustard showing the separation of the two valves leaving the seeds attached to the central axis; B, spinous capsule of Stramonium showing septifragal dehiscence into four valves, the capsule being strictly 2locular but apparently 4 -locular owing to the formation of false dissepiments; C, 5-valved capsule of Geranium in which the carpels become detached from one another and roll upwards remaining attached to the beak-like compound style; D, capsule of Hyoscyamus showing transverse dehiscence by means of a lid ( $\mathrm{I}$ ) and the two loculi containing numerous small seeds; E, fruit of strawberry showing fleshy torus and numerous embedded akenes; F, silicula of shepherd's-purse showing seeds attached to central axis and longitudinal dehiscence of the valves which remain attached below; G, fruit of rose, so-called rose "hip," the akenes being enclosed by the hollow oval torus which shows remains of calyx at the apex; H, multiple fruit of mulberry composed of small drupes, the pulpy portion of each consisting of the fleshy perianth.-Adapted from Warming.

but also of other parts of the flower and torus which persist or develop with it. 
The wall of the fruit is called the PERICARP, and, like the leaf, it consists of three distinct layers, viz.: (I) the outer layer corresponding to the outer epidermis of the ovary is called the EPICARP or EXOCARP; (2) the inner layer corresponding to the inner epidermis of the ovary is called the ENDOCARP, or, from the fact that it is sometimes hard and stone-like, it is called the PUTAMEN, as in the prune; and (3) the middle layer situated between the epicarp and endocarp is called the MESOCARP; and from the fact that it is sometimes succulent or fleshy, as in the prune, it is also called the SARCOCARP.

There are a number of distinctive and descriptive names applied to fruits. Some of the more important are as follows:

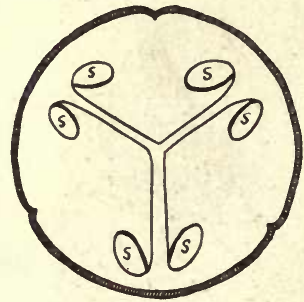

A

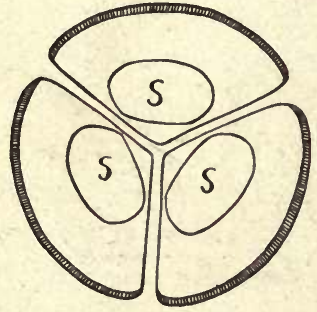

B

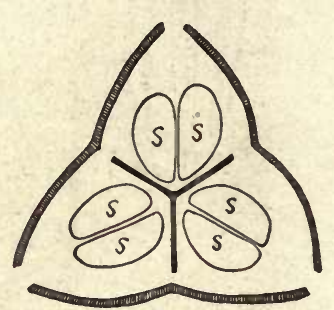

C

FIG. 237. A, transverse section of colocynth showing seeds (s) borne on parietal placentas; B, transverse section of fruit of Ricinus communis showing septicidal dehiscence of capsule, the seeds (s) being borne on axial placentas; C, transverse section of cardamom showing loculicidal dehiscence, the seeds $(s)$, as in B, being borne on axial placentas.

An Achene is a non-fleshy, or so-called dry, unilocular and one-seeded, indehiscent fruit, in which the pericarp is more or less firm, and may or may not be united with the seed. Achenes may be inferior, as in the Compositæ (Fig. 227), where they develop from inferior ovaries, being frequently surmounted by the pappus or calyx; or half inferior, as in the rose (Fig. $236, G$ ), where they develop from half inferior ovaries; or superior, as in the buttercup (Fig. 223, D).

A Berry is a fleshy, indehiscent fruit, the seeds of which are embedded in the sarcocarp; berries are superior when they develop free from the torus, as in belladonna (Fig. 239), capsicum, grape, etc., and inferior when the torus forms a part of the fruit, as in banana, cranberry (Fig. 244), and gooseberry (Fig. 245). 
A Capsule is a dry, dehiscent fruit, consisting of two or more united carpels. Dehiscence in capsules may occur in five different ways: In the castor-bean (Fig. $237, B$ ) the carpels separate from each other along the walls or septa (dissepiments), the seeds being discharged along the ventral suture of the separated carpels, and this mode of dehiscence is called SEPTICIDAL. In mustard (Fig.

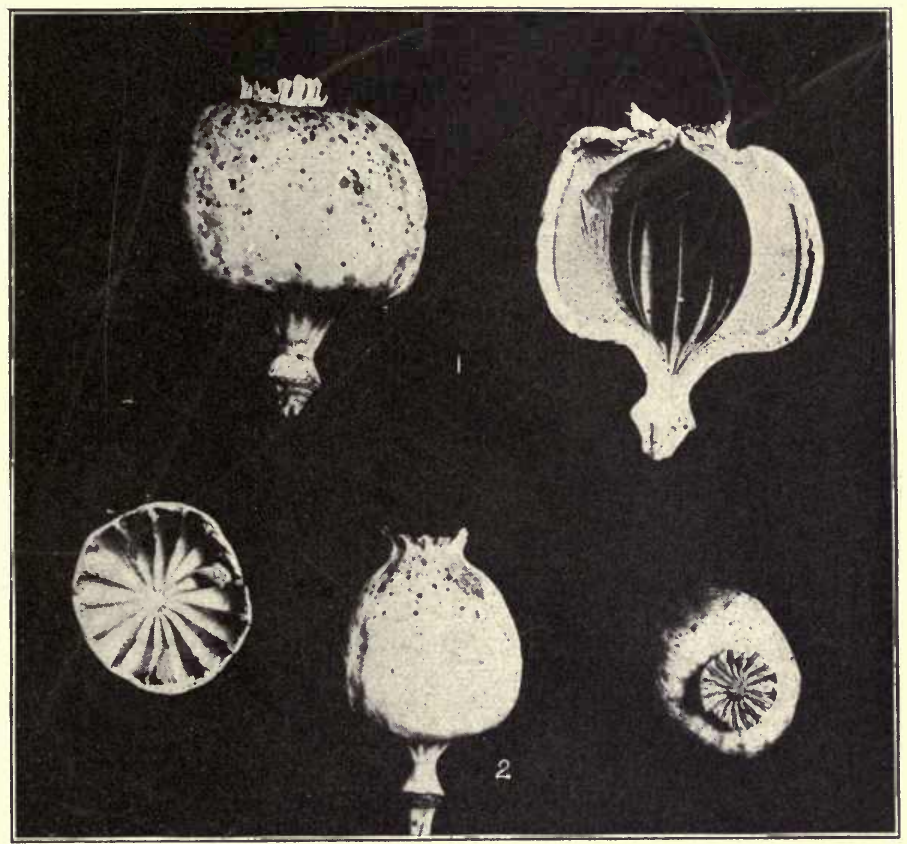

FIg. 238. Capstiles of poppy (Papaver somniferum), whole and in transverse and longitudinal sections, showing dissepiments and remains of radiate stigmas at the apex, which are porous and through which the seeds are discharged. I, French capsules; 2, German capsules.

$236, A)$ the dissepiments remain intact and dehiscence occurs along the margin of the capsule, and is therefore called MARGINICIDAL; but as the partial carpels (or valves, as they are termed) separate from the walls or septa, the dehiscence is also known as SEPTIFRAGAL. In cardamom (Fig. 237, $C$ ) the septa as well as valves are united, and at maturity the latter separate and dehisce at points in the margin corresponding to the mid-vein of the carpel, and 
this form of dehiscence is known as LOCulicidal. In poppy capsules (Fig. 238) there are a few openings beneath the united

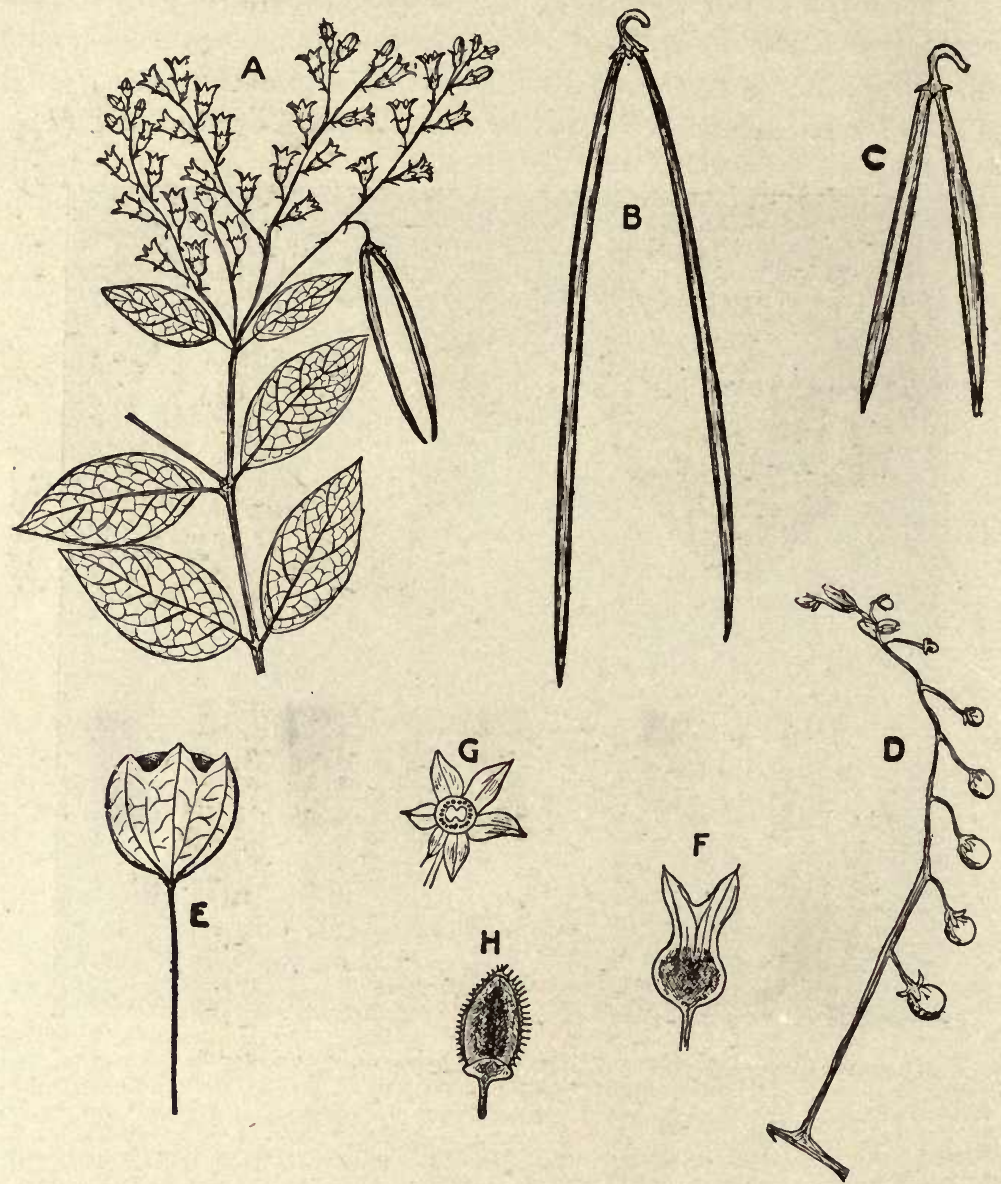

FIG. 239. Several forms of fruits: A, branch of Apocynum androsamifolium showing numerous flowers and a single fruit with 2 long, slender follicles. Comparative size of follicles in $A$. androsamifolium (B), and A. cannabinum (C). Branch of Solanum carolinense showing a number of small superior berries (D). Pyxis of Scopolia carniolica showing slightly lobed calyx and upper portion of fruit (E). Pyxis in Hyoscyamus niger showing calyx lobes extending much above the fruit (F). Berry of Atropa Belladonna cut transversely and showing the numerous small seeds (G). Young spinose capsule of Datura Stramonium $(\mathrm{H})$.

stigmas through which the seeds are expelled, and this form of dehiscence is known as porous. In hyoscyamus (Fig. $236, D$ ) a 
portion of the capsule comes off from the remainder like a lid, and this form of dehiscence being circular or transverse to the
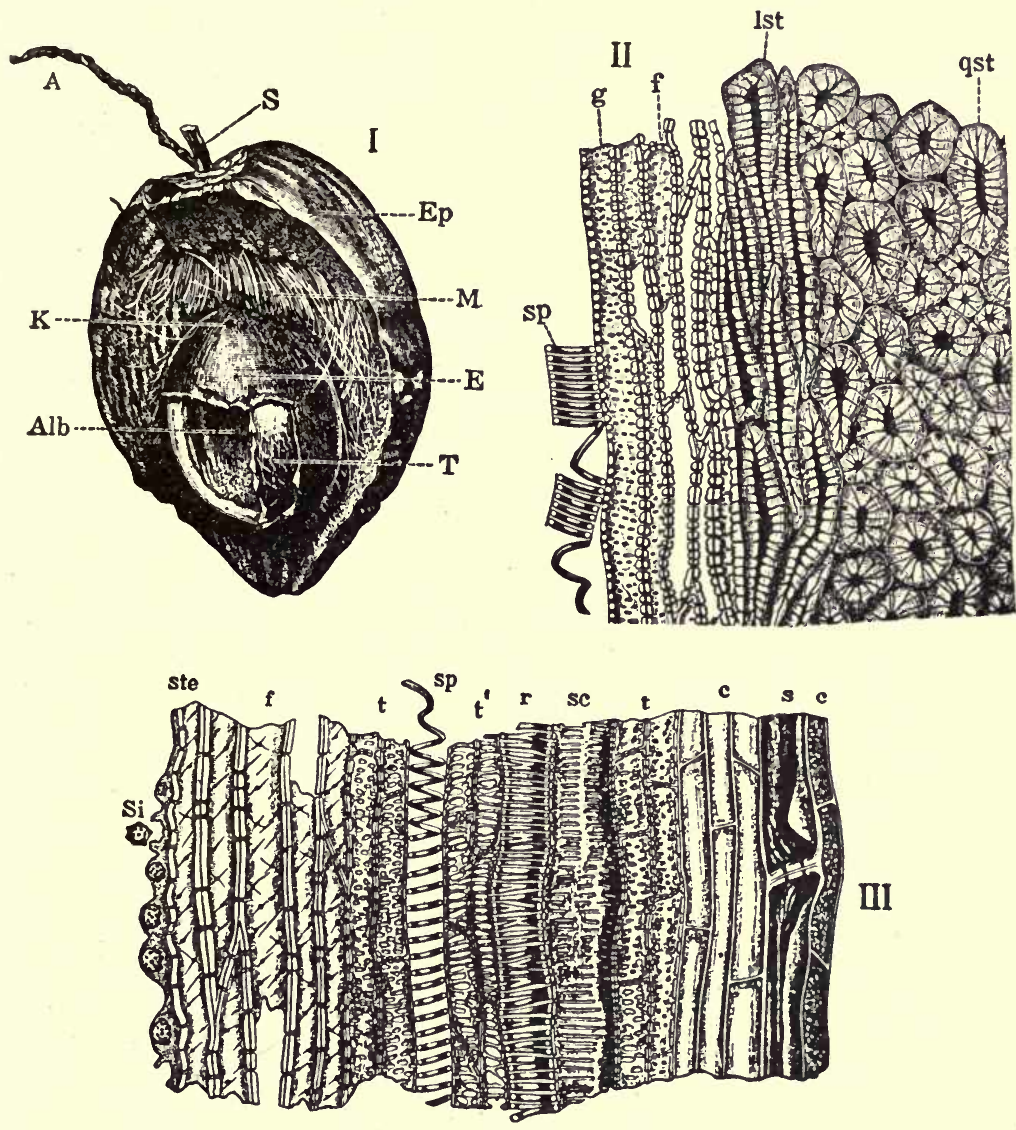

FIg. 240. The fruit of the cocoanut palm (Cocos nucifera): I, ripe cocoanut fruit showing lower part of axis forming the stem (S), upper end of axil with scars of male flowers (A), epicarp (Ep), mesocarp (M) with fibers, endocarp or hard shell (E), portion of testa adhering to endosperm ( $T$ ), endosperm surrounding cavity of nut (Alb) and germinating eye (K); II, longitudinal-radial section of endocarp through the stone cells and edge of bundle showing transversely elongated and isodiametric stone cells (qst), longitudinally elongated stone cells (Ist), thick-walled porous cells (f), pitted tracheæ (g) and spiral tracheæ (sp); III, longitudinal section of a large (mesocarp) fiber showing stegmata (ste), silicious body ( $\mathrm{Si}$ ), bast fibers (f), tracheids with small pits (t), tracheids with large pits $\left(t^{\prime}\right)$, spiral tracheæ $(s p)$, reticulated tracheæ $(r)$, scalariform tracheæ $(s c)$, sieve tube (s) and cambiform cells (c and $\left.\mathrm{c}^{\prime}\right)$.-After Winton.

sutures of the carpel, it is called cIRcumcissile. A capsule of this kind is known as a Pyxis or Pyxidium. 

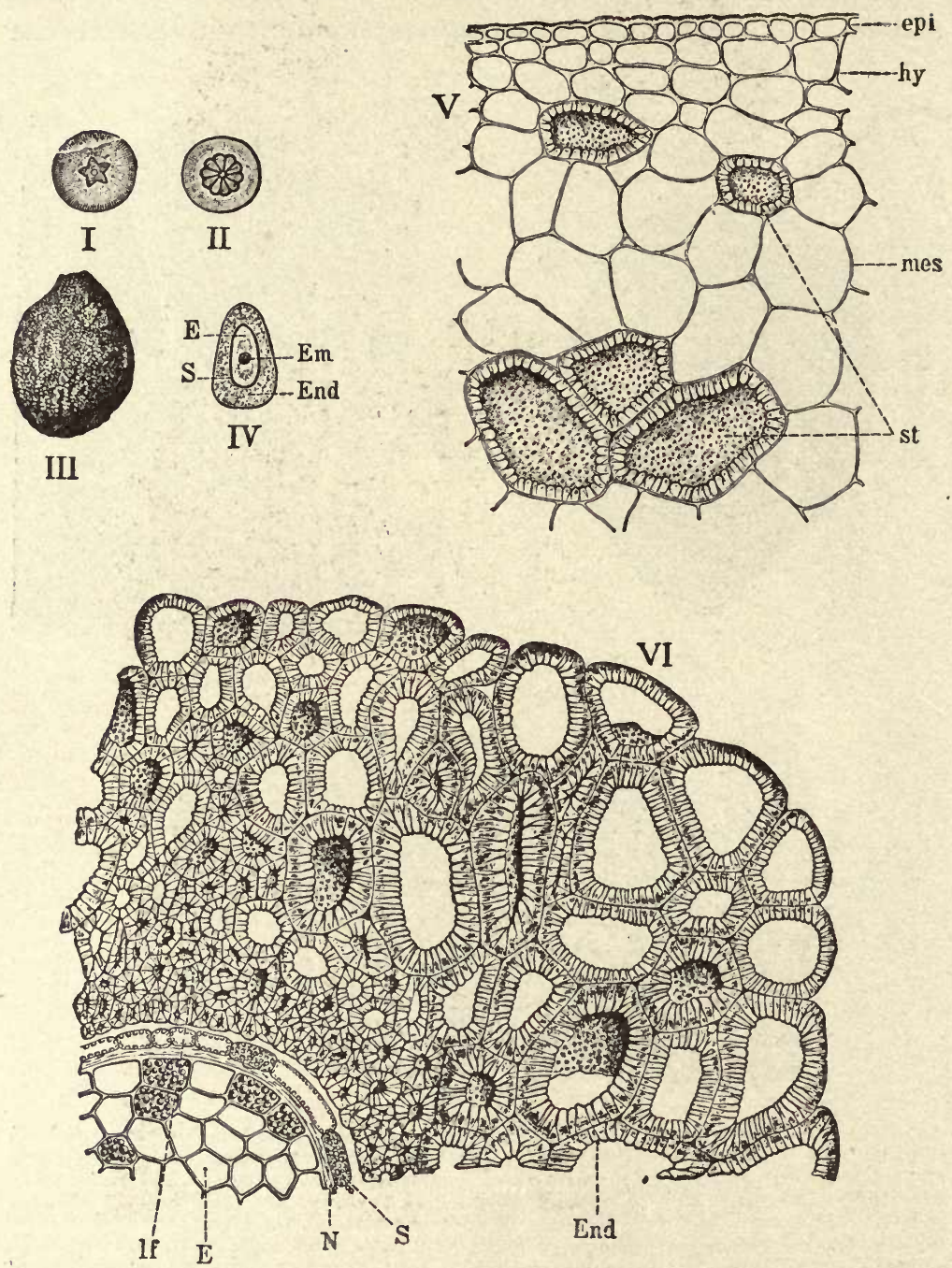

Fig. 24I. Fruit of the huckleberry (Gaylussacia resinosa): I, fruit seen from above; II, transverse section of fruit; III, stone; IV, transverse section of stone showing endocarp (End), testa $(\mathrm{S})$, endosperm $(\mathrm{E})$ and embryo $(\mathrm{em}) ; \mathrm{V}$, transverse section of outer portion of the pericarp showing epicarp (epi), hypoderm (hy), mesocarp (mes) and stone cells (st); VI, transverse section of endocarp and seed showing large isodiametric stone cells (End), narrow longitudinally extended fibers (1f), testa (S), hyaline layer or nucellus (N) and endosperm (E).-After Winton. 

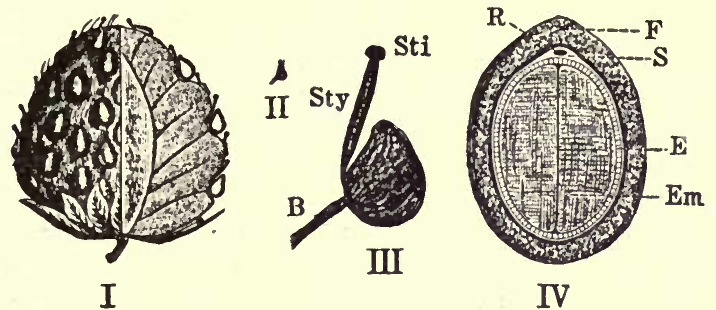

IV
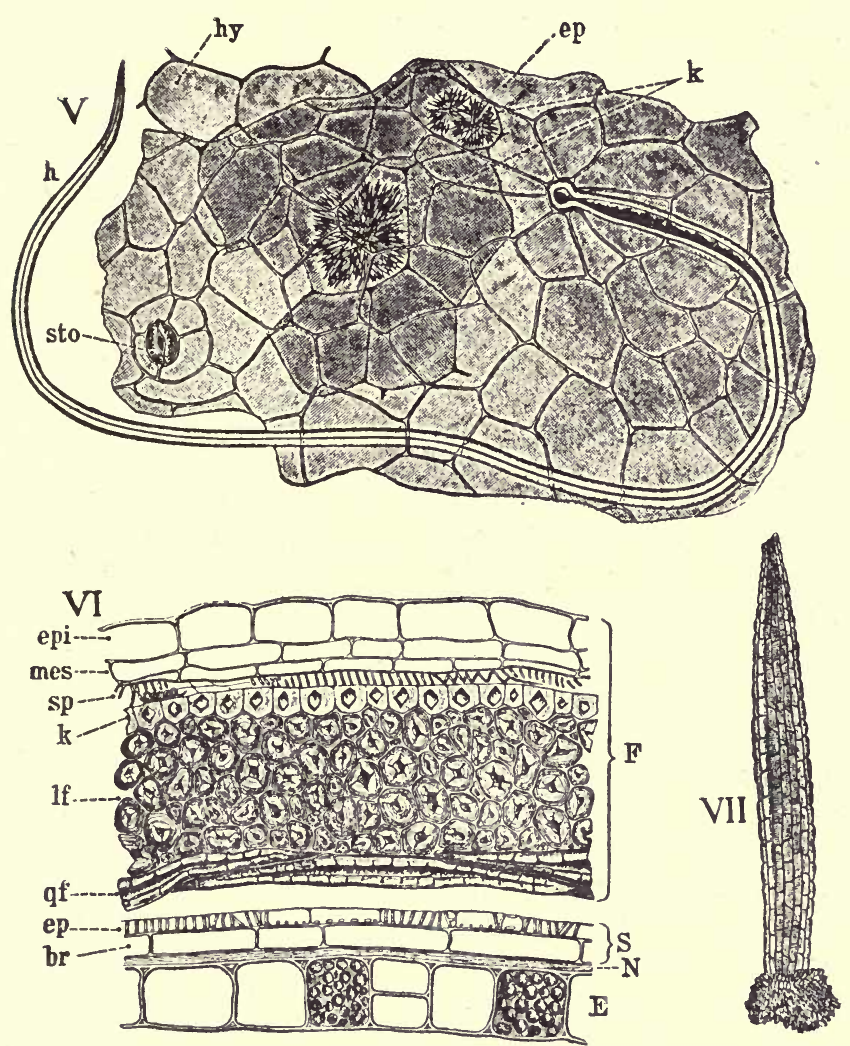

FIG. 242. Cultivated strawberry (Fragaria chiloënsis): I, Compound fruit showing fleshy receptacle bearing the achenes in deep depressions; II, isolated achene; III, achene showing style (Sty), stigma (Sti) and connecting bundle (B); IV, achene in transverse section, pericarp $(\mathrm{F})$, testa $(\mathrm{S})$, raphe $(\mathrm{R})$, endosperm $(\mathrm{E})$ and embryo $(\mathrm{Em}) ; \mathrm{V}$, receptacle in surface view showing epidermis (Ep), with hair (h), and stoma (sto); hypoderm (hy) and sphero-crystals (k); VI, achene in transverse section showing pericarp (F) consisting of epicarp (epi), mesocarp (mes), spiral vessels (sp), crystal layer (k), outer endocarp (1f) with longitudinally extended fibers and inner endocarp (qf) with transversely extended fibers; testa ( $\mathrm{S}$ ) consisting of epidermis (ep) with reticulated cells, elongated brown cells (br), hyaline iayer or nucellus (N) and endosperm (E) consisting of a single layer of aleurone grains; VII, style and stigma.-After Winton. 


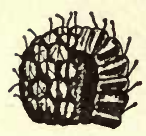

I
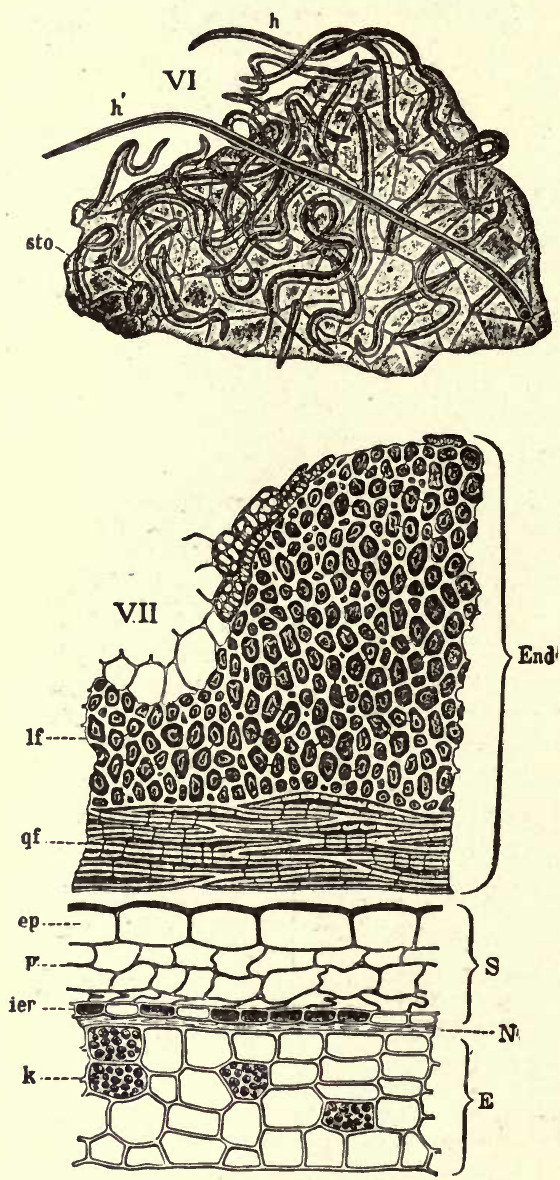
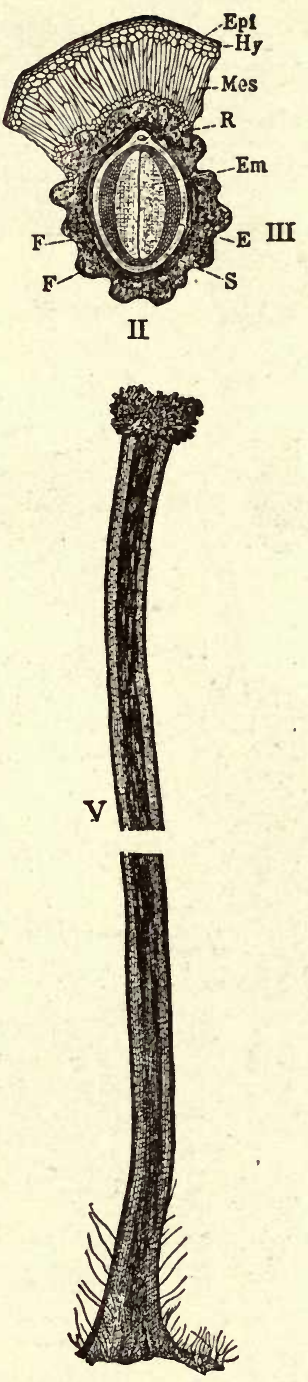

FIG. 243. Red Raspberry (Rubus Idaus): I, Compound fruit consisting of a number of drupelets crowded together on the top and sides of the receptacle; II, transverse section of a drupelet showing epicarp (epi), hypoderm ( $\mathrm{Hy}$ ), mesocarp (Mes), outer endocarp (F), inner endocarp $\left(\mathrm{F}^{\prime}\right)$, testa $(\mathrm{S})$, raphe $(\mathrm{R})$, endosperm $(\mathrm{E})$, and embryo $(\mathrm{Em})$; III, stone including endocarp and seed; IV, stone somewhat magnified; V, style and stigma; VI, surface section of epicarp showing straight hair $\left(h^{\prime}\right)$, sinuous hairs $(h)$ and stoma (sto); VII, transverse section of endocarp and seed showing endocarp (End) consisting of longitudinally extended fibers (If), transversely extended fibers (qf), testa (S) consisting of epidermis (ep), parenchyma or nutritive layer (p), and inner epidermis (iep); hyaline layer or nucellus $(N)$, endosperm $(E)$ with aleurone grains $(k)$.-After Winton. 
A Caryopsis, or Grain, is an indehiscent, non-fleshy fruit possessing a thin pericarp, which is closely adherent to the thin seed-coats, as in wheat, corn, and other Graminex (Figs. $255,256)$.

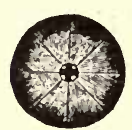

I

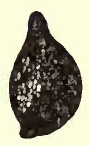

III

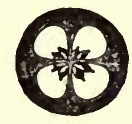

II
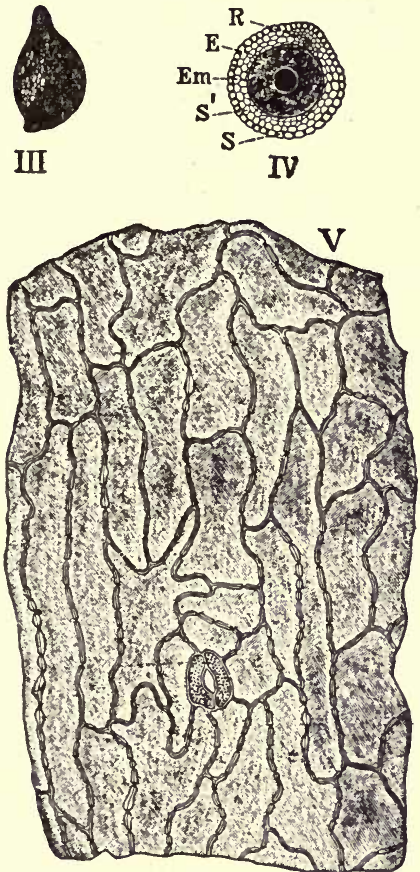
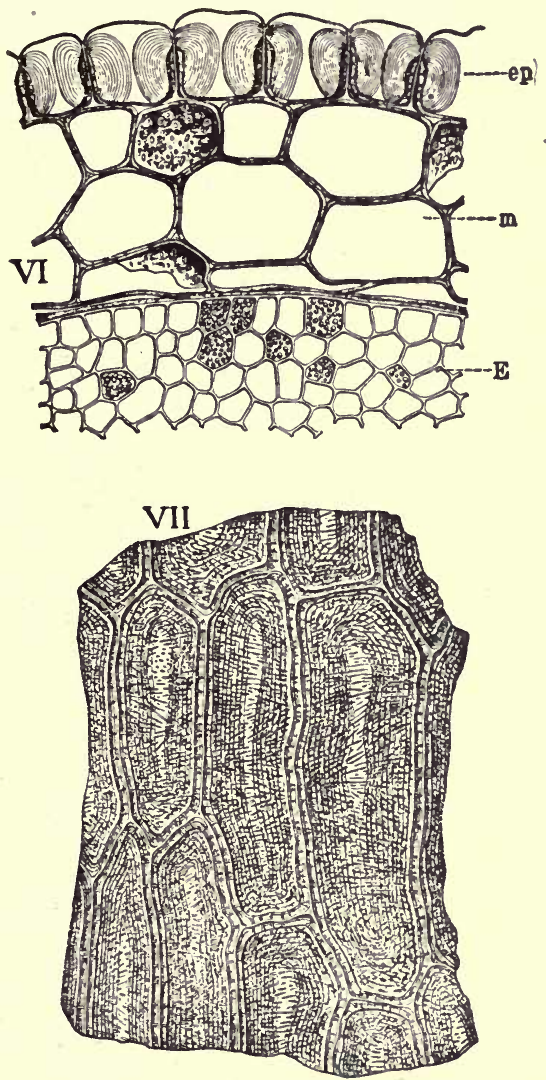

FIG. 244. The fruit of the cultivated cranberry (Vaccinium macrocarpon): I, berry seen from above; II, transverse section of berry; III, single seed;. IV, transverse section of seed showing outer epidermis $(\mathrm{S})$, inner layer of seed-coat $\left(\mathrm{S}^{\prime}\right)$, raphe $(\mathrm{R})$, endosperm $(\mathrm{E})$ and embryo $(\mathrm{Em})$; V, surface section of endocarp with stoma; VI, seed in transverse section showing epidermis of seed-coat (ep) with sclerenchymatized and mucilaginous layers, inner layer of seed-coat (m) and endosperm (E); VII, surface section of epidermis of seedcoat.-After Winton.

A Cremocarp is a dry, indehiscent fruit which consists of two inferior achenes, known as MERICARPS; these are separated from each other by means of a stalk known as a CARPOPHORE. 

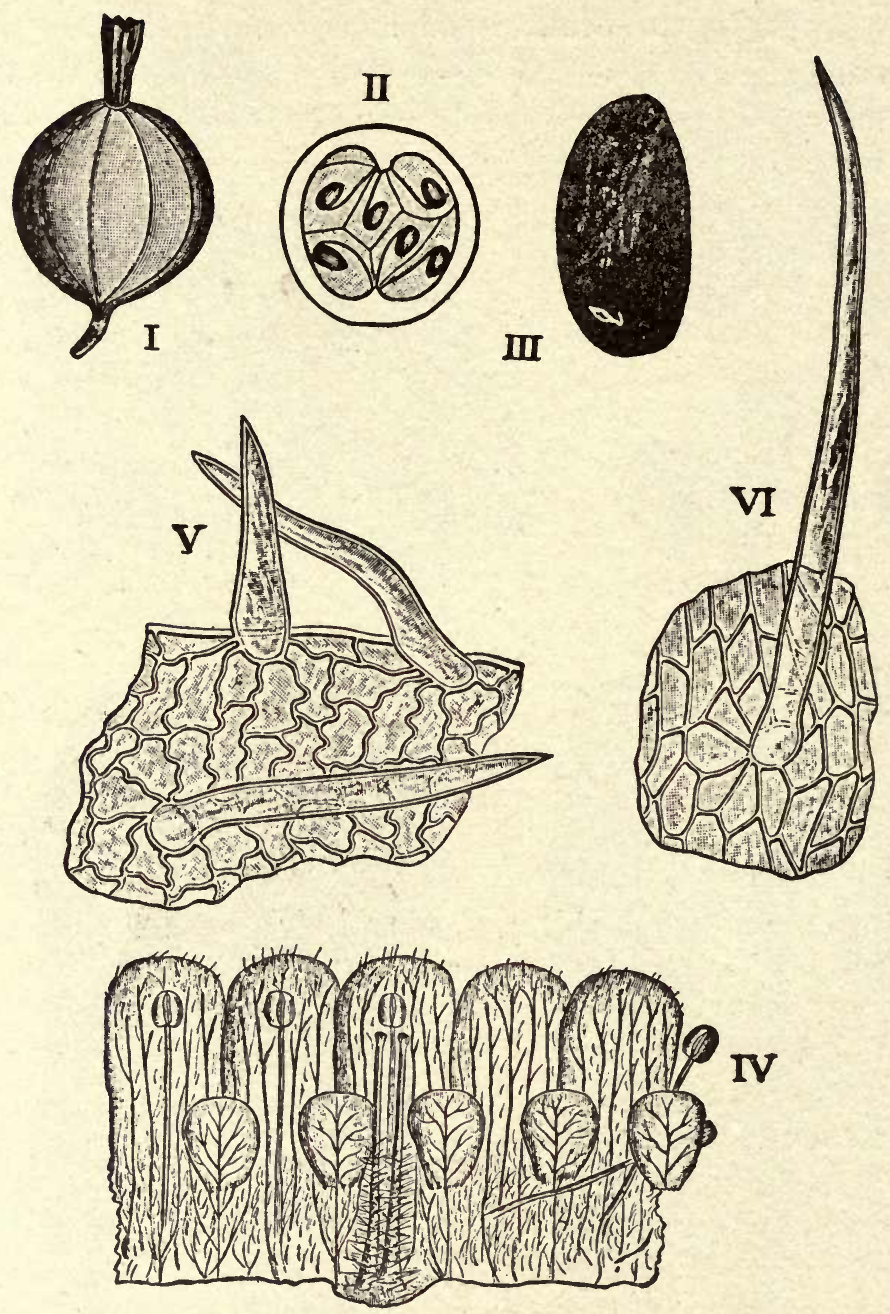

FIG. 245. The fruit of the American Gooseberry (Ribes oxyacanthoides): I, whole fruit; II, transverse section of fruit with seeds; III, seeds deprived of gelatinous coat; IV, floral parts; V, surface section of epidermis from margin of calyx with hairs; VI, surface section of epidermis from throat of calyx with hair.-After Winton.

This fruit is characteristic of the Umbelliferc. (Consult Volume II for pharmacognosy of medicinal umbelliferous fruits.)

A Drupe is a fleshy, indehiscent fruit with a more or less succulent and well-developed sarcocarp and an indurated endo- 
carp. Drupes are superior when they are free from the torus, as in prune; inferior when the torus forms a part of the fruit, as in pimenta. Drupes are also spoken of as "dry" when the sarcocarp is less succulent, as in Rhus glabra, or when they are collected unripe, as in pepper, pimenta, and cubeb. The fruits of the raspberry and blackberry consist of a collection of little drupes, the whole being known as an ETARIO. In the blackberry the drupelets cohere with the fleshy torus, while in the raspberry the drupelets cohere with one another, forming a cap which is separable from the cone-shaped torus. If the drupelets of the raspberry are examined closely it will be found (Fig. 243) that each has from 4 to 7 facets on the sides formed by the pressure of the adjoining drupelets. These facets are usually slightly convex or concave. Tschierske states that the individuals cling together, first, because of the closely-fitting adjoining facets, the slightly convex surface of one fitting into a corresponding concave surface of another; and, second, because of the interlocking of the sinuous hairs.

A Follicle is a dry, dehiscent fruit which consists of one or more separate carpels, the dehiscence being usually along the ventral suture (Fig. 239); in Delphinium the carpels are single; in aconite from 3 to 5 , and in star-anise (Illicium) from 7 to 8 ; in magnolia the carpels are numerous, forming a kind of succulent cone, and dehisce along the dorsal suture.

A Galbalus is a berry-like fruit, formed by the coalescence of fleshy, open scales, as in juniper (Fig. 75).

Hesperidium.-The fleshy, indehiscent, superior fruit of citrus, as lemon and orange, is known as a hesperidium. The pericarp is more or less coriaceous, and from the inner walls secretion hairs develop, which contain sugar and an acid cell-sap, these constituting the fleshy portion in which the seeds are embedded.

A Legume is an elongated, monocarpellary, usually dry, dehiscent fruit, in which dehiscence takes place along both sutures, the carpel thus dividing into two halves, or valves, as in the garden pea (Pisum) and other members of the Leguminosæ (Fig. 23I). In some cases legumes are jointed or articulated and indehiscent, breaking up at maturity into a number of parts which are dispersed in much the same manner as samara-fruits, as in Meibomia. 
Legumes may be not only indehiscent but fleshy, as in Cassia fistula.

A Nut is an achene-like fruit, the pericarp of which is more or less indurated. Nuts are sometimes subtended (as in acorns) or enclosed (as in chestnuts) by a kind of involucre, forming what is technically known as a cupule; and a fruit consisting of a nut and cupule is known as a GLans. The achene-like fruit of the Labiatæ is spoken of as a Nutlet.

A Pepo is an inferior berry, in which the placentas have become developed into succulent layers, as in the watermelon, cucumber, and colocynth.

A Pod is a general term used to designate all dry, dehiscent, apocarpous, or syncarpous fruits, as capsules, follicles, and legumes.

A Pome is an indehiscent, half-inferior, fleshy, syncarpous fruit, as in the apple. The carpels constitute the core, and the fleshy part is developed from the torus.

A Samara is a winged, achene-like fruit. The winged appendage may be at the apex, as in white ash, or around the edge, as in elm. Two samaras may be united into one fruit, which is called a "double samara," as in maple.

A Silique is a narrow, elongated, 2-valved capsule which is separated by the formation of a false dissepiment into 2 locules, as in the Cruciferæ (Fig. 236, $A$ ).

A Sorosis is a fleshy fruit resulting from the aggregation of the carpels of several flowers, as in mulberry (Fig. 236, $H$ ) and pineapple.

A Strobile or cone is a scaly fruit, at the base of each scale of which there is either a seed, as in the Pinacea, or an achene-like body, as in hop.

A Syconium consists of a succulent hollow torus, which encloses a number of achene-like bodies, as in the fig (Ficus).

An Utricle is an inferior achene with a thin and loose pericarp, as in Chenopodium.

Classification of Fruits.-More or less artificial classifications of fruits have been made. They may be grouped either according to structure or according to their manner of protection or dispersal, the following classification being based on the structure: 


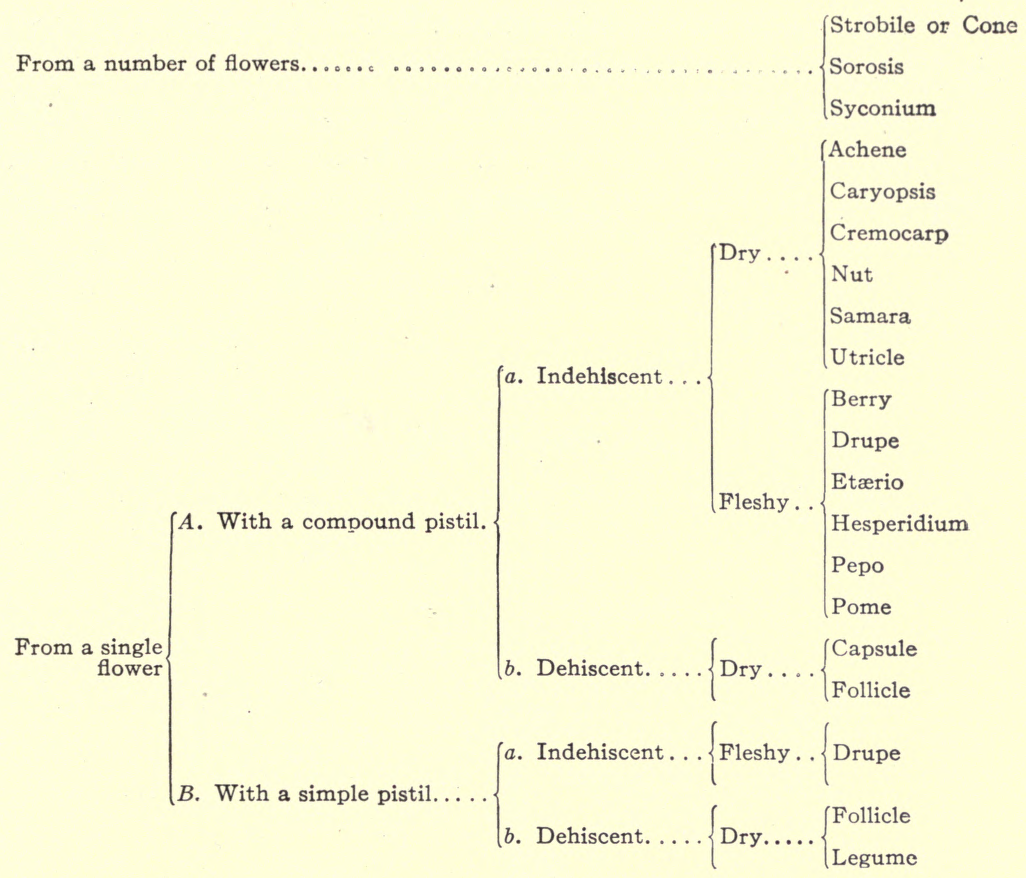

THE INNER STRUCTURE OF FRUITS.

The inner structure of fruits is quite variable and it is difficult to treat of this in a general way. In the simplest fruits there are three distinct layers, as in the capsule of cardamom, in which there is an outer epidermis of isodiametric or polygonal cells, an inner epidermis of more or less obliterated and elongated cells, between which is a thin-walled parenchyma traversed by a number of fibrovascular bundles.

In some cases the other epidermis contains numerous stomata, as in poppy capsules, or is developed into hairs and other outgrowths or appendages, as in anise, arnica, sumach (Fig. I48), and raspberry (Fig. 243).

The inner epidermis may also contain stomata, as in the poppy, or be developed into hairs, as in vanilla and orange, or more or less obliterated, as in achene-like fruits, or modified to sclerenchymatous elements, as in drupes. 
The middle layer, which is composed of parenchyma, may contain protoplasm, starch, sugars, calcium oxalate, coloring principles, alkaloids and other principles, and it may also have oil-secretion cells, as in cubeb and pepper, or oil-secretion canals, as in orange (Fig. I2I) and the fruits of the Umbelliferæ, in the latter
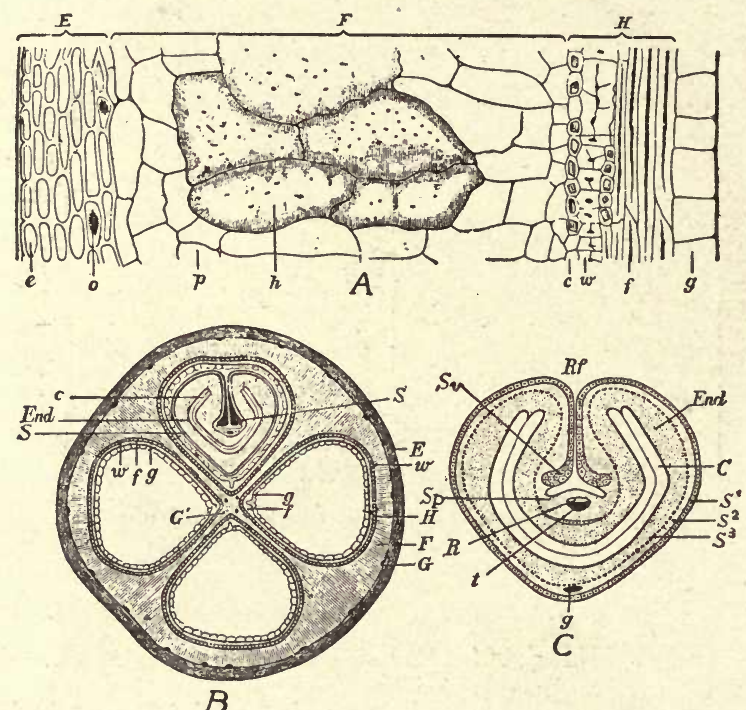

FIG. 246. Rhamnus cathartica. A, cross-section through wall of the pericarp. E, epicarp; F, sarcocarp; H, endocarp; e, epidermis; o, calcium oxalate in cells of hypodermis; $p$ parenchyma; $h$, secretion cells containing a substance which is insoluble in alcohol or chloral solutions, soluble in solutions of potassium hydroxide, and colored reddish brown or greenish with ferric chloride solutions; $c$, calcium oxalate cells of endocarp; $w$, sclerotic cells; $f$, stereome cells. B, cross-section of entire fruit, showing one seed; E, F. H, g, f, w, as in A; $\mathrm{S}$, seed-coat; $\mathrm{S}^{1}$, outer wall of seed-coat; End, endosperm; c, cotyledons; $g$, vascular bundle. $\mathrm{C}$, cross-section of a seed: $\mathrm{S}^{1}, \mathrm{~S}^{2}, \mathrm{~S}^{3}$, different layers of the seed-coat: $\mathrm{R}$, vascular bundle of raphe; $t$, position of vessels of mestome strand; $g$, mestome strand; $R f$, cleft in which raphe is situated; End, endosperm; C cotyledons; Sv, cells with thick walls;Sp, parenchymatous cells.-After Meyer.

of which they are known as vittæ (see Volume II); milk vessels sometimes occur, as in poppy; a collenchymatous layer is sometimes developed beneath the epidermis, as in capsicum; in some cases sclerenchymatous cells may be present, as in pimenta and cubeb (Fig. I35); and in still other instances the entire pericarp may be made up of stone cells, as in the nuts. 
VI. THE OUTER MORPHOLOGY OF THE SEED.

The seed may be defined as the fertilized and developed ovule. The seeds of different fruits vary in number as well as in size

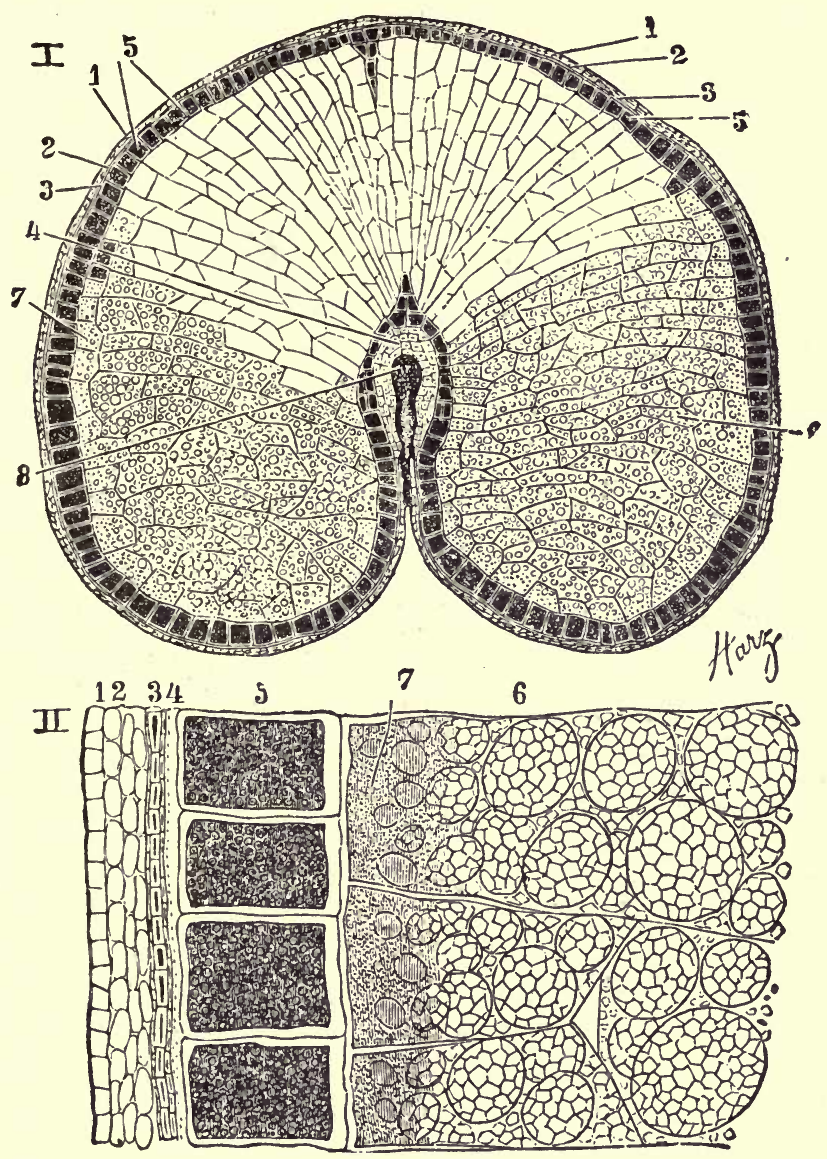

FIG. 247. Transverse (I) and longitudinal (II) sections of oat grain (Avena sativa): I, 2, cells of pericarp; 3, seed-coat; 4, remains of perisperm; 5, cells containing gluten; 7 , endosperm cells containing considerable proteins and some starch; 6 , endosperm cells with polygonal compound starch grains; 8, fibrovascular bundle of the pericarp.-After Harz.

and shape. In form they correspond to the ovules; in size they vary from about $0.600 \mathrm{~mm}$., as in lobelia, belladonna, etc., to to or I 5 centimeters in diameter, as in the cocoanut palm. Seldom are 
all of the ovules of the pistil fertilized, hence the number of seeds is usually less than the number of ovules.

Structure of Seed.-After the fertilization of the egg-cell certain changes take place in the embryo-sac: At one end the developing embryo is attached to the wall by a short stalk or suspensor (Fig. 82); the nuclei, lying in a mass of cytoplasm
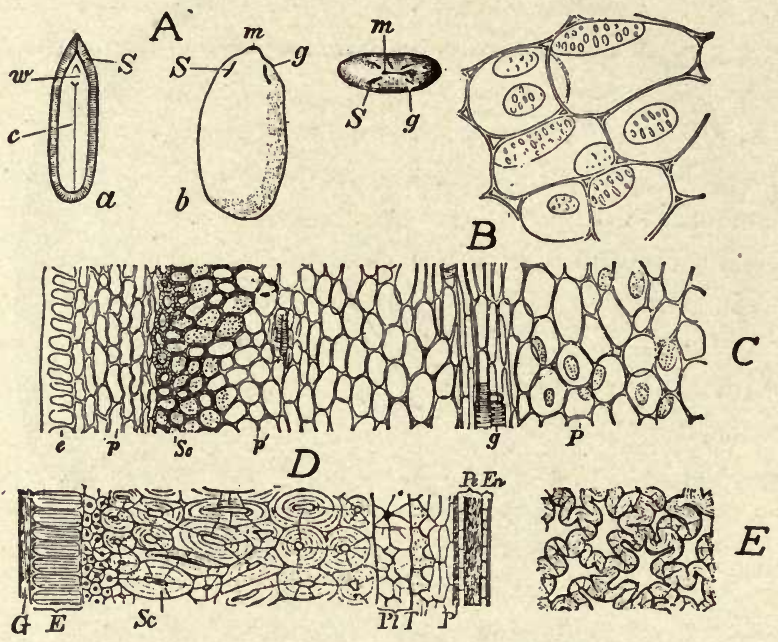

FIG. 248. Citrullus Colocynthis. A, seed: $\mathrm{a}$, in longitudinal section, and b, surface view; $\mathrm{S}$, deep clefts or fissures; $\mathrm{m}$, micropyle; $\mathrm{g}$, hilum; $\mathrm{w}$, radicle; $\mathrm{c}$, cotyledons. $\mathrm{B}$, parenchyma cells of ripe fruit showing simple pores, the walls are colored blue with chlor-zinc-iodide. C, lengitudinal section of wall of pericarp of ripe fruit showing e, epidermis; $p$, parenchyma; Sc, sclerotic cells which gradually pass into a thick-walled parenchyma consisting of small cells $\left(\mathrm{p}^{\prime}\right) ; \mathrm{g}$, spiral vessels; $\mathrm{P}$, isodiametric, porous parenchyma cells, containing air and of which the fruit for the most part consists. D, cross-section of seed-coat showing, G, an outer layer which is more or less easily separable from the rest of the seed and the walls of which are somewhat mucilaginous; E, epidermis of palisade-like cells; Sc, sclerotic cells; Pl, a layer of tabular cells with undulate walls; T, a layer of small somewhat branching cells, the walls of which are not strongly thickened and either porous or reticulate; $P$, several layers of parenchyma and the collapsed epidermis; Pe, perisperm; En, endosperm. E, tangential section of tabular sclerotic cells of seed-coat shown in P1 in Fig. D.-After Meyer.

around the wall of the embryo-sac, divide and re-divide; the large vacuole in the center becomes filled with a watery or milky fluid, and later the nuclei, with portions of the cytoplasm, may be enclosed by a cellulose wall and become permanent cells, in which the embryo is embedded. Likewise in the nucellus, changes are also taking place; the cells are found to be dividing, and storing starch, oil, aleurone, and other food materials, like the cells of the 
embryo-sac. The cells in which these materials are stored are known as reserve cells, and in the nucellus they constitute the PERISPERM, while those formed in the embryo-sac make up the ENDOSPERM. Usually the endosperm of seeds is prominently developed, while the perisperm occurs as a thin layer; in some seeds, however, the endosperm and perisperm are both well developed. In some instances the embryo may not fill the embryo-sac, as in cocoanut, and sometimes, as in the almond, both of the reserve layers are consumed in the development of the embryo, when the seed is said to be without endosperm (Fig. 248).

The perisperm and endosperm are sometimes spoken of together as the albumen of the seed, but as the cells comprised in these layers contain not only protoplasmic contents and aleurone grains, but starches, oils, and other substances, the term is misleading. On this basis, seeds containing either endosperm or perisperm, or both, have been designated as albuminous, but on account of these layers containing larger proportions of other. substances than proteins it would be better to speak of them as RESERVE LAYERS (Figs. 247, 250).

While these changes in the nucellus and embryo-sac have been going on there have been equally great changes in the coats of the ovules, which develop into the seed-coats. In the seed the two coats are generally readily distinguishable. The inner, as in Ricinus, Pepo, etc., is thin, light in color, of a delicate structure, and is known as the TEGMEN ; the outer is more or less thickened, of a darker color and firmer in structure, and is known as the TESTA. In some instances the perisperm, or both perisperm and endosperm, may be reduced to a thin layer when it is considered to form a part of the seed-coat, as in mustard. In other cases the two coats are so closely united that they are not easily distinguished, as in stramonium.

The terms used in describing the kinds of ovules (atropous, anatropous, campylotropous, etc.) are retained in the description of the seeds; and in describing the different parts of the seed some of the terms which were applied to the ovule are also retained, as chalaza and raphe; the seed when ripe usually becomes detached from its stalk, and the resulting scar is called the Hilum; that part of the seed corresponding to the foramen of the ovule is more or less closed and is known as the micropyle; the embryo 
develops in such a way that the tip of the young root always points in the direction of the micropyle.

In the fully developed embryo three distinct parts may be differentiated (Fig. I6I) : ( I) The cotyledons; (2) the part below the cotyledons, known as the HYPOCOTYL, the apical portion of which constitutes the young root or RADICLE; (3) the part above

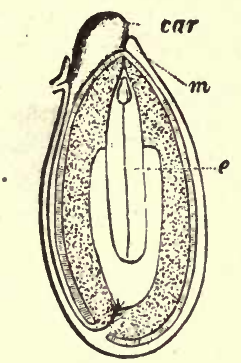

A

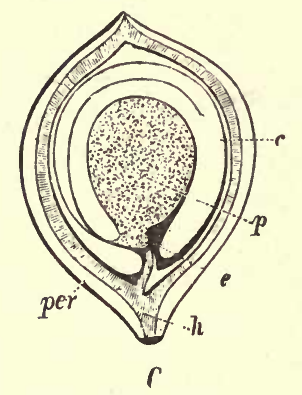

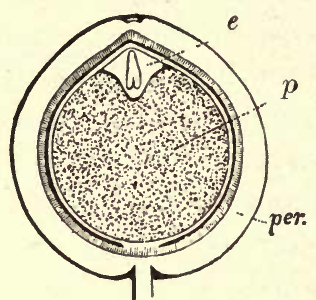

$B$

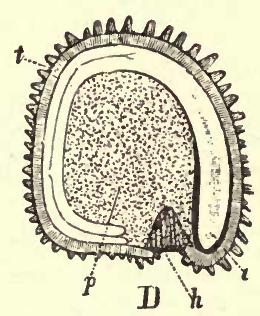

I $/ h$

FIG. 249. Forms of embryo and distribution of endosperm in various seeds and fruits. A, Ricinus seed: car, caruncle; $m$, micropyle; e, embryo. B, superior drupe of Piper: per, pericarp; e, endosperm; p, perisperm. C, spinach fruit and D, corn cockle seed (Agrostemma Githago): per, pericarp; t, seed-coat; h, hilum; p, perisperm; e, endosperm c, curved embryo.-A, C, D, after Harz; B, after Baillon.

the cotyledons, known as the EPICOTYL, the apex of which consists of a more or less developed bud spoken of as the PLUMULE.

The position of the embryo (Figs. 249, 250) in the seed varies somewhat: in most seeds it lies in the center, as in strophanthus and linum; it may, however, be excentral, as in colchicum and nutmeg. The cotyledons are usually situated above the hypocotyl, but in the Cruciferæ; either their edges lie against the hypocotyl, as in the mustards, when they are said to be ACCUMBENT or con- 
duplicate, or they lie so that the back of one is against the hypocotyl, as in Lepidium, which position is known as INCUMBENT.

Externally, the seed-coats vary considerably; they may be nearly smooth, as in ricinus; finely pitted, as in the mustards; prominently reticulate, as in staphisagria; hairy, as in cotton, strophanthus, and apocynum (Fig. 25I) ; or winged, as in the seeds of the catalpa. There are also a number of other appendages, these having received special names: the wart-like development at the micropyle or hilum of some seeds, as in castor-bean and violet, is known as the CARUNCLE; in the case of sanguinaria, a wing-like development extends along the raphe, and this is known as the STROPHIOLE; in some cases the appendage may completely envelop the seed, when it is termed an ARILlus; when such an envelope arises at or near the micropyle of the seed, as the mace in nutmeg, it is known as a "false arillus," or ARILLODE.

Seed Dispersal.-Seeds and fruits are distributed in various ways, and so are often found growing in localities far from their native habitat. In some instances seeds are adapted for distribution by the wind, being winged, as in Paulownia, Catalpa, anc' Bignonia, or plumed and awned, as in Strophanthus Kombe, Asclepias, and Apocynum (Fig. 25I). As examples of fruits having special parts which aid in their distribution may be mentioned the achene of Taraxacum which is provided with a pappus (Fig. 227), the bladder-like pericarp of Chenopodium, and the winged fruit or samara of maple. The hooked or barbed appendages on some fruits serve to attach them to animals, and thus they may be widely distributed, as in the burdock and Spanish needles (Bidens bipinnata). In still other cases fruits may be carried long distances by water currents, or even by ocean currents, as those of the Double-cocoanut palm (Lodoïcea sechellarum), which while native of the Seychelles Islands is now found on many of the islands in the Pacific and Indian Oceans. It may also be mentioned in this connection that a number of fruits, as the garden balsam, castor-oil plant, violets (pansy, etc.), Wistaria, etc., are elastically dehiscent and discharge the seeds with considerable force.

THE INNER STRUCTURE OF THE SEED.

The SEED-COAT usually consists of from two to six layers of cells: (I) an outer layer or so-called epidermis, (2) a layer of 
sclerenchymatous cells or stone cells, (3) a pigment layer, $(4,5)$ one or two rows of parenchymatous cells, (6) a row of more or less obliterated parenchyma cells.

The EPIDERMAL CELLS vary considerably in different species
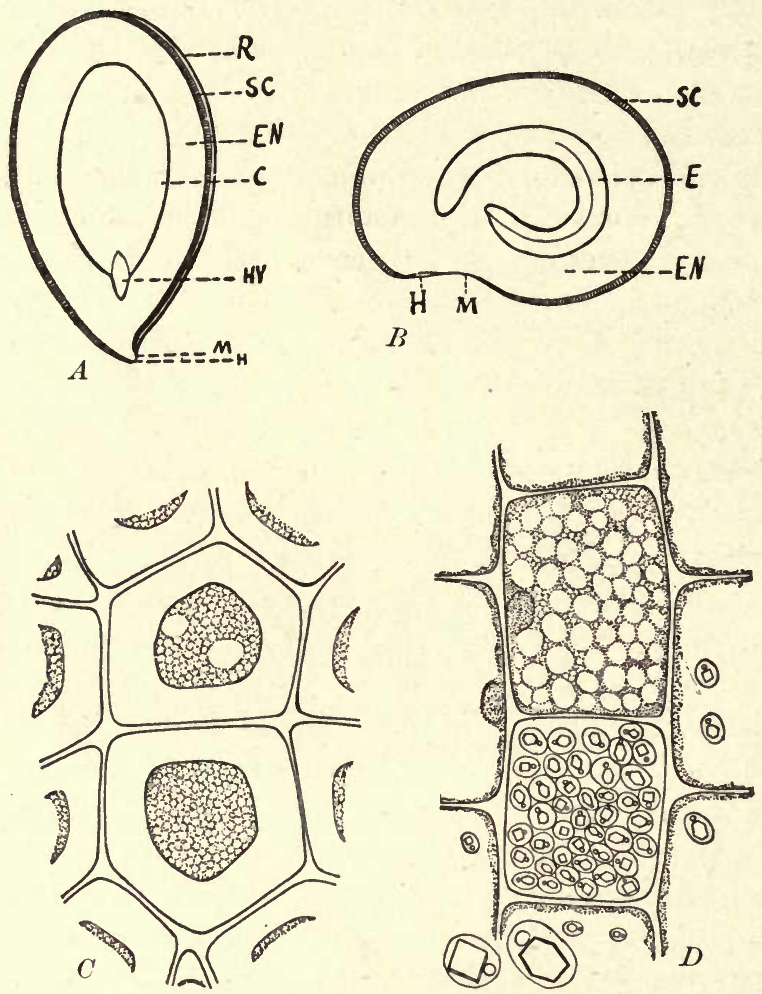

FIG. 250. A.-Longitudinal section through anatropous seed of linum: R, raphe; SC, seed-coat; M, hilum; H, micropyle; EN, endosperm; C, cotyledon; HY, hypocotyl. B.Longitudinal section through stramonium seed: $\mathrm{SC}$, seed-coat; $\mathrm{H}$, micropyle; $\mathrm{M}$, hilum; EN, endosperm; E, curved embryo. C.-Transverse section through endosperm of nux vomica showing thick-walled parenchyma, the cells containing oil and protoplasm. D. Transverse section through endosperm of seed of Ricinus communis, one cell filled with aleurone grains, each with a crystalloid and globoid, and another in which the aleurone grains have been dissolved, the cytoplasm and nucleus remaining.

both as regards the form of the cells and the composition of the walls (Fig. I36). The cells may be more or less isodiametric in cross-section, as in cardamom (see Vol. II) ; elliptical, as in almond (Fig. I36, D) ; palisade-like, as in Abrus precatorius, or more or 
less irregular, as in Delphinium. While the outer and side walls are usually thickened, in hyoscyamus (Fig. 25I), it is the inner and side walls which are thickened, the outer wall remaining thin. The outer wall may be in part modified to mucilage, as in mustard and flaxseed (Fig. II9) ; or to non-glandular hairs which consist either of cellulose, as in cotton (Fig. I39), or lignocellulose, as in nux vomica (Fig. II9).

The PERISPERM and ENDOSPERM (Fig. 249) consist chiefly of parenchyma cells, which contain, besides protoplasm, starch, as
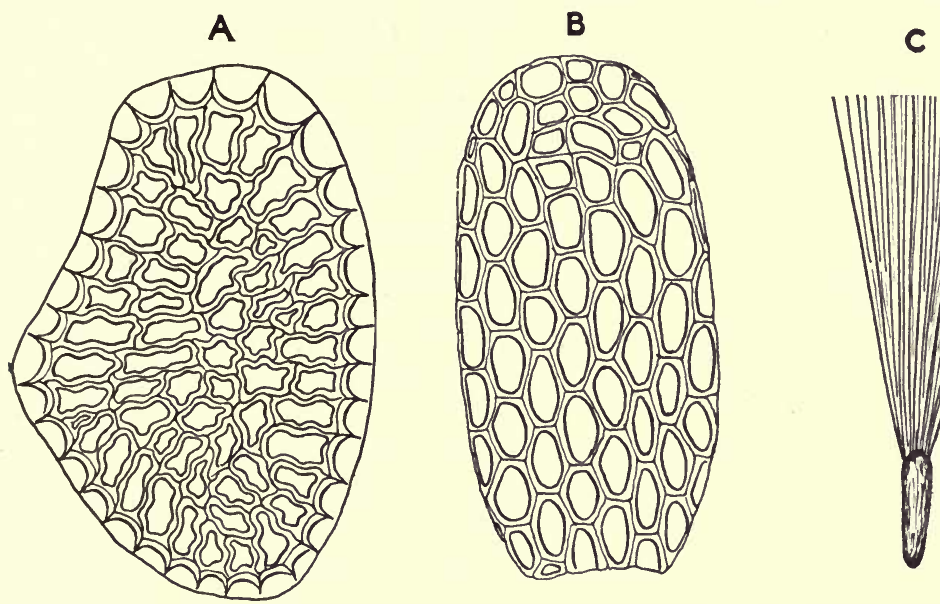

FIG. 25I. Seeds: A, of Hyoscyamus muticus with epidermal cells having wavy, thickened walls, those at the edge are seen in section and showing that the outer wall is not thickened. B, of Lobelia inflata showing reticulate seed-coat composed of uniformly thickened and strongly lignified cells. C, of A pocynum cannabinum with numerous long I-celled hyaline hairs.

in physostigma; oil, as in flaxseed and cottonseed; aleurone grains, as in ricinus (Fig. 250); glucosides, as in almond; alkaloids, as in stramonium. The walls are usually thin, but may in some instances be considerably thickened, as in coffee, colchicum, and nux vomica (Fig. I35).

The embryo consists chiefly of parenchyma cells with a few fibrovascular bundles: the cotyledons may be thin and leaf-like, as in ricinus and nux vomica, or thick and fleshy, as in almond and cola, or partly developed, as in strophanthus; the hypocotyl is usually small, but in the Umbelliferæ it is as large as the cotyledons. 


\section{CHAPTER IV.}

\section{BOTANICAL NOMENCLATURE.}

LET the student consult the various manuals on Botany and even some of the larger authoritative works and he will be immediately impressed that there is more or less confusion concerning the names of certain plants. For instance, in looking up the botanical origin of the False Solomon's Seal, one author will give it as Smilacina racemosa, while another writer will use the name of Vagnera racemosa. Again, if the student desires to use the correct family name he will be confused both as to the correct spelling of the name as well as the name of the family itself, the Grass Family being given as Graminaceæ or Gramineæ; the Leguminosæ may be divided into the Mimosaceæ, Cæsalpinaceæ and Papilionaceæ. At first thought it might seem that this inconsistency is peculiar to botanical science, but as a matter of fact we find the same difficulties in the language of other sciences. This confusion is due to the fact that up until now there has not been an international agreement or even one of a national character regarding the rules to be observed in botanical nomenclature.

"For many decades it has been almost universally felt that botanical nomenclature should rest in a general way on the principle of priority of publication, or, in other words, that the name of a plant was the first one assigned to it. Nearly all botanists of note have readily assented to this general idea, but great difficulties have arisen regarding the precise limitations which should be imposed upon the principle. Thus, botanists of past generations, including such great leaders as the De Candolles, Bentham, the Hookers, Gray, von Martius, Eichler, Baillon, and others, have followed the principle of priority, yet they have made frequent exceptions based on considerations of taste and convenience as well as practicality."

"With the expansion of the subject the difficulty of agreement on these exceptions has increased, and some recent writers have been disposed at times to criticise rather harshly the earlier botanists for making any exceptions whatever. It should be noticed, 
however, that even the more strenuous of these reformers themselves admit certain exceptions. They have found it necessary, for instance, to fix initial dates, and to rule out certain names as too vague in their definition or too uncouth in their form to be accepted."

"Ideas as to the best mode of establishing rules or reaching a general agreement regarding the necessary exceptions to the bald principle of priority have differed widely and given rise to lively controversy. To some it has seemed best to advise an ideal system and then, without much reference to the wishes or convenience of their colleagues, to apply it in local publication. To the vast majority, however, it has been clear that the subject was a broad one, involving much mutual sacrifice before the now divergent usages at different botanical centers could be brought into harmony. The question is also an international one, requiring the botanists of different nations to attain a common agreement. For some years there was a growing desire for an international meeting of representative botanists who should give the matter of nomenclature careful consideration and come, if possible, to some agreement on the fundamental rules to be followed. This feeling took definite form in the year 1900, when preliminary sessions of such a gathering were held in connection with the Paris Congress of Botanists. At this meeting a bureau was formed for the organization of an International Botanical Congress to be held at Vienna in June, I905." This congress convened in Vienna and was attended by between five and six hundred botanists, representing the leading botanical institutions of the world. They framed international rules which should be used in the botanical nomenclature of vascular plants, and a complete list of these will be found in Rhodora, the journal of the New England Botanical Club, for March, 1907. A few of the general considerations and leading principles will be mentioned, however, in order that the student may have some understanding of the subject.

According to the Vienna Congress, the prescriptions, which should govern the system of botanical nomenclature, are divided into ( I) principles, (2) rules, and (3) recommendations.

Among the principles that should be adhered to is that scientific 
names are to be in Latin for all groups. When taken from another language, a Latin termination is given them, except in cases sanctioned by custom. If translated into a modern language, it is desirable that they should preserve as great a resemblance as possible to the original Latin names.

Among the rules to be followed in designating the nature and the subordination of the several groups, the following were adopted:

Every individual plant belongs to a species (species), every species to a genus (genus), every genus to a family (familia), every family to an order (ordo), every order to a class (classis), every class to a division (divisio). In a number of species varieties and forms are also distinguished. In some cultivated species there are unlimited modifications. The crossing of one species with another species gives rise to a hybrid.

Regarding the point of nomenclature and limitation of principle of priority, it was agreed at the congress that botanical nomenclature should begin with the Species Plantarum of Linnæus, ed. I ( 1753 ), for all groups of vascular plants. It was further agreed to associate genera, the names of which appear in this work, with descriptions given of them by him in his Genera Plantarum, ed. 5 ( I754). However, to avoid disadvantageous changes in the nomenclature of genera by the strict application of the rules of nomenclature, and especially of the principle of priority in starting from 1753 , the rules provide a list of names which must be retained in all cases. These names are by preference those which have come into general use in the fifty years following their publication, or which have been used in monographs and important floristic works up to the year 1890 .

Among the recommendations, the following suggestions were made in regard to the nomenclature of divisions, classes, families, genera, and species:

I. Names of divisions and subdivisions, of classes and subclasses are taken from one of their characters. They are expressed by words of Greek or Latin origin, some similarity of form and termination being given to those that designate groups of the same nature, as Angiospermæ, Gymnospermæ; Monocotyledoneæ, Dicotyledoneæ; Coniferæ; Pteridophyta. Among Cryptogams old 
family names such as Fungi, Lichenes, Algæ, may be used for names of groups above the rank of family.

2. Orders are designated preferably by the name of one of their principal families, with the ending -ales, e.g., Polygonales from Polygonaceæ. Suborders are designated in a similar manner, with the ending -ineæ, e.g., Malvineæ from Malvaceæ. But other terminations may be retained for these names, provided that they do not lead to confusion or error.

3. The names of families are designated by the name of one of their genera or ancient generic names with the ending -acex, e.g., Rosaceæ from Rosa, etc. The following names, owing to long usage, are an exception to the rule: Palmæ, Graminex, Cruciferæ, Leguminosæ, Guttiferæ, Umbelliferæ, Labiatæ, and Compositæ.

4. The names of genera should be substantives (or adjectives used as substantives) in the singular number and written with a capital letter, which may be compared with our own family names. These names may be taken from any source whatever and may even be composed in an absolutely arbitrary manner, as Rosa, Convolvulus, Liquidambar, Impatiens, and Manihot.

5. The names of all species, even those that singly constitute a genus, are designated by the name of the genus to which they belong, followed by a name (or epithet) termed specific, usually of the nature of an adjective (forming a combination of two names, a binomial, or binary name). The specific name should, in general, give some indication of the appearance, the characters, the origin, the history, or the properties of the species. If taken from the name of a person, it usually recalls the name of the one who discovered or described it, or was in some way concerned with it. Specific names begin with a small letter, except those which are taken from names of persons or those which are taken from generic names.

The student should endeavor to fix in mind the general principles concerning botanical nomenclature and should devote special attention to the generic and specific names and the rules which govern their formation. In addition he should familiarize himself with the meaning of the names, as this will enable him to memorize and spell them correctly. The following is a partial list of some of the principal generic and specific names, giving as far as possible the origin of the names and their significance: 
Abelmoschus. Muskmallow. From Arab. Abu-l-misk, father of musi; producing musk.

Abies. Fir. The classical Latin name.

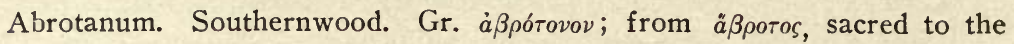
gods, immortal; probably in allusion to the odor.

Abrus. Indian licorice. From Gr. á $\beta$ pós, graceful; in allusion to the flowers.

Absinthium. Wormwood. The ancient Greek name.

Abyssinicus-a-um. Pertaining to Abyssinia.

Acacia. The ancient Greek name of an Egyptian species. From $\dot{a} \kappa \dot{\eta}$, a point; referring to the thorns.

Acer. Maple. The classical Latin name.

Acer, acris, acre. Sharp, pungent. From root $a k$, to be sharp.

Achillea. Yarrow, Milfoil. Named for the Greek warrior Achilles, who is said to have discovered the virtues of the plant.

Aconitum. Monkshood, Wolfsbane. The ancient Greek name.

Acorus. Sweet flag. The ancient classical name.

Actæa. Baneberry, Cohosh. Ancient Greek name of the elder.

Acuminatus-a-um. Acuminate, tapering. Lat. acumino, to make pointed. Acutifolius-a-um. Having sharp-pointed leaves. Lat. acutus, sharp, + folium, a leaf.

Adiantum. Maidenhair. The ancient name. From Gr. a priv., + dıaiv $\omega$, to wet, hence unwetted, incapable of being wet.

Adonis. Pheasant's eye. A plant fabled to have sprung from the blood of the beautiful Adonis.

Advena. Yellow pond lily. From Lat. advena, strange, foreign. (Of doubtful application.)

Aégle. Bengal quince. Name of a nymph in Greek mythology. Perhaps from $a i \gamma \lambda \eta$, brightness, splendor.

Esculus. Horsechestnut. The Latin name of an oak or some other mastbearing tree.

Estivalis-e. Pertaining to the summer. The classical Latin word is astivalis.

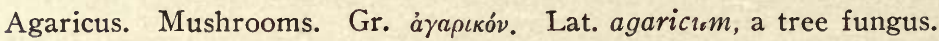

Agave. American aloe. Gr. áyáv $\eta$ noble, illustrious. Appropriately applied to Agave americana, the century plant.

Agrimonia. Probably a corruption from argemone. According to others, it is derived from Gr. áyós, field, $+\mu o ́ v o s$, alone.

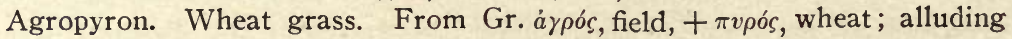
to the fact that it grows wild in wheat fields.

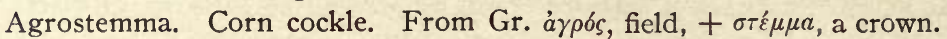

Ailanthus. Tree of heaven. Said to be from aylanto, the name of the tree in the Moluccas, in allusion to its height.

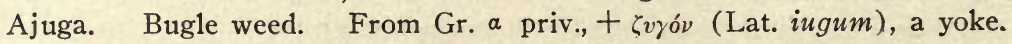
From the fact that the lower lip of the corolla has a single, conspicuous middle lobe. 
Albizzia. Name derived from the Albizzi, a noble family of Italy, one of whom is said to have introduced this genus into European cultivation.

Albus-a-um. White.

Alchemilla. Lady's mantle. From the Arabic name alkemelyeh; in reference to the silky pubescence of some species.

Aletris. Star grass, Colic-root. From Gr. à $\lambda_{\varepsilon} \rho i s$, a female slave who grinds; in allusion to the mealy appearance of the blossoms.

Algæ. Plural of alga, sea-weed; probably a shortened form of alliga, from $a d$, to, + ligo, to bind.

Allium. Onion, Garlic. The ancient Latin name for garlic; perhaps connected with Lat. oleo, to emit a smell.

Alnus. Alder. The ancient Latin name.

Aloe. The ancient Greek name.

Alsine. Chickweed. Greek name of a plant.

Alstonia. Dita. Named for Dr. Charles Alston, botanist, of Edinburgh ( I683-I;60).

Althæa. Marshmallow. Hollyhock. The classical name. From Gr. àtaiv , to heal, cure; in allusion to the medicinal properties of the plant.

Alyssum. Greek name of a plant believed to check hydrophobia; from a priv., $+\lambda i \sigma \sigma a$, raging madness. Or a plant used to check hiccup; from $a$ priv., $+\lambda \hat{v} \zeta \omega$, to have the hiccup.

Amaranthus. Amaranth. From Gr.ápápavtos, unfading; because the bracts are dry and persistent.

Amarus-a-um. Bitter.

Amaryllis. Belladonna lily. Greek name of a shepherdess.

Ambrosia. Ragweed. The Greek and Latin name of several plants, as well as of the food of the immortals.

Ambrosioides. Gr. $\dot{a} \mu \beta \rho \sigma \sigma i a+o-\varepsilon \iota \delta \eta s$, like, resembling ambrosia.

Americanus-a-um. Belonging to America.

Ammania. Named for Paul Ammann, a German botanist prior to Linnæus.

Ammoniacum. A resinous gum which exudes from a tree that grew near the temple of Jupiter Ammon. The Greek name.

Amomum. Cardamom. Greek name of an Indian spice plant.

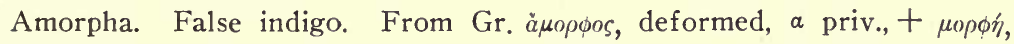
form; in allusion to the absence of four of the petals.

Amygdalus. Almond. Peach. Ancient Greek name. From á $\mu$ vi $\sigma \sigma \omega$, to tear, rend; in allusion to the furrows on the endocarp.

Amylum. Starch. The Greek name. From a priv., $+\mu v^{\prime} \eta \eta$, a mill; referring to its fineness, which makes it unnecessary for it to be ground.

Anacardium. Cashew. From Gr. àvá, similar to, $+\kappa a \rho \delta i a$, heart. The fruit of the plant is thought to resemble the heart of a bird.

Anacyclus. Pellitory. An abbreviation for ananthocyclus. From Gr. a priv., $+\dot{a} \nu H_{0}$, flower, $+\kappa^{k} i k \lambda o s$, circle; in allusion to the pistillate or infertile rays. Meaning rather vague. 
Anagallis. Pimpernel. The ancient Greek name. Probably from á $\alpha$, again, $+\dot{a} \gamma a \dot{\lambda} \lambda \omega$, to delight in.

Anamirta. An Indian name synonymous with Menispermum.

Ananas. Pineapple. Sp. ananas, from the native American name.

Andira. Vouacapoua. From the vernacular Brazilian name.

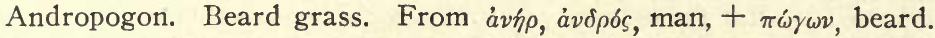

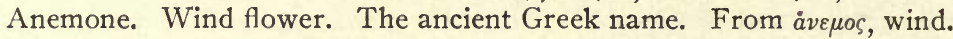

Anethum. Dill. The ancient Greek name. Probably related to àvıoov, anise.

Angelica. From Gr. ă $\gamma \gamma \varepsilon \lambda o s$, messenger, angel; in allusion to its cordial and medicinal properties.

Angostura. Name of a city in Venezuela, whence angustura bark is imported.

Angustifolius-a-um. Having narrow leaves. From Lat. angustus, narrow, + folium, leaf.

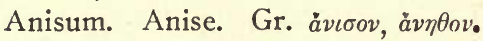

Annuus-a-um. Of one year's duration. Lat. annus, a year.

Anogra. Evening primrose. Name formed by transposition of letters of Onagra, another name for this plant.

Anthelminticus-a-um. Worm-destroying. From Gr. àvi, against, + $\varepsilon \lambda \mu \iota v s$, worm.

Anthemis. The ancient Greek name of chamomile.

Anthoxanthum. Sweet vernal grass. From Gr. àvfos, flower, $+\xi$ avfós, yellow.

Aparine. Cleaverwort. The ancient Greek name of a plant.

Apocynum. Dogbane. Indian Hemp. The classical name. From á $\pi \dot{b}$, from, $+\kappa v \omega v$, dog.

Aquaticus-a-um. Growing in or by the water.

Aquifolium. Holly-leaved barberry. Ancient Latin name for the holly tree or the scarlet holm.

Arabicus-a-um. Pertaining to Arabia.

Aralia. Derivation of name unknown.

Araroba. From East Indian name $a r(a r) o b a$ as applied to the bark.

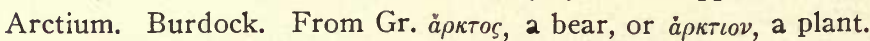

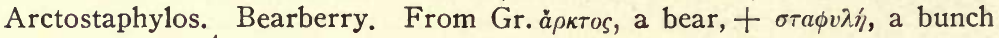
of grapes.

Areca. Betel-nut. Sp. and Port. areca, from East Indian vernacular name. Argemone. Prickly poppy. The ancient Greek name for poppy. According to others, from à $\rho \gamma \varepsilon \mu \alpha$, a disease of the eye, for which the juice of a plant so called by the Greeks was a supposed remedy.

Argithamnia. From Gr. à $\rho \gamma v \rho o s$, silver, $+\theta a$ avos, bush; from the hoariness of the original species.

Arisæma. Indian turnip. From Gr. à $\rho \iota$, a kind of arum, + aỉ $\mu$, blood; from the spotted leaves of some species.

Aristolochia. Birthwort. From Gr. à once thought to ease labor. 
Arnica. From Gr. àsvakis, sheepskin, Lat. arnacis, a coat of sheepskin; in reference to the hairy stem and leaves; or, according to others, from G: $\mathrm{G}_{\text {: }} \pi \alpha \rho \mu \iota \kappa o ́ s$, Lat. ptarmicus, causing to sneeze.

Aromaticus-a-um. Aromatic, fragrant.

Artemisia. Wormwood, ancient Greek name of an herb. From the queen Artemisia, wife of Mausolus.

Artemisiæfolius-a-um. Having leaves resembling those of Artemisia.

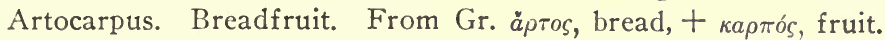

Arum. Also Aron. The ancient Greek name ăoov.

Arundinaceus-a-um. Reed-like. From Lat. arundo, a reed.

Arvensis-e. Cultivated. From Lat. arva, an arable field.

Asagræa. From Asa Gray, the eminent American botanist.

Asarum. Hazelwort, Wild ginger. The ancient Greek name.

Asclepias. Milkweed, Silkweed. Named in honor of Esculapius, the Latin tutelary god of medicine.

Asimina. North American papaw. The Northern Algonkin corruption of rassimina, in allusion to the shape of the fruit.

Asparagus. From the ancient Greek name áorápayos, asparagus.

Asperula. Woodruff weed. From Lat. asper, rough; in allusion to some scabrous species.

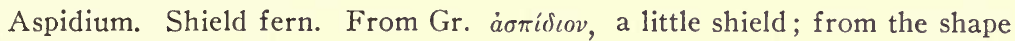
of the indusium.

Aspidosperma. From Gr. á $\sigma \pi i c$, a shield, $+\sigma \pi \varepsilon \rho \mu a$, seed; from the shape of the seed.

Asplenium. Spleenwort. From Gr. a priv., $+\sigma \pi \lambda i v$, the spleen; because of its supposed remedial properties.

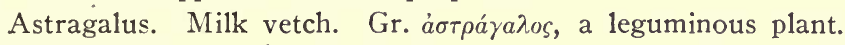

Athamanticus-a-um. Of Athamas, a mountain in Thessaly; with reference to the habitat of the plant.

Atriplex. The ancient Latin name for orach; a corruption of the Greek

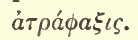

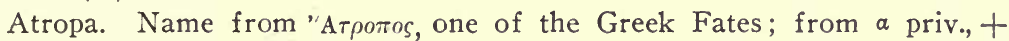
$\tau \rho \circ \pi \dot{\eta}$, a turn; hence unchangeable, inflexible.

Atropurpureus-a-um. From Lat. ater, dark, + purpureus, purple; dark purple.

Aurantium. Orange. From Lat. aurum, gold, referring to the color of the fruit.

Australis-e. Southern. Lat. auster, the South wind.

Autumnalis-e. In the autumn; referring to the time of blooming.

Avena. Oats. The classical Latin name.

Baccharis. Groundsel tree. The classical name of a shrub dedicated to Bacchus.

Baccifer-a-um. Producing berries. Lat. bacca, a berry, + fero, to bear.

Ballota. Fetid horehound. The ancient Greek name. 
Balsamifer-a-um. Producing balsam. Lat. balsamum, balsam, + fero, to bear.

Balsamum-ea. The classical name of the several trees yielding a balsam; also in allusion to the balsamic oleo-resins obtained from the trees.

Baptisia. False indigo. From Gr. $\beta a \pi \tau i \zeta \omega$, to dye.

Barbarea. Winter cress. Anciently called the Herb of St. Barbara.

Barosma. Buchu. From Gr. $\beta a \rho v ́ s$, heavy, $+\dot{\delta} \sigma \mu \dot{\eta}$, odor; in reference to its strong smell.

Belladonna. Ital. bella, beautiful, +donna, lady. It is said that Italian ladies used the berries as a cosmetic and to dilate the pupil of the eye, thus giving themselves a striking appearance.

Benedictus-a-um. Blessed, consecrated. Past participle of Lat. benedico, to bless.

Benzoin. Wild allspice, Fever bush. Named from its odor, which resembles that of benzoinum.

Benzoinum. A resinous substance from Styrax Benzoin, a tree of Sumatra, Java. French benjoin, from Arabic luban-jawi, incense of Java.

Berberis. Barberry. Name derived from berberys, the Arabic name of the fruit.

Beta. Beet. The ancient Latin name.

Betonica. Betony. The ancient Latin name (betonica, vettonica) of wood betony.

Betula. Birch. The ancient Latin name.

Betulinus-a-um. Pertaining to birch; alluding to the fact that the leaves resemble birch leaves.

Bidens. Bur marigold. From Lat. bidens, two-toothed.

Biennis-e. Of two years' duration. Lat. bis, twice, t annus, year.

Biflorus-a-um. Bearing two flowers, biflorate.

Bignonia. Named for the Abbé Jean'Paul Bignon, court-librarian at Paris and friend of Tournefort.

Bistorta. Adderswort. From bis, twice, + tortus (past participle of torqueo), twisted.

Boehmeria. False nettle. Named after G. R. Boehmer, German botanist and professor at Wittenberg in the eighteenth century.

Botrychium. Moonwort. From Gr. $\beta 6 \tau \rho v s$, a bunch of grapes; from the appearance of the fructification.

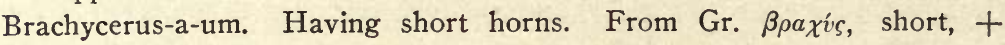
ќ́pas, a horn.

Brasiliensis-e. Belonging to Brazil.

Brassica. Mustard. Turnip. The ancient Latin name for cabbage.

Brauneria. Purple cone-flower. Named for Jacob Brauner, German botanist of the eighteenth century.

Bryonia. Bryony. The ancient Greek name. From $\beta \rho$ ów, to swell, grow luxuriantly.

Bursa. Capsella. Bursa is a late Latin word meaning purse. 
Bursa-pastoris. Shepherd's purse.

Butneria. Spice bush.

Buxus. Boxwood. The ancient Latin name. Gr. $\pi \dot{\xi} \xi o s$.

Cacao. Span. from Mex. kakahuatl; native name of the tree Theobroma Cacao.

Cactus. The ancient Greek name of some thorny plant.

Cæsalpinia. Sappan. Named for Andreas Cæsalpinus, Italian botanist, who died in 1603 .

Cajuputi. Name of Malayan origin. From kayu, tree, + putih, white; in reference to the appearance of the branches.

Calamus. Reed, cane. The classical word. So named because its scape is reed-like.

Calendula. Marigold. Lat. calenda, calends, the first day of the month; so called because it flowers every month.

Californicus-a-um. Pertaining to California.

Calisaya. A name given to the bark of a tree of Peru by Spaniards and Indians.

Calla. Water arum. Linnæus derived calla from Gr. кá $\lambda \lambda a \iota a$, a cock's wattles, but compare Lat. calla, calsa, name of an unknown plant, and Greek $\kappa a \lambda o ́ s$, beautiful.

Calluna. Heather. From Gr. $\kappa a \lambda \lambda v \nu \omega$, to brush or sweep, brooms being made from the twigs.

Calophyllum. Tacamahac. From Gr. $\kappa a \lambda o s$, beautiful, $+\phi \dot{v} \lambda \lambda o v$, a leaf.

Caltha. Marsh marigold. An ancient Latin name for the common marigold.

Calumba. From kalumb, its native name in Mozambique.

Cambogia. From Cambodia, a French protectorate in Farther India.

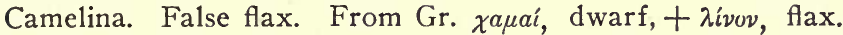

Campechianus-a-um. Belonging to Campeachy.

Campestris-e. Growing in uncultivated fields.

Camphora. Gr. кaфovpá, from Arab. kafur, camphor.

Camptosorus. Walking leaf. From Gr. $\kappa a \mu \pi \tau \delta \varsigma$, flexible, $+\sigma \omega \rho \delta s$, sorus, fruit dot.

Canadensis-e. Of or belonging to Canada.

Cannabinus-a-um. Pertaining to cannabis.

Cannabis. Hemp. The ancient Greek name.

Caoutchouc. Native South American name for the milky sap of several plants. Also called India rubber.

Capillaceus-a-um. Hairy, very slender, like a hair. From Lat. capillus, hair. Capillus-Veneris. Maidenhair. The Latin for hair of Venus.

Capsella. Shepherd's purse. Diminutive of capsa, a box.

Capsicum. Red pepper. From Lat. capsa, a box; alluding to the shape of the fruit. Or from Gr. $\kappa a ́ \pi \tau \omega$, to bite, from its hot, pungent properties. Cardamomum. The ancient classical name for the spice cardamom.

Carex. Sedge. The ancient Latin name. 
Carica. Papaw. The Latin name for dried fig, from Caria, in Asia Minor.

$\left.\begin{array}{l}\text { Carolinensis-e. } \\ \text { Carolinianus-a-um. }\end{array}\right\}$ Belonging to Carolina.

Carota. Carrot. The classical Latin word.

Carpinus. Hornbeam. The ancient Latin name.

Carum. Caraway. Gr. אápov, Lat. careum. Probably from Caria, in Asia Minor.

Carvi or Carui. Probably an assimilated Latin genitive, as in Carui semina.

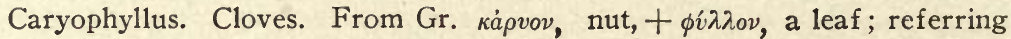
to the appearance of the flower buds.

Cascara Sagrada. Span. Cascara, bark, and sagrada, sacred; holy bark.

Cascarilla. The bark of a Peruvian tree. Diminutive of cascara.

Cassia. Senna. An ancient Greek plant name kafia, probably from the Hebrew getsiah, gatsa, to cut, peel off.

Castanea. The chestnut tree. The ancient Latin name, from a town in Thessaly.

Catalpa. Indian bean. The aboriginal name.

Cataria. Catnip. From late Latin catus, a cat.

Catechu. East Indian name of extract from the acacia tree, applied natively to all astringent extracts.

Cathartocarpus. Cleansing, purgative. From Gr. каяартєко́, cleansing, + $\kappa a \rho \pi \delta s$, fruit.

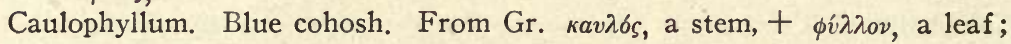
a stem-leaf.

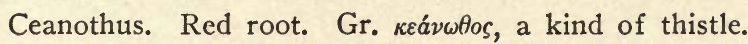

Cedron. Cedron seed. From Gr. $\kappa \varepsilon ́ \delta \rho o v$, the fruit of the cedar.

Celastrus. Staff tree. The ancient Greek name of an evergreen tree.

Centaurea. Star thistle. Ancient Greek name of a plant. The plant of the Centaurs.

Centifolius-a-um. Having a hundred leaves or petals. From Lat. centum, hundred, + folium, a leaf.

Cephaëlis. Ipecacuanha. From Gr. $к \varepsilon \phi a \lambda i$, head, $+\varepsilon i \lambda \omega$, to collect, roll up. The flowers are collected into a capitulum.

Cephalanthus. Buttonbush. From Gr. кєфaìn, head, + à $\nu 0$, , flower. Flowers aggregated in spherical peduncled heads.

Ceratonia. St. John's bread. Greek name for the carrob or locust tree. From $\kappa \varepsilon \rho a s$, a horn; alluding to the horn-shaped pods.

Cerealis-e. Pertaining to grain or agriculture. From Ceres, the Latin goddess of agriculture.

Cetraria. Iceland moss. From Lat. catra, a shield; in reference to the shield-shaped apothecia.

Chamænerion. Willow-herb. From Gr. $\chi a \mu a i$, on the ground, + vnp rose-laurel.

Chamomilla. Earth apple. From Gr. $\chi \alpha \mu a i$, on the earth, $+\mu \bar{\eta} \lambda o v$, an apple. From the apple-like odor of the flowers. 
Chekan. The Chilian name of Eugenia Chekan.

Chelidonium. Celandine. From Gr. $\chi \varepsilon \lambda \iota \delta \omega v$, a swallow, the flowers appearing at the same time as the swallows.

Chelone. Turtlehead. Snakehead. From Gr. $\chi \varepsilon \lambda \dot{\omega} \omega \eta$, a tortoise, the corolla being shaped like the head of a reptile.

Chenopodium. Goosefoot. Pigweed. The ancient Greek name. From $\chi \dot{\eta} v$, goose, $+\pi$ oís, foot.

Chimaphila. Pipsissewa. Bitter wintergreen. Love-in-winter. From Gr. $\chi \varepsilon \tilde{\imath} \mu a$, winter, $+\phi i \lambda \dot{\varepsilon} \omega$, to love; in allusion to the several popular names.

Chionanthus. Fringe-tree. From Gr. $\chi \iota \iota v$, snow, + àv00s, flower; in reference to the snow-white clusters of the flowers.

Chirata or Chirayita. From the Hindoo name chiraita.

Chondrodendron. From Gr. $\chi \delta$ bo $\rho \circ \varsigma$, ‘ granule $+\delta \varepsilon v \delta \rho o v$, a tree; alluding to the warty protuberances on the bark.

Chondrus. Sea moss. From Gr. $\chi \delta$ bo $\rho o s$, cartilage; in reference to the cartilaginous fronds.

Chrysanthemum. Gold-flower. The ancient Greek name.

Chrysarobinum. From Gr. $\chi \rho v \sigma \sigma \sigma$, gold, + araroba, a foreign name of Goa powder.

Chrysophyllum. Star apple. From Gr. $\chi \rho v \sigma o ́ s$, gold, $+\phi \dot{v} \lambda \lambda \lambda_{o v}$, leaf.

Chrysosplenium. Golden saxifrage. From Gr. $\chi \rho v \sigma 6 s$, gold, $+\sigma \pi \lambda \dot{\eta} v$, the spleen. From its reputed medicinal properties.

Cichorium. Gr. ki $x o \rho a$, 'Succory, Chicory.

Cicuta. Water hemlock. The ancient Latin name of the hemlock.

Cimicifuga. Bugbane. From Lat. cimex, a bug, + fugo, to drive away. Cinchona. Named for the countess of Chinchon, who brought the remedy to Europe, when she returned with her husband, viceroy of Peru, in I640.

Cinereus-a-um. Ash-colored. From Lat. cinis, ashes.

Cinnamomum. Cinnamon. The classical name.

Circæa. Enchanter's nightshade. Named after the enchantress Circe.

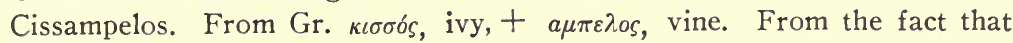
it climbs like the ivy.

Citrullus. Melon. From Lat. citrus, the citron tree.

Citrus. Citron, Orange. The Latin name for the citron tree.

Clava-Herculis. Club of Hercules; from the appearance of the cone-like cork-wings.

Clavatus-a-um. Club-like. From clava, a club.

Claviceps. Ergot. From Lat. clava, a club, + caput, head; alluding to the shape of the mycelium or sclerotium.

Clematis. Virgin's bower. Greek name of a creeping plant with long, lithe branches. Probably clematis or periwinkle.

Clinopodium. Field thyme. Calamint. From Gr. $\kappa \lambda i v \eta$, a bed, + rov́s, foot.

Clove. From Lat. clavus, a nail; in allusion to the shape of the dried fruit. 
Cnicus. Blessed thistle. Latin name of the safflower, from the Gr. $\kappa \nu \tilde{\eta} о \varsigma$.

Coca. Span. from native name of tree.

Cocculus. Diminutive of coccus, a berry.

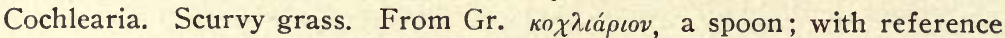
to the shape of the leaves.

Coffea. Coffee. From Turk. qahveh, Arab. qahuah, name of a beverage. Colchicum. Meadow saffron. From Gr. Kon $\chi^{\prime} \varsigma$, Colchis, an ancient province in Asia Minor, where this plant flourished.

Collinsonia. Horsebalm. Named in honor of Peter Collinson, English botanist of the eighteenth century.

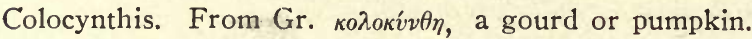

Commelina. Day-flower. Named after the Dutch botanists J. and G. Commelin, who lived in the seventeenth century.

Commiphora. Myrrh. From Gr. кó $\mu \iota$, gum, + фopós, bearing ; in allusion to the exudation.

Communis-e. Common, general.

Conifer-a-um. From Lat. conus, a cone, + fero, to bear, cone-bearing.

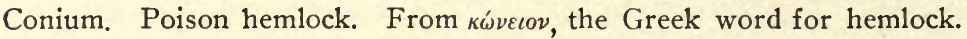

Convallaria. Lily of the valley. From Lat. convallis, a valley.

Convolvulus. Bindweed. The ancient Latin name from convolvo, to entwine.

Copaiba. Span. and Port. from Brazil. cupauba, the native name of the tree and its product.

Coptis. Goldthread. From Gr. $\kappa$ ó $\tau \omega$, to cut; in allusion to the divided leaves.

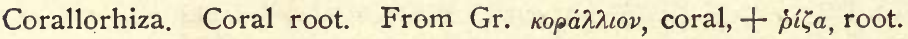

Cordifolius-a-um. Heart-leafed. From Lat. cor, cordis, heart, + folium, leaf.

Coriandrum. Coriander. The ancient Latin name, from Gr. корі́⿻上丨ov.

Coriarious-a-um. Pertaining to leather. Lat. corium, leather.

Cornus. Cornel. Dogwood. From Lat. cornu, a horn; alluding to the hardness of the wood.

Coronilla. Axseed. Diminutive of Lat. corona, a crown; alluding to the inflorescence.

Corylus. Hazelnut, Filbert. The classical name. Probably from Gr. кópvs, a helmet, from the helmet-like involucre.

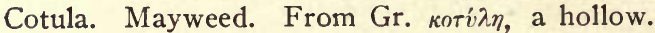

Cratægus. Hawthorn. The Greek name of a kind of flowering thorn. Perhaps derived from крáтos, strength.

Crenulatus-a-um. Notched. From crena, a notch, referring to the leaves. Crispus-a-um. Curled, crisped.

Crocus. Saffron. The ancient Greek name. According to mythology, a youth, Crocus, was changed into this flower.

Crotalaria. Rattle-box. From Gr. кро́талov, a rattle; from the rattling of the loose seeds in the pod. 
Croton. From Gr. $\kappa \rho \circ \tau \omega \dot{\nu}$ or $\kappa \rho \sigma \tau \omega \nu$, a tick, because the seed was thought to resemble a tick. Also applied to the castor-oil seed.

Crucifer-a-um. Cross-bearing. From Lat. crux, cross, + fero, to bear. With reference to the form of the flowers.

Cruciger-a-um. Cross-bearing. From Lat. crux, cross, + gero, to bear. Cubeba. Span. and Port. from Arab. kababat, native name of the plant.

Cucumis. Cucumber Melon. The ancient Latin name.

Cucurbita. Gourd, Squash. The ancient Latin name.

Cuminum. Cumin. The ancient Greek name.

Cunila. Dittany. Ancient Latin name for a plant, a species of orizanum. Cupana. After Father Francis Cupani, Italian monk and botanist; died in 1710 .

Cusparia. Angostura.

Cusso. Abyssinian name of the tree Hagenia Abyssinica.

Cyanus. Blue-bottle. The old Greek word for any dark-blue substance.

Cyminum. Cumin. Same as cuminum.

Cynoglossum. Hound's tongue. The classical name. From kíwv, dog, + $\gamma \bar{i} \omega \sigma \sigma a$, tongue; from the shape and texture of the leaves.

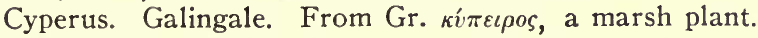

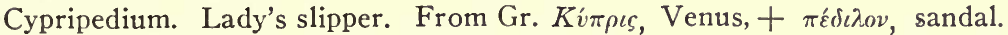

Cytisus. Broom. An ancient classical name for a shrubby kind of clover, perhaps Medicago arborea.

Damascenus-a-um. Pertaining to Damascus.

Daphne. Mezereum. Ancient Greek name of the bay-tree; from the nymph, whom Apollo transformed into a laurel.

Datura. Jimson weed. Thorn apple. Name derived from Sans. dhattura, Arab. tatura, tatula, the native name.

Daucus. Carrot. The ancient Greek name.

Decandrus-a-um. Having ten stamens. From Gr. déka, ten, + ávíp, àvóós, man.

Delphinium. Larkspur. Ancient Greek name, from $\delta \varepsilon \lambda \phi i s ~\left(\delta \varepsilon \lambda \phi^{i} \nu\right)$, dolphin, in allusion to the shape of the flower.

Dentatus-a-um. Dentated, toothed. Lat. dens, tooth.

Desmodium. Tick Trefoil. From Gr. $\delta \varepsilon \sigma \mu o ́ s$, a bond or chain; from the connected joints of the pods.

Dianthus, Pink. Carnation. From Gr. $\Delta \iota \delta \varsigma$, of Jupiter, + àvfos, flower.

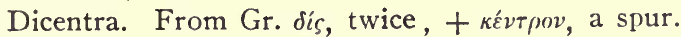

Dictamnus. Dittany. The classical name. From Mt. Dicte, in Crete, on which the plant grew luxuriantly.

Didymus-a-um. Twin, found in pairs. Gr. didvpos, double.

Diervilla. Bush honeysuckle. Named for Dr. N. Dierville, who carried it from Canada to Tournefort.

Digitalis. Foxglove. Lat. digitalis, of or belonging to the finger; alluding to the finger-shaped corollas. 
Dioicus-a-um. Unisexual. The two sexes on different plants. Gr. di-, dis, twice, + oikos, a house.

Dioscorea. Yam. Dedicated to the Greek naturalist, Dioscorides.

Diospyros. Persimmon. From Gr. $\Delta \iota \delta s$, of Jupiter, $+\pi v \rho b s$, grain.

Diphyllus-a-um. Having two leaves. Gr. $\delta t_{-}, \delta i s$, twice, $+\phi \dot{v} \lambda \lambda_{o v}$, a leaf.

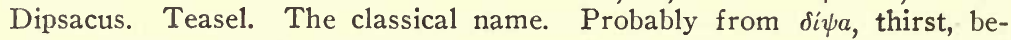
cause the united cup-shaped bases of the leaves of some species hold water.

Dirca. Leatherwood. Moosewood. Name of uncertain origin.

Domesticus-a-um. Domestic, common.

Domingensis-e. Of Santo Domingo.

Dorema. Ammoniac plant. From Gr. $\delta \omega \rho \eta \mu a$, a gift, benefit.

Dorstenia. Contrayerva. Named for T. Dorsten, German botanist, sixteenth century.

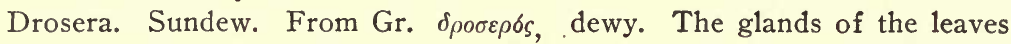
exude drops of a clear glutinous fluid, which glitter like dewdrops.

Dryopteris. Greek name of a fern growing on oaks. From $\delta \rho \tilde{v} s$, oak, + $\pi \tau \varepsilon$ pis, a fern.

Dulcamara. Bittersweet. From Lat. dulcis, sweet, +amarus, bitter.

Dulcis-e. Sweet.

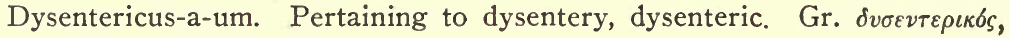
afflicted with dysentery.

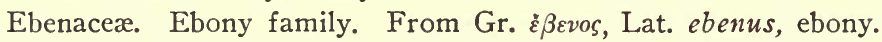

Ecballium. Squirting cucumber. From Gr. $\dot{\varepsilon} \kappa$, out of, $+\beta a ́ \lambda \lambda \omega$, to throw. Elasticus-a-um. Elastic, gummy. Probably formed from Gr.è $\lambda$ av $v \omega$, to drive.

Elaterium. Classic name for a medicine prepared from the juice of the wild cucumber. From Gr. $\dot{\varepsilon} \lambda a v i v \omega$, to drive away.

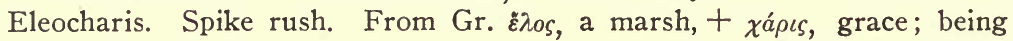
marsh plants.

Elettaria. Cardamom. From elettari, native name of plant in Malabar.

Eleuteria. From Eleuthera, one of the Bahama Islands.

Epigæa. Ground laurel. Trailing arbutus. From Gr. $\dot{\boldsymbol{\varepsilon}} \pi i$, upon, $+\gamma \bar{\eta}$, earth, in reference to its trailing growth.

Equisetaceæ. Horsetail family. Ancient Latin name equisatum (equiseta), the plant horsetail.

Equisetum. Horsetail. Ancient Latin name. Derived from equus, horse, + sata (seta), a bristle.

Erectus-a-um. Upright, elevated, lofty.

Ergota. Ergot. From French ergot, a spur.

Ericaceæ. Heath family. From Gr. غ̇eíkn, heath, heather.

Erigeron. Fleabane. Ancient Greek name of a groundsel, probably Senecio vulgaris. From $\dot{\eta} \rho$, early, $+\gamma^{\prime} \rho \omega \nu$, old man, from the hoary appearance of some vernal species.

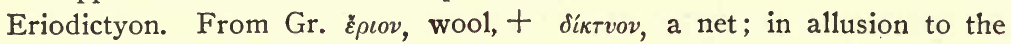
woolly, net-veined leaves. 
Erysimum. Treacle mustard. The Greek name of the hedge mustard; from $\dot{\varepsilon} \rho \dot{v} \omega$, to draw.

Erythroxylun. From Gr. $\dot{\rho} \rho \theta \rho \rho$, red, $+\xi \dot{v} \lambda \omega v$, wood; referring to the color of the trees or shrubs.

Esculentus-a-um. Good to eat, edible, esculent.

Eucalyptus. From Gr. $\varepsilon \dot{v}$, well, $+\kappa a \lambda v \pi \tau o ́ s$, covered; from the conical covering of the buds, which falls off at anthesis.

Eugenia. Clove-tree. Named in honor of Prince Eugene of Savoy.

Euonymus. Spindle tree. Ancient classical name for a shrub. From Gr. $\varepsilon \dot{v}$, well, $+\delta v_{v o \mu}$, name.

Eupatorium. Thoroughwort. Dedicated to Eupator, king of Pontus, who is said to have used one of the species in medicine.

Euphorbia. Spurge. Gr. $\varepsilon \dot{v} \phi o ́ \rho \beta \iota v$, name of an African plant. Named for Euphorbus, physician to king Juba.

Europæus-a-um. Belonging to Europe.

Excelsus-a-um. Lofty, high, surpassing.

Exogonium. From Gr. $\hat{\varepsilon} \xi \omega$, outside, $+\gamma$ ovos, offspring; in allusion to the exserted stamens and pistils.

Fagus. Beech. The ancient Latin name, from Gr. $\varphi$ areiv, to eat; in allusion to the esculent nuts. Compare $\phi \eta \gamma$ ś a kind of oak bearing esculent acorn.

Fagopyrum. Buckwheat. From Lat. fagus, beech, + Gr. $\pi v \rho o ́ s$, wheat; from the resemblance of the grain to the beech-nut.

Farfara. Colt's-foot. Feminine form of farfarus, the ancient Latin name. Farinosus-a-um. Pertaining to meal, mealy; Lat. farina, meal.

Fastigiatus-a-um. High, pointed, tapering; with reference to the shape of the fruit. From Lat. fastigium, the top of a gable, summit.

Fertilis-e. Fruitful, fertile.

Ferula. Asafœtïda. Latin name for the plant fennel-giant. From ferio, to strike.

Ficus. The ancient Latin name for fig.

Filix-mas. Male fern. Lat. Filix, fern. Mas, male. In reference to its asexual fructification.

Fistula. Reed, pipe, cane; from the appearance of the long, slender fruit.

Fœniculum. Fennel. The classical Latin name. Diminutive of fœnum, hay.

Fœtidus-a-um. Fetid, stinking. From Lat. fotor, an offensive smell.

Fragaria. Strawberry. Lat. fraga, strawberries. From fragro, to emit fragrance.

Fragrans. Fragrant, sweet-scented. Pres. partic. of fragro, to emit fragrance.

Frangula. Buckthorn. From Lat. frango, to break; in allusion to the brittle stems.

Frasera. American Calumba. Named for John Fraser, an English botanical collector of the eighteenth century. 
Fraseri. Of Fraser. Latinized genitive.

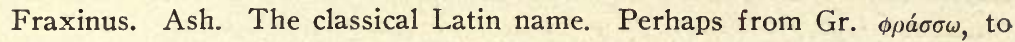
hedge in.

Fulvus-a-um. Yellow, tawny.

Fumaria. Fumitory. From Lat. fumus, smoke. Probably from the nitrous odor of the fresh roots.

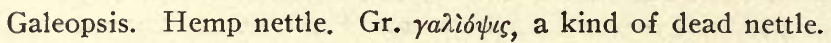

Galium. Bedstraw. Cleavers. Ancient Greek name of a plant. Perhaps from $\gamma$ á $\lambda a$, milk, which is coagulated by some species.

Galla. Nutgall. Ancient Latin word for oak-apple, gall-nut.

Gallicus-a-um. Belonging to Gaul, now France.

Garcinia. Mangosteen. Named for Laurent Garcin, French botanist of the early part of the eighteenth century.

Gardenia. Cape Jasmine. Named after the author, Alexander Garden of South Carolina (I757-I829).

Gaultheria. Aromatic wintergreen. Named for Dr. Gaulthier, of Quebec, a court physician about the middle of the eighteenth century.

Gaylussacia. Huckleberry. Named for the French chemist, Gay-Lussac.

Gelsemium. Yellow Jasmine. From gelsomino, the Italian name of Jasmine.

Genista. Woad-waxen. Whin. From the Celtic gen, a bush.

Gentiana. Gentian. The ancient classical name. From Gentius, king of Illyria, who according to Pliny discovered the medicinal property of the plant.

Geranium. Cranesbill. The Greek name. From yépavos, a crane. The long fruit-bearing beak was thought to resemble the bill of the crane.

Geum. Avens. Latin name of plant, found by Pliny.

Gigartina. Sea moss. From Gr. riyaptov, a grape stone. From the resemblance of the fruit bodies (cystocarps), which appear as elevated tubercles on the frond or thallus.

Githago. Corn-cockle. Provincial Eng. and Welsh Gith.

Glaber-bra-brum. Smooth, hairless; referring to the leaves.

Glandulifer-a-um. Gland-bearing. Lat. glandula, gland, + fero, to bear. Glandulosus-a-um. Full of glands, glandulous.

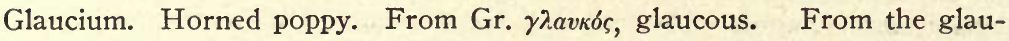
cous foliage.

Globulus. Latin diminutive of globus; a little ball, globular; referring to the button-like form of the fruit.

Glutinosus-a-um. Glutinous, viscous; referring to the resinous leaves and stems. From Lat. gluten, glue.

Glycyrrhiza. Liquorice. From Gr. $y \lambda v \kappa v s$, sweet, $+\dot{\rho} i \zeta \alpha$, root; referring to the taste of the root.

Gnaphalium. Cudweed. Everlasting. Ancient Greek name of a downy

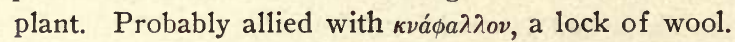

Gossypium. Cotton. From Lat. gossypion, the cotton-tree. 
Gouania. Chew-stick.

Gramineæ. Grass family. From Lat. gramen, grass.

Granatum. Pomegranate. The ancient Latin name.

Gratiola. Hedge hyssop. From Lat. gratia, favor; because of its supposed medicinal virtue.

Graveolens. Strong-smelling. Lat. gravis, strong, + oleo, to emit a smell.

Grindelia. Gum-plant. Tar-weed. Named for Prof. D. H. Grindel, a Russian botanist, who died in 1836 .

Guaiacum. Guaiac. From Span. guayaco, the native Haytian name of the plant.

Guarana. Portuguese name formed from the native Brazilian name.

Gummifer-a-um. Gum-producing. From Lat. gummi, gum, + fero, to bear.

Guttifer-a-um. Gum-exuding. From Lat. gutta, a drop, +fero, to bear.

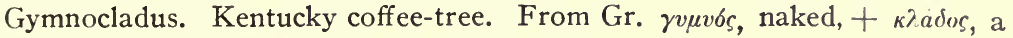
branch, the branches being for long periods destitute of spray.

Gypsophila. From Gr. $\gamma \dot{v} \psi \omega \varsigma$, chalk, gypsum, $+\phi i \lambda \dot{\varepsilon} \omega$, to love.

Habenaria. Fringed orchis. From Latin habena, a thong or rein.

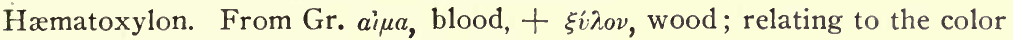
of the heart wood.

Hagenia. Cusso. Named after Dr. K. G. Hagen, German physician and apothecary (I749-1829).

Hamamelis. Witch-hazel. Ancient Greek name of a tree with fruit like a pear $(\mu \eta \lambda i s)$. Of doubtful application, as the fruit is a woody capsule.

Hanburii. Latinized genitive from Hanbury, an eminent English pharmacognosist and traveller.

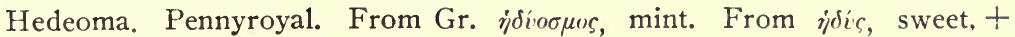
$\dot{o} \sigma \mu \dot{\eta}$, scent.

Hedera. Ivy. The classical Latin name.

Helenium. Sneeze-weed. Ancient Greek name of a plant, said to be named after Helenus, son of Priam.

Helianthemum. Rockrose. From Gr. $\dot{\eta} \lambda \iota s s$, the sun, $+\dot{a} \nu H_{\varepsilon} \mu(\nu)$, flower. The large flowers open only once, in sunshine.

Helianthus. Sunflower. From Gr. $\ddot{\lambda} \lambda \iota s$, the sun, $+\dot{a} \nu$ Hoc, a flower.

Heliotropium. Heliotrope. Turnsole. The ancient Greek name. From $\dot{\eta} \lambda \iota s$, the sun, $+\tau \rho \circ \pi \dot{\eta}$, a turn; alluding to the flowering at the summer solstice.

Helleborus. Hellebore. The ancient classical name.

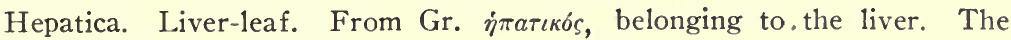
leaves were thought to resemble the liver in shape.

Herbaceus-a-um. Herbaceous, grassy. From Lat. herba, grass, herbage.

Hesperis. Rocket. Greek name for evening flower. From $\dot{\varepsilon} \sigma \pi \varepsilon \rho a$, evening; alluding to the evening fragrance.

Heuchera. Alum root. Named for Prof. J. H. Heucher, who died in 1747.

Hevea. Brazilian rubber tree. From vernacular name heve. 
Hibiscus. Rose mallow. The ancient classical name.

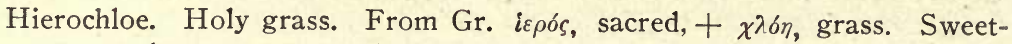
scented grasses strewn before church doors on saints' days.

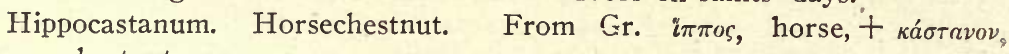
chestnut.

Hirsutus-a-um. Hirsute, rough, hairy.

Hispidus-a-um. Rough, shaggy, bristly.

Hordeum. Barley. The ancient Latin name.

Houstonia. Bluets. Named for Dr. William Houston, an English botanist. Humulus. Hop. Name of uncertain origin. Perhaps from Lat. humus, ground, alluding to the fact that the plant creeps on the ground unless supported.

Hydrangea. From. Gr. $\boldsymbol{v} \delta \omega \rho$, water, $+\dot{a} \gamma \gamma e \tilde{\iota} o v$, a vessel; from the shape of the capsule.

Hydrastis. Golden seal. Orange root. From Gr. $v \delta \omega \rho$, water, + $\delta \rho a ́ \omega$, to act, accomplish. Probably with reference to the active properties of the juice.

Hydropiper. Smartweed. Water pepper. Gr. $v \delta \omega \rho$, water, +piper, pepper.

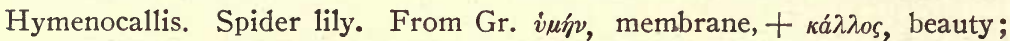
alluding to the crown.

Hyoscyamus. Henbane. The ancient Greek and Latin name. From Gr.

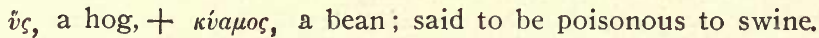

Hypericum. St. John's-wort. The ancient Greek name. Probably from

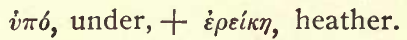

Icthyomethia. Jamaica dogwood. From Gr. ¿xflús, a fish, $+\mu \varepsilon^{\prime} \theta \eta$, strong drink, intoxicant.

Idæus. From Gr. 'Idaios, pertaining to Mt. Ida, near Troy, where the raspberry once flourished.

Ilex. Holly. The ancient Latin name for the holm oak or holly oak.

Illicium. Star anise. A Latin word meaning an allurement; alluding to the odor and attractive appearance.

Impatiens. Touch-me-not. A Latin word meaning "that cannot bear or suffer," from in, not, + patiens, enduring; from the sudden bursting of the pods when touched.

Indicus-a-um. Pertaining to India.

Inflatus-a-um. Inflated, swollen, puffed up.

Inula. Elecampane. The ancient Latin name.

Ipecacuanha. Ipecac. Portuguese name from Brazilian ipe-kaa-guena; properly a creeping plant that causes vomiting.

Ipomœa. Morning glory. From Gr. $i \psi, i \pi \delta \varsigma$, a worm, + o $\mu o \iota s$, like ; alluding to the twining stems.

Iris. Fleur-de-lis. Blue flag. From Gr. i $\rho$ s, the rainbow.

Islandicus-a-um. Belonging to Iceland.

Isoëtes. Quillwort. Ancient name used by Pliny, probably for a houseleek or evergreen. 
Iva. Marsh elder. Name of unknown derivation.

Ixina. From native Ixine, at Cumana, Venezuela, where Loefling discovered the plant in 1754 .

Jaborandi. Native name of a South American rutaceous shrub.

Jalapa. So called from Jalapa, a town in Mexico, whence it was first obtained.

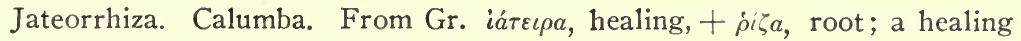
root.

Jeffersonia. Twinleaf. Named in honor of Thomas Jefferson.

Juglans. Walnut. Name contracted from Jovis glans, nut or acorn of Jupiter.

Juncus. Rush. Bog rush. Ancient Latin name; from jungo, to join, the stems being used for bands.

Juniperus. Juniper. The classical Latin name; probably from juvenis, young, + pario, to produce. Youth-producing; in allusion to its evergreen appearance.

Kalmia. Sheep laurel. Named for Peter Kalm, pupil of Linnæus.

Kamala. Hindoo name of the dusty hairs of the capsules of Mallotus Philippinensis, used as an orange dye for silks.

Kino. East Indian name of the dried juice of Pterocarpus Marsupium.

Krameria. Rhatany. Named for Drs. J. G. H. and W. H. Kramer, German botanists of the eighteenth century.

Kuhnia. False boneset. Named for Dr. Adam Kuhn, of Philadelphia, who carried the living plant to Linnæus.

Kuhnistera. Prairie clover. Named from its resemblance to Kuhnia.

Labiatæ. Mint family. From Lat. labium, lip; referring to the irregular corolla.

Lacinaria. Blazing star. From Lat. lacinia, the lappet or flap of a garment; hence fringed, from the appearance of the flower heads.

Laciniatus-a-um. Slashed, having a fringed border. Lat. lacinia, flap, lappet.

Lactuca. Lettuce. The ancient Latin name; from lac, milk; referring to the milky juice.

Lactucarium. The inspissated juice of the lettuce (lactuca).

Lamium. Dead nettle. From Gr. iaıuós, throat; alluding to the ringent corolla.

Lanceolatus-a-um. Armed with little lance or point, lanceolate. From Lat. lanceola, a small lance.

Langsdorffii. Named after M. Langsdorff, Russian consul at Rio, I829, from whom Desfontaines received his specimens.

Laportea. Wood nettle. Named for François L. de Laporte, Count of Castlenan, an entomologist of the nineteenth century.

Lappa. Burdock. The ancient Latin word for burr.

Laterifolius-a-um. Growing by the side of the leaf at its base, as a laterifolius flower. Lat. latus, side, + folium, leaf. 
Lathyrus. Vetchling. Everlasting pea. Ancient name of a plant of Theophrastus.

Lauaceæ. Laurel family. From Lat. laurus, laurel tree.

Lavandula. Lavender. From Lat. lavo, to wash; alluding to the use made of its distilled water.

Lawsonia. Henna plant. Named for Dr. John Lawson, who lived in the eighteenth century.

Ledum. Labrador tea. Ancient Greek name of an Oriental shrub.

Leguminosæ. Pulse fámily. From Lat. legumen, pulse.

Lemnaceæ. Duckweed family. From Gr. $\lambda \varepsilon \dot{\varepsilon} u v a$, a water plant.

Lens. Lentil. The ancient Latin name.

Lentiscus. Classical Latin name for the mastic-tree.

Lentus-a-um. Pliant, flexible.

Leonurus. Motherwort. From Gr. $\lambda \varepsilon \omega v$, a lion, + oivá, a tail.

Lepidium. Peppergrass. Classical name of a cress. Also meaning a little scale; in allusion to the fruit.

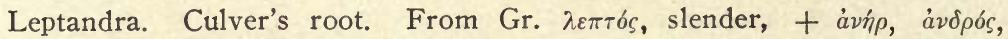
man; referring to the slender stamens.

Leucadendron. From Gr. $\lambda_{\varepsilon} v \kappa \delta s$, white, $+\delta \varepsilon \dot{v} \delta \rho o v$, a tree.

Levisticum. Lovage. Name said to be a corruption of ligusticum.

Ligusticum. Lovage. The ancient Latin name. Derived from Liguria, an Italian province where the plant abounded.

Ligustrum. Privet. The ancient Latin name.

Liliacex. Lily family. From Lat. lilium (Gr. Así $\rho \circ v)$, a lily.

Limonium. Sea lavender. The ancient Greek name; probably from $\lambda \varepsilon \iota \mu \omega \dot{\omega}$. a meadow.

Limonium. Lemon. Ital. limone, from Arabic laimun.

Linaceæ. Flax family. From Lat. linum (Gr. Rivov), flax, linen, thread.

Lippia. Fog-fruit. Named for Agostino Lippi, Italian naturalist.

Liquidambar. Sweet gum tree. From Lat. liquidus, fluid, + Arabic ambar, amber; alluding to the color and fragrance of the exudation.

Liriodendron. Tulip tree. From Gr. $\lambda \varepsilon i \rho \iota o v, ~ l i l y$, flower, $+\delta \varepsilon \dot{v} \delta \rho o v$, a tree.

Lithospermum. Gromwell. Puccoon. The ancient Greek name. From $\lambda_{i}$ Aos, stone, $+\sigma \pi \varepsilon \varepsilon^{\prime} \mu \alpha$, seed; alluding to the hard nutlets.

Lobeliacex. Lobelia family. From lobelia. Named after Matthias de l'Obel, an early Flemish botanist.

Loganiaceæ. Logania family. Named after J. Logan, a distinguished botanist.

Lonicera. Honeysuckle. Named for Adam Lonitzer, German botanist, who died in 1586.

Loranthaceæ. Mistletoe family. From Gr. $2 \tilde{\omega} \rho o v$, a thong, $+\dot{a} v$ thos, a flower.

Lotus. Bird's-foot trefoil. An ancient Greek plant name.

Lunaria. Moonwort. From Lat. luna, the moon; alluding to the silvery septum of the fruit. 
Lupinus. Lupine. Sun-dial. Ancient Latin name of a plant. From lupus, a wolf; because these plants were thought to devour the fertility of the soil.

Lupulus. Diminutive of Lat. lupus, wolf; wolfish, because it chokes the shrubbery on which it climbs.

Lusitanicus-a-um. Pertaining to Lusitania, the western part of Spain.

Luteus-a-um. Of or belonging to the yellow-weed (luteum); hence golden yellow, flame-colored.

Lychnis. Campion. Ancient Greek name for a plant with flame-colored

flower. From $\lambda u ́ x v o s$, a light or lamp.

Lycopodiaceæ. Club-moss family. From Lycopodium, club-moss.

Lycopodium. Club-moss. From Gr. дíкоs, a wolf, $+\pi o^{\prime}$ 's, a foot; in reference to the appearance of the shoots.

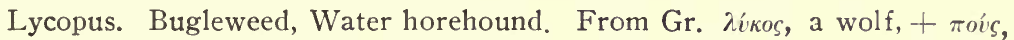
a foot; from a fancied likeness in the leaves.

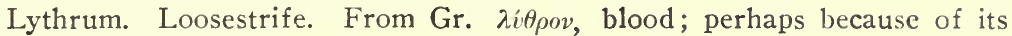
styptic properties.

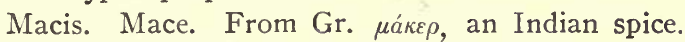

Maclura. Osage orange. Named for William Maclure, an early American geologist.

Maculatus-a-um. Spotted, mottled. From Lat. macula, a spot.

Magnolia. Named for Pierre Magnol, professor of botany at Montpellier, France, during the early seventeenth century.

Majalis. Emasculated. From Latin majalis, a barren hog.

Majorana. Marjoram. Old Eng. majoran, late Latin majoraca, classical Latin amaracus.

Major-us. Larger, greater. Comparative of magnus, large.

Mallotus. Kamala. From Gr. $\mu a \lambda \lambda \omega \tau o ́ s$, woolly, fleecy; the young branches, leaves and capsules being covered with fine hair or wool.

Malvaceæ. Mallow family. From Lat. malva, mallow.

Mamillosus-a-um. Filled with papillæ or "little breasts." From Lat. mamilla, little breast, in allusion to the stalked cystocarps.

Manna. The dried exudation of Fraxinus Ornus. Gr. pávva, a grain, from Hebrew man, gift.

Marginalis-e. Marginal, belonging to the margin. From Lat. margo, margin, edge; with reference to the marginal position of the sori.

Mariana. Carduus. Milk thistle, Virgin Mary's thistle, named from Maria, Latin name for Mary.

Marilandicus-a-um. Pertaining to Maryland.

Maritimus-a-um. Belonging to the sea. From Lat. mare, the sea.

Marmelos. Bengal quince. From Portuguese marmelo, quince.

Marrubium. Horehound. Latin classical name, derived from the Hebrew marrob, bitter; a bitter juice.

Marsilea. Named for Aloysius Marsili, an early Italian naturalist.

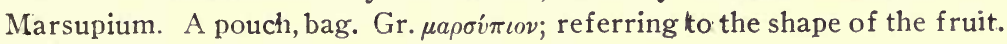




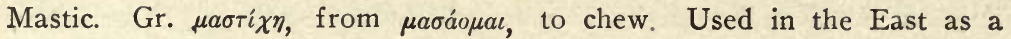
chewing gum.

Matico. Dried leaves of Piper angustifolium. Said to have been named from a Spanish soldier, who applied the green plant to a wound and stopped the bleeding.

Matricaria. Wild chamomile. From Lat, matrix, the womb; in allusion to its supposed effect on that organ.

Medicus-a-um. Medical, curative.

Melaleuca. Cajaputi. From Gr. $\mu \varepsilon \dot{\lambda} \alpha \varsigma$, black, $+\lambda \varepsilon v \kappa \delta \varsigma$, white; the bark of the trunk being black, that of the branches white.

Melilotus. Sweet clover. From Gr. $\mu \varepsilon \lambda_{\imath}$, honey, $+\lambda \omega \tau o ́ s$, a kind of clover.

Melissa. Balm. From Gr. $\mu \dot{\varepsilon} \lambda \iota \sigma \sigma \alpha$, a bee; the flowers yielding an abundance of honey.

Menispermum. Moonseed. From Gr. $\mu \eta v i s$, crescent, $+\sigma \pi \varepsilon \dot{\rho} \mu \alpha$, seed; in reference to the crescent-shaped seeds.

Mentha. Mint. The ancient Latin name. From Gr. $\mu i \nu \theta \eta$, mint.

Menyanthes. Buckbean. Probably from Gr. $\mu \dot{\eta} v$, month, + à $\nu \theta \varsigma$, a flower. Perhaps because it blooms for about a month.

Mercurialis. Mercury. Ancient Latin name of a plant; meaning belonging to Mercury, the messenger of the gods.

Methysticum. Kava-kava. Gr. $\mu \varepsilon \theta v \sigma \tau \iota \kappa \delta$, intoxicating; from $\mu \varepsilon \dot{\theta} \theta \nu$, wine. Meum. Spignel. Bearwort. The ancient Greek name $(\mu \tilde{\eta} o v)$.

Mezereum. French mézéréon, from Persian māzriyun.

Microcarpus-a-um. Having small fruit. From Gr. $\kappa a \rho \pi o ́ s$, fruit.

Mikania. Climbing hempwood. Named for J. G. Mikan, professor in the University of Prague, who died in 1814 .

Milaceus-a-um. Of or pertaining to millet, Lat. milium, millet.

Millefolium. Yarrow. The ancient Latin name; from mille, thousand, + folium, leaf.

Mitchella. Partridge berry. Named for Dr. John Mitchell, a botanist of Virginia, eighteenth century.

Mitella. Mitrewort. Bishop's cap. Diminutive of Lat. mitra, a cap; alluding to the form of the young pod.

Mollis-e. Pliant, soft, mild.

Monarda. Horse mint. Named for Nicholas Monardes, Spanish botanist and author of the sixteenth century.

Monniera. Hedge hyssop. Named for Prof. L. Guillaume le Monnier, a French botanist of the eighteenth century.

Monotropa. Indian pipe. From Gr. $\mu$ óvos, one, $+\tau \rho \circ \pi \eta$, a turn; the summit of the stem being turned to one side.

Montanus-a-um. Belonging to the mountain, mountainous.

Morus. Mulberry. Ancient Latin name for the mulberry tree.

Mucuna. Cowhage. From the vernacular Brazilian name. 
Muricatus-a-um. Rough with short, hard points. Lat. murex, a pointed rock.

Myosotis. Forget-me-not. The ancient classical name. From Gr. $\mu$ ús, a mouse, ov́s, $\dot{\omega} \cos _{\text {s, }}$ the ear. From the short and soft leaves in some species.

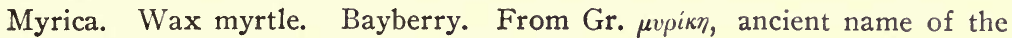
tamarisk.

Myristica. Nutmeg. From Gr. $\mu v \rho i \zeta \omega$, to be fragrant.

Myrrha. Myrrh. Ancient classical name for the balsamic juice of the Arabian myrtle.

Myrtus. Myrtle tree. The ancient classical name.

Napæa. Glade mallow. From Gr. vá $\eta$, a woody dell.

Napellus. Little turnip. Diminutive of Lat. napus, a turnip.

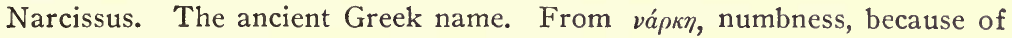
its narcotic properties. Or, according to others, from Narcissus, a youth, who according to a myth was changed into this flower.

Nardus. Spikenard. The ancient Greek name.

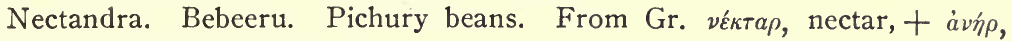
man, nectar stamen.

Nelumbo. Sacred bean. Lotus lily. From vernacular, Ceylon.

Nepeta. Catnip. Cat mint. The ancient Latin name.

Neslia. Ball mustard. Named for J. A. N. de Nesle, French botanist.

Nicotiana. Tobacco. Named for Jean Nicot, a French diplomat, who was thought to have introduced tobacco into Europe (1530-1600).

Nigella. Fennel flower. Diminutive of Lat. niger, black, from the color of the seeds.

Niger-gra-grum. Black, dark.

Nobilis-e. Famous, noted, well-born.

Nux-vomica. Lat. $n u x$, a nut, and vomo, to vomit.

Nymphæa. Yellow pond lily. Ancient Greek name for the water lily, which was dedicated to the water nymphs.

Nyssa. Tupelo. Pepperidge. The Latin name of a water nymph, nurse of Bacchus; because the original species of the plant grows in water.

Obtusifolius-a-um. Having leaves blunted or rounded at the end. Lat. obtusus, blunted, + folium, leaf.

Gccidentalis-e. Occidental. Western.

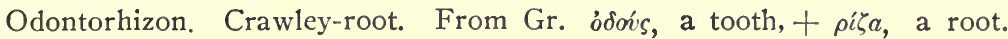

Odoratus-a-um. Emitting a smell, especially sweet-smelling, fragrant.

Enothera. Evening primrose. An ancient Greek name of a plant.

Officinalis-e. Pertaining to the shop. From Lat. officina, a workshop.

Oleaceæ. Olive family. From Lat. olea, olive tree.

Oleum. Gr. $\dot{\varepsilon} \lambda a \iota$, olive oil; hence oil.

Onoclea. Sensitive fern. Ancient Greek name of a plant.

Operculina. Turpeth root. Probably from Lat. operculum, a covering.

Opium. Gr. $8 \pi \iota \nu$, poppy juice. 
Opulus. Ancient Latin name of a kind of maple.

Opuntia. Prickly pear. Ancient Greek name of a plant, perhaps from 'Oroṽs, a town in Locris.

Orientalis-e. Pertaining to the Orient or East.

Origanum. Wild marjoram. The ancient Greek name. Probably from ò $\rho o \varsigma$, mountain, + rávos, brightness, joy.

Ornus. Wild mountain ash. The classical Latin word. Perhaps from Gr. öpos, mountain.

Osmunda. Flowering fern. From Osmunder, Saxon name of the Celtic divinity, Thor.

Ostrya. Hop hornbeam. Ironwood. The ancient classical name.

Oxalis. Wood sorrel. Ancient classical name; from Gr. ócús, sour.

Oxycedrus. Prickly cedar. Ancient Greek name; from ó źvs, sharp, + $\kappa \varepsilon \delta \rho o \varsigma$, cedar. Cedar with pointed leaves.

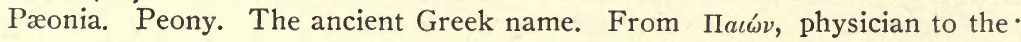
gods.

Palmatus-a-um. Pertaining to a palm, like a palm. From Lat. palma, a palm.

Palustris-e. Fenny, marshy, swampy. From Lat. palus, a marsh.

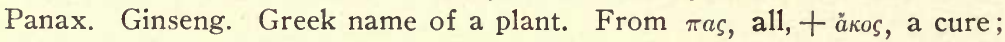
all-healing, panacea.

Paniculatus-a-um. Having panicles. From Lat. panicula, a tuft or panicle.

Panicum. Panic grass. Ancient Latin name of Italian panic grass.

Papaver. Poppy. The classical Latin name.

Papyrifer-a-um. Producing papyrus. Lat. papyrus, + fero, to bear.

Parviflorus-a-um. Having small flowers. Lat. parvus, small, + flos, a flower.

Passiflora. Passion flower. Adaptation of the Latin flos passionis, flower of passion. From a supposed resemblance of the parts of the flower to the implements of the crucifixion.

Pauciflorus-a-um. Having few flowers. Lat. paucus, few, + flos, a flower.

Paullinia. Guarana. Named for C. F. Paullini, a German botanist (I643I7I2).

Pedatus-a-um. Having pedates or lobes. Lat. pedo, to supply with feet.

Peltatus-a-um. Peltate or shield-like. Lat. pelta, a shield.

Pcnnatifolius-a-um. Feathered, winged. Lat. pennatus, winged, + folium, leaf.

Penthorum. Ditch stonecrop. From Gr. $\pi \dot{\varepsilon} v \tau \varepsilon$, five, + ö $\rho \circ$, a rule; referring to the quinary order of the flower.

Pepo. Pumpkin. Melon. The ancient Latin word.

Pereiræ. Of Pereira. Named in honor of Jonathan Pereira, an English pharmacologist, who visited South America (I804-I853).

Perfoliatus-a-um. Perfoliate. Stem apparently passing through the leaves. Lat. per, through, + folium, leaf. 
Perforatus-a-um. Perforate, having holes as if pricked through. Lat. perforo, to pierce through.

Persea. Avocado. Ancient name of an Egyptian tree with fruit growing on the stem.

Persicaria. Lady's thumb. From Lat. persicus, a peach tree.

Petroselinum. Parsley. An ancient Greek plant-name. From $\pi \hat{\varepsilon} \tau \rho a$, a rock, $+\sigma \varepsilon \hat{\lambda} \iota \nu o v$, parsley.

Phaseolus. Kidney bean. The ancient classical name.

Philadelphus. Mock orange or Syringa. Ancient Greek name of a sweet flowering shrub; applied by Linnæus to this genus.

Phillipinensis-e. Belonging to the Philippine Islands.

Phlox. Greek name of a plant with flame-colored flowers. From $\phi \lambda \delta \xi$, a flame.

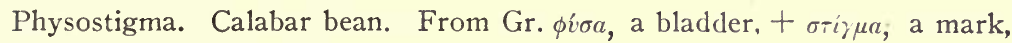
stigma.

Phytolacca. Pokeweed. From Gr. $\phi v \tau o b v$, plant, + Ital. lacca, lake color; alluding to the coloring matter which the berries yield.

Picea. Spruce. The classical Latin name of the pitch-pine.

Picrasma. Quassia. From Gr. $\pi \iota \kappa \rho a \sigma \mu o ́ s$, bitterness.

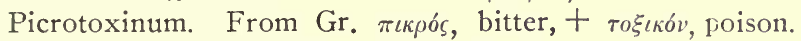

Pilocarpus. Jaborandi. From Gr. $\pi \tilde{\imath} \lambda o s$, a hair, $+\kappa a p \pi o ́ s$, fruit; referring to the shape of the fruit.

Pimenta. Allspice. From Spanish pimienta, allspice. Derived from Latin pigmentum, spice.

Pimpinella. Pimpernel. Said to be formed from Lat. bipinnula, equivalent to bipennis, two-winged; referring to the bipinnate leaves.

Pinus. Pine. The ancient Latin rame. Probably akin to pinna, a feather.

Piper. Pepper. The classical Latin name.

Piperitus-a-um. Peppery, pungent. Lat. piper, pepper.

Pipsissewa. Chimaphila. An American Indian name.

Piscipula. From Lat. piscis, fish.

Pistacia. Pistachio. The ancient classical name.

Planifolius-a-um. Having flat leaves. Lat. planus, flat, plane, + folium, leaf.

Plantago. Plantain. The ancient Latin name.

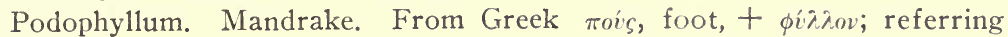
to the foot-like leaves.

Podostemon. Riverweed. From Gr. $\pi$ ovs, foot, + orí $\mu \omega v$, thread, stamen ; the two stamens being apparently raised on a stalk by the side of the ovary.

Polemonium. Greek valerian. An ancient Greek name of a plant. From $\pi \delta ́ \lambda \varepsilon \mu \rho \varsigma$, war.

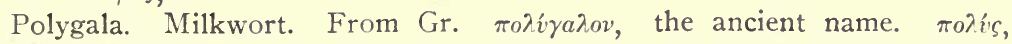

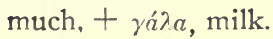


Polygamus-a-um. Having some perfect flowers and others with stamens

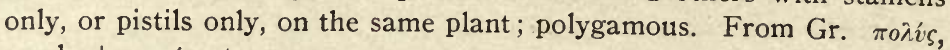
much, $+\gamma a \mu \varepsilon \dot{\omega} \omega$, to marry.

Polygonatum. Solomon's seal. Ancient Greek name of a plant. From

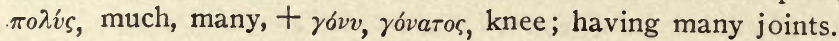

Polygonum. Knotweed. The ancient classical name. From Gr. nonis, much, many, $+\gamma \delta$ óv, knee; having many knots or joints.

Polypodium. Polypody. The ancient Greek name. From monís, much, many, $+\pi o v s$, foot; alluding to the branching rootstock.

Polyporus. Agaric. From Gr. $\pi$ odís, many, $+\pi \delta \rho o s$, a pore; referring to the porous texture of the plant.

Populus. Poplar. Aspen. The classical Latin name.

Potentilla. Cinquefoil. Five-finger. Name is a diminutive form of Lat. potens, powerful; from the reputed medicinal powers of one of the species.

Pratensis-e. Growing in meadow-land. Lat. pratum, meadow.

Precatorius-a-um. Imploring, beseeching. From Lat. precor, to pray; in allusion to the use of the seeds as beads in rosaries.

Primula. Primrose. Cowslip. The name is a diminutive of Lat. primus, first; from the flowering of the primrose in early spring.

Procumbens. Lying on the ground. From Lat. procumbo, to incline forward.

Prunifolius-a-um. Having leaves resembling those of the plum tree. From Lat. prunus, plum tree, + folium, leaf.

Prunum. Plum. Classical Latin name for the fruit.

Prunus. Plum, cherry. Classical Latin name for the plum tree.

Pruriens. Itching. From Lat. prurio, to itch; in reference to the hairs, which occasion an intolerable itching.

Psyllium. Flea-seed. Ancient Greek name for fleawort.

Psoralea. From Gr. $\psi \omega \rho a \lambda \dot{\varepsilon} o \varsigma$, scurfy; in reference to the glandular dots on the calyx and pods.

Ptelea. Hop-tree. Ancient Greek name for the elm.

Pteris. Brake or Bracken. Ancient Greek name for a kind of fern. From $\pi \tau \varepsilon \rho \sigma v$, a wing; alluding to the pinnate or feathery fronds.

Pterocarpus. From Gr. $\pi \tau \varepsilon \rho o ́ v$, a wing, $+\kappa a \rho \pi \delta s$, fruit; in allusion to the winged legumes.

Puber-a-um. Downy.

Pubescens. Downy, hairy, woolly. From Lat. pubesco, to become downy.

Pulegioides. Like fleabane. From Lat. pulegium (Gr. $\psi v \lambda \lambda i o v)$, fleabane, $+-0-\varepsilon \hat{\varepsilon} \delta \eta$, resembling; in allusion to the appearance and odor.

Pulicaria. Fleawort. The ancient Latin name.

Pulmonaria. Lungwort. From Lat. pulmonarius, beneficial to the lungs. From its supposed curative properties.

Pulsatilla. Pasque flower. From Lat. pulso, to strike, agitate; of uncertain application. 
Punica. Pomegranate. From Lat. punicum, pomegranate tree.

Purpureus-a-um. Purple-colored.

Purshianus-a-um. Adjective formed from Purshia. Named for Fred.

Pursh, a German botanist and author of Flora Americe Septentrionalis.

Pyrethrum. Pellitory. Feverfew. Ancient Greek name for a hot, spicy plant.

Pyrus. Pear, Apple. Ancient Latin name for the pear tree.

Quassia. Named for a negro, Quassy or Quash, who prescribed this remedy as a specific.

Quebracho-blanco. From Sp. quebrantar, to break, + hacha, an axe; in allusion to the hard and tough bark. Blanco, white.

Quercus. Oak. The classical Latin name.

Quillaja. Soap bark. From vernacular quillai, Chili.

Racemosus-a-um. Having racemes or clusters.

Radicans. Rooting. From Lat. radico, to take root; alluding to the fact that the stems send out roots.

Ranunculus. Crowfoot. Buttercup. The Latin name for a little frog; some species being aquatic.

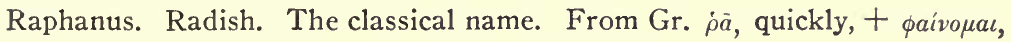
to appear; alluding to the rapid germination.

Repens. Creeping. From Lat. repo, to creep.

Reptans. Creeping. From Lat. repto, to creep.

Reseda. Mignonette. From Lat. resedo, to calm, heal; from its supposed sedative properties.

Reticulatus-a-um. Reticulate, net-like. Lat. retia, a net; leaf-veins forming a net-work.

Rhamnus. Buckthorn. The ancient classical name.

Rhaponticus-a-um. Rhapontic. From Lat Rha, the Volga river, + ponticus, pertaining to the Pontic or Black Sea. The rhubarb growing on the banks of the Rha.

Rheum. Rhubarb. From Lat. Rha, the river Volga, on whose banks the plant grew.

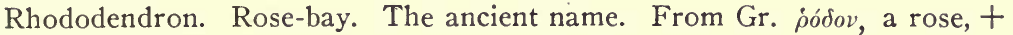
$\delta \varepsilon ́ v \delta \rho o v$, a tree.

Rhus. Sumach. The ancient classical name.

Ribes. Currant. Gooseberry. From Arabic ribās, a plant with an acid juice.

Ricinus. Castor bean. The ancient Latin name.

Robinia. Locust. Named for John and Vespasian Robin, royal gardeners of Paris, seventeenth century.

Robustus-a-um. Robust, strong, oaken. Lat. robur, oak.

Rosa. Rose. The ancient Latin name.

Roseus-a-um. Rose-colored, rosy. Lat. rosa, a rose.

Rosmarinus. Rosemary. From Lat. ros, dew, + marinus, belonging to the sea; from its maritime habitat. 
Rostratus-a-um. Beaked, curved, rostrate. Lat. rostrum, a beak.

Rotundifolius-a-um. Having round leaves. Latin rotundus, round, + folium, leaf.

Ruber-ra-rum. Red, ruddy.

Rubus. Bramble. Blackberry. Ancient Latin name, akin to ruber, red.

Rugosus-a-um. Wrinkled, creased. Lat. ruga, a wrinkle.

Rumex. Dock Sorrel. The classical Latin name.

Ruta. Rue. The ancient classical name.

Sabadilla. Cevadilla. From Span. ccvadilla. Probably from Lat. cibus, food, though the seeds are poisonous.

Sabal. Palmetto. From vernacular, Mexico or South America.

Sabina. From Lat. Sabinus, of the Sabines; a people of Italy who used the juniper as an incense.

Saccharum. The classical name for sugar.

Saigonicus-a-um. Of Saigon, a city and province in southern Annam.

Salix. Willow. The classical Latin name.

Salvia. Sage. The ancient Latin name. From salvo, to save; because of its supposed healing qualities.

Sambucus. Elder. The old Latin name, perhaps from Gr. $\sigma \alpha \mu \beta i v \kappa \eta$, a musical instrument.

Sanctus-a-um. Holy, sacred, consecrated.

Sanguinaria. Bloodroot. From Lat. sanguinarius, bloody; from the color of the juice.

Sanicula. Black snakeroot. Sanicle. From Lat. sano, to heal.

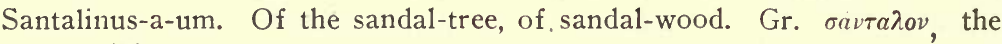
sandal-tree.

Santalum. Sandal-wood. The ancient Greek name for sandal-tree.

Saponaria. Soapwort. From Lat. sapo, soap; the juice forming a lather with water.

Sarracenia. Pitcher plant. Named for Dr. Michel Sarrasin, of Quebec.

Sassafras. The Spanish name. Probably a modification of saxifrage.

Sativus-a-um. Cultivated. Propagated by seed.

Scammonia. Scammony. Classical name of a plant.

Scandens. Climbing. Lat. scando, to climb.

Scilla. Squill. The ancient Greek name for the medicinal squill.

Scirpus. Rush. The ancient Latin name.

Scolopendrium. Adder's tongue. The ancient Greek name. From $\sigma \kappa\left(\hat{)} \pi \varepsilon \boldsymbol{v} \delta_{j a}\right.$, the centipede; alluding to the sori.

Scoparia. Broom-weed. From Lat scopa, a broom.

Scutellaria. Skullcap. From Lat. scutclla, a dish; alluding to the calyx.

Secale. Rye. Latin name for a kind of grain. From seco, to cut.

Sedum. Stonecrop. Orpine. Latin name of a houseleek. From sedco, to sit; alluding to the manner in which the plants attach themselves to walls and rocks.

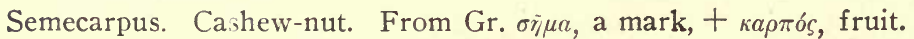


Sempervirens. Evergreen. Lat semper, always, + vireo, to be green.

Senecio. Groundsel. Ragwort. Squaw-weed. From Lat. senex, old man; alluding to the hoariness of some species.

Senega. Seneca root. From the Seneca tribe, North American Indians, who used it as a remedy for snake bites.

Senegal. Name of a country and river in W. Africa. Habitat of the plant Acacia Senegal.

Senna. Senna leaves. Name derived from Arabic Sanā or sena.

Serenoa. Saw palmetto. Named for Prof. Sereno Watson of Harvard University ( $1826-1892$ ).

Serotinus-a-um. Late, backward; relating to the flowers and fruit.

Serpentaria. Snakeroot. The ancient Latin name. From serpens, a serpent.

Serrulatus-a-um. Serrulate, notched. From Lat. serrula, a saw.

Sesamum. Sesame. The classical name of the sesame.

Siliqua. The classical Latin name for a pod.

Silphium. Rosin weed. Ancient Greek name of some resinous plant.

Simaba. Cedron. From vernacular name, Guiana.

Sinapis. Mustard. The ancient Greek name was óivanı. The Latin had both forms, sinapis and sinapi.

Sinensis-e. More commonly Chinensis. Pertaining to China.

Sisymbrium. Hedge mustard. The ancient Greek name of a sweet-scented plant.

Smilax. Green brier, cat brier. An ancient Greek name for the yew, and for several plants.

Socotrinus-a-um. Of Socotra, an island east of Africa.

Solanum. Nightshade. The ancient Latin name.

Solidago. Goldenrod. From Lat. solido, to make whole, to heal ; in reference to its supposed healing properties.

Somnifer-a-um. Sleep-producing. From Lat. somnus, sleep, + fero, to bear, bring.

Sorbilis-e. Sorbile, fit to be drunk or sipped. Lat. sorbeo, to suck.

Sorbus. Mountain ash. The ancient Latin name.

Sorghum. Derivation uncertain. Probably of Chinese or East Indian origin.

Spicatus-a-um. Supplied with spikes, spicate.

Spigelia. Pink root. Worm-grass. Named for Adrian von der Spiegel, Flemish botanist of the seventeenth century.

Spiræa. Hardhack. Meadow-sweet. The ancient Greek name. From $\sigma \pi \varepsilon i \rho a$, a coil or twist; from the twisting of the pods in some species. Squarrosus-a-um. Scabby, scurfy, ragged.

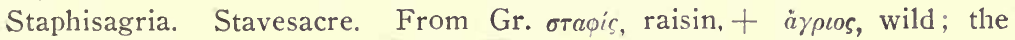
fruit clusters resemble wild grapes.

Stillingia. Named for Dr. B. Stillingfleet, English botanist of the eighteenth century. 
Stramonium. Stinkweed. From French stramoine.

Striatus-a-um. Marked with lines or ridges, striate; Lat. strio, to groove, mark.

Strophanthus. From Gr. : $\sigma \tau \rho \circ \phi \eta ́$, a turn, twist, + à $\nu$ $0 \varsigma$, a flower; from the twisted and tailed lobes of the corolla.

Strychnos. The ancient Greek name of a poisonous plant.

Styraciflua. A tree producing storax. From Lat. styrax, storax, $+f u o$, to flow.

Styrax. Storax. The ancient Greek name of the storax tree.

Succirubra. From Lat. succus, juice, + ruber, red; - the sap becomes red on exposure.

Swertia. Chiretta. Named for Emanuel Sweert, herbalist of the seventeenth century.

$\left.\begin{array}{l}\text { Sylvaticus-a-um. } \\ \text { Sylvestris-e. }\end{array}\right\}$ Pertaining to the woods. Lat. silva, a wood, forest.

Symphoricarpos. Snowberry. From Gr. $\sigma v \mu \phi \rho \rho \varepsilon \dot{\varepsilon}$, to bring together, +карло́, fruit; from the clustered berries.

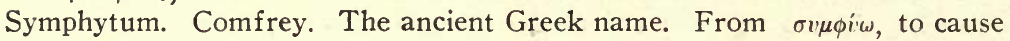
to grow together; because of its reputed healing virtues.

Syringa. Lilac. From Gr. $\sigma \tilde{v} \rho \iota \xi \xi$, a pipe; in reference to the tubular corolla, or to the use of the wood for pipe-stems.

Tabacum. Tobacco. Span. tabaco, from the Indian word denoting the tube or pipe used in smoking the plant.

Tamarindus. Indian date. From Arabic tamarhindi, tamar, a dried date, + Hind, India.

Tanacetum. Tansy. From the French name, tanaisie, derived from Gr. átávatos, immortal.

Taraxacum. Dandelion. From $\tau \alpha \rho a ́ \sigma \sigma \omega$, to stir up, disorder; in allusion to its medicinal properties.

Terebinthina. Turpentine. From Gr. $\tau \varepsilon \rho \varepsilon \beta \iota \nu \theta \rho \varsigma$, the turpentine tree.

Teucrium. Germander. Named for Teucer, king of Troy.

Thalictroides. Resembling thalictrum. From Gr. Há $\iota \kappa \tau p o \nu,+o-\varepsilon \iota \delta \eta \varsigma$, like.

Thalictrum. Meadow rue. Ancient Greek name of a plant.

Thea. Tea. French Thć, from Chinese tsha.

Theobroma. Cacao. From Gr. Á́os, a god, $+\beta \rho \tilde{\omega} \mu \alpha$, food.

Thuja. Arbor Vitæ, Cedar. Ancient Greek name for an African tree with sweet-smelling wood.

Thymus. Thyme. Ancient Greek name. From five, to sacrifice; alluding to the sweet odor.

Tiarella. False mitrewort. Coolwort. Diminutive of Lat. tiara, cap; from some fancied resemblance of the capsules.

Tilia. Linden. Basswood. The classical Latin name.

Tinctorius-a-um. Pertaining to dyeing, containing coloring matter. Lat. tingo, to dye, color. 
Tinctorum. Of the dyers. Genitive plural of tinctor, a dyer.

Toluifera. Balsam tree. Said to be formed from Tolu (Santiago de Tolu, in New Granada), whence balsam was first brought, + fero, to bear.

Tomentosus-a-um. Tomentose. Woolly. Lat. tomentum, stuffing.

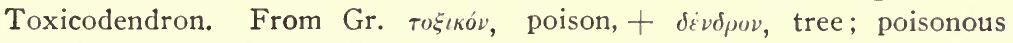
shrubs.

Tradescantia. Spiderwort. Named for John Tradescant, gardener to Charles I.

Tragacantha. Tragacanth. The ancient Greek name for the Astragalus. From tpázos, a goat, $+\dot{a} \kappa a v t a$, a thorn; in allusion to the character of the gummy exudation.

Tragopogon. Salsify. Goat's beard. Ancient Greek name of a plant.

From $\tau \rho a ́$ ' $о \varsigma$, a goat, $+\pi \dot{\omega} \gamma \omega \nu$, beard; alluding to the pappus.

Triandrus-a-um. Having three stamens. Gr. $\tau \rho \varepsilon i s$, three, $+\dot{a} v \dot{v} \rho$, man.

Tricolor. Having three colors, tricolored. Lat. tres, three, + color, color.

Tricuspidatus-a-um. Ending in three points. Lat. tricuspis, three-pointed.

Trifolium. Clover. Trefoil. The ancient Latin name. Three-leafed.

Trilisa. Vanilla-leaf. Deer's tongue. Name an anagram of Liatris.

Trillium. Wake robin. Birtliroot. From Lat. tres, three; all the parts being in threes.

Triphyllus-a-um. Having three leaves. Gr. $\tau \rho \varepsilon i c$, three, $\phi \hat{\lambda} \lambda \lambda \_\nu$, leaf.

Triticum. Wheat. The ancient Latin name. From tritus, past participle of tero, threshed or ground.

Trivialis-e. Common, trivial. Lat. tres, three, + via, road; three roads, growing along many roads.

Tsuga. Hemlock. The Japanese name of one of the species.

Tuberosus-a-um. Tuberous. Lat. tuber, lump, tumor.

Turpethum. Turpeth. From Persian tirbia, a cathartic: turbad, a purgative root.

Tussilago. Coltsfoot. The ancient Latin name. From tussis, a cough, for which the plant is a reputed remedy.

Ulmaria. Queen of the meadow. From ulmus, elm; hence elm-like.

Ulmus. Elm. The classical Latin name.

Umbellatus-a-um. Umbellated, like an umbel. Lat. umbella, little shade, umbel.

Umbellularia. Bay-laurel. From umbellula, little umbel, a late Latin diminutive of umbella.

Uniflorus-a-um. Bearing one flower only. Lat. unus, one, + flos, flower.

Urginea. Squill. Sea onion. From Lat. urgeo, to press; alluding to its flattened seeds.

Urtica. Nettle. The ancient Latin name.

Usitatissimus-a-um. Most useful, common, familiar; superlative degree of usitatus.

Ustilago. Smut, Bunt. An ancient Latin name of a plant.

Uva-ursi. Bearberry. From Latin $u v a$, a grape, $+u r s i$, of a bear. 
Valeriana. Valerian. Probably from Lat. valeo, to be strong.

Vanilla. From Spanish vainilla, diminutive of vaina, a sheath, pod; because its seeds are contained in little pods.

Variifolius-a-um. With varying leaves. Lat. varius, various, changing, + folium, a leaf.

Venenosus-a-um. Poisonous, deadly. Lat. venenum, poison.

Veratrum. False hellebore. The classical Latin name.

Veronica. Speedwell. Dedicated to St. Veronica.

Versicolor. Having various colors. Lat. verto, to turn, change, + color, color.

Verticillatus-a-um. Disposed in a whorl. Lat. verticillus, diminutive of vertex, a whirl; referring to the leaves or flowers.

Verus-a-um. True, genuine, original.

Viburnum. Black haw. Arrow-wood. The ancient Latin name.

Victorialis. Ancient Latin name of a plant.

Villosus-a-um. Hairy, shaggy, villous.

Vinifer-a-um. Wine-producing. Lat. vinum, wine, + fero, to bear.

Viola. Violet. Heart's ease. The ancient Latin name of the genus.

Virginianus-a-um.

Virginicus-a-um. $\}$ Of or belonging to Virginia.

Viridiflorus-a-um. Having green flowers. Lat. viridis, green, $+f l o s$, a flower.

Viridis-e. Green.

Virosus-a-um. Having a bad odor, fetid. Lat. virus, an offensive smell.

Vitis. Grape. The classical Latin name.

Vouacapoua. Araroba tree. From vernacular name, Central America.

Vulgaris-e. Common, general, ordinary.

Wisteria. Named in honor of Prof. Caspar Wistar, distinguished anatomist of Philadelphia.

Xanthium. Clotbur, Cocklebur. Greek name of some plant used to dye the hair. From $\xi a v \theta 6 s$, y yellow.

Xanthoxylum. Prickly Ash. From Gr. $\xi a v \theta b s$, yellow, $+\xi i \lambda_{o v}$, wood; referring to the color of the roots.

Zea. Maize. Indian corn. Ancient classical name for a kind of grain.

Zeylonicus-a-um. Of or belonging to Ceylon.

Zingiber. Ginger. The ancient Greek name. 


\section{CHAPTER V}

\section{CLASSIFICATION OF ANGIOSPERMS YIELDING ECONOMIC PRODUCTS}

IN this chapter will be given in natural sequence a list of the principal orders of plants that yield medicinal and other economical products. While great stress will be laid upon the plants used in medicine, yet considerable attention will also be given to the other economic substances furnished by the angiosperms, as foodproducts, fibers, coloring principles, woods, and timbers, as well as to the plants commonly cultivated for ornamental purposes. It will be found that the number of plants useful to man is a very large one, being derived from all the important families, so that in their consideration the student will gain a rather comprehensive view of the entire group.

\section{A. CLASS MONOCOTYLEDONEA.}

The Monocotyledons are mainly distinguished as follows: The embryo has only one cotyledon; the leaves are mostly scattered and parallel-veined; the fibrovascular bundles of the stem are of the closed type, and the flowers are typically trimerous.

\section{ORDER PANDANALES.}

This order includes members which are aquatic or marsh plants, with narrow, elongated leaves and very small, imperfect and incomplete flowers in spikes or heads.

The TYPHACEA or Cat-tail family has the flowers borne in densely crowded terminal spikes, the-staminate flowers being at the upper end of the spike, while the pistillate flowers which are beneath are more persistent.

The SPARGANIACEE or Bur-reed family have the flowers borne in densely globose heads, the staminate heads being rather small and near the upper part of the stalk, while the pistillate heads are larger and situated a short distance below the staminate ones (Fig. 252). 


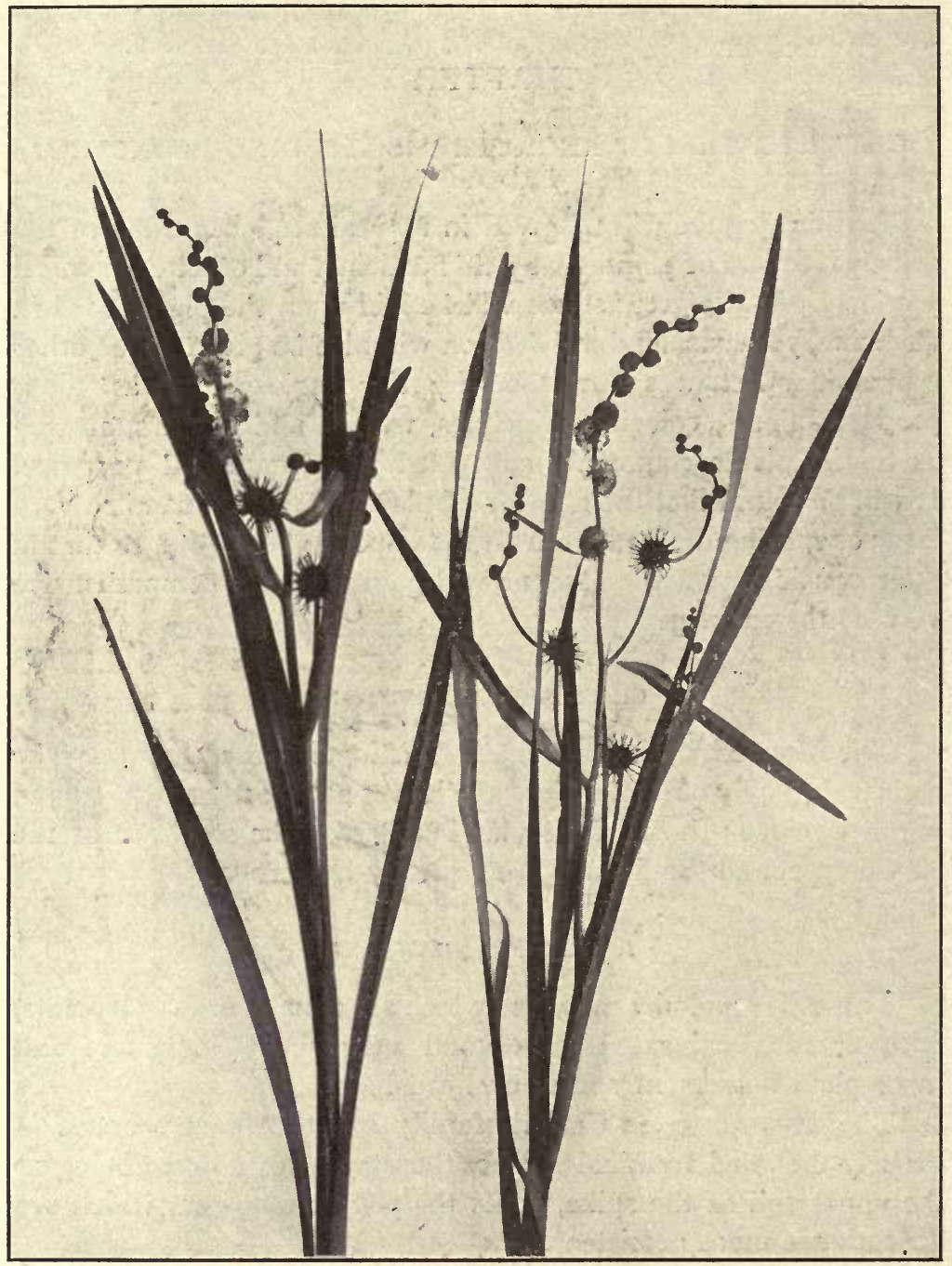

FIG. 252. Bur-reed (Sparganium eurycarpum), a perennial plant flowering throughout the summer and growing on the borders of ponds, lakes, and rivers throughout the United States. It grows to a height of 8 to I $2 \mathrm{dm}$., and produces long, ribbon-like leaves. The flowers are in heads, becoming bur-like from the divergent beaks. - After Brown. 


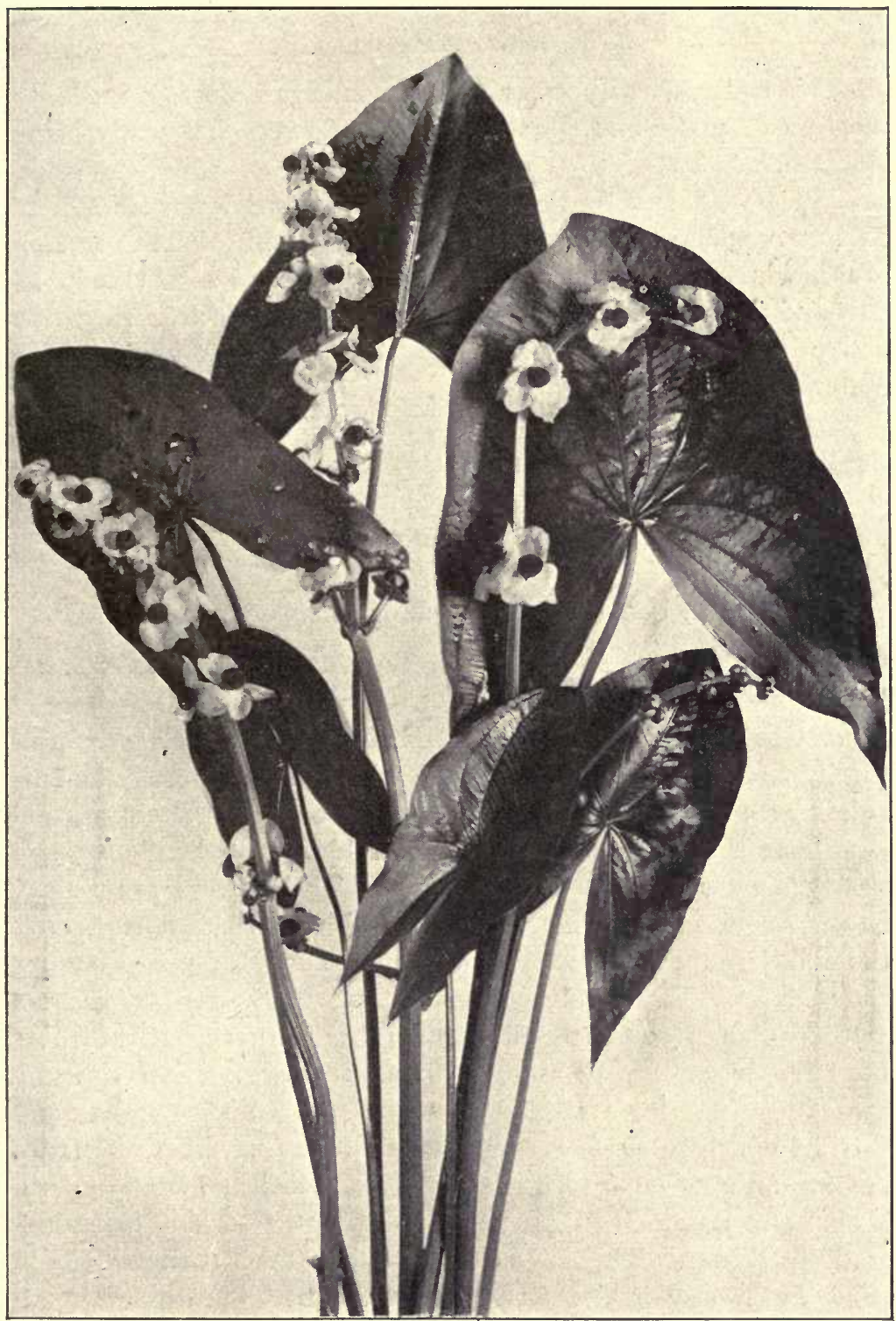

Fig. 253. Arrow-head (Sagittaria latifolia), a common marsh or aquatic plant and very widely distributed. The leaves are variable, but almost always sagittate. It produces naked scapes which are sheathed by the bases of the petioles; the white flowers are produced all summer.-After Troth. 


\section{ORDER NAIADALES.}

This order, as with other rather primitive orders, is made up mostly of aquatic and marsh plants, the flowers frequently being spicated.

The NAIADACE $E$ or Pond-weed family comprises such genera as Potamogeton, the common Pond-weed, and Zostera, or Eelgrass, which is extremely common in bays and estuaries in all parts of the country, and in many places its collection forms an active industry. It is used in upholstery work and as a packing material.

To the ALISMACE $\approx$ or Water-Plantain family belong Alisma, the Water-Plantain, and Sagittaria, or Arrow-head, which is a very attractive plant (Fig. 253). Of the latter there are a large number of species which are widely distributed.

\section{ORDER GRAMINALES OR GLUMIFLORE.}

This order is composed of the two families, grasses (Gramineæ) and sedges (Cyperaceæ).

a. GRAMINEÆ OR GRASS FAMILY.-The plants of this family are nearly all herbs having cylindric, generally hollow culms with swollen nodes. The leaves are exactly alternate, and have long sheaths which are split or seldom closed, tubular, and nearly always with a distinct ligule. The flowers are mostly hermaphrodite and borne in spikelets with alternate floral-leaves, the spikelets themselves being borne in spicate or paniculate inflorescences. Each spikelet (Figs. 255, 256) consists of two (seldom more) empty glumes, which are the lowest floral-leaves in each spikelet; a varied number of flowering glumes, frequently awned or toothed, are situated inside the empty glumes, and each of which subtends a short branch (the rhachilla), the latter bearing an adorsed fore leaf (the pale), which is generally twokeeled and two-toothed, enclosing two minute scales (lodicules) and the flower. The flower has mostly three stamens (there being six stamens in Oryza and Bambusa), with the anthers versatile, and a simple gynæcium consisting of one carpel having two styles and a plumose stigma. The ovary is unilocular with one ascending or pendulous ovule. The fruit is a grain or caryopsis, 
the seed being always firmly united with the thin pericarp (except in Sporobolus, Eleusine, etc.). The embryo is situated at the base, on the outer convex surface of the seed, outside the endosperm. On germination the cotyledons remain in the seed.

The endosperm contains numerous starch grains and oil, while the gluten layer around the endosperm contains proteins. The number of layers of gluten- or aleurone-containing cells varies in the different cereals. In corn, wheat, and rye it consists of but a single layer; in oat (Fig. 247) and rice, of I or 2 layers; while in barley it is made up of 2 to 4 layers.

The Grasses comprise about 3500 species and are distributed in all parts of the world. While most of the plants are grass-like,
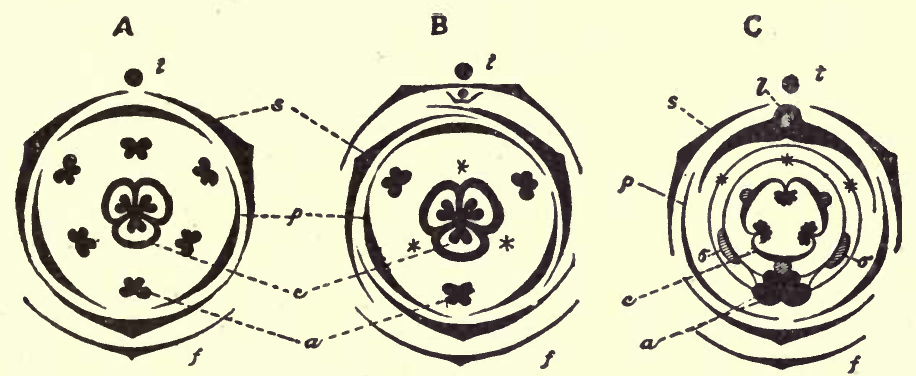

FIG. 254. Diagrams of cross-sections of monocotyledonous flowers: $t$, stem of plant; $f$, bract; s, sepals or outer circle of perianth; $p$, petals or inner circle of perianth; a, stamens; c, ovary. A, regular flower of the lily; B, irregular flower of iris. C, flower of an orchid, in which 1 is the position of the lip and $\delta \delta$ of the two staminodes.-After Warming.

still some of them, as the bamboos of the Tropics, become quite tall, having woody siliceous stems and bearing many branches in the axils of the leaves. The grasses yield the cereal grains forming so large a proportion of the food of man, and forage constituting the food of many of the lower animals. The following are some of the important cereals: Wheat (Triticum sativum and its varieties), corn (Zea Mays), oat (Avena sativa), rice (Oryza sativa), barley (Hordeum sativum and its varieties), rye (Secale cereale). A number of the species yield a sweet cell-sap from which cane sugar is made, of which the most important are the sugar cane (Saccharum officinarum) and sorghum (Andropogon arundinaceus saccharatus and other varieties). (Consult pp. I48, I 56, I98.) 
A large number of the grasses are used in medicine, one of which, couch-grass (Agropyron repens); is official.

Agropyron repens is a common perennial grass, forming slender jointed rhizomes, by means of which the plant is extensively propagated; the culms vary from one to four feet in height, the spikelets are 3 - to 7 -flowered ; and the empty glumes, 5 - to 7 -nerved, acute or with an awn-like apex.

Hordeum sativum is an annual grass with the flowers in ter-

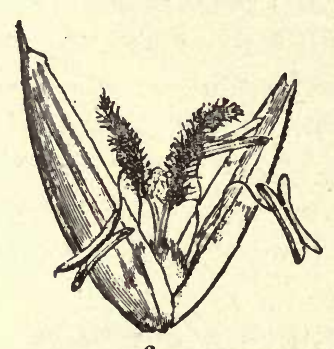

c.

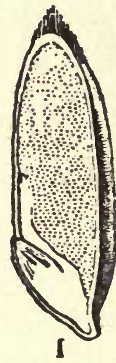

eUMAKTE.

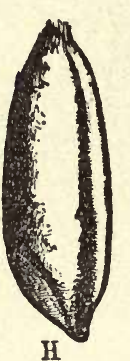

H

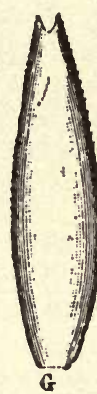

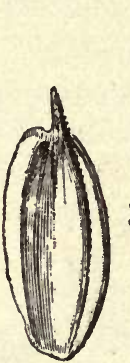
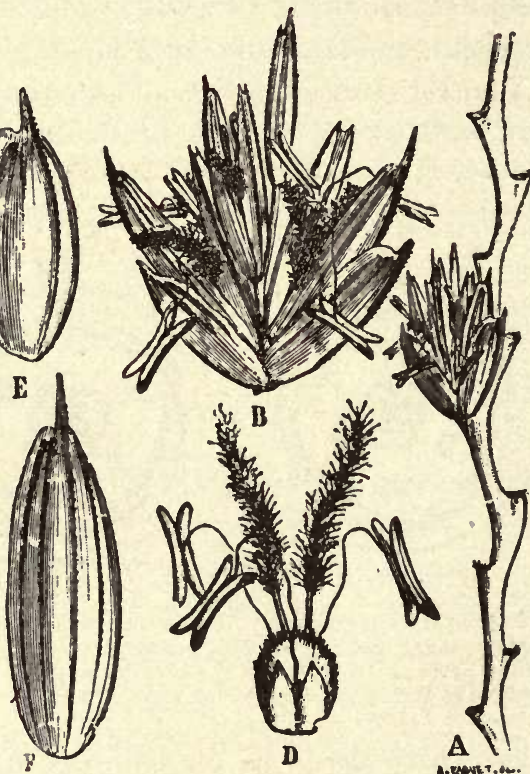

FIG. 255. Wheat (Triticum): A, zigzag axis or rachis of ear showing the notches where the spikelets were inserted; B, an entire spikelet; C, a flower with the pales; D, a flower without the pales, showing the lodicules at the base; E, glume; F, outer pale; G. inner pale; H, fruit (caryopsis); I, longitudinal section of fruit.-After Warming.

minal cylindrical spikes resembling wheat. The spikelets are sessile, I-flowered, and usually in clusters of three on opposite sides of the notched rachis. The empty glumes are long and narrow, forming a kind of involucre around the spikelet. It is supposed that Hordeum sativum is a cultivated form of $H$. spontaneum growing in the countries between Asia Minor and other parts of Western and Southwestern Asia. Three important varieties are distinguished, depending upon the number of rows of grains in 
the ear. H. sativum distichon includes the plants having 2-rowed ears, and these are chiefly grown in Middle Europe and England. $H$. sativum hexastichon includes the plants having the grains in 6 rows, these having been cultivated since prehistoric times and furnishes the winter barley. $H$. sativum vulgare includes the plants in which the grains are in 6 irregular rows, and these are cultivated in northern temperate regions. The latter plant is cultivated in the United States and furnishes the spring or summer barley, largely used in the preparation of malt.

Zea Mays (Indian Corn) is a cereal plant probably indigenous to Central Mexico. It is extensively cultivated in the United

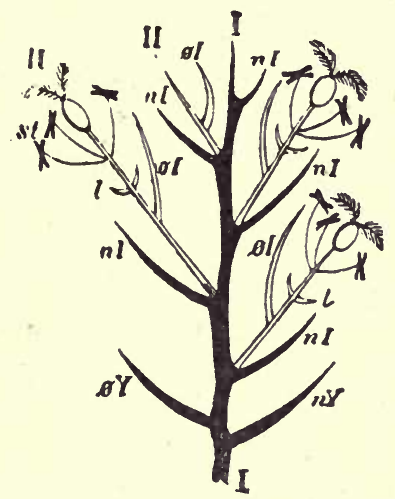

FIG 256. Diagrammatic outline of a spikelet: $\mathrm{nY}$, lower glume; $\phi \mathrm{Y}$, upper glume; $\mathrm{nI}$, outer pale; $\phi \mathrm{I}$, inner pale; 1,1 , lodicules; st, stamens; I-I, main axis; II, lateral axes or branches.-After Warming.

States and other parts of the world for its grain. From a multiple, primary, somewhat fibrous root arise one or more erect simple culms, which are grooved on alternate sides in the successive internodes and from the nodes of which arise aërial secondary roots. The leaves are alternate and consist of 3 parts: (a) a blade, which is long, broadly-linear and tapering toward the apex, the tip being pendulous; $(b)$ a lower sheathing portion which is open; and $(c)$ a short, translucent, somewhat hairy ligule, situated between the sheath and the blade. The flowers are monœcious, the staminate, which are arranged in a terminal panicle, maturing first; the pistillate occur in axillary spikes, the axes of which constitute the corn cob. They are enclosed in 
spathe-like bracts or husks, from which the long filiform styles (p. 178) protrude. The grain is somewhat ovate or triangular, flattened, pointed at the base, grooved on one side, indicating the position of the embryo, from Io to $15 \mathrm{~mm}$. long and about Io $\mathrm{mm}$. broad, more or less translucent, and varies in color in the different varieties. The constituents of the corn grain are 50 to 75 per cent. of starch; about Io per cent. of proteins ; 4.29 per cent. of a fixed oil; about 5 per cent. of sugar, and r.29 per cent. of ash.

There are a large number of varieties and sub-varieties of $Z e a$ Mays, some of the former being ranked as species. The following well-defined varieties may be mentioned:

( I) Zea Mays everta, to which belong the POP-CORns. The size of the ears and grains is about one-half or less that of the other corns; the grains have a more or less translucent and horny endosperm, the cells of the latter containing numerous compactly arranged polygonal starch grains, which are from 7 to $10 \mu$ in diameter and have a central rarefied area from 2 to $7 \mu$ in diameter. It is owing to the structure of the starch grains that the peculiar popping of the corn grains results when they are heated. Heating the corn grains at $145^{\circ}$ to $160^{\circ} \mathrm{C}$. for from 4 to Io minutes causes the bursting of the starch grains, and at the same time a rupture of the cells and splitting of the pericarp into 4 parts. The white appearance of the popped grains is due to the inclusion of air in the bursted cells. During the heating the starch is converted into a soluble form, and this gives popped corn its nutritive value. Some of the flint and dent corns show a similar tendency to pop when heated, but it is only in those parts of the endosperm that are horny and the cells of which contain compactly arranged polygonal starch grains in which the rarefied area is at least from one-tenth to one-fifth the diameter of the entire grain. Pieces of the pop-corn, as well as the horny portions of some of the flint and dent corns, will pop as readily as the whole grains.

(2) Zea Mays indentata yields the DENT or FLINT CORNs, the grains of which have a corneous (horny) endosperm on the sides and are indented at the summit, owing to the shrinking of the cells which contain more cell-sap and less compactly arranged starch grains.

The starch grains in the cells of the horny endosperm resem- 


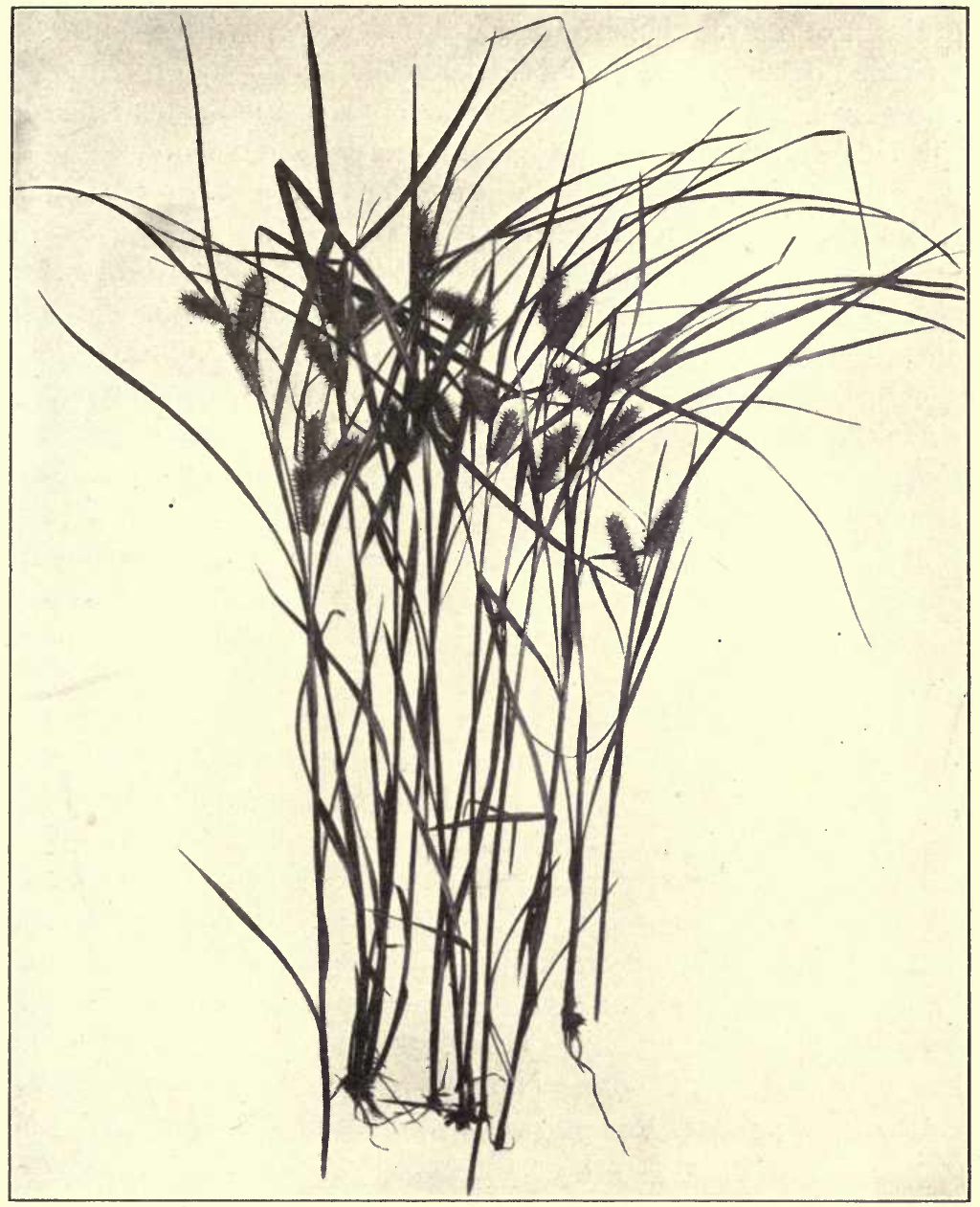

FIG. 257. Carex lurida, one of the Sedge family (Cyperacea), found throughout the summer in swamps and wet meadows in the eastern and central United States. It is a perennial grass-like herb with triangular culms, 3-ranked leaves, and with 2 to 4 spikes of flowers. The genus is a vast one of more than a thousand species, widely distributed and most abundant in the temperate zones.-After Troth.

ble those of pop-corn, but the starch grains in the other cells are more or less rounded or slightly polygonal, and vary from 5 to $25 \mu$ in diameter; the central rarefied area is either wanting or usually not more than $2 \mu$ in diameter.

(3) Zea Mays saccharata yields the SUg.IR CORNs. While the 
grains are more or less translucent and horny, they have a wrinkled or shrivelled surface. The cells of the endosperm contain gum-like substances and a relatively small number of nearly spherical starch grains from 4 to Io $\mu$ in diameter.

Broom CORN (Andropogon arundinaceus vulgare) is a plant which is cultivated for the panicles or seed heads, which are used in the manufacture of brooms. This plant differs from the other species of Andropogon in that the branches of the panicles are longer, straighter, and stronger, forming a so-called "brush."

Quite a number of the grasses contain odorous principles, as Andropogon citratus, which yields lemon-grass oil; $A$. Schonanthus, which yields gingergrass or geranium-grass oil; $A$. squarrosus, the rhizome of which is known as Vetiver. Coumarin is found in Vanilla grass (Anthoxanthum odoratum) and white or Dutch clover (Hierochlce odorata). Some species of Stipa are used in the manufacture of paper (Alfa or Esparto) in North Africa and Spain.

b. CYPERACEÆ OR SEDGE FAMILY.-These plants are all herbaceous, the majority being perennial (seldom annual). The rhizomes are mostly sympodial (being monopodial, however, in certain Carices), and the stems are mostly solid and triangular, without swollen nodes. The leaves are grass-like, generally arranged in three rows, and the sheath is closed, being mostly without ligules. The flowers may be hermaphrodite or unisexual, sometimes diœcious, and arranged in spikes or racemes. The perianth is wanting or only represented by 6 bristles, or by an indefinite number of hairs. The number of stamens is 3 , with the anthers attached by their bases to the filament. The gynæcium consists of 2 to 3 carpels, with one style divided into 2 or 3 branches, and provided with papillæ. The fruit is a nut, whose seed is generally united with the pericarp. The embryo is small and is centrally situated at the base of the seed, being surrounded. by the endosperm. On germination, the cotyledon is freed from the seed.

A number of the sedges yield food products, as the rhizomes of Cyperus esculentus and Eleocharis tuberosa, the latter of which is used in the manufacture of starch in China and India. Quite a number of species of Scirpus, Cyperus, Carex, etc., are used in 
medicine. Various species of Cyperus (C. scariosus, of the East Indies, and $C$. pertenuis, of India) yield ethereal oils and are used in making perfumery. Cyperus Papyrus is used in medicine and also furnished the paper of the Ancients.

\section{ORDER PRINCIPES.}

In this order is included that interesting group of tropical and sub-tropical plants the PALMs (Palmæ). They are arborescent, having simple unbranched trunks which are terminated by clusters of leaves, in the axils of which flowers are produced. The leaves are pinnate (Feather Palms) or palmate (Fan Palms) and often very large. The petiole is well developed, with an amplexicaul, more or less fibrous sheath. The inflorescence is usually lateral, in some cases forming a large spadix with a woody, boatshaped spathe. In comparison the individual flowers are very small. The fruit is either a berry, as in the Date palm, or a drupe, as in the Cocoa-nut palm, generally I-seeded and with a large horny or bony endosperm, as in the Date palm (p. I35) and Phytelephas macrocarpa, the latter of which yields vegetable ivory, used in the making of buttons (Fig. 258).

The fruit of the saw palmetto [Serenoa (Sabal) serrulata], one of the fan palms, is official. The saw palmetto is characterized by having a creeping, branching root-stock or rhizome, one end of which rises a short distance above ground, this portion being surmounted by a dense crown of leaves. The petioles are slender and spinose on the edges; the blade is fan-shaped and consists of a number of palmate divisions which are slightly cleft at the apex. The inflorescence is densely tomentose and shorter than the leaves. The fruit is a I-seeded clrupe.

The palms yield a number of useful products. The Betel-nut palm (Areca Catechu) produces a seed having medicinal properties (Fig. 259). The seeds, known as ARECA NUT, are 20 to 25 $\mathrm{mm}$. long, conical, grayish-brown, with numerous spiral, reddish veins, heavy, hard, somewhat aromatic, astringent, and slightly acrid. They contain about o.I per cent. of an oily liquid alkaloid, arecoline, which chemically and in its physiological action resembles pelletierine; I4 per cent. of tannin, resembling catechutannic acid; gallic acid; a red coloring principle; and $\mathrm{I} 4$ per cent. of a 
fixed oil. They also contain 3 other alkaloids: arecaine, a recaidine, and guvacine, but these do not seem to give the drug its properties.

CArNAUba-wax is obtained from the Carnauba-palm of Brazil (Copernicia cerifera). The wax exudes from the surface of the young leaves and is obtained by boiling them with water. DraGon's

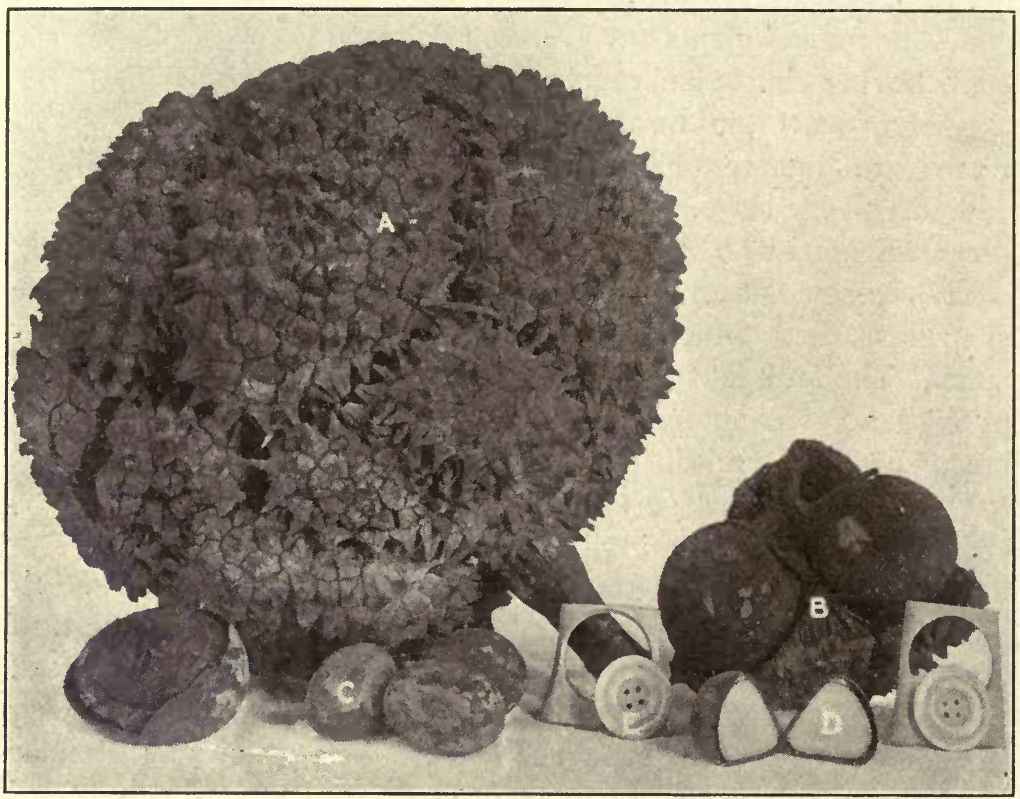

Fig. 258. Vegetable Ivory, the endosperm of the seeds of a Central American palm (Phytelephas macrocarpa). The fruits are produced near the ground, are nearly globular, measuring about $\mathrm{I}$ meter in circumference, and weigh about 14 pounds each. They are covered with a woody spinose wall (A), and enclose a number of drupes (B), each of which contains a single hard seed (C). The latter contains a hard, white, fine-grained endosperm (D); it is used in making small articles of turnery, as buttons, etc.-Reproduced by permission of The Philadelphia Commercial Museum.

BLOOD, a bright red resinous substance, is obtained from the juice of the fleshy fruit of Calamus Draco. It consists chiefly of resin, some tannin, and about 3 per cent. of benzoic acid.

The Oil palm (Elcis guineensis) of equatorial West Africa yields a drupe with an oily sarcocarp, from which, by means of pressure or boiling with water, PALM oIL is obtained. The Cocoanut palm (Cocos nucifera) yields the COCOA NUT of the market, 
and is probably one of the most useful palms to the natives, furnishing, as it does, food, clothing, utensils of all kinds, building materials, etc. The Sago-palms (Metroxylon Rumphii and $M$. lave) yield sago, which is prepared by washing out the starch from the cut stems and subsequently heating it. A tree I5 years old yields from three to four hundred kilograms of sago starch. The Date palm (Phonix dactylifera) yields the DATEs of the

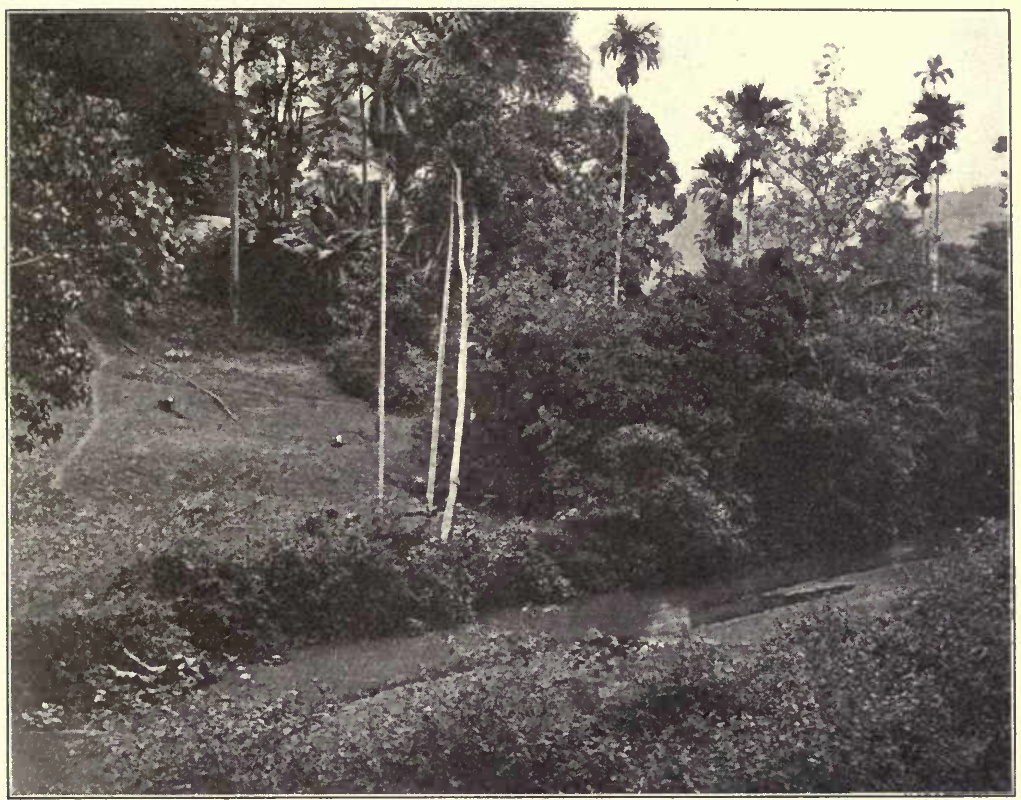

FIG. 259. A number of Areca-nut palms (Areca Catechu) growing in Ceylon. The stems are slender, attaining a height of 25 meters or more, with a diameter of 3 to $4 \mathrm{dm}$. and bearing a cluster of leaves at the summit. The palm is also known as the Betel-nut palm, and is extensively cultivated throughout tropical India.--Reproduced by permission of The Philadelphia Commercial Museum.

market, and it is interesting to note that since very early times the fruits produced by the growers in the Orient have been the result of artificial or hand-pollination.

\section{ORDER ARALES OR SPATHIFLORA.}

This order includes two families which are markedly different in their habits: (I) The Aracex, which are rather large herbs with an inflorescence known as a spadix and consisting of a fleshy 


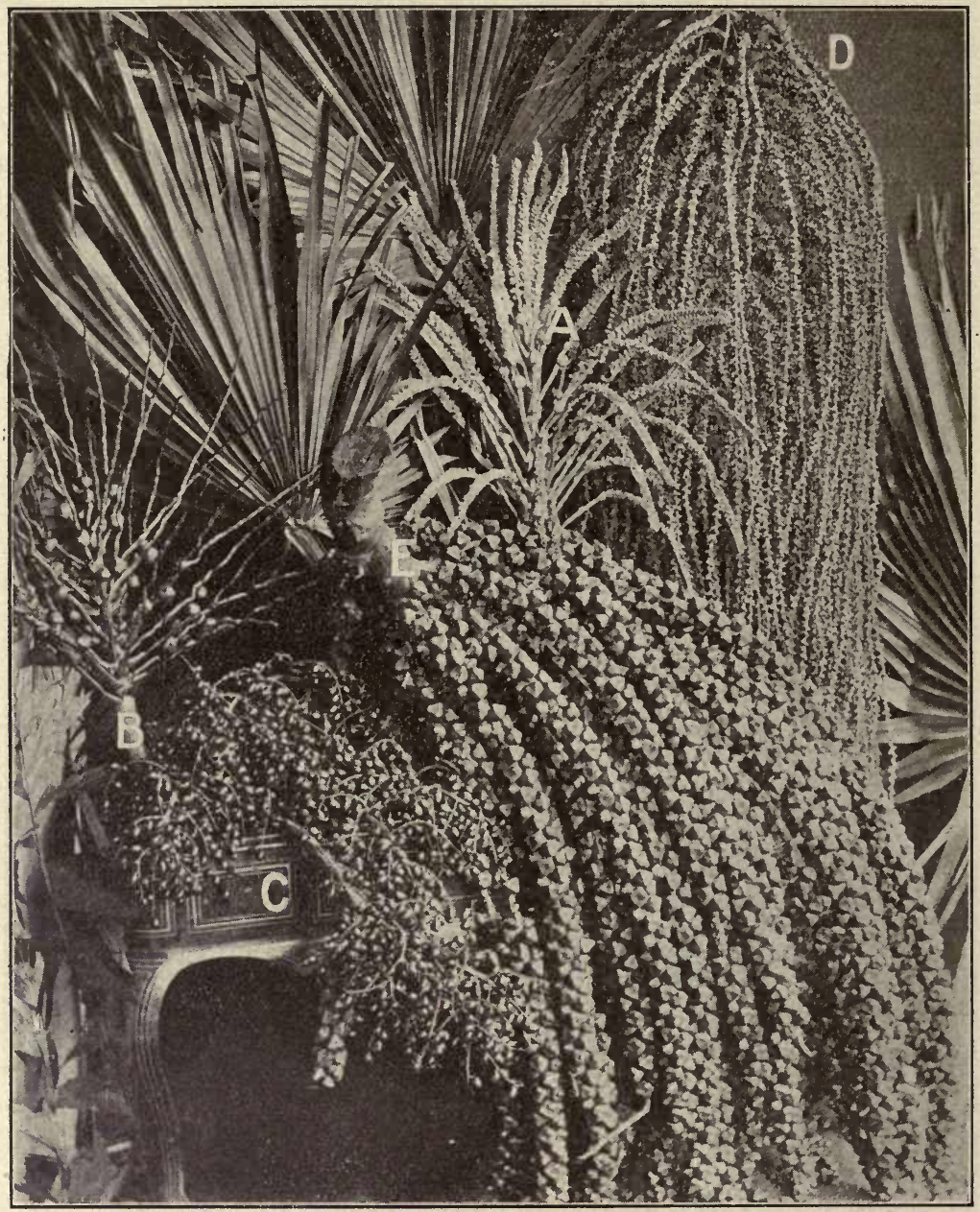

FIG. 260. Fruits and Howers of several of the palms. A, cluster of flowering spikes of the cocoanut palm (Cocos nucifera); $\mathrm{B}$, number of the young fruits of the cocoanut palm; C, cluster of the ovoid fruits of the betel-nut palm (Areca Catechu); D, compound inflorescence of drooping spikes of the kittul (kittool) palm (Caryota urens); E, large clusters of deltoid fruits of kittul palm.-Reproduced by permission of the Philadelphia Commercial Museum.

The cocoanut palm yields a larger number of economic products than any other tree in the world; the fruit is edible and yields the cocoanut oil, the sap produces an alcoholic beverage, the leaves are used for making useful articles, and the wood is employed in cabinet making.

The Betel-nut palm yields a number of valuable products, the most important being the seed, which is not only used to stimulate digestion, but is used in many religious ceremonies, as well as in regulating the intercourse of the more polished classes of the East. The hase of the leaf stalks of the kittul palm yield a fiber which is elastic, shows considerable tenacity, and is used in the making of brushes for brewers' use. 


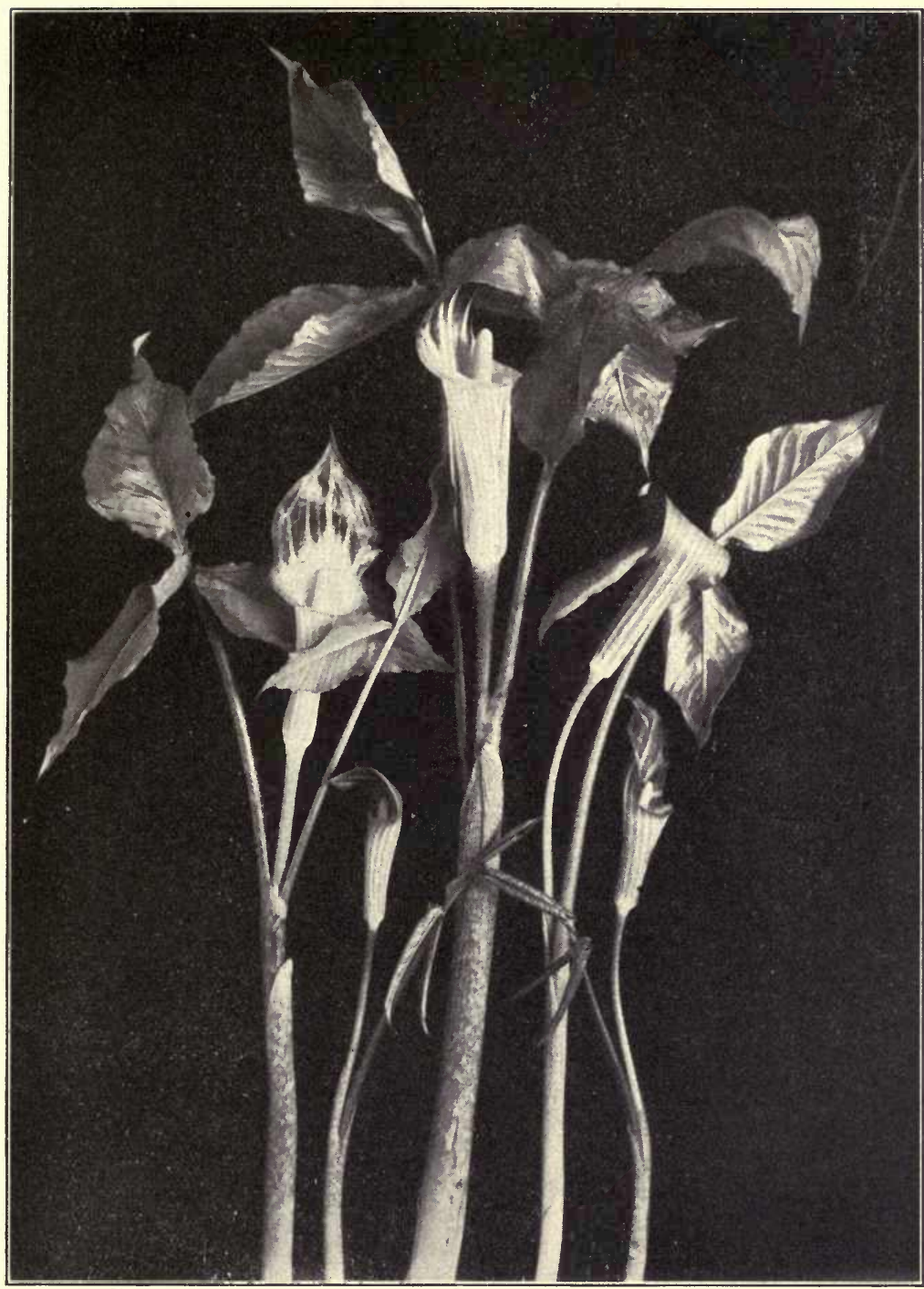

FIG. 26r. Jack-in-the-Pulpit, or Indian Turnip (Arisama triphyllum), a very common perennial herb growing in woods and thickets of the eastern and central parts of the United States and Canada, and characterized by $\mathbf{I}$ or 2 leaves which are divided into 3 ellipticalovate, pointed leafiets and a characteristic spathe of a greenish color, frequently purplestriped and curving in a broad flap over the top of the club-shaped spadix. The plant produces a turnip-shaped corm with an intensely acrid juice.-After Tioth. 
spike, which is subtended or enclosed by a large bract known as a spathe, as in the Calla-lily, where it is large and white, and (2) the Lemnaceæ or duckweed family, which is composed of minute,

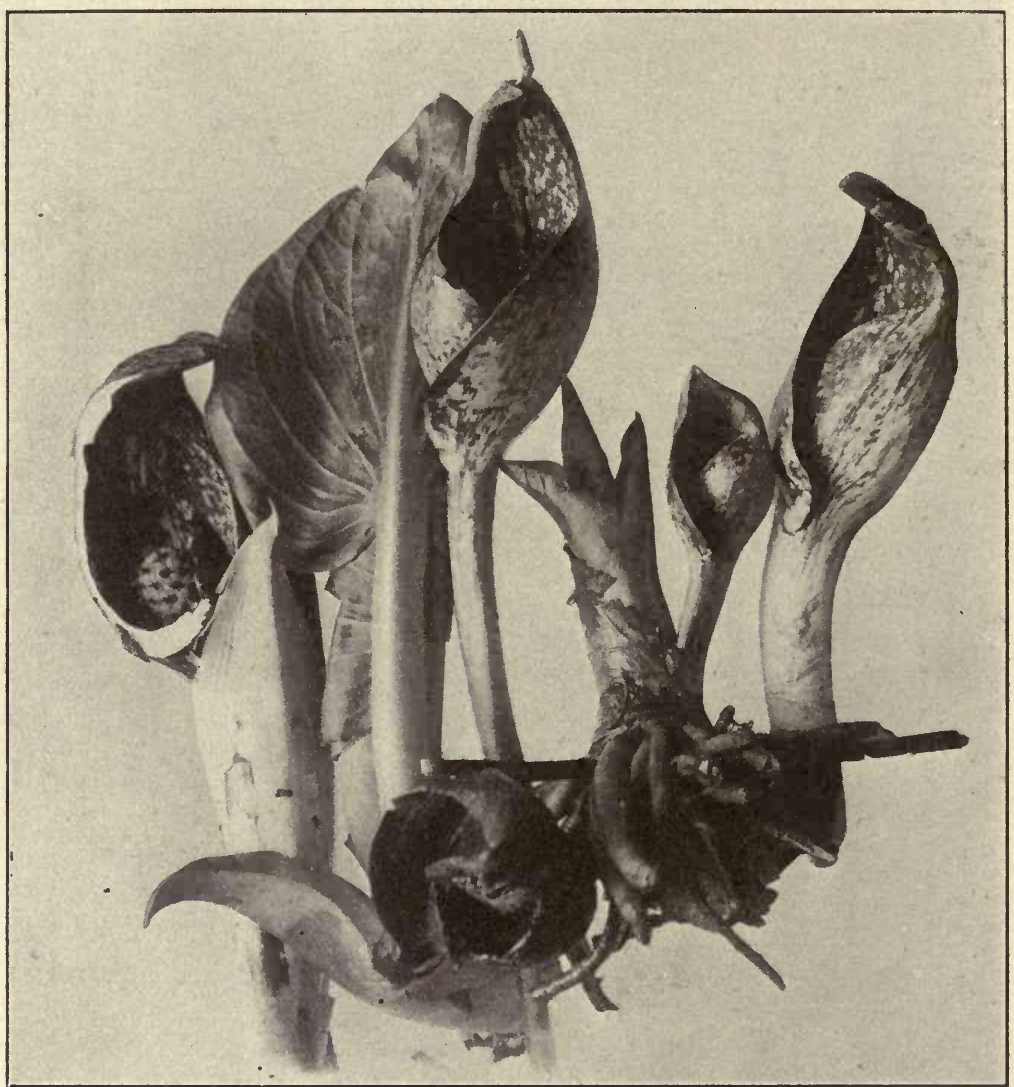

FIG. 262. Skunk Cabbage (Symplocarpus fatzdus), a perennial herb producing a very thick rhizome, from which arise in the early spring the flowers crowded on a spadix surrounded by a large, shell-like spathe which barely rises out of the ground and is striped or spotted with purple and yellowish-green. These are followed by a cluster of ovate, cordate leaves becoming 3 to $6 \mathrm{dm}$. long. In the illustration are shown 4 of the spathes, the one at the left being cut open to show the globular or ovoid spadix, and a single leaf unfolding.After Troth.

floating, thalloid plants that develop one or more flowers on the margin or upper surface of the thallus.

ARACEA, OR ARUM FAMILY.-The plants belonging to this family are perennial herbs with tuberous or fleshy rhizomes 
and simple or compound leaves which are usually long-petioled. The spadix is densely flowered, the staminate flowers being above and the pistillate below on the same axis, or the plants are wholly diœcious. The perianth when present consists of 4 to 6 scale-like segments. Frequently the spadix is subtended or enclosed by a more or less showy spathe. The fruit is usually a berry, sometimes a utricle.

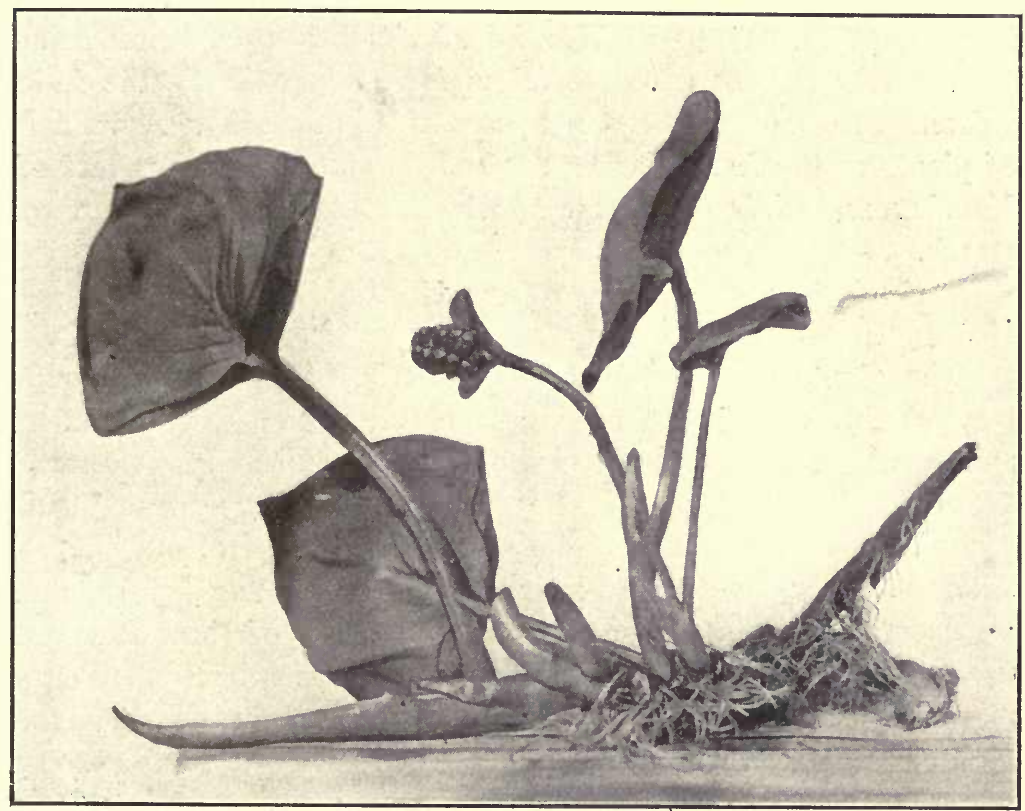

FIG. 263. Water Arum (Calla palustris), showing portion of rhizome, the broadly ovate and cordate leaves, and the inflorescence, which consists of a cylindrical spadix and an elliptical spreading spathe.

A number of the plants of this family have medicinal properties, and one of them yields the unofficial drug calamus. The drug is derived from sweet flag (Acorus Calamus), a plant common in swamps and along streams in the Eastern United States, and characterized by its long, narrow, linear, bilateral leaves, which are from 6 to $18 \mathrm{dm}$. in height and about $25 \mathrm{~mm}$. in width. The inflorescence is a spike-like spadix having greenish-yellow flowers. Many of the Araceæ possess an acrid juice. The acridity is 
probably due either to saponin or an acrid volatile principle rather than to raphides of calcium oxalate. Frequently these principles are dissipated or destroyed on cooking, and the plants are then used as food, as the WATER ARUM (Calla palustris), which on account of its acrid principles is used as a remedy for snake bites when in the fresh condition, but which on drying loses. its acridity and being rich in starch is used as a food (Fig. 263). To this family also belong Jack-in-the-pulpit, or INDIAN TURNIP (Arisama triphyllum), the acrid corm of which is used in medicine (Fig. 26I); SKUNK CABBAGE (Symplocarpus fotidus), the fetid rhizome of which has medicinal properties (Fig. 262). A number of plants of the Arum family are rich in starch, as the tubers of Xanthosoma edule of Surinam, which contain 62 per cent. of starch.

\section{ORDER XYRIDEALES OR FARINOSÆ.}

The plants are mostly perennial herbs of tropical and subtropical America. The order includes a number of families, among which is BROMELIACE E, to which the pineapple (Ananas sativus) belongs. Pineapple is a native of Brazil and is now cultivated in warm countries of the eastern and western hemispheres. The fruit contains a proteolytic enzyme resembling trypsin and also a milk-curdling ferment. The bast fibers of the leaves are used for textile purposes. Some of the Bromeliacex are epiphytic (air-plants), the best known member being probably the FLORIDA MOSS (Tillandsia usneoides), which is used in upholstery (Fig. 264).

The family Commelinaceæ is represented in the United States by Commelina or day-flower, some species of which have medicinal properties. The roots of some tropical species contain saponin, as $C$. deficiens, of Brazil. The rhizomes of a number of species of Commelina contain notable quantities of starch and are edible. The spiderworts (Tradescantia) common in rich soil in the United States, and the Wandering Jew (Tradescantia Zebrina) commonly cultivated as an ornamental plant, also belong to this family. To the PONTEDERIACE E belong several perennial aquatic or bog plants, whose leaves are usually thick or in some cases long and grass-like. The flowers are frequently arranged in Spikes subtended by leaf-like spathes (Fig. 265). 


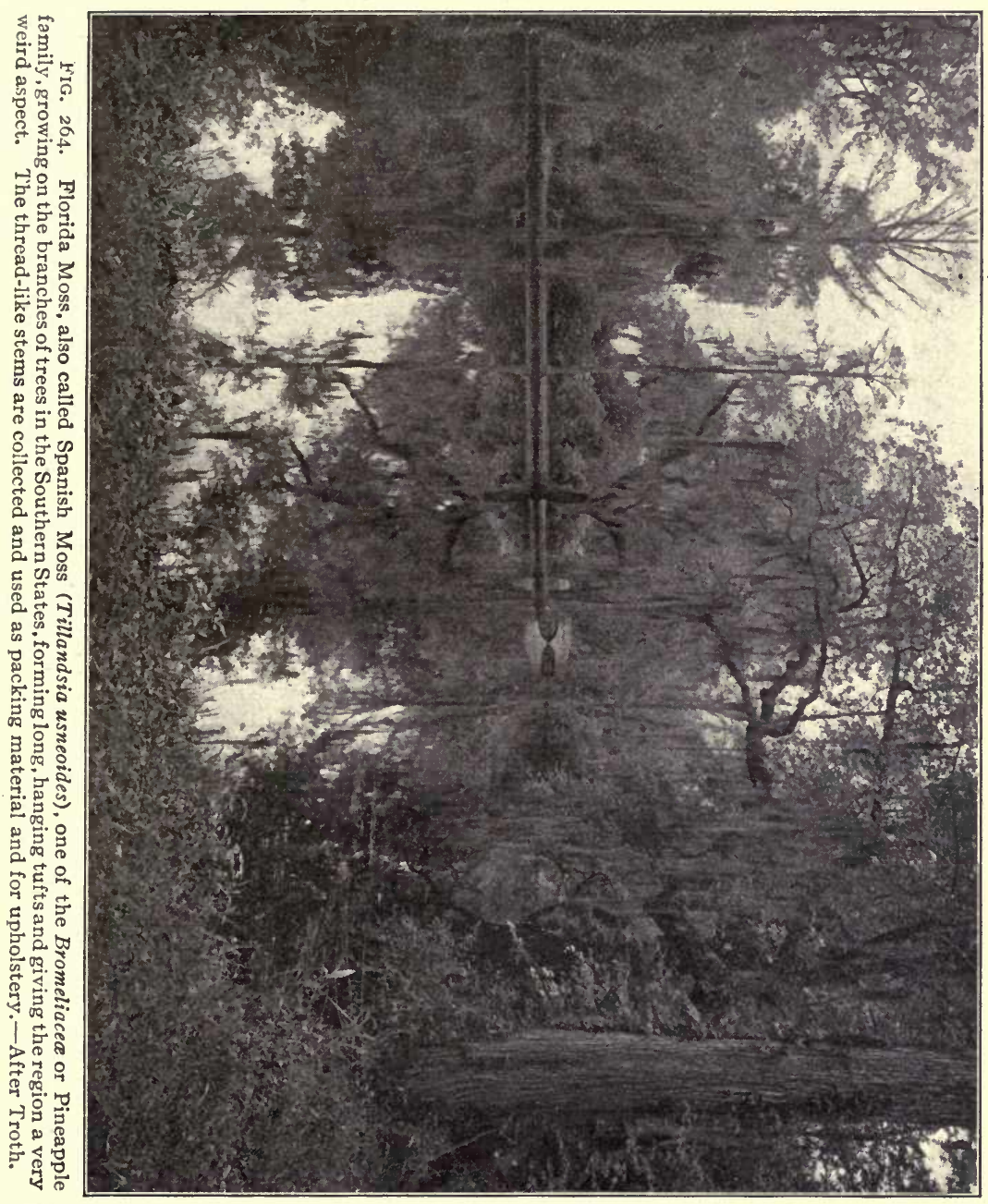




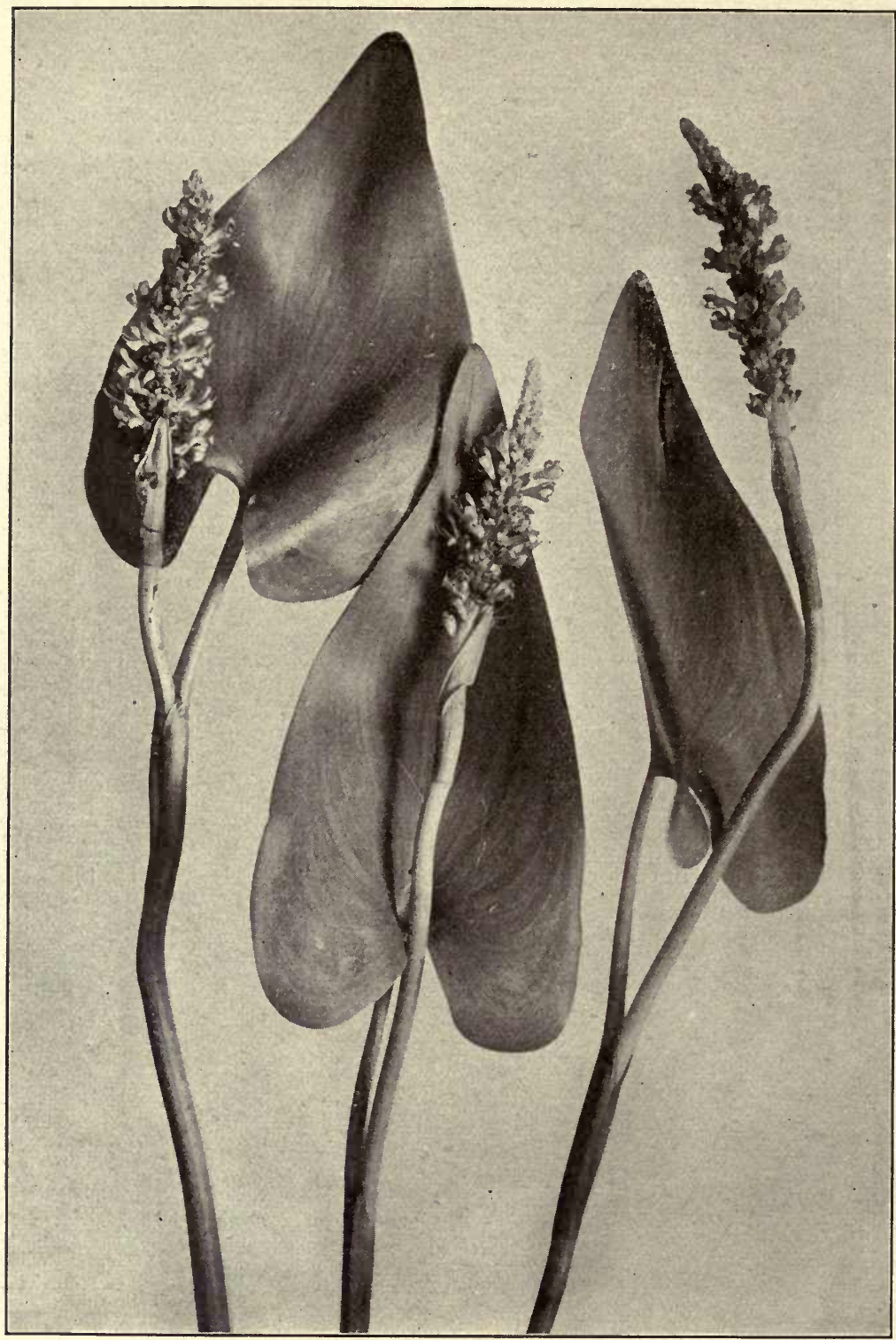

FIG. 265. Pickerel Weed (Pontederia cordata), a common aquatic herb growing along the margin of slow sireams. It is a very hardy plant occurring far north and grows best in water ten or twelve inches deep. It produces long-petioled leaves and a single stem bearing a spike of violet-blue, ephemeral flowers.-After Troth. 


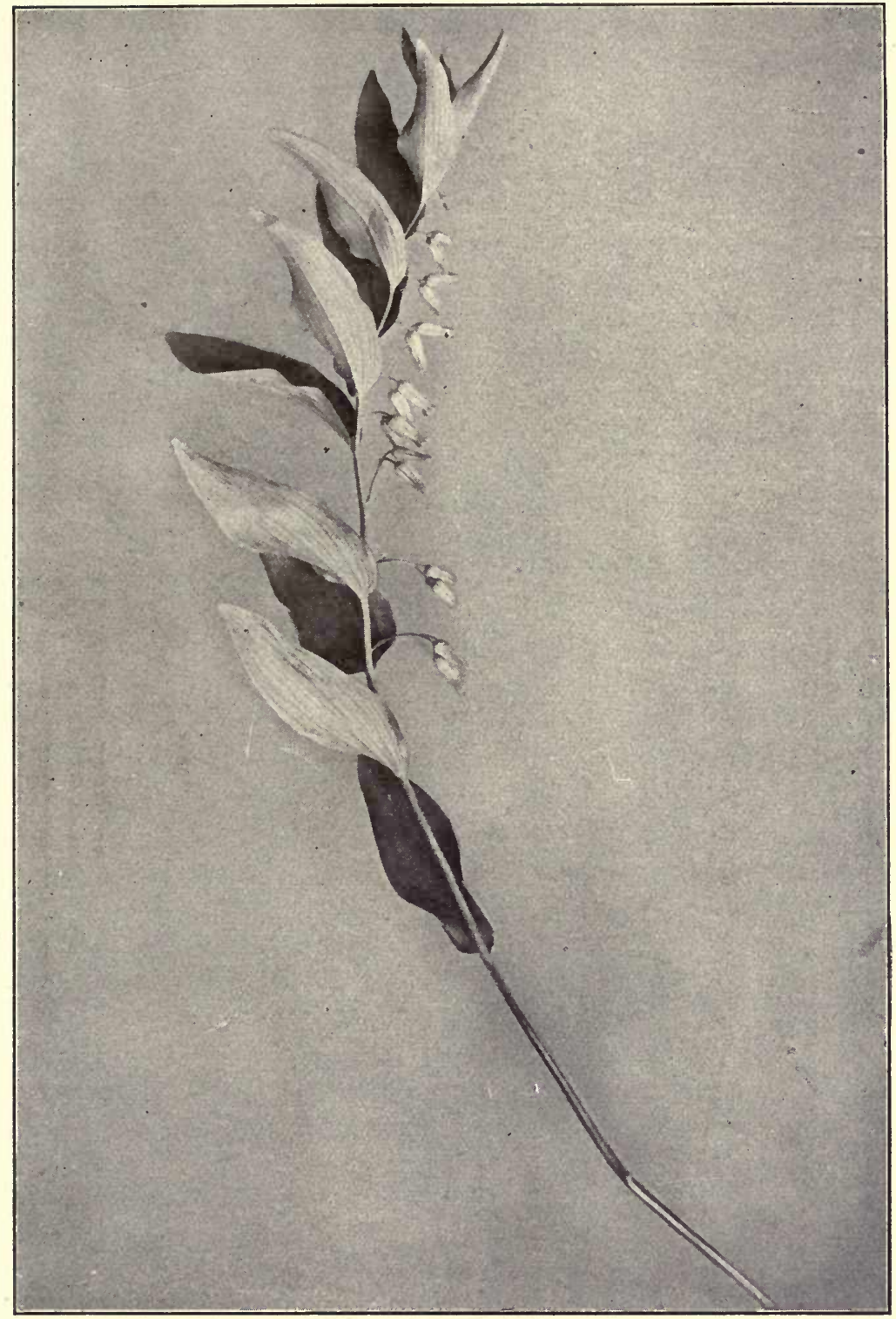

Fig. 266. Small Solomon's Seal, also commonly known as true Solomon's Seai (Polygonatum biflorum). It is a perennial herb with lance-oblong, sessile leaves, in the axils of which are usually two nodding greenish flowers. The plant grows in moist woods or wooded hillsides, and receives its common name from the creeping knotted rhizomes, on the upper surface of which are usually one or more prominent circular scars, formed upon the decay of the aërial shoots.-After Brown. 


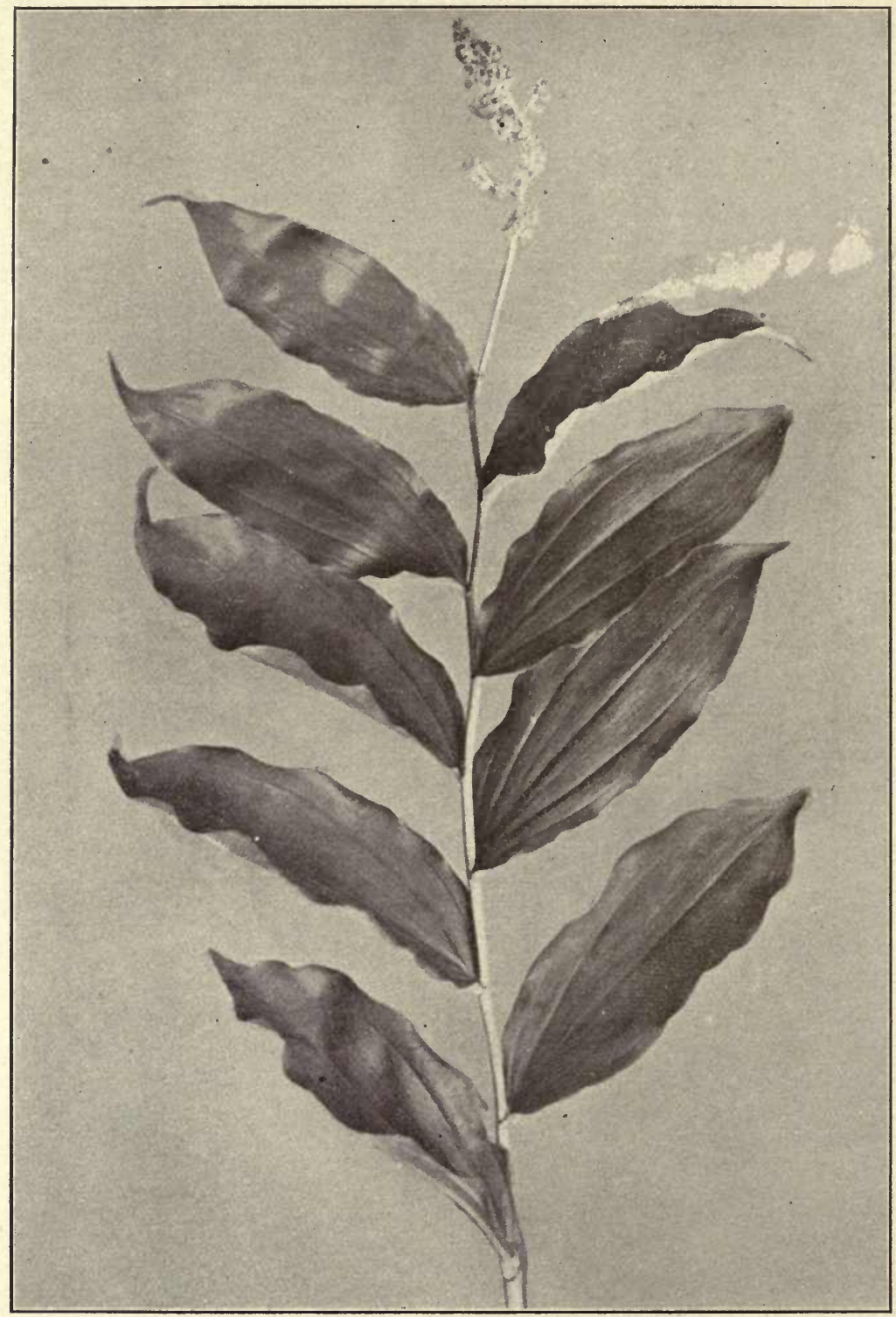

FIG. 267. False Solomon's Seal or False Spikenard (Smilacina racemosa), a perennial herb with a somewhat stout stem, a number of alternate parallel-veined leaves and a terminal raceme of whitish, sometimes fragrant, flowers. It forms a horizontal knotted rhizome, on the upper surface of which are found circular scars. It may be found growing in underbrush in moist woods. - After Brown. 
VII. ORDER LILIALES OR LILIIFLORE.

The plants of this order are mostly perennial herbs with rhizomes, tubers, bulbs, or fibrous roots. The leaves are parallelveined.

a. LILIACE $Æ$ OR LILY FAMILY.-The plants are the most typical of the Monocotyledons. They are scape-like herbs with bulbs; the flowers are symmetrical, and the perianth is parted into 6 more or less distinct segments (Fig. I23); the anthers are introrse. The ovary is free, 3 -locular, with a single style, and the fruit is a 3 -locular, loculicidally dehiscent capsule.

The Liliacex is one of the most important families, containing about 2500 species, many of which are of great economic interest. Quite a number are cultivated on account of the beauty and fragrance of their flowers. Among the latter are the hyacinth, lily, lily-of-the-valley, tuberose, tulip, and yucca. Of those yielding food products we have asparagus, being the young shoots of Asparagus officinalis. The edible bulbs include the onion (Allium Cepa), garlic (Allium sativum), the leek or scullion (Allium Porrum), and chives (Allium Schonoprasum). A number of the Liliaceæ are among the common wild flowers, as swamp pink (Fig. 272), bellwort (Uvularia), lily (Lilium), dog's-tooth violet (Erythronium), Star of Bethlehem (Ornithogalum), False Solomon's Seal (Fig. 267), True Solomon's Seal (Fig. 266), Indian Cucumber-root (Medeola), colic-root (Fig. 27I), cat brier (Smilax), etc. The following plants are of medicinal interest:

Veratrum viride is a plant 2 to 8 feet high, which is characterized by the broad, clasping, strongly plicate leaves, and by having the flowers in large terminal panicles (Fig. 268). The plant is found in swamps and wet woods in the United States in spring and early summer. The rhizome is upright, and it with the roots is used in medicine. The plant, including the rhizome, closely resembles the Veratrum album of Europe.

Colchicum autumnale.-This is the autumnal-flowering colchicum, a perennial herb but a few inches high which arises from a corm and bears proportionately large lilac-colored flowers. The fruit consists of 3 follicles containing numerous seeds. The corm and seeds of this and other species of Colchicum are used in 


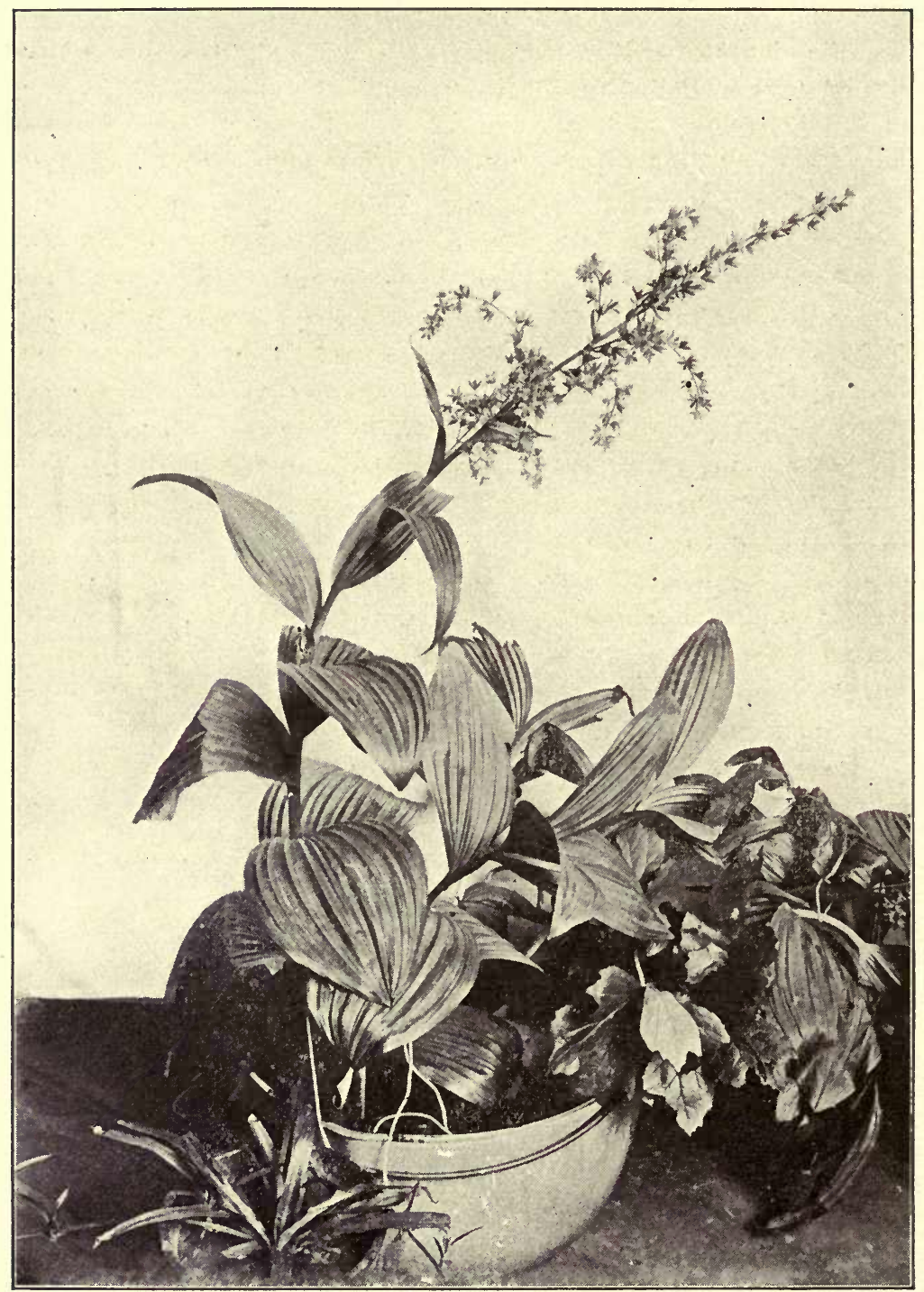

FIG. 268. Flowering specimen of Veratrum viride, showing the spreading, spike-like racemes and the parallel-veined leaves. 
medicine. Among the species yielding large corms and extensively cultivated is Colchicum Burmanii (Fig. 269).

Aloe species.-The stems are abcut a meter high and bear at the summit a cluster of thick, succulent leaves which are lanceolate and spinous-toothed (Fig. 270). The inflorescences are in long spikes which are quite showy and characteristic for the different species. Aloe Perryi, which yields the Socotrine aloes, possesses leaves with white spines and flowers that are orange-red or scarlet at the base, the stamens being unequal; Aloe vera, which yields the Barbadoes or Curacao aloes, has leaves with yellow or reddish spines and yellow flowers in which the stamens are as long as the corolla; Aloe ferox and some other African species, which yield CAPE and UGANDA ALOEs, have flowers in close spikes, the petals being white and marked by green lines, and the stamens much longer than the corolla. The inspissated juice is official in all the pharmacopœias.

Urginea maritima, which yields the drug squill, is characterized by its large, onion-like bulb, from which arise ten to twenty broadly lanceolate, grayish-green leaves; and by having the inflorescence in long spikes consisting of whitish flowers which have a distinctly purple stripe on each division of the perianth.

Convallaria majalis or Lily-of-the-valley is a plant which is well known. It produces a raceme of delicately odorous white flowers and beautiful oblong leaves with prominent parallel veins. The rhizome and roots are official.

Smilax species.-The drug sarsaparilla is yielded by at least four different species of Smilax. These are mostly vines with woody or herbaceous, often prickly stems and leaves with petioles which have a pair of persistent tendril-like appendages. The flowers are small, mostly greenish, diœcious and in axillary umbels. The fruit is a globose berry. Not a great deal is known of the species which yield the drug, with the exception of Smilax medica, which yields the Mexican or Vera Cruz sarsaparilla. In Smilax medica the leaves vary from more or less cordate to auriculatehastate; in Smilax officinalis, which yields the native Jamaica sarsaparilla, they are ovate, as they are also in Smilax papyracea, which yields Para sarsaparilla. The Jamaica Sarsaparilla, official in the British Pharmacopœia, is obtained from plants of Smilax 
ornata growing in Costa Rica and subsequently shipped to Jamaica. Nothing is known of the plant yielding Honduras sarsaparilla, although this drug has been in use for nearly four centuries. It

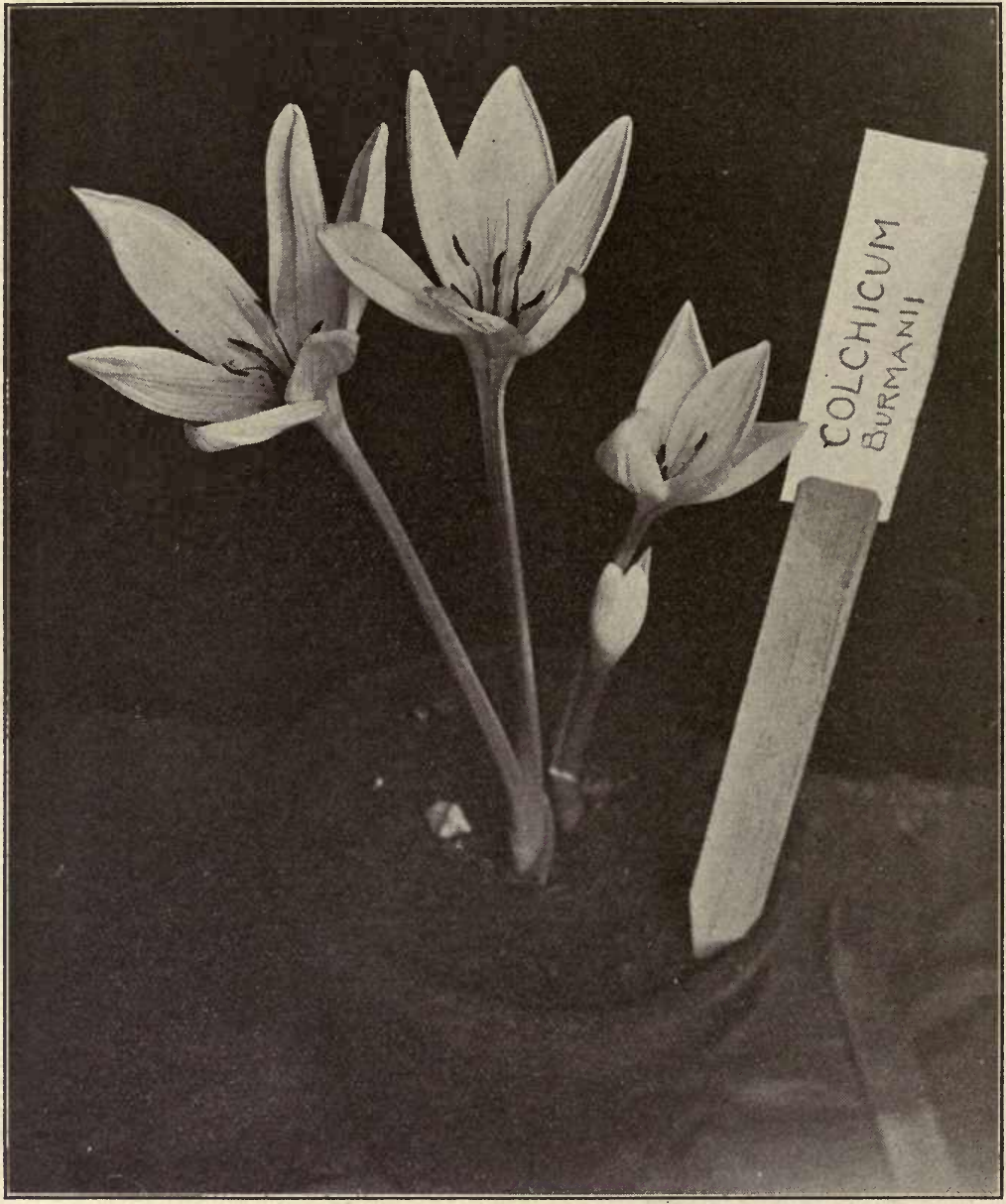

FIG. 269. Flowering plant of Colchicum Burmanit, a form producing very large corms and extensively cultivated in Holland.

is said to be derived from Smilax officinalis. The sarsaparilla plants have short rhizomes which give rise to long roots, which are the part used in medicine.

A DRAGON'S BLOOD, resembling that derived from Calamus 
Draco, is obtained from Dracana Draco, a tree growing in the Canary Islands. Some of the trees of this species are of historic interest, as the dragon tree of Orotava, which is 46 feet in circumference at the base.

A number of the plants of this family contain saponin, as the species of Smilax. Some contain coniferin and vanillin, as Asparagus officinalis. Some of the group contain glucosidal principles which under the influence of ferments yield ethereal oils contain-

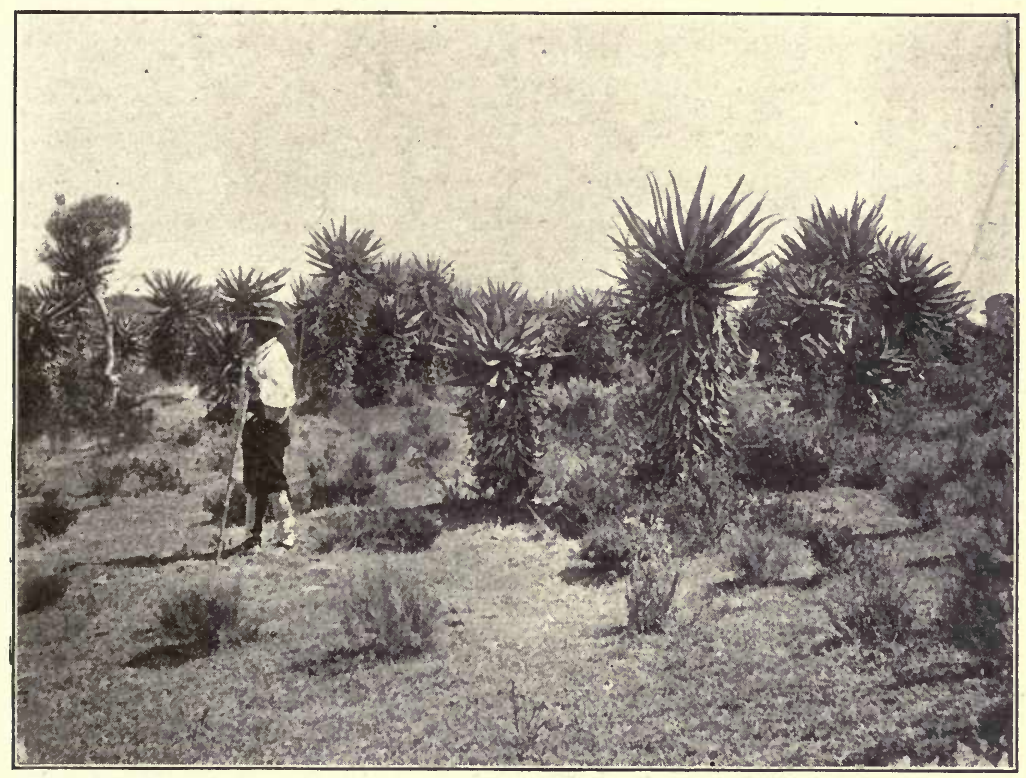

FIG. 270. A field of Aloe plants, growing in the Riversdale District, Cape Colony. The stems are simple, with one or more clusters of leaves; the latter are from 3 to $6 \mathrm{dm}$. in length, fleshy and very thorny-prickly at the margin.--Reproduced by permission of the Philadelphia Commercial Museum.

ing sulphur, as the varrous species of Allium. Garlic (Allium sativum) contains a glucoside, allisin, which on hydrolysis with an oxidase (allisin) forms the essential oil of garlic. A number also are quite poisonous when fresh but edible when cooked.

b. AMARYLLIDACE E. OR AMARYLLUS FAMILY.This group is of special interest because it includes the Agave or Century plant. This is a characteristic genus of plants of the hot and arid regions of North America. The best known of these 
is the Century plant (Agave americana), which is one of the most important economic plants of Mexico. The stem axis of the plant is very short and the thick; fleshy leaves form a tuft at

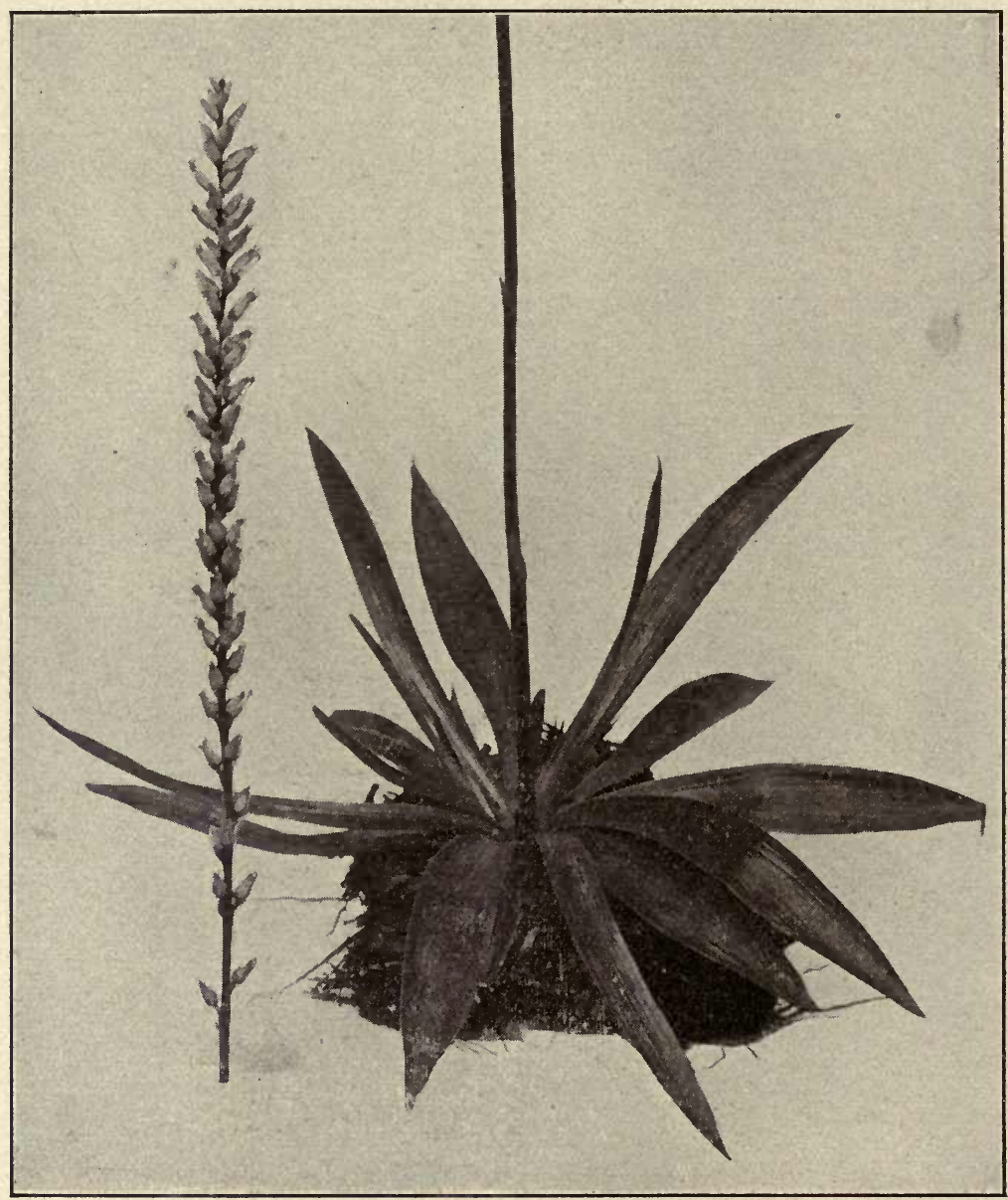

FIG. 27I. Plant of Aletris farinosa showing characteristic rosette of lanceolate leaves at the base and portion of long slender scape with numerous tubular flowers. The plant is common in dry coniferous woods in the eastern part of the United States.

the summit. The leaves are lanceolate, with spinose margins, and furnished with stout terminal spines. The leaves as well as the roots contain a large amount of mucilage which retains water and 


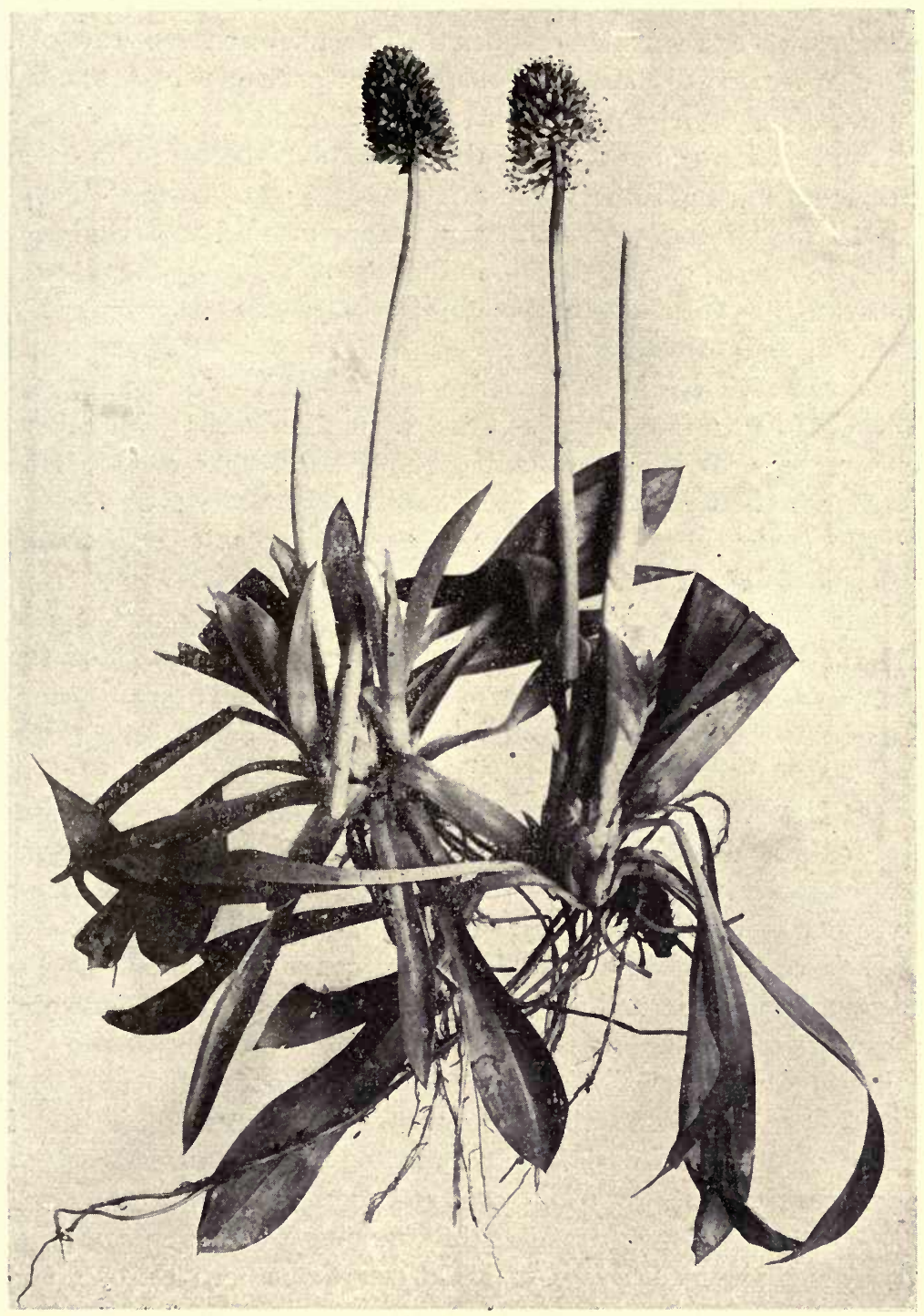

Fig. 272. Swamp Pink (Helonias bullata) is a rather rare plant found only in certain localities, particularly in wet places, extending from southern New York to Virginia. It produces a tuberous root-stock, and the evergreen leaves are clustered near the base of a naked scape which bears in the early spring a short raceme of purplish flowers. This should not be confounded with the plant yielding the drug known as Helonias or false unicorn root, the latter being derived from Chamalirium luteum, and at one time known as Helonias dioica.-After Troth. 
thus helps to adapt the plants to these arid regions. The plants grow. slowly and may flower when they are ten or twelve years old.

The Agaves contain saponin and other principles of medicinal value. They yield a number of other products, as follows: Pulous, a fermented drink of the Mexicans; Mezcal, a distilled drink resembling rum; various fibers, as SisAL HeMp, "Henequen" or "Sacci," etc. Other members of the Amaryllidacex likewise find use as medicines and as foods, many of them being cultivated as ornamental plants, as Narcissus, Hymenocallis, Crinum, and Amaryllis.

c. DIOSCOREACE E OR YAM FAMILY.-The plants belonging to this family are twining shrubs or herbs with tubers either above or below ground. The general characters of the plants are shown in the wild yam-root (Dioscorea villosa) of the United States (Fig. I80). Several species, notably, D. Batatas, yield the YAMs or Chinese potatoes of commerce.

Many of the species of Dioscorea, as well as other members of this family, contain active principles which, like those of the Araceæ and Liliaceæ, are destroyed on heating. The rhizome of Tamus communis contains saponin, and Rajania subamarata contains tannin.

d. IRIDACEÆ OR IRIS FAMILY.-The plants of this family are perennial herbs with mostly equitant (bilateral) leaves and horizontal rhizomes, or corms. The flowers are regular or irregular and with a petalloid stigma (Fig. 254, B).

Iris versicolor is a flag-like plant, commonly known as the LARGER BLUE FLAG, and found abundantly in the marshes and wet meadows of the Eastern United States. It is distinguished by its tall stems and sword-shaped, somewhat glaucous leaves. The flowers are violet-blue. The rhizome somewhat resembles that of calamus, but is of a dark brown color and contains 25 per cent. of acrid resins, a volatile oil, starch, and tannin.

Iris florentina, which yields the ORRIS ROOT of commerce (Fig. I90), is a plant cultivated in Middle and Southern Europe, and closely resembles the above-mentioned species. The rhizome contains a volatile oil resembling that found in violets, and is used in perfumery. Orris root is also obtained from Iris germanica and I. pallida. The violet odor is developed on keeping the rhizome a year or two. 
Crocus sativus, the orange-red stigmas of which have been used in medicine since ancient times, is an autumnal-flowering plant. The flowers are lilac-purple, somewhat like those of Colchicum, and occur at the summit of a scape rising 15 to $20 \mathrm{~cm}$. above ground. The leaves are linear and rise directly from a more or less globular corm. The plant is cultivated in Spain and other parts of Europe and in the United States as well. The stigmas constitute the drug SAFFRON (Crocus), which was formerly official, and contain a coloring principle, I part of which will impart a distinct yellow color to I00,000 parts of water. Saffron contains a yellow glucoside, CROCIN, which is soluble in alcohol but not in water, and is colored blue by sulphuric acid. The drug also contains 7.5 to Io per cent. of a volatile oil, which appears to be derived from a coloring principle that resembles carotin; and the bitter principle picro-crocin.

e. JUNCACE $\approx$ OR RUSH FAMILY.-These are grass-like marsh plants, which are distinguished by the fact that the flowers are small, with a 6-parted glumaceous perianth, and the fruit is a loculicidally dehiscent capsule. The stems are mostly solid, slender, usually arise in tufts from the rhizome, and are characterized by stellate parenchyma cells, among which are large, intercellular spaces, the latter also being characteristic of the leaves. The rushes are principally found in cold and temperate regions.

Several species of Juncus and Luzula have been used in medicine, particularly in Europe. The seeds of Luzula compestris, a common wood rush of the United States naturalized from Europe, are edible. Soft rush (Juncus effusus) and Hard rush ( $J$. conglomeratus) are used in Japan in the manufacture of rush matting. In Holland the rush is grown on the embankments along the coast to prevent the action of the tides.

VIII. ORDER SCITAMINALES OR SCITAMINEA.

The plants of this order are mostly found in the Tropics and are perennial herbs with fleshy rhizomes. The leaves are large, more or less elliptical and pinnately veined. The leaf sheaths close tightly around each other and form a kind of false stem. The flowers are epigynous, unsymmetrical or zygomorphic, and frequently only one stamen is completely developed. 
a. THE ZINGIBERACE $Æ$ OR GINGER FAMILY is distinguished from the other Scitamineæ by the fact that the seeds have endosperm as well as perisperm. The plants are rich in volatile oils, and a number are used in medicine and perfumery.

Zingiber officinale yields the official ginger (Fig. 273). From a creeping, fleshy, branching and laterally compressed rhizome (Fig. I87) arises a stem about. I M. high bearing numerous lanceolate leaves. The flowering stalk arises directly from the rhizome, terminating in a spike which bears flowers having greenish-yellow petals with violet or purple stripes.

Elettaria Cardamomum (E. repens) yields the cardamom of the several pharmacopoias (Fig. 237). The plant has a leafy as well as floral stem which rises from a tuberous rhizome. The leaves are broadly lanceolate. The flowers are greenish-white, the labellum (consisting of two petal-like staminodes) being bluish. The fruit is a capsule, and the seeds are the part used in medicine.

The so-called PARADISE GRAins are the seeds of Amomum Melegueta growing in Western Africa. They are about $3 \mathrm{~mm}$. in diameter, dark brown, nearly smooth, friable, and contain a volatile oil.

GALANGAL, which is used in perfumery, is the rhizome of Alpinia Galanga growing in the East Indies and cultivated in China and Bengal. It is frequently referred to as "Galangal major" to distinguish it from the rhizome of Alpinia officinarum growing in China near Hainan. Galangal occurs in short, branched pieces of a reddish-brown color, with numerous circular scars, and has an aromatic and pungent taste. It contains 0.5 per cent. of a volatile oil, the principal constituent of which is cineol; a pungent principle, galangol; an acrid, pungent resin; 25 per cent. of starch; and three crystalline principles.

CURCUMA or TURMERIC is the rhizome of Curcuma longa, a reed-like plant which is largely cultivated in India and other tropical countries. In preparing the rhizome for market it is subjected to a scailding or parboiling process which agglutinates the starch in the cells. While turmeric is used as a condiment, it is also used on account of its color as an adulterant of mustard, rhubarb, and other articles, but is very easily detected. Several forms of curcuma are found in commerce, as " round curcuma," 
consisting of the main rhizome, and "long curcuma," composed of the short branches. They occur in cylindrical or ovoid pieces,

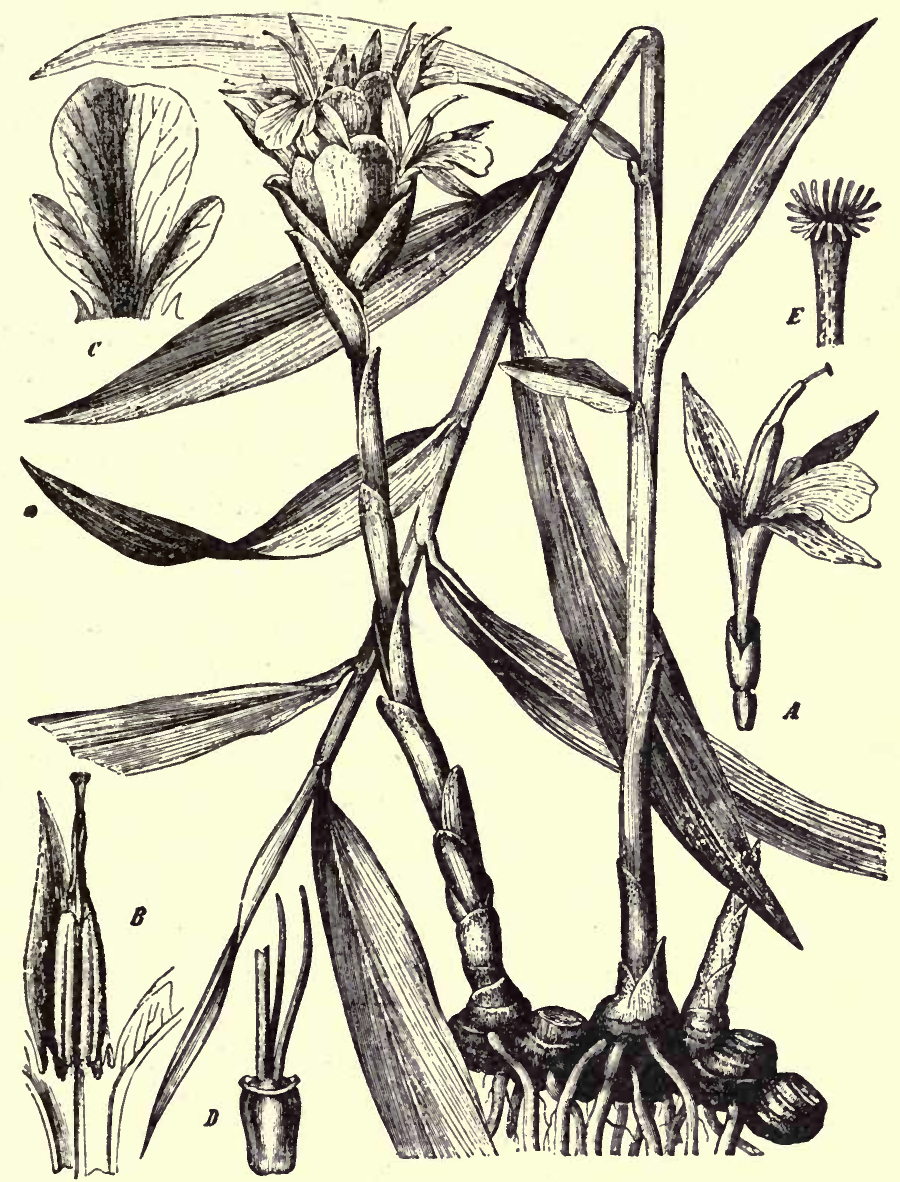

FIG. 273. Zingiber officinale, the rhizome of which constitutes the ginger of the market. Entire plant showing rhizome and roots, a leaf-branch and a flower-branch, as also scars of previous year's growth after decay of leaf- and flower-branches. A, entire flower; B, section of flower showing beak-like appendage at the apex of the fertile stamen, which encloses the style; C, three-parted labellum or irregular segment of corolla showing 2 toothlike staminodes (rudiments of stamens) at the base; D, the ovary with lower portion of style and two epigynous, filiform processes which secrete nectar; E, apex of funnel-shaped, fringed stigma.-After Berg and Schmidt.

2 to $5 \mathrm{~cm}$. long, of a yellowish-brown color externally, bright yellow internally, and aromatic odor and taste. Curcuma contains 
I per cent. of volatile oil containing phellandrene and turmerol; 0.3 per cent. of a yellow crystalline principle, CURCUMIN, which is soluble in alcohol, sparingly soluble in water, forms reddish-brown solutions with alkalies and is converted into vanillin with weak oxidizing agents. It also contains considerable starch and a small quantity of an alkaloid.

Other families of the Scitamineæ are of great importance on account of the food-products obtained from them, as the Musacece, which contains the group of plants to which the BANANA (Musa paradisiaca and M. Sapientum) belongs. To the Cannacea belong the cultivated Cannas, one of them, Canna edulis, being grown extensively in the West Indies and Australia as a vegetable, and another, Canna coccinea, which grows in the West Indies and South America, furnishing "Tous les mois," the arrow-root starch of the English and French. To the Marantacea belongs Maranta arundinacea, which is cultivated in tropical America, and the rhizome of which yields the starch, Maranta ARROWROOT (Fig. 88, $B$ ), and is largely used in the preparation of infants' food.

\section{ORDER ORCHIDALES OR MICROSPERM}

The most important family of this order is the ORCHIDACEA or ORCHID FAMILY. The orchids are the most highly specialized of the Monocotyledons. They are perennial herbs with diverse habits, many tropical species being epiphytes, and of varying morphological structure, which is particularly evident in the zygomorphic flowers. The perianth consists of 6 segments. The 3 outer correspond to sepals and are similar. Two segments of the inner circle correspond to petals and are alike, while the third, which is known as the LIP, is remarkably modified, being usually larger, often spurred, and frequently reversed, being turned forwards and downwards by the twisting or torsion of the ovary. Only one of the stamens - the anterior of the external whorl-is developed and bears an anther. The other stamens are entirely wanting or present as staminodes (except in Cypripedium and the Apostasiex). The filament is united with the style to form a column, the so-called "stylar column," and the anther is thus placed on its apex, and behind the stigma. The 3 carpels form a unilocular ovary with 3 parietal, deeply bifid placentæ. The fruit 
is a pod or capsule, which dehisces mostly by means of 6 valves, and contains numerous minute seeds, which are without endosperm, and the embryo of which lacks frequently any trace of external organs. The seed-coat is membranous and loose.

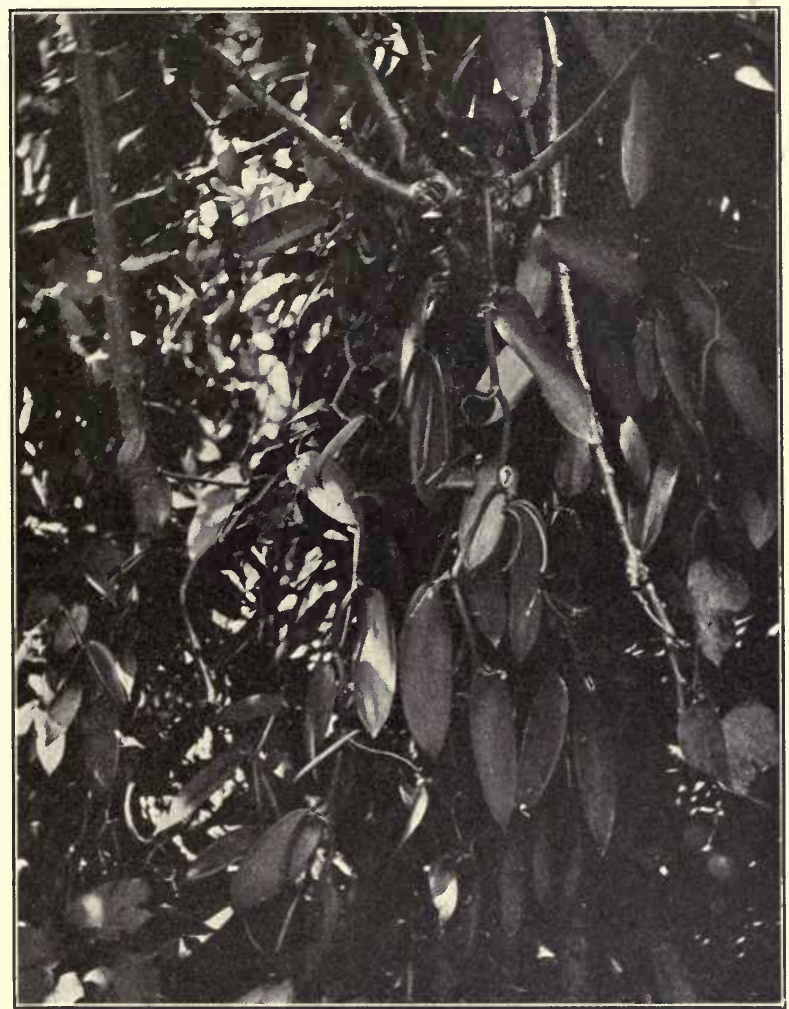

Fig. 274. A fruiting plant of Vanilla planifolia, an epiphytic orchid, which is indigenous to Mexico and extensively cultivated in tropical countries, especially in Mexico and Java. The photograph is of a plant growing in Dominica, an island of the West Indies, and shows the long, elliptical leaves, also some of the long, slightly curved, slender pods. The latter are not fragrant, but develop their characteristic aroma by a process of slow curing.-Reproduced by permission of The Philadelphia Commercial Museum.

Vanilla planifolia, which yields the official vanilla, is a highclimbing plant with long internodes and distinct nodes from which arise more or less oval or broadly lanceolate, somewhat fleshy leaves and also commonly a single aërial root. The long stem is terminated by a raceme, flowers also arising in the axils of the 


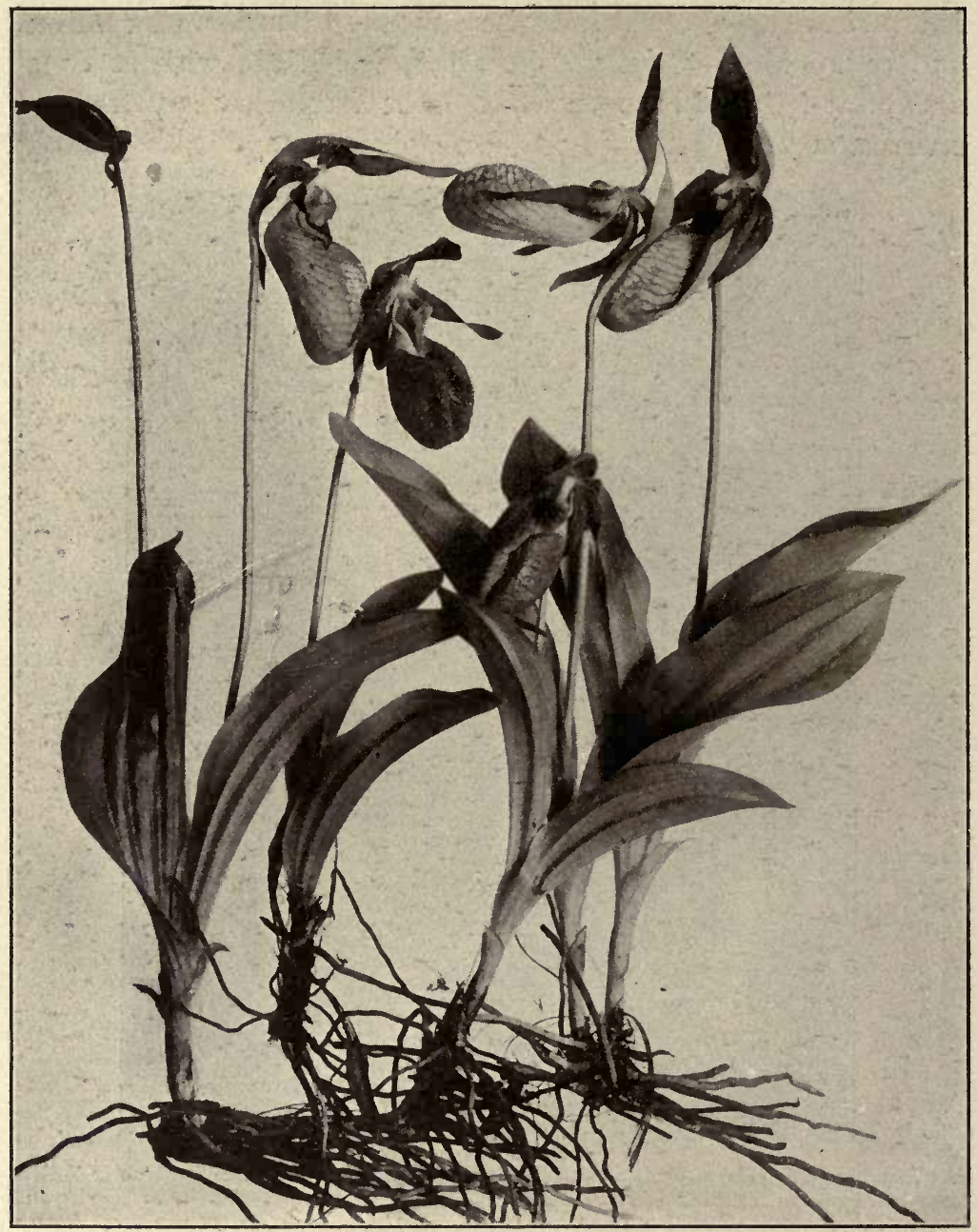

Fig. 275. Moccasin Flower or Pink Lady's Slipper (Cypripedium acaule), one of the commonest and most beautiful of the orchids, found growing in sandy and rocky woods from Newfoundland to North Carolina, and westward from Minnesota to Kentucky. The crimson pink flowers are solitary at the summit of long scapes; the lip is large inflated. slipper-shaped, drooping and with a fissure in front instead of a circular opening as in the other species.-After Troth.

leaves for some distance back on the stem. The flowers are yellowish-green and the segments of the perianth are similar, and erect or spreading. The lip is united with the column, forming a 


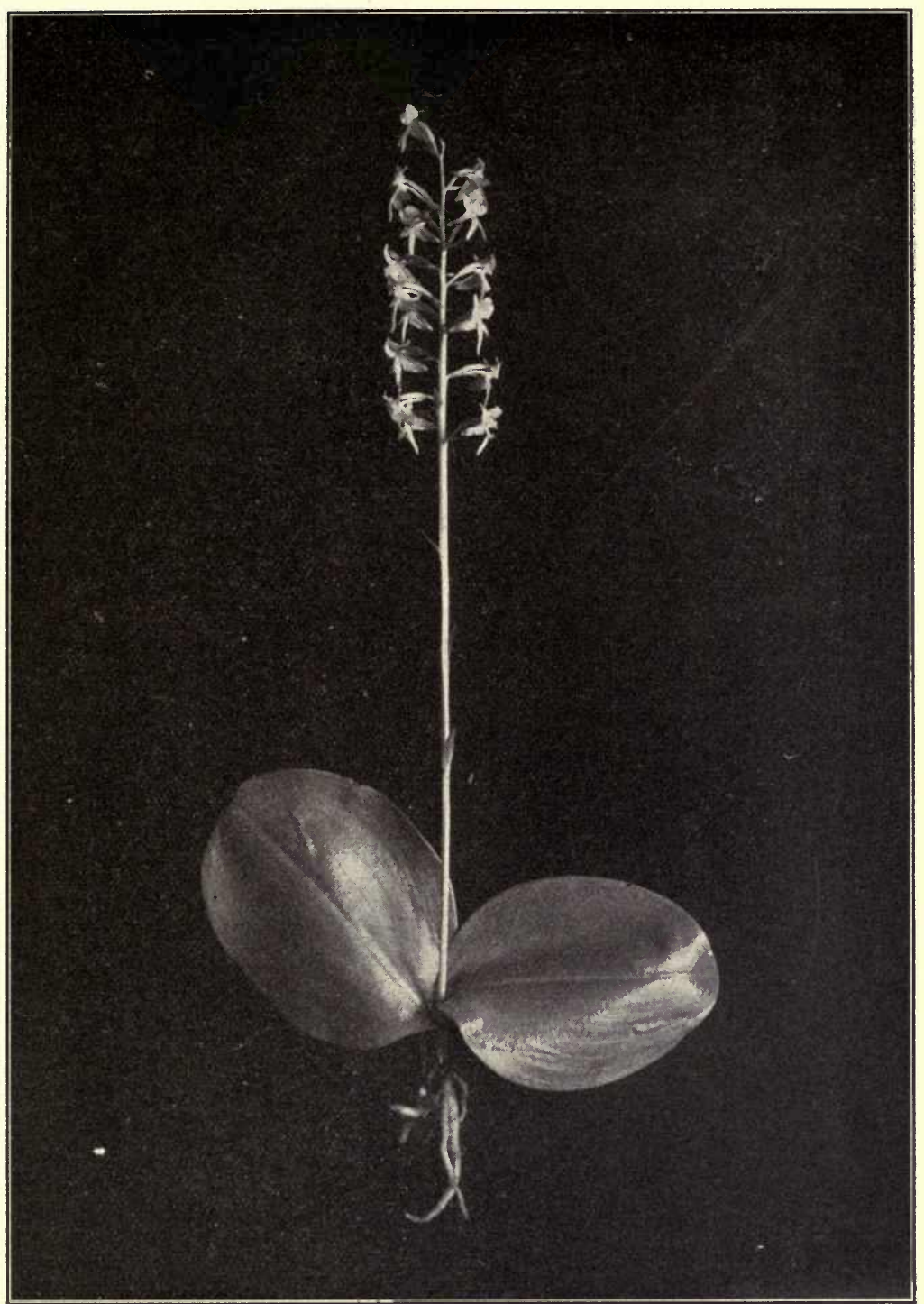

FIG. 276. Round-leaved Orchis (Habenaria orbiculata), an interesting orchid found growing in rich deep woods in the north temperate regions of the United States. It has a leafless scape, at the base of which are two orbicular or elliptical leaves spreading flat on the ground. The flowers are in a loose raceme, greenish-white, the lip being oblong linear and about the same length as the spur.-After Troth. 


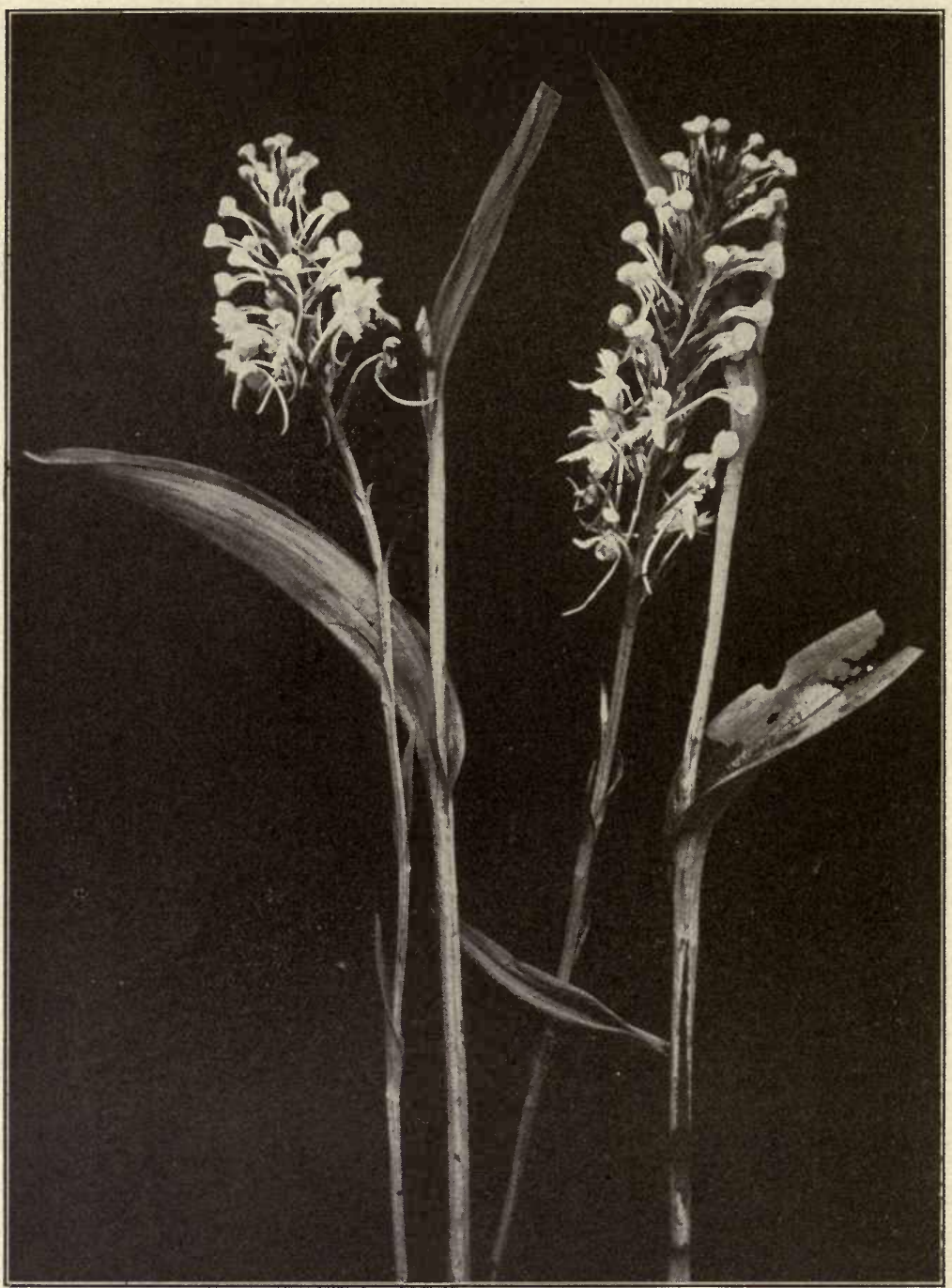

FIG. 277. White Fringed Orchis (Habenaria blepharigiottis), an attractive and rather common orchid growing in bogs and peaty lands throughout the eastern and centra! United States. The stems are from 4 to $6 \mathrm{dm}$. in length, terminated by many-flowered spike. The flowers are white, the lip being copiously fringed and the spur about $2 \mathrm{~cm}$. in length.-After Troth.

. cylindrical body which is strongly concave on one side and spreading at the upper portion. The pollinia are granular. Pollination 
may be effected by insects, but is usually brought about by artificial means (hand-pollination). The fruits require several months to become fully grown, and an equal period of time is necessary for their maturity, which is indicated by their yellow color. They are then gathered and cured by alternately steaming and drying them, until they acquire the dark brown color and the odor of the commercial article. Vanilla is cultivated in all tropical countries where the temperature does not fall below $18^{\circ} \mathrm{C}$., and the humidity is considerable. Usually vanilla culture is combined with that of Cacao. The plants begin to yield fruits the third year and continue bearing for thirty or forty years (Fig. 274).

The yellow-flowering Cypripediums of the United States ( $C$. parviflorum and $C$. parviflorum pubescens) yield the cypripedium which was formerly official. The plants are a foot or two high. The leaves are oval or elliptical (in the latter) or elliptical or lanceolate (C. parviflorum). In C. pubescens the lip is pale yellow with purple veins, 25 to 50 millimeters long, and possesses a tuft of white, jointed hairs at the throat. In C. parviflorum the lip is smaller and non-hairy. C. acaule is shown in Fig. 275.

The root-stocks of a number of Orchids are rich in mucilage and yield the drug salep or a product resembling it. Salep occurs. in the form of globular or somewhat flattened, more or less translucent, light yellowish-brown tubers, 2 to $4 \mathrm{~cm}$. long, of a horny texture and a mucilaginous taste. The principal constituent is mucilage, which originates in the cell-contents. It may contain in addition either starch or sugar.

While the Orchidacex, which contains about 6,000 species, ranks second in numbers to the Compositæ, there is probably no family which exceeds it in interest. The plants are extensively cultivated, and some of their flowers are the highest priced known in the commercial world. There are few localities in which there are not some orchids to be found, illustrations of several of which are here shown (Figs. 275 to 279).

\section{B. CLASS DICOTYLEDONEÆ.}

The following are some of the prominent features of the Dicotyledons: ( I) The leaves are reticulately (open) veined and usually with an irregular margin, being sometimes deeply lobed; 


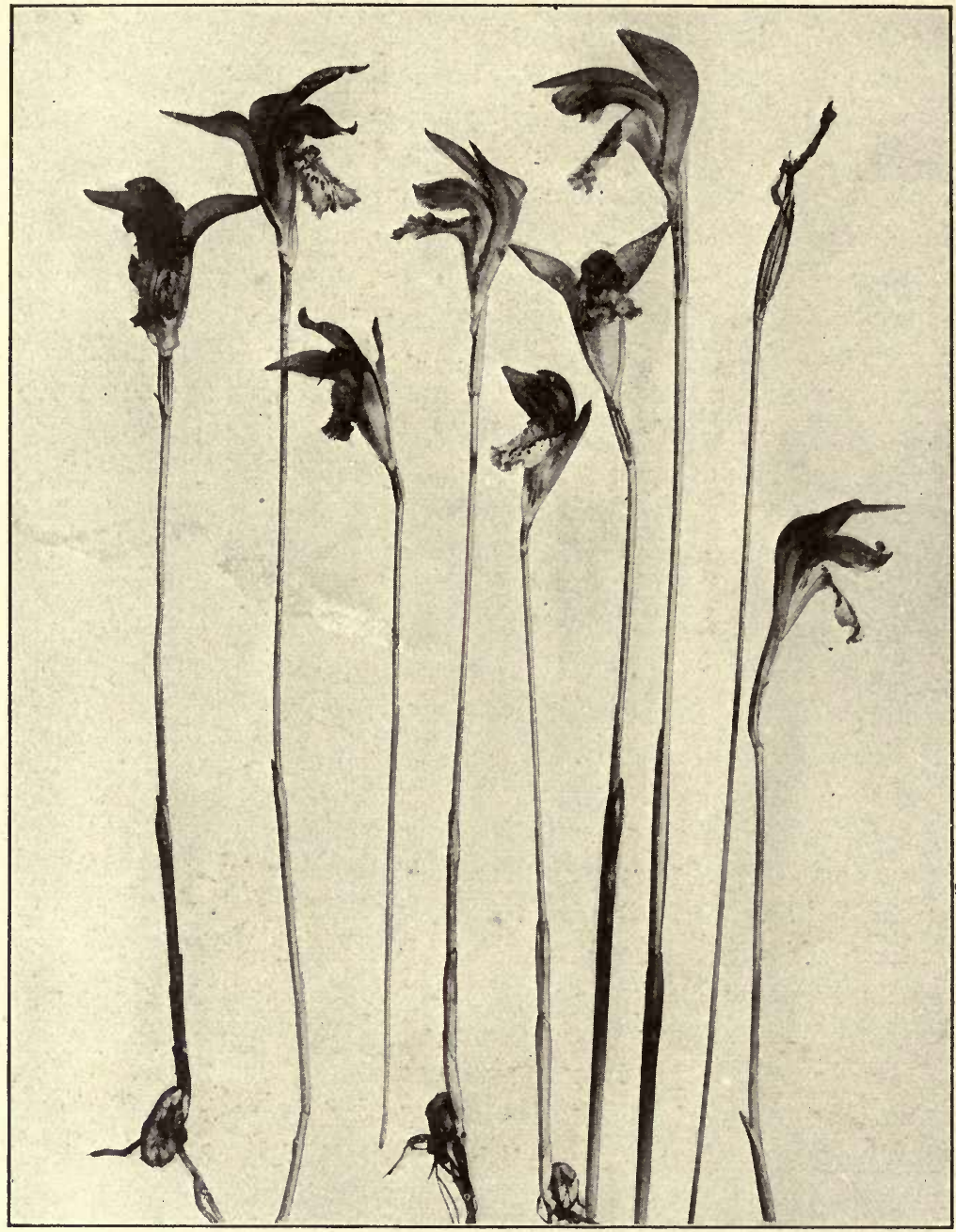

Fig. 278. Arethusa bulbosa, an Orchid growing in bogs from Newfoundland to South Carolina, and west to Minnesota. It produces a solitary magenta-crimson flower on a long, slender scape, in the sheaths of which a solitary linear leaf arises and protrudes after the flower opens. In the illustration are shown a number of plants, some of which show the small bulbs at the base.-After Troth.

(2) the parts of the flower are usually in circles of 2 to 5 each; (3) the stems and roots generally increase in thickness by means of a cambium, and the vascular bundles are open, varying from 


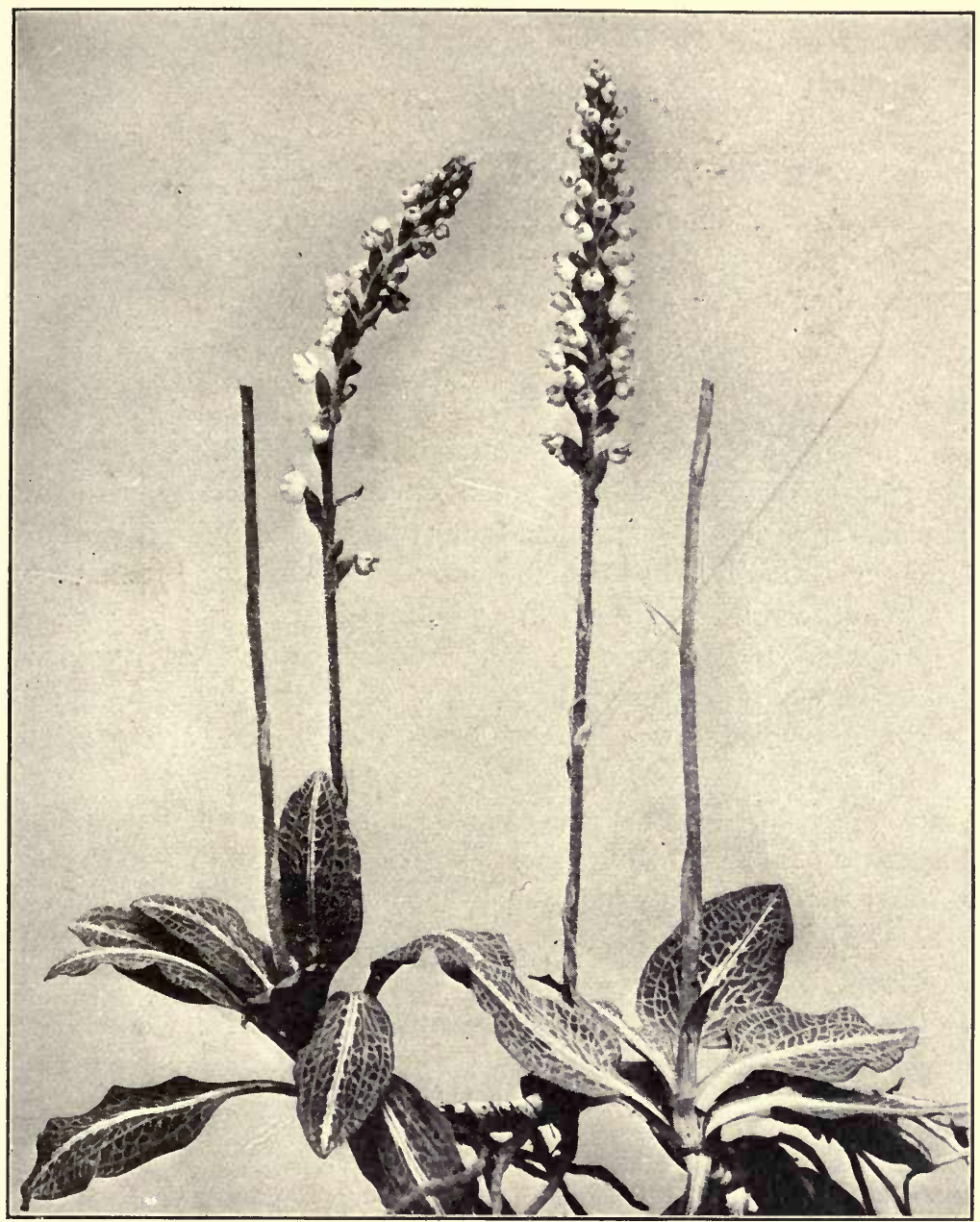

FIG. 279. Rattlesnake Plantain, a rather common orchid, variously known as Epipactis, Peramium, or Goodyera pubescens. It is generally found growing in coniferous woods and characterized by the dark-green basal leaves with their prominent nerves and numerous white reticulating veins. The flowers are greenish-white, numerous and crowded on the erect scapes.-After Troth.

simple collateral to bi-collateral; annular rings are formed in the perennial stems; (4) the germinating plant usually has two cotyledons which are opposite each other. The Dicotyledons are divided into two series or sub-classes, depending upon whether 
the parts of the corolla are distinct or are united, namely, the Archichlamydeæ and Metachlamydeæ.

\section{ARCHICHLAMYDEÆ OR CHORIPETALÆ.}

The Archichlamydeæ or Choripetalæ comprise those dicotyledonous plants in which the petals are separate and distinct from one another or are entirely wanting.

\section{ORDER PIPERALES.}

The plants of this order are mostly tropical herbs and shrubs and possess very small flowers which have neither petals nor sepals. The leaves are simple and without stipules, the most important family medicinally, as well as in other ways, being the PIPERACEÆ, to which the following medicinal plants belong.

Piper nigrum is a woody climber that has leathery, grayishgreen, ovate-elliptical leaves (Figs. 28I, 282), with three prominent middle nerves and two side nerves; the flowers are perfect, sessile and form an elongated fleshy spike; the fruit is a berry which is yellowish-red when ripe. The unripe fruit constitutes the BLACK PEPPER of commerce. WHITE PEPPER is the ripe berry of Piper nigrum from which the epicarp is removed, while " LONG PEPPER" is obtained from Piper longum, an entirely different plant, and consists of the entire spikes with immature fruits.

Piper Cubeba is a climbing perennial, with leathery ellipticalovate or long elliptical leaves; the flowers are diœcious and arranged in spikes; the fruit is a berry, the pedicel becoming much elongated after fertilization. The unripe fruit is the part used in medicine and is official as cubeb.

Piper angustifolium yields MATICO, formerly official. The plant is a shrub growing in Central and South America and is characterized by its long, oblong-lanceolate, deeply reticulate, very hairy leaves. The flowers and fruits are very small and arranged in long, slender spikes, which are frequently found in the drug. Matico contains 2 to 3 per cent. of a volatile oil, containing a stearoptene matico camphor, which appears to be the most important constituent. It also contains an acrid resin, a bitter principle, and a crystalline principle, artanthic acid. Other related 

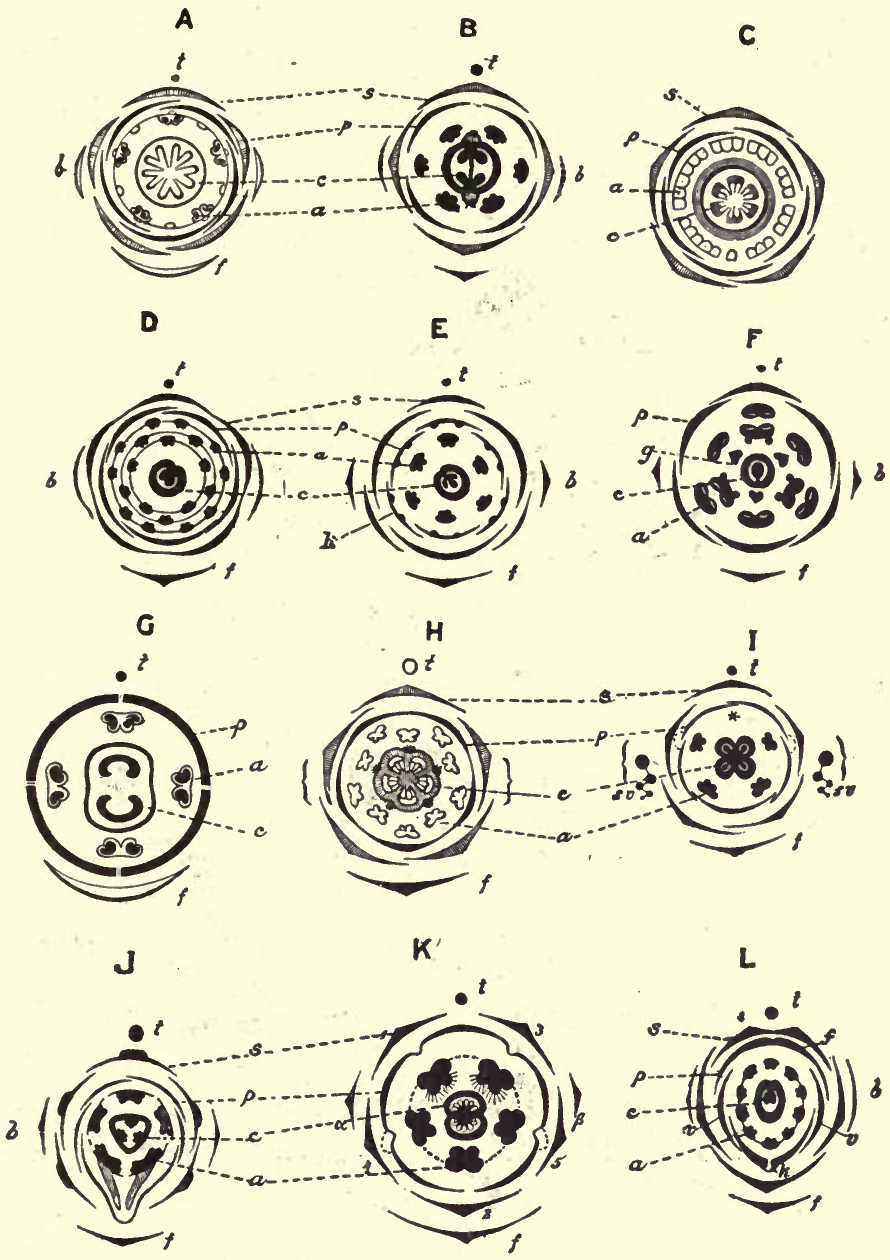

FIG. 280. Diagrams of cross sections of the flowers of a number of families of dicotyledonous plants showing the number and position of the parts with reference to each other: $t$, stem of plant; $f$, foliage leaf; $b$, bracts or leaves on the flower-stalk; s, sepals; $p$, petals; a, stamens; c, ovary; per, perianth. A, Linaceæ; B, Cruciferæ; C, genus Citrus; D, Rosaceæ; E, Berberidaceæ, showing nectaries (k) on the petals; F, Lauraceæ, showing staminodes $(\mathrm{g})$; $\mathrm{G}$, epigynous flower of Rubiaceæ; H, Ericaceæ; I, Labiatæ, showing position of other flowers (sv) in the cymes; J, Violaceæ showing spurred stamens; K, Campanulaceæ, showing bracts $(\alpha, \beta)$ the relation of the sepals $(1,2,3,4$ and 5$)$, and two posterior hairy stamens; L, Leguminosæ, showing the large posterior petal (p) known as the vexillum or standard, the two lateral petals (v) situated under the standard known as alae or wings, and the two anterior petals which are covered by the wings and partly cohering to form a prow-shaped body called the carina or keel (k).-Adapted from Warming. 


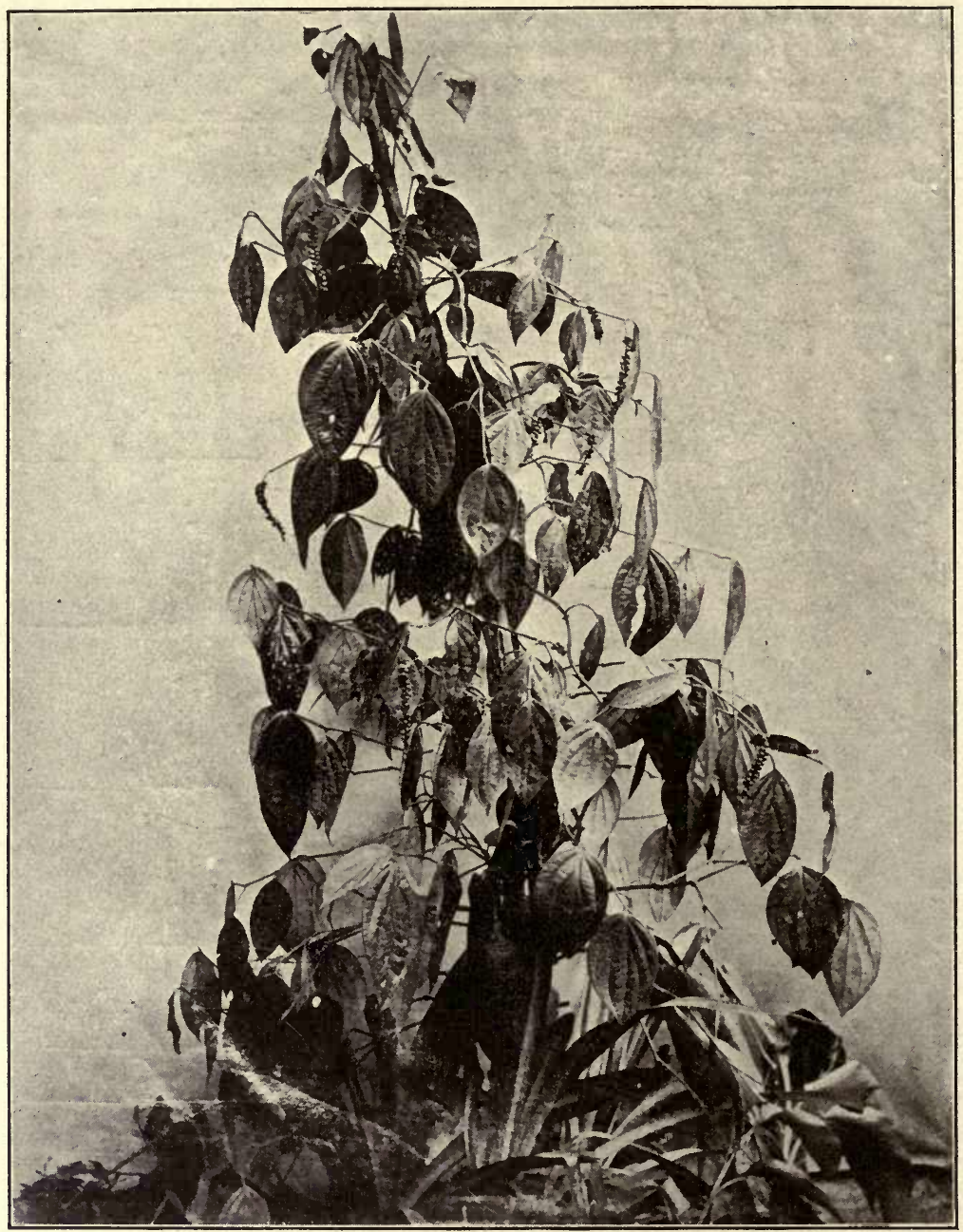

FIG. 281. Black pepper (Piper nigrum), a climbing shrub growing in Botanic Gardens, Port of Spain, Trinidad. The illustration shows the ovate-elliptical leaves, opposite which are the fruiting spikes, which when ripe are of a yellowish-red color. The plant has been introduced into many tropical countries and is not infrequently seen in botanic gardens throughout the civilized world. - Reproduced by permission of The Philadelphia Commercial Museum.

species of Piper are used in tropical America similarly to Piper angustifolium.

The leaves of a number of species of Piper (known as "betel 


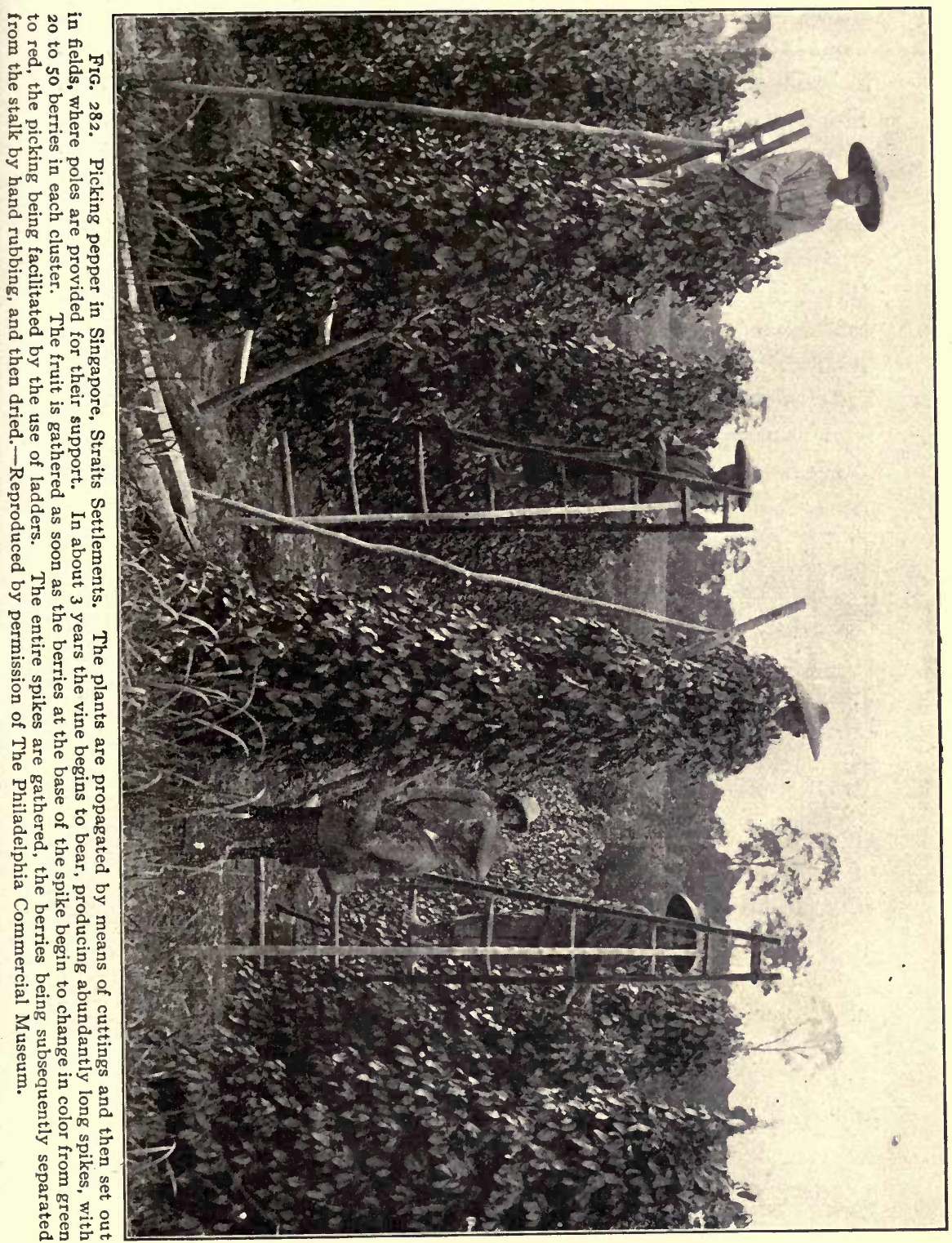


leaves") are mixed with the Areca nut and lime and constitute what is known as "BETEL," which compound is used for chewing, in India and other countries, chiefly on account of its astringency. The root of Piper methysticum is also chewed, and when mixed with the milk of the Cocoanut yields an intoxicating drink which is used by the inhabitants of the Sandwich Islands. The dried root has been used in medicine under the name of METHysticum or KAVA-KAVA. It consists of large, branching, soft, spongy, dark brown pieces, which are tough, fibrous, and with a pungent, somewhat bitter taste. Kava-kava contains 3 resins, one of which has marked anæsthetic properties; an alkaloid, kavaine; a neutral body, methysticin; and about 50 per cent. of starch. The drug is free from calcium oxalate crystals, these being usually wanting in the Piperaceæ.

\section{ORDER SALICALES.}

This order comprises but a single family, namely, the SALICACEE or Willow Family, to which belong the willows and poplars. The plants are diœcious shrubs and trees; the flowers being in aments or catkins and without petals or sepals. The fruit is a capsule containing many seeds which are small and with long, silky hairs at the base.

The barks of a number of the members of this group contain glucosides, as salicin, which is found in Salix alba, the white willow of Europe and the United States, and the brittle willow Salix fragilis; and populin, which is found in the white or silver-leaf poplar (Populus alba) of Europe, Asia, and the United States and Populus pyramidalis of Italy. These principles are also found in other species of willow and poplar. A number of the barks contain a yellow coloring principle allied to quercitrin, as Salix daphnoides of Europe and Salix alba. Tannin is a common constituent in both the willows and poplars. The buds of mainy of the poplars contain in addition a volatile oil which is in the nature of a diterpene, as those of Populus pyramidalis. Populus balsamifera, the tacamahac or balsam poplar of the United States and Canada, furnishes the BALM OF GILEAD buds which are coated with an oleo-resin that gives them their aromatic properties. Populus 
nigra yields a volatile oil, of which the important constituent is humulene.

The charcoal used medicinally is prepared by burning the wood of the young shoots of the white and black willow, poplar, beech, or linden without access of air.

III. ORDER MYRICALES.

This group somewhat resembles the Salicales in that the flowers are in aments. The flowers are either pistillate or staminate, and mostly diœcious in our native species. The most important family is the MYRICACE e or Bayberry Family. The genus Myrica is especially characterized by the fact that the outer layer of the drupe is waxy. This is particularly true of the following species: Myrica cerifera, the wax myrtle of the sandy swamps of the United States, contains a volatile oil. The fruit of sweet gale (M. Gale) yields a volatile oil containing a camphor. The sweet fern (Comptonia peregrina) found in the United States yields a volatile oil resembling that of cinnamon. The rhizome of this plant contains also tannin and possibly gallic and benzoic acids.

\section{ORDER JUGLANDALES.}

The plants are trees with alternate, pinnately-compound leaves. The staminate flowers are in drooping aments, the pistillate being solitary or several together. The flowers are monœcious and have a more or less distinct perianth consisting of 3 to 6 lobes. The fruit is a kind of drupe formed by the union of the torus with the wall of the ovary. There is but one family in this order, namely, the JuglandACE $E$ (Walnut family), which includes the hickory (Hicoria) and walnut. The black walnut (Juglans nigra) of the United States yields a valuable timber and an edible nut; the white walnut or butternut ( $J$. cinerea) of the United States yields the butternuts which are edible, and a bark which has medicinal properties and was formerly official under the name of Juglans. It contains about 7 per cent. of a yellow, crystalline acrid principle which is colored purple with alkalies; 2 to 2.5 per cent. of a crystalline resin; volatile oil, tannin, sugar, and a fixed oil. The bark of the stems of the butternut tree is used in dyeing. The ripe fruits are edible, as also the green nuts when 
pickled. The sap of the tree contains a sugar. The wood, though inferior to black walnut, is used in cabinet making.

$J$. regia, native of Persia and cultivated in various parts of Europe and California, yields the edible ENGLISH WALNUT.

The following species of hickory yield edible nuts: The shellbark hickory (Hicoria ovata); the pecan (H. pecan) common from Illinois southward; and western shell-bark hickory $(H$. sulcata). The wood of these as well as H. glabra and other species of hickory is used where strength and elasticity are required.

Coloring principles are found in the barks of a number of species and are used for technical purposes. The following contain yellow coloring principles: Hicoria ovata, $H$. sulcata, and H. glabra (pig-nut hickory) ; green coloring principles are found in $H$. tomentosa, and yellowish-brown principles in Juglans nigra, $J$. cinerea, and J. regia.

The fatty oils from the cotyledons (kernels) of both hickorynuts and walnuts are articles of commerce, and they have been used in medicine.

\section{ORDER FAGALES.}

The plants are trees or shrubs with alternate, petiolate, simple, pinnately veined leaves. The flowers are in aments, monœcious, and with a more or less distinct perianth. The fruit is a nut which is subtended by the mature involucre (bur or cup) or samara, the seeds being without endosperm (Fig. 283).

a. BETULACE $\approx$ OR BIRCH FAMILY.-The plants are aromatic trees or shrubs and are represented in the United States by such trees as hornbeam (Carpinus), ironwood (Ostrya), and birch (Betula) ; and by such shrubs as the hazelnut (Corylus) and alder (Alnus). The plants yield a volatile oil consisting largely of methyl salicylate. The bark of the sweet birch (Betula lenta) yields the oil of betula which is official and closely resembles the oil of wintergreen. The bark of a number of plants of this family yields tannin and yellow coloring principles. A number of species of Betula yield a sweet sap, as B. lenta, and B. Bhojpattra of Russia. The nuts of some species are edible, as the filbert or hazelnut of Europe (Corylus Avellana), the hazelnut of the Orient ( $C$. Colurna), the American hazelnut ( $C$. americana). 
b. FAGACEÆ OR BEECH FAMILY.-This family includes some of our largest forest trees, these being rather characteristic of temperate regions. They are all highly valued for their timber, and yield other valuable products besides. One notable characteristic is that all of the chestnuts and oaks and some of the beeches

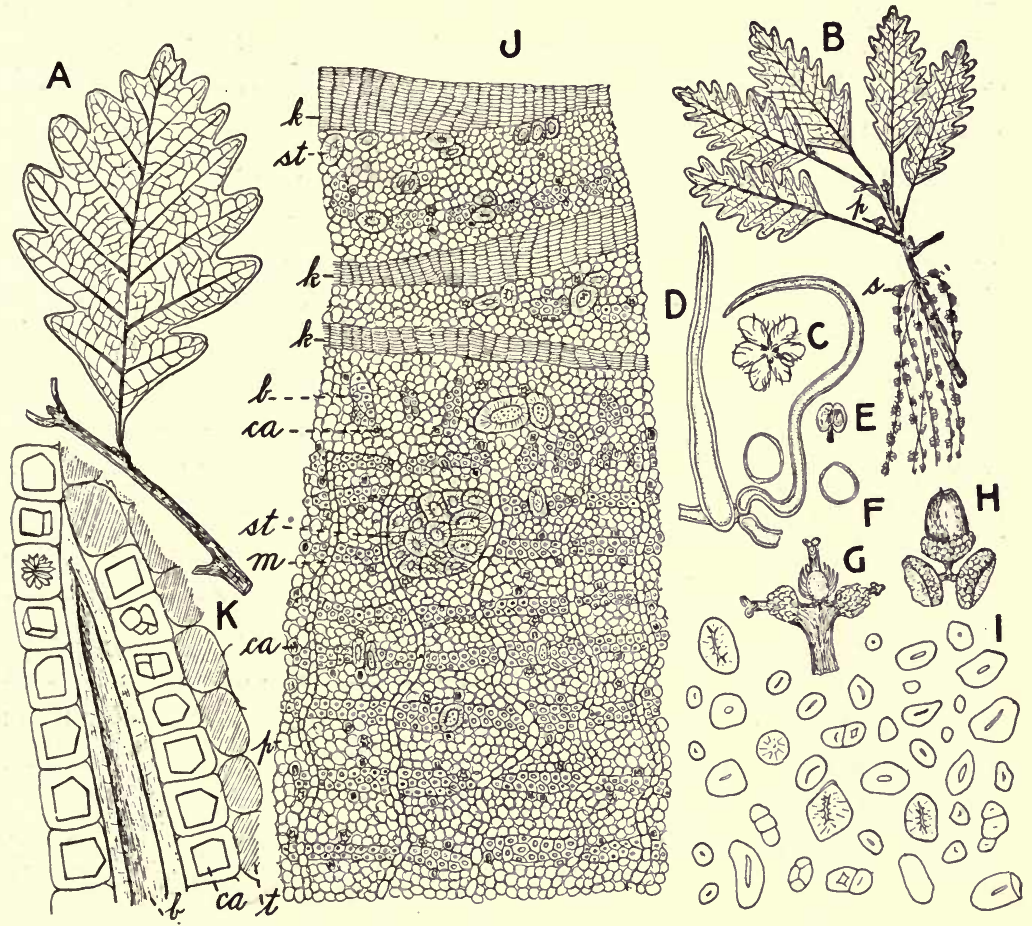

FIG. 283. White oak (Quercus alba): A, characteristic, lobed leaf; B, young branch showing pistillate $(p)$ and staminate (s) flowers; C hairy bracts of a staminate flower; $D$, group of hairs from bract; E, stamen; F. pollen grains; G, cluster of pistillate flowers; $H$, acorn with cupule; I, starch grains from acorn, which vary from to to $25 \mu$ long: J. transverse section of bark showing cork (k). stone cells (st), bast fibers (b), crystal fibers (ca), medullary rays $(m)$, parenchyma $(p) ; K$, longitudinal section of bark showing end of bast fiber (b) crystal fibers (ca) and parenchyma cells ( $t$ ) containing tannin.

contain tannin in the wood, bark, and leaves. The oaks are further notable in being prone to the attack of gall-producing insects (various species of Cynips) whereby the peculiar excrescences known as galls are formed on the leaves and young shoots. Among the oaks which yield galls rich in tannin are the following: Quercus infectoria of the Mediterranean, which yields the official Turkish 
or Aleppo galls (pp. 206, 334); Quercus Robur, which is sometimes divided into $Q$. pubescens and $Q$. pedunculata, yields a European gall; the live oak ( $Q$. virginiana) of Texas; and Q. lobata of California. Various oaks of the Southern States also produce "ink balls" or "ink galls," as Q. coccinea and Q. imbricaria. Several species of oak are used in the tanning industry, as that of white oak (Quercus alba), red oak (Q. rubra), Spanish oak (Q. digitata), and black oak (Q. velutina), all of North America; $Q$. pedunculata and sessiliflora of Germany, and $Q$. dentata of Japan.

The glucosidal coloring principle quercitrin is found in the bark of Quercitron or black oak ( $Q$. velutina). Q. coccifera of Southern Europe yields a red coloring principle which is used in dyeing.

The wood of the American beech (Fagus americana) and of the European red beech ( $F$. sylvatica) yields a tar from which on distillation the official CREOSOTE is obtained.

The cork of commerce which is used for a variety of purposes is derived from the bark of several species of Quercus, namely, Q. Suber and Q. occidentalis, growing in Spain, Southern France, and Algiers.

The cotyledons of the seeds of the Beech family are rich in proteins, starch, and oil, and some of the nuts are edible, as the Spanish chestnuts obtained from Castanea vulgaris, American chestnut from $C$. dentata, and CHINQUAPIN from C. pumila (Fig. 202).

\section{ORDER URTICALES.}

This order embraces three families which, while they agree in certain characters, are quite distinct in other ways.

a. ULMACE E OR ELM FAMILY.-The plants are trees or shrubs with alternate, simple, serrate, petiolate leaves. The flowers are monœcious or diœcious, with a 4- to 6-divided perianth. The fruit is a I-seeded drupe, samara, or nut. The typical group of this family is that of the elms, of which the American or white elm (Ulmus americana) is the most prized for ornamental purposes. The elms yield valuable timber, and the bark of Ulmus campestris of Europe is used for tanning and dyeing because of the presence of tannin and a yellow coloring principle. 
The inner bark of the red or slippery elm (Ulmus fulva) is used in medicine on account of its mucilaginous character (see Fig. II9, C). The tree has a gray, fragrant bark; leaves which are very rough above and become fragrant on drying, and the wood is reddish-brown. The samara is not hairy as in some of the other species.

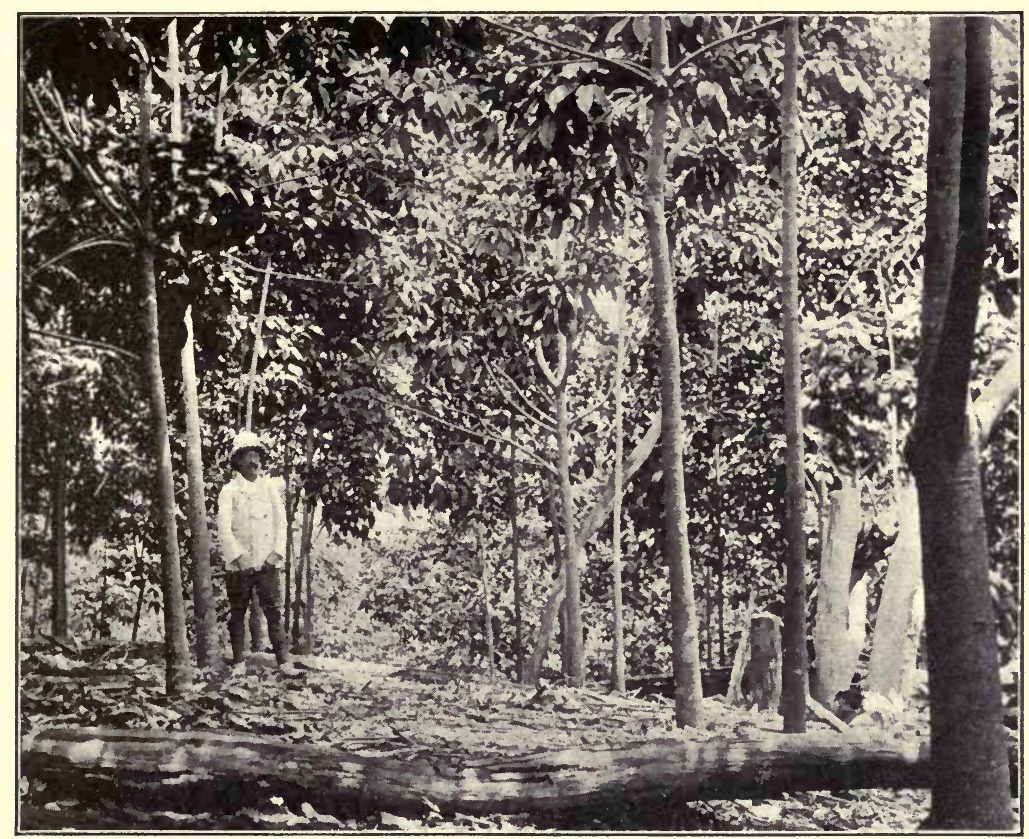

FIG. 284. View taken in Ceylon of a part of a grove of 4-year-old rubber trees (Ficus elastica). This tree is extensively cultivated in Ceylon and other portions of tropical Asia, and most all of the Asiatic rubber is produced by this tree. The trees may be tapped when 25 years old, and for 50 succeeding years yield 40 pounds caoutchouc every 3 years.Reproduced by permission of The Philadelphia Commercial Museum.

b. MORACE $\mathrm{E}$ OR MULBERRY FAMILY.-The members of this family are herbs, shrubs, or trees, many of them containing a milk-juice or latex. There are many representatives in the tropical regions and some in temperate regions. The flowers are unisexual, with a 4- to 5-parted perianth, and occur in spikes or ament-like clusters.

Cannabis sativa.-This is the plant yielding hemp and also the 
drug Cannabis indica. The plant is an annual branching herb from I to $3 \mathrm{M}$. high. The leaves are alternate above, opposite below, digitate with 5 to I I linear-lanceolate, deeply serrate lobes. The flowers are diœcious, the staminate occurring in panicles and the pistillate in erect simple spikes (Figs. 409, 410, 412). From the inner bark of the stem, which is fibrous, the HEMP FIBER is prepared.

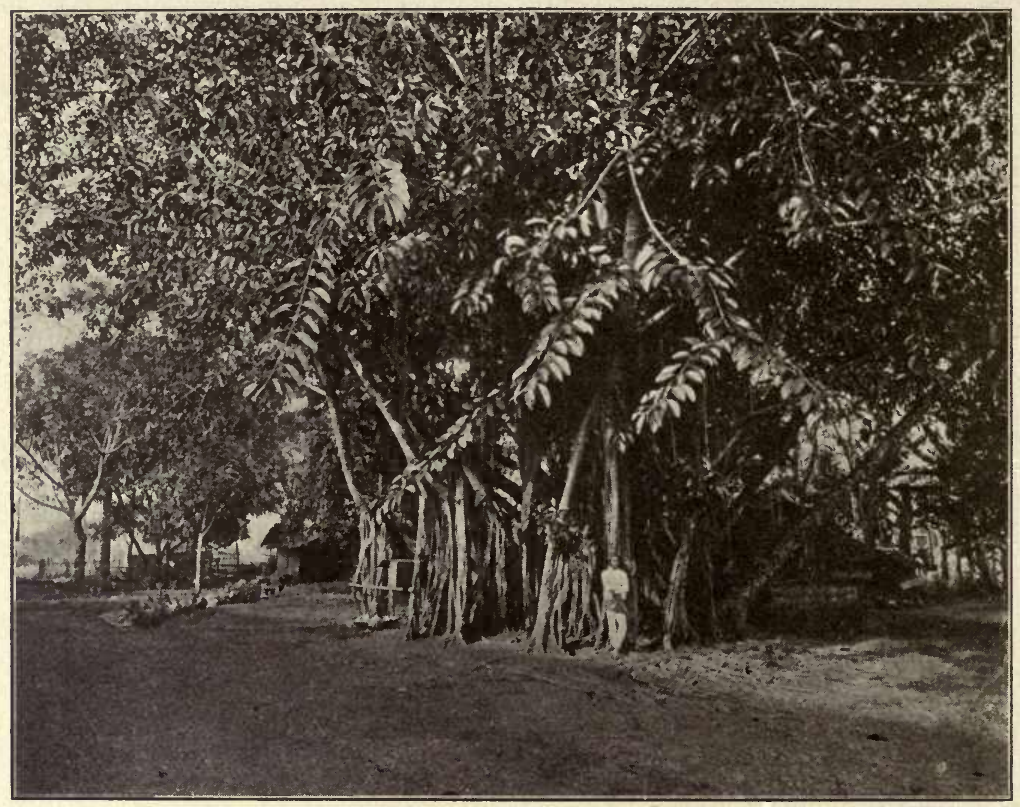

Fig. 285. Several large rubber trees (Ficus elastica) growing in Java and showing the production of numerous aerial roots from the branches. It occurs in damp forests from the base of the Sikkim Himalaya eastward to Assam and Arracan. There are large government plantations in Assam, and it is also being cultivated in other provinces. Kurz remarks that it is frequent in Upper Burma, and that whole forests of the species are said to exist in the valley of Hookhoom.-Reproduced by permission of The Philadelphia Commercial Museum.

Humulus Lupulus or hop is a twining perennial plant, curving to the right, with opposite, palmately $3^{-}$to 7 -lobed (or simply dentate above) rough leaves (Fig. 286). The flowers are diœcious, the staminate ones occurring in panicles and the pistillate in ament-like spikes. On the inner surface of each scale of the ament occur two flowers consisting of a membranous perianth 
and a bicarpellary ovary with two long styles. After fertilization the aments become cone-like, and this compound fruit constitutes the hop of commerce. This fruit differs essentially from the true strobiles or cones of the Gymnosperms in that the seed in the latter is replaced by an akene. "Hops" are extensively used

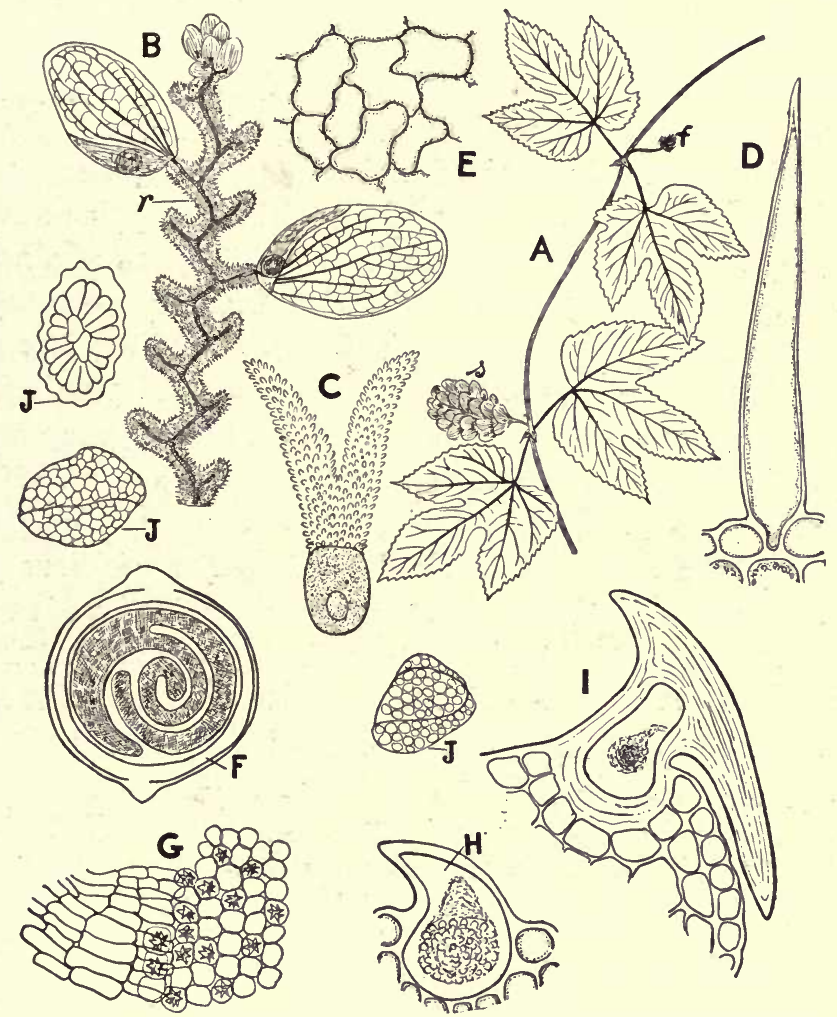

F1G. 286. Hop vine (Humulus Lupulus): A, portion of branch with pistillate flowers (f) and cone-like fruit (s): B, portion of rachis of strobile with two scales enclosing akenes; $C$, pistil; D, hair from rachis; E, epidermis of scale; F, longitudinal section of akene showing coiled embryo; $\mathrm{G}$, surface view of bract showing epidermis and cells containing calcium oxalate; H, cystolith of leaf; I, cystolith of stem; J, glandular hairs (lupulin).

in the manufacture of various beers and to a limited extent in medicine.

Ficus Carica, which yields the edible fig, is a deciduous tree from 3 to $7 \mathrm{M}$. high, and with large, 5 -lobed, petiolate leaves. The flowers are situated in a hollow torus the walls of which 
after fertilization become thick and fleshy, constituting the fruit. The best figs come from Turkey, Italy, Spain, and Provence.

A large number of the plants belonging to the Moraceæ yield economic products, some of which, as the drug Cannabis indica obtained from Cannabis sativa, are powerful narcotics. HasHISH or BHANG is a preparation made from the dried leaves, stems, and flowers of the pistillate plants and is smoked either alone or with tobacco, or chewed in combination with other substances, or an intoxicating drink is made from it, it being extensively used by the inhabitants of Arabia, Persia, India, and other Oriental countries. The leaves of Ficus Ribes of the Philippine and Molucca Islands are smoked like opium. The milk-juice of a number of plants belonging to the Moraceæ is the source of arrow poisons. The URARI POISON of Brazil is obtained from Ficus atrox; the IPOH ARROW POISON of Java and Borneo is derived from the Upastree, Antiaris toxicara. Many of the plants of the group contain emetic principles, as the CocILlanA BARK of Guarea Rusbyi, a tree of Bolivia.

The milk-juice of quite a number of species of Ficus yields India-rubber or caoutchouc (Fig. I28), as Ficus elastica of the East Indies, F. toxicaria of South America, F. clliptica and F. prinoides of New Granada and several other species of Brazil, Brosimum spurium of Jamaica, Cecropia peltata of the West Indies and South America, and Castilloa elastica of Mexico and the West Indies. Ficus benghalensis of India and tropical Africa, and Ficus Tsiela of India, yield gum-lac. Ficus altissima and F. religiosa of tropical Asia yield shellac on the puncture of the stems by a hemipterous insect (Coccus lacca).

A yellow coloring principle is found in Cudrania javanensis of tropical Asia and Africa, Chlorophora tinctoria of Mexico, Maclura aurantiaca (Toxylon pomiferum) or osage orange, a hedge plant of North America; Ficus tinctoria of the Friendly Islands and $F$. asperrima of India. A fixed oil is obtained from Artocarpus Blumei of Java.

A large number of the plants of the Moracex yield edible fruits besides the fig tree already described, as the BREAD-FRUIT trees (Artocarpus incisa) of the Sunda Islands and the JACK-TREE 
(A. integrifolia) of the East Indies, the white mulberry (Morus alba) and the BLACK MULBERRY (Morus nigra).

The leaves of the white mulberry (Morus alba), indigenous to China and cultivated since the twelfth century in Europe and now in cultivation to a limited extent in the United States, are the chief food of the silkworm.

c. FAMILY URTICACEÆ.-The plants belonging to the Urticaceæ or Nettle family are chiefly herbs with mostly petiolate, stipulate, simple leaves. The flowers are small and with 2 to 5 distinct or more or less united sepals. The fruit is an achene; the embryo is straight and surrounded by an oily endosperm. The stems and leaves of several of the genera are characterized by stinging hairs, this being especially true of the sub-group to which the genus Urtica or stinging nettle belongs. Of the stinging nettles the following are used in medicine: Urtica dioica of Europe and naturalized in the United States, U. spatulata of Timor, Laportea crenulata of tropical Asia, L. moroides of Queensland, and Girardinia palmata of India. In the small nettle (Urtica urens) of Europe and the United States an alkaloid has been found, and Laportea stimulans has been used as a fish poison. Boehmeria cordata of Brazil is used as a substitute for Arnica. The fibers of a number of the Urticaceæ have been found useful, of which the following may be mentioned: Urtica cannabina of Asia, $U$. dioica, $U$. urens and Boehmeria nivea of the Sunda Islands and China, the latter of which yields RAmie. The akene of Debregeasia edulis of Japan and the rhizome of Pouzolzia tuberosa of China and Japan are edible.

\section{ORDER PROTEALES.}

The members of this group are mostly shrubs and found principally in the Tropics and southern hemisphere, several species being cultivated in greenhouses for the sake of the beautifully colored flowers which are in crowded inflorescences. The order is represented by but a single family, namely, the Proteacex. The leaves are leathery and vary even on the same plant from simple to compound. The glucoside proteacin and a bitter principle are found in Leucadendron argenteum and L. concinnum, both 
of Africa. A gum-resin is found in Grevillea robusta of Australia, and a tannin in the bark of Lomatia obliqua of Chile.

A golden-yellow coloring principle is obtained from the flowers of Persoonia saccata of Australia. The wood of Protea grandiflora of Abyssinia is used in wagon building, and Leucospermum conocarpum of Cape Colony yields a valuable red wood and a tan bark.

Banskia cemula of Australia and the sugar-bush (Protea mellifera) of Australia and $P$. speciosa have a sugary cell-sap. The oily seeds of the Chilean hazelnut (Guevina Avellana) are highly prized as food by the inhabitants. The seeds of Brabeium stellatifolium or wild chestnut of Cape Colony are poisonous when fresh, but on roasting they become edible and are used as a substitute for coffee.

\section{ORDER SANTALALES.}

This order embraces a number of families which are quite distinct in several respects.

a. LORANTHACEÆ OR MISTLETOE FAMILY.-The plants are half-parasites with well-developed leaves containing chloroplastids. They live on trees by means of haustoria. To this family belongs the American mistletoe (Phoradendron flavescens), parasitic on oaks, elms, the tupelo (Nyssa), red maple and other deciduous trees. The white, globose berries of this plant are quite poisonous, as are also those of the European mistletoe (Viscum album) and the oak mistletoe of Southern Europe (Loranthus europous). Viscum album contains a volatile alkaloid, viscine, a glucoside and a resinous principle. This substance serves to attach the seeds to the barks of trees, where they germinate, and it is used in the manufacture of BIRD-LIME, which owing to its viscid character is used to catch small birds.

b. SANTALACE E OR SANDALWOOD FAMILY.The plants are chlorophyllous herbs or shrubs which are common in warm countries, and many of which are parasitic on the roots of other plants. A number of them contain volatile oils, as the wood of various species of Santalum. The official oil of sandal is obtained from the scented wood of the white sandalwood (Santalum album), a small tree growing wild and also cultivated in India and the 
East Indian Archipelago. The wood from the East Indies is known as Macassar sandalwood and yields I.6 to 3 per cent. of oil, while the Indian wood yields 3 to 5 per cent. The oil consists of 90 to 98 per cent. of santalol. Fiji oil of santal is obtained from S. Yasi; and Australian oil of santal from Fusanus acuminatus and F. spicatus. The Chinese oil is obtained from Santalum Freycinctianum and S. Preisci.

c. FAMILY BALANOPHORACE正.-The plants of this group are indigenous to tropical and sub-tropical regions. They are root-parasites and develop tuberous rhizomes and fleshy shoots which are yellow and without foliage leaves. Balanophora elongata of Java grows on the roots of Ficus and other plants, and contains a large quantity of wax and resin. Sarcophyte sanguinea of Cape Colony, which lives on the roots of certain Acacias, contains a principle with the odor of scatol. Cynomorium coccineum, found in the countries bordering the Mediterranean, has a bloodred, astringent sap. The torus of the flower of Langsdorffia hypogoa of tropical America is edible. The plant is also rich in wax, and in New Granada it is sold under the name of "Siejas" and burnt like a candle.

IX. ORDER ARISTOLOCHIALES.

This order includes two families which are very different in their general habits. $a$. The Rafflesiaceæ are parasitic herbs that are almost devoid of chlorophyll. The reddish vegetative parts penetrate into the tissues of the host, and from these arise almost mushroom-like flowers which in the case of Rafflesia Arnoldii of Sumatra are I M. in diameter, being probably the largest flowers known. The plants of this family are rich in astringent substances.

b. ARISTOLOCHIACE $\mathrm{E}$ OR BIRTHWORT FAMILY. -The plants are non-parasitic herbs or shrubs, some of which are twining. The leaves are simple and in many of the plants more or less cordate and reniform. The flowers are perfect and the perianth is 3 - to 6-lobed. While the flowers of our native species are rather small and insignificant, those of the tropical plants are extremely curious, being generally of some striking color and of various odd forms.

Aristolochia reticulata is one of the plants that furnishes the 
official drug serpentaria (see Vol. II). From a slender rhizome with numerous hair-like roots arise one or more short, leafy branches which are more or less simple, somewhat hairy, and bear oblong-cordate, prominent-reticulate, hairy leaves (Fig. 287). The flowers are borne on slender, scaly, basal branches; the calyx tube is purplish and curved like the letter "s," being enlarged around the ovary and at its throat. The fruit is a capsule containing numerous flat or concave seeds. An allied species, Aristolochia Serpentaria, furnishes the drug Virginia snakeroot. It is a more delicate plant, the leaves being ovate-lanceolate, acuminate; the flowers are solitary, and in some cases cleistogamous. This species is found growing in the United States, more especially east of the Mississippi, while Aristolochia reticulata is found west of the Mississippi from Arkansas to Texas. The plants of this genus contain volatile oils, and in addition to the two species mentioned 45 other species are used in medicine in various parts of the world.

Asarum canadense (Canada snakeroot or wild ginger) is a plant common in the Northern United States and Canada (Fig. 288). The long and slender rhizomes are used in medicine. They are 5 to $\mathrm{I} 5 \mathrm{~cm}$. long, about $2 \mathrm{~mm}$. thick, more or less bent and curved, purplish-brown externally; whitish internally; the bark is thick, wood with about 12 fibrovascular bundles, pith large ; the odor is aromatic; the taste pungent and bitter. The drug contains 2 to 3 per cent. of a volatile oil containing a fragrant body, asarol; a pungent, fragrant resin; a yellow coloring principle which is colored dark green with ferric salts; and starch. The volatile oil obtained from $A$. europoum contains a principle (asarone) which forms irritating vapors on heating.

\section{ORDER POLYGONALES.}

This order is represented by a single family, the Polygonacex cr Buckwheat family. The plants are mostly herbs, but include some twining vines and shrubs. The leaves are simple, mostly entire, and characterized by having a stipulate appendage (ocrea) which sheaths the stem. The flowers are small, perfect, and with a 2- to 6-parted perianth. The fruit is a 3 - to 4 -angled akene. The cmbryo is either straight or curved, and the endosperm is mealy. 


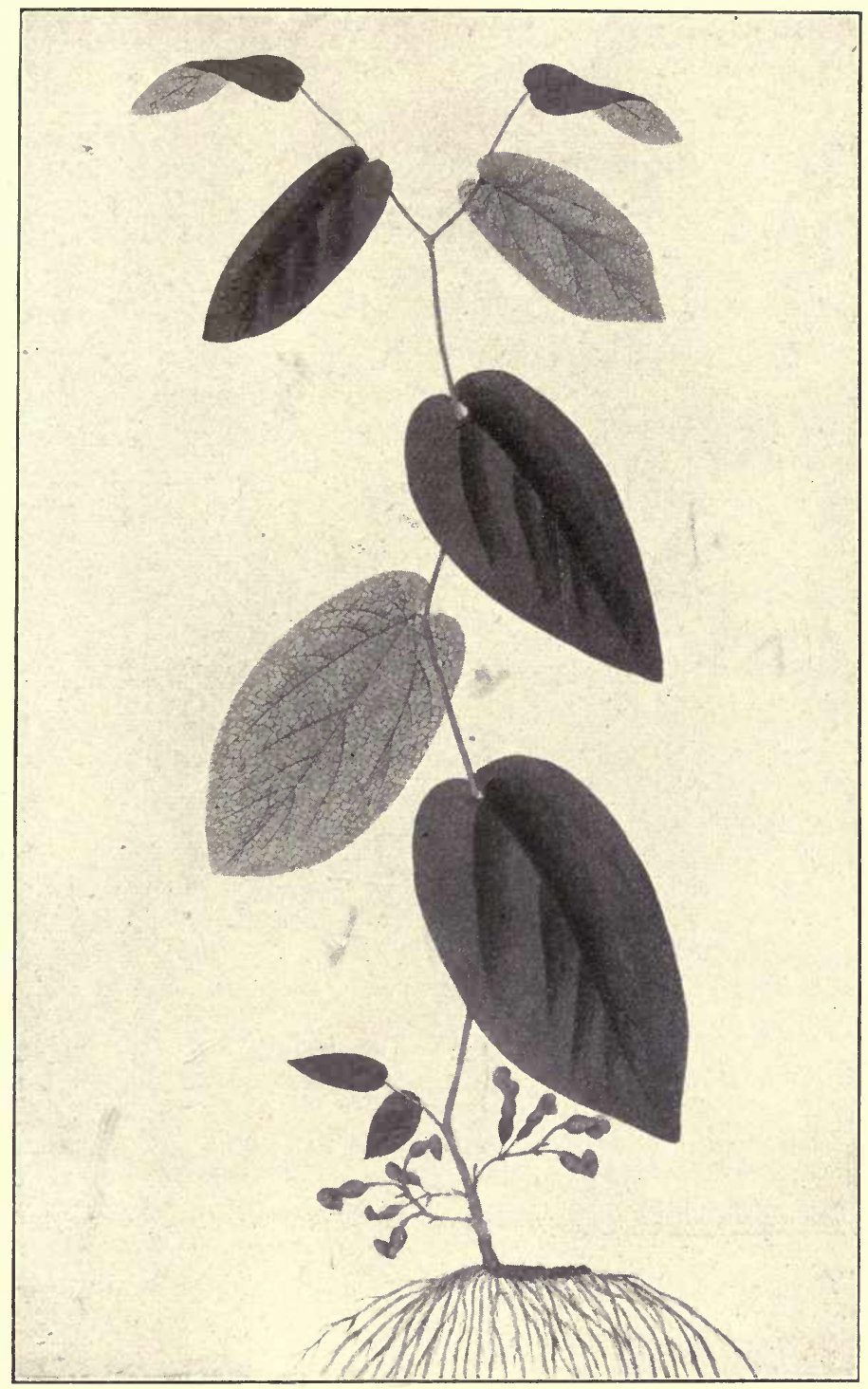

FIG. 287. Southern serpentaria (Aristolochia reticulata) showing the cordate, reticu. lately-veined leaves, and the clusters of irregular flowers on the lower part of the stem. -After Carson. 
Rheum officinale is the source of the "South China" rhubarb from Szechwan, Kanzu, and Shensi. The plant is a perennial herb resembling the garden rhubarb. The rhizome is vertical and gives rise to a leafy branch terminated by the inflorescence, which is a panicle. The leaves are large, with a sub-cylindrical petiole,

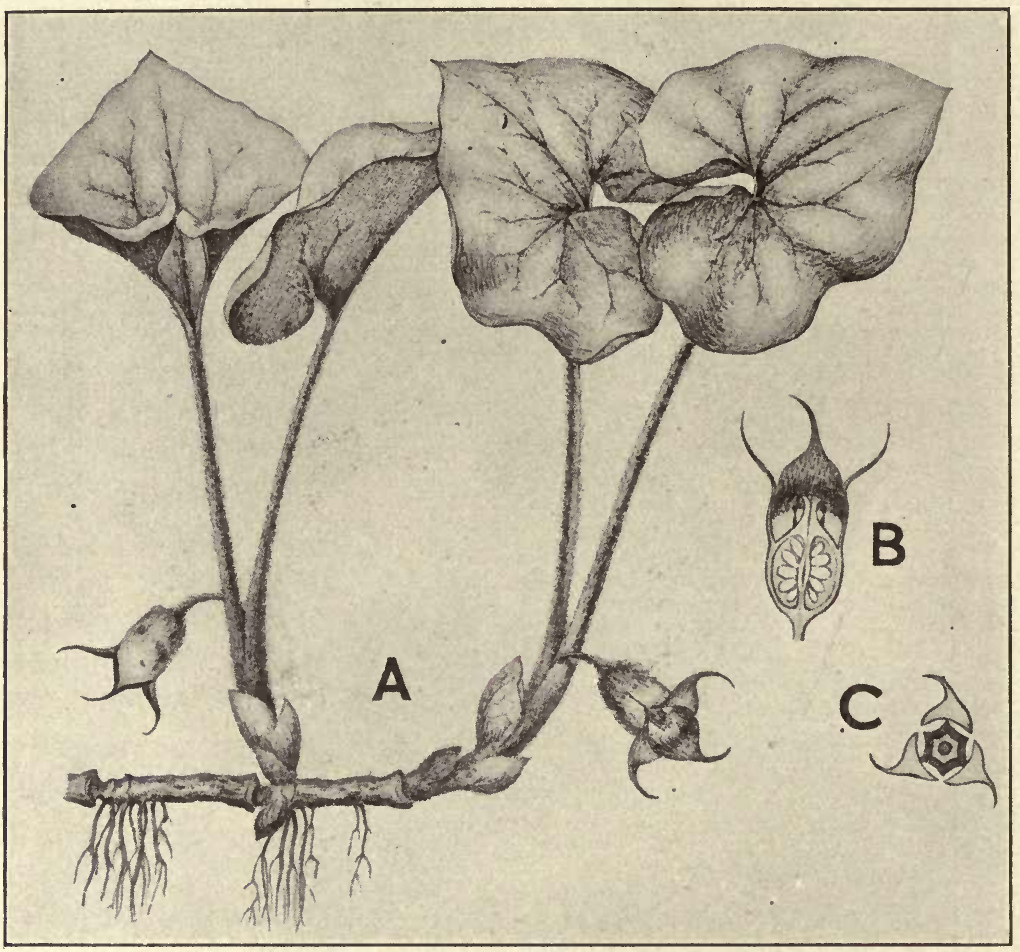

FIG. 288. Wild Ginger (Asarum canadense), A, showing habit of plant, consisting of underground root-stock, the kidney-shaped leaves on long petioles, and the short peduncled, bell-shaped flower which develops close to the ground; B, longitudinal section of flower, and $\mathrm{C}$, a transverse section of flower.-Bicknell, in Bulletin Torrey Bot. Club, Nov., I897.

a cordate or orbicular lamina which is either entire or coarsely and irregularly dentate. There are several nearly related species which also yield the drug. Rheum palmatum of Northern China has leaves which are lobed or deeply incised, which character is especially marked in the variety tanguticum. Rheum Rhaponti$\mathrm{cum}$, which yields English rhubarb, has leaves which are heart- 
shaped at the base and with a more or less irregularly undulate margin. All of these species are more or less common in cultivation in botanical gardens in Europe.

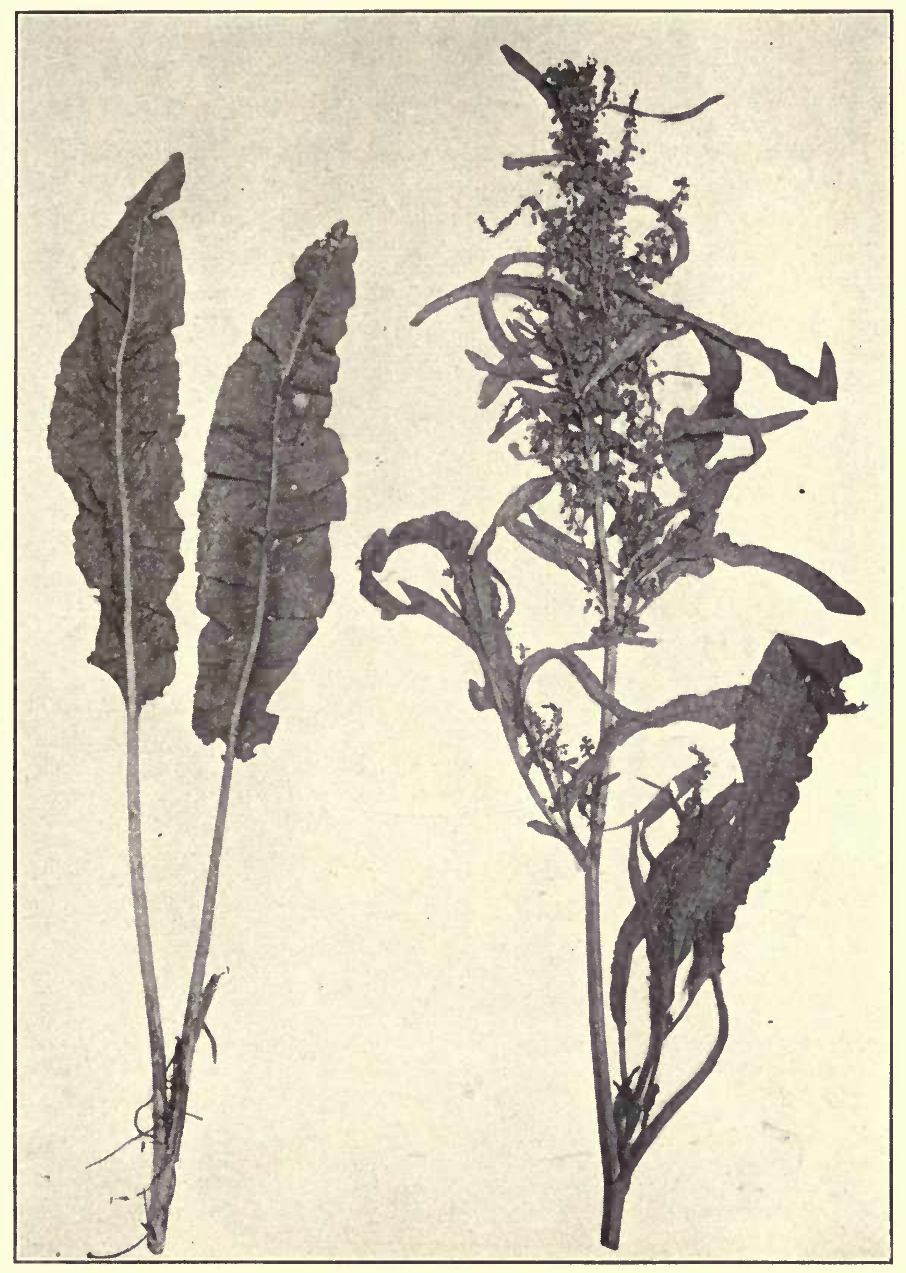

Frg: 289. Curled dock (Rumex crispus) showing two of the lower, long-petioled, oblonglanceolate and wavy-margined leaves, and a flowering branch, the upper leaves of which are narrowly-oblong and short-petioled.

Rumex crispus or curled dock is a perennial herb growing in fields and waste places in the United States and parts of Canada. 


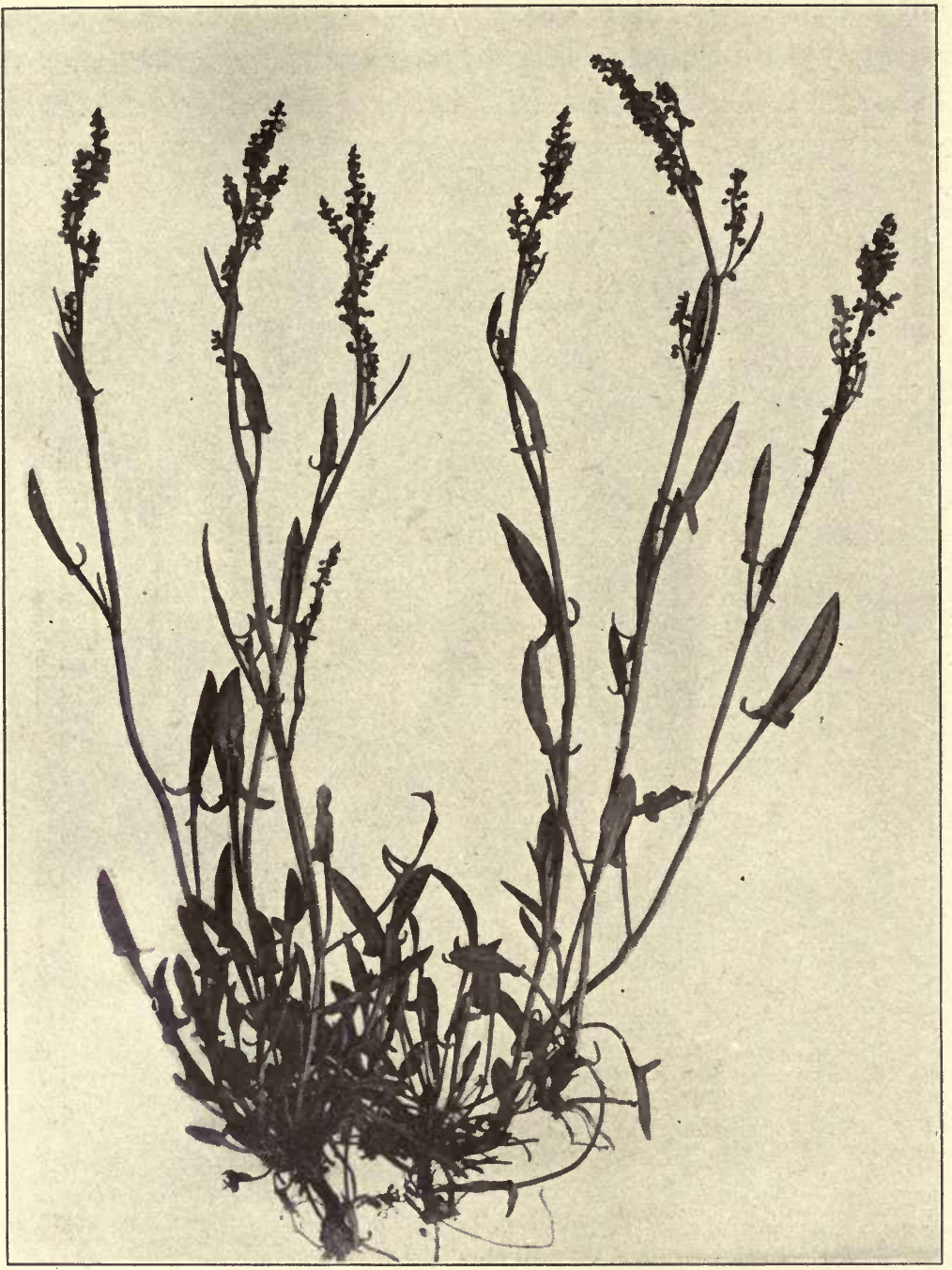

FIG. 290. Field or sheep sorrel (Rumex acelosella), a common weed containing a sour juice and growing in open fields; 1 to $3 \mathrm{dm}$. higb, having narrow-lanceolate or halberdshaped leaves, and somewhat reddish flowers in a panicled raceme.-After Brown.

The leaves are oblong-lanceolate, with an undulate margin and rather long petiole. The flowers have a 6-parted, dark green perianth, and are perfect or polygamo-diøcious. The fruit is a 
dark brown, cordate-winged, 3-angled akene. The dried root is somewhat fusiform, reddish-brown, and with a bitter, astringent

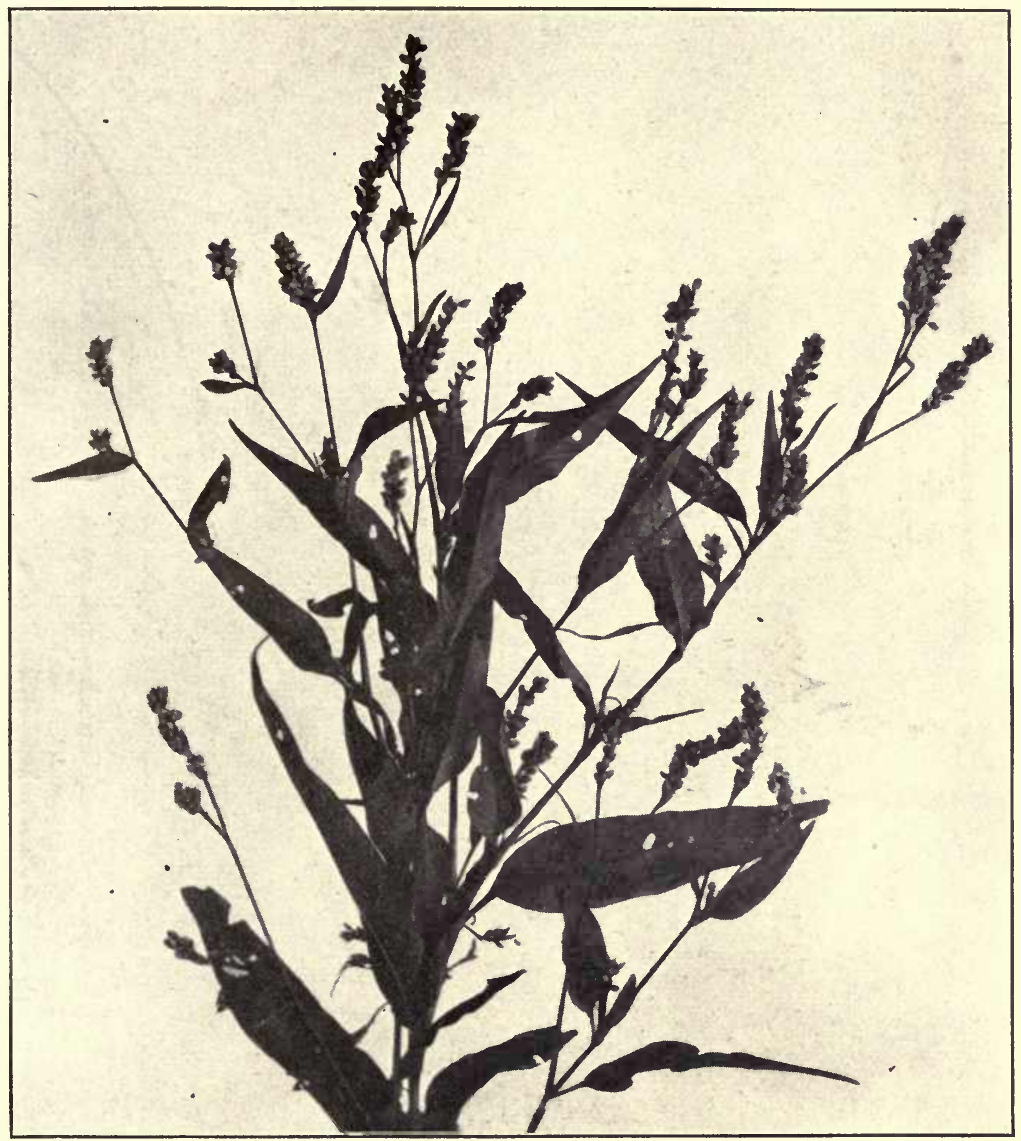

FIG. 291. Polygonum pennsylvanicum (Fam. Polygonaceæ), one of about 30 species of knotweeds, being common in waste places, all herbaceous, and characterized by the leaves having sheathing stipules. Typical of this group is $P$. pennsylvanicum, having lanceolate leaves and short, erect terminal spikes with bright rose-colored flowers.-After Brown.

taste. It contains chrysophanic acid, tannin, calcium oxalate, and some of the other constituents found in rhubarb (Fig. 289).

Rumex Acetosella (field or sheep sorrel), is a slender annual herb with hastate leaves, having flowers in compound racemes. 
The leaves contain oxalic acid, both free and in combination with calcium and potassium (Fig. 290).

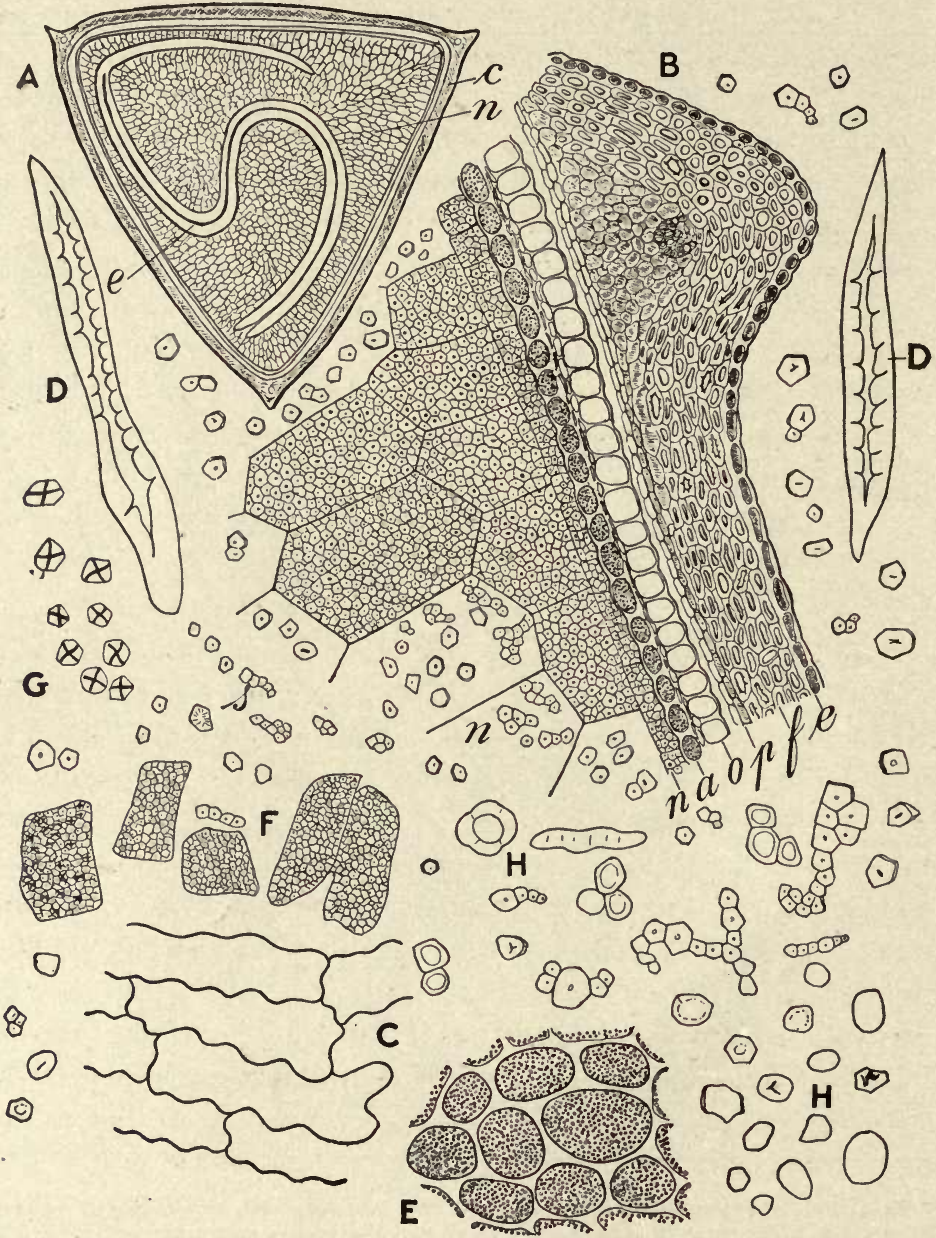

FIG. 292. Buckwheat (Fagopyrum esculentum): A, transverse section of grain showing pericarp (c), endosperm (n) and slender coiled embryo (e); B, transverse section of portion of grain showing epicarp (e), fibrous layer (f), pigment layer ( $p$ ), outer epidermis of spermoderm (o), aleurone cells (a), endosperm cells containing starch (n); C, surface view of cells of epicarp; D, isolated fibers of pericarp; E. surface view of aleurone cells; F, isolated parenchyma cells of endosperm filled with starch grains as seen in buckwheat flour; $G$, appear. ance of starch grains when mounted in oil and viewed with polarized light; $H$, swollen and altered starch grains which are two to three times the size of the normal grains.

Tannin is obtained from a number of the plants belonging to the Polygonaceæ, as the root of Rumex hymenosepalus of Texas 
which is known as CANAIgre; the rhizome of Polygonum bistorta of Europe which yields the drug Bistorta.

Polygonum cuspidatum of the gardens contains emodin; polygonin, a glucoside yielding emodin; and probably emodin methyl ether. Rumex ecklonianus of South Africa contains emodin, a volatile oil and a resin. The latter consists of emodin monomethyl ether; chrysophanic acid, physosterol (resembling rhamnol), etc. Polygonum Hydropiper and P. aviculare, both common in the United States, are poisonous to sheep.

A number of the plants of this family yield food products. Buckwheat is the fruit of Fagopyrum csculentum indigenous to Central Asia and cultivated in many parts of the world (Fig. 292).

Some are also cultivated as ornamental plants, as the Prince's feather (Polygonum orientale).

XI. ORDER CHENOPODIALES OR CENTROSPERM E.

This order includes seven families, in all of which the embryo is curved or coiled, and the reserve consists chiefly of perisperm.

a. CHENOPODIACEÆ OR GOOSEFOOT FAMILY.The plants are annual or perennial herbs with simple leaves and small perfect flowers, the fruit being a utricle. The fruits of a number of the group cuntain volatile oil, and are used in medicine, as the common wormseed (Chenopodium ambrosioides anthelminticum), which is found in waste places in the United States. Most of the oil is distilled in Maryland and is known in commerce as "Baltimore oil."

Chenopodium mexicanum yields saponin. Atriplex hortensis of Tartary yields indigo. The ash of very many species of Atriplex as well as genera of the Chenopodiaceæ yields soda. The seeds of several species are edible, as of Chenopodium viride of Europe and Asia, C. Quinoa of Chile, etc. Seeds of Spinacia tetandra of the Orient are used in bread-making.

A number of species are used as garden vegetables, as spinach (Spinacia oleracea) and beet (Beta vulgaris).

The SUGAR BEET (Beta vulgaris Rapa), which contains from 4 to 5 per cent. of cane sugar (sucrose), is largely cultivated in Germany, as well as to some extent in the United States, and is an important source of cane sugar. While the juice of the beet 
contains a larger amount of nitrogenous substances than that of the sugar cane, it is practically free from invert sugar.

b. AMARANTACEÆ.-The plants are weed-like and much resemble the Chenopodiaceæ. They yield anthelmintic principles, edible seeds, and the leaves of a number of species are used as vegetables. The ash yielded by some species contains potash, as Achyranthes aspera and Amaranthus ruber. Some are ornamental plants having a fasciated inflorescence, as the Cock's-comb (Celosia cristata).

c. NYCTAGINACE $Æ$ OR FOUR-O'CLOCK FAMILY.The plants are mostly herbs growing in America. The leaves are entire and simple, and the flowers are regular and in terminal or axillary clusters. The perianth consists of a 4- to 5-lobed corollalike calyx. The most common representative of this family is the Marvel-of-Peru or four-o'clock (Mirabilis Jalapa). While this plant is an annual in the United States, in the Tropics the tuberous root is used as a substitute for jalap, and is sometimes sold for it. The seeds of this plant are edible, as are also the leaves of several species, as of Borhavia erecta, which are used as green vegetables. Some members of the group, as Bougainvillea spectabilis, are handsome plants with bright rose-colored bracts which envelop the small greenish flowers.

d. PHYTOLACCACEÆ.-The plants of this family are mostly tropical and are represented in this region by only one species, namely, the common poke (Phytolacca decandra), the root and fruit of which are used to some extent in medicine. This is a succulent, branching herb I to $4 \mathrm{M}$. high, having a large perennial root. The stem is hollow except for the thin, papery partitions. The leaves are simple, ovate-lanceolate, petiolate. The flowers are in racemes and characterized by having ten stamens. The fruit is a dark purple, juicy berry (Fig. 293).

The roots of this species as well as others contain powerful drastic principles, as Pircunia littoralis and Anisomeria drastica of Chile. Phytolacca abyssinica contains saponin, and a red coloring principle is found in the berries of Phytolacca decandra and Rivinia tinctoria of Venezuela. The leaves of some species of Phytolacca are used as greens.

e. AIZOACE $Æ$. This is a group of mostly tropical plants, 


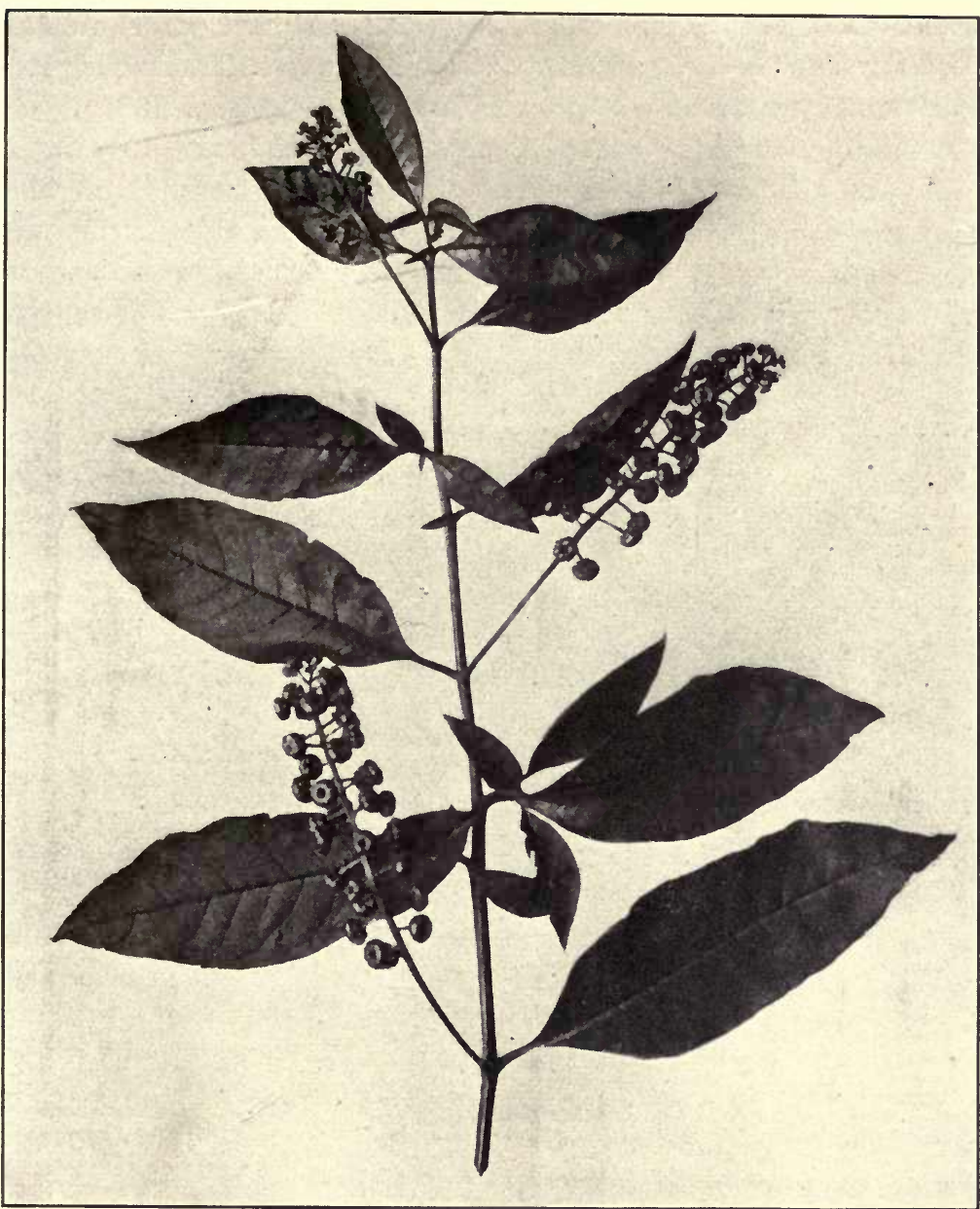

FIG. 293. Poke weed (Phytolacca decandra), a common weed growing in low grounds and waste places. The plant is a perennial herb, usually sending up from a large, fleshy root a number of stout stalks, I to $3 \mathrm{M}$. high; the leaves are ovate-oblong, and opposite which may arise the racemes of whitish flowers. The roots are quite frequently mistaken for parsnips, and when eaten may cause serious illness. The young shoots and leaves are sometimes gathered in the spring and may be used for a table vegetable. The juice of the berries is said to have been used in Portugal to color Port wine.-After Brown.

very many of them having fleshy leaves and adapted to arid regions. Many of the plants, particularly those belonging to the genus Mesembryanthemum, are much prized on account of their 
beautiful flowers, which expand only in the sunshine. The common ice-plant of the gardens, so called because of the numerous glistening globules of water which cover the leaves, is M. crystal-

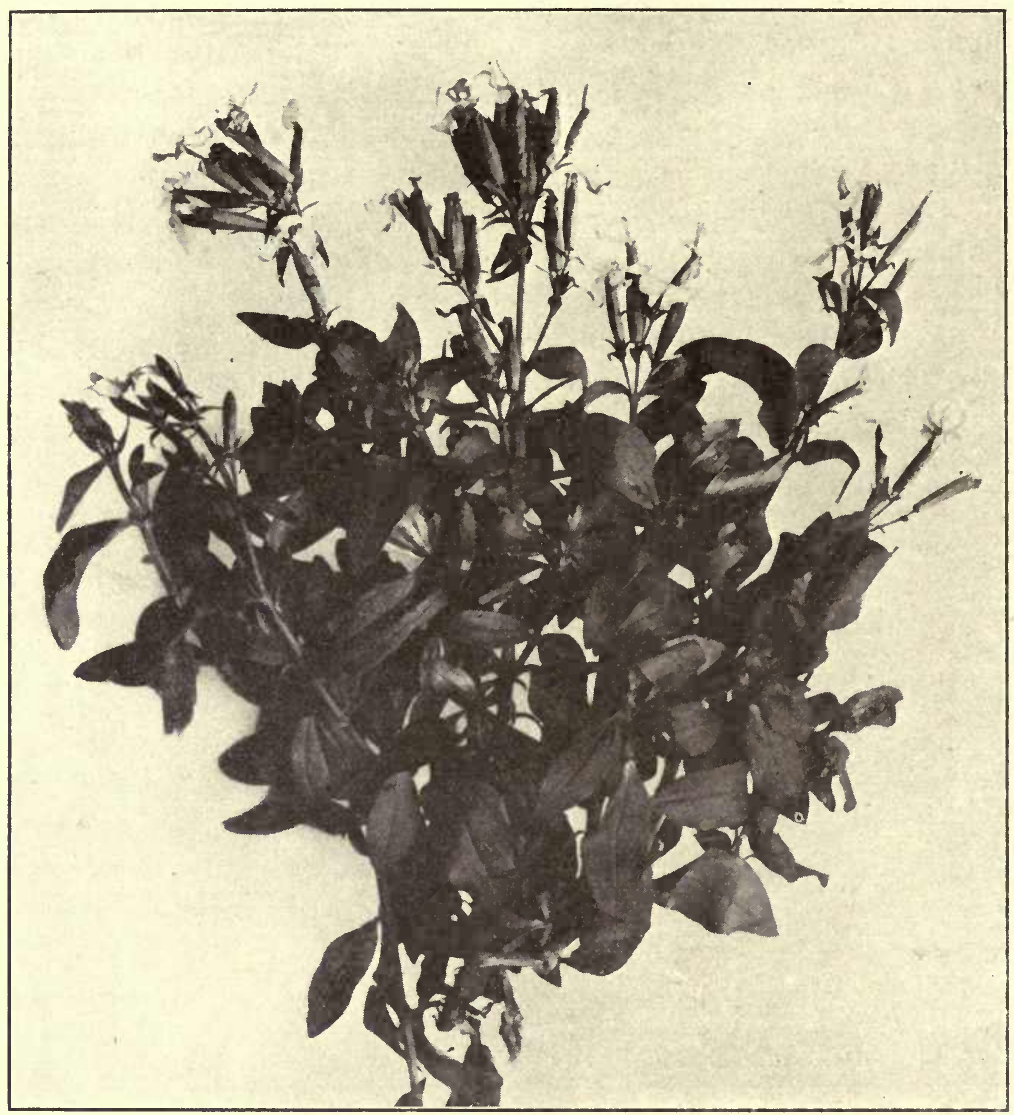

FIG. 294. Soapwort, Bouncing Bet (Saponaria officinalis), a perennial herb growing to a height of 3 to $6 \mathrm{dm}$. and producing opposite, entire leaves, and cymose clusters of rosecolored flowers, commonly double. This plant has been more or less cultivated; it has, however, escaped from the garden, and, in spite of its beauty, has become a troublesome weed in some places. The plant contains saponin and therefore forms a lather with water. It has been used as a detergent.-After Brown.

linum. This plant as well as other species of Mesembryanthemum are used in medicine. The ashes yielded by the plants of this family also contain soda. The seeds of some species of Mesem- 
bryanthemum as well as other members of this family are edible, and the leaves of some species are used as vegetables like lettuce.

f. PORTULACACEÆ.-The plants are fleshy or succulent herbs mostly indigenous to America. The two common representatives are the spring beauty (Claytonia virginica), the tubers of which are rich in starch, and purslane (Portulaca oleracea), sometimes used as a green vegetable. The seeds of the latter plant as well as of other species of Portulaca are used in medicine.

g. CARYOPHYLLACEÆ.-The plants are annual or perennial herbs, often swollen at the nodes, with opposite, entire leaves, and usually perfect regular flowers. The perianth has a distinct corolla of 4 or 5 petals. The fruit is a capsule and the seeds are half anatropous. The plants are most abundant in the northern hemisphere; and some of them are quite showy, as the CARNATION (Dianthus caryophyllus) and pinks (Dianthus species) and the cultivated pink or Sweet William (D. barbatus). A number of the members of this group contain saponin, as Bouncing Bet (Saponaria officinalis), which is naturalized in the United States (Fig. 294), Gypsophila Struthium of Spain and other species of this genus, as well as species of Lychnis and Herniaria. The leaves of Paronychia argentea are used in Morocco as a substitute for tea. The roots of Scleranthus perennis of Eastern Europe are inhabited by an insect (Coccus polonica) which is used in the preparation of a red dye. The fleshy stitch-wort (Alsine crassifolia) of Europe and the United States is poisonous to horses.

XII. ORDER RANALES.

The plants are mostly herbs, but include some shrubs and trees, and comprise eight families of economic importance.

a. NYMPHÆACE无 OR WATER LILY FAMILY.These are aquatic perennial herbs with thick root-stocks and floating, peltate leaves. The flowers are perfect and have large petals. The seeds are enclosed in an aril, and the embryo has fleshy cotyledons.

Nuphar luteum of Europe and Middle Asia contains the alkaloid nupharine and tannin, the latter of which splits into ellagic and gallic acids. The yellow pond lily (Nymphoca advena) of the 
United States contains similar principles. The seeds and rhizomes are rich in starch and are used as food, in some cases starch being manufactured from them, as of various species of Nymphcea, Nelumbo (Lotus) and Victoria, and Euryale ferox.

b. RANUNCULACE $Æ$ OR CROWFOOT FAMILY.These are annual or perennial herbs with simple or compound leaves, regular or irregular flowers, and fruits which are akenes, follicles, or berries.

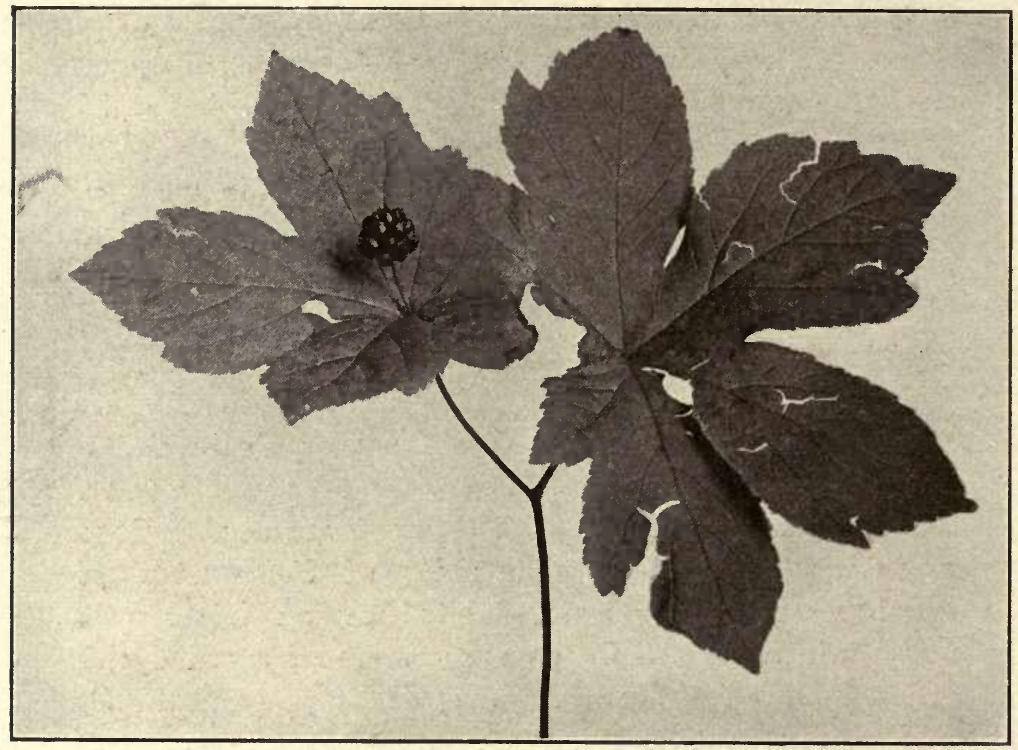

Fig. 295. Fruiting top of Golden Seal (Hydrastis canadensis), showing the two large palmate leaves, above one of which is a berry-like fruit which is bright red when ripe.

Hydrastis canadensis yields the official drug hydrastis. From a short, thick, horizontal rhizome with numerous slender roots rises a short stalk with a few palmately lobed, reniform, petiolate, pubescent leaves. The flowers are small, solitary and greenishwhite, and the fruit is a head of crimson berries somewhat resembling the raspberry (Fig. 295).

Cimicifuga racemosa (black cohosh or black snakeroot) yields the official drug cimicifuga. This is a tall perennial herb with large knotty rhizome, large decompound leaves, and a long raceme of white flowers (Fig. 296). 


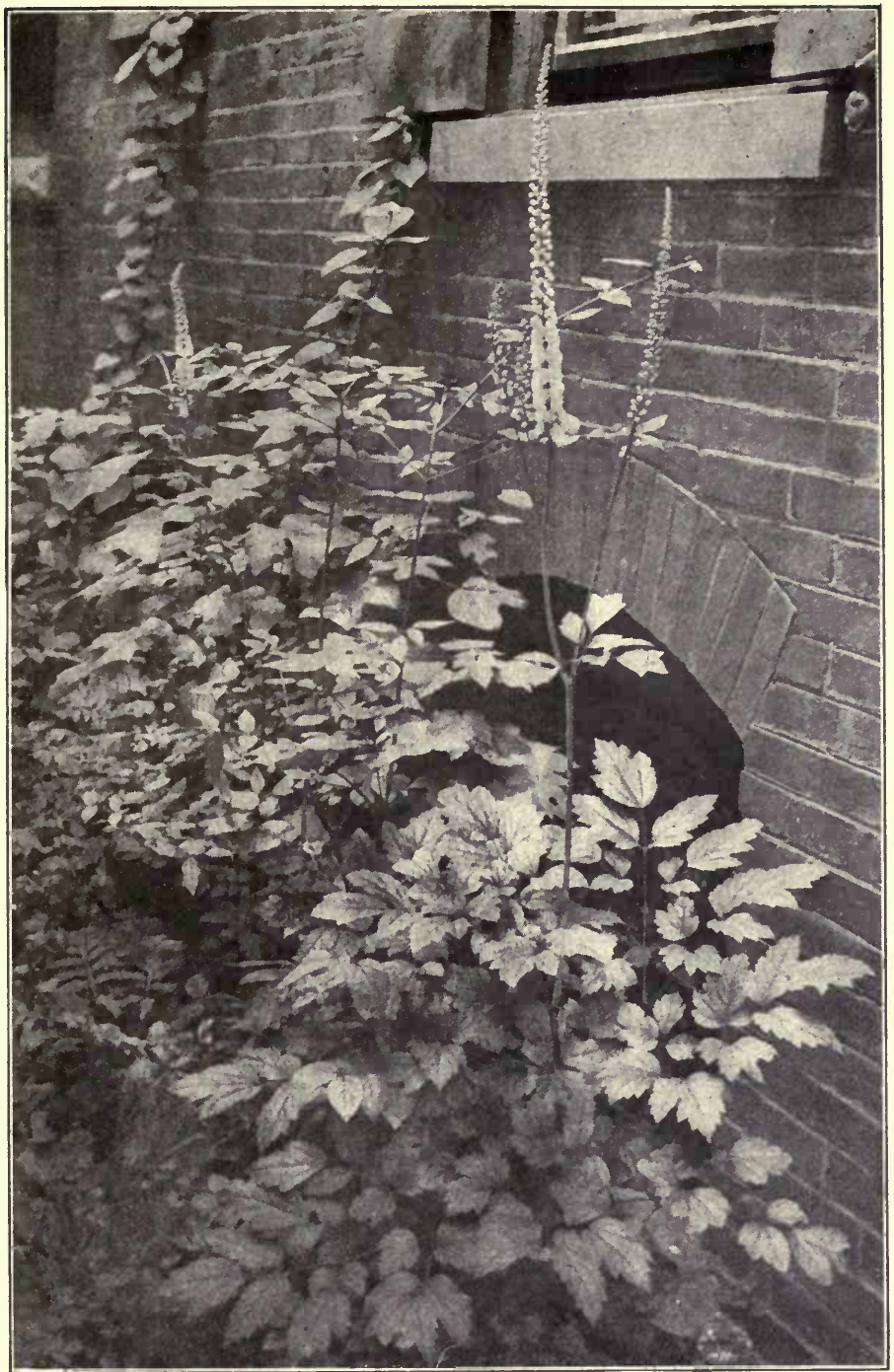

FIG. 296. A group of transplanted wild plants with a plant of Cimicifuga racemosa in the foreground, showing the characteristic, large, decompound leaves and long raceme of flowers.

Aconitum Napellus yields the official drug aconite (Fig. 186). This is a perennial herbaceous plant indigenous to Europe and extensively cultivated. From a tuberous root arises a simple leafy 
stem with palmately lobed or divided leaves, and large, irregular, blue flowers which form a rather loose panicle (Fig. 297). The sepals are 5 in number, the posterior upper one being large and

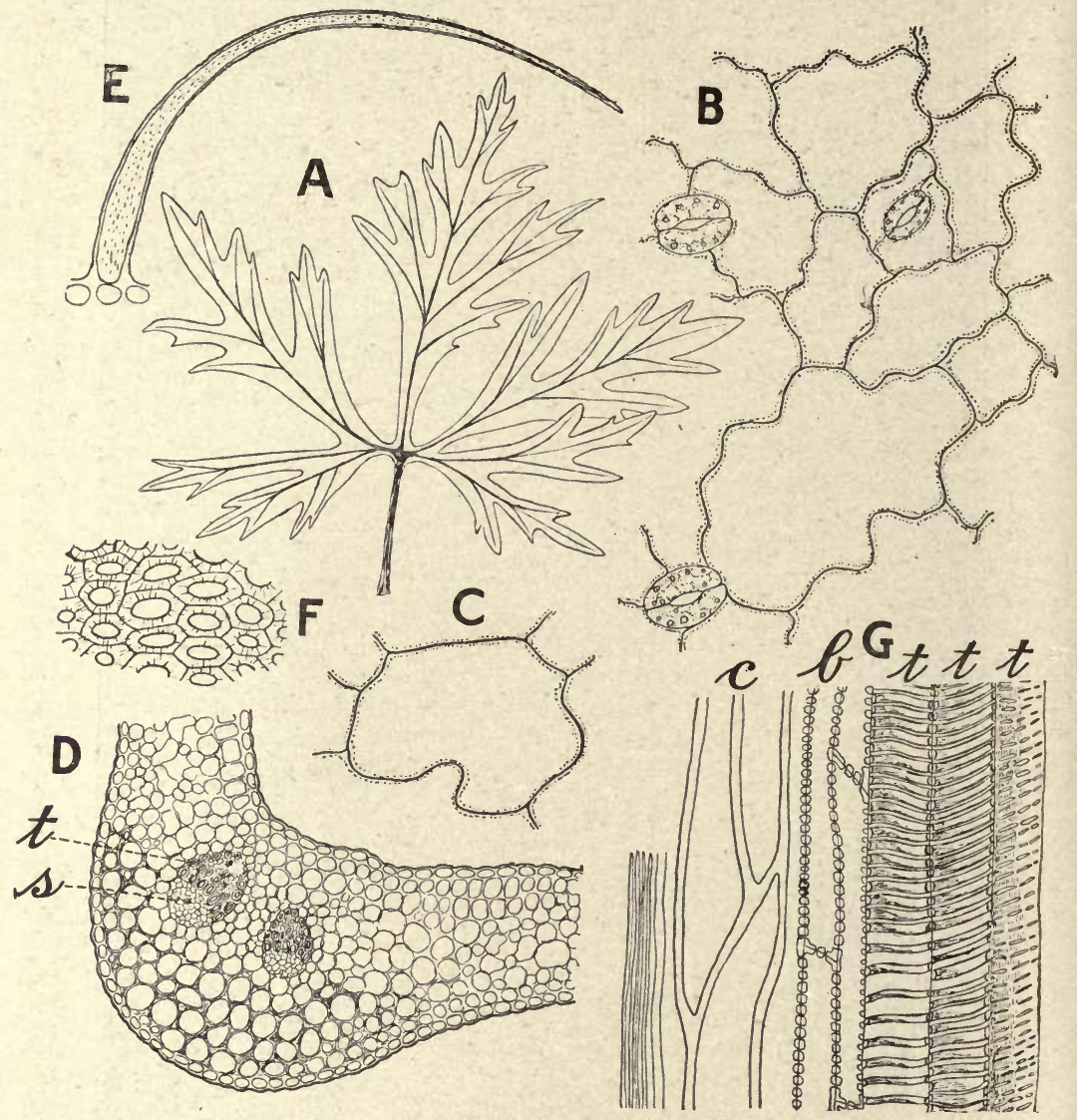

FIG. 297. Aconitum Napellus. A, one of the long-petiolate, divided leaves; B, epidermal cells of lower surface; c, an epidermal cell of the upper surface; D, transverse section through one of the principal veins showing two fibrovascular bundles, and strongly collenchymatic cells beneath the lower epidermis: $E$, one of the few hairs from the petiole; $F$, lignified bast fibers surrounding the sieve in the petiole; $G$, longitudinal section through fibrovascular bundle showing spiral and reticulate tracheæ $(t)$, bast fibers $(b)$ and some of the collenchyma cells (c), those at the left exhibiting longitudinal pores which give a crystal-like effect.

helmet-shaped. The petals are 2 to 5 and rather small; the two posterior or upper ones which are hooded and concealed in the helmet-shaped sepal are nectar-secreting (Fig. 223, E). The fruit is a follicle and contains numerous small seeds. 


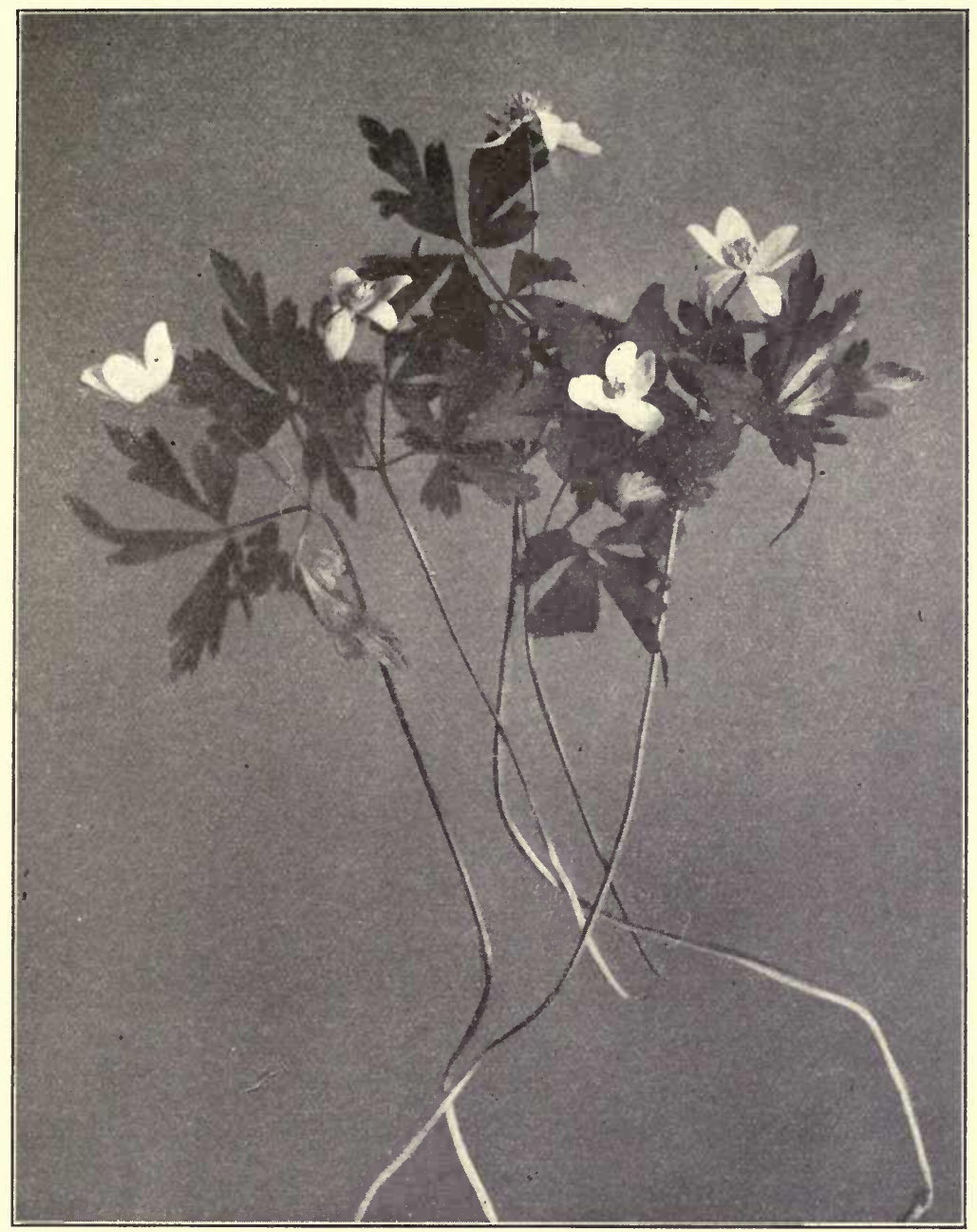

FIG. 298. Wood anemone, wind flower (Anemone quinquefolia), one of the earliest flowering woodland plants. It is a low, slender plant with 3 trifoliate leaves forming an involucre, from the junction of which arises a peduncle, bearing a solitary flower. The sepals vary in number as well as in color; there are generally 5 , which are usually whitish, or slightly tinged with purple.-After Brown.

Delphinium Staphisagria, which yields the official staphisagria or stavesacre, is a handsome, tall, biennial larkspur, with dark green, palmate 5 - or 7 -lobed leaves and blue or purplish flowers in 


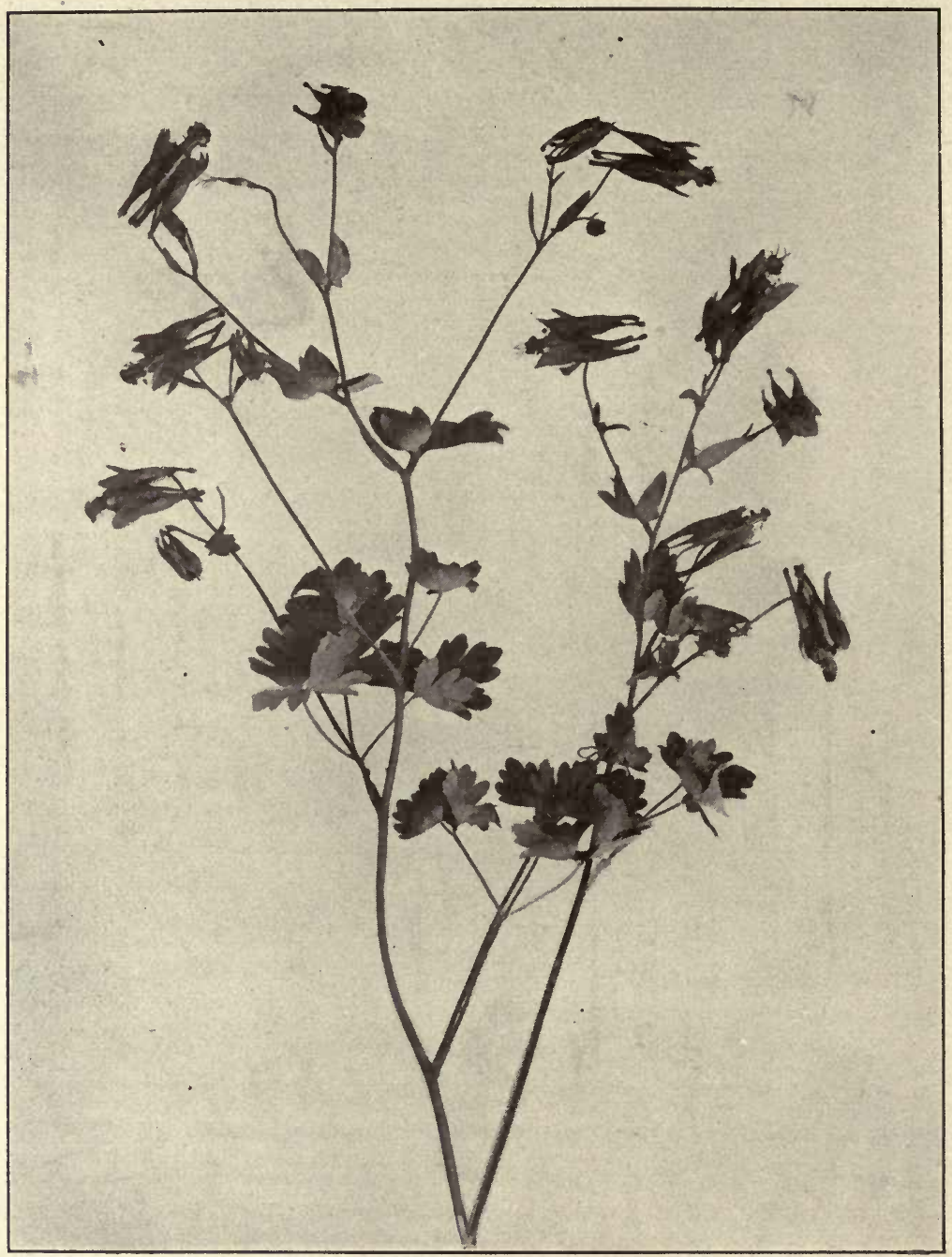

FIG. 299. Wild Columbine (Aquilegia canadensis), one of the most interesting plants of the Ranunculaceæ. It grows in the crevices of rocks and in open woods, and is a very striking plant, with its 5 long-spurred, scarlet petals. A number of species of Aquilegia are cultivated, and their flowers show considerable variation in form and color.-After Brown.

racemes. The flowers are zygomorphic and somewhat resemble those of Aconite. 
Pulsatilla, which was formerly official, is obtained from several species of Anemone growing in Europe. These are perennial herbs (Fig. 206) with basal leaves which are deeply lobed or dissected, those of the stem forming a kind of involucre near the flower. The flowers are rather large and with numerous petaloid sepals. The fruit is a densely woolly achene in those species which are used in medicine. The entire plant is used and contains an acrid volatile oil, the principal constituent of which is an anemone camphor (anemonol). The latter is easily decomposed into anemonon, which on fusion becomes exceedingly acrid. Similar principles are found in other species of Anemone as well as in certain species of Ranunculus (buttercup) and Clematis Vitalba of Europe.

Very many of the other Ranunculaceæ contain active principles. The glucoside helleborein, which resembles digitalin in its medicinal properties, is found in Helleborus niger, the BLACK HELLEBORE of Europe, and probably in other species of Helleborus, as well as in Actoca spicata, the baneberry of Europe, and Adonis vernalis, the false hellebore of Europe and Asia.

c. BERBERIDACE $E$ OR BARBERRY FAMILY.-The plants of this family are herbs or shrubs with simple or compound leaves, and flowers either single or in racemes (Figs. I34, E; $8 \mathrm{I}, T)$. The fruit is a berry or capsule.

Berberis Aquifolium (trailing mahonia) yields the unofficial drug berberis. It is a low, trailing shrub with 3 - to 7 -compound, scattered leaves. The leaflets vary from oval to nearly orbicular, are obtuse at the apex, slightly cordate at the base, finely reticulate, and spinose-dentate. The flowers are yellow and in dense terminal racemes. The fruit is a blue or purplish berry.

Caulophyllum thalictroides or blue cohosh of the Eastern United States is a perennial herb with a thick rhizome and large ternately compound leaves (Fig. 300). The flowers are small and greenish-purple. The fruit is peculiar in that it resembles a berry and consists only of blue, globular, naked seeds, the pericarp being ruptured and falling away soon after fertilization. The rhizome and roots were formerly official. It is a horizontal, much branched rhizome with broad, concave stem-scars, and numerous roots; it is grayish-brown externally, sweetish, slightly bitter and 
somewhat acrid. The drug contains an acrid, saponin-like glucoside, leontin; a crystalline alkaloid, caulophylline; two resins; and starch. For analysis of the seeds see Chem. News, 1908, p. I80.

Podophyllum peltatum or May apple is the source of the official podophyllum. This is an early, herbaceous, low, perennial plant forming large patches by reason of its long dichotomously branch-

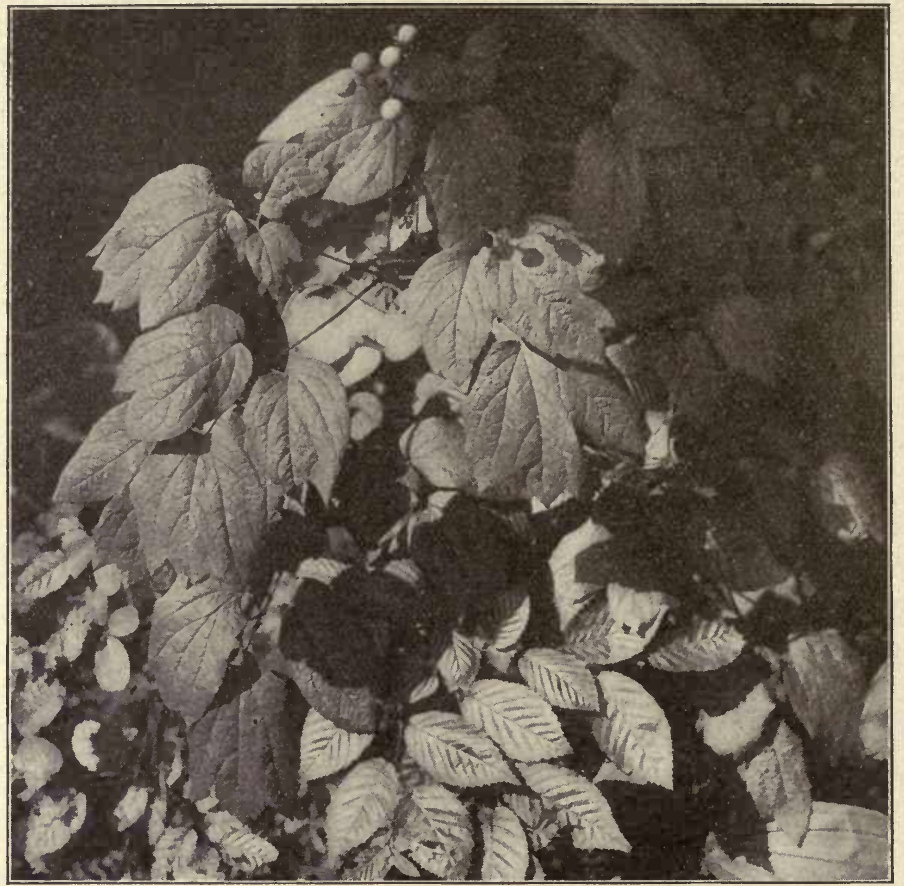

FIG. 300. A group of transplanted plants, showing in the upper portion a fruiting plant of blue cohosh (Caulophyllum thalictroides).

ing rhizome (Fig. I82). It forms two kinds of branches, one bearing a single, peltate, $5^{-}$to 7 -lobed leaf ; and another bearing in the axil of two similar leaves a white flower which gives rise to a large, yellowish, ovoid berry which is edible.

d. MENISPERMACE $\nexists$ OR MOONSEED FAMILY.The plants are climbing or twining, herbaceous or woody vines with simple, entire or lobed leaves and small, greenish-white diœ- 
cious flowers. The fruit is a drupe and contains a characteristic crescent-shaped seed.

Menispermum canadense or Canada moonseed yields the drug menispermum which was formerly official. It grows in the Northern United States and Canada and is a high-climbing vine with broadly ovate, cordate and 3 - to 7 -lobed leaves (Fig. I80). The flowers are in panicles giving rise to a characteristic cluster of bluish-black berries.

The rhizome occurs in pieces which are 5 to $7 \mathrm{dm}$. long and 2 to $5 \mathrm{~mm}$. in diameter; externally it is longitudinally wrinkled, of a yellowish-brown color and somewhat resembles Sarsaparilla. In transverse section, however, it is very distinct (Fig. 194). The drug has a bitter taste and contains a bitter alkaloid menispine, berberine and starch. In addition it contains the alkaloid oxyacanthine which is also found in Berberis vulgaris of Europe and the West Indies.

Jateorhiza palmata yields the official drug calumba (columbo). The plant is a herbaceous climber somewhat resembling Menispermum, the leaves being more decidedly lobed. The flowers form long racemes.

Chondrodendron tomentosum, the source of the unofficial drug pareira, is a high woody twiner. The leaves are large, petiolate, broadly ovate or rounded, slightly cordate, and densely tomentose on the lower surface.

Anamirta paniculata is a woody climber of the East Indies. The fruits, known as fishberries or Cocculus, are used as a fish poison by the natives and contain the neutral principle picrotoxin.

Very many other plants of the Menispermacex contain powerful toxic principles and are used as fish poisons and as antidotes to snake poison. Several species of Abuta are used in the preparation of curare poison.

e. MAGNOLIACE $Æ$ OR MAGNOLIA FAMILY.-The plants are mostly trees or shrubs and are represented in the United States by the magnolias and tulip tree (Liriodendron. Tulipifera). The latter is a magnificent tree with characteristic leaves (Fig. 204) and large, fragrant, orange-colored, tulip-like flowers.

The plants of this family contain a variety of constituents. 
Ethereal oils containing anethol and resembling those of anise are found in the fruit of Illicium anisatum. (I. verum) or STAR ANISE, a small evergreen tree growing in the mountains of Southern China. A volatile oil with a disagreeable odor is found in a closely related species $I$. religiosum (Shikimi) of Japan. The fruit of the latter plant is known as JAPANESE STAR ANISE and contains in addition a poisonous neutral principle. The fruits of both star anise (Illicium) and the Japanese star anise are made up of 6 to 8 radially arranged follicles, which are dark brown, dehiscent on the upper (ventral) surface and each contains a single, brown, shiny seed. Star anise has an odor and taste resembling anise. Japanese star anise has a bitter taste and in addition is brownish-black, very woody and strongly beaked.

Volatile oils are also found in the flowers of the various species of Magnolia and in Michelia Champaca found in the Malay Archipelago and cultivated in India and Brazil, and in $M$. nilagirica of India, the latter being used in perfumery.

Winter's bark is derived from Drimys Winteri, a shrub of South America. It occurs in quills which are from 5 to $10 \mathrm{~mm}$. thick; externally it is grayish-brown and covered with numerous lichens; the fracture is short, the broken surface being marked by stone cells and resin canals; the odor is fragrant; taste aromatic, pungent and bitter. The drug contains a volatile oil which consists essentially of a hydrocarbon known as winterin; it also contains a resin.

A crystalline principle magnolin, a glucoside and a volatile oil are found in Magnolia macrophylla (or cucumber-tree of the Southern States) and $M$. tripetala or umbrella tree growing southward from Pennsylvania. A bitter principle liriodendrin, a volatile oil, an alkaloid, and a glucoside are found in the tulip poplar or tulip tree.

The bitter and aromatic bark of Michelia montana of Java is used like cascarilla (Euphorbiaceæ). A bitter resin is found in the fruit of Talauma Plumieri of the Antilles.

A glucoside which dissolves the blood corpuscles is found in Talauma macrocarpa of Mexico. A red coloring principle soluble in water occurs in the leaves of Michelia Tsiampaca of Java. The fruits of Schizandra propinqua of Nepal and Kadsura Rox- 
burghiana of Japan contain considerable mucilage and are edible. The latter plant is also used as a hair-restorer. From the ash of Schizandra chinensis of China and Japan sodium chloride is obtained.

The flowers of Magnolia Juglans are used to flavor tea and the

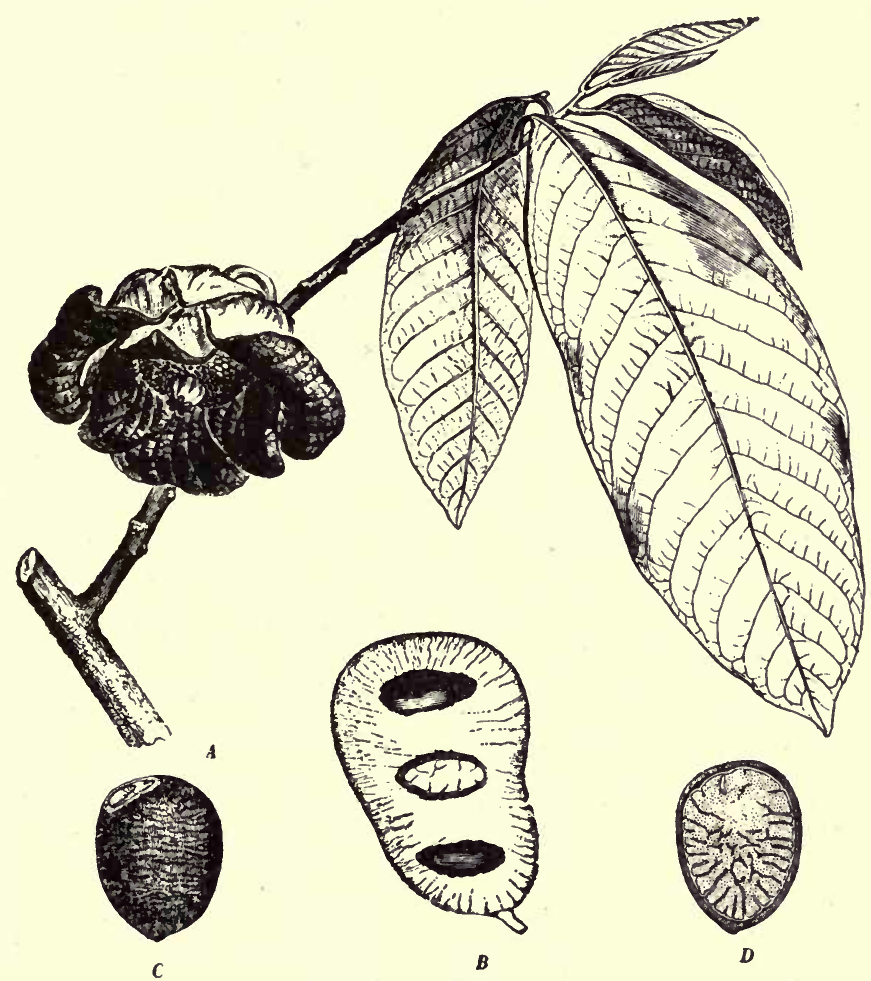

Fig. 301. North American papaw (Asimina triloba): A, branch showing lateral nodding flower and the large, pinnately-veined, entireleaves: B, section of the oblong, 3-seeded berry; C, D, seeds, the one in longitudinal section.-After Baillon.

leaves of Talauma ovata are used as a substitute for tea in Brazil.

f. ANONACE $\mathrm{E}$ OR CUSTARD-APPLE FAMILY.These are shrubs or small trees chiefly inhabiting warm-temperate and tropical regions. They yield very many economic products. The fruit of Xylopia brasilensis is used as a substitute for cubeb. Some yield fruits having an aroma similar to that of nutmeg, as 
Monocarpia Blancoi of Africa and Jamaica. The flowers of Cananga odorata of tropical countries are used in the preparation of a pomade from which the perfume YLANG-YLANG is made. Ethereal oils are also found in other species, as Unona ligularis of Ambyona, the seeds of which are used in perfumery. The bark of Popowia pisocarpa of Java contains an alkaloid.

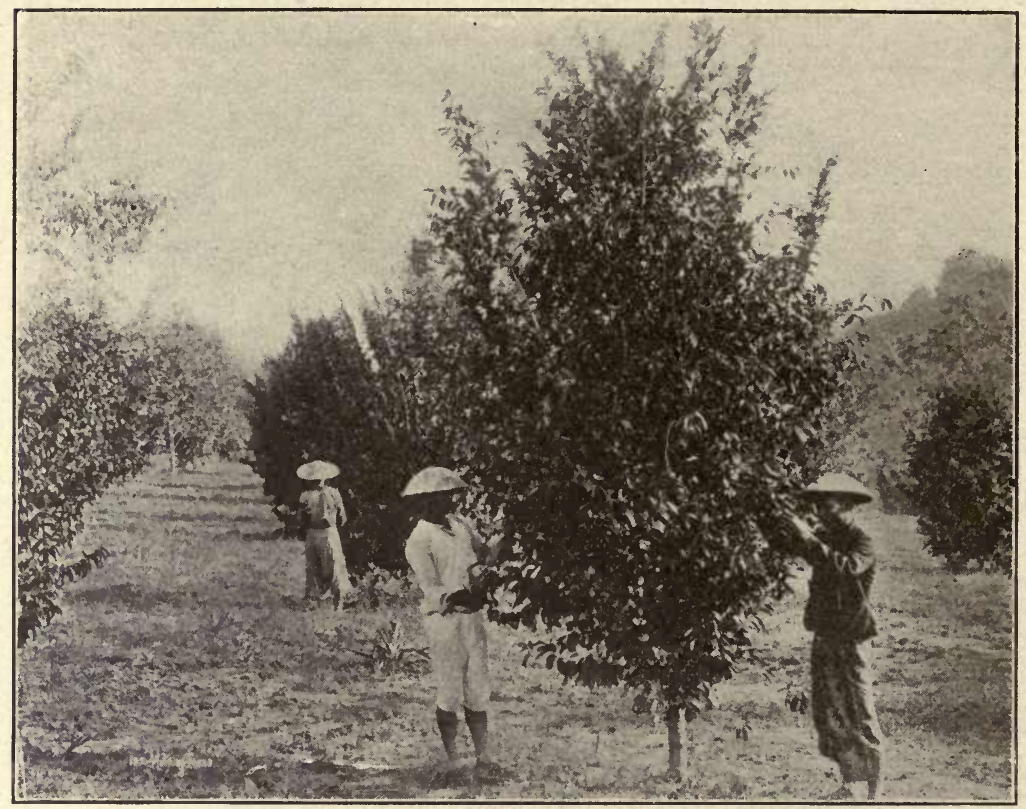

FIG. 302. Nutmeg trees growing in Singapore. The frees are handsome, evergreen shrubs, extensively cultivated in the East Indies, and to some extent in tropical America.Reproduced by permission of The Philadelphia Commercial Museum.

The seeds of Xylopia salicifolia of Trinidad and X. muricata of Jamaica are very bitter, as are also the wood and bark of $X$. glabra of the West Indies.

The seeds of Asimina triloba, the North American papaw (Fig. 30I), contains an emetic principle. This plant should not be confounded with Carica Papaya (Caricaceæ) which contains the ferment papain.

Many of the Anonacer yield large succulent fruits, some of which are edible, as the sugar apple obtained from Anona squa- 
mosa and CUSTARD APPLE from $A$. reticulata both abundant in the Tropics. The fruit of $A$. muricata sometimes weighs as much as two kilograms.

g. MYRISTICACE $Æ$ OR NUTMEG FAMILY.-This family is represented by the single genus Myristica. Nutmeg

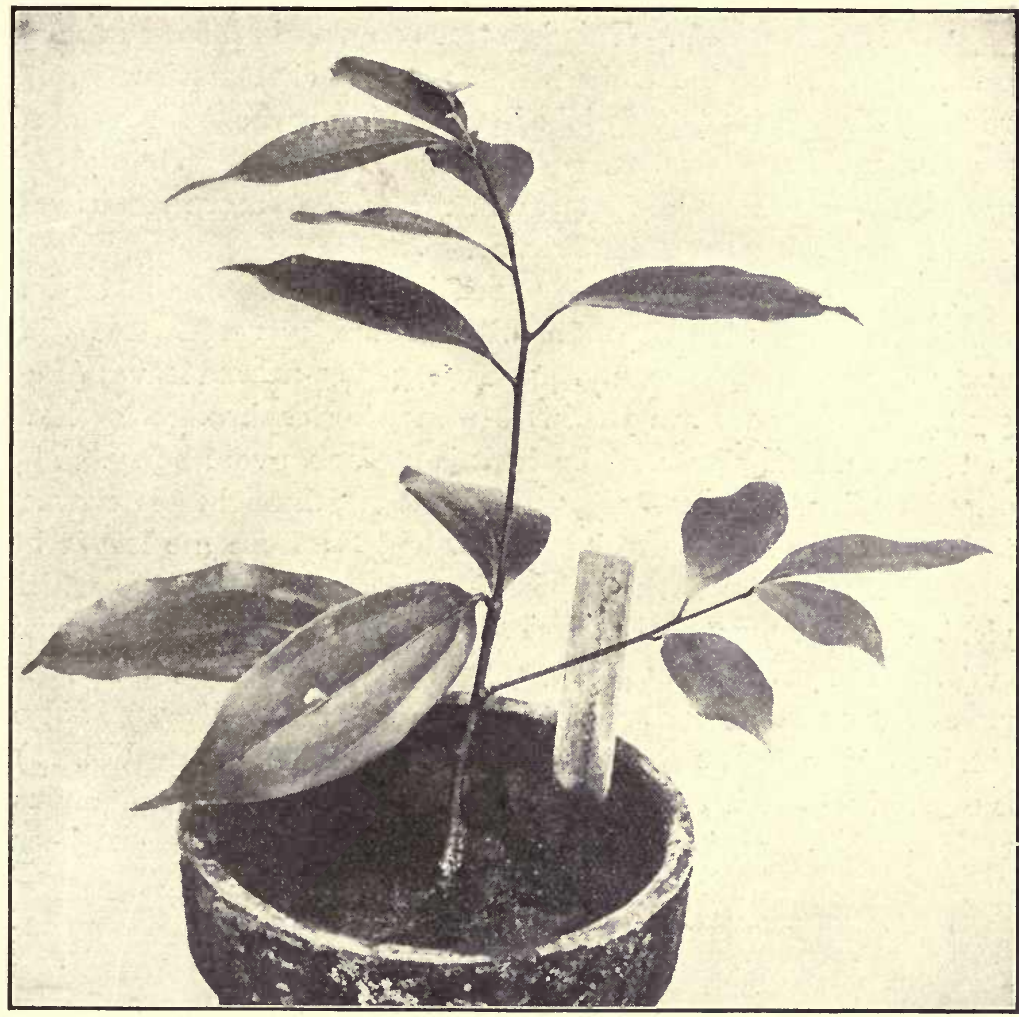

FIG. 303. Young plant of Cinnamomum zeylanicum grown from cutting.

(Fig. 302) and mace are obtained from Myristica fragrans, an evergreen tree with ovate, petiolate, coriaceous, entire and pinnately-veined leaves. The flowers are small, yellow and diœcious. The fruit is a berry having somewhat the shape and size of the green fruit of black walnut. It has a line of dehiscence, and when ripe is yellow. The arillode of the seed constitutes MACE, 
while the kernel is the NUTMEG, the pericarp of the fruit and coat of the seed being rejected.

h. LAURACEÆ OR LAUREL FAMILY.-The members of this family are chiefly shrubs and trees which are distributed mostly in the Tropics, although a few are found in the temperate zones (Fig. 280, F).

Sassafras officinale.-This is a tree common in the eastern and central portion of the United States and is characterized by its rough bark and its I- to 3 -lobed leaves, from whence it received its former name Sassafras variifolium (Fig. 203). The flowers are yellow, diœcious and appear in the spring before the leaves. The fruit is an oblong, blue drupe.

Cinnamomum zeylanicum, which is the source of the Ceylon cinnamon (Fig. 304), is a small, handsome, evergreen tree with opposite, coriaceous, broadly lanceolate, 3 - to 5-nerved leaves (Fig. 303). The flowers are yellowish-white, hermaphrodite, or both pistillate and staminate. The fruit is a black, ovoid berry. The oil of Ceylon cinnamon from the bark and branches is characterized by its content of cinnamic aldehyde; from the leaves by eugenol; and from the root bark by camphor. C. Cassia which yields Cassia cinnamon is a tree growing in China, Sumatra, and cultivated in Java. It has long, oblong-lanceolate leaves which are pubescent on the lower surface. Cassia cinnamon (bark) is also obtained from Cassia Burmanni. Saigon cinnamon (see Vol. II) is derived apparently from wild trees growing in the mountainous regions of Anam, the botanical origin of which has not been determined.

The volatile oils of the members of the Lauraceæ vary considerably in composition. In addition to the oils of Sassafras and Cinnamon the following may be mentioned: A CINNEOLcontaining oil is found in Cinnamomum Oliveri of Australia, Umbellularia californica of Western North America and Laurus nobilis the noble laurel of the Mediterranean and Mexico. A BorNEOL-containing oil is obtained from the root of Dicypellium caryophyllatum of Guiana, the wood of which is known in Cayenne as rose-wood. An oil containing a notable amount of METHYL SALICYLATE is obtained from the spice-bush (Lindera Benzoin) of the United States. 


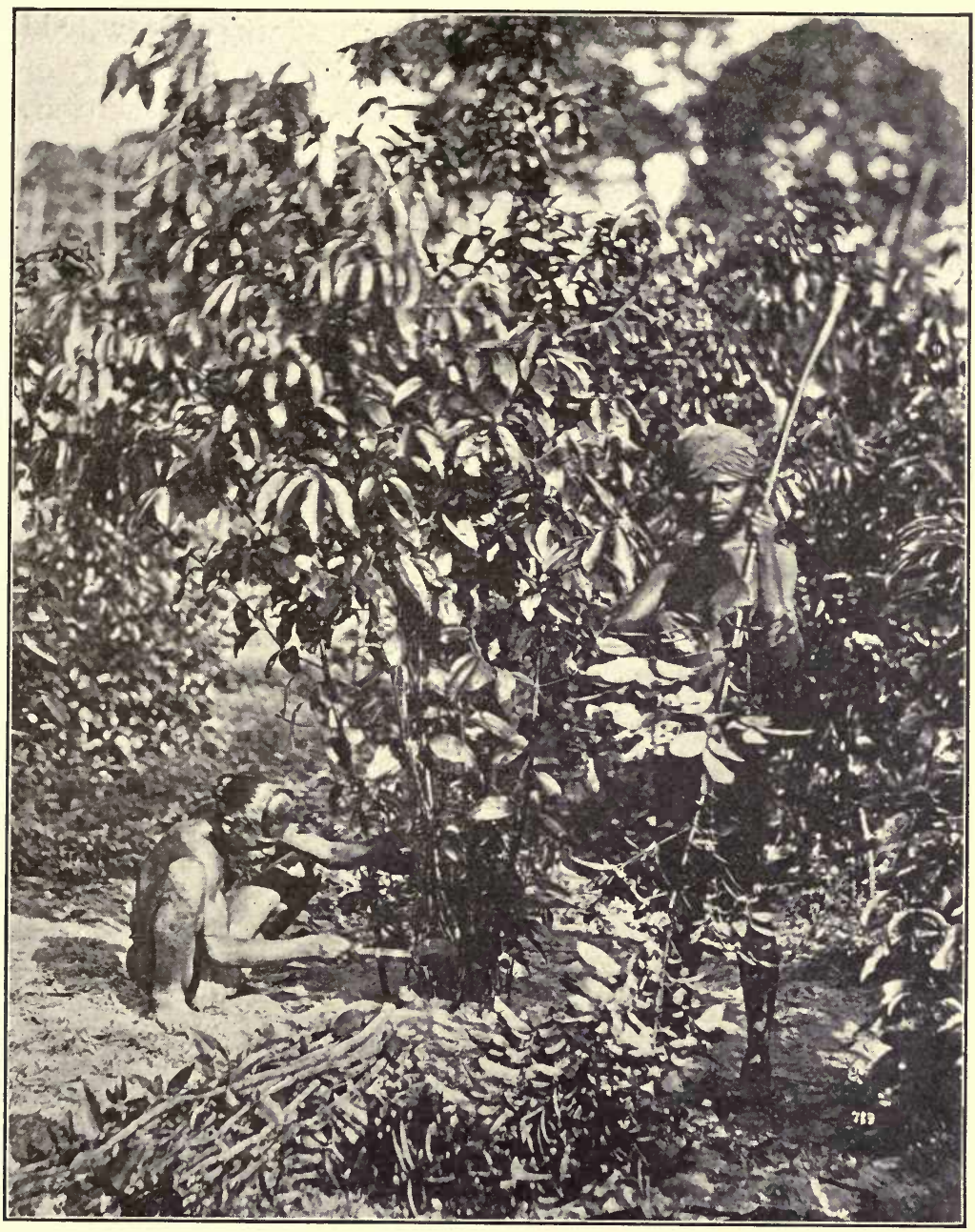

FIG. 304. Cutting cinnamon in Ceylon. Cinnamomum zeylanicum is a native of the forests of Ceylon and is extensively cultivated, not only on the western coast of that island but in other countries of tropical Asia. The manner of cultivation is such that a number of stems are allowed to grow from a single root. When of sufficient height these are cut down and the smaller branches removed, as shown in the illustration. The bark is then separated from the thicker portion of the stems, gathered into bundles and placed under mats until a slight fermentation takes place. After the corky layer is removed the product is ready for the market. - Reproduced by permission of The Philadelphia Commercial Museum.

Cinnamomum Camphora, or the camphor tree, is indigenous to China, Japan and Formosa, and is now cultivated in many warm 
countries as a shade and ornamental tree, growing very well in Southern California and the Southeastern States. All parts of the tree contain a volatile oil which on oxidation yields camphor, which latter is obtained on distillation and sublimation. Camphor of poor quality is obtained from C. Parthenoxylon of Burmah, Malaya and China, and C. glanduliferum of the Himalayas. Camphor is also a constituent of other ethereal oils of this same family, as the Massoy bark oil obtained from the root bark of C. zeylanicum and C. Burmanni of Java.

A EUGENol-containing volatile oil is obtained from Ravensara aromatica of Madagascar, and Machilus Thunbergii of Japan. Eugenol is also found in oil of laurel leaves (L. nobilis), Massoy bark oil, the oil of the leaves of Ceylon cinnamon, and the oils obtained from Cinnamomum Culilawan of the Malay Peninsula and China, and C. Wightii of East India, and possibly is also found in Dicypellium caryophyllatum.

The wood and the bark of Nectandra or Beeberu (Nectandra Rodici) of Guiana and Brazil contain several alkaloids, one of which is known as beeberine and is supposed to be identical with the alkaloids in Buxus sempervirens (Fam. Buxaceæ); pelosine found in Pareira; and paricine found in the bark of the cultivated cinchonas of Java. Coto bark, which is used in medicine, is obtained from an unknown tree in Northern Bolivia belonging to this family. The bark contains a volatile oil having a pungent taste, and a volatile alkaloid.

Fatty oils are obtained from Ravensara aromatica of Madagascar, Litsea glauca of Japan and other species of Litsea found growing in Cochin China and India. A red sap with a very fetid odor is obtained from Ocotea fetens of tropical and sub-tropical America, and the stink-wood of South Africa (O. bullata).

XIII. ORDER RHCEADALES OR PAPAVERALES.

These are mostly herbaceous, seldom woody, plants. The flowers are perfect and the fruit capsular. This order includes two families of importance medicinally.

a. PAPAVERACE $\mathrm{E}$ OR POPPY FAMILY.-These are herbs with a milky or colored latex.

Papaver somniferum or opium poppy is an annual herb I to 2 
M. high. The stem is sparingly branched, with alternate, deeply lobed, pubescent, clasping (by a cordate base), dull green leaves (Fig. $305, A$ ). The flowers in the variety album, from which opium is obtained, are white or silver-gray, and in many cultivated varieties are large and extremely showy. The two sepals drop away with the expansion of the corolla; the ovary is smooth, more or less globular and subtends the radiate stigma; the fruit is a
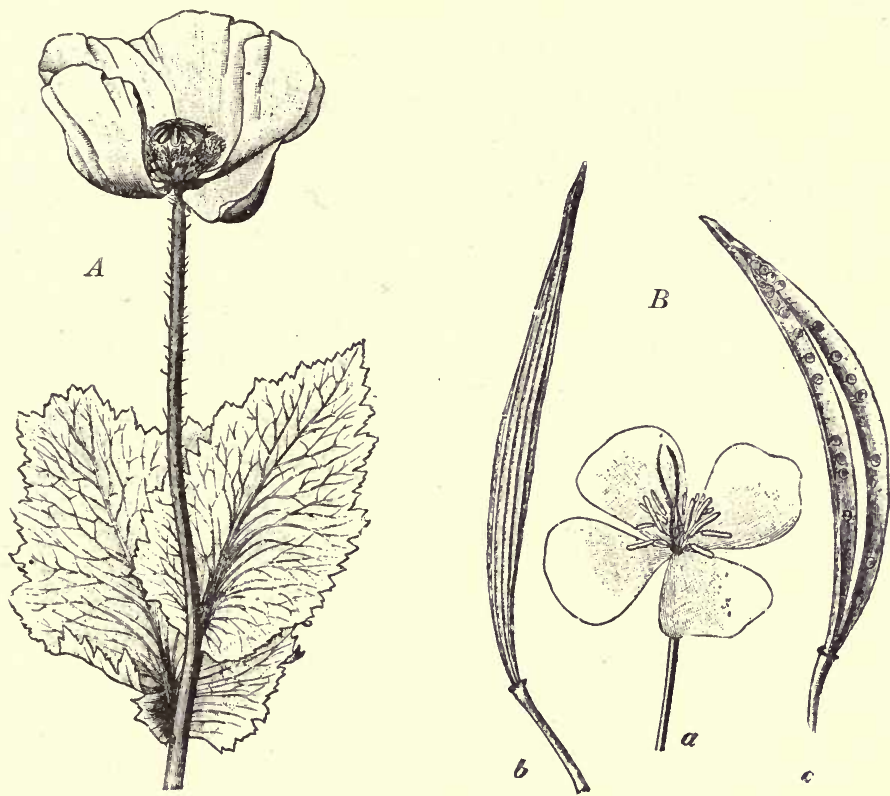

FIG. 305. A, Opium poppy (Papaver somniferum); B, California poppy (Eschs-holtzin californica) showing flower (a), and capsules (b, c), one of which (c) is dehiscent.-After Schimper.

capsule (Fig. 238), dehiscing by means of terminal pores, and contains a large number of extremely small white seeds, known as MAW-SEED, and which yield a fixed oil known as poppy-oil. The latex of this plant (Figs. 306, 307) yields opium.

Other allied members of the Papaveracex possess narcotic properties, but the alkaloid morphine has not been isolated from any of them, as the California poppy (Eschscholtzia californica) (Fig. 305, B) ; the Mexican poppy (Argemone mexicana); Hypecoum procumbens, and Fumaria plicata, both of Southern 
Europe. These latter plants probably contain also the alkaloid protopine which is apparently identical with fumarine.

Sanguinaria canadensis or bloodroot, the rhizome of which is official. The plant is a small, herbaceous, perennial herb with a red latex. The rhizome is horizontal, short and thick, and gives rise to a single, petiolate, palmately $5^{-}$to 9 -lobed leaf and a single white flower with a long peduncle (Fig. 308). The capsule is

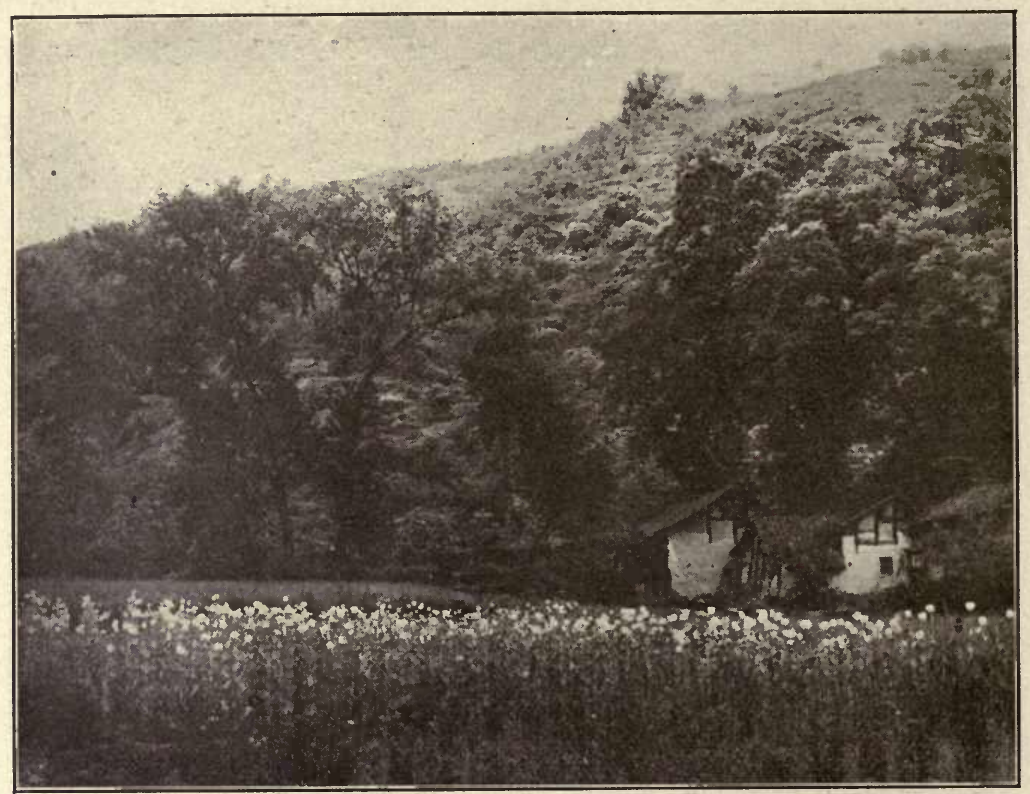

FIG. 306. Poppy fields in the meadows 8 miles northwest of Ping-li, Shensi, China, showing the plants with large terminal flowers. - Reproduced by permission of The Philadelphia Commercial Museum.

oblong, 2-valved, and contains a number of smooth but crested seeds.

Chelidonium majus (celandine) is the source of the herb CHELIDONIUM which was formerly official. The plant is a delicate branching herb about $0.5 \mathrm{M}$. high; with alternate, deeply pinnatifid leaves; yellow flowers; slender elongated capsule resembling that of the mustards, and a yellow latex in every part. Celandine is indigenous to Europe and Asia and is common in waste places in the United States. The drug contains the following alkaloids: 


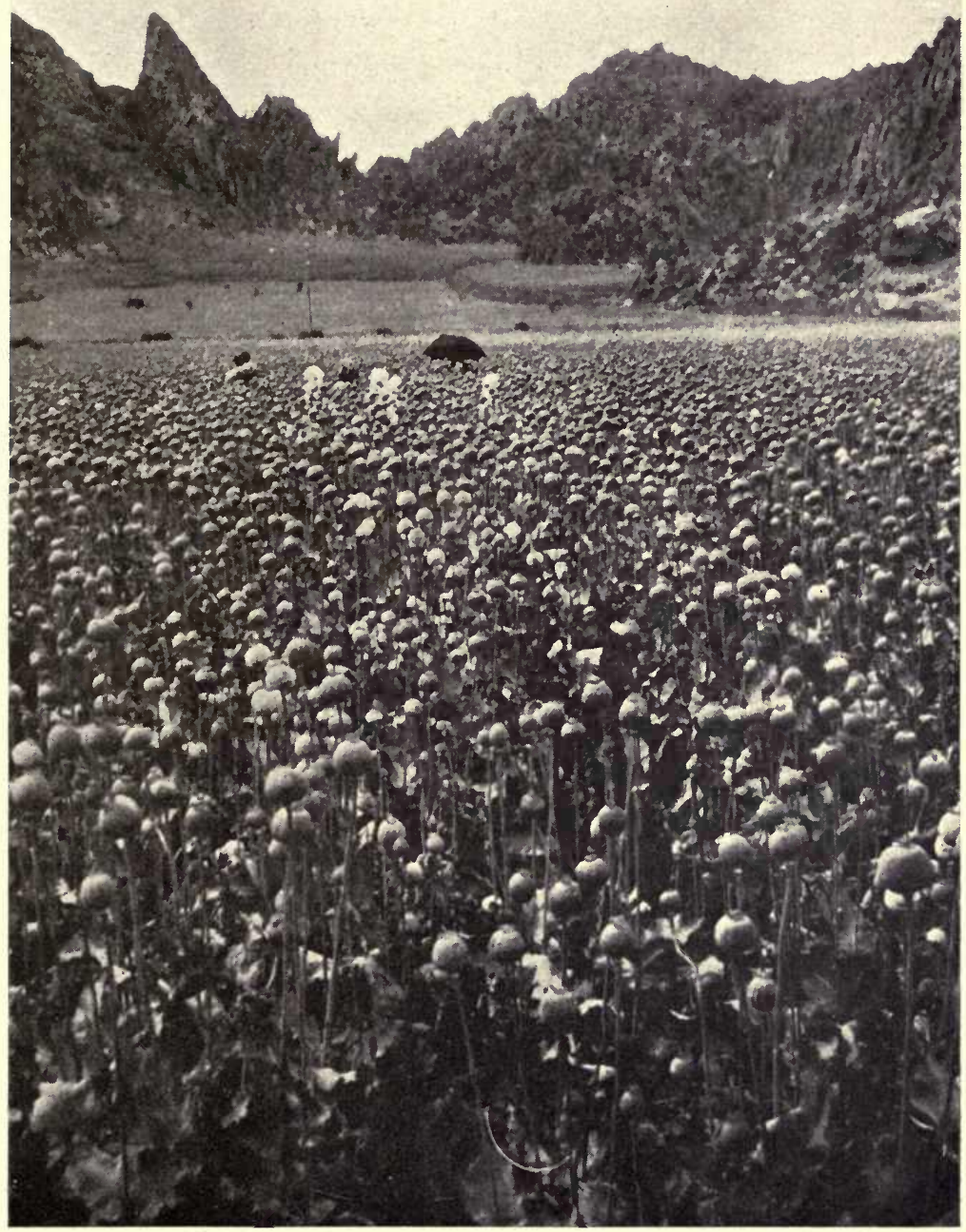

FIG. 307. Poppy fields in Afionkarohissar, Turkish Empire. The capsules are ready to be incised allowing the milky juice to exude, which is then collected and constitutes the opium of commerce.-Reproduced by permission of The Philadelphia Commercial Museum. 
Chelidonine (identical with stylophorine), chelerythrine (which is fluorescent), and protopine (found also in opium and sanguinaria). It also contains a bitter neutral principle chelidoxanthin and several organic acids (Fig. 309).

To this family belong a number of other plants which contain principles similar to or identical with those found in Sanguinaria and Chelidonium, and of these the following are common in the

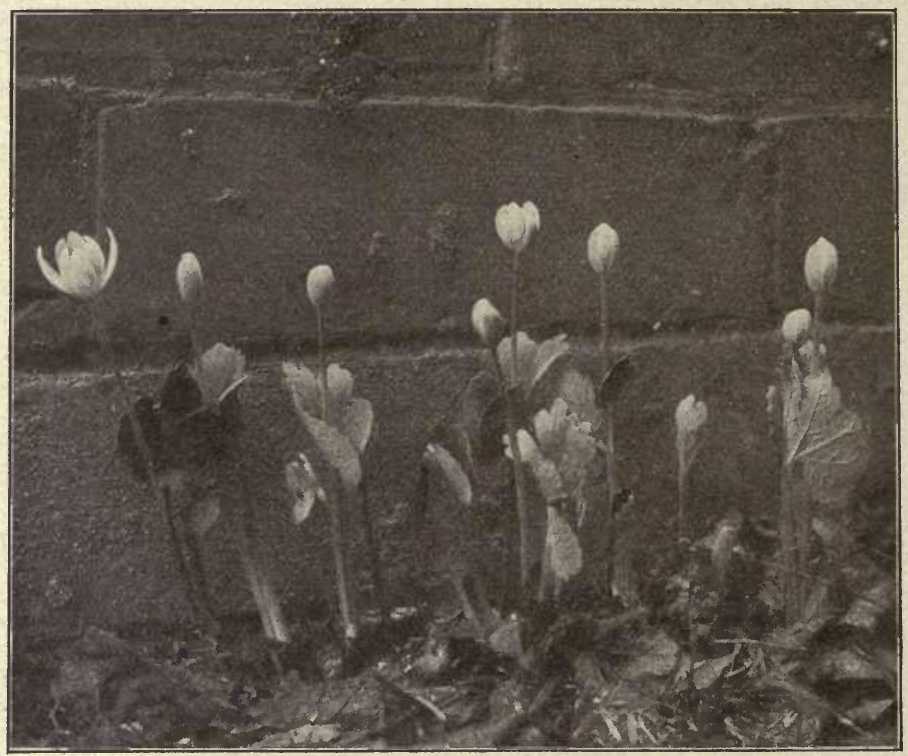

Fig. 308. A group of transplanted bloodroot plants (Sanguinaria canadensis) showing I-flowered scapes, and the palmately veined and lobed leaves.

United States: Yellow or celandine poppy (Stylophorum diphyllum) and the Dutchman's breeches (Bicuculla Cucullaria).

The alkaloid PRotopine (fumarine) is found in the following plants of this family: Sanguinaria canadensis; Chelidonium majus; Stylophorum diphyllum; Eschscholt ia californica; Glaucium corniculatum of Middle Europe; Bicuculla Cucullaria; Adlumia fungosa, the climbing fumitory of the United States and Canada; Fumaria officinalis, the fumitory of Europe, which is naturalized in the United States and Canada; Bocconia cordata of China and Japan, and B. frutescens of the West Indies, Mexico 
and Paraguay; Dicentra pusilla of Japan and several species of corydalis. The tubers of squirrel corn or corydalis (Bicuculla canadensis) contain the alkaloidal corydaline.

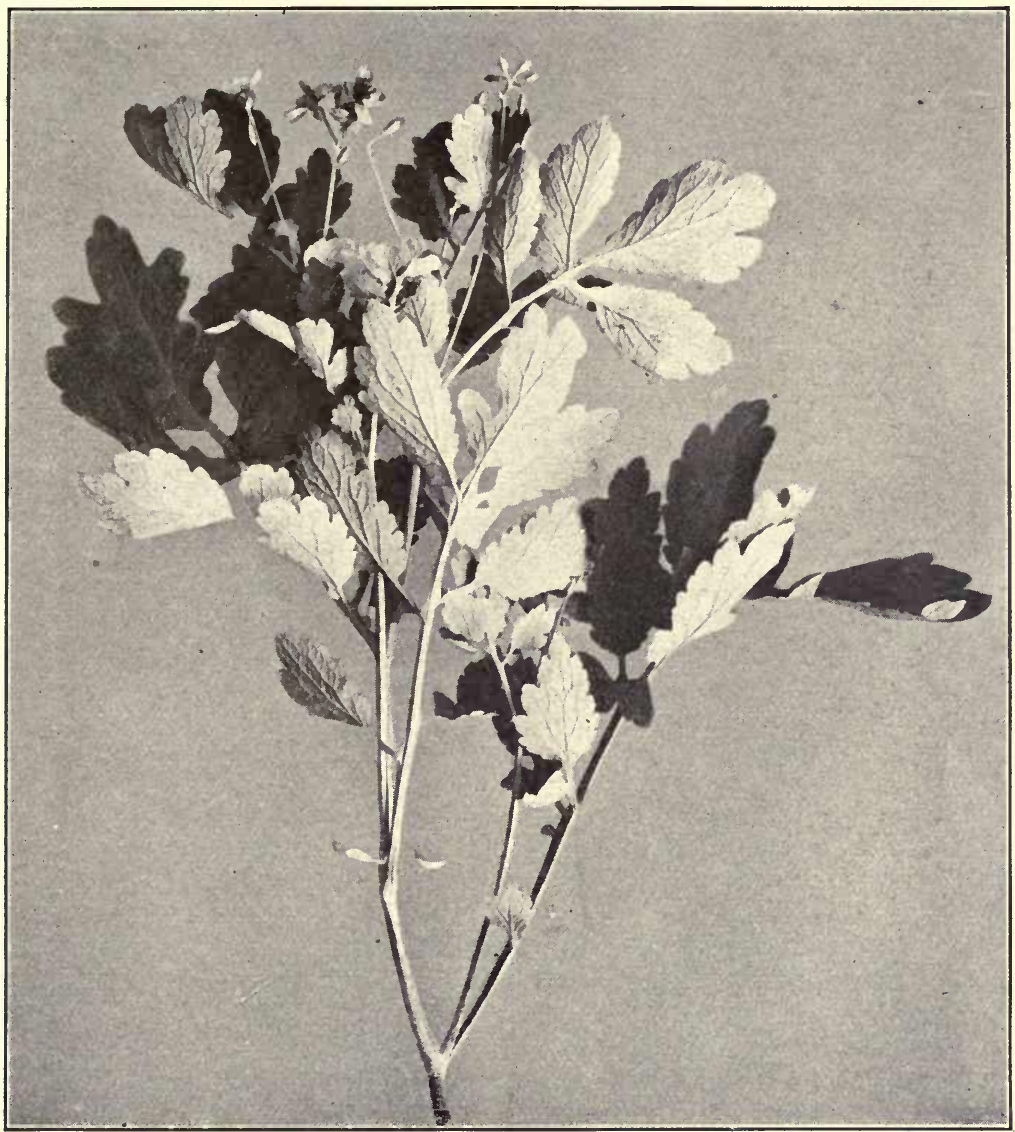

FIG. 309. Celandine (Chelidonium majus), a biennial herb, with pinnately divided leaves, and terminal clusters of small, yellow flowers. The plant has an orange-colored latex.-After Brown.

b. CRUCIFER E OR MUSTARD FAMILY.-These are herbaceous plants with characteristic flowers and fruits. The flowers have four deciduous sepals, four petals which are more or less spreading and clawed at the base, and six stamens which are tetradynamous (Fig. 280, $B$ ). The fruit is a 2-celled silique or 


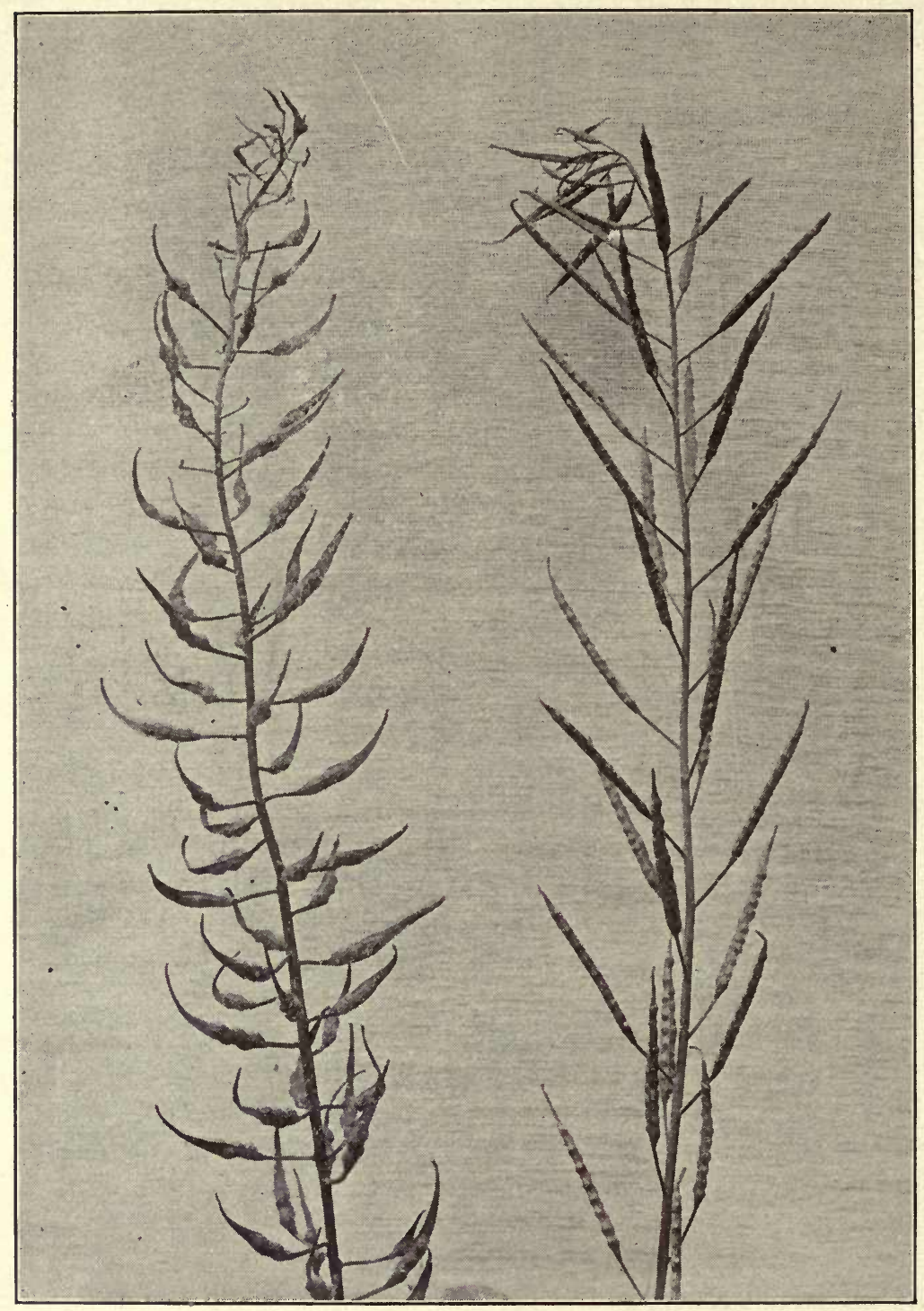

Frg. 310. Fruiting specimens of the two mustards, the one on the left White Mustard (Brassica alba), and the one on the right Black Mustard (Brassica nigra).-After Newcomb. 
silicle, which varies in shape in the different genera (Fig. 310). Brassica alba (white mustard).-The plant is a slender, branching, more or less hispid (bristly hairy) annual or biennial herb usually less than $0.5 \mathrm{M}$. high, with deeply pinnatifid lower leaves and lanceolate, dentate upper leaves. The flowers are yellow, and the silique is densely hispid, constricted between the seeds and terminated by a long, flat, sword-like beak (Fig. 3IO). The seeds are official as white mustard (Sinapis alba) but are known in commerce as yellow mustard.

Brassica nigra or black mustard, the seeds of which constitute the official black mustard (Sinapis nigra), is a larger, more branching plant than Brassica alba, being from I to $3 \mathrm{M}$. high. The silique is erect, more cylindrical and with a slender, filiform beak (Fig. 3ro).

Glucosides similar to those which occur in Brassica ALBA and BrassiCA NIGRA are also found in other species of BrassiCA, as well as in the following related plants, but the oils produced are not identical: Horseradish (Roripa Armoracia), the oil being similar to volatile oil of mustard; water cress ( $R$. Nasturtium); garden radish (Raphanus sativus); Sisymbrium Alliaria of Europe, and the hedge mustard ( $S$. officinale) naturalized in the United States; TURNIP (Brassica Rapa) of Europe; field penny-cress (Thlaspi arvense) of Asia and found in waste places in the Eastern and Middle United States; the narrow leaved peppergrass (Lepidium ruderale) naturalized from Europe; scurvy-grass (Cochlearia officinalis) of Northern and Middle Europe, the herb of which, known as Herba cochleariæ, is used in medicine; "HONESTY" (Lunaria annua) common in cultivation on account of the ornamental use of the dry pods; Parrya macrocarpa of Southern Europe; treacle mustard (Erysimum cheiranthoides) of Northern Europe and the United States, and garlic mustard ( $E$. Alliaria).

The seeds of most of the Cruciferæ are also rich in fixed oils, and the commercial oils are obtained from the following species: Wild mustard or charlock (Brassica arvensis) naturalized in the United States from Europe; Hesperis tristis of Southern Europe; cabbage (Brassica oleracea). An INDIGo-forming glucoside is found in Isatis tinctoria of Europe and I. indigotica of China; 
Neslia paniculata of Europe and the Orient ; and Lepidium owaihiense of the Hawaiian Islands. Shepherd's purse (Capsella Bursa-pastoris) contains an alkaloid (bursine) and tannin. The leaves and roots of many of the Cruciferæ are used as garden vegetables, and some are cultivated as ornamental plants. The seeds of Lunaria biennis (or "honesty") contain an orange-red crystalline alkaloid, or possibly a mixture of alkaloids.

c. There are several other families of the Rhœadales which yield economic products. The REsEDACEx include the mignonette (Reseda odorata), the flowers of which yield a fragrant volatile oil ; and $R$. Luteola of Europe, which contains a yellow coloring principle and also an anthelmintic principle. The Moringace. comprise a single genus, Moringa. The root of $M$. oleifera of tropical and sub-tropical countries contains a volatile oil resembling the volatile oil of mustard, and the stem yields an astringent gum resembling that of Bombax malabaricum (Bombaceæ).

\section{ORDER SARRACENIALES.}

This order includes several families which are of special interest because of the fact that the leaves are of peculiar construction and adapted to the catching and digestion of insects (Fig. 208).

Probably all of the plants of this order produce proteolytic ferments resembling those in the pinc-apple and are capable of acting upon and digesting animal substance. Some writers have supposed that the properties of these plants might be due to bacteria present in the liquid contained in the pitchers of the leaves, but there seems to be no question that a distinct enzyme resembling trypsin is formed in those plants which have been studied.

(a) The genus Sarracenia of the family SARRACEniaces or pitcher-plant family, is represented in the United States by a number of species. The rhizome of Sarracenia purpurea (Fig. 3II) contains several alkaloids, one of which, sarracenine, seems to have some resemblance to veratrine. (b) The Droserace $£$ or sundew family includes the Droseras or sundew plants and Dionoa muscipula, the Venus's flytrap of North Carolina (Fig. 209). A number of species of Drosera contain a red coloring principle similar to that isolated from the rhizomes of $D$. Whittakerii of Australia and is a derivative of methylnaphthoquinone. Citric 


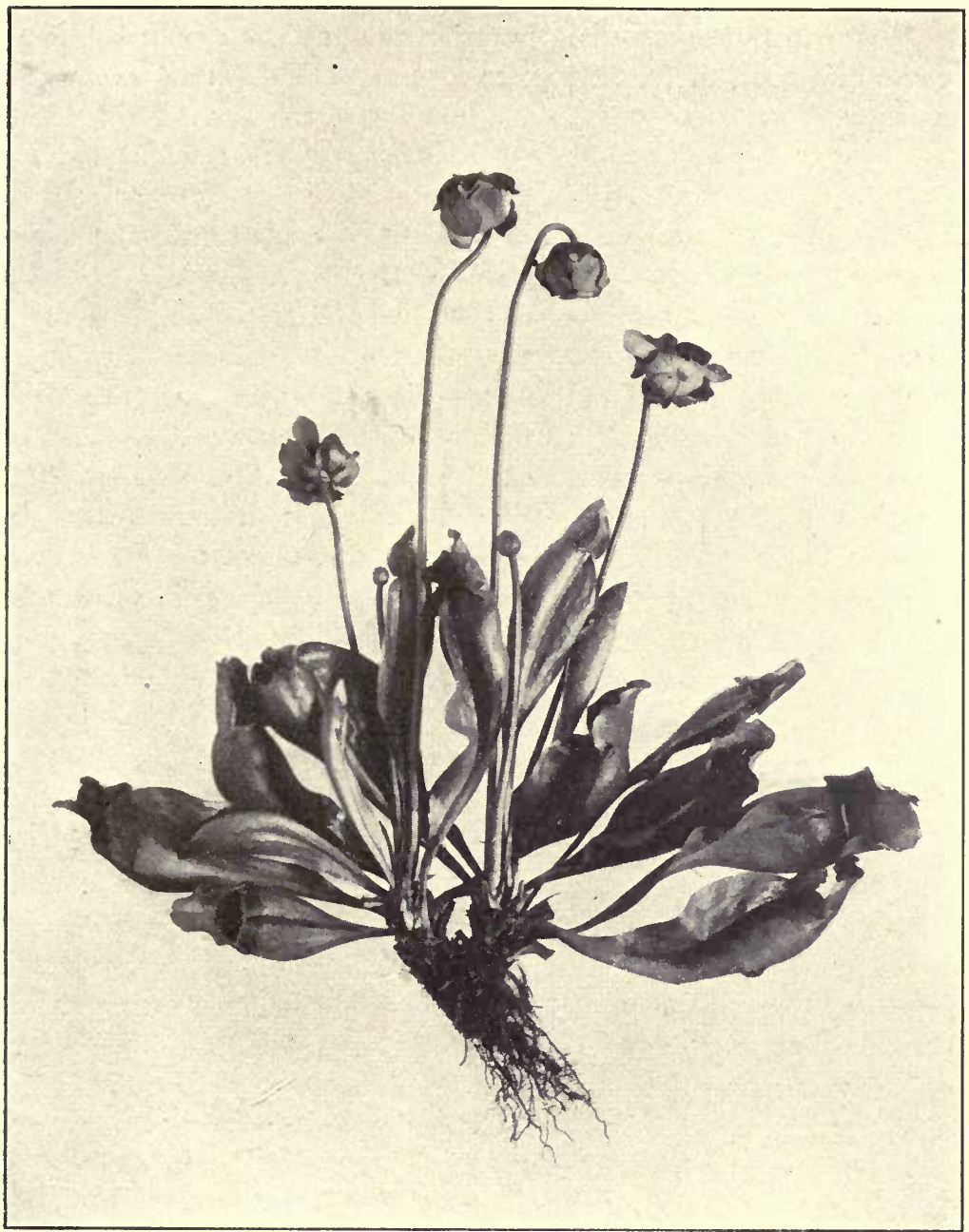

FIG. 3Ir. Pitcher Plant (Sarracenia purpurea). The plant grows in peat bogs, and the pitcher-shaped leaves are usually half filled with water and serve as a trap for insects, which are finally digested and furnish the plant with nitrogenous food. The flowers are single on a naked scape and of a deep purple color, the petals being arched over the style. Many species of Sarracenia are prized by horticulturists because of their odd trumpetshaped leaves.-After Troth.

acid has been found in D. longifolia, a sundew common in the - United States as well as in Europe and Asia. (c) The family NePenthacex contains the single genus Nepenthes, several spe- 
cies of which are extensively cultivated in greenhouses. The leaves and roots of $N$. Boschiana of Borneo contain an astringent principle.

\section{ORDER ROSALES.}

The plants range from herbs to shrubs and trees and have complete flowers which are mostly perigynous. The carpels are solitary, or several either distinct or united.

a. PODOSTEMACE E OR RIVER-WEED FAMILY.The plants are aquatic and more or less alga-like, and are represented in the United States by the river-weed (Podostemon Ceratophyllum), which is a densely tufted plant found in running water attached to stones. The ash of these plants contains a considerable amount of sodium chloride, the ash of Mourera Weddelliana of Brazil containing 50 per cent. of salt and being used as a source of table salt.

b. CRASSULACE $Æ$ OR ORPINE FAMILY.-The plants are chiefly succulent herbs and represented by such plants as houseleek (Sempervivum tectorum), which is cultivated largely as an ornamental plant, and the common sedums, of which there are numerous species in temperate regions. The common mossy stonecrop or wall-pepper (Sedum acre), naturalized in the Northern United States contains a ferment capable of dissolving the membrane formed in diphtheria and croup; Sempervivum balsamiferum of the Canary Islands contains a substance resembling the viscine found in certain Loranthaceæ. Ditch or Virginia stonecrop (Penthorum sedoides) contains tannin.

c. SAXIFRAGACE E OR SAXIFRAGE FAMILY.-The plants are mostly found in temperate regions and among the important members are mitrewort (Mitella), false mitrewort (Tiarella cordifolia), alum root (Heuchera americana), golden saxifrage (Chrysosplenium), grass of Parnassus (Parnassia), mock orange (Philadelphus coronarius) and the wild hydrangea ( $H y$ drangea arborescens).

The plants are rich in tannin, as the alum root of Eastern and Central North America, which contains io to 20 per cent. of tannin. A glucoside hydrangin, a volatile oil, and possibly also a saponin are found in "SEVEN BARKS" or wild hydrangea $(H$. 


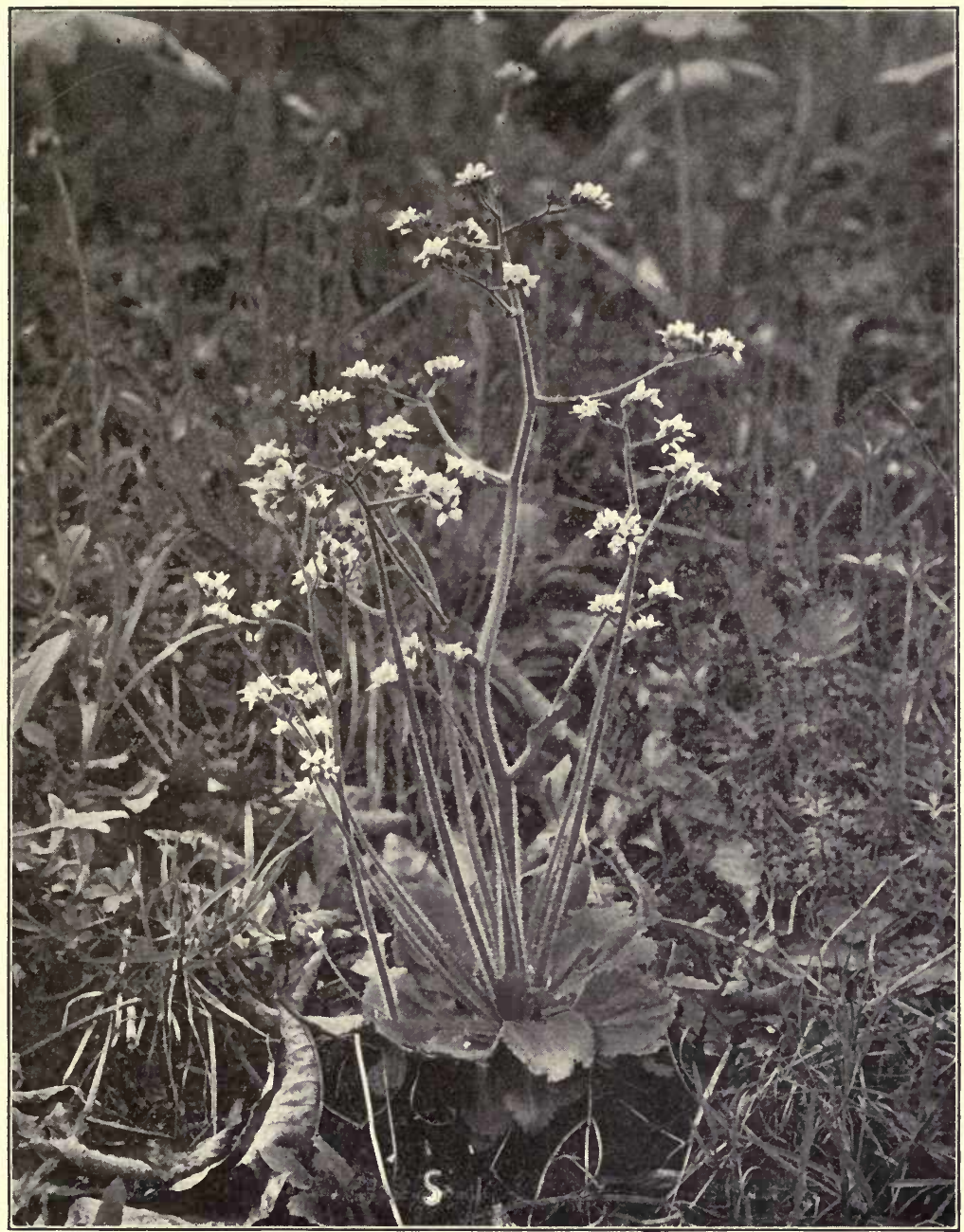

FIG. 312. Early Saxifrage (Saxifraga virginiensis), a perennial herb with a whorl of root leaves from which arise the flower scapes bearing open and loosely panicled cymes. It grows in the clefts of rocks, and the name is derived from the Latin, meaning to break a rock. No doubt because of its habit, medicinal virtues were earlier ascribed to it, and it was used to cure stone in the bladder.-After Troth.

arborescens); a glucoside is also found in the root of garden hydrangea ( $H$. paniculata grandiflora).

In this family are also included the gooseberries (Fig. 245) 
and currants. The cultivated curRants are varieties of Ribes rubrum: the cultivated GOOSEBERRIES are varieties of $R$. Uvacrispa. Both of these plants are natives of Europe and Asia and have escaped from cultivation in the United States and Canada. The fruits contain fruit-acids and fruit-sugars and are used in a variety of ways. The fetid currant (Ribes prostratum) has a very fetid odor and it is said that the flowers of the buffalo currant (Ribes aureum) contain hydrocyanic acid.

e. HAMAMELIDACE $Æ$ OR WITCHHAZEL FAMILY.The plants are shrubs or trees and are most abundant in subtropical countries.

Hamamelis virginiana, or witchhazel, the leaves and bark of which are used in medicine, is a shrub which is especially characterized by its asymmetric, undulate leaves and by its producing flowers in the autumn when the leaves are falling and the mature, but not ripe, capsules of the preceding year are still present (Fig. 3I3).

The forked branches of the witchhazel, as also the twigs of the peach and other plants, are used in various parts of the United States for detecting the presence of underground water. These are operated somewhat as follows: The branched arms are held by the operator in a horizontal position and as the operator surveys the field, it is supposed the main stem will dip in the direction indicating either underground water, petroleum, etc. It is the honest belief of the operators that the working of the rod is influenced by agencies-usually regarded as electrical currents following underground springs of water-that are entirely independent of their own bodies, and many uneducated people have implicit faith in their ability to locate underground waters in this way. However, it is held by scientists that the operation of the divining rod is generally due to the unconscious movements of the body or muscles of the hand.

Liquidambar styraciflua or sweet gum-tree of the Atlantic coast of the United States and Mexico, is a tall tree with characteristic cork-wings on the branches ; 3 - to 7 -lobed, petiolate, finely serrate leaves; monœcious flowers, and a spiny, globular, capsular fruit. The tree yields a balsam allied to the official styrax 
(storax), which is obtained from a very similar tree ( $L$. orientalis).

f. PLATANACEÆ OR PLANE TREE FAMILY.-This

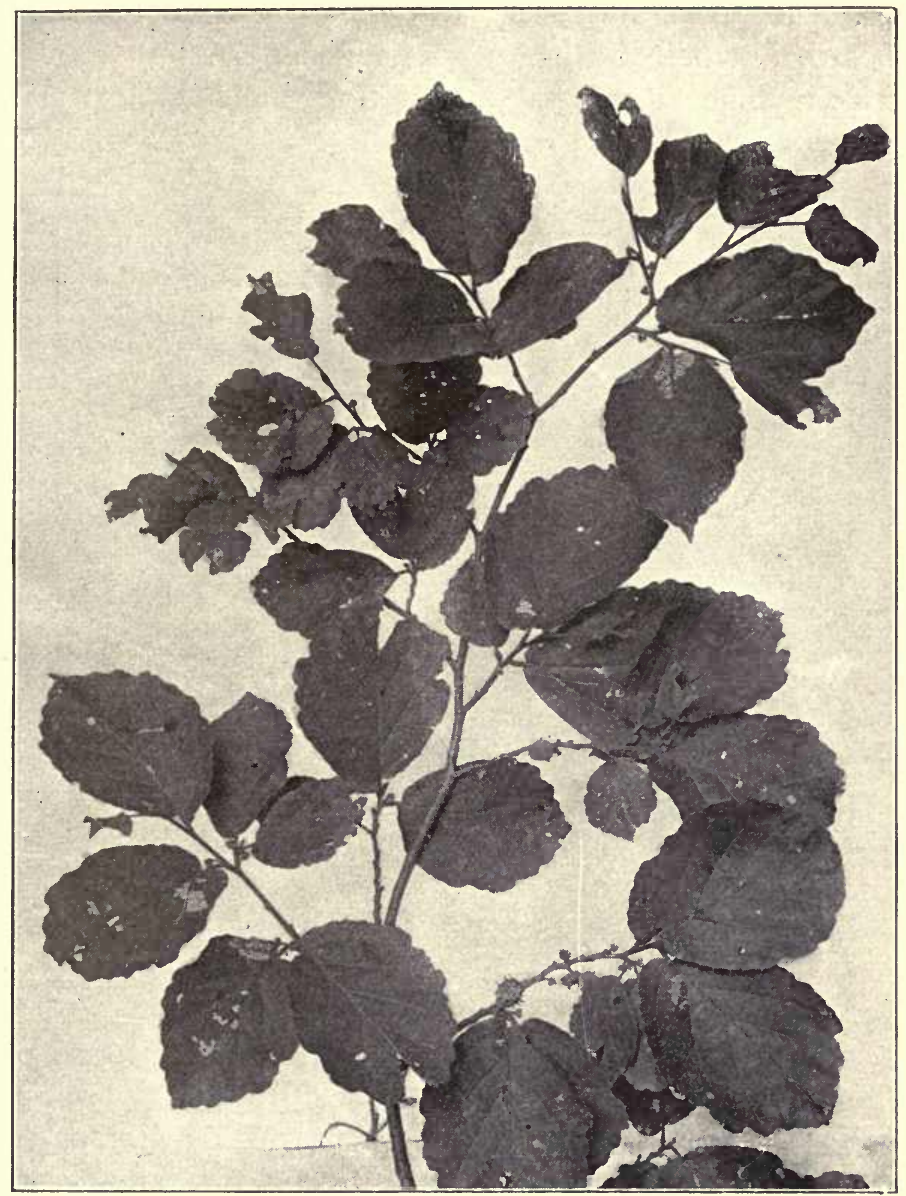

FrG. 313. Branch of Witchhazel (Hamamelis virginiana) showing alternate, shortpetiolate and pinnate-reticulately veined leaves, having a broadly oval or obovate outline, round, acute, or slightly acuminate apex; slightly cordate, inequilateral base; and undulate or sinuous margin.

family consists of but one genus, Platanus, of which there are 7 species. It includes the sycamore or buttonwood (Platamus occidentalis), one of our largest trees, easily recognized by its 
mottled exfoliating bark. The leaves are palmately lobed and within the base of the petioles are formed the winter buds. The flowers are staminate and pistillate heads, borne on separate peduncles. The fruits are spherical heads about $2 \mathrm{~cm}$. in diameter, composed of numerous achenes, and persist on the trees throughout the winter. The wood is not only used for building purposes, but also for butchers' blocks.

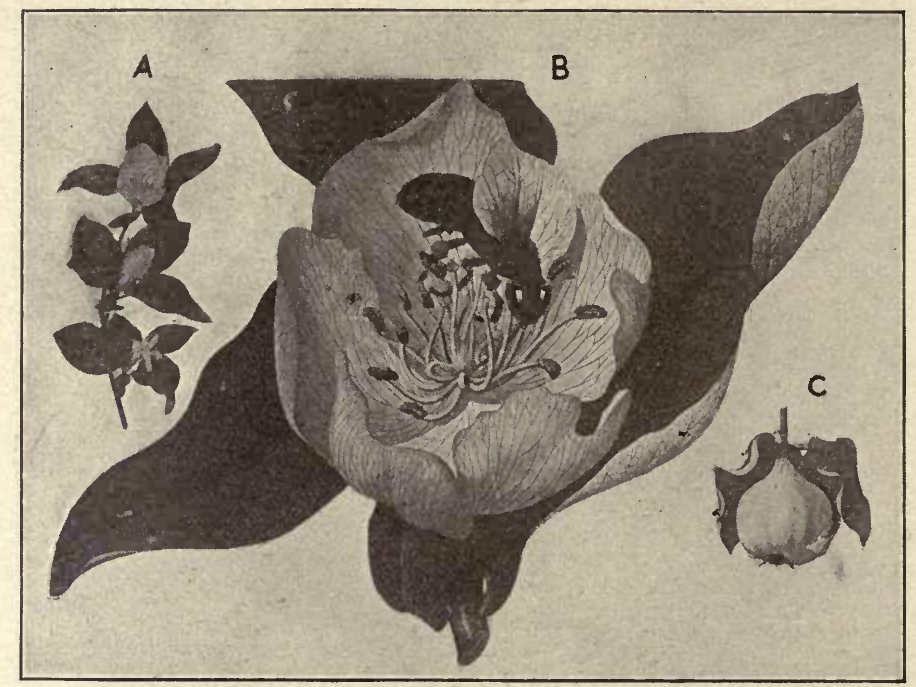

FIg. 3r4. Cross-pollination through the agency of a bee, in flower of quince $(C y$ donia vulgaris). A, flowering branch; $\mathrm{B}$, flower showing bee extracting nectar, and masses of pollen adhering to its legs, some of which will fall upon the stigmas of other flowers when it visits them; C, ripe inferior fleshy fruit (pome) of quince.-After Dodel-Port.

f. ROSACE $\mathrm{E}$ OR ROSE FAMILY.-The plants are herbs, shrubs or trees usually with alternate, stipulate, simple or compound leaves, and regular perfect flowers with or without petals, and numerous stamens (Fig. 280, D). The fruit is a pome (Fig. 3I4), drupe (Fig. 3I5), follicle or achene (Fig. 236).

Prunus serotina or wild black cherry is a tree varying from Io to $30 \mathrm{M}$. in height, with a more or less smooth bark marked by prominent transverse lenticels, and showing a tendency to peel off in semicircular pieces, which gives the older bark, which is more or iess black, a roughened appearance. The leaves and inner 
bark have an agreeable aromatic odor; the leaves are oval- or oblong-lanceolate, acute or acuminate, and serrate, the teeth being

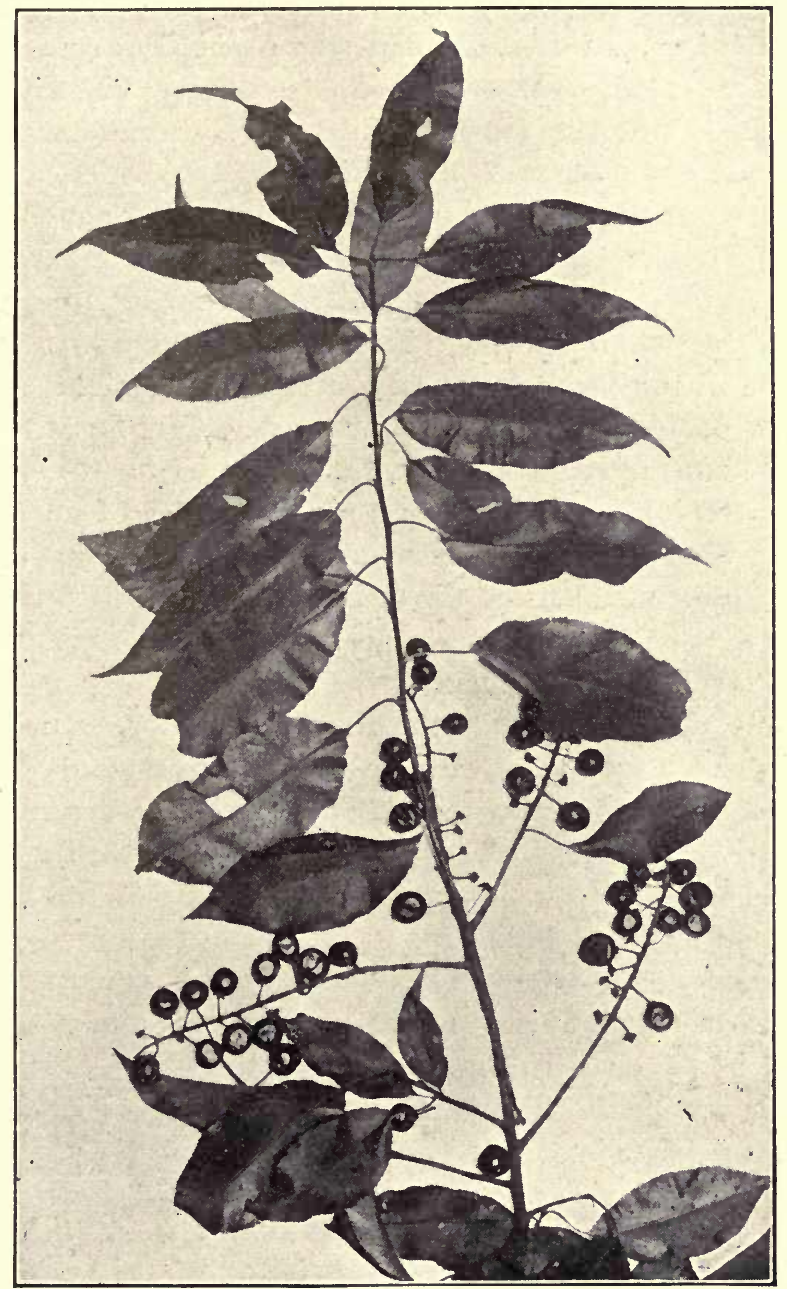

FIG. 315. Fruiting branch of wild black cherry (Prunus serotina).

glandular; the flowers are white and in racemes; the fruit is a dark purple or blackish, globular drupe (Fig. 3I5). The nearly related species wild cherry or choke cherry (Prunus virginiana) 
is a shrub or small tree with broadly oval, acuminate leaves, red or nearly black drupes, and flowers and fruits several weeks earlier than $P$. serotina.

Prunus Amygdalus is a small tree resembling somewhat the peach tree. The leaves are lanceolate, serrate; the flowers are rose-colored, and the fruit is a dehiscent drupe in which the leathery sarcocarp separates from the endocarp, which latter, with the seed which it encloses, constitutes the edible almond of the market. The kernels of some of the seeds are quite bitter (bitter almonds), and some are bland and free from bitterness. By a process of selection plants yielding the latter are now extensively cultivated in sub-tropical and warm-temperate regions, and yield the sweet or Jordan almond of the market. In Turkestan some of the almonds have a smooth endocarp.

A glucosidal substance having the properties of amygdalin is found in the buds, leaves, bark and seeds, more especially the latter, of some members of the following genera: Prunus, Sorbus (mountain ash), Cotoneaster, Amelanchier, and Eriobotyra ( $E$. japonica or Japanese medlar).

Prunus domestica yields the French plum or prune of commerce. The leaves are ovate or ovate-lanceolate, dentate, and pubescent on the lower surface. The flowers are greenish-white, with a hairy peduncle. The fruit is a drupe, with a black or bluish-black epicarp, a brownish sarcocarp, and a hard, oval, smooth and flattened endocarp.

The endocarps of the members ot tne genus Prunus vary greatly. The endocarp in the apricot $(P$. Armeniaca) is quite smooth, as is also that of the cherry (P. Cerasus); in the peach (Prunus Persica) it is reticulate. The bark of Pyrus Toringo yields a yellow coloring principle known in Japan as "dzaini." It also contains a white, crystalline glucoside (toringin), and pyrus-quercitrin, the latter forming yellow needles and on hydrolysis yields quercetin and rhamnose. The bark is also used to adulterate licorice, gentian and other drugs in the powdered form.

The apple (Pyrus Malus), the pear (Pyrus communis), and the quince (Cydonia vulgaris) are inferior fruits known as pomes, the fleshy part developing from the torus and persistent calyx, the core being composed of the united carpels. The edible fruits 
of the Rosaceæ contain a number of FRUIT-ACIDS, such as malic, citric, tartaric, and FRUIT-SUGARS, as dextrose and levulose. The acids vary from 0.20 per cent. in pears to 1.50 per cent. in plums; and the sugars from 4.48 per cent. in peaches to 8.26 per cent. in pears. The carbohydrates mannit and sorbit are found in the fruit of Prumus Laurocerasus of Europe. In the unripe fruits there is more or less tannin and also a principle known as PECTOSE. This latter during the ripening of the fruit is converted into PECTIN, a viscid principle which is further changed into pectic and pectosic acids, the solutions of which gelatinize on cooling, so that these fruits are adapted to jelly making (see pp. 243, 255).

Rubus nigrobaccus, or high bush-blackberry, is a branching shrub I to $2 \mathrm{M}$. high with reddish, prickly, erect or recurved stems. The leaves are 3- to 5-foliate, the leaflets being ovate, coarsely and unequally serrate, and midrib and petiolules with stout, recurved prickles. The flowers are white, in terminal racemes and with hairy and prickly stalks. The fruit is broadly ovoid and consists of an aggregate of drupelets which ripen in August and September.

Rubus villosus Ait. (Rubus canadensis L.) or low-blackberry (Northern dewberry) is a trailing, shrubby, prickly plant the leaves of which are 3 - to 7 -foliate, the leaflets being oval or ovatelanceolate, serrate and nearly smooth. The flowers are in racemes and the fruit resembles that of $R$. nigrobaccus, but is smaller.

Rubus cuneifolius or sand-blackberry of the Eastern and Southern States is a small shrub less than I M. high, much branched, and with straight or recurved, stout prickles. The leaflets are ovate or cuneate, and densely pubescent, as are also the young shoots. The inflorescence consists of two to five flowers, the petals of which are white or pinkish. The fruit is oblong, more or less cylindrical, and sometimes $20 \mathrm{~mm}$. long.

Rubus Idous or the cultivated European red-raspberry is a shrub with a glaucous, bristly stem and with 3 - to 7 -foliate leaves. The flowers are white and the red fruit consists of a cap-like collection of hairy drupelets which is easily detached from the nonfleshy receptacle. The fruit is used in the preparation of syrup of raspberry which is used for flavoring. There are a number of varieties of this species of raspberry in cultivation, the fruits of 
which vary in color from crimson, brown, or yellow to nearly white. The fine flavored but watery fruit of the wild red-raspberry ( $R$. strigosus) is sometimes substituted for the fruit of Rubus Idous (Fig. 243).

Rosa gallica, which yields the red rose-petals, official in a number of the pharmacopœias, is a native of Southern Europe and is extensively cultivated.

Rosa centifolia, which is now known only in cultivation, and of which there are a large number of varieties, is distinguished by its glandular leaflets, and its pale red or pink petals. The cone-like collection of petals of the flower-bud is the part which is used in medicine, but it is deficient in coloring principles and fragrance as compared to Rosa gallica.

Rosa damascena, the petals of which yield the oil of rose or attar of rose, is extensively cultivated in Bulgaria and to some extent in France and Germany. It flowers very profusely, and the yield of oil is about 0.02 per cent. The oil consists of a crystallizable hydrocarbon known as rose-camphor which is odorless, and a liquid portion consisting of geraniol, 1-citronellol, 1-linalool, citral, n-nonyllic aldehyde and phenyl ethyl alcohol. Similar oils are obtained from other species of Rosa growing in Northern Africa, Abyssinia and Northern India, as $R$. moschata, and R. sempervirens.

The fruits of wild brier (Rosa canina) naturalized from Europe, as well as of other species of Rosa ( $R$. pomifera and $R$. rugosa), contain considerable malic and citric acids and fruitsugars, and are made into a confection by boiling with syrup. In addition to the fruit-ethers found in the common edible fruits of this family and the volatile oil of rose, it should be mentioned that oils containing salicylic acid are also present. A number of species of Spirca contain salicylic aldehyde and methyl salicylate.

Quillaja Saponaric is a large tree having a thick bark and hard wood. The leaves are oval, coriaceous, slightly dentate and evergreen (Fig. 316). The flowers are monœcious or diœcious, white, apetalous, and axillary in groups of one to four. The ovary consists of 4 to 5 carpels and on ripening forms a star-like, spreading group of follicles. The inner bark is the part ured in medicine. 
A spurious quillaja bark (Q. Poppigii) differs from the official in being thinner, darker and in having the surface covered with a coarse network of whitish lines. Another bark, occurring in quilled pieces, from $8-\mathrm{I} 5 \mathrm{~cm}$. long, and $\mathrm{I}-5 \mathrm{~cm}$. wide, has also been found in commerce.

Hagenia abyssinica is an ornamental tree with 7 - to 13 -foliate leaves. The flowers are monœcious and occur in panicles; the staminate being greenish-yellow and with 20 stamens; and the pistillate fragrant, bicarpellary, and with a reddish calyx (Fig.
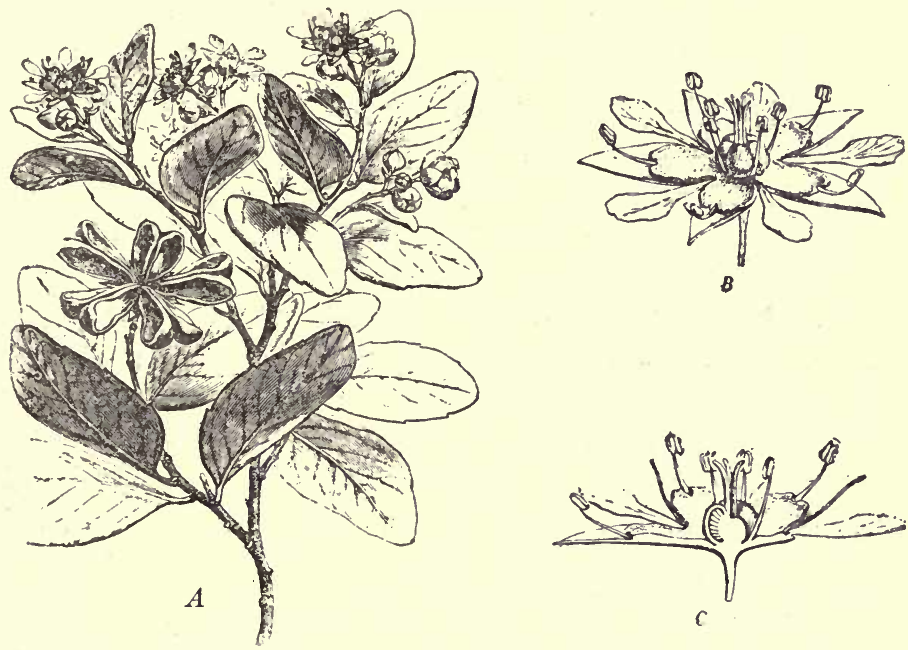

Fig. 316. Soap-bark tree (Quillaja Saponaria): A, flowering branch; B, one of the hermaphrodite flowers; C, the latter in longitudinal section.-After Baillon.

3I7). The fruit is a nutlet. The pistillate flowers are official under the name of Cusso.

Various species of Prunus yield Gums, as cherry, peach, apricot, etc. Mucilage is found in the testa of certain seeds, as of quince. The manna of Luristan is obtained from Pyrus glabra of Persia. Tannin and gallic acid are found in Tormentilla rhizome which is obtained from Potentilla silvestris, a perennial herb of Europe, and other species of Potentilla. The fruit of the hawthorn (Crategus Oxyacantha) contains quercitrin. A bitter principle and tannin are found in Purshia tridentata of the Rocky Mountains. Phloridzin is found in the root bark of a number of species of Purus and Prumus 


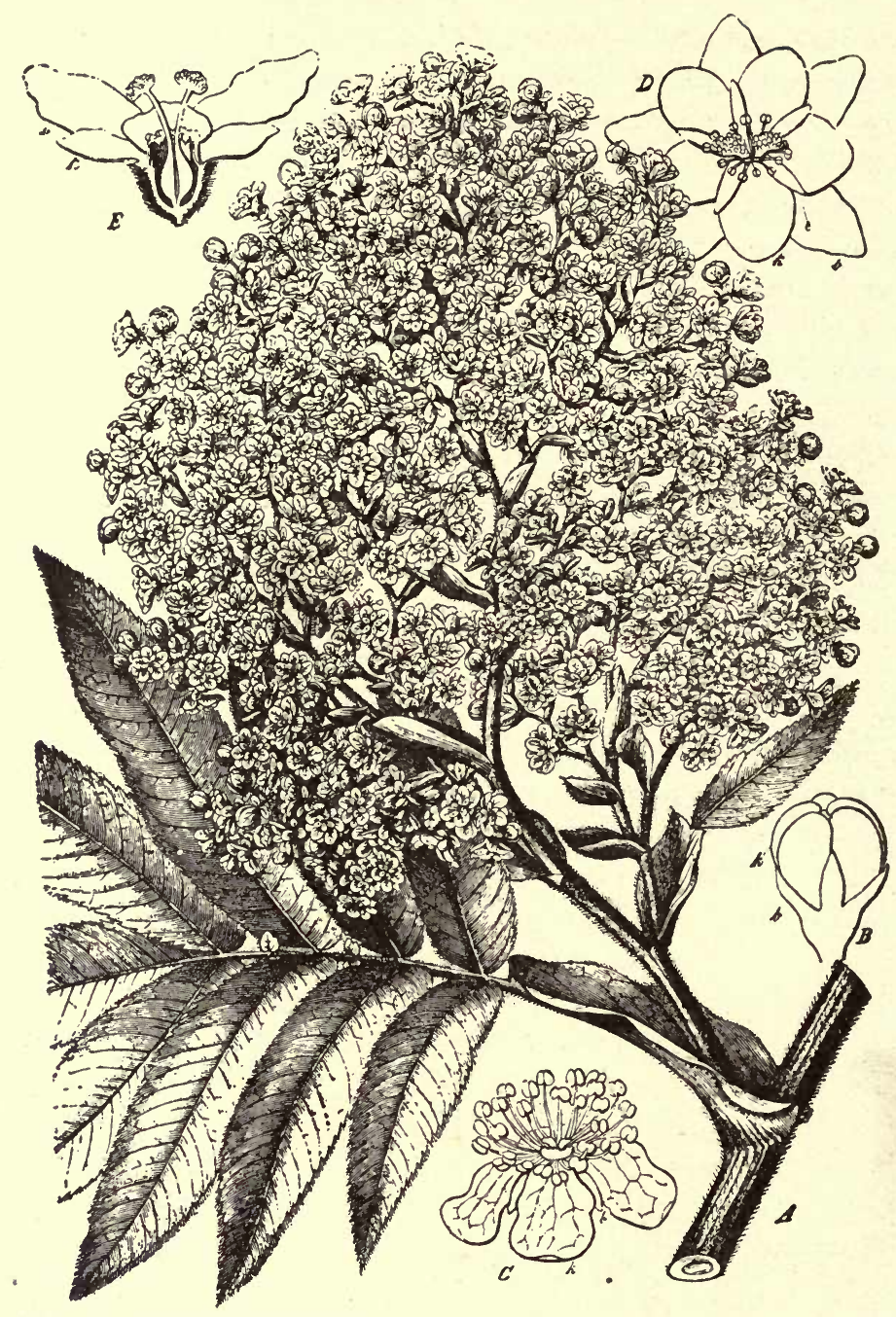

FIG. 317. Hagenia abyssinica: A, branch showing a large panicle of pistillate flowers and the stipulate, compound leaves; B, C, staminate flowers; D, E, pistillate flowers.-After Berg and Schmidt.

In the genus Fragaria to which the strawberry belongs, the torus becomes large and fleshy and is the edible part of the fruit. The garden strawberry ( $F$. chilonsis) has a large fruit, the achenes being sunken in the periphery of the torus (Fig. 242). In 
the wild strawberries the fruit is smaller, usually somewhat fleshcolored and the achenes are either embedded in the torus as in $F$. virginiana or borne on the surface as in $F$. vesca. The strawberry fruit contains about 87 per cent. of water; 6 per cent. of cane sugar; 5 per cent. of invert sugar (a mixture of dextrose and levulose); I per cent. of free fruit-acids; and about 2 per cent. of nitrogenous substances.

g. LEGUMINOSÆ OR PULSE FAMILY.-The plants are herbs, shrubs, trees, or vines with alternate, stipulate and usually compound leaves. The flowers are complete, and the corolla is either regular or irregular; the stamens are usually united, and the pistil is simple and free, becoming in fruit a legume. The plants are widely distributed, many of them being found in the Tropics. Three principal sub-groups, which have been ranked as families by some botanists, are recognized.

I. Papilionate.-Those species with papilionaceous flowers are separated into a group called the Papilionatx. This sub-group has a number of representatives in the United States, as clover, locust, and Baptisia (Fig. 280, L).

2. CASALPINIOIDE 2 include the sennas and have flowers which are nearly regular, or imperfectly, or not at all papilionaceous.

3. The Mrmosoides include the acacias and have flowers that are regular.

Cassia acutifolia is a small shrub with leaves that are 8- to Io-foliate. The leaflets are official as Alexandria or Tripoli senna; the flowers are yellowish and in axillary racemes; the fruit is a smooth, flat, dehiscent pod, with 6 to 8 seeds.

Cassia angustifolia is a shrub which is cultivated in Southern India and resembles Cassia acutifolia. The leaflets which constitute India senna or Tinnevelly senna are longer and narrow-lanceolate, and the pods are longer, and slightly crescent-shaped, as compared to those of $C$. acutifolia.

Cassia Fistula or purging cassia, the pods of which are used in medicine, is a tree about I $5 \mathrm{M}$. high. The leaves are ro- to I2foliate; the flowers golden-yellow and in racemes; and the fruit is a very long, cylindrical, indehiscent legume. The leaves of quite a number of species of Cassia are used in medicine and the 
following are the source of Folia Malabathri: C. Tamala of Assam and C. javanica.

Glycyrrhiza glabra is a perennial herb, with 8- to I4-foliate

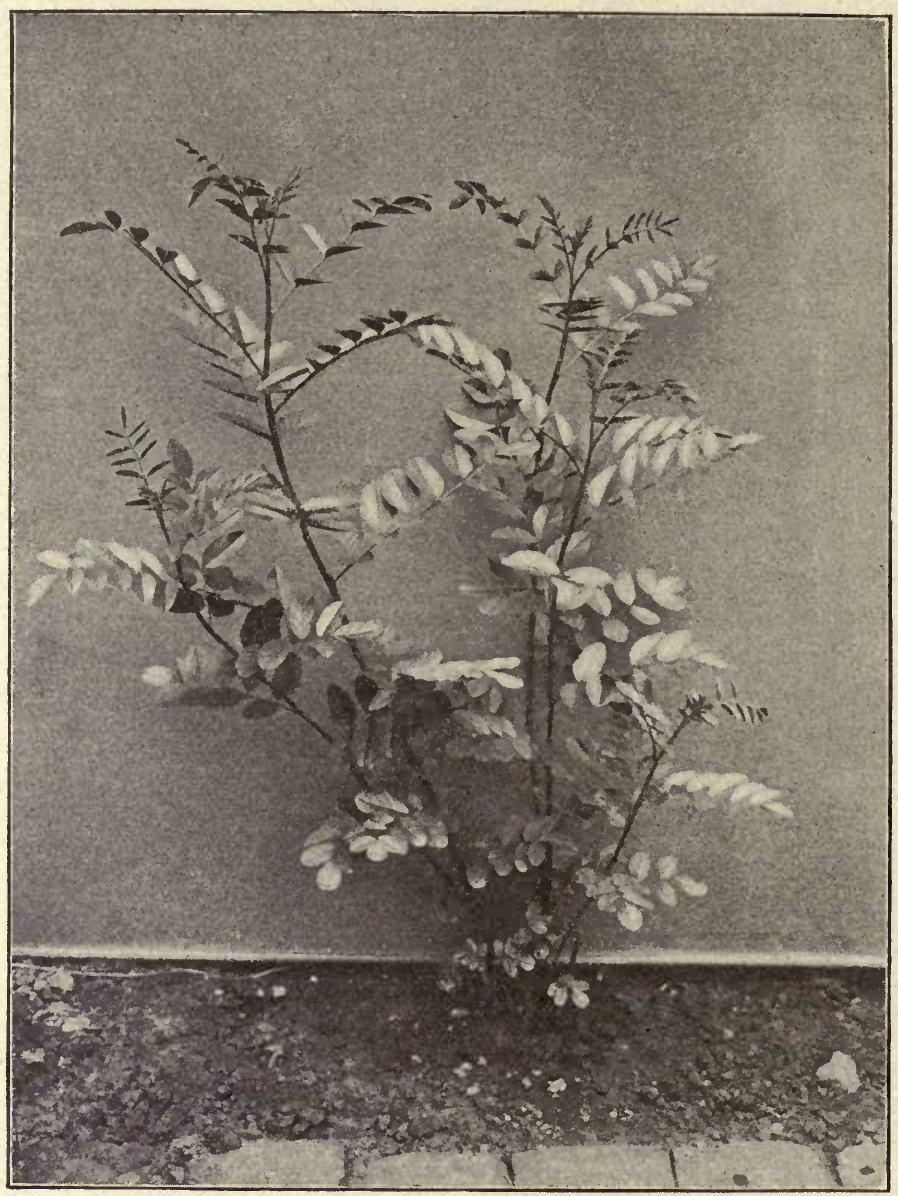

FIG. 3I8. Spanish licorice (Glycyrrhiza glabra) plant grown from a cutting by the late Henry N. Rittenhouse of Philadelphia.

leaves (Fig. 318), the leaflets being glandular in the variety glandulifera; the flowers have a violet-colored, papilionaceous corolla, and the fruit is a flat, dehiscent legume. The rhizome and roots are the parts used in medicine. 
Cytisus scoparius or green or Scotch broom is a shrub naturalized from Europe. The branches are numerous, slender, erect and grow close together, adapting them for use as brooms. The tops are used in medicine.

Tamarindus indica is a tree attaining a height of $25 \mathrm{M}$. The leaves are pinnately compound, having numerous sessile, entire,

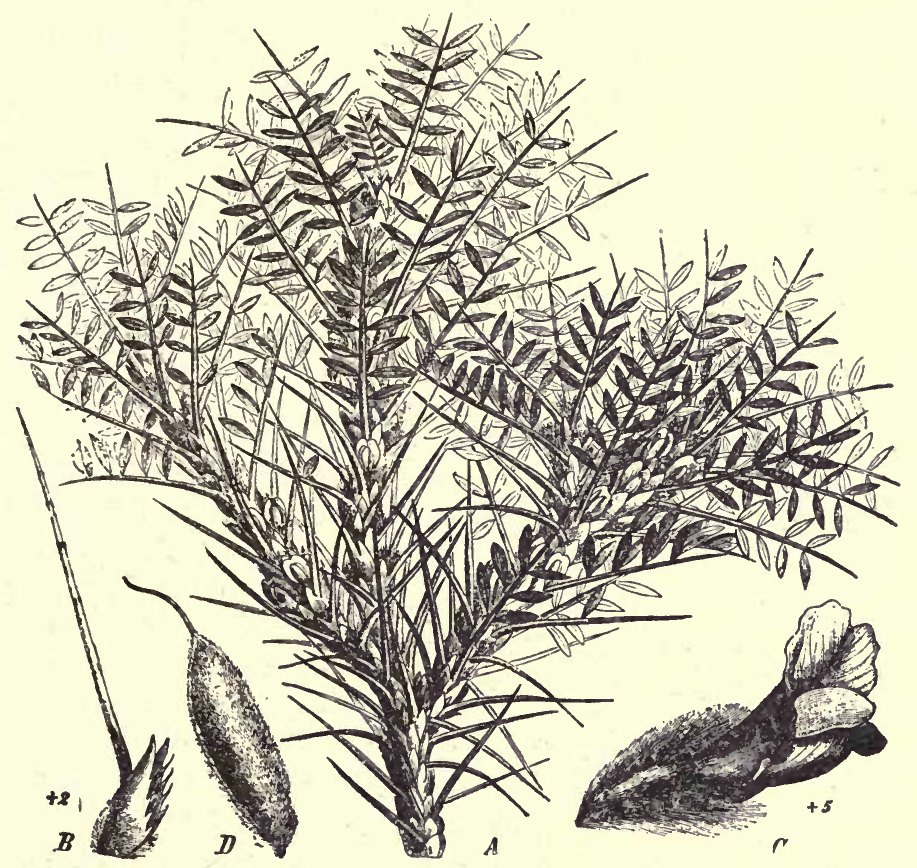

FIG. 3I9. Tragacanth plant (Astragalus gummifer): A, flowering branch; B, modified, thorn-like leaf with stipules at the base; C, irregular (bilateral) flower; D, legume of A. aristatus.-After Taubert.

oblong leaflets; the flowers are in terminal racemes and the petals are yellow with reddish veins; the fruit is a curved, indehiscent legume which has a thin epicarp and a pulpy sarcocarp with numerous fibers, and contains a number of flat, quadrangular seeds. The pulp is the part used in medicine as a laxative and refrigerant.

Astragalus gummifer is a tomentose shrub less than I M. high. The leaves are pinnately compound, the leaflets being narrow 
and elliptical; the flowers are pale yellow, sessile and axillary; the fruit is a small, somewhat cylindrical, hairy pod or legume. The gummy exudation constitutes the Tragacanth of commerce.

Acacia Senegal, which yields gum Arabic or acacia gum, is a small tree with bipinnate leaves which are subtended by curved spines; the flowers are yellow and in dense spikes; the fruit is a broad pod containing five or six seeds.

Acacia Catechu is a small tree which resembles Acacia Senegal and furnishes Black Catechu.

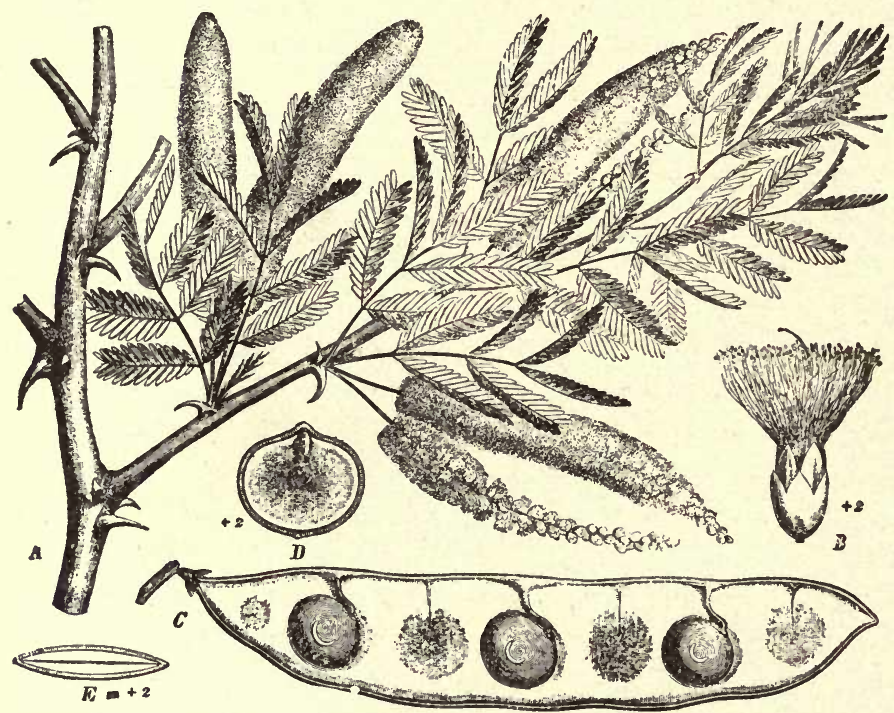

FIG. 320. Acacia Senegal: A, flowering branch: B, a single flower showing numerous stamens; C, part of legume showing attachment of seeds; D, E, sections of seeds.Alcer Taubert.

Pterocarpus Marsupium is a fine timber tree with spreading branches. The leaves are $5^{-}$to 7 -foliate, the leaflets being coriaceous, obovate, and emarginate; the flowers are pale yellow, and the fruit is an indehiscent, orbicular pod with a single reniform seed. The official Kino is prepared from the juice.

The trees yielding kino are under State control in Madras. According to v. Höhnel the kino is present in special celis in the bark, which are arranged in radial rows in the region of the leptome. The cells are from 50 to $100 \mu$ wide and from 100 to 
$500 \mu$ long, the walls consisting of cellulose. The term "kino" is applied to the red astringent juices obtained from a number of plants. "AMERICAN KINo" is a synonym sometimes applied to the extract of Geranium maculatum (Fam. Geraniaceæ).

Pterocarpus santalinus is a small tree with trifoliate leaves, and flowers and fruits resembling those of $P$. Marsupium. The heart-wood is official.

Hamatoxylon campechianum is a small tree with irregular spinous branches. The leaves are 8 - to Io-foliate, the leaflets being sessile and obcordate. The flowers are fragrant, have a purple calyx and yellow corolla, and are in racemes. The fruit is a slender, lanceolate, flat pod, which dehisces laterally instead of along the sutures. The heart-wood of this tree constitutes the commercial Logwood, of which about 200,000 pounds are consumed annually, its chief use being as a dye-wood.

Krameria triandra is a shrub with a few, simple, ovate-lanceolate, sessile, silver-white, glistening leaves. The flowers are complete, having two purple petals and three stamens. The fruit is a I-seeded, globular, prickly, indehiscent pod. K. Ixina, found growing from Mexico to Northern South America, and $K$. argentea of Northern Brazil, are distinguished by having flowers with three petals and four stamens. The root is the part used in medicine.

Copaiba Langsdorffi is a smali tree found growing in Brazil. The leaves are 6- to Io-foliate, the leaflets being ovate-lanceolate, glabrous, coriaceous, and glandular punctate. The flowers are apetalous, and the fruit is an ellipsoidal, coriaceous, 2-valved pod having a single glandular seed with an arillus. An oleo-resin collects in longitudinal cavities in the trunk of the tree, often amounting to many liters, and sometimes the pressure thus produced is sufficient to burst the trunk in places. The oleo-resin is official as Coparba. The latter consists of 30 to 75 per cent. of a volatile oil from which the sesquiterpene caryophyllene has been isolated; a bitter acrid resin and a bitter principle. A similar product is obtained from a number of other species of Copaiba growing in South America, as well as C. copallifera of Western Africa, and Hardwickia Mannii of tropical Africa, and $H$. pinnata of India. An oleo-resin known by the natives in the province of Velasco 
in Bolivia as "Copaiba" is obtained from Copaiba paupera. It is thick, like Maracaibo balsam, but lighter in color and resembles in odor and taste true copaiba. It is distinguished from the other specimens of American copaiba by its dextro-rotation $[a] \mathrm{D}+36^{\circ}$. On the addition of one to two volumes of petroleum ether it forms a clear solution, giving a white precipitate on the addition of more ether.

Toluifera Balsamum is a tree about $25 \mathrm{M}$. high, with a straight trunk, on which the branches first appear at a height of from I 5 to 20 M., and is found growing in Northern South America. The leaves are compound and with seven to eleven alternate, oblong, acuminate, glandular-punctate leaflets; the flowers are white and in simple axillary racemes; the fruit is a winged, indehiscent, I-seeded legume. The plants yield a balsam (official in all the pharmacopoias and known as BALSAM of TOLU) which occurs in schizogenous cavities in the bark of young twigs, and is obtained by incising the bark, it being usually collected in gourds. The balsam consists of 75 to 80 per cent. of resin, which is a compound of tolu-resinotannol, cinnamic and benzoic acids; 8 to 20 per cent. of free cinnamic acid; 0.2 to I per cent. of a volatile oil; and 0.5 per cent. of vanillin. A good tolu balsam is also obtained from $T$. peruifera growing in the northeastern part of South America.

Toluifera Pereirce is a tree about I5 M. high, which has a short trunk and begins to branch at a height of 2 or $3 \mathrm{M}$. It otherwise resembles T. Balsamum. It is found over the whole of Northern South America, extending through Central America to Mexico, and is cultivated in Singapore. The balsam, which is formed as a result of injury to the trunk, consists chiefly of esters of benzoic and cinnamic acids, some free cinnamic acid, and vanillin. A very fragrant vanilla-like balsam is obtained from the fruit of this same plant, and in San Salvador it is known as white Peru balsam to distinguish it from the black Peru balsam obtained from the trunk.

Physostigma venenosum is a woody climber. The leaves are 3-foliate, the leaflets being ovate-acuminate; the flowers are violet in color and in axillary racemes; the fruit is a broadly linear, somewhat flattened, distinctly veined, dehiscent pod which tapers 
at both ends, and usually contains two or three seeds. The seeds are official as Physostigma.

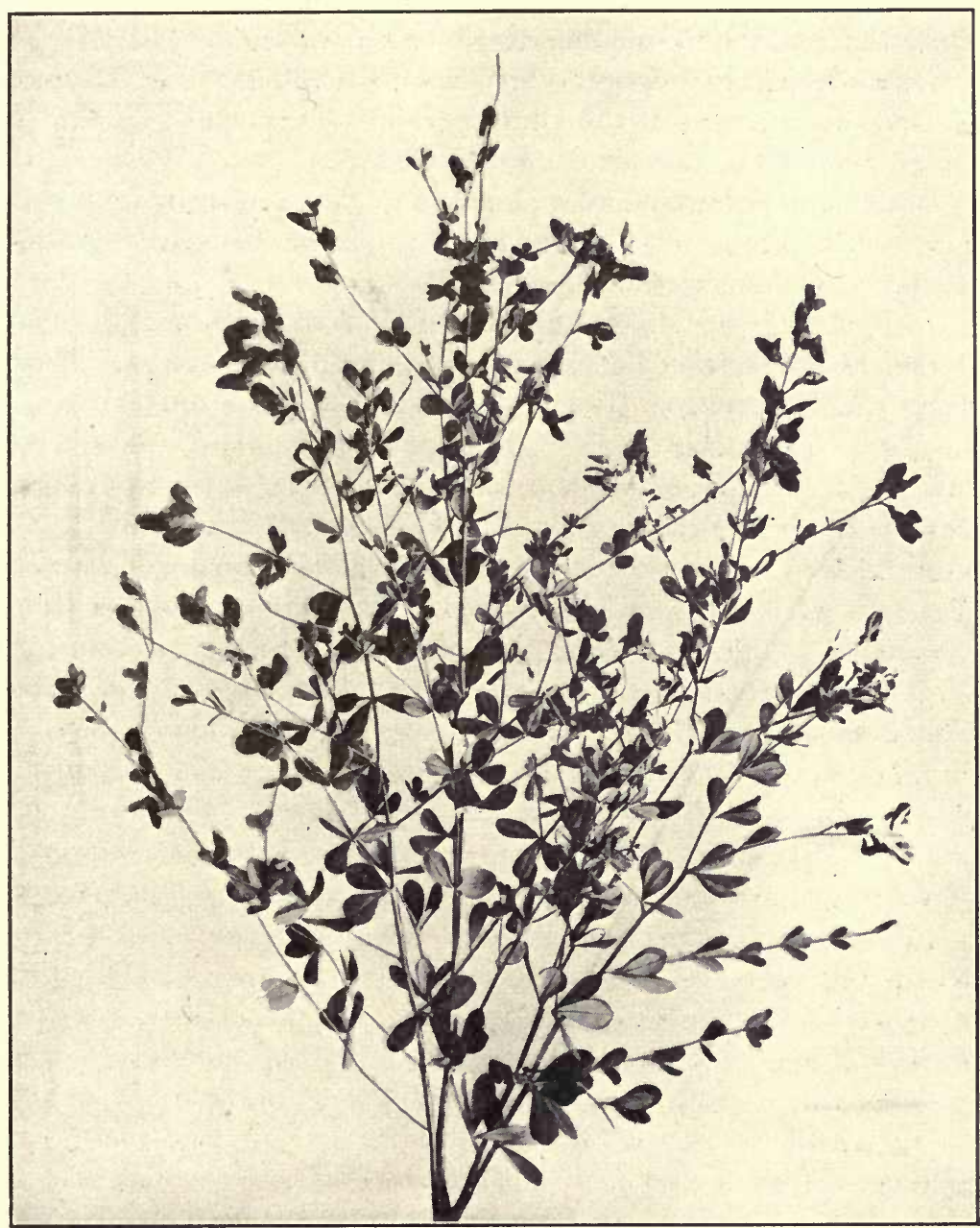

FIG. 321. Wild Indigo (Baptisia tinctoria), a perennial herb resembling a shrub, possessing nearly sessile, 3 -foliate leaves, and having, at the ends of the branches, loose racemes of yellow flowers. A pale blue coloring principle has been obtained from the plant resembling indigo, though somewhat inferior.-After Brown.

The blue coloring principle INDIGO is mostly obtained from the herbs Indigofera tinctoria and $I$. Anil which are indigenous 
to, and cultivated in, tropical and sub-tropical countries. It is prepared by extracting the leaves with water. The glucosidal principle indican (or mother-substance of indigo blue) undergoes oxidation and the insoluble indigo blue separates out. This is the commercial indigo. A similar principle is found in the wild indigo (Baptisia tinctoria) of the United States and Canada; the leaves of Robinia Pseud-acacia of North America; several species of Psoralea and Amorpha, as well as some other Leguminosæ. It is also found in other families, as in Polygonaceæ, Cruciferæ, Asclepiadaceæ, and Apocynaceæ.

A yellow coloring principle is found in the dyer's broom (Genista tinctoria) of Europe and Asia and naturalized in the New England States. G. ovata of Europe yields a similar dye.

Copal Resins are derived from a number of the Leguminosæ: American copal from Hymenca Coubaril of the West Indies and South America; Brazilian copal from H. Martiana of Rio Negro; Zanzibar or Chakazzi-copal from Trachylobium mossambicense of Western Africa; Sierra Leone copal (yellow gum, red gum) from Copaiba Guibourtia of Sierra Leone; Inhambane copal from Copaiba conjugata and C. Gorskiana of Singapore, Jamaica and Australia.

A number of the LOCO-WEEDS containing principles poisonous to cattle belong to the Leguminosæ. The word "loco," meaning crazy, is of Spanish origin, and is applied in reference to the peculiar nervous symptoms manifested by the affected animals. The plants causing greater loss than all other poisonous plants combined and regarded as loco-plants par excellence are Aragallus Lamberti and Astragalus mollissimus. Of these two Aragallus Lamberti, also commonly known as rattleweed or white loco, is the most poisonous and has a wide range, extending from Alaska on the north down through the whole grazing region of the Great Plains, where it is very abundant. Astragalus mollissimus, known as purple loco, woolly loco, or Texas loco, is more limited in its range. Among other plants causing heavy losses to stockmen on the grazing lands of the Great Plains east of the Rocky Mountains may be mentioned the following: Zygadenus elegans (Fam. Liliaceæ), especially dangerous to sheep; the larkspurs or Delphiniums (Fam. Ranunculaceæ), causing losses among cattle; and lupines, 
causing losses especially among sheep. The water hemlock (Cicuta maculata, Fam. Umbelliferæ) is poisonous to all higher animals, including man. Among other plants poisonous to cattle the following may be mentioned: California loco-weed (Astragalus Crotalarice), Texas or woolly loco-weed (A. mollissimus), rattle-box (Crotalaria sagittalis) found in the Eastern United States and Canada. The poisonous action of some of these plants has been ascribed to the presence of barium salts, although this has not been substantiated in all cases. Clitoria glycinoides of Brazil and Phaca ochroleuca of Chile are poisonous to horses and should probably be included with the loco-weeds.

A large number of the plants belonging to the Leguminosæ contain toxic principles and those which have not already been considered might be grouped according to the principles which they contain.

I. Arrow-Poison group, including the genera Erythrophlœum, Afzelia and Pithecolobium.

2. Fish-POISON group, including the genera Albizzia, Afzelia, Bauhinia, Barbiera, Enterolobium, Leucæna, Millettia, Tephrosia, Acacia, Abrus, Clitoria, Mundulea, Derris, Lonchocarpus, Piscidia ( $P$. Erythrina or Jamaica dogwood, which contains a curarelike alkaloid).

3. SAPonin-containing plants as the genera Acacia, Albizzia, Entada (E. scandens or the sea bean of the East and West Indies), Enterolobium, Gleditsia and Gymnocladus ( $G$. dioica or Kentucky coffee-tree growing in the United States and Canada).

4. Cytisine-containing plants; the alkaloid cytisine is found in Laburnum vulgare and L. alpinum growing wild in Southern Europe and also cultivated, and in one or more species of the following genera: Anagyris, Baptisia, Coronilla, Crotalaria, Genista, and Ulex.

Abrin, composed of a globulin and albumose and whose properties are affected at a temperature of $50^{\circ} \mathrm{C}$. or over, is found in the seeds of JEQuirity (Abrus precatorius) and Cassia hispidula of Mexico; two alkaloids (lupinine and lupinidine) and a bitter glucoside (lupinin) are found in the white lupine (Lupinus albus) of Europe and in other species of Lupinus; a glucoside (wistarin) and a poisonous resin are found in WISTARIA, species of Wisteria, 
a common woody climber in cultivation as an ornamental plant; the glucoside ononin is found in RADIX ONonidis, the root of Ononis spinosa of Europe; the glandular hairs on the pods of Mucuna pruriens and $M$. urens growing in the Tropics of both hemispheres constitute the cOWHAGE of medicine; butyric acid is found in ST. JoHn's BREAD, the fruit of Ceratonia Siliqua, which grows in European countries bordering the Mediterranean, and also in Eperua falcata of Guiana.

A bitter principle, bondicine, known as poor man's quinine, is found in Casalpinia Bonducella and other species of Casalpinia growing in Sumatra, Borneo, New Zealand and Brazil; the seeds of Phaseolus lunatus of the East Indies contain a principle from which hydrocyanic acid is derived.

The seeds of many of the plants belonging to the Leguminosæ are rich in starch and proteins and hence are used as foods. The protein LEGUMIN is characteristic of this family. The following are some of the important food plants: the garden pea (Pisum sativum), the garden bean (Phaseolus vulgaris); lentil (Lens esculenta), Japanese Soy bean (Glycine hispida). The peanut (Arachis hypogca) indigenous to Brazil and extensively cultivated in most of the Southern States and in Southern Europe, belongs to the group of plants which have geocarpic fruits, that is, fruits which penetrate the soil during their development and ripen under ground (Fig. 23I). In peanuts the starch is replaced by a fixed oil which is present to the extent of about 45 per cent. and which is an article of commerce. In addition to the seeds mentioned those of a number of other plants as well as some fruits, roots and leaves are used as foods in various parts of the world, particularly in the Tropics. The plants of a number of species are used as forage, as those of clover (Trifolium); some are cultivated as ornamental plants, as sweet pea (Lathyrus odoratus), and some yield valuable timber, as the locust (Robinia).

Soy Bean (Glycine hispida) is an important food plant and forage crop. The plant is an annual with trifoliate hairy leaves, rather inconspicuous pale or violet-colored flowers, and with broad pods containing 2 to 5 seeds. The seeds are more or less compressed, spherical or elliptical and vary in color from whitishor yellowish-green to brownish-black. The yield of seed per 
acre may run as high as 40 bushels. As a forage crop it yields as high as 2 to 3 tons of cured hay per acre. The seeds contain about 5 per cent. of starch and nearly 50 per cent. protein substances. The seeds are therefore very nutritive and are extensively used in feeding of live stock. In Japan the seeds are known as " Soy," being derived from the Japanese word " Shoyu," in allusion to a preparation made from the seeds. In Europe it is also used to a limited extent as a food. In this country it is used to some extent as a food for persons suffering from diabetes.

Alfalfa or Lucerne (Medicago sativa) is one of the most valuable forage plants known to man. It is a perennial herb with obovate-oblong leaves, bluish purple flowers occurring in racemes, and twisted pods. Alfalfa is extensively cultivated in all parts of the United States. It is an exceptionally deep-rooted leguminous plant and under the best conditions is long lived, growing in the arid lands of the West as well as in the rich soils of the East. In many essentials and in feeding for stock alfalfa resembles the clover. The alfalfa is relatively somewhat richer in digestible protein than the clover but considerably lower in fat.

Vegetable Bezoars are concretions formed in the stomachs of ruminating animals. They consist of the hairs of crimson clover and the awns of oats, barley and other cereal grains. They are spherical in shape, of a yellowish-brown color, with smooth, even surfaces, of a firm texture, and saturated with intestinal juices. The balls when dried shrink but little and vary from to to $\mathrm{I} 2 \mathrm{~cm}$. in diameter. Since the introduction into the United States of crimson clover as a forage plant or green manure, there have been numerous deaths reported among horses and other cattle due to their eating crimson clover, which leads to the formation of bezoars caused by the undigested hairs matting together. An examination of these bezoars shows that the hairs of which they are composed, lie with the broken or basal end toward the center of the ball, the sharp summit being directed toward the surface.

\section{ORDER GERANIALES.}

This order includes a number of families of economic importance. The sepals are mostly distinct; the stamens are few; the carpels are united, and the ovules are pendulous (epitropous). 
a. GERANIACE正 OR GERANIUM FAMILY.-The plants are herbs with alternate or opposite, usually stipulate leaves, regular and perfect flowers, and capsular fruit (Fig. 236, C).

Geranium maculatum is a perennial herb (Fig. 322) with a short, thick, horizontal rhizome, from which arises a simple, some-

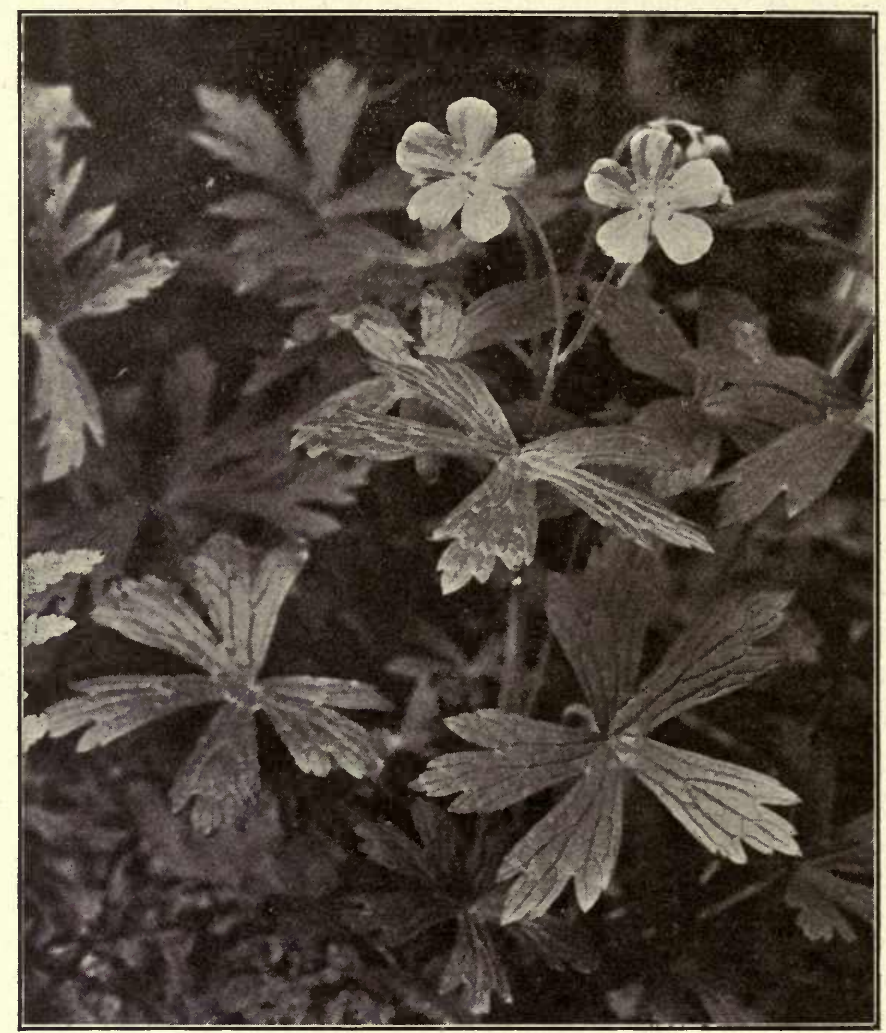

FIG. 322. Geranium maculatum showing typical dicotyledonous flowers and the 5-parted, reticulately-veined leaves.

what branching, hairy stem, with 3 - to 5 -parted, variously toothed and cleft, petiolate leaves, those on the upper part of the stem being opposite; the flowers are regular and 5-merous, occurring singly or in twos in the axils of the leaves; the petals are rosepurple and hairy at the base; the fruit is a dehiscent capsule; the 
five carpels when ripe separate and roll upwards, remaining attached to a central column by means of a slender carpophore, the individual carpels being in the nature of achenes. The rhizome is the portion used in medicine.

The cultivated geraniums belong to the genus Pelargonium, and some of the species furnish oil of rose geranium, as $P$. odoratissimum, $P$. capitatum and $P$. Radula, all of which are cultivated in France, Spain, Germany, Algiers and Reunion for the oil, which is largely used in perfumery. The oil contains geraniol, citronellol, and various esters. The leaves of Pelargonium peltatum, growing in certain parts of Africa and Australia, contain oxalic acid and acid oxalates.

b. OXALIDACE $Æ$ OR WOOD-SORREL FAMILY.-To this family belongs the genus Oxalis, some species of which have leaves that are quite sensitive to light as well as mechanical stimuli, which applies especially to the cultivated forms of South Africa, and to the common wood-sorrel (Oxalis Acetosella) of the United States and Canada, as well. The leaves contain oxalic acid and acid oxalates.

c. THE TROP EOLACE E OR NASTURTIUM FAMILY comprises but a single genus, Tropæolum. Some species are cultivated for ornamental purposes and are the nasturtiums of the garden. The young shoots are succulent and taste like some of the cresses, hence they have received the name "Indian cress." They contain volatile constituents resembling those of the Cruciferæ, and in the leaves of Tropacolum majus benzyl mustard-oil is found. The flower-buds and young fruits of this species are used for pickling like capers.

d. LINACE $Æ$ OR FLAX FAMILY.-The most important plant of this family is the common flax (Linum usitatissimum). This is an erect, slightly branching annual herb with alternate, lanceolate and 3 -nerved leaves. The flowers are in terminal, leafy panicles, the pedicels being slender, the calyx non-glandular, and the petals blue (Fig. 280, $A$ ). The fruit is a Io-locular, Io-seeded capsule. The seeds are official. There are a number of cultivated varieties and the seeds of the var. humile contain a glucoside which yields, under the influence of ferments, hydrocyanic acid. A cathartic principle has been found in L. catharticum growing in 
Europe. The bast fibers of Linum usitatissimum are used in the manufacture of linen. These fibers are distinguished from many other vegetable fibers in not containing lignin.

e. ERYTHROXYLACEÆ OR COCA FAMILY.-This family contains but two genera, one of which is Erythroxylon.

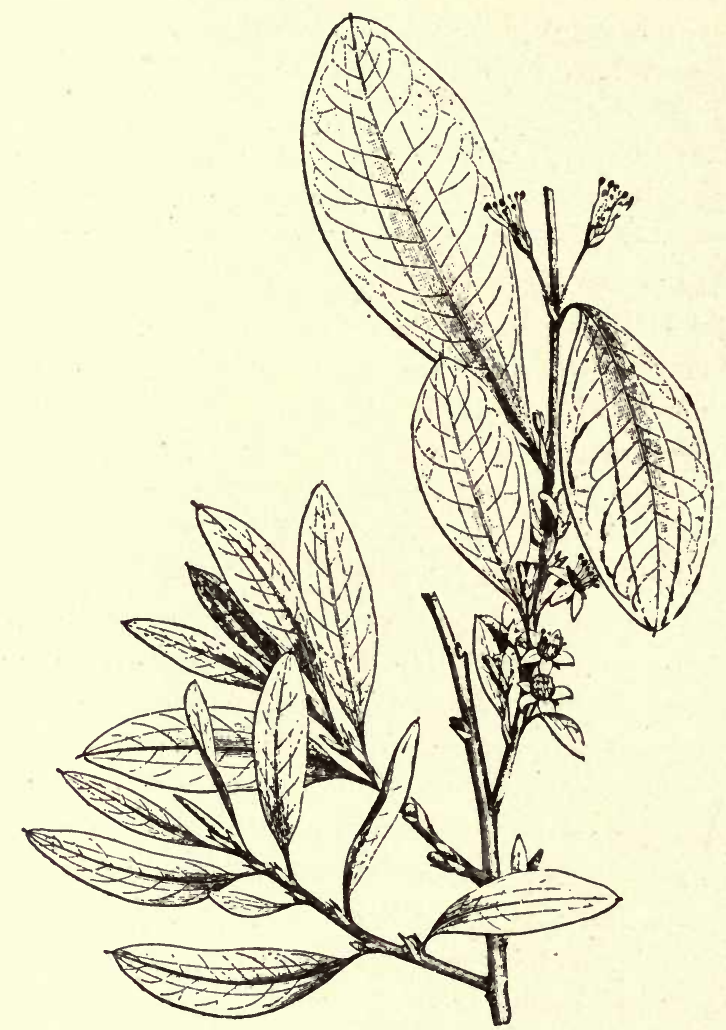

FIG. 323. Flowering branch of Erythroxylon Coca showing the parallel lines on either side of the midrib, which are not true veins, but due to an extra development of hypodermal cells in this region.-After Reiche.

The official coca leaves (Fig. 323) are obtained from Erythroxylon Coca. The plant is a shrub and requires a very humid atmosphere and a comparatively high elevation. The leaves are alternate, petiolate and entire; the flowers are white and very small; the fruit is a reddish drupe resembling that of dogwood. Coca leaves contain several alkaloids, including cocaine, cinna- 
myl-cocaine, truxilline and ecgonine. Of these cocaine is the most important, the Bolivian leaves containing the greatest amount, or 0.5 to I per cent. ; the other alkaloids preponderate in the Peruvian leaves, which usually do not contain more than one-half or twothirds as much cocaine as the Bolivian leaves; the Java leaves also contain benzoyl-pseudotropine; in addition, coca leaves contain a volatile aromatic principle; and a tannin giving a green color with ferric salts.

Cocaine (benzoyl-methyl-ecgonine) occurs in monoclinic prisms. The hydrochloride of cocaine with palladous chloride forms a characteristic crystalline double salt (Fig. 97).

Other species of Erythroxylon also yield useful products. An aromatic oil is found in the wood of E. monogynum of Ceylon and India, and the wood is known as "bastard cedar" or "bastard santal." A brownish-red coloring principle is found in the redwood (E. crolatum) of Jamaica and in E. suberosum and $E$. tortuosum. Purgative and anthelmintic principles are found in some species of this genus.

f. ZYGOPHYLLACE $Æ$ OR CALTROP FAMILY.-The plants are mostly herbs and shrubs which are widely distributed in warm-tropical regions. The leaves are mostly opposite, pinnate and stipulate. The genus Guaiacum is of interest on account of the wood containing considerable resin, which is used in medicine.

Guaiacum officinale is a small tree with 4- to 6-foliate leaves, the leaflets being ovate, entire and sessile; the flowers are large, blue, and in axillary clusters; and the fruit is a 2 -valved capsule (Fig. 324). G. sanctum is a tree resembling G. officinale, but is distinguished by having leaves which are 8 -foliate and with smaller leaflets, and a 4 - to 5-valved capsule. The resin of both species is official.

A resin having an odor resembling that of creosote occurs in the CREOSOTE BUSH (Covillea tridentata) of Mexico and Texas.

The juice of Peganum Harmala contains a yellow coloring principle used in dyeing. A number of the plants of this family contain powerful poisonous principles.

g. RUTACE E OR RUE FAMILY.-The plants are shrubs or trees, seldom herbs, with lysigenous oil-secretion cells. The 
leaves are usually alternate, simple or compound and glandularpunctate (Fig. 280, C).

Zanthoxylum americanum or northern prickly ash is a shrub or small tree with $5^{-}$to II-compound leaves, the leaflets being ovate and nearly sessile; the flowers are diøcious, greenish, and in axillary cymes; the fruit is a black, 2 -valved capsule. Z. ClavaHerculis or the southern prickly ash is a very prickly shrub, which

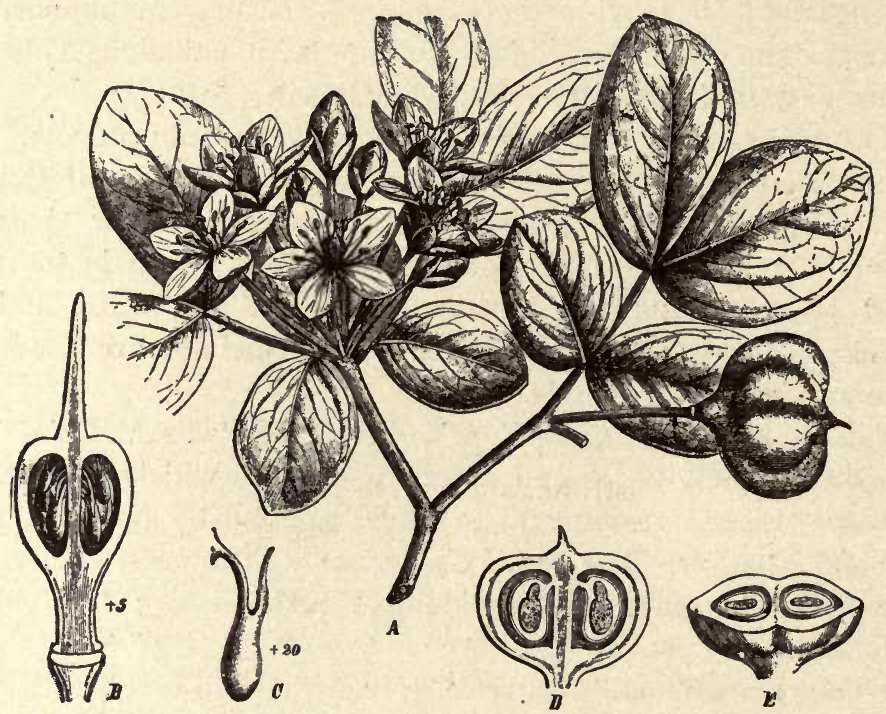

FIG. 324. Guaiacum officinale: A, flowering and fruiting branch; B, gynæcium in longitudinal section showing the pendulous ovules; C, a seed; D, E, the fruit in longitudinal and transverse sections.-After Berg and Schmidt.

is characterized by having cork-wings on the bark. The leaves are 5- to 17 -foliate, the leaflets being ovate and crenulate; the flowers are in terminal racemes and have a calyx of 4 or 5 sepals, the calyx being wanting in $Z$. americanum. The bark of these two species is official.

Pilocarpus.-To this genus belong a number of species which are shrubs or small trees and indigenous to tropical America. The leaves are mostly pinnately-compound, the leaflets being coriaceous and entire; the flowers are small, greenish and in axillary or terminal racemes; the fruit is a I-seeded, 2 -valved 
capsule. The leaves of three species are official as Pilocarpus or Jaborandi.

Barosma.-The buchu leaves of medicine are obtained from several species of Barosma (see Vol. II). The plants are branching shrubs with opposite, coriaceous, serrate or dentate leaves with glandular margins; the flowers are white or reddish and occur, I to 3 , in the axils of the leaves; the fruit is a 5 -valved capsule. The leaves contain a volatile oil, one of the constituents of which is diosphenol.

Citrus.-The fruits of a number of species of this genus are edible, and the plants are also valued for their volatile oils. They are aromatic, glandular, mostly thorny shrubs or small trees indigenous to tropical and sub-tropical Asia, and now extensively cultivated in tropical, sub-tropical and warm-temperate regions. The leaves are more or less winged-petiolate, glaucous, coriaceous, mainly unifoliate (or trifoliate); the flowers are complete, with a 3 - to 6-toothed gamosepalous calyx, and 4 to 8 glandular petals; the stamens are 20 to 60 , in groups of $I$ to 9 ; the ovary is subtended by a cushion-shaped disk, and the fruit is a spherical, oblong or pear-shaped berry, having a coriaceous pericarp with numerous lysigenous oil-glands, a juicy pulp made up of peculiar hair-structures which arise from the endocarp, and in which are embedded white polyembryonic seeds (Fig. 280, C).

Botanists have divided this genus into two sub-groups: $(a)$ the Pseudo-Ægle group is represented by the trifoliate orange (Citrus trifoliata), cultivated widely in the United States as a hedge. The leaves are trifoliate and deciduous, the petals spatulate and the ovary and disk hairy. ( $b$ ) In the Eucitrus group the leaves are unifoliate and evergreen, the petals oblong, and the ovary and disk glabrous. This latter group includes the two species which yield most of the edible Citrus fruits.

Citrus Aurantium includes a number of sub-species and varieties. The plants are small trees with leaves having winged petioles; fragrant, white flowers; and a more or less globular fruit. The Sweet Orange (Malta, Portugal) is derived from the sub-species sinensis. The Bitter Orange (Seville, Curaçao) is derived from the sub-species amara. The flowers of both the Sweet and Bitter Orange tree contain a volatile oil known as OrL 
oF Neroli, and composed of limonene, geraniol, linalool, etc. The oil from the rind of the fruit is known as OIL OF ORANGE PEEL, and is obtained chiefly from Italy and Sicily. It is composed of limonene, citral, citronellol, etc. The oil from the Bitter Orange peel has a superior flavor and is known as BIgaradia oil. The Bergamot Orange is the fruit of the sub-species Bergamia, cultivated in Europe, but only rarely in the United States. The oil of the rind of the fruit is known as BERGAMOT oIL and consists largely of linalyl acetate. In the group of MANDARIN or Kidglove orange (Citrus nobilis) the fruit is compressed, spherical, 5-6 cm. in diameter and with an orange-yellow, loose and easily removable rind. The SHADDOCK or grape-fruit is derived from the sub-species sinensis var. decumana, a tree indigenous to the Malay Archipelago and extensively cultivated in India, Florida, California and elsewhere. The fruits are quite large, sometimes weighing several kilograms, and those which are round are the most valuable commercially, being known as Pomelos or Grape-Fruits. The Blood Orange is the fruit of the sub-species sinensis var. sanguinea. The Otaheite Orange, which is extensively cultivated as a dwarf pot plant and the foliage and flowers of which resemble those of lemon, is probably a variety of the sub-species sinensis, or it may be a hybrid of lemon and orange. The Navel Orange is a sweet orange in which an additional compound ovary is developed within the fruit.

LEMON and LIME fruits are derived from sub-species of Citrus Medica, which are mostly shrubs with simple, petiolate leaves, reddish twigs and flowers, and more or less ellipsoidal fruits. Lemons are derived from the sub-species Limonum. The rind of the fruit yields the oIL OF LEMON, which consists of limonene, citral, etc. Most of the commercial article comes from Sicily and Calabria. Lime fruits or limes are derived from the sub-species acida, a shrub cultivated in the West Indies and Florida. The Citron fruit, the rind of which is used in the making of preserves and confections, is derived from the sub-species genuina. The fruit is large and lemon-like but with a thick rind, the plant being cultivated to some extent in Florida and California.

The Kumguat Orange is obtained from Citrus japonica, a thornless tree with spreading dwarf habit extensively cultivated 
in China and Japan and very hardy even in Northern Florida. The fruit is round or oblong, from 3 to $5 \mathrm{~cm}$. long and 2 to $3 \mathrm{~cm}$. in diameter, and of an orange-yellow color; the rind is sweet, while the pulp is acid, and usually free from seeds, although from I to 4 slightly beaked seeds may be present.

The inner white portion of the rind of the Citrus fruits contains a crystalline, tasteless glucoside known as hesperidin (see pp. I5I-I 54). Those which are bitter contain in addition several bitter glucosides, namely, aurantiamarin and naringin. (See Aurantii Amari Cortex, and Aurantii Dulcis Cortex, in Vol. II.)

Volatile oils are also found in other members of the Rutaceæ. The garden rue (Ruta graveolens), the leaves of which are used in medicine, contains a volatile oil consisting of several ketones. It also contains a glucoside known as rutin which resembles the barosmin of buchu; and quercetin, which is said to be derived from rutin. The Hop tree (Ptelea trifoliata) of Eastern North America contains besides a volatile oil, a resin and an alkaloid. The volatile oil of pepper-moor (Zanthoxylum piperitum) of China and Japan is known as Japanese oil of pepper.

Angustura BARK obtained from Cusparia trifoliata or $C$. officinalis, plants growing in the region of the Orinoco River, contains a volatile oil, resin, a bitter principle and four alkaloids. The wood of Amyris balsamifera of Guiana and Jamaica, yields on distillation a volatile oil resembling Oleum Rhodii.

h. SIMARUBACE王 OR AILANTHUS FAMILY.-The plants are chiefly shrubs or trees with alternate and pinnatelycompound leaves. The flowers are regular, diœcious or polygamous and in axillary racemes. The plants are natives of tropical countries and are distinguished from the Rutaceæ, which they somewhat resemble by the absence of oil secretory cavities. They are widely employed particularly in the tropics, on account of their bitter principles, and are considered valuable tonics, febrifuges and remedies for dysentery.

Picrasma excelsa is a small tree with 9- to I7-foliate leaves, the leaflets being ovate and more or less tomentose, particularly in the bud; the flowers are yellow, polygamous and in axillary panicles; the fruit is a large, spherical drupe. The wood of the plant constitutes Jamaica quassia. 
Quassia amara is a small tree or shrub with 4 - to 5 -foliate leaves; the leaflets are narrow, obovate and acuminate, and the rachis and petiole or stalk are winged; the flowers are hermaphrodite, with Io stamens, bright red corolla, and in terminal racemes; the fruit is a 5 -valved indehiscent pod or nutlet. The wood constitutes Surinam quassia.

A red coloring principle is found in Samadera indica of India, Ceylon and Java. The alkaloid cedronin is found in the seeds of Simaba Cedron of New Granada, the seeds being used as an antidote for the bites of poisonous animals. A similar principle may exist in the bark of Simaruba versicolor of Brazil, the plant being used for a similar purpose. The alkaloid brucamarine is found in the fruit of Brucea sumatrana. A tragacanth-like gum is obtained from Ailanthus excelsa of India. Dika or Gabun ChocOLATE is obtained from the seeds of Irvingia gabonensis of tropical West Africa. Cay-Cay-Butter is obtained from the seeds of Irvingia Oliveri and I. malayana of Malacca and Cochin China.

A gum resembling acacia is also obtained from the bark, petioles and seeds of the species of Irvingia.

$i$. BURSERACEÆ OR MYRRH FAMILY.-The plants are shrubs or trees, the latter being sometimes quite large, with resin-canals in the bark, and alternate compound leaves; the flowers are small, occurring in racemes. The members of this family are found in tropical countries.

Commiphora abysinica is a shrub Io M. high, the branches being modified to thorns ; the leaves are trifoliate, the leaflets being oblong, dentate, sessile and the terminal one much larger than the other two; the flowers are diøcious, and the fruit is a drupe with a fleshy, resinous sarcocarp. The official Myrrh is probably obtained from this plant as well as other species of Commiphora.

A number of other resinous products are yielded by plants of this family. West India Elem resin or Elemi Occidentale (Anime) is obtained from the stems of Protium Icicariba of Brazil. The resin is greenish-yellow, soft, with a bitter taste and dill-like odor. Manila Elemi is a soft, granular, lemon-yellow or grayish-white resin derived from Canarium commune of the Philippine Islands. Bengal Elemi is derived from Commiphora Agallocha of the East Indies and Madagascar. The TAсAмaнaC 
REsins are balsamic resins, of which there are several commercial varieties: Mauritius tacamahaca is obtained from Protium heptaphyllum of Columbia, and Mexican or West Indian tacamahaca from Bursera tomentosa of Mexico, West Indies, and South America. India Bdellium is a resin obtained from the bark of Commiphora Roxburghiana of Northwestern India and Belu-

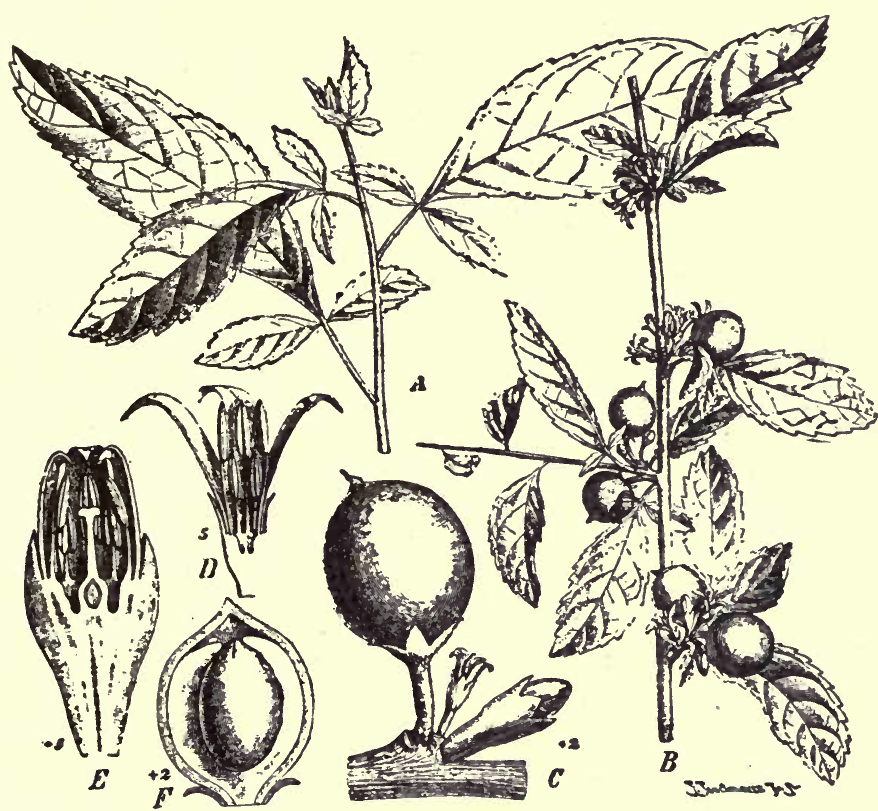

Fig. 325. Myrrh plant (Commiphora abyssinica): A, young branch showing trifoliate leaves; B, flowering and fruiting stem with thorn-like branches; C, leaf axis in which occur a fruit and staminate and pistillate flowers; D, staminate flower in longitudinal section; E, longitudinal section of pistillate flower; F, longitudinal section of fruit showing arillus-like mesocarp and the easily dehiscent endocarp.-After Engler.

chistan. Copal-like resins are obtained from Canarium bengalense (East Indian Copal) and possibly several species of Bursera. BlAck DAMMAR resin is obtained from Canarium rostratum of the Molucca Islands. Olibanum or Frankincense is a gum-resin obtained from several species of Boswellia of Asia and Somaliland. American Olibanum or Soft Resin of Cayenne exudes spontaneously from the stems of Protium heptaphyllum and P. guianense. Gilead Balsam is obtained from Protium 
altissimum and P. Carana of Guiana and Brazil. Mexican LinALE OIL is obtained from Bursera graveolens, and several species of Bursera of Mexico are used as a substitute for Aloe wood.

$j$. MELIACE $Æ$ OR MAHOGANY FAMILY.-This is a large family of tropical trees and shrubs with mostly alternate, compound and exstipulate leaves, the leaflets being entire, with secretion cells, but not glandular-punctate (Fig. 326). The flowers

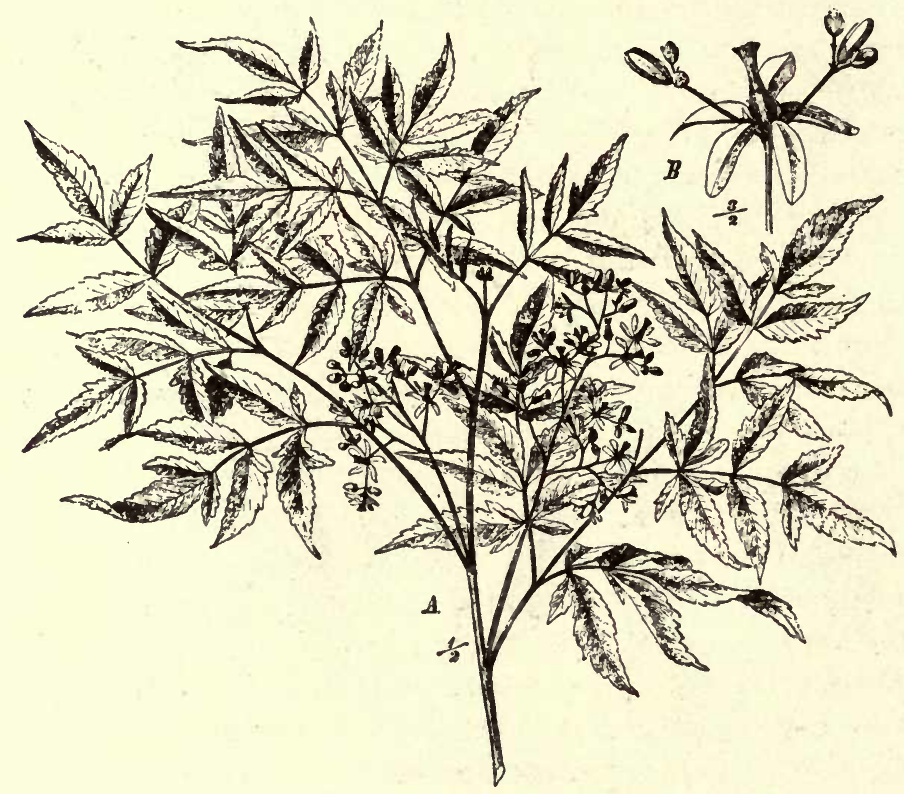

FIG. 326. Pride of China (Melia Azedarach): A, flowering branch; B, a part of the inflorescence.-After Harms.

are complete, the filaments being united into a tube; and they occur in axillary clusters or racemes; the fruit is a capsule, berry or drupe; the seeds are sometimes winged and with fleshy or leaflike cotyledons.

The bitter principle mangrovin is found in the bark of the China Tree or Pride of China (Melia Azedarach) indigenous to Asia, and extensively cultivated in tropical and warm-temperate regions, and naturalized in the southern part of the United States (Fig. 326). A similar principle is found in other plants of this family. 
Carapa Oil, which has a characteristic odor and bitter taste and is toxic to insects, is obtained from the seeds of Carapa procera and $C$. guianensis, of tropical West Africa and tropical America, and also from Swietenia Mahagoni (Mahogany Tree). Cedar-wood oil ("Oleum Cedrelæ") is obtained from several species of Cedrela growing in tropical America. The most important constituent of the oils is cadinine. Oils with a garlic-like odor are found in the seeds of Melia Azedarach, the bark of Cedrela australis of Australia and the fruit of Dysoxylum binectariferum of Java. Besides the Mahogany tree there are other trees of this family which yield valuable woods. Cigar boxes and sugar boxes are made from the wood of Cedrela odorata of the West Indies and Guiana, and from other species of Cedrela.

$k$. MALPIGHIACE $Æ$ is a rather large family of shrubs, small trees, or lianes with anomalous stem-structure, found in the Tropics, principally in South America. The leaves are usually opposite, the sepals are glandular, and the fruit is a winged samara somewhat like that of maple (Acer).

The plants contain a notable amount of tannin and the woods of some species contain a red coloring principle.

l. POLYGALACE $Æ$ OR MILKWORT FAMILY.-The members of this family are herbs or shrubs, occurring in all parts of the world except in the Arctic regions.

Polygala Senega is a perennial herb about $1 / 3 \mathrm{M}$. high. It has a fleshy root, producing at the crown a large number of buds and giving rise to a cluster of overground stems or so-called plants. The leaves are alternate, lanceolate or oblong-lanceolate and sessile; the flowers are faintly greenish-white and in cylindrical spikes; the capsule is loculicidally dehiscent, and the seed is hairy and slightly longer than the lobes of the caruncle. The root is official.

Polygala alba or White Milkwort yields the White or Texas Senega. The stems are numerous and taller than those of P. Senega; the leaves are narrow-lanceolate or linear with revolute margin; the flowers are white and in elongated conic spikes; the caruncle lobes are about half as long as the seed. The plant is found west of the Mississippi River, extending as far south as Texas and Mexico and west as far as Arizona and New Mexico. 
$m$. EUPHORBIACE plants are herbs, shrubs or trees with acrid and often milky latex. The fruit is mostly a trilocular, dehiscent capsule; the seeds are anatropous and have an oily endosperm.

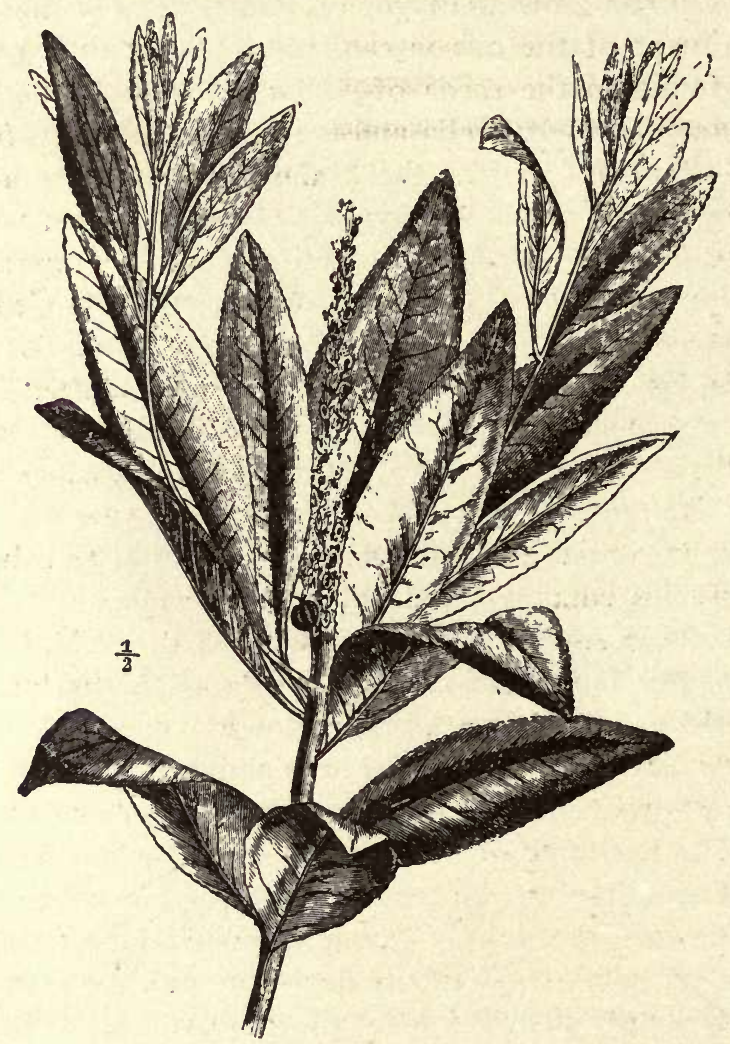

FIG. 327. Stillingia sylvatica: showing the more or less closely arranged leaves and the terminal spike of flowers.-After Bentley and Trimen.

Stillingia sylvatica or Queen's-Root yields the official Stillingia (Fig. 327). The plant is a perennial herb about I M. high and diffusely branched. The leaves are obovate, short-petiolate, with glandular-serrate margin; the flowers are in terminal spikes, light yellow, monœcious, the staminate being above and the pistillate below, the latter solitary in the axils of the lower bractlets. 
Ricinus communis or Castor-Oil Plant is an annual herb in the temperate regions but is shrub-like and perennial in tropical and sub-tropical countries. In temperate regions the plant is from I to $5 \mathrm{M}$. high; the leaves are peltate and 6- to I I-palmately-lobed; the flowers are greenish, apetalous, monœcious and in racemes, the pistillate being above the staminate on the flower-axis; the fruit is a 3 -locular, oval, spinous capsule, which dehisces septicidally (Fig. 237, $B$ ). The seeds are anatropous, somewhat flattened-oblong; Io to $16 \mathrm{~mm}$. long and 4 to $8 \mathrm{~mm}$. in diameter; smooth, mottled grayish-brown or yellowish-red, with a prominent caruncle; hard but brittle testa, thin white tegmen, large oily endosperm, and thin foliaceous cotyledons at the center. The seeds contain 45 to 50 per cent. of oil which constitutes the Castor Oil of medicine and a large amount of proteins in the form of aleurone grains (Fig. 250, D). The cake from which the oil is expressed contains a poisonous principle known as ricin which is apparently poisonous to cattle, but not to poultry.

Croton Tiglium is a shrub or small tree indigenous to tropical Asia and extensively cultivated in tropical countries; the leaves are alternate, oblong-lanceolate with petioles which are glandular at the base, but wanting in the star-shaped hairs so characteristic of other species of this genus; the flowers are small, monœcious and in terminal racemes, the pistillate being above and the staminate below; the fruit is a 3 -locular, septicidally dehiscent capsule. The seeds resemble those of Ricinus in size and structure, except that they are less smooth, more brownish in color and the caruncle is quite small.

They contain a fixed oil which is obtained by expression and which is poisonous and a powerful cathartic. The seeds of a number of the other members of the Euphorbiaceæ contain fixed oils resembling those of Croton and Ricinus, as CuRCAS, the seeds of Jatropha Curcas of tropical America. Mexican Croton OiL is obtained from the seeds of Euphorbia calyculata. The seeds of the Caper Spurge or Wild Caper (Euphorbia Lathyris), naturalized in the United States from Europe, also contain a fixed oil resembling that of Croton. The seeds of Joannesia Princeps of the maritime provinces of Brazil are also powerful purgatives. Mallotus philippinensis is a shrub or small tree found in trop- 
ical countries of the Eastern Hemisphere: The leaves are alternate, petiolate, ovate, acuminate, coriaceous and evergreen; the flowers are small, diœcious, and in racemes; the fruit is a 3 -locular, glandular-hairy capsule. The hairs of the capsule are official in a number of pharmacopœias under the name of KAMALA and occur as a reddish-brown, granular powder, consisting of two kinds of hairs, the one colorless and occurring in branching clusters (Fig. I5I) and the other with yellowish-red, multicellular, glandular heads. The important constituent is about 80 per cent. of a dark brownish-red resin composed of a crystalline principle rottlerin, isorottlerin, two reddish-yellow resins, a coloring principle and wax. It also contains a trace of volatile oil, starch, sugar, tannin, oxalic and citric acids.

A red coloring principle is found in the bark of Aleurites triloba of the Polynesian Islands, Euphorbia parviflora of Ceylon, E. pulcherrima of Mexico and Brazil and the other species of Euphorbia.

CASCARILla BARK is obtained from Croton Eluteria and other species of Croton growing in the Bahama Islands and other parts of the West Indies and Florida. Cascarilla bark is official in a number of pharmacopœias. It occurs in small curved pieces or quills, I to $3 \mathrm{~mm}$. thick, externally brownish-gray; inner surface is reddish-brown, the fracture short, resinous ; odor aromatic ; particularly on burning; taste aromatic and bitter. Cascarilla contains I to $\mathrm{r} .5$ per cent. of a volatile oil, containing eugenol, limonene, an oxygenated portion, and some other constituents; 15 per cent. of resin; a bitter principle, cascarillin; tannin and vanillin.

COPALCHI BARK or Quina blanca which is derived from Croton niveus of Mexico contains a bitter principle, copalchin, which is also found in other species of Croton. Malambo bark is derived from Croton Malambo of Venezuela, the latter two barks being sometimes substituted for Cascarilla bark.

Elastica or India Rubber (Caoutchouc) is the prepared milkjuice obtained from one or more species of the following genera: Hevea, Mabea, Euphorbia, etc. (see pp. 238-24I). The fresh latex of a number of species is a powerful irritant, as that of the Sand-box tree (Hura crepitans) of tropical America, which contains a highly toxic albuminoid; the Blinding-tree (Excrecaria 
Agallocha) of Southern Asia and Australia, the juice of which produces blindness.

The gum-resin EUPHORBIUM is obtained from Euphorbia resinifera, a cactus-like plant of Morocco, and is also found in other species of Euphorbia. It contains, among other constituents, 38 per cent. of an acrid resin, and 22 per cent. of a crystalline principle ęuphorbon.

The milk-juice of several species of Euphorbia is used in the preparation of arrow poisons in Brazil. One or more species of the following genera are used as fish poisons: Flueggea, Phyllanthus, Bridelia, Excœcaria and Euphorbia. A number of plants are used as remedies for the bites of serpents, as the bark of Phyllanthus mollis of Java and Euphorbia pilulifera of South America and India. Euphorbia pilulifera, common in tropical countries, contains an alkaloid, a wax-like substance, several resins and tannin. (Ph. Jour., 29, July 3I, I909, p. I4I.)

A camphor-containing oil is found in the bark of Pentalostigma quadriloculare of Australia; the aromatic wood of Colliguaya odorifera of Chile is used as a substitute for santal and on burning emits a rose-like odor; the leaf of Croton menthodorus of Peru contains an oil with an odor of mentha; a balsam resembling Copaiba is derived from the bark of Croton origanifolius of the West Indies; methylamine is found in Mercurialis annua of Europe and other species of Mercurialis. Tannin is found in the following genera: Macaranga, Phyllanthus and Bridelia; Brazil kino is obtained from a species of Croton ( $C$. erythrcus?) of Brazil. A gum-lac is formed on the stems of Aleurites laccifera of the Antilles and Ceylon as a result of the sting of an insect, and contains among other substances a large amount of methyl- and ceryl-alcohols, and a substance resembling abietic acid. The sap of Euphorbia Cyparissias of Europe yields a resin which is sometimes substituted for scammony.

A reddish resinous substance resembling dragon's blood is obtained from Croton erythrema of Brazil; a yellow coloring principle is found in the seed of Croton tinctorius of Mexico; poncetin, a violet coloring principle, occurs in Euphorbia heterophylla of Brazil; a blue coloring principle is found in Chrozophora tinctoria of Southern Europe and Africa and in Argitham38 
nia tricuspidata lanceolata of Chile; an indigo-like principle is obtained from Mercurialis perennis of Europe. The fresh latex of Euphorbia phosphorea of Brazil is phosphorescent.

Quite a number of the seeds of this family contain fatty oils. The Chinese Tallow tree (Sapium sebiferum) yields a fat which is used for burning and for technical purposes; a similar fat is obtained from the seeds of several species of Aleurites and Euphorbia.

TAPIOCA starch is derived from the tuberous roots of Manihot utilissima, extensively cultivated in tropical countries; other species of Manihot also yield starchy food products.

Edible fruits are obtained from the following genera: Phyllanthus, Baccaurea and Antidesma ; the seeds of Hevea brasiliensis are edible; a sweet sap is found in Baccaurea ramiflora of Cochin China and Brazil; a peptone-like ferment is found in Euphorbia heterodoxa of South America and other species of Euphorbia.

XVIr. ORDER SAPINDALES.

The plants of this order are chiefly trees and shrubs. The flowers are mostly regular and the seeds usually without endosperm. The order has a number of representatives in both tropical and temperate regions.

a. BUXACE E OR BOX TREE FAMILY.-The plants are shrubs with alternate or opposite, evergreen leaves, and usually axillary monœcious or diœcious flowers. The most important plant of this family is the Box tree (Buxus sempervirens), which is extensively cultivated. The wood is used for making musical instruments and for other purposes, and the twigs have been used in medicine. The latter contain several alkaloids, the most important being buxine, which resembles beberine; a volatile oil containing butyric acid and a wax containing myricyl alcohol and myricin.

b. FAMILY CORIARACEÆ.-This family is represented by but a single genus, Coriaria. The plants are shrubs found in Europe, Asia and South America, and yield several important economic products. The leaves and bark of $C$. myrtifolia of Southern Europe and Northern Africa are rich in tannin and used in dyeing. This plant also contains a narcotic principle, resem- 
bling picrotoxin, known as coriamyrtin, which is also found probably in C. atropurpurea of Mexico. The leaves of Coriaria myrtifolia or TANNER'S SUMAC are coriaceous, distinctly 3 -nerved, astringent and bitter and were at one time substituted for senna leaves. A black dye is obtained from C. ruscifolia of New Zealand and Chile. While the fruits of some species are quite poisonous, the sap of the fleshy leaves is used in New Zealand in making an intoxicating drink.

c. ANACARDIACE $\approx$ OR SUMAC FAMILY.-The plants are trees or shrubs with an acrid, resinous or milky latex, and alternate leaves.

Rhus Toxicodendron, Poison Ivy or Poison Oak, is a woody vine, climbing by means of aërial roots and sometimes becoming quite shrub-like, which is common along roadsides in the United States. The leaves are 3 -foliate, the leaflets being ovate, acuminate, nearly entire, inequilateral and with short stalks; the flowers are green and in loose axillary panicles; the fruit is a globular, glabrous, grayish drupe (Fig. 328). The nature of the poisonous constituents of Poison Ivy is not definitely known. It was originally considered to be in the nature of a volatile principle. Pfaff and his pupils seemed to show that the poisonous principle was a non-volatile brownish-red resin which is soluble in alcohol and called toxicodendrol. Schwalbe, on the other hand, states that the poisonous substance is of a volatile nature, being formed in the laticiferous vessels and by osmosis is transferred to the hairs. The poison may be transmitted either by direct contact with the hairs, much as in the same manner with the nettles, or by volatilization of the oil when the hairs are broken. The experience of most plant collectors would seem to indicate that in Poison Ivy there is a volatile toxic constituent (Amer. Jour. Pharm., March, I9I4). On the other hand, Rost and Gilg were unable to find a volatile poison in either the hairs or pollen of Poison Ivy. In some experiments conducted by Warren on pollen grains, similar negative results were obtained (Amer. Jour. Pharm., Dec., I9r3). The poisonous principle occurring in several species of Rhus is an amber-red, non-volatile liquid. It is of a resinous nature, combining with the alkali hydroxides to form nigrescent compounds, and otherwise behaves like certain phenolic compounds. The toxic 
resin exists in the plant in the form of an emulsion which readily blackens with the alkali hydroxides. So delicate is this reaction that minute amounts of the substance may be detected by means

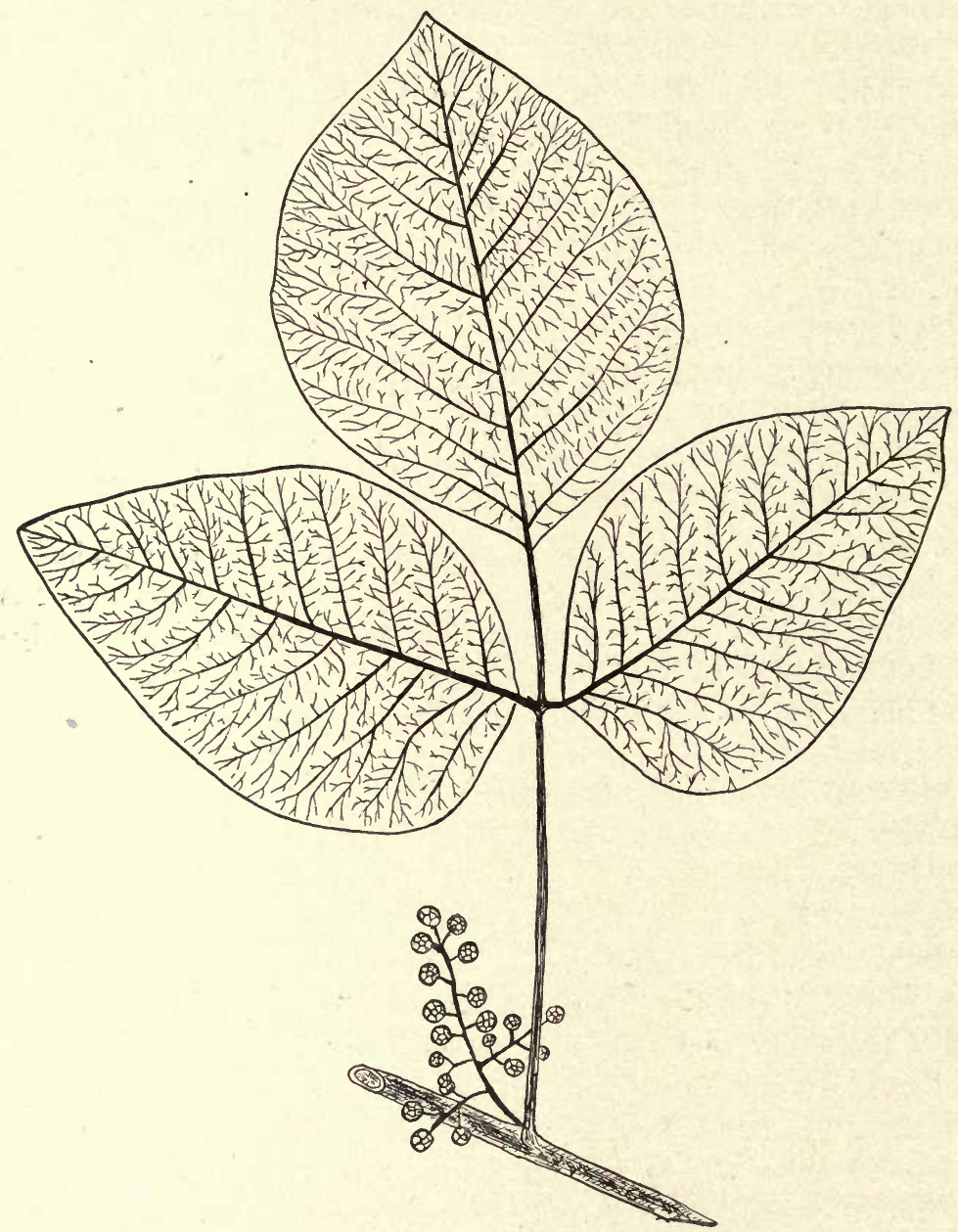

FIG. 328. Leaves and fruit of the poison ivy (Rhus radicans). This is a 3 -foliate compound leaf, the leaflets being ovate and having veins which bifurcate and end free.

of the microscope if the plant tissues are mounted in an alcoholic solution of potassium hydroxide. A vesicating principle CARDOL is found in the Cashew NUT. The latter is the fruit of Anacardium 
occidentale, a shrub growing in tropical America. A principle resembling cardol is found in the East India Marking tree or Ink tree(Semecarpus Anacardium) and Holigarna ferruginea of India.

The Poison Sumac or Poison Elder (Rhus Vernix) is a shrub or small tree found in swamps in the United States and Canada. The leaves are 7 - to 13 -foliate, with obovate or oval, acuminate, entire leaflets; the flowers are small, green, and in axillary panicles; the fruit resembles that of $R$. radicans (Fig. 328). The plant is poisonous like $R$. Toxicodendron and probably contains the same principle. Other species of Rhus are also poisonous, as the western Poison Oak ( $R$. diversiloba) of the Pacific Coast, and the Japanese Lacquer or Varnish tree ( $R$. vernicifera and $R$. succedanea). The lacquer trees grow wild in both China and Japan, where they are also cultivated. The lac is obtained by incising the bark and removing it with a pointed spatula. The grayish-white emulsion is strained and on exposure to air it changes to brown, becoming finally black. This change is due to the oxidizing enzyme laccase. The natural lac (Kiurushi) contains a non-volatile poisonous resin-like principle and is closely associated with other resinous substances. Japanese lac is thinned with camphor, or mixed with linseed oil, and on drying in a moist atmosphere forms the most indestructible varnish known. Various pigments are used, as vermilion, gamboge, acetate of iron and other substances. The best glossy black colors are obtained by the addition of iron.

Rhus glabra or the Scarlet Sumac is a smooth shrub. The leaves are II - to $3 \mathrm{I}$-foliate, the leaflets being lanceolate, acuminate, sharply serrate, dark green above and lower face glaucous; the flowers are greenish, polygamous and in terminal panicles; the fruits of this plant and of R. typhina (Fig. 329) are used in medicine.

CHINESE GALLS are excrescences produced on Rhus semialata as a result of the stings of an Aphis. JAPANESE GALLS are similar formations occurring on Rhus japonica. (See pp. 206, 334.)

Pistacia Lentiscus is a shrub or tree, which is found growing in the Grecian Archipelago. The leaves are pinnately compound and with winged axis, the leaflets being alternate, oblong, entire, sessile; the flowers are small, diøcious, and in axillary clusters. In the bark of this plant there are large cavities which contain 


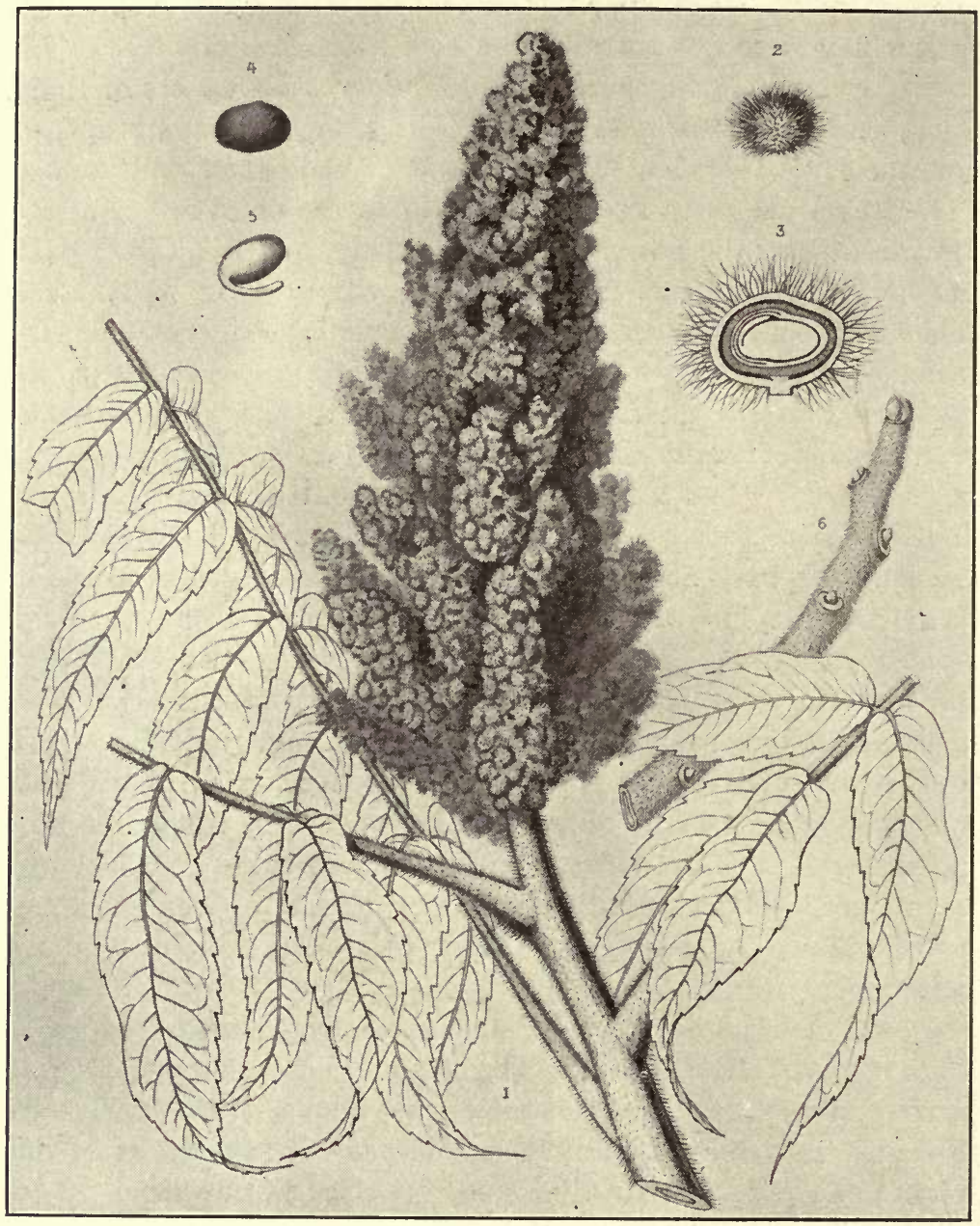

Fig. 329. Fruiting branch with leaves of Rhus typhina. Reproduced from Sargent's "Silva of North America."

Rhus typhina is commonly known as the "staghorn sumac" in allusion to the soft brown pubescence covering the twigs and branches. It is also known as the "vinegar tree" and "Virginia sumac." It may attain the height of a tree, and is usually found growing in uplands in good soil, ocasionally being found like Rhus glabra on barren gravelly banks. It is very abundant in the eastern United States and apparently sparingly distributed west of the Appalachian Mountains. 
an oleo-resin that is official as Mastic in a number of pharmacopœias (see Vol. II). The wood of Schinopsis Lorentzii and S. Balanse, growing in Argentine and Paraguay, is known in commerce as Quebracho COLORADO. It is red, very hard and contains tannin, gallic and ellagic acids.

The Pistacio nuts or Pistacia almonds are obtained from Pistacia vera indigenous to Syria and Mesopotamia and extensively cultivated in the countries bordering the Mediterranean. The kernels are used extensively in confectionery. The nuts are

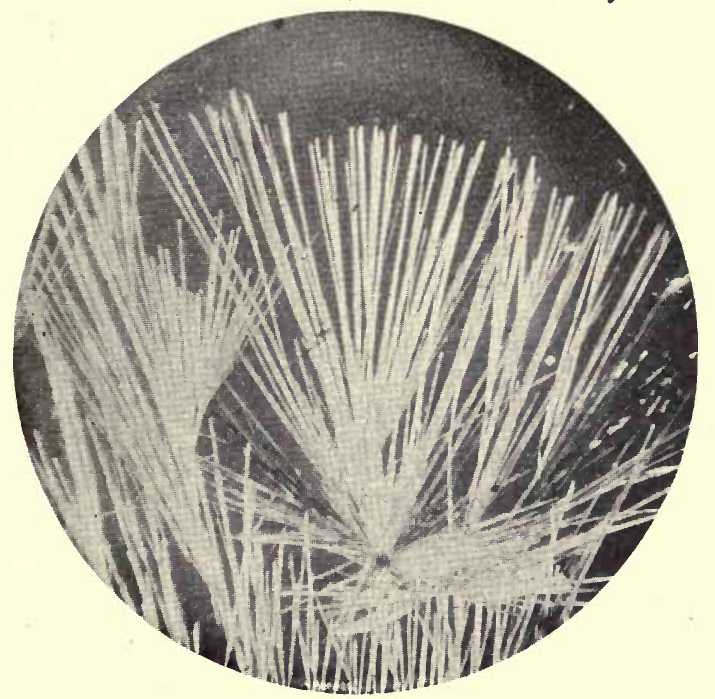

FIG. 330. Gallic acid: long orthorhombic crystals obtained from an aqueous solution.

about $20 \mathrm{~mm}$. long, somewhat quadrangular in cross section, and the seed consists of two fleshy, green cotyledons. The seeds of Buchanania latifolia and other species of Buchanania are used in India much like almonds.

Gums are found in several species of Anacardium and Sclerocarya. Achjou gum is obtained from Anacardium occidentale. Considerable sugar and citric acid are found in MAngos, the fruit of Mangifera indica native of Farther India and Ceylon and cultivated in the Tropics. A fruit used like lemons is obtained from Dracontomelon mangiferum of Malacca and the Sunda Islands. 


\section{d. AQUIFOLIACE $玉$ (ILICACE $\mathrm{E}$ ) OR HOLLY FAM-} ILY.-The plants are mostly shrubs or trees with alternate, petiolate, simple leaves and small, white, regular flowers. The fruit is a berry-like drupe containing several nutlets. The most important genus of this family is Ilex, a number of species of which are found in the United States.

The European holly (Ilex Aquifolium) contains a bitter glucosidal principle, ilicin, which is found in the bark as well as the drupes. The drupes contain a principle which is a homologue of benzyl alcohol, and a glutinous substance which renders them useful in the manufacture of bird lime. The American holly ( $I$. opaca) growing in the Eastern United States probably contains similar constituents to the European holly. This is the plant which furnishes the Christmas Holly.

Maté, Paraguay or Brazilian tea, consists of the leaves of Ilex paraguariensis (Fig. 33I) found in Brazil, Argentine and Paraguay. They contain about 2 per cent. of caffeine, II per cent. of tannin and some volatile oil, and are used like tea in the making of a beverage. Cassine or Appalachian tea consists of the leaves of the Dahoon holly (Ilex Cassine) growing in the Southern United States. These leaves contain about half as much caffeine and tannin as Maté.

$e$. CELASTRACE $\approx$ OR STAFF-TREE FAMILY.-These are shrubs, as Euonymus, or woody climbers, as the climbing bittersweet (Celastrus scandens). The plants are especially characterized by their dehiscent fruits and scarlet or reddish arilled seeds.

Euonymus atropurpureus (Wahoo or Burning Bush) is a shrub or small tree. The twigs have four distinct cork-wings, making them somewhat 4 -angled. The leaves are opposite, petiolate, ovate-oblong, acuminate, crenulate-serrulate and hairy beneath. The flowers are purplish and in axillary cymes. The fruit is a 3 - to 4 -lobed, persistent, loculicidally dehiscent capsule with 6 to 8 scarlet seeds. The bark of the root is official.

The leaves of Catha edulis growing in Arabia and Abyssinia are chewed and also used like tea. They contain the alkaloids cathine and celastrine which are supposed to have similar properties to cocaine, as well as tannin and an ethereal oil. A yellow coloring principle is found in the bark of Euonymus tingens of 


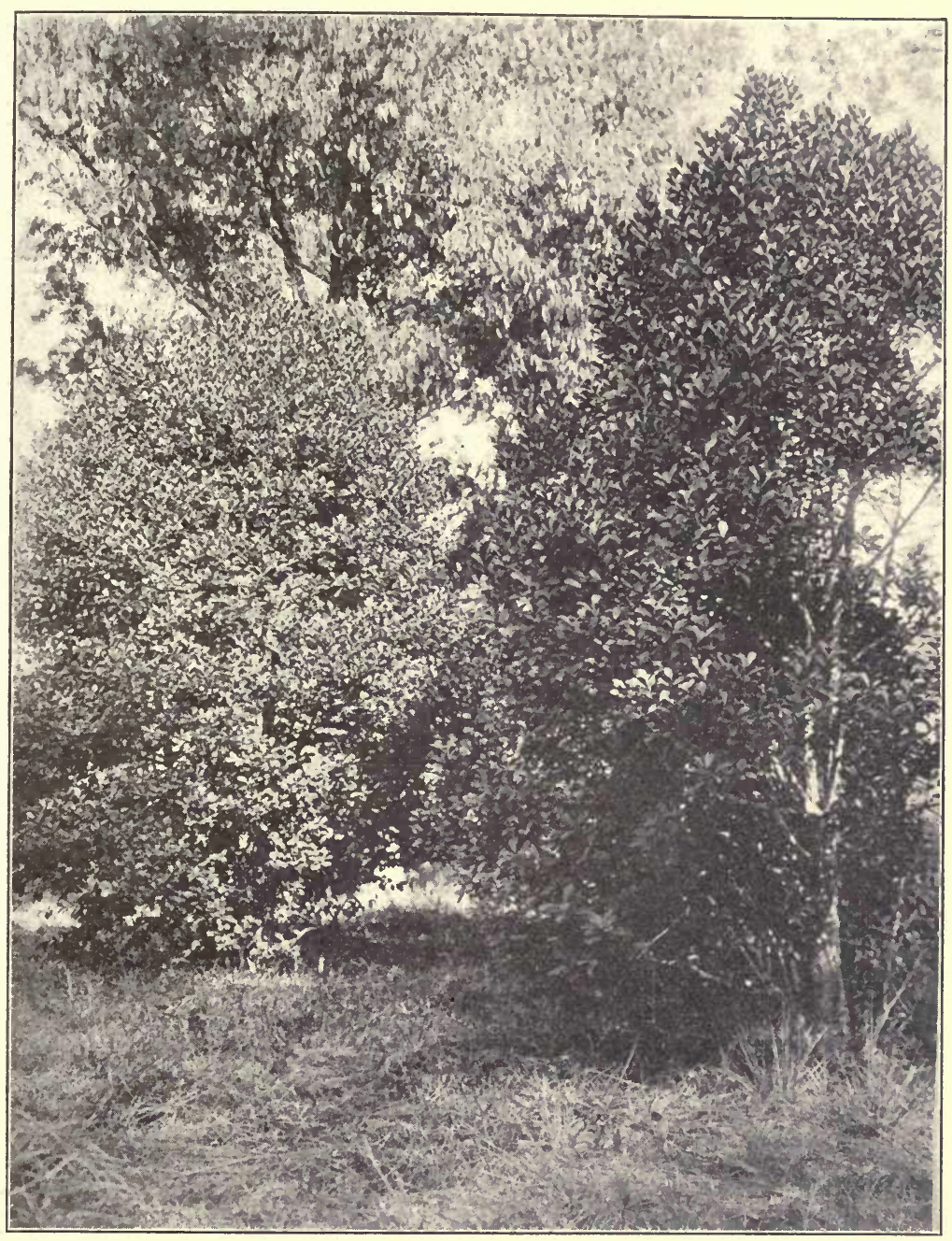

FIG. 33r. Yerba Maté trees (Ilex paraguariensis) growing in Pereira Continho and Almeido, Santos, Brazil. The plants are shrubs or small trees, with ovate or nearly spatu. late, dentate and slightly coriaceous leaves. The latter are used, under the name of Paraguay tea, in the preparation of a tea-like beverage. The trees are extensively cultivated in South America. and large quantities of Maté are consumed annually. 'The young branches are gathered between December and August, dried over a fire, the leaves being separated, and are then ready for markct.-Reproduced by permission of The Philadelphia Com. mercial Museum. 
the East Indies. The yellow coloring principle in the arils of the seeds of Celastrus and Euonymus appears to closely resemble carotin. The seeds of a number of plants of this family contain a considerable quantity of fixed oil, as Celastrus macrocarpus of Peru, and Maytenus Boaria of Chile.

f. ACERACEÆ OR MAPLE FAMILY.-The plants of this family are trees or shrubs, the most widely distributed representative of which is the maple (Acer). The most distinguishing character of this family is the fruit, which is a double samara. The sap of a number of species of Acer contains cane sugar or sucrose, and the sap of the sugar maple (Acer saccharinum) which grows in the United States and Canada contains from 3 to 4 per cent. The making of maple syrup and maple sugar is quite an industry in some localities. Maple sugar is also obtained from the black sugar maple (Acer nigrum) and the ash-leaved maple (A. Negundo). The bark of the latter species is used to some extent in medicine. Valuable timber is yielded by the maple trees.

g. HIPPOCASTANACE $\AA$ OR BUCKEYE FAMILY.The plants are shrubs or trees with opposite, petiolate, and 3 - to 9-digitately-foliate leaves. The flowers are in terminal panicles and the fruit is a 3 -lobed capsule, which usually contains one large, shiny seed.

The horse-chestnut (Esculus Hippocastanum) contains in the bark two fluorescent bitter principles, æsculin and paviin, the former of which is in the nature of a glucoside; and in the bark, leaves and flowers the coloring principle, quercitrin is present; in the seed-coat saponin is supposed to occur, and the glucoside æsculin as well. The cotyledons contain considerable starch, some proteins and sugar, a small quantity of a fixed oil, and argyresin, to which the antihemorrhoidal action appears to be due. A narcotic principle is present in the bark, twigs and leaves of the red buckeye (Esculus Pavia) of the Southern United States.

h. SAPINDACE王 OR SOAPBERRY FAMILY.-The plants are mostly trees or shrubs indigenous to the Tropics. In some genera they are herbaceous or woody vines (lianes). The plants of this family usually have either a milky sap or contain saponin, and it seems strange that a plant yielding caffeine, namely, 
Paullinia Cupana, which furnishes the official Guarana, should belong to this group.

The fruit shells of Nephelium lappaceum contain a toxic saponin (Ph. Weekblad., 45, I, I56, 1908). Four or five per cent.

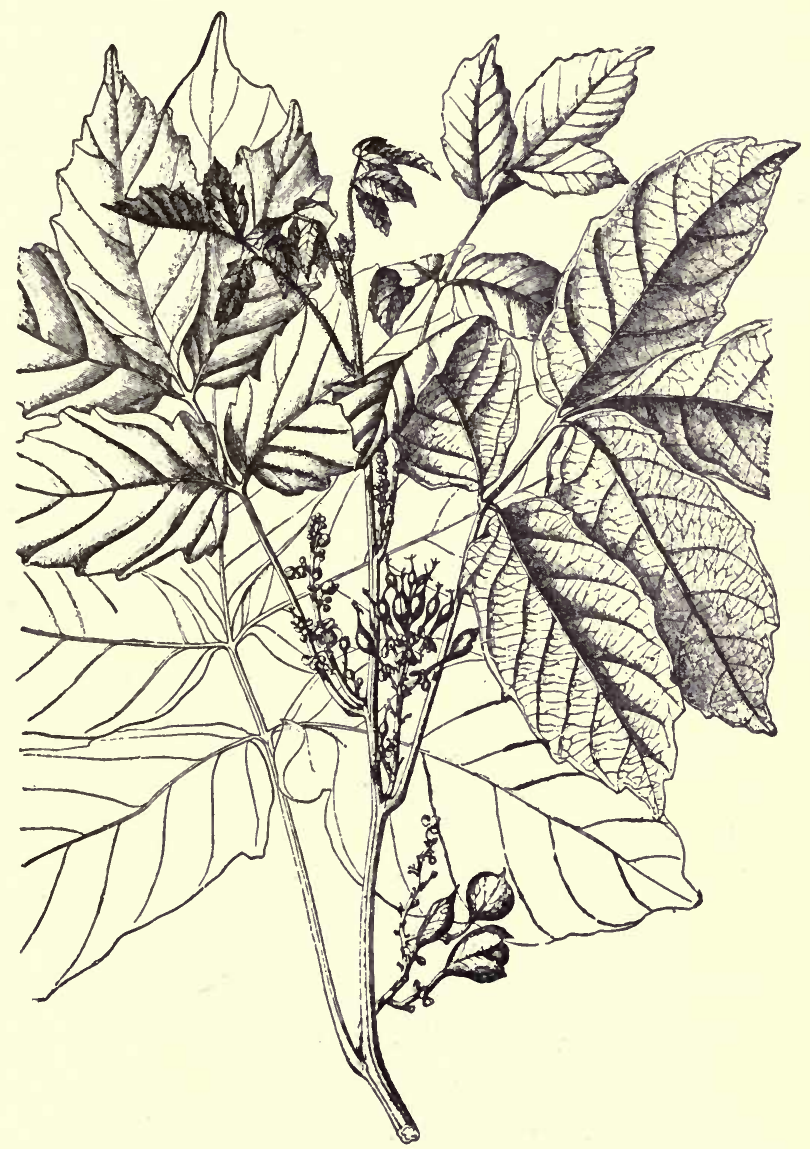

FIG. 332. Flowering and fruiting branch of Brazilian cocoa (Paullinia Cupana) yielding the Guarana used in medicine.-After Radlkofer.

of SAPONIN is found in the fruit of Sapindus trifoliatus of India. A principle related to saponin is found in Sapindus Saponaria of tropical America. Saponin is also found in the fruits of other species of Sapindus, the bark of Pometia pinnata of the Sunda 
and South Sea Islands, and the kernels of the seeds of the two species of Magonia indigenous to Brazil. The latter plants also yield a poisonous nectar and the root-bark is used in the poisoning of fish. A shellac is obtained from Schleichera trijuga of India and the seeds of this plant yield "marcassa oil."

Paullinia Cupana is a woody climber indigenous to and cultivated in Northern and Western Brazil. The leaves are alternate and 5 -foliate, the leaflets being oblong, acuminate, coarsely, irregularly dentate, and with short stalks; the flowers are yellow and in axillary panicles; the fruit is a 3 -locular, 3 -seeded sub-drupose capsule (Fig. 332).

i. BALSAMINACE E OR JEWEL-WEED FAMILY.The plants are succulent herbs with alternate, petiolate leaves and conspicuous axillary flowers; the fruit is a capsule which at maturity breaks into five valves, discharging the seeds with considerable force.

The balsam of the gardens (Impatiens Balsamina), which flowers all summer, belongs to this family. Other species of Impatiens are also cultivated.

The stem sap as well as that of the flowers of a number of species of Impatiens is used on account of its red and yellow coloring matters, to color the skin of the hands and feet as also the nails by the people of India, Tartary and Japan. The seeds of some species of Impatiens yield an oil which is used for burning.

\section{ORDER RHAMNALES.}

This order includes two large families which are characterized by having 4 or 5 stamens which are either alternate with the sepals or opposite the petals when the latter are present. The ovules are atropous.

a. RHAMNACE $\mathrm{E}$ OR BUCKTHORN FAMILY.-The plants are woody climbers, shrubs or small trees.

Rhamnus Purshianus is a large shrub or small tree. The leaves are petiolate, oblong, elliptical, acuminate, finely serrate and pubescent beneath; the flowers are small and in axillary umbellate cymes, and the fruit is 3-lobed, black, ovoid, and drupaceous. The bark constitutes the official Cascara sagrada (Fig. 333).

Rhammus Frangula or Alder Buckthorn is a shrub the botan- 
ical characters of which closely resemble those of $R$. Purshianus. The bark of this plant is also official.

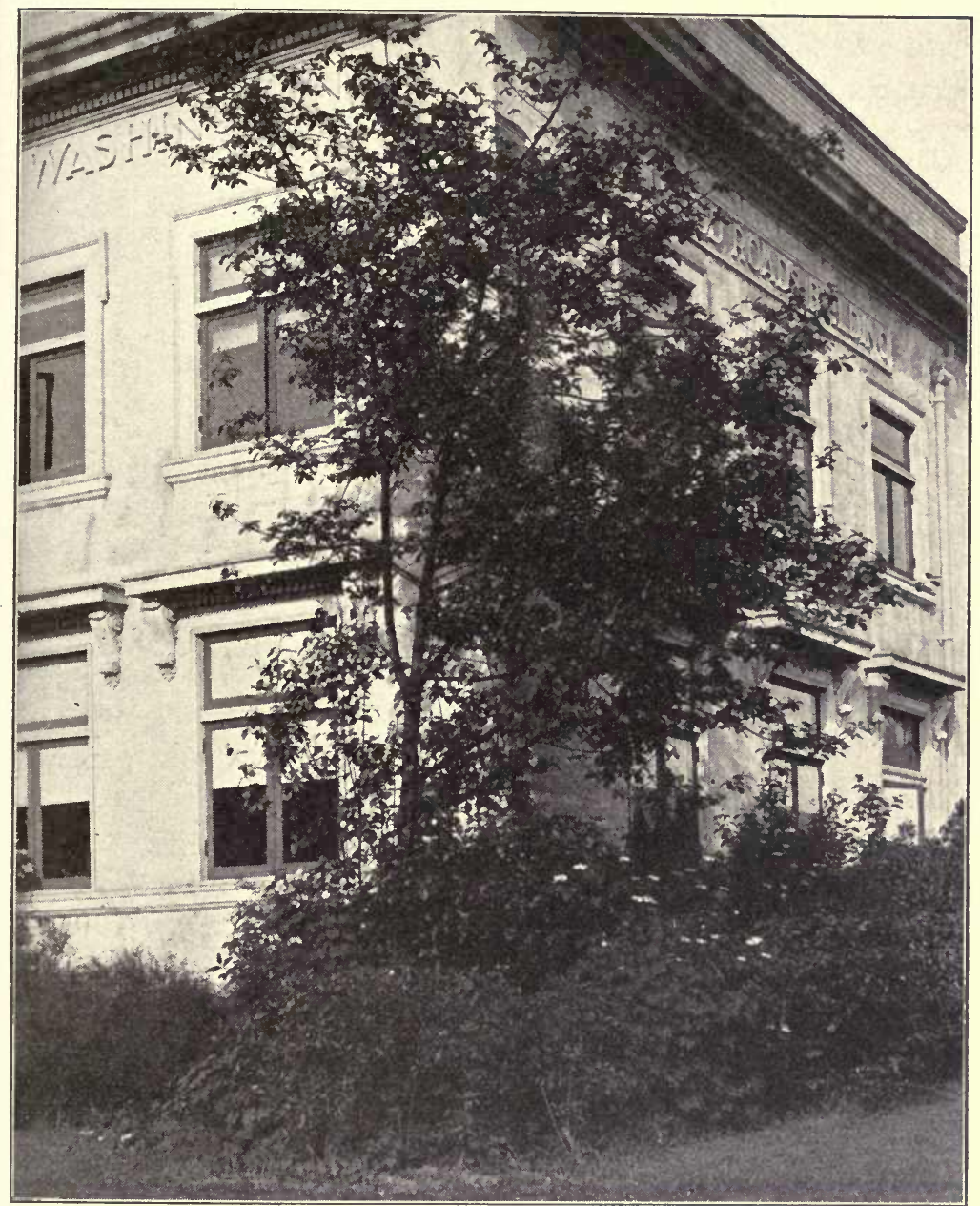

FIG. 333. A Cascara tree on University of Washington campus.-After Johnson and Hindman, Amer. Jour. Pharm., I914, p. 389.

The leaves of the shrub known as New Jersey Tea (Ceanothus americanus) are said to have been used as a substitute for tea during the Revolutionary times. This plant is found in the East- 
ern United States and Canada and the root, which contains considerable tannin and possibly an alkaloid, has been used in medicine. The leaves of Sageretia theezans of Asia have also been used as a substitute for tea. A number of plants of this family have been SUBSTITUTED FOR HOPS in the fermentation industry, as Ceanothus reclinatus of the West Indies; Colubrina fermenta of Guiana, and Gouania domingensis of Martinique and Hayti. Saponin is found in the bark of Gouania tomentosa of Mexico. A crystalline bitter principle, colletin, occurs in the wood of $\mathrm{Col}$ letia spinosa of South America. The bark of Discaria febrifuga of Brazil has been used as a substitute for cinchona. A number of genera furnish fish poisons, as Zizyphus, Tapura, and Gouania. Gum-lac is formed on the twigs of Zizyphus Jujuba of Asia as the result of the sting of an insect (Coccus lacca).

The fruits of several species of Zizyphus, thorny shrubs found growing in South America, are edible and enter into the French or Spanish confection known as JUJUBE-PASTE.

b. VITACEÆ OR GRAPE FAMILY.-The plants of this family are woody climbers or erect shrubs with alternate, petiolate leaves, and small, greenish, regular flowers, the fruit being a berry.

The most important genus, economically, is Vitis, to which belong the cultivated grapes, the fruits of which furnish raisins, wine and brandy. The GRAPE-vine indigenous to Europe (Vitis vinifera) is cultivated in all temperate and sub-tropical countries, and the variety silvestris which is found distributed in the Mediterranean countries as far east as the Caucasus Mountains is supposed to have furnished the cultivated wine grape. The CONCORD and CATAWBA GRAPES are cultivated varieties of the northern Foxor Plum-grape (Vitis Labrusca) indigenous to the Northern United States east of Minnesota. The Delaware grapes are cultivated varieties of the frost-grape ( $V$. cordifolia) and the sweetscented grape ( $V$. vulpina) of the Eastern United States. The pulpy part of the grape contains from 9 to 18 per cent. of grapesugar and 0.5 to 1.36 per cent. of tartaric acid. In unfavorable seasons the tartaric acid is replaced in part by malic acid. The soil has a marked influence on the quality of grapes, a sandy soil 
producing a light colored wine, a soil rich in calcium $a$ sweet wine, and a clay soil a fine bouquet, etc.

Wines are made by fermenting the grape juice, and contain from 5 to 20 per cent. of alcohol, from I or 2 to 12 per cent. of sugar, about 0.5 per cent. of tartaric, acetic and other fruit-acids, tannin and coloring matter from a trace to o.3 per cent., and various compound ethers, giving them their characteristic flavors or bouquets. White wines are made from the juice of the pulp of the white or colored grapes after separation from the epicarp and seeds. In the manufacture of RED WINE no care is taken to separate the seeds and skins of colored grapes or even the stems on which the fruits are borne. PORT wiNe is made from a grape grown in Portugal, the wine being chiefly exported from Oporto. The term CLARET is applied to a red wine containing a small amount of alcohol. BRANDY is obtained by the distillation of the fermented juice of the grape. CHAMPAGNe is a product obtained by fermenting grape juice to which other substances have been added, and contains about ro per cent. of alcohol and 67 per cent. of carbon dioxide. RaIsins are obtained from a variety of $V$ itis vinifera containing a high percentage of sugar. In the preparation of raisins the ripe grapes are dried either by exposure to the sun or artificial heat. In grape preserves in addition to the indistinguishable cells of sarcocarp, raphides of calcium oxalate occur.

A principle resembling toxicodendrol is found in Vitis inconstans of Japan. A greenish-blue coloring principle occurs in Vitis sicyoides of South America. The leaves and twigs of Virginia CREEPER or American ivy (Psedera quinquefolia) contain tartaric acid, glycollic acid, catechin and inosit.

\section{ORDER MALVALES.}

This order includes several families having rather diversified characters. The stamens are numerous, the sepals are valvate and the placentas are axillary.

a. FAMILY ELÆOCARPACE E.-The members of this family are shrubs or trees mostly indigenous to the Tropics. They are distinguished from the plants of the other families of this order in not containing lysigenous mucilage canals. A principle yielding hydrocyanic acid is found in Echinocarpus Sigun 


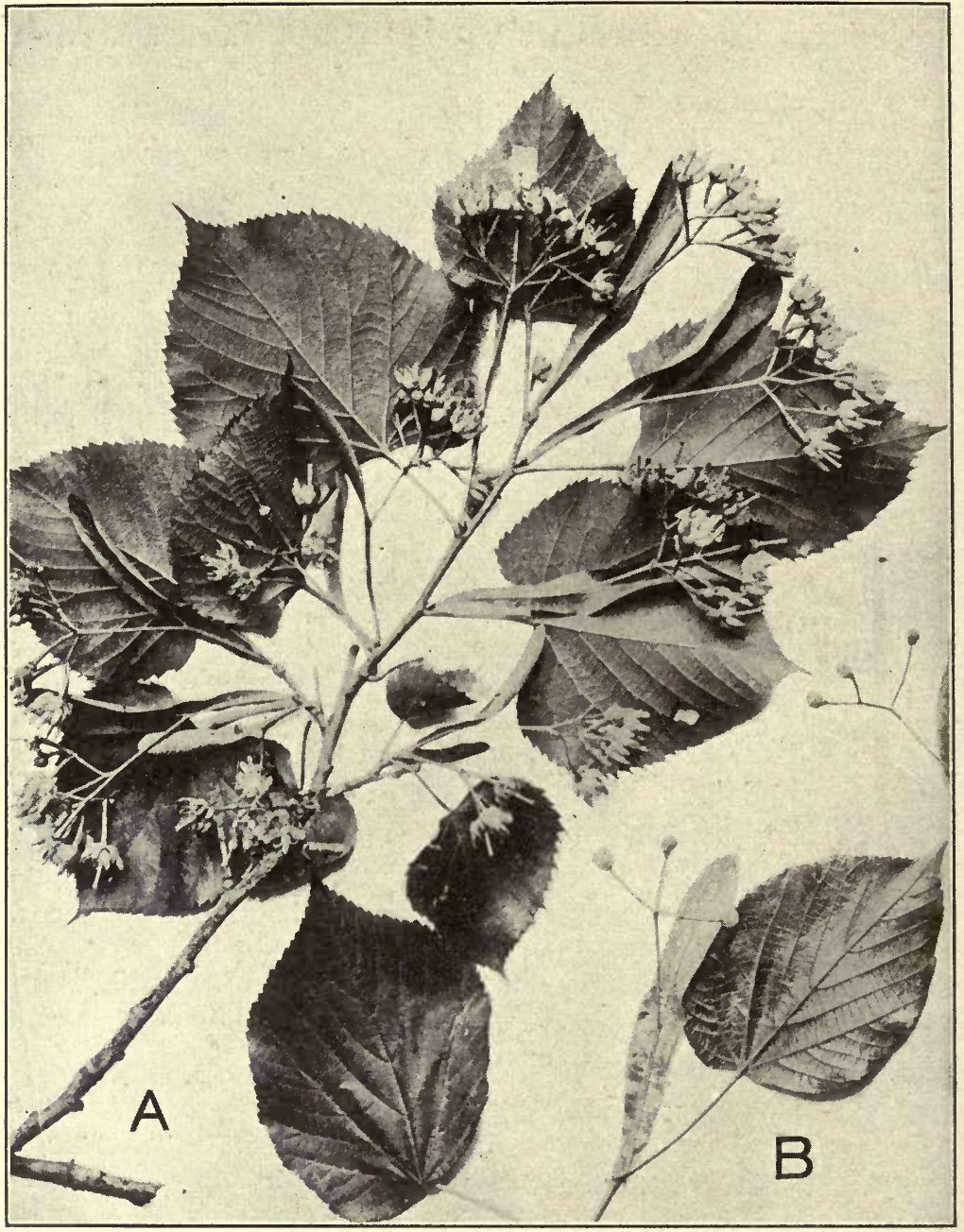

FIG. 334. American Linden, Basswood or Lime tree (Tilia americana). A, flowering branch showing the obliquely heart-shaped, serrate leaves with conspicunus midrib and primary veins, and cymose clusters of yellowish-white fragrant flowers, which are attached to the midvein of an oblong, leaf-like bract. B, several of the ovoid or spherical, nut-like fruits about the size of peas.-From Bulletin 26, U. S. Department of Agriculture.

of Java. A yellow coloring principle is found in the leaves of Vallea cordifolia of Peru. A fatty oil is found in the seeds of several species of Elcoocarpus. A number of fruits of this family 
are edible. Maqui Fruit is obtained from Aristotelia Maqui of Chile and is used to color wine. The seeds of Sloanea dentata are eaten like chestnuts in Guiana.

b. TILIACE $A$ OR LINDEN FAMILY.-The plants are shrubs or trees with alternate, simple leaves, and with white flowers in cymes or panicles. In the Linden or Basswood (Tilia) the peduncles are partly adnate with the long, leaf-like bracts. The fruits are dry drupes (Fig. 334).

The flowers of the European Linden (Tilia europca) contain a fragrant volatile oil and are used in medicine. The flowers of other species of Tilia also contain volatile oils, and the flowers of Tilia tomentosa of Southern Europe are used to flavor champagne. The leaves of Tilia europaa contain the glucoside tiliacin. Several species of Grewia are used as fish poisons. A purgative principle is found in the seeds of Corchorus olitorius of Southern Asia, Africa and South America. A bitter principle occurs in the seeds of Corchorus tridens of Arabia, India and Egypt. A reddish-colored, fatty oil known as Apeiba oil is obtained from the seeds of Apeiba Tibourbon of Guiana. The root of Grewia scabrophylla is used as a substitute for Althæa in India. Mucilage is found in the flowers and fruits of a number of genera. The leaves of Corchorus siliquosus are used in Panama as a substitute for tea. A number of the fruits of this family are edible, as of Muntingia and Apeiba. The bast fibers of several species of Corchorus, particularly C. capsularis of China and India, constitute jute, which is used in the making of cordage. The fiber is separated by cold retting in stagnant water.

c. MALVACE $A$ OR MALLOW FAMILY.-The plants are mostly herbs or shrubs with alternate, simple leaves, and regular, perfect, large flowers, with the stamens united into a column which encloses the styles (Fig. 222, $E$ ), and a capsular fruit. The cultivated ornamental Hollyhock and Althæa belong to this family.

Althcea officinalis or marshmallow is a perennial herb about I M. high with broadly ovate, petiolate, acute, dentate and lobed, pubescent leaves; the flowers are 2 to 4 in number in the axils of the leaves and have rose-colored petals. The bractlets are linear and the fruit consists of 15 to 20 indehiscent carpels. The root is used in medicine as a demulcent. 
Gossypium species.-The plants are herbs or shrubs with 3- to 5-lobed leaves, and large axillary flowers; the fruit is a 5-locular, dehiscent capsule or pod; the seeds are spherical or somewhat angular and covered with long I-celled hairs, which latter constitute cotton. (Fig. 139).

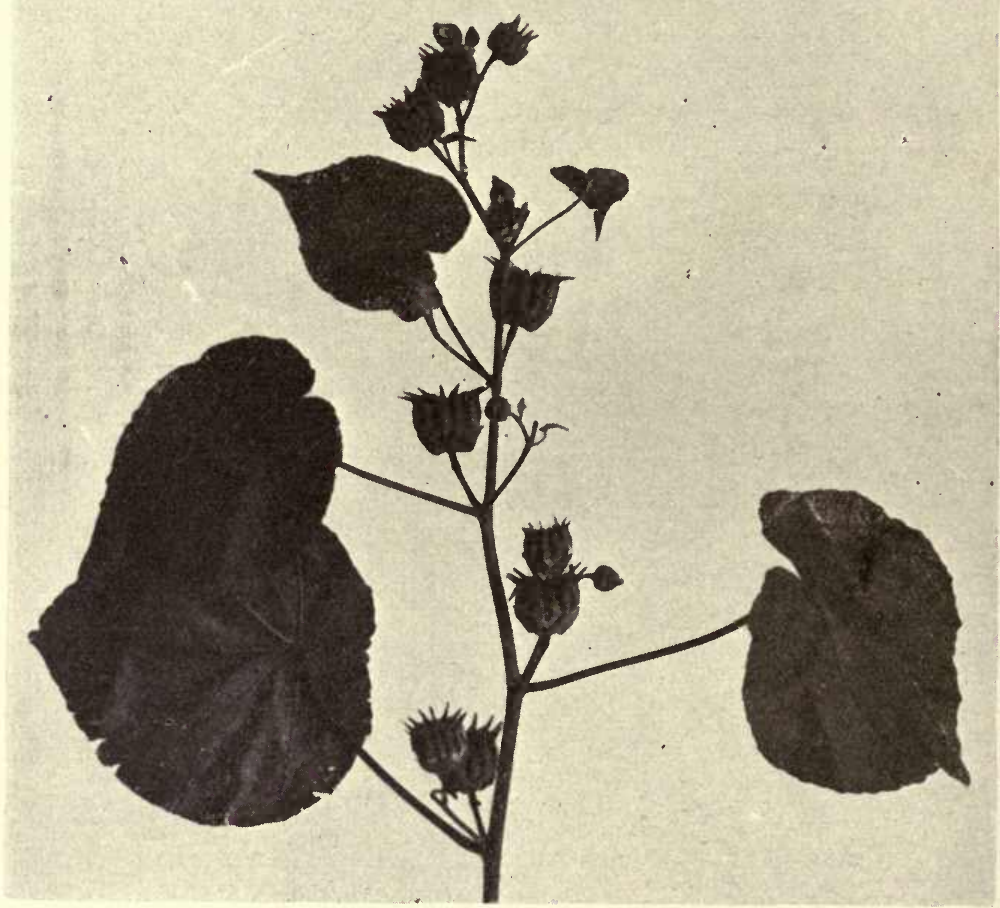

Fig. 335. Indian mallow, velvet leaf (Abutilon Theophrasti). A common plant growing in waste places, with velvety, heart-shaped leaves; yellow flowers; and characteristic fruits, consisting of 12 to 15 beaked carpels. - After Brown.

There are three important cultivated species. (I) SEA IsLand Cotton is obtained from Gossypium barbadense, a plant which is principally cultivated in the Southern United States and also in Northern Africa, Brazil, Peru and Queensland. This species is distinguished by the fact that after removal of the hairs from 
the seeds they are smooth. (2) G. arboreum has purplish-red flowers, yields a particularly white cotton, and is cultivated in Egypt, Arabia and India. (3) G. herbaceum is distinguished by its broadly lobed leaves and yellowish flowers. This plant has been cultivated for over 26 centuries in Arabia and the East Indies, and since 1774 in the United States. Of this latter species there are a number of cultivated varieties. The bark of the root constitutes the cotton-root bark of medicine.

The seeds of the genus Gossypium contain a large percentage of fixed oil, which is obtained by expression and is official as CotTon seed oil. The residue is known as cotton seed oil-cake, and contains a considerable amount of proteins with a small quantity of oil and a poisonous principle, ricin. A fat resembling that of Cacao is obtained from the seeds of Pachira macrocarpa of Brazil ; Kapak oil is derived from the seeds of Eriodendron anfractuosum caribcum of the West Indies.

The flowers of some of the members of the Malvacex contain coloring principles, and have been used for dyeing, as Hollyhock (Althá rosea) and Mallow (Malva sylvestris). MUSK SEED or Amber seed, which is used in perfumery as a substitute for musk, is obtained from Abelmoschus moschatus indigenous to the East Indies and now cultivated in other tropical countries. Malva moschata also has the odor of musk, and is found in Middle and Southern Europe.

Saponin is found in the roots of Sida jamaicensis and Hibiscus Sab̉dariffa of the East and West Indies; Sida paniculata of Peru is used as an anthelmintic and the action is supposed to be due to the glandular hairs. The seeds of several members of this family are used as substitutes for coffee, as Abutilon muticum of Egypt, and Okra or Gumbo (Hibiscus esculentus). The leaves of Sida canariensis and S. retusa, the latter of India, have been substituted for tea leaves. The fruits of several of the members of this family are edible, as Hibiscus esculentus, which yields the vegetable okra, and $H$. ficulneus of Ceylon and Egypt, which are used like beans.

Fibers are obtained from a number of the other members of this family, as the bast fibers of Hibiscus tiliaceus of the Tropics, H. cannabinus of the East Indies, Urena lobata, Abutilon indicum, 
Sida retusa, and Napca lavis, all cultivated more or less in tropical countries.

d. FAMILI BOMBACE无.-This is a group of tropical trees yielding a variety of useful products. A gum is obtained from Bombax malabaricum, and mucilage is contained in the genus Ochroma and several species of Bombax. The root of Bombax malabaricum contains tannin in addition. The bast fibers of a number of the plants of this family are used like cotton in making fabrics, as species of Bombax, Chorisia and Adansonia. The fruits of several of the Bombaceæ contain tartaric acid, as the Sour Cucumber tree or CREam-of-TARTAR tree (Adansonia Gregorii) of Northern Australia; and the Monkey-bread Tree or ВАовав (Adansonia digitata) of India and South America, which attains a diameter of $9 \mathrm{M}$. The green fruit of Matisia cordata of the Andes region is edible. The seeds of Bombax insigne and Matisia Castaño of South America yield a product on roasting which is used like cacao bean. The seeds of Cavanillesia umbellata of Peru are edible and contain a considerable quantity of fixed oil.

e. STERCULIACE E OR COLA FAMILY.-The plants are herbs, shrubs or trees, sometimes lianes, with mostly simple, petiolate, alternate leaves; the flowers are small and form a rather complex inflorescence.

Theobroma Cacao is a small tree 5 to Io M. high, with coriaceous, glaucous, entire leaves, and clusters of brownish 5-merous flowers arising from the older branches or stem; the fruit is large, fleshy, ovoid, Io-furrowed longitudinally, yellow or reddish, and contains five rows of seeds, Io or I 2 in each row (Fig. 336). The seeds are ovoid, somewhat flattened, and with large, convoluted cotyledons which break up into more or less angular fragments on drying. The seeds contain 35 to 50 per cent. of a fixed oil known as CACAo BUTter and official as Oleum Theobromatis; I 5 per cent. of starch; I 5 per cent. of proteins; I to 4 per cent. of theobromine; 0.07 to 0.36 per cent. of caffeine, about 0.5 per cent. of sugar, and also a small amount of tannin. The red color of the seed is due to a principle known as cacao-red which is formed by the action of a ferment on a glucoside.

The Cacao tree is indigenous to the countries bordering the Gulf of Mexico and is now cultivated in many tropical countries. 


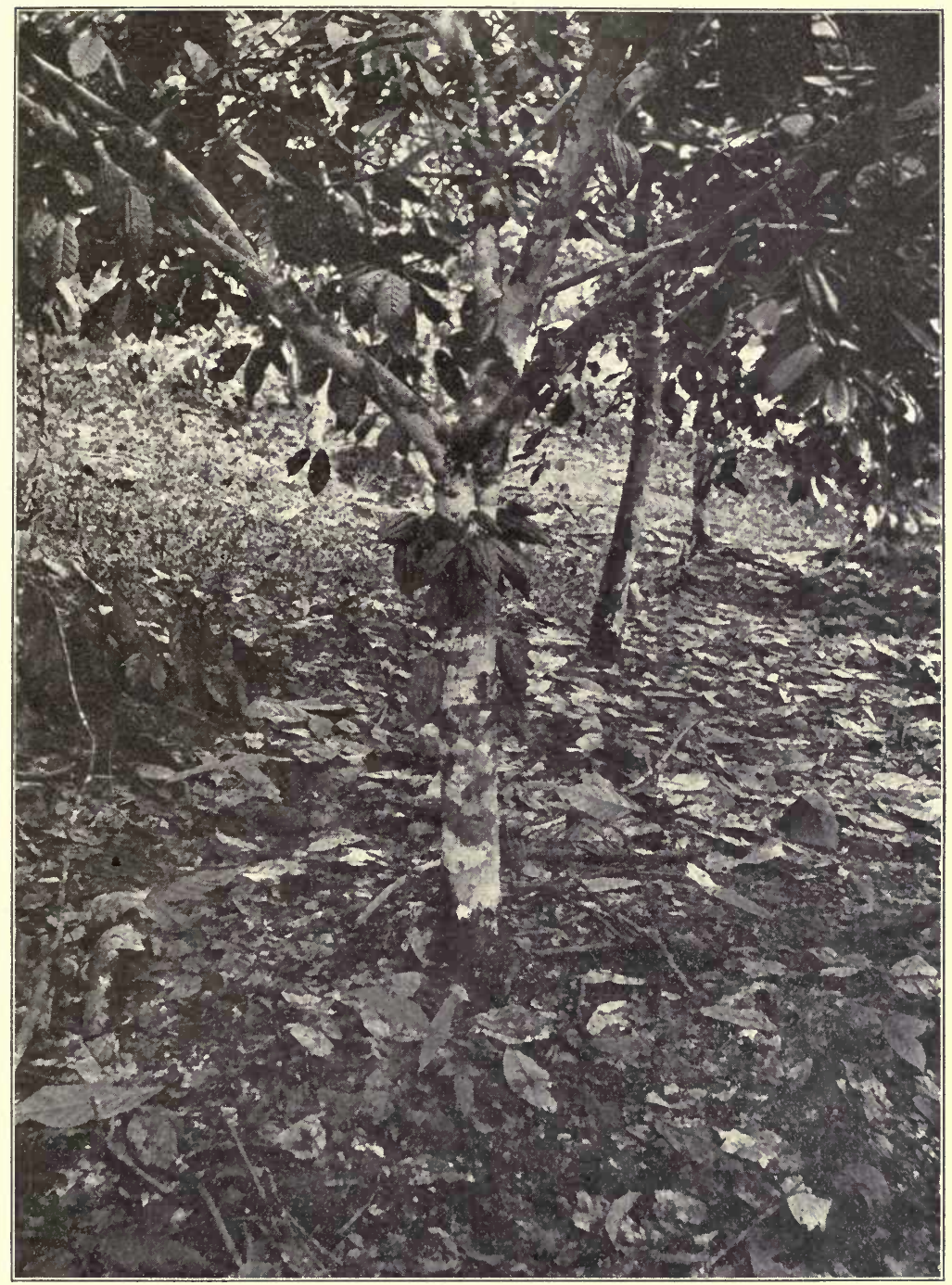

FIG. 336. Cacao tree (Theobroma Cacao), growing in Rio Hondo, Costa Rica. In the illustration is shown the peculiar habit of this tree in producing large, ovoid, fleshy fruits on the main axis or trunk, as well as on the older branches. When Cortez conquered Mexico he found the Aztecs using Cacao seeds to make a beverage; this was later introduced into Europe, previous to either coffee or tea.-Reproduced by permission of The Philadelphia Commercial Muscum. 


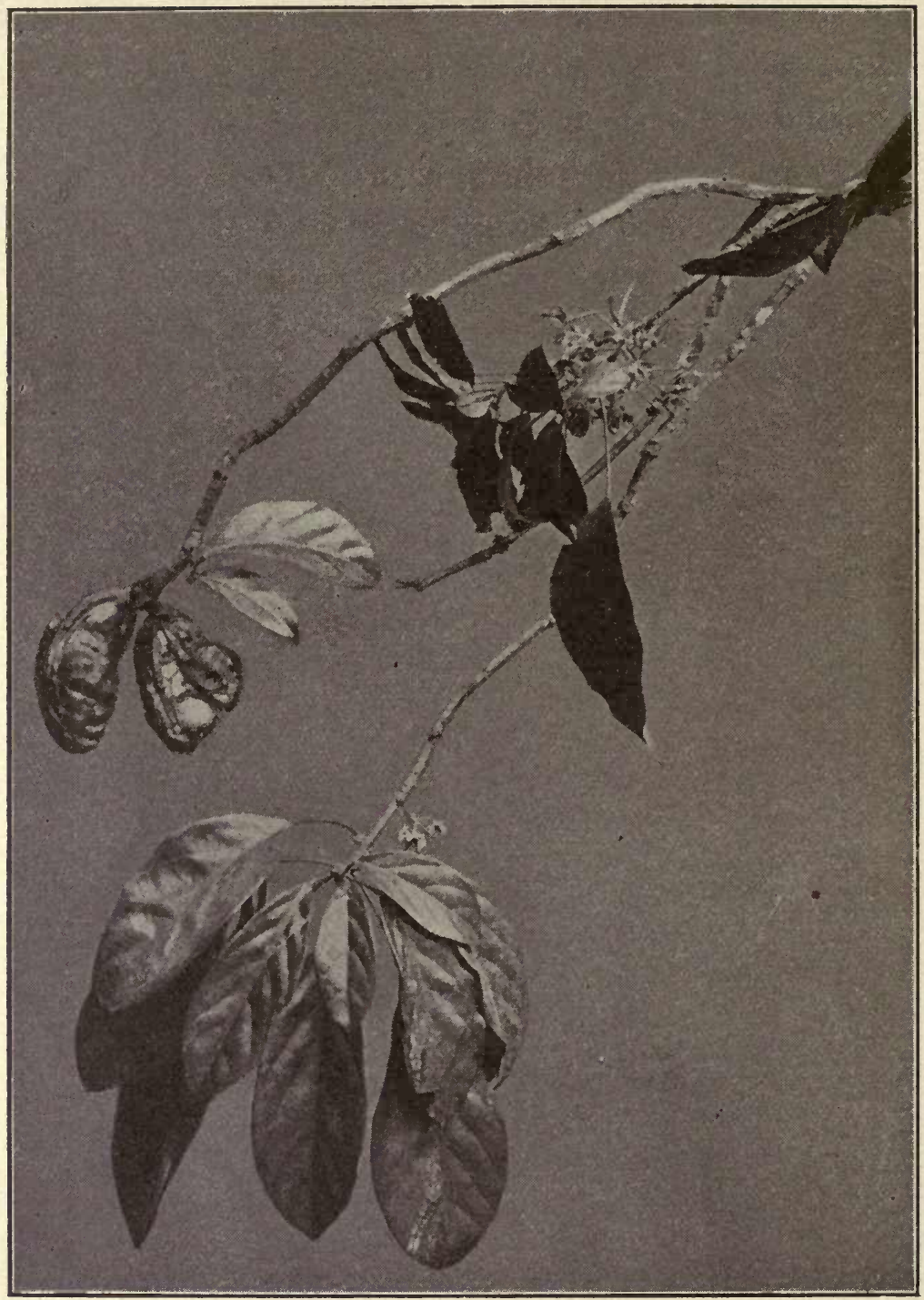

FIG. 337. A flowering branch of the Kola nut tree (Cola acuminata), growing in Trinidad. The leaves are obovate or lanceolate, acuminate, and in the axils are borne small clusters of purplish flowers. The tree is indigenous to Africa and is extensively cultivated in the West Indies and Brazil, in which countries it has become naturalized.-Reproduced by permission of The Philadelphia Commercial Museum. 
Most of the cacao of the market is obtained from Ecuador (the Guayaquil variety being especially valued), Curaçao, Mexico, Trinidad, and the Philippine Islands. The seeds of the wild plants contain a bitter principle, the quantity of which is found to be greatly reduced in the plants when under cultivation. The bitter principles in the raw product are more or less destroyed by the process of fermentation to which the seeds are subjected in preparing them for use, which at the same time develops the aroma.

Cola acuminata is a tree with lanceolate or obovate, acuminate, entire, petiolate leaves. The flowers are purplish, unisexual, and in small axillary clusters, frequently arising from the old wood; the fruit consists of five follicles, each containing 4 to 8 seeds. The seed is made up of two large, fleshy cotyledons. They have much the same constituents as Cacao, but the proportions of these differ (Fig. 337). The leaves of Waltheria glomerata are used as a hemostatic in Panama like matico, as are also the leaves of Pterospermum acerifolium. The inner bark of Fremontia californica is used for purposes similar to those of elm bark. Mucilage is also found in the following genera: Pentapetes, $W$ altheria, Guazuma, Helicteres, and Sterculia. Tannin is found in the bark of Guazuma ulmifolia of South America. An oil is manufactured from the seeds of Sterculia fotida of the East Indies and Cochin China. The seeds of a number of species of Sterculia are edible. Abroma angusta of India yields a fiber which has been suggested as a substitute for silk.

XIX. ORDER PARIETALES.

This is a group of plants of rather wide distribution, and includes perennial herbs like the violets; evergreen shrubs, such as the Tea Plant; and vines like the Passion flower. As the name indicates, the plants of this order are characterized by the flowers having, for the most part, ovaries with parietal placentas.

a. FAMILY DILLENIACEÆ.-The plants are mostly tropical trees which yield valuable timber. The wood of a species of Dillenia growing in the East Indies also contains red coloring substances. The fruits of Dillenia indica contain citric acid and are used like lemons. The leaves of Curatella americana contain considerable silicon and are used to polish wood. Dillenia speciosa 


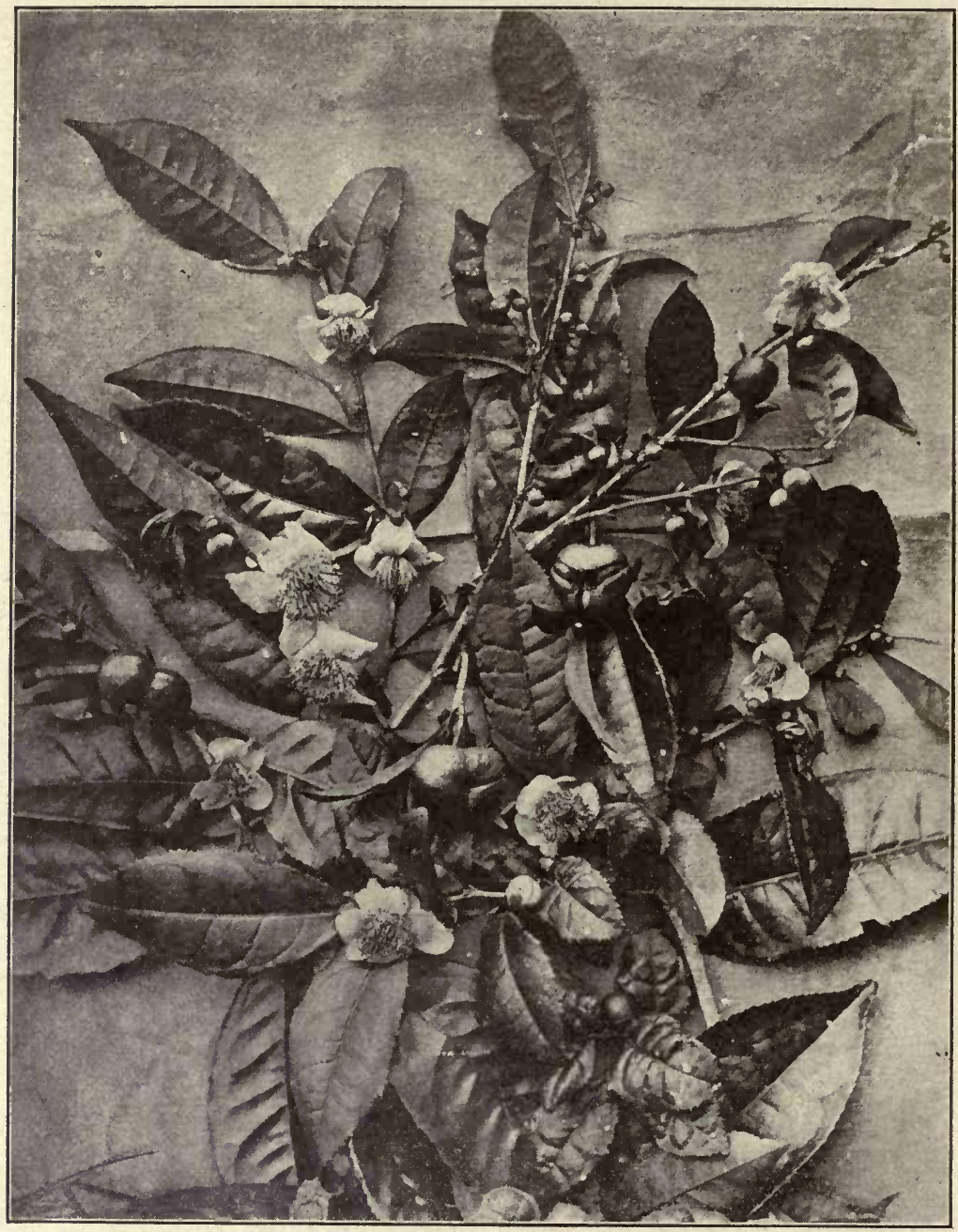

FIG. 338. Leaves, flowers, and fruits of the Tea plant (Thea sinenis, or Camellia viridis). The plant is a shrub or small tree bearing lanceolate, evergreen leaves, and in the axils occur the rather large, white, fragrant flowers. The fruits are small, globular capsules.-Reproduced by permission of The Philadelphia Commercial Museum.

of India contains a large percentage of tannin. Some species of Dillenia are cultivated and the foliage and flowers combine to make the plants the most beautiful in the plant kingdom.

b. MARCGRAVIACE无.-The members of this family are 
partly epiphytic, and have dimorphic leaves, the smaller ones being pitcher-like. The plant which is cultivated in greenhouses, Marcgravia umbellata, is used in the Antilles in medicine.

c. THEACEÆ OR TEA FAMILY.-The plants are shrubs or trees with alternate, evergreen leaves, and perfect, regular

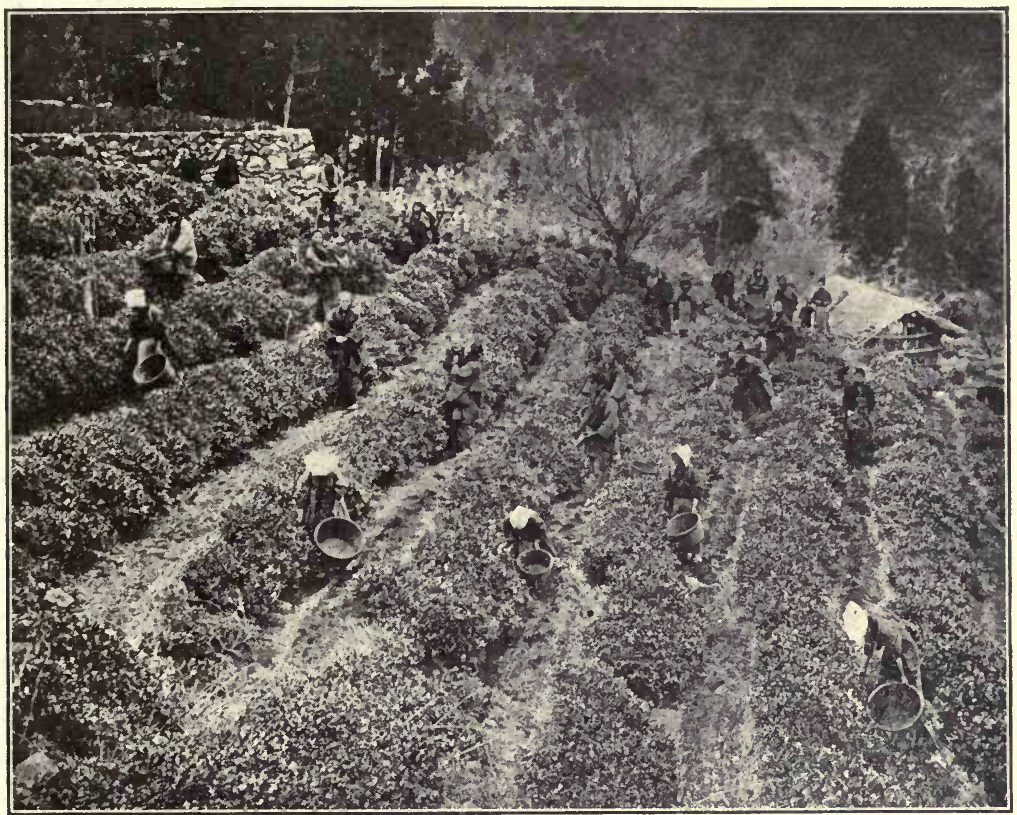

FIG. 339. Picking tea on a plantation in Japan, the wall at the left probably being the ruins of an ancient temple. While the plant ordinarily is a shrub, it is kept trimmed and is a bush from 2 to 5 feet high. The plants begin to bear in the third year, and continue to yield a commercial article from 3 to 7 years thereafter. The number of crops per year is determined by the geographical location. In the tropical fields of Ceylon, India, and Japan leaves are picked frequently, while in northern Japan they secure only one crop a year.-Reproduced by permission of The Philadelphia Commercial Museum.

flowers with numerous stamens, occurring one or more in the axils of the leaves. The fruit is a 3 - to 5-locular, dehiscent capsule. The most important member of this fanily is Thea sinensis, the two varieties viridis and Bohea furnishing the leaves known as TEA. The Tea tree is indigenous to Eastern Asia, and is now extensively cultivated in China, Japan, India, Java, Brazil, Sicily, Portugal and France, and to some extent in the Southern United States (Figs. 338, 339). 
The fresh leaves of Thea do not have the properties which characterize the commercial article, the aroma and other qualities being developed after special treatment. Two general classes of tea are found in commerce, these depending on the mode of treatment. Those which are rapidly dried by means of artificial heat constitute GREEN TEA. The leaves which are slowly dried, permitting fermentation to set in, furnish BLACK TEA. Tea leaves contain 1.5 to 3.5 per cent. of caffeine; theobromine and theophylline (an isomer of theobromine) ; Io to 20 per cent. of gallotannic acid; quercitrin, and a volatile oil containing, among other components, methyl salicylate. The seeds contain about 30 per cent. of fixed oil, I per cent. of caffeine, and saponin. The leaves furnish one of the sources of the official caffeine. Saponin is found in the seeds of Thea Sasanqua of China and Japan. Two saponin-like substances (assamin and assaminic acid) are found in the seeds of Thea assamica. The flowers of $T$. Sasanqua are used in China and Japan to flavor teas. The flowers and leaves of Thea kissi are used as an insecticide. The red colored sap of Laplacea Hamatoxylon of New Granada is used in medicine.

d. GUTTIFER $\mathrm{E}$ OR GAMBOGE FAMILY.-The plants are principally shrubs and trees of the Tropics, that is, if we exclude the Hypericaceæ which are now put in a group by themselves.

Garcinia Hanburyi is a tree with ovate, petiolate, coriaceous, opposite leaves. The flowers are small, yellow, diocious, occurring in small clusters in the axils of the leaves. The fruit is a pome-like berry, with a papery endocarp and an oily sarcocarp, and 3 or 4 seeds, I in each loculus (Fig. 340). The trees are chiefly valued on account of the gum-resin known as gamboge which they contain.

A resin used in making plasters is obtained from Calophyllum brasiliense of Brazil. Balsams resembling Copaiba have been obtained from Calophyllum Calaba of the West Indies. Balsams known as TACAMAHAC are also derived from the following plants: Bourbon Tacamahac from Calophyllum Tacamahaca, India Tacamahac from $C$. apetalum and Brazilian Tacamahac from Rheedia Madruno. Balsams are also obtained from Caraipa grandiflora 
of Brazil, and Rheedia acuminata of Peru. Resins and balsams are obtained from a number of species of Clusia.

A yellow coloring principle, mangostin, is obtained from the bark and fruit of Mangosteen (Garinia Mangostana) of the East Indies. Yellow coloring principles are found in Ochrocarpos

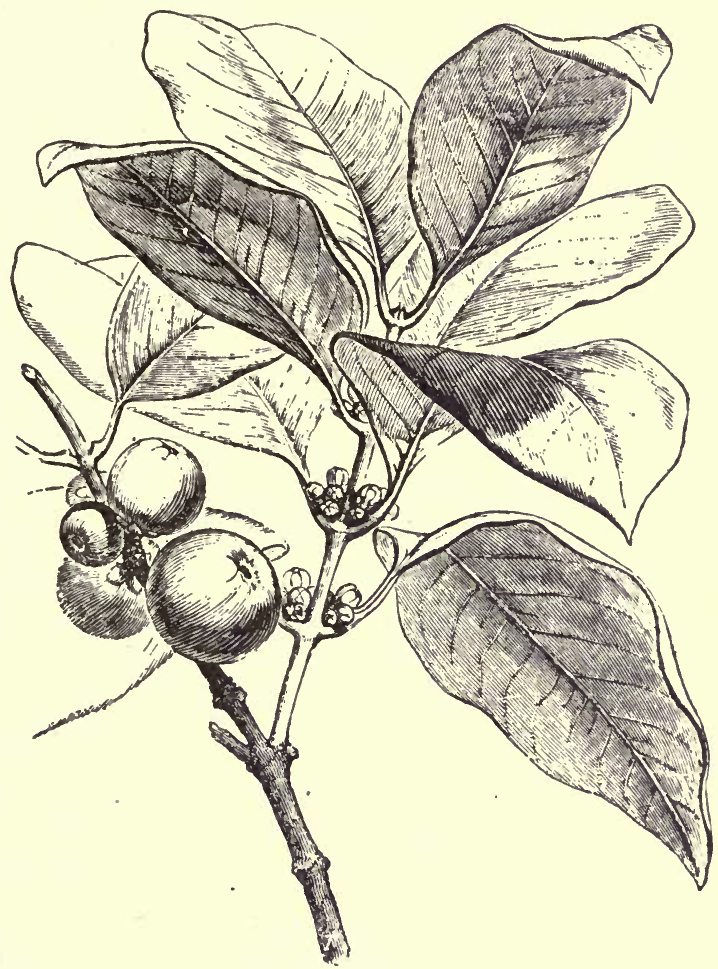

FIG. 340. Gamboge plant (Garcinia Hanburyi). A branch showing the axillary pistillate flowers and pome-like fruits.-After Baillon.

longifolius of India and Vismia acuminata of South America. Tannin occurs in Mahurea palustris of Brazil, Mesua ferrea of the East Indies, that flower-buds of Ochrocarpos longifolius of India, and several species of Cratoxylum of China and Java.

A butter-like fat is obtained from the seeds of Garcinia indica. A fixed oil known as LAUREL-NUT oIL is derived from the seeds of Calophyllum Inophyllum and other species of Calophyllum 
growing in the East Indies, Cochin China and Brazil, as well as the seeds of Symphonia fasciculata of Brazil.

The bark of Clusia pseudochina is used in Peru as a substitute for cinchona. An alkaloid is found in Vismia robusta of Java. A gum is obtained from Calophyllum tomentosum of India and Vismia acuminata, that of the latter being purgative. The flower buds of the India Suringi (Ochrocarpos longifolius) have an aromatic odor resembling cloves. Aromatic principles are also found in other plants of this family.

Edible fruits are yielded by the following plants: MaNGo FRUIT from Garcinia Mangostana and other species of Garcinia; Mammei Apple or Apricot of St. Domingo from Mammea americana of tropical America, the latter being used in the preparation of Mammey wine or "Toddy" and a liquor known as "Eau de Creole." The seeds of Platonia insignis are used like almonds in Brazil and Paraguay; the fruit of the latter plant is quite acid and is eaten with sugar.

e. HYPERICACE 1 OR ST. JOHN'S-WORT FAMILY.The plants are herbs or shrubs of the temperate regions, and are represented in the United States by the Hypericums, which are quite common. The flowers are characterized by the numerous stamens which are united into distinct groups or clusters. The flowers of Hypericum perforatum or Common St. John's-wort contain yellow and red coloring principles. Yellow coloring principles have also been isolated from Hypericum laricifolium of Ecuador and $H$. elodes of Northern Europe. The entire plant of $H$. perforatum is used in medicine and contains considerable resin, and a small amount of volatile oil.

f. FAMILY DIPTEROCARPACE E.-The plants of this family are principally trees and indigenous to tropical Asia. The family derives its name from the winged fruits of the principal genus Dipterocarpus. A number of economic products are furnished by this group of plants. BORNEO CAMPHOR is obtained from Dryobalanops aromatica. The camphor separates in canals in the older parts of the wood and between the wood and bark, and is obtained by felling the trees, splitting the wood, and then removing the camphor by hand. Owing to the fact that some of the trees do not contain camphor, it is sometimes necessary to fell 
a hundred trees in order to obtain 6 or $8 \mathrm{~K}$. of the product. The young twigs of this plant as well as the older wood yield a volatile oil known as Oil of Borneo camphor.

GURJUn BALSAM or Wood oil is obtained from a number of species of Dipterocarpus growing in the East Indies by incising the stems as in the collection of turpentine. The balsam is used as a substitute for copaiba and contains an ethereal oil which consists chiefly of a sesquiterpene, an indifferent resin, and gurjunic acid. Sindor BALSAM is obtained from Dipterocarpus marginatus of Borneo. A resin known as "Piney Resin," which is used as a substitute for Dammar, is obtained from a number of species of Vateria growing in India. CHAIA RESIN is obtained from Shorea rubifolia of Cochin China. The bark of Shorea robusta of Northern India contains 32 per cent. of tannin. The seeds of species of Shorea, Pinanga, Gysbertsiana and Isoptera yield the fatty oil known in Java as TANGKawang. The seeds of a number of plants of this family contain considerable starch, as Vateria, Vatica and Doona. The woods of the following genera are extensively used: Vatica, Shorea, and Hopea.

g. FAMILY TAMARICACEÆ.-The plants are halophytic shrubs found in the desert regions of Central Asia and Mediterranean countries and one genus (Fouquieria) is found in Mexico. Fouquieria splendens is cultivated to some extent, and is known as Ocotilla or Coach-whip Cactus. The bark contains gum, resin and wax; the latter is known as Ocotilla wAx and resembles beeswax. The twigs of Myricaria germanica of Europe are used as a substitute for hops. A manna-like sugar is formed on the stems of Tamarix mannifera growing in Egypt, Arabia and Afghanistan, as the result of the sting of an insect (Coccus manniparus). Tannin is found in a number of species of Tamarix as well as in the galls formed on the plants, the tannin being used for dyeing. A table salt is prepared from the ash of several species of Reaumuria found in Northern Africa and the East Mediterranean region.

h. FAMILY BIXACEÆ.-These are shrubs or trees found in the Tropics, and are of interest chiefly on account of the seeds of Bixa Orellana which furnish the coloring matter known as Annatro (Orlean, Arnotta). The plant is found in tropical 
America and also in Polynesia and Madagascar. The seeds are covered with a fleshy arillus from which the coloring matter is prepared by means of water. The insoluble matter is collected, made into cakes and chiefly used for dyeing and coloring. Annatto contains a red crystalline principle, bixin, a yellow coloring principle, orellin, and an ethereal oil. The root of this plant also contains some coloring matter. A yellow coloring principle is found in Cochlospermum tinctorium of Senegambia and an aromatic resin is obtained from Cochlospermum Gossypium of Ceylon and Malabar.

i. FAMILY CANELLACE王 OR WINTERANACE压These are trees with aromatic barks having an odor of cinnamon; pellucid-punctate leaves; and golden-yellow flowers. The most important member of this family is Winterania Canella growing in the Antilles and in Southern Florida, which furnishes the CANELLA BARK or False Winter's bark used in medicine. The bark occurs in large quills or broken pieces, from 3 to Io $\mathrm{mm}$. thick, with the periderm nearly entirely removed, the outer surface yellowish or orange-red with transversely elongated patches of cork and shallow, whitish depressions; the fracture is short with numerous resin canals; the odor aromatic; taste aromatic, bitter and pungent. It contains mannitol, resin and 0.5 to 1.28 per cent. of a volatile oil containing eugenol, cineol, caryophyllene and pinene. The bark of one or more species of Cinnamodendron of tropical America is sometimes substituted for Canella bark, but it is distinguished by containing tannin, which constituent is not found in Canella.

j. VIOLACE $Æ$ OR VIOLET FAMILY.-The plants are herbs or shrubs with basal or alternate leaves, perfect, irregular flowers, and 3-valved dehiscent capsules (Fig. 280, J). The best known representatives of this group are the cultivated species of the genus Viola, including the English or sweet violet (Viola odor$a t a$ ), which produces a volatile oil containing ionon; and the varieties of Viola tricolor vulgaris which furnish the pansies of the garden. The entire herb of Viola tricolor has been used in medicine and contains the yellow coloring principle viola-quercitrin, salicylic acid and methyl salicylate (Figs. 201, 232).

k. FAMILY FLACOURTIACEÆ. - These are tropical shrubs and trees, and are chiefly of interest because of their valuable woods and acid, juicy fruits. A number of them are of 
medicinal interest. Chaulmugra oil is said to be obtained from the seeds of Gynocardia odorata of Farther India. The seeds also contain gynocardic acid and hydrocyanic acid. The latter is also present in the seeds of Hydnocarpus venenata of Southern India and Ceylon and the leaves of Kiggelaria africana.

A number of species of Latia growing in Cuba yield a resin resembling sandarac. The Coccos oil which is used in perfumery is obtained from several species of Myroxvlon growing in Polynesia. The fixed oils from the seeds of Gynocardia oarorata and of several species of Pangium are used in cooking. A bitter principle occurs in the bark of Casearia adstringens of Brazil. A purgative principle is found in C. esculenta of tropical Asia and Australia. The root of Homalium racemosum of Guiana contains an astringent principle.

l. FAMILY TURNERACEÆ.-These plants are herbs, shrubs and trees mostly found in tropical America, and are of interest on account of the leaves of Turnera diffusa, particularly the variety aphrodisiaca, which yield the Damiana of medicine esteemed as a tonic laxative like Rhamnus Purshianus. The drug usually consists of leaves, although the reddish stems, yellowish flowers and globular capsules may be present. The leaves are about $25 \mathrm{~mm}$. long, varying from oblanceolate to obovate; the margin is serrate-dentate; the color, light-green (older leaves somewhat coriaceous and pubescent); the odor aromatic; taste aromatic and bitter. Damiana contains a volatile oil, resin, and the bitter principle damianin. Ethereal oils are found in other species of Turnera, and T. angustifolia of Mexico contains considerable mucilage.

$m$. PASSIFLORACE $A$ OR PASSION-FLOWER FAMILY.-The plants are mostly herbaceous or woody vines climbing by means of tendrils, with alternate, palmately-lobed, petiolate leaves and solitary, perfect, regular flowers. The flowers are peculiar in that between the corolla and stamens there are numerous, frequently petaloid, colored, sterile, filamentous bodies which are known collectively as the "corona." The fruit is a berry or dehiscent capsule. The genus Passiflora is known as the Passionflower because the flowers are considered to be emblematic of the Crucifixion, the corona representing the crown of thorns, the 
stamens the nails, and the gynæcium with its three styles, the three thieves. The rhizomes of the Passion-flowers of the Southern States (Passiflora incarnata and P. lutea) have been used in medicine. Not much is known with regard to the active principles of these two plants or of the thirty other species of Passiflora which are used in medicine. The fruits of several species of Passiflora are edible, and a number of them are cultivated on account of their beautiful as well as odorous flowers.

n. CARICACE $£$ OR PAPAW FAMILY.-This family is composed of two genera of latex-containing trees growing in tropical America, the best known of which is the genus Carica. The Papaw or Melon tree (Carica Papaya) is a small tree with a straight, slender, usually unbranched trunk which bears at the summit a cluster of long-petiolate, deeply-lobed leaves. The flowers are diœcious, and the fruit is a large, melon-like berry. The green fruits as well as the leaves contain a milk-juice which is obtained by incising them. The material is dried and is used in medicine on account of its containing a proteolytic ferment, papain or papayotin, which is active in the presence of both acids and alkalies. The leaves and fruit also contain the alkaloid carpaine, and in addition the leaves contain the glucoside carposid. The root contains a glucoside somewhat resembling potassium myronate and a ferment which has a decomposing action upon it. A proteolytic ferment is also present in the leaves of Carica quercifolia of Argentina. The melon tree is cultivated on account of the fruits, which are edible.

o. BEGONIACE E.-This is a family of tropical plants which are extensively cultivated. They are herbs or shrubs frequently with tuberous rhizomes and with characteristic, asymmetric, variegated leaves. They are easily propagated by cuttings, providing they have sufficient moisture, even the leaves giving rise to new plants. The roots of Begonia anemonoides of South America and $B$. gracilis of Mexico contain purgative principles. Calcium oxalate and acid oxalates are found in the leaves of probably all of the species of Begonia. The roots of a number of species of this genus are astringent.

p. DATISCACE正.-The plants are trees or shrubs found principally in the Tropics. A bitter principle is found in the 
Yellow hemp (Datisca cannabina) of Southern Europe and the Orient. The root contains a yellow coloring principle, datiscin, which is used in the dyeing of silk. The wood of Octomeles and Tetrameles is used in the making of tea-chests.

\section{ORDER OPUNTIALES.}

The plants of this order are succulent, with much reduced leaves, and with flowers characterized by having a perianth with numerous segments and an inferior ovary.

a. CACTACE E OR CACTUS FAMILY.-This is a remarkable family of succulent plants growing largely in the arid regions of Mexico, Brazil and other parts of America. The stems are more or less flattened, terete or tuberculated, in some cases becoming branched and woody. The leaves are reduced to scales, but are sometimes larger, more or less cylindrical or dorsiventral, and usually drop off sooner or later. In the axils of the leaves or leaf-scars there are usually groups of hairs and spines. The flowers are mostly solitary, sessile, perfect, regular and conspicuous. The fruit is usually a fleshy berry, the fruits of a number of species being edible.

Quite a number of the Cacti have been used in medicine, the one most commonly employed being the Night-BLooming CEREus (Cereus grandiflorus), which is extensively cultivated on account of its flowers. The flowers and fresh stems are the parts used. They contain several acrid principles, including probably an alkaloid and a glucoside, the drug resembling in its action digitalis.

Mescal buttons (Anhalonium) are the dried tops of several species of Lophophora growing in Northern Mexico. The main axis of the plant is under the ground and produces at certain points small aërial shoots which are more or less button-shaped or disk-like, being about 20 to $50 \mathrm{~mm}$. in diameter. In the center of the disk occur tufts of hairs which vary in the different species, and among which are usually found one or more pinkish flowers. The drug has been used like Night-blooming Cereus, and contains several alkaloids, namely, anhalonine (similar to pellotine), mescaline, anhalonidine and lophophorine. Alkaloidal principles are also found in other members of this family.

The sap of several species of Cereus of the Antilles has anthel- 


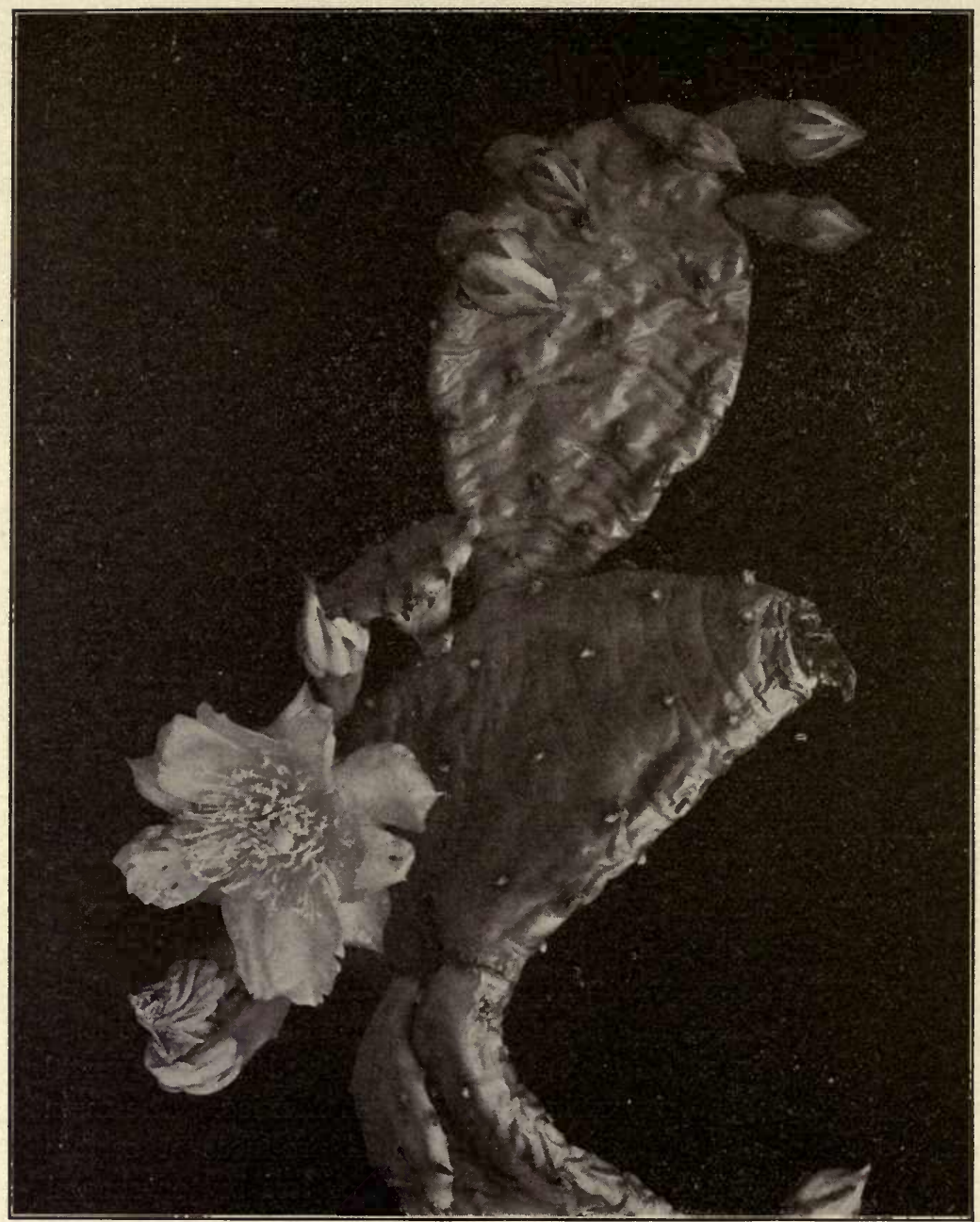

Fig. 34r. Prickly Pear or Indian Fig (Opuntia vulgaris), a prostrate, more or less spreading cactus, composed of flattened stems bearing very small, awl-shaped and deciduous leaves and short, yellowish-green bristles and occasionally solitary spines. The flowers are pale yellow, opening in the sunshine. The fruit is a succulent berry about $2.5 \mathrm{~cm}$. long. Various of these cacti are used as food by the cattle, which often eat them with the bristles. Frequently the spines are burnt off by the cattlemen with the use of gasolene torches, so as to prevent the accumulation of spines in the stomachs of the cattle in the form of phyto-bezoars, which are globular accumulitions of vegetable tissues. (See p. 577.) After Troth. 
mintic properties, as also that of certain species of Rhipsalis and Opuntia. A caoutchouc-like exudation is obtained from Opuntia vulgaris and other species of Opuntia growing in the West Indies. An astringent principle is found in the root and bark of Opuntia Karwinskiana of Mexico. A tragacanth-like gum is found in Peireskia Guacamacho of Venezuela, Opuntia rubescens of Brazil and O. Tuna of the West Indies, Mexico and South America. An alcoholic beverage is made by the Indians of Sonora from the fruit-juice of Cereus Thunbergii.

A number of species of Opuntia yield edible fruits. The PrICkLy PEAR is the fruit of Opuntia Tuna growing in the West Indies and tropical America; Indian FIG is derived from Opuntia Ficus-Indica growing in Southern Europe, particularly Sicily; a fruit also known as Prickly pear or Indian fig is derived from Opuntia vulgaris, a common Cactus growing in sandy soil in the Eastern United States. The Cochineal insect which is official under the name of coccus in a number of pharmacopœias (Coccus Cacti) feeds upon various of the Cactacece, more especially the Nopal plant, Nopalea (Opuntia) coccinellifera, a native of Mexico and Peru. (See Kraemer, Amer. Jour. Pharm., I9I3, p. 344.)

\section{ORDER MYRTALES OR MYRTIFLORA.}

The plants are herbs or shrubs with complete flowers, rarely apetalous, producing one or more ovules in each loculus.

a. THYMEL EACE $Æ$ OR MEZEREUM FAMILY.-The characters of this family are illustrated by the Spurge laurel or Mezereon (Daphne Mezereum), which is a small shrub about I M. high, with oblong-lanceolate, acute, entire, sessile leaves, and small groups of fragrant flowers, the perianth tube of which is purplishred or white. The fruit is an ovoid, reddish drupe. The bark of Daphne Mezereum and other species of Daphne is used in medicine.

The bark of Funifera utilis of Brazil contains a vesicating principle. A principle with similar properties is found in the bark of Leather wood (Dirca palustris) of the Eastern United States and Canada. The fruit and leaves of Gnidia carinata of Cape Colony contain emetic and drastic principles. A poisonous principle is found in Pimelea trichostachya of Australia. A 
yellow coloring principle is found in several species of Daphne and Thymelaa. The wood of Aquilaria Agallocha of India and China is aromatic and resembles the "Aloe wood." A balsam is obtained from the wood of Pimelea oleosa of Cochin China. The bast fibers of quite a number of plants are used in the making of paper, as of Daphne in India, Gnidia of Madagascar, Lagetta ( $L$. lintearia or Lace-tree) of Jamaica and St. Domingo, Thymelca of the Mediterranean countries and Linodendron of Cuba. The fibers of Leather wood (Dirca palustris) of the Eastern United States and Canada are said to be used in a similar manner.

b. FAMILY ELÆAGNACEA.-This is a small family represented in the United States by several genera, among which is the Buffalo berry (Lepargyrca argentea), a thorny shrub found in the western part of the United States and the Northwest Territory. The fruit is a reddish drupe-like berry which contains a small amount of citric and malic acids, 5 per cent. of sugar, and in composition is much like the currant. It is eaten by the Indians, and used to a great extent in the Western States in the making of jellies. The leaves and flowers of a number of species of Elæagnus are used in medicine.

c. LYTHRACEA OR LOOSESTRIFE FAMILY.-The members of this family are herbs, shrubs and trees usually with opposite, entire leaves. The flowers are in racemes and the fruit is a capsule. Quite a number of the plants yield valuable woods and a number are cultivated as ornamental plants.

The flowers of Woodfordia floribunda of India contain a red coloring principle, and the bark and leaves of Lafonsia Pacari of Brazil contain a yellow coloring principle. Considerable tannin is found in the root of the Purple loosestrife (Lythrum Salicaria) of the Northern United States and Canada, and widely distributed in the Old World; and also in the fruit of Woodfordia floribunda, a plant which is extensively cultivated in greenhouses. A bitter principle, nessin, is found in the leaves of Nesca syphilitica of Mexico and probably other species of this genus. Cuphea viscosissima of Mexico is said to resemble digitalis in its physiological action. A vesicating principle, resembling cantharidin in its action, is obtained from the fresh leaves of Ammannia baccifera of India. A narcotic principle is found in the seeds of Lager- 
stromia Flos-regince of India. The flowers of Lawsonia inermis, native to and cultivated in the Orient, have an odor resembling that of the Tea rose. The shrub is also cultivated to some extent in the West Indies and is known in the Orient as the Henna PLAnt. The leaves are used in the preparation of the cosmetic Hinna. They contain an orange or brownish-yellow dye which is used in the dyeing of the skin and hair.

d. PUNICACE $\mathrm{E}$ OR POMEGRANATE FAMILY includes a single genus of two species. The Pomegranate (Punica granatum) indigenous to the Levant and now extensively cultivated is of chief interest. The plants are small trees, the young twigs of which are 4-angled and frequently thorn-like. The leaves are opposite, ovate-lanceolate, entire and short-petiolate. The torus, calyx and corolla are scarlet, and the gynæcium consists of two whorls of carpels. The fruit is an inferior edible berry with a hard pericarp or rind. The pulpy portion is formed from the outer layer of the seed-coat. The bark of the root and stem is used in medicine ( see Granatum, Vol. II). The rind of the fruit is used as an astringent because of the tannin which it contains. It does not appear, however, to contain the alkaloids found in the official bark.

$e$. FAMILY LECYTHIDACEÆ.-The plants are mostly shrubs and trees indigenous to the Tropics. They are of chief interest on account of the BRAZIL-NUT (Fig. 342) obtained from Bertholletia excelsa, and the Sapucaya-nut obtained from the Monkey-pot tree (one or more species of Lecythis), both genera of South America. The seeds (so-called nuts) are rich in oil and proteins and are edible. The fruit of Careya arborea is drupaceous and is also edible, the seeds being considered, however, to be poisonous. Bitter narcotic or poisonous principles are also found in the fruit of Planchonia valida of the Molucca Islands and the seeds of a number of species of Lecythis. The fruits and roots of a number of species of Barringtonia are used in China and Java to stupefy fish. The pericarp of the fruit of Fotida moschata of Guiana contains considerable quantities of an ethereal oil. The flowers of Grias cauliflora of the Antilles are used like tea. A cooling drink is made from the sarcocarp of Couroupita guianensis of the West Indies and Guiana 
f. RHIZOPHORACEÆ OR MANGROVE FAMILY.These are tropical shrubs or small trees with evergreen, coriaceous leaves, small cymose and axillary flowers, and seeds which germinate while the fruit is still attached to the plant. The best

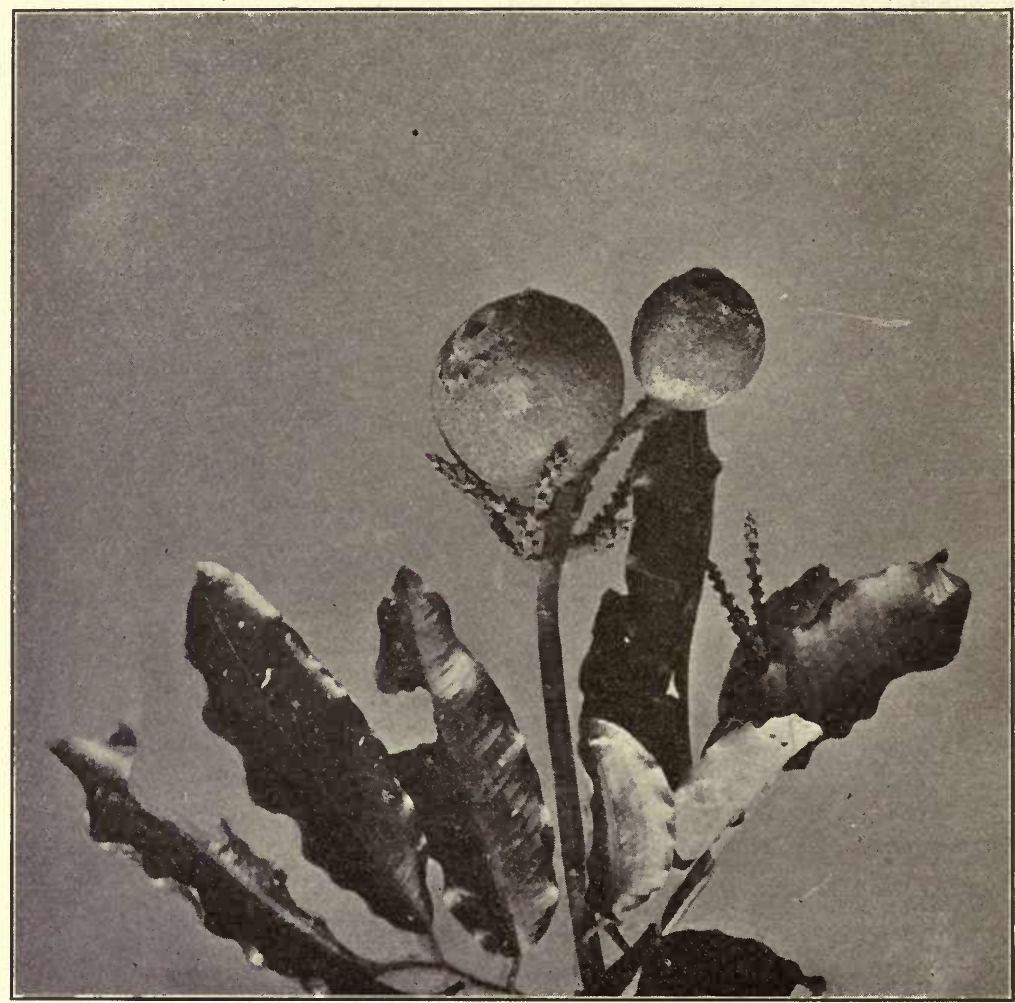

Fig. 342. Brazil-nut (also known as Para nut, cream nut, and nigger-toe), the seeds of Bertholletia excelsa, a Brazilian tree belonging to the Fam. Myrtaceæ. In the illustration is shown a portion of the fruiting branch with some of the long, leathery leaves. The fruits terminating the branches are woody, vary from ro to $15 \mathrm{~cm}$. in diameter, and are in the nature of a pyxis,-i.e., opening by means of a lid. It encloses about 20 brownish-gray, 3 -sided seeds, which are largely exported from Para.-Reproduced by permission of The Philadelphia Commercial Museum.

known genus of this family is Rhizophora (Mangrove tree), of which there are three species, the American Mangrove being $R$. Mangle. This tree produces aërial roots on the stems and branches, and leaves which are characterized by a number of layers of 
water-containing cells. The plants grow in muddy swamps, or along the sea-coast where the water is brackish, a number together forming the so-called "Mangrove swamps" (Fig. I65).

The root and bark of the Mangrove, as well as other species of Rhizophora and several species of Bruguiera, contain a large quantity of tannin which resembles catechu. The aërial roots of Rhizophora are used by the natives of Polynesia in the making of bows, and the woods of several genera are used in carpentry.

g. MYRTACE $Æ$ OR MYRTLE FAMILY.-This is a group chiefly of shrubs and trees, some, as of species of Eucalyptus, being the loftiest trees known, attaining a height in some instances of I05 M. The plants are indigenous to Australia and tropical America and some are extensively cultivated.

Eucalyptus species.-The leaves frequently vary in shape and in arrangement on the young and older branches of the same plant. On the young branches they may be, as in Eucalyptus Globulus, ovate or broadly elliptical, opposite and sessile, while on older branches they are scythe-shaped, glandular-punctate, glabrous, petiolate and alternate. In the latter case the petioles are twisted and the leaves stand edgewise so that both surfaces are equally exposed to the light and hence of similar structure. The flowers are solitary, or in cymes or umbels, occurring in the axils of the leaves. Petals are wanting and the whitish stamens, which are numerous and inflexed in the bud, are covered by an operculum or lid which is considered to be formed by the union of the sepals, and which dehisces on the maturing of the stamens, this being one of the most characteristic features of the genus. The fruit is a 3 - to 6-locular truncated capsule or pyxis.

This is a very important genus from an economic point of view, among the products being the volatile oil (oil of eucalyptus), and eucalyptol, both of which are official, and the tannin or so-called “gum,” known as Eucalyptus kino.

Jambosa Caryophyllus (Eugenia caryophyllata).-This is a small tree indigenous to the Molucca Islands and now extensively cultivated in the Tropics. The leaves are opposite, ovate-lanceolate, acuminate, petiolate, entire and evergreen. The flowers are rose-colored and in cymes; the fruit is berry-like and constitutes the Anthophylli or Mother-Clove. The unexpanded flower-buds 
constitute the drug or spice known as Cloves. (See Vol. II.)

Pimenta officinalis is a tree with opposite, lanceolate, acute, petiolate, pellucid-punctate and evergreen leaves. The flowers are small, white and in axillary racemes. The fruit, known as "Allspice," is used for flavoring.

Not only are ethereal oils obtained from the genera Eucalyptus, Jambosa and Pimenta already described, but also from other members of the Myrtaceæ. OIL of BAY or oil of Myrcia is distilled from the leaves of Pimenta acris of the West Indies. The oil consists largely of eugenol, methyl-eugenol, chavicol, methyl-chavicol, citral, phellandrene and myrcene, and is used in the preparation of BAY RUM. The fruits of $P$. acris yield $3 \cdot 3$ per cent. of an oil resembling the leaf oil.

Cheken leaves are obtained from Eugenia Chekan. They are about $25 \mathrm{~mm}$. long, ovate or rectangular, with entire, somewhat revolute margin, light green, pellucid-punctate, aromatic, astringent and bitter. Cheken leaves yield about I per cent. of a volatile oil containing cineol and pinene; 4 per cent. of tannin; a volatile alkaloid and a glucoside.

Oil of Cajeput is obtained from the leaves and twigs of Melaleuca Leucadendron, particularly the varieties Cajeputi and minor of the East Indies. The principal constituents of this oil are cineol, terpineol, pinene, and a number of aldehydes and acid esters. An oil resembling Cajeput oil is obtained from the leaves and flowers of Myrceugenia camphorata of Chile.

The leaves of Myrtus communis, a plant extensively cultivated in the Mediterranean countries of Europe, yield a distillate with water known as EAU D'ANGE and used as a toilet article.

The leaves of the following plants are used as substitutes for tea leaves: Myrtus Molince of Chile, Melaleuca genistifolia of Australia, and Leptospermum scoparium and other species of this genus growing in New Zealand. The seeds of Eugenia disticha are known in the Antilles as Wild coffee. Quite a number of the genera of this family yield edible fruits. GuAva or Guayava fruit is obtained from Psidium Guajava of tropical America. Rose APPLE is the fruit of Jambosa malaccensis, growing in the East Indies and Oceanica. JAMBUSE BERRIES are derived from Jambosa vulgaris which is extensively cultivated in the Tropics. The 
lemon-like fruit of Myrcia coriacea is used in medicine, the bark in tanning, and the wood in dyeing. The fibrous bark of Eugenia ligustrina is used like oakum.

$h$. FAMILY COMBRETACE E.-The members of this family are shrubs or trees, sometimes climbing; with usually alternate, petiolate, simple leaves; sessile flowers in racemes; somewhat fleshy, winged, I-seeded fruits, and are mostly found in the Tropics.

Like the Fagaceæ the plants of this family contain a tannin, similar to gallotannic acid, in nearly all parts of the plant. The Myrobalans of the East Indies are the young fruits of Terminalia Chebula. The pericarp contains from 5 to 45 per cent. of tannin, the latter amount being found in the fruits known as Long or Chebula Myrobalans. The fruits also contain ellagic and chebulinic acids. The fruits of Terminalia Bellerica constitute the Beleric Myrobalans. The galls of Terminalia macroptera of Africa and other species of Terminalia as well as of Bucida Buceras of tropical America are particularly rich in tannin. A yellow coloring principle is found in Terminalia Brownii of Africa and is used in dyeing leather. The bark of T. Catappa of Asia and Africa is used to dye leather black.

A gum-resin with cathartic properties is obtained from Terminalia fagifolia of Brazil. An aromatic resin is found in Terminalia angustifolia of the East Indies. The fruits of one or more of the Combretaceæ are said to be used in the preparation of the arrow-poison of the Negritos. The seeds of Terminalia Catappa and Combretum butyrosum contain about 50 per cent. of fixed oil. These seeds as well as those of other species of Terminalia and Quisqualis indica of Farther India and tropical Africa are edible. The seeds of the latter plant when unripe are said to be used like mustard. The woods of a number of the plants of the Combretacex are valuable for building purposes, and some of the genera furnish ornamental plants which are cultivated in greenhouses.

$i$. FAMILY MELASTOMATACEA.-This is a large family of herbs, shrubs, and trees with opposite, $3^{-}$to 9-nerved leaves and regular, perfect, often showy flowers. They are chiefly found in South America and are represented in temperate regions by 
the Meadow beauty (Rhexia). Quite a number of the plants are cultivated and a large number yield edible fruits. The fruits, barks and leaves frequently contain COLORING PRINCIPLES. A yellow coloring principle is found in the leaves of a number of species of Memecylon of the East Indies and Africa, which resembles that of saffron and curcuma. Red coloring principles are found in the berries of a number of species of Blakea of South America. A black coloring principle is obtained from the fruit of several species of Tamonea of tropical America, Melastoma malabathricum of the East Indies and Tococa guianensis of Northern South America and Tibouchina Maximiliana of Brazil. Tannin is found in considerable quantity in the barks of Tibouchina, Dissotis and Rhynchanthera.

The leaves of Tamonea thecaans are used in Peru as a substitute for tea. A mucilage is found in the bark of Medinilla crispata of the Molucca Islands. The flowers of the latter plant as well as of $M$. macrocarpa are used as a remedy for the bite of poisonous serpents.

$j$. ONAGRACE $\mathrm{E}$ OR EVENING PRIMROSE FAMILY. -These are mostly annual or perennial herbs with usually entire or toothed, simple leaves. The flowers are perfect, regular or irregular, epigynous, variously colored, solitary in the axils of the leaves or in somewhat leafy spikes. The fruit is a dehiscent capsule, berry, drupe, or nut. This family is represented in temperate regions by such plants as the Willow herb (Epilobium), Evening primrose (Enothera), on which de Vries has carried on his famous mutation experiments, and Enchanter's nightshade (Circæa). The cultivated Fuchsia also belongs to this family. A yellow coloring principle is obtained from the herb and unripe fruits of Jussieua pilosa of Brazil. The roots of Enothera biennus, O. muricata and other species of this genus are edible.

This family also includes the group of aquatic plants, represented by a single genus and one of which, Trapa natans or Water chestnut, is naturalized to some extent in the ponds of Massachusetts and New York. The fruit is coriaceous, 2- to 4 -spinose, and I-seeded. The cotyledons are unequal, rich in starch, and are edible, sometimes being ground and made into bread by the people of Europe and Northern Asia. 


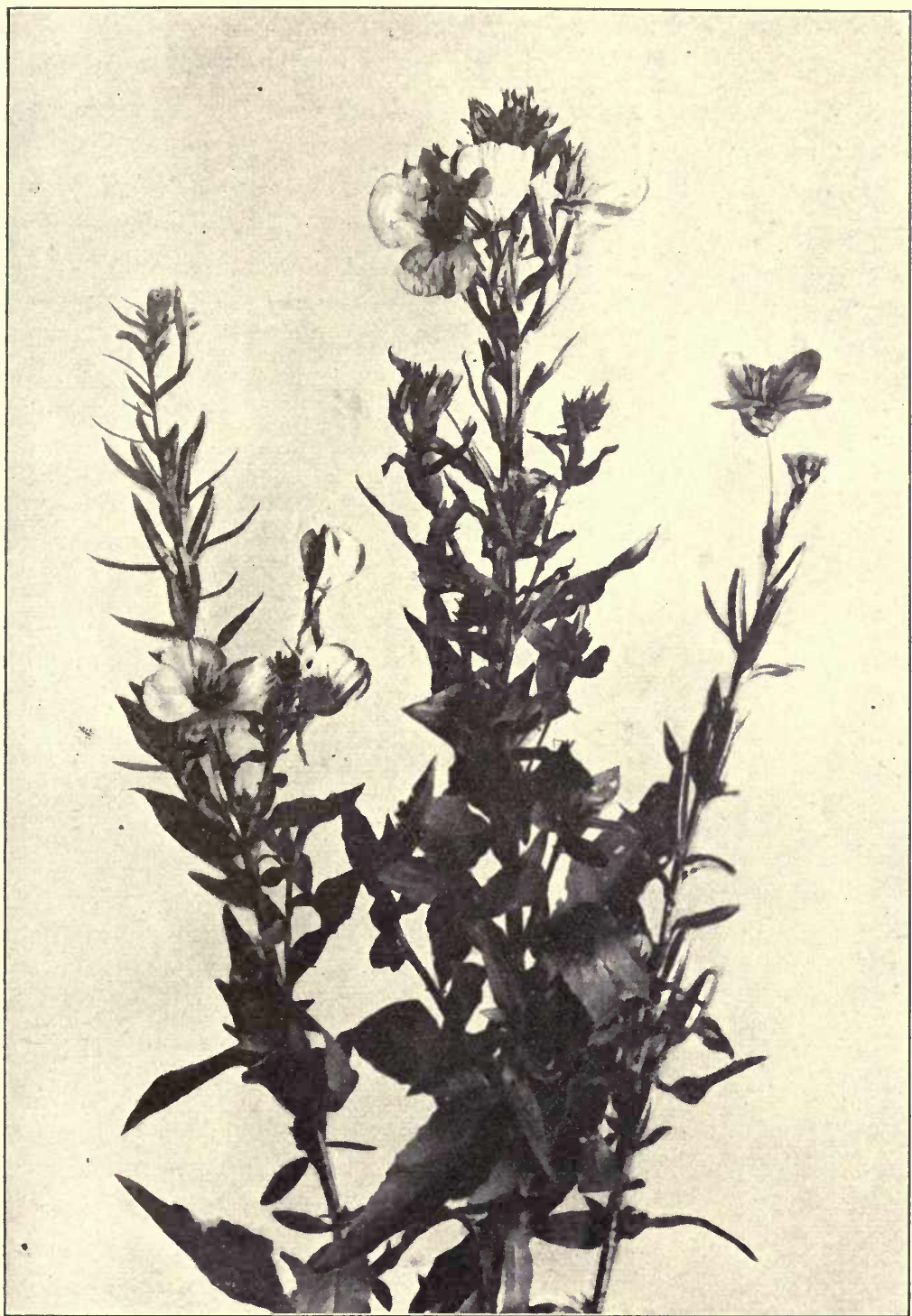

Fig. 343. Evening Primrose (Enothera biennis), a simple, sometimes more or less branching herb growing to a height of 3 to $15 \mathrm{dm}$. The leaves are lanceolate or oblonglanceolate; the flowers are symmetrical, with yellow petals; and the capsules are narrow and 4-valved. This plant is one of the commonest of the Enotheras, growing in open places. It is a biennial like the other species, but it is possible for horticulturists to develop its life history in one year.-After Brown. 
XXIII. ORDER UMBELLALES OR UMBELLIFLORÆ.

The plants of this order are widely distributed in northern temperate regions, although there are some representatives in the Tropics. The flowers are small, 4- or 5-merous and epigynous.

a. ARALIACE $\approx$ OR GINSENG FAMILY.-The plants are mostly trees or shrubs with alternate, petiolate, simple or $3^{-}$to 7 -compound leaves. The flowers are either in umbels or panicles. The fruit is a drupe or berry. The best known representatives of this family are the English ivy (Hedera Helix) of Europe, and Ginseng (Panax quinquefolium) (Fig. 345) growing in the Eastern and Central United States. This plant is the source of the ginseng root of commerce, considerable quantities of which are exported to China, where it is used like the root of Panax Ginseng, a plant growing wild in Manchuria and Korea. Both plants are also cultivated in the United States, the roots from the wild plants being preferred. The root contains a volatile oil, and considerable starch. Several species of Aralia are used in medicine (Fig. 344).

The leaves of the English ivy contain the glucoside helixin, and a carbohydrate, inosit. They also contain formic, oxalic, malic, tannic and hederic acids, besides the yellow principle carotin. The fruits of the ivy contain a purplish-red coloring substance and are said to be poisonous.

The Chinese RICE PAPER is made from the pith of Tetrapanax papyriferum, which grows wild in Formosa and is extensively cultivated in China. .The pith is cut spirally into thin strips, which are spread out flat and then cut into pieces varying from $I_{5}$ to $30 \mathrm{~cm}$. long and ro to $12 \mathrm{~cm}$. broad. This paper differs from other papers in that it is a natural product.

The rhizome of Panax repens, growing in Japan, contains 20.8 per cent. of a non-toxic saponin with hemolytic properties.

b. UMBELLIFER $Æ$ OR CARROT FAMILY.-The plants are herbs, frequently with hollow stems; alternate, simple or compound leaves, the base of the petiole often forming an inflated sheath; and small white, yellowish, greenish or somewhat purplish flowers occurring in simple or compound umbels. The fruit is a cremocarp, having characters which are of important taxonomic 
value, as the presence or absence of secondary ribs, number and position of the vittæ, etc.

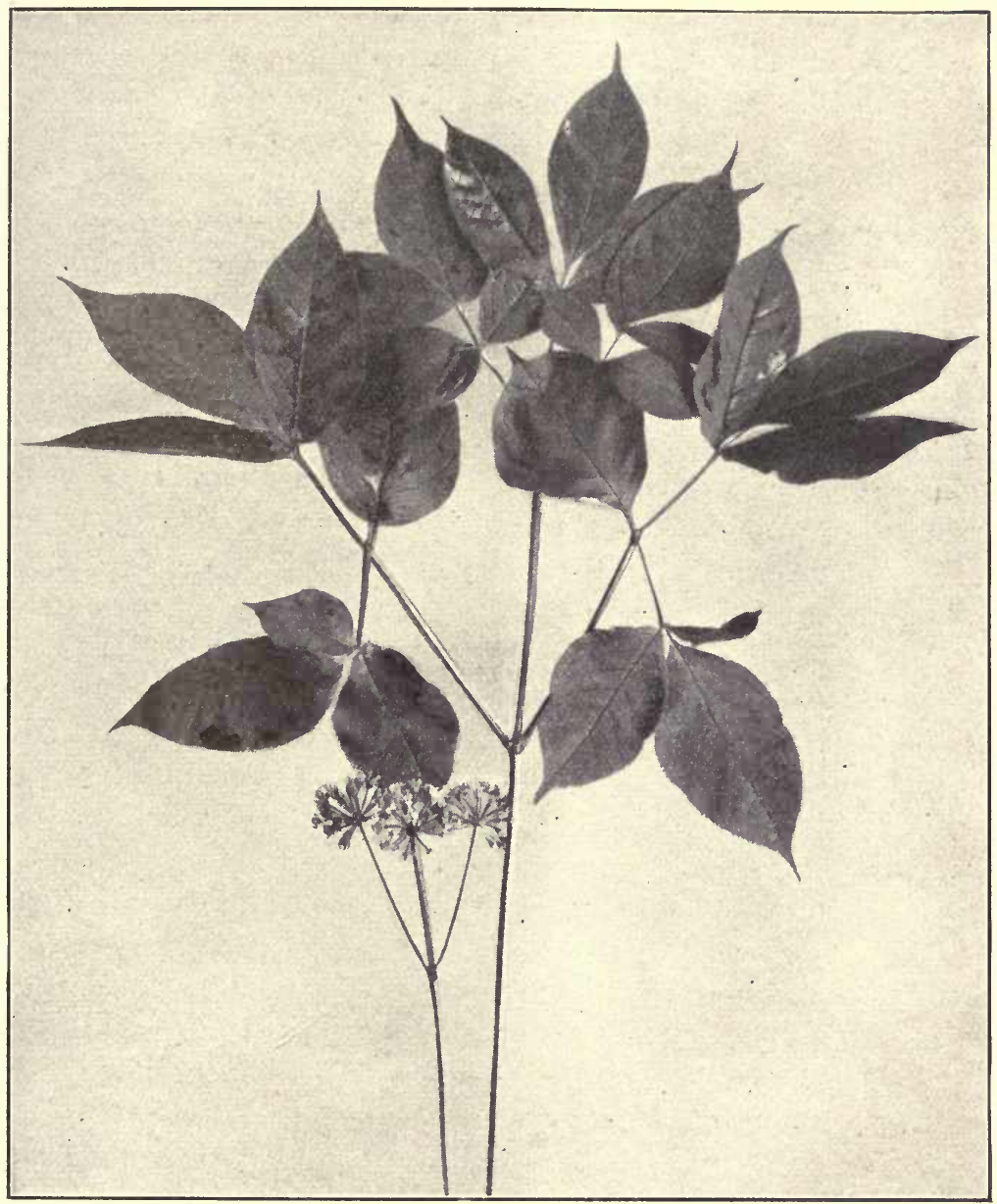

FIG. 344. Wild Sarsaparilla (Aralia nudicaulis). The plant produces a long, cylindrical rhizome at or near the surface of the ground, and sends out at various points a single, long-stalked compound leaf, and a shorter, naked scape bearing 2 to 7 umbels of greenishwhite flowers. The rhizome is sold as American Sarsaparilla, but it has none of the constituents of the true Sarsaparilla.-After Brown.

Coriandrum sativum is an annual herb the fruits of which are official. The compound leaves are bi- or tri-pinnate, the leaflets 
being narrow linear-lanceolate; and the flowers are white or rosecolored.

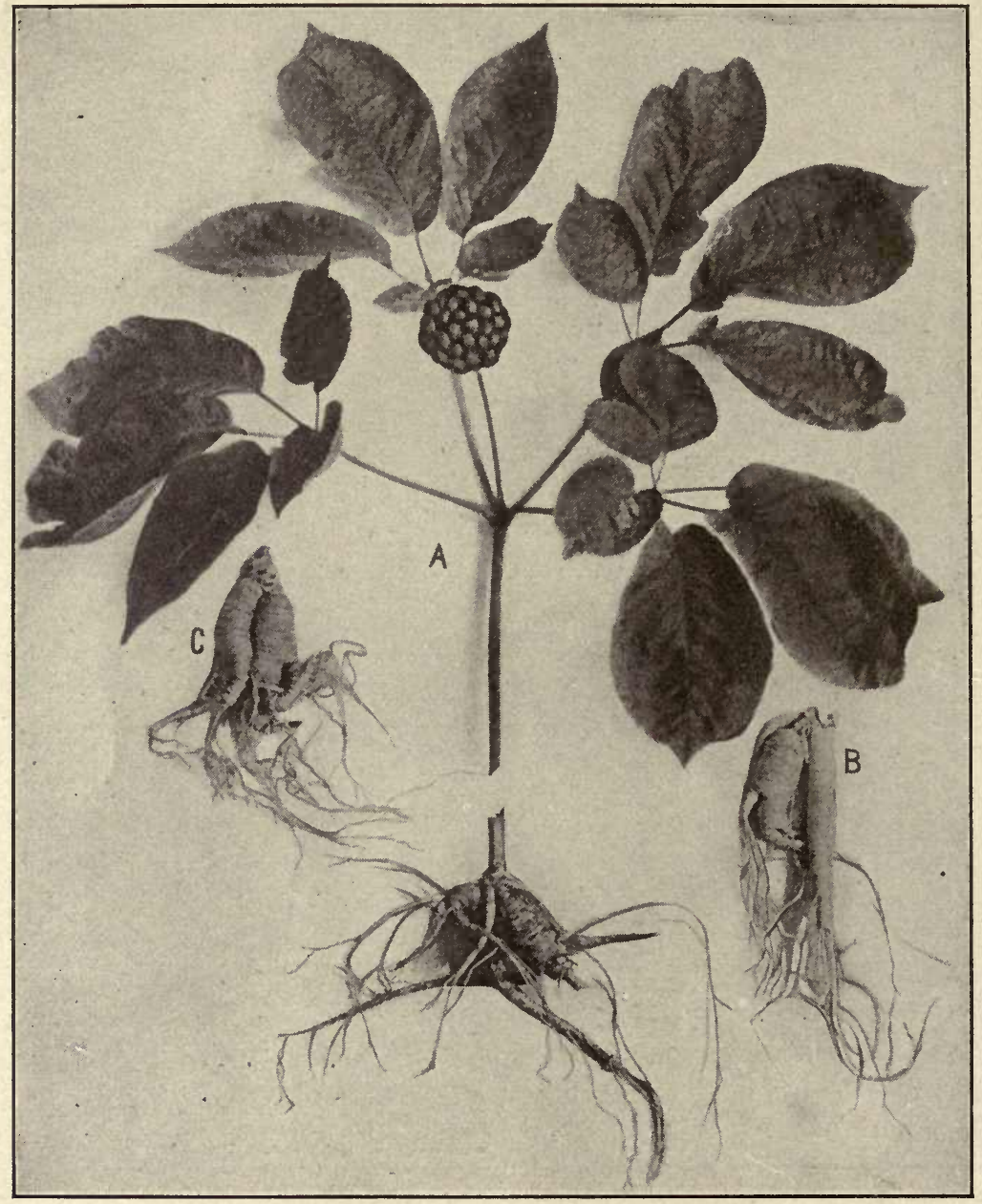

FIG. 345. Panax quinquefolium (Ginseng): A, upper portion of plant showing palmately-compound leaves with long-stalked leaflets and the berry-like drupes; B, fusiform root; C, roots showing characteristic stem scars at the upper portion.-From a photograph by Wyss. (See also Fig. I66, p. 305.)

Conium maculatum or Poison Hemlock is a tall, erect, branching, biennial plant, with purplish spotted stems, large pinnately 
decompound leaves and small, white flowers (Figs. 346, 347). The fruit as well as the leaves is used in medicine.

Carum Carvi (Caraway) is a biennial herb with bi- or tripinnate, deeply incised leaves, and white flowers. The fruit is official and the leaves are also used in medicine.

Pimpinella Anisum is a small, hairy, annual herb. The leaves are variable, the lower being somewhat cordate and serrate, the middle distinctly lobed, and the upper ones trifid; the flowers are white. The fruit is official and is also used for flavoring.

Foniculum vulgare is an annual or perennial, glabrous herb with very finely dissected leaves, the divisions being narrow-linear. The flowers are yellow, and the involucre and involucels are wanting. The fruit is official.

Ferula foctida is a stout, perennial herb with few, ternately compound leaves and small, polygamous, light yellow flowers. The root is rather large and yields the gum-resin asafetida. Asafetida is also derived from other species of Ferula.

Ferula Sumbul is a tall perennial herb with purplish latexcontaining stems. The basal leaves are ternately compound and with amplexicaul base. The leaves decrease in size from the base upward, becoming bract-like near the inflorescence. The flowers are polygamous, resembling those of $F$. fotida. The root is official and is probably also obtained from other closely. related species of Ferula.

A large number of the plants belonging to the Umbelliferæ contain essential oils, resins, gum-resins and related substances. The gum-resin AMMONIAC is an exudation found on the stem and branches of Dorema Ammoniacum and other species of Dorema as a result of the sting of an insect. The plant is found in Western Asia. The gum-resin occurs in yellowish-brown, globular, or somewhat flattened tears which are brittle, milky-white internally, with a distinct balsamic odor and bitter, acrid, nauseous taste. It contains a small quantity of volatile oil having the odor of Angelica. AFRICAN AMMONIAC is obtained from Ferula tingitana growing in Northern Africa and Western Asia.

The gum-resin GALBANUM is obtained by incising the root of Ferula galbaniflua and other species of Ferula growing in the Levant. Galbanum occurs in pale yellowish-brown agglutinated 


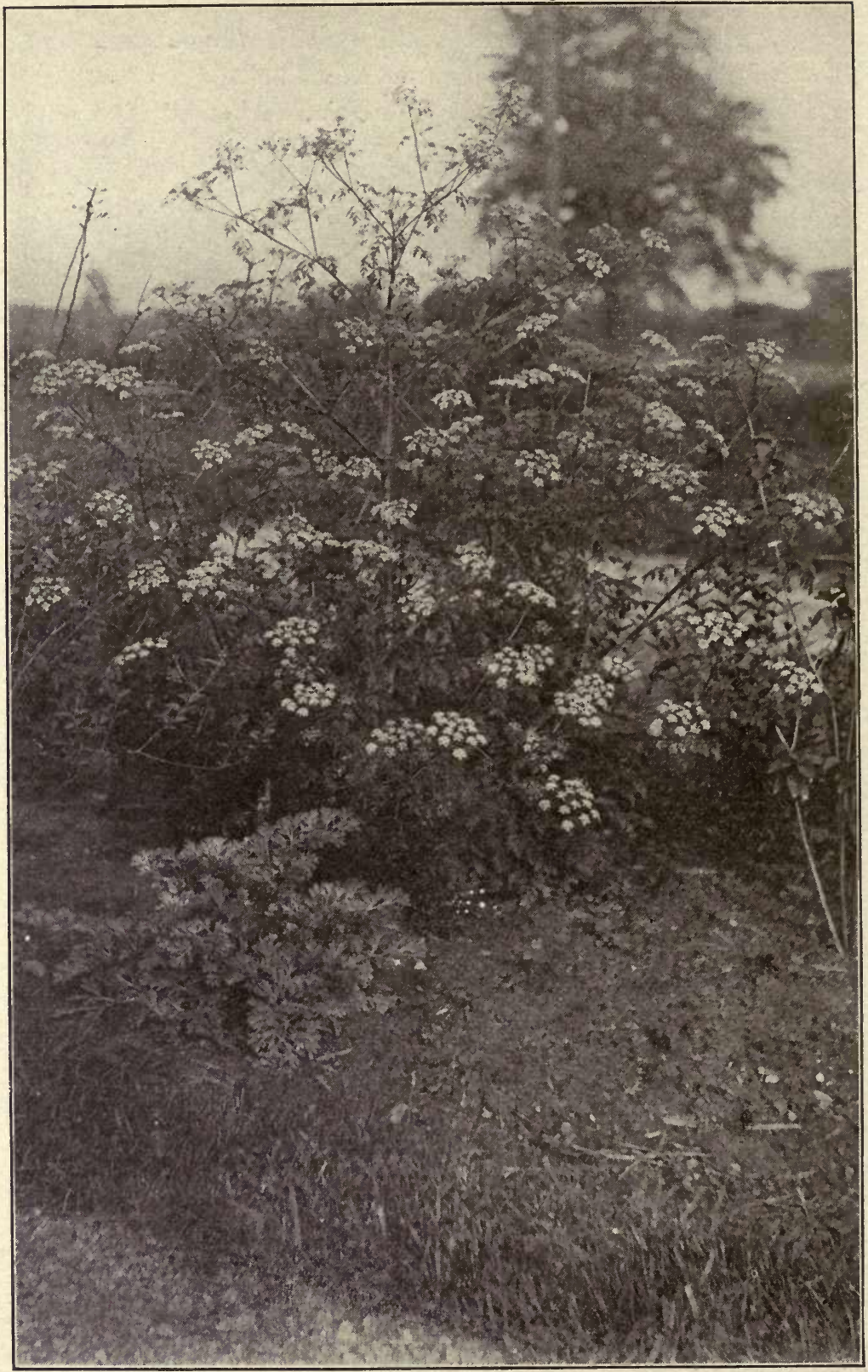

FIG. 346.-Poison Hemlock (Conium maculatum), showing the spreading habit of the plant and the prominent large compound umbels of flowers.-After Bornemann. 


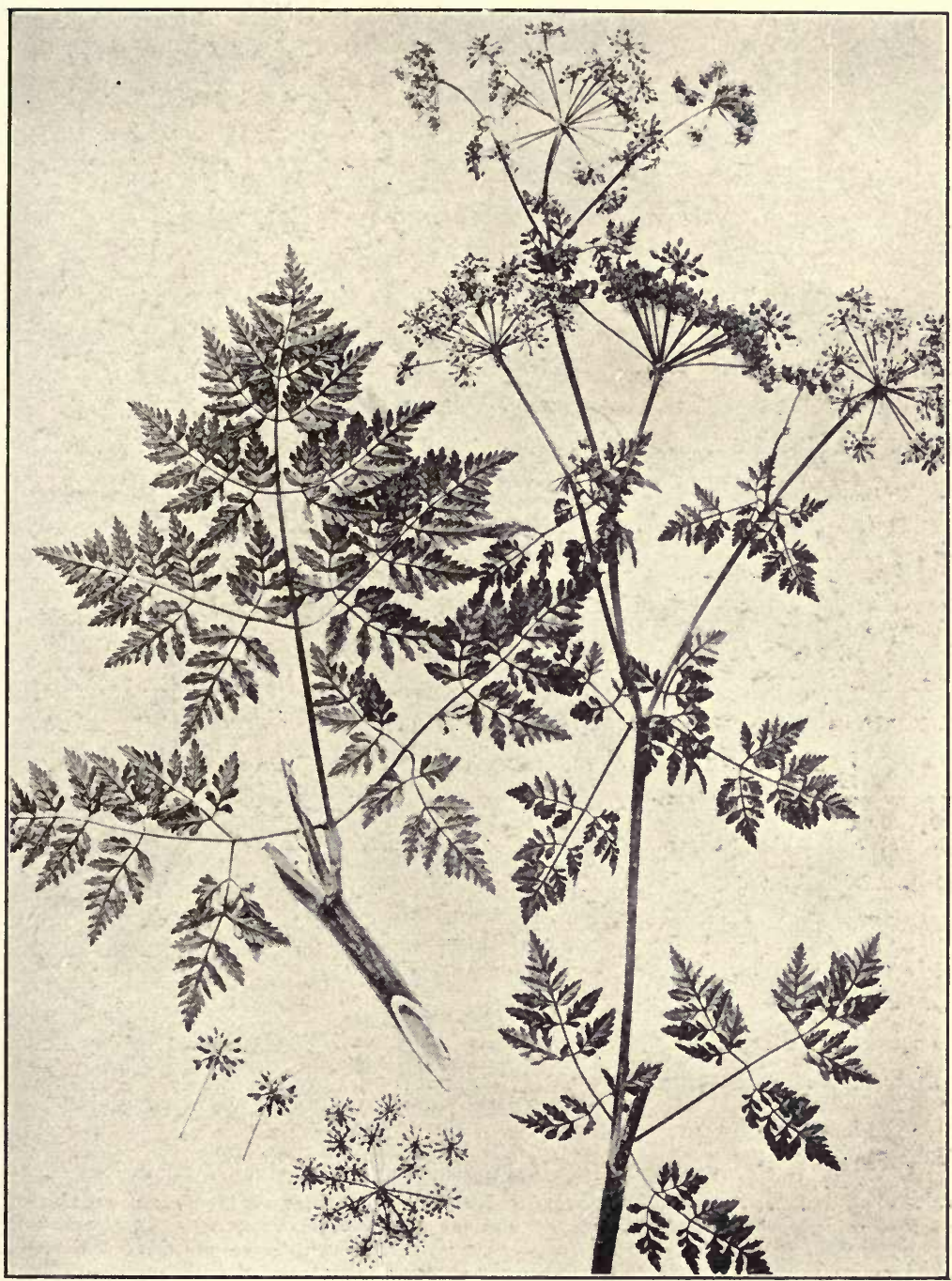

FIG. 347. Conium maculatum, showing the large decompound leaves with pinnatifid leaflets, and the compound umbels of flowers, with detached, enlarged views of umbels and a compound umbel.-From Bulletin No. 26, U. S. Department of Agriculture.

The fresh juice of Conium maculalum was used in the preparation of the famous hemlock potion which was employed by the Greeks in putting their criminals to death. This is not the same plant under the name of Conium which is referred to in Roman and mediæval Latin literature, the latter being Cicuta virosa, which does not grow in Greece and in Southern Europe. 

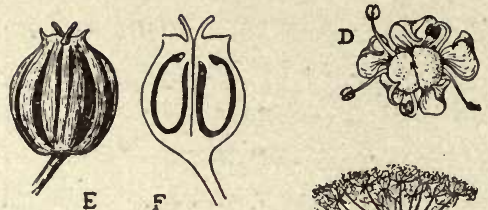

E

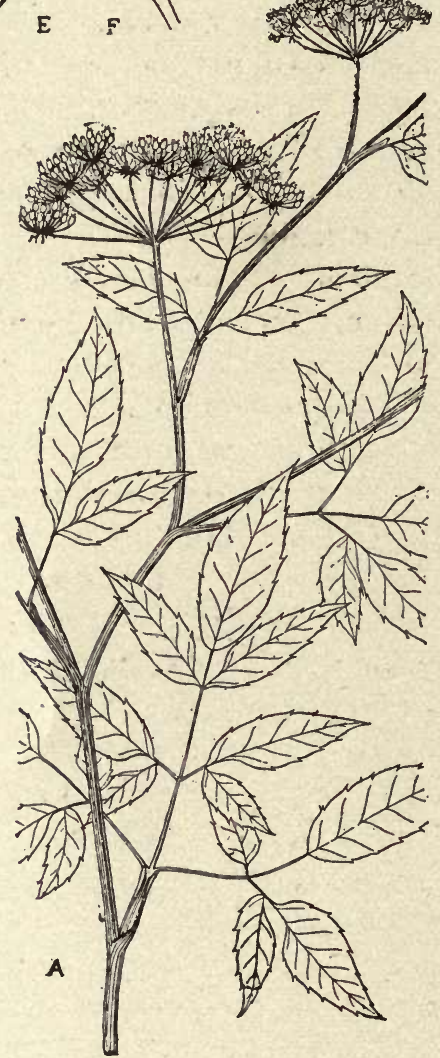

FIG. 348. Cicuta maculata (Water Hemlock): A, upper part of stem with leaves and compound umbels; B, base of the stem and the thick tuberous roots; C, cross-section of stem showing part of a mestome-strand and the pith with secretory cells (a), vessels (v), libriform (St), pith (p); D, a flower showing petals with long inflexed summit and the five stamens inserted on the disk that crowns the ovary; E, the fruit; F, fruit in longitudinal section showing the two ovules; G, cross-section of a mericarp showing the six vittæ or oiltubes.-After Holm.

tears, forming a more or less hard mass, which is brittle when cold but soft and sticky at $37^{\circ} \mathrm{C}$.; the odor is distinct, balsamic; the taste bitter and acrid. It contains from to to 20 per cent. of a volatile oil composed of d-pinene, cadinene, and other principles. 
A volatile oil, known as AJowaN oIL, and containing thymol, is obtained from the fruit of Carum Ajowan of Europe, Asia and Africa. A volatile oil containing APIOL is found in the fruit and leaves of the garden parsley (Petroselinum sativum). Dill orl is obtained from the garden Dill (Anethum graveolens). The fruit of Sweet cicely (Washingtonia longistylis) yields a volatile oil known as sweet anise oil, which contains anethol. The oil of water fennel (Enanthe Phellandrium) contains about 8o per cent. of phellandrene. CUMIN oIL is obtained from Cuminum Cyminum of Turkestan and Egypt, and contains cymene.

The roots of a number of the plants of this family contain volatile oils, as Lovage (Levisticum officinale) of Southern Europe; European angelica or garden angelica (Angelica Archangelica); American angelica or the purple-stemmed angelica (A. atropurpurea) found in the Northern and Eastern United States and Canada; Wild angelica (A. sylvestris) of Europe.

c. CORNACE无 OR DOGWOOD FAMILY.-The plants are shrubs or trees with simple, opposite leaves, and flowers in cymes or heads, which in the case of the Flowering dogwood (Cornus florida) are subtended by four large, petal-like, white, or pinkish bracts. The fruit is a I- or 2-seeded drupe.

The bark of Cormus florida, a shrub or small tree growing in the United States, contains a bitter principle, cornin; and a small quantity of gallic and tannic acids.

Aucuba japonica, a plant indigenous to the Himalayas, China and Japan and extensively cultivated on account of its crimson berries, contains a glucoside aucubin. It is found in the different: varieties and varies in amount from 0.3 I to 1.96 per cent.

\section{METACHLAMYDE $A$ OR SYMPETALÆ.}

This is the highest group of plants and is marked by the following characters: The corolla is sympetalous; the flowers are mostly perigynous or epigynous and both the corolla and stamens are borne on the perianth tube. The number of parts is definite, there being 5 sepals, 5 petals, 5 or ro stamens and 2 or 5 carpels. This sub-class includes but six orders, to which, however, belong a large number of medicinal and economic plants. 


\section{ORDER ERICALES.}

The plants of this order are distinguished by the fact that the stamens are mostly free from the perianth tube.

a. PIROLACEA.-The plants are small, mostly evergreen perennials, and are represented in the United States by several genera.

Chimaphila umbellata (Prince's pine or Pipsissewa) is a small trailing or creeping plant producing distinct flower- and leafbranches. The leaves are used in medicine. The flowers are in small corymbs and the petals are white or pinkish. In Chimaphila maculata the leaves are lanceolate, mottled with white along the veins and the flowers are considerably larger.

With the Pirolaceæ are sometimes grouped the saprophytic plants of the genus Monotropa. There are two representatives of this genus which are common in the United States, namely, Indian pipe (Monotropa uniflora) and false beech-drops (M. Hypopity's). The latter contains a glucoside or an ester of methyl salicylate, and a ferment gaultherase (Fig. 349).

b. ERICACE $Æ$ OR HEATH FAMILY.-This is a large family and the plants are widely distributed, especially in the northern mountainous parts of both the Eastern and Western Continents. They vary from perennial herbs to trees. The flowers are usually regular, the stamens being mostly 2-spurred (Fig. $22 \mathrm{I}, S)$, and the fruit is either a superior or inferior drupe or berry (Fig. 28o, $H$ ).

Arctostaphylos Uva-Ursi is a low branching shrub which trails or spreads on the ground. The leaves are used in medicine (Fig. 355). The flowers are small, white or pink, few and in short racemes. The fruit is a red, globular drupe.

Trailing arbutus (Epigca repens) is a trailing, shrubby, hairy plant with broadly elliptical or ovate, coriaceous, evergreen leaves and white or rose-colored, fragrant flowers which are either perfect, with styles and filaments of varying length, or diœcious. The leaves contain similar constituents to those in Uva-Ursi and Chimaphila (Fig. 353).

The leaves of wintergreen (Gaultheria procumbens) are the source of true oil of wintergreen, which consists almost entirely 


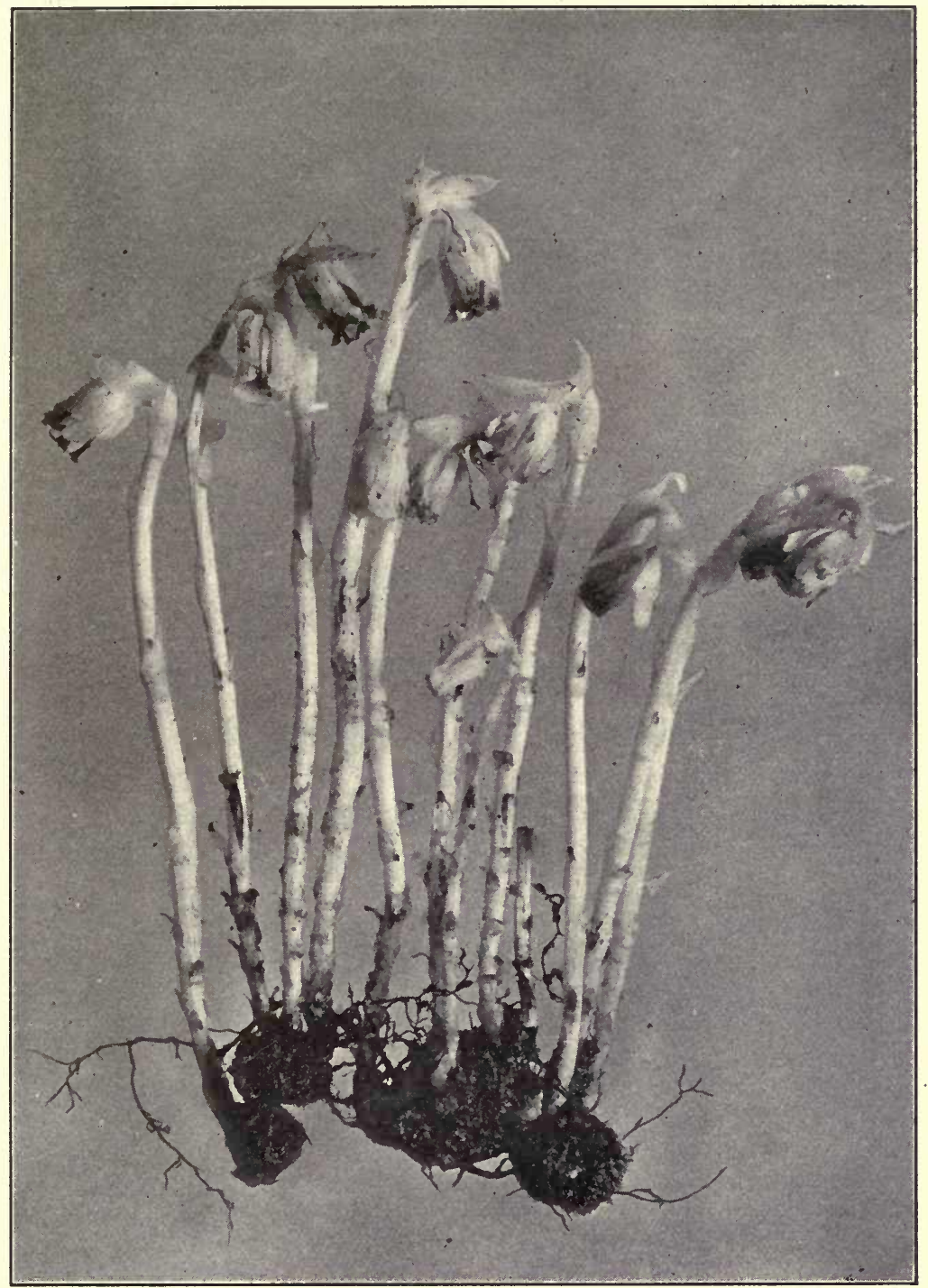

FIG. 349. Indian Pipe (Monotropa uniflora), a parasitic plant of the Ericaceæ growing on roots of various plants and on decomposing vegetable matter. The stems are white or yellowish-red, furnished with scales or bracts in place of leaves, and surmounted usually with a single nodding flower becoming in fruit erect.-After Troth. 


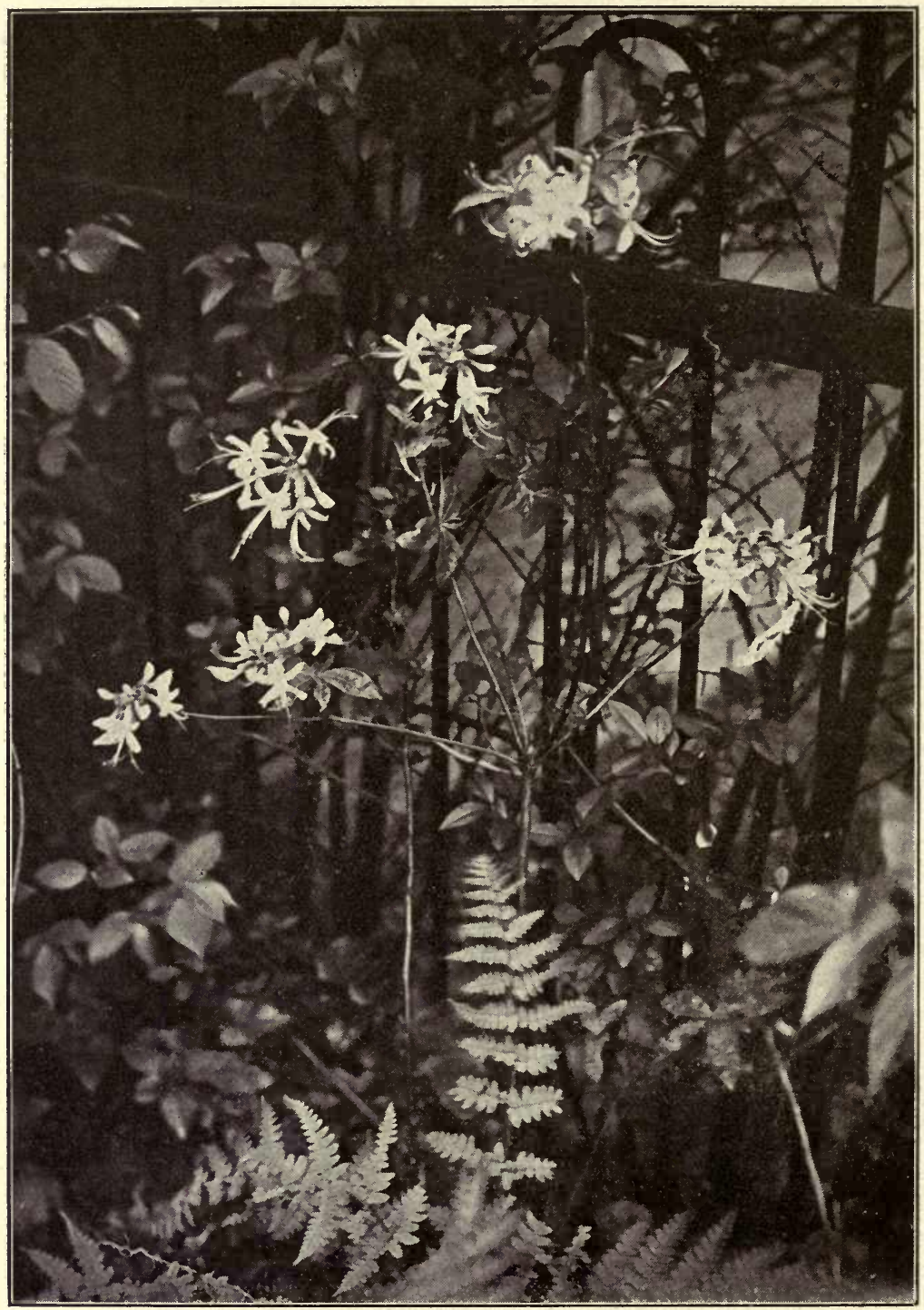

Fig. 350. Purple Azalea or Pinkster Flower (Rhododendron nudiflorum), showing the upright lower stalk surmounted by several spreading branches, each bearing a number of showy tubular flowers at its extremity. The flowers of this plant often appear before the leaves. 
of methyl salicylate. It contains a small quantity of an alcohol and an ester giving the characteristic odor. The same principles

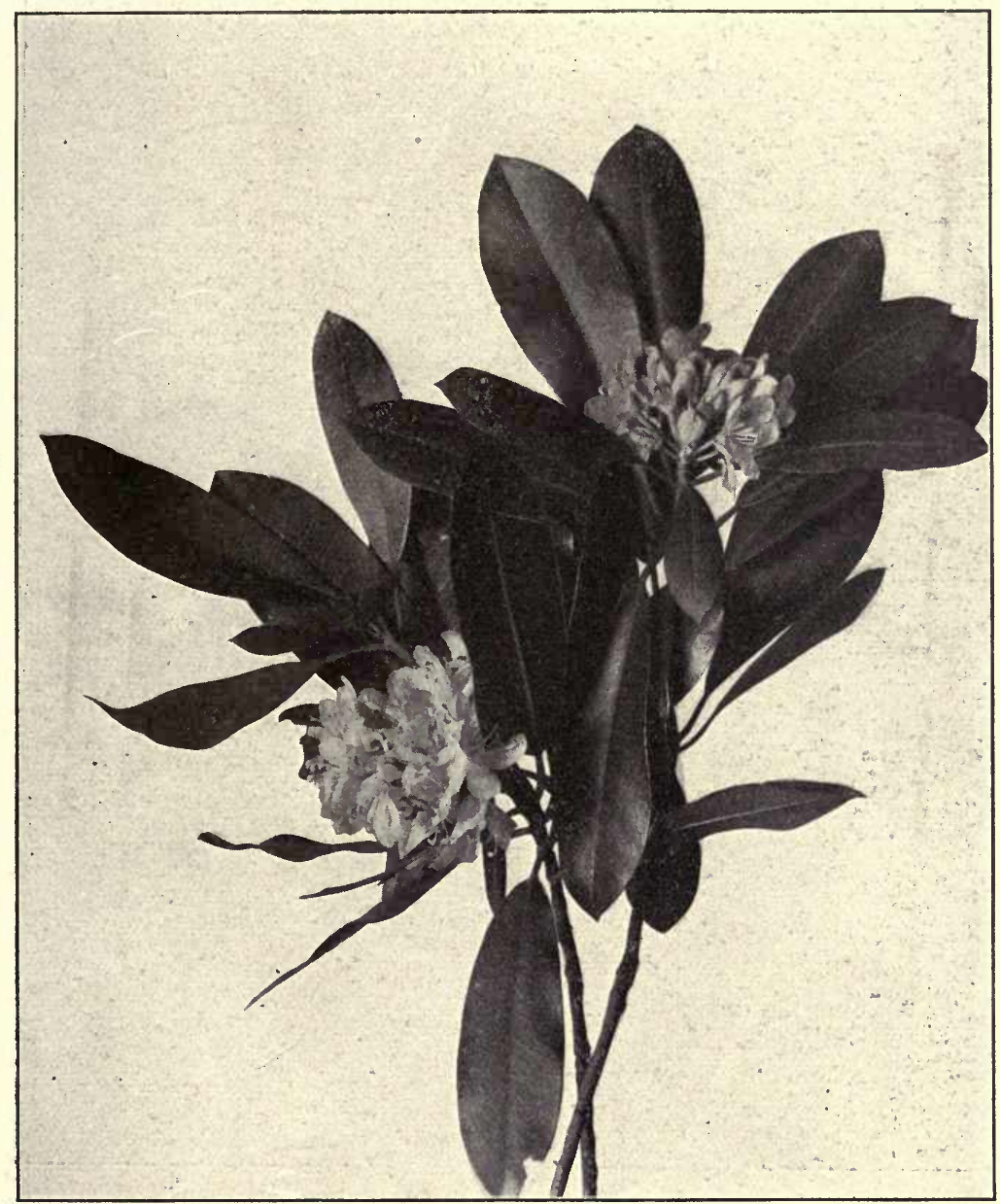

FIG. 35I. Great Laurel or Rose Bay (Rhododendron maximum), an evergreen shrub found in low woods and along streams, chiefly in the mountains of the eastern United States, often forming impenetrable thickets. It is one of the most beautiful of the flowering shrubs, producing from scaly, cone-like buds numerous corymbose clusters of flowers varying from pale rose to white.-After Troth.

probably also occur in several other species of Gaultheria (Fig. $354)$. 


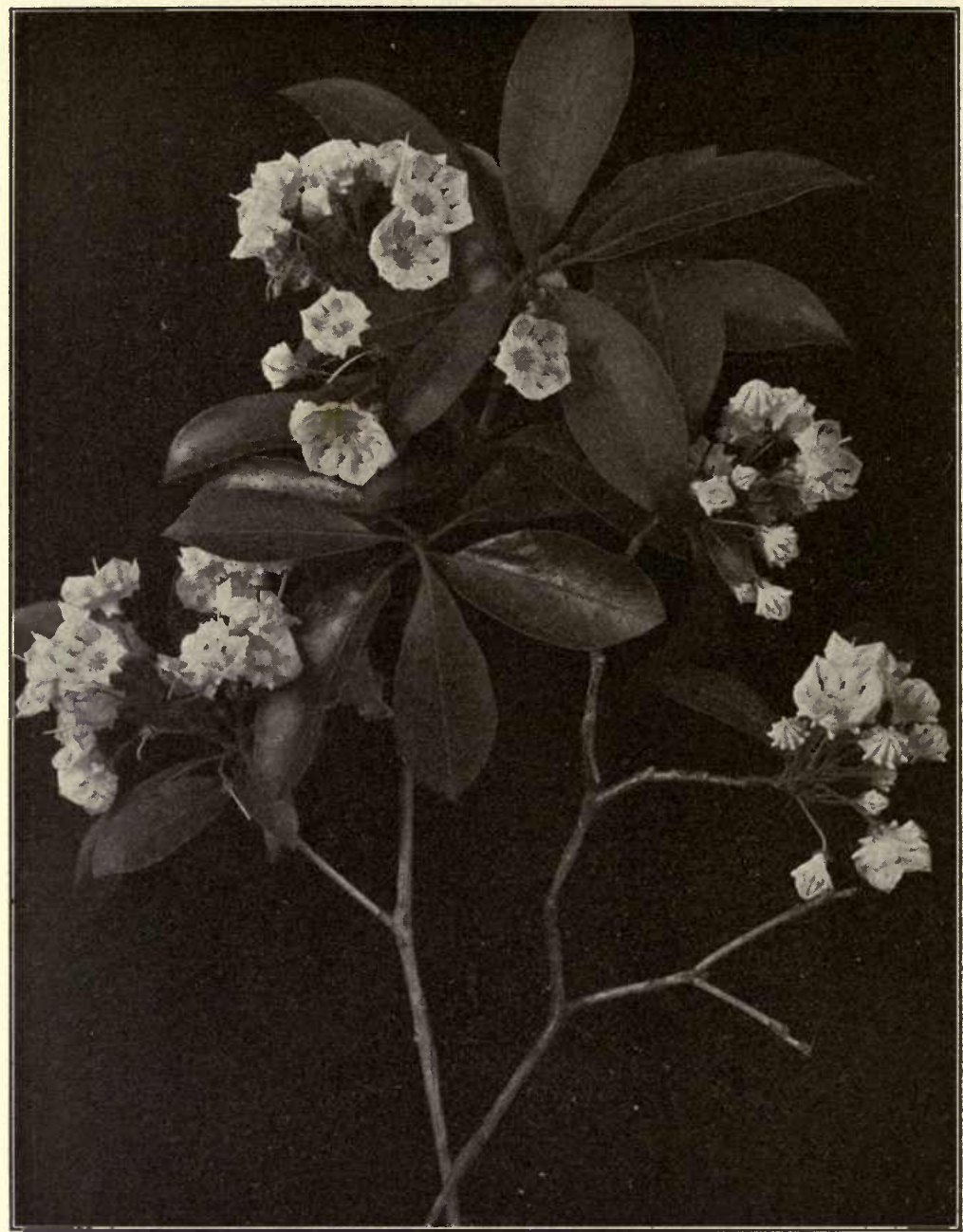

FIG. 352. Mountain Laurel (Kalmia latifolia). This is a handsome evergreen shrub growing on rocky hills and in damp soils in the eastern United States. The foliage is bright green, and the showy flowers occur in terminal corymbs, being either of a whitish or pink color. The leaves of many species of Kalmia are said to be poisonous to animals, which is especially true of the Sheep Laurel, known as Lambkill (Kalmia angustifolia), which is not infrequent on hillsides and pastures.-After Troth.

The poisonous principle andromedotoxin is found in a number of species of Rhododendron, Leucothœ, and Pieris. This principle is a powerful emetic and one of the most toxic principles known. 


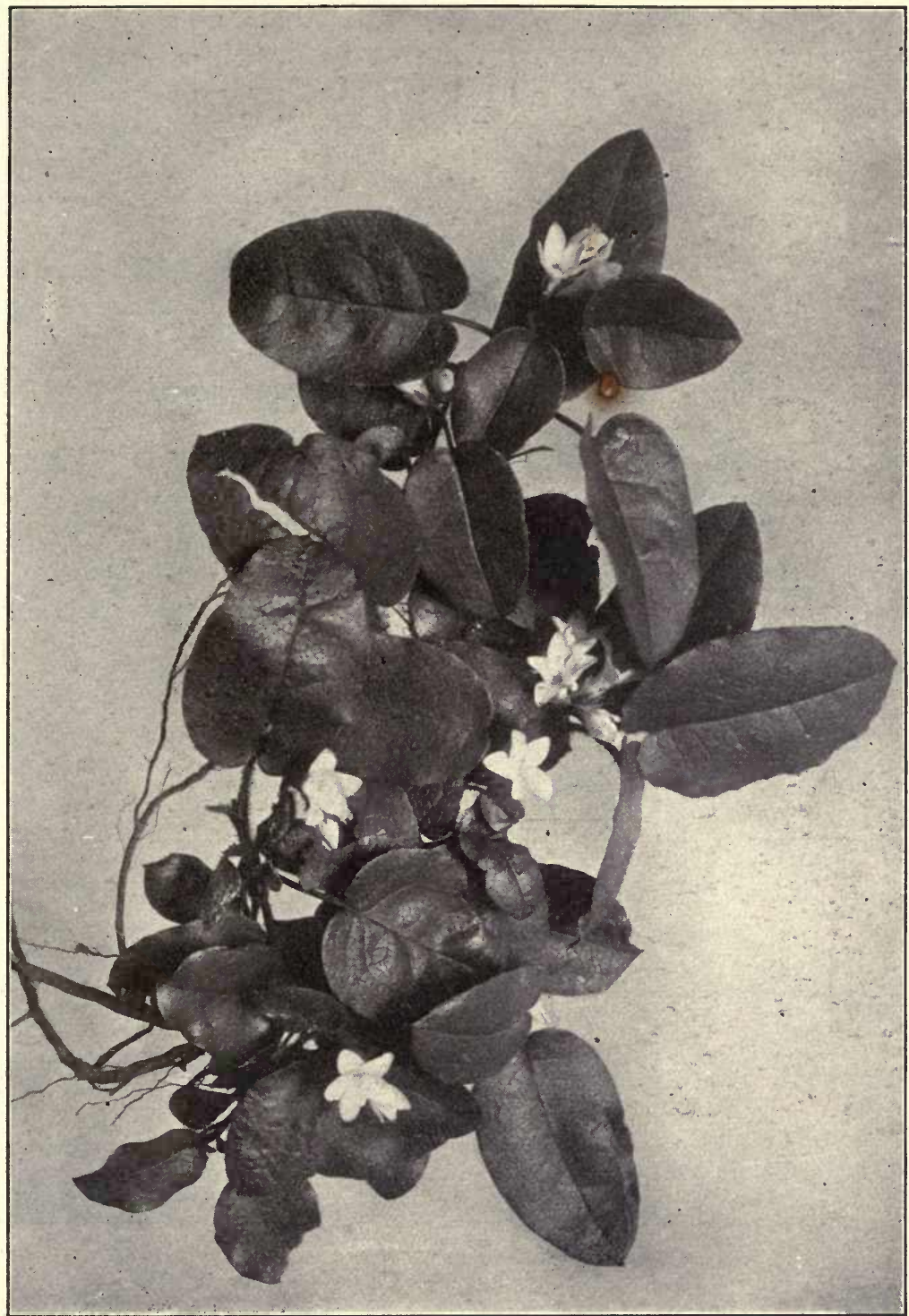

FIG. 353. Trailing Arbutus or Mayflower (Epigaa repens). This is one of the first of the early spring flowering plants. It is a prostrate woody plant, usually more or less covered up with the autumn leaves and with rounded and heart-shaped evergreen leaves. The flowers occur in small axillary clusters, are of a rose-red color, dimorphic as to styles and stamens, and are very fragrant. They are transplanted with difficulty, and require an acid soil, as do many other Ericaceæ.-After Troth. 


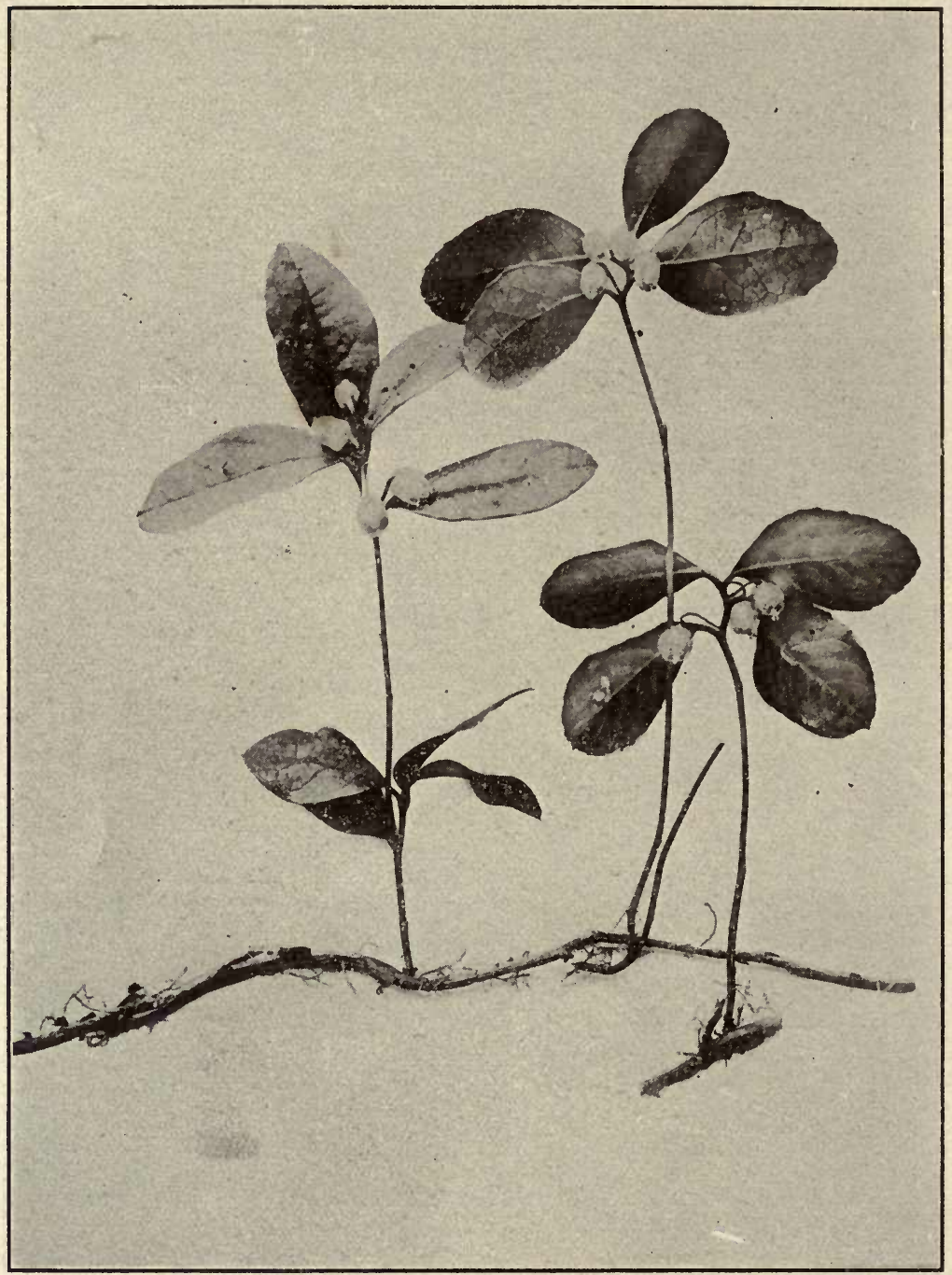

FIG. 354. Wintergreen, teaberry (Gaultheria procumbens), a low shrub producing slender stems lying at or beneath the surface of the earth and having ascending flowering branches rising to a height of 7 to $12 \mathrm{~cm}$. The leaves are evergreen, obovate or oval, and very sparingly toothed; the flowers are whitish, urn-shaped and axillary. The fruit is capsular, surrounded by the fleshy calyx, which forms the reddish aromatic globular berries. - Bureau of Plant Industry, U. S. Department of Agriculture. 


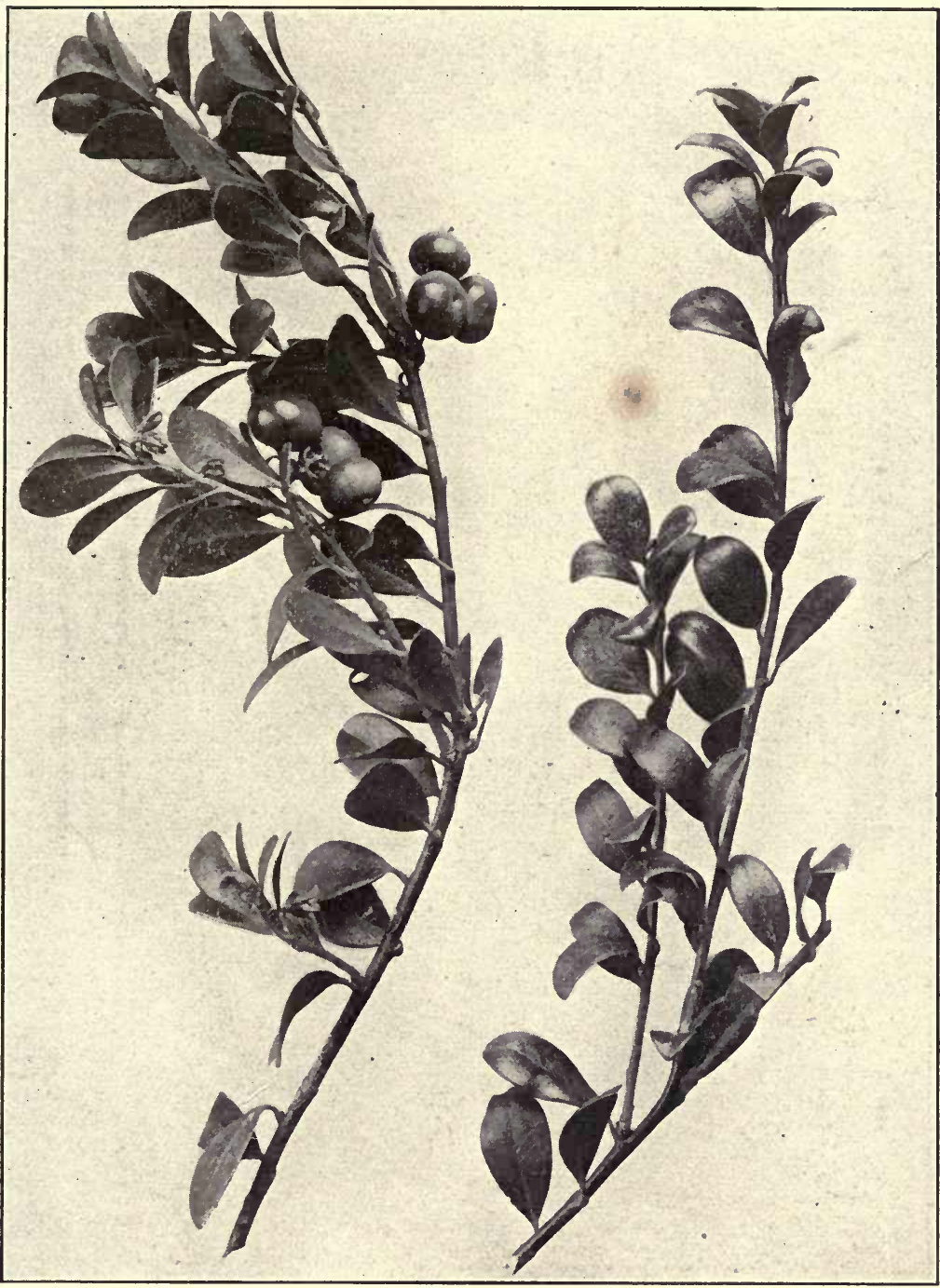

Fig. 355. Bearberry (Arctostaphylos Uva-ursi), a trailing, shrubby plant with thick evergreen, alternate leaves and whitish flowers in terminal racemes. The fruit is a globular, reddish, berry-like drupe about the size of a pea, with a mealy, insipid pulp. A . alpina, growing in the Alpine summits of Maine and New Hampshire, develops a blackish drupe with a juicy and edible pulp.-Bureau of Plant Industry, U. S. Department of Agriculture. 


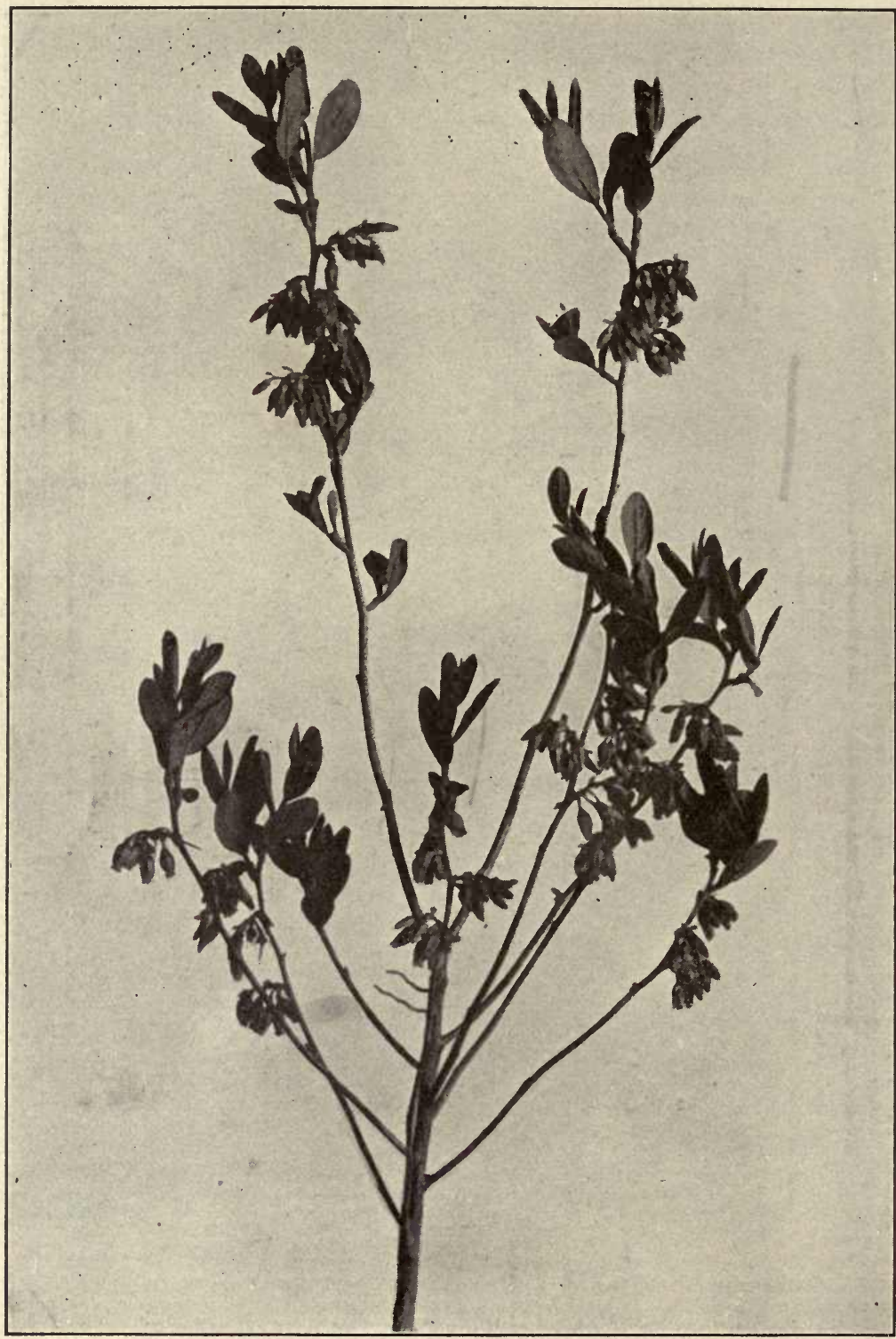

Fig. 356. Black or High-bush Huckleberry (Gaylussacia baccata or G. resinosa). An erect shrub with straggling branches, having leaves and flowers that are densely covered with resinous dots; the leaves vary from oval to oblong; the flowers are reddish-yellow, clustered in short racemes on terminal and axillary branches; the fruit is a sweet, blackish, berry-like drupe. In some varieties it is smooth and shiny, in others it is bluish and covered with a bloom.-After Brown. 
It probably occurs in the nectar of the flowers of Kalmia and Rhododendron, being the cause of the poisonous properties of the honey from this source. The leaves of several species of laurel

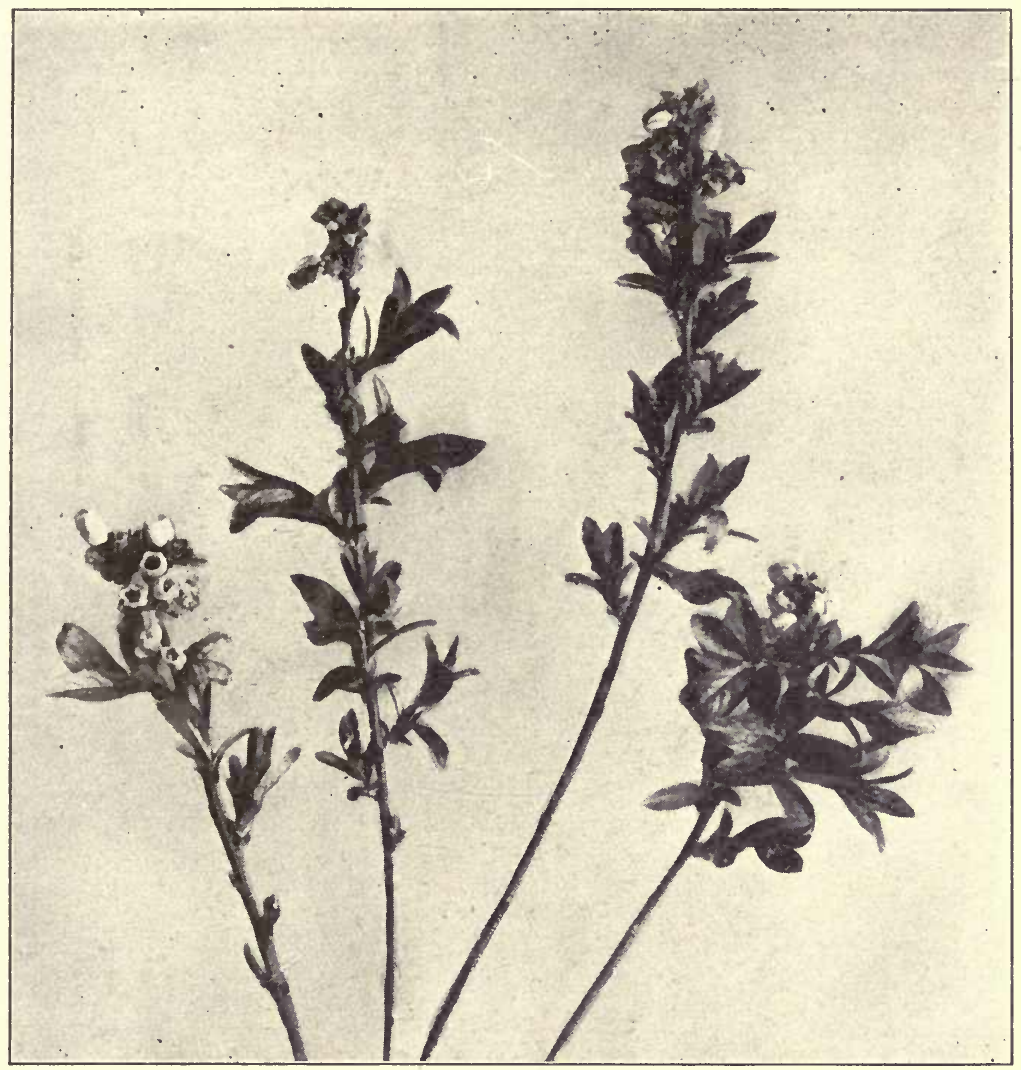

FIG. 357. Dwarf Blueberry or Early Sweet Blueberry (Vaccinium pennsylvanicum). A low shrub growing to a height of 2 to $6 \mathrm{dm}$. The leaves are lanceolate or oblong, of a bright green color and minutely serrate with bristle-pointed teeth; the flowers are few, in short racemes, the corolla being whitish and cylindrical; the berries are bluish, covered with a bloom, and ripen during July and August.-After Brown.

(Kalmia) contain considerable quantities of this principle, and are poisonous to cattle.

The plants of the genus Gaylusaccia are small shrubs distinguished by having an inferior, berry-like drupe with ten loculi. To this genus belong the huckleberries, as black huckleberry 
(G. baccata) ; blue huckleberry ( G. frondosa) ; and dwarf huckleberry (G. dumosa). The latter plant grows in sandy swamps in both the United States and Canada and the fruit ripens in May and June. The fruits of the other two species ripen in July and August (Fig. 356).

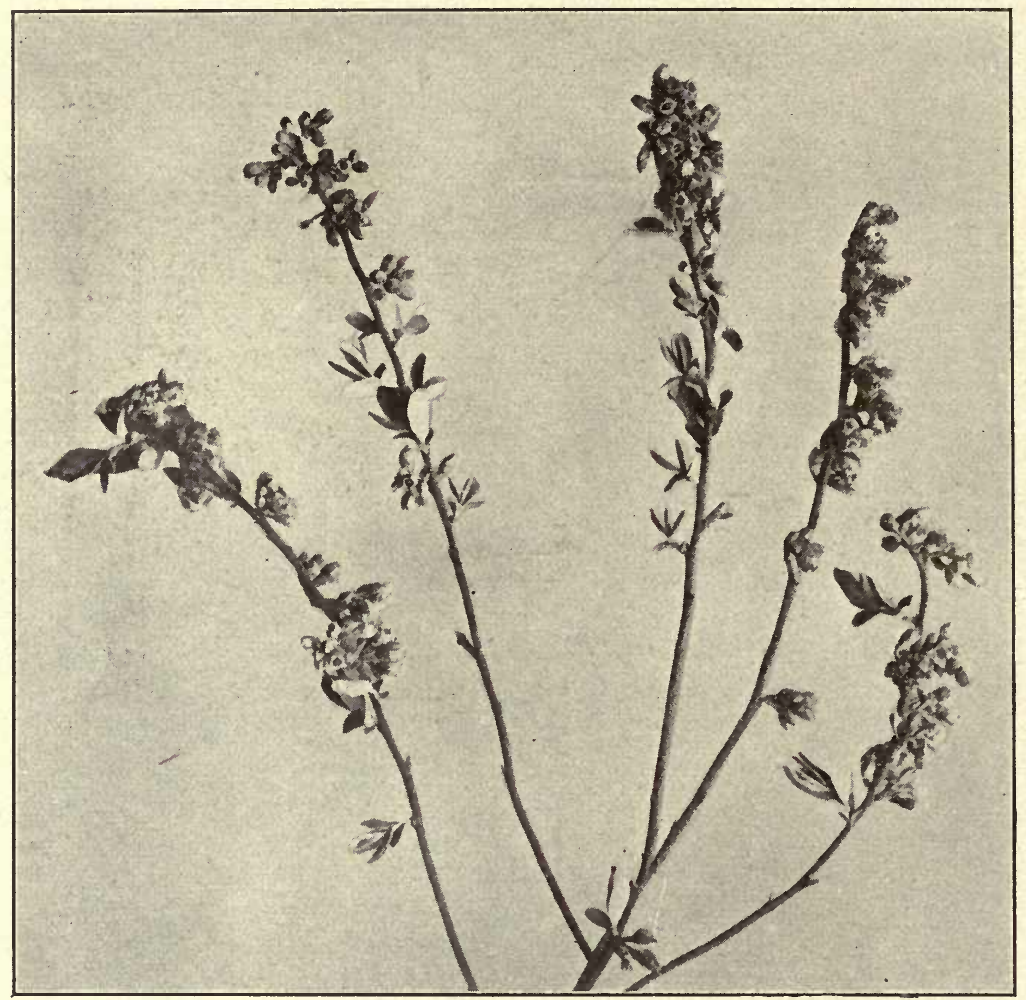

FIG. 358. Low Blueberry or Blue Huckleberry (Vaccinium vacillans). A small shrub with yellowish-green branchlets having nearly entire, narrow, obovate leaves. The flowers are in racemose clusters, appearing before the leaves are half grown, as shown in the illustration; the corolla is pinkish-white, oblong-cylindrical, and somewhat constricted at the throat. The berries are blue, covered with a bloom, and ripen in August and September.-After Brown.

The plants belonging to the genus Vaccinium vary from very small shrubs to tree-like shrubs and the fruit is an inferior, 5-locular berry with numerous seeds. The blueberries or bilberries (whortleberries) are the fruits of several species of Vaccinium. 
The low-bush blueberry ( $V$. pennsylvanicum) yields the berries which ripen in June and July, while the high-bush blueberry ( $V$. corymbosum) furnishes the fruits which are found in the market in July and August (Figs. 357, 358).

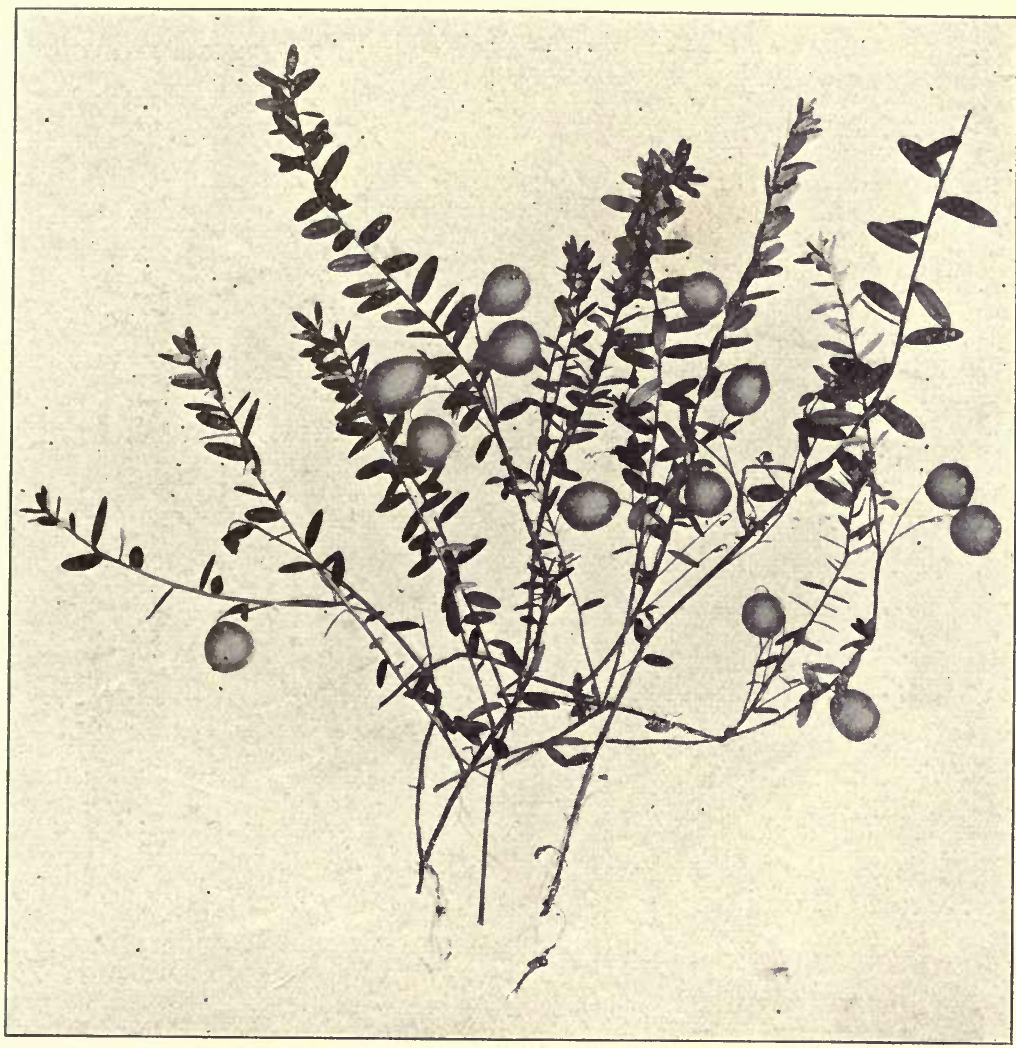

Fig. 359. Small Cranberry (Vaccinium Oxycoccos). A trailing evergreen shrub, which produces slender erect or ascending branches with oblong revolute leaves, rose-colored nodding flowers, and a 4-locular, reddish, acid fruit. The berry of the American Cranberry ( $V$. macrocarpon) is much larger and furnishes the fruit of the market. There are many varieties in cultivation.- After Brown.

The bilberry of Europe, Vaccinium Myrtillus, a plant growing in Northern Europe and Asia and the Western United States and Canada, is said to destroy Bacillus typhosus and B. Coli, an infusion of the dried berries being used for this purpose. The leaves of this plant contain ericolin and kinic acid. 
Cranberry is the fruit of several species of Vaccinium which are sometimes grouped in a separate genus, Oxycoccos. There are two principal species: The large or American Cranberry ( $V$. macrocarpon) in which the berries are ovoid or oblong and the small or European Cranberry ( $V$. Oxycoccos) in which the berries are globose. The berries contain from I.4 to 2.8 per cent. of citric acid; and a bitter glucoside, oxycoccin (Fig. 359).

Many attempts have been made to cultivate the blueberry, trailing arbutus, and other plants of the Ericaceæ. For some years a number of the agricultural experiment stations in the United States have attempted to grow the blueberry as a fruit, but none of these attempts has resulted in the commercial success of blueberry culture, and the experimental results have been chiefly of a negative character. The reason for this has been due, as pointed out by Coville (Bull. No. I93, Bureau of Plant Industry, U. S. Department of Agriculture), to a misunderstanding of the soil requirements for this plant. Plants will thrive only in soil having the following properties: $\mathrm{I}$. The soil must have a distinctly acid reaction, such as is found in peat bogs or on the surface of the ground in sandy, oak, or pine woods. 2. Aëration of the soil is necessary. The rootlets of the swamp blueberry are remarkable in having no root hairs whatsoever, so that their absorptive surface is only about one-tenth that of other plants having root hairs. The growth of the rootlet of the blueberry is much less than that of other plants, being about at the rate of only $\mathrm{I} \mathrm{mm}$. per day under favorable conditions. The rootlets of healthy blueberry plants are inhabited further by a mycorrhizal fungus which apparently has the property of assimilating nitrogen.

\section{ORDER PRIMULALES.}

Of the three families belonging to this order, there are two which are to some extent represented in temperate regions.

a. PRIMULACE E OR PRIMROSE FAMILY.-The plants are mostly perennial herbs with perfect regular flowers, and capsular fruits. The family is chiefly of horticultural interest, as it contains the genera Primula and Cyclamen. There are several species of Primula cultivated, and they are among the most popular and beautiful of the florist's flowers (Fig. 360). Several of the 


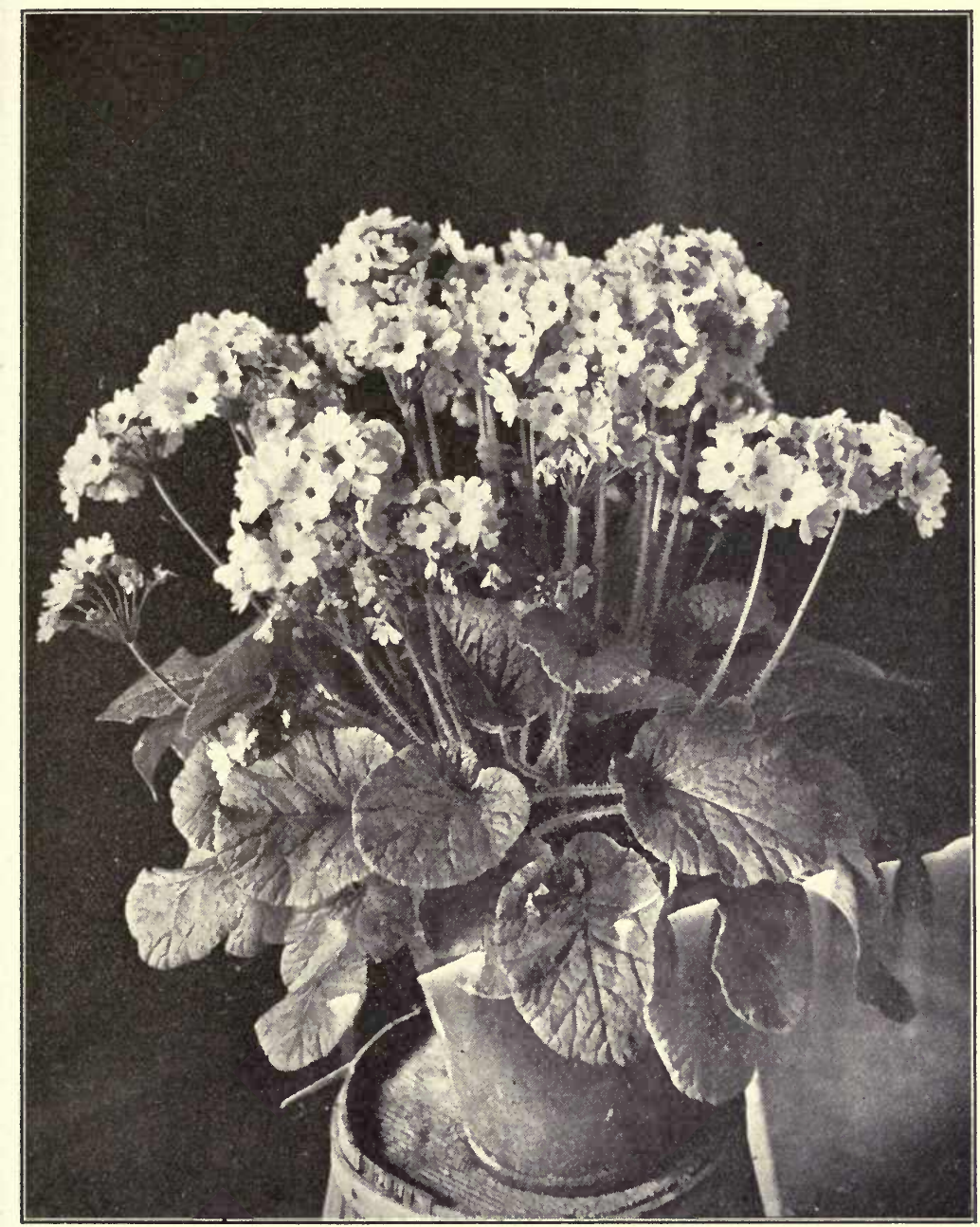

Fig. 360. Primula (Primula obconica), one of several species of Primula which are cultivated in greenhouses and as house plants. The leaves are circular heart-shaped, long petiolate, and very hairy; the flowers are pinkish or lilac color and occur in umbels. The hairs of this plant are very irritating, and cause a dermatitis similar to that produced by poison ivy.-After Guernsey.

species are found in Northern United States and Canada. During recent years it has been reported that the wild primrose $(P$. farinosa) and also the cultivated species ( $P$. obconica) possess 
hairs which are very irritating and cause a dermatitis similar to that produced by poison ivy.

A number of the primulas have been examined chemically. The subterranean parts of Primula officinalis contain two crystalline glucosides, primeverin and primulaverin, which by the action of the ferment, primeverase, produce an anise-like odor. The odors of the other species of Primula are probably due to distinct glucosides: $(a)$ one producing an anise-like odor, as in $P$. officinalis, $P$. capitata, and $P$. denticulata; $(b)$ one producing the odor of methyl salicylate, as in $P$. longiflora, $P$. elatior, and $P$. vulgaris; $(c)$ one producing the odor of coriander, as in $P$. auricula, $P$. panonica, and $P$. Palinuri. The flowers of a number of species are light in color and somewhat luminous in the dark.

b. PLUMBAGINACE $\nexists$ OR LEADWORT FAMILY.Perennial, mostly acaulescent herbs, growing in saline locations. Sea lavender or marsh rosemary (Limonium carolinianum) is found in the salt meadows from Labrador to Texas. The plant is reported to contain tannin and has been used in medicine.

\section{ORDER EBENALES.}

This order includes three families which are chiefly indigenous to the Tropics. The leaves are alternate, and the flowers vary in the different families, the fruit being a berry or drupe.

a. SAPOTACE $Æ$ OR SAPODILLA FAMILY.-The plants usually have a milky latex, and many of them yield GUTTA-PERCHA, of which the following may be mentioned: Palaquium Gutta, $P$. oblongifolium, $P$. borneense and $P$. Treubii, all growing in the East Indies. The latex is obtained by incising the trees and collecting the exuding juice in suitable vessels. It soon coagulates and forms grayish or reddish-yellow hard masses, which are plastic at $65^{\circ}$ to $70^{\circ} \mathrm{C}$. Owing to the fact that the material is plastic when heated and firm and tenacious when cold, it is used for a variety of purposes, as in the manufacture of surgical instruments and as material for filling teeth. Gutta-percha as it exudes from the tree is supposed to consist of a terpene-like hydrocarbon, which on coagulation is oxidized, forming a number of resinous compounds. The plants of other genera of this family also yield 
gutta-percha, as Mimusops Balata, M. Elengi, and about fifteen species of Payena growing in the East Indies.

Gum Balata is obtained from Mimusops Balata, a tree of Guiana. The gum is more resinous and flexible than gutta-percha. It contains $\beta$-amyrin acetate and probably lupeol acetate.

A gum resembling gutta-percha is obtained from the Sabodilla tree (Achras Sapota). This gum is known in commerce as Gum CHICLE and is obtained from Yucatan. It is whitish, brittle, and yet somewhat elastic, aromatic, and contains 45 per cent. of a colorless crystallizable resin, soluble in alcohol and ether; and I8 per cent. of caoutchouc. It is used in large quantities in the making of chewing gum.

The seeds of Illipe butyracea yield a fixed oil which is known as vegetable butter. A fixed oil is also obtained from other species of Illipe as well as various species of Bassia, Argania, and Butyrospermum, that from the latter being known as "shea butter."

The family is notable on account of the hard woods, known as Ironwoods, which it furnishes, these being yielded by Mimusops Kauki of Farther India and tropical Australia and Argania Sideroxylon of Southwestern Morocco.

A number of species also yield highly prized edible fruits, as the SApotilla yielded by Achras Sapota indigenous to the Antilles and cultivated in tropical countries, and STAR APPLE yielded by Chrysophyllum Cainito of tropical America.

b. EBENACEÆ OR EBONY FAMILY.-The plants differ from those of the preceding family in not containing a latex. The flowers are monœcious or diœcious and they usually have from two to eight styles. The chief interest is in the genus Diospyros, which yields the wood known as EBONY. Black ebony is obtained from various species of Diospyros growing in tropical Africa, and Asia, and the Philippine Islands. White ebony is obtained from several species of Diospyros growing in the Philippines. A red ebony is obtained from $D$. rubra of Mauritius, a green ebony from $D$. Chloroxylon of Farther India, and a striped ebony from several species growing in the Philippines.

Persimmon fruit is obtained from Diospyros virginiana, a tree growing from Rhode Island south to Texas. The astrin- 
gency of the unripe fruit is due to the tannin which it contains. When it is ripe, which is not until after the appearance of frost, it is palatable and contains considerable malic acid and sugars. The Japanese persimmon is a cultivated variety of D. Kaki and produces a large orange-colored fruit which is not uncommon in the fruit markets in many parts of the world. At the present time the plant is cultivated in California.

The bark of our native persimmon is used in medicine. It contains considerable tannin which resembles gallotannic acid, and a crystalline resinous principle with a peculiar odor and slightly astringent taste.

c. STYRACACE $\approx$ OR STORAX FAMILY.-The flowers of this family somewhat resemble those of the Ebenaceæ, but the filaments of the stamens are united in a single series, and there is a single slender style.

Styrax Benzoin is a medium-sized tree with long, ovate, acuminate leaves which are very hairy on the under surface. The flowers occur in terminal racemes, and are silvery white on the outer surface and reddish-brown on the inner surface. The balsamic resin yielded by this plant is official as benzoin.

\section{ORDER GENTIANALES OR CONTORTE.}

The plants of this order have opposite leaves, the flowers are regular and the gynæcium consists of two separate carpels. The order includes five families, all of which furnish medicinal plants.

a. OLEACE $A$ OR OLIVE FAMILY.-This family is chiefly of interest because of the olive and manna trees.

The olive tree (Olea europaca) is indigenous to the Orient and is now cultivated extensively in Southern Europe, Northern Africa, the islands of the Mediterranean, tropical America, including the Southern United States, and in California. The leaves are narrow-lanceolate, entire, coriaceous and evergreen. The flowers are small, white, diandrous and in axillary racemes. The fruit is a drupe, the sarcocarp of which is rich in a fixed oil known as olive oil. The oil is obtained by expression, and is official. Depending upon the character of the fruits and the amount of oil which they yield, over forty varieties are recognized. 
The fresh green olives contain a glucoside oleuropein, which disappears on the maturation of the fruit.

Fraxinus Ornus is a tree resembling the ash, with 7 -foliate leaves, and polygamous flowers occurring in compound racemes. The fruit is a flat samara with the wing at the apex. The saccharine exudation from this plant is official as manna.

The white ash (Fraxinus americana) is a valuable tree on account of the timber which it yields. The bark contains a bitter glucoside, fraxin, the solutions of which are fluorescent; a bitter substance, fraxetin; an ethereal oil of a butter-like consistency, and tannin. Some of these principles are also found in other species of Fraxinus growing in the United States and Europe.

The bark of the fringe tree (Chionanthus virginica) of the Southern United States contains an intensely bitter glucosidal principle, chionanthin, and possibly also saponin.

The leaves of the garden lilac (Syringa vulgaris) contain a crystalline glucoside, syringin, and syringopicrin, both of which are probably also found in other species of Syringa as well as the bark and leaves of privet (Ligustrum vulgare), which latter plant is extensively used for hedges.

$b$. LOGANIACE $\mathbb{E}$ OR LOGANIA FAMILY.-The plants are variable in character, being herbs, shrubs, trees or vines.

Yellow jessamine (Gelsemium sempervirens) is a twining woody vine, sometimes trailing on the ground for a considerable distance. The leaves are oblong-lanceolate and evergreen. The flowers are bright yellow and dimorphic. The fruit is a septicidally dehiscent capsule. The rhizome and roots are official.

Carolina pink (Spigelia marilandica) is a perennial herb with ovate-lanceolate, more or less actute and nearly sessile leaves. The flowers are yellow on the inner and scarlet on the outer surface, and occur in a I-sided spike or scorpioid cyme. The fruit is a loculicidal, few-seeded, 2-valved capsule (Fig. 361). The rhizome and roots are official.

Strychnos $N u x$-vomica is a small tree with broadly elliptical, 3- to 5-nerved, reticulately-veined, somewhat acuminate, coriaceous leaves. 'The flowers are whitish and in terminal cymes. The fruit is a berry of varying size and contains several seeds, the seeds being official. 
CURARE, which is used by the Indians of South America as an arrow-poison, is supposed to be made from the bark of Strychnos toxifera growing in Guiana, and probably other species of

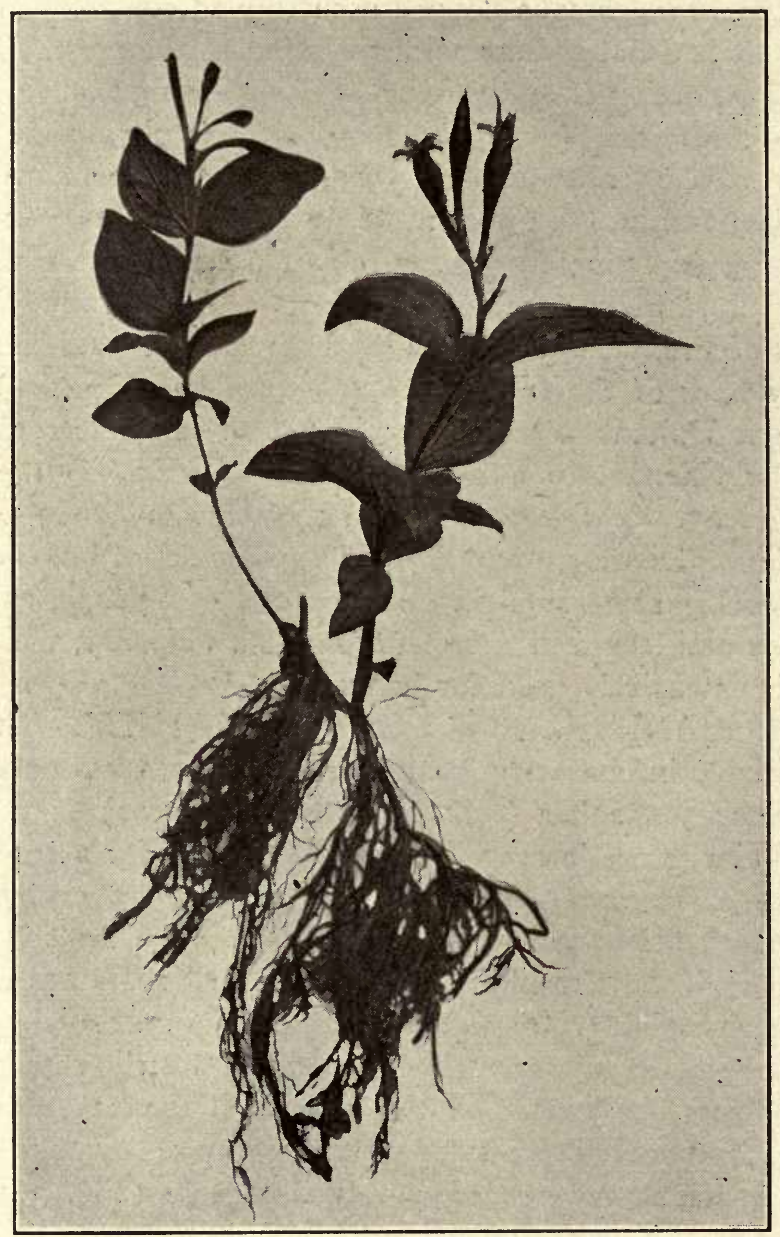

FIG. 361. Carolina pink (Spigelia marilandica) showing the rhizome bearing two branches with opposite leaves and flowers in terminal scorpioid cymes.

this genus. The active principle of this poison is the alkaloid curarine, which when administered hypodermically has a powerful action resembling that of digitalis. 


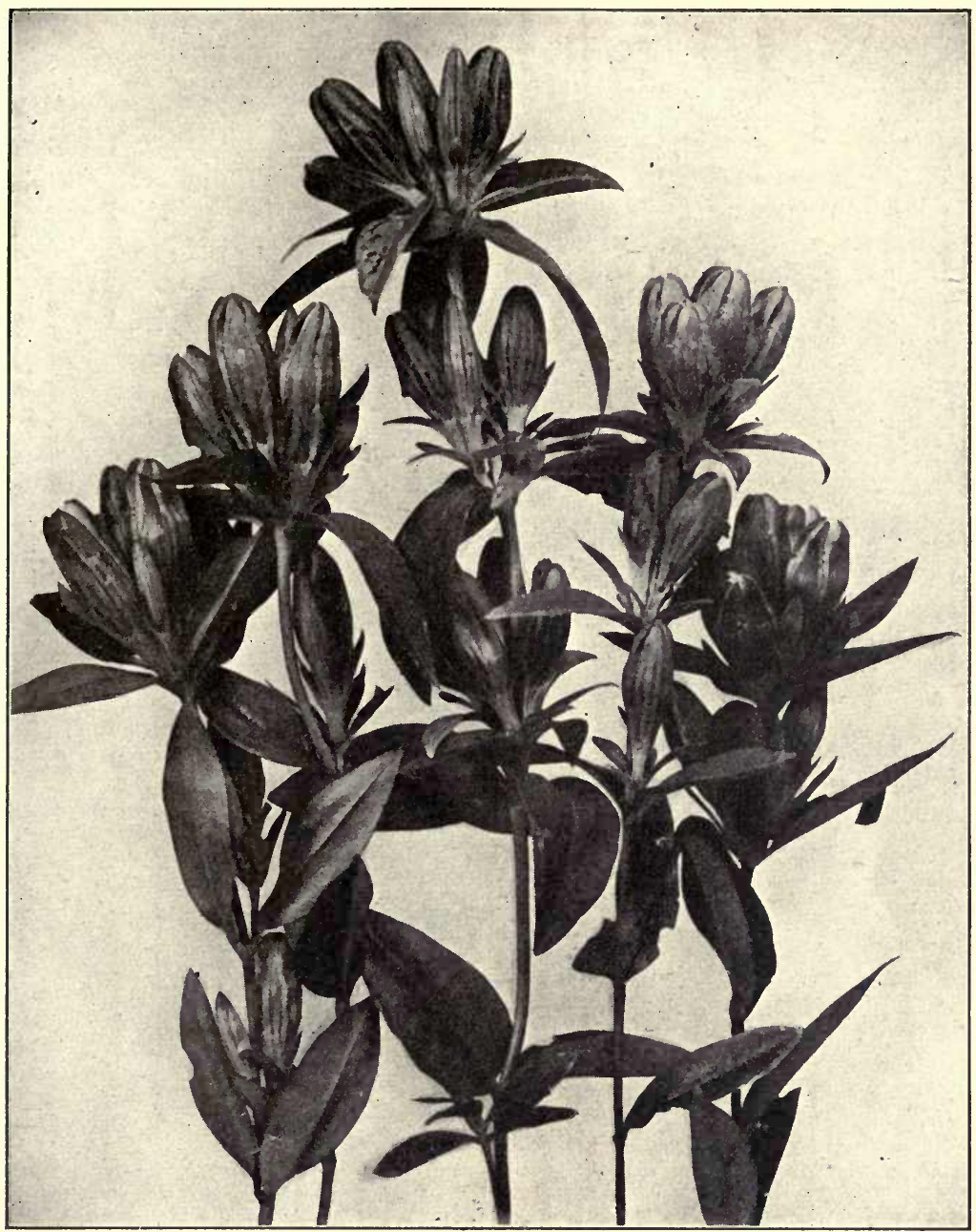

FIG. 362.- Closed Gentian (Gentiana Anurewsii), probably one of the most abundant of the fall-flowering Gentians. It is a perennial, forming stout, leafy stems, terminated by sessile clusters of blue flowers. The corolla is closed, and hence this Gentian is sometimes called "Bottle Gentian." It grows in moist ground throughout most of the eastern United States and Canada.-After a photograph by Troth.

c. GENTIANACE无 OR GENTIAN FAMILY.-The plants are mostly herbs with regular, perfect, showy flowers occurring usually in small cymes or racemes (Fig. 362).

Yellow gentian (Gentiana lutea) is a large, perennial herb 
(see Vol. II) with large, 5- to 7-nerved, broadly elliptical leaves. The flowers are yellow and occur in axillary cymes. The fruit is a 2-valved, ovoid capsule. The rhizome and roots are official. Many of the gentians are among the most highly prized of the wild flowers, some of them, as the fringed gentian (Gentiana crinita), being one of the most beautiful. The closed gentian (Fig. 357 ), so called because the flowers remain closed, is quite abundant in moist grounds throughout most of the United States and Canada. The roots of a number of species of American gentian have medicinal properties resembling that of G. lutea.

Menyanthes, the yellowish-white horizontal rhizome of $\mathrm{Men}$ yanthes trifoliata (Fig. 363), contains an amorphous glucoside which is slightly soluble in water, soluble in alcohol, and is precipitated with tannin. Upon hydrolysis menyanthin yields a volatile oil possessing an odor reminding one of bitter almonds.

Swertia Chirata.-The entire plant is official.

Herba Centaurii minoris, the entire plant of Erythraa Centaurium of Europe, contains a glucoside, erytaurin, which forms small colorless prismatic and bitter crystals and is slowly hydrolyzed by emulsin. Sabbatia Elliottii, occurring in the pine barrens of the Southern States, is known as the "quinine herb."

d. APOCYNACE $E$ OR DOGBANE FAMILY.-The plants vary from perennial herbs to shrubs and trees, contain an acrid latex, and have flowers with the stigmas and styles united and the stamens distinct. They are mostly found in the Tropics.

Apocynum cannabinum is a perennial herb with erect or ascending branches. The leaves are oblong-lanceolate, opposite, nearly sessile or with short petioles (Figs. 226, 25I ). The flowers are greenish-white, the lobes of the corolla being nearly erect and the tube about as long as the calyx. The fruit is a slender, terete follicle containing numerous seeds tipped at the micropylar end with a tuft of hairs. The root is official.

The root of a closely. related species, namely, spreading dogbane (Apocynum androsamifolium), is sometimes substituted for the official drug. The plant is distinguished by being more spreading in its habit. The leaves are ovate (Figs. 226, 364), the flowers are pinkish, the lobes being revolute, and the tube several times as long as the calyx. 


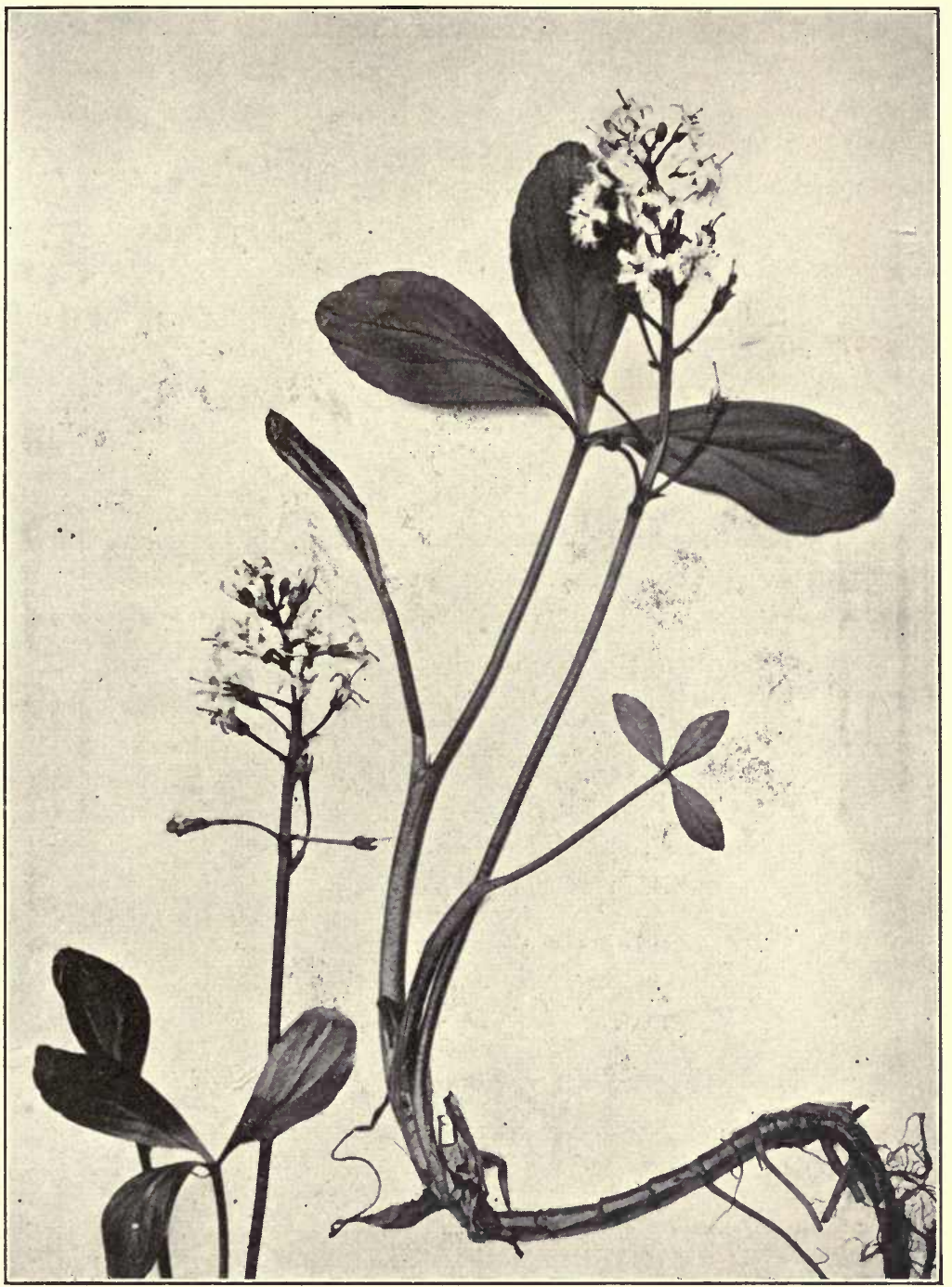

FIG. 363. Buckbean or Bogbean (Menyanthes trifoliata), a perennial herb with a fleshy horizontal rhizome, producing erect stems, bearing three oval or oblong leaflets, and a raceme with numerous, white or rose-colored, fringed flowers. The plant grows in bogs and shallow water in northern United States and Canada.-Bureau of Plant Industry, U. S. Department of Agriculture. 


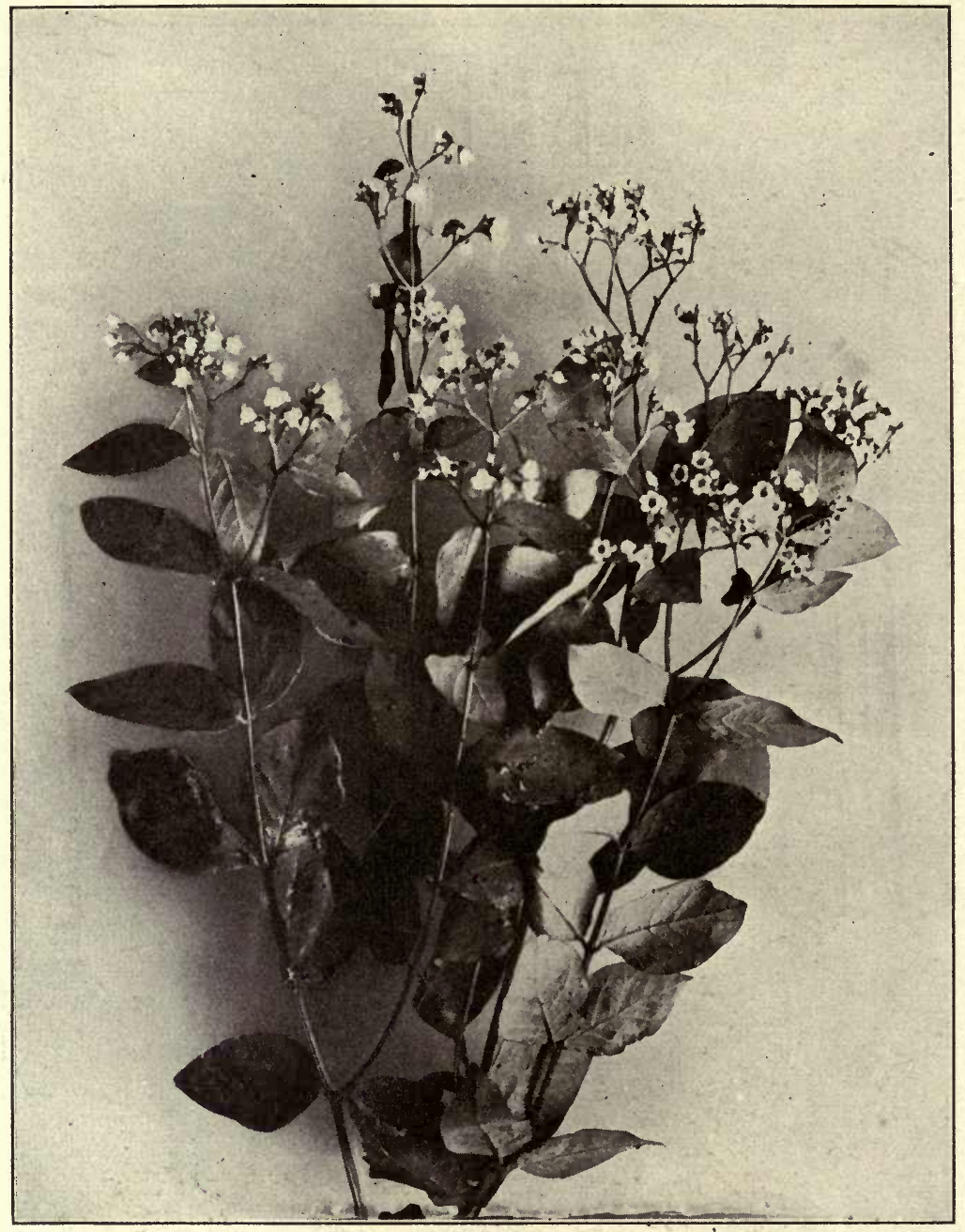

FIG. 364. Spreading Dogbane (Apocynum androsamifolium), a perennial, branching herb, with ovate-oblong, opposite leaves, and small, pinkish fragrant flowers occurring in terminal cymes. All parts of the plants contain a white acrid latex. - After Brown.

Strophanthus Kombe.-The plant is a woody climber with elliptical-acuminate, hairy leaves. The flowers are few, characterized by long styles, and occur in axillary racemes. The fruit consists of two long follicles containing numerous awned seeds, 
which are official. In the closely related plant $S$. hispidus the flowers are numerous and occur in terminal cymes.

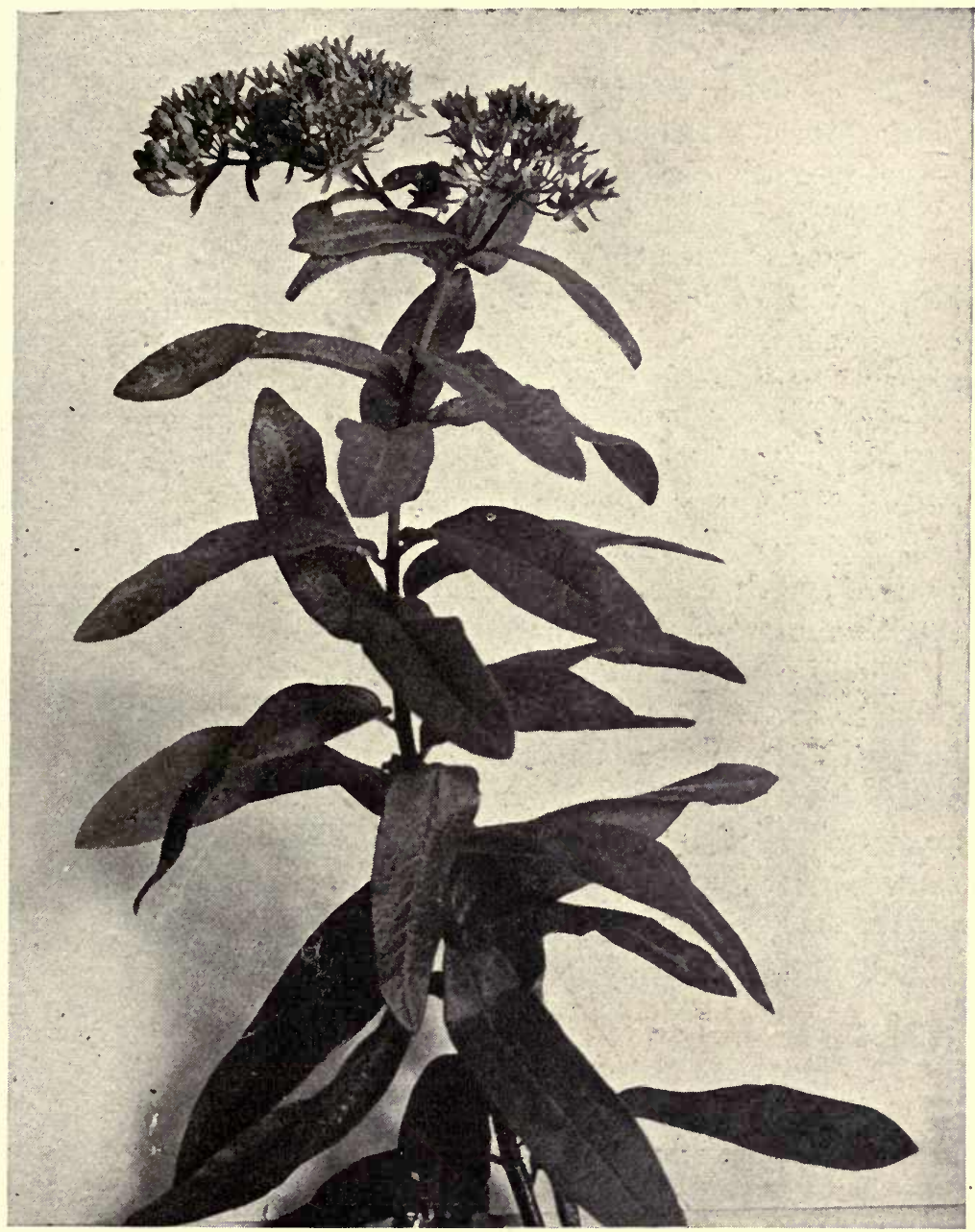

FIG. 365. Butterfly-weed or Pleurisy-root (Asclepias tuberosa), showing the sessile, oblongovate leaves and the simple, many-flowered umbels.

Quebracho or Aspidosperma is the bark of Aspidosperma Quebracho-blanco, a tree growing in Argentine. It contains a number of alkaloids and is used to some extent in medicine. 
The leaves and bark of the cultivated oleander (Nerium Oleander) contain the glucoside oleandrin, resembling digitalin in its action; a fluorescent principle, and probably several other principles.

The common periwinkle (Vinca minor) contains the principle vincin, which is supposed to be a glucoside and which probably occurs in other species of Vinca.

e. ASCLEPIADACE $\approx$ OR MILKWEED FAMILY.-The plants somewhat resemble those of the Apocynacex. The flower, however, is distinguished by having distinct styles, a 5-lobed corona connecting the corolla and stamens, which latter are mostly monadelphous, and pollen grains that are coherent, forming characteristic pairs of pollinia. Few of the plants are of any economic importance. The latex of the stems and the hairs of the seeds are deserving of attention. PlEURISY ROOT, which was formerly offcial, is obtained from Asclepias tuberosa, a plant growing in the Eastern United States and one of the two members of this genus that have orange-colored flowers (Fig. 365).

Condurango is the bark of Marsdenia Cundurango, a liane of Ecuador and Colombia. It occurs in quilled pieces, the bark' being from 2 to $6 \mathrm{~mm}$. thick. Externally it is brownish-gray and with a more or less scaly cork. The taste is bitter, acrid, and aromatic. The drug contains an amorphous glucoside; an unsatu-' rated alcohol occurring in large prisms; and a volatile oil ( 0.3 per cent.).

\section{ORDER POLEMONIALES OR TUBIFLORÆ.}

This is a large order of plants, which are mostly herbaceous. The leaves are either opposite or alternate; the flowers are regular or irregular, the stamens being usually adnate to the corolla.

a. CONVOLVULACE王 OR MORNING-GLORY FAMILY.-The plants are mostly herbs or shrubs, frequently twining (to the left). They are found mostly in the Tropics, but quite a number of genera occur in temperate regions (Fig. 366).

Exogonium Purga is a perennial twining herb with distinctly veined, cordate leaves; purple flowers with the stamens exserted, and occurring in cymes. The fruit is a 2 -locular capsule. The 
plants produce slender rhizomes with tuber-like roots, these being used in medicine.

Convolvulus Scammonia is a perennial twining herb, with a large tap root, containing a resinous latex, and is the source of the official scammony root. The leaves are sagittate; the flowers are large, yellowish-white and funnel-form, as in the morning-

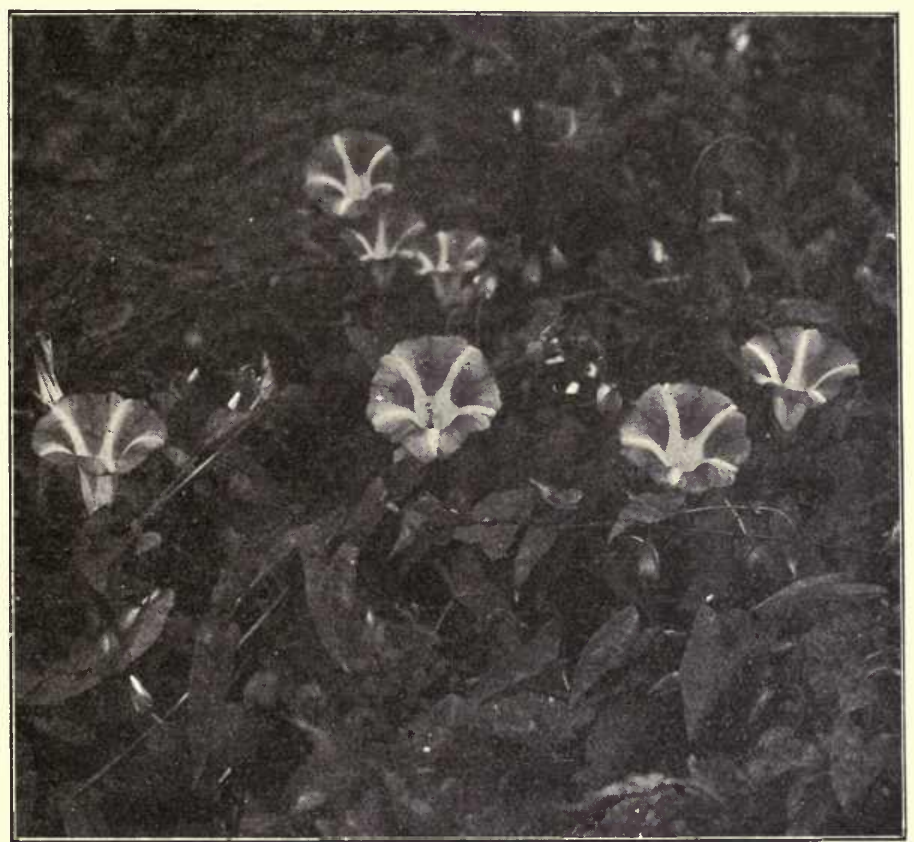

FIG. 366. Great bind weed (Convolvulus sepium) showing trailing or twining habit, the hastate leaves and funnel-shaped corolla. The plant is very resistant to noxious fumes and is usually found in smelter regions.

glory, and occur in the axils of the leaves, either solitary or in clusters. The fruit is a 4-seeded, 4-locular, dehiscent capsule.

A number of the plants of the Convolvulaceæ are cultivated, probably the most important of which is the SWEET POTATo vine (Ipomoca Batatas), a plant extensively cultivated in tropical and sub-tropical countries on account of the edible tuberous roots. The roots contain from 3 to Io per cent. of sugar and 9 to 5 per cent. of starch, which occurs in larger proportion in plants grown 
in sub-tropical countries. The starch is a commercial product and is known as sweet-potato starch or BRAzILIAN ARROW-ROOT. The grains are more or less bell-shaped and 2-or 3-compound, about the size of wheat-starch grains, and in other ways resemble those of tapioca.

To this family also belongs rather an interesting group of parasitic plants, namely, dodder (Cuscuta): They contain the principle cuscutin, and quite a number have been used in medicine.

b. POLEMONIACE E OR POLEMONIUM FAMILY.A family mostly of herbs and chiefly of horticultural interest. It contains the genus Phlox, which is indigenous exclusively to North America. A number of the species are cultivated and are included among the most valuable hardy, herbaceous perennials. The flowers are among the most beautiful and persistent of our garden plants. Another interesting genus belonging to this family is Polemonium, a number of species of which have been long under cultivation as border plants. Polemonium reptans is rather common in the woods of the Northern United States (Fig. 367).

c. HYDROPHYLLACE $Æ$ OR WATERLEAF FAMILY.The plants are herbs or shrubs which are indigenous to Western North America. Very few of the plants of this family are of use medicinally, although quite a number are ornamental plants.

Eriodictyon californicum (E. glutinosum) or Yerba Santa is a shrub growing in Northern Mexico and California. The leaves are official (Fig. 368). The flowers are funnel-form, white or purple, occurring in cymes. The fruit is a dehiscent capsule and the seeds are small and few.

d. BORAGINACE $\mathrm{E}$ OR BORAGE FAMILY.-The plants are mostly herbs with regular blue flowers, occurring in scorpioid inflorescence. The best examples of the group are the forget-me-not (Myosotis), the roots of several species of which have been used in medicine; and the garden heliotrope (Heliotropum peruvianum), the fragrance of the flowers being due to a volatile oil. This plant, as well as other species of Heliotropum, contains a poisonous volatile alkaloid.

At one time considerable interest attached to ALKANET, the root of Alkanna tinctoria of Southern Europe and Asia, on account of the red coloring principle aikannin, which is soluble in alcohol, 


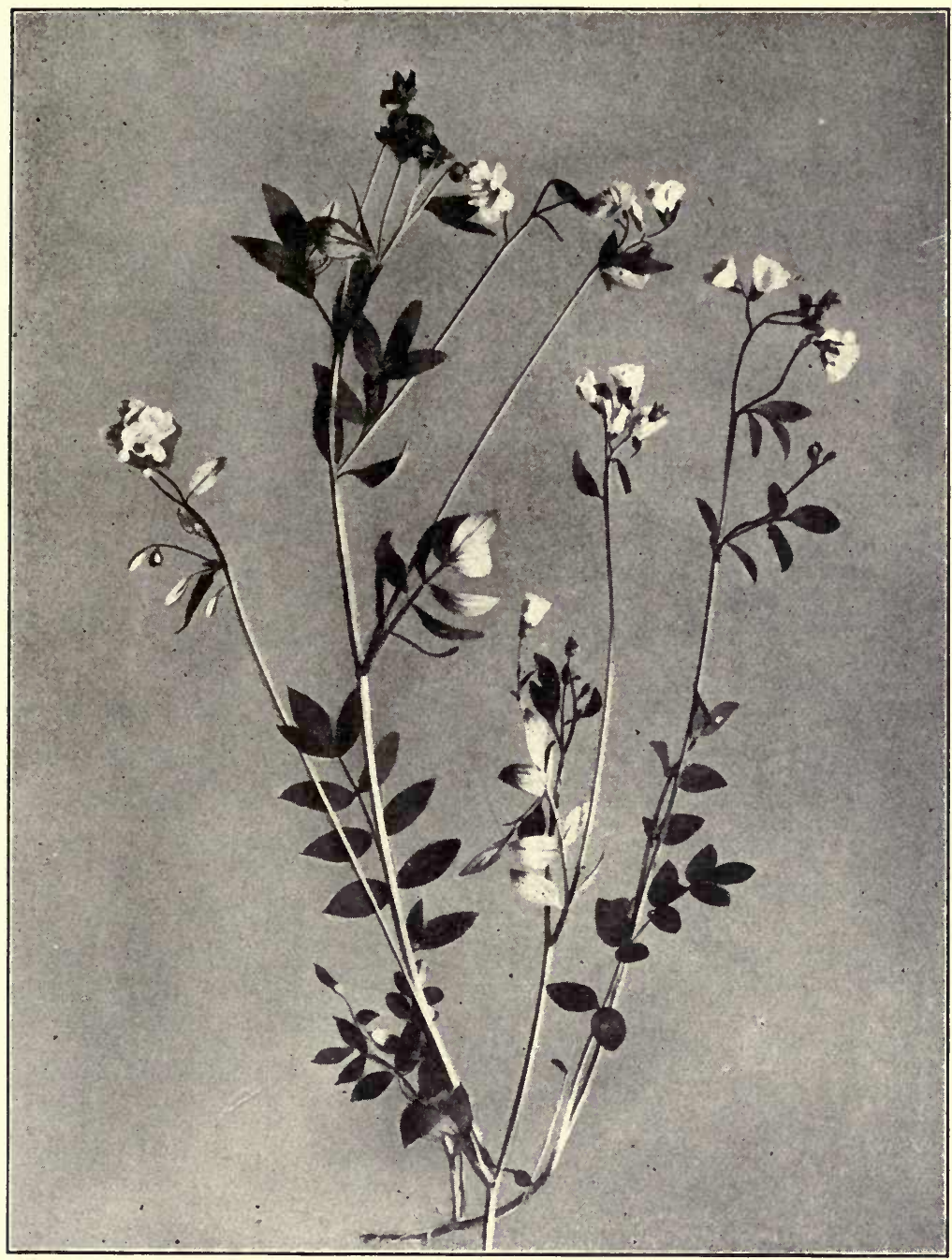

FIG. 367. Greek Valerian (Polemonium reptans), a perennial, 2 to $4 \mathrm{dm}$. in height, having alternate pinnate leaves and light blue flowers in corymbs.-After Brown.

ether, fixed and ethereal oils, but insoluble in water. COMFREY or sympнyтum is the root of Symphytum officinale and other species of this genus naturalized from Europe in waste places in the United States. It occurs on the market in small, purplish- 


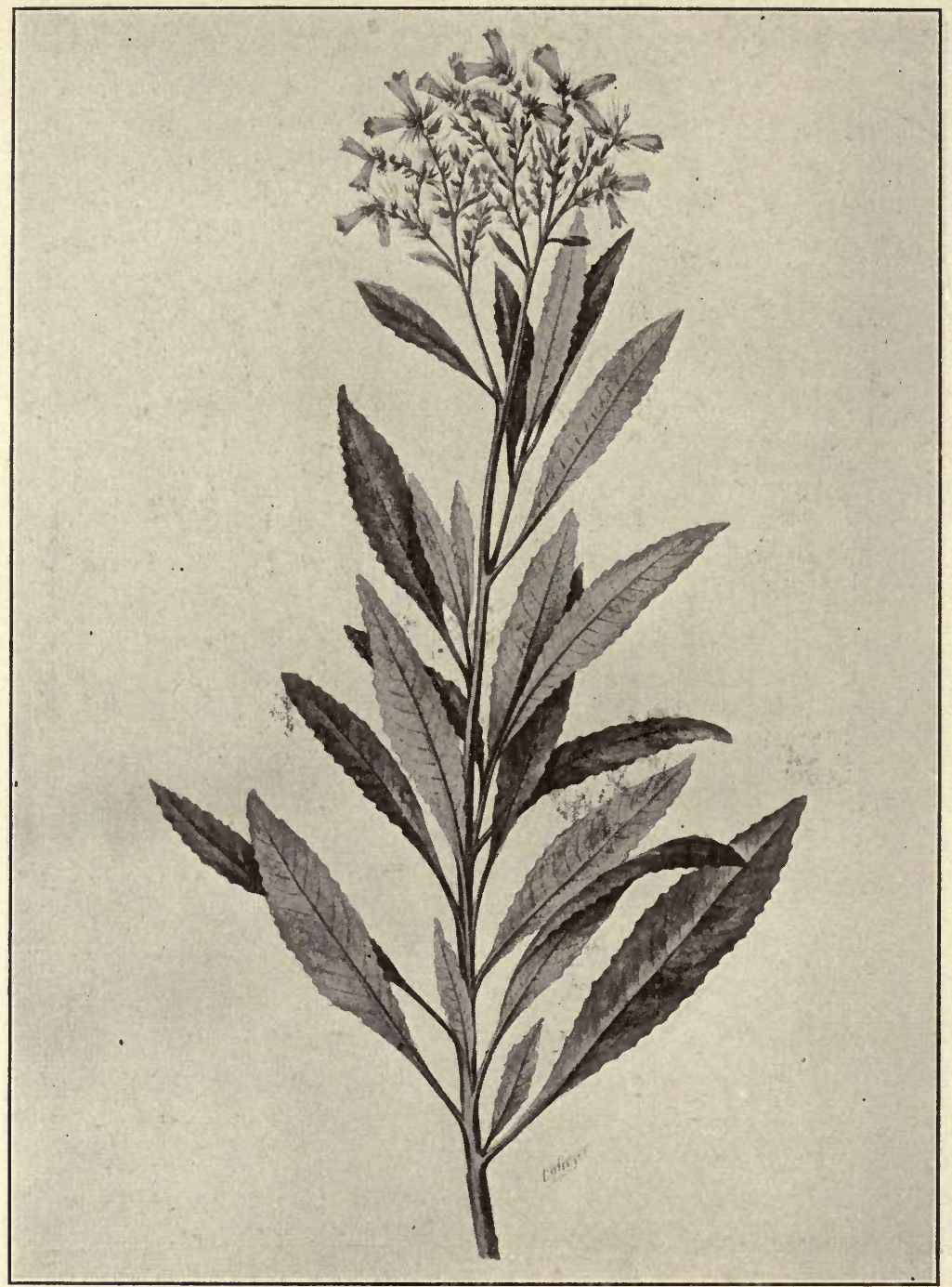

Fig. 368. Yerba Sante (Eriodictyon californicum), a low, evergreen, aromatic shrub, the leaves and stems being covered with a resinous exudation. The leaves are lanceolate, irregularly serrate or nearly entire, and woolly hairy beneath; the flowers are violet or purple in color, and occur in cymose panicles.-Bureau of Plant Industry, U. S. Department of Agriculture. 
black, more or less curved pieces, which are quite mucilaginous and astringent to the taste. The drug contains a gluco-alkaloid, consolidin, and an alkaloid, cynoglossine. It also contains a small amount of amylo-dextrin, i.e., starch which is not colored blue with iodine, and tannin. The root and herb of HOUND'S TONGUE (Cynoglossum officinale) are both used in medicine. The drug contains the powerful alkaloid cynoglossine, which resembles curarine in its action; and the gluco-alkaloid, consolidin.

$e$. VERBENACE E OR VERVAIN FAMILY.-The plants are chiefly herbs or shrubs with usually opposite or verticillate leaves and more or less irregular flowers (Fig. 369).

To this family belongs the group of verbenas, some of which are used in medicine, as blue vervain (Verbena hastata), which resembles eupatorium in its medicinal properties; nettle-leaved vervain ( $V$. urticifolia), which contains a bitter glucoside. The drug LIPPIA MEXICANA consists of the leaves of Lippia dulcis mexicana, and contains a volatile oil, the camphor lippiol, tannin, and quercetin. Lippia citriodora, found growing in the central part of South America, contains a volatile oil, of which citral is a constituent. TEAK-WOOD, which is one of the hardest and most valuable of woods, is derived from the teak tree (Tectona grandis), a large tree indigenous to Farther India and the East Indies.

f. LABIAT E OR MINT FAMILY.-The plants are mostly aromatic herbs or shrubs, with square stems, simple, opposite leaves, bilabiate flowers, and a fruit consisting of four nutlets. The calyx is persistent, regular or 2-lipped and mostly nerved. The corolla is mostly 2-lipped, the upper lip being 2 -lobed or entire, and the lower mostly 3 -lobed. The stamens are adnate to the corolla tube, and are either 4 and didynamous, or 2 perfect and 2 aborted. The ovary is deeply 4-lobed (Fig. 280, I).

The Labiatæ are especially distinguished on account of the volatile oils which they yield, and a few contain bitter or glucosidal principles.

I. The following PLANTS ARE USED IN MEDICINE:

Scutellaria lateriflora (skullcap). The plant is a perennial herb producing slender stolons somewhat resembling those of 43 


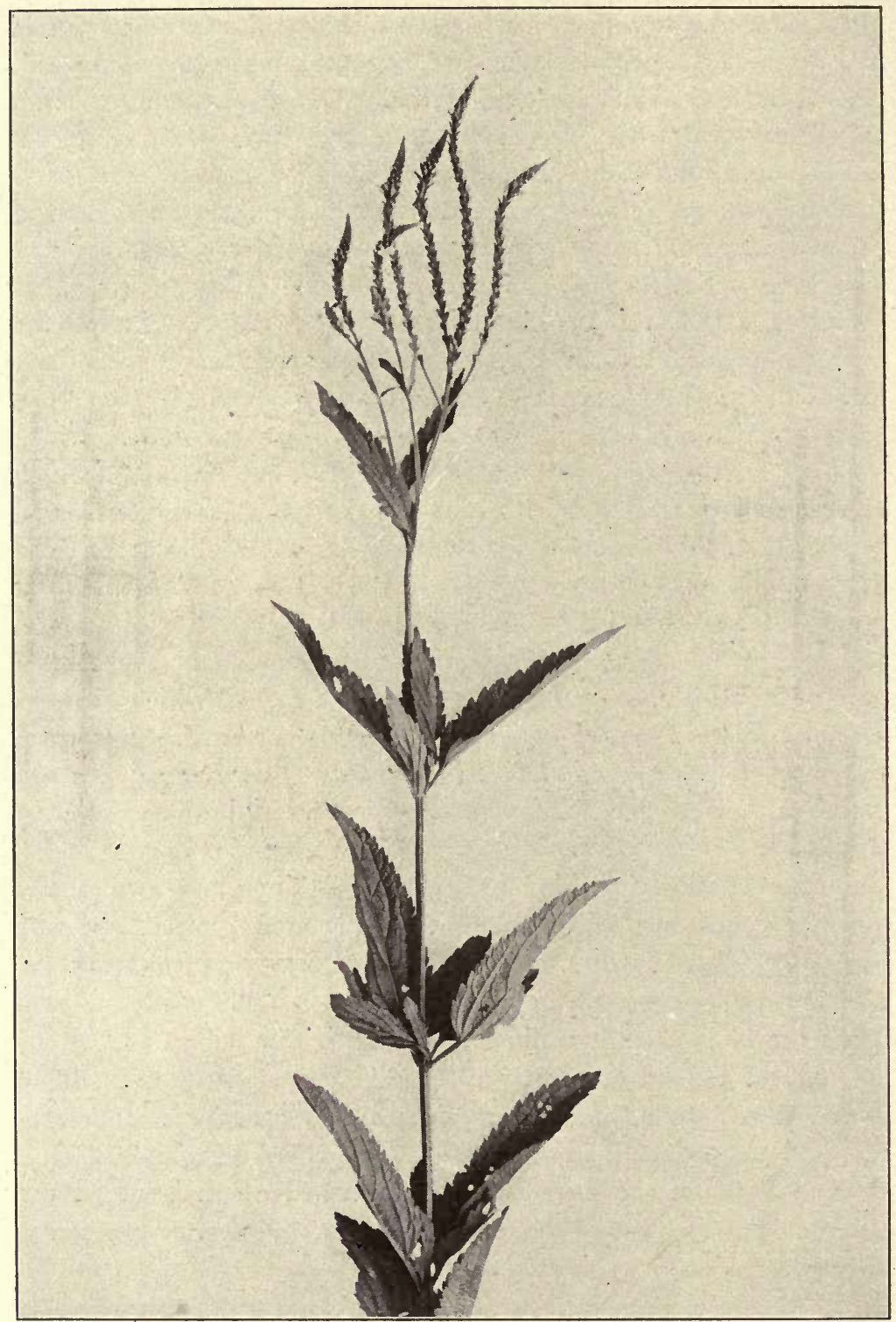

FIG. 369. Blue Vervain (Verbena hastata), a tall, perennial herb, with oblong-lanceolate leaves, and numerous terminal spikes of violet-blue flowers.-After Brown. 


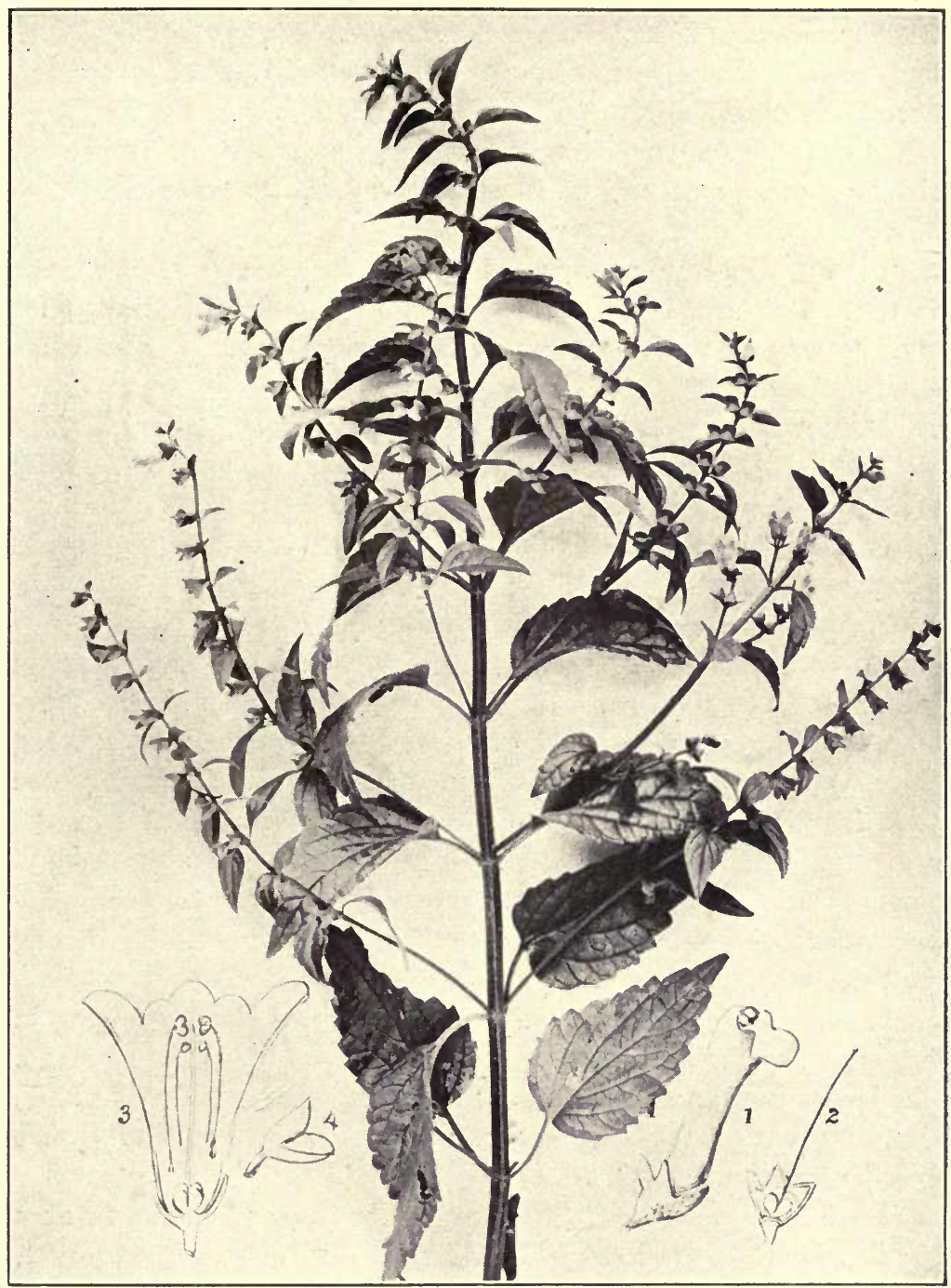

FIG. 370. Mad-dog Skullcap (Scutellaria lateriflora), a perennial herb growing in wet, shady places with an upright, quadrangular stem, bearing opposite ovate-oblong, serrate leaves, in the axils of which are formed the blue bilabiate flowers.-Bureau of Plant Industry, U. S. Department of Agriculture.

peppermint and spearmint. The stems are erect or ascending, commonly branching and from 22 to $55 \mathrm{~cm}$. high (Fig. 370). 
Marrubium vulgare (white hoarhound) is a perennial woolly herb with ascending branches; the leaves and flowering tops are used in medicine.

Salvia officinalis or garden sage is a perennial, somewhat shrubby, pubescent herb. The leaves are ovate, crenulate. The flowers are bluish, somewhat variegated, the calyx and corolla both being deeply bilabiate. Only the two anterior stamens are fertile (bear anthers); the connective is transverse, the upper end bearing a perfect pollen-sac, and the lower a somewhat enlarged rudimentary pollen-sac (Fig. 223, F).

Hedeoma pulegioides (American pennyroyal) (Fig. 37I).

Mentha species.-The plants are nearly glabrous, diffusely branching herbs, which form leafy stolons that are perennial (Fig. 184). The leaves and flowering tops of both Mentha piperita (Fig. 372) and Mentha spicata are official.

2. Volatile oils of the following plants are official:

Rosmarinus officinalis is a shrub growing in the Mediterranean countries. The plant has linear, coriaceous leaves, and bluish, bilabiate flowers, the middle lobe of the lower lip of the corolla being large, concave, and toothed on the margin. The flowering tops yield from I to I.5 per cent. of oil which is composed of I 5 to $I \delta$ per cent. of borneol; about 5 per cent. of bornyl acetate; and pinene, camphene, camphor, and cineol. There are two commercial varieties of the oil, the Italian and French, the latter having the finer odor.

Lavandula officinalis (garden lavender) is a shrub growing in the Northern Mediterranean countries, as well as in England. The leaves are linear, coriaceous ; the flowers are small, light blue, bilabiate, with a tubular calyx, and occur in opposite cymes (verticillasters).

The oil is derived from the fresh flowering tops, the flowers yielding about 0.5 per cent. Two kinds of oil are on the market, namely, French and English. The French oil contains 30 to 45 per cent. of 1-linalyl acetate; linalool; geraniol, both of which latter constituents occur free and as esters. The English oil contains about 5 to Io per cent. of linalyl acetate and a slight amount of cineol. Spike lavender (Lavandula Spica) is sometimes distilled with true lavender (see p. 679). 


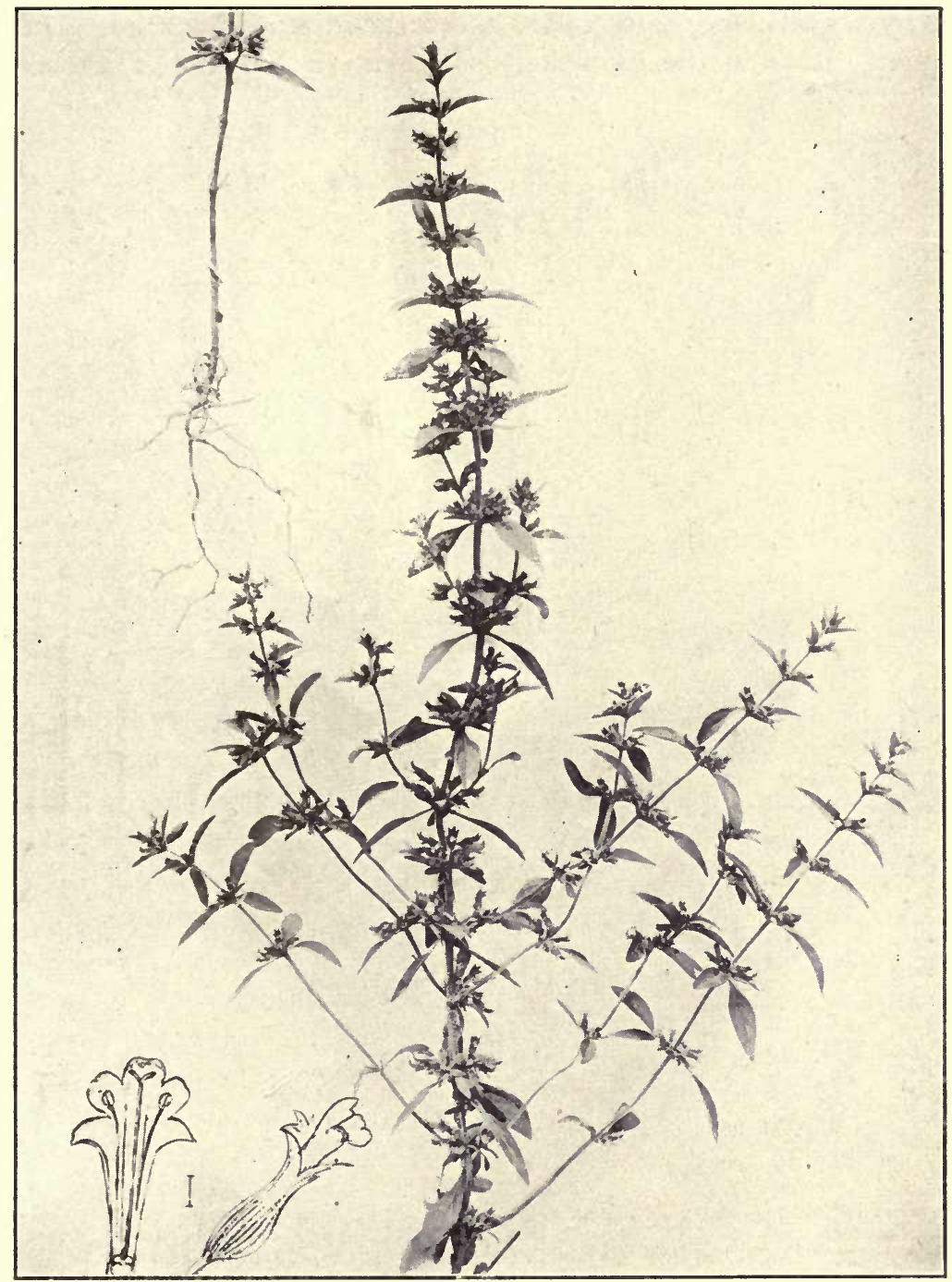

Fig. 37r. American Pennyroyal (Hedeoma pulegioides), a low, annual plant, growing in dry soil; having small, opposite, elliptical leaves; and loose clusters of bilabiate flowers, often forming terminal leafy racemes.-Bureau of Plant Industry, U. S. Department of Agriculture.

Thymus vulgaris (garden thyme) is a small shrub having linear or linear-lanceolate leaves, and pale blue flowers with 
strongly bilabiate, hairy calyx, and occur in axillary cymes. The plant grows in the mountains of Southern France. The herb

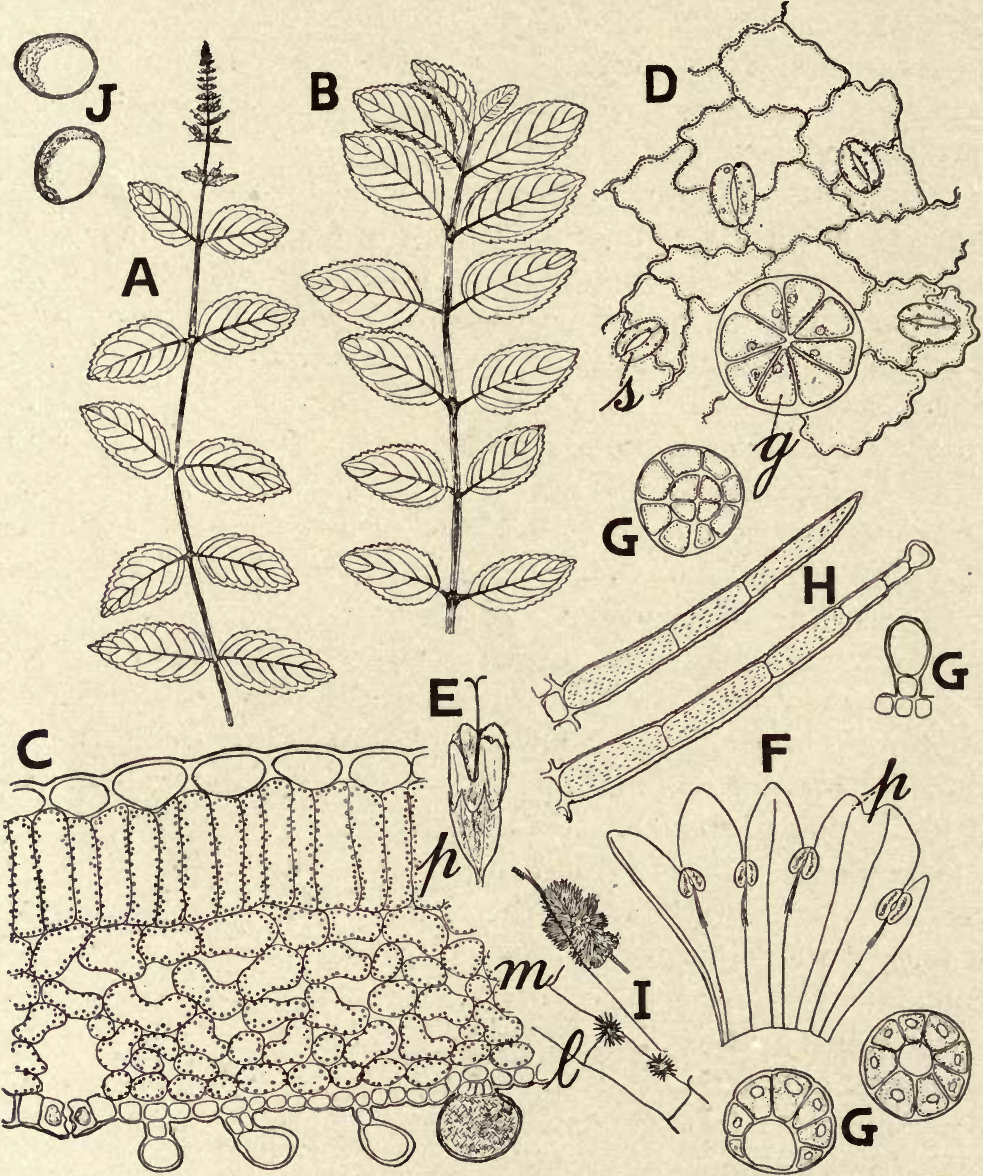

FIG. 372. Peppermint (Mentha piperita): B, portion of shoot showing petiolate leaves; C, transverse section of leaf showing several forms of glandular hairs on lower surface. loose parenchyma $(\mathrm{m})$ and palisade cells $(\mathrm{p})$; D, lower surface of leaf showing stoma $(\mathrm{s})$ and glandular hair $(\mathrm{g})$. Spearmint (Mentha spicata): A, portion of shoot showing flowers and nearly sessile leaves; E, flower; F, outspread corolla showing cleft posterior lobe (p) and the four adnate, included stamens; G, H, hairs from calyx; I, sphere crystals (sphærites) of a carbohydrate found in the corolla and style; $\mathrm{J}$, pollen grains.

contains from 0.3 to 0.9 per cent. of volatile oil, which is of a dark reddish-brown color, and contains from 20 to 25 per cent. of thymol; and cymene, 1-pinene, borneol and linalool. The Spanish 
oil of thyme contains from 50 to 70 per cent. of carvacrol, but no thymol.

3. Of other plants of the labiate which are of interest, the following may be mentioned:

Lavandula Spica yields oil of spike, which has an odor of lavender and rosemary. The oil contains camphor, borneol, cineol, linalool, and camphene.

Origanum Majorana (Sweet marjoram) is an annual cultivated herb that has more or less oval, entire leaves, white flowers, and an aromatic odor and taste. It produces a volatile oil which contains terpinene and d-terpineol. Origanum vulgare (Wild marjoram) grows in fields and waste places in the Eastern United States and Canada. The calyx is equally 5 -toothed and the corolla varies from white to pink or purple. It contains a volatile oil having an odor somewhat like that of the oil of O. Majorana. Origanum hirtum and $O$. Onites yield an origanum oil containing carvacrol and cymene. The oils obtained from Cretian Origanum are the source of commercial carvacrol.

Pogostemon Patchouli, a plant cultivated in Southern China and the East and West Indies, furnishes the oil of PATCHOULI used in perfumery. Patchouly camphor and cadinene have been isolated from the oil, but nothing, however, appears to be known of the nature of the odorous principle.

Hyssopus officinalis (Garden hyssop) contains about 0.5 per cent. of volatile oil to which the characteristic odor of the plant is due. Satureia hortensis (summer savory) yields a volatile oil containing carvacrol, cymene and terpene. Ocimum Basilicum (Sweet basil) is an herb growing in Europe, and yields an oil which is used in the preparation of Chartreuse and similar liquors. The oil contains methyl chavicol, linalool, cineol, camphor, pinene, and terpin hydrate.

Melissa officinalis (Sweet balm) is a perennial herb indigenous to Europe and Asia and also cultivated. The leaves are ovate, dentate, and the flowers are bilabiate, the calyx being bell-shaped and 13 -nerved. The taste is bitter, this being due to a bitter principle. The fresh leaves are quite aromatic and produce from O.I to 0.25 per cent. of a volatile oil containing a stearoptene.

Several species of Monarda known as HORSEMINT or wild 


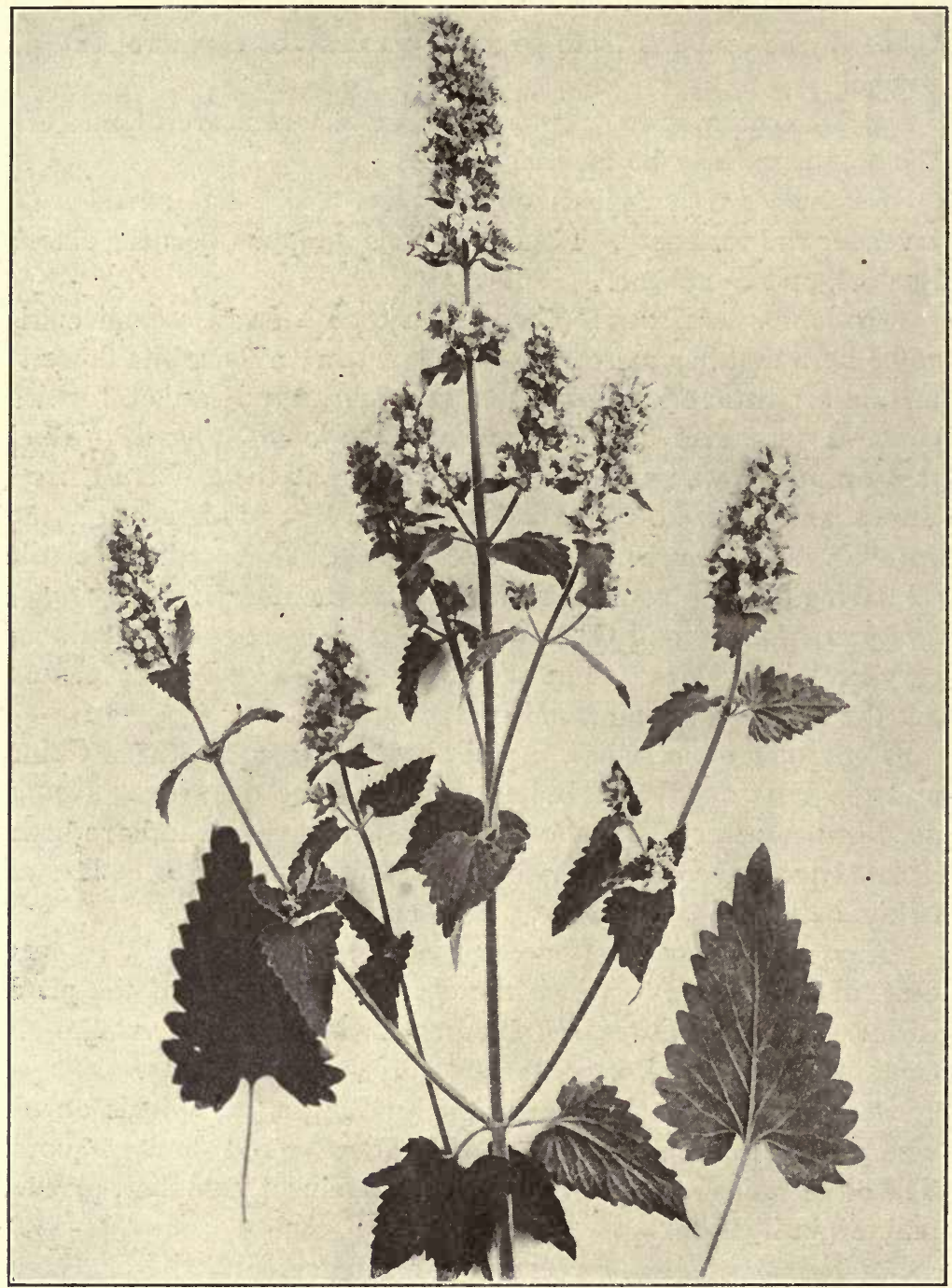

FIG. 373. Cat Mint or Catnip (Nepeta Cataria), a hardy perennial herb with heartshaped, oblong, deeply crenate, velvety, whitish green leaves, bearing in the axils dense whorls of light purplish flowers. It is a common weed and derives its common name from the fact that cats are fond of it, eating it and rubbing themselves upon it.-Bureau of Plant Industry, U. S. Department of Agriculture.

bergamot are used in medicine. The oil was at one time official. The oil of Monarda punctata, a perennial herb found growing 
from New York to Texas, contains thymol, thymoquinone, hydrothymoquinone, carvacrol, cymene, and limonene.

Nepeta Cataria (catnip) is a perennial herb naturalized in the United States from Europe (Fig. 373). It contains a bitter

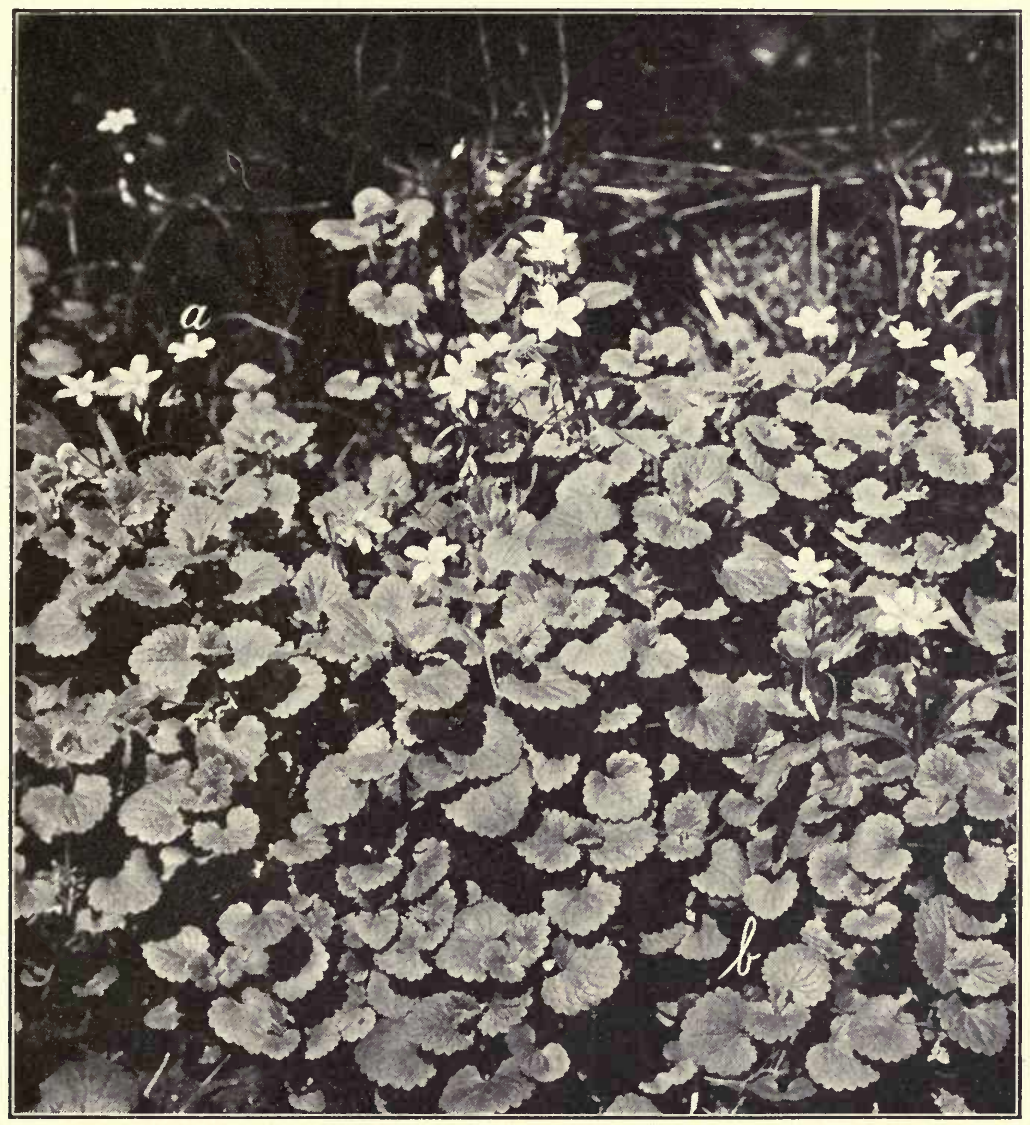

Fig. 374. (b) A mass of Ground Ivy (Nepeta hederacea) growing on an embankment, with (a) Spring Beauty (Claytonia virginica).

principle, tannin, and an oxygenated volatile oil. Nepeta hederacea or GROUND IVY is a creeping perennial herb with blue bilabiate flowers and reniform leaves (Fig. 374). It contains a bitter principle and volatile oil. Cunila origanoides, or American DIT- 
TANY, is a small perennial herb growing from New York to Florida, and characterized by its pungent aromatic properties.

Leonurus Cardiaca or MOTHERWORT is a perennial herb naturalized in the United States and Canada from Europe. The

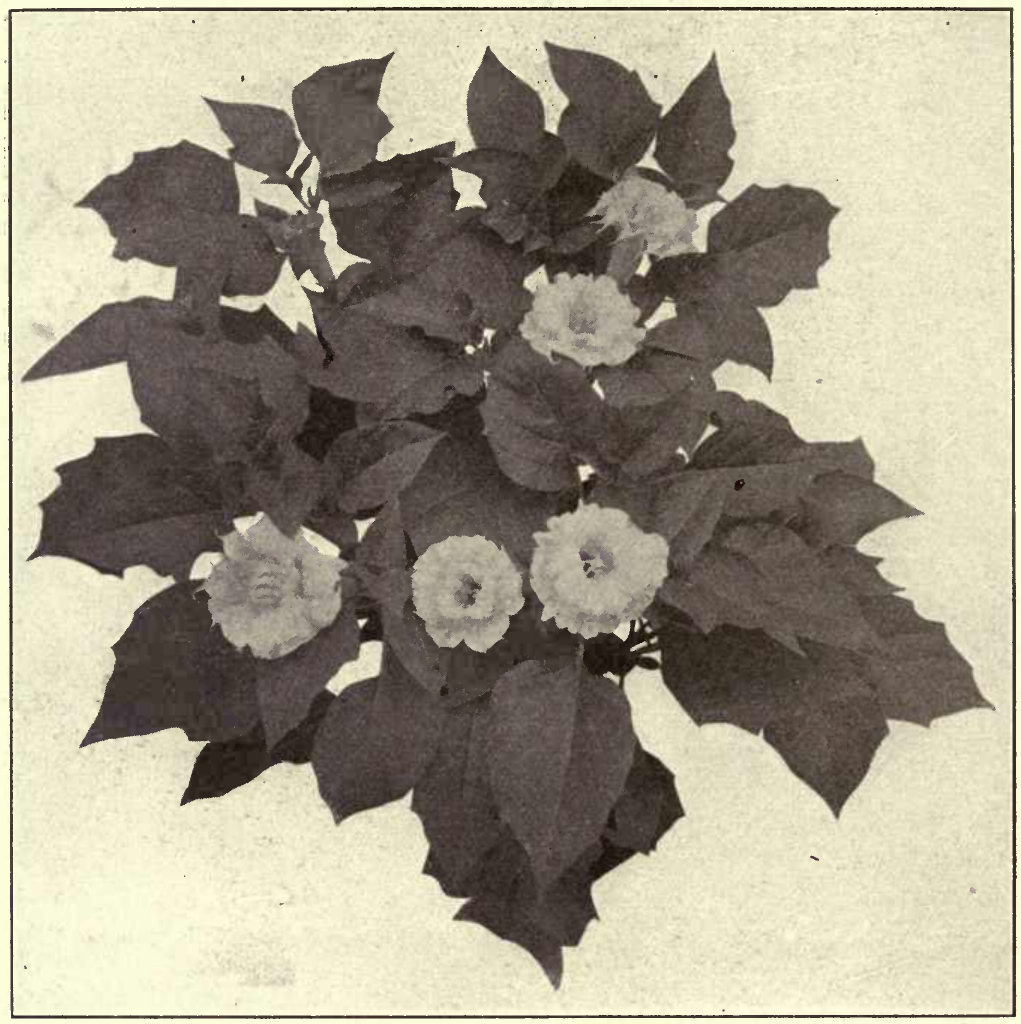

FIG. 375. Flowering tops of Datura fastuosa flava, a variety of a plant growing in the East Indies, the Malay Archipelago, and tropical Africa, containing much the same constituents as Datura Stramonium. - After Newcomb.

leaves are 3 -lobed; the calyx is 5 -nerved and with 5 priclily teeth; the corolla varies from white to pink or purple. The plant contains a volatile oil of rather an unpleasant odor; a bitter principle; two resins and several organic acids, namely, malic, citric and tartaric. 
f. SOLANACE $\approx$ OR POTATO FAMILY.-The family includes herbs, shrubs, trees, and vines, which are most abundant in tropical regions. The leaves are alternate and vary from entire

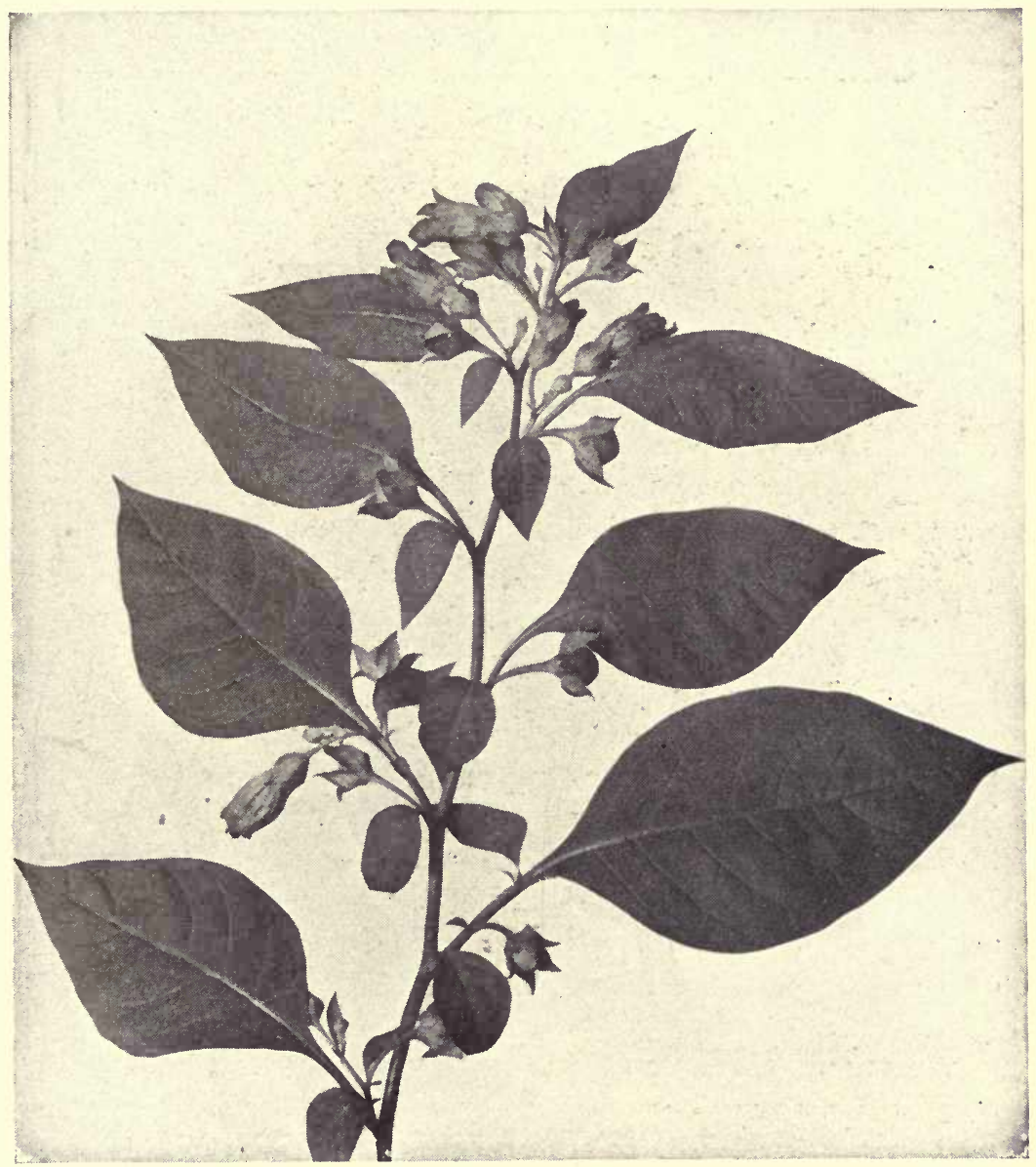

Fig. 376. Atropa Belladonna showing the alternate, petiolate, ovate, entire leaves, in the axils of which are the solitray fruits or flowers with large. leafy bracts.

to dissected. The flowers are mostly regular, except in hyoscyamus. The stamens are adnate to the corolla tube, the anthers connivent, and the pollen-sacs apically or longitudinally dehiscent. The fruit is a berry or capsule in which the sepals mostly persist 
and sometimes become enlarged or inflated. The seeds have a large reserve layer, and the embryo is frequently curved.

Datura Stramonium (Jimson weed, thorn apple) is a large, annual, branching herb, found in waste places in the United States. and parts of Canada, being naturalized from Asia. The leaves and flowering tops are official. The large, spiny capsule is shown in Fig. 236, B. D. fastuosa (Fig. 375) has similar medicinal properties.

Atropa Belladonna (Deadly nightshade) is a perennial herb producing a large, fleshy root, which is used in medicine (Fig. $376)$, as are also the leaves and flowering tops.

Scopolia carniolica is a perennial herb with nearly entire or somewhat irregularly toothed leaves. The flowers are campanulate and dark purple. The fruit is a globular, transversely dehiscent capsule (pyxidium).

Hyoscyamus niger or henbane is a biennial herb (Fig. 377), the leaves and flowering tops of which are official.

Pichi is the dried leafy twigs of Fabiana imbricata, a shrub with small, scale-like leaves, indigenous to Chile. It contains a volatile oil ; o.I per cent. of a bitter alkaloid; a glucoside resembling æsculin; and a bitter resin.

Solanum Dulcamara (Bitter sweet) is a perennial, climbing herbaceous plant, indigenous to Europe and Asia and naturalized in the Northern United States. The branches which have begun to develop periderm are collected, and were formerly official as Dulcamara. They are cut into pieces 10 to $20 \mathrm{~mm}$. long which are greenish-brown, hollow, with a sweetish, bitter taste and contain a glucoside, dulcamarin, and the gluco-alkaloid solanine (Fig. 378).

Solanum carolinense (Horse nettle) is a perennial herb having numerous yellow prickles on the branches and leaves. The leaves are oblong or ovate, irregularly lobed (Fig. 379). The flowers are white or light blue and occur in lateral cymes. The fruit is an orange-yellow, glabrous berry. The plant is common in waste places in Canada and the United States east of the Mississippi. The root and berries are used in medicine. The root is simple and quite long, 5 to $10 \mathrm{~mm}$. in diameter, yellowish-brown, the bark readily separating from the wood. It has a narcotic odor 


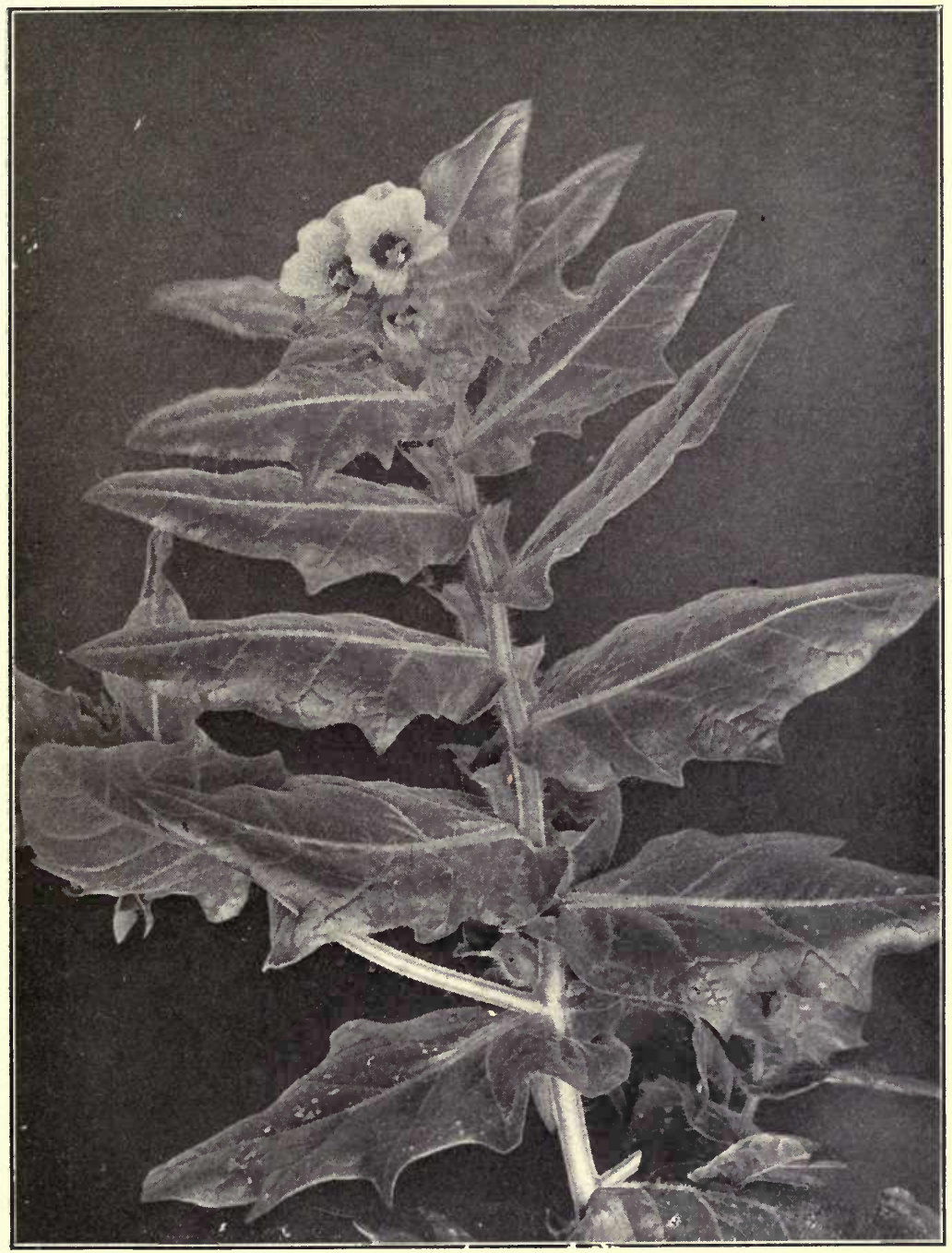

Fig. 377. Flowering branch of Hyoscyamus niger annuum, showing sessile, acutely lobed leaves and two of the funnel-form flowers.-After Newcomb.

and a sweetish, bitter, somewhat acrid taste. Both the root and berries contain the gluco-alkaloid solanine, which varies from O.I5 (in the root) to 0.8 per cent. (in the berries). 


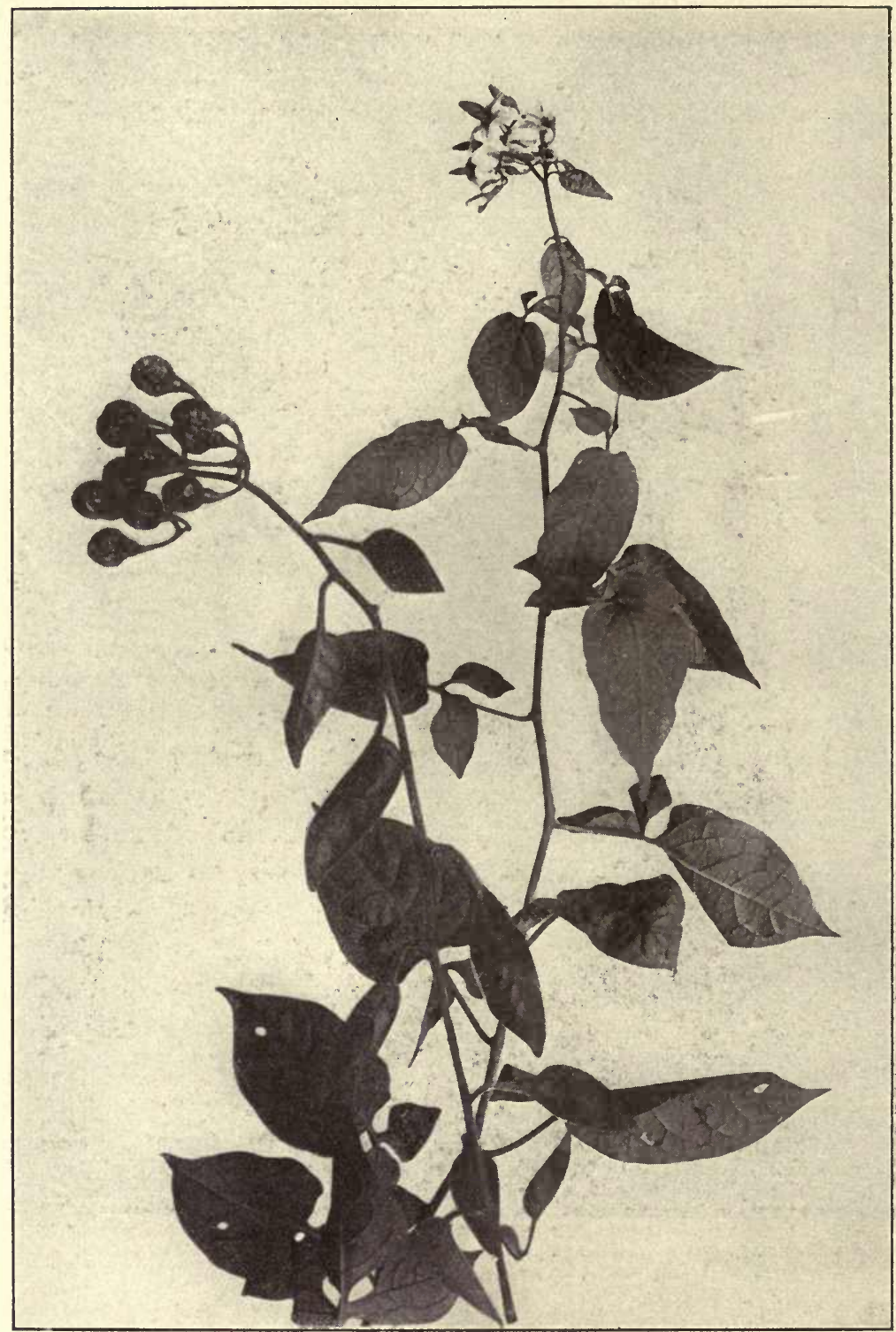

Fig. 378. Bittersweet (Solanum Dulcamara), a perennial, climbing or twining shrub, with several types of leaves, varying from ovate heart-shaped. The flowers are blue or purplish and hang in ioose cymose clusters. The fruit is an ovoid, reddish berry and very poisonous. It is sometimes eaten by children, producing fatal effects.-After Brown. 
Capsicum fastigiatum (Cayenne pepper) is a perennial, smooth, herbaceous, or somewhat shrubby plant, with ovate, acuminate, petiolate, entire leaves; the flowers are greenish-white, and solitary

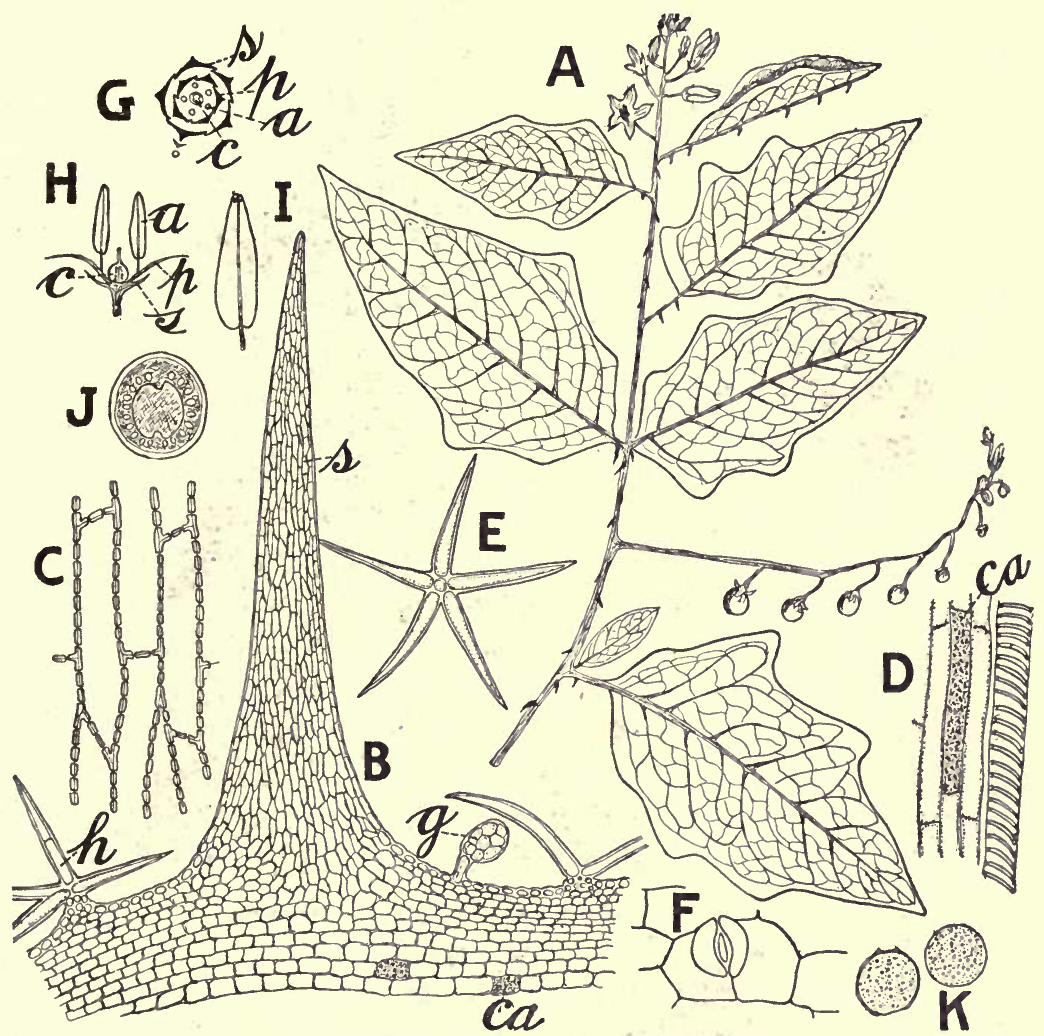

FIG. 379. Horse nettle (Solanum carolinense): A, portion of shoot showing flowers and fruits and spines on leaves and stem; B, longitudinal section of spine (s) and portion of stem showing glandular $(\mathrm{g})$ and non-glandular $(\mathrm{h})$ hairs, and cells containing small sphenoidal crystals (ca); C, thick-walled, strongly lignified cells of spine; D, portion of fibrovascular bundle showing small sphenoidal crystals (ca) of calcium oxalate in the cells accompanying the sieve; E, stellate, non-glandular hair; F, stoma of stem; G, diagram cf cross section of flower showing sepals (s), petals ( $p)$, stamens (a), ovary (c); H, longitudinal section of flower; I, stamen showing terminal pores; J, cross section of 2-locular berry; $\mathrm{K}$, pollen grains, $30 \mu$ in diameter.

in the axils of the leaves. The fruit is official and is known in commerce as African or Cayenne pepper. This plant and a number of other species of Capsicum are indigenous to tropical 
America, where they are extensively cultivated, as also in Africa and India.

Nicotiana Tabacum (Virginia Tobacco plant) is a tall annual herb indigenous to tropical America and widely cultivated. The stem is simple, giving rise to large, pubescent, ovate, entire, decurrent leaves, the veins of which are prominent and more or less hairy. The flowers are long, tubular, pink or reddish, and occur in terminal spreading cymes. The various forms of tobacco are made from the leaves, which are hung in barns, whereby they undergo a slow drying or process of curing. Other species of Nicotiana are also cultivated, as $N$. persica, which yields Persian tobacco; and N. rustica, the source of Turkey tobacco. Tobacco leaves contain from 0.6 to 9 per cent. of the alkaloid nicotine; an aromatic principle nicotianin or tobacco camphor, to. which the characteristic flavor is due and which is formed during the curing of the leaves. The dried leaves yield from 14 to $\mathrm{x} 5$ per cent. of ash, consisting in large part of potassium nitrate.

Solanum tuberosum (Potato plant) is indigenous to the Andes region of South America and is extensively cultivated on account of the edible tubers. The tubers (potatoes) contain about 75 per cent. of water, 20 per cent. of starch, and nearly 2 per cent. of proteins in the form of large protein crystalloids. The fruits and young shoots contain the gluco-alkaloid solanine and the alkaloid solanidine. The tubers contain a small amount of solanine, which is increased when they are attacked by certain fungi or exposed to light. (Consult pp. 142, 148, 194, and 198.)

Besides the potato plant, several other plants belonging to the Solanaceæ yield vegetables, as the Tomato plant (Solanum Lycopersicum) and the Egg plant (Solanum Melongena). Various cultivated species of Capsicum annum furnish the common red peppers of the market.

g. SCROPHULARIACEA OR FIGWORT FAMILY.The plants are herbs, shrubs or trees with opposite or alternate leaves and perfect, mostly complete and irregular flowers. The corolla and stamens show some resemblance to those of the Labiatæ in that the corolla is frequently more or less 2-lipped and the stamens are didynamous. The fruit is a dehiscent capsule and 
the seeds have a reserve layer and a straight or slightly curved embryo. ,

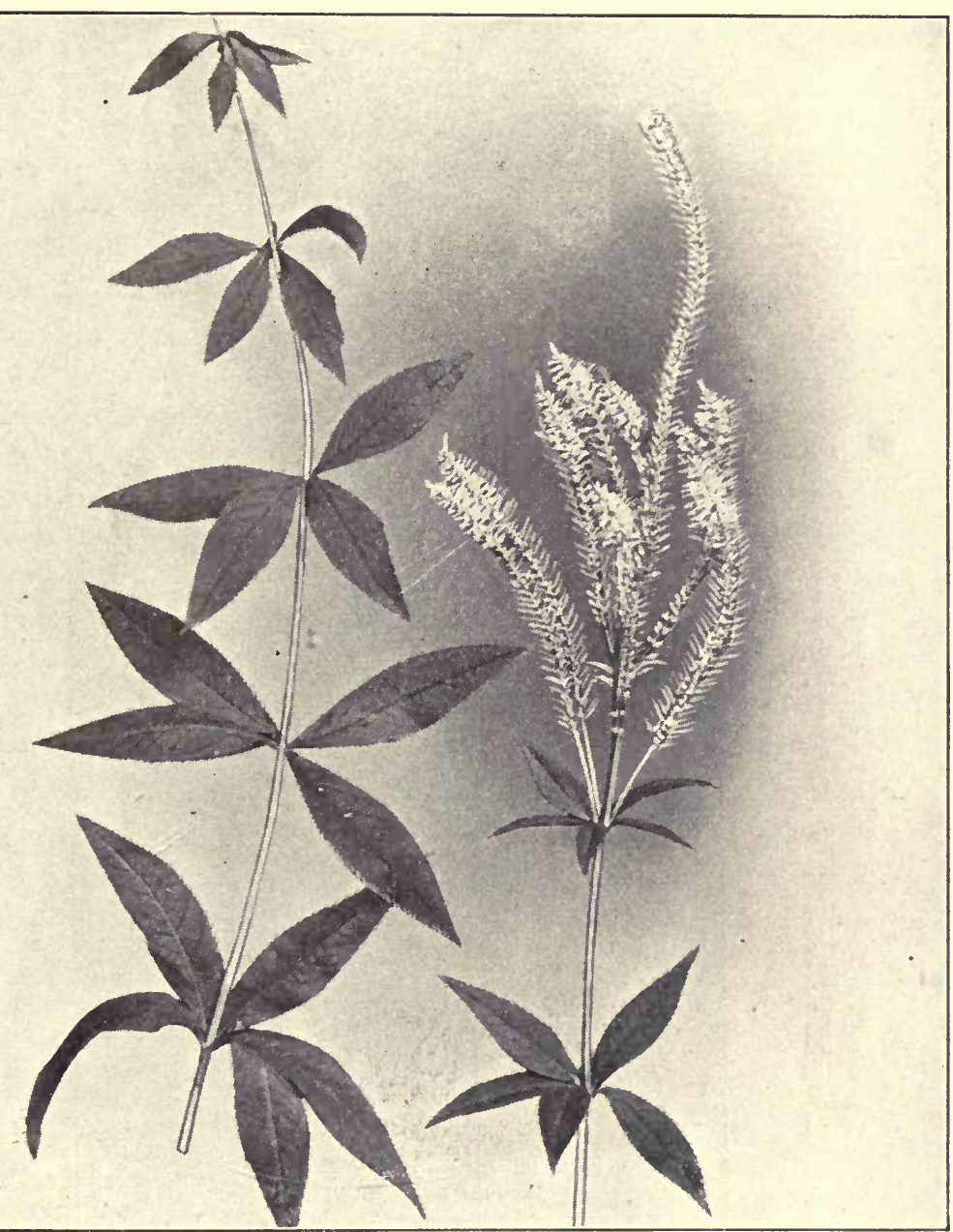

FIG. 380. Culver's-root (Leptandra virginica) showing the verticillate leaves and the long spike-like terminal racemes.

Leptandra virginica (Veronica virginica), or Culver's root, is a perennial herb with leaves in whorls of 3 to 9 , those on the upper part of the stem being opposite. They are lanceolate, serrate, 
and pinnately veined; the flowers are white or bluish, tubular, and in dense racemes. The rhizome and roots are official (Fig. 380).

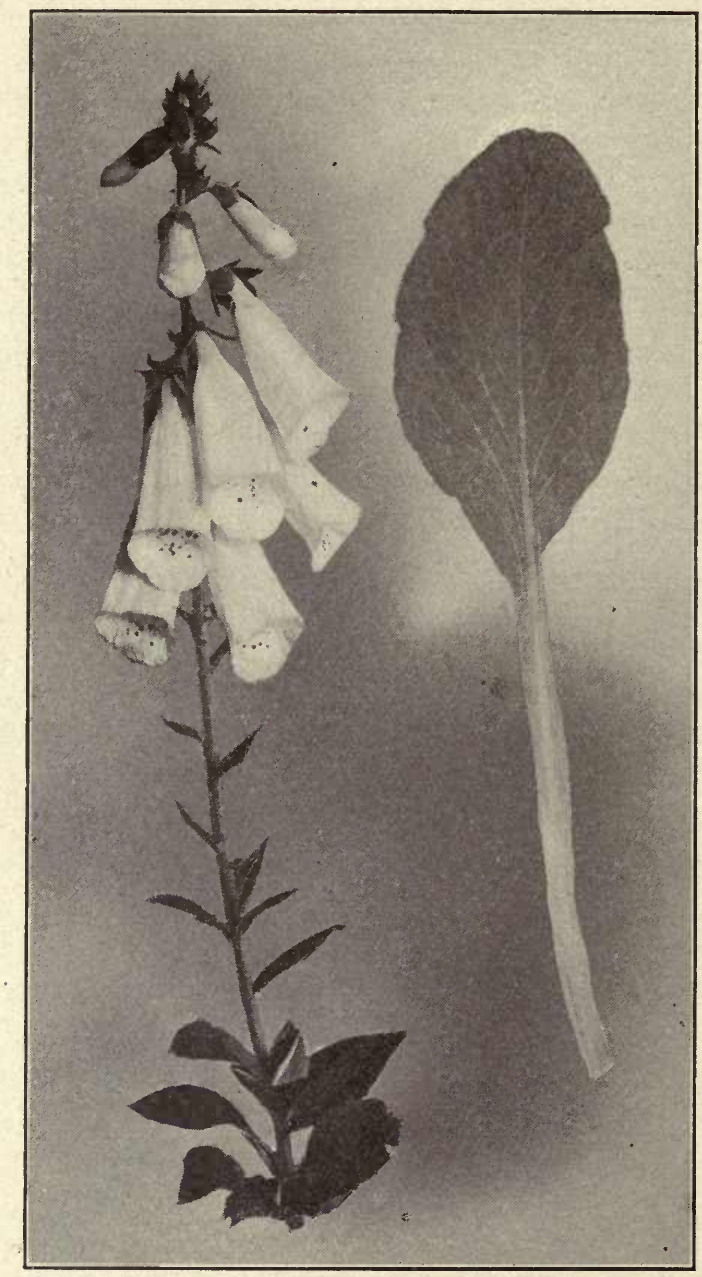

FIG. 38r. Foxglove (Digitalis purpurea): The terminal I-sided raceme with slightly irregular, declined, tubular flowers, and a leaf of the first year's plant with long, winged or laminate petiole.

Digitalis purpurea (Foxglove) is a tall, biennial, pubescent herb, producing the first year a large number of basal leaves (Fig. 38I), and the second, a long raceme of drooping, tubular, 
slightly irregular, purplish flowers; the inner surface of the corolla is spotted, the stamens are didynamous, and the upper calyx segment is narrower than the others. The leaves are official in all the pharmacopœias.

The Scrophulariacea are well represented in the United States, and a number of the plants have medicinal properties. The common MULLeIN (Verbascum Thapsus) contains a volatile oil, two resins, and a bitter principle. The flowers of mullein contain the same principles and in addition a yellow coloring principle. Other species of Verbascum are used in medicine in different parts of the world.

ButTER-AND-EGGS (Linaria vulgaris) contains a crystalline principle, linariin, antirrhinic acid, a volatile oil, resin, and tannin. Several species of Scrophularia, as S. nodosa of Europe and $S$. marilandica of the Eastern United States, contain a pungent resin and a trace of an alkaloid. TURTLE-HEAD (Chelone glabra) (Fig. 382) contains a bitter principle and gallic acid. The plant of HYSSOP (Gratiola officinalis) of Europe contains gratiolin, a bitter glucoside, and gratiosolin. The leaves of Curanga amara of the East Indies contain a glucoside, curanjiin, which resembles digitalin in its action.

$h$. BIGNONIACE E OR TRUMPET-CREEPER FAMILY.-The plants are shrubs, trees or woody vines, and are represented in the United States by the catalpa tree (Catalpa bignonioides) and the trumpet creeper (Tecoma radicans). The bark, pods, and seeds of CATALPA have been used in medicine and contain a bitter principle, catalpin, a glucoside, and several crystalline principles. The TRUMPET CREEPER contains narcotic poisonous principles. The leaflets of CAROBA (Jacaranda Copaia) and other species of Jacaranda contain the alkaloid carobine, an aromatic resin, carobone, and a principle having the odor of coumarin.

$i$. PEDALIACE $\nexists$.- The plants are herbs indigenous to the Tropics of the Old World, some of which are now cultivated in the Tropics of both hemispheres. Benne oil (oil of sesame) is obtained from the seeds of Sesamum indicum by expression. It consists chiefly of a glycerite of oleic acid, a glycerite of linoleic acid, and myristin, palmitin, and stearin. It is a bland, non-drying oil and is used like olive oil. 


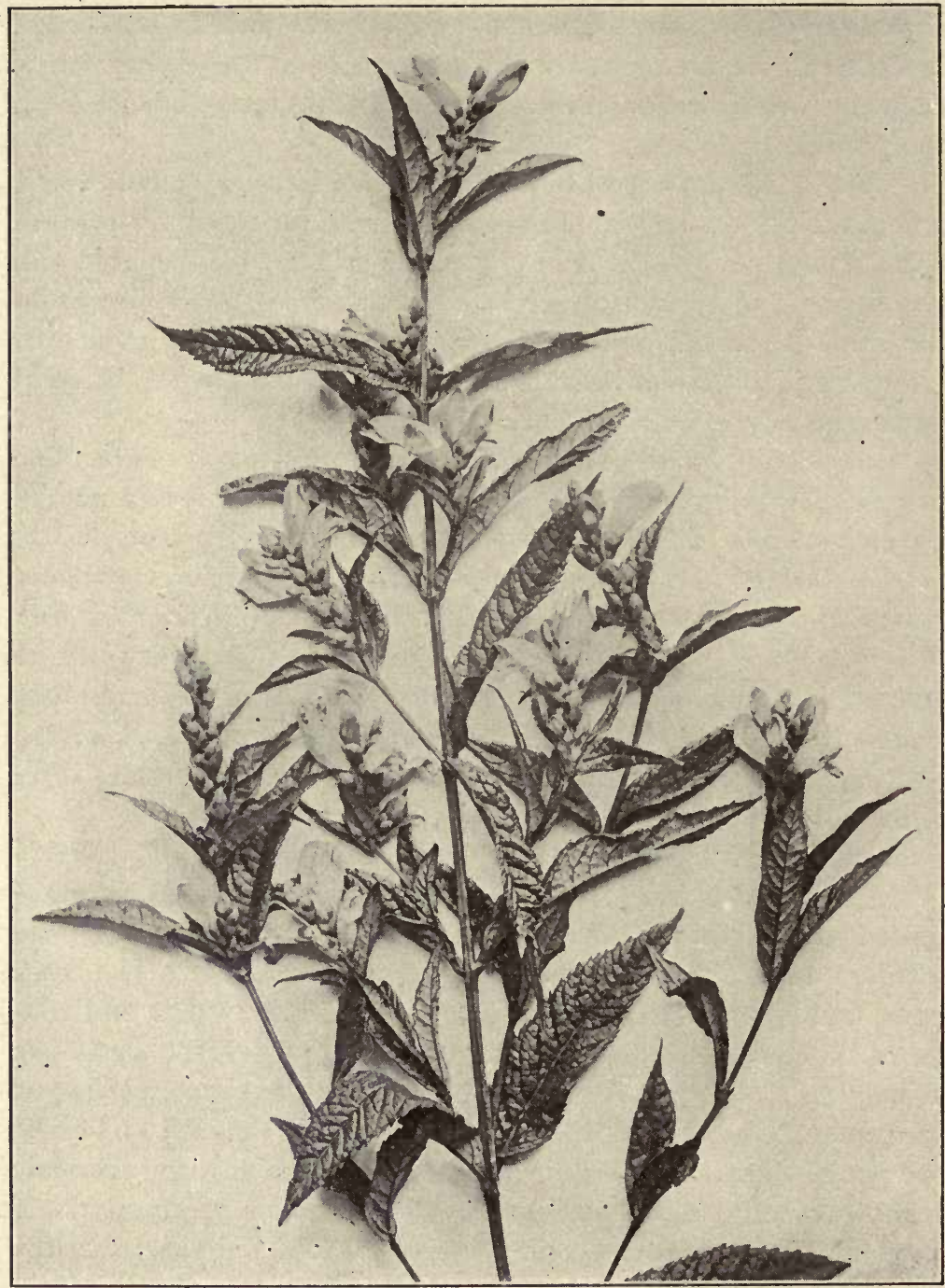

FIG. 382. Turtle-head (Chelone glabra), a perennial herb with lanceolate, serrate, opposite leaves and short, terminal spikes of whitish or purplish flowers. The corolla is bilabiate, the mouth slightly open, the upper lip broad and arched, suggesting the head of a turtle or snake, hence the origin of the common name.-Bureau of Plant Industry, U. S. Department of Agriculture. 


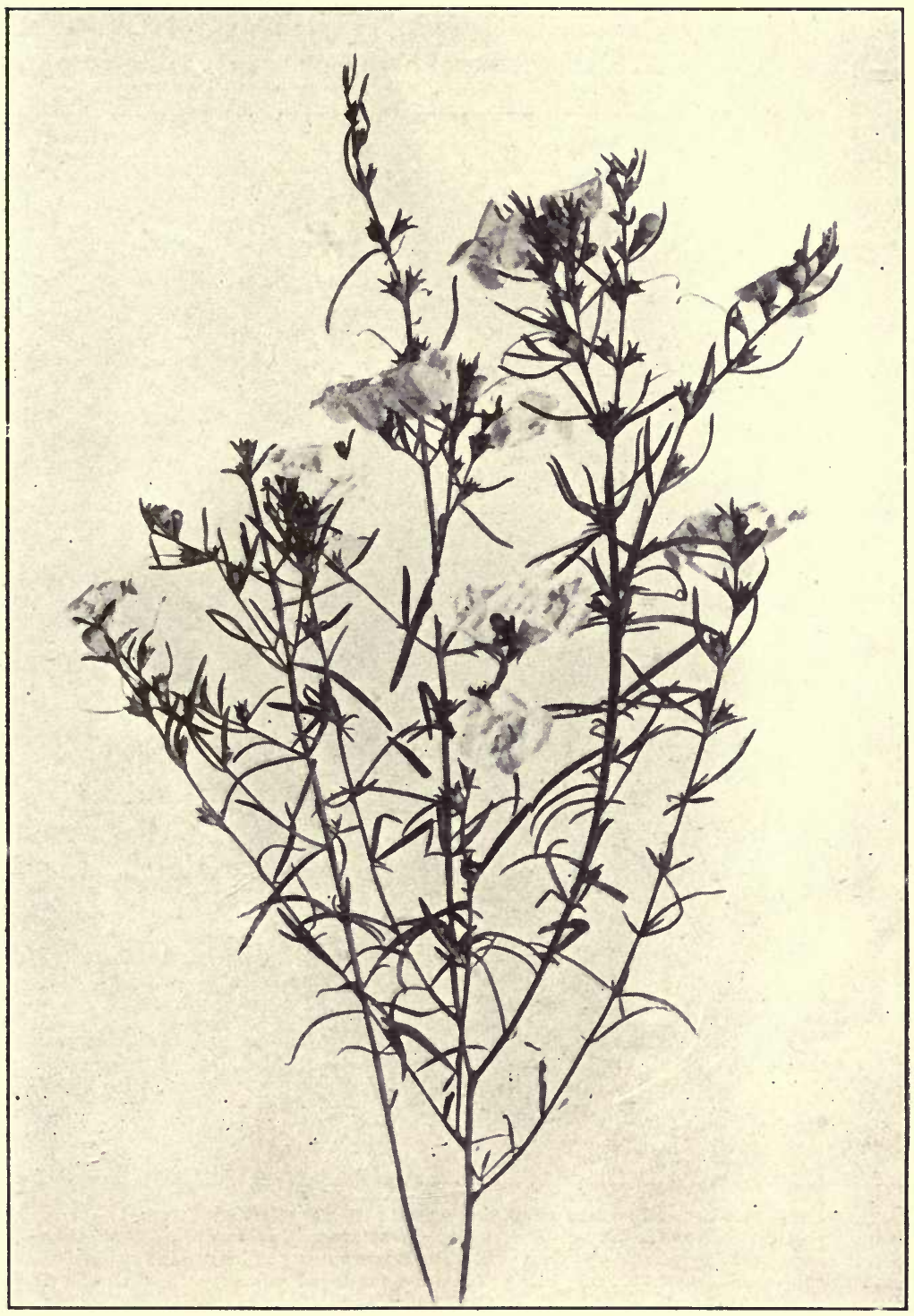

FIG. 383. Purple Gerardia (Gerardia purpurea, Fam. Scrophulariaceæ), a branching herb with linear leaves; and large, bright purplish-pink, bilabiate flowers.-After Brown. 
j. ACANTHACE $Æ$ OR ACANTHUS FAMILY.-The plants are mostly tropical perennial herbs, or shrubs with opposite

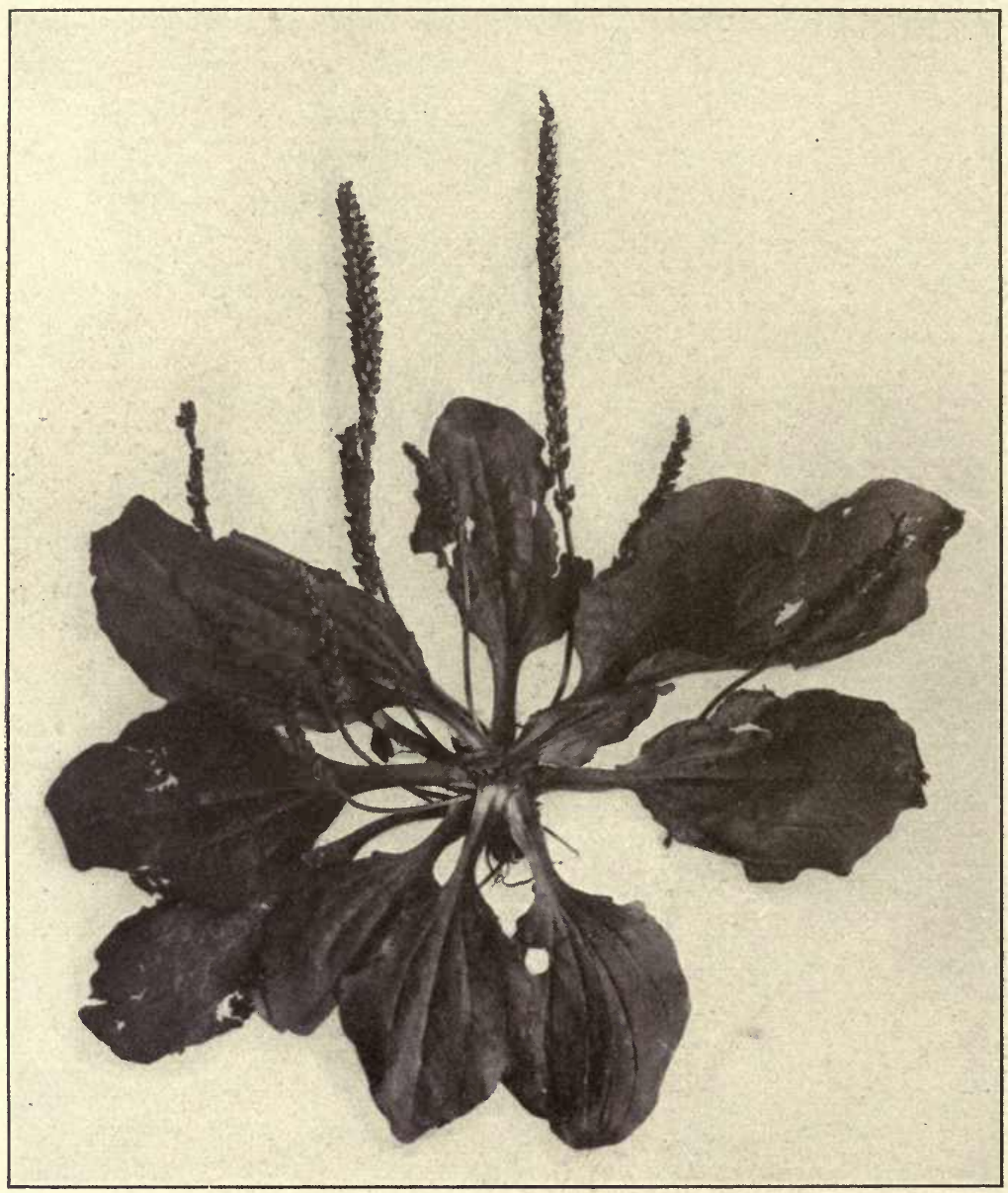

Fig. 384. Common Plantain (Plantago major). A very familiar weed found along waysides and in poorly kept lawns. The leaves are clustered, lying near the ground, broadly elliptical and with prominent parallel veins. The flowers occur in long, dense spikes which give rise to small, capsular fruits, being sometimes employed as a green bird food.-After Brown.

leaves; in the mesophyll or epidermal cells and parenchyma of the axis occur cystoliths. Several genera are represented in the United States, one of which, Ruellia (Ruellia ciliosa), is the source 


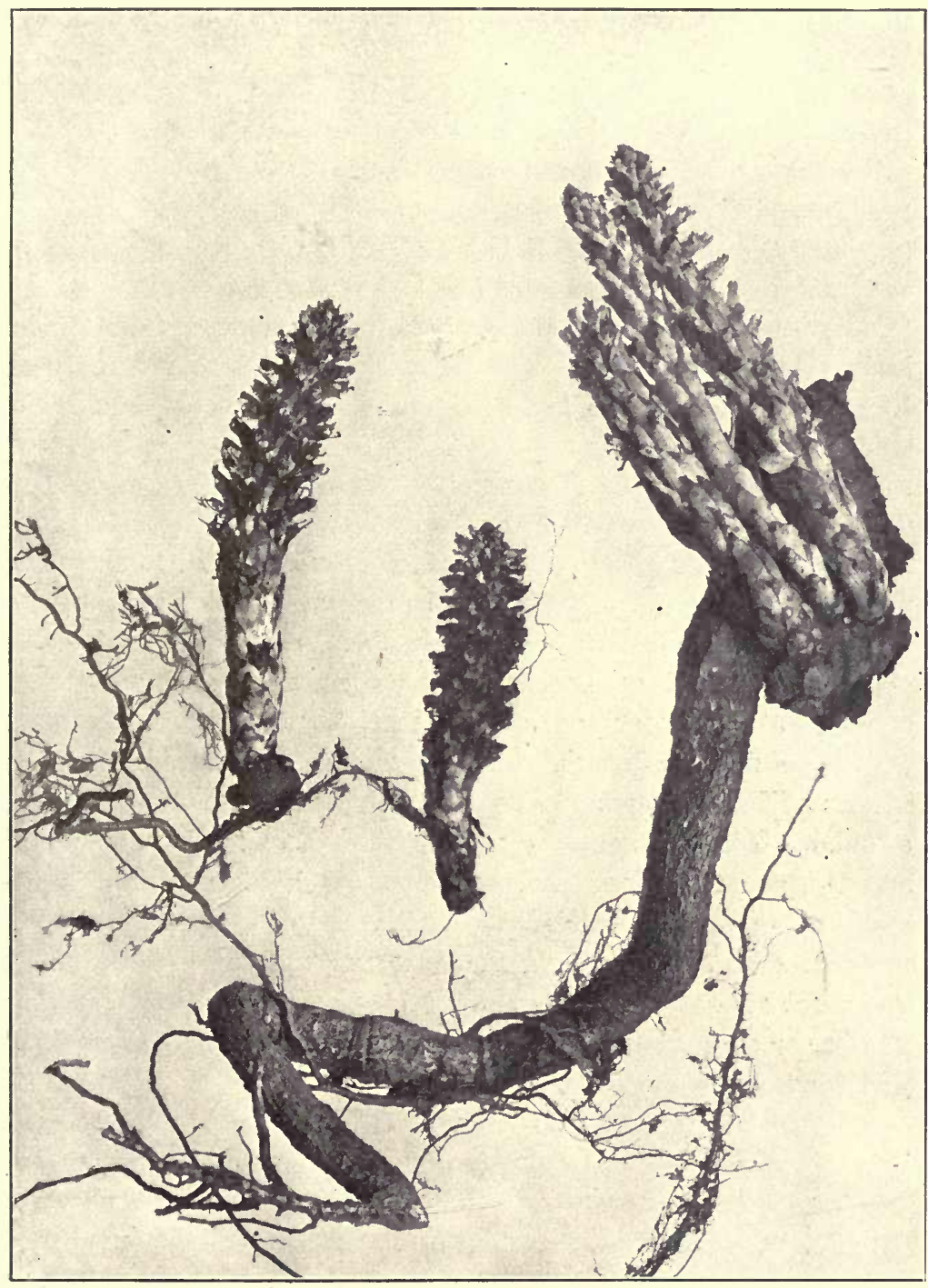

Fig. 385. Squaw-root, also known as Cancer-root (Conopholis americana), one of the Orobanchacece or root parasites. It is shown here growing on the roots of another plant. The flowering plants are from $\mathrm{I}$ to $2 \mathrm{dm}$. high, and consist of a cone-like stalk with fleshy scales surmounted by a spike of more or less yellowish flowers.-After Troth. 
of the spurious spigelia which has been on the market for some years past.

Ruellia ciliosa is a perennial herb which is distinguished from the other species of the genus Ruellia by the leaves, stems, and calyx being distinctly pubescent. The leaves are ovate-lanceolate, nearly sessile and entire; the flowers are blue,-sessile, solitary, or two or three in a cluster, in the axils of the leaves; the stamens are 4 , and exserted. The fruit is an oblong, terete capsule containing from 6 to 20 orbicular seeds. The plant is found from New Jersey and Pennsylvania to Michigan and as far south as Florida and Louisiana. Long cystoliths are found in some of the epidermal cells of both surfaces of the leaf.

Quite a number of the plants of the Acanthacex are used in the Tropics in medicine. One of these, Adhatoda Vasica of tropical Asia, contains the alkaloid vasicine, and is said to have the property of destroying algæ which grow in the rice swamps.

k. PLANTAGINACE $Æ$ OR PLANTAIN FAMILY.-The plants are annual or perennial herbs, represented by but few genera, but numerous species. The principal genus is Plantago, which includes 200 species that are widely distributed. Several species of Plantago are used in medicine. The common plantain (Plantago major) contains a glucoside, acubin; emulsin; and invertin, and the short rhizome, considerable starch. The seedcoat has an outer mucilaginous layer, and the mucilage of the seeds of Plantago Psyllium, $P$. arenaria (both of Europe), and $P$. Ispaghula (of the East Indies) is used as a sizing material. The seeds of a number of the species of Plantago are used as bird food, particularly for canaries.

l. OROBANCHACEA OR BROOM-RAPE FAMILY.This very interesting family is made up of plants which are parasitic upon the roots of other plants and are consequently rather light in color, as they develop no chlorophyll. Squaw-root or Cancer-root (Conopholis americana) has the flowers arranged in the form of a spike looking like an elongated cone, especially after the flowers have begun to turn brown (Fig. 385). Another little plant, also more or less white or yellow in color, is Beechdrops (Epifagus), which develops upon the roots of the beech. 
VI. ORDER RUBIALES.

The plants of this order are distinguished from all of the preceding Sympetalæ by having flowers which are distinctly epigynous. The leaves are opposite or verticillate.

$a$. RUBIACE $Æ$ OR MADDER FAMILY.-The plants are herbs, shrubs, or trees, and of the representatives found in the United States the following may be mentioned: Bluets (Hous-

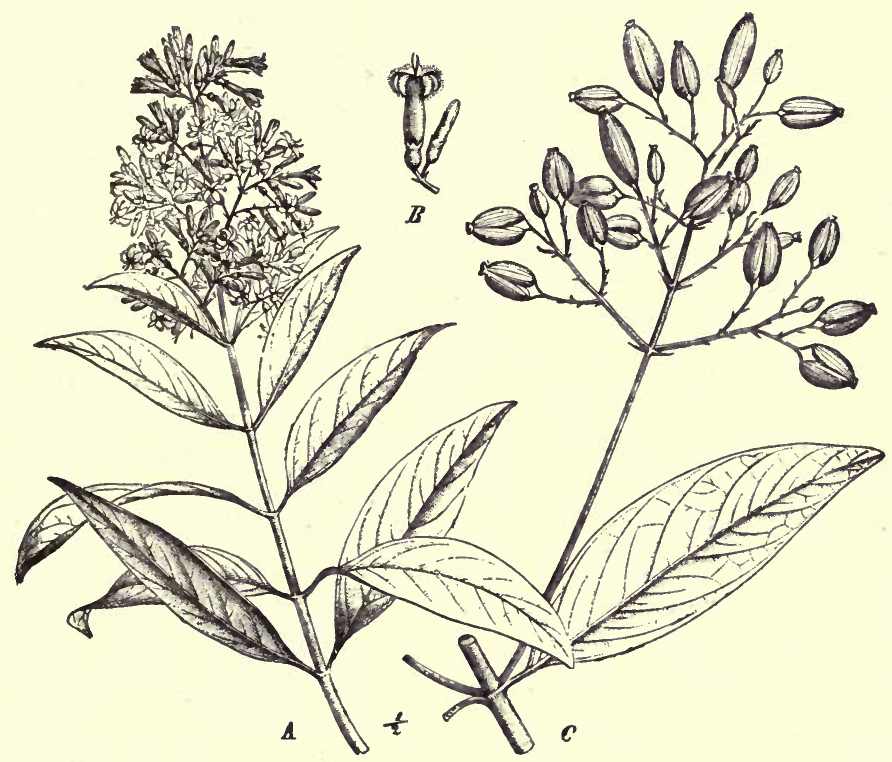

FIG. 386. Cinchona Ledgeriana: A, flowering branch; B, bud and open flower; $\mathrm{C}$, fruiting branch.-After Schumann.

tonia species), Partridge-berry (Mitchella repens), and Bedstraw (Galium species). In Mitchella and Houstonia the flowers are dimorphic.

Cinchona species.-The plants are mostly trees, or rarely shrubs, with elliptical or lanceolate, entire, evergreen, petiolate, opposite leaves (Fig. 386). The flowers are tubular, rose-colored or yellowish-white, and occur in terminal racemes. The fruit is a capsule, which dehisces into two valves from below upward, the valves being held above by the persistent calyx. The seeds 


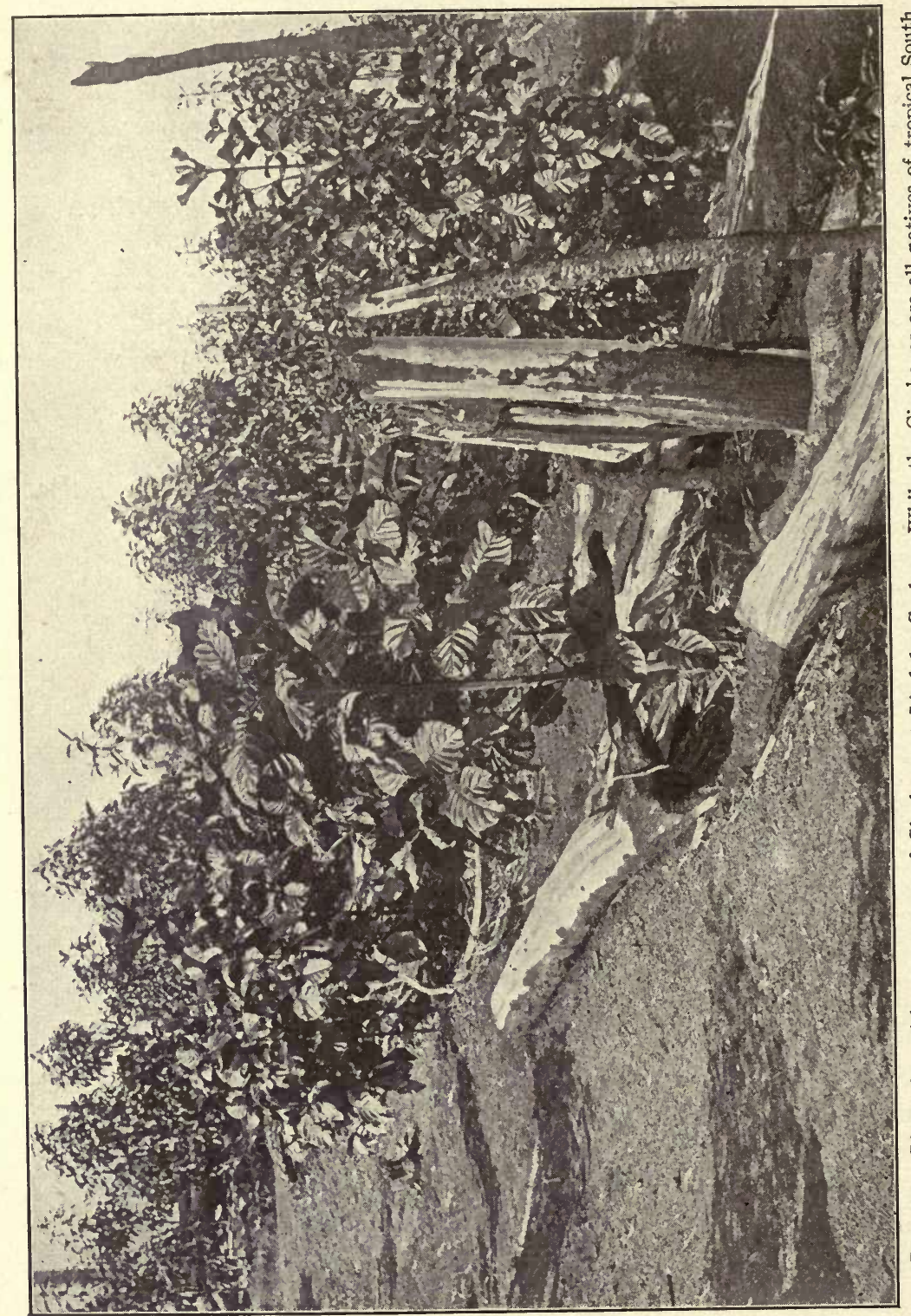

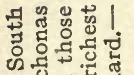

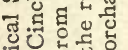

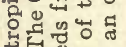

政江

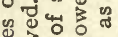

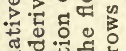

$=$ मु

तु

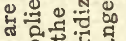

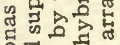

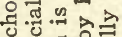

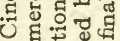

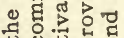

它志吉

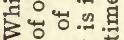

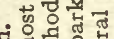

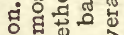

경뎡 웡

고용

䆑茄.

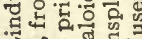

구워

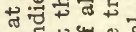

돈

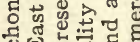

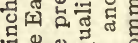

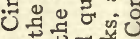

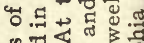

\& 0

$+7$.

此造造

م०

औ

家.

돓

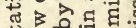

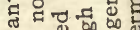

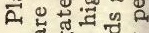

$\therefore$ 同

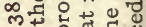

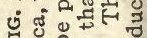

का

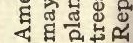


are numerous and winged. There are from 30 to 40 species of Cinchona found growing in the Andes of South America at an elevation above 800 M. in a restricted area about 500 miles in length extending from Venezuela to Bolivia. The plants are

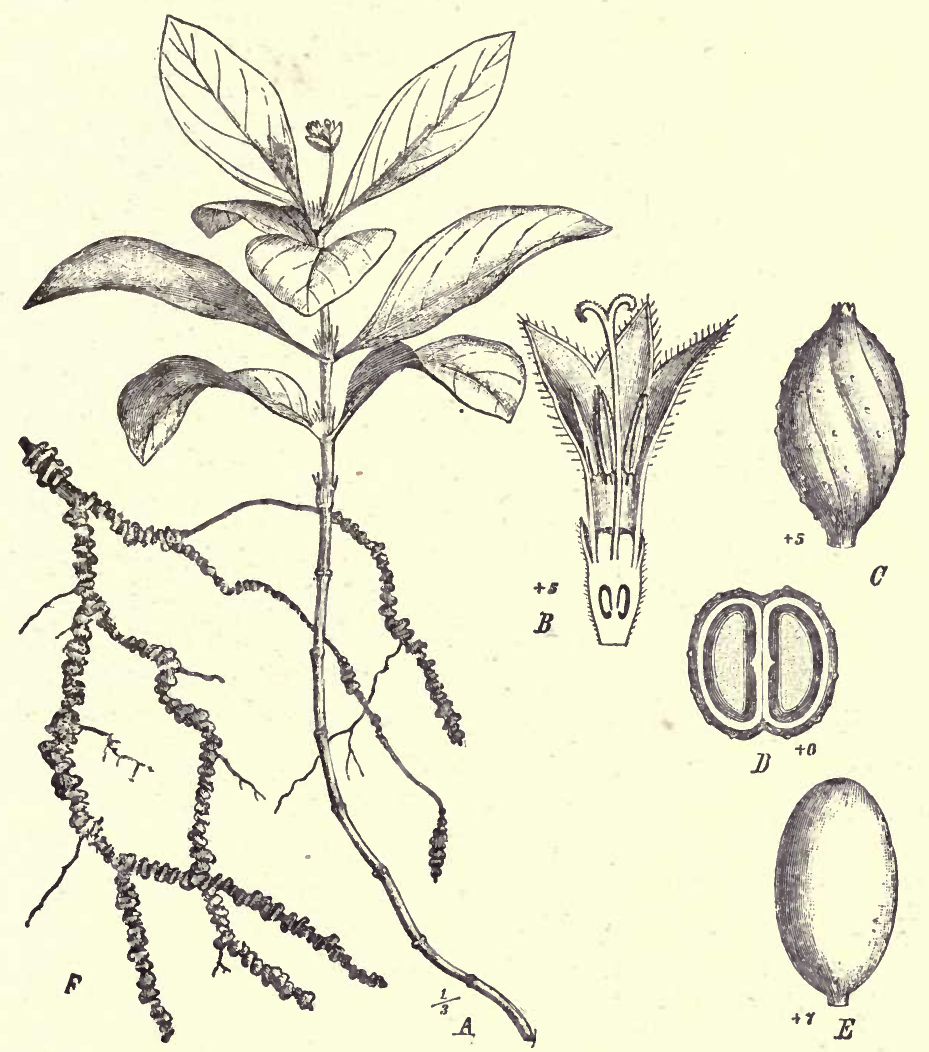

FIG. 388. Ipecac plant [Cephaëlis (Uragoga) Ipecacuanha]: A, flowering shoot; B, flower in longitudinal seetion; C, fruit; D, fruit in transverse section; E, seed; F, annulate root.-After Schumann.

cultivated in Java, Ceylon, New Zealand, and Australia, as well as in Jamaica (Fig. 387).

There are two species which furnish the Cinchona bark of medicine: (I) Cinchona Ledgeriana (C. Calisaya Ledgeriana), which has small, elliptical, coriaceous leaves, the under surface of which is reddish; small, yellowish, inodorous flowers, and a 
short capsule; (2) C. succirubra, which has large, thin, broadlyelliptical leaves, purplish-red calyx, rose-colored petals, and a very long capsule. While $C$. Ledgeriana yields barks containing the highest amount of alkaloids, C. succirubra is most cultivated.

Uragoga (Cephä̈lis) Ipecacuanha.-The plants are perennial herbs Io to $20 \mathrm{~cm}$. high, with a creeping, woody, hypogeous stem. The roots are official in all of the pharmacopoias (see Vol. II). The leaves are elliptical, entire, short-petiolate, and with divided stipules (Fig. 386). The flowers are white and form small terminal heads. The fruit is a blue berry, with characteristic spiral arrangement of the carpels.

Coffea arabica is a small evergreen tree or shrub with lanceolate, acuminate, entire, slightly coriaceous, dark green, shortpetiolate leaves, which are partly united with the short interpetiolar stipules at the base. The flowers are white, fragrant, and occur in axillary clusters. The fruit is a small, spherical or ellipsoidal drupe with two locules, each containing one seed, or COFFEE GRAIN. The coffee plant is indigenous to Abyssinia and other parts of Eastern Africa, and is cultivated (Fig. 389) in tropical countries, notably in Java, Sumatra, Ceylon, and Central and South America, particularly Brazil, over 600,000 tons being produced annually in the latter country. The yield of one tree is between $I$ and I 2 pounds. There are two methods of freeing the seeds from the parchment-like endocarp: In the one case the fruits are allowed to dry and are then broken; in the other case, which is known as the wet method, the sarcocarp is removed by means of a machine, and the two seeds with the parchment-like endocarp are allowed to dry in such a manner as to undergo a fermentation, and after drying the endocarp is removed. Coffee seeds contain from I to 2 per cent. of CAFFEINE; from 3 to 5 per cent. of tannin; about I 5 per cent. of glucose and dextrin; Io to 13 per cent. of a fatty oil consisting chiefly of olein and palmitin; Io to I 3 per cent. of proteins; and yield 4 to 7 per cent. of ash. The official caffeine is derived in part from coffee seeds.

In the ROASTING of coffee there is a change in the physical character of the seeds, as well as a change in some of the constituents. The AROMA is supposed to be due to an oil known as coffeol, which is said to be a methyl ether of saligenin. 


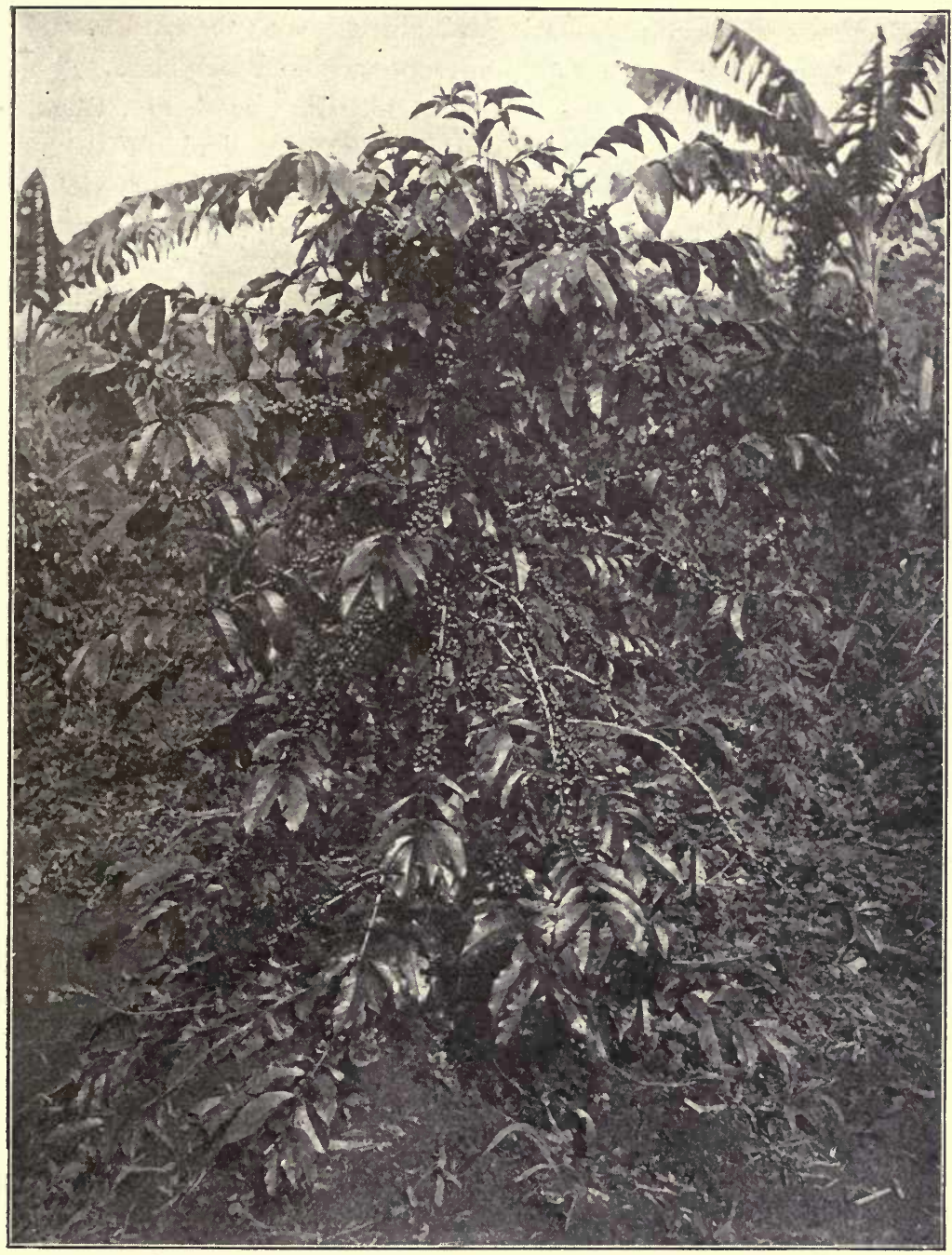

Frg. 389. Coffee tree growing in Costa Rica. An evergreen shrub, with elliptical leaves resembling somewhat those of the laurel. The flowers are white, fragrant, and are formed in clusters among the branches, being followed by the berry-like fruits, which when ripe are about the size of and resemble the cranberry. Each fruit contains two elliptical plano-convex seeds, which on being separated constitute the so-called coffee bean of commerce.-Reproduced by permission of The Philadelphia Commercial Museum. 
Yoнiмвi (Yohimbihi) bark is obtained from Corynanthe $Y_{O^{-}}$ himbe, a tree growing in the Cameroon region of Africa. The pieces of bark are $25 \mathrm{~cm}$. or more in length, 5 to $8 \mathrm{~mm}$. thick, externally dark brown or grayish-brown, and somewhat bitter. Numerous bast fibers are present, but no sclerotic cells. It yields 4 alkaloids ( 0.3 to $\mathrm{I} .5$ per cent.), the principal one being yohimbine (corymbine or corynine), which forms white prismatic

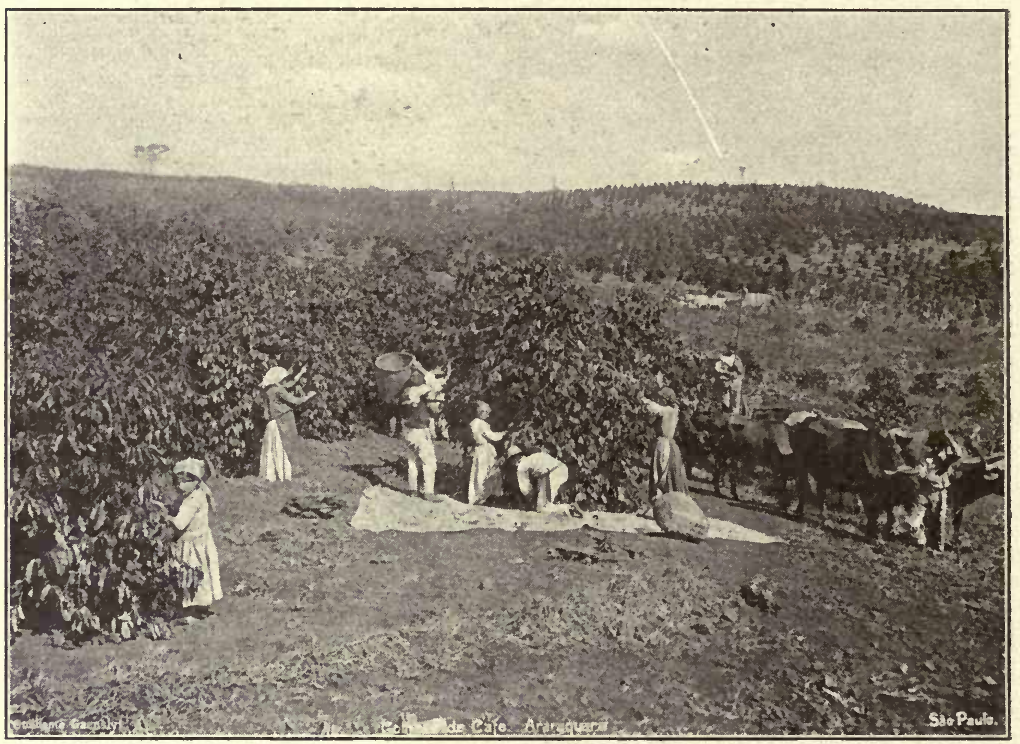

FIG. 390. Ficking coffee in Brazil. The coffee shrub is cultivated in plantations, and when the berries are ripe they are collected either by shaking the tree and allowing the berries to fall upon a cloth or they are picked by hand directly from the branches, and removed from the field by oxen teams. More than half of the coffee of the world is grown in Brazil, the remainder being obtained in various parts of tropical America and East India.Reproduced by permission of The Philadelphia Commercial Museum.

needles, soluble in alcohol and almost insoluble in water, and on treatment with nitric acid becomes first deep green and then yellowish, changing to a cherry-red if followed with an alcoholic solution of potassium hydroxide (distinction from cocaine).

A number of the Rubiaceæ contain valuable coloring principles, as the madder plant (Rubia tinctorum), which is a perennial herb occurring wild in Southern Europe and formerly cultivated in France and Germany on account of the coloring principle 


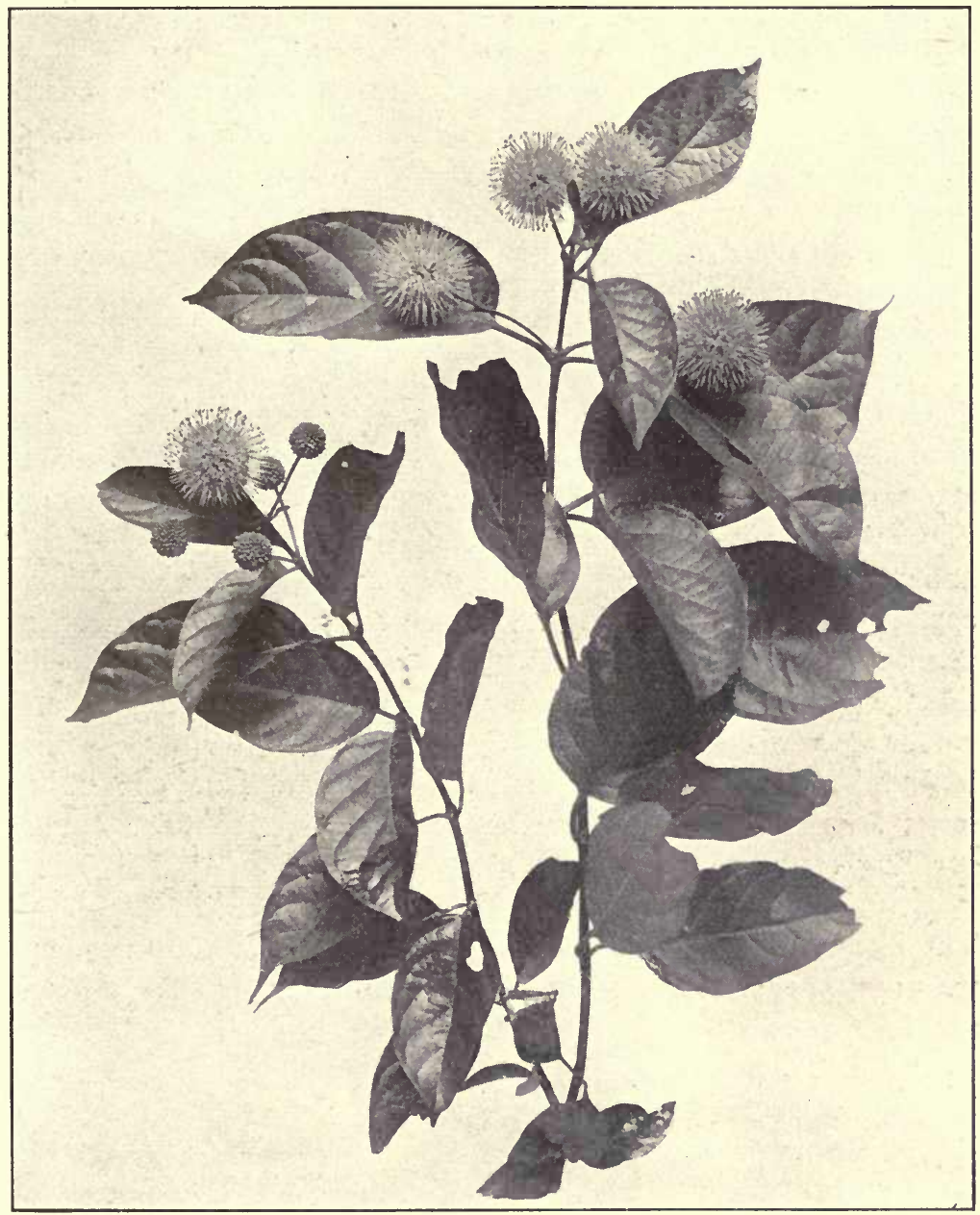

Fig. 39r. Buttonbush (Cephalanthus occidentalis), a small shrub growing in swamps and along streams throughout the United States. The leaves are opposite or whorled in threes. The flowers are white and densely aggregated in spherical peduncled heads; they secrete large quantities of nectar, and are sought to such a degree by the bees that the bush is often called "Honey balls."-After Troth.

in its roots. The root is known commercially as MADDER, and contains when fresh a yellow coloring principle, which on the drying of the root breaks up into several glucosides, one of which on further decomposition yields ALIZARIN, the principle to which the 
red color of the dried root is due. At present alizarin is made artificially from anthracene, a coal-tar derivative.

Morinda citrifolia, a shrub widely distributed in tropical countries, contains a red coloring principle in the flowers and a yellow coloring principle in the roots, the latter being known as morindin and resembling the color principle in madder.

The pulp of the fruit of Cape jasmine (Gardenia jasminoides) contains a yellow coloring principle resembling crocin, found in Crocus.

The stem and root barks of Button-bush (Cephalanthus occidentalis), common in swampy regions in the United States, are used in medicine (Fig. 39I). The barks contain a bitter glucoside, cephalanthin, and a tasteless glucoside which is fluorescent in solution. Mitchella repens contains a saponin-like body in the fruit and a tannin and bitter principle in the leaves. Quite a number of species of Galium (bedstraw) are used in medicine and for other purposes. A principle resembling glycyrrhizin is found in wild licorice (Galium circezans), a perennial herb growing in dry woods in the United States, and also in Galium lanceolatum, which is found from Virginia northward to Ontario. The yellow bedstraw (Galium verum), naturalized from Europe, contains a milkcurdling ferment.

b. CAPRIFOLIACE $Æ$ OR HONEYSUCKLE FAMILY.The plants are perennial herbs, shrubs, trees, or woody climbers with opposite, simple or pinnately compound leaves. The flowers are perfect, epigynous, regular, or bilabiate, and arranged in corymbs. The fruit is a berry, drupe, or capsule. They are mostly indigenous to the northern hemisphere.

Viburnum prunifolium (Black haw) is a shrub or small tree $25 \mathrm{~cm}$. in diameter. The winter buds are acute and reddishpubescent; the leaves are ovate, elliptical, obtuse or acute at the apex, somewhat rounded at the base, finely serrulate, glabrous, and short-petiolate (Fig. 392); the flowers are white and in nearly sessile cymes; the fruit is a small, oval, bluish-black, glaucous, inferior drupe. The root-bark is official.

Viburnum Opulus (Wild guelder-rose or cranberry-tree) is a shrub about half the height of $V$. prunifolium, with broadly ovate, deeply 3 -lobed and coarsely dentate pubescent leaves. The 
flowers are white and in compound cymes, the outer being sterile and large and showy. The fruit is a reddish, globular, very acid drupe, clinging to the branches all winter. The Snow-ball or guelder-rose of the gardens is a sterile variety of this species. Another variety (edule) is also cultivated on account of its edible fruits, particularly in Canada and the Northern United States.

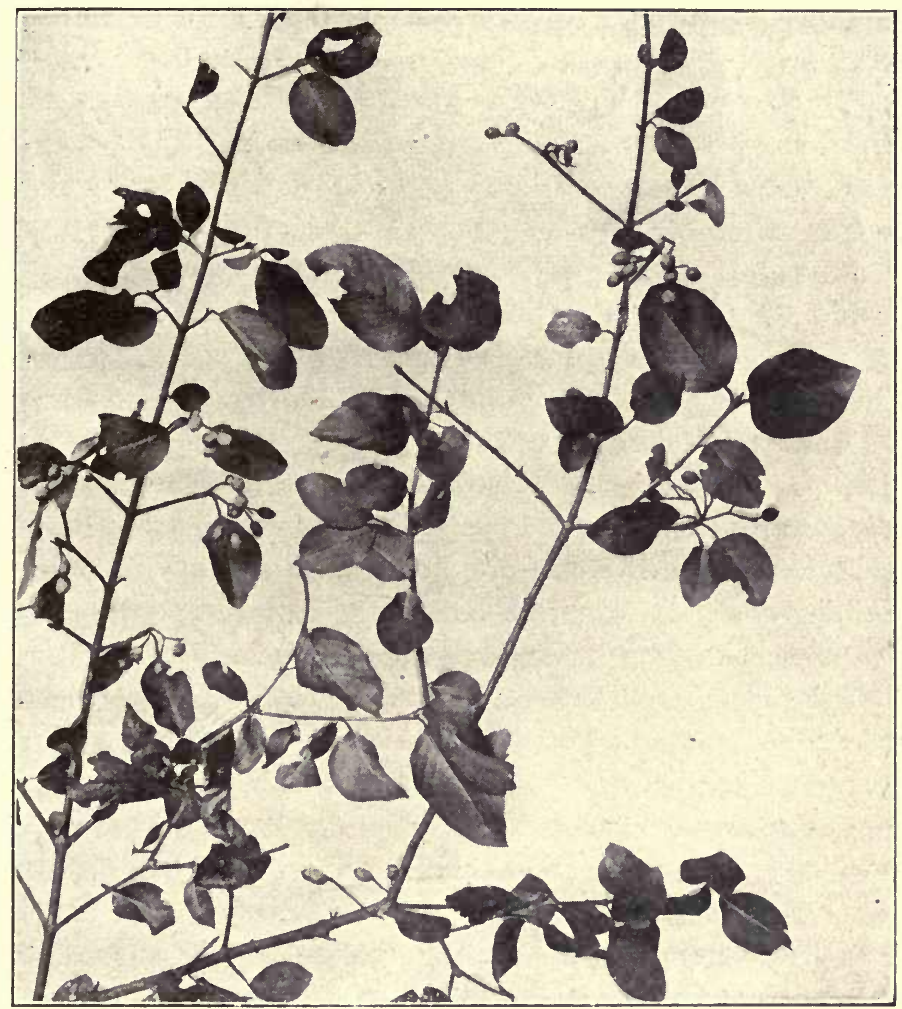

Fis. 392. Fruiting branch of Viburnum prunifolium.

A number of species of Viburnum are rather common in various parts of the United States, as the Maple-leaved arrowwood ( $V$. acerifolium), which is a small shrub with deeply 3-lobed, coarsely dentate leaves and small, nearly black drupes; Arrow-wood ( $V$. dentatum), with broadly ovate, coarsely dentate leaves and blue drupes, which become nearly black when 
ripe; Soft-leaved arrow-wood ( $V$. molle), which somewhat resembles $V$. dentatum, but has larger leaves that are crenate or dentate and stellate-pubescent on the lower surface ; Larger witherod $(V$.nudum), having nearly entire leaves and a pink drupe, which becomes dark blue.

Sambucus canadensis (American elder) is a shrub growing in moist places in the United States as far west as Arizona and in Canada. The leaves are 5- to 7-foliate, the leaflets being ovate, elliptical, acuminate, sharply serrate, and with a short stalk; the flowers are small, white, and in convex cymes. The fruit is a deep purple or black berry-like drupe. The dried flowers are used in medicine. They are about $5 \mathrm{~mm}$. broad, with a 5-toothed, turbinate calyx, and a 5 -lobed, rotate corolla, to which the 5 stamens are adnate. The odor is peculiar and the taste is mucilaginous and somewhat aromatic and bitter.

The active principles have not been determined, but are probably similar to those of $S$. nigra. The inner bark is also used in medicine and contains a volatile oil, a crystallizable resin, and valerianic acid. It does not appear to contain either tannin or starch. The roots of elder contain a volatile principle somewhat resembling coniine. The pith consists chiefly of cellulose, is delicate in texture and has a variety of uses (Fig. 132).

The Black elder (Sambucus nigra), which is a shrub common in Europe, is characterized by narrower leaflets, a 3 -locular ovary, and black berries. The flowers are official in some of the European pharmacopœias. They contain about 0.4 per cent. of a greenish-yellow, semi-solid volatile oil, which when diluted has the odor of the flowers. They also contain an acrid resin.

The Red-berried elder or mountain elder ( $S$. pubens) somewhat resembles the common elder, but the stems are woody, and the younger branches have a reddish pith. The flowers are in paniculate cymes, and the fruits are scarlet or red.

Other plants of the Caprifoliaceæ are also used in medicine. Horse gentian (Triosteum perfoliatum), a perennial herb with connate-perfoliate leaves and small, orange-red, globular drupes, growing in Canada and the United States as far west as Kansas, furnishes the drug (rhizome) known as WILD IPECAC or Triosteum. The rhizome is yellowish-brown, somewhat branched, 
cylindrical, to to $20 \mathrm{~cm}$. long, to to $15 \mathrm{~mm}$. in diameter, with numerous cup-shaped stem-scars, and coarse, spreading roots; it is rather hard and tough, and has a bitter, nauseous taste. Triosteum contains an emetic alkaloid, triosteine, and considerable starch. The seeds of Triosteum perfoliatum are sometimes roasted and employed like coffee, the plant being known as Wild coffee.

The roots and stems of the following plants are sometimes employed: The Snowberry (Symphoricarpos racemosus), the Bush honeysuckle (Diervilla Lonicera), and various species of Lonicera, these being also known as honeysuckles.

VII. ORDER VALERIANALES OR AGGREGATE.

The plants are mostly herbs with an inferior ovary, which is either unilocular with a single pendulous ovule, or tri-locular with frequently but a single anatropous ovule.

a. VALERIANACEÆ OR VALERIAN FAMILY.-The plants are herbs with opposite, exstipulate leaves, small, perfect, or polygamo-diœcious flowers, occurring in corymbs. The fruit is dry, indehiscent, and achene-like. The calyx is persistent, becoming elongated and plumose, and resembling the pappus in the Compositæ.

Valeriana officinalis (Garden or Wild valerian) is a tall, perennial herb, more or less pubescent at the nodes. The leaves are mostly basal, pinnately parted into seven or more segments, which are lanceolate, entire, or dentate. The flowers are white or pink and arranged in corymbed cymes. The calyx is much reduced, consisting of 5 to 15 pinnately branched teeth (pappus); the corolla is tubular, somewhat sac-like on one side, but not spurred as in other members of this family; the stamens are 3 in number and adnate to the corolla tube; the stigma is 3 -lobed. The fruit is ovoid, glabrous, and with a conspicuous plumose pappus. The rhizome and roots are official.

The young leaves of several species of Valerianella are used as a salad and are cultivated like spinach, as the European cornsalad ( $V$. olitoria), which is also cultivated to some extent in the United States.

b. DIPSACACE E OR TEASEL FAMILY.-The plants are annual or perennial herbs, chiefly indigenous to the Old World. 
The flowers are arranged in heads on a common torus, resembling in some cases those of the Compositæ.

Some of the plants are used in medicine, as the roots, leaves, flowers, and seeds of Fuller's teasel (Dipsacus fullonum), the roots of Succisa pratensis of Europe, and several species of Scabiosa and Cephalaria. The seeds of Cephalaria syriaca when admixed with cereals give a bread that is dark in color and bitter. This family is, however, chiefly of interest on account of Fuller's teasel, which is a cultivated form of Dipsacus ferox, indigenous to Southwestern Asia, the plant being cultivated in Europe and New York State. The elongated, globular heads, with their firm, spiny, and hooked bracts, are used in the fulling of cloth.

VIII. ORDER CAMPANULATA.

This order differs from the two preceding by having the anthers united into a tube (syngenesious). It includes three principal families, which are distinguished by differences in the character of the andrœcium: (a) Cucurbitaceæ, in which there are three stamens, having not only the anthers united but the filaments also (monadelphous); (b) Campanulaceæ, in which there are five stamens, both the filaments and anthers being united into a tube; (c) Compositæ, in which there are five stamens, but the anthers only are united, the filaments being separate (Fig. 82, $A$ ).

a. CUCURBITACEÆ OR GOURD FAMILY.-The plants are mostly annual, tendril-climbing or trailing herbs (Fig. 66), mainly indigenous to tropical regions. The leaves are alternate, being opposite the tendrils, petiolate, and entire, palmately lobed or dissected. The flowers are epigynous; the petals are borne on the calyx tube and frequently are united (campanulate); the ovary is I- to 3 -locular and with few or many anatropous ovules. The fruit is a pepo, which is indehiscent but may burst somewhat irregularly.

Citrullus Colocynthis is a trailing herb with deeply lobed leaves. The flowers are yellow, axillary, and monœcious, the staminate being with short filaments and glandular pistillodes (aborted pistils), and the pistillate having a 3 -locular, globose ovary and three short staminodes. The fruit is globular, 5 to ro 
$\mathrm{cm}$. in diameter, smooth, greenish, and mottled. The fruit deprived of the epicarp is official.

Cucurbita Pepo (pumpkin-vine) is an extensively trailing hispid vine, with large, nearly entire, cordate leaves having long petioles. The tendrils are branching. The flowers are large, deep yellow, and monœcious; the staminate ones being in groups and the pistillate single. The fruit is a large, yellowish berry, sometimes weighing from io to $72 \mathrm{~K}$. The seeds are numerous and are official as Pepo.

Ecballium Elaterium (Squirting cucumber) is a bristly-hairy, trailing perennial herb with thick, rough-hairy, cordate, somewhat undulate leaves. The flowers are yellow, monœcious. The fruit is ellipsoidal, about $4 \mathrm{~cm}$. long, rough-hairy or prickly, pendulous, and at maturity separates from the stalk, when the seeds are discharged upward through a basal pore. The plant is indigenous to the European countries bordering the Mediterranean, the Caucasus region, Northern Africa and the Azores. The juice of the fruit yields the drug Elaterium, which is official in the British Pharmacopœia. Elaterium yields 30 per cent. of the Elaterin of the Pharmacopœias. From the latter by fractional crystallization from 60 to 80 per cent. of $a$-elaterin, a lævo-rotatory crystalline substance is separated, which is completely devoid of purgative action; and varying amounts of $\beta$-elaterin, a dextrorotatory crystalline compound which possesses a very high degree of physiological activity (Power and Moore, Ph. Jour., 29, Oct. 23, I909, p. 501 ; and Proc. Chem. Soc., No. 362, 1909, p. 1985).

Bryonia or BRYONY is the dried root of Bryonia alba (White bryony), a climbing herb indigenous to Southern Sweden, Eastern and Central Europe, including Southern Russia, and Northern Persia (Fig. I8I). The root contains two bitter glucosides, bryonin and bryonidin; two resinous principles and considerable starch. Bryonia dioica (Red bryony) also has medicinal properties and is a source of the drug. $B$. dioica has red berries, while the fruit of $B$. alba is black. The latter plant is sometimes known as Black bryony, but this plant should not be confounded with Tamus communis (Fam. Dioscoreaceæ), of Southern Europe, the rhizome of which is known commercially as Black bryony. The fruits and seeds of various members of the Cucurbitaceæ 
contain powerful drastic and anthelmintic principles. A number of the plants, however, are cultivated on account of the fruits, which are used as food, as the pumpkin already mentioned, the WATER MELON (Citrullus vulgaris), indigenous to Southern Africa and cultivated in Egypt and the Orient since very early times; CANTALOUPE or musk-melon, derived from cultivated varieties of Cucumis Melo, indigenous to tropical Africa and Asia, also cultivated since early times. The common CUCUMBER is obtained from Cucumis sativus, which is probably indigenous to the East Indies. These fruits contain from 90 to 95 per cent. of water, and the water melon contains 3.75 per cent. of dextrose, 5.34 per cent. of saccharose, and yields 0.9 per cent. of ash.

Luffa cylindrica is an annual plant indigenous to the Tropics of the Old World. It is cultivated to some extent in America, but especially in the Mediterranean region. The fruit is more or less cylindrical and $20 \mathrm{~cm}$. or more long. The pulp is edible and the fibrovascular tissue forms a tough network, which, when the seeds, epicarp, and pulpy matter are removed, constitutes the LUFFA-SPONGE.

The fruits of Luffa operculata and L. echinata, both found in Brazil, contain a bitter principle resembling colocynthin.

b. CAMPANULACE $Æ$ OR BELL-FLOWER FAMILY.The plants are mostly annual or perennial herbs, but are sometimes shrubby, with an acrid juice containing powerful alkaloids. The rhizomes and roots of about twelve of the genera contain inulin. The leaves are alternate; the corolla is regular, campanulate and rotate, or irregular, as in Lobelia. The fruit is a capsule or berry containing numerous small seeds.

Lobelia inflata (Indian or Wild tobacco) is an annual, pubescent, branching herb (Fig. 224), the dried leaves and tops of which are official (see Vol. II): About 15 different species of Lobelia are used in medicine. The most important of those grow. ing in the United States is the Cardinal flower or Red lobelia (Lobelia cardinalis), a plant found in moist soil from Canada to Texas, and characterized by its long; compound racemes of bright scarlet or red flowers. The Blue cardinal flower or Blue lobelia (L. syphilitica) is a plant of nearly the same habit and same gen- 
eral character, except that the flowers are of a bright dark blue color or occasionally white.

c. FAMILY COMPOSIT E.-This is a large group of plants, which are annual, biennial, or perennial herbs, under-shrubs, shrubs, trees and twiners or even climbers, a few being aquatic. They contain inulin, a constituent peculiar to this group of plants. The most distinguishing character is the inflorescence, which is a head or capitulum (Fig. 228), consisting of one or two kinds of flowers, arranged on a common torus, and subtended by a number of bracts, forming an involucre. The flowers are epigynous and the fruit is an achene, usually surmounted by the persistent calyx, which consists of hairs, bristles, teeth or scales, which are known collectively as the PAPpUs (Fig. 227).

The individual flowers are called florets (Figs. 24I, 242), and may be hermaphrodite or pistillate, monœcious, diœcious, or neutral. Depending upon the shape of the corolla, two kinds of flowers are recognized, one in which the corolla forms a tube, which is 5 -lobed or 5-cleft, known as TUBULAR FLowers (Figs. $227,228, C)$; and one in which the petals are united into a short tube, with an upper part that forms a large, strap-shaped, usually 5-toothed limb, known as Ligulate Flowers (Figs. 227, 228, $D$ ).

In some of the plants of the Compositæ the head consists of ligulate flowers only, but in the larger number of plants the head is composed of both tubular and ligulate flowers or tubular flowers alone and accordingly two main groups or sub-families are distinguished. The sub-family in which all of the flowers are ligulate is known as Liguliflore, or CiCHORIACEx, by those who give the group the rank of a family. This group includes plants like dandelion, chicory, lettuce, and Hieracium. The group or sub-family in which the flowers are all tubular or ligulate on the margin only is known as the Tubuliflore. When the head consists only of tubular flowers it is called DISCOID, but when ligulate flowers are also present it is called RADIATE. When the heads are radiate, as in the common daisy, the tubular flowers are spoken of as DISK-FLOWERS, and the ligulate flowers as RAYFLOWERS. The disk-flowers are usually perfect, while the rayflowers are pistillate or neutral (without either stamens or pistils). By some systematists the Tubulifloræ are divided into groups 
which have been given the rank of families. This division is based especially on the characters of the stamens. In a small group represented by the ragweed and known as the AmbrosiACE $E$, the anthers, while close together (connivent), are not united, and the corolla in the marginal or pistillate flowers is reduced to a short tube or ring. In a large group, which includes probably Io,000 species and which is considered to be the Compositas proper, the stamens in the tubular flowers are syngenesious and the marginal or ray-flowers are distinctly ligulate. This group includes the daisy, sunflower, golden-rod, aster, thistle, and most of the plants which yield official drugs.

It may also be added that the Compositæ is considered to be the highest and youngest group of plants.

Taraxacum officinale (Dandelion) is a perennial, acaulescent herb with milky latex; oblong-spatulate, pinnatifid or runcinate, decurrent leaves, and with a I-headed scape, the stalk of which is hollow. The flowers are ligulate, golden-yellow and numerous; the involucre consists of two series of bracts, the inner one of which closes over the head while the fruit is maturing, afterward becoming reflexed. The fruit consists of a loose, globular head of achenes, each one of which is oblong-ovate and with a slender beak at the apex which is prolonged into a stalk bearing a radiate tuft of silky hairs, which constitute the pappus. The root is fusiform and usually bears at the crown a number of branches 2 to 5 $\mathrm{cm}$. long, having a small pith and other characters of a rhizome. The root is official.

Lactuca virosa (Poison lettuce) is a biennial prickly herb, with milky latex and oblong-obovate, spinose-toothed, runcinate basal leaves and with alternate, somewhat sessile or auriculate, scattered stem leaves, the apex and margin being spinose. The flowers are pale yellow and occur in heads forming terminal panicles. The involucre is cylindrical and consists of several series of bracts. The flowers are all ligulate and the anthers are sagittate at the base. The achenes are flattish-oblong, and the pappus, which is raised on a stalk, is soft-capillary, as in Taraxacum. The prepared milk-juice is official as Lactucarium.

Eupatorium perfoliatum (Boneset or Common thoroughwort). -The leaves and flowers are used in medicine. 
Eupatorium sebandianum, which is added to Maté as a sweetening agent, contains two sweet glucosides; eupatorin and rebandin; a bitter principle, and a resin.

GRINDELIA species.-The plants are perennial, greenish-yellow, resinous herbs, sometimes being under-shrubs, with alternate, sessile or clasping, oblong to lanceolate, spinulose-dentate leaves, and large, terminal, yellowish heads, consisting of both ligulate and tubular flowers. The leaves and flowering tops of Grindelia camporum, G. cuneifolia and $G$. squarrosa are official.

Erigeron canadensis or Leptilon canadense (Canada fleabane) is an annual or biennial, hispid-pubescent herb found growing in fields and waste places in nearly all parts of the world. The stems are simple, with numerous crowded leaves and numerous flowers occurring in terminal panicles. The plants are sometimes branched and I to $3 \mathrm{M}$. high. The leaves are linear, nearly entire, of a pale green color, the lower and basal ones being spatulate, petiolate and dentate or incised. The flowers are white and the heads are composed of both ligulate and tubular florets, the former being pistillate and not longer than the diameter of the disk. The pappus consists of numerous capillary bristles and the involucre, which is campanulate, consists of five or six series of narrow, erect bracts. The fresh flowering herb contains 0.3 to 0.4 per cent. of a volatile oil which is official, tannin, and a small amount of gallic acid. The oil is obtained by distillation and consists chiefly of d-limonene.

The genus Erigeron includes a number of species which have medicinal properties. E. annuus (Sweet scabious or Daisy fleabane) is a low, branching, annual herb, characterized by its linearlanceolate or ovate-lanceolate leaves and its conspicuous flowers, which resemble those of the common daisy, the ray-flowers often being tinged with purple (Fig. 393). It contains a volatile oil resembling that of Canada fleabane, and tannin. The Philadelphia fleabane (Erigeron philadelphicus) is a perennial herb producing stolons, and has clasping or cordate leaves, the basal being spatulate, and is further distinguished by its light purplish-red ray-flowers.

Anthemis nobilis (Roman chamomile) is an annual or peren- 
nial, procumbent, branched herb, with numerous 2- to 3-pinnately divided leaves, the ultimate segments being narrow-linear. The flowers occur in terminal heads with long peduncles, a conical torus and few white pistillate ray-flowers. The flowers of culti-

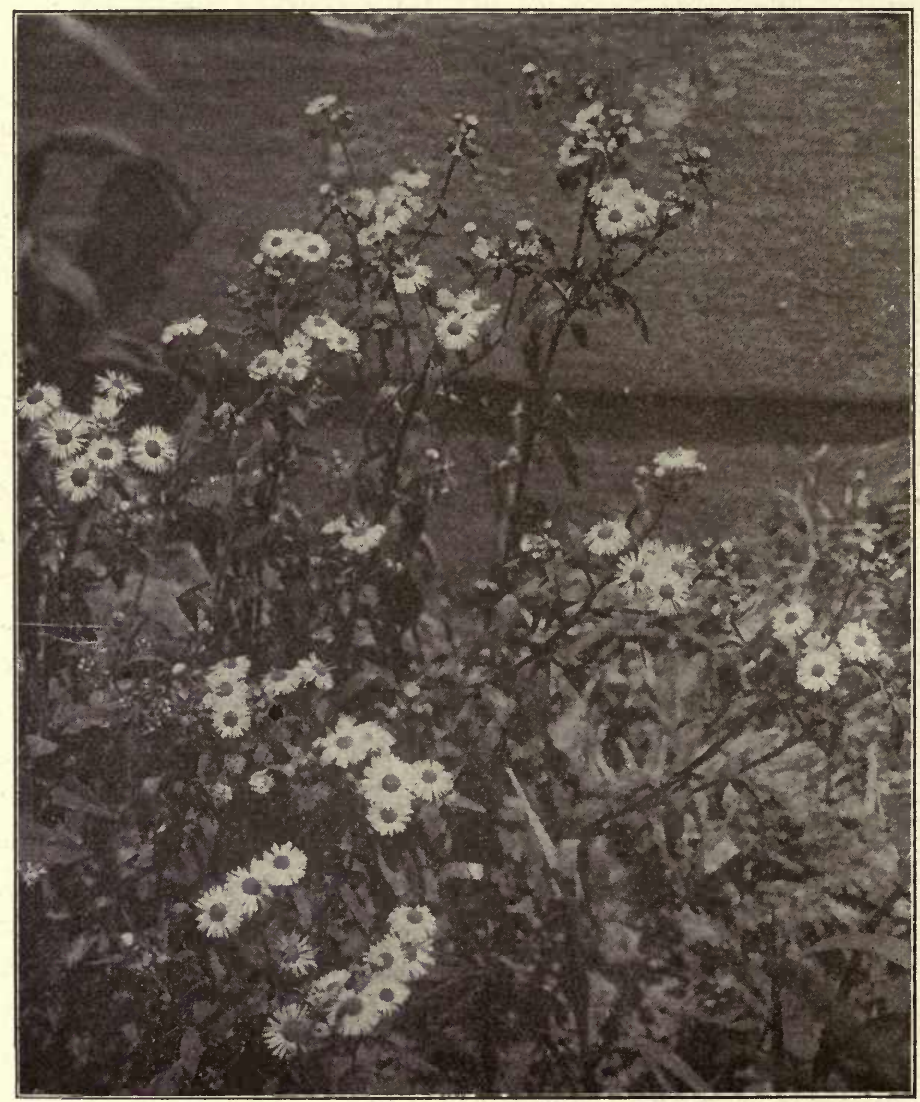

FIG. 393. Daisy-fleabane (Erigeron annuus).

vated plants are official (see Vol. II), the heads consisting mostly of ligulate flowers, forming so-called " double flowers," as in the cultivated chrysanthemums.

Anacyclus Pyrethrum (Pellitory) is a perennial herb resembling Anthemis nobilis in its general characters. The ray-flowers, 
however, are white or purplish, and the pappus consists of a ring or scale. The root is official.

Matricaria Chamomilla (German chamomile) is an annual, diffusely branched herb, with pinnately divided leaves, consisting of few, linear segments. The flowers are official (Figs. 228, 394).

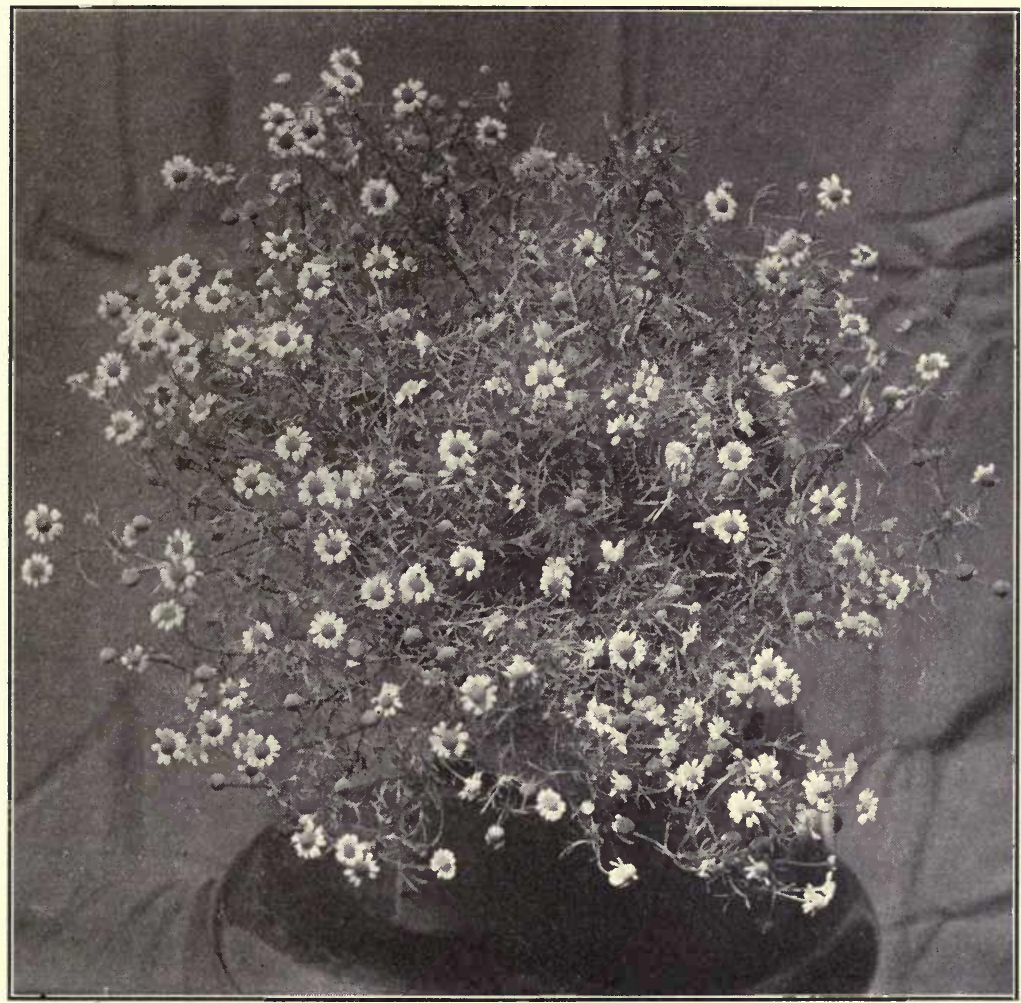

FIG. 394. A single plant of Matricaria Chamomilla, showing finely divided leaves and numerous composite flowers.-After Newcomb.

Arnica montana is a perennial herb with small rhizome; nearly simple stem; opposite, somewhat connate, entire, spatulate, hairy leaves, and yellow flowers in large heads with long peduncles. The flowers are official.

Arctivim Lappa (Burdock) is a coarse, branched, biennial or 


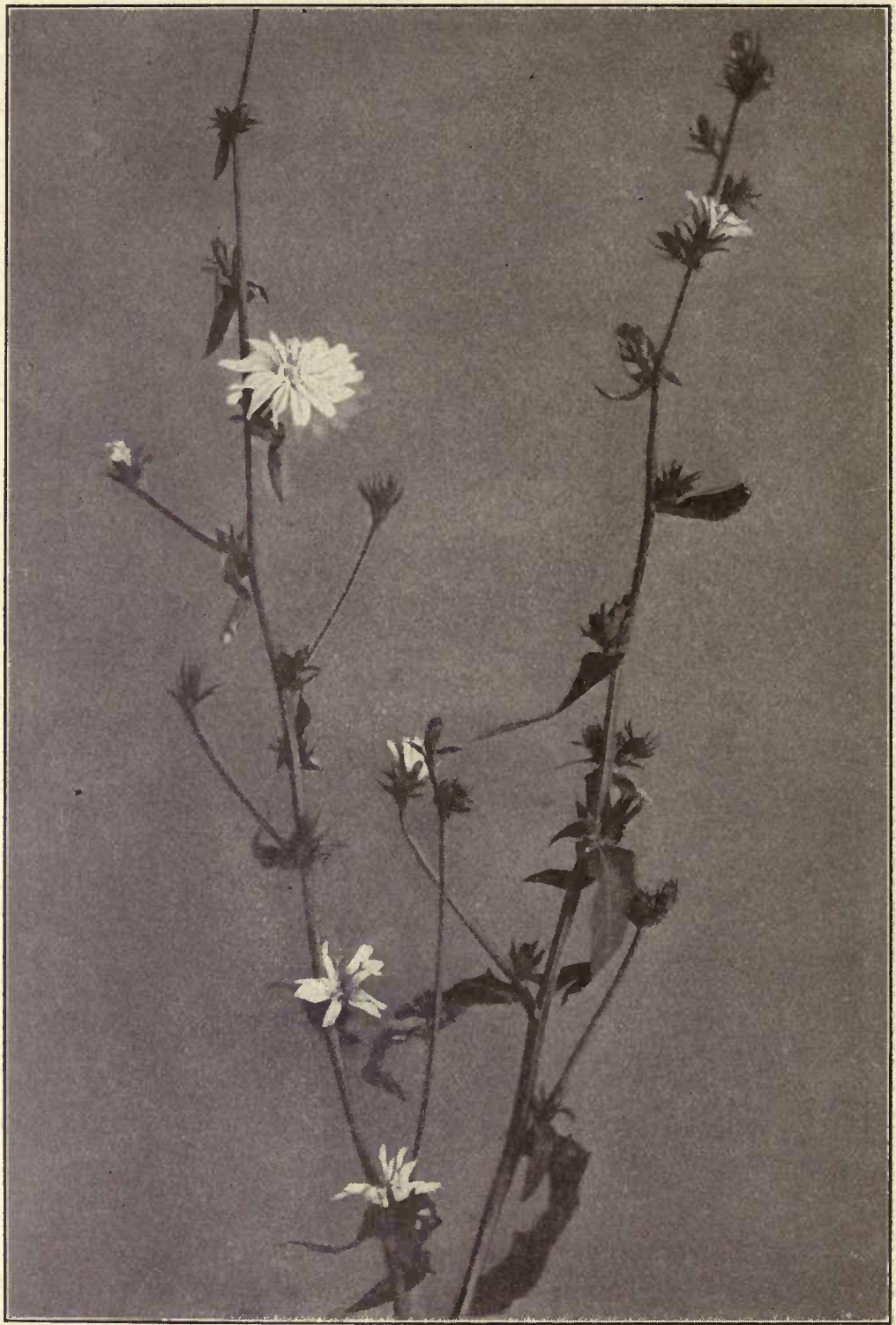

FIG. 395. Chicory or Succory (Cichorium Intybus), a branching perennial herb with oblong or lanceolate, more or less clasping leaves and axillary clusters of violet-blue flowers. The plant is cultivated as a pot herb and salad, and the young roots are used like carrots. The plant is more widely grown for its roots, which are used in the preparation of a substitute of coffee.-After Brown. 
perennial herb, with alternate, broadly ovate, repand, entire, tomentose, mostly cordate leaves, the basal ones being from 30 to $45 \mathrm{~cm}$. long. The flowers are purplish-red or white, tubular and form rather large corymbose heads; the involucre consists of numerous lanceolate, rigid, nearly glabrous bracts, which are tipped with

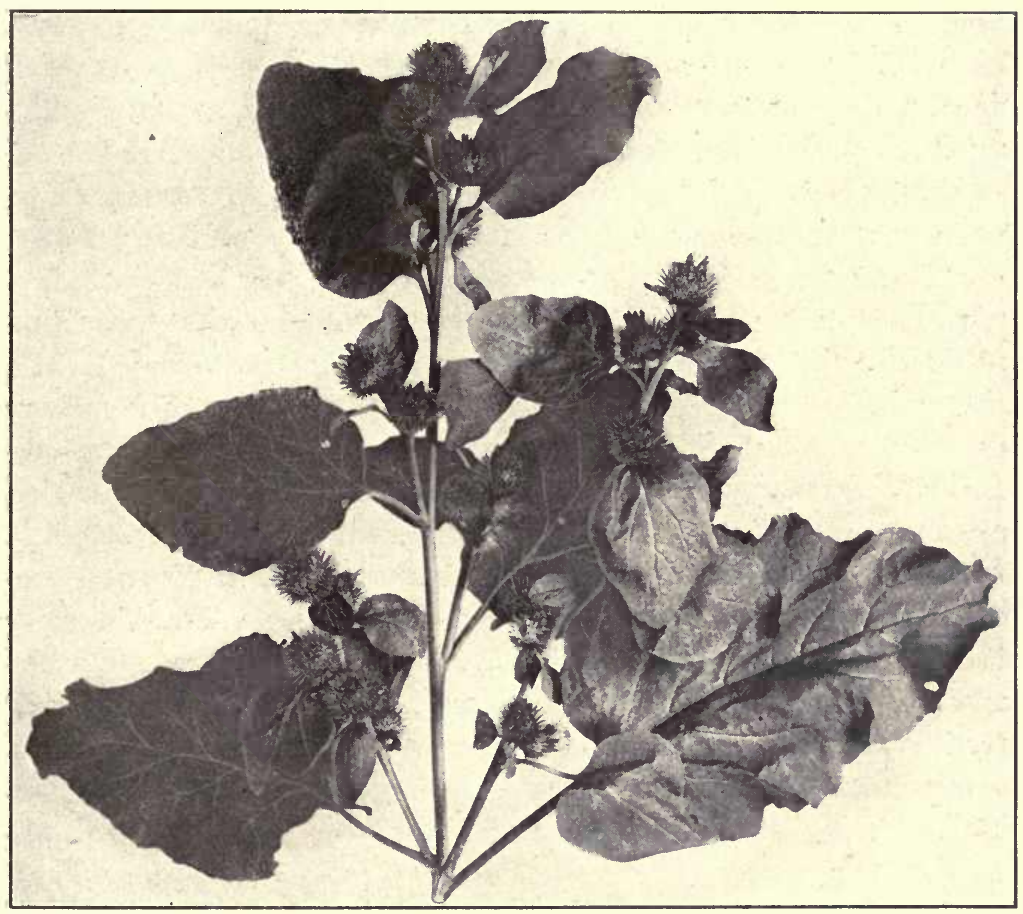

FIG. 396. Burdock (Arctium Lappa), a biennial herb with large, mostly cordate leaves crowded at the base of the stems, and bearing small clusters of purplish flowers in the shorter branches above. It is a common roadside weed, and well known because of the burr-like fruits, consisting of the hooked tips of the bracts of the involucre.-After Brown.

hooked, spreading bristles. The achenes are oblong and somewhat 3 -angled, and the pappus consists of numerous short bristles (Fig. 396). The root is used in medicine.

The common burdock (Arctium minus) resembles A. Lappa, but is a smaller plant and is more common in the United States. The heads are smaller and the inner bracts are shorter than the 
tubular flowers, the bristles of this series being erect and with the outer spreading.

Calendula officinalis (Marigold) is an annual herb with alternate, spatulate, oblanceolate, entire or serrate leaves. The flowers are yellow and form solitary heads, consisting of both ray and tubular florets. In the cultivated varieties most of the tubular florets are changed to ligulate, the latter being official (Fig. 227).

While the Compositæ include a large number of genera and species, the plants do not yield many important drugs, although a number are used in medicine and for other purposes.

The so-called Insect Flowers (Pyrethri Flores) are the partly expanded flower-heads of several species of Chrysanthemum, and are used in the preparation of a powder which is a powerful insecticide. The plants are perennial herbs resembling in their habits the common white daisy (C. Leucanthemum). The Dalmatian Insect Flowers are obtained from $C$. cinerariafolium, growing in Dalmatia, and cultivated in Northern Africa, California and New York. The heads as they occur in the market are about $12 \mathrm{~mm}$. broad, light yellowish-brown and have a slightly rounded or conical torus, which is about $12 \mathrm{~mm}$. in diameter and consists of 2 or 3 series of lanceolate involucral scales. The rayflorets are pistillate, the corolla varying in length from I to $2 \mathrm{~cm}$. and having numerous delicate veins and 3 short, obtuse or rounded teeth. The tubular flowers are perfect and about $6 \mathrm{~mm}$. long. The ovary is 5 -ribbed and the pappus forms a short, toothed crown. The odor is distinct and the taste bitter.

Persian Insect Flowers are derived from $C$. roseum and $C$. Marschallii, growing in the Caucasus region, Armenia and Northern Persia. The heads are about the size of those of $C$. cineraricefolium; the torus is dark brown; the involucral scales and rayflorets are purplish-red; the ovary is Io-ribbed.

Insect flowers contain from a trace to 0.5 per cent. of a volatile oil, the Persian flowers containing the larger proportion, and the amount decreasing with the maturing of the flowers. They also contain two resins, varying from 4 to 7 per cent., the larger amount being found in the Dalmatian flowers; a small quantity of a glucoside and a volatile acid.

The principle toxic to insects is Pyrethron, an amber-yellow, 
syrupy substance which is the ester of certain unidentified acids, and on saponification yields the alcohol pyrethrol which crystallizes in fine needles. The acids combined in the ester pyrethron do not give crystalline salts.

WORMWOOD or Absinthium consists of the dried leaves and flowering tops of Artemisia Absinthium, a perennial, somewhat woody, branching herb, indigenous to Europe and Northern Africa, cultivated in New York, Michigan, Nebraska and Wisconsin and naturalized in the United States from plants that have escaped from cultivation. The leaves are grayish-green, glandular-hairy, I- to 3-pinnately divided, the segments being obovate, entire, or lobed; the flowers are yellowish-green, the heads being about $4 \mathrm{~mm}$. broad and occurring in raceme-like panicles; the torus is hemispherical and the involucre consists of several series of linear bracts, the inner being scale-like; the florets are all tubular, the outer ones sometimes being neutral. The herb is aromatic and very bitter.

The fresh drug contains about 0.5 per cent. of a voLATILE oIL which is of a dark green or blue color, has a bitter, persistent taste but not the pleasant odor of the plant, and consists of d-thujone (absinthol), thujyl alcohol free and combined with acetic, isovalerianic and palmitic acids, phellandrene and cadinene. The other constituents of the drug include a bitter glucosidal principle, ABSINTHIIN, which forms white prisms and yields on hydrolysis a volatile oil; a resin; starch; tannin; succinic acid, potassium succinate, and about 7 per cent. of ash. The plant is used in the preparation of the French liquor known as ABsinthe.

Artemisia Cina yields the official Santonin.

Other species of Absinthium also yield volatile oils, as the Common MUGWORT (Artemisia vulgaris), which yields from o.I to 0.2 per cent. of an oil containing cineol ; Artemisia Barrelieri, which contains an oil consisting almost entirely of thujone, and said to be used in the preparation of Algerian absinthe.

SAFFlower consists of the dried florets of Carthamus tinctorius, an annual herb which is known only in cultivation. The florets are tubular, yellowish-red, the corolla tube being about $2 \mathrm{~cm}$. long and with 5 small, linear lobes; the stamens are exserted. The ovary with the long, slender style is usually not present in 
the drug (Fig. 227, C). Safflower contains a small percentage of a yellow coloring principle (safflower-yellow), which is soluble in water, and 0.3 to 0.6 per cent. of a red coloring principle (carthamin or carthamic acid), which is insoluble in water but soluble in alcohol, the solution having a purplish-red color. A volatile oil is also present. Carthamin is used in conjunction with French chalk in the preparation of a rouge.

TANsy is the dried leaves and tops of Chrysanthemum (Tanacetum vulgare), a perennial, aromatic herb indigenous to Europe, extensively cultivated and naturalized in the United States. The leaves are large and pinnately divided, and the flowers, both tubular and ligulate, are yellow, the heads being in terminal corymbs.

The plant yields from o.I to 0.3 per cent. of a volatile oil, consisting of thujone, borneol and camphor; and 3 resins.

Elecampane (Inula Helenium) is a large, perennial, densely pubescent herb with alternate leaves and large, solitary terminal heads, consisting of yellow tubular and ligulate florets (Fig. 227). The plant is indigenous to Central Europe and Asia, and naturalized in North America from Canada to North Carolina. The root is used in medicine and was formerly official as INULA.

The root of Polymnia Uvedalia, a plant closely related to Inula, but indigenous to the United States east of the Mississippi, contains a volatile oil, a glucoside, tannin, and a resinous substance consisting of two resins, one of which is pale yellow and soft, the other dark brown and hard.

The following Compositæ, while not of very great importance, are used in some localities:

YARRow (Achillea Millefolium) is a common weed naturalized from Europe (Fig. 397), and contains about o.I per cent. of a dark blue volatile oil with a strongly aromatic odor and a small amount of a bitter alkaloid, achilleine. The roots of yarrow, on the other hand, yield a volatile oil with a valerian-like odor. Achillea nobilis of Europe contains an oil resembling that of yarrow, but it is of finer quality and has a spice-like taste. Achillea moschata, an alpine plant of Europe, yields three alkaloids and a volatile oil containing cineol, and is used in Italy in the preparation of the liquor, "Esprit d' Iva." Achillea tanacetifolia yields a blue volatile oil having the odor of tansy. 


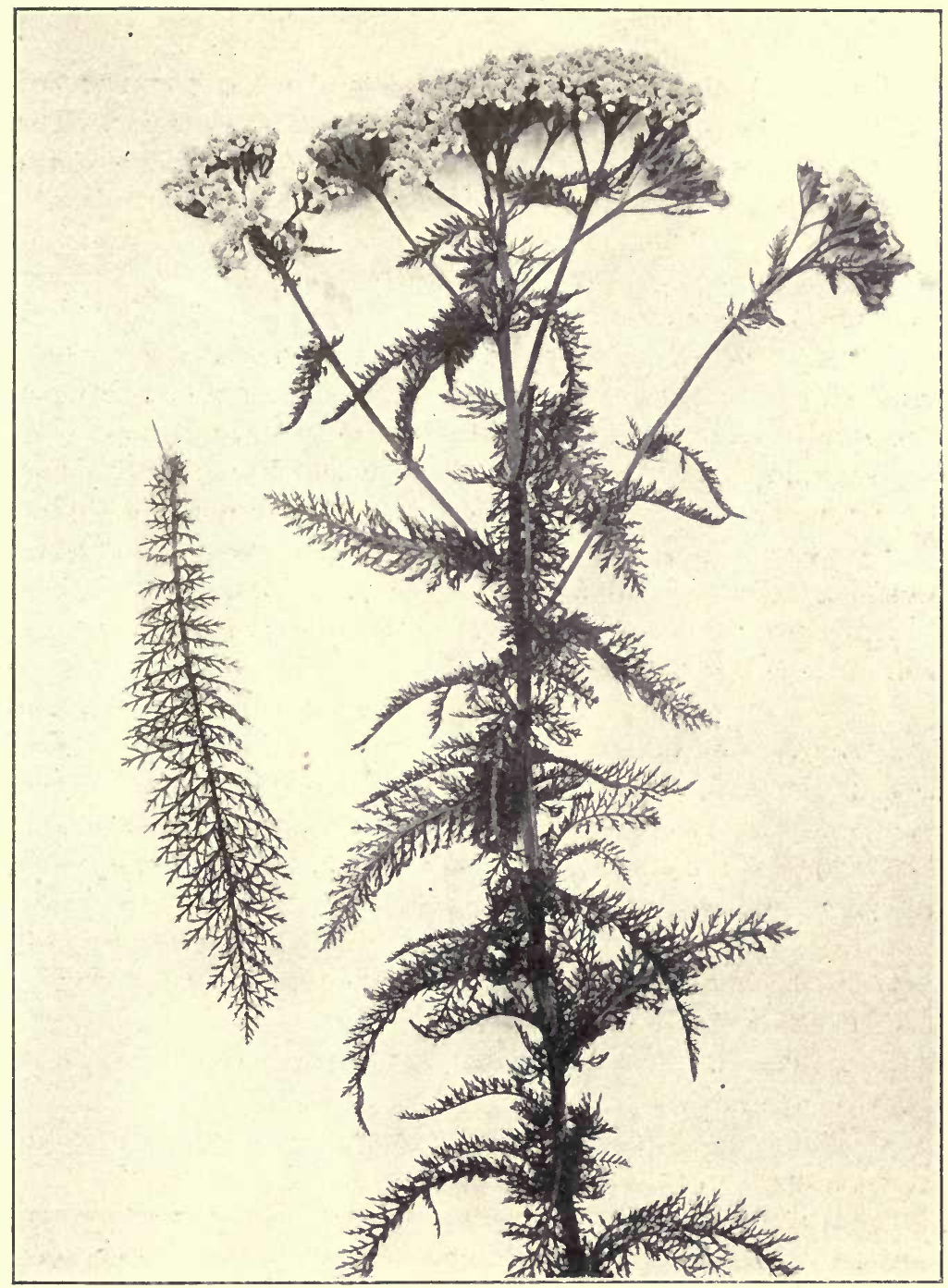

Fig. 397. Yarrow or Milfoil (Achillea Millefolium), a perennial herb, branching only at the top and bearing deeply pinnatifid leaves, the segments being very narrow. The flowers are small, white, occasionally crimson and arranged in large, terminal corymbs.Bureau of Plant Industry; U. S. Department of Agriculture.

The High Golden-Rod (Solidago canadensis) yields 0.63 per cent. of a volatile oil, consisting chiefly of pinene, with some phel- 
landrene and dipentene, and containing about 9 per cent. of borneol, 3 per cent. of bornyl acetate and some cadinene. The True or ANise-scented Golden-Rod (Solidago odora) yields an aromatic volatile oil and a small amount of tannin.

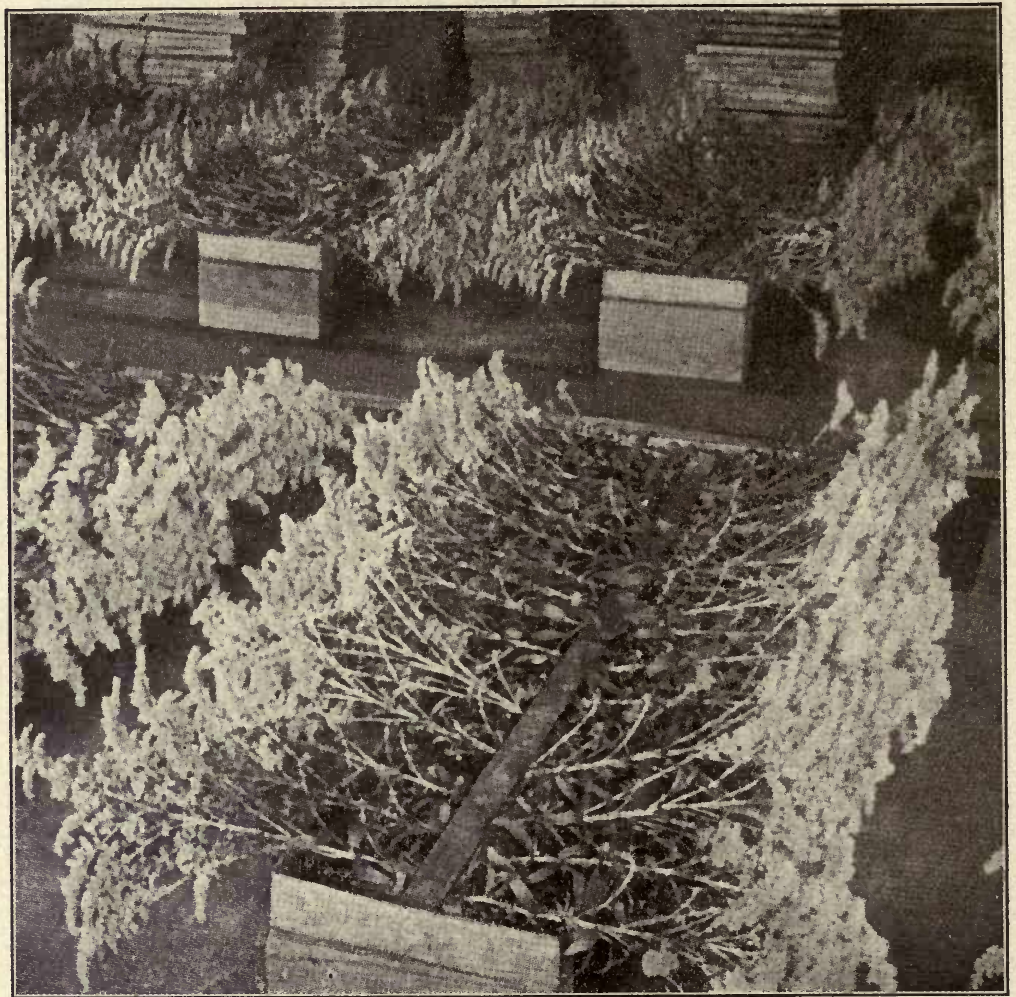

FiG. 398. Method of gathering the pollen of Golden-rod (Solidago Shortii) for immunizing the hay-fever horses. The plant is gathered just about the time that the pollen-sacs are ready to open, then taken to a sunny room-free from draft and air disturbancesplaced slanting in a basin filled with water, the blossoms drooping over the sides of the vessel, with clean, smooth paper spread underneath them. The following morning the pollen will be on the paper and can readily be gathered with a feather-top or a quill.After Schimmel \& Co.

The rhizome of the large Button-snakeroot (Lacinaria scari$o s a)$, growing in the eastern and central portion of the United States and Canada, contains o.I per cent. of volatile oil, about 5 per cent. of resin, and 2 per cent. of a caoutchouc-like substance. 
Coltsfoot (Tussilago Farfara) is a plant indigenous to Europe and naturalized in the Northern United States and Canada. It is an acaulescent herb with a slender rhizome 30 to 40 $\mathrm{cm}$. long; nearly orbicular, somewhat lobed and tomentose leaves, and large, solitary, yellow flowers appearing before the leaves. The plant contains an acrid volatile oil, a bitter glucoside, resin and tannin.

Echinacea is the root of Brauneria (Rudbeckia) purpurea, a plant growing in rich soil from Virginia to Illinois and southward, and of $B$. angustifolia, growing from the Northwest Territory to Texas (Fig. 399). The drug contains an alkaloid and 0.5 to I per cent. of an acrid resinous substance to which the medical properties are due.

Rosin Weed or Compass Plant (Silphium laciniatum), found growing from Ohio to South Dakota and south to Texas, produces an oleo-resin which exudes either spontaneously or from the punctures of insects, and contains about I9 per cent. of volatile oil, and 37 per cent. of acid resin.

The Thistle (Cnicus benedictus) contains a crystalline bitter principle, cnicin, which is colored red with sulphuric acid.

The Mexican drug PIPITzAHoAC is the rhizome of Perezia Wrightii, $P$. nana and $P$. adnata, plants found in Southwestern Texas and Mexico. It contains about 3.6 per cent. of a goldenyellow crystalline principle, pipitzahoic acid, which appears to be related to oxythymoquinone and is colored an intense purple with alkalies and alkaline earths.

Lion's FOOT, the root of Prenanthes Serpentaria, $P$. alba and other species of Nabalus growing in the United States, contains bitter principles, resin and tannin. Mro Mio (Baccharis cordifolia), of South America, is poisonous to sheep and cattle and contains an alkaloid, baccharine, and a bitter principle. Spiny CLOTBUR (Xanthium spinosum) contains a bitter resin and possibly a volatile alkaloid. The fruit of Xanthium spinosum, a common weed naturalized from Europe, contains an amorphous, non-glucosidal substance, xanthostrumarin, which forms precipitates with a number of the alkaloidal reagents. SNEEzE-WEed (Helenium autumnale) contains a volatile oil, a bitter glucoside and tannin. Helenium tenuifolium, of the Southern United States, 


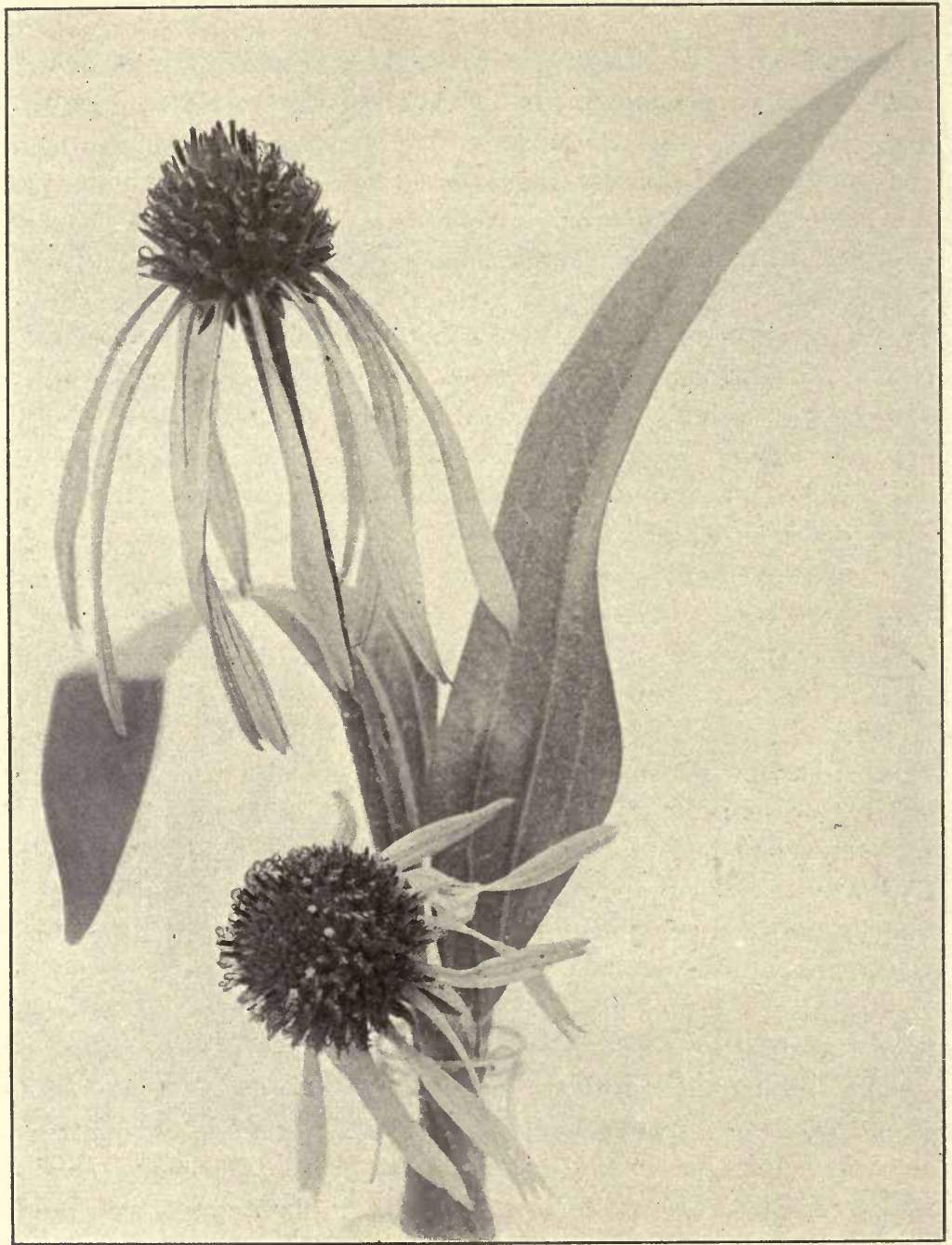

FIG. 399. A flowering specimen of the Purple Cone-flower (Brauneria angustifolia), showing the 3-nerved lanceolate leaves and 2 of the flower heads with the characteristic long spreading rays.-After Newcomb.

is a narcotic poison. PARA CREss (Spilanthes oleracea), of tropical America, contains a soft pungent resin and a crystallizable principle, spilanthin. The common white daisy (Chrysanthemum 
Leucanthemum) yields about o.I5 per cent. of a greenish volatile oil with the odor of chamomile and mint.

CHICORy, the root of Cichorium Intybus, a perennial herb with blue or purplish ligulate florets, indigenous to and cultivated in Europe and naturalized in the United States (Fig. 395), is used in medicine as well as in the preparation of a coffee substitute. The root is spindle-shaped, somewhat resembling Taraxacum, but is of a light brown color and the laticiferous vessels are arranged in radial rows in the somewhat thinner bark. It contains a bitter principle and a large amount of inulin. In the preparation of a coffee substitute the root is cut into rather large, equal pieces and roasted, after which it is ground to a yellowish-brown, coarse powder. The grains are heavier than water, imparting to it a yellowish-brown color. Under the microscope it is distinguished by the branching latex-tubes and rather short, oblique trachex with rather large, simple pores.

The Sunflower (Helianthus annuus) is an annual herb indigenous to tropical America and extensively cultivated. The plant is grown on a large scale in Russia, Hungary, Italy and India for its fruits, which yield a fixed oil resembling that of cotton seed. The achenes (so-called seeds) are obovate, flattened, externally black or with alternate white and black stripes, the pappus consisting of two deciduous, chaffy scales. Sunflower seed-cake is readily distinguished by a few of the fragments of the epicarp, with the characteristic twin, unicellular, non-glandular hairs and large, oblique, but rather short, sclerenchymatous fibers. Besides 40 per cent. of a fixed oil, the seeds contain a peculiar glucosidal tannin, helianthic acid, which is colored deep green with ferric chloride and yellow with alkalies. The root contains inulin; the shoot asparagin, and the fresh pith about I.5 per cent. of potassium nitrate. The pith has been used in the preparation of MoxA, a combustible vegetable material which burns without fusing and is used by the Portuguese to destroy any deep-seated inflammation. The pith of various species of Artemisia, which also contains considerable potassium nitrate, furnishes the Chinese Moxa.

Jerusalem Artichoke (Helianthus tuberosus) is a large, coarse, pubescent herb with yellow ray-florets, which is indigenous 
to the Middle United States and sometimes cultivated. The tubers, which resemble artichokes, are more or less elongated or pear-shaped, reddish-brown, somewhat annulate, and internally white or reddish. They have been used as a substitute for potatoes and contain about 16 per cent. of the following carbohydrates: Inulin, pseudo-inulin, inulenin, saccharose, helianthenin, and synantherin. In early spring with the development of the tubers there is formed a small quantity of dextrose and levulose.

The Globe artichoke of the gardens (Cynara Scolymus) is a hardy perennial and is valued on account of the fleshy involucral scales and torus, which are edible.

The POLLEN of a number of plants of the Compositæ, as ragweed (Ambrosia), golden-rod (Solidago), aster and chrysanthemum, is said to be responsible for the autumnal cold, known as HAY FEVER. A similar disease is produced in spring and early summer by the pollen of certain grasses. It has been found that the pollen grains of these plants contain a highly toxic substance, belonging to the toxalbumins, which is the cause of the disease. By inoculation of rabbits, goats and horses with this toxalbumin a serum containing an antitoxin is obtained which neutralizes the pollen toxin and protects those who are susceptible to hay fever from its attacks. In practice the serum is prepared by injecting the toxalbumin subcutaneously into horses, the serum being known in commerce as pollantin (Fig. 398).

The pollen of the following plants is toxic: aster, barley, chrysanthemum, convallaria, corn-flower, golden-rod, grasses, honeysuckle, oats, œnothera, ragweed, rice, rye, spinach, wheat, and zea. The constituents of rye pollen are 86.4 per cent. of organic matter, 10.2 of water, and 3.4 of ash. The organic matter consists of 40 .per cent. of toxic substances, 3 of fixed oil, 25 of carbohydrates, and 18 of a non-albuminous substance. The number of pollen grains per gram varies in different plants: from Indian corn being $7,000,000$, of rye $20,000,000$, of golden-rod $80,000,000$, and of ragweed $90,000,000$.

The flowers of the Japanese chrysanthemum "Riuno-kiku" (Chrysanthemum sinense japonicum) yield 0.8 per cent. of a volatile oil containing an optically inactive crystalline iso-camphor. 


\section{CHAPTER VI.}

\section{CULTIVATION OF MEDICINAL PLANTS.}

WHEN the forests and woods were full of wild medicinal plants that could be easily gathered, there was hardly an incentive to consider the farming of them. Now that they are becoming scarcer, the need is especially apparent. Our interest in the cultivation of medicinal plants, however, is not primarily because there is a growing scarcity of the sources of supply, but in order that drugs of uniform quality and increased value may be had. Fortunately, there is a tendency on the part of some manufacturing pharmacists to concentrate their efforts upon a few plants yielding drugs and to study them in relation to their active principles throughout different periods of the season. In addition to these actual experiments, there are numerous inquiries made regarding the possibilities of the successful farming of medicinal plants. These inquiries come from various people who, for one reason or other, would like to get into country life and have some definite work to do. Many of them have never had any practical experience in growing plants other than taking care of a garden plot. Nearly all know nothing of the commerce of drugs and have no idea of the problems connected with the disposition and marketing of them. Fortunately, some experiments have been conducted and there is some general information as to how one should proceed in the work. However, it must be said at the outset, no one can grow medicinal plants without having some training and special education for it ; and unless one is familiar with the practical conditions of trade, that is in regard to the markets and prices paid for drugs, even though successful in raising a good crop, one may not be able to dispose of it. It is very difficult to lay down any one rule that can be invariably followed on this subject. In fact, very little work has been done to enable us to draw other than very broad conclusions. The first thing to be considered is locality. Of course, tropical plants would not grow in the temperate zone, nor mountainous plants at the seaside, although even here there are exceptions that only experiments can show. 
Then again, there are plants which grow only in the rich woodland soil, while others grow in barren soil in open places. Some plants require special kinds of soil, as Atropa Belladonna and Cannabis sativa, which do not seem to reach a high state of cultivation except in a calcareous soil. On the other hand, the plants of the Ericaceæ are peculiar in that they require an acid soil (pp. 250,656).

In beginning this work in a new locality it is very important to make a rather careful survey of the plants growing wild, or those which have become naturalized. It would be safe to say that within certain limits, if there are a number of genera of any family well represented that has some of the habits of the plant with which one desires to experiment with, there is a probability that it may be grown successfully. This can be ascertained to some extent by the nature of the plants that are brought under cultivation. For instance, digitalis might be grown very successfully in localities where it is cultivated and has become naturalized. By a priori reasoning, in the cultivation of licorice, the ideal location for growing the plant would be in the West and Northwest. where the wild licorice, Glycyrrhiza lepidota, is indigenous. In addition, it is necessary to study the best ways of propagating the plant one wishes to grow. Sometimes this is by means of seeds, as in belladonna and digitalis; at other times it is by propagation of rhizomes, as hydrastis and glycyrrhiza; or again by root-stocks or prostrate stems, as in the mints. Sometimes both seeds and cuttings may be used, as in the case of hydrastis.

Plants Grown from Seeds.-A large number of plants can be grown from seeds, and when they are grown in this manner, especially in a temperate climate, where the growing season is rather short, it is necessary to begin the germination of the seed early in the spring. This must be done in the house or under conditions where there is some protection. They may be sown either in small boxes or seed pans, in which the soil is quite sandy or made up largely of broken granitic rock (Fig. 400), and which must be clean and free from organic matter that is likely to mould. The seeds should not be planted too deep, and the boxes or pans should be covered with glass so as to condense or hold moisture. Of course, where there is the necessary attention, so far as keeping the earth moist is concerned, this can be dispensed with. The 


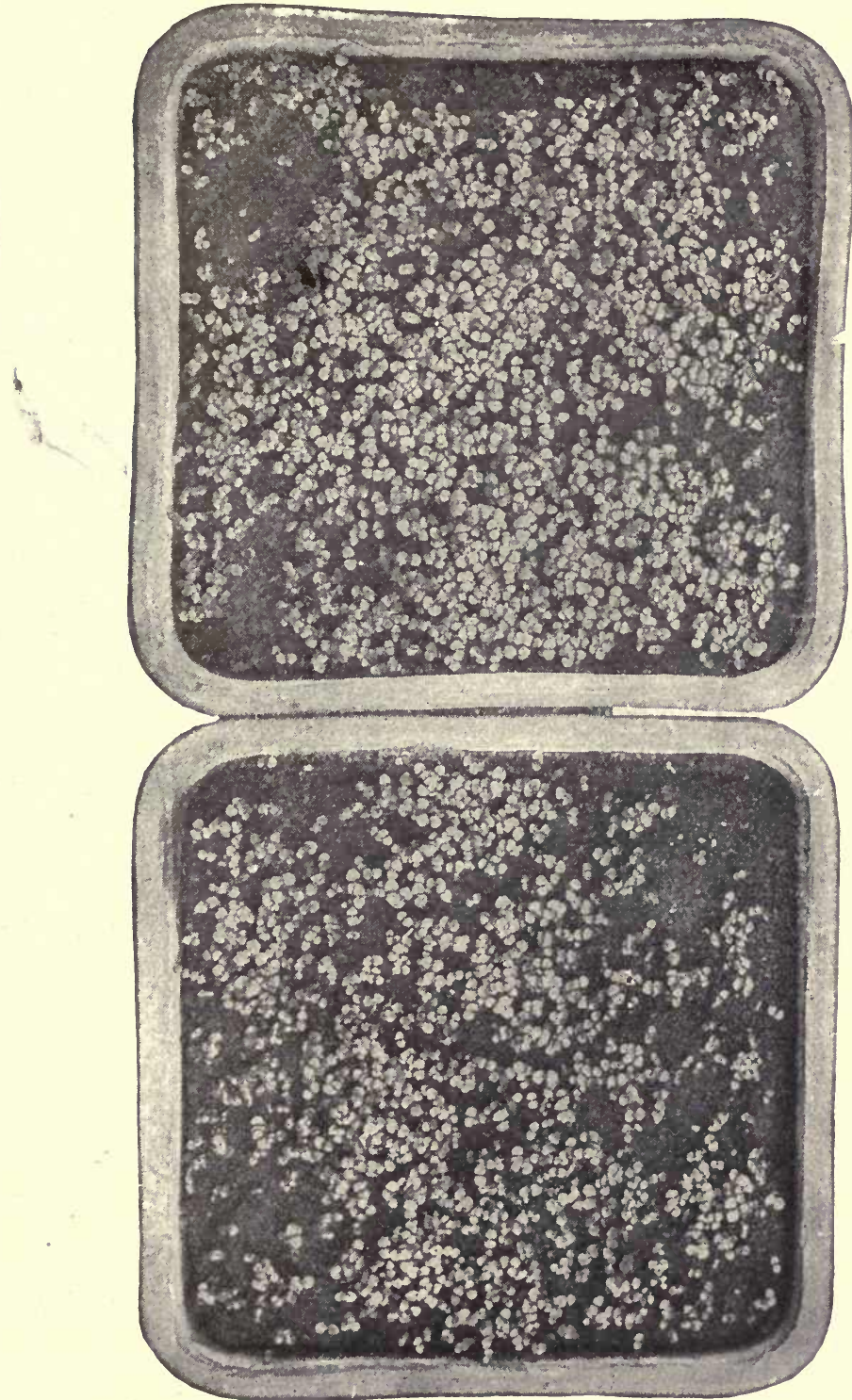

FIG. 40o. Digitalis Seedlings in seed pans, ready to be transplanted into plant flats. This is the first step in the propagation of Digitalis. -From the Experimental Farm of Eli Lilly \& Company, Indianapolis, Ind. 
time required in germination will vary considerably. Many seeds will germinate well within two weeks; usually probably four or five weeks are necessary. Occasionally some seeds, as with roses, may require a year or two. The present tendency is to shorten the period of germination in several ways. The simplest, possibly, is to place the seeds in water for 24 hours. If the seed-coat is more or less lignified and non-porous, boiling water is poured upon them, or some special treatment may be given, as the use of dilute

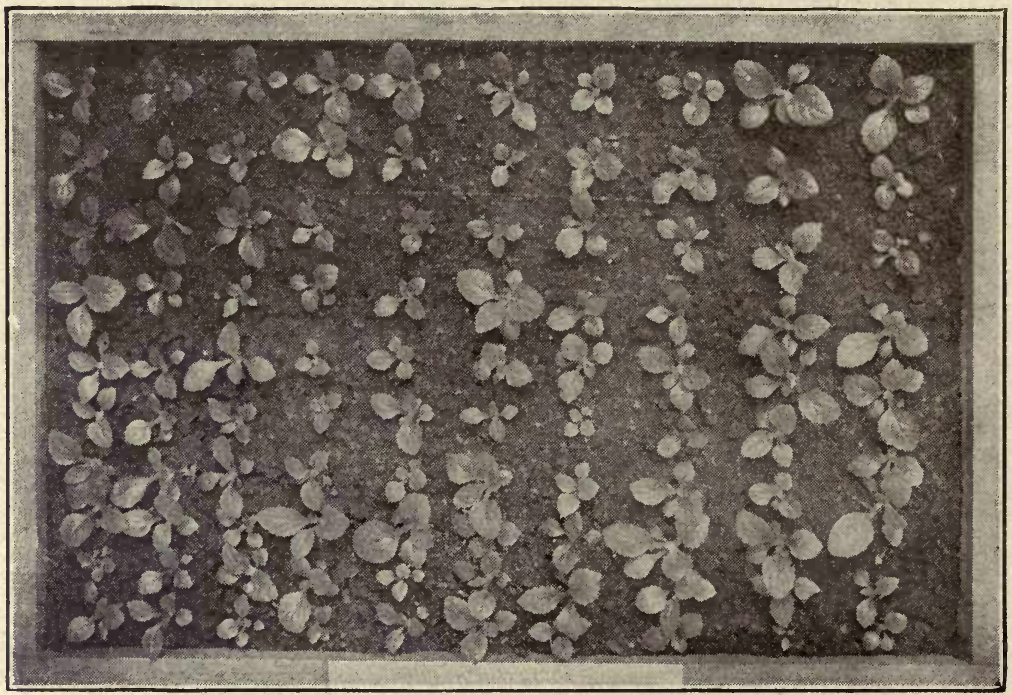

FIG. 40r. Digitalis Seedlings in plant flat, three months after transplanting from seed pans. These plants are now ready to be transferred to cold frames.-From the Experimental Farm of Eli Lilly \& Company, Indianapolis, Ind.

or even concentrated mineral acids. For instance, in the cultivation of Paraguay tea or maté, for many years it was found that the seeds would not germinate unless they had previously passed through the alimentary tract of certain birds. Later it was found that the same results could be obtained by placing the seeds in solutions of hydrochloric acid. Miller reports that he has obtained good results in the case of belladonna by first placing the seeds for 30 or 40 seconds in concentrated sulphuric acid. The germination of seeds may also be hastened by certain mechanical means. These are employed when the seed-coat is unusually thick and not easily 
penetrated by the moisture; or if the seeds are large, they may be filed in one or two places; when they are small they may be shaken with sharp, angular sand until the exterior is somewhat roughened.

After the seedlings have put forth a few leaves they are then set out in suitable boxes known as flats (Fig. 4OI) which contain a soil having a fair amount of nutriment. The plants must be watched at this point to see that there is no damping off and loss by reason of attacks by soil micro-organisms.

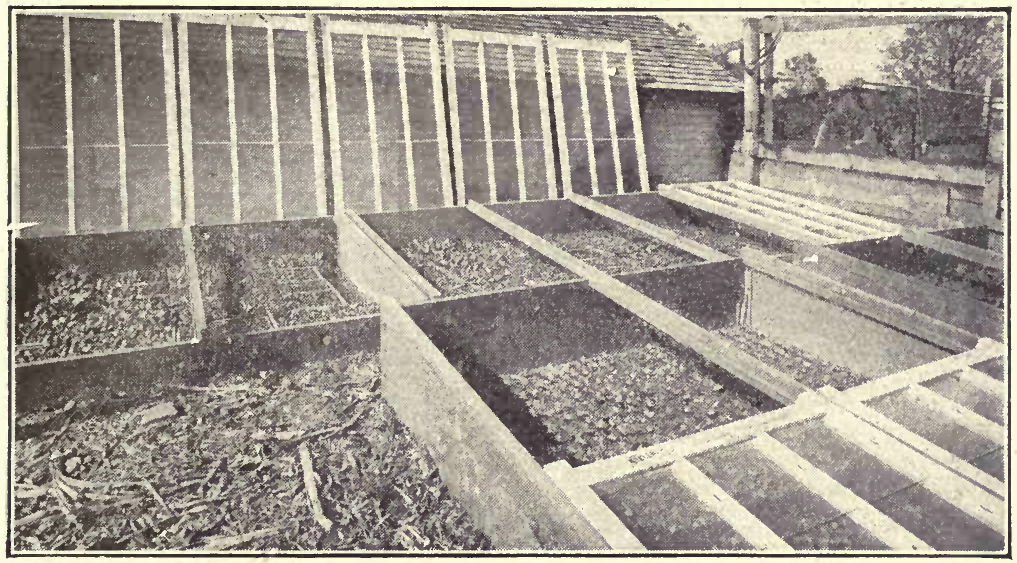

FIG. 402. Cold frames for use in propagating such plants as Digitalis, Belladonna, Henbane, etc. The young seedling plants are transferred from the greenhouse to these cold frames in late spring for the purpose of hardening them before transplanting to the open field.-From the Experimental Farm of Eli Lilly \& Company, Indianapolis, Ind.

Should there be a damping off and loss of seedlings some method should be employed to overcome it. Recently the Department of Agriculture has utilized dilute sulphuric acid, which Kraemer has shown is the active principle produced whenever sulphur is used in the greenhouse, for the destruction of insect pests, as well as the blights due to fungi and other microorganisms.

The plants are allowed to grow in the flats until they have developed a good root system and have produced a shoot with 3 or 4 leaves. They are then transferred to cold frames (Fig. 402), where they remain until they are acclimatized or hardened 
sufficiently to be planted directly in the soil. This transferring should be done not later than the early part of May. The structure and use of the cold frame is perfectly familiar to the practical gardener.

Sometimes the individual plants are removed from the flats and placed directly in the soil of cold frames. This may give them a temporary setback, as the roots are more or less disturbed

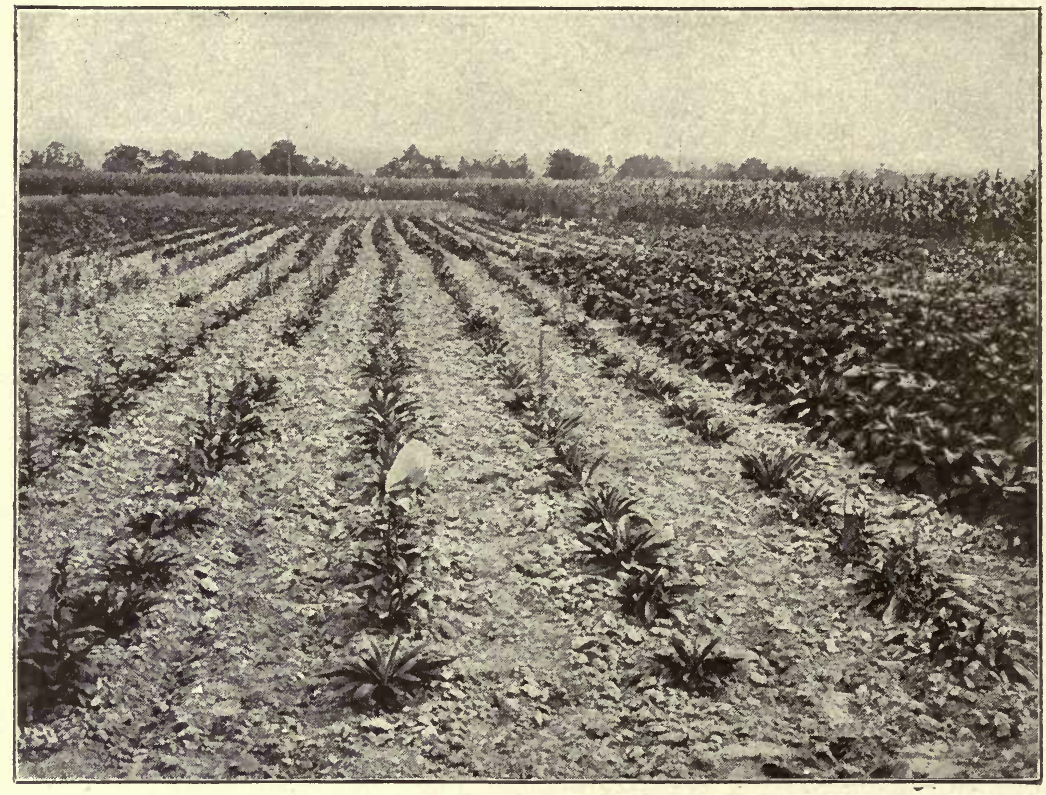

FIG. 403. A general view of the testing and breeding of medicinal plants at the Experimental Farm of Eli Lilly \& Company, Indianapolis, Ind.

by the operation, but if the experiment in the cold frames is to be continued considerable time will be saved.

If the plants are to be transplanted out of doors it is desirable that this should be done as soon as possible after the last days are over for the possibility of frost. The plants are arranged in rows and set sufficiently far apart so the maximum crop per acre can be obtained (Figs. 403-407), and also that weeds may be pulled out and the ground worked over.

The above outline given may be used for the propagation of 
most plants by seedlings. Some plants are rather easily grown if care is taken with their culture, as digitalis and belladonna. Other plants, like hyoscyamus, are with some difficulty cultivated, and very few persons, even seedsmen, are uniformly successful in growing aconite. It should also be stated that there are a number of plants yielding medicinal products which are grown from seeds and require no more care than the usual garden plants. Among these are calendula, Chrysanthemum roseum, echinacea,

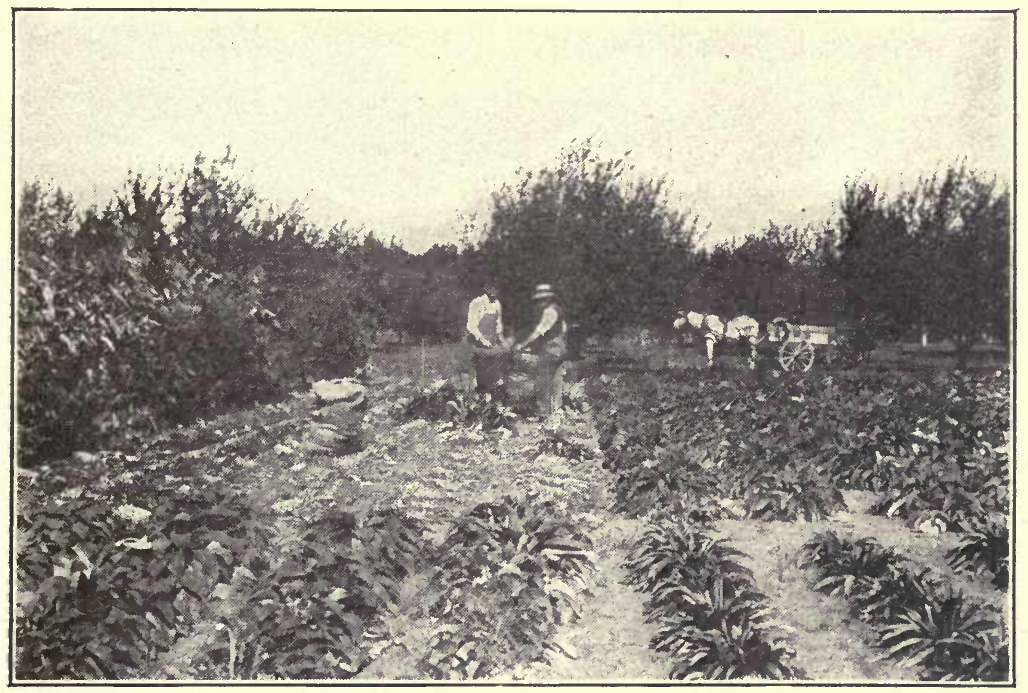

FIG. 404. Harvesting a unit test plot of first-year Digitalis.-From the Experimental Farm of Eli Lilly \& Company, Indianapolis, Ind.

and a number of others grouped under sweet, pot, and medicinal herbs.

Propagation by Cutting.-This is a common method of propagating plants, being extensively employed by florists. A cutting is a severed portion of a stem having one or more nodes or buds. They are derived either from over-ground shoots, as in carnation, rose, geranium, and coleus, or, where the plant produces root-stocks or rhizomes, they are made from these rather than from the over-ground shoots. Not all plants can be propagated equally well from cuttings. Some plants are readily propa- 
gated in this way, as the willows, the twigs of which, when they fall off or are broken off, frequently take root in the moist soil. Other plants, like the oak, are very difficult to grow from cuttings. In propagating plants from rhizomes the latter are cut into pieces, each of which has one or two buds, and these pieces are planted. Among the medicinal plants which have been grown from cuttings of rhizomes are licorice, peppermint, hydrastis, and ginger, but it is likely that all plants which produce rhizomes can be readily

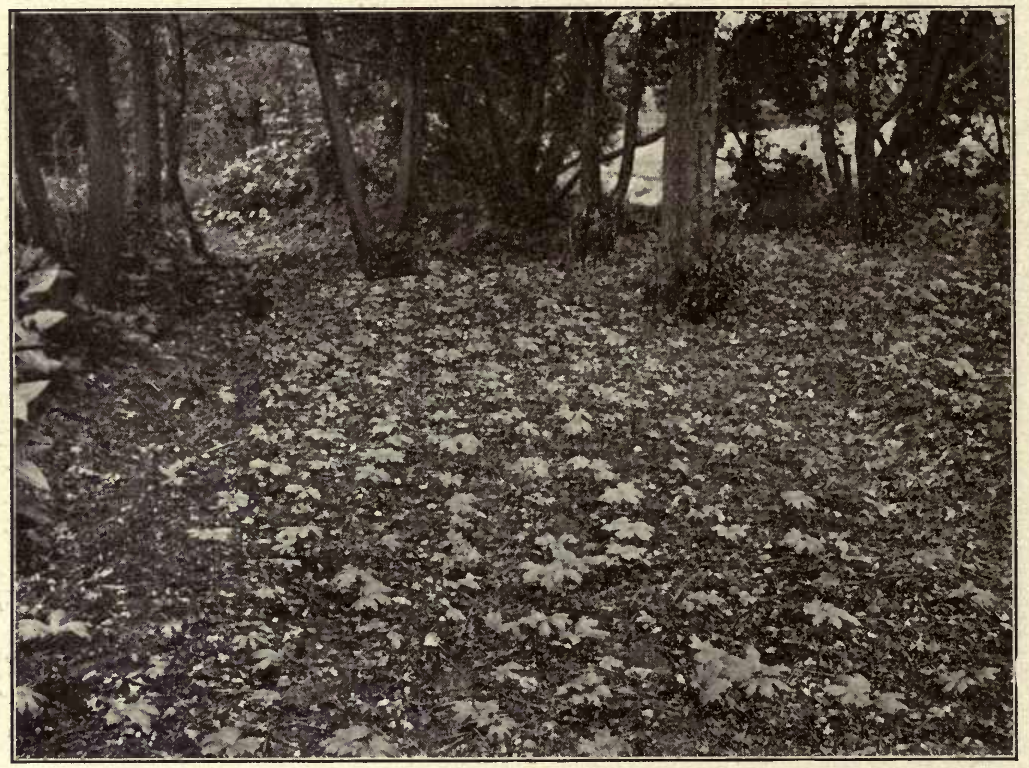

Fig. 405. Goldenseal (Hydrastis canadensis) farming in a natural woodland glade.From Wellcome Materia Medica Farm near Dartford, England.

propagated in this manner. Cuttings of over-ground stems are made from the growing parts of branches, and it is necessary to have them of such a length that at least one node may be placed in the soil. These are at first planted in micaceous soil or river sand, which should be kept well moistened. It is desirable that the leaves be as few as possible, so as to reduce the transpiring surface until the young roots have been formed, which may take several weeks or several months. Usually the lower leaves should be cut off entirely, while the others may be partially trimmed. The 
cuttings should also be protected from strong light, as this tends to increase transpiration, and also guarded against a dry atmosphere, which may be accomplished by covering them with glass, particularly during the day, when the weather is dry. Cuttings of hard wood plants intended for outdoor culture should be made in the fall. They should be 6 or 8 inches in length, kept covered with sand in a suitable place during the winter, and planted in the spring.

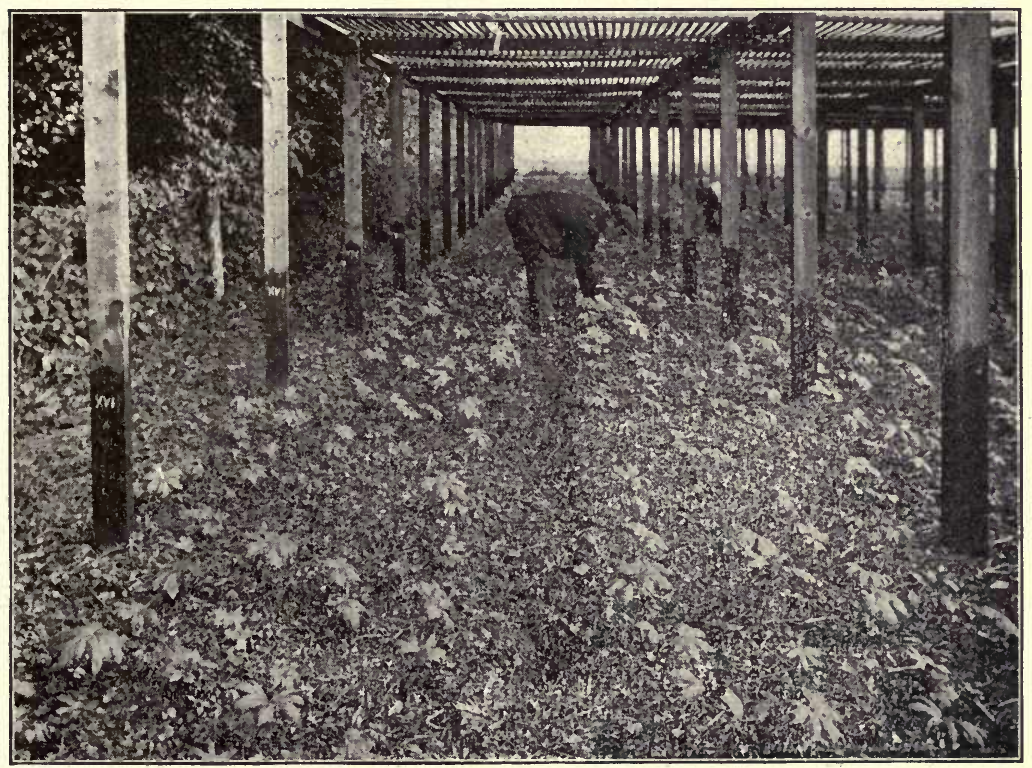

FIG. 406. Goldenseal (Hydrastis canadeizsis) farming under an artificially constructed shade.-From Wellcome Materia Medica Farm near Dartford, England.

In the case of both ginseng and hydrastis, one-year-old plants are often supplied by growers, and, though this is not always desirable, yet there are conditions where, for experimental purposes, they may be used. It should be emphasized that it is not merely a matter of getting rhizomes or young plants, but a very careful study should be made of the conditions governing soil and light, and which favor the maximum returns from the crop (Figs. 405407). Caution should be exercised in the use of manure for increasing the yield of the crop as well as the plant constituents. 


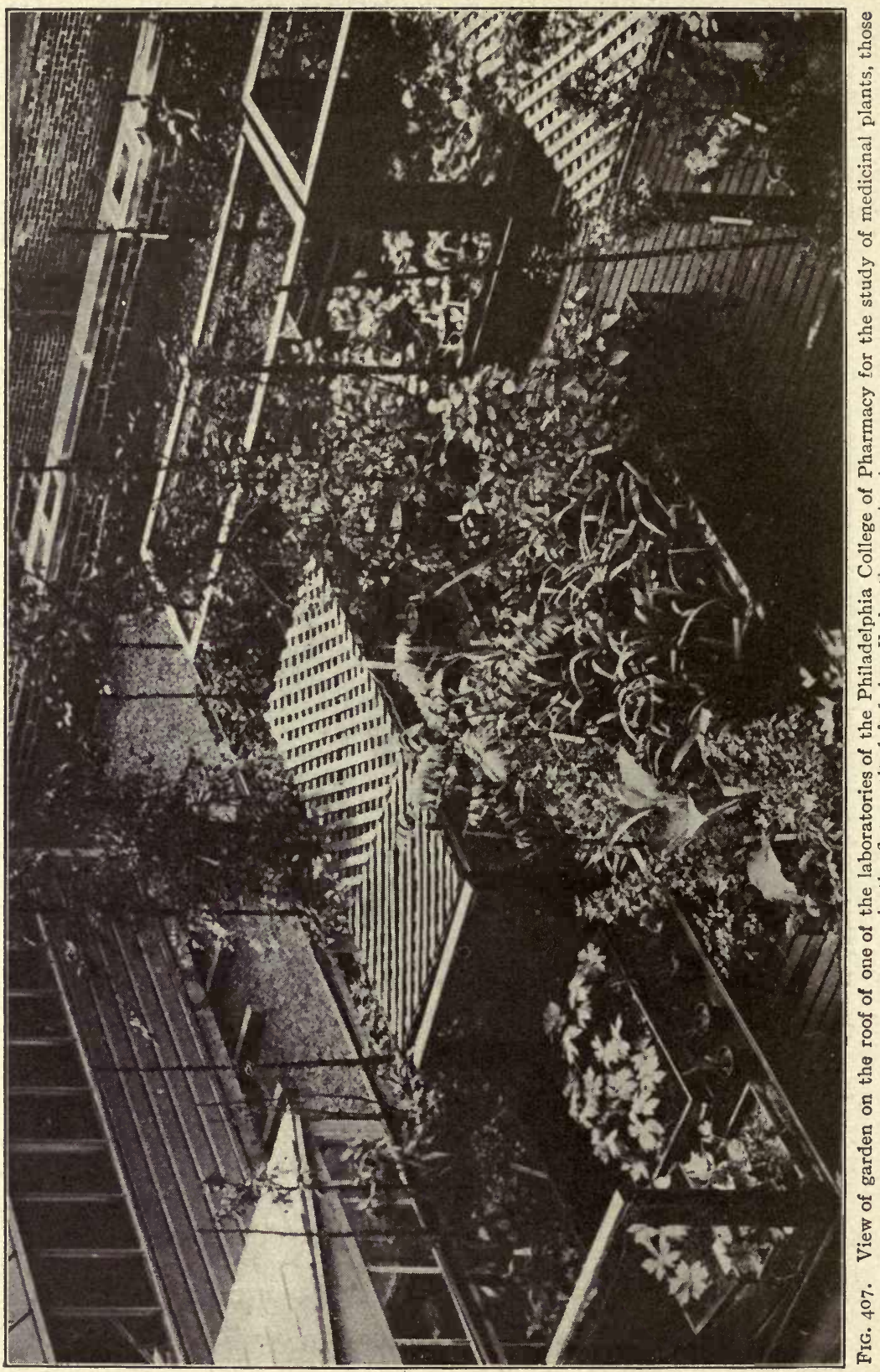


The method for producing new varieties is by hybridization, or cross-pollination, of different related species or varieties (Fig. 403). The offspring is known as a HYBRID, and has a blending of the qualities or characters of the two parent plants. This method is mostly employed by florists who desire to produce some new or striking flower, or by horticulturists who desire to establish some new quality or transfer a desirable quality from a foreign plant to one which is adapted to a given locality. The method has not been largely employed in the cultivation of medicinal plants, except in the case of cinchona, where it is claimed that the barks richest in alkaloids are the direct result of hybridization and selection. By transplanting and special methods of treatment, as that of mossing, the alkaloidal percentage has been increased from 8 per cent. to Io, whereas by hybridization the amount of total alkaloids has reached as high as 16 per cent., about three-fourths being quinine.

Collecting and Drying of Drugs.-The time of the colleecTION of vegetable drugs is of prime importance, and, while it may not be possible to make extended generalizations, still, the following rules for the collection of various drugs may be given:

( I) Roots, rhizomes, and barks should be collected immediately before the vegetative processes begin in the spring, or immediately after these processes cease, which is usually in the fall.

(2) Leaves should be collected when photosynthetic processes are most active, which is usually about the time of the development of the flowers and before the maturing of fruit and seed.

(3) Flowers should be collected prior to or just about the time of pollination.

(4) Fruits should be collected near the ripening period, i.e., full grown but unripe.

(5) Seeds should be collected when fully matured.

It should be emphasized that these are very general rules for the guidance of the collector, and that when one is farming drug plants this question becomes exceedingly vital, as not only do the constituents vary at different times during the season, but there is considerable variation in the amount of drug obtained. The exact information regarding the proper time of gathering any 
specific drug can be obtained only by collecting it at different times during the season, assaying it and making preparations from it. Experiments thus far seem to show that belladonna leaves collected in July and August show a higher toxicity than those gathered in September or October. It is quite possible that after the removal of the leaves high in alkaloidal content in July, another crop can be obtained by October. It is important to bear in mind with some drugs that a very slight difference in time of gathering and manner of drying, great variation of the active constituents may be found, as with many of the Composite flowers. It is only when they are in the bud condition, as in the case of insect flowers, and santonica, that they show the highest amount of active principle. Again, depending on whether an article is gathered to be put upon the market or whether the active principles are to be isolated, as in the manufacture of the essential oils, different methods are followed, depending upon the nature of the plant and what previous experiments have demonstrated should be followed. For instance, while in the preparation of oil of peppermint the herb is first dried, yet in other cases the collected material must be previously macerated in order to obtain the largest yield of oil, as with those plants yielding volatile oils containing either cyano-benzaldehyde or methyl-salicylate.

Too much attention cannot be given to the entire question of the harvesting of the crop and proper methods of drying, and, of course, again, depending upon the locality, different methods will be followed. There are some places at certain times where it would be quite possible to dry the drugs out of doors. In other situations it would be necessary to dry them in barns and even in specially constructed drying ovens where artificial heat would be employed. The drying of leaves, flowers, and seeds is comparatively simple and can usually be rather quickly performed without any special preparation. In the case of roots and fleshy fruits the drying should be under special protection, and is facilitated more or less by slicing or comminuting the article.

In some drugs, in addition to drying, there is a curing process that takes place. By this process of fermentation the active constituents are developed. Among the drugs treated in this manner the following may be mentioned: tobacco, vanilla, gentian, 
guarana, digitalis, the Solanaceous leaves, etc. In some cases the increase in quality can be determined by the assay of some one constituent, but in other cases the acquired value, like that of teas, wines, and tobacco, cannot be determined by an assay process and yet can be detected by the expert.

It has already been pointed out that plants contain a large proportion of water, and when they are collected and dried there is necessarily considerable loss. The loss is greater in the case of herbaceous plants, where the yield of crude drug is only about Io per cent., as in eupatorium and stramonium. Roots and rhizomes yield on an average from 20 to 30 per cent. of dried drug. In some cases, as in hops, the yield of dried drug is over 60 per cent., and in fruits and seeds there is very little loss.

Relative Value of Drugs from Cultivated and Wild Plants.-For some years it has been a question whether the activity of drugs obtained from cultivated plants is equal to that of those derived from wild plants. We find in some of the foreign pharmacopœias the specific statement that certain drugs, as digitalis, belladonna leaves, and belladonna root, must be derived from wild plants. This would naturally lead to the inference that wild plants are better, and yet it may be that this provision was made with the intention of securing uniformity of drugs rather than because the materials from wild plants are superior. In I907 Rippetoe conducted some experiments in Virginia which showed that cultivated plants of belladonna yielded both leaves and roots which were equal, if not superior, to the average drug on the market. As this work was done without any particular care and in a limited way, it was more than gratifying to those who were especially interested in this subject. Carr has shown by careful comparative experiments that cultivated plants of belladonna contain a little more alkaloid than do the wild plants. The investigations of Sievers also point to a similar conclusion. Sievers has also shown that the percentage of alkaloids in the leaves of different cultivated plants is exceedingly large, and that plants high in alkaloids will continue to breed plants high in alkaloids, so that by mere selection a better commercial article may be produced. Coming to the question of digitalis, there are some very interesting results. Hale, for in- 
stance, showed that cultivated digitalis leaves yield a much higher potency than those obtained from wild-grown plants, and yet he concludes that it is doubtful whether the fact that they were cultivated had anything to do with the high activity. One of the most valuable facts brought out in connection with these experiments is that the leaves of one-year-old plants seem to have as great toxicity as those of the two-year-old plants. Hale distinctly states that "first-year leaves are not necessarily weaker than second-

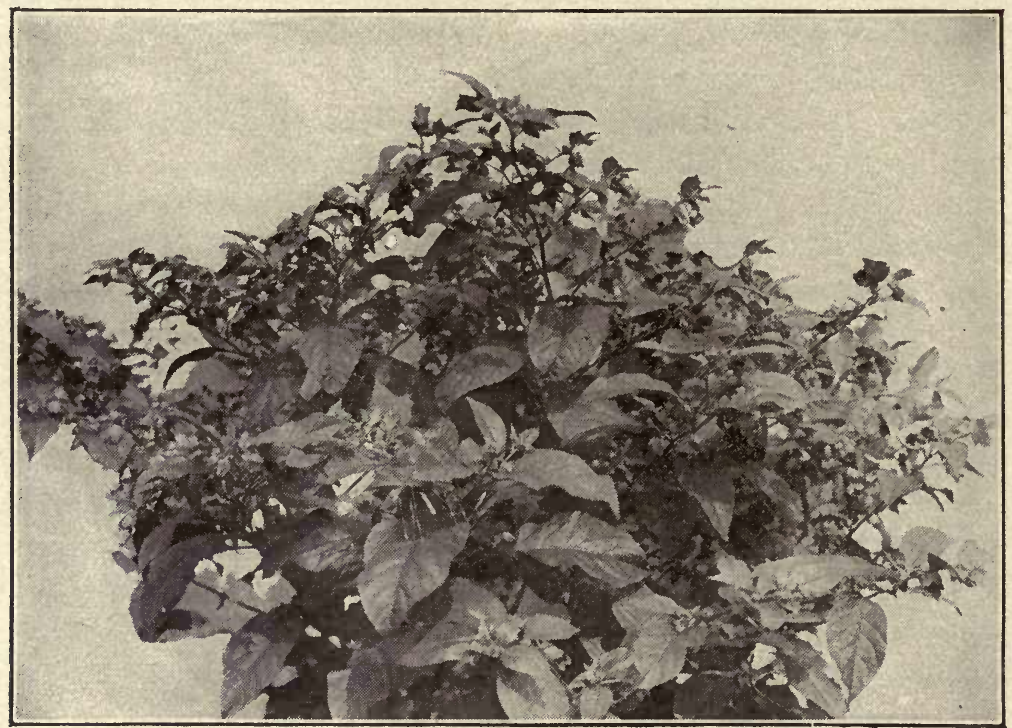

Fig. 408. Atropa Belladonna, first year's growth from seed planted January Ist. Photograph in July of the same year.-From the Experimental Farm of Eli Lilly \& Company, Indianapolis, Ind.

year leaves, and might be used in preparing assayed digitalis preparations." This means that one does not have to wait two years before securing a crop, so that practically one can obtain twice the quantity of the drug during the same period.

There may be some instances during this experimental stage which might seem to indicate that certain external conditions, such as climate as well as soil, have a very great influence in the growing of plants of exceptional value. In the case of American-grown cannabis, Eckler and Miller have shown that repeated plantings 
from carefully selected plants of American and Indian cannabis have failed to yield, when in cultivation near Indianapolis, a product testing over 65 per cent. of the active value of good Indian-grown drug, and that the majority of the plants tested 50 per cent. and even less.

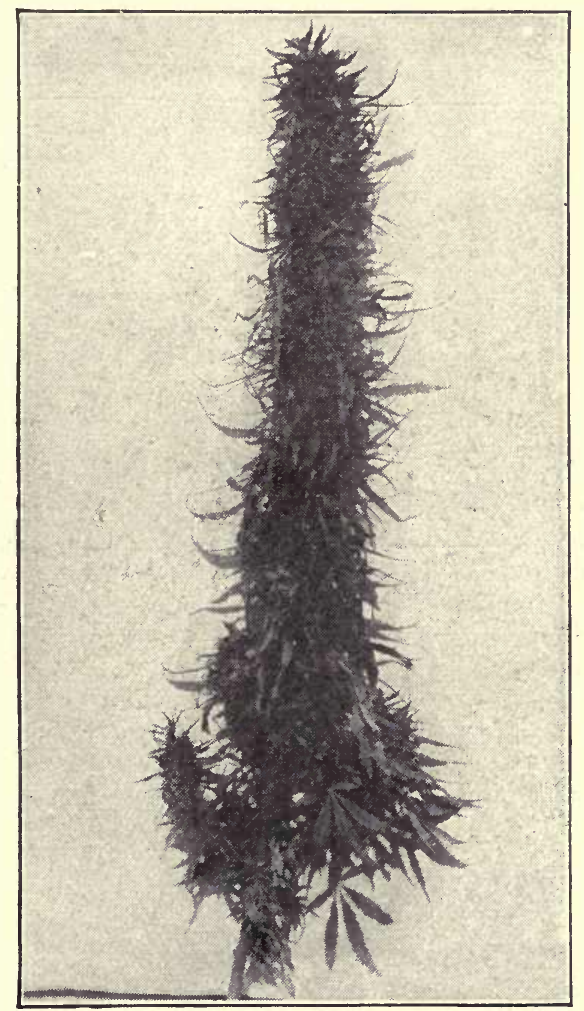

Fíg. 409. Form of American Cannabis developed by F. A. Miller. Such forms are obtained by selection and result in strains that are better adapted to modern methods of agriculture and from which the collection of the pistillate inflorescence is greatly simplified.From the Experimental Farm of Eli Lilly \& Company, Indianapolis, Ind.

Experiments conducted near Timmonsville, S. C., by the U. S. Department of Agriculture have shown that in that locality a drug of a somewhat higher degree of potency can be grown. Of course, it is well known that the hemp plant is grown extensively for fiber in Kentucky and other parts of the middle West. This 
may be due in large part to the fact that it requires a limestone soil, and in practice the most favorable results are obtained where there is an underlying bed of blue limestone. Sufficient has been said to show that success will attend the cultivation of medicinal plants, and indeed, by a priori reasoning on the basis of other

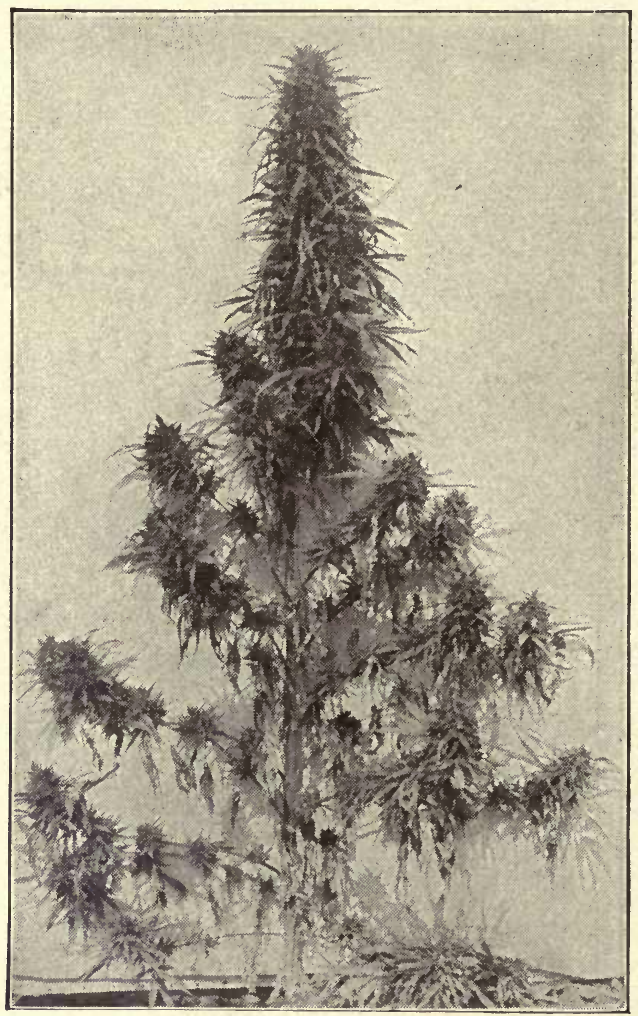

Fig. 4ro. Form of American Cannabis developed by F. A. Miller. Such forms are obtained by selection and result in strains that are better adapted to modern methods of agriculture and from which the collection of the pistillate inflorescence is greatly simplified. -From Experimental Farm of Eli Lilly \& Company, Indianapolis, Ind.

agricultural efforts, one would expect that medicinal plants could be grown with the same certainty of increasing the yields of any particular constituent or quality that might be desired. Indeed, the history of the sugar beet industry has been duplicated in the work on Cinchona, and the same thing can be said with regard to any other plant that man desires to conserve and cultivate. There 
are no insurmountable obstacles in this work, and there are no intricate processes to be solved before success results. There are merely a few underlying principles that must be adhered to, and by persistent effort and with a full understanding of market conditions success must crown the efforts of anyone who undertakes

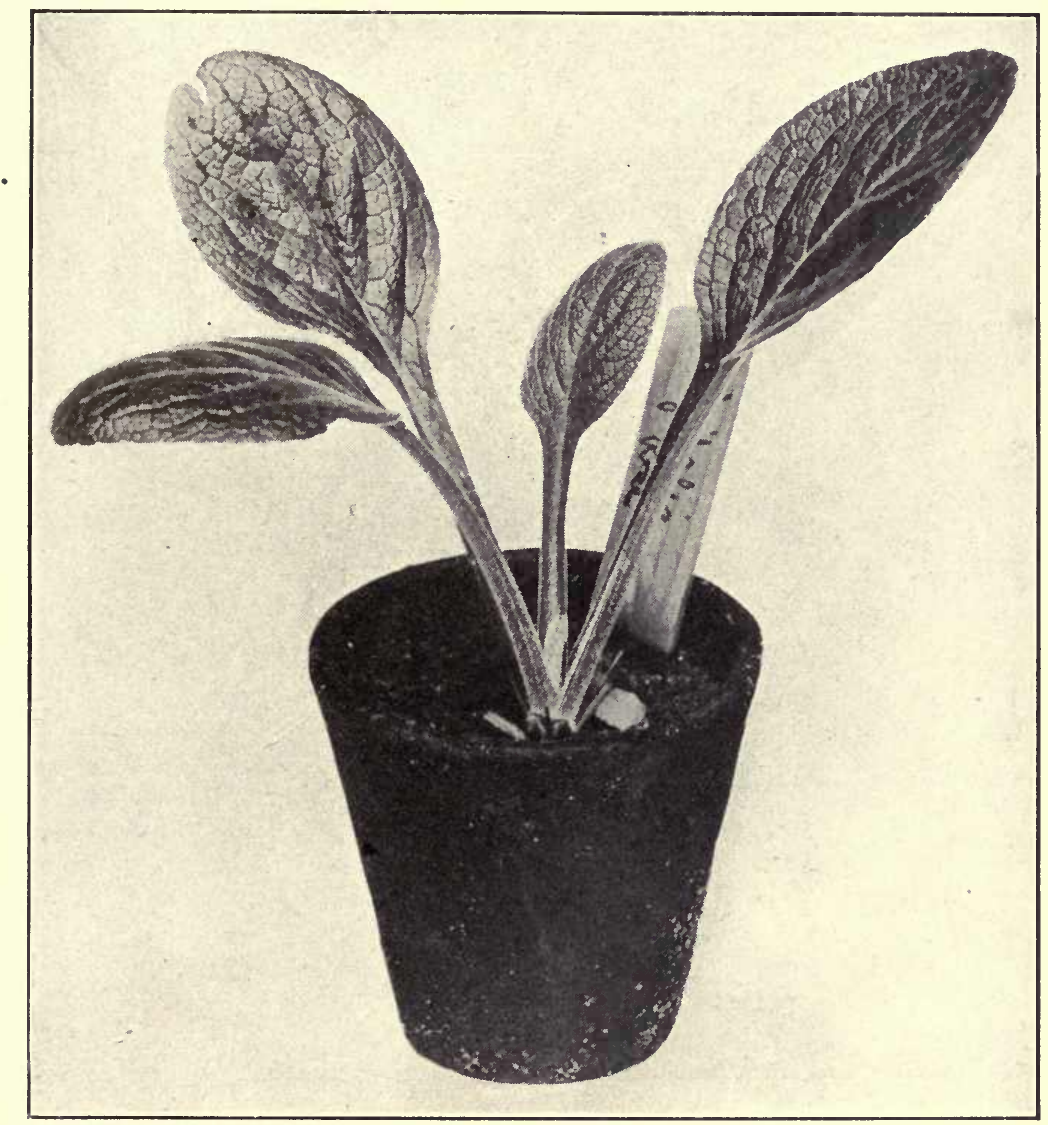

FIG. 4II. A seedling plant of Digitalis about six months old.

this work. What has been done in the selection of fruits and vegetables can be equally well accomplished in drugs with the proper incentive.

Progress in the United States.-We can scarcely appreciate that, while the development of medicinal plant culture has been 
an exceedingly slow one, yet as a matter of fact, by reason of some of the products being more extensively used, as in the case of hops, it is one of the oldest agricultural industries in the United States. The history of the cultivation of hops is very similar to

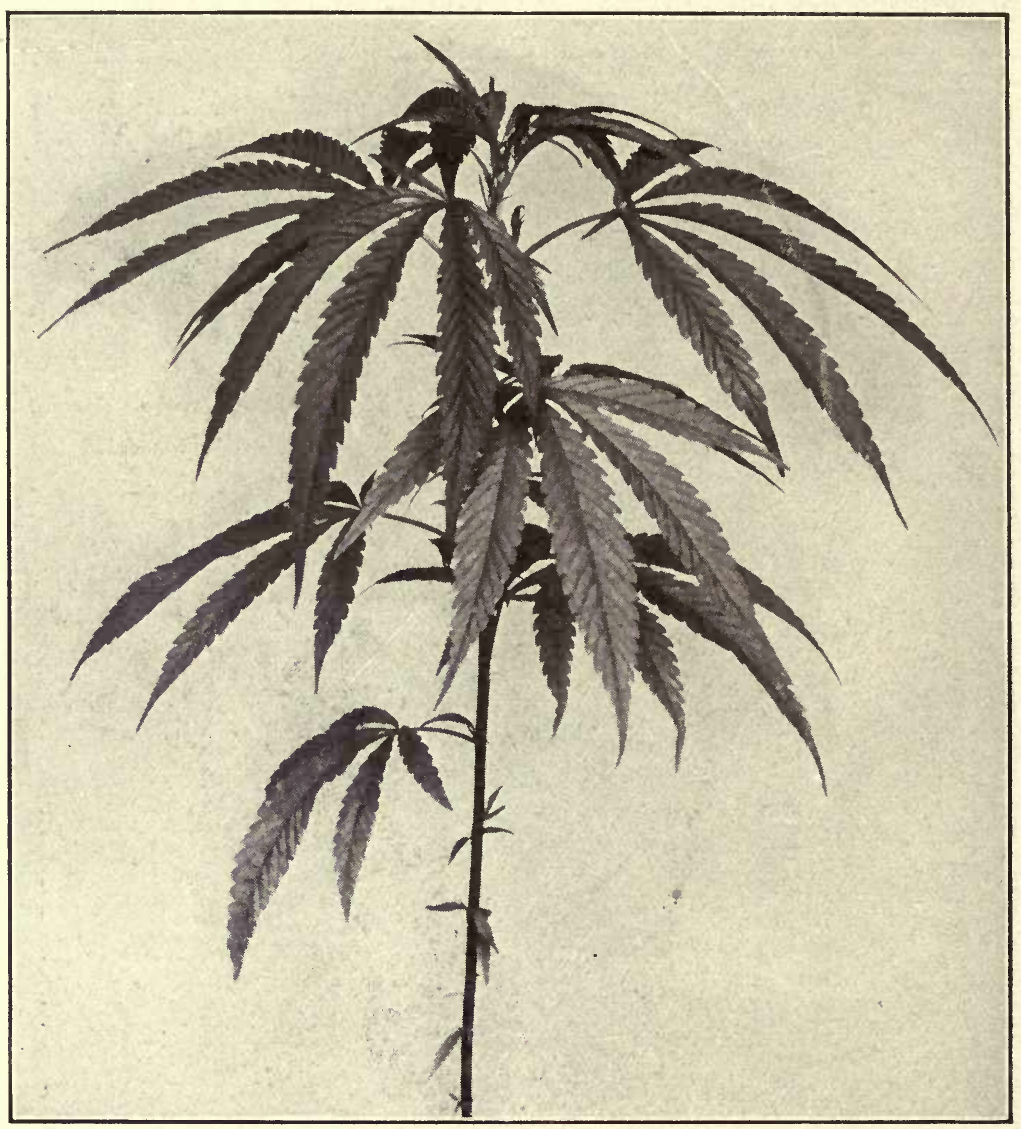

FIG. 4I2. Cannabis sativa: Young plant grown from seed found in the drug Cannabis indica.

the experience with other medicinal plants. For instance, it was grown in Virginia with poor results, and in Vermont and Massachusetts, where it was very successful. By virtue of the success obtained in the New England States it was, in the early part of the last century, introduced into New York State and later spread 
into some of the Middle States, as Michigan, Wisconsin, Indiana, and Ohio. Since that time the cultivation has been extended to

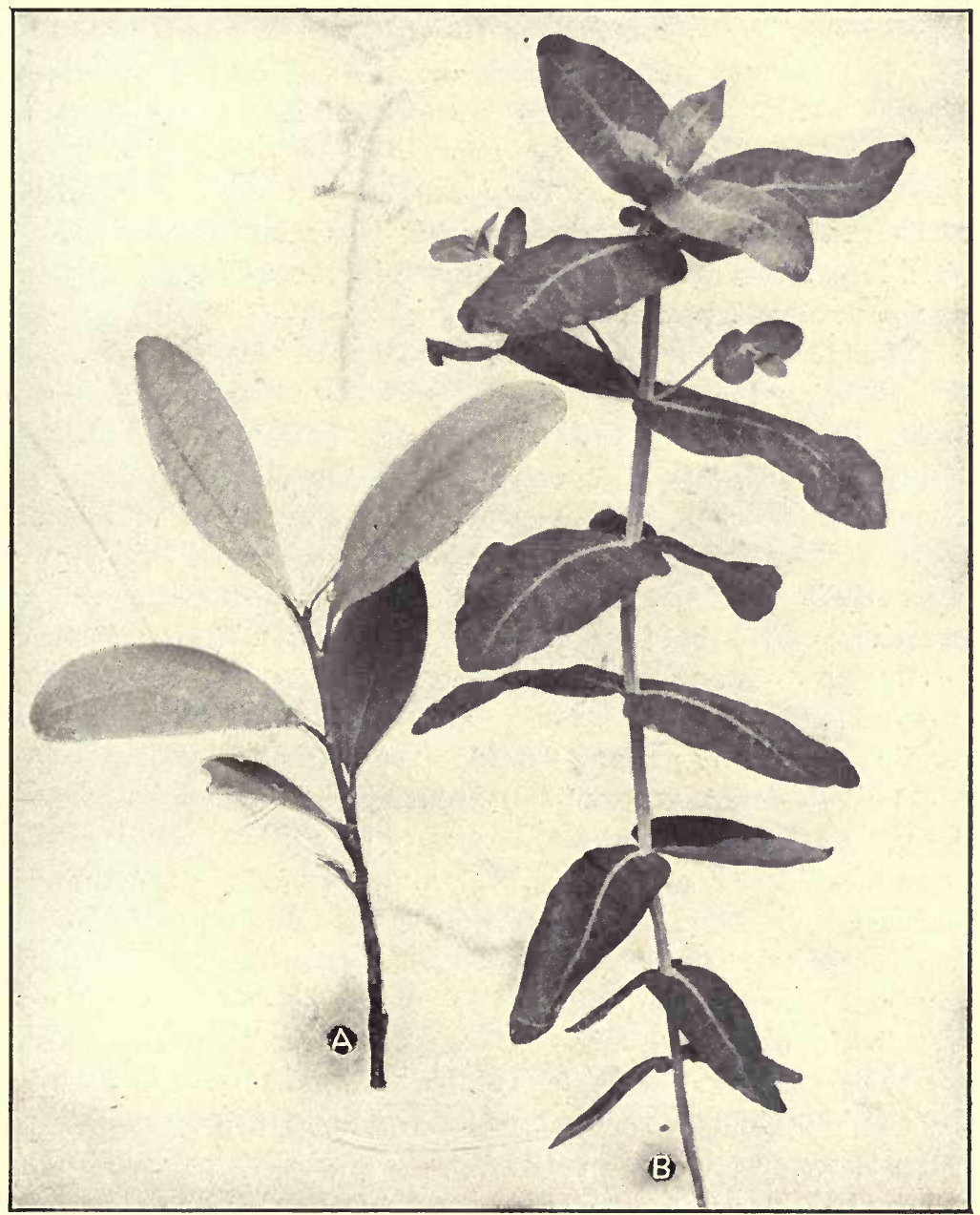

Frg. 4r3. Seedling plants of Erythroxylon Coca (A) and Eucalyptus globulus (B).

some of the States on the Pacific coast, notably Oregon, Washington, and northern California.

The peppermint industry shows a similar history. This industry was first developed in Wayne County, New York. Later it 
spread into Michigan, Ohio, and some of the Southern States, and by reason of the more favorable climate and soil conditions in Michigan the industry here has outstripped that of even New York State, being practically .abandoned in Ohio and the other States. The men connected with the Division of Botany of the United States Department of Agriculture have always manifested a keen interest in the possibilities of the cultivation of medicinal plants, and have done what they could to encourage interest in this subject, and the records show that they have supplied information as it might be needed by those disposed to take up the work in a practical manner.

The development of the tea industry in North Caroiina is one of the most creditable pieces of work of the National Government. Bulletin No. 234 of the Bureau of Plant Industry, on "The Cultivation and Manufacture of Tea in the United States," by George F. Mitchell, should serve as an inspiration to anyone contemplating drug culture. If a plant of this kind can be grown successfully here and the technique of manufacture developed to such an extent that the cultivation at Pinehurst, North Carolina, has become remunerative, there is no question but that within reasonable limits nearly any plant except the strictly tropical ones can be successfully grown in the United States.

Without doubt, the camphor industry will become successful in some of the Southern States. Nearly fifty years ago, when the price of camphor was very high, the government started some experiments in Florida in the growing of the camphor tree. These experiments were subsequently abandoned, as there was hardly any likelihood of anyone being interested in this commercially on account of the low price of camphor. During the past few years, however, interest in this culture has been revived in Florida and southern Georgiaby reason of the fact that frosts destroyed the citrus fruits and the landowners began a search for other possible crops which would not be so injured. Circular No. 12, Division of Botany, United States Department of Agriculture, shows just what can be done for the successful cultivation of this tree in the Southern States, and some recent experiments of the government show that by utilization of leaves and twigs there are great possibilities in the economical manufacture of camphor in the United States in spite of the high price of labor. 
Owing to the fact that essential oils are used in such large quantities it is quite likely that the cultivation of many of these plants may be made successful, providing at the same time that suitable apparatus for their distillation is also installed upon the farms.

By reason of the fact that the cultivation of chicory is a permanent agricultural industry in nearly all of the countries having a temperate climate in Europe, experiments have been conducted in the United States in a small way, and these have led to the conclusion that it may be successfully cultivated in those States where the sugar beet industry has flourished.

As a summary, the following general points might be held in mind by those who desire to take up the cultivation of medicinal plants :

In the first place, he ought to determine whether there is a market for any drug under consideration, and this can only be obtained by personal inquiry and investigation, as not even any of the government publications give this information.

In the next place, if one is satisfied that it is worth while to take up the cultivation of any particular plant, its geographical range should be studied, both as to where it is indigenous and where it has become naturalized. The literature should be gone over not only for facts regarding the cultivation and distribution of the particular plant in view, but also of some of the related plants.

At the same time that these preliminary studies are made, a careful survey should be taken of the plants which are indigenous and under cultivation in the particular locality where one is proposing to locate the farm. Then, of course, everything should be done on a small scale at first. If there is no information available, then he must, on the basis of the general principles laid down for the cultivation of medicinal plants, proceed with their culture, conducting parallel experiments with propagation by both seeds and cuttings.

Then when the crop is harvested he must, by analytical and other means, satisfy himself as to the value of his product compared with the commercial article, and with these facts in hand submit specimens and request quotations from the dealer in crude drugs, and the wholesale druggist. On this basis he will arrange 
for all future crops with some certainty as to their market value. Experience has shown that cultivated crops command a higher price than the drugs obtained from wild plants, even though their superiority cannot always be demonstrated by analytical means. For instance, no one is trying to determine by an analytical process whether any given lot if tobacco, tea, or coffee is of superior value, and yet the competent dealer and the discriminating public even recognize the qualities of the grades that are offered. This is even more marked with the products that have been derived thus far from cultivated medicinal plants, and are appreciated by some pharmacists and physicians.

\section{BIBLIOGRAPHY.}

Cultivation of Belladonna: A. F. Sievers, Amer. Jour. Pharm., March and November, 1914; Francis H. Carr, Ibid., November, I9I3; F. A. Miller, Ibid., July, ris3.

Cultivation of Digitalis: E. L. Newcomb, Amer. Jour. Pharm., November, I9I I ; John A. Borneman, Ibid., December, I9I2; F. A. Miller, Ibid., July, I9I3.

Cultivation of Hydrastis: John Uri Lloyd, Proc. A. Ph. A., 1905, p. 307, and in Jour. A. Ph. A., Vol. I, p. 5 ; Alice Henkel and G. Fred. Klugh, Circ. No. 6, Bureau of Plant Industry, U. S. Department of Agriculture; J. C. Baldwin, Amer. Jour. Pharm., April, I9I3.

Cultivation of Ginseng: George V. Nash, Bulletin No. I6, Division of Botany, U. S. Department of Agriculture.

Cultivation of Eucalyptus: A. J. McClatchie, Bulletin No. 35, Bureau of Forestry, U. S. Department of Agriculture.

Cultivation of Peppermint: A. M. Todd, Proc. A. Ph. A., 1903, p. 277; Alice Henkel, Bulletin No. 90, Bureau of Plant Industry, U. S. Department of Agriculture.

Cultivation of Cannabis Sativa: C. R. Eckler and F. A. Miller, AmerJour. Pharm., November, 1912.

Cultivation of Camphor: Circ. No. I2, Division of Botany, U. S. Department of Agriculture.

Cultivation of Tea: Bulletin 234, Bureau of Plant Industry, U. S. Department of Agriculture.

Cultivation of Chicory: Bulletin No. 19, Division of Botany, U. S. Department of Agriculture.

A number of valuable articles by Mitlacher and other members of the pharmacognostical department of the University of Vienna have been published in Zeitschrift für das landwirtschaftliche Versuchswesen in Oesterreich since IgII. 


\section{CHAPTER VII.}

\section{MICROSCOPIC TECHNIQUE AND REAGENTS.}

Making of Sections.-In order to examine objects by means of the compound microscope they must be relatively thin and transparent ; furthermore, they must be mounted in water or other mounting fluids. In material consisting of single cells, or, at most, a layer of a few cells, the specimen may be mounted directly in water. This manner of mounting may also be used in the examination of pollen grains, hairs, and thin organs, as petals. Usually in the examination of the latter some clearing agent, as solution of hydrated chloral, is necessary in order to make the specimen transparent. As most objects consist of a large number of cells, it is necessary to examine small portions of them, and these are termed sections. They are made with a razor and correspond to the shavings made by a carpenter's plane. As each object has three dimensions, it is necessary that three different kinds of sections be made. (I) A transverse or cross section is one made horizontally through the object, therefore its plane lies at right angles to the long axis. (2) A radial-longitudinal section is one made at right angles to the cross section and it lies in the plane of the radius, so that in a dicotyledonous stem the section would be made parallel with the medullary rays. (3) A tangential-longitudinal section differs from the preceding in that it lies parallel to the outer surface of the object, or in a plane tangent to the cylinder. These several forms of sections are readily understood from the adjoining illustration (Fig. 4I4).

Sections of roots, stems, barks, and many fruits and seeds can be made directly without embedding the material, and while sections can be made holding the material in the hand, between the thumb and three fingers, the hand microtome for holding the material may be used by those who are less experienced. In the sectioning of leaves and other material that is not firm, and fruits and seeds which are too small to hold in the hand, the material should be embedded in some substance which will hold it and give it stability. When the tissues are not too hard the 
material may be placed between pieces of elder or sunflower pith. In some cases the making of sections is facilitated by moistening both the pith and the razor. In the case of seeds and fruits which are very small and at the same time very hard, as colchicum and mustard, it is best to use a velvet or fine grade of cork for holding the material. The cork is indented by means of forceps and the seed or fruit forced into the cavity.

In the case of very delicate tissues, where the protoplasmic contents of the cells are to be studied, as in the ovaries of flowers, prothalli of ferns and other parts of the plant, where cell division is going on, the material should be embedded in paraffin or celloi-
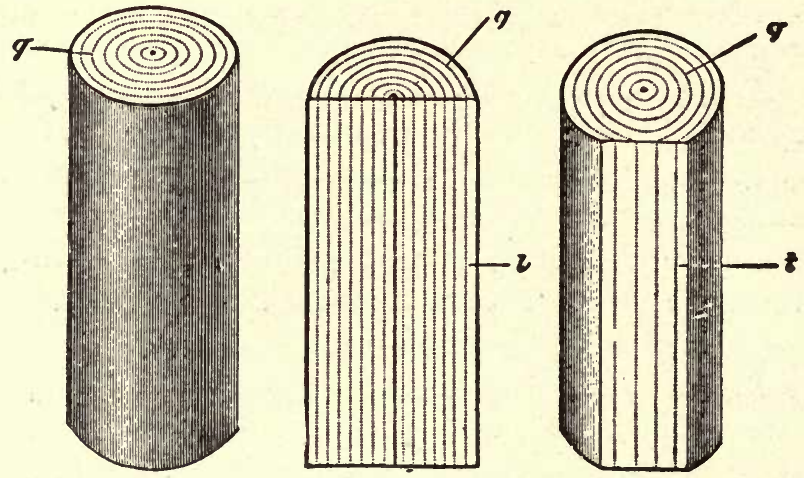

FIG. 4r4. Schematic presentation of the three types of sections: $q$, cross or transverse section; $l$, radial-longitudinal section; $t$, tangential-longitudinal section.-After Meyer.

din, subsequently hardened, and sectioned by means of a finely adjusted microtome.

Dried Material.-Most of the vegetable drugs and some of the vegetable foods occur in commerce in a more or less dried condition, and in order to study them microscopically it is usually necessary to give them some preliminary treatment. With the majority of drugs, soaking in hot or cold water from a few minutes to a few hours will render them sufficiently pliable or soft for sectioning. After this the material is hardened by placing it in alcohol ( 60 to 70 per cent.) for a few hours or over night. It may then be sectioned and treated with special reagents or stains as desired. Very hard material, as the shells of nuts and 
seeds, may be softened by soaking in solutions of potassium hydrate.

Some Practical Suggestions.-The following are some of the rules which should be borne in mind by the student when using the microscope in the examination of microscopic material :

I. Always mount the sections (including powdered material) in water or other suitable reagent prior to examination; never attempt to examine dry material except in special cases.

2. Use sufficient of the mounting medium or reagent to cover the specimen, but avoid an excess or more than will be held under the cover-glass.

3. Always endeavor to have the object properly illuminated by making use of the concave mirror.

4. Always be particular about having the eye-piece and objectives clean.

5. In examining a microscopic object, always use the lowpower objective first.

6. The edge of a section is always the thinnest, and this part being the best for study, should be brought to the center of the field.

7. When the object is properly centered, raise the objective, swing it to one side, bring the high-power objective into its place, and cautiously lower it until it is brought to about the distance of a millimeter from the cover-glass. Then holding the slide with the left hand, the proper focus of the object is obtained by making use first of the coarse adjustment and then of the fine adjustment, the right hand being used for this purpose. In examining the object always hold the slide with the left hand, and use the right hand for maintaining the proper focus by means of either the coarse or fine adjustment.

8. In all cases where practicable make drawings of the sections examined.

9. In some cases it is desirable to apply a reagent after the material has been mounted, as in the addition of an iodine solution to a section to determine the presence of starch, and this is accomplished by placing a drop or two of the reagent, by means of a pipette or dropper, near the edge of the cover on one side and 
taking up the excess of liquid by temporarily placing a piece of filter paper on the opposite side (Fig. 4I5).

Air-Bubbles.-The beginner in the use of the microscope is often confused by the presence of air-bubbles, mistaking them for portions of the material under examination, as starch grains, oil-globules, or even the cells themselves. While it is not prac-

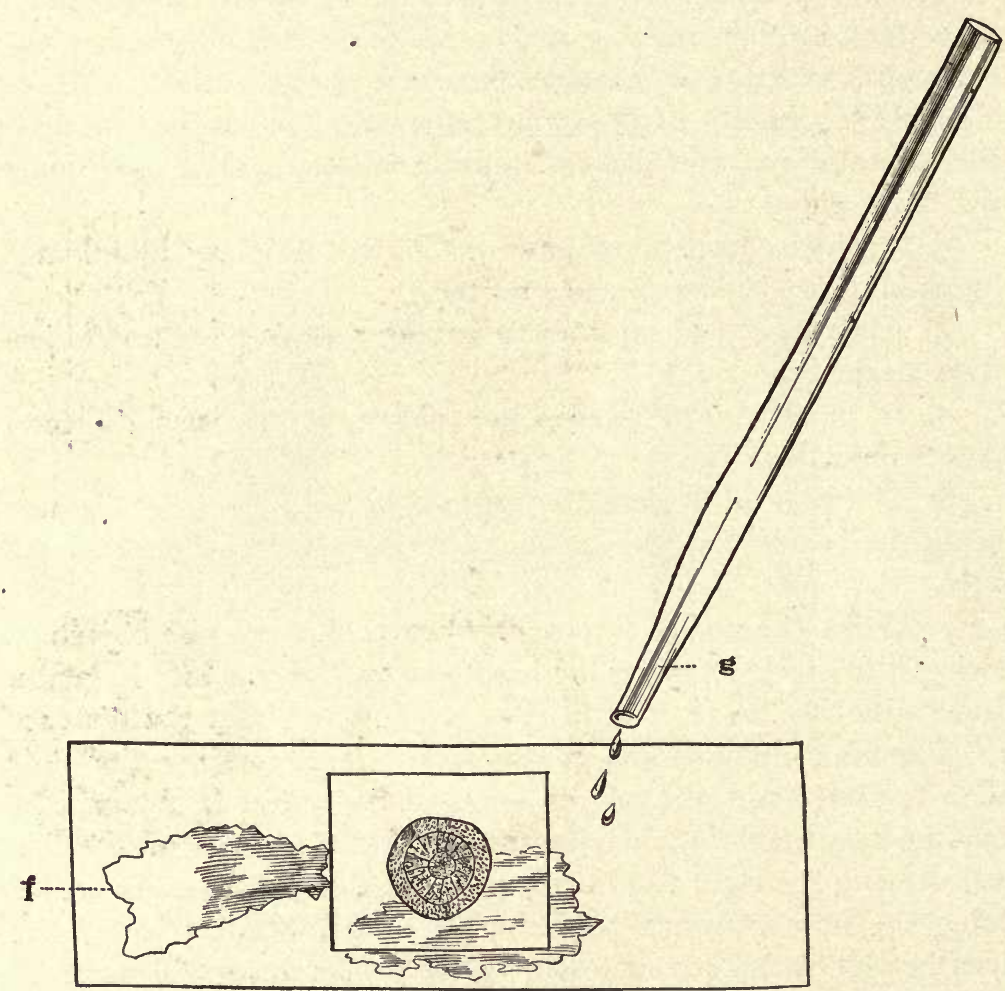

FIG. 4I5. Method of applying reagent to material already mounted. $g$, pipette; $f$, filter paper.

ticable to avoid their presence entirely, their identity may be determined by the manner of focussing upon them. When focussing above on an air-bubble it always appears dark (Fig. $416, C$ ), but when the focus is lowered, it becomes lighter (Fig. $4 \mathrm{I} 6, D)$; while in the case of an oil-globule or starch grain the reverse is true, i.e., it is lightest when the focus is above (Fig. 
$4 \mathrm{I} 6, E$ ) and darker when the focus is lowered (Fig. $4 \mathrm{I} 6, F$ ). To obviate as much as possible the formation of air-bubbles, the edge of the cover-glass should first be applied to the liquid on one side and then allowed to drop upon it. When particular care is required, a pair of forceps may be used for holding the cover and lowering it gradually.
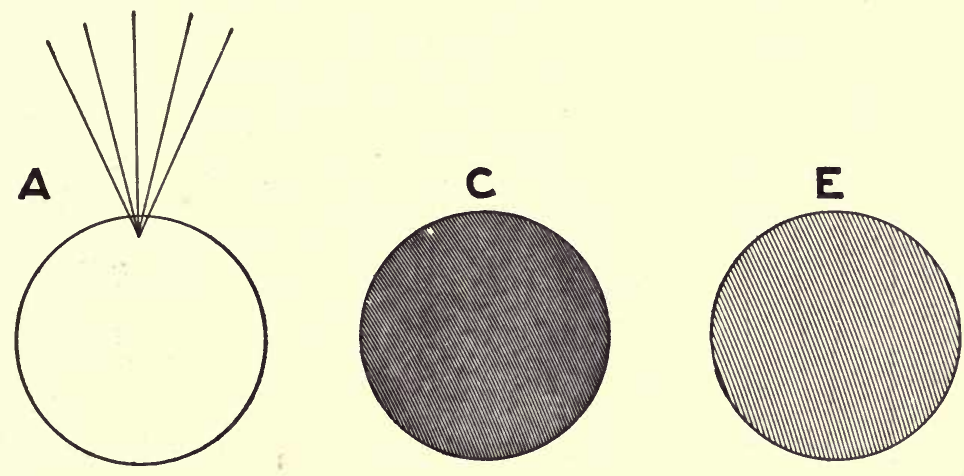

B
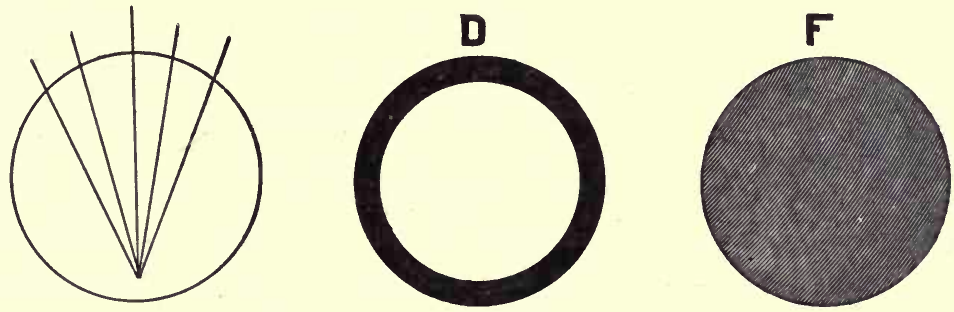

FIG. 4I6. Diagrams showing the difference between an air-bubble and an oil-globule in different foci: When the focus is above, as at A, the air-bubble (C) is dark gray and the oil-globule (E) light gray. When the focus is at the lower portion, as at B, the airbubble (D) is light in the center and the oil-globule (F) dark gray. The same optical effects as are obtained with oil-globules are observed with cell walls, starch grains and crystals.

Frequently also simple pores in the cell-walls are mistaken for cell-contents, and sometimes even the lumen of the cell has been mistaken for a prism of calcium oxalate. The beginner will therefore find it an advantage to study the simple pores in the pith cells of elder or sassafras (Fig. I32). In sections showing either the upper or lower wall of the cells, the pores appear as circular or elliptical markings, which may be mistaken for cell- 
contents, but which in focussing upon them are seen to be optical or microscopical sections of the pores.

Micrometry or Microscopic Measurement.-In the micro-

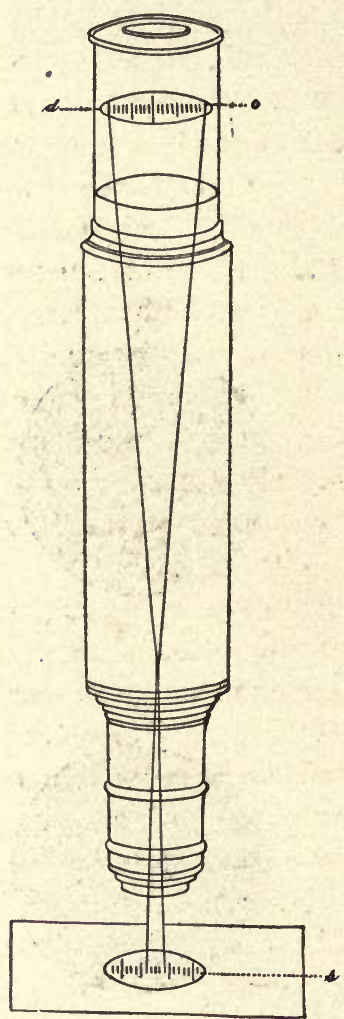

FIG. 4I7. Section of micro scope showing the relation of the ocular micrometer (o) and the stage micrometer (s). As here represented 20 divisions of the ocular scale are equivalent to 4 divisions of the stage micrometer, and thus each division of the ocular is equivalent to 2 microns (see p. 813 ). d, diaphragm in eye-piece, on which the ocular microm. eter rests. lengths employed. The stage micrometer is usually divided into tenths and hundredths of a millimeter, and the millimeter being equivalent to 1000 microns (the micron being indicated by the edge of the comparative size of the elements is often of much help in determining the identity of material under examination, and for this reason the student should early learn to measure the characteristic elements, or those showing a variation in size in different plants, as starch grains, calcium oxalate crystals, diameter of cells, thickness of cell-walls, etc. The method best adapted for this work is that involving the use of a micrometric scale which is placed in the eyepiece and known as the ocular micrometer. But to determine the value of the ocular micrometer it is necessary to use another scale known as the stage micrometer. The stage micrometer, as its name indicates, is used on the stage, and when placed in juxtaposition to an object indicates its size. However, it is obviously impracticable always to place an object alongside of the scale, and hence in practice the ocular micrometer is used, the value of the divisions of which are determined by comparison with those of the stage micrometer (Fig. 4I7). The value of the divisions of the ocular scale varies for different objectives, eye-pieces and tube lengths, hence it is necessary to ascertain the value of the divisions for the different optical combinations and tube scopic study of any substance a knowl- 
Greek letter $\mu$ ), the smaller divisions are equivalent to Io microns $($ Iо $\mu$ ). For example, suppose, using a low-power objective, that Io divisions of the ocular scale equal 20 of the smaller divisions of the stage micrometer. Thus, 20 divisions of the stage micrometer are equivalent to 20 times Io $\mu$, or $200 \mu$; then, since ro divisions of the ocular scale equal 20 divisions of the stage micrometer, one division of the ocular scale is equivalent to $\mathrm{I} / \mathrm{IO}$ of $200 \mu$, or $20 \mu$. Or, using the high-power objective, we may suppose that 80 divisions of the ocular scale equal 24 divisions of the stage micrometer. Thus, I division of the ocular micrometer is equivalent to $\mathrm{I} / 80$ of $240 \mu$, or $3 \mu$. Then, if an object has a diameter covering 3 divisions of the ocular micrometer, its diameter is equivalent to 3 times $3 \mu$ (the value of one division), or $9 \mu$.

REAGENTS. - The reagents that have been recommended for microscopical work are quite numerous, and, while nearly all of them may have more or less special merit, the number of reagents actually required in practice is fortunately quite small.

It is important that the student recognize the necessity for a thorough understanding of the structure of the material under examination rather than place too much dependence upon the effects produced by reagents; in other words, the study of structure should precede the use of reagents, particularly stains, when it will often be found that the latter can be dispensed with entirely.

The chemicals that are employed in microscopical work, either as reagents or for other purposes, may be classified as follows: ( I) Preservatives, (2) Fixing and Killing Agents, (3) Hardening and Dehydrating Agents, (4) Clearing Agents, (5) Stains, and (6) Special Reagents.

Preservatives are substances used to preserve material which is to be examined. The most important of these are alcohol (from 40 to 95 per cent.) and formalin [ 2 to 6 per cent. aqueous or alcoholic (6o per cent. alcohol) solution], the latter of which is considered advantageous in the preservation of specimens containing coloring substances, as leaves, flowers, etc. Almost any antiseptic of the proper strength may be used as a preservative.

Fixing or Killing Agents are more especially employed in the study of the protoplasmic cell-contents, where by their use the life-processes of the cell are brought to a sudden termination, 
the object being to fix the contents in a condition approaching as nearly as possible the normal living state. In order to carry out this operation successfully, the living specimen must be placed in the fixing or killing agent as soon as collected, and if the specimen is large it should be cut into small pieces. The following are some of the common fixing agents: Chromic acid in 0.5 to I per cent. aqueous solution; osmic acid in I to 2 per cent. aqueous solution; Flemming's mixture, which is an aqueous solution of chromic acid ( 0.25 per cent.) containing 0.I per cent. of osmic acid and o.I per cent. of acetic acid; picric acid in concentrated aqueous or alcoholic solution; picric-sulphuric acid, a concentrated aqueous solution of picric acid containing 2 per cent. by volume of sulphuric acid; and mercuric chloride (corrosive sublimate) used in 0.1 to I per cent, aqueous or alcoholic solution.

Hardening or Dehydrating Agents are those substances which are employed for the purpose of hardening the specimen so as to facilitate sectioning and for removing the water, which would interfere with its examination. Alcohol is to be regarded as the principal hardening or dehydrating agent, and considerable care is necessary in its use; the specimen is treated successively with alcoholic solutions of gradually increasing strength, beginning with a 35 per cent. solution, in which the specimen is kept for twenty-four hours ; then it is placed in 50 per cent. alcohol for from six to twenty-four hours, and then in 70 per cent. alcohol, in which it may be kept until ready for use. In order to avoid shrinking of the material at this stage, it may be kept in a solution of alcohol and glycerin, or oil of bergamot, or a mixture of xylol and paraffin. When the material is to be examined it should be removed to 85 per cent. alcohol for from six to twenty-four hours, then to 95 per cent. alcohol and absolute alcohol successively for the same length of time. Of the other dehydrating agents the most important are anhydrous glycerin, pure carbolic acid, and anhydrous sulphuric acid, the latter being used in a desiccator and not applied directly to the specimen.

Clearing Agents.-Most dehydrating agents are also clearing agents, because of the fact that the air and water in the specimen are replaced by a medium having greater refractive properties. Some clearing agents act chemically on the tissues and cell- 
contents. Among the clearing agents most frequently employed are: Chloral in saturated aqueous solution, and chloral-glycerin solution (a solution of equal parts of glycerin and water saturated with chloral). Essential oils, as clove, turpentine, cedar, marjoram, etc., are also useful for this purpose, particularly when the specimen is to be mounted in Canada balsam.

Starning Agents are those that produce more or less definitely colored compounds with the cell-contents or -walls. They include: (I) the Aniline Dyes and (2) Non-aniline Stains.

The aniline stains may be used in aqueous solutions, weak alcoholic solutions or strong alcoholic solutions, containing from I to 3 per cent. of the dye. The following are the aniline stains most frequently employed: Aniline blue, Bismarck brown, fuchsin, gentian violet, methylene blue, methyl violet and safranin. In addition to these, aniline hydrochloride or sulphate is used in what is known as Wiesner's Reagent, which is a 25 per cent. solution of alcohol containing 5 per cent. of either of these salts, a drop of either hydrochloric or sulphuric acid being used with a drop of the solution, according as the hydrochloride or sulphate has been used.

Löffler's Methylene Blue.-This reagent is prepared by adding 30 c.c. of a concentrated alcoholic solution of methylene blue to roo c.c. of water containing Io milligrams of potassium hydrate.

Ziehl's CARbol-Fuchsin.-This solution is prepared by adding 15 c.c. of a concentrated alcoholic solution of fuchsin to IOO c.c. of water containing 5 grams of carbolic acid.

Aniline Dyes are usually employed in concentrated aqueous solution, but owing to the difference in solubility of the dyes the solutions vary in strength. Saturated solutions of eosin or gentian violet may be prepared by dissolving I gram of the dye in Ioo c.c. of water, while to make a saturated solution of methylene blue requires $0.400 \mathrm{Gm}$. of the dye to roo c.c. of water. Some investigators prefer to replace the distilled water with aniline water, which is prepared by adding about 3 grams of anilin oil to Ioo c.c. of distilled water.

Reagent Bottle for Sterile Solutions.-The solutions of the aniline dyes as ordinarily prepared deteriorate more or less rapidly and are usually made up fresh each time they are required 
for use. These solutions, as well as other reagents that are prone to decomposition, may, however, be kept for months or even years by preparing them with care and keeping them in a special kind of bottle (Fig. 4I8). An ordinary bottle may be used, and is fitted with a rubber stopper perforated so as to allow the introduction of two glass tubes. These tubes are bent twice at right angles and the free ends directed downwards. One of the tubes is connected with an atomizer bulb and serves for forcing out the

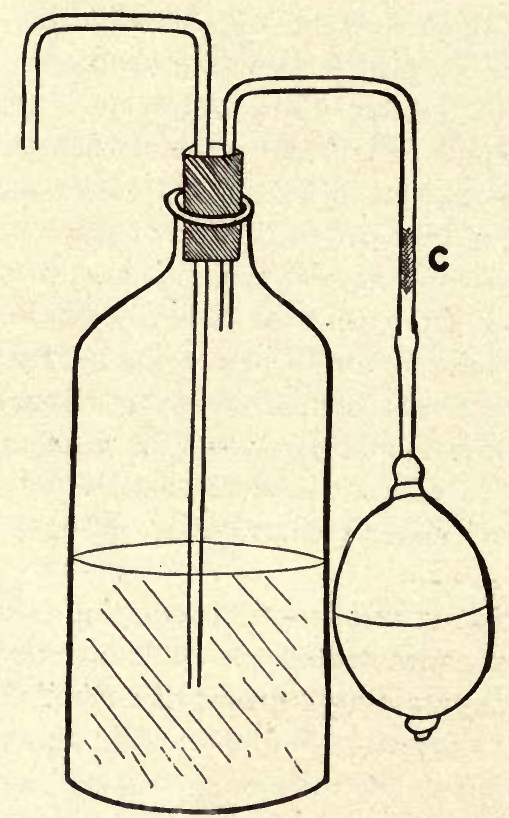

Frg. 418. Reagent bottle for sterile solutions.

liquid. A small plug of absorbent cotton is placed in the tube at the point $C$, so as to filter the air. This may be improved by blowing a bulb in the tube for holding the cotton. The bottle should be sterilized before placing the solution in it, and the solution should be made by adding the dye to sterile water contained in the bottle. The solution may be afterwards further sterilized by means of steam if this should be found necessary, as in this way only a perfectly sterile solution could be produced. 


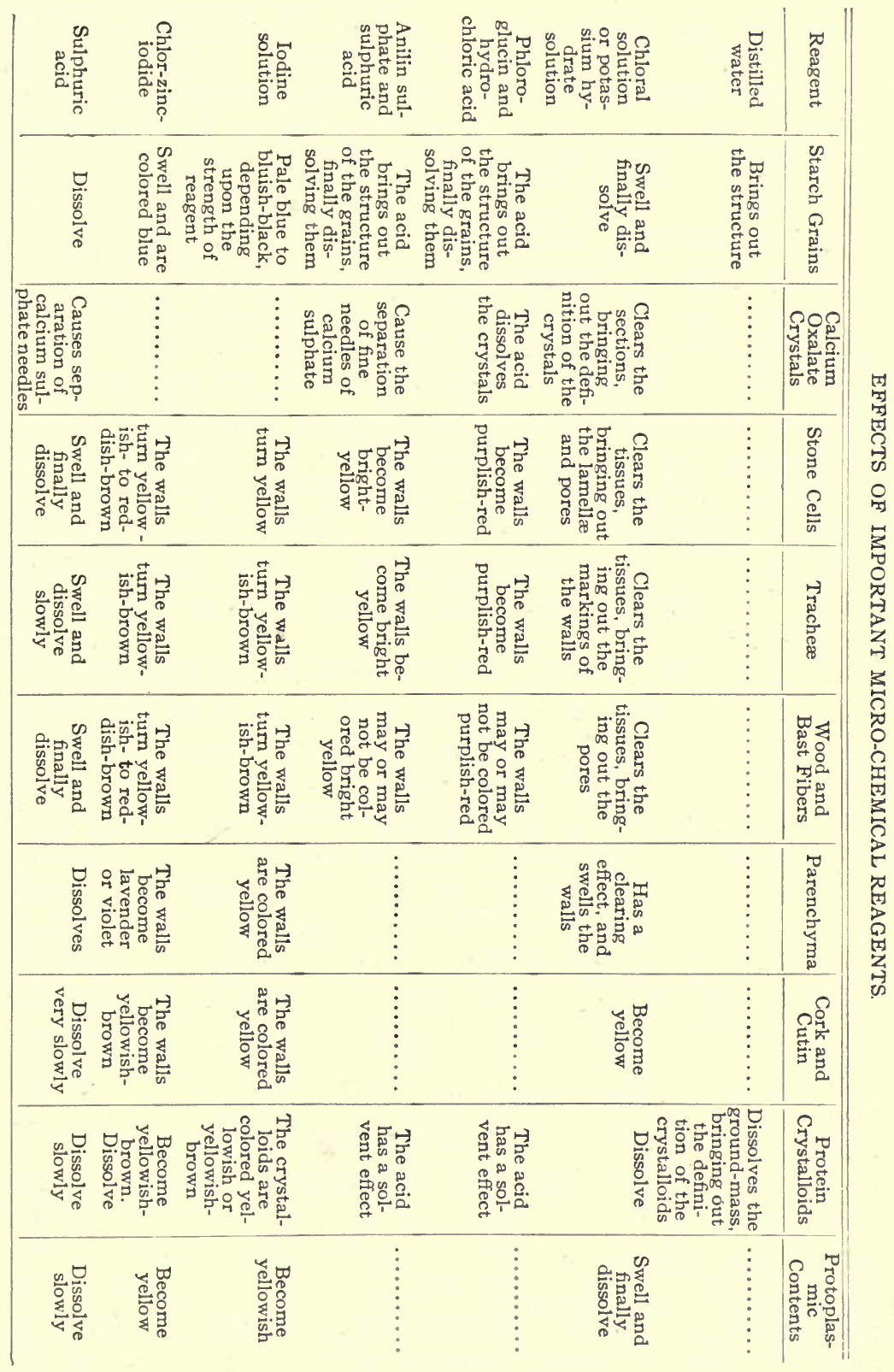


The non-aniline stains give, as a rule, more reliable and constant results in the study of cell-walls, as in the roots, stems, and other parts of the plant, than the aniline stains. They include the following:

Beale's Carmine Solution, which is made as follows: Mix o. $6 \mathrm{Gm}$. carmine with $3.75 \mathrm{Gm}$. ammonia water (Io per cent.); heat on a water-bath for several minutes; then add $60 \mathrm{Gm}$. of glycerin, $60 \mathrm{Gm}$. of water and $5 \mathrm{Gm}$. of alcohol, and filter.

Grenacher's Borax-Carmine Solution.-Dissolve 2 to 3 $\mathrm{Gm}$. of carmine and $4 \mathrm{Gm}$. of borax in 93 c.c. of water and then add 100 c.c. of alcohol ( 70 per cent.); shake and filter. When this stain is employed the sections are freed from an excess by the use of alcoholic solutions of borax or oxalic acid.

Hoyer's Picro-Carmine Solution is made by dissolving carmine in a concentrated solution of neutral ammonium picrate. A solution of carmine and picric acid is known as Picro-Carmine Solution. Carmine solutions give to cellulose, the nucleus and proteins a red color.

Chlor-Zinc-IOdide Solution, or Schulze's Cellulose Reagent, consists of anhydrous zinc chloride, $25 \mathrm{Gm}$.; potassium iodide, 8 Gm., and water, $8.5 \mathrm{Gm}$., to which as much iodine is added as the solution will dissolve. This reagent gives a violet color with cell-walls containing cellulose. Of the cell-contents, starch is the only one which is affected by it, being colored blue.

Bohmer's Hamatoxylin Solution is prepared by mixing the two following solutions and filtering after allowing the mixture to stand for several days: (a) one part of a 3.5 per cent. alcoholic (95 per cent.) solution of hæmatoxylin and $(b)$ three parts of a 0.4 per cent. aqueous solution of potassium alum.

Delafield's Hamatoxylin Solution, which is also incorrectly called "Grenacher's Hæmatoxylin Solution," is made by mixing the following solutions: (a) Hæmatoxylin $4 \mathrm{Gm}$., alcohol 25 c.c., and (b) 400 c.c. of a saturated aqueous solution of ammonia alum; this solution is exposed to the light for three or four days, filtered, and then 100 c.c. each of glycerin and methyl alcohol are added, the solution allowed to stand for several days and finally filtered. An excess of the stain is removed from the sections by subsequent washing either with a 2 per cent. alum solution 
or an acidified alcoholic solution. This solution gives to cellulose, lignin and the protoplasmic cell-contents a violet color.

Iodine and Potassium-Iodide Solution consists of iodine, $2 \mathrm{Gm}$.; potassium iodide, $6 \mathrm{Gm}$.; water, Ioo c.c.

IODINE WATER is prepared by adding as much iodine to distilled water as it will dissolve (about $\mathrm{I}: 5000$ ).

Chloral-Iodine Solution consists of a saturated aqueous solution of chloral, to which iodine is added. This reagent is useful for staining the starch grains in the chloroplasts.

Phloroglucin Solution, used as a test for lignin, is a 0.5 to 2 per cent. alcoholic solution of phloroglucin, which is used in conjunction with hydrochloric acid. The reagent should be protected from light.

IRON Solutions are aqueous or alcoholic solutions containing 5 to 20 per cent. of ferric acetate or ferric chloride. These are mostly used as tests for tannin, giving either a bluish-black or greenish-black coloration or precipitate.

Copper-Acetate Solution is a 7 per cent. aqueous solution of cupric acetate. It is the most distinctive test for tannin, particularly with fresh material, producing a reddish-brown precipitate in the cells containing tannin. The fresh material should be cut into small pieces and immediately placed in the solution of copper acetate and allowed to remain for from 24 to 48 hours. The excess of the reagent is then washed out and the material placed in alcohol.

Scrulze's Macerating Solution is prepared by adding crystals of potassium chlorate from time to time to warm conceritrated nitric acid. It is employed in the isolation of lignified cells. The material is allowed to remain in the solution for a short time or until there appears to be a disintegration of the tissues. A large excess of water is then added. The material is carefully washed, the cells teased apart and mounted in a solution of methylene blue.

Special Reagents comprise all those substances which are employed in the morphological study of the cells, and include solutions of the alkalies (O.I to 6 per cent.) solutions of the mineral acids, which may be weak or concentrated, and solutions of organic acids, as acetic and citric. 
Double Staining, or the use of two stains in the examination of a specimen, furnishes not only a means of beautifying the specimen, but also has a certain diagnostic value. The following are some of the combinations used: $(a)$ aqueous solutions of carmine in connection with alcoholic solutions of iodine green; $(b)$

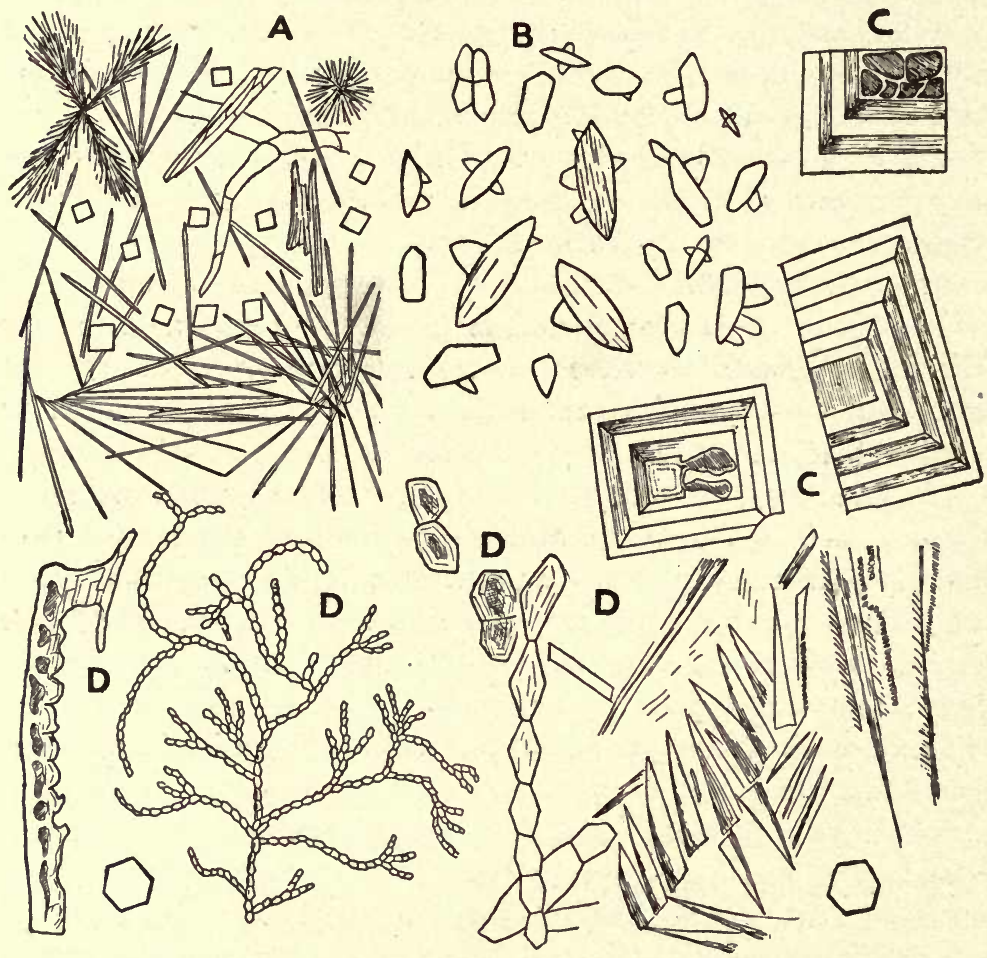

FIG. 4I9. Crystals of some of the common reagents which not infrequently separate on the slide and may be mistaken for cell contents: A, isotropic crystals of chloral which occur in cubes about to $\mu$ in diameter or long needles about $50 \mu$ long; B, phloroglucin which occurs in broad rectangular plates or ellipsoidal dises from to to $35 \mu$ in diameter which are doubly refracting with a play of colors: C, cubes of potassium iodide which are isotropic; $\mathrm{D}$, crystals from potassium hydrate solution which separate in broad prisms and branching chains that are doubly refracting and give marked color effects.

alcoholic solutions of hæmatoxylin and safranin; $(c)$ solutions of eosin and methylene blue; $(d)$ solutions of fuchsin and methylene blue; $(e)$ solutions of gentian violet and Bismarck brown.

Mounting of Specimens.-Microscopic preparations or mounts are of two kinds: they may serve a temporary purpose 
only or they may be prepared so as to serve for future study, the latter being known as PERMANENT MOUNTS.

In taking up the study of a specimen it should first be mounted in water and examined; then the water may be replaced by a weak aqueous solution of glycerin ( 5 to ro per cent.) and the specimen examined again. After this preliminary examination other agents and reagents may be employed. Specimens mounted in glycerin will keep for several days and even months. Generally speaking, the only effect which the glycerin has on the tissues or contents is that of swelling them, which is obviated, to a greater or less extent, however, if the glycerin is washed out after an examination is made.

In addition to the methods involving the use of glycerin, there are two ways of making permanent mounts, depending upon the employment either of Canada balsam or glycerin jelly as the mounting medium. The method involving the use of the latter is the simpler, and leaves the specimen in such a condition that a re-examination with reagents can be made if desirable. GLycErinJELLY mounts are made as follows: Specimens which have been previously treated are transferred to glycerin and allowed to remain for several hours, the excess of glycerin removed, and the specimen transferred to a warm slide on which a drop of glycerin jelly ${ }^{1}$ has been placed. The preparation is warmed slightly to remove air-bubbles, and a warm cover-glass applied, care being taken to prevent the formation of air-bubbles. Evaporation of the glycerin jelly is prevented by the use of shellac cements, asphalt varnish or candlewax.

The following method may be used for the preparation of CANAdA BALSam mounts: The specimen is cleared, dehydrated by the use of alcohol and then placed in chloroform or benzol. The clearing of the specimen is materially assisted by placing it in oil of cloves or turpentine prior to mounting it. A drop of Canada balsam solution ( $\mathrm{I}$ part of balsam to 3 parts of chloroform or

${ }^{1}$ Kaiser's Glycerin Jelly.-Digest $7 \mathrm{Gm}$. of gelatin in $42 \mathrm{Gm}$. of water for two hours on a hot water-bath; dissolve I Gm. of carbolic acid in $49 \mathrm{Gm}$. of glycerin; mix the two solutions; heat on a water-bath, with occasional stirring, for fifteen minutes, and finally filter through glass wool. The jelly is warmed slightly to liquefy it before using. 
benzol) is placed on a slide and the specimen mounted. When nearly dry, scrape off the excess of balsam, clean the slide and cover-glass with chloroform or benzol, and ring with cement.

THE MICRO-POLARISCOPE is a useful accessory in conjunction with the microscope. It is employed in the study of technical products, and is chiefly applicable in the examination of crystals, starch grains and cell-walls. A number of substances, owing to certain peculiarities of structure, are double-refracting or ANISOTROPIC, i.e., they polarize light. If the double refraction is strong enough these substances show a play of colors. Of these may be mentioned the raphides and the rosette aggregates of calcium oxalate, cane sugar, citric acid, benzoic acid, caffeine, salicin, aloin, phloroglucin, and the salts of berberine, strychnine, and atropine. The acicular crystals which separate in chloral preparations of gambir also show a play of colors. Among the substances which are anisotropic but give no chromatic effects are starch grains, inulin, mannit, the rhombohedra in catechu and the various types of cell-walls. All substances which form crystals belonging to the isometric system are ISOTROPIC or single-refracting, i.e., do not polarize light, as sodium chloride, the octahedra in gambir, potassium iodide and chloral.

When glass, which is an isotropic compound, is heated and suddenly cooled it is changed into an anisotropic body. Microscopic glass beads formed by quickly cooling very thin pieces of glass show polarization effects similar to those of wheat starch grains. This has led to the supposition that the polarization effects produced by starch grains are due to tension rather than to a crystalline structure. But this point cannot be definitely settled until it has been determined whether any of the substances composing the layers of the starch grains are capable of crystallization.

The Spectroscope in Microscopic Analytical Work.-To a limited extent at the present time, and yet very effectively by those who are competent to employ it, the Spectroscope is being employed in the examination of organic coloring substances. This method has the advantage that accurate results can be obtained with small quantities of material. With the proper instruments and with practice one may attain a skill equal to that attained in 
qualitative and quantitative analytical work. The Spectroscope can be used in checking chemical methods and also employed frequently in the detection of mixtures, just as the microscope is used where qualitative chemical methods are not available. The Spectroscope is used not only in the examination of single coloring principles, but where there are mixtures, and whether these are in solution, on fabrics, on paper, etc. So that for technical chemists, especially for those interested in dyeing and allied industries, it has a very great value.

- There are several different types of spectroscopes: (I) the ordinary, in which the liquid is placed in a long glass cell between the source of light and the slit of the spectroscope; (2) a comparison spectroscope, where an unknown liquid can be compared with that of a known; (3) the micro-spectroscope, in which a spectroscope is attached to a microscope and the liquid is placed in small tubes.

A characteristic spectrum is obtained only when the solution is of the proper dilution. The solutions must be prepared carefully and interfering substances removed as much as possible.

(Consult: "Untersuchung und Nachweis organischer Farbstoffe auf spektroskopischen Wege," by Jaroslav Formanek and Dr. Eugen Grandmougin, Second Edition. "Zur Biologie des Chlorophylls Laubfarbe und Himmelslicht Vergilbung und Etiolement," by Ernst Stahl. "The Origin and Nature of Color in Plants," Kraemer, in Proc. Am. Phil. Soc., I904, p. 259.)

Dark Field Illumination and the Ultra-microscope.The study of minute particles which are otherwise not visible under the microscope by direct illumination may be accomplished by a simple contrivance known as a reflecting condenser. The principle upon which this operates is similar to when a pencil of sunlight enters a more or less darkened room, causing the particles of dust to become visible. In the same manner the invisible particles in a colloidal solution and the ordinarily structureless substances in an animal or vegetable cell are rendered visible by reason of the contrast between these particles and their dark surroundings.

The apparatus consists essentially of two parts: (I) a paraboloid condenser which has two reflecting surfaces so as to bring 
the rays of light to a focus on the objective and against a dark background; and (2) a funnel stop objective. The latter is an ordinary immersion objective with the addition of a funnel stop back of the lenses so that the diffused rays only enter the eye to the exclusion of the direct rays.

An ordinary microscope with a reflecting condenser and a funnel stop objective thus constitutes an ultra-microscope. The illumination is by means of an arc light. If a Welsbach lamp is used it is necessary to employ a bull's-eye lens to concentrate the light upon the mirror. The light is ordinarily reflected through the condenser from the plane mirror of the microscope. Cover-glasses of a standard thickness, 0.17 mm., should be used. The space between the top of the condenser and the microscopic slide containing the object must be filled with a layer of cedar oil in the same way as between the cover-glass and the objective. Time must be taken to perfectly center the condenser with reference to the objective.

(Consult: "Dunkelfeldbeleuchtung und Ultramikroskopie," by N. Gaidukov.)

\section{MICRO-ANALYSIS.}

The value of the microscope is well established in the examination not only of the living plant but in the study of various technical products. It is usual to give greater prominence to the ANATOMICAL or HISTOLOGICAL method of study, based largely upon the form of cells and the structure and composition of their walls. The study of cell contents, as starch grains, calcium oxalate, phyto-globulins, and other definite substances, is being utilized very largely in the examination of technical products and to some extent by students of botany.

A number of books have been published dealing with the micro-chemistry or histo-chemistry of some of these substances. For the most part the study of microscopic crystals has been of a very general nature, in that statements are given regarding the general shape of the crystals or their aggregates and their behavior with certain test solutions. The time has come when the study of the crystalline substances found in plants requires, if any real progress is to be made in this direction, that the 
CRYSTALLOGRAPHIC METHOD of examination be utilized. This method originated in the examination of thin sections of rocks and it has been possible by this study to identify the numerous rock-forming mineral species. In those species which are mixed crystals, i.e., made up of isomorphous mixtures of two or more components, it has been possible to determine with some accuracy their composition simply by their optical properties, as for exam-

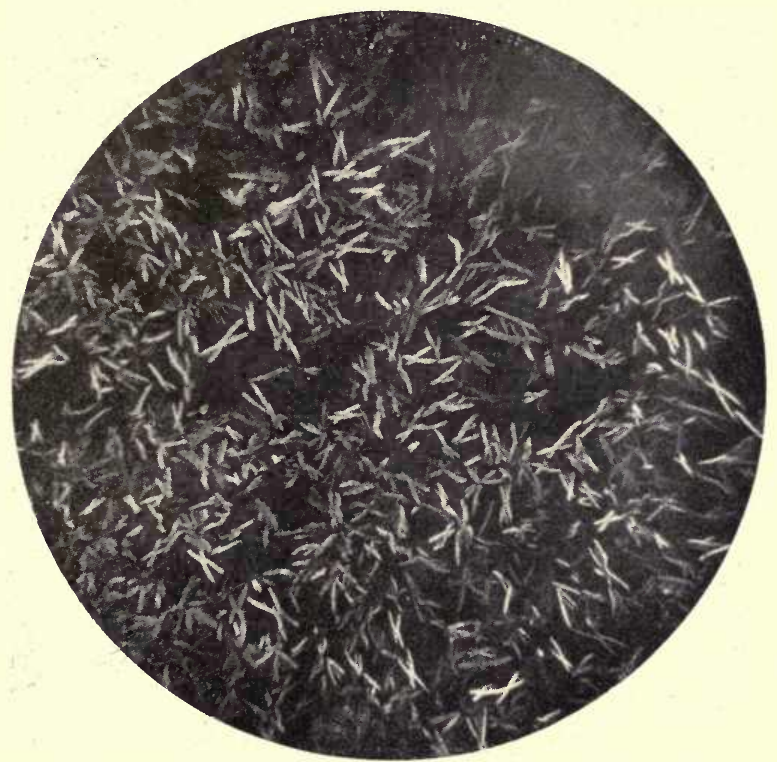

FIG. 420, Codeine: $x$-shaped skeleton crystals from ro per cent. alcoholic solution.

ple the feldspars. Furthermore, it has been possible to draw conclusions as to the ultimate composition of rocks and the conditions under which they were formed.

The value and possibilities of the employment of the crystallographic method in biological studies is well exemplified in the recent work of Reichert and Brown, "The Crystallography of the Hemoglobins." By special means individual crystals of the hemoglobins were obtained and by purely crystallographic methods, including a study of the forms and optical properties of such crystals, the hemoglobins of the 200 species of animals 
studied were differentiated in a manner that could not have been accomplished by chemical analysis or other methods of procedure.

A careful study of much that has been written, and especially of the illustrations that have been made, of micro-crystals in plants and drugs, shows that erroneous conclusions may be easily drawn from the general appearance of crystalline precipitates or aggregates of crystals that are formed. For instance, Vogl has

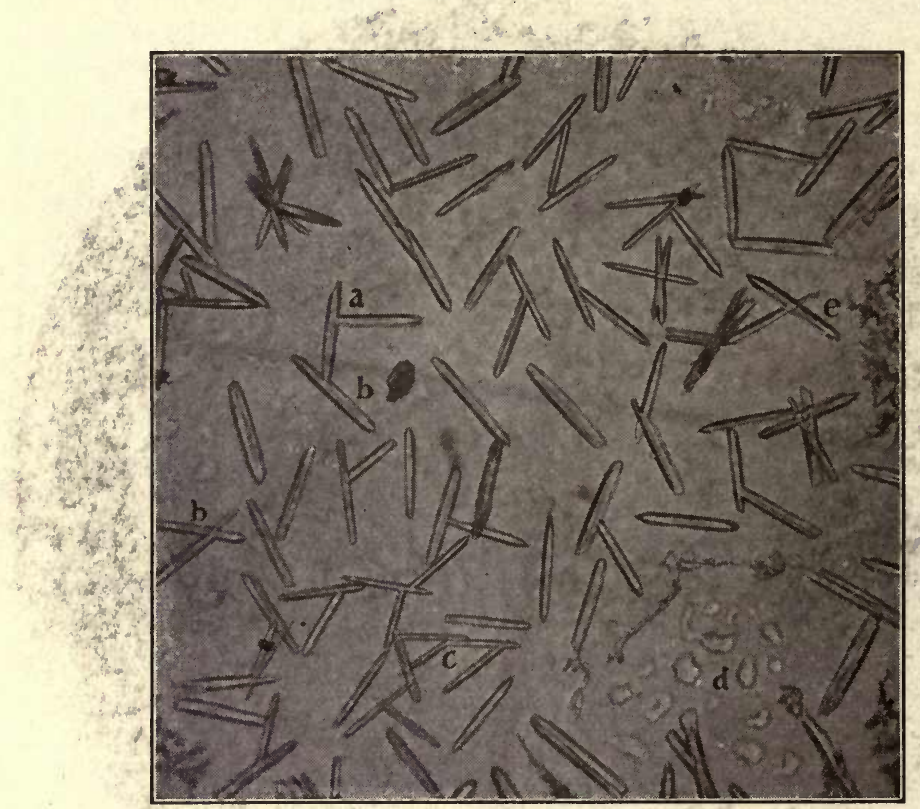

FIG. 421. Cubebin: orthorhombic crystals from Prollius' solution, showing various types of twinning $(a, b, c) ; d$, amorphous material in the form of oily drops (under-cooled liquid); e, this amorphous material crystallizing in aggregates.

shown that the sphero-crystals, found in the glandular hairs of Mentha piperita and considered by some to be menthol, are found in leaves of many of the Labiatæ. Again, very many substances produce aggregate groups which closely resemble each other, as of citric acid, cocaine hydrochloride, etc.

In regard to the value of the crystallographic method we quote the following paragraph from Brown (loc. cit.): "When a chemical compound solidifies from fusion, solution or vapor under conditions which are favorable to the development of 
individuals, its particles tend to arrange themselves in regular order, so that a definite structure is produced. The external form of the individuals is also regular, being bounded by planes in definite relation to each other so that polyhedral solids are produced which are called CRYSTALS. The regular arrangement of the atoms among themselves, and of the molecules which

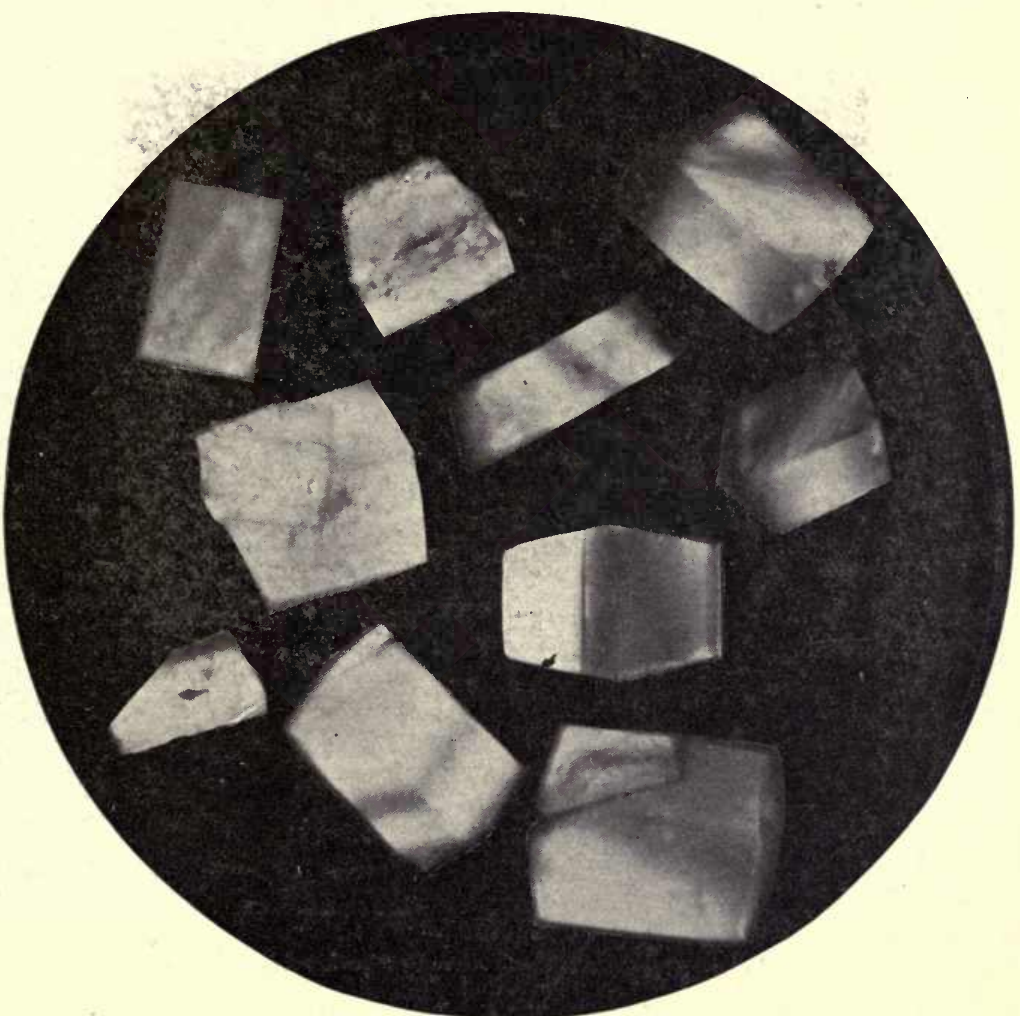

FIG. 422. Strychnine sulphate: tetragonal crystals in polarized light, showing side aspect.

they build up, is so characteristic of substances of definite composition that the crystalline condition of dead matter is the normal condition. Differences in chemical constitution are accompanied by differences of physical structure, and the crystallographic test of differences of chemical constitution is recognized as the most delicate test of such differences." 
It is apparent that, apart from their solubility, color reactions, behavior towards reagents, etc., the substances with which we are dealing should be prepared in such a manner that isolated crystals are formed and not aggregates or groups. These isolated crystals can then be studied independently. The reason why

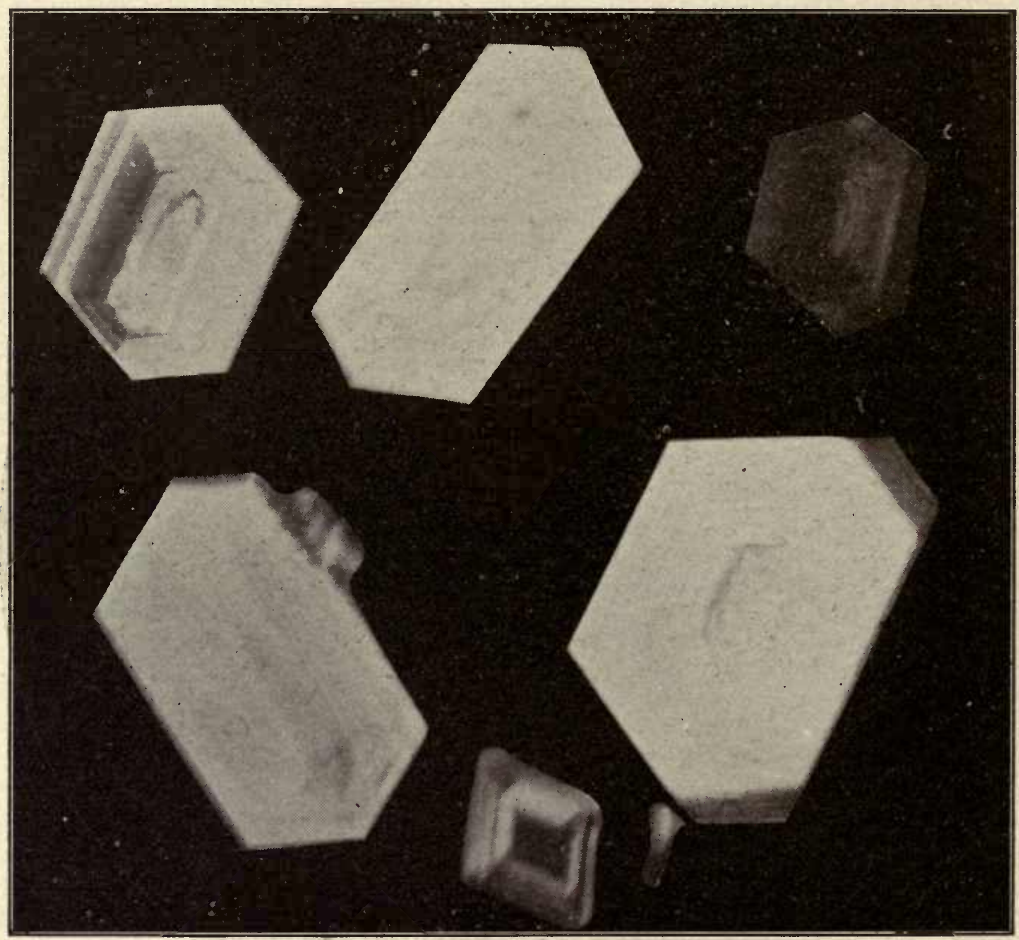

FrG. 423. Hydrastine: large, nearly equidimensional orthorhombic crystals from alcoholic solution.

aggregates are formed is because the crystals are permitted to grow too rapidly on the slide. This is usually the case in the usual method of procedure in securing crystals, i.e., by adding a drop of a solution to the slide, and then allowing it to evaporate spontaneously, under ordinary conditions. If, on the other hand, the rate of evaporation is lessened so that there is a slowing down of the growth of the crystals, individuals may be obtained of 
almost any size desired. And it will be found that these isolated crystals may be quite as easily prepared as the aggregates which seem so characteristic to the average student. Special methods, however, may be necessary to obtain such isolated crystals. For instance, single crystals of menthol (Fig. I26) are obtained by

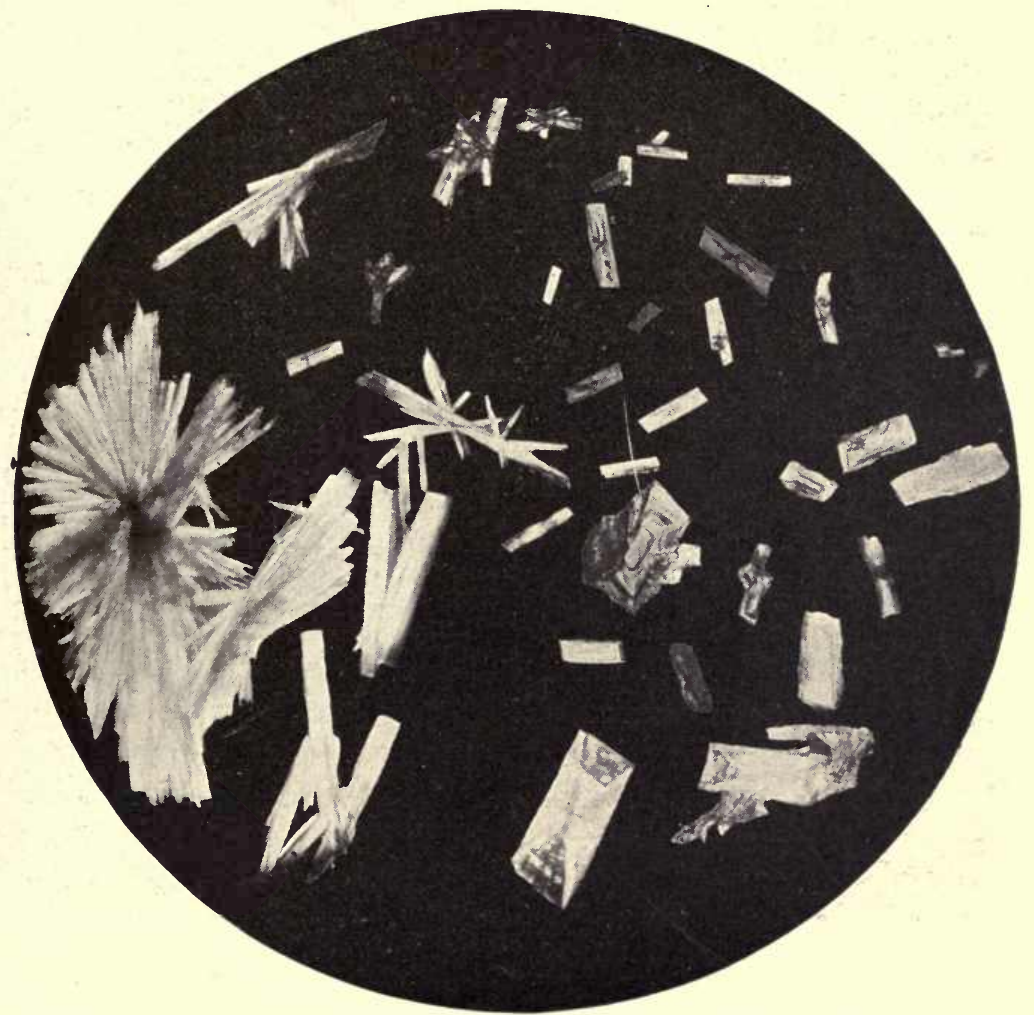

FIG. 424. Piperine: monoclinic crystals, mostly on the clinopinacoid, showing the oblique terminations, obtained from hot alcoholic solution.

means of sublimation rather than from solutions. Cumarin crystals are easily obtained by controlling the temperature of the melted mass, etc.

The interest in these crystalline substances is becoming greater as foods and drugs and technical products are subject to standards of purity. Most of the crystalline constituents common to 
plant products are usually said to be calcium oxalate. This substance is insoluble in water, alcohol, and acetic acid, soluble in the mineral acids and occurs usually in definite crystals. These crystals are rather easily studied in Iris, Quillaja, etc. (see page I86). They are found to crystallize either in the tetragonal or monoclinic systems, sphenoids of the latter being present in Belladonna (see pages I83-192).

Some substances occur in a crystalline form even upon the commercial product, as vanillin upon vanilla pods and cumarin upon tonka seeds; or crystals may be found in special cells, as piperine (Fig. 424) in Piper album and Piper nigrum. In alcoholic material, particularly of the Compositæ, characteristic spherocrystals are found, as in inula (see pages I 50-I 54). Sometimes similar sphero-crystals are observed upon soaking the drug of commerce in water and then adding alcohol, as in Scilla. Again, crystalline substances separate upon the addition of mineral acids, as when nitric acid or sulphuric acid is added to sections of Hydrastis (Fig. 95). Again, upon dissolving the product either in water, as with catechu, or in solutions of chloral, as with gambir, a crystalline residue remains. Finally, upon extracting the dried plant with suitable solvents, as Prollius' solution, and evaporating the solvent, characteristic crystals separate, as with coca, hydrastis, nux-vomica, cinchona, cola, guarana, etc.; or distinct crystalline precipitates may be obtained upon the addition of special reagents, as palladous chloride to solutions containing cocaine hydrochloride (Fig. 97), or gold chloride to solutions containing caffeine (Fig. 96). Attention has already been directed to the fact (pages $173-176$ ) that quite a number of plant principles are capable of being sublimed.

For some time past, in the study of certain of the cryptogams, as bacteria, yeasts, and fungi, there has been a disposition to rely upon physiological rather than morphological characters, this being due not only to the fact that these are more constant and characteristic in these organisms, but also to the fact that distinct morphological characters are entirely wanting in some cases. While the necessity for this additional study in the higher plants is not so apparent on account of the presence of well-defined morphological characters, still the value of physiological marks 
as one of the bases of classification is coming to be recognized. The best illustration of this is to be found in the monograph of the genus Eucalyptus by Baker and Smith, in which they have utilized the chemical properties and physical characters of the oils, coloring principles, tannins, etc., in establishing differences of affinities or species. There is a growing tendency on the part of investigators to study micro-chemically some of the characteristic plant constituents, as alkaloids, etc. As a rule, however, the descriptions are superficial and the identification is by means of color reactions. No real scientific progress will be made until the botanist employs the petrographical microscope and is fairly well grounded in the principles of physical and chemical crystallography. The work is by no means so simple as in ordinary microscopic work, but when the principles governing the optical study of crystals are mastered, the study will appeal to botanists not only as a fertile field for research but also as a subject of importance in both morphological and taxonomic work.

The study of microscopic crystals is accomplished by means of the petrographical microscope. Brown (loc. cit.) has stated succinctly the nature and use of this instrument:

"The necessity of studying small crystals, . . . has resulted in the evolution of a form of microscope which is at once a goniometer, a polariscope, and an instrument for measuring optic axial angles-in short, for determining the physical crystallographic constants of small crystals. . . . The polariscope portion of the petrographical microscope enables the observer to determine the position and relative value of the elasticity axes of crystals, to observe the position of the optic axes, and to determine their inclination to each other and to the elasticity axes. From these data the optical character of the crystal is determined. These optICAL REACTIONS may be studied by this instrument with as much ease, and in general with as much accuracy, as with the larger and better graduated polariscope; and the data thus obtained are quite as accurate in most cases as those obtained by the use of the larger instruments. The use of the special eye-pieces arranged with artificial twins of calcite or quartz enables the observer to determine the extinction 
angles of the crystals with as much accuracy as can be done with any form of polariscope.

"From such observations made with the aid of this form of microscope the following constants may be determined:

" ( I) The plane angles of the crystals, in most cases the interfacial angles, giving the data from which the axial ratios are computed-in other words, the morphological constants of single crystals.

" (2) The relation of the composite crystals or twins to each other, their angles, and the position of the twin plane, twin axis, composition plane, and other constants of the twin crystals.

" (3) The pleochroism of the crystals, the character of the colors of the light vibrating parallel to the elasticity axes in the crystals. This is effected by the use of the single polarizing prism below the stage. By analyzing this light with the microspectroscope the differences of tint and color may be given quantitative values in wave lengths.

" (4) The position and relative values of the light elasticity axes in the crystals, upon which depend the angles of extinction of the crystals, measured from certain crystallographic axes or planes or edges. In uniaxial crystals (tetragonal and hexagonal systems) there are two such elasticity axes-the ordinary ray designated as $\omega$, and the extraordinary ray, designated as $\varepsilon$. Either one of these may be the axis of greater or less elasticity; and according as the extraordinary ray is the axis of less elasticity or of greater elasticity the crystal is called optically positive or optically NEGATIVE. In biaxial crystals (orthorhombic, monoclinic and triclinic systems) there are three elasticity axes at right angles to each other, and these are designated as $\mathbf{a}$, the axis of greatest elasticity; $\mathfrak{b}$, the axis of mean elasticity; and $\mathfrak{c}$, the axis of least elasticity. ${ }^{1}$

"(5) The position and angle of inclination of the optic axes or lines of single refraction through the crystals. These always lie in the plane of the elasticity axes $\mathfrak{a}$ and $\mathfrak{c}$ and the angles between the optic axes are bisected by the axes $\mathfrak{a}$ and $\mathfrak{r}$. Accord-

${ }^{1}$ Elasticity in the optical sense is the reciprocal of refractive index; hence $\mathbf{a}, \mathfrak{b}, \mathbf{c}$, are the axes of least, mean and greatest refractive index. 
ing as to whether $\mathbf{c}$ or $\mathfrak{a}$ is the axis bisecting the acute angle, the ACUTE BISECTRIX, $B x_{a}$, the crystal is called optically positive or optically NEGATIVE. Thus if $B x_{a}=\mathfrak{c}$, the optical character is Positive. The apparent angle between the optic axes is determined by means of an eye-piece micrometer in an observation of the interference figure, looking along the acute bisectrix of the optic axes, and this angle is designated as $2 E$. The character of the double refraction may be determined by this angle."

It is not possible in this work even to attempt to treat of the principles underlying the study of physical crystallography. The study is one requiring special laboratory instruction. Of the excellent works which the student will find useful the following may be mentioned:

P. Groth : Physikalische Krystallographie, 4th Ed., r905.

Theodor Liebisch: Grundriss der Physikalischen Krystallographie, I896. Henry A. Miers: Mineralogy, ig02. In this work will be found several excellent chapters dealing with the principles of the measurement of crystals and the study of their optical properties.

Rosenbusch and Wülfing: Mikroskopische Physiographie der Mineralen und Gesteine.

P. GRoth: An Introduction to Chemical Crystallography. Translated by Hugh Marshall, 1906.

In the Zeitschrift für Krystallographie will be found references to the crystallographic studies which have been made upon some of the important plant constituents, but as these studies were mostly made upon relatively large crystals, which could be measured and examined by means of the goniometer, these observations must be interpreted and applied to crystals which are formed upon microscopic slides.

A rather large number of substances have been examined and only a few of the more important are included at this time. While drawings might have been made to illustrate the form of crystals and optical orientations, it was deemed advisable to use some of the photo-micrographs made by the author. The fourcolor plate (Figs. 99, I00) is introduced to show the chromatic effects observed by using crossed nicols. The plate illuplrates salicin and cocaine hydrochloride and is a nearly exact reproduction of the effects obtained with the micro-polariscope, the electros 
having been made from Lumière autochrome plates, using direct sunlight.

The method of obtaining the crystals was rather simple. The solvents used were distilled water, alcohol, ether, chloroform and a mixture of chloroform and alcohol. To a weighed amount of the substance was added a sufficient quantity of solvent to give a saturated solution. A drop of this was added to a slide which was covered either with a bell-jar or the cover of a Petri dish. If the crystals formed too rapidly, giving rise to crystal aggregates, more dilute solutions were made from the original solution until single crystals were obtained therefrom. In some instances, as with physostigmine salicylate, where the edges of the crystal are likely to be re-dissolved, the slides were finally dried in a desiccator over sulphuric acid. With caffeine gold chloride, the best crystals were obtained when the solutions were relatively weak. Again, it was found that after crystals were mounted in balsam, as cocaine hydrochloride, caffeine gold chloride, etc., the isolated crystals grew considerably in size at the expense of amorphous material. A rather unique instance of growth of large crystals was with menthol when the slide containing the silky aggregates was covered with another slide. Finally it should be stated that some patience and experience are necessary to obtain satisfactory crystals.

\section{WORKS OF REFERENCE.}

Principles of Microscopy. By A. E. Wright.

Das Mikroskop. By Leopold Dippel.

Anleitung zur Mikrochemischen Analyse. By H. Behrens.

Die Botanische Mikrotechnik. By A. Zimmermann.

Methods in Plant Histology. By Charles J. Chamberlain.

Elements of Drawing. By John Ruskin.

For Drawing of Crystals, consult "Crystallography and Practical Crystal Measurement," by A. E. H. Tutton.

Physical Optics By Robert W. Wood. 


\section{INDEX.}

Abelmoschus, 434

Abies, II9, 2 I3, 434

Abnormal root structure, 319

stem structure, 344

Abortive, 39 I

Abrin, I98, 575

Abroma, 6I 5

Abrotanum, 434

Abrus, 434, 575

Absinthe, 719

Absinthin, 7 I9

Absinthium, 434, 7 I9

Abuta, 539

Abutilon, 6I0, 6II

Acacia, 434, 567, 569, 575

Acajou gum, 599

Acanthaceæ, 694

Acanthus family, 694

Accumbent, 426

Acer, 434, 602

Aceraceæ, 602

Acetaldehyde, 234

Achene, 4IO

Achillea, I 72, 434, 720

Achilleine, I72

Achras, 659

Achyranthes, 528

Acid abietic, 237

acetic, 234

amido-succinamic, 168

amino-acetic, I92

antirrhinic, 69I

arabic, 222

arachidic, 2 I 2

behenic, 2 I 2

benzoic, 234

capric, 2 I 2

caproic, 212

caprylic, 212

carthamic, 720

cerasic, 223

chaulmoogric, 2 I 4

chebulinic, 633

chromic, 756

cinnamic, 234, 572

formic, 234, 287

gallic, 599

gurjunic, 621

gynocardic, 623

hederic, 636

hydrocyanic, 198, 235

hypogæic, 2 I 3

isovaleric, 234

japanic, 213

kinic, 655
Acid, lactic, zymase, 245

lauric, 2 I 2

lichen, 72 .

lignoceric, 2 I 2

linoleic, 213

lycopodic, 213

magenta, 182

methysticinic, 177

myristic, 2 I 2

oleic, 2 I 3

palmitic, 2 I 2

pectinic, 243

phosphomolybdic, I64

phosphoric, 214

picric, 165,756

picric-sulphuric, as fixing agent, 756

pipitzahoic, 723

protocatechuic, 204

rapic, 213

resinolic, 237

ricinoleic, $2 \mathrm{I} 3$

salicylic, 234

stearic, 2 I 2

succino-abietic, 237

sulphuric, in germination, $73 \mathrm{I}$

tiglic, 2 I 3

yellow A. T., I 82

Aconite, 434, 533, 534

Aconitum, tubers of, 328

Acorn-cups, tannin in, 206

Acorus, 434, 479

Acre, 434

Acris, 434

Actæa, 434, 537

Actinomorphic, 393

Acubin, 696

Acuminate, 355, 434

Acuminatus-a-um, 434

Acute, 354

Acutifolius-a-um, 434

Adansonia, 612

Adder's tongue, 458

Adderwort, 438

Adhatoda, 696

Adhesion, 390

Adiantum, 88, 434

Adlumina, 550

Adnate, $38 \mathrm{I}$

Adnation, 390

Adonis, 434, 537

Advena, 434

Adventitious root, $30 \mathrm{r}$

Acidiospores, 69

Æcidium, 69
Aégle, 434

Aërial root, 306

Aërobes, 252

Esculin, I69, 602

Asculis, 602 tannin in, 206

Estivalis, 434

African ammoniac, 639

Afzelia, 575

Agar-agar, 34

Agaric, 63, 64, 456 surgeon's, 65

Agaricaceæ, 59

Agaricus, 434 campestris, 59 protein in, 200 muscarius, 155

Agave, 434, 489 constituents of, 492 fiber, 269

Agavose, 155

Agglutins, 198

Aggregatæ, 707

Aglykone, 169, I70

Agrimonia, 434

Agropyron, 434, 468

Agrostemma, I 7 2, 426, 434

Ailanthus, 434, 586 family, 585

Air-bubbles, 752 method of detection, 752

Air plants, 480

Aizoaceæ, $\mathbf{5 2 8}$

Ajowan oil, 643

Ajuga, 434

Akene (see Achene), 4 Io

Albizzia, 575, 435

Albumins, 194, 195

Albus-a-um, 435

Alchemilla, 435

Alcoholase, 245

Alcohol, benzyl, 233

camphyl, 233

ceryl, 2 I 4

cinnamic, 233

ethyl, 233

melissyl, 2 I 4

methyl, 233

Aldehyde, 234 cinnamic, 544 salicylic, 564

Alder, 435, 5 I0 buckthorn, 604

Aletris, 435, 480

Aleurites, 592 oil in, 213 
Aleurone, grains, I93

Alfa, 472

Alfalfa, 577

Algæ, 7, 435

blue-green, 8

characteristic, 16

classes, 17

economic uses of, 40

of Red Sea, 8

of Yellowstone Park, 8

polluting water, 8

used as food, 40

used in medicine, 40

Alga-fungi, 42

Alisma, 466

Alismaceæ, 466

Alizarin, I79, 703

preparation of, 704

Alkaloids, 159

chemical classification, I 66

effect of climate on, I65

families yielding, I 65

from cultivated and wild plants, 739

functions of, 172

microchemistry of, I60

origin of, r6o

properties of, $\mathrm{r} 63$

reagents for, 163

Alkanet, 670

Alkanna, 670

Alkannin, 670

Allisin, 489

Allium, 435, 485, 489 vascular bundle of, 309

Allspice, 455 wild, 438

Almond, 435 emulsin, 243 oil in, 213

Alnus, 435, 5 ro glandular hairs in, 230

Aloe, 435 species of, 487

wood, 628

Alpinia, 494, 65 I

Alsine, $435,53 \mathrm{I}$

Alstonia, 435

Alteration in forms of plants. 332

Alternation of generation, 78,86

Althæa, 435, 609, 6II

Alum root, 447,556

Alyssum, 435

Amandin, 195

Amanita, 60-65

Amarantaceæ, 528

Amaranth, 435

Amaranthus, 435, 528

Amarus-a-um, 435

Amaryllidaceæ, 489

Amaryllis, 435, 492

Amaryllus family, 489
Amber, 1 I9, 237

fossil, II 9

seed, $6 \mathrm{II}$

Ambrosia, 435, 726

Ambrosiaceæ, 712

Ambrosioides, 435

Amelanchier, 562

Aments, 508

American aloe, 434 copal, 574

kino, $569,57 \mathrm{I}$

linden, 608

pennyroyal, 676

senna, 360

Americanus-a-um, 435

Amino-acid, 167

Ammanni, 435

Ammoniac, 639 African, 639

plant, 444

Ammoniacum, 435

Amomum, 435, 494

Amorpha, 435, 574

Amygdalin, I69, I 70

Amygdalus, 435

Amylo-dextrin, 145

Amylo-pectinase, 242

Amylose, I44, 242

Amylum, 435

Amyris, 585

Anabasis, 527

Anacardiaceæ, 595

Anacardium, 435, 596, 599

Anacyclus, 4357 I 4

Anaërobes, 252

Anagallis, 436

Anagyris, 575

Analysis, micro, 776

Anamirta, 436, 539

Ananas, 436,480

Anatomical differences in leaves, 370

Anatomy, I

Anatropous, 379

Andira, 436

Androecium, 38 I

Andromedotoxin, 648

Andropogon, 436, 467, 472

Anemone, 359, 436, 535, 537

Anemonol, 537

Anemonon, 537

Anemophilous flowers, 399

Anethol, 234, 643

Anethum, 436, 643

Angelica, 436

American, 643

European, 643

purple stemmed, 643

wild, 643

Angiosperms, II 9

classification of, 463

development of, 120

economic importance of, I 28

flowers of, 375
Angostura, 436, 443, 585

Angustifolius-a-um, 436

Anhalonidine, 625

Anhalonine, 625

Anhalonium, 625

Aniline blue, as staining agent, 757

Anime, 586

Anise, 436, 448, 639

Japanese star, 540 protein in, 200 star, 448

Anise-scentcd golden-rod, 722

Anisomeria, 528

Anisum, 436, 448, 639

Annatto, 62 I

Annual herbs, 330 rings, 343

Annular, 273

Annulus or ring, $6 \mathrm{I}$

Annuus-a-um, 436

Anogra, 436

Anona, 542

Anonaceæ, 54I

Anthelminticus-a-um, 436

Anthemis, 436, 7 I 3

Anther, 379 appendages of, $38 \mathrm{I}$

Antheridium, 5

Antherozoid, 5

Anthoceros, 83

Anthocyanin, 209, 2 I0 origin of, 180

Anthophylli, 631

Anthotaxy, 393

Anthoxanthum, 436, 472

Anthracene, I 70

derivatives, 179

Antidesma, 594

Antirrhinic acid, 691

Aparine, 436

Apeiba, 609

A pex of leaf, 354

Apiin, 169, I 70

Apiol, 234, 643

Apiose, I69

Aplastic, 172

A pocarpous, 376

A pocynaceæ, 574, 664

Apocynum, 386, 436, 664

fruit, 4 I 2

seed, 429

Apostasieæ, 496

Apothecia, 73

Appendages of anther, $38 \mathrm{I}$

Apple, 457, 562

cedar, I I 5

earth, $44^{\circ}$

may, 538

protein in, 199

rose, 632

rust, II5

star, 441, 659

sugar in, I 56 
Apricot, 562, 620

oil in, 213

protein in, 199

sugar in, 156

Aquaticus-a-um, 436

Aquifoliaceæ, 600

Aquifolium, 436

Aquilaria, 628

Aquilegia, 536

Arabicus-a-um, 436

Arabin, 222

Araceæ, 475, 478

Arachis, 40I, 576

Arachnoidiscus, 35

Aragallus, 574

Arales, 475

Aralia, 436, 636, 637

Araliaceæ, 636

Araroba, 436

tree, 462

Arbor, 460 vitæ, I 8

A r butin, I69, I70, I74, I 76

Arbutus, trailing, 644, 649

Archegoniates, 75

Archegonium, 75

Archesporium, 79, I 24

Archichlamydeæ, 504

Arctium, 436, 715, 71 7

Arctostaphylos, I 74, 436 , 644,65 I

Areca, 436, 473

Arecaidine, 474

Arecaine, 474

Arecoline, 473

Arethusa, 502

Argania, 659

Argemone, 436, 547

Arginin, 253

Argithamnia, 436, 594

Arillode, 427

Arillus, 427

Arisæma, 436, 477, 480

Aristolochia, 436, 519,521

Aristolochiales, 5 I9

Aristotelia, 609

Arnica, 437, 7 I 5 pollen of, 404

Arnotta, 621

Aromaticus-a-um, 437

Aros, 437

Arrow-head, 466

Arrow-poison, 516, 575, 593, 633,662

Arrow root, 462 Maranta, 496 soft-leaved, 706 starch, 496

Arrow wood, 705 maple-leaved, 705 soft-leaved, 706

Artemisia, 437, 719

hairs of, 285

Artemisiæfolius-a-um, 437
Arthrospore, 12

Artichoke, ferment in, 244 globe, 726

Jerusalem, 725

Artificial coloring of flowers, I 82

Artocarpus, 437,516

Arum, 437, 478

Arundinaceus-a-um, 437

Arvensis-e, 437

Asafœtida, 445, 639

Asagræa, 437

Asarone, 520

Asarum, 365, 437, 520

Asci, 47

Asclepiadaceæ, 574, 668

Asclepias, 437, 667, 668

Ascomycetes, 47

Ascophyllum, 30

Ascus, 47

Asexual generation, 298 spore, 298

Ash, 446

mountain, 562

prickly, 462

white, 66I

wild mountain, 454

Asimina, 437, 54I

Asparagine, $167,253,725$

Asparagus, 437, 485, 480 protein in, 199 sugar in, 156

Aspen, 456

Aspergillus, 49

- emulsin, 243

Asperula, 437

Aspidium, 437

Aspidosperma, 437, 667

Asplenium, 437

Assimilation root, 306 shoot, 299

Aster, 7 1 2, 726

Astragalus, 437, 569, 574 gum in, 218

Athamanticus-a-um, 437

Atmospheric nitrogen, fixation of, 307

Atriplex, 437, 527

Atropa, 437, 683, 684 fruit, 4 I 2

Atropous, 379

Atropurpureus-a-um, 437

Attar of rose, 564

Aucuba, 643

Aucubin, 643

Aurantiamarin, 585

Aurantium, 437

Auric chloride, I65

Australis-e, 437

Autumnalis-e, 437

Auxochrome, I 79

Auxospores, 37

Avena, 437, 467 structure of, 423

Avenalin, 195
Avens, 416

Avocado, 455

Ax-seed, 442

Azalea, glandular hairs in, 230

purple, 646

Baccaurea, 594

Baccharis, 437, 723

Baccifer-a-uin, 437

Bacillus, I4

hay, I 3

subtilis, I 3

typhosus, destroyer of, 655

Bacteria, I 2

aërobic, I 2

anaërobic, I 2

classes of, I3

sulphur, I4

Bacterium, I4

Balanophora, 519

Balanophoraceæ, 519

Balata, gum, 659

Balatium, 24 I

Ballota, 437

Balm, 452

of Gilead, 508

sweet, 679

Balsam, 225

Canada, as mounting medium, 757

gurjun, 62 I

Maracaibo, 572

mounts, 763

of fir, I I 8

of the gardens, 604

of Tolu, 572

Oregon, I I 9

poplar, 508

Sindor, 621

tree, $46 r$

Balsamifer-a-um, 438

Balsaminaceæ, 604

Balsams, 236

Balsamum, 438

Bambusa, 466

Banana, 496 protein in, 199 sugar in, 156

Baneberry, 434, 537

Banskia, 5 I 8

Baobab, 61 2

Baptisia, 438, 567, 573, 575

Baptisin, 169

Barbaloin, I69

Barbarea, 438

Barberry, 438

family, 537

Barbiera, 575

Barium salts, 575

Bark, 3 I 7

Barley, 448

lecithin in, 214

protein in, 199 
Barley, starch in, 148 sugar in, 156

Barosma, 438, 583

Barringtonia, 629

Base of leaf, 356

Basidiomycetes, 56

Basil, sweet, 679

Bassia, 659

Bassorin, 223

Basswood, 609

Bastard cedar, 580 santal, 580

Bauhinia, 575

Bayberry, 2 I 2, 508

Bay oil, 632

rum, 632

Beale's carmine solution, 760

Bean, 576

buck, 452

garden, 576

Indian, 440

Japanese soy, 576

kidney, 455

lima, 199

pichury, 453

protein in, 199

Sacred, 453

sea, 575

Bearberry, 436, 46r, 65I

Beard grass, 436

Bearwort, 452

Beauty, meadow, 634

Bebeeru, 453, 546

Bedstraw, 446, 697, 704 yellow, 704

Beeberine, 546

Beech, 445, 5 Io

American, 512

drops, 696

false, 644

nut, protein in, 199

purple, 178

red, 5 I 2

Beer manufacture, 5 I 5

Beet, 438, 527

garden, protein in, 199 sugar in, 156

sugar, 527

proteins in, 199

sugar in, 156

Beggiatoa, I 4

Begonia, 624

hairs in, 282

Begoniaceæ, 624

Belladonna, $438,683,740$

hairs of, 284

lily, 435

root, cross section of, 318

Bell-flower family, 7 ro

Bellwort, 485

Benedictus-a-um, 438

Bengal quince, 434

Benne oil, 69r

Benzaldehyde, 234

Benzoinum, 438, 660
Benzo-quinhydrone, I 79

Benzoquinone, I 79

Benz-pyrrol, I80

Berberidaceæ, 537

Berberine, 162,180

Berberis, 438, 537

Bergamia, 584

Bergamot, 679

oil, 584

wild, 679

Berry, 4 Io

partridge, 452

Bertholletia, 629

Beta, 438, 527 stomata on leaves, 367

Betel, 508

leaves, 506

nut, 436,473

palm, 476

Betonica, 438

Betony, 438

Betula, 438,5 Io cross-section of wood, 346

Betulaceæ, 5 I 0

Betulase, 243

Betulinus-a-um, 438

Bezoars, vegetable, 577

Bhang, 516

Bicollateral mestome strands, 34 I

Bicuculla, 550, $55 \mathrm{r}$

Bidens, 438

Biennial herb, 330

Biennis-e, 438

Bifacial leaves, 349,366

Biflorus-a-um, 438

Bigardia oil, 584

Bignonia, 438

Bignoniaceæ, 69 I

Bilabiate, 386

Bilberry, 654, 655

Bind weed, 442

Birch, 438, 5 I0

family, 5 Io

white, cross-section of wood, 346

Bird food, 696

Bird-lime, 5 I 8

Birthroot, 46r

Birthwort, 436

family, 5 I 9

Bisectrix, 775

Bishop's cap, 452

Bismarck brown, as staining agent, 757

Bistorta, 438, 527

Bitter sweet, 444,684

Bixa, 621

Bixaceæ, 62I

Bixin, 622

Blackberry, 458

bush, 563

low, 563

sand, 563

sugar in, 156
Black catechu, 569

haw, 462, 704

hellebore, 537

Bladder-wrack, 28

Blade, 348

Blakea, 634

Blazing star, 449

Blights, 44

Blinding tree, 592

Blood orange, 584 root, 458,547

Blueberry, cultivation of 656

dwarf, 653

early sweet, 653

high bush, 655

low, 654

low-bush, 655

Blue flag, larger, 492 indigo, 574

Bluets, 448, 697

Bocconia, 550

Bœhmeria, 438, 5 I 7 fibers in, 269

Bœrhavia, 528 hairs in, 282

Bogbean, 665

Bog plants, 480

Bogs, sphagnum, 84

Böhmer's hæmatoxylin solution, 760

Boletus, $6 \mathrm{r}$

Bombaceæ, 554, 6r 2

Bombax, 554, 6I 2

Bondicine, 576

Boneset, 712 false, 449

Borage family, 670

Border, 386

Bork, 293

Borneo camphor, 620

Borneol, 233, 544, 676

Borraginaceæ, 670

Boswellia, 587 hairs in, 282

Botrychium, 365, 438

Bottle, reagent, for sterile solutions, 757

Bougainvillea, 528

Bouncing bet, 530, 531

Bower, Virgin's, 44I

Box tree family, 594

Boxwood, 439

Brabeium, 518

Brachycerus-a-um, 438

Bracts, 388, 393, 402

Bramble, 458

Branches, lateral, 3 I 2

Brandy, 607

Brasiliensis-e, 438

Brassica, 438, 552, 553

Brauneria, 438, 723, 724

oil canals in, 224

phytomelane in, 260

Brazilian copal, 574 
Brazilin, I79, I80

Brazil-nut, 629 aleurone grains of, 194

Breadfruit, 437,516

Bread, St. John's 576

Breadstone, 39

Breathing root, 306

Bridelia, 593

Brier, cat, 459 green, 459

Bromeliaceæ, 480

Bromelin, 244

Broom, 443

green, 569

Scotch, 569 weed, 458

Broom-rape family, 696

Brosimum, 516

Brucamarine, 586

Brucea, 586

Bruguiera, 63I

Brush, 472

Bryonia, 438, 709

sieve in, 276

tendril of, 323

Bryonidin, 709

Bryonin, 709

red, 709

white, 709

Bryophytes, 76 economic uses of, 84

Bubbles, air, 752

Buchania, 599

Buchu, I 52, 438, 583

Buckbean, 665

Buckeye family, 602

Buckthorn, 445, 457 family, 604

Buckwheat, 445, 526, 527

family, 520

flowers, 400 protein in, 199 sugar in, 156

Bud, apical, 32 I axillary, $32 \mathrm{I}$ scale, 120 scaly, $32 \mathrm{r}$ terminal, $32 \mathrm{r}$

Buds, 32 r

Buffalo berry, 628

Bugbane, 44 I

Bugle weed, 434, 45 I

Bulb, 227

Bulbils, 327

Bulblets, 327

Bunt, 46r

Bur, 5 ro

Burdock, 436, 449, 7 I 5, 7 I 7

Burning bush, 600

Bur-reed, 464 family, 463

Bursa, 438 pastoris, 439

Bursera, 587

Burseraceæ, 586
Bursine, 554

Butcher's blocks, 560

Butneria, 439

Butter, cacao, 6r 2 shea, 659 vegetable, 659

Butter-and-eggs, 691

Buttercup, 457, 537

Butter-fly weed, 667

Butternut, 509

Buttonbush, 440, 703, 704

Buttons, 473 mescal, 625

Button-snakeroot, 722

Buttonwood, 559

Butyrospermum, 659

Buxaceæ, 594

Buxine, 594

Buxus, 439, 546, 594

Cabbage, 553

Cacao, r48, 2 Ir, 439, 460, 612

butter, 6r 2

protein in, 199

red, 6 r 2

seeds, $6 \mathrm{r}_{2}$

starch in, 148

sugar in, I 56

tree, 612

Cactaceæ, 625

Cactus, 439, 621, 625 coach-whip, $62 \mathrm{I}$

family, 625

Cadinene, 233, 589, 642

Caducous, 388

Cæsalpinia, 439, 576 coriaria, tannin in, 206

Cæsalpinioideæ, 567

Caffëine, $162,176,600,6$ r 8 , 700

Cajuputi, 439, 452

Calabar bean, 455

Calamint, 44r

Calamites, 100

Calamus, $439,474,479$

Calcarate, 388

Calcium carbonate, 200 oxalate, 183 phosphate, I 86

Calendula, $387,439,718$

hairs in, 288 pollen of, 405

Calisaya, 439

Calla, 439, 479

Calla-lily, 478

Callitris, I I 9

Calluna, 439

Callus, 277

Calophyllum, 439, 6r8, 6r9 inophyllum, 212

Caltha, 439

Caltrop family, $58 \mathrm{I}$

Calumba, 439, 539

American, 445
Calyptrogen, 254

Calyx, 402

duration of, 388

Cambium, 3 r 4 intrafascicular, $34 \mathrm{r}$

ring, $34 \mathrm{r}$

Cambogia, 439

Camelina, 439

Campanulaceæ, 708, 710

Campanulatæ, 708

Campanulate, 388

Campechianus-a-um, 439

Campestris-e, 439

Camphene, 676

Camphor, $439,544,546,620$ Borneo, 620 culture, 746 Japanese, 234 Laurus, 234 tree, 545

Campion, $45 \mathrm{r}$

Camptosorus, 439

Campylotropous, 379

Canada fleabane, 713 moonseed, 539

Canadensis-e, 439

Canaigre, 527

Canango, 542

Canarium, 586

Cancer root, 695,696

Cane, 439, 445

Cane-sugar, $155,{ }_{5} 6$

Canella, 622 bark, 622 substitute, 622

Canellaceæ, 622

Canna, 496

Cannabinus-a-um, 439

Cannabis, $439,5 \times 3$ American, 741, 742, 744 . fiber, 269 hairs of, 284

Cannaceæ, 496

Cantaloupe, 7 ro sugar in, 156

Cantharellus, 58

Caoutchouc, 439, 513,516 , 592 threads, 240

Cape jasmine, 704

Caper, 579 spurge, $59 \mathrm{I}$ wild, $59 \mathrm{r}$

Capillaceus-a-um, 439

Capillus-Veneris, 439

Capitulum, 7 II

Caprifoliaceæ, 704

Capsella, 438, 439, 554 ferment in, 244

Capsicum, 439, 687 protein in, 200

Capsule, 4 I I

Caraipa, 618

Caramel, synthetic, 159

Carapa oil, 589 
Caraway, 440, 639 protein in, 200

Carbamases, 244

Carbohydrates, origin of, 157 photosynthetic, I 57

Carbon dioxide assimilation, 299, 350

Carboniferous age, 99

Carbon-like substance, 258

Cardamom, 4I0, 435, 439, 444,494 protein in, 200 starch in, 148

Cardinal flower, 710

Cardol, 596

Carduus, $45 \mathrm{I}$

Carex, 439, 47 I, 472

Careya, 629

Carica, 440, 542, 624 ferment in, 244

Caricaceæ, 624

Carices, 472

Carnation, 443, 53 I

Carnauba-palm, 214, 474

Carnauba-wax, 474

Carnivorous plants, $36 \mathrm{r}$

Caroba, 69 I

Carobine, 69I

Carobone, 69I

Carolianus-a-um, 440

Carolina pink, 66r

Carolinensis, $44^{\circ}$

Carota, 440

Carotin, 493, 636

Carpaine, 624

Carpel, I 20, 374-376

Carpinus, 440,510

Carpophore, $4 \mathrm{I} 7$

Carposid, 624

Carragheen, 3 I

Carrot, 440, 443 family, 636 protein in, 199 starch in, 148 sugar in, 156

Carthamic acid, 720

Carthamin, 720

Carthamus, 387,719 pollen of, 405

Carum, 440, 639, 643

Caruncle, 427

Carvacrol, 234, 679

Carvi, 440

Carvone, 234

Carya, 333 cross-section of wood, 346

Caryophyllaceæ, 53 I

Caryophyllene, 57 I

Caryophyllus, 440,632

Caryopsis, 4I 7, 466

Caryota, 476

Cascara, 440, 604

Cascarilla, 440, 592

Cascarillin, 592

Casearia, 623
Cashew, 435 . nut, 458,596

Cassia, 360, 440, 567, 575 purging, 567 species of, 567

Cassine, 600

Castanea, 440 cross-section of wood, 346 species of, 5 I 2

Castilloa, 24 I, 5 I 6

Castinin, 195

Castor bean, 457 aleurone grains in, 194 plant, 443,59 I

Catabolism, 252

Catalases, 245

Catalpa, 440, 69I

Catalpin, 69I

Cataria, $44^{\circ}$

Catawba grape, 606

Cat brier, 485

Catechin, 180

Catechu, 440 black, 569

Catha, 600

Cathartocarpus, 440

Cathine, 600

Catkin, 394

Cat mint, 680

Catnip, 440, 453, 680, 68 I

Cat-tail family, 463

Cauliflower, protein in, 199 sugar in, 156

Caulophylline, 538

Caulophyllum, 440, 537

Cavanillesia, 6 12

Cay-Cay butter, 586

Ceanothus, 440,604

Cecidien, 334

Cedar, 460

apples, I I 5

bastard, $58 \mathrm{r}$

prickly, 454

red, II 5, I 8

uses of, I I 5-I I 7

white, I 8

wood oil, 589

Cedrela, 589

Cedron, 440, 459 seed, 440

Cedronin, 586

Cedrus, I 8

Celandine, 44 I, 548, 55 I

Celastraceæ, 600

Celastrine, 600

Celastrus, 440, 600

Celery, protein in, 199

Celloidin, 749

Cells, 2

antipodal, 124

apical, 254

conducting, 272

contents, examination of, 246
Cells, contents reaction with microchemical reagents, 759

cork, 290 ,

division, 3

epidermal, 277

forms of, 262

guard, 279

helping, I 24

inclusion, 207

kinds of, 297

laticiferous, 239

protecting, 277

sclerenchyma, 266

sclerotic, 267

secretory, 226

stereomatic, 268

stone, 267

tapetal, I2I, 404

Cellulases, 244

Cellulose, 256

walls, protective, 257

Cell-wall, reaction with microchemical reagents, 759

stratification in, 258

striation in, 259

Celosia, 528

Centaurea, 440

Centifolius-a-um, 440

Centrifugal,development 262

Centripetal, development. 262

Centrospermæ, $\mathbf{5 2 7}$

Centrospheres, I35

Century plant, 489

Cephaëlis, 440, 699

Cephalanthin, 704

Cephalanthus, 440, 703, 704

Cephalaria, 708

Ceramium, 40

Cerasin, 223

Ceratonia, 440, 576

Cerealis-e, 440

Cereus, 625,627 night-blooming, 625

Cetraria, 73, 440

Cevadilla, 458

Chakazzi copal, 574

Chamælirium, 440, 49 r

Chamomile, German, 7 I 5

Roman, 713

wild, 452

Chamomilla, 440

Champagne, 607

Chanterelle, 58

Characeæ, 26

Charcoal, 508, 509

Charlock, 553

Chartreuse, 679

Chavicol, 632

Chebulinic acid, 633

Chekan, Eugenia, 441, 632

Chelerythrine, 550

Chelidonine, 550 
Cheliodonium, 44I, 548, 550, 55 I

Chelidoxanthin, 550

Chelone, 44I, 69 I

Chemical stimuli, 248

Chenopcdiaceæ, 527

Chenopodiales, 527

Chenopodium, 44I, 527

hairs in, 282

Cherry, 456

bark of, 294

choke, 56 I

cross-section of wood, 346

protein in, 199

sugar in, 156

wild, 56I

black, 560

Chestnut, 5 I I

American, 5 I 2

bark disease, 54

cross-section of wood, 346

horse, 206, 602

oak, tannin in, 206

protein in, 199

Spanish, 5 I 2

starch in, 148

sugar in, 156

tree, 440

wild, 5 18

Chests, tea, 625

Chewing gum, 659

Chew-stick, 447

Chickweed, 435

Chicory, 441, 716, 725

culture, 747

Chimaphila, 44 I, 455, 644

Chinese galls, 597

potatoes, 492

rice paper, 636

tallow tree, 594

Chinquapin, 5 I 2

starch in, 148

Chionanthin, 66I

Chionanthus, 44I, 66I

Chirata, 44 I, 664

Chirayita, 44I, 664

Chiretta, 460, 664

Chives, 485

Chloral, crystals, 762

Chloranthy, 391

Chlorenchyma, 366

Chlorococcum, 72

Chlorophora, 5 I6

Chlorophyceæ, r7, 20

Chlorophyll, I 38, I 58

Chloroplastids, I 37

Chloroplasts, 137

Chlorosis, 391

Chlor-zinc-iodide solution, 760

Choke cherry, 56I

Chondrodendron, 44I, 539

Chondrus, 3I, 44 I

Choripetalæ, 504
Choripetalous, 383

Chorisepalous, 383

Chorisia, 6r 2

Chorisis, 390

Christmas holly, 600

Chromatin, 136

Chromatophore, 136

fixed oils in, 2 10

Chromene, 180

Chromic acid, 756

Chromogen, 179

Chromophores, I 79

Chromoplastids, 137,138 occurrence of, I 8 I

Chromosomes, 136

Chrozophora, 593

Chrysanthemum, 44r, 7 r4, 7 1 8, 724, 726

Chrysarobinum, 44I

Chrysophyllum, 44 I, 659

Chrysosplenium, 441, 556

Chymases, 244

Cicely, sweet, 643

Cichoriaceæ, 7 I I

Cichorium, 441, 716, 725

Cicuta, 44I, 575, 642

Cigar boxes, I I 7, 589

Cimicifuga, 44I, 532, 533

Cinchona, 44I, 697 cultivated, 546, 690, 698 plantation, 698 species of, 699 substitute, 606, 620

Cineol containing oil, 544

Cinereus-a-um, 44 I

Cinnamic acid, 572 aldehyde, 544

Cinnamodendron, 622

Cinnamomum, 44 I, 543, 544, 545

Cinnamon cultivation, 545 cutting, 545 oil, 544 starch in, 148

Cinquefoil, 456

Circæa, 44 1, 634

Circinate, 364

Circumcissile, 4 I 3

Circumnutation, 360

Cirrhiferous, 357

Cissampelos, $44 \mathrm{I}$

Cistus, hairs in, 282

Citral, 233, 234, 564, 583

Citron, 44I, 584

Citronellol, 564, 579

Citrullus, 44I, 708, 710

Citrus, 44I, 583, 584

Cladonia, 72, 74

Claptonia, $53 \mathrm{I}$

Claret, 607

Clavatus-a-um, 44I

Clava-Herculis, $44 \mathrm{I}$

Clavaria, 58

Clavariaceæ, 59

Claviceps, 44 I
Claviceps purpurea, 52

Claw, 385

Clearing agents, 755,756

Cleavers, 446

Cleaverwort, 436

Cleft, 356

Clematis, 44 I, 537 cork in, 293

Climbers, 324 root, 324

Clinopodium, 44I

Clitoria, 575

Clotbur, 462

Clove, 440, 44I, 632 protein in, 200 starch in, 148 tree, 445

Clover, 567,576 prairie, 449 sweet, 452

Club-like, $44 \mathrm{I}$

Clusia, 619, 620

Cnicin, 723

Cnicus, 44I, 723

Coach-whip cactus, $62 \mathrm{I}$

Coal age, 99 deposits, I 19

Coalescence, 390

Coca, 442,580 family, 580 seedling, 745

Cocaine, $163,170,58 \mathrm{I}$

Cocci, I3

Coccos oil, 623

Cocculus, 442,539

Coccus, 442, $516,531,606$, 621,627

lacca, 238

Cochineal insect, 627

Cochlearia, 442, 553

Cochlospermum, 223, 622

Cocillana, 5 I 6

Cocklebur, 462

Cock's-comb, 528

Cocoa (see Cacao)

Brazilian, 603

Cocoa-nut, 2 I 2, 474 palm, 474

double, 427

fruit, 413

protein in, 199

Cocos, 474, 476

fruit, 413

Codeine crystals, 767

Coffea, 442, 700

Coffee, 442, 700

aroma, 700

caffeine in, I62

cultivation, 700

Kentucky, 447

picking, 702

protein in, 199

roasting, 700

substitutes, 6I I, 7 I6

sugar in, I5 6 
Coffee tree, 575,70 wild, 632,707

Coffeol, 700

Cohesion, 390

Cohosh, 434

black, 532

blue, 440,537

Cola, 6I 4,6 I 5

caffeine in, 162

family, 6I2

Colchicum, 442, 485

Cold frames, 731

Colic-root, 435,485

Coliguaya, 593

Collateral mestome strands, $34 \mathrm{I}$

Collenchyma, 265

Colletin, 606

Collinsonia, 442

Colloidal, I40

Colocynth, 708

fruit, 410,424

seed, 424

Colocynthis, 442

Color in autumn leaves, 178 in lichens, 72 principles, chemistry, I79 substances, cell-sap, I 76, I 8 I

substances, distribution of, I 81

Coloring of flowers, artificial, 182

Colors, cell-sap, 176 function of, I $8 \mathrm{I}$

Coltsfoot, $387,445,46 \mathrm{r}, 723$

Colubrina, 606

Columbine, wild, 536

Columbo, 539

Combretaceæ, 633

Combretum, 633

hairs in, 282

Comfrey, 460, 67 I

Commelina, 442,480

Commelinaceæ, 480

Commiphora, 442, 586

Common mossy stonecrop, 556

Communis-e, 442

Compass plant, $\mathbf{7 2 3}$

Complete flower, 298

Compositæ, 7 I I, 7 I 2 flowers of, 387 hairs in, 288

Compound leaves, 356

Comptonia, 509

Concentric mestome strands, 342

Conduplicate, 364

Condurango, 668

Cones, 375

Confluent, $38 \mathrm{I}$

Conglutin, 195

Conidia, 4 I

Conifera-um, 442
Coniferæ, uses of, II 7

Coniferin, I69, I 70, I 7 I, 489

Conium, 442, 638, 640

Conjugatæ, I 7

Conjunctive tissue, 313

Connate-perfoliate, 356

Connective, I 22, 38 I

Conopholis, 695, 696

Consolodin, 673

Contortæ, 660

Contraction of roots, 3 I 9

Contrayerva, 444

Convallamarin, I70, 442, 486

Convallaria, 487

Convolute, 364

Convolvulaceæ, 668

Convolvulus, 442, 669

Copaiba, 442, 571, 574 substitute, 62 I

Copal, American, 574

Brazilian, 574

Chakazzi, 574

East Indian, 587

Inhambane, 574

resins, 574

Sierra Leone, 574

Zanzibar, 574

Copalchi, 592

Copalchin, 592

Copernicia, 474

cerifera, 2 I 4

Copper acetate solution, $76 \mathrm{I}$ treatment of water, 8

Coptis, 442

Coral root, 442

Corallorhiza, 442

Corchorus, 269, 609

Cordifolius-a-um, 442

Coriamyrtin, 595

Coriander, 442 protein in, 200

Coriandrum, 442, 637

Coriaraceæ, 594

Coriaria, 594

Coriarious-a-um, 442

Cork cells, 290 development, 293

Corm, 329, 477

Corn, 467

Black Mexican, 178

cockle, 434,446 seed, 426

Indian, 462 root-tip, 300

oil in, 213

protein in, 199

silk, I 78

starch in, I 48

sugar in, 156

Cornaceæ, 643

Cornel, 442

Cornin, 643

Cornus, $442,388,643$

Corolla, 382,402
Corona, 623

Coronilla, 442, 575

Cortex, 3 Io

secondary, 3 r 3

Corydaline, $55 \mathrm{I}$

Corydalis, 209, 55 I

Corylus, 442, 5 I0

Corymb, 394

Corymbine, 702

Corynine, 702

Cotoneaster, 562

Cotton, 447

fiber, 269

protein in, 199

Sea Island, 6 ro

seed, oil in, $2 \mathrm{I} 3$ oil, 6 I I

Cotula, 442

Cotyledon, 299, 426

Couch-grass, 468

Coumarin, 472

in polypodium, 96

Couroupita, 629

Corillea, 58 I

Cowhage, 452,576

Cranberry, 656

American, 655

European, 656

fruit, $4 \mathrm{I} 7$

small, 655

tree, 704

Cranesbill, 446

Crassulaceæ, 556

Cratægus, 442, 565

Crateriform, 388

Cratoxylum, 6Ig

Crawley root, 453

Cream nut, 630

Cream-of-tartar tree, 6I 2

Crecopia, 5 I6

Cremocarp, 4I 7, 636

Crenate, 356

Crenulatus-a-um, 442

Creosote, 5 I 2 bush, 580

Cress, Indian, 579

Cretian origanum, 679

Crinum, 492

Crispus-a-um, 442

Croceine M. O. O., I82

Crocin, 493, 704

Croc1s, 442, 493, 704 pollen of, 404.405 stigma of, 405

Crops, harvesting of, 738

Cross-pollination, 560

Cross-section, 749

Crotalaria, 442, 575

Crotin, 198

Croton, 443, 591-593 oil in, 2 I 3

Crowfoot, 457,532

Crown-galls, 335

Crucifer-a-um, 443

Cruciferæ, 55 I, 574 
Cruciger-a-um, 443

Cryptogams, 5 vascular, 86

Crystal, 769

biaxial, 774

clusters, I 85

codeine, 767

columnar, I 83

fibers, 187

hexagonal, 774

hydrastine, 770

membrane, I 89

micro, 187

microtechnic, 776

monoclinic, $183,184,774$

of fixed oils, 2 I I

of reagents, 762

orthorhombic, I 83, 774

piperine, $77 \mathrm{I}$

sand, 188

solitary, I 83

sphere, I92

strychnine crystals, 769

tetragonal, 183,774

triclinic, 774

uniaxial, 774

Crystalline wax, 2 I6

Crystallographic method of examination, 767

Crystalloidal, 140

Crystalloids, 193, 199

Cubeb, 443, 504

substitute, 54 I

Cubebin, crystals, 768

Cuckoo-pint, 437

Cucumber, 7 ro

protein in, $x 99$

squirting, 444,709

sugar in, 156

tree, 540

sour, 6I2

Cucumis, 443, 7 ro

Cucurbita, 443, 709

Cucurbitaceæ, 708

Cudbear, 74

Cudrania, 5 I 6

Cud weed, 446

Cultivated and wild plants, value of, 739

Cultivation of medicinal plants, 727

progress in, 744

Culver's root, 450,689

Cumarin, I 73

Cumin, 443, 643

oil, 643

Cuminum, 443, 643

Cunila, 443, 68 I

Cup or bur, 5 Io

Cupana, 443

Cuphea, 628

Cupule, 420

Curanga, 69I

Curanjiin, 69I

Curare, 662
Curare poison, 539

Curarine, 662

Curatella, 6r5

Curcas, oil in, 213

Curcin, I98

Curcuma, 494 protein in, 200

Curcumin, 496

Currant, 457,558

Buffalo, 558

fetid, 558

protein in, 199

sugar in, I 56

Cuscuta, 670

Cuscutin, 670

Cusparia, 443, 585

Cusso, 443, 447, 565

Custard apple, 543 family, 54 I

Cutin, 277

Cutose, 257

Cyanol, F. F., I 82

Cyanophyceæ, 8 glycogen in, 154

Cyanus, 443

Cycads, II I

Cyclamen, 656 hairs in, 282

Cydonia, 560

Cylindric leaves, 349

Cyme, 395

dibrachious, 395

helicoid, 395

monobrachious, 395

Cymene, 643

Cyminum, 443

Cynara, 726

Cynips, 5 I I

Cynoglossine, 673

Cynoglossum, 443, 673

Cynomorium, 5 I 9

Суреraceæ, 472

Cyperus, 443, 472, 473

Cypripedium, 443, 496, 498, 501

Cystoliths, 200

Cystopus, 44

Cystotyles, 20 I

Cytases, 244

Cytisine, 575

Cytisus, 443, 569

Cytology, r38

Cytoplasm, 2, I35

Daisy, 7 I2

fleabane, $7 \times 3$

white, 718,724

Damascenus-a-um, 443

Damiana, 623

Damianin, 623

Dammar, black, 587

Dandelion, 460, 712 hairs in, 288

Dapine, 443,627

Daphnin, r 70
D-arabinose, I69

Dark field illumination, 765

Date palm, 208, 473 endosperm in, 265

Dates, 475

Datisca, 625

Datiscaceæ, 624

Datiscin, 169,625

Datura, 443, 682, 684 ferment in, 244

Daucus, 443

Day-flower, 442, 480

Deadly nightshade, 684

Decandrus-a-um, 443

Deciduous, 388

Definite inflorescence, 394

Dehiscence, 4 I I

Dehydrating agent, 755,756

Delafield's hæmatoxylin solution, 760

Delphinium, 443, 535, 574

Dentate, 356

Dentatus-a-1,, 443

Dermatogen, 253

Derris, 575

Descent of plants, I33

Desmids, I 7

Desmodium, 36I, 443

Development, arrested, 39 I of stomata, 368

Devil's apron, 30

Devonian age, 99

Dewberry, Northern, 563

Dextrin, I47

Dextro-glucose, I 55

Dextrose, I55, 563

Diandrous, $38 \mathrm{I}$

Dianthus, 443 species of, $53 \mathrm{I}$

Diaporthe parasitica, 54

Diastase, 242

Diatomaceous Earth, 38

Diatoms, 35

Dibrachious (cyme), 395

Dicentra, 443, 55 I

Dicotyledonous stem structure, 339

Dicotyledons, I 20, 50 I

Dictamus, 225, 443

Dicypellium, 544, 546

Didymus-a-um, 443

Didynamous, $38 \mathrm{r}$

Diervilla, 443, 707

Digitalin, I69, I 70

Digitalis, 443,690

hairs of, 284,285

section of leaf, 372

seedlings, 743

Digitalose, I69

Digitonin, I60

Digitoxin, I69

Dill, 436

garden, 643

oil, 643

protein in, 200 
Dillenia, 6r 5

Dilleniaceæ, 6r5

Dimorphic flowers, 399

Dioicus-a-um, 444

Dionæa, 362, 554

Dioscorea, 444, 492 stem of, 322

Dioscoreaceæ, 492

Diosphenol, 582

Diospyros, 444, 659 hairs in, 282

Dipentene, 722

Diphyllus-a-um, 444

Diplococci, I4

Dipsacaceæ, 707

Dipsacus, 444, 708

Dipterocarpaceæ, 620

Dipterocarpus, 620

Dirca, 444, 627

Disaccharose, I54

Discaria, 606

Discoid head, 7 I I

Disk-flower, 7 I I

Dissepiment, 4 I I, 378 false, 378

Dissotis, 634

Distichous, 363

Dita, 435

Ditch stonecrop, 454, 556

Dittany, 443 American, 682

Divergence, 363

Divided, 356

Divi-divi, tannin in, 206

Divining rod, 558

Division, internal, 5

Doassansia, 67

Dock, curled, 523 sorrel, 458

Dodder, 670

Dogbane, 436 family, 664 spreading, 664

Dog's-tooth violet, 485

Dogwood, 442

family, 643

flowering, 643

Jamaica, 448, 575

Domesticus-a-um, 444

Domingensis-e, 444

Doona, 62 I

Dorema, 444, 639

Dorsal pneumatic tissue, 366 suture, 377

Dorsiventral flowers, 393 leaves, 349, 366

Dorstenia, 444

Double flowers, 7 I 4 staining, 762

Douglas fir, $\mathrm{Ir}_{4}$ spruce, ris

Dracæno, 489

Dracontomelum, 599

Dragon's blood, 474,488

Dragon tree, 489
Drimys, 540

Drosera, 36r, 444, 554

Droseraceæ, 554

Drugs, curing of, 738 drying of, 737,738 physiological testing of, 248

selection of, 737

Drupe, 418, 426

Drüzenzotten, 222

Dryobalanops, 620

Dryopteris, $87,90,92,444$ hairs of, 284

Dry yeast, lecithin in, 214

Duckweed, 450

family, 478

Ducts (see Tracheæ), 273

Dulcamara, 444, 684

Dulce, Irish, 34

Dulcis-e, 444

Dulcitol, I 56

Duration of calyx and corolla, 388

Dutch clover, 472

Dutchman's breeches, $55^{\circ}$

Dwarf branch, 374

Dye, leather, 633

Dyer's broom, $\mathbf{5 7 4}$

Dyes, aniline, as staining agents, 757

non-aniline, as staining agents, 757

Dyna_nic centers of cell, 140

Dysentericus-a-um, 444

Dzaini, 562

Early sweet blueberry, 653

Eau D'Ange, 632 de Creole, 620

Ebenaceæ, 444, 659

Ebenales, 658

Ebony, 444, 659

black, 659

family, 659

green, 659

red, 659

striped, 659

white, 659

Ecballium, 444, 709

Echinacea, 723

oil canals in, 224

phytomelane in, 260

Echinate, 354

Echinocarpus, 607

Ecology, I

Edestin, 195

Eelgrass, 466

Egg apparatus, 298

cell, 124, 298

plant, 688

Elæagnaceæ, 628

Elæagnus, 628

Elæis, 474

Elæocarpaceæ, 607

Elæocarpus, 608
Elastic, 444

Elastica, 24I, 592

Elasticity, 774

Elasticus-a-um, 444

Elaterin, 709

Elaterium, 444, 709

Elaters, 82

Elder, 458

American, 706

black, 706

mountain, 706

red-berried, 706

Elecampane, 448, 720

Elemi, Bengal, 586

Manila, 586

resin, 586

West India, 586

Eleocharis, 444,472

Elettaria, 444, 494

Eleusine, 467

Elm, 46I, 5 I 2

American, 512

cross-section of wood, 346

family, 5 I 2

slippery, 513

white, 5 I 2

Eluteria, 444

Emarginate, 355

Emasculated, $45 \mathrm{I}$

Embryo-sac, 108, 1 20, 298

Emodin, 170

Emulsins, 243

Enchanter's nightshade, 634

Endocarp, 4ro

Endodermis, 3 Io

Endosmosis, 25 I

Endosperm, ro8, I 27, 425

of date palm, 265

structure of, 429

Endospore, I 2, 4 I

Endothecium, 404

Endothia radicalis, 54

Entada, 575

Enterolobium, 575

Entomophilous, 402

Environment, I30

Enzymes, 24I diastatic, 242

Eperua, 576

Ephemeral, 388

Epicarp, 4 I0

Epicotyl, 299, 426

Epidermal cells, 277

Epidermis, 309, 360

Epigæa, 444, 644, 649

Epigeous shoot, 321,322

Epigynous, 389

Epilobium, 634

Epipactis, 503

Epiphytes, 306

Equisetaceæ, 444

Equisetales, 96

Equisetums, 96, 444

Equitant leaves, 349

Erectus-a-um, 444 
Ergot, 52, 1 55, 441, 444

Ericaceæ, 444, 644 microsublimates of, 173

Ericales, 644

Ericolin, 655

Erigeron, 444, 713

Eriobotyra, 562

Eriodendron, 6II

Eriodictyon, 444, 670 hairs of, 284, 286

Erysimum, 445, 553

Erytaurin, 664

Erythræa, 664

Erythronium, 485

Erythrophlœum, 575

Erythroxylaceæ, 580

Erythroxylon, 445, 580

Eschscholtzia, 547. 550

Esculentus-a-um, 445

Esparto, 472

Esters, 234

Estivation, 389

Etærio, 419

Ether, phenol, 234

Euasci, 47

Eucalyptol, 631

Eucalyptus, 445, 63 I

kino, 631

oil, 631

seedling, 745

species of, $63 \mathrm{I}$

Eucitrus, 583

Eugenia, 445, 63I

Eugenol, 234, 544, 546

Euonymus, 239, 445, 600

Eupatorin, 713

Eupatorium, 445, 712

Euphorbia, 445, 591, 592, 594

Euphorbiaceæ, 590

Euphorbium, 593

Euphorbon, 593

Europæus-a-um, 445

Euryale, 532

Evening primrose, 436, 634 , 635

family, 634

Evergreen, 459

Evernia, 73

Evolution, I 29, 247

Excelsin, 195

Excelsus-a-um, 445

Excœcaria, 592

Exine, 123, 404

Exocarp, 410

Exodermis, 309

Exogonium, 445, 668

Exosmosis, 25 I

Exospores, 4I

Exothecium, 404

Experimental farms, 732735

Extraordinary ray, 774

Extrorse, 380
Fabiana, 684

Fagaceæ, 5 I I

Fagales, 5 I0

Fagopyrum, 445, 526, 527

Fagus, 445 species of, 512

Fairy-ring fungus, 58

False beech-drops, 644 dissepiment, 378

flax, 439

hellebore, 462, 537

indigo, 435,438

mitre wort, 460,556

nettle, 438

Solomon's seal, 484,485

spikenard, 484

unicorn root, 491

winter's bark, 622

Fan palms, 473

Farfara, 445

Farinosæ, 480

Farinosus-a-um, 445

Farms, experimental, 732735

Fastigiatus-a-um, 445

Fats, 2 Io physiology, 2 I 6

Fatty oils, 546 resins, 238

Fegatella, 272

Fennel, 445, 639

flower, 453

protein in, 200

Ferments, 24 I

in stinging hairs, 287

in yeast, 49

microchemistry of, 245

Fern, flowering, 454

fossil, 104

male, 445

palms, I I I

sensitive, 453

used in medicine, 96

walking, 92

water, 94

Fertile, I 2 I

Fertilis-e, 445

Fertilization, I 25, 397

Ferula, 445, 639

Fetid, 445

Fever bush, 438

hay, 726

Fibers, bast, 268

isolation of, 270

sclerenchymatous, 268,270

strength of, 269

Fibrovascular strand, 3 I 3

Ficus, 24I, 445, 5 I3 5 I 4 , 5 I 5

ferment in, 244

latex in, 240

species of, 516

Field sorrel, 524, 525

penny cress, 553

Fig, 5 I 5

ferment in, 244
Fig, Indian, 626, 627

protein in, 199

Figwort family, 688

Fiji oil, 519

Filament, 379, 404

Filbert, 442, 5 Io

Filicales, 87

Filix-mas, 445

Fir, 213, 434

California silver, II

red, I 19

Scotch, I I 7

tannin in, 206

white, II9

Fisetin, 180

Fishberries, 539

Fish poison, 517, 539, 604, 606

Fistula, 445

Fixing agents, 755

Flacourtiaceæ, 622

Flats, plant, 730

Flavon, 170

Flavone, I80

Flax, 450

family, 579

Flaxseed, oil in, 2 I 3 protein in, 199 structure of, 428

Fleabane, 144

Canada, 7 1 3

daisy, 713

Philadelphia, 713

sweet scabious, 713

Flea seed, 456

Fleur-de-lis, 448

Floral envelopes, 382

leaves, 120,375

Florets, 7 II

Florida moss, 480

Flour, gluten, 196

Graham, 196

Flower, 374

Flowers, classes of, 392

cleistogamous, 391

complete, 392

diagrams, 505

double, 390, 7 I4

inner structure of, 402

insect, 718

ligulate, 395,7 I I

of Angiosperms, 375

of Compositæ, 387

of Gymnosperms, 375

of Solanaceæ, 385

outer morphology of, 374

parts of, 374

stalks, 376, 402

sun, 447

tubular, $39^{\circ}, 7$ I I

types of, 303

Flueggea, 593

Fœniculum, 445, 639 aleurone grains of, I94

Fœtida, 629 
Fœtidus-a-um, 445

Fog-fruit, 450

Folia Malabanthri, 568

Follicle, 4 I 9

Fontinalis, 85

Food, bird, 696 of plants, 248

Fore-leaves, 393, 466

Forget-me-not, 453, 670

Formaldehyde, 234

Forms of leaves, 354 of plants, alterations in. 332

Fossil Coniferæ, I 19

Fouquieria, 62I

Four o'clock family, 528

Foxglove, 443, 690

Fragaria, 445, 566 fruit, 4 I 5 species of, 567

Fragilaria, 37

Fragrance due to volatile oils, 234

Fragrans, 445

Fragrant, 445

Frames, cold, 731

Frangula, 445

Frangulin, 169, 170 .

Frankincense, 587

Frasera, 445

Fraseri, 446

Fraxetin, 66I

Fraxin, 169, 170, 661

Fraxinus, 446, 66I glandular hairs in, 230

Fremontia, 6I 5

French plum, 562

Fringe tree, 44I, 66I

Fructose, I 54, I 55

Fructosidase, 242

Fruit acids, 563

ethers, 564

jellies, 243

outer morphology of, 408 structure of, 42 I sugars, 155, 563

Fruits, classification of, 42 I different types of, 409

Fuchsia, 634

Fuchsin, as staining agent, 757

Fucose, I 54

Fuller's teasel, 708

Fulvus-a-um, 446

Fumaria, 209, 446, 547, 550

Fumariaceæ, 209

Fumarine, 548, 550

Fumitor y, 446, 550 European, 550

Funaria, 85

Function of leaf, 350

Fungi, 7,40

constituents of $4 \mathrm{I}$

coral, 58, 59

detection of, 70
Fungi, economic uses, 65 edible, 59 ferments of, 242,244

gill,

glycogen in, 154

groups of, 4 I

imperfecti, 70

jelly, 59

leather, 59

poisonous, $6 \mathrm{I}$

pore, 59

rust, 65,68

smut, 65

stinck-horn, 59

Fungus chirurgorum, 65

Funifera, 627

Fusanus, 5 I9

Fustin, 169, I 70

Galactose, 169

Galangal, 494

Galbalus, 419

Galbanum, 639

Galeopsis, 446

Galetæ, 388

Galium, 446, 697, 704

Gallicus-a-um, 446

Galls, 206, 334, 446, 5 I I

Chinese, 597

crown, 335

fungus, 334

hard, 334

Japanese, 597

of Terminalia, 633

soft, 334

Gamboge, 597, 618, 619

Gamete, 5, 298

Gametophyte, 75, 108, 298

Gamopetalous, 385

Gamosepalous, 385

Garcinia, 446, 6r8, 6r9, $6 \approx 0$

Garden bean, 576 beets, protein in, 199 heliotrope, 670 lilac, 66r

pea, 576

rue, 585

strawberry, 566

Gardenia, 446, 704

Garlic, 435,485

mustard, 553 protein in, 199

Gaultherase, 243, 644

Gaultheria, 446, 644, 650

Gaultherin, 169, 170

Gaylussacia, 446, 652 fruit, 4 I 4

Gelidium, 34

Gelsemium, 446, 66I

Genista, 446, 574, 575

Gentian, 446, 663

American, 664

bottle, 663

closed, 663
Gentian family, 663

fringed, 664

horse, 706

rhizome of, 331

violet, as staining agent. 757

yellow, 663

Gentianaceæ, 663

Gentianales, 660

Gentinin, 169

Gentisein, 180

Geotropism, negative, 320 positive, 302

Geraniaceæ, 578

Geraniales, 577

Geraniol, 233, 564, 579, 583

Geranium, 446, 57 I

family, 578

fruit, 409

grass oil, 472

hairs in, 282

rose, 579

Geranyl acetate, 234

Gerardia, purple, 693

German chamomile, 7 I 5

Germander, 460

Germination, time of, 730

Geum, 446

Gigartina, 33, 446

Gilead balsam, 587

Ginger, 462, 494

beer, 49

family, 494

grass oil, 472

protein in, 200

starch in, 148

wild, 437,520

Ginseng, $305,454,636,638$ cultivation of, 735

family, 636

Girardinia, 517

Githago, 446

Glaber-bra-brum, 446

Glabrous, 369

Glæocapsa, 72

Glandular, 354

Glandulifer-a-um, 446

Glandulosus-a-um, 446

Glans, 420

Glaucium, 446, 550

Glaucous, 370

Glechoma, 68I

Gleditschia, 575

Gliadins, I 95

Globe artichoke, 726

Globoids, I 93

Globulins, 192

Globulus, 446

Glœocapsa, 8

Gloiopeltis, 34

Gluco-alkaloids, 172

Glucose, 154

Glucosidal resins, 238

Glucosidase, 242

Glucoside, 155, I67 
Glucoside, classification of, 169

dextrose, 169

distribution of, 160

function of, 172

microchemistry of, I7 I rhamnose, 169

Glumes, 466

Glumifloræ, 466

Glutamin, 253

Glutelins, 194, 195

Gluten, 196 flour, I 96

Glutinosus-a-um, 446

Glutinous, 446

Glycerin-jelly, 763

Glycine, 576

Glycinin, 195

Glycocoll, 192

Glycogen, I 54

Glycoside, 167

Glycyphyllin, 169

Glycyrrhiza, 446, 568

Gnaphalium, 446

Gnidia, 627

Goa powder, 44I

Goat's beard, 46I

Goldenrod, 459, 7 1 2, 726 anise-scented, 722 high, 72 I

Golden seal, 448, 532

Gold flower, 44I

Goldthread, 442

Gonidium, 7 I

Goodyera, 503

Gooseberry, 457, 557

fruit, 4 I 8

protein in, 199

sugar in, 156

Goosefoot, 441, 527

Gossypitrin, 169

Gossypium, 447, 6ro fiber, 269

Gouania 447, 606

Gourd, 443

family, 708

Gracilaria, 34

Graham flour, 196

Grain, 4 I 7 pollen, 298

Graminales, 466

Gramineæ, 447, 466

Granatum, 447, 629

Grape, 462, 606

fern, Virginia, 365

fruit, 584

protein in, 199

seed, oil in, 213

sugar, 155, 606

sugar in, 156

vine, 606

Grass, 447

beard, 436

family, 466

holy, 448
Grass of Parnassus, 556

panic, 454

pepper, 450,553

scurvy, 442, 553

sweet vernal, 436

worm, 459

Gratiola, 447, 691

Gratiolin, 69 I

Graveolens, 446

Gravity, influence of, 301

Greek valerian, 67 I

Grenacher's borax-carmine solution, 760

hæmatoxylin solution, 760

Grevillea, 518

Grewia, 609

Grias, 629

Griffithsia, 40

Grimmia, 85

Grindelia, 447, 713

Gromwell, 450

Groundsel, 459 tree, 437

Growing point, 253

Growth, factors influencing, 246,247

Guaiac, 447

Guaiacum, 447, 580, $58 \mathrm{I}$

Guarana, 162, 447, 454, 603

Guarea, 5 I 6

Guava, 632

Guayava, 632

Guazuma, 615

Guelder-rose, wild, 704

Gulf weed, 3 I

Gum, 21 8, 565, 599

acajou, 599

anacardium, 223

arabic, 222,569

balata, 659

chagual, 223

chewing, 659

chicle, 659

cocoa-palm, 223

East Indian, 223

exuding, 447

moringa, 223

plant, 447

red, 574

resin, 225,236

spruce, II 9

tragacanth, $218,569,570$

tree, sweet, 558

yellow, 574

Gumbo, 6I I

Gummifer-a-um, 447

Gummy, 444

Gurjun balsam, 62 I

Gurjunic acid, 62I

Gutta-percha, 241, 658

Guttiferæ, 6I 8

Guvacine, 474

Gymnocladus, 447, 575

Gymnosperms, I 1
Gymnosperms, flowers of 375

groups of, III

Gymnosporangium, I 5

Gynæcium, 376

Gynandrous, 382

Gynocardia, 623

Gypsophila, 447, 53 I

Gysbertsiana, 621

Habena1 ia, 447, 499, 500

Hadrome, 3 I 2

Hæmatoxylin, I 80

Hæmatoxylon, 447, 57 I

Hagenia, 447, 565, 566

Hairs, abietiform, 287

candelabra, 287

crystal containing, 287

false plant, 290

glandular, 222, 228, 28 I

hooked, 286

lignified, 290

nonglandular, 283

papillose, 286

peltate, 286

plant, 279

shaggy, 285

stellate, 286

stinging, 287

types of, $28 \mathrm{I}$

uniseriate, 286

Hamamelidaceæ, 558

Hamamelis, $447,558,559$

Hanburii, 447

Hand microtome, 749

Hardening agent, 755, 756

Hard galls, 334

Hardhock, 459

Hard rush, 493

Hardwickia, 57 I

Harvesting of crops, 738

Hashish, 516

Haustoria, 306, 518

Haw, black, 704

Hawthorn, 442, 565

Hay fever, 726

Hazelnut, 442, 510

Chilian, 518

oil in, 213

protein in, 199

Hazelwort, 437

Head, 395

Heart's ease, 462

Heath, 444

family, 644

Heather, 439

Hedeoma, 447, 676

Hedera, 447, 636

Hederic acid, 636

Hedge hyssop, 447, 452

Helenium, 447, 723

Helianthemum, 447

Helianthenin, I 50, 726

Helianthus, 447,725

Helicteres, 6r 5 
Heliotrope, 447 garden, 670

Heliotropism, 349

Heliotropium, 447, 670

Helixin, 636

Hellebore, 447

black, 537

false, 537

Helleborein, 537

Helleborus, 447, 537

Helonias, 49 I

Hemiasci, 47

Hemlock, I I 3,46 I poison, $442,638,640$ tannin in, 205, 206 (Tsuga), I I 9 water, 44I, 575, 642

Hemp, 439

fiber, 269, 5 I 4

nettle, 446

oil in, 213

sisal, 492

yellow, 625

Hempwood, climbing, 452

Henbane, 448, 684

Henequen, 492

Henna plant, 629

Hepaticæ, 80, 447

Herb, annual, 329, 330

biennial, 330

perennial, 330

quinine, 664

Herba Centaurii Minoris, 664

cochleariæ, 553

Herbaceous, 447

Herbaceus-a-um, 447

Herbs, 329

Hercules, club of, 44I

Hermaphrodite, 392

Herniaria, 531

Hesperidin, I51, 169, 170 , 585

Hesperidium, 419

Hesperis, 447,583 hairs in, 282

Heterocysts, I I

Heterosporous, 87

Heuchera, 447, 556

Hevea. 24I, 447, 592, 594

Hexose, I 54

Hibiscus, 448,6 II

Hickory, 333, 509 cross-section of wood, 346

Hicoria, 365, 509, 510

Hierochloe, 448, 472

High-bush huckleberry, 652

Hilum, 425 of starch grain, 144

Hinna, 629

Hippocastanaceæ, 602

Hippocastanum, 448

Hirsute, 354

Hirsutus-a-um, 448

Hispid, 354
Hispidus-a-um, 448

Histology, I

Hoarhound, white, 676

Hold-fast, 30

Holly, $44^{8}$

American, 600

Christmas, 600

dahoon, 600

European, 600

family, 600

leaved barberry, 436

Hollyhock, 435, 609, 6 I I

Homalium, 623

Honesty, 553, 554

Honey, 402

dew, 157

poison, 402

Hcneysuckle, 450

bush, 443, 707

family, 704

Hopea, 621

Hop, hornbeam, 454 substitute, 606,621 tree, $\mathbf{5 8 5}$

Hops, 448, 515

Hordeum, 448, 467, 468

Horehound, fetid, 437 water, $45 \mathrm{I}$

Hornbeam, 440, 5 I0

Horsebalm, 442

chestnut, 434, 448, 602

gentian, 706

mint, 679

radish, 553

tails, 96, 444

Hound's tongue, 443,673

Houstonia, 448, 697

Hoyer's picro-carmine solution, 760

Huckleberry, 446, 654

black, 652

fruit, 4I 4 sugar in, 156

Humulene, 508, 509

Humulus, 448, 5 I4 hairs in, 282

Humus, 249

Hura, 592

Hyacinth, 485

Hydnocarpus, 623

Hydrangea, 448, 556 wild, 556

Hydrangin, 556

Hydrastine, 162,770

Hydrastis, I6I, 448, 532 alkaloids, 174,175

farming, 734, 735

Hydrochinon, 176

Hydrodictyon, 22

Hydrophilous, $40 \mathrm{r}$

Hydrophyllaceæ, 670

Hydropiper, 448

Hymenenæa, 574

Hymenium, 57

Hymenocallis, 448, 492
Hyoscyamus, $385,448,684$ branching hairs in, 289

fruit, 409, 4 I 2

structure of seed, 429

tracheæ of, 274

Hypecoum, 547

Hypericaceæ, 618, 620

Hypericum, 448, 620

Hypha, 4I

Hypnum, 85

Hypocotyl, 299, 426

Hypocrateriform, 388

Hypodermis, 309

Hypogeous shoot, 321,325

Hyssop, 691

garden, 679

Hyssopus, glandular hairs in, 230

hesperidin in, 153

Ice-plant, 529

Icthyomethia, 448

Idæus, 448

Idioblasts, 207, 208

Ilex, 448, 600, 60I

Ilicaceæ, 600

Ilicin, 600

Illicium, 448, 540

Illipe, 659

Imbricated, 389

Impari-pinnate, 357

Impatiens, 448, 604

Imperfect flower, 392

Incumbent, 427

Indefinite inflorescence, 394

Index, refractive, 774

India Bdellium, 587

rubber, 516,592

senna, 567

Indian cress, 579

cucumber, 485

root, 435

fig, 626,627

hemp, 436

licorice, 434

mallow, 6 ro

pipe, 452,644

Suringi, 620

tobacco, 710

turnip, 477,480

Indican, 169,574

Indicus-a-um, 448

Indigo, 527,573

blue, 180,574

forming glucoside, $\mathbf{5 5 3}$ wild, 573

Indigofera, 573 tinctoria, 180

Indigotin, 180

Inflatus-a-um, 448

Inflorescence, 393, 394

Influence of gravity, $30 \mathrm{r}$

Inf undibuliform, 388

Infusorial earth, 38

Inhambane copal, 574 
Injury to plants, $\mathbf{I 7}_{2}$

Ink-ball, 335, 5 I 2

gall, 335,5 I 2

tree, 597

Innate, $38 \mathrm{I}$

Inner structure of leaf, 365 of root, 309 of stem, 338

Inosit, 607, 636

Insect flowers, 718

Insect visitation of flowers, 399

Insectivorous plants, ferments in, 244

Intine, 404

Intraf ascicular cambium, 34 I

Inula, 387, 448, 720

hairs in, 288 phytomelane in, 26r

Inulenin, 150,726

Inulin, 150, 725

Inulinase, 242

Invertase, 242

Involucre, 395

Involute, 364

Iodine in seaweeds, 40 solution, 76I in water, 760,761

Ionon, 622

Ipecac, 448, 699 wild, 706

Ipecacuanha, 440, 448

Ipomœa, 448

Iridaceæ, 492

Iridin, 160

Iris, $332,448,492$

Iron solutions, 76 I

Irone, 234

Ironwood, 454, 510, 659

Irregular flower, 393

Irritability, 358

Irvingia, 586

Isatis, 553

Islandicus-a-um, 448

Isoetes, 97, 449

Isometric system, 764

Isoptera, $62 \mathrm{I}$

Isoquinoline, $x 66,180$

Isosporous, 87

Iva, 448

Ivory, vegetable, endosperm in, 265

Ivy, 441,447

English, 636

ground, $68 \mathrm{I}$

poison, 595, 596

Ixina, 449

Jaborandi, 449, 455, 582

Jacaranda, 69 I

Jack-in-the-pulpit, 477

Jack-tree, 5 I 6

Jalapa, 449

substitute, 528

Jamaica dogwood, 575
Jambosa, 63 I

Jambuse berries, 632

Japanese lacquer, 597

medlar, 562

soy bean, 576

Japan-wax, 2 I 2

Jateorhiza, 539

Jatropha, 59r

Jellies, fruit, 243

Jelly, Kaiser's glycerin, 763

Jequirity, 575

Jessamine, yellow, 66I

Jewel-weed family, 604

Jimson weed, 443,684

Joannesia, 59 I

Juglandales, 509

Juglans, $449,509,510$ cross-section of wood, 346

Juglansin, 195

Juglon, I 79

Julocroton, hairs in, 282

Juncaceæ, 493

Juncus, 493

Jungermania, 83,85

Juniper, I 16

Juniperus, I 18

Jussieua, 634

Jute fiber, 269

Kadsura, 540

Kaiser's glycerin-jelly, 763

Kalmia, I 74, 449, 648

Kamala, 449, 45I, 592

hairs of, 285

Kapac oil, 6 I I

Kavaine, 508

Kava-kava, I 77, 452, 508

Ketones, 234

Kidney bean, protein in, $x 99$

Kiggelaria, 623

Killing agent, 755

Kinic acid, 655

Kino, 449, 569

American, 569, $57 \mathrm{I}$

Brazil, 593

eucalyptus, $63 \mathrm{I}$

Kittool, 476

Kittul, 476

Kiurushi, 597

Kleister, I 45

Knot weed, 456

Kola nut tree, 6I4

Krameria, 449, 57 I

Kraunhia, 575

Kristallsand, I 88

Kuhnia (Wisteria), 449

Kuhnistera, 449

Kumquat orange, 584

Labellum, 388

Labiatæ, 449, 673

Laburnum, 575

Lac, 597

Japanese, 597

tree, 245
Laccase, 597

Laccases, 245

Lace-tree, 628

Lacinaria, 449, 722

Laciniat us-a-um, 449

Lacquer, black, 245 Japanese, 597 trees, 597

Lactarius, 65

Lactuca, 449, 7 I 2 milk-juice of, 24 t

Lactucarium, 24I, 44) 712

Lady's mantle, 435 slipper, 443 thumb, 455

Laetia, 623

Lævulose, I 55

Lafænsia, 628

Lagerstrœmia, 629

Lagetta, 628

Lamellæ, 259 middle, 254 secondary, 255

Lamina, 348,385

Laminaria, 30

Lamium, 449

Lanate, 354

Lanceolatus-a-um, 449

Landolphia, 24 I

Langsdorffia, 5 I9

Langsdorffii, 449, 57 I

Laplaceæ, 6 I 8

Laportea, 449, 5 I 7

Lappa, 449

Larch, tannin in, 206

Larix, I I 8

Larkspur, 443, 535, 574

Lateral branches, 3 I 2 root, $30 \mathrm{I}, 3 \mathrm{I} 2$

Laterifolius-a-um, 449

Laticiferous vessels, 240

Latex, 238, 546

Lathyrus, 450,576

Lauraceæ, 450,544

Laurel, 450, 544

bay, 46 I

great, 647

ground, 444

mountain, 648

noble, 544

nut, $2 \times 2$ oil, 619

sheep, 449,648 spurge, 627

Laurus, 544

Lavandula, 450 hairs in, 282,284

Lavender, 450,676 pollen of, 404

sea, 450

spike, 676

true, 676

Lawsonia, 450, 629

Layer, resinogenous, 226

Leaf, apex of, 354 
Leaf, base of, 356

bifacial, 366

climber, 324

dorsiventral, 366

functions of, 350

inner structure of, 365

margin of, 356

mold, formation of, 249

netted-veined, 353

outer morphology of leaf, 348

palmi-nerved, 353

parallel-veined, 352

reticulate, 353

simple, 348

teeth, glandular, 283

unifacial, 366

venation, 352

Leaflets, 356

Leather, dye, 633 wood, 444,627

Leaves, 299, 348 anatomical differences in, 370

autumn, I 78

bifacial, 349

compound, 356

cylindric, 349

decay of, 250

divergence of, 363

dorsiventral, 349

equitant, 349

foliage, 120

forms of, 354

modified, 364

movement of, 357

scale, 120

sporangial, I 20

surface of, 353

sword-shaped, 349

texture of, 354

Lecanora, 74

Lecidea, 75

Lecithin, 2 I 4

Lecythidaceæ, 629

Lecythis, 629

Ledum, 450

Leek, 485

Legume, 4 I9

Legumelin, 195

Legumin, I95, 576

Leguminosæ, $450,567,575$

Lemna, 300

Lemnaceæ, 450,478

Lemon, 450,584 oil, 584 protein in, 199

Lens, 450,576

Lenticels, 29I, 292

Lenticus, 450

Lentil, 450, 576 protein in, 199 starch in, 148 sugar in, 157

Lentus-a-um, 450
Lenzites, 62

Leontin, 538

Leonurus, 450,682

Lepargyræa, 628

Lepidium, 450, 544

Lepidodendron, I0o

Leptandra, 450

Leptilon, 7 I3

Leptome, 276, 3 I 2

Leptospermum, 632

Lettuce, 449 poison, 712

Leucadendron, 450,517

Leucæna, 575

Leuco-compounds, I 79

Leucoplastids, 136, I37

Leucosin, I95

Leucospermum, 5 I 8

Leucothœ, 648

Levisticum, 450, 643

Levo-glucose, I 55

Levulose, I55, 563

Lianas, 324

Liane, 324, 602

Libriform, 270

Lichens, 7 I

color in, I 79

economic uses of, 73

on Rhamnus Purshianus, 292

roots of, 73

Licorice, 568

fern, 96

section of, 27 I

Spanish, 568 wild, 704

Life-processes, I34

Light relation of leaves, 349 shoot, 329

Lignin, 256, 580

Lignocellulose, 256

Lignone, 256

Ligulate flower, 7 I I

Ligule, 356

Ligulifloræ, 7 I I

Ligusticum; 450

Ligustrum, 450, $66 \mathrm{I}$

Lilac, 460 garden, $66 \mathrm{I}$

Liliaceæ, 450,485

Liliales, 485

Liliifloræ, 485

Lilium, 485

Lily, 450,485

lotus, 453

of the valley, $442,485,487$

spider, 448 yellow pond, 453

Lima beans, protein in, 199

Limb, 386

Lime fruit, 584 tree, 608

Limnophila, 358

Limonene, 583

Limonium, 450
Limonum, 450,584

Linaceæ, 450, 579

Linalool, $233,564,583$

Linalyl acetate, 234

Linamarin, I69

Linaria, 69I

Linariin, 69r

Linden, 46I, 608, 609 hesperidin in, 153

Lindera, 544

Linen, 580

Linodendron, 628

Linseed, oil in, 213

Linum, 579 structure of, 428

Lion's foot, 723

Lippia, 450, 673

Lippiol, 673

Liquidambar, 450,558

Liquorice (see Licorice)

Liriodendrin, 540

Liriodendron, 450, 539

Lithospermum, 450

Litmus, 74

Litsea, 546

Liverworts, $76,80,82,83$

Lobed, 356

Lobelia, 384, 450, 710

blue, 7 Io

red, 7 IO

section of leaf, 370

seed-coat, 429

Lobeliaceæ, 450

Loco, 574, 575

Loculicidal, $4 \mathrm{I} 2$

Locust, $457,567,576$

Loeffler's methylene blue, 757

Logania, 450, 66I

Loganiaceæ, 450, 66 I

Logwood, 57 I

Lomatia, 518

Lonchocarpus, 575

Lonicera, 450, 707

Loosestrife, 45 I, 628 purple, 628

Lophophora, 625

Lophophorine, 625

Loranthaceæ, 450,5 I 8

Loranthus, 518

Lotus, 450, 532

Lovage, 450,643

Lucerne, 577

Luffa, 710

Luffa-sponge, 7 Io

Lumen, false, 269

Lunaria, $450,553,554$

Lungwort, 456

Lupeol acetate, 659

Lupine, 45 I, 574 seeds, lecithin in, 2 I 4

Lupinidine, 575

Lupinin, 575

Lupinine, 575

Lupinus, 45 I, 575 
Lupinus luteus, protein in, 199

root tubercles on, 307

Lupulin, 5 I 5

Lupulus, 45 I

Lusitanicus-a-um, 45 I

Luteus-a-um, 45 I

Luzula, 493

Lychnis, 45 I, 53 I

Lycoperdaceæ, 59

Lycopodiaceæ, 97, 45 I

Lycopodium, 99, 2 I 3

Lycopus, 45 I

Lyngbya, ro

Lysigenous, 226

Lysimachia, hairs in, 282

Lythraceæ, 628

Lythrum, 400, 451, 628

Mabea, 592

Macaranga, 593

Macassar, 519

Mace, 2I 2, 45 I, 543

protein in, 200

starch in, 148

Macis (see Mace)

Maclura, 45 I, 5 I6

Maclurin, 180

Macrocystis, 30

Maculatus-a-um, 45I

Madder, 697, 702, 703

Mad-dog skullcap, 675

Magnolia, 45 I, 539, 540

Magnoliaceæ, 539

Magnolin, 540

Magonia, 604

Mahogany family, 588

tree, 589

Mahonia, trailing, 537

Mahurea, 6ro

Maidenhair, 434, 439

Maize, 462

Majalis, 45 I

Majorana, 45 I

Major-us, $45 \mathrm{I}$

Malabanthri folia, 568

Malambo bark, 592

Male generative-cell, 298

Mallotus, 45 I, 59 I

hairs of, 285

Mallow, 609, 6I I

glade, 453

Indian, 6 ro

rose, 448

Malpighia glabra, tannin in, 206

Malpighiaceæ, 589

Maltase, 242

Maltose, I 55

Malva, 6I I

Malvaceæ, 45I, 609

Malvales, 607

Mamillosus-a-um, 45 I

Mammea, 620

Mammei apple, 620
Mammey wine, 620

Mandarin, 584

Mandrake, 455

Mangifera, 599

Mango, 620

Mangos, 599

Mangosteen, 446, 6r9

Mangostin, 619

Mangrove, American, 630

forest, 304

swamps, $63 \mathrm{I}$

Mangrovin, 588

Manihot, 594

Manna, I 55, 45 I, 565, 66I

Briancon, I 8

of Israelites, 74

Persian, I 55

Mannit, 563

Mannitol, I 55

Mannose, I69

Manometer, 306

Maple, 434, 602

sugar, 157

syrup, 602

Maracaibo balsam, $\mathbf{5 7 2}$

Maranta, 496

arrow root, 496

Marantaceæ, 496 .

Marasmius, 58

Marcescent, 388

Marcgravia, 6I 7

Marcgraviaceæ, 6 I6

Marchantia, 8I

Marginal, 45I

Marginalis-e, 45 I

Marginicidal, 4 I I

Margin of leaf, 356

Mariana, 45I

Marigold, 387, 7 I 8

bur, 438

marsh, 439

Marilandicus-a-um, 452

Maritimus-a-um, 45 I

Marjoram, 45 I

sweet, 679

wild, 454, 679

Marking tree, East Indian, 597

Marmelos, 45 I

Marrubium, 451, 676

Marsdenia, 668

Marsh elder, 448

Marshmallow, 435, 609

Marsilea, 45I

Marsilia, 94, 95

Marsupium, 45 I

Marvel-of-Peru, 528

Massoy bark oil, 546

Mastic, 452, 599 tree, 450

Mastigocoleus, 8

Maté, 600 germination of, 730

Matico, 452, 504 section of leaf, 37 I
Matisia, 6I2

Matricaria, 452, 7 I5

Mawseed, 547

May apple, 538

Mayflower, 649

Maysin, I95

Maytenus, 602

May weed, 442

Meadow beauty, 634

sweet, 459

Meal, mountain, 39

Measurement, microscopic, 754

Medeola, 485

Medicago, 577

ferment in, 244

Medicinal plants, cultivation of, 727

Medicus-a-um, 452

Medinilla, 634

Medlar, Japanese, 562

Medullary rays, 3 I 4

Megasporangium, 108, 298, 375

Megaspore, 86, 298 germination of, 298

Megasporophylls, I08, 375

Melaleuca, 452, 632

Melastoma, 634

Melastomataceæ, 633

Melia, 588

Meliaceæ, 588

Melibiose, I 55

Melilotus, 452

Melissa, 452, 679

Melon, 44I, 454

cucumber, 443

musk, protein in, 199

tree, 624

Membrane, primary, 255

Memecylon, 634

Mendel's Law, I32

Menispermum, 539

Menispermaceæ, 538

Menispermum, fibrovascular bundle of, 337

woody vine of, 322

Menispine, 539

Mentha, 452, 678, 384 species of, 676

Menthol, 233

Menyanthes, 452, 664, 665

Menyanthin, 664

Mercurialis, 452, 593

Mercuric chloride, as fixing agent, 756

Mericarp, 4I 7

Meristems, 253, 254, 29 I

Mermaid's hair, Io

Mescal, 492

buttons, 625

Mescaline, 625

Mesembryanthemum, 529

Mesocarp, 4 ro

Mesophyll, 366 
Mestome, 272

sheaths, 367

strand, 3 I 3, 34I, 342, 343

Mesua, 6ro

Metabolism, 252

Metachlamydeæ, 504, 643

Methyl salicylate, 234

Methylene blue, as staining agent, 757

Methysticin, I 77, 508

Methysticum, 452,508

Metroxylon, 475

Meum, 452

Mexican linaloe oil, 588

Mezereum, 443, 452, 627

Michelia, 540

Microcarpus-a-um, 452

Micrococci, I4

Micrometer, 754

Micrometry, 754

Micron, 754

Micro-polariscope, 764

Micropyle, 425

Microscope, ultra, 765

Microscopic measurement, 754

Microsomata, I36

Microsomes, 136

Microspermæ, 496

Microsporangia, I 20, 298

Microspore, 298, 375

germination of, 298

Microsporophylls, I05, 375

Microtome, 749

Midrib, 353

Mignonette, I 20, 457, 554

Mikania, 452

Milaceus-a-um, 452

Mildews, 44

Milfoil, 434

Milk, clotting of, 244

juice, 238

ropy, 244

vetch, 437

Milkweed, 437

family, 668

Milkwort, 455 family, 589 white, 589

Millefolium, 452

Millet, starch in, 148

Millettia, 575

Millimeter, 754

Mimosoideæ, 567

Mimusops, 659

Mineral cellulose walls, 258

Mint, 449, 452

cat, 453,680

family, 673

horse, 452

Mio Mio, 723

Miocene, II 7

Mirabilis, 528

Mistletoe, 450

American, 53I
Mistletoe, European, 5 I 8

family, 5 I 8

oak, 518

Mitchella, 452, 697, 704

Mitella, 452, 556

Mitrewort, 452,556 false, 556

Moccasin flower, 498

Mock orange, 556

Modified leaves, 364 roots, 306

Mold, black, 45 water, 42

Mollis-e, 452

Monandrous, $38 \mathrm{I}$

Monarda, 452, 679 oil, 680

Monkey-bread tree, $6 \mathrm{I}_{2}$

Monkey-pot tree, 629

Monkshood, 434

Monniera, 452

Monocarpia, 542

Monoclinic crystals, I83, I 84

Monocotyledons, I 20, 463

Monœcious, 392

Monosaccharose, I 54

Monotropa, 452,644

Montanus-a-um, 452

Moonseed, Canada, 322, 539 family, 538

Moonwort, 438,450

Moraceæ, 513

Morchella, 58

Morel, 58

Morinda, 704

Morindin, 170,704

Moringa, 223, 554 pterygosperma, 2 I 2

Moringaceæ, 554

Morning glory, 448, 668

Morphine, 547

Morphology, I

Morus, 452, 5 I 7

Moss, bird's nest, $\mathrm{IO}_{3}$

club, $97,45 \mathrm{I}$

groups, 84

Iceland, $73,44^{\circ}$

Irish, 3 I

reindeer, 74

scale, 83

sea, $44 \mathrm{I}, 446$

Mother-clove, $63 \mathrm{I}$

Motherwort, 450,682

Mould (see Mold)

Mountain ash, 459

elder, 706

laurel, 648

Mounting of specimens, 762

Mounts, permanent, 763

Mourera, 556

Movements of leaves, 357

Moxa, 725

Mucedo, 45

Mucilage, 2 I 8, 565 chemical classification, 222
Mucilage, forms of, 22 I in sassafras, 263 walls, 257

Mucor, 45

Mucuna, 452,576

Mugwort, common, 719

Mulberry, 452

black, 5 I 7

family, $5 \mathrm{I} 3$

fruit, 409

white, 5 I 7

Mullein, 69r hairs of, 286

Mundulea, 575

Muntingia, 609

Muricatus-a-um, 453

Musa, 496

Musaceæ, 496

Musci, 84

Mushrooms, 434

common, 59

edible, 58

lecithin in, $2{ }_{4}$

poisonous, 58

propagation, 56

Muskmallow, 434

Musk-melon, 7 Io protein in, 199

Musk seed, 6 II substitute, 6 I I

Mustard, 438, 459

ball, 453

black, 552,553

family, 55 I

fruit, 409

garlic, 553

hedge, 459,553

protein in, I99, 200

treacle, 445,553

white, 552,553

wild, 553

yellow, germination of, 299

Mutation, 132, 247

Mycelium, 4I

Mycose, I55

Myelin, forms, 2 I 5

Myosotis, 453,670

Myrcene, 632

Myrceugenia, 632

Myrcia, oil, 632

Myrica, 2I I, 453, 508, 509

cerifera, 2 I 2

Nagi, tannin in, 206

species, 508, 509

Myricaceæ, 508, 509

Myricales, 508, 509

Myricaria, 621

Myricin, 594

Myristica, 453, 543

Myristicaceæ, 543

Myristin, 69I

Myrobalans, 633

beleric, 633

chebula, 633 
Myrobalans, long, 633 tannin in, 206

Myrosin, 243

Myroxylon, 623

Myrrh, 442, 453, 586, 587

Myrtaceæ, 63I

Myrtales, 627

Myrtifloræ, 627

Myrtle family, 63I

tree, 453

wax, 2 I 2,453

Myrtus, 453, 632

Nabalus, 723

Naiadaceæ, 466

Naiadales, 466

Naked flowers, 393

Napaca, 453

Napæa, 6r 2

Napellus, 453

Naphthalene, derivatives, I 79

Naphthol black B., I 83

Narcissus, 453,492

Nardus, 453

Naringin, I69, I 70, 585

Nasturtium family, 579

Natural selection, I3 I

Navel orange, 584

Navicola, 37

Nectandra, 453,546

Nectar, 402 apparatus, 408 poisonous, 402

Nelumbo, 453,532

Nepenthaceæ, 555

Nepenthes, $\mathbf{5 5 5}$

Nepeta, 453, 680, 68I

Nephelium, 603

Nerium, 668

Neroli, 583

Nerved leaf, 352

Nerves, 352

Nesæa, 628

Neslia, 453, 554

Nessin, 628

Netted-veined leaf, 353

Nettle, 46I, 5 I 7

dead, 449

horse, 684

small, 5 I 7

stinging, 287, 517

wood, 449

Nicotiana, 453, 688

Nicotianin, 688

Nicotine, 688

Nigella, 453

Niger-gra-grum, 453

Nigger-toe, 630

Night-blooming cereus, 625

Nightshade, 459

deadly, 684

enchanter's, 44I, 634

Nitrogen bacteria, 307

Nobilis-e, 453
Node, 320

Nomenclature, 2 Botanical, 430

Nopalea, 627

North American papaw, 542

Nostoc, I I

Nucellus, ro8, I 24, 298

Nucleo-proteins, 194

Nucleoles, I 36

Nucleus, 2, 136 function of, I 40 of starch grain, 144

Nuphar, 531

Nupharine, 53 I

Nut, 420

Nutation, 358

Nutgall, 334, 446

Nutlet, 420

Nutmeg, 21 2, 453, 542, 543 protein in, 200

starch in, 148

Nux-vomica, 453, 66I endosperm of, 265,428 hairs of, 286

Nyctaginaceæ, 528

Nyctinastic, 36I

Nyctitropic, 36r

Nymphæa, 453

Nymphæaceæ, 53 I

Nyssa, 453

Nyșso, 5 I 8

Oak, 457, 5 I I

acorns, 148 sugar in, 157

bark of, 295

black, 5 I 2

mistletoe, 5 I 8

poison, 595 western, 597

red, 5 I 2 tannin in, 206

tannin in, 206

white, 5 I I, 5 I 2 tannin in, 206

Oats, 437 protein in, 199 starch in, 148 structure of, 423 sugar in, 157

Obcordate, 355

Obtuse, 355

Obtusifolius-a-um, 453

Occidentalis-e, 453

Ochrocarpus, 6r9, 620

Ochroma, 6r 2

Ocimum, 679

Ocotea, 546

Ocotilla, 62I

wax, $62 \mathrm{I}$

Ocrea, 520

Octomeles, 625

Ocular micrometer, 754

Odontorhizon, 453

Odoratus-a-um, 453
Edogonium, 25

Enanthe, 643

Enothera, 453, 634, 635

Officinalis-e, 453

Oil, ajowan, 609

apeiba, 643

apopin, 234

bay, 632

ben, 212

benne, 69r

bergamot, 584

bigardia, 584

cajeput, 632

candle nut, 213

carapa, 580

cedar, as clearing agent, 757

cedar-wood, 589

chaulmoogra, 214, 623

cineol containing, 544

clove, as clearing agent, 757

coccos, 623

cocoa-nut, 2 I 2

Coniferæ, II 9

cotton seed, 6II

Croton, Mexican, 591

cumin, 643

curcas, 59 I

dill, 643

essential, as clearing agent, 757

Eucalyptus, 63 I

fatty, 546

Fiji, 5 I9

fixed, 2 Io

as a reserve, $2 \mathrm{I} 7$

function of, 235

globule, detection of, $\mathbf{7 5 2}$

kapac, 6I I

laurel-nut, 6 I9

lemon, 584

marjoram, as clearing agent, 757

massoy bark, 546

Mexican linaloe, 588

Monarda, 680

myrcia, 632

Neroli, 583

non-drying, 69r

olive, 213,660

orange peel, 583

palm, 2 I r, 474

palm-nut, 2 I 2

pepper, Japanese, 585

rose, 564

sandal, 518

santal, Australian, 5 rg

sesame, 69 I

spike, 679

sweet anise, 643

tunga, 2 I 3

turpentine, as clearing agent, 757

volatile. 225 
Oil, volatile, botanical classification, 232 characteristics of, 23 I composition, 233 culture of plants yield ing, 747

formation, 235

micro-chemistry of, 23 I water fennel, 643

Okra, 6r I

Olea, 660

Oleaceæ, 453, 660

Oleander, 668 cork in, 293

Oleandrin, 668

Oleo-resin, 225

Oleum, 453

Cedralæ, 589

Lavandula, 676

Rosmarinus, 676

Theobromatis, $6 \mathrm{I} 2$

Oleuropein, $66 \mathrm{r}$

Olibanum, 587

American, 587

Olive, 453,660

family, 660

oil, 660

tree, 660

Onagraceæ, 634

Onion, 435,485

sea, 46I

sets, 327

starch in, 148

sugar in, 157

Onoclea, 92, 453

Ononidis, 576

Ononis, 576

Ontogeny, I 30

Oogonium, 5

Oomycetes, 42

Oosphere, 5

Oospore, 5

Opegrapha, 75

Operculina, 453

Operculum, 79

Opium, 24I, 453 collection of, 549

poppy, 546, 547

Optical reactions, 773

Opulus, 454

Opuntia, 454, 626, 627

Opuntiales, 625

Orange, 437, 44I, 582

bitter, 583

blood, 584

Curacao, 583

G. G., I 82

kidney-glove, 584

kumquat, 584

Malta, 583

mock, 455,556

navel, 584

osage, 451,5 I 6

otaheite, 584

Portugal, 583
Orange, protein in, 199 root, 448

Seville, 583

sugar in, I 56

sweet, 583

Orcein, 74

Orchid, 496

Orchidaceæ, 496

Orchidales, 496

Orchil, 75

Orchis, fringed, 447 round-leaved, 499 white fringed, 500

Orcin, color in, 179

Ordinary ray, 774

Orellin, 622

Organography, I

Organs, nutritive, 3 plant, 3

sexual, 3

vegetative, 3

Orientalis-e, 454

Origanum, 454, 679 Cretian, 679 oil, 679

Orlean, 62 I

Ornithogalum, 485

Ornus, 454

Orobanchaceæ, 696

Orpine family, 556

Orris root, 332, 492 starch, I 43

Orthotoschies, 363

Oryza, 467

Oscillaria, ro

Oscillatoria, Io

Osmosis, 25 I

Osmunda, 365, 454

Ostrya, 454, 5 Io

Otaheite orange, $\mathbf{5 8 4}$

Ovary, I 20, 376 tissues of, 406

Ovules, 376,378 development of, I 24 forms of, 379 positions of, 379

Oxalidaceæ, 579

Oxalis, 454, 579

Oxidation, 252

Oxyacanthine, 539

Oxycedrus, 454

Oxycoccin, 656

Oxycoccos, 656

Oxydases, 245

Oxygen, 252

in fucus, 28

Oxymethylanthraquinone, I 76

Pachira, 6I I

Pæonia, 454

Palaquim, 658

Pale, 466

Palisade tissue, 366

Palmæ, 473
Palmately-compound, 356

Palmately-veined leaves, 353

Palmatus-a-um, 454

Palmetto, 458 saw, 459

Palmi-nerved leaf, 353

Palm oil, 474

Palms, 473

Palustris-e, 454

Panax, 305, 454, 636, 638

Pandanales, 463

Pangium, 198,623

Panicles, 396

Paniculatus-a-um, 454

Panicum, 454

Pansy, 622

Papain, 244, 542, 624

Papaver, 454, 546, 547

Papaveraceæ, 546

Papaverales, 546

Papaw family, 624

ferment in, 244

North American, 437, 542 tree, 624

Papayotin, 624

Paper, Chinese rice, 636

Papilionaceous, 386

Papilionatæ, 567

Papillæ, 45 I

Pappus, 7 I I

Paprika, protein in, 200

Papyrifer-a-um, 454

Paracatechin, 607

Para cress, 724

Paradise grains, 494

Parallel-veined leaf, 352

Para-nut, 629, 630

Parasites, 40

Pareira, 539

Parenchyma, forms of, 262 rays, secondary, 3 I 4 sheaths, 367

Paricine, 546

Parietales, 6 I5

Pari-pinnate, 357

Parnasia, 209, 556

Paronchia, 53 I

Parrya, 553

Parsley, 455 garden, 643

Parsnips, protein in, 199

Partridge berry, 697

Parviflorus-a-um, 454

Pasque flower, 456

Passiflora, 454, 623

Passifloraceæ, 623

Passion flower, 454, 615, 623

Patchouli oil, 679

Patchouly, 679

Pauciflorus-a-um, 454

Paullinia, 454, 603

Paviin, 602

Payena, 659

Pea, 198, 576

everlasting, 450 
Pea, garden, 576 germination of, 299 lecithin in, 214 protein in, 199 starch in, 148 sweet, 576

Peach, 435, 562 oil in, 213 protein in, 199 sugar in, 156

Peanut, I99, 576 oil in, 213 plant, $40 \mathrm{I}$

Pear, 457, 562 prickly, 454, 526, 627 protein in, 199

Peat, bog, 250 upland, 250

Pectase, 243

Pectin, 243, 563 origin of, 255

Pectinase, 243

Pectose, 243, 563

Pedaliaceæ, 69x

Pedatus-a-um, 454

Pedicel, 393

Peganum, 58I

Pelargonium, 579

Pellitory, 435, 457, 7 I 4

Pellotine, 625

Pelosine, 546

Peltatus-a-um, 454

Pencils, I 7

Penicillium, 49

Pennatifolius-a-um, 454

Penny cress, field, 553

Pennyroyal, 447 American, 676

Pentalostigma, 593

Pentapetes, 6i 5

Pentastichous, 363

Penthorum, 454, 556

Pentose, 154

Peony, 454

Pepo, 420, 454, 708

Pepper, 455

African, 687

black, 504, 505

cayenne, 200, 687

grass, 553

long, 504

moor, 585 picking, 507

protein is, 200 red, 439,688

starch in, 148

water, 448

white, 504

Pepperidge, 453

Peppermint, 676,678

camphor, 233

culture, 746

Peramium, 503

Pereiræ, 454

Perennial herb, 330
Perezia, 723

Perfect flower, 392

Perfoliate, 356,454

Perfoliatus-a-um, 454

Perforatus-a-um, 455

Perianth, 382

Periblem, 253

Pericambium, 3 I 2

Pericarp, 4 I0

Pericycle, 3 I 2

Periderm, 29I

Perigynous, 389

Perisperm, 425 structure of, 429

Peristome, 79

Periwinkle, 668

Permanent mounts, making of, 763

Peronospora, 43

Persea, 455

Persian tobacco, 688

Persicaria, 455

Persimmon, 444, 660 fruit, 659

Japanese, 660

Persistent, 388

Personate, 388

Persoonia, 5 I 8

Pertusaria, 73

Petals, 120, 374, 382

Petiole, 348

Petroselinum, 455, 643

Peziza, 46

Phaca, 575

Phæophyceæ, I 7, 28

Phaius, 137

Phallaceæ, 59

Phanerogams, 5

Phaselin, 195

Phaseoleæ, hairs in, 282

Phaseolin, 195

Phaseolus, 455, 576 apical region, $32 \mathrm{I}$

Phasins, 198

Pheasant's eye, 434

Phellandrene, 632, 643

Phellogen, 290, 29I, 313

Phenol, derivatives, 179

Phenolases, 245

Phenols, 234

Phenyl ethyl alcohol, 564

Philadelphia fleabane, 7 I3

Philadelphus, 455, 556

Phillipinensis-e, 455

Phlobaphene, 203

Phloem, 3 I 2

Phloridzin, 169, 565

Phloroglucin, crystals, 762 reaction, 256 solution, $76 \mathrm{I}$

Phlox, 455, 670 tracheæ of, 274

Phœnix, 475 endosperm in, 265

Phoradendron, 5 I 8
Phospholipines, 217

Photosynthesis, 137, 299. 350

fixed oils in, 210

Phycocyanin, 8

Phycomycetes, 42

Phyllanthus, 593, 594

Phyllotaxis, 363

Phylogeny, I 29

Physica, 73

Physical basis of life, 138

Physiological experiments, 350

Physiology, I

Physostigma, 455, 572

Phytelephas, 473 endosperm in, 265

Phyto-bezoars, 626

Phyto-cecidien, 334

Phyto-globulins, 193, 197

Phytolacca, 455 leaf, section of, 369 root, section of, 3 I 8

Phytolaccaceæ, 528

Phytomelane, 258

Phytosterol, 214

Phytovitellins, I93

Pianeze III b, 70

Picea, 109, I19, 455

Pichi, 684

Pickerel weed, 482

Picramnia, hairs in, 282

Picrasma, 455, 585

Picric acid, 756

Picric-sulphuric acid, as fixing agent, 756

Picro-crocin, 493

Picrotoxin, 455, 539

Piereskia, 627

Pieris, 648

hairs in, 282

Pigments, 138 resins, 238 respiration, I $8 \mathrm{I}$

Pignone, II 7

Pignut hickory trees, 333

Pigweed, 44I

Pileus, 57

Pilocarpus, 455, 582

Pimelea, 627

Pimenta, 455, 632 starch in, 148

Pimpernel, 436, 455

Pimpinella, 455, 639

Pinaceæ, groups of, II 3

Pinanga, $62 \mathrm{I}$

Pine, 455

Cuban, I I 3

frankincense, II 2

great sugar, I 12

loblolly, I 12

long-leaved, I I 3

nut, II 7

oil in, 213

pitch, II 2 
Pine, prince's, 644 seeds, I I 7 spruce, II 2 sugar, I 7 swamp, II3 torch, I I 2 Weymouth, 106 white, 106 yellow, I 13

Pineapple, 436,480 ferment in, 244

Piney resin, 62 I

Pinguicula, ferment in, 244

Pink, 443, 53 I Carolina, 66 I cultivated, $53 \mathrm{I}$ lady's slipper, 498 root, 459

Pinkster flower, 646

Pinnately-compound, 356

Pinus, 455

Strobus, ro6

sylvestris, 213

tannin in, 206

Piper, 426, 455, 504, 506 (see also Pepper)

methysticum, I77 species of, 504

Piperaceæ, 504

Piperales, 504

Piperine, 161 crystals, $77 \mathrm{I}$

Piperitus-a-um, 455

Pipitzahoic acid, 723

Pipsissewa, 455, 644

Pircunia, 528

Pirolaceæ, 644

Piscidia, 575

Piscipula, 455

Pistachio, 455, 599

Pistacia, 208, 455, 597

Pistil, I20, 376

compound, 376

different types of, 377 simple, 376

Pistillate, 392

Pisum, 576

ferment in, 244 germination of, 299

Pitch, Burgundy, I I9 Canada, I 19

Pitcher-plant, $36 \mathrm{I}, 458,555$ family, 554

Pith, sassafras, 263

Pithecolobium, 575

Pityrodia, hairs in, 282

Placenta, 377 structure of, 408

Plaited, 389

Planchonia, 629

Plane tree family, 559

Planifolius-a-um, 455

Plant hairs, 353

henna, 450

Plantaginaceæ, 696
Plantago, 455, 694, 696 ferment in, 244

Plantain, 455, 694 common, 694

family, 696

flowers, 400

Plastids, 2, 138

Platanaceæ, 559

Platanus, 559

Plates, sieve, 276

Platinic chloride, 165

Platonia, 620

Pleistocene clays, II 7

Plerome, 253

Pleurisy-root, 667, 668

Pleurococcus, 20

Pleurosigma, 36

Plicate, 364, 389

Plum, 456

French, 562

grape, 606

oil in, 213

protein in, 200

sugar in, 156

Plumule, 127,426

Pod, 420

Podophyllum, 455, 538 rhizome of, 324

Podostemaceæ, 556

Podostemon, 455, 556, 679

Point of origin of growth, I 44, 300

of vegetation, 300

Poison, arrow, 575, 593, 597, 633,662

curare, 539

fish, 539, 575, 604, 606

ivy, 595, 596

oak, 595

snake, antidotes, 539

Poke weed, 455

Polariscope, micro, 764

Polemoniaceæ, 670

Polemoniales, 668

Polemonium, 455, 670, 676

family, 670

Pollantin, 726

Pollen, I 20, I 22, 298, 375. 404,726

composition of, 726

method of gathering, 722

pine, 107

sac, 298

toxic, 726

tube, III

weight of, $\mathbf{7 2 6}$

Pollination, I I I, I 25, 397

Pollinia, 123

Polygala, 172, 455, 589

Polygalaceæ, 589

Polygamous, 392

Polygamus-a-um, 456

Polygonaceæ, 520, 574

Polygonales, 520

Polygonatum, 456, 483
Polygonatum, rhizome of, 325

Polygonum, 456, 525, 527

Polymnia, 720

Polynesia, 63I

Polypeptides, ro9

Polypodium, 456

Polypody, 456

Poly poraceæ, 59

Polyporus, 456

resins in, 237

Polytrichum, 77, 78, 85

Pome, 420

Pomegranate, $447,457,629$

Pomelos, 584

Pometia, 603

Pond lily, yellow, 53 I

Pond-weed family, 466

Pontederia, 482

Pontederiaceæ, 480

Poplar, 456, 508

Popowia, 542

Poppy, 454, 548, 549

California, 547

celandine, 550

family, 546

horned, 446

Mexican, 547

oil, 547

in, 213

opium, 546,547

prickly, 436

yellow, 550

Populin, I69, I70, 508

Populus, 456,508

species, 508

Pores, bordered, 275

sieve, 276

simple, 263

water, 279

Port wine, 607

coloring of, 529

Portulaca, 55 I

Portulacaceæ, 53 I

Potassium hydrate, crystals, 762

iodide, crystals, 762

Potato, 688

Chinese, 492

family, 683

phyto-globulins in, 194

plant, 688

protein in, 199

starch, I42, I 48

in, 148

manufacture of, 148

with polariscope, 146 substitute, 726

Potentilla, 365, 456, 565

Potometer, $35 \mathrm{I}$

Pouzolzia, 5 I 7

Pratensis-e, 456

Precatorius-a-um, 456

Prefloration, 389

Prefoliation, 364 
Preservatives, 755

Prickly pear, 626

Pride of China, 588

Primary root, 301 cross-section of, 3 Io

structure, 309 of dicotyledonous roots, 345 of stem, 338 summary, 345 summary, 3 I?

Primeverase, 658

Primeverin, 658

Primrose, 456 evening, 453, 634, 635 family, 656

Primula, 456, 656, 657 structure of flower, 407

Primulaceæ, 656

Primulales, 656

Primulaverin, 658

Prince's feather, 527 pine, 644

Principes, 473

Privet, 450, 66r

Procumbens, 456

Prolamins, 194, 195

Promycelium, 66

Propagation by cutting, 733

Propagative organs, 298

Prophylla, 393

Protaceæ, 5 I 7

Protea, species of, 5 I 8

Proteacin, 517

Proteales, 5 I 7

Protection of plants, 172

Proteinase, 244

Proteins, 192 classification of, 193 origin of, 193 percentage of, 199 toxic, I96

Protium, 586

Protococcus, 20

Protonema, 78

Protopine, 548, 550

Protoplasm, 2, 134

Protoplasmic movement, 26

Protoplast, 2, 134

Prulaurasin, 169

Prune, 562 protein in, 200 sugar in, 156

Prunifolius-a-um, 456

Prunum, 456

Prunus, 560, 562, 565 cork of, 294 ferments in, 243 section of wood, 346

Pruriens, 456

Pseudo- Egle group, 583

Pseudococcus, 627

Pseudoinulin, I50

Pseudomonas, 307

Pseudotsuga, I I 4
Psidium, 632

Psoralea, 456, 574

Psyllium, 456

Ptelea, 456, 585

Pteridophytes, 86

Pteris, 456

Pterocarpus, 456, 569, 57 I

Pterospermum, 6r5

Puber-a-um, 456

Pubescens, 456

Pubescent, 353

Puccinia graminis, 69

Puccoon, 450

Puffball, 58, 59

Pulegioides, 456

Pulegone, 234

Pulicaria, 456

Pulmonaria, 456

Pulque, 492

Pulsatilla, 456, 537

Pulse, 450

family, 567

Pulvinis, 360

Pumpkin, 454 protein in, 200 sugar in, 156 vine, 709

Punica, 457, 629

Punicaceæ, 629

Purging cassia, 567

Purine, 167

Purple cone-flower, 724 gerardia, 693

Purpureus-a-um, 457

Purshia, 565

Purshianus-a-um, 457

Purslane, 53 I

Putamen, 4 Io

Pycnidia, 73

Pycnoconidia, 73

Pyrenoids, I 7, I 49

Pyrethri Flores, 718

Pyrethron, 7 I 8

Pyrethrum, 457

Pyridine, I66

Pyrocatechol, 204

Pyrogallol, 204

Pyrola, I74

Pyrone, I 80

Pyrrolidine, I 66

Pyrus, 457, 562, 565 quercitin, 562

Pyxidium, 4I3

Pyxis, 4r 3, 630

Quassia, 455, 457, 585, 586 Jamaica, 585

Quebracho, 667

blanco, 457

Colorado, 599

extract, tannin in, 206

Queen's root, 590

Quercitin, I69, I 79, I80, 508, $512,562,565$

Quercitrin, I 70
Quercus, 457, 5 I2

bork of, 295

galls on, 335

Quillaja, I 72, 457, 564

Quillwort, 449

Quina blanca, 592

Quince, 560, 562, 565

Bengal, 45I

Quinine herb, 664

Quinoline, I 66

Quisqualis, 633

Raceme, 394

Racemosus-a-um, 457

Radial flower, 393

Radial-longitudinal section, 749

Radiate head, 7 II

Radicans, 457

Radicle, 426

Radish, 457 color in, 178 protein in, 199

Ragweed, 435, 459, 726

Rain trees, 157

Raisin, 606, 607 sugar in, 156

Rajania, 492

Ramie, 269, 5 I 7

Ranales, 53 I

Ranunculaceæ, 532

Ranunculus, 457,537 ferment in, 244

Rape-seed, protein in, 199

Raphanus, 457,553

Raphia, 269

Raphides, I 86

Raspberry fruit, 4 I 5 protein in, 200 red, 563 sugar in, 156 syrup of, 563

Rattle-box, 442, 575

Rattlesnake plantain, 503

Rattleweed, 574

Ravensara, 546

Ray-flowers, 395, 7 I I

Reactions, optical, 773

Reagents, 755 alkaloidal, I63

Mayer's, I64 Sonnenschein's, I64 special, 755

Wagner's, I64

Wormley's, I65

Reaumuria, 621

Rebandin, 713

Receptacle, 375 secretory, 226

Reclinate, 364

Red gum, 574 raspberry, 563

root, 440

wine, 607

Reed, 439, 445 
Refractive index, 774

Regular flower, 393

Repand, 356

Repens, 457

Reptans, 457

Reseda, 457, 554

Resedaceæ, 554

Resene resins, 237

Reserve layers, 425

Resin, 236, 255

balsamic, 225

chaia, 62I

fossil, 237

micro-chemistry of, 23 I

origin of, 238

piney, $62 \mathrm{I}$

soft, 587

Resinol resins, 237

Resinolic acid resins, 237

Resins, origin of, 238

Respiration, 350

Reticulate, 354, 457

Reticulatus-a-um, 457

Retuse, 355

Rhamnetin, I 80

Rhamnose, I54, 562

Rhamnus, 457,604

bark of, 342

fruit, 422

wood of, 344

Rhapontic, 457

Rhaponticus-a-um, 457

Rhatany, 449

Rheedia, 6 r9

Rhein, r70

Rheum, 457, 521

species, 522

Rhexia, 634

Rhipsalis, 627

Rhizogenous layer, 312

Rhizome, 325

Rhizophora, 304, 630

Rhizophoraceæ, 630

Rhodeose, I60

Rhododendron, 457,646 glandular hairs in, 230 hairs in, 282

Rhodophyceæ, I7, 3 I

Rhodymenia, 34

Rhœadales, 546, 554

Rhubarb, 457, 522

garden, 522

South China, 522

Rhus, 457, 595, 596, 597, 598 ferment in, 245

hairs of, 280,284

poisonous, 597

species of, 597

tannin in, 206

Rhynchanthera, 634

Ribes, 457,558

fruit, 4 I 8

Riccia, 82

Rice, 467

protein in, 199
Rice, starch in, 148

Ricin, I95, 196, 590, 6 I I

Ricinus, I $96,457,59 \mathrm{r}$ aleurone grains of, I94, 428

ferment in, 244

fruit, 410

protein in, 199

seed, 426

Ringent, 388

Riuno-kiku, 726

River-weed, 455

family, 556

Rivinia, 528

Robin, 198

Robinia, 457, 574, 576

Robinin, 169

Robustus-a-um, 457

Roccella, 74

Rocket, 447

Rockrose, 447

Rockweeds, 28

Roman chamomile, 7 I3

Root, 299

abnormal structure of, 3 I 9

absorption, 25 I

adventitious, $30 \mathrm{r}$

aẽrial, 306

assimilation, 306

belladonna, cross-section of, 318

branches, 319

breathing, 306

cap, 299, 301

climber, 324

contraction of, 319

hairs, 299, 301, 309

inner structure of, 309

lateral, 30I, $3 \mathrm{I}_{2}$

modified, 306

outer morphology of, 299

phytolacca, cross-section of, 3 I 8

pressure, 252

primary, $30 \mathrm{I}$ structure of dicotyledons, 345

primordia, $30 \mathrm{I}$

secondary, $30 \mathrm{I}$

stele, 313

stock, 325

tap, 30I

true, 299

tubercle, 306

tuberous, 305, 327

Roripa, 553

Rosa, 457, 564

Rosaceæ, 560

Rosales, 556

Rose, 457,564

apple, 632

bay, 457,647

camphor, 564

family, 560

geranium, 579
Rose, hip, 409

oil, 564

petals, 564

tea, 629

wood, 544

Rosemary, 457

Roseus-a-um, 457

Rosin, weed, 459, 723

Rosmarinus, 457,676

Rostratus-a-um, 458

Rotate, 388

Rottlerin, I 80, 592

Rotundifolius-a-um, 458

Rubber, India, 241, 592 trees, 24 I

Ruberithrinic, 169

Ruber-ra-rum, 458

Rubia, 702

Rubiaceæ, 697

Rubiales, 697

Rubus, 458,563

cork in, 293

fruit, 4 I 6

Rudbeckia, 723

Rue, 458

anemone, 535

family, $58 \mathrm{I}$

garden, 585

meadow, 460

Ruellia, 694

Rugose, 354

Rugosus-a-um, 458

Rum, bay, 632

Rumex, 458, 523

Runner, 325

Rush, 458

bog, 449

family, 493

matting, 493

scouring, 96

soft, 493

spike, 444

wood, 493

Rust, wheat, 69

Ruta, 458

Rutaceæ, 58 I

Rutin, I 70, 585

Rye, 458, 467 lecithin in, 214 protein in, 199 starch in, 148 sugar in, 157

Sabadilla, 458

Sabal, 458,473

Sabbatia, 664

Sabina, II 5, 458

Sable tetraedrique, I 88

Sabodilla tree, 659

Sac, pollen, I20

Saccate, 388

Saccharomyces, 47

Saccharomycetes, 47

Saccharose, I 54, I 55

Saccharum, 458,467 
Sacci, 492

Safflower, 387, 7 I 9

oil in, $2 \mathrm{I} 3$

yellow, 720

Saffron, 442, 493 meadow, 442

Safranin, as staining agent, 757

Sage, 458

garden, 676

hairs of, 284

Sageretia, 606

Sagittaria, 465

Sago, 475

palms, 475

starch, 475

Sagrada, 440

Saigonicus-a-um, 458

Salegenin, 700

Salicaceæ, 508

Salicales, 508

Salicin, I69, I 70, 508

Salicylic aldehyde, 564

Salix, 458, 508

tannin in, 206

Salsify, 46I

Salt, table, source of, 556

Salvia, 458,676

hairs of, 230,285

Samadera, 586

Samara, 420, 510,602

Sambucus, 458, 706 cork in, 293

Sambunigrin, 169

Sanctus-a-um, 458

Sandal, oil, 5 I 8

tree, 458

wood, 458

family, 5 I 8

Sandarac, I 9

Sand-box tree, 592

Sanguinaria, $458,548,550$ latex, 24 I

Sanicula, 458

Santal, bastard, 58 I oil, Chinese, 519

Santalaceæ, 5 I 8

Santales, 5 I 8

Santalinus-a-um, 458

Santalol, 5 I9

Santalum, 458, 518

Santonin, 710

Sap, ascent of, 252 cell, I 34

Sapindaceæ, 602

Sapindales, 594

Sapindus, 603

Sapium, 594

Sapodilla family, 658

Saponaria, I72, 458, 530, $53 \mathrm{I}$

Saponarin, 169

Saponin, I 7 I, 575, 603, 6II

occurrence of, 172

Sapotaceæ, 658
Sapotilla, 659

Sapotoxin, I 70

Sappan, 439

Saprolegnia, 42

Saprophytes, 40

Sapucaya nut, 629

Sarcocarp, 40, 4ro

Sarcophyte, 5 I9

Sargassum, 3 I

Sarracenia, 36r, 458, 554,555

Sarraceniaceæ, 554

Sarraceniales, 554

Sarracenine, 554

Sarsaparilla, 487 wild, 637

Sassafras, 458,544 mucilage in, 263 oil, 544

Sativus-a-um, 458

Satureia, 679

Savin, I 19

Savory, summer, 679

Saxifragaceæ, 556

Saxifrage family, 556 golden, 44I, 556, 557

Scabiosa, 708

Scadens, 458

Scale, seminiferous, 108

Scammonia, 458

Scammony, 458 root, 669

Scarlet sumac, 597

Scatol, 5 I0

Schinopsis, 599 tannin in, 206

Schizandra, 540

Schizogenous, 226

Schizo-lysigenous, 226

Schizomycetes, I 2

Schizophyceæ, 8

Schizophytes. 7

Schulze's cellulose reagent, 760

macerating solution, 761

Scilla, 458

Scillain, I 70

Scirpus, 458, 472

Scitamineæ, 493

Scitaminales, 493

Scleranthus, 531

Sclerenchyma, 266

Sclerenchymatous fibers, 268

Sclerocarya, 599

Sclerotium, 52

Scolopendrium, 458

Scoparia, $45^{8}$

Scopolia, 684

fruit, 4 I 2

tracheæ in, 274

Scopolin, I 70

Scotch broom, 569

Scrophularia, 691

Scrophulariaceæ, 688

Scullion, 485

Scurvy grass, 553
Scutellaria, $384,458,673$

Scytonema, 72

Sea bean, 575

Island cotton, 610

lettuce, 25

weed, 435

protein in, 200

Secale, 458,467

Secondary corter, $312,3 \times 3$

roots, 30I

structure, 3 I 3

of stems, summary, 345

summary, 3 I 7

Secretory canals, 228

cavities, 227

cavity in pines, 107

cells, 226

Sections, 749

making of, 749

Sedge, 439, 472

Sedum, 458, 556 purpurascens, 368

Seed, 379 development of, 125

dispersal, 427

inner structure of, 427

outer morphology of, 423

pans, 729

plants grown from, 728

structure of, 424

Selaginella, 86, 98-rof

Semecarpus, 458

Sempervirens, 459

Sempervivum, 556

Seneca root, 459

Senecio, 459

Senega, 459, 589

Texas, 589

white, 589

Senegal, 459

Senna, 440, 459, 567

Alexandria, 567

American, 360

hairs of, 285

India, 567

Tinnevelly, 567

Tripoli, 567

Sepals, I 20, 374, 382

Septa, 4I I

Septicidal, 4I I

Septifragal, 4 I I

Sequoia, II 7

Serenra, 459, 473

Scriceous, 354

Serotin, 169

Serotinus-a-um, 459

Serpentaria, 459, 520

Southern, 52 I

Serrate, 356

Serrulatus-a-um, 459

Sesame, 459

oil in, 213,691

Sesamum, 459, 69I

Seudo tanga, II9

Seven barks, 556 
Sexual generation, 298 spore, 298

Shaddock, 584

Shea butter, 2 I 2, 659

Sheep laurel, 648 sorrel, 524

Shepherd's purse, 439, 554

Shield fern, 437

Shikimi, 540

Shoot, 299

aërial, 329

axis, 299

creeping, 304

epigeous, $32 \mathrm{I}, 322$

hypogeous, $32 \mathrm{I}, 325$

overground, 32 I

subterranean, 329

underground, 32 I

undeveloped, $32 \mathrm{I}$

Shorea, 621

Shoyu, 577

Shrubs, 329

Sida, 6I I

Siejas, 519

Sierra Leone copal, 574

Sieve, 276

Sigillaria, I00

Silene, hairs in, 282

Silica, 202

forms of, 188

Silique, 420,459

Silk, 269

dye, 625

Silkweed, 437

Silkworm, food, 5 I 7

Silphium, 723

Silver-leaf poplar, 508

Simaba, 459

Simaruba, 586

Simarubaceæ, $\mathbf{5 8 5}$

Simple leaf, 348

Sinalbin, I69, I70

Sinapis, 459,553 germination of, 299

Sindor balsam, 621

Sinensis-e, 459

Sinigrin, 169, I70

Sinuate, 356

Sisal fiber, 260

Sisymbrium, 459, 553

Skullcap, 458, 673

Skunk cabbage, 478,480

Sleep movements, $36 \mathrm{I}$

Slime molds, 2

Sloanea, 609

Small nettle, 5 I 7 Solomon's seal, 483

Smartweed, 448

Smilacina, 484

Smilax, 459, 485 species of, 487

Smut, 46I corn, 67

Snakehead, 44I

Snakeroot, 459
Snakeroot, black, 458,532

Canada, 520

Virginia, 520

Sneeze-weed, 447, 723

Snow-ball, 705

Snow berry, 460,707

Soap bark, 564, 565 berry family, 602 plants, I 7 I

Soapwort, 458, 520

Socotrinus-a-um, 459

Soda, plants yielding, 530

Sodium in seaweeds, 28

Soft galls, 334

Soil acidity, 249

bacterium, 307 organic constituents of, 250

Soja beans, 199

Solanaceæ, 683 flowers of, 385

Solanidine, 688

Solanine, I 72, 684

Solanum, $385,459,684$ fruit, 4I 2

Solidago, 459, 521, 722, 726

Solomon's seal, 456

Solution, Beale's carmine, 760

Bohmer's hænhatoxylin, 760

chloral-iodine, $76 \mathrm{I}$

chlor-zinc-iodine, 760

copper acetate, $76 \mathrm{I}$

Delafield's hæmatoxylin, 760

Grenacher's borax-carmine, 760

Grenacher's hæmatoxylin, 760

Hoyer's picro-carmine, 760 iodine and potassium iodide, 76 I

iron, $76 \mathrm{I}$

phloroglucin, $76 \mathrm{r}$

Schulze's macerating, $76 \mathrm{r}$

Somnifer-a-um, 459

Sorbile, 459

Sorbilis-e, 459

Sorbit, 563

Sorbus, 459,562

Sorghum, 459, 467

juice, percentage of sugar in, 157

Sorosis, 420

Sorrel, field, 524

sheep, 524, 525

Southernwood, 434

Soy, 577

Spadix, 394, 475

Spanish licorice, 568 moss, 48I

Sparganiaceæ, 463

Sparganium, 464

Spathe, 394, 478
Spathifloræ, 475

Spawn, 56

Spearmint, $384,676,678$ plant of, 326

Special reagents, $755,76 \mathrm{r}$

Specimens, mounting of, 762

Spectroscope, 764, 765

Speedwell, 462

Sperm, 5

Spermophytes, I00

Sphærites, I92, 678

Sphærobacteria, I3

Sphagnum, 84, 85

Sphere crystals, 678

Spicatus-a-um, 459

Spice bush, 439,544

Spiderwort, $46 \mathrm{I}, 480$

Spigelia, 459, 66r tracheæ of, 274

Spignel, 452

Spike, 394 oil, 679

Spikelet, 394, 469

Spikenard, 453

Spilanthes, 724

Spilanthin, 724

Spinach, 527 protein in, 199 sugar in, 157

Spinacia, 527

Spindle tree, 445

Spinose, 354

Spiræa, 459, 564

Spiral, thickening, development of, 272

Spirogyra, I 8

Spleenwort, 437

Sporangia, 375

Sporangium, 4

Spores, 3 asexual, 4, 298 sexual, 4,298 staining of, 7 I swarm, 5

Sporidia, 66

Sporobolus, 467

Sporogonium, 79

Sporophylls, 375

Sporophyte, 75 embryo, 298

Spring beauty, 531

Spruce, I09, 455 beer, II 9

black, I I 2

Douglas, II 4

Norway, II

pine, I I 2

white, tannin in, 206

Spurge, 445, 500, 590

Squarrosus-a-um, 459

Squash, 443

Squaw-root, 695,696

Squaw weed, 459

Squill, 458, 46I, 487

Staff tree, 440,600 
Stage micrometer, 754

Staining agents, 757 of bacteria, 16 double, 762

Stains, 755

Stalk, 348

Stamen, 1 20, 374, 375, 379 different types of, 380

Staminate, 392

Staminodia, 39 I

Staminodes, 39 I

Staphisagria, 459, 535

Star apple, 659 grass, 435 of Bethlehem, 485

Starch, I40, 435

assimilation, 140

botanical distribution of, 147

Brazilian arrow-root, 670

characteristics of, 145

grain, composition of, I 43 development of, I4I structure of, 143

manufacture of, 148 occurrerice of, $\mathrm{I} 43$ percentage of, 148 properties of, 145 reserve, 137,143

seen with the micropolariscope, 146

sweet-potato, 670

with iodine, 147

Stavesacre, 459,535

Stem, 299, 320

branches, 320

inner structure of, 338

of dicotyledons, 338

outer morphology of, 320

primary structure of, 338

structure, abnormal, 344

dicotyledonous, 339

primary, summary, 345 secondary, summary, 345

underground, 325

Sterculia, 6I5

seeds, 6 I 5

Sterculiaceæ, 6 I 2

Sterilization, I 5

Stick-lac, 238

Sticta. 73

Stigma, 1 20, 376, 378 different types of, 377 epithel, 406 structure of, 405

Stillingia, 459, 590

Stinck weed, 460

Stinging nettle, 517

Stink-wood, 546

Stipa, 472

Stipe of fungi, 57

Stipules, 348

function of, 348

Stitch-wort, 53 I
St. John's bread, 440,576 wort, 448 family, 620

Stolon, 325

Stoma, 279

Stomata, 278, 367, 368 on leaves of Beta, 367

Stonecrop, 458 common mossy, 556 ditch, 556

Virginia, 556

Stoneworts, 26

Storax, 460, 559, 660

Stramonium, 460, 684

fruit, 409,412

hairs of, 284

seed, 428

transverse section of midrib, 366

Strawberry, 445, 566

fruit, 409, 4 I 5

garden, 566

protein in, 200 wild, 567

Striatus-a-um, 460

Strigose, 354

String beans, 199

Strobile, 375, 420

Strobiles, 375

Strophanthin, I69, I70, I7 1

Strophanthus, 460,666 hails of, 284,285

Strophiole, 427

Structure, basis of, I of wood, 347 primary, 254, 309 summary, 317 secondary, 254 summary, 319 stem, classification of, $34 \mathrm{I}$

primary, summary, 345

Strychnine crystals, 769

Strychnos, 460, 66I

Stryphnodendron polyphyllum, tannin in, 206

Style, I 20, 376, 378 structure of, 406

Styloids, 183

Stylophorine, 550

Stylophorium, 550

Styracaceæ, 660

Styraciflua, 460

Styrax, 460, 558, 660

Suberin, 257, 290

Suberose, 257

Sublimable principles, 173

Succisa, 708

Succory, 44I, 7 I 6

Sucrose, 155, 527

Sugar, 154

beet, 527 protein in, 199

bush, 5 I 8

cane, 467
Sugar,cane,juice,percentage of sugar in, 157

in cereals, percentage of. I56

in plants, 156

in vegetables, 156

Sumach, 457,595

poison, 597

scarlet, 597

tanner's, 595

Sumbul, 639

Summer savory, 679

Sundew, 36I 444, 554

Sun-dial, 45 I

Sun-flower, 712

oil in, 213

seed-cake, 725

seed, protein in, $x 99$

Sun's energy, 138

Suppressed, 391

Surface of leaves, 353

Suringi, India, 620

Survival of the fittest, $13 \mathbf{x}$

Suspensor, I 25

Suture, dorsal, 377

ventral, 377

Swamp pink, 485,490

Sweet, 444 almond, protein in, 199

anise oil, 643

balm, 679

basil, 679

cicely, 643

fern, 509

flag, 479

gale, 509

gum tree, 450,558

marjoram, 679

pea, 576

potatoes, protein in, 199 percentage of sugar in, I 57

starch, 670

vine, 669

scabious fleabane, 713

William, $53 \mathrm{I}$

wine, 607

Swertia, 460, 664

Swietenia, 589

Sycamore, 559

Syconium, 420

Sylvaticus-a-um, 460

Sylvestris-e, 460

Symmetrical, flower, 392

Sympetalæ, 643

Sympetalous, 385

Symphonia, 620

Symphoricarpos, 460, 707

Symphytum, 460, 67 I

Symplocarpus, 478,480

Synantherin, 150, 726

Syncarpous, 376

Synergids, 124

Syngenesious, 382

Synura, I I 
Syringa, $455,460,66 \mathrm{I}$

Syringin, 169, 66I

Syringopicrin, 66I

Tabacum, 460

Table salt, source of, 556

Tacamahac, $439,508,6 I_{3}$

Bourbon, 618

Brazilian, 6 I 8

India, 618

resins, 587

West Indian, 587

Tagetes, hairs in, 288

Talauma, 540

Tallow tree, Chinese, 594

Tamaricaceæ, $62 \mathrm{I}$

Tamarindus, 460,569

Tamarix, 62 I

Tamonea, 634

Tamus, 492, 709

Tanacetum, 460, 720

Tangential-longitudinal section, 749

Tangkawang, $62 \mathrm{I}$

Tanner's sumac, 595

Tannides, 202

Tannin, 202

chemical properties of, 203

distribution of, 205

idioblast, 207, 208

in galls, 335

micro-chemistry of, 204

pathological, 207

physiological, 207

Tannol resins, 236

Tansy, 460, 720

Tapetum, I 2 I

Tapioca starch, 594

Tap-root, 30 I

Tapura, 606

Taraktogenos kurzii, 2 I4

Taraxacum, 239, 387, 46o

Taxus, $\mathrm{I}_{3}$

Tea, 460,6 I 7

Appalachian, 600

black, 6 I 8

Brazilian, 600

caffeine in, 162

cassine, 600

chests, 625

culture, 746

family, 617

green, 6 I 8

Labrador, 450

New Jersey, 605

Paraguay, 600 germination of, 730

plant, 6I5

rose, 629

seed, oil in, $2 \times 3$

substitute, 53I, 634

tree, 6 I 7

Teaberry, 650

Teak-tree, 673

Teak-wood, 673
Teasel, 444, 707

Technique, bacteriological, I 4

Tecoma, 69r

Tectona, 673

Tegmen, 425

Telegraph plant, $36 \mathrm{I}$

Teleutospores, 68

Temperature, 247

Tendril, 323

climber, 324

Tephrosia, 575

Terebinthina, 460

Terminalia, 633

Terpenes, 233

Terpinene, 679

Terpineol, 632

Terra silicea purificata, 38

Testa, 425

Testing of drugs, 248

Tetradynamous, $38 \mathrm{I}$

Tetragonal crystals, I 83

Tetrameles, 625

Tetrapanax, 636

Teucrium, 460

Texture of leaves, 354

Thalictroides, 460

Thalictrum, 460

Thallophytes, 6

Thallus, 6

Thea, 460, 6 I6

Theaceæ, 617

Thein, I73, I76

Thelephoraceæ, 59

Theobroma, 460, 612

Theobromine, 6I2, 6I8

Theophylline, 618

Thistle, 7 I2, 723

blessed, 442

milk, 45 I

star, 440

Virgin Mary's, 45 I

Thlaspi, 553

Thorn apple, 684

Thoroughwort, 445, 712

Thuja, I I 8,460

Thujone, 7 I9

Thyme, 460

field, $44 \mathrm{r}$

garden, 677

Thymelæa, 628

Thymelæaceæ, 627

Thymol, 234, 678, 68I

Thymo-quinhydrone, 179

Thymoquinone, I 79, $68 \mathrm{I}$

Thymus, 460

Tiarella, 460, 556

Tibouchina, 634

Tick Trefoil, 443

Tilia, 46r, 608, 609

hesperidin in, 153

species of, 609

Tiliaceæ, 609

Tillandsia, 480

Tinctorium, 460
Tinctorius-a-um, 460

Tissue, I 2 I

conjunctive, 3 I 3

laticiferous, 296

mechanical, 264

milk, 296

Tobacco, $453,460,688$

camphor, 688

Indian, 710

Persian, 688

plant, Virginia, 688

Turkey, 688

wild, 710

Tococa, 634

Toddy, 620

Tolu, balsam of, 572

Tolu-resinotannol, 572

Toluifera, 46I, 572

Tomato plant, 688 sugar in, 157

Tomentose, 354

Tomentosus-a-um, 46 I

Toothed, 385

Toringin, 562

Tormentilla, 565

Torus, 375,380

Touch-me-not, 448

Touranose, 155

Tous les mois, 496

Toxalbumins, 196, 726

Toxicodendrol, 595

Toxicodendron, $46 \mathrm{r}$

Toxylon, 5 I6

Tracheæ, 273, 313 markings of, 273

Tracheids, 275

Trachylobium, 574

Tradescantia, 46I, 480

Tragacanth, 2 I8, 46I, 569, 570

Tragopogon, 46 I hairs in, 288

Trailing mahonia, 537

Transpiration, 350

Transverse heliotropism, 349 section, 749

Trapa, 634

Treacle mustard, 553

Tree of heaven, 434

Trees, 329 green coating on, 2 I

Trefoil, clover, $46 \mathrm{r}$ bird's foot, 450

Trehalose, I 55

Tremellaceæ, 59

Triandrus-a-um, 46r

Triassic period, IOI

Trichodesmium, 8

Tricolor, 46 I

Tricuspidatus-a-um, $46 \mathrm{I}$

Trifolium, 46I, 576

Trilisa, 46r

Trillium, $46 \mathrm{I}$

Trimorphic flowers, 399

Triosteine, 707 
Triosteum, 706

Triphyllus-a-um, 46 I

Tristichous, 363

Triticum, 46r, 467, 468

Trivial, $46 \mathrm{r}$

Trivialis-e, $46 \mathrm{r}$

Tropæolaceæ, 579

Tropæolum, 579

True root, 299

Solomon's seal, 483

Truffles, 65

Trumpet-creeper, 69I

Truncate, 355

Tsuga, I I3, I 1 8, 46 I

Tuber, 326

Tubercle, root, 306

Tuberin, 195

Tuberose, 485

Tuberosus-a-um, 46r

Tubifloræ, 668

Tubular flowers, 7 II

Tuckahoe, 65

Tulip, 485

bulb, 330

tree, 450, 539

Tupelo, 453,518

Tumeric, 494

Turmerol, 496

Turnera, 623

Turneraceæ, 623

Turnip, 438, 553

Indian, .436

little, 453

protein in, 199

sugar in, 157

Turpentine, I 18,460

as a clearing agent, 757

Canada, 118

Strassburg, I I9

Venice, I 8

Turpeth, $46 \mathrm{I}$ root, 453

Turpethum, 46I

Turtlehead, 44I, 69I

Tussilago, 387, 46r, 723

Twin leaf, 449

Twiner, 324

Types of mestome strands, 343

Typhaceæ, 463

Ulex, 575

Ulmaceæ, 512

Ulmaria, 461

Ulmus, 46 I

section of wood, 346

species of, $5 \mathrm{I}_{2}$

Ultra-microscope, 765

Ulva, 25

Umbel, 394, 636

Umbellales, 636

Umbellated, $46 \mathrm{I}$

Umbellatus-a-um, $46 \mathrm{x}$

Umbelliferæ, 575, 636

fruit of, 417
Umbellifloræ, 636

Umbellularia, 46 I, 544

Umbrella tree, 540

Unguis, 385

Unifacial leaf, 366

Uniflorus-a-um, 46r

Unisexual, 444

flower, 392

Unona, 542

Upas-tree, 516

Uragoga, 699, 700

Urari poison, 5 I 7

Urceolate, 388

Uredineæ, 65

Uredospores, 69

Urena, 6II

Urginea, 461, 487

Uroglena, 8, ro

Ưrtica, 46r, 5 I 7

Urticaceæ, 5 I 7

Urticales, 512

Use and disuse, I $3 \mathrm{I}$

Usitatissimus-a-um, 46r

Usnea, 73

Ustilagineæ, 65

Ustilago, 67, 46 I

Utricle, 420, 527

Utricularia, 299

Uva-ursi, 46r, 644

Uvularia, 485

Vaccinium, I74, 653 fruit, 417

Vacuole, I34

Valerian, 462, 707

garden, 707

Greek, 67 I

wild, 707

Valeriana, 462, 707

Valerianaceæ, 707

Valerianales, 707

Valerianella, 707

Vallea, 608

Valonia, tannin in, 206

Valvate, 389

Vanilla, 462, 497

grass, 472

hairs of, 284

leaf, $46 \mathrm{I}$

sugar in, 157

Vanillin, 173, 572

Variifolius-a-um, 462

Various woods, coarse structures of, 346

Varnish tree, 597

Vasicine, 696

Vateria, 621

Vatica, 62I

Vaucheria, 22, 40

Vegetable agglutinins, 198 bezoars, 577

butter, 659

ivory, 473,474

Vegetative organ, 299

Veins, 352
Venation in Dicotyledons, 353 Monocotyledons, 352

leaf, 352

Venenosus-a-um, 462

Ventral palisade tissue, 366 suture, 377

Venus's fly-trap, 362, 554

Veratrum, 462, 485 section of root, 320

Verbain, blue, 674

Verbascum, 691 hairs of, 286 hesperidin in, 153

Verbenaceæ, 673

Verbenas, 673, 674

Vermilion, 597

Vernation, 364

Veronica, 462, 689

Verrucose, 354

Versatile, 380

Versicolor, 462

Verticillatus-a-um, 462

Verus-a-um, 462

Vervain, 673 nettle-leaves, 673

Vessels, 273, 313

Vetchling, 450

Viburnum, 462, 704, 705

Vicia faba, 199

Vicianin, 169

Vicilin, 195

Victoralis, 462

Victoria, 532

Vignin, r95

Villosus-a-um, 462

Vinca, 668 .

Vinifer-ra-rum, 462

Viola, 462, 622 glandular hairs in, 230 leaf of, 348 quercitin, 622 stem in section, 336 stomata in, 278 structure of flower, 403

Violaceæ, 622

Violet, 462 dog's tooth, 485

English, 622

family, 622 leaf of, 348 sweet, 622

Virginia creeper, 607 grape-fern, 365

Virginianus-a-um, $4 \mathrm{r}_{2}$

Virginicus-a-um, 462

Viridiflorus-a-um, 462

Viridis-e, 462

Virosus-a-um, 462

Viscine, 518

Viscum, 518

Vismia, 619, 620

Vitaceæ, 606

Vitæ, arbor, 460

Vitis, 462,607

Vittæ, 637 
Volvox, 2 I

Vouacapoua, 436, 462

Vulgaris-e, 462

Wahoo, 600

Wake-robin, 437,46 I

Walking leaf, 439

Wall, composition of, 254

kinds of, 258

marking of, 260

mucilage, 257

origin of, 254

pepper, 556

thickening of, 260

Walnut, 449, 509

black, 509

English, cross-section of wood, 346

family, 509

oil in, 2 I 3

white, 509

Waltheria, 6I5

Wandering Jew, 480

Washingtonia, 643

Water, 247

arum, 439, 479

cress, 553

fennel oil, 643

hemlock, 575, 642

iodine, $76 \mathrm{I}$

leaf family, 670

lily family, 53 I

melon, 7 I0

net, 22

plantain, 466

pores, 279

Wax, $210,216,277$

carnauba, 2, 4

crystalline, 2 I 6

forms of, 216

Japan, 2 I 2 .

myrtle, 2II, 212, 500

ocotilla, 62I

opium, 2 I4

Wheat, 461,467

grass, 434

lecithin in, 214

protein in, 199

starch in, 148

sugar in, 157

White clover, 472
White clover, colors, 178

wines, 607

Whortleberry, 654

Wild black cherry, 560

brier, 564

caper, 59 I

cherry, 56 I

indigo, 573

marjoram, 679

strawberry, 566

yam root, 492

Willow, 458, 508

herb, 440,634

flowers, 400

Wind flower, 436

Wine, 607

light colored, 607

mammey, 620

port, 607

red, 607

sweet, 607

white, 607

Winterana, 622

Winteranaceæ, 622

Winter cress, 438

Wintergreen, 644, 650

Winterin, 540

Winter's bark, 540

Wistarin, 575

Wisteria, 462, 575

Witch-hazel, 447, 558, 559

Witch's brooms, 334

Wolfsbane, 434

Wood, 3 I 7

bass, $46 \mathrm{I}$

carving, 117

fibers, 270

in coal, I 9

pulp, 1 I 7

red, 117

rush, 493

sorrel, $454,544,579$

structure of, 346

Woodfordia, 628

Woodruff weed, 437

Wool, 269

Woolly, 354

Wormseed, 527

Spanish, 527

Wormwood, 434, 437, 710

hairs of, 285
Xanthium, 462,723

Xanthone, I 80

Xanthorhamnin, I69, I70

Xanthosome, 480

Xanthostrumarin, 723

Xanthoxylum, 462,582

Xerase, 49

Xylem, 3 I 2

Xylopia, 54I, 542

$\mathrm{X}$ ylose, 169

Xyrideales, 480

Yam, 444, 492 root, wild, 322,492

Yarrow, 434, 452

Yeast, 47 dry, lecithin in, 2 I 4 glycogen in, 154

Yellow gum, 574 pond lily, 434, 53 I

Yerba Maté, 60I Santa, 670

Yew, I 13

Ylang-ylang, 542

Yohimbi bark, 702

Yohimbihi bark, 702

Yohimbine, 702

Yucca, 485

Zanthoxylum, 58r, 582

Zanzibar copal, 574

Zea, 462, 467, 469 root-tip, 300

Zeora, 75

Zeridine, 49

Zeylonicus-a-um, 462

Ziehl's carbol-fuchsin, 757

Zingiber, 462, 494, 495

Zingiberaceæ, 494

Zizyphus, 606

Zollikoferia, hairs in, 282

Zoo-cecidien, 335

Zoospores, 5

Zostera, 466

Zygadenus, 574

Zygomorphic, 393

Zygomycetes, 42

Zygophyllaceæ, 58 I

Zygospore, 5

Zymase, 244 




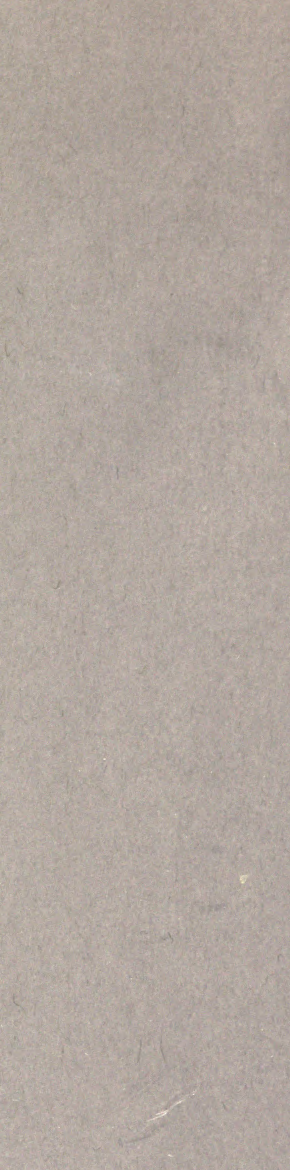

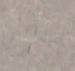

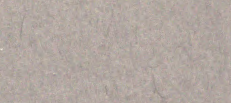




\section{DAY USE}

RETURN TO DESK FROM WHICH BORROWED BIOLOGY LIBRARY

TEL. NO. 642-2532

This book is due on the last date stamped below, or the date to which renewed.

Renewed books are subject to immediate recall.
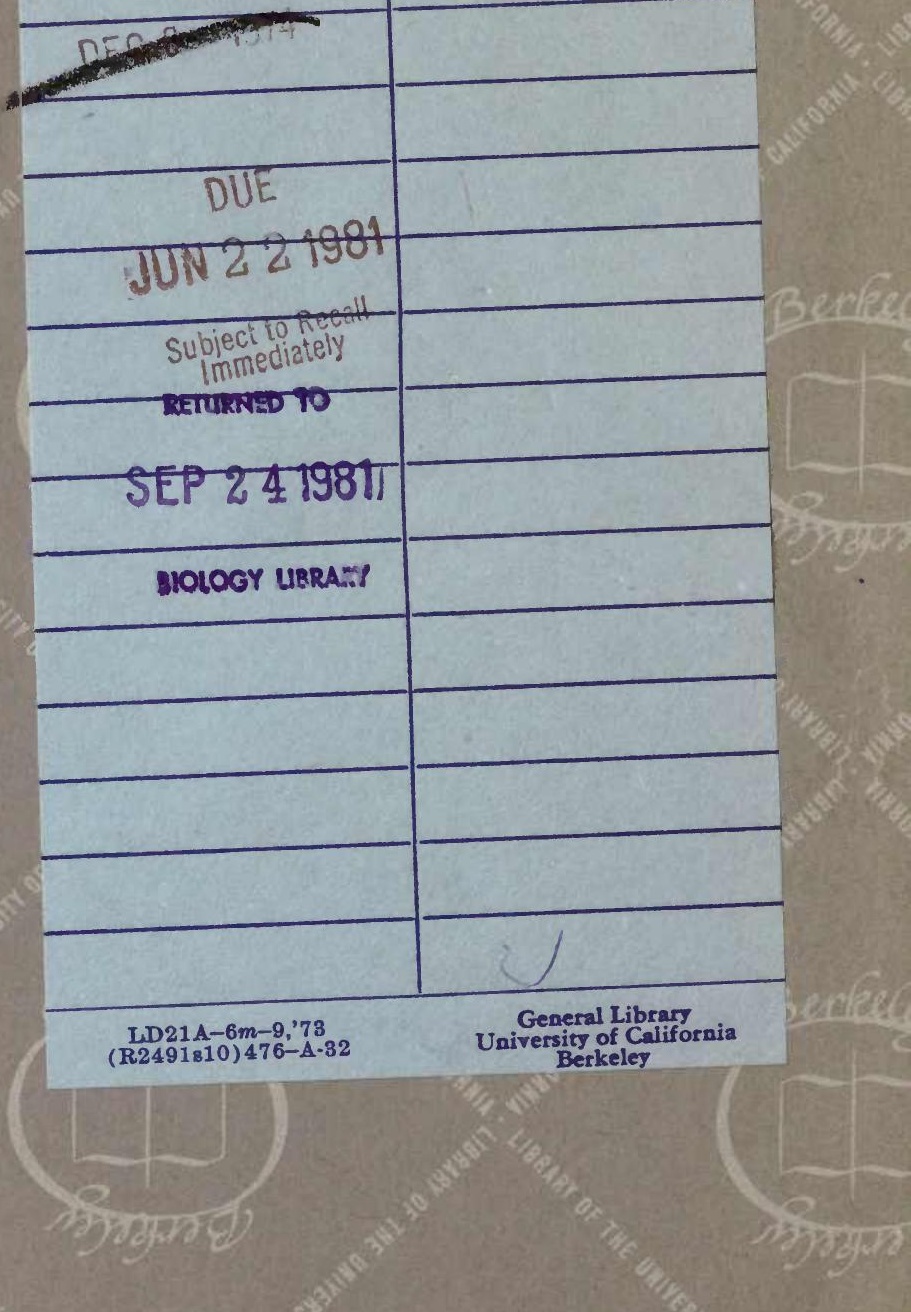


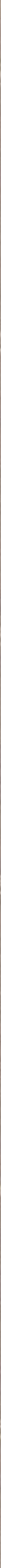


